Nevada

Environmental

Restoration

Project

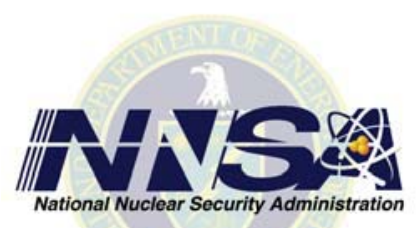

Corrective Action Decision

Document for Corrective Action

Unit 271: Areas 25, 26, and 27

Septic Systems,

Nevada Test Site, Nevada

Controlled Copy No.:

Revision No.: 0

September 2002

Approved for public release; further dissemination unlimited.

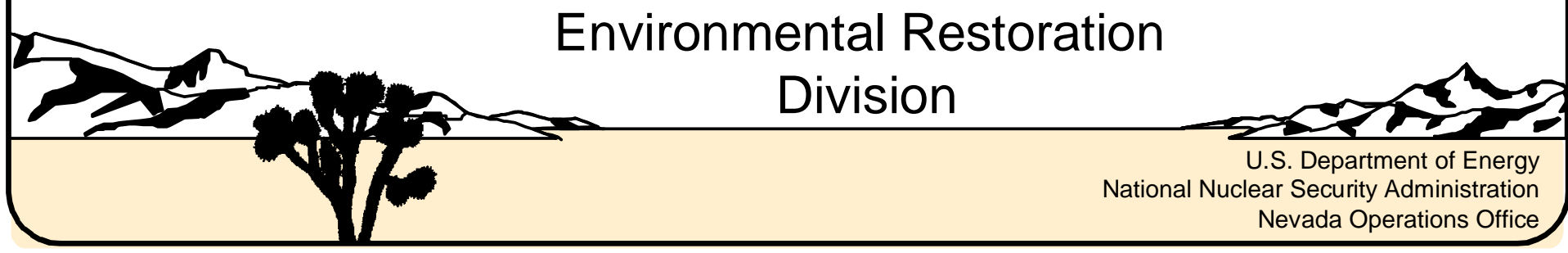


Available for public sale, in paper, from:

U.S. Department of Commerce

National Technical Information Service

5285 Port Royal Road

Springfield, VA 22161

Phone: 800.553 .6847

Fax: 703.605.6900

Email: orders@ntis.fedworld.gov

Online ordering: http://www.ntis.gov/ordering.htm

Available electronically at http://www.doe.gov/bridge

Available for a processing fee to U.S. Department of Energy and its contractors, in paper, from:

U.S. Department of Energy

Office of Scientific and Technical Information

P.O. Box 62

Oak Ridge, TN 37831-0062

Phone: 865.576 .8401

Fax: 865.576.5728

Email: reports@adonis.osti.gov

Reference herein to any specific commercial product, process, or service by trade name, trademark, manufacturer, or otherwise, does not necessarily constitute or imply its endorsement, recommendation, or favoring by the United States Government or any agency thereof or its contractors or subcontractors. 


\title{
CORRECTIVE ACTION DECISION DOCUMENT FOR CORRECTIVE ACTION UNIT 271: AREAS 25, 26, AND 27 SEPTIC SYSTEMS, NEVADA TEST SITE, NEVADA
}

\author{
U.S. Department of Energy \\ National Nuclear Security Administration \\ Nevada Operations Office \\ Las Vegas, Nevada
}

Controlled Copy No.:

Revision No.: 0

September 2002

Approved for public release; further dissemination unlimited. 


\section{CORRECTIVE ACTION DECISION DOCUMENT FOR}

CORRECTIVE ACTION UNIT 271:

AREAS 25, 26, AND 27 SEPTIC SYSTEMS, NEVADA TEST SITE, NEVADA

Approved by: Signature Approved

Date: $9 / 16 / 02$

Janet Appenzeller-Wing, Project Manager

Industrial Sites Project

Approved by: Signature Approved

Date: $9 / 16 / 02$

Runore C. Wycoff, Division Director

Environmental Restoration Project 


\section{Table of Contents}

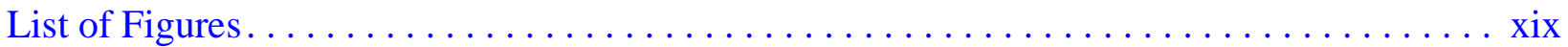

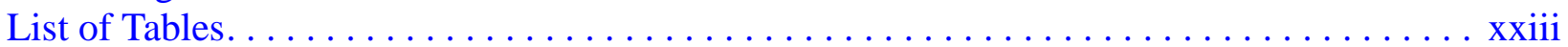

List of Acronyms and Abbreviations $\ldots \ldots \ldots \ldots \ldots \ldots \ldots \ldots \ldots \ldots \ldots \ldots \ldots \ldots \ldots \ldots \ldots$

Executive Summary . . . . . . . . . . . . . . . . . . . . . . . . ES-1

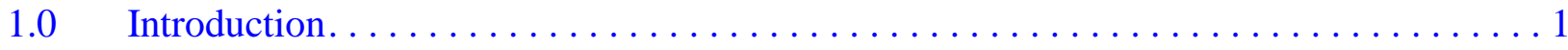

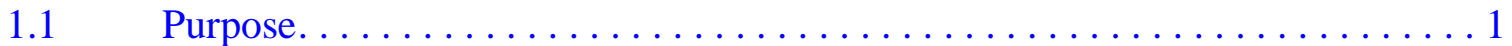

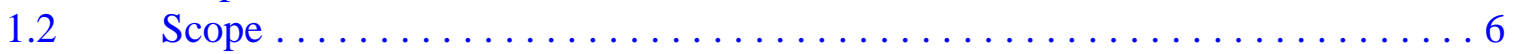

Corrective Action Decision Document Contents. . . . . . . . . . . . . 7

2.0 Corrective Action Investigation Summary $\ldots \ldots \ldots \ldots \ldots \ldots \ldots \ldots \ldots$

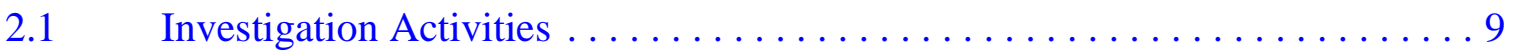

2.1.1 Security Checkpoint Septic System (CAS 25-04-01) . . . . . . . 16

2.1.2 PAN-AM Trailers Septic System (CAS 25-04-03) . . . . . . . . . . 17

2.1.3 Reactor Control Point Septic System (CAS 25-04-04) . . . . . . . . 19

2.1.4 BREN Tower Septic System (CAS 25-04-08) . . . . . . . . . . . 21

2.1.5 Engine Test Stand No. 1 Septic System (CAS 25-04-09) . . . . . . . 22

2.1.6 Rad-Safe Trailers Septic System (CAS 25-04-10) . . . . . . . . . 24

2.1.7 South of LASL Trailers Septic System (CAS 25-04-11) . . . . . . 25

2.1.8 Port Gaston Training Area Contaminated Water Reservoir (CAS 26-03-01) ......................... 28

2.1.9 Area 26 Check Station (Bldg. 2105) Septic System (CAS 26-04-01) ......................... 29

2.1.10 Hot Critical Facility (Bldg. 2103) Septic System (CAS 26-04-02) ......................... 30

2.1.11 Buildings 2201 and 2202 Radioactive Leachfield

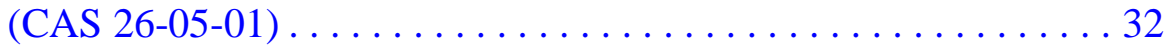

2.1.12 Building 2203 Septic System (CAS 26-05-03) . . . . . . . . . 34

2.1.13 Building 2201 Septic System (CAS 26-05-04) . . . . . . . . . 35

2.1.14 Buildings 2101, 2102, and 2107 Septic System (CAS 26-05-05) .......................... 37

2.1.15 Building 5200 Septic System (CAS 27-05-02) . . . . . . . . 40

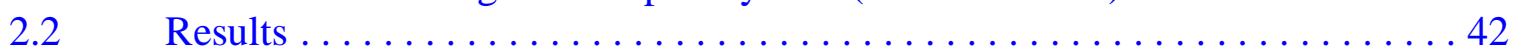

2.2.1 Summary of Characterization Data . . . . . . . . . . . . 42

2.2.1.1 Security Checkpoint Septic System

(CAS 25-04-01) .................. 44

2.2.1.2 PAN-AM Trailers Septic System (CAS 25-04-03) .................. 45

2.2.1.3 Reactor Control Point Septic System (CAS 25-04-04) .................. 46

2.2.1.4 BREN Tower Septic System (CAS 25-04-08) . . . 47 


\section{Table of Contents (Continued)}

2.2.1.5 Engine Test Stand No. 1 Septic System

2.2.1.6 Rad-Safe Trailers Septic System (CAS 25-04-10) ...................... 49

2.2.1.7 South of LASL Trailers Septic System (CAS 25-04-11) .................... 50

2.2.1.8 Port Gaston Training Area Contaminated Water Reservoir (CAS 26-03-01) . . . . . . . . . . . . 51

2.2.1.9 Area 26 Check Station (Bldg. 2105) Septic System (CAS 26-04-01) .................... 52

2.2.1.10 Hot Critical Facility (Bldg. 2103) Septic System (CAS 26-04-02) ..................... 52

2.2.1.11 Buildings 2201 and 2202 Radioactive Leachfield (CAS 26-05-01) .................... 53

2.2.1.12 Building 2203 Septic System (26-05-03) . ...... 54

2.2.1.13 Building 2201 Septic System (CAS 26-05-04) .... 55

2.2.1.14 Buildings 2101, 2102, and 2107 Septic System (CAS 26-05-05) .................... 56

2.2.1.15 Building 5200 Septic System (CAS 27-05-02) . . . . 57

2.2.2 Data Assessment Summary .................... 58

$2.3 \quad$ Need for Corrective Action . . . . . . . . . . . . . . . . . . . . . . 59

2.3.1 Security Checkpoint Septic System (CAS 25-04-01) . . . . . . . 60

2.3.2 PAN-AM Trailers Septic System (CAS 25-04-03) ........... 61

2.3.3 Reactor Control Point Septic System (CAS 25-04-04) . . . . . . 62

2.3.4 BREN Tower Septic System (CAS 25-04-08) ............ 63

2.3.5 Engine Test Stand No. 1 Septic System (CAS 25-04-09) . . . . . . 64

2.3.6 Rad-Safe Trailers Septic System (CAS 25-04-10) . . . . . . . . 65

2.3.7 South of LASL Trailers Septic System (CAS 25-04-11) . . . . . 65

2.3.8 Port Gaston Training Area Contaminated Water Reservoir (CAS 26-03-01) ............................66

2.3.9 Area 26 Check Station (Bldg. 2105) Septic System (CAS 26-04-01) ............................67 67

2.3.10 Hot Critical Facility (Bldg. 2103) Septic System (CAS 26-04-02) ..........................67 67

2.3.11 Buildings 2201 and 2202 Radioactive Leachfield (CAS 26-05-01) ...........................68

2.3.12 Building 2203 Septic System (26-05-03) . . . . . . . . . . 69

2.3.13 Building 2201 Septic System (CAS 26-05-04) . . . . . . . . . . 70

2.3.14 Buildings 2101, 2102, and 2107 Septic System (CAS 26-05-05) . . 71

2.3.15 Building 5200 Septic System (CAS 27-05-02) ........... 72 


\section{Table of Contents (Continued)}

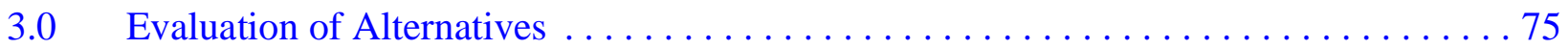

$3.1 \quad$ Corrective Action Objectives. ......................... 75

$3.2 \quad$ Screening Criteria . . . . . . . . . . . . . . . . . . . . . . . . . . 76

3.2.1 Corrective Action Standards . . . . . . . . . . . . . . . . . . . 77

3.2.2 Remedy Selection Decision Factors $\ldots \ldots \ldots \ldots \ldots \ldots \ldots$

3.3 Development of Corrective Action Alternatives .................... 80

3.3.1 Alternative 1 - No Further Action ................. 81

3.3.1.1 Rad-Safe Trailers Septic System (CAS 25-04-10) . . 81

3.3.2 Alternative 2 - Clean Closure .................... 81

3.3.2.1 Security Checkpoint Septic System

(CAS 25-04-01) .................... 82

3.3.2.2 PAN-AM Trailers Septic System

(CAS 25-04-03) ................... 82

3.3.2.3 Reactor Control Point Septic System

(CAS 25-04-04) ..................... 82

3.3.2.4 BREN Tower Septic System (CAS 25-04-08) . . . . 83

3.3.2.5 Engine Test Stand No. 1 Septic System

(CAS 25-04-09) ..................... 84

3.3.2.6 South of LASL Trailers Septic System

(CAS 25-04-11) .................... 84

3.3.2.7 Port Gaston Training Area Contaminated Water

Reservoir (CAS 26-03-01) . . . . . . . . . . . . . 84

3.3.2.8 Area 26 Check Station, Building 2105,

Septic System (CAS 26-04-01) . . . . . . . . . 85

3.3.2.9 Hot Critical Facility, Building 2103,

Septic System (CAS 26-04-02) . . . . . . . . . . 85

3.3.2.10 Buildings 2201 and 2202 Radioactive Leachfield

(CAS 26-05-01) ................... 86

3.3.2.11 Building 2203 Septic System (CAS 26-05-03) . . . 86

3.3.2.12 Building 2201 Septic System (CAS 26-05-04) . . . 8 87

3.3.2.13 Building 2102, 2102, and 2107 Septic System

(CAS 26-05-05) .................... 87

3.3.2.14 Building 5200 Septic System (CAS 27-05-02) . . . 88

3.3.3 Alternative 3 - Close in Place with Administrative Controls . . . . 89

3.3.3.1 Security Checkpoint Septic System

(CAS 25-04-01) .................... 89

3.3.3.2 PAN-AM Trailers Septic System

(CAS 25-04-03) ..................... 90

3.3.3.3 Reactor Control Point Septic System

(CAS 25-04-04) ......................92 


\section{Table of Contents (Continued)}

3.3.3.4 BREN Tower Septic System (CAS 25-04-08) . . . 94

3.3.3.5 Engine Test Stand No. 1 Septic System (CAS 25-04-09) .................... 96

3.3.3.6 South of LASL Trailers Septic System (CAS 25-04-11) ................... . 97

3.3.3.7 Port Gaston Training Area Contaminated Water Reservoir (CAS 26-03-01) . . . . . . . . . . . . . . . 99

3.3.3.8 Hot Critical Facility, Building 2103, Septic System (CAS 26-04-02) . . . . . . . . . 101

3.3.3.9 Buildings 2201 and 2202 Radioactive Leachfield (CAS 26-05-01) . . . . . . . . . . . . . . . . . 102

3.3.3.10 Building 2203 Septic System (CAS 26-05-03) . . . 104

3.3.3.11 Building 2201 Septic System (CAS 26-05-04) . . . 106

3.3.3.12 Buildings 2101, 2102, and 2107 Septic Systems (CAS 26-05-05) . . . . . . . . . . . . . . . . 107

3.3.3.13 Building 5200 Septic System (CAS 27-05-02) . . 109

3.4 Evaluation and Comparison of Alternatives $\ldots \ldots \ldots \ldots \ldots \ldots \ldots \ldots$

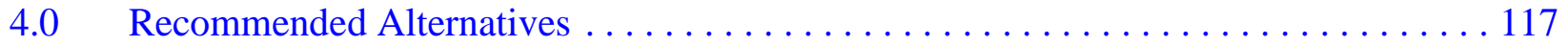

$5.0 \quad$ References.......................................... 119

\section{Appendix A - Corrective Action Investigation Report for CAU 271}

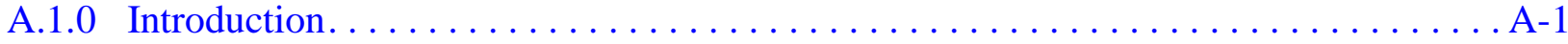

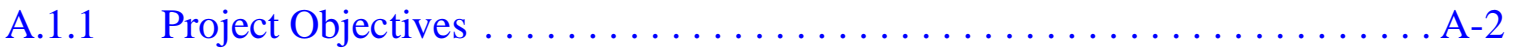

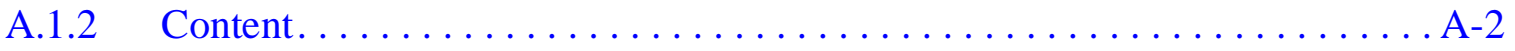

A.2.0 Investigation Overview $\ldots \ldots \ldots \ldots \ldots \ldots \ldots \ldots \ldots \ldots \ldots \ldots \ldots \ldots \ldots \ldots \ldots$

A.2.1 Preliminary Conceptual Model $\ldots \ldots \ldots \ldots \ldots \ldots \ldots \ldots \ldots \ldots \ldots \ldots$

A.2.2 Sample Locations. . . . . . . . . . . . . . . . . . . . A-6

A.2.2.1 Housekeeping Removal of Debris . . . . . . . . . . . . . A-7

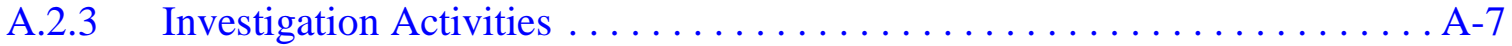

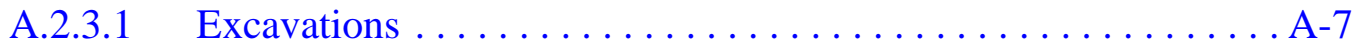

A.2.3.2 Field Screening $\ldots \ldots \ldots \ldots \ldots \ldots \ldots \ldots \ldots \ldots \ldots \ldots \ldots \ldots$

A.2.3.3 Septic Tank and Distribution Box Integrity Soil Sampling . . . . . A A-9

A.2.3.4 Leachfield Soil Sampling. . . . . . . . . . . . . . . . . . . A-9

A.2.3.5 Septic Tank, Distribution Box, and Collection System Piping Inspections and Sampling . . . . . . . . . . . A-10

A.2.3.6 Unrestricted Release Criteria Determination. . . . . . . . . . . . A-11

A.2.3.7 In Situ Measurements. . . . . . . . . . . . . . . . . . . . . . . . A-12 


\section{Table of Contents (Continued)}

A.2.3.8 Surface Soil Sampling $\ldots \ldots \ldots \ldots \ldots \ldots \ldots \ldots \ldots \ldots \ldots \ldots \ldots \ldots$

A.2.4 Geology ....................................

A.2.5 Hydrology ................................. A 14

A.2.6 Laboratory Analytical Information $\ldots \ldots \ldots \ldots \ldots \ldots \ldots \ldots \ldots \ldots \ldots \ldots \ldots \ldots \ldots \ldots$

A.2.7 Comparison to Preliminary Action Levels ................... A-16

A.3.0 Security Checkpoint Septic System (CAS 25-04-01) . . . . . . . . . . . . . . . A-17

A.3.1 Corrective Action Investigation. . . . . . . . . . . . . . . . A-17

A.3.1.1 Deviations .............................. A-17

A.3.2 Investigation Results ............................. A-17

A.3.2.1 Septic Tank Contents...................... A-17

A.3.2.2 Septic Tank Integrity Soil Sampling ............... A-19

A.3.2.3 Leachfield Excavation Soil Sampling ............... A-21

A.3.2.4 Additional Sampling ........................ A-22

A.3.2.5 Collection System Pipe Inspections................ A-22

A.3.2.6 Field-Screening Results ..................... A-23

A.3.2.7 Radiological Survey Results ................... A-23

A.3.2.8 Sample Analysis . ........................ A-24

A.3.3 Analytes Detected Above Minimum Reporting Limits.............. . A-24

A.3.3.1 Analytical Results for Soil Samples ................. A-24

A.3.3.1.1 Total Volatile Organic Compounds ........... A-24

A.3.3.1.2 Total Semivolatile Organic Compounds ........ A-25

A.3.3.1.3 Total Petroleum Hydrocarbons $\ldots \ldots \ldots \ldots \ldots$. A-25

A.3.3.1.4 Total RCRA Metals ................... A-25

A.3.3.1.5 Polychlorinated Biphenyls .............. A-26

A.3.3.1.6 Gamma Spectrometry $\ldots \ldots \ldots \ldots \ldots \ldots$. . . 26

A.3.3.1.7 Isotopic Uranium ................... A-28

A.3.3.1.8 Isotopic Plutonium . ................. A-28

A.3.3.1.9 Strontium-90 . . . . . . . . . . . . . . . A-29

A.3.3.2 Septic Tank Sample Results . . . . . . . . . . . . . . A-29

A.3.4 Contaminants of Concern .......................... A-31

A.3.5 Nature and Extent of Contamination ..................... A-31

A.3.6 Revised Conceptual Model ......................... A-31

A.4.0 Pan American Trailers Septic System (CAS 25-04-03) . . . . . . . . . . . . . . A A-32

A.4.1 Corrective Action Investigation. . . . . . . . . . . . . . . . . A-32

A.4.1.1 Deviations ...............................

A.4.2 Investigation Results . . . ....................... A-39

A.4.2.1 Septic Tank Contents....................... A-39

A.4.2.2 Septic Tank Integrity Soil Sampling ............... A-39

A.4.2.3 Leachfield Excavation Soil Sampling .............. A-40 


\section{Table of Contents (Continued)}

A.4.2.4 Additional Sampling . . . . . . . . . . . . . . . A-40

A.4.2.5 Collection System Pipe Inspections. . . . . . . . . . . . . . . . . A-41

A.4.2.6 Field-Screening Results . . . . . . . . . . . . . . . . A-42

A.4.2.7 Radiological Survey Results . . . . . . . . . . . . . . . . . A-42

A.4.2.8 Sample Analysis . . . . . . . . . . . . . . . . . . A-43

A.4.3 Analytes Detected Above Minimum Reporting Limits . . . . . . . . . . . . A-43

A.4.3.1 Analytical Results for Soil Samples . . . . . . . . . . . . . . . A-43

A.4.3.1.1 Total Volatile Organic Compounds .......... A-43

A.4.3.1.2 Total Semivolatile Organic Compounds ... . . . . A-44

A.4.3.1.3 Total Petroleum Hydrocarbons . . . . . . . . . A-46

A.4.3.1.4 Total RCRA Metals ................ A-46

A.4.3.1.5 Polychlorinated Biphenyls ............ A-48

A.4.3.1.6 Gamma Spectrometry $\ldots \ldots \ldots \ldots \ldots \ldots$ A-48

A.4.3.1.7 Isotopic Uranium . . . . . . . . . . A-50

A.4.3.1.8 Isotopic Plutonium . . . . . . . . . . . A-50

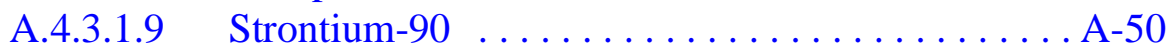

A.4.3.2 Septic Tank Sample Results . . . . . . . . . . . . . A-50

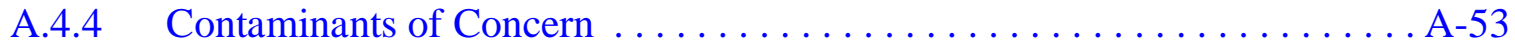

A.4.5 Nature and Extent of Contamination . . . . . . . . . . . . . . A-53

A.4.6 Revised Conceptual Model . . . . . . . . . . . . . . . . A-53

A.5.0 Reactor Control Point Septic System (CAS 25-04-04) . . . . . . . . . . . . A-54

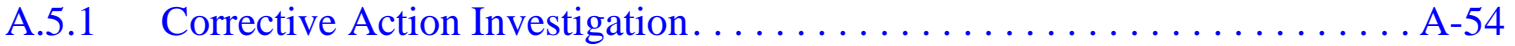

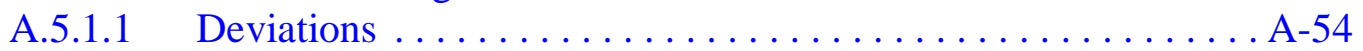

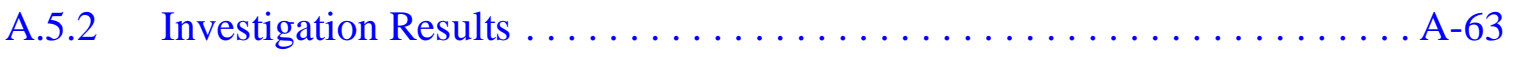

A.5.2.1 Septic Tank Contents...................... A-63

A.5.2.2 Distribution Box Contents . . . . . . . . . . . . . . . . . A A-64

A.5.2.3 Septic Tank and Distribution Box Integrity Soil Sampling. . . . A A-64

A.5.2.4 Leachfield Excavation Soil Sampling . . . . . . . . . . . . . A-65

A.5.2.5 Additional Sampling . . . . . . . . . . . . . . . . . A-66

A.5.2.6 Collection System Pipe Inspections. . . . . . . . . . . . . . . A-67

A.5.2.7 Field-Screening Results . . . . . . . . . . . . . . . . . . A A-68

A.5.2.8 Radiological Survey Results . . . . . . . . . . . . . . . A-68

A.5.2.9 Sample Analysis . . . . . . . . . . . . . . . . . . . . A-69

A.5.3 Analytes Detected Above Minimum Reporting Limits . . . . . . . . . . . . . A-69

A.5.3.1 Analytical Results for Soil Samples . . . . . . . . . . . . . . . . . A-69

A.5.3.1.1 Total Volatile Organic Compounds . . . . . . . . A A-70

A.5.3.1.2 Total Semivolatile Organic Compounds ..... . . A-70

A.5.3.1.3 Total Petroleum Hydrocarbon . . . . . . . . . A A-70

A.5.3.1.4 Total RCRA Metals ............... A-71

A.5.3.1.5 Polychlorinated Biphenyls ............ A-73 


\section{Table of Contents (Continued)}

\begin{tabular}{|c|c|}
\hline A.5.3.1.6 & Total Pesticides \\
\hline A.5.3.1.7 & Total Herbicides \\
\hline A.5.3.1.8 & Gamma Spectrometry Results \\
\hline A.5.3.1.9 & Isotopic Uranium . . . . . . . . \\
\hline A.5.3.1.10 & Isotopic Plutonium \\
\hline A.5.3.1.11 & Strontium-90 . . . \\
\hline
\end{tabular}

A.5.3.2 Septic Tank Sample Results . . . . . . . . . . . . . . . . . . . . A-77

A.5.4 Contaminants of Concern . . . . . . . . . . . . . . . . . A-78

A.5.5 Nature and Extent of Contamination . . . . . . . . . . . . . A-78

A.5.6 Revised Conceptual Model . . . . . . . . . . . . . . . . . . . A-81

A.6.0 BREN Tower Septic System (CAS 25-04-08) . . . . . . . . . . . . . . . . A-82

A.6.1 Corrective Action Investigation. . . . . . . . . . . . . . . . A-82

A.6.1.1 Deviations ........................... A-86

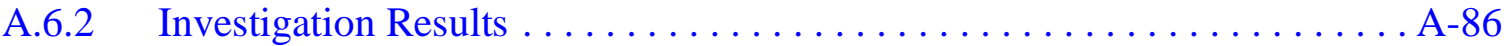

A.6.2.1 Septic Tank Contents. ...................... A-86

A.6.2.2 Distribution Box Contents . . . . . . . . . . . . . . A-86

A.6.2.3 Septic Tank and Distribution Box Integrity Soil Sampling. . . . . A-88

A.6.2.4 Leachfield Excavation Soil Sampling . . . . . . . . . . . . . . A-88

A.6.2.5 Additional Sampling . . . . . . . . . . . . . . . A-88

A.6.2.6 Collection System Pipe Inspections. . . . . . . . . . . . . A-89

A.6.2.7 Field-Screening Results . . . . . . . . . . . . . . . . . A A-89

A.6.2.8 Radiological Survey Results . . . . . . . . . . . . . . . . . . A A-89

A.6.2.9 Sample Analysis . . . . . . . . . . . . . . . . . . . A A-90

A.6.3 Analytes Detected Above Minimum Reporting Limits . . . . . . . . . . . . . A-90

A.6.3.1 Analytical Results for Soil Samples . . . . . . . . . . . . . . . . A A-90

A.6.3.1.1 Total Volatile Organic Compounds ............ A-90

A.6.3.1.2 Total Semivolatile Organic Compounds . . . . . . . A-91

A.6.3.1.3 Total Petroleum Hydrocarbons ............ A-91

A.6.3.1.4 Total RCRA Metals ................ A-91

A.6.3.1.5 Gamma Spectrometry Results . . . . . . . . A-92

A.6.3.1.6 Isotopic Uranium . . . . . . . . . . . . . A-94

A.6.3.1.7 Isotopic Plutonium . . . . . . . . . . . . . A-94

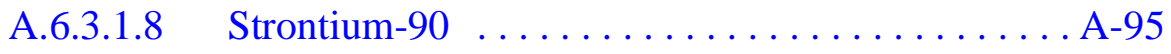

A.6.3.2 Septic Tank Sample Results . . . . . . . . . . . . . . . . . . A A-95

A.6.4 Contaminants of Concern . . . . . . . . . . . . . . . . . . . A-95

A.6.5 Nature and Extent of Contamination . . . . . . . . . . . . . . A-95

A.6.6 Revised Conceptual Model . . . . . . . . . . . . . . . . . . A-98

A.7.0 Engine Test Stand No.1 Septic System (CAS 25-04-09) . . . . . . . . . . . . . . . . A-99

A.7.1 Corrective Action Investigation. . . . . . . . . . . . . . . . A-99 


\section{Table of Contents (Continued)}

A.7.1.1 Deviations . . . . . . . . . . . . . . . . . . . . . A-99

A.7.2 Investigation Results . . . . . . . . . . . . . . . . . . . . . . . A-99

A.7.2.1 Septic Tank Contents. . . . . . . . . . . . . . . . . . . . . A-99

A.7.2.2 Septic Tank Integrity Soil Sampling .............. A-105

A.7.2.3 Leachfield Excavation Soil Sampling ................. A-105

A.7.2.4 Collection System Pipe Inspections................... A-106

A.7.2.5 Field-Screening Results ..................... A-107

A.7.2.6 Radiological Survey Results . . . . . . . . . . . . . A-108

A.7.2.7 Sample Analysis . ........................ A-108

A.7.3 Analytes Detected Above Minimum Reporting Limits.............. A-109

A.7.3.1 Analytical Results for Soil Samples ................. A-109

A.7.3.1.1 Total Volatile Organic Compounds .......... A-109

A.7.3.1.2 Total Semivolatile Organic Compounds ....... A-109

A.7.3.1.3 Total Petroleum Hydrocarbons . ............. A-109

A.7.3.1.4 Total RCRA Metals .................... A-109

A.7.3.1.5 Polychlorinated Biphenyls .............. A-112

A.7.3.1.6 Gamma Spectrometry $\ldots \ldots \ldots \ldots \ldots \ldots$. A-112

A.7.3.1.7 Isotopic Uranium . . . . . . . . . . . . . . . A-114

A.7.3.1.8 Isotopic Plutonium ................... A-114

A.7.3.1.9 Strontium-90 .................. A-114

A.7.3.2 Septic Tank Sample Results .................... A-115

A.7.4 Contaminants of Concern ............................ A-115

A.7.5 Nature and Extent of Contamination....................... A-115

A.7.6 Revised Conceptual Model .......................... A-115

A.8.0 Rad-Safe Trailers Septic System (CAS 25-04-10) . . . . . . . . . . . . . . . . . A-119

A.8.1 Corrective Action Investigation. . . . . . . . . . . . . . . . . A-119

A.8.1.1 Deviations ............................. A-125

A.8.2 Investigation Results . . . . . . . . . . . . . . . . . . . A 125

A.8.2.1 Septic Tank Contents........................ A-125

A.8.2.2 Distribution Box Contents ................... A-126

A.8.2.3 Septic Tank and Distribution Box Integrity Soil Sampling... . A-126

A.8.2.4 Leachfield Excavation Soil Sampling. ............... A-128

A.8.2.5 Collection System Pipe Inspections. . . . . . . . . . . A-128

A.8.2.6 Field-Screening Results ........................ A-129

A.8.2.7 Radiological Survey Results . . . . . . . . . . . . . . . . A-130

A.8.2.8 Sample Analysis . ....................... A-130

A.8.3 Analytes Detected Above Minimum Reporting Limits............. . . A-130

A.8.3.1 Analytical Results for Soil Samples .................. A-130

A.8.3.1.1 Total Volatile Organic Compounds .......... A-130

A.8.3.1.2 Total Semivolatile Organic Compounds ....... A-131 


\section{Table of Contents (Continued)}

A.8.3.1.3 Total Petroleum Hydrocarbons $\ldots \ldots \ldots \ldots$. . . . 131

A.8.3.1.4 Total RCRA Metals ................ A-131

A.8.3.1.5 Gamma Spectrometry Results .......... A-133

A.8.3.1.6 Isotopic Uranium . . . . . . . . . . . . A-135

A.8.3.1.7 Isotopic Plutonium . . . . . . . . . . A-136

A.8.3.1.8 Strontium $-90 \ldots \ldots \ldots \ldots \ldots \ldots \ldots \ldots \ldots \ldots$ A-136

A.8.3.2 Septic Tank, Distribution Box, and Pipe Content

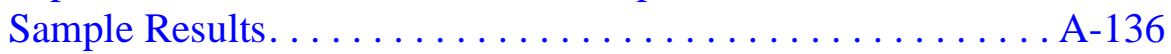

A.8.4 Contaminants of Concern . . . . . . . . . . . . . . . A-136

A.8.5 Nature and Extent of Contamination . . . . . . . . . . . . . A-136

A.8.6 Revised Conceptual Model . . . . . . . . . . . . . . . . . . . A-136

A.9.0 South of LASL Trailers Septic System (CAS 25-04-11) . . . . . . . . . . . . . . A-137

A.9.1 Corrective Action Investigation. . . . . . . . . . . . . . . A-137

A.9.1.1 Deviations . . . . . . . . . . . . . . . . . . A-137

A.9.2 Investigation Results . . . . . . . . . . . . . . . . . . A-142

A.9.2.1 Septic Tank Contents. .................... A-142

A.9.2.2 Distribution Box Contents . . . . . . . . . . . . . . . . . . A-144

A.9.2.3 Septic Tank and Distribution Box Integrity Soil Sampling. . . . A-145

A.9.2.4 Leachfield Excavation Soil Sampling . . . . . . . . . . . . . . A-145

A.9.2.5 Additional Sampling . . . . . . . . . . . . . . . A-145

A.9.2.6 Collection System Pipe Inspections. . . . . . . . . . . . . . . . A-146

A.9.2.7 Field-Screening Results . . . . . . . . . . . . . . . . . A-147

A.9.2.8 Radiological Survey Results . . . . . . . . . . . . . . . . . . A-147

A.9.2.9 Sample Analysis . . . . . . . . . . . . . . . . . . . A-148

A.9.3 Analytes Detected Above Minimum Reporting Limits . . . . . . . . . . . . A A-148

A.9.3.1 Analytical Results for Soil Samples . . . . . . . . . . . . . . . . A-148

A.9.3.1.1 Total Volatile Organic Compounds . . . . . . . . A-149

A.9.3.1.2 Total Semivolatile Organic Compounds ... . . . A-149

A.9.3.1.3 Total Petroleum Hydrocarbons ........... A-149

A.9.3.1.4 Total RCRA Metals ................ A-151

A.9.3.1.5 Polychlorinated Biphenyls ............ A-153

A.9.3.1.6 Gamma Spectrometry Results ........... A-153

A.9.3.1.7 Isotopic Uranium . . . . . . . . . . . . . A-153

A.9.3.1.8 Isotopic Plutonium . . . . . . . . . . A-155

A.9.3.1.9 Strontium-90 ................ A-155

A.9.3.2 Septic Tank and Manhole Sample Results . . . . . . . . . . . A-156

A.9.4 Contaminants of Concern . . . . . . . . . . . . . . . . A-156

A.9.5 Nature and Extent of Contamination . . . . . . . . . . . . . . . A-159

A.9.6 Revised Conceptual Model . . . . . . . . . . . . . . . . . . . A-160 


\section{Table of Contents (Continued)}

A.10.0 Port Gaston Training Area Contaminated Water Reservoir (CAS 26-03-01) . . . . A-161

A.10.1 Corrective Action Investigation. . . . . . . . . . . . . . . A-161

A.10.1.1 Deviations . . . . . . . . . . . . . . . . . . . . A-161

A.10.2 Investigation Results . . . . . . . . . . . . . . . . . . . .

A.10.2.1 Additional Sampling . . . . . . . . . . . . . . . A-165

A.10.2.2 Field-Screening Results . . . . . . . . . . . . . . . A-165

A.10.2.3 Radiological Survey Results . . . . . . . . . . . . . . . . . . A-166

A.10.2.4 Sample Analysis . . . . . . . . . . . . . . . . . A-167

A.10.3 Analytes Detected Above Minimum Reporting Limits . . . . . . . . . . . . . A-167

A.10.3.1 Analytical Results in Soil Samples . . . . . . . . . . . . . . . . A-167

A.10.3.1.1 Total Volatile Organic Compounds .......... A-167

A.10.3.1.2 Total Semivolatile Organic Compounds . . . . . A A-167

A.10.3.1.3 Total Petroleum Hydrocarbons . . . . . . . . A-168

A.10.3.1.4 Total RCRA Metals and Beryllium .......... A-168

A.10.3.1.5 Total Pesticides and Total Herbicides ........ A-168

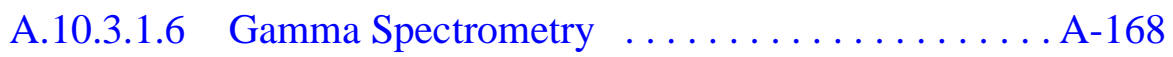

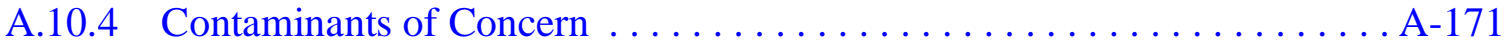

A.10.5 Nature and Extent of Contamination . . . . . . . . . . . . . . . . A-171

A.10.6 Revised Conceptual Model . . . . . . . . . . . . . . . . . . . A -171

A.11.0 Area 26 Check Station (Building 2105) Septic System (CAS 26-04-01) . . . . . . A-172

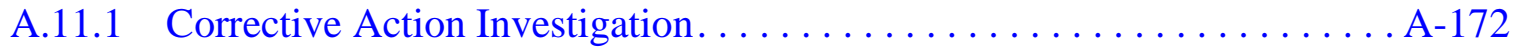

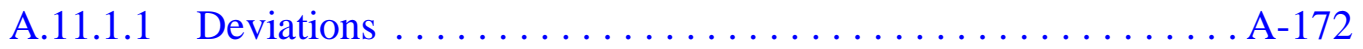

A.11.2 Investigation Results . . . . . . . . . . . . . . . . .

A.11.2.1 Septic Tank Contents. ..................... A-172

A.11.2.2 Distribution Box Contents . . . . . . . . . . . . . . . A-176

A.11.2.3 Septic Tank and Distribution Box Integrity Soil Sampling. . . . A-176

A.11.2.4 Leachfield Excavation Soil Sampling . . . . . . . . . . . . . . . . A-177

A.11.2.5 Additional Sampling . . . . . . . . . . . . . . . . . . . A-179

A.11.2.6 Collection System Pipe Inspections. . . . . . . . . . . . . . . . . A-179

A.11.2.7 Field-Screening Results . . . . . . . . . . . . . . . . . A-180

A.11.2.8 Radiological Survey Results . . . . . . . . . . . . . . . A-180

A.11.2.9 Sample Analysis . . . . . . . . . . . . . . . . . A-181

A.11.3 Analytes Detected Above Minimum Reporting Limits . . . . . . . . . . . . . A-181

A.11.3.1 Analytical Results for Soil Samples . . . . . . . . . . . . . . . A-181

A.11.3.1.1 Total Volatile Organic Compounds .......... A-182

A.11.3.1.2 Total Semivolatile Organic Compounds .... . . A-182

A.11.3.1.3 Total Petroleum Hydrocarbons ............ A-182

A.11.3.1.4 Total RCRA Metals ................ A-183

A.11.3.1.5 Total Beryllium $\ldots \ldots \ldots \ldots \ldots \ldots \ldots \ldots$ A-184 


\section{Table of Contents (Continued)}
A.11.3.1.6 Total Pesticides
A-184
A.11.3.1.7 Gamma Spectrometry
A-184
A.11.3.1.8 Isotopic Uranium
A-185
A.11.3.1.9 Isotopic Plutonium
A-186
A.11.3.1.10 Strontium-90
A-186

A.11.3.2 Septic Tank and Distribution Box Sample Results . . . . . . . . A-186

A.11.4 Contaminants of Concern . . . . . . . . . . . . . . . . . . . A-187

A.11.5 Nature and Extent of Contamination ................... A-187

A.11.6 Revised Conceptual Model . . . . . . . . . . . . . . . . A-187

A.12.0 Hot Critical Facility (Building 2103) Septic System (CAS 26-04-02) . . . . . . . . A-189

A.12.1 Corrective Action Investigation. . . . . . . . . . . . . . . . A-189

A.12.1.1 Deviations ........................... A-189

A.12.2 Investigation Results . . . . . . . . . . . . . . . . . . . A-189

A.12.2.1 Septic Tank Contents . . . . . . . . . . . . . . . . . . . A-189

A.12.2.2 Distribution Box Contents . . . . . . . . . . . . . . A-193

A.12.2.3 Septic Tank and Distribution Box Integrity Soil Sampling. . . A A-193

A.12.2.4 Leachfield Excavation Soil Sampling . . . . . . . . . . . . . . . . A-194

A.12.2.5 Collection System Pipe Inspections. . . . . . . . . . . . . . . . A-196

A.12.2.6 Field-Screening Results . . . . . . . . . . . . . . . . . . A-196 . . . . . . . A-196

A.12.2.7 Radiological Survey Results . . . . . . . . . . . . . . . . A-196

A.12.2.8 Sample Analysis . . . . . . . . . . . . . . . . . . . . . . . A-197

A.12.3 Analytes Detected Above Minimum Reporting Limits . . . . . . . . . . . . . A A-197

A.12.3.1 Analytical Results for Soil Samples . . . . . . . . . . . . . . . A-197

A.12.3.1.1 Total Volatile Organic Compounds . . . . . . . . . A-197

A.12.3.1.2 Total Semivolatile Organic Compounds .... . . A A-198

A.12.3.1.3 Total Petroleum Hydrocarbons . . . . . . . . . . A-198

A.12.3.1.4 Total RCRA Metals ................. A-198

A.12.3.1.5 Total Beryllium ................ A-200

A.12.3.1.6 Polychlorinated Biphenyls ............. A-200

A.12.3.1.7 Gamma Spectrometry Results . . . . . . . . . . A-200

A.12.3.1.8 Isotopic Uranium . . . . . . . . . . . . . A-200

A.12.3.1.9 Isotopic Plutonium . . . . . . . . . . . . A-200

A.12.3.1.10 Strontium $-90 \ldots \ldots \ldots \ldots \ldots \ldots$ A-202

A.12.3.2 Septic Tank Sample Results . . . . . . . . . . . . . . . . . . . . A-202

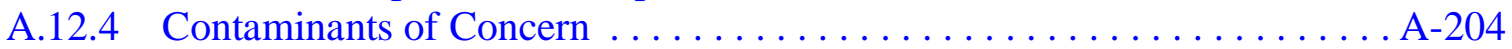

A.12.5 Nature and Extent of Contamination . . . . . . . . . . . . . . A-205

A.12.6 Revised Conceptual Model . . . . . . . . . . . . . . . . A-205 


\section{Table of Contents (Continued)}

A.13.0 Buildings 2201 and 2202 Radioactive Leachfield (CAS 26-05-01) . . . . . . . . A-206

A.13.1 Corrective Action Investigation. . . . . . . . . . . . . . A-206

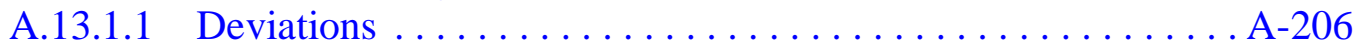

A.13.2 Investigation Results . . . . . . . . . . . . . . . . . . . A-206

A.13.2.1 Distribution Box Contents . . . . . . . . . . . . . . . A-206

A.13.2.2 Distribution Box Integrity Soil Sampling . . . . . . . . . . . . A-211

A.13.2.3 Leachfield Excavation Soil Sampling . . . . . . . . . . . . . A A-211

A.13.2.4 Additional Sampling . . . . . . . . . . . . . . . . A-212

A.13.2.5 Collection System Pipe Inspections. . . . . . . . . . . . A-212

A.13.2.6 Field-Screening Results . . . . . . . . . . . . . . . A-215

A.13.2.7 Radiological Survey Results . . . . . . . . . . . . . . . . . A-215

A.13.2.7.1 In Situ Cone Penetrometer Measurements . . . . . A A-215

A.13.2.7.2 Radiological Screening Results . . . . . . . . A-216

A.13.2.7.3 Swipe Measurements ............... A-216

A.13.2.8 Sample Analysis . . . . . . . . . . . . . . . . . . . . . . . A-219

A.13.3 Analytes Detected Above Minimum Reporting Limits . . . . . . . . . . . . . A-220

A.13.3.1 Analytical Results for Soil Samples . . . . . . . . . . . . . . A-220

A.13.3.1.1 Total Volatile Organic Compounds ............ A-220

A.13.3.1.2 Total Semivolatile Organic Compounds ....... A-221

A.13.3.1.3 Total Petroleum Hydrocarbons ........... A-221

A.13.3.1.4 Total RCRA Metals ............... A-221

A.13.3.1.5 Total Beryllium .................. A-223

A.13.3.1.6 Polychlorinated Biphenyls ............. A-223

A.13.3.1.7 Gamma Spectrometry Results . . . . . . . . A A-223

A.13.3.1.8 Isotopic Uranium . . . . . . . . . . . A-223

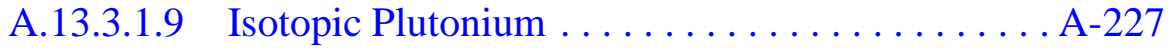

A.13.3.1.10 Strontium-90 . . . . . . . . . . . . . A-227

A.13.3.2 Manhole 1 Sample Results . . . . . . . . . . . . . . . A-228

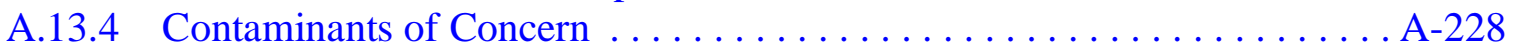

A.13.5 Nature and Extent of Contamination . . . . . . . . . . . . . . A-228

A.13.6 Revised Conceptual Model . . . . . . . . . . . . . . . . . . . A-230

A.14.0 Project Pluto Test Area - Building 2203 Septic System (CAS 26-05-03) . . . . . . A A-231

A.14.1 Corrective Action Investigation. . . . . . . . . . . . . . . A-231

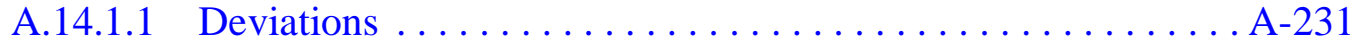

A.14.2 Investigation Results . . . . . . . . . . . . . . . . .

A.14.2.1 Removal of Housekeeping Debris and Surface Surveys . . . . . A-231

A.14.2.2 Septic Tank Contents. . . . . . . . . . . . . . . . . A-236

A.14.2.3 Distribution Box Contents . . . . . . . . . . . . . . A-238

A.14.2.4 Septic Tank and Distribution Box Integrity Soil Sampling. . . A-238 


\section{Table of Contents (Continued)}

A.14.2.5 Leachfield Excavation Soil Sampling . . . . . . . . . . . . . A A-240

A.14.2.6 Collection System Pipe Inspections. . . . . . . . . . . . . . . . . A-240

A.14.2.7 Field-Screening Results . . . . . . . . . . . . . . . . . . . . . . . A-241

A.14.2.8 Radiological Survey Results . . . . . . . . . . . . . . . . A-241

A.14.2.8.1 In Situ Cone Penetrometer Measurements . . . . . A A-241

A.14.2.8.2 Radiological Screening Results . . . . . . . . . A-242

A.14.2.8.3 Swipe Measurements ............... A-243

A.14.2.9 Sample Analysis . . . . . . . . . . . . . . . . . . . A-243

A.14.3 Analytes Detected Above Minimum Reporting Limits . . . . . . . . . . . . . . A-244

A.14.3.1 Analytical Results for Soil Samples . . . . . . . . . . . . . . . A-244

A.14.3.1.1 Total Volatile Organic Compounds . . . . . . . . . A-244

A.14.3.1.2 Total Semivolatile Organic Compounds .... . . A-245

A.14.3.1.3 Total Petroleum Hydrocarbons ........... A-245

A.14.3.1.4 Total RCRA Metals ................ A-245

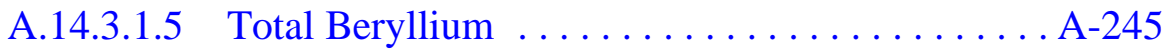

A.14.3.1.6 Polychlorinated Biphenyls ............ A-245

A.14.3.1.7 Gamma Spectrometry Results . . . . . . . . . A-247

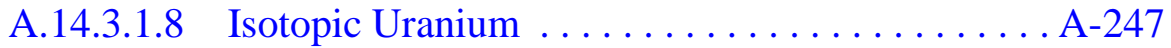

A.14.3.1.9 Isotopic Plutonium . ................ A-247

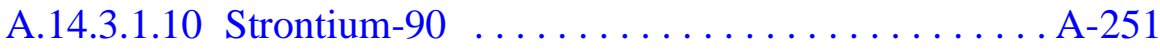

A.14.3.2 Septic Tank/Manhole \#1 Results . . . . . . . . . . . . . . A-251

A.14.4 Contaminants of Concern . . . . . . . . . . . . . . . . A-253

A.14.5 Nature and Extent of Contamination . . . . . . . . . . . . . . A-253

A.14.6 Revised Conceptual Model . . . . . . . . . . . . . . . . A-253

A.15.0 Building 2201 Septic System (CAS 26-05-04) . . . . . . . . . . . . . . . . . A-254

A.15.1 Corrective Action Investigation. . . . . . . . . . . . . . . . A-254

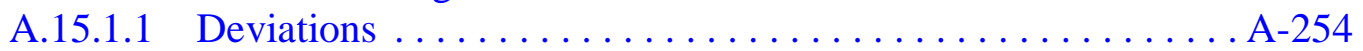

A.15.2 Investigation Results . . . . . . . . . . . . . . . . . . A-262

A.15.2.1 Septic Tank Contents. ........................ A-262

A.15.2.2 Distribution Box Contents . . . . . . . . . . . . . . . . . . A A-262

A.15.2.3 Septic Tank and Distribution Box Integrity Soil Sampling. . . . A-263

A.15.2.4 Leachfield Excavation Soil Sampling . . . . . . . . . . . . . . . . A-265

A.15.2.5 Additional Sampling . . . . . . . . . . . . . . . A-266

A.15.2.6 Collection System Pipe Inspections. . . . . . . . . . . . . . A-266

A.15.2.7 Field-Screening Results . . . . . . . . . . . . . . . . . . A-267

A.15.2.8 Radiological Survey Results . . . . . . . . . . . . . . . . . . A-267

A.15.2.9 Sample Analysis . . . . . . . . . . . . . . . . . . A A-268

A.15.3 Analytes Detected Above Minimum Reporting Limits . . . . . . . . . . . . . . A-269

A.15.3.1 Analytical Results for Soil Samples . . . . . . . . . . . . . . . . . A-269

A.15.3.1.1 Total Volatile Organic Compounds . . . . . . . . . A-269 


\section{Table of Contents (Continued)}
A.15.3.1.2 Total Semivolatile Organic Compounds . . . . . A A-269
A.15.3.1.3 Total Petroleum Hydrocarbons . . . . . . . . . A-270
A.15.3.1.4 Total RCRA Metals . . . . . . . . . . . . . . A-270

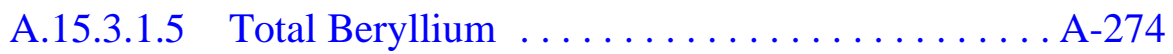
A.15.3.1.6 Polychlorinated Biphenyls . . . . . . . . . . A A-274
A.15.3.1.7 Gamma Spectrometry Results . . . . . . . . . A A-275
A.15.3.1.8 Isotopic Uranium . . . . . . . . . . . . . A-276
A.15.3.1.9 Isotopic Plutonium . . . . . . . . . . . . A-276
A.15.3.1.10 Strontium $-90 \ldots \ldots \ldots \ldots \ldots \ldots$. . . . . . . . . . . . . . . . . . . .

A.15.3.2 Septic Tank Sample Results . . . . . . . . . . . . . . . . . . A-277

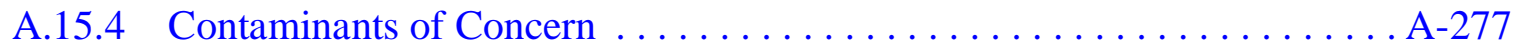

A.15.5 Nature and Extent of Contamination . . . . . . . . . . . . . . A-281

A.15.6 Revised Conceptual Model . . . . . . . . . . . . . . . . A-281

A.16.0 Buildings 2101, 2102, and 2107 Septic System (CAS 26-05-05) . . . . . . . . A-282

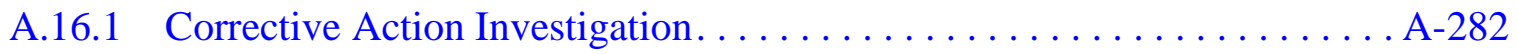

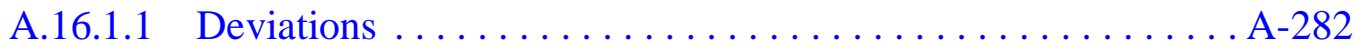

A.16.2 Investigation Results . . . . . . . . . . . . . . . . . . A A-290

A.16.2.1 Septic Tank Contents. . . . . . . . . . . . . . . . . . . A-290

A.16.2.2 Distribution Box Contents . . . . . . . . . . . . . . . . A-291

A.16.2.3 Septic Tank and Distribution Box Integrity Soil Sampling. . . . A-291

A.16.2.4 Leachfield Excavation Soil Sampling . . . . . . . . . . . . . . . A-293

A.16.2.5 Additional Sampling . . . . . . . . . . . . . . . . . . A A-293

A.16.2.6 Collection System Pipe Inspections. . . . . . . . . . . . . . . . . A A-294

A.16.2.7 Field-Screening Results . . . . . . . . . . . . . . . . . . A-295

A.16.2.8 Radiological Survey Results . . . . . . . . . . . . . . . . . A-296

A.16.2.9 Sample Analysis . . . . . . . . . . . . . . . . . . . . . . A-296

A.16.3 Analytes Detected Above Minimum Reporting Limits . . . . . . . . . . . . . A-296

A.16.3.1 Analytical Results for Soil Samples . . . . . . . . . . . . . . . . . A-297

A.16.3.1.1 Total Volatile Organic Compounds . . . . . . . . . . A-297

A.16.3.1.2 Total Semivolatile Organic Compounds . . . . . A A-297

A.16.3.1.3 Total Petroleum Hydrocarbons . . . . . . . . . . . A-297

A.16.3.1.4 Total RCRA Metals ................ A-298

A.16.3.1.5 Total Beryllium ............... A-300

A.16.3.1.6 Polychlorinated Biphenyls ............. A-300

A.16.3.1.7 Gamma Spectrometry Results . . . . . . . . . . A-301

A.16.3.1.8 Isotopic Uranium . . . . . . . . . . . . . A-301

A.16.3.1.9 Isotopic Plutonium . . . . . . . . . . . A-301

A.16.3.1.10 Strontium-90 .................. A-301

A.16.3.2 Septic Tank Sample Results . . . . . . . . . . . . . . . . . . A-301

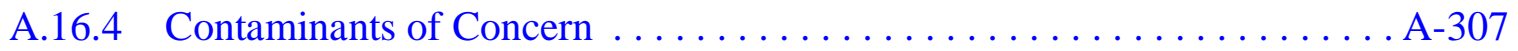




\section{Table of Contents (Continued)}

A.16.5 Nature and Extent of Contamination . . . . . . . . . . . . . . A-307

A.16.6 Revised Conceptual Model . . . . . . . . . . . . . . . . . . A A-307

A.17.0 Building 5200 Leachfield (CAS 27-05-02) . . . . . . . . . . . . . . . . . . A-309

A.17.1 Corrective Action Investigation. . . . . . . . . . . . . . . . A-309

A.17.1.1 Deviations ............................. . . . . . . . .

A.17.2 Investigation Results . . . . . . . . . . . . . . . . . . A-309

A.17.2.1 Septic Tank Contents. . . . . . . . . . . . . . . . . A-309

A.17.2.2 Distribution Structure Contents . . . . . . . . . . . . . A-315

A.17.2.3 Septic Tank and Distribution Structure Integrity

Soil Sampling. . . . . . . . . . . . . . . . . . A-316

A.17.2.4 Leachfield Excavation Soil Sampling . . . . . . . . . . . . A-316

A.17.2.5 Additional Sampling . . . . . . . . . . . . . . A-317

A.17.2.6 Collection System Pipe Inspections. . . . . . . . . . . . . . A-318

A.17.2.7 Field-Screening Results . . . . . . . . . . . . . . . . . A-319

A.17.2.8 Radiological Survey Results . . . . . . . . . . . . . . . . . . A-319

A.17.2.9 Sample Analysis . . . . . . . . . . . . . . . . . . . . A-319

A.17.3 Analytes Detected Above Minimum Reporting Limits . . . . . . . . . . . . . A-320

A.17.3.1 Analytical Results for Soil Samples . . . . . . . . . . . . . . A A-320

A.17.3.1.1 Total Volatile Organic Compounds .......... A-320

A.17.3.1.2 Total Semivolatile Organic Compounds ....... A-320

A.17.3.1.3 Total Petroleum Hydrocarbons . ... . . . . . A-320

A.17.3.1.4 Total RCRA Metals ............... A-320

A.17.3.1.5 Polychlorinated Biphenyls . . . . . . . . . . A-321

A.17.3.1.6 Total Pesticides ................ A-323

A.17.3.1.7 Gamma Spectrometry Results . . . . . . . . . A-324

A.17.3.1.8 Isotopic Uranium . . . . . . . . . . . . A-324

A.17.3.1.9 Isotopic Plutonium . . . . . . . . . . . A-324

A.17.3.1.10 Strontium $-90 \ldots \ldots \ldots \ldots \ldots$. . . . . . . . . . . . .

A.17.3.2 Septic Tank and Distribution Structure Sample Results . . . . . A-324

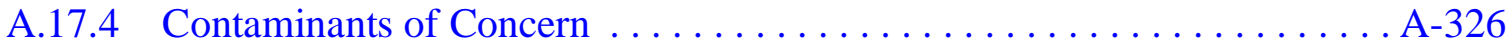

A.17.5 Nature and Extent of Contamination . . . . . . . . . . . . . A-330

A.17.6 Revised Conceptual Model . . . . . . . . . . . . . . . . . A-330

A.18.0 Waste Management. . . . . . . . . . . . . . . . . . . . . . . A-331

A.18.1 Characterization............................. A-331

A.18.2 Waste Streams . . . . . . . . . . . . . . . . . . $\ldots \ldots 31$

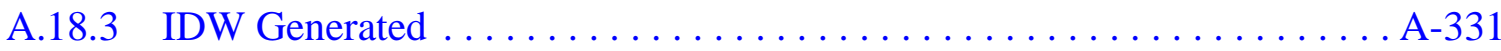

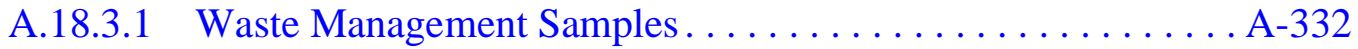




\section{Table of Contents (Continued)}

A.19.0 Quality Assurance. . . . . . . . . . . . . . . . . . . . . .

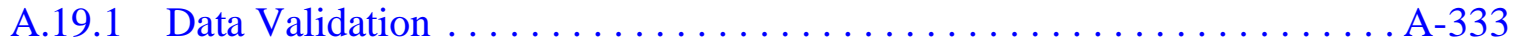

A.19.1.1 Tier I Evaluation $\ldots \ldots \ldots \ldots \ldots \ldots \ldots \ldots \ldots \ldots \ldots \ldots \ldots \ldots \ldots \ldots$

A.19.1.2 Tier II Evaluation. . . . . . . . . . . . . . . . . . . A-334

A.19.1.3 Tier III . . . . . . . . . . . . . . . . . . . A-335

A.19.2 Field Quality Control Samples . . . . . . . . . . . . . . . . A-336

A.19.2.1 Laboratory Quality Control Samples. . . . . . . . . . . . . . . A-337

A.19.3 Field Nonconformances. . . . . . . . . . . . . . . . . A-337

A.19.4 Laboratory Nonconformances . . . . . . . . . . . . . . . . . . . . A-338

A.20.0 Summary . . . . . . . . . . . . . . . . . . . . . . . . . . . A-339

A.21.0 References. . . . . . . . . . . . . . . . . . . . . . . . . . . . . . . . . A-343

\section{Appendix B - Data Assessment}

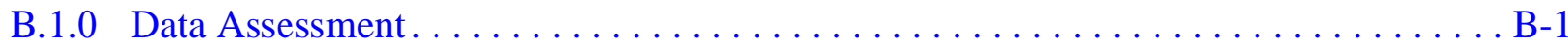

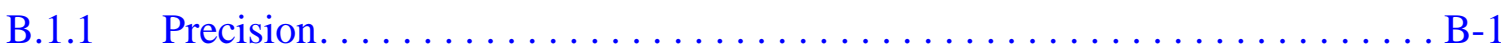

B.1.1.1 Precision for Chemical Analyses................. B-2

B.1.1.2 Precision for Radiochemical Analysis. . . . . . . . . . . . . B-6

B.1.1.3 Precision Summary . . . . . . . . . . . . . . . . . . . B-9

B.1.2 Accuracy . . . . . . . . . . . . . . . . . . . . . . . . . .

B.1.2.1 Accuracy for Chemical Analysis . . . . . . . . . . . . . . B-10

B.1.2.2 Accuracy for Radiochemical Analysis . . . . . . . . . . . . B-13

B.1.2.3 Accuracy Summary . . . . . . . . . . . . . . . . . . . . . B-15

B.1.3 Completeness..............................

B.1.3.1 Security Checkpoint Septic System (CAS 25-04-01)

Rejected Data........................... B-19

B.1.3.2 PAN-AM Trailers Septic System (CAS 25-04-03)

Rejected Data.......................... B-20

B.1.3.3 Reactor Control Point Septic System (CAS 25-04-04)

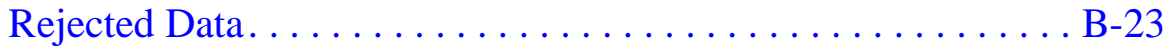

B.1.3.4 BREN Tower Septic System (CAS 25-04-08) Rejected Data. . . B-30

B.1.3.5 Engine Test Stand No. 1 Septic System (CAS 25-04-09)

Rejected Data........................... B-32

B.1.3.6 Rad-Safe Trailers Septic System (CAS 25-04-10)

Rejected Data. . . . . . . . . . . . . . . . . B-35

B.1.3.7 South of LASL Trailers Septic System (CAS 25-04-11)

Rejected Data........................ B-37

B.1.3.8 Port Gaston Training Area Contaminated Water Reservoir

(CAS 26-03-01) Rejected Data . . . . . . . . . . . . B-41 


\section{Table of Contents (Continued)}
B.1.3.9 Area 26 Check Station (Bldg. 2105) Septic System
(CAS 26-04-01) Rejected Data .................... B-41
B.1.3.10 Hot Critical Facility (Bldg. 2103) Septic System
(CAS 26-04-02) Rejected Data .................. B-44
B.1.3.11 Buildings 2201 and 2202 Radioactive Leachfield
(CAS 26-05-01) Rejected Data .................. B-44
B.1.3.12 Building 2203 Septic System (26-05-03) Rejected Data. ..... B-47
B.1.3.13 Building 2201 Septic System (CAS 26-05-04) Rejected Data . . B-49
B.1.3.14 Buildings 2101, 2102, and 2107 Septic System
(CAS 26-05-05) Rejected Data .................. B-51
B.1.3.15 Building 5200 Septic System (CAS 27-05-02)
Rejected Data......................... B-53
B.1.3.16 Completeness Summary ...................... B-55
B.1.4 Representativeness. . . . . . . . . . . . . . . . . . . . . . B-55
B.1.5 Comparability ............................... B-56
B.1.6 Reconciliation of Conceptual Site Model(s) to the Data............ B-56
B.1.6.1 Initial Conceptual Site Models . . . . . . . . . . . . B-56
B.1.6.2 Investigation Design and Contaminant Identification ........ B-57
B.1.6.3 Contaminant Nature and Extent. . . . . . . . . . . . . . . . . B-59

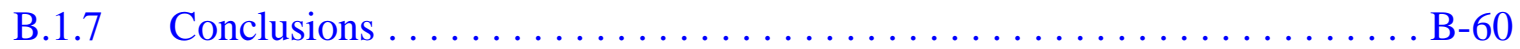

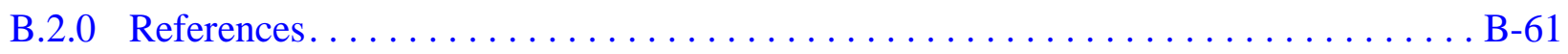

\section{Appendix C - Cost Estimates for CAU 271}

Appendix D - Sample Location Coordinates for CAU 271: Areas 25, 26, and 27 Septic Systems Nevada Test Site, Nevada

D.1.0 Sample Location Coordinates. . . . . . . . . . . . . . . . . . . . D -1

D.1.1 Security Checkpoint Septic System (CAS 25-04-01) .............. D-1

D.1.2 PAN-AM Trailers Septic System (CAS 25-04-03) ................. D-1

D.1.3 Reactor Control Point Septic System (CAS 25-04-04) . . . . . . . . . . . D-1

D.1.4 BREN Tower Septic System (CAS 25-04-08) ................ .

D.1.5 Engine Test Stand No. 1 Septic System (CAS 25-04-09) . . . . . . . . . . . . D-10

D.1.6 Rad-Safe Trailers Septic System (CAS 25-04-10) ................. D-10

D.1.7 South of LASL Trailers Septic System (CAS 25-04-11) ........... D-10

D.1.8 Port Gaston Training Area Contaminated Water Reservoir

(CAS 26-03-01) ................................

D.1.9 Area 26 Check Station, Bldg. 2105, Septic System (CAS 26-04-01) . . . . . D-10

D.1.10 Hot Critical Facility, Bldg. 2103, Septic System (CAS 26-04-02) . . . . . . . D-22

D.1.11 Buildings 2201 and 2202 Radioactive Leachfield (CAS 26-05-01) ...... D-22 


\section{Table of Contents (Continued)}

D.1.12 Building 2203 Septic System (CAS 26-05-03) . . . . . . . . . . . . D-22

D.1.13 Building 2201 Septic System (CAS 26-05-04) . . . . . . . . . . . . . . D-22

D.1.14 Buildings 2101, 2102, and 2107 Septic System (CAS 26-05-05) . . . . . . . D-22

D.1.15 Building 5200 Septic System (CAS 27-05-02) . . . . . . . . . . . . D-22

D.1.16 Cone Penetrometer Technology Survey Locations . . . . . . . . . . . . . D-38

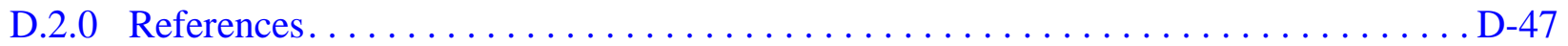

Appendix E - Project Organization for CAU 271

E.1.0 Project Organization $\ldots \ldots \ldots \ldots \ldots \ldots \ldots \ldots \ldots \ldots \ldots \ldots \ldots \ldots \ldots \ldots \ldots \ldots \ldots \ldots$ 


\section{List of Figures}

Number

Title

Page

1-1 Nevada Test Site . . . . . . . . . . . . . . . . . . . . . . . . . . . 2

1-2 CAU 271: Area 25 Corrective Action Sites

Nevada Test Site, Nye County, Nevada ......................... 3

1-3 CAU 271: Area 26 Corrective Action Sites

Nevada Test Site, Nye County, Nevada ....................... 4

1-4 CAU 271: Area 27 Corrective Action Sites

Nevada Test Site, Nye County, Nevada ........................ 5

A.3-1 Security Checkpoint Septic System (CAS 25-04-01) Sample Locations ........ A-20

A.3-2 CAS 25-04-01 Septic Tank, Interior View (Photograph Taken 01-08-2002). . . . A-21

A.3-3 CAS 25-04-01 Septic Tank, Inlet End (Photograph Taken 01-08-2002) . . . . . . A-22

A.4-1 Pan Am Trailer Septic System (CAS 25-04-03) Sample Locations .......... A A-38

A.4-2 CAS 25-04-03 Septic Tank, Manholes (Photographs Taken 12-04-2001) ... . . . A-40

A.5-1 RCP Septic System (CAS 25-04-04) Sample Locations. . . . . . . . . . . . . A-62

A.5-2 CAS 25-04-04 Septic Tank Manholes (Photographs Taken 02-18-2002) ...... A-64

A.5-3 CAS 25-04-04 Distribution Box (Photographs Taken 12-03-2001) ......... A-65

A.5-4 CAS 25-04-04 Location C09 (Photographs Taken 11-16-2001) ............ A-66

A.5-5 CAS 25-04-04 North Bypass Manhole (Photograph Taken 02-18-2002). . . . . . A-67

A.6-1 BREN Tower Septic System (CAS 25-04-08) Sample Locations . . . . . . . . . . A-85

A.6-2 CAS 25-04-08 Septic Tank Manholes (Photographs Taken 11-12-2001) ...... A-87

A.6-3 CAS 25-04-08 Distribution Box (Photograph Taken 11-09-2001).......... A-87

A.7-1 ETS-1 Septic System (CAS 25-04-09) Sample Locations . . . . . . . . . . . . A-104

A.7-2 CAS 25-04-09 Septic Tank, Integrity Sample and Inlet End (Photograph Taken 12-04-2001) ......................... A-105 


\section{List of Figures (Continued)}

Number

Title

Page

A.7-3 CAS 25-04-09 Manhole Leading to Active Sewage Lagoons

(Photograph Taken 12-04-2001) . . . . . . . . . . . . . . . . . . . . . A-107

A.8-1 Rad-Safe Trailers Septic System (CAS 25-04-10) Sample Locations . . . . . . . A-124

A.8-2 CAS 25-04-10 Septic Tank Chambers (Photographs Taken 11-13-2001) . . . . A-126

A.8-3 CAS 25-04-10 Distribution Box (Photograph Taken 11-13-2001) . . . . . . . . . A-127

A.8-4 CAS 25-04-10 Septic Tank, Influent End (Photograph Taken 11-13-2001) . . . A A-127

A.8-5 CAS 25-04-10 Pipe Break Located $23 \mathrm{ft}$ North of Septic Tank

(Photograph Taken 11-13-2001) . . . . . . . . . . . . . . . . . . . A-129

A.9-1 LASL Trailers Septic System (CAS 25-04-11) Sample Locations . . . . . . . . . A A-143

A.9-2 CAS 25-04-11 Distribution Box, Integrity Sample

(Photograph Taken 11-14-2001) . . . . . . . . . . . . . . . . . . A-144

A.10-1 Contaminated Water Reservoir (CAS 26-03-01) Sample Locations. . . . . . . . . A-164

A.10-2 CAS 26-03-01 Sampling Locations (Photograph Taken 01-10-2002) . . . . . . . A-165

A.11-1 Check Station Septic System (CAS 26-04-01) Sample Locations . . . . . . . . . A-175

A.11-2 CAS 26-04-01 Septic Tank, Interior (Photograph Taken 11-07-2001) . . . . . . A-176

A.11-3 CAS 26-04-01 Distribution Box, Interior (Photographs Taken 11-07-2001) . . . A-177

A.11-4 CAS 26-04-01 Septic Tank, Effluent Integrity Sample (Photograph Taken 11-07-2001) . . . . . . . . . . . . . . A-178

A.11-5 CAS 26-04-01 Distribution Box, Effluent Integrity Sample

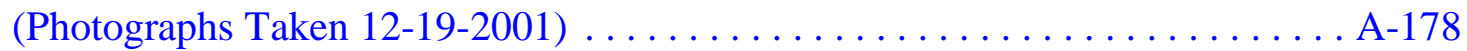

A.12-1 Building 2103 Septic System (CAS 26-04-02) Sample Locations . . . . . . . . . A-192

A.12-2 CAS 26-04-02 Septic Tank, Interior (Photograph Taken 01-07-2002) . . . . . . . A-193

A.12-3 CAS 26-04-02 Distribution Box, Interior (Photographs Taken 01-07-2002) . . . A-194 


\section{List of Figures (Continued)}

Number

Title

Page

A.12-4 CAS 26-04-02 Septic Tank, Effluent Integrity Sample

(Photograph Taken 12-21-2001) . . . . . . . . . . . . . . . . . . A-195

A.12-5 CAS 26-04-02 Distribution Box, Effluent Integrity Sample

(Photograph Taken 12-17-2001) . . . . . . . . . . . . . . . . A-195

A.13-1 Buildings 2201 and 2202 Radioactive Leachfield (CAS 26-05-01)

Sample Locations. . . . . . . . . . . . . . . . . . . . A-210

A.13-2 CAS 26-05-01 Distribution Box, Interior (Photographs Taken 02-01-2002) . . . A-211

A.13-3 CAS 26-05-01 Distribution Box, Effluent Integrity Sample (Photograph Taken 01-22-2002) . . . . . . . . . . . . . . . . . A-212

A.13-4 CAS 26-05-01 Collection System Manholes. . . . . . . . . . . . . . . . . A-213

A.14-1 Test Bunker Septic System (CAS 26-05-03) Sample Locations . . . . . . . . . . . A-237

A.14-2 CAS 26-05-03 Septic Tank, Interior (Photographs Taken 02-04-2002) . . . . . . A-238

A.14-3 CAS 26-05-03 Distribution Box, Interior (Photographs Taken 02-04-2002) . . . A-239

A.14-4 CAS 26-05-03 Septic Tank, Effluent Integrity Sample

(Photograph Taken 02-04-2002) . . . . . . . . . . . . . . . . . . . . A-239

A.15-1 Building 2201 Septic System (CAS 26-05-04) Sample Locations . . . . . . . . . A A-261

A.15-2 CAS 26-05-04 Septic Tank, Interior (Photographs Taken 01-17-2002) . . . . . . A-263

A.15-3 CAS 26-05-04 Distribution Box, Interior (Photographs Taken 01-09-2002) . . . A-264

A.15-4 CAS 26-05-04 Septic Tank, Influent Integrity Sample

(Photograph Taken 01-16-2002) . . . . . . . . . . . . . . . . . . . . A-264

A.15-5 CAS 26-05-04 Distribution Box, Effluent Integrity Sample

(Photograph Taken 01-09-2002) . . . . . . . . . . . . . . . . . A-265

A.16-1 Buildings 2201, 2202, and 2207 Septic System (CAS 26-05-05)

Sample Locations. . . . . . . . . . . . . . . . . . . . A-288 


\section{List of Figures (Continued)}

Number

Title

Page

A.16-2 CAS 26-05-05 Distribution Boxes, Interiors

(Photographs Taken 01-17-2002)

A.16-3 CAS 26-05-05 Septic Tank 1, Integrity Samples

A.16-4 CAS 26-05-05 Septic Tank 2, Integrity Samples

A.17-1 Building 5200 Leachfield (CAS 27-05-02) Sample Locations

A.17-2 CAS 27-05-02 Septic Tank, Interior (Photographs Taken 02-12-2002)

A.17-3 CAS 27-05-02 Distribution Box and Septic Tank (Photographs Taken 02-07-2002)

A.17-4 CAS 27-05-02 Integrity Samples. . . . . . . . . . . . . . . . A-317

D.1-1 Cone Penetrometer Technology Sample Locations for CAS 26-05-01 . . . . . . . D-39

D.1-2 Cone Penetrometer Technology Sample Locations for CAS 26-05-03 . . . . . . . . D-40 


\section{List of Tables}

Number

Title

Page

1-1 Corrective Action Unit 271 Corrective Action Sites . . . . . . . . . . . . . . 6

2-1 CAS Excavation Activities.............................. 11

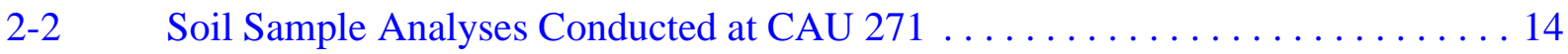

2-3 Liquid, Sludge, and Sediment Sample Analyses Conducted at CAU 271 ...... 15

3-1 Corrective Action Alternatives. ........................... 80

3-2 Detailed Evaluation of Alternatives for Corrective Action Unit 271. . . . . . . . 112

3-3 Comparative Evaluation of Alternatives for Corrective Action Unit 271 . . . . 116

A.2-1 Corrective Action Investigation Activities Conducted at Each Corrective Action Site to Meet Corrective Action Investigation Plan Requirements . . . . . . A-4

A.2-2 Laboratory Analytical Parameters and Methods,

CAU 271 Investigation Samples .......................... A-15

A.3-1 Samples Collected at CAS $25-04-01 \ldots \ldots \ldots \ldots \ldots \ldots \ldots \ldots \ldots . \ldots \ldots$

A.3-2 Soil Sample Results for Total VOCs Detected

Above Minimum Reporting Limits at CAS 25-04-01 ............... A-25

A.3-3 Soil Sample Results for Total RCRA Metals Detected

Above Minimum Reporting Limits at CAS 25-04-01 ............. A-26

A.3-4 Soil Sample Results for Gamma-Emitting Radionuclides Detected

Above Minimum Reporting Limits at CAS 25-04-01 . . . . . . . . . . . . . A-27

A.3-5 Soil Sample Results for Isotopic Uranium Detected Above

Minimum Reporting Limits at CAS $25-04-01 \ldots \ldots \ldots \ldots \ldots \ldots \ldots \ldots$ A-28

A.3-6 Liquid and Sludge Sample Results Above Minimum Reporting Limits

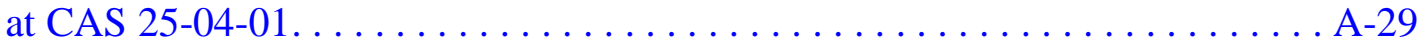

A.4-1 Samples Collected at CAS $25-04-03 \ldots \ldots \ldots \ldots \ldots \ldots \ldots \ldots \ldots . \ldots \ldots \ldots$ 


\section{List of Tables (Continued)}

Number

Title

Page

A.4-2 Soil Sample Results for Total VOCs Detected

Above Minimum Reporting Limits at CAS 25-04-03 . . . . . . . . . . . . . . A-44

A.4-3 Soil Sample Results for Total SVOCs Detected

Above Minimum Reporting Limits at CAS 25-04-03 . . . . . . . . . . . . A-45

A.4-4 Soil Sample Results for Total RCRA Metals Detected

Above Minimum Reporting Limits at CAS 25-04-03 . . . . . . . . . . . . A A-47

A.4-5 Soil Sample Results for Gamma-Emitting Radionuclides Detected

Above Minimum Reporting Limits at CAS 25-04-03 . . . . . . . . . . . . . A-49

A.4-6 Soil Sample Results for Isotopic Plutonium and Uranium Detected

Above Minimum Reporting Limits at CAS 25-04-03 . . . . . . . . . . . . A-51

A.4-7 Liquid and Sludge Samples Results Detected

Above Minimum Reporting Limits at CAS 25-04-03 . . . . . . . . . . . . . A-52

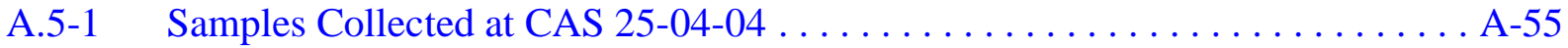

A.5-2 Soil Sample Results for Total VOCs Detected

Above Minimum Reporting Limits at CAS 25-04-04 . . . . . . . . . . . . A-70

A.5-3 Soil Sample Results for TPH-DRO Detected

Above Minimum Reporting Limits at CAS 25-04-04 . . . . . . . . . . . . . . A-71

A.5-4 Soil Sample Results for Total RCRA Metals Detected

Above Minimum Reporting Limits at CAS 25-04-04 . . . . . . . . . . . . A-72

A.5-5 Soil Sample Results for Pesticides Detected

Above Minimum Reporting Limits at CAS 25-04-04 . . . . . . . . . . . . . . A-75

A.5-6 Soil Sample Results for Gamma-Emitting Radionuclides Detected

Above Minimum Reporting Limits at CAS 25-04-04 . . . . . . . . . . . . . . A-76

A.5-7 Soil Sample Results for Isotopic Uranium Detected

Above Minimum Reporting Limits at CAS 25-04-04 . . . . . . . . . . . . . . . . A-77 


\section{List of Tables (Continued)}

Number

A.5-8 Liquid and Sludge Sample Results Detected

Above Minimum Reporting Limits at CAS 25-04-04 . . . . . . . . . . . . . . . . A-79

A.6-1 Samples Collected at CAS $25-04-08 \ldots \ldots \ldots \ldots \ldots \ldots \ldots \ldots \ldots$. . . . . . . . . . . .

A.6-2 Soil Sample Results for Total SVOCs Detected Above Minimum

Reporting Limits at CAS $25-04-08 \ldots \ldots \ldots \ldots \ldots \ldots \ldots \ldots \ldots$. . . . . . . . . . . .

A.6-3 Soil Sample Results for Total RCRA Metals Detected Above Minimum

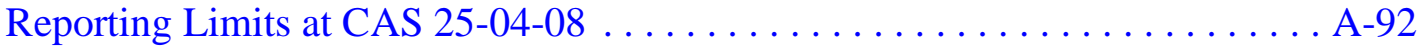

A.6-4 Soil Sample Results for Gamma-Emitting Radionuclides Detected

Above Minimum Reporting Limits at CAS 25-04-08 . . . . . . . . . . . . . A-93

A.6-5 Soil Sample Results for Isotopic Plutonium and Uranium

Detected Above Minimum Reporting Limits at CAS 25-04-08 . . . . . . . . . . A-94

A.6-6 Liquid and Sludge Sample Results Detected Above Minimum

Reporting Limits at CAS $25-04-08 \ldots \ldots \ldots \ldots \ldots \ldots \ldots \ldots \ldots \ldots$. . . . . . . . . . . .

A.7-1 Samples Collected at CAS $25-04-09 \ldots \ldots \ldots \ldots \ldots \ldots \ldots \ldots \ldots \ldots \ldots$

A.7-2 Soil Samples Results for Total VOCs Detected

Above Minimum Reporting Limits at CAS 25-04-09 . . . . . . . . . . . . A-110

A.7-3 Soil Sample Results for Total RCRA Metals Detected

Above Minimum Reporting Limits at CAS 25-04-09 . . . . . . . . . . . . . . A-111

A.7-4 Soil Sample Results for Gamma-Emitting Radionuclides Detected

Above Minimum Reporting Limits at CAS 25-04-09 . . . . . . . . . . . . A A-113

A.7-5 Isotopic Uranium Sample Results Detected

Above Minimum Reporting Limits at CAS 25-04-09 . . . . . . . . . . . . . A-114

A.7-6 Sludge Sample Results Detected

Above Minimum Reporting Limits at CAS 25-04-09 . . . . . . . . . . . . A-116

A.8-1 Samples Collected at CAS $25-04-10 \ldots \ldots \ldots \ldots \ldots \ldots \ldots \ldots \ldots \ldots$ 


\section{List of Tables (Continued)}

Number

Title

Page

A.8-2 Soil Sample Results for Total VOCs Detected

Above Minimum Reporting Limits at CAS 25-04-10 . . . . . . . . . . . . . A-131

A.8-3 Soil Sample Results for Total RCRA Metals

Detected Above Minimum Reporting Limits at CAS 25-04-10

A.8-4 Soil Sample Results for Gamma-Emitting Radionuclides Detected

Above Minimum Reporting Limits at CAS 25-04-10 . . . . . . . . . . . . A-134

A.8-5 Soil Sample Results for Plutonium and Uranium Isotopes Detected

Above Minimum Reporting Limits at CAS 25-04-10 . . . . . . . . . . . . . A-135

A.9-1 Samples Collected at CAS $25-04-11 \ldots \ldots \ldots \ldots \ldots \ldots \ldots \ldots \ldots \ldots \ldots \ldots$

A.9-2 Soil Sample Results for Total SVOCs Detected

Above Minimum Reporting Limits at CAS 25-04-11 . . . . . . . . . . . . A-150

A.9-3 Soil Sample Results for TPH-DRO Detected

Above Minimum Reporting Limits at CAS 25-04-11 . . . . . . . . . . . . A-151

A.9-4 Soil Sample Results for Total RCRA Metals

Detected Above Minimum Reporting Limits at CAS 25-04-11 . . . . . . . . A-152

A.9-5 Soil Sample Results for Gamma-Emitting Radionuclides Detected

Above Minimum Reporting Limits at CAS 25-04-11 . . . . . . . . . . . . . A-154

A.9-6 Soil Sample Results for Isotopic Uranium

Detected Above Minimum Reporting Limits at CAS 25-04-11 . . . . . . . . A-155

A.9-7 Sludge, Liquid, and Sediment Sample Results Detected

Above Minimum Reporting Limits at CAS 25-04-11 . . . . . . . . . . . . . . A-157

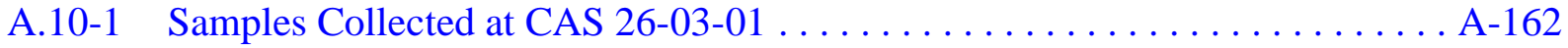

A.10-2 Soil Sample Results for Total RCRA Metals

Detected Above Minimum Reporting Limits at CAS 26-03-01 . . . . . . . . A-169 


\section{List of Tables (Continued)}

Number

A.10-3 Soil Sample Results for Gamma-Emitting Radionuclides Detected Above Minimum Reporting Limits at CAS 26-03-01 . . . . . . . . . . . . . A-170

A.11-1 Samples Collected at CAS 26-04-01 . . . . . . . . . . . . . . . A-173

A.11-2 On-Site Gamma Spectroscopy Results at CAS 26-04-01 . . . . . . . . . . . A-180

A.11-3 Soil Sample Results for Total VOCs Detected Above Minimum

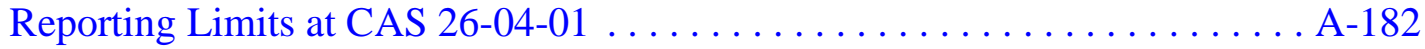

A.11-4 Soil Sample Results for Total RCRA Metals Detected Above Minimum

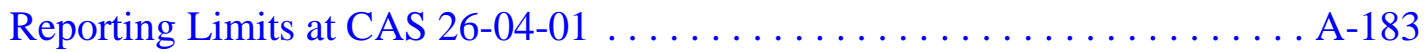

A.11-5 Soil Sample Results for Pesticides Detected Above Minimum

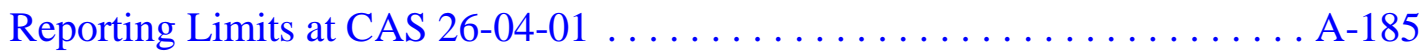

A.11-6 Soil Sample Results for Gamma-Emitting Radionuclides

Detected Above Minimum Reporting Limits at CAS 26-04-01

A.11-7 Soil Sample Results for Isotopic Uranium Detected Above Minimum

Reporting Limits at CAS 26-04-01 . . . . . . . . . . . . . . A-186

A.11-8 Liquid and Sediment Sample Results Detected Above Minimum

Reporting Limits at CAS $26-04-01 \ldots \ldots \ldots \ldots \ldots \ldots \ldots \ldots \ldots \ldots . \ldots \ldots$

A.12-1 Samples Collected at CAS $26-04-02 \ldots \ldots \ldots \ldots \ldots \ldots \ldots \ldots \ldots \ldots$ A $\ldots \ldots \ldots$

A.12-2 Soil Sample Results for Total VOCs Detected Above Minimum

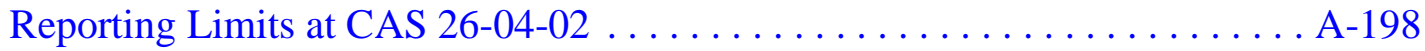

A.12-3 Soil Sample Results for Total RCRA Metals Detected

Above Minimum Reporting Limits at CAS 26-04-02 . . . . . . . . . . . . . A-199

A.12-4 Soil Sample Results for Gamma-Emitting Radionuclides Detected

Above Minimum Reporting Limits at CAS 26-04-02 . . . . . . . . . . . . A-201

A.12-5 Soil Sample Results for Isotopic Uranium Detected

Above Minimum Reporting Limits at CAS 26-04-02 . . . . . . . . . . . . . A-202 


\section{List of Tables (Continued)}

Number

Title

Page

A.12-6 Septic Tank Sediment Sample Results Detected

Above Minimum Reporting Limits at CAS 26-04-02 . . . . . . . . . . . . . . . A-203

A.13-1 Samples Collected at CAS $26-05-01 \ldots \ldots \ldots \ldots \ldots \ldots \ldots \ldots \ldots \ldots$ A $\ldots \ldots \ldots$

A.13-2 Radiological Survey Results at CAS 26-05-01 . . . . . . . . . . . . A-217

A.13-3 Swipe Radiological Sample Analysis Results at CAS 26-05-01 . . . . . . . . A-219

A.13-4 Soil Sample Results for Total VOCs Detected Above Minimum

Reporting Limits at CAS $26-05-01 \ldots \ldots \ldots \ldots \ldots \ldots \ldots$ A 220

A.13-5 Soil Sample Results for TPH-DRO Detected Above Minimum

Reporting Limits at CAS $26-05-01 \ldots \ldots \ldots \ldots \ldots \ldots \ldots \ldots$ A-221

A.13-6 Soil Sample Results for Total RCRA Metals Detected Above Minimum

Reporting Limits at CAS $26-05-01 \ldots \ldots \ldots \ldots \ldots \ldots \ldots$ A-222

A.13-7 Soil Sample Results for Gamma-Emitting Radionuclides Detected

Above Minimum Reporting Limits at CAS 26-05-01 . . . . . . . . . . . . A A-224

A.13-8 Soil Sample Results for Isotopic Plutonium and Uranium

Detected Above Minimum Reporting Limits at CAS 26-05-01 . . . . . . . . A-226

A.13-9 Manhole Sediment Sample Results Detected

Above Minimum Reporting Limits at CAS 26-05-01 . . . . . . . . . . . . A-229

A.14-1 Samples Collected at CAS $26-05-03 \ldots \ldots \ldots \ldots \ldots \ldots \ldots \ldots \ldots \ldots \ldots \ldots \ldots$

A.14-2 Radiological Survey Results at CAS $26-05-03 \ldots \ldots \ldots \ldots \ldots \ldots \ldots$. . . . . . . . . .

A.14-3 Swipe Radiological Sample Analysis Results at CAS 26-05-03 . . . . . . . A A-243

A.14-4 Soil Sample Results for Total VOCs Detected Above Minimum

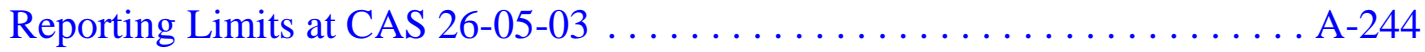

A.14-5 Soil Sample Results for Total RCRA Metals Detected Above Minimum

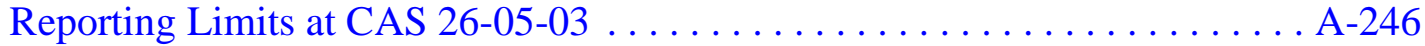




\section{List of Tables (Continued)}

Number

A.14-6 Soil Sample Results for PCB Detected Above Minimum

Reporting Limits at CAS 26-05-03 . . . . . . . . . . . . . . . . . A A-247

A.14-7 Soil Sample Results for Gamma-Emitting Radionuclides

Detected Above Minimum Reporting Limits at CAS 26-05-03

A.14-8 Soil Sample Results for Isotopic Plutonium and Uranium

Detected Above Minimum Reporting Limits at CAS 26-05-03

A.14-9 Sediment Samples Results Detected Above Minimum

Reporting Limits at CAS $26-05-03 \ldots \ldots \ldots \ldots \ldots \ldots \ldots \ldots$ A $\ldots \ldots \ldots 25$

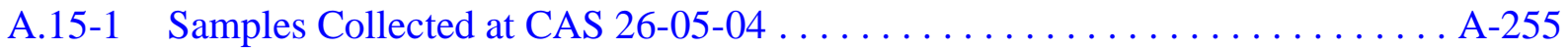

A.15-2 Soil Sample Results for Total VOCs Detected Above Minimum

Reporting Limits at CAS 26-05-04 . . . . . . . . . . . . . . . . A-269

A.15-3 Soil Sample Results for TPH-DRO Detected Above Minimum

Reporting Limits at CAS 26-05-04 . . . . . . . . . . . . . . . A-270

A.15-4 Soil Sample Results for Total RCRA Metals Detected Above Minimum

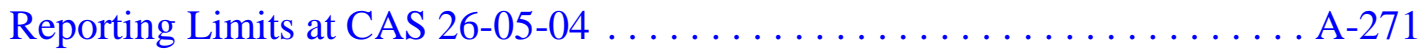

A.15-5 Soil Sample Results for PCBs Detected Above Minimum

Reporting Limits at CAS $26-05-04 \ldots \ldots \ldots \ldots \ldots \ldots \ldots$ A . . . . . . . . . . . . .

A.15-6 Soil Sample Results for Gamma-Emitting Radionuclides

Detected Above Minimum Reporting Limits at CAS 26-05-04

A.15-7 Soil Sample Results for Strontium and Uranium Isotopes

Detected Above Minimum Reporting Limits at CAS 26-05-04

A.15-8 Liquid and Sludge Sample Results Detected Above Minimum

Reporting Limits at CAS $26-05-04 \ldots \ldots \ldots \ldots \ldots \ldots \ldots$ A . . . . . . . . . . . . .

A.16-1 Samples Collected at CAS $26-05-05 \ldots \ldots \ldots \ldots \ldots \ldots \ldots \ldots \ldots \ldots \ldots$ 


\section{List of Tables (Continued)}

Number

Title

Page

A.16-2 Soil Sample Results for TPH-DRO Detected Above Minimum

Reporting Limits at CAS 26-05-05 . . . . . . . . . . . . . . . . . . . . . . A-297

A.16-3 Soil Sample Results for Total RCRA Metals Detected Above Minimum

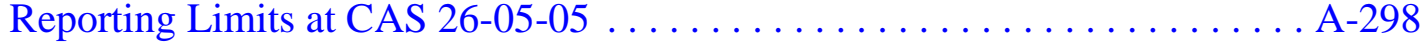

A.16-4 Soil Sample Results for PCB Detected Above Minimum

Reporting Limits at CAS $26-05-05 \ldots \ldots \ldots \ldots \ldots \ldots \ldots \ldots \ldots \ldots \ldots$

A.16-5 Soil Sample Results for Gamma-Emitting Radionuclides Detected

Above Minimum Reporting Limits at CAS 26-05-05 . . . . . . . . . . . . . . A-302

A.16-6 Soil Sample Results for Isotopic Uranium Detected Above Minimum

Reporting Limits at CAS 26-05-05 . . . . . . . . . . . . . . . . A-303

A.16-7 Liquid, Sediment, and Sludge Sample Results Detected Above Minimum

Reporting Limits at CAS 26-05-05 . . . . . . . . . . . . . . A-304

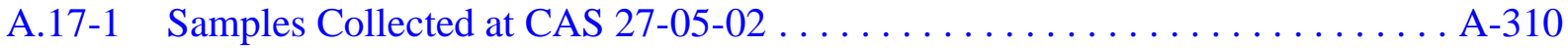

A.17-2 Soil Sample Results for Total RCRA Metals Detected Above Minimum

Reporting Limits at CAS $27-05-02 \ldots \ldots \ldots \ldots \ldots \ldots \ldots \ldots \ldots \ldots \ldots \ldots \ldots \ldots$

A.17-3 Soil Sample Results for PCBs Detected Above Minimum

Reporting Limits at CAS $27-05-02 \ldots \ldots \ldots \ldots \ldots \ldots \ldots$ A-322 . . . . . . . . . . . . . . .

A.17-4 Soil Sample Results for Pesticides Detected Above Minimum

Reporting Limits at CAS $27-05-02 \ldots \ldots \ldots \ldots \ldots \ldots \ldots \ldots \ldots \ldots \ldots \ldots \ldots \ldots$

A.17-5 Soil Sample Results for Gamma-Emitting Radionuclides Detected

Above Minimum Reporting Limits at CAS 27-05-02 . . . . . . . . . . . . A A-325

A.17-6 Soil Sample Results for Isotopic Uranium Detected Above Minimum

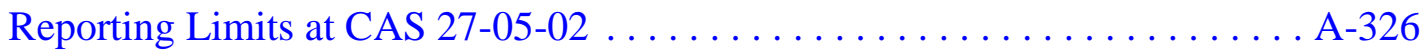

A.17-7 Liquid and Sludge Sample Results Detected Above Minimum

Reporting Limits at CAS $27-05-02 \ldots \ldots \ldots \ldots \ldots \ldots$. . . . . . . . . . . . . . . . . . . 


\section{List of Tables (Continued)}

Number

B.1-1 Chemical Analysis Precision Measurements for CAU $271 \ldots \ldots \ldots \ldots$. . . . 3

B.1-2 Toxicity Characteristic Leaching Procedure Precision Measurements

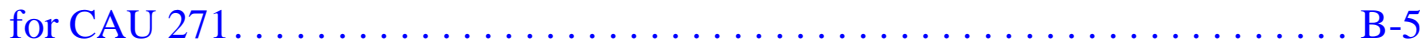

B.1-3 Laboratory Results for Field Duplicates of Radioanalytes . . . . . . . . . . . . B-7

B.1-4 Laboratory Precision for Radioanalytes..................... B-7

B.1-5 Chemical Analysis Accuracy Measurements for CAU $271 \ldots . . \ldots \ldots \ldots$. . . . 11

B.1-6 Toxicity Characteristic Leaching Procedure Accuracy Measurement

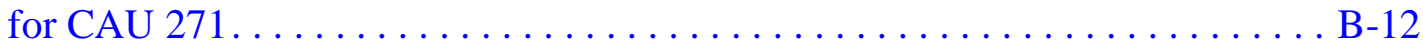

B.1-7 Radioanalyte Laboratory Control Sample Accuracy ................... B-14

B.1-8 Radioanalyte Matrix Spike Sample Accuracy . . . . . . . . . . . . . . . . . . B-14

B.1-9 Chemical Completeness Measurements for CAU $271 \ldots \ldots \ldots \ldots \ldots \ldots$ B-16

B.1-10 Toxicity Characteristic Leaching Procedure Chemical Completeness

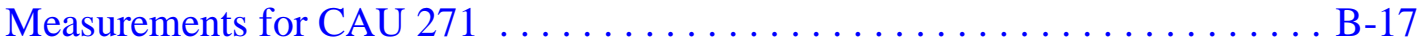

B.1-11 Radiological Completeness Measurements for CAU $271 \ldots \ldots \ldots \ldots$....... B-18

B.1-12 CAU 271 Rejected Data for CAS 25-04-01.................... B-19

B.1-13 CAU 271 Rejected Data for CAS 25-04-03.................... B-21

B.1-14 CAU 271 Rejected Data for CAS 25-04-04.................... B-24

B.1-15 CAU 271 Rejected Data for CAS 25-04-08.................... B-31

B.1-16 CAU 271 Rejected Data for CAS $25-04-09 \ldots \ldots \ldots \ldots \ldots \ldots \ldots \ldots . . \ldots . . \ldots \ldots$

B.1-17 CAU 271 Rejected Data for CAS 25-04-10................... B-36

B.1-18 CAU 271 Rejected Data for CAS 25-04-11................... B-38

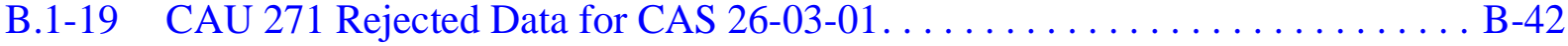

B.1-20 CAU 271 Rejected Data for CAS $26-04-01 \ldots \ldots \ldots \ldots \ldots \ldots \ldots . . \ldots . . \ldots \ldots$ 


\section{List of Tables (Continued)}

Number

B.1-21 CAU 271 Rejected Data for CAS $26-04-02 \ldots \ldots \ldots \ldots \ldots \ldots \ldots \ldots$ B-45

B.1-22 CAU 271 Rejected Data for CAS $26-05-01 \ldots \ldots \ldots \ldots \ldots \ldots \ldots \ldots . . \ldots \ldots$

B.1-23 CAU 271 Rejected Data for CAS $26-05-03 \ldots \ldots \ldots \ldots \ldots \ldots \ldots \ldots . . \ldots \ldots$

B.1-24 CAU 271 Rejected Data for CAS $26-05-04 \ldots \ldots \ldots \ldots \ldots \ldots \ldots \ldots$ B-50

B.1-25 CAU 271 Rejected Data for CAS $26-05-05 \ldots \ldots \ldots \ldots \ldots \ldots \ldots \ldots . . \ldots \ldots$

B.1-26 CAU 271 Rejected Data for CAS 27-05-02 ................... B-54

D.1-1 Sample Location Coordinates for CAS 25-04-01 Sample Locations and Points of Interest. . . . . . . . . . . . . . .

D.1-2 Sample Location Coordinates for CAS 25-04-01 Sample Locations and Points of Interest. . . . . . . . . . . . . . . . . . . . . . . .

D.1-3 Sample Location Coordinates for CAS 25-04-04 Sample Locations and Points of Interest. . . . . . . . . . . . . . . . .

D.1-4 Sample Location Coordinates for CAS 25-04-08 Sample Locations and Points of Interest. . . . . . . . . . . . . . . . . . . . . . . . . .

D.1-5 Sample Location Coordinates for CAS 25-04-09 Sample Locations and Points of Interest. . . . . . . . . . . . . . . . . . .

D.1-6 Sample Location Coordinates for CAS 25-04-10 Sample Locations and Points of Interest. . . . . . . . . . . . . . . . . . . . .

D.1-7 Sample Location Coordinates for CAS 25-04-11 Sample Locations and Points of Interest. . . . . . . . . . . . . . . . . . . .

D.1-8 Sample Location Coordinates for CAS 26-03-01 Sample Locations and Points of Interest. . . . . . . . . . . . . . . . . . . . . . . . . .

D.1-9 Sample Location Coordinates for CAS 26-04-01 Sample Locations and Points of Interest. . . . . . . . . . . . . . . . . . . 


\section{List of Tables (Continued)}

D.1-10 Sample Location Coordinates for CAS 26-04-02 Sample Locations and Points of Interest. . . . . . . . . . . . . . . . . . . . . . . D-23

D.1-11 Sample Location Coordinates for CAS 26-05-01 Sample Locations and Points of Interest. . . . . . . . . . . . . . . . . . . . . . . D-25

D.1-12 Sample Location Coordinates for CAS 26-05-03 Sample Locations and

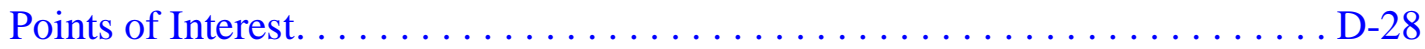

D.1-13 Sample Location Coordinates for CAS 26-05-04 Sample Locations and Points of Interest. . . . . . . . . . . . . . . . . . . . . . . . . . . . D-30

D.1-14 Sample Location Coordinates for CAS 26-05-05 Sample Locations and Points of Interest. . . . . . . . . . . . . . . . . . . . . . . . .

D.1-15 Sample Location Coordinates for CAS 27-05-02 Sample Locations and Points of Interest. . . . . . . . . . . . . . . . . . . . . . . .

D.1-16 Sample Location Coordinates for CAS 26-05-01 CPT Survey Locations. . . . . D-41

D.1-17 Sample Location Coordinates for CAS 26-05-03 CPT Survey Locations. . . . . D-44 


\section{List of Acronyms and Abbreviations}

bgs $\quad$ Below ground surface

BREN Bare Reactor Experiment-Nevada

CADD Corrective Action Decision Document

CAI Corrective Action Investigation

CAIP Corrective Action Investigation Plan

CAS Corrective Action Site

CAU Corrective Action Unit

CFR Code of Federal Regulations

CLP Contract Laboratory Program

$\mathrm{cm}^{2} \quad$ Square centimeter

COC Contaminants of concern

COPC Contaminants of potential concern

CPT Cone penetrometer technology

DOE U.S. Department of Energy

dpm Disintegrations per minute

DQI Data quality indicator

DQO Data quality objective

DRO Diesel-range organics

EPA U.S. Environmental Protection Agency

ERD Environmental Restoration Division

ESHD Environment Safety and Health Division

ETS-1 Engine Test Stand No. 1

FADL Field activity daily log

FD Field duplicate

FFACO Federal Facility Agreement and Consent Order

FSL Field-screening level 


\section{List of Acronyms and Abbreviations (Continued)}

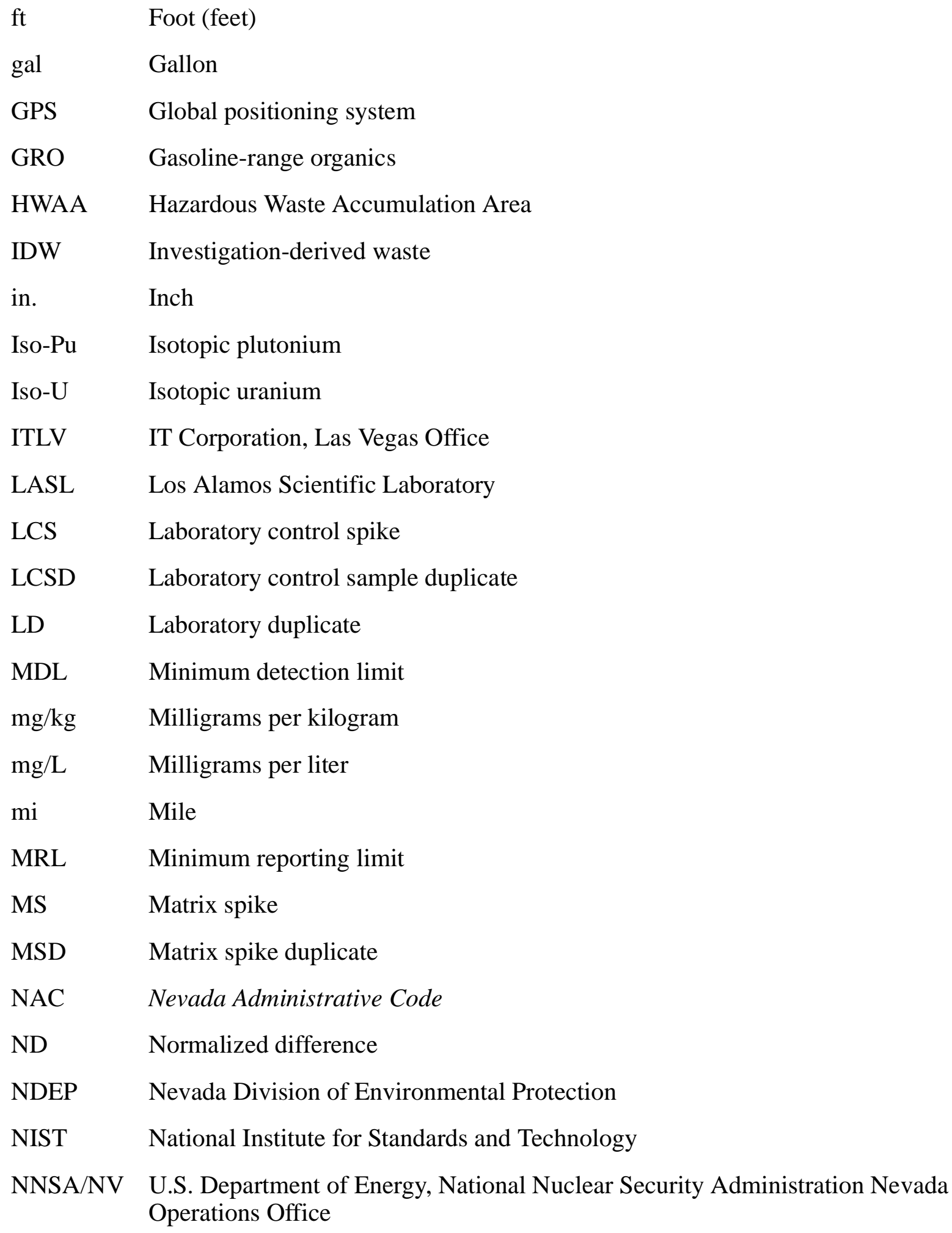




\section{List of Acronyms and Abbreviations (Continued)}

NTS Nevada Test Site

NUWAX Nuclear Weapons Accident Exercise

PAL Preliminary action level

Pan Am Pan American Airways, Inc.

PCB Polychlorinated biphenyls

$\mathrm{pCi} / \mathrm{g} \quad$ Picocuries per gram

POC Performance objective criteria

ppm Parts per million

PRG Preliminary Remediation Goal

$\mathrm{Pu} \quad$ Plutonium

QA Quality assurance

QAPP Quality Assurance Project Plan

QC Quality control

Rad-Safe Radiological-Safety

RCP Reactor Control Point

RCRA Resource Conservation and Recovery Act

RPD Relative percent difference

SDG Sample delivery group

Sr-90 Stronium-90

SSHASP Site-specific health and safety plan

SVOC Semivolatile organic compounds

TCLP Toxicity characteristic leaching procedure

TPH Total petroleum hydrocarbons

TPU Total propagated uncertainty

VCP Vitrified clay pipe

VOC Volatile organic compounds

$\mathrm{U}$

Uranium 


\section{List of Acronyms and Abbreviations (Continued)}

$\mathrm{yd}^{3} \quad$ Cubic yards

$\mu \mathrm{g} / \mathrm{kg} \quad$ Micrograms per kilogram

$\mu \mathrm{g} / \mathrm{L} \quad$ Micrograms per liter

$\% \mathrm{R} \quad$ Percent recovery 


\section{Executive Summary}

This Corrective Action Decision Document has been prepared for Corrective Action Unit 271, Areas 25, 26, and 27 Septic Systems. The purpose of this Corrective Action Decision Document is to identify and provide a rationale for the recommendation of a corrective action alternative for each Corrective Action Site (CAS) within Corrective Action Unit 271. The corrective action investigation was conducted in accordance with the Corrective Action Investigation Plan for Corrective Action Unit 271: Areas 25, 26, and 27 Septic Systems, Nevada Test Site, Nevada (DOE/NV, 2001), as developed under the Federal Facility Agreement and Consent Order (FFACO, 1996). Corrective Action Unit 271 is comprised of the following CASs:

- CAS 25-04-01 - Septic System (Security Checkpoint)

- CAS 25-04-03 - Septic System (Pan-Am Trailer)

- CAS 25-04-04 - Septic System (Reactor Control Point)

- CAS 25-04-08 - Septic System (BREN Tower)

- CAS 25-04-09 - Septic System (Engine Test Stand No. 1)

- CAS 25-04-10 - Septic System (Rad-Safe Trailer)

- CAS 25-04-11 - Septic System (South of LASL Trailers)

- CAS 26-03-01 - Contaminated Water Reservoir (Port Gaston Training Area)

- CAS 26-04-01 - Septic System (Area 26 Check Station)

- CAS 26-04-02 - Septic System (Hot Critical Facility)

- CAS 26-05-01 - Radioactive Leachfield (Buildings 2201 and 2202)

- CAS 26-05-03 - Septic System (Building 2203)

- CAS 26-05-04 - Septic System (Building 2201)

- CAS 26-05-05 - Septic System (Buildings 2101, 2102, and 2107)

- CAS 27-05-02 - Leachfield (Building 5200)

Analytes detected during the corrective action investigation of leachfield and contaminated water reservoir soil were evaluated against appropriate preliminary action levels, and septic tank, distribution box, and manhole sample results were evaluated against regulatory action levels to determine contaminants of concern for each CAS. Radiological measurements of collection system components were compared to unrestricted release criteria. Assessment of the data generated from investigation activities revealed the following:

- CAS 25-04-01 contains hydrocarbon-contaminated media exceeding regulatory action levels in the septic tank. 
- CAS 25-04-03 contains hydrocarbon-contaminated media exceeding regulatory action levels in the septic tank. Fecal coliform bacteria were also identified in the tank contents. At two locations, subsurface leachfield soil samples contain the semivolatile organic compound benzo(a)pyrene in concentrations exceeding the preliminary action level, however, it is possible that the results may be due to inadvertent introduction of pieces of "Orangeburg" leachfield pipe in these two samples.

- CAS 25-04-04 contains mixed waste with hydrocarbon-contaminated media exceeding regulatory action levels in the septic tank. Fecal coliform bacteria were also identified in the tank contents. Subsurface leachfield soil samples contain total petroleum hydrocarbons in concentrations exceeding the regulatory action level.

- CAS 25-04-08 contains hydrocarbon-contaminated media exceeding regulatory action levels in the septic tank. Subsurface leachfield soil samples contain radionuclide concentrations exceeding radiological preliminary action levels.

- CAS 25-04-09 contains hydrocarbon-contaminated media exceeding regulatory action levels in the septic tank.

- No contaminants of concern were identified at CAS 25-04-10.

- CAS 25-04-11 contains hydrocarbon-contaminated media exceeding regulatory action levels in the septic tank and the G35 Manhole. At two locations, subsurface leachfield soil samples contain the semivolatile organic compound benzo(a)pyrene in concentrations exceeding the preliminary action level, however, it is possible that the results may be due to inadvertent introduction of pieces of "Orangeburg" leachfield pipe in these two samples.

- CAS 26-03-01 contained surface soil samples exhibiting gamma-emitting radionuclide concentrations exceeding radiological preliminary action levels.

- CAS 26-04-01 contains low-level waste with hydrocarbon-contaminated media exceeding regulatory action levels in the septic tank.

- CAS 26-04-02 contains hydrocarbon-contaminated media exceeding regulatory action levels in the septic tank.

- CAS 26-05-01 Manhole 1 contains low-level waste with hydrocarbon-contaminated media exceeding regulatory action levels. Subsurface leachfield soil samples contain radionuclide concentrations exceeding radiological preliminary action levels.

- CAS 26-05-03 contains hydrocarbon-contaminated media exceeding regulatory action levels in the septic tank and manhole 1.

- CAS 26-05-04 contains hydrocarbon-contaminated media exceeding regulatory action levels in the septic tank. Fecal coliform bacteria were also identified in the tank contents. 
- CAS 26-05-05 contains hydrocarbon-contaminated media exceeding regulatory action levels in septic tank 1. Septic tank 2 contains mixed waste with hydrocarbon-contaminated media exceeding regulatory action levels. At one location, subsurface leachfield soil contains total petroleum hydrocarbons in concentrations exceeding the regulatory action level.

- CAS 27-05-02 contains polychlorinated biphenyls, hydrocarbons, and radiologically contaminated media in both the septic tank and distribution box exceeding regulatory action levels. The surface and subsurface soil in portions of the leachfield contain polychlorinated biphenyls in concentrations exceeding the preliminary action level.

Based on the evaluation of analytical data from the corrective action investigation, review of future and current operations in Areas 25, 26, and 27 of the Nevada Test Site, and the detailed and comparative analysis of the potential corrective action alternatives, the following corrective actions were selected for Corrective Action Unit 271 CASs.

No Further Action is the preferred corrective action for CAS 25-04-10. No contaminants of concern were identified at the CAS. It is recommended that the septic tank be filled as a best management practice.

Clean Closure is the preferred corrective action for the following CASs:

- CAS 25-04-01 - Septic tank

- CAS 25-04-03 - Septic tank

- CAS 25-04-04 - Septic tank, distribution box, and contaminated soil adjacent to the influent end of the septic tank

- CAS 25-04-08 - Septic tank and contaminated leachfield soil

- CAS 25-04-09 - Septic tank

- CAS 25-04-10 - Septic tank

- CAS 25-04-11 - Septic tank and manhole

- CAS 26-03-01 - Contaminated reservoir surface soil

- CAS 26-04-01 - Septic tank and distribution box

- CAS 26-04-02 - Septic tank and distribution box 
- CAS 26-05-01 - Manhole, distribution box, and contaminated leachfield soil

- CAS 26-05-03 - Septic tank, distribution box, and manhole

- CAS 26-05-04 - Septic tank and distribution box

- CAS 26-05-05 - Septic tanks 1 and 2, distribution boxes 1 and 2, and contaminated leachfield soil

- CAS 27-05-02 - Septic tank, distribution box, and contaminated surface and subsurface leachfield soil within the fenced leachfield boundary

The preferred corrective action alternatives were evaluated on technical merit focusing on performance, reliability, feasibility, and safety. The alternatives were judged to meet all requirements for the technical components evaluated. The alternatives meet all applicable state and federal regulations for closure of the site and will eliminate potential future exposure pathways to the contaminated media at Corrective Action Unit 271. 


\subsection{Introduction}

This Corrective Action Decision Document (CADD) has been prepared for Corrective Action Unit (CAU) 271, Areas 25, 26, and 27 Septic Systems, Nevada Test Site (NTS), Nevada, in accordance with the Federal Facility Agreement and Consent Order (FFACO) that was agreed to by the State of Nevada; U.S. Department of Energy (DOE); and the U.S. Department of Defense (FFACO, 1996). The NTS is approximately 65 miles (mi) north of Las Vegas, Nevada (Figure 1-1). The Corrective Action Sites (CASs) within CAU 271 are located in Areas 25, 26, and 27 of the NTS, in Nye County, Nevada (Figure 1-2, Figure 1-3, and Figure 1-4). Corrective Action Unit 271 is comprised of the 15 CASs identified in Table 1-1. As shown in Table 1-1, the FFACO has categorized 12 of these CASs as septic systems, 2 as leachfields, and 1 as a contaminated water reservoir; however, subsequent field investigations identified CAS 27-05-02 as a septic system. Therefore, this CADD addresses CAS 27-05-02 as a septic system.

\subsection{Purpose}

The 13 septic systems included in CAU 271 were designed to receive sanitary and process effluent associated with building maintenance and personal hygiene. Only CAS 26-05-01 (Buildings 2201 and 2202 Radioactive Leachfield) was designed to receive radioactive effluent. In addition, the Port Gaston Training Area Contaminated Water Reservoir (CAS 26-03-01) was intentionally contaminated with short-lived radionuclides as part of training conducted under the Nuclear Weapons Accident Exercise (NUWAX) program. The Corrective Action Investigation Plan (CAIP) for Corrective Action Unit 271: Areas 25, 26, and 27 Septic Systems, Nevada Test Site, Nevada (DOE/NV, 2001) provides information relating to the history, planning, and scope of the investigation; therefore, it will not be repeated in this CADD.

This CADD identifies potential corrective action alternatives and provides a rationale for the selection of a recommended corrective action alternative for each CAS within CAU 271. The need for evaluation of corrective action alternatives is based on process knowledge and the results of investigative activities conducted in accordance with the CAIP (DOE/NV, 2001). 


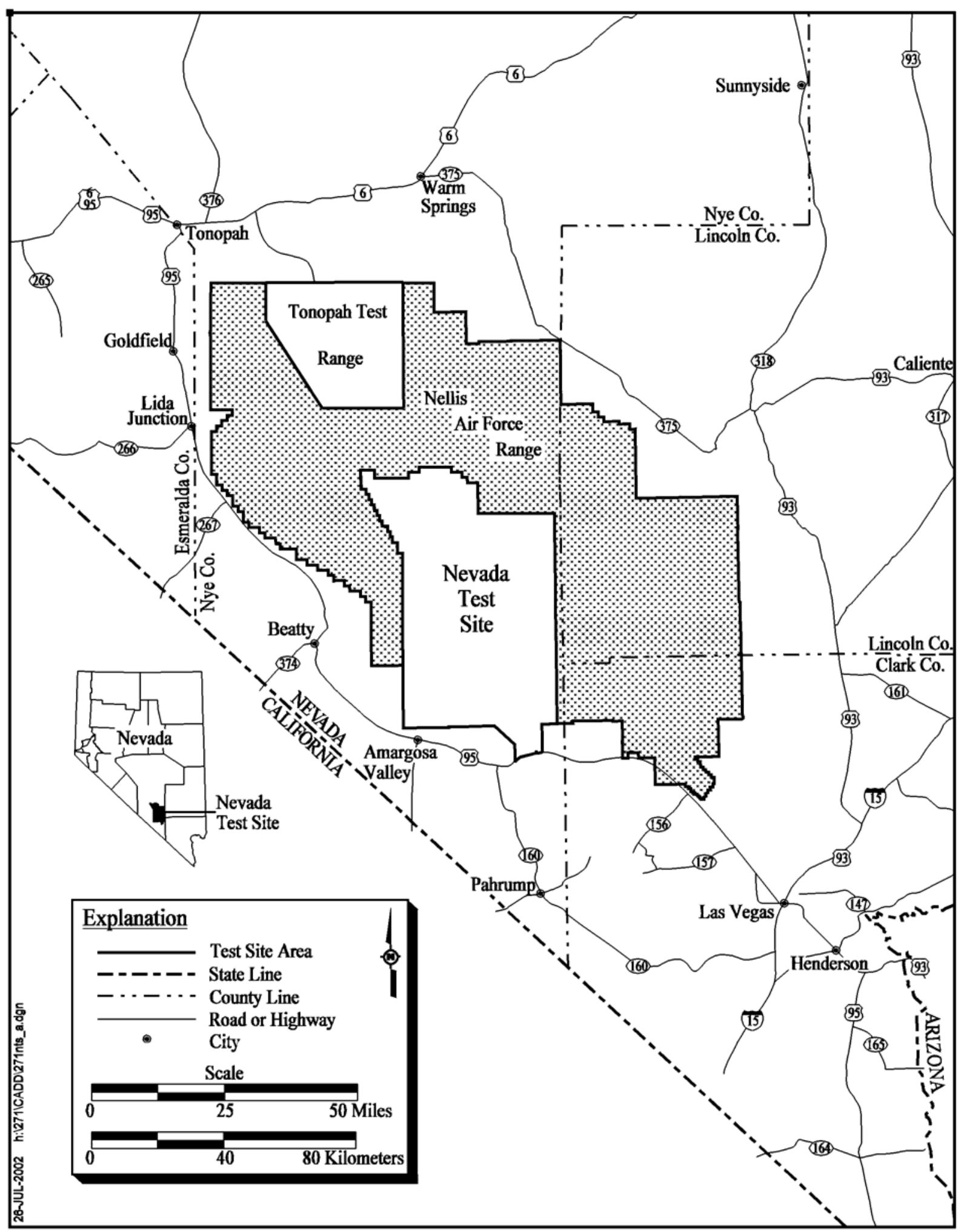

Figure 1-1

Nevada Test Site 


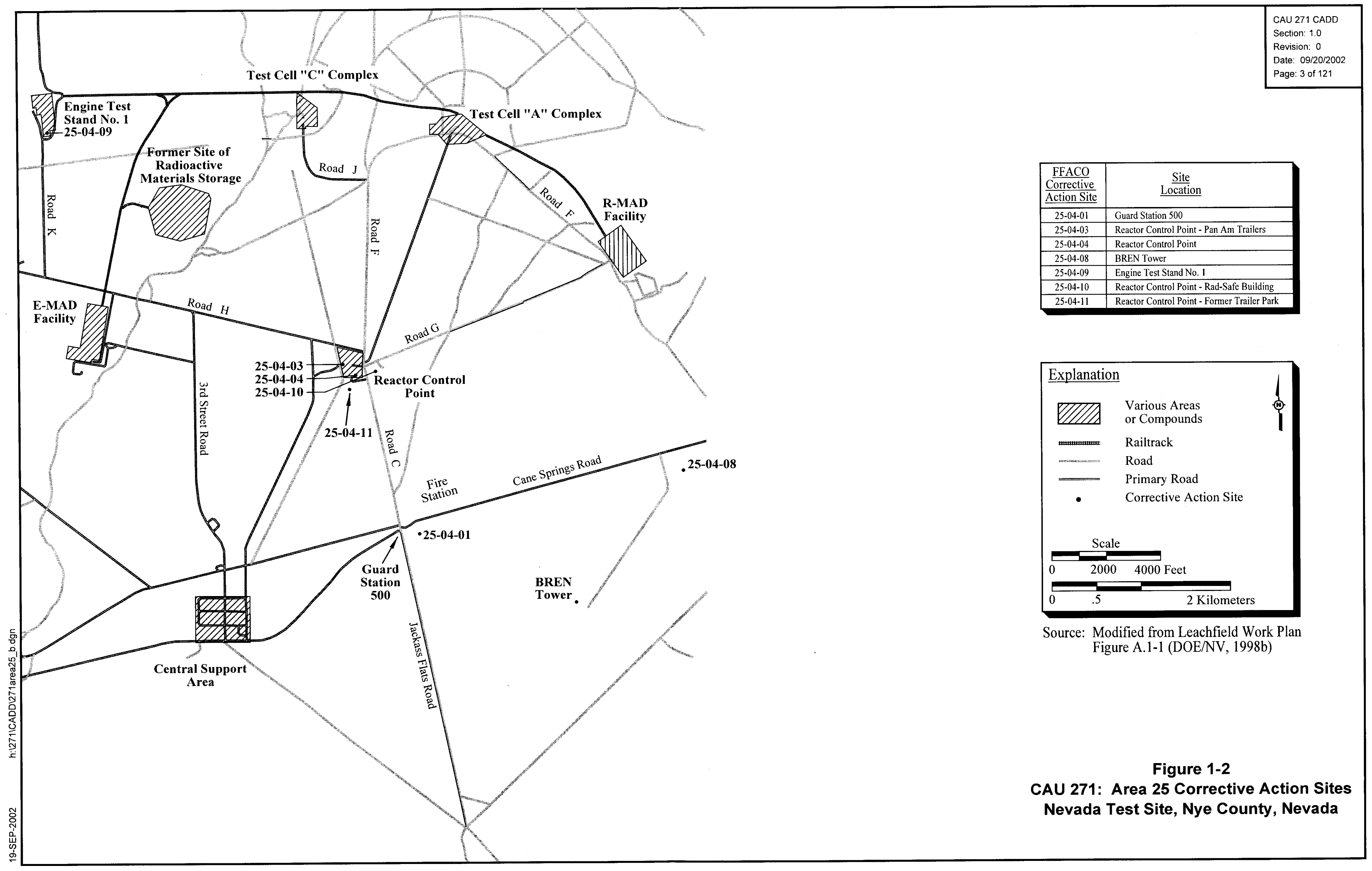




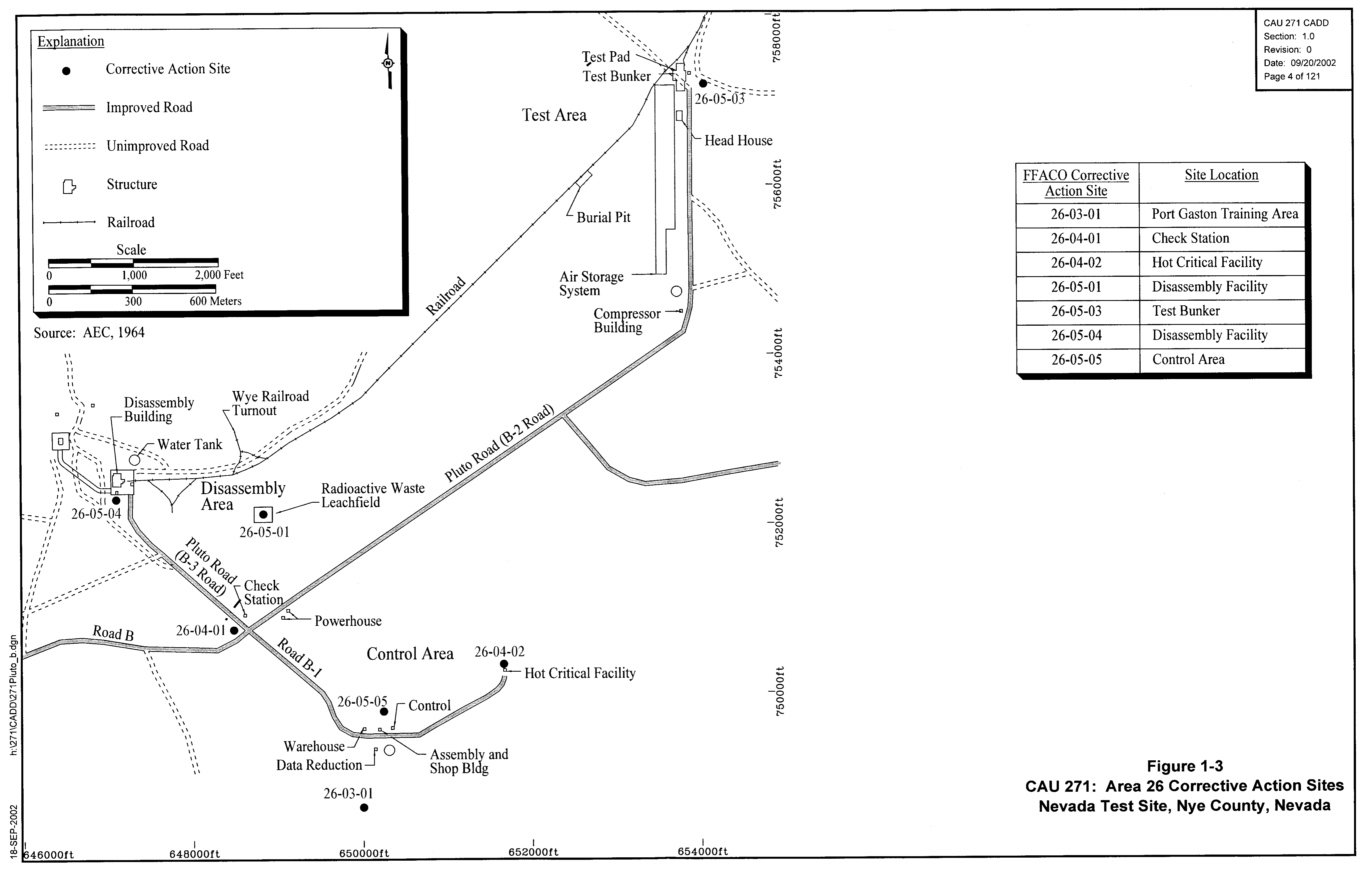




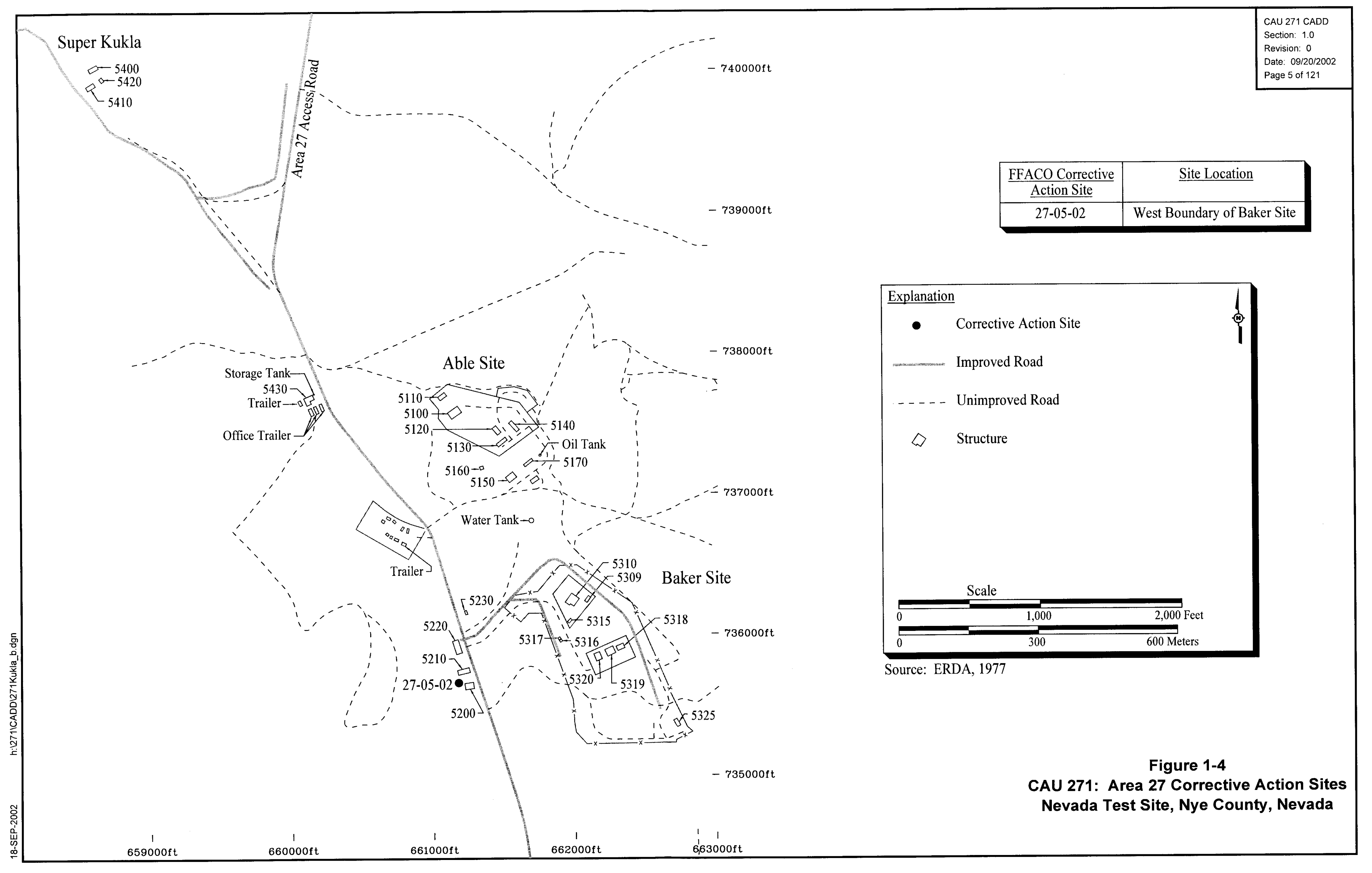


Table 1-1

Corrective Action Unit 271 Corrective Action Sites

\begin{tabular}{|c|c|c|c|}
\hline $\begin{array}{l}\text { Nevada Test } \\
\text { Site Area }\end{array}$ & $\begin{array}{c}\text { Corrective Action } \\
\text { Site }\end{array}$ & CAS Description ${ }^{a}$ & Facility Association ${ }^{b}$ \\
\hline \multirow{7}{*}{ Area 25} & $25-04-01$ & Septic System & Security Checkpoint \\
\hline & $25-04-03$ & Septic System & PAN-AM Trailers \\
\hline & $25-04-04$ & Septic System & Reactor Control Point \\
\hline & $25-04-08$ & Septic System & BREN Tower \\
\hline & $25-04-09$ & Septic System & Engine Test Stand No. 1 \\
\hline & $25-04-10$ & Septic System & Rad-Safe Trailers \\
\hline & $25-04-11$ & Septic System & South of LASL Trailers \\
\hline \multirow{7}{*}{ Area 26} & 26-03-01 & $\begin{array}{c}\text { Contaminated Water } \\
\text { Reservoir }\end{array}$ & Port Gaston Training Area \\
\hline & $26-04-01$ & Septic System & Area 26 Check Station \\
\hline & $26-04-02$ & Septic System & Hot Critical Facility \\
\hline & $26-05-01$ & Radioactive Leachfield & Buildings 2201 and 2202 \\
\hline & $26-05-03$ & Septic System & Building 2203 \\
\hline & $26-05-04$ & Septic System & Building 2201 \\
\hline & $26-05-05$ & Septic System & $\begin{array}{l}\text { Buildings } 2101,2102 \text {, and } \\
2107\end{array}$ \\
\hline Area 27 & $27-05-02$ & Leachfield $^{\mathrm{C}}$ & Building 5200 \\
\hline
\end{tabular}

${ }^{a}$ CAS description from the FFACO (1996)

${ }^{\mathrm{b}}$ General location from the FFACO (1996)

'Site initially identified as a leachfield but actually consists of a septic tank, distribution structure, leachfield system, and associated collection system pipes.

\subsection{Scope}

The scope of this CADD consists of the following:

- Develop corrective action objectives.

- Identify corrective action alternative screening criteria.

- Develop corrective action alternatives.

- Perform detailed and comparative evaluations of corrective action alternatives in relation to corrective action objectives and screening criteria.

- Recommend and justify a preferred corrective action alternative for each CAS within CAU 271. 


\subsection{Corrective Action Decision Document Contents}

This CADD is divided into the following sections:

Section 1.0 - Introduction: summarizes the purpose, scope, and contents of this CADD.

Section 2.0 - Corrective Action Investigation Summary: summarizes the investigation field activities, the results of the investigation, and the need for corrective action.

Section 3.0 - Evaluation of Alternatives: documents steps taken to determine a preferred corrective action alternative.

Section 4.0 - Recommended Alternatives: presents the preferred corrective action alternative and the rationale for its selection based on the corrective action objectives and screening criteria.

Section 5.0 - References: provides a list of all referenced documents.

Appendix A: Corrective Action Investigation Report for CAU 271: Areas 25, 26, and 27 Septic Systems, Nevada Test Site, Nevada: provides a description of the project objectives, field investigation and sampling activities, investigation results, waste management, and quality assurance. Section A.3.0 through Section A.17.0 provide CAS-specific information regarding field activities, sampling methods, and laboratory analytical results from the investigation sampling.

Appendix B: Data Assessment of Sample Results for CAU 271: Areas 25, 26, and 27 Septic Systems, Nevada Test Site, Nevada: summarizes the investigation results and compares them to the requirements set forth during the data quality objective (DQO) process.

Appendix C: Cost Estimates for CAU 271: Areas 25, 26, and 27 Septic Systems, Nevada Test Site, Nevada: provides an estimate of the costs to be incurred during the closure activities at each CAS.

Appendix D: Sample Location Coordinates for CAU 271: Areas 25, 26, and 27 Septic Systems, Nevada Test Site, Nevada: provides coordinates for investigation sample locations and septic system features. 
Appendix E: Project Organization: identifies the Project Manager and other appropriate personnel involved with the CAU 271 characterization and closure activities.

Appendix F: NDEP Comment Responses: contains responses to Nevada Department of Environmental Protection (NDEP) comments on the Draft CADD. 


\subsection{Corrective Action Investigation Summary}

Corrective action investigation activities were performed as set forth in the CAU 271 CAIP (DOE/NV, 2001) from October 29, 2001 through February 22, 2002, and April 29, 2002 through

June 25, 2002. To ensure all project objectives, health and safety requirements, and quality control procedures were adhered to, all investigation activities were performed in accordance with the following documents:

- $\quad$ CAIP (DOE/NV, 2001)

- Work Plan for Leachfield Corrective Action Units: Nevada Test Site and Tonopah Test Range, Nevada (Leachfield Work Plan) (DOE/NV, 1998b)

- Industrial Sites Quality Assurance Project Plan (QAPP) (DOE/NV, 1996)

- $\quad$ FFACO (1996)

- $\quad$ Project Management Plan (DOE/NV, 1994)

The following sections describe and summarize these activities, provide the investigation results, and identify the need for corrective action at the CAS level. For detailed investigation results, refer to Appendix A.

\section{$2.1 \quad$ Investigation Activities}

The primary purpose of the CAU 271 corrective action investigation was to:

- Determine if contaminants of potential concern (COPCs) are present within the septic/leachfield system components and/or soils associated with the components.

- Determine if COPCs are present in soil at the CAS 26-03-01 contaminated water reservoir.

- Determine whether the COPCs, if present, exceed regulatory levels (if they do, they become contaminants of concern [COCs]).

- Define the lateral and vertical extent of contamination, if COCs were detected.

- Generate information and data to satisfy DQO data needs and evaluate corrective action alternatives for each CAS. 
The scope of the corrective action investigation for CAU 271 included:

- Collecting integrity samples from the influent and effluent ends of septic tanks and effluent ends of distribution boxes.

- Sampling contents of septic tanks, distribution boxes, manholes, and other appropriate collection system features.

- Inspecting collection system pipes through video mole survey, radiological swipes, and/or sampling, where appropriate.

- Conducting exploratory excavations to confirm leachfield configurations.

- Conducting discrete field screening.

- Collecting soil samples from biased or a combination of biased and random locations within the boundaries of the leachfields.

- Collecting soil samples at step-out locations, as necessary, to further define the extent of possible contamination.

- Collecting soil samples from biased locations, both above and below a liner at CAS 26-03-01.

- Submitting select soil samples for off-site laboratory analyses of COPCs.

- Collecting a geotechnical/hydrological sample of native soil at each CAS for possible future analysis.

\section{Excavation}

The primary purpose of backhoe excavations was to collect soil samples for characterization purposes. Excavation was also necessary to access the collection system pipes for visual inspections at each CAS, except CAS 26-03-01 (Table 2-1). Most of the septic systems were consistent with the anticipated configurations. However, variances in leachfield size were identified at CASs 25-04-10 and 26-05-05, and were addressed by applying a linear transformation to reconfigure sample locations. Trenching also identified deviations from the anticipated leachfield configurations at CAS 25-04-03. The actual configuration of CAS 25-04-03 (Figure A.4-1) varied significantly from the anticipated layout and the "Visual Sample Plan" model (a contingency to the CAIP) was employed to identify new random sampling locations. 
Table 2-1

CAS Excavation Activities

\begin{tabular}{|c|c|c|c|c|c|c|c|c|c|c|c|c|c|c|c|}
\hline \multirow[b]{2}{*}{ Purpose of Excavation } & \multicolumn{15}{|c|}{ Corrective Action Site } \\
\hline & 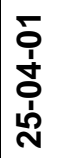 & 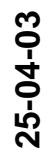 & 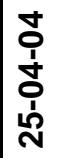 & 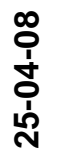 & 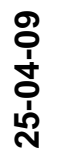 & 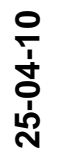 & 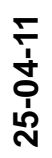 & $\begin{array}{l}\text { o } \\
\text { ల్ } \\
\text { ’े }\end{array}$ & 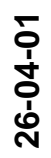 & 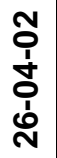 & $\begin{array}{l}\text { ' } \\
\text { மீ } \\
\text { ’े }\end{array}$ & $\begin{array}{l}\text { O̊ } \\
\text { ஸे } \\
\text { ํํ }\end{array}$ & 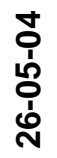 & $\begin{array}{l}\text { 오 } \\
\text { மீ. } \\
\text { ஸे } \\
\text { ஸे }\end{array}$ & 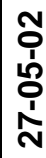 \\
\hline Located leachfield system components & $\mathrm{X}$ & $\mathrm{X}$ & $\mathrm{X}$ & $\mathrm{X}$ & $\mathrm{X}$ & $\mathrm{X}$ & $\mathrm{X}$ & & $\mathrm{X}$ & $\mathrm{X}$ & $\mathrm{X}$ & $\mathrm{X}$ & $\mathrm{X}$ & $\mathrm{X}$ & $\bar{x}$ \\
\hline Exposed biased and/or random sampling horizons & $\mathrm{X}$ & $\mathrm{X}$ & $\mathrm{X}$ & $\mathrm{X}$ & $\mathrm{X}$ & $\mathrm{X}$ & $\mathrm{X}$ & $\mathrm{X}$ & $\mathrm{X}$ & $\mathrm{X}$ & $\mathrm{X}$ & $\mathrm{X}$ & $\mathrm{X}$ & $\mathrm{X}$ & $\mathrm{X}$ \\
\hline Removed soil from excavations for sampling & $\mathrm{X}$ & $\mathrm{X}$ & $\mathrm{X}$ & $\mathrm{X}$ & $\mathrm{X}$ & $\mathrm{X}$ & $\mathrm{X}$ & $\mathrm{X}$ & $\mathrm{X}$ & $\mathrm{X}$ & $\mathrm{X}$ & $\mathrm{X}$ & $\mathrm{X}$ & $\mathrm{X}$ & $\mathrm{x}$ \\
\hline Exposed the septic tank lids & & $\mathrm{X}$ & & $\mathrm{X}$ & & $\mathrm{X}$ & & & & & & & & & $x$ \\
\hline $\begin{array}{l}\text { Collected integrity samples at the influent and } \\
\text { effluent ends of septic tanks }\end{array}$ & $X$ & $\mathrm{X}$ & $\mathrm{X}$ & $\mathrm{X}$ & $\mathrm{X}$ & $\mathrm{X}$ & $x$ & & $x$ & $x$ & & $x$ & $X$ & $\mathrm{X}$ & $x$ \\
\hline $\begin{array}{l}\text { Collected integrity samples at the effluent end of } \\
\text { distribution boxes }\end{array}$ & & & $\mathrm{X}$ & $\mathrm{X}$ & & $\mathrm{X}$ & $X$ & & $\mathrm{X}$ & $X$ & $X$ & $\mathrm{X}$ & $X$ & $\mathrm{X}$ & $\mathrm{X}$ \\
\hline $\begin{array}{l}\text { Provided access to inspect the collection system } \\
\text { piping to appraise the contents of the pipes }\end{array}$ & $\mathrm{X}$ & $X$ & $\mathrm{X}$ & $\mathrm{X}$ & $\mathrm{X}$ & $\mathrm{X}$ & $X$ & & $\mathrm{X}$ & $x$ & $x$ & $x$ & $X$ & $\mathrm{X}$ & $\mathrm{X}$ \\
\hline $\begin{array}{l}\text { Allowed for the removal of pipe segments for } \\
\text { unrestricted release criteria determinations }\end{array}$ & & & & & & & & & & & $x$ & $\mathrm{X}$ & & & \\
\hline
\end{tabular}

\section{Field Screening}

Field screening was conducted on soil samples using the headspace method for volatiles, total coliform analysis for fecal bacteria, hand-held instrument surveys for alpha and beta/gamma radiation, and gas chomatography for total petroleum hydrocarbons (TPH), when appropriate. Field screening was conducted for volatile organic compounds (VOCs) using a photoionization detector and for alpha and beta/gamma radioactivity using an Electra survey instrument.

\section{Inspections and Sampling}

Subsurface soil samples were collected using excavation (drilling was not required because excavation was adequate for collection of all necessary subsurface samples). Subsurface soil samples were collected from the backhoe bucket and placed into a stainless-steel bowl using a disposable scoop. After being homogenized, the material was screened for VOCs and radiation, sample containers were filled, and then the samples were submitted to an off-site laboratory for analysis to determine the presence and concentrations of COPCs. Samples for VOC and TPH gasoline range organics (GRO) analyses were collected and placed directly into containers without homogenization to reduce volatilization. 
Surface soil samples were collected at CASs 26-03-01 and 27-05-02. In accordance with the CAIP (DOE/NV, 2001), surface samples were collected above the reservoir plastic liner at CAS 26-03-01. At CAS 27-05-02, surface soil samples were collected during additional sampling efforts conducted in June 2002. Surface soil samples were collected in the same manner as subsurface samples, except that samples were collected directly from the ground surface, not from a backhoe bucket.

The number of samples collected and submitted to the laboratory depended on field screening results. At each location, all samples were field screened, but a minimum of one sample was submitted for off-site analysis. Field screening was used to establish vertical and lateral contamination boundaries determined by two successive measurements below field screening levels (FSLs). When field screening indicated that two consecutive soil sampling intervals were below FSLs, the first sample (upper-most) was submitted for laboratory analysis. The second (lower) sample collected with screening results below FSLs was returned to the sampling location and not submitted for off-site analysis. In addition, samples with screening results above FSLs were generally submitted for laboratory analysis.

Samples collected for geotechnical and hydrological analyses were not analyzed since the results would not impact corrective action decisions; however, the samples were archived for possible future geotechnical analysis. Several samples were collected for waste management purposes and are discussed in Appendix A.

Septic tanks, distribution boxes, and collection system components were inspected for the presence of sludge, liquid, and sediment, and sampled if appropriate and adequate material was present. Samples were submitted to an off-site laboratory for analysis. Material that was clearly not representative of system operation was not collected (e.g., gravel, minimal residue, plant and animal matter).

At most CASs, collection system pipes (piping upstream of the septic tank, distribution box, manholes can be along collection system pipeline and/or leachfield) were visually inspected primarily using a video mole. The mole has a camera mounted on the end of a flexible cable that is pushed into the pipeline; the video of the pipe is observed on a monitor and findings are recorded in field documentation. Access points for video mole inspection included excavated breaks in the pipe, manholes, and other features such as risers. Pipes were inspected to document the presence or 
absence of locations that might require further investigation (e.g., breaks or blockages) and to determine if sediment was available in the pipe for sampling.

Collection system features at some CASs were also screened and swiped for radiological characterization. The features included segments of pipe obtained by excavation, manholes, and distribution boxes.

Visual observations made during the excavation, sampling, and collection system inspection activities were recorded in field activity daily logs (FADLs).

\section{Laboratory Analysis}

Laboratory analysis of soil, liquid, and sludge samples provide a means for quantitative measurement of COPCs. Based on process knowledge and the results of previous sampling efforts, an analytical program was established in the CAIP to determine the nature of potential contamination at each CAS.

Laboratory analyses for soil samples typically included total VOCs, total semivolatile organic compounds (SVOCs), total Resource Conservation and Recovery Act (RCRA) metals, and total TPH (diesel-range organics [DRO] and GRO). Other analyses performed on select soil samples include polychlorinated biphenyls (PCBs), total beryllium, total pesticides and herbicides, gamma-emitting radionuclides, isotopic uranium (Iso-U), isotopic plutonium (Iso-Pu), and strontium-90 ( $\mathrm{Sr}-90$ ). The soil sample analytical program followed during the investigation is presented in Table 2-2.

Additional analyses were performed on sediment, sludge, and liquid samples to support waste determinations. As appropriate to the sample matrix, these analyses typically included: total VOCs, Toxicity Characteristic Leaching Procedure (TCLP) VOCs, total SVOCs, TCLP SVOCs, total RCRA metals, TCLP RCRA metals, TPH DRO and GRO, PCBs, total pesticides and herbicides, Iso-U, Iso-Pu, $\mathrm{Sr}-90$, tritium, gamma-emitting radionuclides, and gross alpha and gross beta radioactivity. The analytical program applied to liquid, sludge, and sediment samples collected from septic tanks, distribution boxes, and collection system components is presented in Table 2-3.

\section{Conceptual Site Models}

The general conceptual model was applied at all of the CASs within CAU 271 except for CAS 26-03-01. The general conceptual model included soil potentially impacted by subsurface 
Table 2-2

Soil Sample Analyses Conducted at CAU 271

\begin{tabular}{|c|c|c|c|c|c|c|c|}
\hline \multirow[b]{2}{*}{ Corrective Action Site } & \multicolumn{7}{|c|}{ Analyses } \\
\hline & 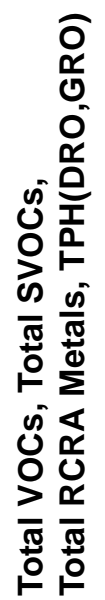 & 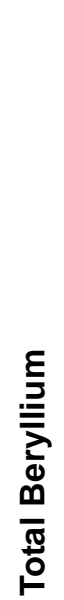 & 只 & 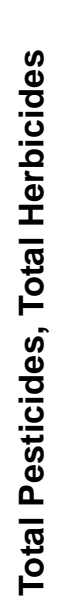 & 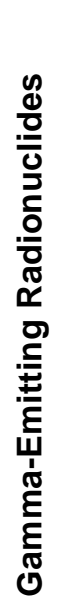 & 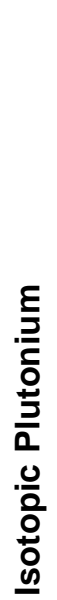 & 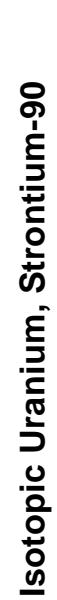 \\
\hline$\overline{C \text { CAS 25-04-01 }}$ & $\overline{\bar{X}}$ & & & & $\bar{X}$ & $\overline{\bar{X}}$ & $\overline{\bar{x}}$ \\
\hline CAS 25-04-03 & $\bar{X}$ & & $\bar{X}$ & & $\bar{X}$ & $\bar{X}$ & $\bar{x}$ \\
\hline CAS 25-04-04 & $\bar{X}$ & & $\mathrm{X}$ & $\bar{X}$ & $\mathrm{X}$ & $\bar{x}$ & $\bar{x}$ \\
\hline CAS 25-04-08 & $\bar{X}$ & & & & $\bar{X}$ & $\bar{X}$ & $\bar{x}$ \\
\hline CAS 25-04-09 & $\bar{X}$ & & $\mathrm{X}$ & & $\mathrm{X}$ & $\bar{X}$ & $\bar{x}$ \\
\hline CAS 25-04-10 & $\bar{X}$ & & & & $\mathrm{x}$ & $\bar{x}$ & $\bar{x}$ \\
\hline CAS 25-04-11 & $\bar{X}$ & & $\bar{X}$ & & $\bar{X}$ & $\bar{x}$ & $\bar{x}$ \\
\hline CAS 26-03-01 & $\bar{X}$ & & & $\bar{X}$ & $\mathrm{X}$ & & \\
\hline CAS 26-04-01 & $\bar{X}$ & $\bar{X}$ & & & $\mathrm{X}$ & $\bar{X}$ & $\bar{x}$ \\
\hline CAS 26-04-02 & $\bar{x}$ & $\bar{X}$ & $\mathrm{X}$ & & $\mathrm{X}$ & $\mathrm{X}$ & $\mathrm{x}$ \\
\hline CAS 26-05-01 & $x$ & $\mathrm{X}$ & $\bar{x}$ & & $\mathrm{X}$ & $\bar{x}$ & $x$ \\
\hline CAS 26-05-03 & $\bar{X}$ & $\bar{X}$ & $\bar{X}$ & & $\mathrm{X}$ & $\bar{X}$ & $x$ \\
\hline CAS 26-05-04 & $\mathrm{X}$ & $\mathrm{X}$ & $x$ & & $x$ & $\mathrm{X}$ & $\mathrm{X}$ \\
\hline CAS 26-05-05 & $\bar{X}$ & $\bar{X}$ & $\mathrm{X}$ & & $\mathrm{X}$ & $\mathrm{X}$ & $\mathrm{x}$ \\
\hline CAS 27-05-02 & $\bar{X}$ & & $\bar{X}$ & $\bar{X}$ & $\mathrm{X}$ & $\bar{X}$ & $\mathrm{X}$ \\
\hline
\end{tabular}

disposal/release of effluent. The mechanisms for this type of release include both designed (e.g., underground discharge points) and accidental releases (e.g., septic tank breach, collection system pipe breach). This model assumed that any contamination would be concentrated in the soil located immediately beneath and adjacent to the disposal component (e.g., distribution lines). The extent of underlying soil impact is expected to be variable and dependent upon the volume of effluent 
Table 2-3

Liquid, Sludge, and Sediment Sample Analyses Conducted at CAU 271

\begin{tabular}{|c|c|c|c|c|c|c|c|c|c|c|}
\hline & \multicolumn{10}{|c|}{ Analyses } \\
\hline Corrective Action Site & 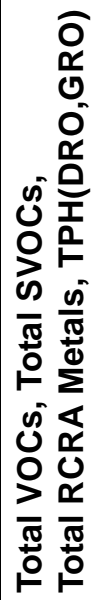 & 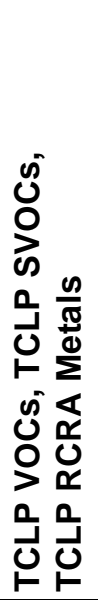 & 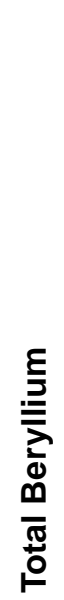 & O্ & 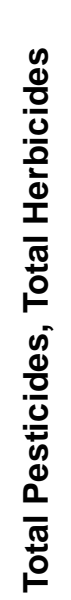 & 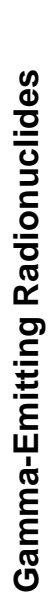 & 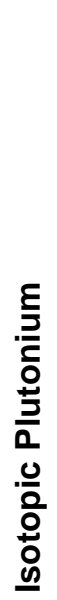 & 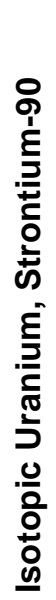 & 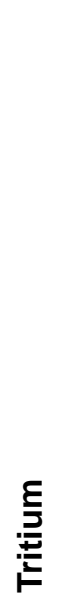 & 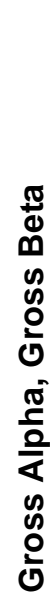 \\
\hline$\overline{\text { CAS 25-04-01 }}$ & $\overline{\bar{X}}$ & $\overline{\bar{X}}$ & & & & $\overline{\bar{X}}$ & $\overline{\bar{X}}$ & $\overline{\bar{X}}$ & $\overline{\bar{X}}$ & \\
\hline CAS 25-04-03 & $x$ & $\mathrm{X}$ & & $x$ & & $x$ & $\mathrm{x}$ & $x$ & $x$ & $\mathrm{x}$ \\
\hline CAS 25-04-04 & $x$ & $\bar{x}$ & & $\bar{x}$ & $\mathrm{X}$ & $\bar{x}$ & $\bar{x}$ & $\bar{x}$ & $\bar{x}$ & $\mathrm{x}$ \\
\hline CAS 25-04-08 & $x$ & $\mathrm{X}$ & & & & $x$ & $x$ & $x$ & $x$ & $x$ \\
\hline CAS 25-04-09 & $x$ & $\mathrm{X}$ & & $x$ & & $\mathrm{X}$ & $\mathrm{X}$ & $\mathrm{X}$ & $\bar{x}$ & \\
\hline CAS 25-04-10 & \multicolumn{10}{|c|}{ Septic tank was empty } \\
\hline CAS 25-04-11 & $\bar{X}$ & $\bar{X}$ & & $\bar{x}$ & & $\mathrm{X}$ & $\bar{X}$ & $\bar{X}$ & $\bar{x}$ & $\bar{x}$ \\
\hline CAS 26-03-01 & \multicolumn{10}{|c|}{ No septic tank } \\
\hline CAS 26-04-01 & $\bar{x}$ & $\mathrm{X}$ & $\bar{x}$ & & & $\bar{x}$ & $\bar{x}$ & $\bar{x}$ & $\bar{x}$ & $\mathrm{X}$ \\
\hline CAS 26-04-02 & $\mathrm{X}$ & $\bar{x}$ & $\bar{X}$ & $\bar{x}$ & & $\bar{X}$ & $\bar{X}$ & $\bar{x}$ & $\bar{x}$ & \\
\hline CAS 26-05-01 & $\mathrm{x}$ & & $x$ & $\bar{x}$ & & $\bar{x}$ & $\bar{x}$ & $\bar{x}$ & & \\
\hline CAS 26-05-03 & $X$ & $\mathrm{X}$ & $\mathrm{X}$ & $\mathrm{X}$ & & $x$ & $\mathrm{X}$ & $\mathrm{x}$ & $\mathrm{x}$ & \\
\hline CAS 26-05-04 & $\bar{x}$ & $\mathrm{X}$ & $\bar{X}$ & $\bar{x}$ & & $\mathrm{X}$ & $\bar{X}$ & $\bar{x}$ & $\bar{x}$ & $\mathrm{X}$ \\
\hline CAS 26-05-05 & $\mathrm{x}$ & $\mathrm{X}$ & $\mathrm{X}$ & $x$ & & $x$ & $\bar{x}$ & $\bar{x}$ & $\bar{x}$ & $\mathrm{X}$ \\
\hline CAS 27-05-02 & $X$ & $X$ & & $\mathrm{X}$ & & $X$ & $\bar{X}$ & $\bar{X}$ & $x$ & $\mathrm{x}$ \\
\hline
\end{tabular}

released, the leachfield system design, geological conditions, the nature of COPCs, and other factors. The general conceptual site model for CAU 271 is consistent with the general conceptual model for leachfield CAUs provided in Section 3.1 of the Leachfield Work Plan (DOE/NV, 1998b). 
The specific conceptual model for CAS 26-03-01 water reservoir included surface soil impacted by intentional spraying of water containing radionuclides into the reservoir. The model assumed that any contamination would be concentrated above the plastic liner present in the reservoir.

Specific conceptual models were developed for each CAS and were applied during the investigation. Significant variations in the expected leachfield configurations were identified at several CASs. Contingencies were included in the CAIP to address this issue and to modify existing or select new sampling locations. Therefore, difference between planned and actual leachfield configurations at several CASs did not invalidate the conceptual model. Specific variations identified at each CAS are presented in the CAS-specific sections in Appendix A.

Section 2.1.1 through Section 2.1.15 discuss the investigative activities conducted at each of the CAU 271 CASs.

\subsubsection{Security Checkpoint Septic System (CAS 25-04-01)}

The security checkpoint septic system was designed to receive sanitary effluent generated in 1961 by activities in four temporary office trailers (formerly used as offices for Wackenhut Services, Inc. and

Sheriff's Department security personnel). The septic system was located approximately 50 feet (ft) east of Jackass Flats Road, just south of the guard station at Gate 500. The site was comprised of a leachfield, septic tank, and associated piping.

\section{Excavation}

Excavation by backhoe was used to collect integrity samples from soil adjacent to the influent and effluent ends of the septic tank. No distribution box is associated with this system. Exploratory trenching determined that the configuration of the leachfield was as expected. Excavations provided a visual verification of distribution pipes.

\section{Field Screening}

Soil samples were screened for VOCs and alpha and beta/gamma radioactivity. The field readings were compared to FSLs to guide sampling decisions and determine which samples were to be submitted for laboratory analysis. 


\section{Inspections and Sampling}

Soil samples were collected from intervals beneath the pipes at the leachrock/native soil interface and an interval $2.5 \mathrm{ft}$ below the interface. Eight leachfield soil samples were collected and four were submitted to an off-site laboratory for analysis. Soil sample analyses conducted are listed in Table 2-2. A geotechnical sample was collected outside the boundary of the leachfield. The sample was archived for possible future analysis.

Access points for inspection by video mole survey were created via excavation at locations along the collection pipe. The collection system piping was inspected and found to have two inlet lines running directly into the septic tank. The north line was identified as transite (i.e., asbestos containing material). The presence of asbestos resulted in minor delays prior to conducting the video survey; however, the survey was successfully conducted in this portion of the collection system. The other line leading into the septic tank was identified as vitrified clay pipe (VCP). No sediment, breaches, or offshoot lines were observed. The entire $91 \mathrm{ft}$ length of the collection system piping was inspected. Scaling was present on the piping and a slight amount of moisture was present. The survey identified some sediment in the piping; however, it was not appropriate or adequate material to be sampled.

The manhole of the septic tank was opened and the nature and quantity of the contents were inspected. The concrete, single-chambered septic tank contained both sludge and liquid, and samples of each were collected. The samples were submitted for analyses of COPCs as specified in Table 2-3. On-site analysis was performed on the septic tank contents to determine if fecal coliform bacteria were present.

Investigation activities associated with CAS 25-04-01 are further detailed in Section A.3.2.

\subsubsection{PAN-AM Trailers Septic System (CAS 25-04-03)}

The Pan American Airways, Inc. (Pan Am) trailer septic system was designed to receive sanitary effluent generated by activities that took place in Pan Am housing trailers and one recreational trailer in 1965. The septic system is located approximately $350 \mathrm{ft}$ west of the Reactor Control Point (RCP) fenceline. The site is comprised of a leachfield, septic tank, and associated piping. 


\section{Excavation}

Excavation by backhoe was used to collect integrity samples of soil adjacent to the influent and effluent ends of the septic tank. No distribution box was associated with this system. Exploratory trenching confirmed the actual configuration of the leachfield was significantly different from the anticipated configuration. Consequently, sampling locations changed significantly. New sample locations were selected using the "Visual Sample Plan" model, in accordance with a contingency included in the CAIP (DOE/NV, 2001). Excavation provided a visual verification of distribution pipes.

\section{Field Screening}

Soil samples were screened for VOCs and alpha and beta/gamma radioactivity. The field readings were compared to FSLs to guide sampling decisions and determine which samples were to be submitted for laboratory analysis.

\section{Inspections and Sampling}

Soil samples were collected from beneath the pipes at the leachrock/native soil interface, an interval $2.5 \mathrm{ft}$ below the interface, and an interval $6.5 \mathrm{ft}$ below the interface (at some locations). Sixty-six leachfield soil samples were collected and 39 were submitted to an off-site laboratory for analysis. Soil sample analyses conducted are listed in Table 2-2. A geotechnical sample was collected outside the boundary of the leachfield. The sample was archived for possible future analysis.

To further define the extent of potential contamination, additional step-out sampling was conducted at one location (B04; Figure A.4-1) identified from the original sampling activities as a location of concern due to the presence of SVOCs. Additional samples were collected at step-out locations B37 and B38 (Figure A.4-1). Six samples were collected and three were submitted to an off-site laboratory for analysis of SVOCs.

Access points for inspection by video mole survey were present (i.e., manholes) and were also created at locations along the collection pipe via excavation. As shown on Figure A.4-1, the CAS 25-04-03 leachfield was apparently bypassed, and effluent from the Pan Am trailer area was routed to a sewage lagoon. The original collection system, as well as the bypass line, was inspected during the investigation. The video mole inspection revealed that the collection system pipes at CAS 25-04-03 
were in good structural condition and did not contain any obstructions or material related to the operation of the system. Locations where leaks may have occurred were not observed. The only materials present were very small amounts of plant/animal debris and soil.

Portions of the collection pipe at excavated locations B13, B14, and B15 (Figure A.4-1) were radiologically surveyed and swiped. Other access points (i.e., manholes) were also surveyed and swiped.

The septic tank manholes were opened and the nature and quantity of the contents were inspected. The concrete, single-chambered septic tank contained both liquid and sludge, and samples of each were collected. The samples were submitted for analyses of COPCs as specified in Table 2-3. On-site analysis was performed on the septic tank contents to determine if fecal coliform bacteria were present.

Investigation activities associated with CAS 25-04-03 are further detailed in Section A.4.2.

\subsubsection{Reactor Control Point Septic System (CAS 25-04-04)}

The RCP septic system was designed to receive effluent generated within Building 3101 (Control Point), Building 3102 (Power House), Building 3103 (Los Alamos Scientific Laboratory [LASL] Warehouse), Building 3106 (Storage Building), Building 3104 (Administration Building), Building 3105 (Former Medical/Cafeteria), Building 3107 (Service Station) and Building 3123 (Technical Services). The leachfield system is located just south of the RCP complex fenceline, and the septic tank is within the fenceline. The site is comprised of a leachfield, septic tank, distribution box, and associated piping.

\section{Excavation}

Excavation by backhoe was used to collect integrity samples of soil adjacent to the influent and effluent ends of the septic tank and effluent end of the distribution box. Exploratory trenching confirmed the configuration of the leachfield was as expected. Excavation provided a visual verification of distribution pipes. 


\section{Field Screening}

Soil samples were screened for VOCs and alpha and beta/gamma radioactivity. The field readings were compared to FSLs to guide sampling decisions and determine which samples were to be submitted for laboratory analysis.

\section{Inspections and Sampling}

Soil samples were collected from intervals beneath the pipes, at the leachrock/native soil interface, an interval $2.5 \mathrm{ft}$ below the interface, and an interval $6.5 \mathrm{ft}$ below the interface (at some locations). Seventy-three leachfield soil samples were collected and 40 were submitted to an off-site laboratory for analysis. Soil sample analyses conducted are listed in Table 2-2. A geotechnical sample was collected outside the boundary of the leachfield. The sample was archived for possible future analysis.

To further define the extent of TPH DRO contamination detected near the inlet of the septic tank, additional step-out sampling was conducted. Location C32 (Figure A.5-1) was identified from the original sampling activities as a location of concern. Thirty-eight additional soil samples were collected and submitted to an off-site laboratory for analysis of TPH DRO. Volatile organic compounds, SVOCs, PCBs, and herbicide analyses were also conducted on select soil samples.

As discussed in the CAIP, this system included only approximately $20 \mathrm{ft}$ of collection system pipe. Access points for inspection by video mole survey were present (i.e., manhole) and one was created at the inlet end of the septic tank via backhoe excavation. A video mole was inserted through the VCP at this location to inspect the pipe. Some sediment was identified in the piping, but was not adequate material to be sampled. The inspection confirmed that the septic system had been bypassed.

The septic tank manholes were opened and the nature and quantity of the contents were inspected. The two-chambered, concrete septic tank contained both liquid and sludge, and samples of each were collected. The distribution box manholes were also opened The contents of the distribution box were not sampled, as visual inspection revealed that no liquid or sludge remained. The sludge and liquid samples associated with the septic tank were submitted for analyses of COPCs as specified in Table 2-3. On-site analysis was performed on the septic tank contents to determine if fecal coliform bacteria were present. 
Investigation activities associated with CAS 25-04-04 are further detailed in Section A.5.2.

\subsubsection{BREN Tower Septic System (CAS 25-04-08)}

The Bare Reactor Experiment-Nevada (BREN) septic system was designed to receive effluent generated within a restroom trailer near the BREN Tower access road. The septic system is located approximately $100 \mathrm{ft}$ south of Cane Spring Road, at the entrance to BREN Tower, and east of the BREN Tower access road in Area 25. The site is comprised of a leachfield, septic tank, distribution box and associated piping.

\section{Excavation}

Excavation by backhoe was used to collect integrity samples of soil adjacent to the influent and effluent ends of the septic tank and effluent end of the distribution box. Exploratory trenching confirmed the configuration of the leachfield was as expected. Excavation provided a visual verification of distribution pipes.

\section{Field Screening}

Soil samples were screened for VOCs and alpha and beta/gamma radioactivity. The field readings were compared to FSLs to guide sampling decisions and determine which samples were to be submitted for laboratory analysis.

\section{Inspections and Sampling}

Soil samples were collected from intervals beneath the pipes at the leachrock/native soil interface and an interval $2.5 \mathrm{ft}$ below the interface. Fifteen leachfield soil samples were collected and eight were submitted to an off-site laboratory for analysis. Soil sample analyses conducted are listed in Table 2-2. A geotechnical sample was collected outside the boundary of the leachfield. The sample was archived for possible future analysis.

To further define the extent of potential radiological soil contamination at the edge of the leachfield, additional sampling was conducted. Two locations, D07 and D08 (Figure A.6-1), were identified from the original sampling activities as locations of concern. Ten additional soil samples were collected and six were submitted to an off-site laboratory for analysis of Iso-Pu. 
The collection system piping was inspected and it was found that the pipe was exposed at the ground surface in two locations. The pipes were relatively short in length. Therefore, it was determined that a video mole survey would be unnecessary at this CAS. Excavations were made at three locations (D12, D13, and D14; Figure A.6-1) for radiological swiping and surveys. Some sediment was identified in the piping, but the soil was not related to the operation of the collection system piping and was not sampled. No breaches or offshoot lines were observed.

The septic tank manholes were opened and the nature and quantity of the contents in the septic tank were inspected. The concrete, two-chambered, septic tank contained both liquid and sludge and samples of each were collected. The distribution box manhole was opened, but not sampled since it was found to be filled with soil. The distribution box and lid were broken during the investigation, and the pieces were buried during sampling activities.

The sludge and liquid samples associated with the septic tank were submitted for analyses of COPCs as specified in Table 2-3. On-site analysis was performed on the septic tank contents to determine if fecal coliform bacteria were present.

Investigation activities associated with CAS 25-04-08 are further detailed in Section A.6.2.

\subsubsection{Engine Test Stand No. 1 Septic System (CAS 25-04-09)}

The Engine Test Stand No. 1 (ETS-1) septic system was designed to receive sanitary effluent generated by activities from Building 3340 (Test Cell Building), Building 3330 (Fill Station/Tank Farm and Forward Control Area), Building 3320 (Utility Equipment Building/Substation Area), Building 3319 (Maintenance and Supply Building/Welding and Machine Shop), Building 3310 (Control Point Building), and as many as twenty-two trailers (no longer present). The septic system is located approximately $10 \mathrm{ft}$ south of the southernmost fence of the ETS- 1 complex. The site is comprised of a leachfield, septic tank, and associated piping.

\section{Excavation}

Excavation by backhoe was used to collect integrity samples of soil adjacent to the influent and effluent ends of the septic tank. No distribution box was associated with this system. Exploratory trenching confirmed the configuration of the leachfield was as expected. Excavations provided a 
visual verification of distribution pipes, and soil samples were collected at intervals from beneath the pipes.

\section{Field Screening}

Soil samples were screened for VOCs and alpha and beta/gamma radioactivity. The field readings were compared to FSLs to guide sampling decisions and determine which samples were to be submitted for laboratory analysis.

\section{Inspections and Sampling}

Soil samples were collected at the leachrock/native soil interface, an interval $2.5 \mathrm{ft}$ below the interface, and at an interval $6.5 \mathrm{ft}$ below the interface at some locations. Sixty-five leachfield soil samples were collected and 34 were submitted to an off-site laboratory for analysis. Soil sample analyses conducted are listed in Table 2-2. A geotechnical sample was collected outside the boundary of the leachfield. The sample was archived for possible future analysis.

As discussed in the CAIP, the sewage line from the ETS-1 facility was rerouted to oxidation ponds, bypassing the septic system. However, some collection system pipes, including a line to trailer hook-ups, required inspection. Access points for inspection of these pipes by video mole survey were present (i.e., manhole, risers) or were created via backhoe excavation.

The video mole was passed down through a riser (E34) located northeast of a junction box (Figure A.7-1). Excavations were made at two locations, E35 and E37 (Figure A.7-1), where obstructions were encountered. The obstruction at E35 was reported to be an animal nest. The video mole was passed down the pipe in both directions from location E35. A riser (E36; Figure A.7-1) northeast of E35 was identified and the video mole was passed southwest from location E36 until an obstruction at E37 was encountered. An excavation (E37) was made at a 30-degree elbow in an attempt to complete video mole activities. The video mole was passed downstream (southwest) to where the blockage noted during the E35 inspection was encountered. This blockage appears to be sand and debris that accumulated downstream of the 30-degree elbow.

In addition to the collection system component pipe segments, the manhole providing a bypass of the sewer line leading from the ETS-1 facilities to the active sewage lagoons was inspected. Visual inspection confirmed that a line entered from the ETS-1 facilities and another from the trailer 
connection risers, and one line exited to the sewage lagoons. This inspection confirmed that the CAS 25-04-09 septic system had been bypassed.

Some sediment was identified in the piping, but it was not related to the operation of the system and was not sampled. The amount of sediment and plant and animal matter found in the collection system pipe segments was most likely due to the fact that these pipes had several access points (trailer risers) exposed at the ground surface. Portions of the pipe at the inspected locations (e.g., E34, E35, E36, and E37) were also radiologically surveyed.

The septic tank manholes were opened and the nature and quantity of the components were inspected. The concrete, two-chambered, septic tank contained dry sediment, samples of which were collected. The sediment samples associated with the septic tank were submitted for analyses of COPCs as specified in Table 2-3. On-site analysis was performed on the septic tank contents to determine if fecal coliform bacteria were present.

Investigation activities associated with CAS 25-04-09 are further detailed in Section A.7.2.

\subsubsection{Rad-Safe Trailers Septic System (CAS 25-04-10)}

The radiological safety (Rad-Safe) trailers septic system was designed to receive sanitary effluent generated by activities from one or two trailers that are no longer present. The septic system is located approximately $0.10 \mathrm{mi}$ south of the intersection of C and G Roads in Area 25. The site is comprised of a leachfield, septic tank, distribution box, and associated piping.

\section{Excavation}

Excavation by backhoe was used to collect integrity samples of soil adjacent to the influent and effluent ends of the septic tank and at the effluent end of the distribution box. Exploratory trenching confirmed the configuration of the leachfield was not as expected. Biased locations changed slightly from the CAIP planned locations due to a differing leachfield configuration and size. Linear transformation (a contingency of the CAIP [DOE/NV, 2001]) was conducted to rescale the points to fit the observed leachfield size. Excavation provided a visual verification of distribution pipes. 


\section{Field Screening}

Soil samples were screened for VOCs and alpha and beta/gamma radioactivity. The field readings were compared to FSLs to guide sampling decisions and determine which samples were to be submitted for laboratory analysis.

\section{Inspections and Sampling}

Soil samples were collected from intervals beneath the pipes at the leachrock/native soil interface and an interval $2.5 \mathrm{ft}$ below the interface. Seventy-one leachfield soil samples were collected and 36 were submitted to an off-site laboratory for analysis. Soil sample analyses conducted are listed in Table 2-2. A geotechnical sample was collected outside the boundary of the leachfield. The sample was archived for possible future analysis.

Access points for inspection by video mole were created at locations along the collection pipe via excavation. The collection system piping was inspected by video mole from the influent side of the septic tank. Although the collection system piping had been broken extensively between locations F39 and F40 (Figure A.8-1), no material related to the use of the septic system was found. All pipe segments were clean, and contained only soil where broken. Portions of the pipe at the excavated locations F39 and F40 were radiologically surveyed.

The septic tank was opened and inspected. The septic tank was empty and was not sampled. Some soil inadvertently spilled into the septic tank through the manholes during the investigation. The distribution box was filled with soil to the ground surface, and no samples were collected.

Investigation activities associated with CAS 25-04-10 are further detailed in Section A.8.2.

\subsubsection{South of LASL Trailers Septic System (CAS 25-04-11)}

The LASL trailers septic system was designed to receive sanitary effluent generated by activities from Building 3127 (Cafeteria), Building 3129 (Technical Operations Building), and approximately 48 LASL sleeping trailers. The septic system is located approximately $530 \mathrm{ft}$ south of the RCP complex fenceline. The site is comprised of a leachfield, septic tank, distribution box, and associated piping. 


\section{Excavation}

Excavation by backhoe was used to collect integrity samples of soil adjacent to the influent and effluent ends of the septic tank and effluent end of the distribution box. Exploratory trenching confirmed the configuration of the leachfield was not as expected. Excavation provided a visual verification of distribution pipes.

\section{Field Screening}

Soil samples were screened for VOCs and alpha and beta/gamma radioactivity. The field readings were compared to FSLs to guide sampling decisions and determine which samples were to be submitted for laboratory analysis.

\section{Inspections and Sampling}

Soil samples were collected from intervals beneath the pipes at the leachrock/native soil interface, an interval $2.5 \mathrm{ft}$ below the interface, and at an interval $6.5 \mathrm{ft}$ below the interface at some locations. Sixty-five leachfield soil samples were collected and 35 were submitted to an off-site laboratory for analysis. Soil sample analyses conducted are listed in Table 2-2. A geotechnical sample was collected outside the boundary of the leachfield. The sample was archived for possible future analysis.

To further define the extent of potential SVOC contamination, additional step-out sampling was conducted. Two locations, G02 and G10 (Figure A.9-1), were identified from original sampling activities as locations of concern due to the presence of SVOCs. Twelve additional soil samples were collected and eight were submitted to an off-site laboratory for analysis of SVOCs.

As detailed in the CAIP, the CAS 25-04-11 septic system was bypassed. Most of the collection system pipes are active and are not included in the investigation. However, some abandoned segments of the collection system were inspected. Access points for inspection by video mole were present (i.e., manholes and cleanouts) and were created at locations along the collection system pipe via backhoe excavation.

An excavation (G34) was made approximately halfway between Bypass Manhole 5 and G35 Manhole (Figure A.9-1). The majority of the distance was inspected in both directions from G34 with the video mole; however, obstructions in the form of various types of debris precluded 
inspecting the full distance. The survey found that the G35 Manhole contained septic system debris, so it was opened and sampled. Bypass Manhole 5 was opened and inspected. The inlet enters from the north, and the outlet exits toward the southeast in the direction of the active oxidation ponds. This inspection confirmed that the manhole was installed to bypass the CAS 25-04-11 septic system.

Bypass Manhole 4 (Figure A.9-1) has three inlets and one outlet. Per direction obtained during the DQO phase, the northern inlet (line leading from the RCP) and the outlet were considered active and were not surveyed. The eastern outlet was surveyed by video mole from Bypass Manhole 4 to location G39 (Figure A.9-1). An excavation was made at this location (G39) and video mole activities continued. The video survey was continued until a cleanout (north line cleanout) was found to be the termination point for the north LASL trailer hookup line. An excavation (G40; Figure A.9-1) in the south LASL trailer hookup line was made east from the junction point with the active line. The video mole was passed upstream (east) through the line. Risers entering from the north and south were noted at irregularly spaced intervals on both north and south LASL trailer hookup lines. A cleanout was located at the eastern end of both of the lines.

Some sediment was identified in the piping of the trailer hookup lines but was not related to the operation of the system and, therefore, was not sampled. The sediment may have entered the lines through the risers. Material apparently related to the septic system was present in the manhole and pipe segment immediately upstream of the septic tank. This material was sampled. Portions of the pipe at the excavated locations (designated G34, G39, and G40) were radiologically surveyed and swiped.

The septic tank manholes were opened and the nature and quantity of the contents were inspected. The steel, two-chambered, septic tank contained both liquid and sludge and samples of each were collected. The distribution box manhole was opened and the nature and quantity of the components were inspected. The distribution box was partially filled with soil, so no samples were collected.

The sludge and liquid samples associated with the septic tank and the sediment sample associated with the G35 Manhole were submitted for analyses of COPCs as specified in Table 2-3. On-site analysis was performed on the septic tank contents to determine if fecal coliform bacteria were present. 
Investigation activities associated with CAS 25-04-11 are further detailed in Section A.9.2.

\subsubsection{Port Gaston Training Area Contaminated Water Reservoir (CAS 26-03-01)}

Corrective Action Site 26-03-01 was a water reservoir used for NUWAX training in 1981. The contaminated water reservoir is located approximately $800 \mathrm{ft}$ south of the Port Gaston Complex (Pluto Project control area).

\section{Excavation}

Hand and backhoe excavations were used to collect soil samples from biased locations, both above and below the plastic liner. Excavation by hand was conducted for those sample intervals above the plastic liner. Excavation by backhoe was needed to reach sampling depths beneath the liner due to hard-packed soil conditions.

\section{Field Screening}

Soil samples were screened for VOCs, alpha and beta/gamma radioactivity, and gamma emitters. The field readings were compared to FSLs to guide sampling decisions and determine which samples were to be submitted for laboratory analysis. The gamma spectrometry results were not compared to FSLs, but were used to guide the selection of samples for laboratory analysis.

\section{Sampling}

Twenty-three soil samples were collected from the planned locations within the reservoir. Nine surface and nine subsurface soil samples were submitted to an off-site laboratory for analysis. Soil sample analyses conducted are listed in Table 2-2. A geotechnical sample was collected outside the boundary of the water reservoir. The sample was archived for possible future analysis.

To confirm that downgradient migration in the dry wash had not occurred, a surface soil sample was collected at location H09 (Figure A.10-1) and submitted for gamma-emitting radionuclide analysis.

Investigation activities associated with CAS 26-03-01 are further detailed in Section A.10.2. 


\subsubsection{Area 26 Check Station (BIdg. 2105) Septic System (CAS 26-04-01)}

The Check Station septic system was designed to receive sanitary effluent generated by activities from Building 2105 (Check Station). The septic system is located approximately $200 \mathrm{ft}$ west of the the intersection of the Pluto Road and Cane Springs Road. The site is comprised of a leachfield, septic tank, distribution box, and associated piping.

\section{Excavation}

Excavation by backhoe was used to collect integrity samples of soil adjacent to the influent and effluent ends of the septic tank and effluent end of the distribution box. Exploratory trenching confirmed the configuration of the leachfield was as expected. Excavation provided a visual verification of distribution pipes.

\section{Field Screening}

Soil samples were screened for VOCs and alpha and beta/gamma radioactivity. The field readings were compared to FSLs to guide sampling decisions and determine which samples were to be submitted for laboratory analysis.

\section{Inspections and Sampling}

Soil samples were collected from intervals beneath the pipes at the leachrock/native soil interface and an interval $2.5 \mathrm{ft}$ below the interface. Twenty-one leachfield soil samples were collected and eleven were submitted to an off-site laboratory for analysis. Soil sample analyses conducted are listed in Table 2-2. A geotechnical sample was collected outside the boundary of the leachfield. The sample was archived for possible future analysis.

During the SVOC analysis of soil from location J03 (Figure A.11-1), the laboratory analyst noted the presence of pesticides (chlordane) in the soil. To confirm the presence or absence of pesticides, since they were not initially identified as COPCs, additional step-out sampling was conducted. Six soil samples were collected from locations J03, J19, and J20 (Figure A.11-1) and were submitted for laboratory analysis of total pesticides.

Access points for inspection of collection system piping by video mole survey were excavated locations and a manhole. The video mole was inserted into the inlet side of the septic tank and passed 
upstream (northeast) through the pipe until it could not be pushed further due to equipment limitations. An excavation (location J16; Figure A.11-1) was made southwest of the concrete foundation (where Building 2105 once stood). The video mole was passed upstream (northeast) until an obstruction was encountered. The video mole was also passed downstream (southwest) to where it entered a manhole. The collection system pipe was grouted shut prior to backfilling in the excavation. The manhole (location J17; Figure A.11-1) was uncovered and inspected. The manhole was dry and free of sediment, so no sample was collected.

Some sediment and plant and animal matter were identified in the piping, but was not appropriate material to be sampled. No breaks or blockages related to the operation of the septic system were noted during the inspection. The pipe was radiologically surveyed at location J16.

The septic tank manhole was opened and the nature and quantity of the contents were inspected. The concrete, single-chambered tank, contained both liquid and sludge and samples of each were collected. The distribution box manhole was opened and was found to contain a small amount of sediment, which was sampled.

The sludge and liquid samples associated with the septic tank and the sediment sample associated with the distribution box were submitted for analyses of COPCs as specified in Table 2-3. On-site analysis was performed on the septic tank contents to determine if fecal coliform bacteria were present.

Investigation activities associated with CAS 26-04-01 are further detailed in Section A.11.2.

\subsubsection{Hot Critical Facility (BIdg. 2103) Septic System (CAS 26-04-02)}

The CAS 26-04-02 septic system was designed to receive sanitary effluent generated by activities from Building 2103 (Hot Critical Facility). The septic system is located approximately $100 \mathrm{ft}$ north of Building 2103. The site is comprised of a leachfield, septic tank, distribution box, and associated piping.

\section{Excavation}

Excavation by backhoe was used to collect integrity samples of soil below the base of the influent and effluent ends of the septic tank and below the base of the effluent end of the distribution box. 
Exploratory trenching confirmed the configuration of the leachfield was as expected. Excavation provided a visual verification of distribution pipes.

\section{Field Screening}

Soil samples were screened for VOCs and alpha and beta/gamma radioactivity. The field readings were compared to FSLs to guide sampling decisions and determine which samples were to be submitted for laboratory analysis.

\section{Inspections and Sampling}

Soil samples were collected from intervals beneath the pipes at the leachrock/native soil interface and an interval $2.5 \mathrm{ft}$ below the interface. Twenty-three leachfield soil samples were collected and 13 were submitted to an off-site laboratory for analysis. Soil sample analyses conducted are listed in Table 2-2. A geotechnical sample was collected outside the boundary of the leachfield. The sample was archived for possible future analysis.

Access points for inspection of the collection system by video mole survey were at a manhole and at a break in the line excavated by the backhoe. As shown in Figure A.12-1, one manhole (Manhole 1) is associated with this septic system. Manhole 1 was uncovered and inspected; it was dry and free of sediment so no sample was collected. The video mole was inserted into the manhole and passed downstream (north) until soil from the septic tank integrity sampling location was encountered. The video mole was then passed upstream (southeast) until it stopped at a grout plug (cleanout). The collection pipe line continued to the southwest, upstream of Manhole 1.

An excavation (K16; Figure A.12-1) was made north of Building 2103. The video mole was passed downstream (northeast) until an elbow was encountered. This elbow was the cleanout discussed above. The video mole was then passed upstream (south) until it entered a cleanout. Location K16 was grouted prior to backfilling in the excavation.

Very little sediment was observed in the collection system piping, and no breaks or obstructions in the line were found. The pipe was surveyed at Manhole 1 and location K16.

The septic tank manhole was opened and the nature and quantity of the contents were inspected. The concrete, single-chambered, septic tank contained dry sediment and a sample was collected. The 
distribution box manhole was opened and was found to contain only a very small amount of material, so no sample was collected.

The sediment sample associated with the septic tank was submitted for analyses of COPCs as specified in Table 2-3. On-site analysis was performed on the septic tank contents to determine if fecal coliform bacteria were present.

Investigation activities associated with CAS 26-04-02 are further detailed in Section A.12.2.

\subsubsection{Buildings 2201 and 2202 Radioactive Leachfield (CAS 26-05-01)}

The radioactive leachfield was designed to receive radioactive effluent generated by activities in Building 2201 (Disassembly Building) and Building 2202 (Railcar Washdown). The leachfield system is located approximately 1,450 ft southeast of Building 2201. The site is comprised of a leachfield, distribution box, and associated piping.

\section{Excavation}

In situ shallow subsurface radiation measurements were collected using a gamma detector on the end of a cone penetrometer technology (CPT) rod prior to excavation. The result of the in situ measurement effort showed that the radiological levels were low enough to select excavation as the method of intrusive investigation.

Excavation by backhoe was used to collect integrity samples of soil below the effluent end of the distribution box. Exploratory trenching confirmed the configuration of the leachfield was as expected. Excavation provided a visual verification of distribution pipes.

\section{Field Screening}

Soil samples were screened for VOCs and alpha and beta/gamma radioactivity. The field readings were compared to FSLs to guide sampling decisions and determine which samples were to be submitted for laboratory analysis.

\section{Inspections and Sampling}

Soil samples were collected from intervals beneath the pipes at the leachrock/native soil interface, an interval $2.5 \mathrm{ft}$ below the interface, and at an interval $6.5 \mathrm{ft}$ below the interface at some locations. 
Sixty-three leachfield soil samples were collected and 33 were submitted to an off-site laboratory for analysis. Soil sample analyses conducted are listed in Table 2-2. A geotechnical sample was collected outside the boundary of the leachfield. The sample was archived for possible future analysis.

To further define the extent of possible radiological contamination in the leachfield, additional sampling was conducted. Two locations, L03 and L04 (Figure A.13-1), were identified from the original sampling activities as locations of concern. Four samples were collected from deeper intervals at locations L03 and L04 and submitted for laboratory analysis of Iso-Pu and Iso-U.

The collection system for CAS 26-05-01 consists of approximately 1,800 ft of pipe that connects Buildings 2201 and 2202 with the leachfield. Access points for inspection and radiological screening of the collection system were four manholes and several excavated breaks.

Manhole 1 (L33; Figure A.13-1) was uncovered and inspected. The manhole contained sediment that appeared to be related to system operations, so a sample was collected. A radiological survey was conducted on the manhole and swipes were collected for radiological characterization. Manhole 2 (L35), Manhole 3 (L37), and Manhole 4 (L40) were uncovered and inspected (Figure A.13-1). The manholes did not contain adequate sediment for sample collection. A radiological survey was conducted on the manholes and swipes were collected for radiological characterization.

A video mole survey was also completed through the associated piping and four manholes. The video mole inspected segments of the pipe both upstream and downstream from the manholes. Four excavations (L34, L36, L38, and L39; Figure A.13-1) were made along the collection system piping. The video mole also inspected segments of pipe upstream and downstream from the excavations.

The distribution box was opened and inspected. There was very little sediment in the bottom of the distribution box; therefore, no sample was collected.

Overall, inspected segments of collection system pipe were dry, did not contain any material, and were not broken or obstructed. There was a little sediment observed in each manhole, and some moisture was noted in Manhole 2. As discussed, Manhole 1 contained adequate sediment to sample. This sediment sample was submitted for analyses of COPCs as specified in Table 2-3. 
Investigation activities associated with CAS 26-05-01 are further detailed in Section A.13.2.

\subsubsection{Building 2203 Septic System (CAS 26-05-03)}

The Pluto Test Bunker septic system was designed to receive sanitary effluent generated by activities at Building 2203 (Test Bunker). The septic system is located approximately $60 \mathrm{ft}$ southeast of Building 2203. The site is comprised of a leachfield, septic tank, distribution box, and associated piping.

Prior to conducting the corrective action investigation, Bechtel Nevada personnel moved potentially radiologically contaminated objects out of the fenced leachfield area. A subsequent radiological walkover survey of the surrounding surface soils showed no location with surface contamination above the established range background levels.

\section{Excavation}

In situ shallow subsurface radiation measurements were collected using a gamma detector on the end of a CPT rod prior to excavation. The result of the in situ measurement effort showed that the radiological levels were low enough to select excavation as the method of intrusive investigation.

Excavation by backhoe was used to collect integrity samples of soil adjacent to the influent and effluent ends of the septic tank and the effluent end of the distribution box. Exploratory trenching confirmed the configuration of the leachfield was as expected. Excavation provided a visual verification of distribution pipes.

\section{Field Screening}

Soil samples were screened for VOCs and alpha and beta/gamma radioactivity. The field readings were compared to FSLs to guide sampling decisions and determine which samples were to be submitted for laboratory analysis.

\section{Inspections and Sampling}

Soil samples were collected from intervals beneath the pipes at the leachrock/native soil interface and an interval $2.5 \mathrm{ft}$ below the interface. Seventy leachfield soil samples were collected and 33 were submitted to an off-site laboratory for analysis. Soil sample analyses conducted are listed in 
Table 2-2. A geotechnical sample was collected outside the boundary of the leachfield. The sample was archived for possible future analysis.

Access points for inspection of the collection system by video mole survey were present (i.e., a manhole) and created at locations along the collection pipe via backhoe excavation. The video mole was inserted through the breach in the pipe made during excavation activities at the influent side of the septic tank. The video mole was passed upstream until it entered into Manhole 1 (Figure A.14-1). Manhole 1 was uncovered and inspected. The manhole contained sediment that appeared to be related to system operations, so a sample was collected. Because of a lack of sample volume, the sample was a composite of material from Manhole 1 and the septic tank. The video mole was inserted through Manhole 1 and passed upstream to where the pipe sloped upward into the foundation of Building 2203. The inlet to Manhole 1 was sealed with grout after inspection activities were completed. A radiological survey was conducted on the manhole and swipes were collected for radiological characterization.

Very little sediment was identified in the piping, and it was not adequate material to be sampled. The pipes were in good condition; no breaks or obstructions were found.

The septic tank manhole was opened and the nature and quantity of the contents were inspected. The concrete, single-chambered, septic tank contained very little dry sediment. As discussed above, a composite sample was collected from the septic tank and Manhole 1. The distribution box was opened and found to contain very little sediment, so no sample was collected.

The sediment sample associated with the septic tank and Manhole 1 was submitted for analyses of COPCs as specified in Table 2-3. On-site analysis was performed on the septic tank contents to determine if fecal coliform bacteria were present.

Investigation activities associated with CAS 26-05-03 are further detailed in Section A.14.2.

\subsubsection{Building 2201 Septic System (CAS 26-05-04)}

The Building 2201 septic system was designed to receive sanitary effluent generated by activities at Building 2201 (Disassembly Building). The septic system is located approximately $250 \mathrm{ft}$ south of 
Building 2201. The site is comprised of a leachfield, septic tank, distribution box, and associated piping.

\section{Excavation}

Excavation by backhoe was used to collect integrity samples of soil adjacent to the influent and effluent ends of the septic tank and the effluent end of the distribution box. Exploratory trenching confirmed the configuration of the leachfield was as expected. Excavation provided a visual verification of distribution pipes.

\section{Field Screening}

Soil samples were screened for VOCs and alpha and beta/gamma radioactivity. The field readings were compared to FSLs to guide sampling decisions and determine which samples were to be submitted for laboratory analysis.

\section{Inspections and Sampling}

Soil samples were collected from intervals beneath the pipes at the leachrock/native soil interface, an interval $2.5 \mathrm{ft}$ below the interface, an interval $6.5 \mathrm{ft}$ below the interface, and an interval $10.5 \mathrm{ft}$ below the interface at some locations. Seventy-seven leachfield soil samples were collected and 37 were submitted to an off-site laboratory for analysis. Soil sample analyses conducted are listed in Table 2-2. A geotechnical sample was collected outside the boundary of the leachfield. The sample was archived for possible future analysis.

To further investigate an elevated arsenic detection in the leachfield soil, additional sampling was conducted. One location, N04 (Figure A.15-1), was identified from the original sampling activities as a location of concern. Five step-out soil samples were collected near location N04 and submitted for laboratory analysis of arsenic.

Access points for inspection of the collection system by video mole survey were two manholes. Manhole 1 (Figure A.15-1) was uncovered and inspected; it did not contain adequate sediment to sample. A radiological contamination survey was conducted on the manhole and swipes were collected for radiological characterization. The video mole was inserted through the manhole and passed upstream to a second manhole (Manhole 2). The video mole was passed downstream until backfill from the septic tank inlet integrity sample excavation was encountered. After video mole 
activities were completed, the inlet side of Manhole 1 was grouted closed. Manhole 2 was relatively deep (greater than $10 \mathrm{ft}$ ) and did not contain adequate sediment to sample. A radiological contamination survey was conducted on the accessible portions of the manhole and swipes were collected for radiological characterization. The video mole was inserted through the manhole and passed upstream to a point where the pipe diameter changed from 6 to 4 in. The video mole could not be pushed beyond this point.

Some sediment was identified in the piping but was not adequate to be sampled. The pipe segments surveyed were in good condition, and no breaks or obstructions were found.

The septic tank manholes were opened and the nature and quantity of the contents were inspected. The concrete, two-chambered, tank contained sludge and liquid. Samples of each phase were collected from both chambers. The distribution box manholes were opened and inspected. There was very little sediment in the bottom of the distribution box, so no sample was collected.

The sludge and liquid samples associated with the septic tank were submitted for analyses of COPCs as specified in Table 2-3. On-site analysis was performed on the septic tank contents to determine if fecal coliform bacteria were present.

Investigation activities associated with CAS 26-05-04 are further detailed in Section A.15.2.

\subsubsection{Buildings 2101, 2102, and 2107 Septic System (CAS 26-05-05)}

The septic system was designed to receive sanitary effluent generated by activities at Building 2101 (Control Building), Building 2102 (Assembly Building), and Building 2107 (Data Reduction Building). The septic system is located approximately $235 \mathrm{ft}$ north of Building 2102. The site is comprised of two leachfields, two septic tanks, two distribution boxes, and associated piping. It appears that one system was initially constructed and another system was added at a later time. Both septic systems share a common collection system.

\section{Excavation}

Excavation by backhoe was used to collect integrity samples of soil adjacent to the base of the influent and effluent ends of the two septic tanks and adjacent to the base of the effluent end of the two distribution boxes. Exploratory trenching confirmed the configuration of the leachfield was not 
as expected. Sampling locations changed from the CAIP planned locations due to a differing leachfield size. Linear transformation (a contingency in the CAIP [DOE/NV, 2001]) was conducted to rescale the points to fit the observed leachfield size. Excavation provided a visual verification of distribution pipes.

\section{Field Screening}

Soil samples were screened for VOCs and alpha and beta/gamma radioactivity. The field readings were compared to FSLs to guide sampling decisions and determine which samples were to be submitted for laboratory analysis.

\section{Inspections and Sampling}

Soil samples were collected from intervals beneath the pipes at the leachrock/native soil interface and an interval $2.5 \mathrm{ft}$ below the interface. Sixty-five leachfield soil samples were collected and 35 were submitted to an off-site laboratory for analysis. Soil sample analyses conducted are listed in Table 2-2. A geotechnical sample was collected outside the boundary of the leachfield. The sample was archived for possible future analysis.

To define the extent of TPH DRO contamination, additional step-out sampling was conducted. One location, P25 (Figure A.16-1), was identified from the original sampling activities as a location of concern. Five additional step-out samples were collected and submitted for laboratory analysis of TPH DRO.

Access points for inspection of the collection system by video mole survey were present (i.e., manholes) and were created at locations along the collection pipe via backhoe excavation. The septic system has three associated manholes: Manhole 1, Manhole 2, and Manhole 3 (New Manhole) (Figure A.16-1).

Each manhole was opened and inspected. The manholes did not contain adequate sediment to sample. A radiological survey was conducted at each manhole and swipes were collected for radiological characterization.

The video mole was inserted through Manhole 1 into the lower inlet pipe (main collection system pipe) and passed upstream (south). The video mole was then inserted into the upper inlet pipe and 
passed upstream (southwest) until a vent pipe preventing further inspection was encountered. This is a steel pipe and was not shown on engineering drawings. The pipe is shallowly buried and appears to have been installed subsequent to the construction of septic system 1.

Manhole 2 has two inlets and one outlet. One inlet is the main collection system line and the other is the line from the northeast side of Building 2101 (Figure A.16-1). The video mole was inserted through Manhole 2 and passed downstream (north) until the limits of the video mole were reached. This completed the inspection of the pipe segment between Manholes 1 and 2.

The video mole was then inserted into the inlet pipe from Building 2101 and passed upstream (east) to location P42 (Figure A.16-1), where an excavation was made to continue the inspection. The visual inspection continued on this pipe segment upstream from location P42 until an obstruction, in the form of a grout plug (cleanout), was encountered. After video mole activities were completed, a piece of pipe from location P42 was radiologically surveyed and swiped, and the inlet side of Manhole 2 was grouted closed.

Another excavation (P44; Figure A.16-1) was made between Buildings 2101 and 2102. At this excavation point, two feeder lines originating from Buildings 2101 and 2102 were observed. The video mole was inserted into the southern-most feeder line and passed upstream where the pipe sloped upward as it entered the Building 2101 foundation. The video mole was then inserted into the northern-most feeder line and passed upstream where, again, the pipe sloped upward as it entered the Building 2102 foundation. After video mole activities were completed, the inlet side of each of these feeder lines were grouted closed. Radiological survey and swipe data were collected at location P44.

Manhole 3 (New Manhole) has two inlets and one outlet. The upper inlet led to a riser and the lower pipe led southwest to Building 2107. Video mole activities were not completed at this manhole as the depth (14 ft) was too great. A survey of the inlet line from Building 2107 was attempted; however, the video mole could be pushed only $10 \mathrm{ft}$ upstream. An excavation (P41; Figure A.16-1) was made approximately $51 \mathrm{ft}$ north of the New Manhole to provide access to the collection system pipe. The video mole was inserted into the pipe and passed downstream (north). This completed the inspection of the segment between Manhole 2 and location P41. The video mole was then passed upstream (south) until it entered the New Manhole. After video mole activities were completed, a piece of pipe 
from location P41 was radiologically surveyed and swiped, and the inlet side of this excavation was grouted closed.

Some sediment, soil, and plant and animal matter were identified in the piping, but it was not appropriate or adequate material to be sampled. The collection system was found to be in good condition, with no breaks or blockages noted.

The septic tank 1 manhole was opened and the nature and quantity of the contents were inspected. The concrete, single-chambered, septic tank contained both sludge and liquid and samples of each were collected. The septic tank 2 manholes (three metal tubes) were opened and the nature and quantity of the contents were inspected. The concrete, three-chambered, septic tank contained sediment in each of the chambers, and a composite sample was collected from the three chambers. Distribution boxes 1 and 2 were opened and inspected. Very little sediment was present in distribution box 1 and no sediment was present in distribution box 2, so no samples were collected.

The sludge, liquid, and sediment samples associated with the septic tanks were submitted for analyses of COPCs as specified in Table 2-3. On-site analysis was performed on the septic tank contents to determine if fecal coliform bacteria were present.

Investigation activities associated with CAS 26-05-05 are further detailed in Section A.16.2.

\subsubsection{Building 5200 Septic System (CAS 27-05-02)}

The septic system was designed to receive sanitary effluent generated by activities in Building 5200 (Mechanical Technician Shop) and Building 5210 (Cafeteria). The septic system is located southwest of Building 5210 and west of Building 5200. The site is comprised of a leachfield, septic tank, distribution structure, and associated piping. The investigation also included a natural wash (i.e., arroyo) on the west side of the leachfield.

\section{Excavation}

Excavation by backhoe was used to collect integrity samples of soil adjacent to the base of the influent and effluent ends of the septic tank and adjacent to the base of the effluent end of the distribution box. Exploratory trenching confirmed the configuration of the leachfield was as expected. Excavation provided a visual verification of distribution pipes. 


\section{Field Screening}

Soil samples were screened for VOCs and alpha and beta/gamma radioactivity. The field readings were compared to FSLs to guide sampling decisions and determine which samples were to be submitted for laboratory analysis.

\section{Inspections and Sampling}

Soil samples were collected from intervals beneath the pipes at the leachrock/native soil interface and an interval $2.5 \mathrm{ft}$ below the interface. Sixteen leachfield soil samples were collected and 11 were submitted to an off-site laboratory for analysis. Soil sample analyses conducted are listed in Table 2-2. A geotechnical sample was collected outside the boundary of the leachfield. The sample was archived for possible future analysis.

To define the extent of PCB contamination identified in the leachfield soil, additional step-out sampling was conducted. Location Q09 (Figure A.17-1) was identified from the original sampling activities as a location of concern. Six samples were collected and submitted for laboratory analysis of PCBs.

A soil sample from step-out location Q15 (Figure A.17-1) contained PCBs in concentrations exceeding the preliminary action level (PAL). Because the above sampling event failed to define the lateral extent of contamination, a third sampling effort was required. Thirty additional step-out samples were collected during this third effort, including surface soil samples from all locations and subsurface samples from six of the locations. All samples were submitted for laboratory analysis of PCBs, and select samples were also analyzed for pesticides.

Access points for inspection of the collection system by video mole survey were created at locations along the collection pipe via backhoe excavation. The video mole was passed upstream (southeast) from location Q10 (Figure A.17-1) toward Building 5200. The line turned at $78 \mathrm{ft}$, possibly at a cleanout. Moisture was present in the pipe. When the video mole was removed from the pipe, the camera portion appeared to be covered in excrement. This material was not sampled. The pipe was grouted shut prior to filling in the excavation.

The video mole was passed upstream (northeast) from location Q11 (Figure A.17-1) toward Building 5210 where it encountered a 90-degree bend that stopped the video mole. The pipe made a 
turn at $43 \mathrm{ft}$, based on engineering drawings probably at a cleanout. A line entered the pipe at $49 \mathrm{ft}$ from location Q11. The pipe was grouted shut prior to filling in the excavation.

With the exception of the material noted in the pipe from Building 5200, the inspected pipe segments contained only minor amounts of sediment and scaling. No breaks or blockages were observed. The pipe was radiologically surveyed and swiped at locations Q10 and Q11. No radiation above background levels was noted in either the survey or swipe data.

The septic tank manhole was opened and the nature and quantity of the contents were inspected. The septic tank is constructed of steel, with two chambers. Sludge and liquid were identified in the influent chamber and only liquid was identified in the effluent chamber. Samples of each phase were collected. The distribution box lid was opened and the box was inspected. The concrete distribution box contained sludge, and a sample was collected.

The sludge and liquid samples associated with the septic tank and distribution box were submitted for analyses of COPCs as specified in Table 2-3. On-site analysis was performed on the septic tank contents to determine if fecal coliform bacteria were present.

Investigation activities associated with CAS 27-05-02 are further detailed in Section A.17.2.

\subsection{Results}

A summary of characterization data from the corrective action investigation are provided in Section 2.2.1. This information illustrates the degree of characterization accomplished through the field effort and identifies those COPCs that exceeded PALs for soil and regulatory action levels for disposal of septic tank, distribution box, and manhole contents. Section 2.2.2 summarizes the assessment made in Appendix B, which demonstrates that the investigation results satisfy the DQO data needs.

\subsubsection{Summary of Characterization Data}

Chemical and radiological results for characterization sample concentrations exceeding PALs (DOE/NV, 1998b; DOE/NV, 2001) in each of the CASs are presented in Section 2.2.1.1 through Section 2.2.1.15. The PALs for the CAU 271 investigation were determined during the DQO 
process. For chemical COPCs, PALs are U.S. Environmental Protection Agency (EPA) Region 9 Industrial Preliminary Remediation Goals (PRGs) (EPA, 2000). For radiological COPCs, PALs are listed in the CAIP (DOE/NV, 2001).

Contents of septic tanks, distribution boxes, and manholes were sampled and analyzed to support disposal of the contents during anticipated closure activities. Liquid, sludge, and sediment samples were analyzed in accordance with the requirements in the CAIP. Analytical results are compared to the performance objective criteria (POC) established for the NTS. Performance objective criteria have been established for NTS hazardous waste generators to ensure that all hazardous waste being shipped off-site contains no "added radioactivity" (BN, 1995).

Details of the methods used during the investigation and a comparison of environmental sample results to the COPC PALs are presented in Appendix A. Based on these results, the nature and extent of COCs at CAU 271 have been adequately identified to develop and evaluate corrective action alternatives.

Both chemical and radioanalytical result summaries specific to CASs are presented in the following subsections. Septic tank, distribution box, and manhole sample results revealed the following:

- Seven CASs (25-04-01, 25-04-08, 25-04-09, 25-04-11, 26-04-02, 26-05-03 [including Manhole 1], and 26-05-05 [septic tank 1]) contain hydrocarbon-contaminated media exceeding regulatory action levels in the septic tanks. The G35 Manhole at CAS 25-04-11 also contains hydrocarbon-contaminated sediment exceeding regulatory action levels.

- Two CASs (25-04-03 and 26-05-04) contain hydrocarbon-contaminated media exceeding regulatory action levels in the septic tanks. In addition, fecal coliform bacteria were identified in the septic tanks.

- CAS 25-04-04 contains mixed waste with hydrocarbon-contaminated media exceeding regulatory action levels in the septic tank. Fecal coliform bacteria were also identified in the tank contents.

- CAS 26-04-01 contains low-level waste with hydrocarbon-contaminated media exceeding regulatory action levels in the septic tank.

- CAS 26-05-01 Manhole 1 contains low-level waste with hydrocarbon-contaminated media exceeding regulatory action levels. 
- CAS 26-05-05 (septic tank 2) contains mixed waste with hydrocarbon-contaminated media exceeding regulatory action levels.

- CAS 27-05-02 contains PCB, hydrocarbon, and radiologically contaminated media in both the septic tank and distribution box exceeding regulatory action levels.

Leachfield soil results revealed:

- $\quad$ Two CASs (25-04-08 and 26-05-01) contained subsurface leachfield soil samples exhibiting radionuclide concentrations exceeding radiological PALs.

- Two CASs (25-04-04 and 26-05-05) contained subsurface leachfield soil samples with TPH concentrations exceeding regulatory action levels.

- Two CASs (25-04-03 and 25-04-11) contained subsurface leachfield soil samples exhibiting the SVOC benzo(a)pyrene in concentrations exceeding PALs. However, a field duplicate from CAS 25-04-11 was spiked with pieces of "Orangeburg" pipe, and results showed elevated SVOC concentrations including benzo(a)pyrene. Because these leachfields were constructed of "Orangeburg" pipe, it is possible that fragments of pipe were inadvertently introduced into the samples during collection, and these fragments may be the source of the detections.

- CAS 26-03-01 contained surface soil samples exhibiting gamma-emitting radionuclide concentrations exceeding background levels.

- CAS 27-05-02 contained surface and subsurface soil samples exhibiting PCB concentrations exceeding PALs.

The corrective action investigation analytical results, organized by CAS, are summarized in more detail in the following sections.

\subsubsection{Security Checkpoint Septic System (CAS 25-04-01)}

The PALs (DOE/NV, 1998b; DOE/NV, 2001) were not exceeded in any of the soil samples analyzed for VOCs, SVOCs, TPH, gamma-emitting radionuclides, Iso-U, Iso-Pu, and Sr-90.

No VOCs greater than FSLs were found during soil sample screening. All radiological field-screening results for soil samples from CAS 25-04-01 were below FSLs. The results of the survey of the collection system pipe at location A07 (Figure A.3-1) indicate that the pipeline meets the unrestricted release criteria as defined in the NV/YMP Radiological Control Manual (DOE/NV, 2000). 
Reported levels for all RCRA metals in soil samples were below PALs except for arsenic. Arsenic was detected above the PAL of 2.7 milligrams per kilogram $(\mathrm{mg} / \mathrm{kg})$ in most of the samples analyzed. The arsenic concentrations for the samples analyzed ranged from 3.7 to $5.5 \mathrm{mg} / \mathrm{kg}$. Detected arsenic concentrations are consistent in the leachfield soil and do not appear to represent "hot spots" or evidence of a localized spill. Although arsenic concentrations in the soil exceed the PAL, these concentrations are believed to be within ambient conditions for CAS 25-04-01 and do not represent contamination (NBMG, 1998; Moore, 1999).

Analytical results for the septic tank contents were evaluated for disposal purposes. A sludge and liquid sample were collected from the septic tank for analysis. The sludge sample results indicated the presence of TPH DRO (4,600 mg/kg) and TPH GRO $(2,400 \mathrm{mg} / \mathrm{kg})$ exceeding the NDEP action level of $100 \mathrm{mg} / \mathrm{kg}$ (NAC, 2000d). Fecal coliform bacteria were not detected in the septic tank at this CAS.

Analytical results associated with CAS 25-04-01 are further detailed in Section A.3.3.

\subsubsection{PAN-AM Trailers Septic System (CAS 25-04-03)}

The PALs (DOE/NV, 1998b; DOE/NV, 2001) were not exceeded in any of the soil samples analyzed for VOCs, TPH, PCBs, gamma-emitting radionuclides, Iso-U, Iso-Pu, and Sr-90.

No VOCs greater than FSLs were found during soil sample screening. The beta/gamma field-screening results at four locations slightly exceeded FSLs. Screening results for samples collected from deeper intervals at these locations were below FSLs. All other radiological field-screening results at CAS 25-04-03 were below FSLs. Swipe and radiological survey data from manholes and pipe segments indicate that the collection system meets the unrestricted radiological release criteria as defined in the NV/YMP Radiological Control Manual (DOE/NV, 2000).

Semivolatile organic compound concentrations were exceeded at two locations (B04 and B32;

Figure A.4-1) within the leachfield. Only benzo(a)pyrene exceeded the PAL of 290 micrograms per kilogram $(\mu \mathrm{g} / \mathrm{kg})(1,100$ and $320 \mu \mathrm{g} / \mathrm{kg})$. Additional step-out samples were collected to determine the extent of this possible contamination. None of the step-out samples contained any SVOCs above PALs. The leachfield distribution pipes were "Orangeburg" pipe, which is a tradename of pipe that 
appears to be composed of a compressed tar paper-like material. It is possible that some small pieces of the pipe were inadvertently introduced into the sample during collection. This could be the cause of several detections of SVOC compounds (specifically, benzo[a]pyrene) in soil samples.

Reported levels for all RCRA metals in soil samples were below PALs except for arsenic. Arsenic was detected above the PAL of $2.7 \mathrm{mg} / \mathrm{kg}$ in several of the samples analyzed. Detected arsenic concentrations for the samples analyzed ranged from 1.9 to $3.1 \mathrm{mg} / \mathrm{kg}$. The arsenic concentrations are consistent in the leachfield soil and do not appear to represent "hot spots" or evidence of a localized spill. Although arsenic concentrations in the soil exceed the PAL, these concentrations are believed to be within ambient conditions for CAS 25-04-03 and do not represent contamination (NBMG, 1998; Moore, 1999).

Analytical results for the septic tank contents were evaluated for disposal purposes. The septic tank sludge results indicated the presence of TPH DRO $(160 \mathrm{mg} / \mathrm{kg})$ exceeding the NDEP action level of $100 \mathrm{mg} / \mathrm{kg}$ (NAC, 2000d). Fecal coliform bacteria were detected in the septic tank at this CAS.

Analytical results associated with CAS 25-04-03 are further detailed in Section A.4.3.

\subsubsection{Reactor Control Point Septic System (CAS 25-04-04)}

The PALs (DOE/NV, 1998b; DOE/NV, 2001) were not exceeded in any of the soil samples analyzed for VOCs, SVOCs, PCBs, total pesticides and herbicides, gamma-emitting radionuclides, Iso-U, Iso-Pu, and $\mathrm{Sr}-90$.

No VOCs greater than FSLs were found during soil sample screening. Radiological FSLs were exceeded at three locations (C08, C19, and C30; Figure A.5-1). The results of the radiological survey of the distribution box and pipe at location C32 (Figure A.5-1) indicate that the abandoned section of the collection system meets the unrestricted release criteria as defined in the NV/YMP Radiological Control Manual (DOE/NV, 2000).

One soil sample location adjacent to the influent end of septic tank (C32) had a TPH DRO concentration $(300 \mathrm{mg} / \mathrm{kg}$ ) exceeding the NDEP action level of $100 \mathrm{mg} / \mathrm{kg}$ (NAC, 2000d). Additional sampling was conducted and TPH DRO concentrations exceeding the PAL were identified at two other locations. The TPH DRO contamination is present at relatively shallower 
depths at location C40 and deeper at locations C32 and C38 (Figure A.5-1). The vertical extent of contamination has been defined by sample results below the PAL at all step-out locations and at the original locations where contamination was detected. The lateral extent of contamination has been defined by results below the PAL in samples from other step-out locations.

Reported levels for all RCRA metals in soil samples were below PALs except for arsenic. Arsenic was detected above the PAL of $2.7 \mathrm{mg} / \mathrm{kg}$ in five of the samples analyzed. Detected arsenic concentrations for the samples analyzed ranged from 1.7 to $3.5 \mathrm{mg} / \mathrm{kg}$. The arsenic concentrations are consistent in the leachfield soil and do not appear to represent "hot spots" or evidence of a localized spill. Although arsenic concentrations in the soil exceed the PAL, these concentrations are believed to be within ambient conditions for CAS 25-04-04 and do not represent contamination (NBMG, 1998; Moore, 1999).

Analytical results for the septic tank contents were evaluated for disposal purposes. Several COPCs were detected in the sludge samples. Most COPCs were below regulatory limits except for TPH and chlordane. The sludge sample results indicated the presence of TPH DRO (45,000 and 1,000 mg/kg) and TPH GRO $(6,500 \mathrm{mg} / \mathrm{kg})$ in the septic tank exceeding the NDEP action level of $100 \mathrm{mg} / \mathrm{kg}$ (NAC, 2000d). Chlordane was detected in the sludge sample at 1,000 $\mu \mathrm{g} / \mathrm{kg}$ (alpha-chlordane) and $970 \mu \mathrm{g} / \mathrm{kg}$ (gamma-chlordane). A conservative estimate of the TCLP concentration based on these total chlordane data exceeded the toxicity characteristic level established in Title 40 of the Code of Federal Regulations (CFR) Part 261.24 (CFR, 2000a). Therefore, this waste will carry the EPA D020 waste code if removed from the septic tank unless a TCLP analysis is performed to clarify the regulatory status. Additionally, uranium-234 (U-234) exceeded the unrestricted release criteria as established in the Nevada Test Site Performance Objective for Certification of Non-Radioactive Hazardous Waste (BN, 1995). Fecal coliform bacteria were also detected in the septic tank at this CAS.

Analytical results associated with CAS 25-04-04 are further detailed in Section A.5.3.

\subsubsection{BREN Tower Septic System (CAS 25-04-08)}

The PALs (DOE/NV, 1998b; DOE/NV, 2001) were not exceeded in any of the soil samples analyzed for VOCs, SVOCs, TPH, gamma-emitting radionuclides, Iso-U, and Sr-90. 
No VOCs greater than FSLs were found during soil sample screening. All radiological field-screening results for soil samples from CAS 25-04-08 were below FSLs. Swipe and radiological survey data from inspection points D12, D13, and D14 (Figure A.6-1) indicate that the collection system meets the unrestricted radiological release criteria as defined in the $N V / Y M P$ Radiological Control Manual (DOE/NV, 2000).

Reported levels for all RCRA metals in soil samples were below PALs except for arsenic. Arsenic was detected above the PAL of $2.7 \mathrm{mg} / \mathrm{kg}$ in eleven samples. Detected arsenic concentrations for the samples analyzed ranged from 4.7 to $5.5 \mathrm{mg} / \mathrm{kg}$. The arsenic concentrations are consistent in the leachfield soil and do not appear to represent "hot spots" or evidence of a localized spill. Although arsenic concentrations in the soil exceed the PAL, these concentrations are believed to be within ambient conditions for CAS 25-04-08 and do not represent contamination (NBMG, 1998; Moore, 1999).

One soil sample location at the southern end of the leachfield (D07; Figure A.6-1) had a plutonium-239 (Pu-239) concentration above the PAL. Additional sampling was conducted at four locations (D17, D18, D19, and D20; Figure A.6-1) and a deeper sample interval was collected at location D07. Isotopic plutonium was not detected above PALs in any of the additional samples.

Analytical results for the septic tank contents were evaluated for disposal purposes. The sludge sample results indicated the presence of TPH DRO $(1,700 \mathrm{mg} / \mathrm{kg}$ and $440 \mathrm{mg} / \mathrm{kg})$ in the septic tank sludge exceeding the NDEP action level of $100 \mathrm{mg} / \mathrm{kg}$ (NAC, 2000d). Fecal coliform bacteria were not detected in the septic tank at this CAS.

Analytical results associated with CAS 25-04-08 are further detailed in Section A.6.3.

\subsubsection{Engine Test Stand No. 1 Septic System (CAS 25-04-09)}

The PALs (DOE/NV, 1998b; DOE/NV, 2001) were not exceeded in any of the soil samples analyzed for VOCs, SVOCs, TPH, PCBs, gamma-emitting radionuclides, Iso-U, Iso-Pu, and Sr-90.

No VOCs greater than FSLs were found during soil sample screening. Radiological FSLs were exceeded at two locations (E20 and E23; Figure A.7-1) during leachfield soil sampling. The results of the radiological survey of pipe at the septic tank inlet and locations E34, E35, and E36 
(Figure A.7-1) indicate that the abandoned section of the collection system meets the unrestricted release criteria as defined in the NV/YMP Radiological Control Manual (DOE/NV, 2000).

Reported levels for all RCRA metals in soil samples were below PALs except for arsenic. Arsenic was detected above the PAL of $2.7 \mathrm{mg} / \mathrm{kg}$ in most of the samples analyzed. Detected arsenic concentrations for the samples analyzed ranged from 1.7 to $16 \mathrm{mg} / \mathrm{kg}$. The arsenic concentrations are consistent in the leachfield soil and do not appear to represent "hot spots" or evidence of a localized spill. Although arsenic concentrations in the soil exceed the PAL, these concentrations are believed to be within ambient conditions for CAS 25-04-09 and do not represent contamination (NBMG, 1998; Moore, 1999).

Analytical results for the septic tank contents were evaluated for disposal purposes. The sediment sample results indicated the presence of TPH DRO $(460 \mathrm{mg} / \mathrm{kg}$ and $660 \mathrm{mg} / \mathrm{kg})$ in the septic tank exceeding the NDEP action level of $100 \mathrm{mg} / \mathrm{kg}$ (NAC, 2000d). Fecal coliform bacteria were not detected in the septic tank at this CAS.

Analytical results associated with CAS 25-04-09 are further detailed in Section A.7.3.

\subsubsection{Rad-Safe Trailers Septic System (CAS 25-04-10)}

The PALs (DOE/NV, 1998b; DOE/NV, 2001) were not exceeded in any of the soil samples analyzed for VOCs, SVOCs, TPH, gamma-emitting radionuclides, Iso-U, Iso-Pu, and Sr-90.

No VOCs greater than FSLs were found during soil sample screening. All radiological field-screening results for soil samples from CAS 25-04-10 were below FSLs. The results of the radiological survey of collection system pipe at locations F39, F40, and a riser at the end of the pipe (Figure A.8-1) indicate that the collection system pipeline meets the unrestricted release criteria as defined in the NV/YMP Radiological Control Manual (DOE/NV, 2000).

Reported levels for all RCRA metals in soil samples were below PALs except for arsenic. Arsenic was detected above the PAL of $2.7 \mathrm{mg} / \mathrm{kg}$ in approximately half of the samples analyzed. Detected arsenic concentrations for the samples analyzed ranged from 2.0 to $3.1 \mathrm{mg} / \mathrm{kg}$. The arsenic concentrations are consistent in the leachfield soil and do not appear to represent "hot spots" or evidence of a localized spill. Although arsenic concentrations in the soil exceed the PAL, these 
concentrations are believed to be within ambient conditions for CAS 25-04-10 and do not represent contamination (NBMG, 1998; Moore, 1999).

No material was present in the septic tank, and the distribution box was filled with native material.

Analytical results associated with CAS 25-04-10 are further detailed in Section A.8.3.

\subsubsection{South of LASL Trailers Septic System (CAS 25-04-11)}

The PALs (DOE/NV, 1998b; DOE/NV, 2001) were not exceeded in any of the soil samples analyzed for VOCs, TPH, PCBs, gamma-emitting radionuclides, Iso-U, Iso-Pu, and Sr-90.

No VOCs greater than FSLs were found during soil sample screening. Radiological FSLs were exceeded at three locations (G17, G20, and G30; Figure A.9-1) during the leachfield soils sampling. Swipe and radiological survey data from inspection locations G34, G39, and G40 (Figure A.9-1) indicate that the collection system meets the unrestricted radiological release criteria as defined in the NV/YMP Radiological Control Manual (DOE/NV, 2000).

Two soil sample locations in the leachfield (G02 and G10; Figure A.9-1) contained concentrations of SVOC analytes (benzo(a)pyrene) exceeding the PAL of $290 \mu \mathrm{g} / \mathrm{kg}(420 \mu \mathrm{g} / \mathrm{kg}$ and $320 \mu \mathrm{g} / \mathrm{kg})$.

Step-out sampling was conducted to confirm whether SVOCs were present in the soil of the leachfield. During the additional sampling, a field duplicate was spiked with "Orangeburg" pipe at the direction of the IT Corporation, Las Vegas (ITLV) Task Manager, and results showed elevated SVOC concentrations; thus, it is possible that some of the pipe was inadvertently introduced into the samples during collection. Based on the results of the spiked sample (271G086; Table A.9-2), it appears that soil samples containing pieces of "Orangeburg" pipe would show detections of SVOC compounds (specifically, benzo[a]pyrene) related to the composition of the "Orangeburg" material.

Reported levels for all RCRA metals in soil samples were below PALs except for arsenic. Arsenic was detected above the PAL of $2.7 \mathrm{mg} / \mathrm{kg}$ in approximately 25 percent of the soil samples collected. Detected arsenic concentrations for samples analyzed ranged from 1.7 to $3.3 \mathrm{mg} / \mathrm{kg}$. The arsenic concentrations are consistent in the leachfield soil and do not appear to represent "hot spots" or evidence of a localized spill. Although arsenic concentrations in the soil exceed the PAL, these 
concentrations are believed to be within ambient conditions for CAS 25-04-11 and do not represent contamination (NBMG, 1998; Moore, 1999).

Analytical results for the septic tank contents and manhole were evaluated for disposal purposes. The sludge sample results indicated the presence of TPH DRO in both the influent and effluent chambers (580 mg/kg and 1,200 mg/kg, respectively) of the septic tank exceeding the NDEP action level of $100 \mathrm{mg} / \mathrm{kg}$ (NAC, 2000d). A sediment sample was also collected from the G35 Manhole and showed the presence TPH DRO $(710 \mathrm{mg} / \mathrm{kg})$ exceeding the regulatory limit. Fecal coliform bacteria were not detected in the septic tank at this CAS.

Analytical results associated with CAS 25-04-11 are further detailed in Section A.9.3.

\subsubsection{Port Gaston Training Area Contaminated Water Reservoir (CAS 26-03-01)}

The PALs (DOE/NV, 1998b; DOE/NV, 2001) were not exceeded in any of the soil samples analyzed for VOCs, SVOCs, TPH, total beryllium, and total pesticides and herbicides.

No VOCs greater than FSLs were found during soil sample screening. Radiological FSLs were exceeded at five locations (H01, H02, H04, H05, and H07; Figure A.10-1) during soil sampling activities.

Reported levels for all RCRA metals in soil samples were below PALs except for arsenic. All of the arsenic detections in the soil exceed the PAL of $2.7 \mathrm{mg} / \mathrm{kg}$. Concentrations in samples from above the liner are consistently lower than concentrations from samples taken below the liner. Although arsenic concentrations in the soil exceed the PAL, these concentrations are believed to be within ambient conditions for CAS 26-03-01 and do not represent contamination (NBMG, 1998; Moore, 1999).

Surface soil sample analytical results for the water reservoir indicated gamma-emitting radionuclides were statistically distinguishable from background concentrations for lead-214 and thorium-227 at two locations above the liner (H02 and H07; Figure A.10-1). Because of the short half-life of thorium-227 (18.7 days), the compound must be in equilibrium with its longer-lived parent, actinium-227 (21.8 years). This indicates that actinium-227 is present in these samples at the same concentrations as thorium-227. 
Analytical results associated with CAS 26-03-01 are further detailed in Section A.10.3.

\subsubsection{Area 26 Check Station (BIdg. 2105) Septic System (CAS 26-04-01)}

The PALs (DOE/NV, 1998b; DOE/NV, 2001) were not exceeded in any of the soil samples analyzed for VOCs, SVOCs, TPH, total beryllium, total pesticides, gamma-emitting radionuclides, Iso-U, Iso-Pu, and $\mathrm{Sr}-90$.

No VOCs greater than FSLs were found during soil sample screening. All radiological fieldscreening results for soil samples at CAS 26-04-01 were below FSLs. Radiological survey data for locations J16 and J17 (Figure A.11-1) indicate that the collection system meets the unrestricted release criteria as defined in the NV/YMP Radiological Control Manual (DOE/NV, 2000).

Reported levels for all RCRA metals in soil samples were below PALs except for arsenic. Arsenic was detected above the PAL of $2.7 \mathrm{mg} / \mathrm{kg}$ in most of the samples analyzed. The arsenic concentrations for the samples analyzed ranged from 3.2 to $4.4 \mathrm{mg} / \mathrm{kg}$. Detected arsenic concentrations are consistent in the leachfield soil and do not appear to represent "hot spots" or evidence of a localized spill. Although arsenic concentrations in the soil exceed the PAL, these concentrations are believed to be within ambient conditions for CAS 26-04-01 and do not represent contamination (NBMG, 1998; Moore, 1999).

Analytical results for the septic tank and distribution box contents were evaluated for disposal purposes. One liquid and sludge sample were collected from the septic tank. Cesium-137 and $\mathrm{Pu}-239$ in the sludge sample exceed disposal criteria. Fecal coliform bacteria were not detected in the septic tank at this CAS.

Analytical results associated with CAS 26-04-01 are further detailed in Section A.11.3.

\subsubsection{Hot Critical Facility (BIdg. 2103) Septic System (CAS 26-04-02)}

The PALs (DOE/NV, 1998b; DOE/NV, 2001) were not exceeded in any of the soil samples analyzed for VOCs, SVOCs, TPH, total beryllium, PCBs, gamma-emitting radionuclides, Iso-U, Iso-Pu, and Sr-90. 
No VOCs greater than FSLs were found during soil sample screening. All radiological field-screening results for soil samples from CAS 26-04-02 were below FSLs. The results of the radiological survey of Manhole 1 and a pipe segment at location K16 (Figure A.12-1) indicate that the collection system meets the unrestricted release criteria as defined in the NV/YMP Radiological Control Manual (DOE/NV, 2000).

Reported levels for all RCRA metals in soil samples were below PALs except for arsenic. Arsenic was detected above the PAL of $2.7 \mathrm{mg} / \mathrm{kg}$ in most of the samples analyzed. Detected arsenic concentrations in the soil ranged from 2.5 to $5.4 \mathrm{mg} / \mathrm{kg}$. The arsenic concentrations are consistent in the leachfield soil and do not appear to represent "hot spots" or evidence of a localized spill. Although arsenic concentrations in the soil exceed the PAL, these concentrations are believed to be within ambient conditions for CAS 26-04-02 and do not represent contamination (NBMG, 1998; Moore, 1999).

Analytical results for the septic tank contents were evaluated for disposal purposes. The sediment sample results indicated the presence of TPH DRO $(160 \mathrm{mg} / \mathrm{kg})$ exceeding the NDEP action level of $100 \mathrm{mg} / \mathrm{kg}$ (NAC, 2000d). Fecal coliform bacteria were not detected in the septic tank at this CAS.

Analytical results associated with CAS 26-04-02 are further detailed in Section A.12.3.

\subsubsection{Buildings 2201 and 2202 Radioactive Leachfield (CAS 26-05-01)}

The PALs (DOE/NV, 1998b; DOE/NV, 2001) were not exceeded in any of the soil samples analyzed for VOCs, SVOCs, TPH, total beryllium, PCBs, gamma-emitting radionuclides, and Sr-90.

No VOCs greater than FSLs were found during soil sample screening. Radiological FSLs were exceeded at one location (L09; Figure A.13-1) during leachfield soil sampling. Radiological survey measurements of the piping representative of the collection system were obtained upstream from the distribution box. The pipe interior was screened for both removable and fixed radiological levels for comparison against unrestricted release criteria. All fixed plus removable measurements were below the unrestricted release criteria for the collection system pipes. Only the floor of the distribution box exhibited total beta/gamma contamination exceeding the unrestricted release limit. A radiological swipe survey was also conducted along the collection system piping and the distribution box. The 
unrestricted release criteria for removable contamination were not exceeded in swipes taken from collection system pipes. However, a large-area swipe from the bottom of Manhole 4 exhibited removable beta activity in excess of the unrestricted release criteria.

Reported levels for all RCRA metals in soil samples were below PALs except for arsenic. Arsenic was detected above the PAL of $2.7 \mathrm{mg} / \mathrm{kg}$ in all of the samples analyzed. Detected arsenic concentrations for the samples analyzed ranged from 6.0 to $11.9 \mathrm{mg} / \mathrm{kg}$. The arsenic concentrations are consistent in the leachfield soil and do not appear to represent "hot spots" or evidence of a localized spill. Although arsenic concentrations in the soil exceed the PAL, these concentrations are believed to be within ambient conditions for CAS 26-05-01 and do not represent contamination (NBMG, 1998; Moore, 1999).

Radiological PALs (DOE/NV, 2001) were exceeded in one subsurface leachfield sample for U-234, $\mathrm{U}-235$, and $\mathrm{Pu}-239$. Two other samples also exceeded the radiological PAL for $\mathrm{Pu}-239$ in the leachfield subsurface soil. The soil samples were collected from locations near the distribution box in the leachfield (L03 and L04; Figure A.13-1).

Analytical results for sediment from Manhole 1 were evaluated for disposal purposes. The sediment sample results indicated the presence of TPH DRO $(120 \mathrm{mg} / \mathrm{kg})$ exceeding the NDEP action level of $100 \mathrm{mg} / \mathrm{kg}$ (NAC, 2000d). Cesium-137, U-234, U-235, and Pu-239 also exceeded disposal criteria.

Analytical results associated with CAS 26-05-01 are further detailed in Section A.13.3.

\subsubsection{Building 2203 Septic System (26-05-03)}

The PALs (DOE/NV, 1998b; DOE/NV, 2001) were not exceeded in any of the soil samples analyzed for VOCs, SVOCs, TPH, total beryllium, PCBs, gamma-emitting radionuclides, Iso-U, Iso-Pu, and Sr-90.

No VOCs greater than FSLs were found during soil sample screening. All radiological fieldscreening results for soil samples at CAS 26-05-03 were below FSLs. Radiological survey measurements of the piping representative of the collection system were obtained upstream from the distribution box. Additionally, measurements of the distribution box interior were also collected. None of the measurements exceeded the unrestricted release limits as defined in the $N V / Y M P$ 
Radiological Control Manual (DOE/NV, 2000). A swipe survey was also conducted at several points along the collection system pipeline and the distribution box. None of the swipe measurements exceeded the unrestricted release limits.

Reported levels for all RCRA metals in soil samples were below PALs except for arsenic. Arsenic was detected above the PAL of $2.7 \mathrm{mg} / \mathrm{kg}$ in all of the samples analyzed. Detected arsenic concentrations for the samples analyzed ranged from 3.91 to $9.79 \mathrm{mg} / \mathrm{kg}$. The arsenic concentrations are consistent in the leachfield soil and do not appear to represent "hot spots" or evidence of a localized spill. Although arsenic concentrations in the soil exceed the PAL, these concentrations are believed to be within ambient conditions for CAS 26-05-03 and do not represent contamination (NBMG, 1998; Moore, 1999).

Analytical results for the septic tank and Manhole 1 contents were evaluated for disposal purposes. A sediment sample (composite sample taken from the septic tank and Manhole 1) indicated the presence of TPH DRO (1,300 mg/kg) exceeding the NDEP action level of $100 \mathrm{mg} / \mathrm{kg}$ (NAC, 2000d). Fecal coliform bacteria were not detected in the septic tank at this CAS.

Analytical results associated with CAS 26-05-03 are further detailed in Section A.14.3.

\subsubsection{Building 2201 Septic System (CAS 26-05-04)}

The PALs (DOE/NV, 1998b; DOE/NV, 2001) were not exceeded in any of the soil samples analyzed for VOCs, SVOCs, TPH, total beryllium, PCBs, gamma-emitting radionuclides, Iso-U, Iso-Pu, and Sr-90.

No VOCs greater than FSLs were found during soil sample screening. Radiological FSLs were exceeded at seven locations (N16, N17, N22, N23, and N24; Figure A.15-1) during leachfield soil sampling. The background soil samples used to determine radiological FSLs for CAS 26-05-04 were collected in various locations in Area 26. Only one of these samples was collected from the immediate area of the CAS. Based on the number of mining prospects in the vicinity, the rock and soil in the area may be mineralized and this could explain the slightly elevated screening results for the leachfield soil. Swipe and radiological survey data from the interiors of Manhole 1 (N35) and Manhole 2 (N36) (Figure A.15-1) indicate that the collection system meets the unrestricted 
radiological release criteria as defined in the $N V / Y M P$ Radiological Control Manual (DOE/NV, 2000).

Reported levels for all RCRA metals in soil samples were below PALs except for arsenic. Arsenic was detected above the PAL of $2.7 \mathrm{mg} / \mathrm{kg}$ in all of the samples analyzed. Detected arsenic concentrations for the samples analyzed ranged from 10.5 to $96.1 \mathrm{mg} / \mathrm{kg}$. Due to elevated arsenic concentrations at location N04, additional sampling was conducted. Arsenic concentrations ranged from 12 to $18 \mathrm{mg} / \mathrm{kg}$ in the additional step-out samples collected. It is believed that the leachfield is located in an area of mineralized soil, and the arsenic concentrations represent ambient conditions not contamination (Section A.15.2.8).

Analytical results for the septic tank contents were evaluated for disposal purposes. The septic tank contains sludge with TPH DRO (3,400 mg/kg, 9,000 mg/kg, and $250 \mathrm{mg} / \mathrm{kg})$ and TPH GRO $(520 \mathrm{mg} / \mathrm{kg}$ and $790 \mathrm{mg} / \mathrm{kg}$ ) in concentrations exceeding the NDEP action level of $100 \mathrm{mg} / \mathrm{kg}$ (NAC, 2000d). Fecal coliform bacteria were detected in the septic tank at this CAS.

Analytical results associated with CAS 26-05-04 are further detailed in Section A.15.3.

\subsubsection{Buildings 2101, 2102, and 2107 Septic System (CAS 26-05-05)}

The PALs (DOE/NV, 1998b; DOE/NV, 2001) were not exceeded in any of the soil samples analyzed for VOCs, SVOCs, PCBs, beryllium, gamma-emitting radionuclides, Iso-U, Iso-Pu, and Sr-90.

No VOCs greater than FSLs were found during soil sample screening. All radiological field-screening results for soil samples from CAS 26-05-05 were below FSLs. Swipe and radiological survey data from inspection locations P41, P42, and P44 and Manholes 1, 2, and 3 (Figure A.16-1) indicate that the collection system meets the unrestricted radiological release criteria as defined in the NV/YMP Radiological Control Manual (DOE/NV, 2000).

One soil sample in the leachfield near distribution box 2 exhibited a TPH DRO $(1,500 \mathrm{mg} / \mathrm{kg})$ concentration exceeding the NDEP action level of $100 \mathrm{mg} / \mathrm{kg}$ (NAC, 2000d). Additional sampling was conducted and TPH DRO concentrations did not exceed PALs at the other locations. The contamination was bounded during the additional sampling. 
Reported levels for all RCRA metals in soil samples were below PALs except for arsenic. Arsenic was detected above the PAL of $2.7 \mathrm{mg} / \mathrm{kg}$ in most of the samples analyzed. Detected arsenic concentrations for the samples analyzed ranged from 1.9 to $4.32 \mathrm{mg} / \mathrm{kg}$. The arsenic concentrations are consistent in the leachfield soil and do not appear to represent "hot spots" or evidence of a localized spill. Although arsenic concentrations in the soil exceed the PAL, these concentrations are believed to be within ambient conditions for CAS 26-05-05 and do not represent contamination (NBMG, 1998; Moore, 1999).

Analytical results for both septic tank contents were evaluated for disposal purposes. The results of the septic tank 1 indicates the presence of TPH DRO and GRO $(5,400 \mathrm{mg} / \mathrm{kg}$ and $470 \mathrm{mg} / \mathrm{kg})$ in the sludge of the septic tank exceeding the NDEP action level of $100 \mathrm{mg} / \mathrm{kg}$ (NAC, 2000d). Total mercury, TPH DRO, Pu-239, U-234, and U-235 were identified in the sediment of septic tank 2 in concentrations exceeding regulatory action levels. The waste will carry the EPA code for mercury (D009), unless a TCLP analysis is performed to clarify the regulatory status. Fecal coliform bacteria were not detected in the septic tank at this CAS.

Analytical results associated with CAS 26-05-05 are further detailed in Section A.16.3.

\subsubsection{Building 5200 Septic System (CAS 27-05-02)}

The PALs (DOE/NV, 1998b; DOE/NV, 2001) were not exceeded in any of the soil samples analyzed for VOCs, SVOCs, TPH, total pesticides, gamma-emitting radionuclides, Iso-U, Iso-Pu, and Sr-90.

No VOCs greater than FSLs were found during soil sample screening. All radiological field-screening results for soil samples from CAS 27-05-02 were below FSLs. The results of the radiological survey of pipe at locations Q10 and Q11 (Figure A.17-1) indicate that the collection system meets the unrestricted release criteria as defined in the NV/YMP Radiological Control Manual (DOE/NV, 2000).

Reported levels for all RCRA metals in soil samples were below PALs except for arsenic. Arsenic was detected above the PAL of $2.7 \mathrm{mg} / \mathrm{kg}$ in 50 percent of the samples analyzed. The arsenic concentrations for the samples analyzed ranged from 2.1 to $4.93 \mathrm{mg} / \mathrm{kg}$. Detected arsenic concentrations are consistent in the leachfield soil and do not appear to represent "hot spots" or 
evidence of a localized spill. Although arsenic concentrations in the soil exceed the PAL, these concentrations are believed to be within ambient conditions for CAS 27-05-02 and do not represent contamination (NBMG, 1998; Moore, 1999).

Elevated PCB concentrations were identified at sample location Q09 (Figure A.17-1) within the leachfield soil. Additional sampling was conducted and aroclor-1254 (7,600 $\mu \mathrm{g} / \mathrm{kg})$ was detected at concentrations exceeding the $1,000 \mu \mathrm{g} / \mathrm{kg}$ PAL at one additional location (Q15; Figure A.17-1) within the leachfield. Further sampling revealed 10 additional samples with aroclor-1248 concentrations ranging from 120 to $22,000 \mu \mathrm{g} / \mathrm{kg}$. Eight of those samples had aroclor- 1248 concentrations exceeding the PAL. The higher concentrations were detected in surface soil samples.

Analytical results for the septic tank and distribution box contents were evaluated for disposal purposes. The distribution box contained sludge with TPH DRO $(870 \mathrm{mg} / \mathrm{kg})$ in concentrations above the PAL of $100 \mathrm{mg} / \mathrm{kg}$ (NAC, 2000d). Aroclor-1248 was detected in the sludge samples at $1,500 \mathrm{mg} / \mathrm{kg}$, well above the regulatory levels of $50 \mathrm{mg} / \mathrm{kg}$ (CFR, 2000b). Uranium-234, U-235, and U-238 were also identified in the distribution box sludge sample exceeding POC release levels (BN, 1995).

The septic tank influent chamber sludge contained TPH DRO $(3,000 \mathrm{mg} / \mathrm{kg})$ and TPH GRO $(4,100 \mathrm{mg} / \mathrm{kg}$ ) in concentrations above the PAL of $100 \mathrm{mg} / \mathrm{kg}$ (NAC, 2000d). Aroclor-1248 was detected in the sludge samples at $2,900 \mathrm{mg} / \mathrm{kg}$, well above the regulatory levels of $50 \mathrm{mg} / \mathrm{kg}$ (CFR, 2000b). Uranium-234 and U-235 were also detected in the septic tank sludge sample above the POC release levels (BN, 1995). Fecal coliform bacteria were not detected in the septic tank at this CAS.

Analytical results associated with CAS 27-05-02 are further detailed in Section A.17.3.

\subsubsection{Data Assessment Summary}

An assessment of CAU 271 investigation results determined that the data collected met the DQOs and support their intended use in the decision-making process. The assessment, provided in Appendix B, includes an evaluation of the data quality indicators (DQIs) to determine the degree of acceptability and usability of the reported data in the decision-making process. Additionally, a reconciliation of 
the data with the conceptual site model established for this project was conducted. Conclusions were based on the results of the quality control measurements and are discussed in Section A.19.0 of Appendix A and also discussed in Appendix B.

The overall results of the assessment indicate that the DQI goals for precision, accuracy, completeness, representativeness, and comparability have been achieved. Precision and accuracy of the datasets were demonstrated to be within acceptable limits for a high percentage of the data with the exception of the TPH GRO measurements for accuracy. The percentage of acceptable matrix spikes for TPH GRO was 76 percent. Because there were several samples with high concentrations of TPH, it is likely that the spike concentration was masked by the native contaminant concentration causing a significant number of matrix spike recoveries to be outside acceptable windows. It should be noted that the percentage of acceptable laboratory control spikes (LCSs) was greater than 99 percent for all analyses, indicating that the low recoveries were not an analytical or laboratory problem. Therefore, accuracy results for CAU 271 should be considered to be acceptable.

Completeness objectives for this CAU have been achieved. Rejected data were thoroughly reviewed and questions concerning these data have been addressed in Appendix B.

Representativeness of site characteristics was demonstrated with the CAU 271 data. An evaluation of comparability provides high confidence that the datasets for this project are comparable to other NTS projects and other data generated by accepted industry standards. The evaluation also ensures that project data are comparable to PALs and regulatory disposal limits. Data were analyzed per SW-846 protocol, meeting specifications noted in the CAIP (DOE/NV, 2001) and the Leachfield Work Plan (DOE/NV, 1998b). Achieving all of the DQI goals supports acceptance of the CAU 271 datasets, thereby meeting the DQOs established for this project and the subsequent use of these data in the decision-making process.

\subsection{Need for Corrective Action}

Analytes detected during the corrective action investigation were evaluated against PALs to determine COCs for each CAS in CAU 271. These CAS-specific COCs are provided in the following subsections. Septic tanks must be closed according to the nature of any contents. Septic tanks that do not contain hazardous constituents must be closed in accordance with Nevada Administrative Code 
(NAC) 444.818 (NAC, 2000b). Under this requirement, contents must be removed and properly disposed; the septic tank must be removed for proper disposal or left in place; and remaining voids must be backfilled with an inert material. Septic tanks that contain regulated hazardous or hydrocarbon constituents must be closed by one of two methods:

- Remove and properly dispose of contents, properly dispose of or leave the septic tank in place, and backfill remaining voids with an inert material.

- Close the contents in place, mitigate remaining risk, and backfill any voids with an inert material. Closure in place may be precluded under relevant treatment standards.

The identification of collection system material exceeding unrestricted release criteria; COCs above PALs in surface and subsurface soil, and contaminants of regulatory concern in septic tank and distribution box contents requires corrective action alternatives to be considered and evaluated. The impacted volume/characteristics and site-specific constraints are provided in each CAS-specific subsection. The corrective action alternatives are identified in Section 3.0 and evaluated for their ability to ensure protection of the public and the environment in accordance with NAC 445A (NAC, 2000c), feasibility, and cost effectiveness.

\subsubsection{Security Checkpoint Septic System (CAS 25-04-01)}

The COCs identified within the septic tank are TPH DRO and GRO. Approximately 135 gallons (gal) of hydrocarbon-contaminated material is present in the septic tank. Of this total, 65 gal is liquid and 70 gal is sludge.

No COCs were identified at other locations outside the septic tank, within the collection system piping, or within the leachfield subsurface soil; therefore, no corrective action is necessary for the soil or collection system piping. The tank can be readily accessed from the manhole exposed at ground surface. There are no site-specific characteristics that would constrain remediation at this CAS.

The septic tank contents must either be solidified in place or removed for proper disposal. If the contents are solidified in place, remaining risk must be mitigated and any voids backfilled. If the contents are removed, the septic tank must be backfilled or removed for proper disposal and the resulting void backfilled. 
Based on the identification of COCs in the septic tank, potential corrective action alternatives are identified and evaluated in this CADD. This was done to ensure worker, public, and environmental protection against potential exposure to COCs in accordance with NAC 445A (NAC, 2000c) and the NV/YMP Radiological Control Manual (DOE/NV, 2000).

\subsubsection{PAN-AM Trailers Septic System (CAS 25-04-03)}

Contaminants of concern are present in the septic tank and in the soils under the leachfield. The COCs identified within the septic tank indicated the presence of TPH DRO. Approximately 444 gal of hydrocarbon-contaminated material is in the septic tank. Of this total, 410 gal is liquid and 34 gal is sludge. Fecal coliform bacteria were detected in the septic tank. The leachfield soil contains benzo(a)pyrene in concentrations above the PAL at two locations. However, because this leachfield contained distribution lines constructed of "Orangeburg" pipe, it is possible that the results for benzo(a)pyrene were caused by inadvertent introduction of pieces of pipe fragments in the samples from these locations.

No COCs were identified in the soil surrounding the septic tank or within the collection system piping. No corrective action is necessary for this soil or system piping. The tank can be readily accessed through two manholes approximately $3.5 \mathrm{ft}$ bgs. There are no site-specific characteristics that would constrain remediation at this CAS.

The septic tank contents must either be solidified in place or removed for proper disposal. If the contents are solidified in place, remaining risk must be mitigated and any voids backfilled. If the contents are removed, the septic tank must be backfilled or removed for proper disposal and the resulting void backfilled.

Based on the identification of COCs in the septic tank, potential corrective action alternatives are identified and evaluated in this CADD. This was done to ensure worker, public, and environmental protection against potential exposure to COCs in accordance with NAC 445A (NAC, 2000c) and the NV/YMP Radiological Control Manual (DOE/NV, 2000). 


\subsubsection{Reactor Control Point Septic System (CAS 25-04-04)}

Contaminants of concern are present in the septic tank and soil immediately north of the septic tank influent end. The COCs identified within the influent chamber of the septic tank indicated the presence of TPH DRO. The influent chamber of the septic tank contains approximately 1,178 gal of sludge and 2,978 gal of liquid. The COCs identified within the effluent chamber of the septic tank indicate the presence of TPH DRO, chlordane, and U-234 within the septic tank. The effluent chamber contains approximately 170 gal sludge and 438 gal of liquid (manage as mixed waste) due to the presence of chlordane and U-234. Fecal coliform bacteria were detected in the septic tank. Subsurface soil samples indicate the presence of TPH-contaminated soil above the PAL adjacent to the influent end of the septic tank.

No COCs were identified at locations within the leachfield subsurface soil, the collection system piping, or within the distribution box. Total petroleum hydrocarbons are located within the soil outside the leachfield, adjacent to the influent end of the septic tank. The septic tank can be readily accessed through three manholes exposed at ground surface. The distribution box can be accessed through two manholes exposed at ground surface. There are no site-specific characteristics that would constrain remediation at this CAS.

The distribution box must be closed in accordance with NAC 444.818 (NAC, 2000b). The septic tank influent chamber contents must either be solidified in place or removed for proper disposal. If the contents are solidified in place, remaining risk must be mitigated and any voids backfilled. If the contents are removed, the septic tank must be backfilled or removed for proper disposal and the resulting void backfilled. The septic tank effluent chamber contents must be removed for proper closure.

The total estimated volume of hydrocarbon-contaminated soil adjacent to the influent end of the septic tank is 420 cubic yards $\left(\mathrm{yd}^{3}\right)$. To calculate the conservative volume of impacted material, four triangular-shaped areas were identified: triangle A (locations C41, C32, and C39); triangle B (locations C32, C39, and C33); triangle C (locations C32, C33, and C37); and triangle D (locations C32, C37, and C41) (Figure A.5-1). 
Approximately $3.5 \mathrm{ft}$ of clean overburden is located in the areas of triangles A and B. Subsurface contamination was identified between 4 to $12 \mathrm{ft}$ below ground surface (bgs) at triangle A, and 4 to $14 \mathrm{ft}$ at triangle B. Approximately $11.5 \mathrm{ft}$ of clean overburden is located in the areas of triangles C and D. Subsurface contamination was identified between 12 to $14 \mathrm{ft}$ bgs at triangles $\mathrm{C}$ and $\mathrm{D}$. The surface dimensions of triangle $\mathrm{C}$ and $\mathrm{D}$ outlining the impacted area are $24 \mathrm{ft}$ by $15 \mathrm{ft}$, and $15 \mathrm{ft}$ by $44 \mathrm{ft}$, respectively.

The maximum lateral extent of the contamination is constrained by samples collected from additional step-out sampling and the clean region defined by the leachfield. The maximum vertical extent of hydrocarbon contamination is constrained by sample intervals described in Section A.5.1. A 6-inch (in.) buffer above and below contaminated soils was used in determining the estimated vertical thickness of contaminated material. Soil volumes were calculated from clean sample intervals to clean sample intervals.

Based on the identification of COCs in the septic tank and in the soil adjacent to the septic tank, potential corrective action alternatives are identified and evaluated in this CADD. This was done to ensure worker, public, and environmental protection against potential exposure to COCs in accordance with NAC 445A (NAC, 2000c) and the NV/YMP Radiological Control Manual (DOE/NV, 2000).

\subsubsection{BREN Tower Septic System (CAS 25-04-08)}

Contaminants of concern are present in the septic tank and an area of soil in the southern end of the leachfield. The COCs identified within the septic tank indicated the presence of TPH DRO. The septic tank contains approximately 625 gal of hydrocarbon-contaminated liquid and sludge. The influent chamber contains approximately 288 gal of liquid and 163 gal of sludge. The effluent chamber contains approximately 168 gal of liquid and 6 gal of sludge. One subsurface soil sample from the southern portion of the leachfield indicated the presence of $\mathrm{Pu}-239$ above the PAL.

No COCs were identified at other locations outside the septic tank or within the collection system piping; therefore, no corrective action is necessary for the collection system piping. The septic tank can be readily accessed through two manholes approximately $2 \mathrm{ft}$ bgs. There are no site-specific characteristics that would constrain remediation at this CAS. 
The total estimated volume of radiologically contaminated soil associated with the leachfield is $3 \mathrm{yd}^{3}$. To calculate the conservative volume of impacted material in the southern portion of the leachfield, a triangular-shaped area was identified with corners at locations D19, D08, and D18 (Figure A.6-1).

Approximately $3 \mathrm{ft}$ of clean overburden is located in the area of the triangle. Subsurface contamination was identified between 3.5 to $5.6 \mathrm{ft}$ bgs.

The maximum lateral extent of the contamination is constrained by samples collected from additional step-out sampling and the clean region defined by the leachfield. The maximum vertical extent of contamination is constrained by sample intervals described in Section A.6.1. A 6-in. buffer above and below contaminated soils was used in determining the estimated thickness of contaminated material. Soil volumes were calculated from clean sample intervals to clean sample intervals.

Based on the identification of COCs in the septic tank and in the leachfield soil, potential corrective action alternatives are identified and evaluated in this CADD. This was done to ensure worker, public, and environmental protection against potential exposure to COCs in accordance with NAC 445A (NAC, 2000c) and the NV/YMP Radiological Control Manual (DOE/NV, 2000).

\subsubsection{Engine Test Stand No. 1 Septic System (CAS 25-04-09)}

Contaminants of concern are present in the septic tank sediment which contains TPH DRO. Combining the influent and effluent chambers of the septic tank, approximately 110 gal of hydrocarbon-contaminated sediment is present.

No COCs were identified at other locations outside the septic tank, within the collection system piping, or within the leachfield subsurface soil; therefore, no corrective action is necessary for the soil or system piping. The septic tank can be readily accessed through two manholes exposed at ground surface. There are no site-specific characteristics that would constrain remediation at this CAS.

The septic tank contents must either be solidified in place or removed for proper disposal. If the contents are solidified in place, remaining risk must be mitigated and any voids backfilled. If the contents are removed, the septic tank must be backfilled or removed for proper disposal and the resulting void backfilled. 
Based on the identification of COCs in the septic tank, potential corrective action alternatives are identified and evaluated in this CADD. This was done to ensure worker, public, and environmental protection against potential exposure to COCs in accordance with NAC 445A (NAC, 2000c) and the NV/YMP Radiological Control Manual (DOE/NV, 2000).

\subsubsection{Rad-Safe Trailers Septic System (CAS 25-04-10)}

Contaminants of concern were not detected in the septic tank, in the soil surrounding the septic tank and distribution box, or in soil underlying the leachfield. In addition, radiological survey results for collection system piping were compared to unrestricted release criteria as defined in the NV/YMP Radiological Control Manual (DOE/NV, 2000). The release criteria were not exceeded at any of the inspection locations based on radiological survey results. No corrective action is necessary for the soil, septic tank, or collection system piping.

The septic tank can be readily accessed through two manholes approximately $2.75 \mathrm{ft}$ bgs. There are no site-specific characteristics that would constrain remediation at this CAS.

The septic tank will be filled as a best management practice.

\subsubsection{South of LASL Trailers Septic System (CAS 25-04-11)}

Contaminants of concern are present in the septic tank, in the G35 Manhole immediately upstream (north) of the septic tank, and in a small area of soil under the leachfield. The septic tank contains approximately 700 gal of hydrocarbon-contaminated sludge/liquid. Approximately 294 gal of liquid and 120 gal of sludge are present in the inlet chamber and 39 gal of sludge and 247 gal of liquid are present in the outlet chamber of the septic tank. A minimal amount of TPH DRO-contaminated sediment is present in the G35 Manhole. The soils under the leachfield contain SVOC analytes (benzo(a)pyrene) in concentrations above PALs at two locations; however, it is possible that the results may be due to the inadvertent introduction of pieces of "Orangeburg" leachfield pipe in the samples from these locations (see pertinent discussion in Section 2.2.1.7).

No other COCs were identified at locations within the collection system piping. No corrective action is necessary for the soil or system piping. The septic tank can be readily accessed through two manholes approximately $3.5 \mathrm{ft}$ bgs. Although below-ground, these manholes are accessible from 
ground surface through steel casings. There are no site-specific characteristics that would constrain remediation at this CAS.

The septic tank and manhole contents must either be solidified in place or removed for proper disposal. If the contents are solidified in place, remaining risk must be mitigated and any voids backfilled. If the contents are removed, the septic tank and manhole must be backfilled or removed for proper disposal and the resulting void backfilled.

Based on the identification of COCs in the septic tank, potential corrective action alternatives are identified and evaluated in this CADD. This was done to ensure worker, public, and environmental protection against potential exposure to COCs in accordance with NAC 445A (NAC, 2000c) and the NV/YMP Radiological Control Manual (DOE/NV, 2000).

\subsubsection{Port Gaston Training Area Contaminated Water Reservoir (CAS 26-03-01)}

Radiological COCs are present in the soil above the liner. The radionuclides are concentrated in the first 6 in. of soil, which overlies the plastic liner. The soil contains lead-214 and thorium-227 (and by association, actinium-227) in concentrations above PALs.

Figure A.10-1 shows the sampling locations (H02 and H07) where COCs where identified. The total estimated volume of contaminated material above the liner is $50 \mathrm{yd}^{3}$. To calculate a rectangular volume of impacted material, an average soil depth of 6 in. of soil was used based on the estimated depth of soil above the liner. The surface dimensions of the water reservoir are approximately 75 by $36 \mathrm{ft}$.

The maximum lateral extent of the contamination is constrained by the berms surrounding the water reservoir. The maximum vertical extent of contamination is constrained by the presence of the liner and clean soil samples collected from intervals below the liner. There are no site-specific characteristics that would constrain remediation at this CAS. However, it is located in a steep-sided natural wash. The access into the reservoir may require regrading.

Based on the identification of COCs above PALs in the contaminated water reservoir, potential corrective action alternatives are identified and evaluated in this CADD. This was done to ensure 
worker, public, and environmental protection against potential exposure to COCs in accordance with NAC 445A (NAC, 2000c) and the NV/YMP Radiological Control Manual (DOE/NV, 2000).

\subsubsection{Area 26 Check Station (BIdg. 2105) Septic System (CAS 26-04-01)}

Contaminants of concern are present in the septic tank and distribution box. The septic tank contains cesium-137 and Pu-239 above regulatory disposal limits. Approximately 147 gal of sludge and 885 gal of liquid are present within the septic tank. No COCs were identified at other locations outside the septic tank, within the distribution box, within the collection system piping, or within the leachfield subsurface soil; therefore, no corrective action is necessary for the soil or collection system piping.

The septic tank can be readily accessed from the manhole exposed at ground surface. The distribution box can be readily accessed through one manhole located $10 \mathrm{in}$. above ground surface. There are no site-specific characteristics that would constrain remediation at this CAS.

The septic tank and distribution box must be closed in accordance with NAC 444.818 (NAC, 2000b).

\subsubsection{Hot Critical Facility (BIdg. 2103) Septic System (CAS 26-04-02)}

Contaminants of concern are present in the septic tank. Approximately 34 gal of hydrocarboncontaminated (TPH DRO) sediment is present in the septic tank.

No COCs were identified within the distribution box, outside the septic tank, within the collection system piping, or within the leachfield subsurface soil; therefore, no corrective action is necessary for the soil or system piping. The tank can be readily accessed from the manhole exposed at ground surface. There are no site-specific characteristics that would constrain remediation at this CAS.

The septic tank contents must either be solidified in place or removed for proper disposal. If the contents are solidified in place, remaining risk must be mitigated and any voids backfilled. If the contents are removed, the septic tank must be backfilled or removed for proper disposal and the resulting void backfilled. The distribution box must be closed in accordance with NAC 444.818 (NAC, 2000b). 
Based on the identification of COCs in the septic tank, potential corrective action alternatives are identified and evaluated in this CADD. This was done to ensure worker, public, and environmental protection against potential exposure to COCs in accordance with NAC 445A (NAC, 2000c) and the NV/YMP Radiological Control Manual (DOE/NV, 2000).

\subsubsection{Buildings 2201 and 2202 Radioactive Leachfield (CAS 26-05-01)}

Contaminants of concern are present in the manhole nearest the leachfield (Manhole 1) and in soil in a small area of the leachfield immediately south of the distribution box. The pipe at Manhole 1 contains a small amount of sediment (10 gal) with TPH DRO, U-234, U-235, Pu-239, and cesium-137 COCs.

The small area of leachfield soil contains U-234, U-235, and Pu-239 above PALs. In addition to the COC determination, the distribution box, collection system piping, and manholes were radiologically surveyed and the results were compared to unrestricted release criteria as defined in the NV/YMP Radiological Control Manual (DOE/NV, 2000).

Radiological survey and swipe data were obtained from several locations (L33 through L39; Figure A.13-1) along the collection system pipeline from Buildings 2201 and 2202 to the leachfield. Total and removable radioactivity were below the unrestricted release limits, except at Manhole 4, which is the manhole nearest to Building 2201. Beta activity at Manhole 4 exceeds the removable release limits. However, the results are for a large area swipe and should be considered an estimate.

The Manhole 1 contents must either be solidified in place or removed for proper disposal. If the contents are solidified in place, remaining risk must be mitigated and any voids backfilled. If the contents are removed, the manhole must be backfilled or removed for proper disposal and the resulting void backfilled. The distribution box can readily accessed from the manhole exposed $4.8 \mathrm{ft}$ above the ground surface. The manhole contents must be removed for proper disposal. The distribution box must be closed in accordance with NAC 444.818 (NAC, 2000b).

The total estimated volume of radiologically contaminated soil associated with the leachfield is $24 \mathrm{yd}^{3}$. To calculate the conservative volume of impacted material in the leachfield south of the distribution box, a triangular area bounded by locations L03, L12, and L23 (Figure A.13-1) was 
identified. Approximately $1.5 \mathrm{ft}$ of clean overburden is located in this area. Subsurface contamination was identified between 2.0 to $4.5 \mathrm{ft}$ bgs. The maximum lateral extent of the contamination is constrained by samples collected from additional step-out sampling and the clean region defined by the leachfield. The maximum vertical extent of contamination is constrained by sample intervals described in Section A.13.1. A 6-in. buffer above and below contaminated soils was used in determining the estimated thickness of contaminated material. Soil volumes were calculated from clean sample intervals to clean sample intervals.

Based on the identification of COCs above PALs in leachfield soil and COCs above regulatory action levels in sediment at Manhole 1, potential corrective action alternatives are identified and evaluated in this CADD. This was done to ensure worker, public, and environmental protection against potential exposure to COCs in accordance with NAC 445A (NAC, 2000c) and the NV/YMP Radiological Control Manual (DOE/NV, 2000).

\subsubsection{Building 2203 Septic System (26-05-03)}

Contaminants of concern are present in the septic tank and a collection system manhole. A small volume of dry sediment ( 1 gal) in a composite sample collected from the septic tank and manhole contains TPH DRO. No COCs were identified at other locations outside the septic tank, within the collection system piping, or within the leachfield subsurface soil; therefore, no corrective action is necessary for the soil or system piping.

In addition to the COC determination, distribution box and collection system survey results were compared to unrestricted release criteria as defined in the NV/YMP Radiological Control Manual (DOE/NV, 2000). Unrestricted release criteria were not exceeded at any of the survey locations, based on radiological survey and swipe results.

The septic tank can be readily accessed from the manhole exposed at ground surface. The distribution box can be readily accessed from the manhole located $0.5 \mathrm{ft}$ above the ground surface. There are no site-specific characteristics that would constrain remediation at this CAS.

The septic tank and collection system manhole contents must either be solidified in place or removed for proper disposal. If the contents are solidified in place, remaining risk must be mitigated and any 
voids backfilled. If the contents are removed, the septic tank and manhole must be backfilled or removed for proper disposal and the resulting void backfilled. The distribution box must be closed in accordance with NAC 444.818 (NAC, 2000b).

Based on the identification of COCs in the septic tank and manhole, potential corrective action alternatives are identified and evaluated in this CADD. This was done to ensure worker, public, and environmental protection against potential exposure to COCs in accordance with NAC 445A (NAC, 2000c) and the NV/YMP Radiological Control Manual (DOE/NV, 2000).

\subsubsection{Building 2201 Septic System (CAS 26-05-04)}

Contaminants of concern are present in the septic tank. The influent and effluent chambers of the septic tank contain sludge with TPH DRO and GRO. Approximately 3,098 gal of liquid and 654 gal of sludge are located in the inlet chamber of the septic tank, and approximately 24 gal of liquid and 24 gal of sludge are located in the outlet chamber of the septic tank.

No COCs were identified at other locations outside the septic tank, within the collection system piping, or within the leachfield subsurface soil; therefore, no corrective action is necessary for the soil or collection system piping.

In addition to the COC determination, collection system manhole radiological survey results were compared to unrestricted release criteria as defined in the NV/YMP Radiological Control Manual (DOE/NV, 2000). Unrestricted release criteria were not exceeded at any of the survey locations.

The septic tank can be readily accessed from three manholes exposed at ground surface and the distribution box can be accessed from two manholes located at ground surface. There are no site-specific characteristics that would constrain remediation at this CAS.

The septic tank box contents must either be solidified in place or removed for proper disposal. If the contents are solidified in place, remaining risk must be mitigated and any voids backfilled. If the contents are removed, the septic tank must be backfilled or removed for proper disposal and the resulting void backfilled. The distribution box must be closed in accordance with NAC 444.818 (NAC, 2000b). 
Based on the identification of COCs in the septic tank, potential corrective action alternatives are identified and evaluated in this CADD. This was done to ensure worker, public, and environmental protection against potential exposure to COCs in accordance with NAC 445A (NAC, 2000c) and the NV/YMP Radiological Control Manual (DOE/NV, 2000).

\subsubsection{Buildings 2101, 2102, and 2107 Septic System (CAS 26-05-05)}

Contaminants of concern are present in both septic tanks and in a small area of soil in the leachfield. Septic tank 1 contains sludge with TPH DRO and GRO. Approximately 851 gal of liquid and 71 gal of sludge is present in septic tank 1 . Septic tank 2 contains approximately 57 gal of sediment with TPH DRO, Pu-239, U-234, U-235, and RCRA metals. One subsurface soil sample from leachfield location P25 (Figure A.16-1) indicated the presence of TPH DRO above the PAL. No COCs were identified at other locations outside the septic tanks, distribution boxes, or within the collection system piping.

In addition to the COC determination, radiological survey and swipe results for inspection points along the collection system were compared to unrestricted release criteria as defined in the NV/YMP Radiological Control Manual (DOE/NV, 2000). Unrestricted release criteria were not exceeded at any of the inspection locations in the radiological or swipe surveys.

Septic tank 1 can be readily accessed through one manhole located $1 \mathrm{ft}$ above ground surface. Septic tank 2 can be readily accessed through 3 metal tubes recessed below grade. Distribution box 1 can be readily accessed through one manhole located $2 \mathrm{ft}$ above ground surface, and distribution box 2 can be accessed through one manhole located $1 \mathrm{ft}$ above ground surface. There are no site-specific characteristics that would constrain remediation at this CAS.

The septic tank contents must either be solidified in place or removed for proper disposal. If the contents are solidified in place, remaining risk must be mitigated and any voids backfilled. If the contents are removed, the septic tank must be backfilled or removed for proper disposal and the resulting void backfilled. The distribution boxes must be closed in accordance with NAC 444.818 (NAC, 2000b). The contents of septic tank 2 must be removed for proper closure. 
The total estimated volume of hydrocarbon-contaminated soil associated with the leachfield is $26 \mathrm{yd}^{3}$. To calculate this conservative volume of impacted material in the leachfield, a triangular-shaped area bounded by locations P23, P26, and P45 (Figure A.16-1). Approximately $4.5 \mathrm{ft}$ of clean overburden is located in the area of the triangle. Subsurface contamination was identified between 5.0 to $7.0 \mathrm{ft}$ bgs.

The maximum lateral extent of the contamination is constrained by samples collected from additional step-out sampling and the clean region defined by the leachfield. The maximum vertical extent of contamination is constrained by sample intervals described in Section A.16.1. A 6-in. buffer above and below contaminated soils was used in determining the estimated thickness of contaminated material.

Based on the identification of COCs in the septic tank and soils in the leachfield, potential corrective action alternatives are identified and evaluated in this CADD. This was done to ensure worker, public, and environmental protection against potential exposure to COCs in accordance with NAC 445A (NAC, 2000c) and the NV/YMP Radiological Control Manual (DOE/NV, 2000).

\subsubsection{Building 5200 Septic System (CAS 27-05-02)}

Contaminants of concern are present in the septic tank, distribution box, and the leachfield soil. Sludge in the septic tank and distribution box contain TPH, uranium isotopes, and PCBs. Approximately 836 gal of contaminated material is present in the influent chamber of the septic tank. Of this total, $681 \mathrm{gal}$ is liquid and $155 \mathrm{gal}$ is sludge. The effluent chamber contains approximately 239 gal of liquid. Approximately 5 gal of sludge is present within the distribution box.

Surface and subsurface soil samples indicated the presence of PCBs above the PAL along the eastern edge of the leachfield, particularly near the southeast corner. Concentrations are greatest in surface soil and generally decrease with depth. The surface PCB contamination appears to be unrelated to the operation of the septic system due to the occurrence of contamination above the distribution lines and leachrock/native soil interface. No COCs were identified at other locations outside the septic tank or distribution box. 
The septic tank can be accessed through a manhole located $6.5 \mathrm{ft}$ bgs. It is accessible from the ground surface through a steel casing with a steel lid. The distribution box can be accessed through a concrete lid located $4.5 \mathrm{ft}$ bgs. Access restrictions to Area 27 could impact remediation of this CAS.

The septic tank and distribution box contents must be removed for proper disposal. The septic tank and distribution box must subsequently be backfilled or removed for proper disposal, and the resulting void backfilled.

A conservative estimated volume of PCB-contaminated soil associated with the leachfield system is $1,800 \mathrm{yd}^{3}$. To calculate the conservative volume of impacted material in the surface and subsurface soil of the leachfield, several plan-view areas were defined: Area A (locations Q12, Q13, and Q26); Area B (locations Q06, Q13, Q26, and Q27); Area C (locations Q08, Q09, and Q16); Area D (locations Q06, Q08, Q18, and Q26); and Area E (locations Q09, Q16, Q18, and Q27)

(Figure A.17-1). This estimate included an area outside the leachfield boundary in the adjacent wash. The volume was calculated from clean sample intervals to clean sample intervals.

Areas A and B were used to calculated the surface soil PCB contamination and subsurface contamination to a depth of $6.0 \mathrm{ft}$ bgs. Areas C, D, and E were used to calculated subsurface soil PCB contamination below $6.0 \mathrm{ft}$ bgs. Subsurface contamination was identified in these areas between 6.0 to $12.5 \mathrm{ft}$ bgs.

Of the estimated $1,800 \mathrm{yd}^{3}$, approximately $140 \mathrm{yd}^{3}$ of soil is located between the surface and $1 \mathrm{ft}$ bgs within the fenced leachfield boundaries. In the southwest portion of the leachfield, within the fenced boundaries, approximately $321 \mathrm{yd}^{3}$ of contaminated soil is located from 1 to $9.5 \mathrm{ft}$ bgs.

The maximum lateral extent of subsurface PCB contamination is constrained by samples collected from additional step-out sampling and the clean region defined by the leachfield. The maximum lateral extent of surface soil PCB contamination is constrained by surface soil samples collected from additional step-out sampling and sediment samples collected on the southwest edge of the leachfield. The maximum vertical extent of contamination is constrained by sample intervals described in Section A.17.1. A 6-in. buffer below contaminated soils was used in determining the estimated depth of contaminated material. 
Based on the identification of COCs in the septic tank, distribution box, and soils in the leachfield, potential corrective action alternatives are identified and evaluated in this CADD. This was done to ensure worker, public, and environmental protection against potential exposure to COCs in accordance with NAC 445A (NAC, 2000c) and the NV/YMP Radiological Control Manual (DOE/NV, 2000). 


\subsection{Evaluation of Alternatives}

The purpose of this section is to present the corrective action objectives for CAU 271, describe the general standards and decision factors used to screen the corrective action alternatives, and develop and evaluate a set of corrective action alternatives that could be used to meet the corrective action objectives.

\subsection{Corrective Action Objectives}

The corrective action objectives are media-specific goals for protecting human health and the environment. Based on the potential exposure pathways, the following corrective action objectives have been identified for CAU 271:

- Prevent or mitigate exposure to media containing COCs at concentrations exceeding PALs as defined in the CAIP (DOE/NV, 2001).

- Prevent spread of COCs beyond each CAS.

- Close the septic tanks and distribution boxes in accordance with NAC 444.818 (NAC, 2000b) or NAC 445A (NAC, 2000a), as appropriate.

As identified in the CAIP, the future use for the CAU is assumed to be industrial, similar to current use (DOE/NV, 1998b). A conceptual model was developed as part of the CAIP (DOE/NV, 2001). The model identified the potential exposure mechanism as disturbance (excavation) of contaminated soil by site workers. Potential contact with contaminated septic tank media by site workers should also be considered. This implies a potential exposure pathway through ingestion of, inhalation of, and/or dermal contact with contaminated media under industrial scenarios.

Depth to groundwater for three water supply wells located within Area 25 is approximately 1,041; 740; and $928 \mathrm{ft}$ bgs (USGS, 1995). The regional groundwater table in Area 26 is thought to be at a depth of about 1,700 ft bgs (DRI, 1988). A perched water table also exists beneath parts of Area 26 in a zone of highly fractured rock. The perched water may extend to depths exceeding $261 \mathrm{ft}$ before encountering rocks with a low-fracture permeability. Static-perched water levels can range from 81 to $167 \mathrm{ft}$ below the land surface (Johnson and Ege, 1964). Information on the depth to groundwater beneath Area 27 could not be located. 
The potential lateral migration of contaminants is unknown, but if migration has occurred, it will likely be confined with the boundaries of each leachfield. For CAS 26-03-01, the lateral extent is unknown, but the potential for migration should be limited due to the presence of the plastic liner.

The vertical extent of potential contamination is unknown but, if present, will be primarily adjacent to and below the distribution lines in each leachfield. Potential contamination is probably concentrated at the native soil/leachfield material interface. Vertical extent should be limited by low mobility of COCs and limited driving force after the systems were no longer in use. For CAS 26-03-01, the plastic liner underlying the reservoir should limit the vertical extent. These factors, along with others presented in Section 3.3, support the determination that contaminant migration to groundwater is not considered to be an exposure pathway.

\subsection{Screening Criteria}

The screening criteria used to evaluate and select the preferred corrective action alternatives are identified in the EPA Guidance on RCRA Corrective Action Decision Documents (EPA, 1991) and the Final RCRA Corrective Action Plan (EPA, 1994).

Corrective action alternatives will be evaluated based on four general corrective action standards and five remedy selection decision factors. All corrective action alternatives must meet the general standards to be selected for evaluation using the remedy selection decision factors.

The general corrective action standards are as follows:

- Protection of human health and the environment

- Compliance with media cleanup standards

- Control the source(s) of the release

- Compliance with applicable federal, state, and local standards for waste management

The remedy selection decision factors are as follows:

- Short-term reliability and effectiveness

- Reduction of toxicity, mobility, and/or volume

- Long-term reliability and effectiveness

- Feasibility

- Cost 


\subsubsection{Corrective Action Standards}

The following text describes the corrective action standards used to evaluate the corrective action alternatives.

\section{Protection of Human Health and Environment}

Protection of human health and the environment is a general mandate of the RCRA statute (EPA, 1994). This mandate requires that the corrective action include any necessary protective measures. These measures may or may not be directly related to media cleanup, source control, or management of wastes. The corrective action alternatives are evaluated for the ability to meet corrective action objectives as defined in Section 3.1.

\section{Compliance with Media Cleanup Standards}

Each corrective action alternative must have the ability to meet the proposed media cleanup standards as set forth in applicable state and federal regulations, and as specified in the CAIP (DOE/NV, 2001). For this CAU, EPA Region 9 PRGs (EPA, 2000) which are derived from the Integrated Risk Information System are the basis for establishing the PALs for chemical contaminants under NAC 445A.2272 (NAC, 2000d). The PAL for petroleum substances in soil is $100 \mathrm{mg} / \mathrm{kg}$ in accordance with NAC 445A.2272 (NAC, 2000d). The PALs for radiological contaminants are based on background concentrations. Laboratory results above PALs indicate the presence of COCs at levels that may require corrective action.

\section{Control the Source(s) of the Release}

An objective of a corrective action remedy is to stop further environmental degradation by controlling or eliminating additional releases that may pose a threat to human health and the environment. Unless source control measures are taken, efforts to clean up releases may be ineffective or, at best, will essentially involve a perpetual cleanup. Therefore, each corrective action alternative must use an effective source control program to ensure the long-term effectiveness and protectiveness of the corrective action.

\section{Comply with Applicable Federal, State, and Local Standards for Waste Management}

During implementation of any corrective action alternative, all waste management activities must be conducted in accordance with applicable state and federal regulations (e.g., Nevada Revised Statues 
[NRS] 459.400-459.600, "Disposal of Hazardous Waste" [NRS, 1998]; 40 CFR 260-282, "RCRA Regulations" [CFR, 2000a]; 40 CFR 761.61, "PCB Remediation Waste” [CFR, 2000b]; NAC 444, "Sanitation" [NAC, 2000a]; and NAC 459.9974, "Disposal and Evaluation of Contaminated Soil" [NAC, 2000e]). The requirements for management of the waste, if any, derived from the corrective action will be determined based on applicable state and federal regulations, field observations, process knowledge, characterization data, and data collected and analyzed during corrective action implementation. Administrative controls (e.g., decontamination procedures and corrective action strategies) will minimize waste generated during site corrective action activities. Decontamination activities will be performed in accordance with approved procedures and will be designated according to the COCs present at the site.

\subsubsection{Remedy Selection Decision Factors}

The following text describes the remedy selection decision factors used to evaluate the corrective action alternatives.

\section{Short-Term Reliability and Effectiveness}

Each corrective action alternative must be evaluated with respect to its effects on human health and the environment during implementation of the corrective action. The following factors will be addressed for each alternative:

- Protection of the community from potential risks associated with implementation, such as fugitive dusts, transportation of hazardous materials, and explosion

- Protection of workers during implementation

- Environmental impacts that may result from implementation

- The amount of time until the corrective action objectives are achieved

\section{Reduction of Toxicity, Mobility, and/or Volume}

Each corrective action alternative must be evaluated for its ability to reduce the toxicity, mobility, and/or volume of the contaminated media. Reduction in toxicity, mobility, and/or volume refers to changes in one or more characteristics of the contaminated media by the use of corrective measures that decrease the inherent threats associated with that media. 


\section{Long-Term Reliability and Effectiveness}

Each corrective action alternative must be evaluated in terms of risk remaining at the CAU after the corrective action alternative has been implemented. The primary focus of this evaluation is on the extent and effectiveness of the control that may be required to manage the risk posed by treatment residuals and/or untreated wastes.

\section{Feasibility}

The feasibility criterion addresses the technical and administrative feasibility of implementing a corrective action alternative and the availability of services and materials needed during implementation. Each corrective action alternative must be evaluated for the following criteria:

- Construction and Operation. Refers to the feasibility of implementing a corrective action alternative given the existing set of waste and site-specific conditions.

- Administrative Feasibility. Refers to the administrative activities needed to implement the corrective action alternative (e.g., permits, public acceptance, rights of way, off-site approval).

- Availability of Services and Materials. Refers to the availability of adequate off-site and on-site treatment, storage capacity, disposal services, necessary technical services and materials, and prospective technologies for each corrective action alternative.

\section{Cost}

Costs for each alternative are estimated for comparison purposes only. The cost estimate for each corrective action alternative includes both capital and operation and maintenance costs, as applicable. The following is a brief description of each component:

- Capital Costs. These costs include both direct and indirect costs. Direct costs may consist of materials, labor, mobilization, demobilization, site preparation, construction materials, equipment purchase and rental, sampling and analysis, waste disposal, and health and safety measures. Indirect costs include such items as engineering design, permits and/or fees, start-up costs, and any contingency allowances.

- Operation and Maintenance. These costs include labor, training, sampling and analysis, maintenance materials, utilities, and health and safety measures.

Cost estimates for the corrective action alternatives are provided in Appendix C. 


\subsection{Development of Corrective Action Alternatives}

This section identifies and briefly describes the viable corrective action technologies and the corrective action alternatives considered for the affected media. Based on the review of existing data, future use, and current operations at the NTS, the following alternatives have been developed for consideration at CAU 271:

- Alternative 1 - No Further Action

- Alternative 2 - Clean Closure

- Alternative 3- Closure in Place with Administrative Controls

Other technologies, such as bioremediation, were considered. However, it would not be effective because of the limited volume and concentrations of contaminated material. These alternatives will not receive further consideration in this CADD. Table 3-1 provides list of the corrective action alternatives evaluated for each CAS.

Table 3-1

Corrective Action Alternatives

\begin{tabular}{||c|c|c|c||}
\hline Corrective Action Site & Alternative 1 & Alternative 2 & Alternative 3 \\
\hline \hline CAS 25-04-01 & & $\mathrm{X}$ & $\mathrm{X}$ \\
\hline CAS 25-04-03 & & $\mathrm{X}$ & $\mathrm{X}$ \\
\hline CAS 25-04-04 & & $\mathrm{X}$ & $\mathrm{X}$ \\
\hline CAS 25-04-08 & & $\mathrm{X}$ & $\mathrm{X}$ \\
\hline CAS 25-04-09 & $\mathrm{X}$ & $\mathrm{X}$ & $\mathrm{X}$ \\
\hline CAS 25-04-10 & & $\mathrm{X}$ & $\mathrm{X}$ \\
\hline CAS 25-04-11 & & $\mathrm{X}$ & $\mathrm{X}$ \\
\hline CAS 26-03-01 & & $\mathrm{X}$ & $\mathrm{X}$ \\
\hline CAS 26-04-01 & & $\mathrm{X}$ & $\mathrm{X}$ \\
\hline CAS 26-04-02 & & $\mathrm{X}$ & $\mathrm{X}$ \\
\hline CAS 26-05-01 & & $\mathrm{X}$ & $\mathrm{X}$ \\
\hline CAS 26-05-03 & & $\mathrm{X}$ & $\mathrm{X}$ \\
\hline CAS 26-05-04 & & $\mathrm{X}$ & $\mathrm{X}$ \\
\hline CAS 26-05-05 & & $\mathrm{X}$ & \\
\hline CAS 27-05-02 & & & \\
\hline
\end{tabular}




\subsubsection{Alternative 1 - No Further Action}

Under the No Further Action Alternative, no corrective action activities will be implemented. This alternative is a baseline case with which to compare and assess the other corrective action alternatives and their ability to meet the corrective action standards.

\subsubsection{Rad-Safe Trailers Septic System (CAS 25-04-10)}

The septic tank did not contain any COCs. No further action is the recommended alternative at this CAS. As a best management practice, the septic tank will be filled with an inert material to prevent the potential for collection of stormwater and inadvertent discharge to the leachfield.

\subsubsection{Alternative 2 - Clean Closure}

For septic tanks and distribution boxes, Alternative 2 includes removal and proper disposal of the contents of the septic tank. The influent and effluent ends of the septic tank and distribution box will be grouted. If necessary, the tank will be rinsed and the rinsate will be analyzed to verify clean closure and/or that no contaminants remain. The septic tanks and distribution boxes will then be filled with an inert material. Details for remedial activities are discussed in Appendix C (Cost Estimates).

For contaminated surface and subsurface soil, Alternative 2 includes excavating and disposing of soil and debris with COC concentrations greater than PALs (DOE/NV, 1998b; DOE/NV, 2001). The clean overburden soil will be removed to expose contaminated soil and all impacted soil will be removed. If visible indications of contamination are present, an inspection will be conducted to ensure that debris and visible contamination have been removed. Verification soil samples will also be collected and analyzed for the presence of COCs exceeding PALs. This will verify that the removal of contaminated soil has successfully remediated the site contamination.

Any contaminated material that is removed will be disposed of at an appropriate disposal facility. All excavated areas will be returned to surface conditions compatible with the intended future use of the site. Overburden soil (as feasible), along with additional clean fill, will be used to backfill excavations after removal of the contaminated soil. Clean borrow soil will be removed from a nearby 
location for placement in voids, as feasible. The following subsections discuss Alternative 2 - Clean Closure for each CAS evaluated.

\subsubsection{Security Checkpoint Septic System (CAS 25-04-01)}

Alternative 2 includes removal and proper disposal of the liquid and sludge waste from the septic tank. The tank will be rinsed and the rinsate will be analyzed. The influent and effluent ends of the septic tank will be grouted. The septic tank will be filled with an inert material.

Should this alternative be chosen, this CAS will be closed in accordance with NAC 444.818 (NAC, 2000b) as described in this section.

\subsubsection{PAN-AM Trailers Septic System (CAS 25-04-03)}

Alternative 2 includes neutralization of fecal coliform present in the septic tank, and the removal and proper disposal of the liquid and sludge waste from the septic tank. The septic tank will be rinsed and the rinsate will be analyzed. The influent and effluent ends of the septic tank will be grouted. The septic tank will be filled with an inert material.

Should this alternative be chosen, this CAS will be closed in accordance with NAC 444.818 (NAC, 2000b) as described in this section.

\subsubsection{Reactor Control Point Septic System (CAS 25-04-04)}

Alternative 2 includes neutralization of fecal coliform present in the septic tank, the removal and proper disposal of the liquid and sludge waste from the septic tank, and excavating and disposing of subsurface soil with contamination above PALs upstream of the septic tank.

Liquid and sludge waste from the septic tank will be removed and properly disposed. The septic tank will be rinsed and the rinsate will be analyzed. The influent and effluent ends of the septic tank and distribution box will be grouted. The septic tank and distribution box will then be filled with an inert material.

Clean overburden soil will be removed, as feasible, from the surface grade to a depth of approximately $3.5 \mathrm{ft}$ (triangles $\mathrm{A}$ and $\mathrm{B}$ ) and $11.5 \mathrm{ft}$ (triangles $\mathrm{C}$ and $\mathrm{D}$ ) to expose the 
hydrocarbon-contaminated soil. Approximately $420 \mathrm{yd}^{3}$ of hydrocarbon-contaminated soil adjacent to the influent end of the septic tank will be removed. The triangular-shaped areas are described in Section 2.3.3.

A visual determination will be made to ensure that all contaminated soil has been removed, as applicable. Verification soil samples will also be collected and analyzed for area-specific COCs. This will ensure complete removal of contaminated soil with concentrations exceeding PALs.

Contaminated material will be disposed of at an appropriate disposal facility. All excavated areas will be returned to surficial conditions compatible with on-site maintenance operations. Overburden soil along with additional clean fill will be used to backfill the excavation after removal of the contaminated soil. Clean borrow soil will be removed from a nearby location for placement in voids, as feasible.

Should this alternative be chosen, this CAS will be closed in accordance with NAC 444.818 (NAC, 2000b) and NAC 445A (NAC, 2000c) as described in this section.

\subsubsection{BREN Tower Septic System (CAS 25-04-08)}

Alternative 2 includes removal and proper disposal of the liquid and sludge waste from the septic tank and excavation and disposal of soil with contamination above PALs.

Liquid and sludge waste from the septic tank will be removed and properly disposed. The septic tank will be rinsed and the rinsate will be analyzed. The influent and effluent ends of the septic tank will be grouted. The septic tank will be filled with an inert material.

Clean overburden soil will be removed, as feasible, from the surface grade to a depth of approximately $4 \mathrm{ft}$ to expose the contaminated soil. Approximately $3 \mathrm{yd}^{3}$ of radiologicalcontaminated soil underlying the southern portion of the leachfield will be removed.

A visual determination will be made to ensure that all contaminated soil has been removed, as applicable. Verification soil samples will also be collected and analyzed for area-specific COCs. This will ensure complete removal of contaminated soil with concentrations exceeding PALs. 
Contaminated material will be disposed of at an appropriate disposal facility. All excavated areas will be returned to surficial conditions compatible with on-site maintenance operations. Overburden soil, as feasible, along with additional clean fill will be used to backfill the excavation after removal of the contaminated soil. Clean borrow soil will be removed from a nearby location for placement in voids, as feasible.

Should this alternative be chosen, this CAS will be closed in accordance with NAC 444.818 (NAC, 2000b) and NAC 445A (NAC, 2000c) as described in this section.

\subsubsection{Engine Test Stand No. 1 Septic System (CAS 25-04-09)}

Alternative 2 includes removal and proper disposal of the sediment from the septic tank. The septic tank will be rinsed and the rinsate will be analyzed. The influent and effluent ends of the septic tank will be grouted. The septic tank will then be filled with an inert material.

Should this alternative be chosen, this CAS will be closed in accordance with NAC 444.818 (NAC, 2000b) as described in this section.

\subsubsection{South of LASL Trailers Septic System (CAS 25-04-11)}

Alternative 2 includes removal and proper disposal of the liquid and sludge waste from the septic tank and manhole. The septic tank and manhole will be rinsed and the rinsate will be analyzed. The influent and effluent ends of the septic tank and manhole will be grouted. The septic tank and manhole will then be filled with an inert material.

Should this alternative be chosen, this CAS will be closed in accordance with NAC 444.818 (NAC, 2000b) as described in this section.

\subsubsection{Port Gaston Training Area Contaminated Water Reservoir (CAS 26-03-01)}

Alternative 2 includes excavating and disposing of soil with radionuclide concentrations above PALs and the removal and disposal of material (i.e., liner) with surface contamination greater than the unrestricted release criteria. Approximately $50 \mathrm{yd}^{3}$ of contaminated soil above the liner will be removed and disposed. 
A visual determination will be made to ensure that all contaminated soil has been removed, as applicable. Verification soil samples will also be collected and analyzed for area-specific COCs. This will ensure complete removal of contaminated soil with concentrations exceeding PALs.

Contaminated material will be disposed of at an appropriate disposal facility. All excavated areas will be recontoured to restore the natural drainage. Additional clean fill will be used to backfill the excavations after removal of the contaminated soils, if necessary. Clean borrow soil will be removed from a nearby location for placement in voids, as feasible.

Should this alternative be chosen, this CAS will be closed in accordance with NAC 445A (NAC, 2000c) as described in this section.

\subsubsection{Area 26 Check Station, Building 2105, Septic System (CAS 26-04-01)}

Alternative 2 includes removal and proper disposal of the liquid and sludge waste from the septic tank and sediment from the distribution box.

Liquid and sludge waste from the septic tank and sediment from the distribution box will be removed and properly disposed. The septic tank and distribution box will be rinsed and the rinsate will be analyzed. The influent and effluent ends of the septic tank and distribution box will be grouted. The septic tank and distribution box will then be filled with an inert material.

This CAS will be closed in accordance with NAC 444.818 (NAC, 2000b) as described in this section.

\subsubsection{Hot Critical Facility, Building 2103, Septic System (CAS 26-04-02)}

Alternative 2 includes removal and proper disposal of the sediment waste from the septic tank. The septic tank will be rinsed and the rinsate will be analyzed. The influent and effluent ends of the septic tank and distribution box will be grouted. The septic tank and distribution box will then be filled with an inert material.

Should this alternative be chosen, this CAS will be closed in accordance with NAC 444.818 (NAC, 2000b) as described in this section. 


\subsubsection{Buildings 2201 and 2202 Radioactive Leachfield (CAS 26-05-01)}

Alternative 2 includes removal and disposal of the sediment located in Manhole 1 and excavation and disposal of soil with contamination above PALs.

The sediment contained within Manhole 1 will be properly disposed. The manhole will be rinsed and the rinsate will be analyzed. The influent and effluent ends of Manhole 1 and the distribution box will be grouted. The distribution box and Manhole 1 will be filled with an inert material. The distribution box and Manhole 1 must be closed in accordance with NAC 444.818 (NAC, 2000b).

Clean overburden soil will be removed, as feasible, from the surface grade to a depth of approximately $1.5 \mathrm{ft}$ to expose the contaminated soil. Approximately $24 \mathrm{yd}^{3}$ of radiological contaminated soil south of the distribution box in the leachfield will be removed.

A visual determination will be made to ensure that all contaminated soil has been removed, as applicable. Verification soil samples will also be collected and analyzed for area-specific COCs. This will ensure complete removal of contaminated soil with concentrations exceeding PALs.

Contaminated material will be disposed of at an appropriate disposal facility. All excavated areas will be returned to surficial conditions compatible with on-site maintenance operations. Overburden soil, along with additional clean fill, will be used to backfill the excavation after removal of the contaminated soil. Clean borrow soil will be removed from a nearby location for placement in voids, as feasible.

Should this alternative be chosen, this CAS will be closed in accordance with NAC 444.818 (NAC, 2000b) and NAC 445A (NAC, 2000c) as described in this section.

\subsubsection{Building 2203 Septic System (CAS 26-05-03)}

Alternative 2 includes removal and proper disposal of the sediment from the septic tank/manhole. The septic tank and manhole will be rinsed and the rinsate will be analyzed. The influent and effluent ends of the septic tank, distribution box, and manhole will be grouted. The septic tank, distribution box, and manhole will then be filled with an inert material. 
Should this alternative be chosen, this CAS will be closed in accordance with NAC 444.818 (NAC, 2000b) as described in this section.

\subsubsection{Building 2201 Septic System (CAS 26-05-04)}

Alternative 2 includes neutralization of fecal coliform present in the septic tank and the removal and proper disposal of the liquid and sludge waste from the septic tank. The septic tank will be rinsed and the rinsate will be analyzed. The influent and effluent ends of the septic tank and distribution box will be grouted. The septic tank and distribution box will then be filled with an inert material.

Should this alternative be chosen, this CAS will be closed in accordance with NAC 444.818 (NAC, 2000b) as described in this section.

\subsubsection{Building 2102, 2102, and 2107 Septic System (CAS 26-05-05)}

Alternative 2 includes removal and proper disposal of liquid, sludge, and sediment waste from the septic tanks and excavation and disposal of soil with contamination above PALs.

The liquid and sludge waste from the two septic tanks will be removed and properly disposed. The septic tanks will be rinsed and the rinsate will be analyzed. The influent and effluent ends of the two septic tanks and two distribution boxes will be grouted. The septic tanks and distribution boxes will then be filled with an inert material.

Approximately $26 \mathrm{yd}^{3}$ of hydrocarbon-contaminated soil underlying the leachfield will be removed. Clean overburden soil will be removed, as feasible, from the surface grade to a depth of approximately $4.5 \mathrm{ft}$ to expose the contaminated soil.

A visual determination will be made to ensure that all contaminated soil has been removed, as applicable. Verification soil samples will also be collected and analyzed for area-specific COCs. This will ensure complete removal of contaminated soil with concentrations exceeding PALs.

Contaminated material will be disposed of at an appropriate disposal facility. All excavated areas will be returned to surficial conditions compatible with on-site maintenance operations. Overburden soil, along with additional clean fill will be used to backfill the excavation after removal of the 
contaminated soil. Clean borrow soil will be removed from a nearby location for placement in voids, as feasible.

Should this alternative be chosen, this CAS will be closed in accordance with NAC 444.818 (NAC, 2000b) and NAC 445A (NAC, 2000c) as described in this section.

\subsubsection{Building 5200 Septic System (CAS 27-05-02)}

Alternative 2 includes removal and proper disposal of liquid and sludge waste from the septic tank and distribution box, and excavation and disposal of soil with contamination above PALs.

The liquid and sludge waste from the septic tank and distribution box will be removed and properly disposed. The septic tank and distribution box will be rinsed and the rinsate will be analyzed. The influent and effluent ends of the septic tank and distribution box will be grouted. The septic tank and distribution box will then be filled with an inert material. The septic tank and distribution box must be closed in accordance with NAC 444.818 (NAC, 2000b).

Approximately $461 \mathrm{yd}^{3}$ of PCB contaminated surface and subsurface soil within the fenced leachfield boundary will be removed. A visual determination will be made to ensure that all contaminated soil has been removed, as applicable. Verification soil samples will also be collected and analyzed for area-specific COCs. This will ensure complete removal of contaminated soil with concentrations exceeding PALs.

Contaminated material will be disposed of at an appropriate disposal facility. All excavated areas will be returned to surficial conditions compatible with on-site maintenance operations. Overburden soil, along with additional clean fill, will be used to backfill the excavation after removal of the contaminated soil. Clean borrow soil will be removed from a nearby location for placement in voids, as feasible.

Should this alternative be chosen, this CAS will be closed in accordance with NAC 444.818 (NAC, 2000b) and NAC 445A (NAC, 2000c) as described in this section. 


\subsubsection{Alternative 3 - Close in Place with Administrative Controls}

Alternative 3 will use administrative controls to prevent inadvertent contact with COCs and contaminated media with activity exceeding the unrestricted release criteria. These controls would consist of use restrictions to minimize access and prevent unauthorized intrusive activities (e.g., fencing, signage). The future use of the CAU would be restricted from any activity that would alter or modify the containment control unless appropriate concurrence was obtained from the NDEP.

This alternative does not apply to septic tanks at CASs 25-04-04 (outlet chamber - mixed waste), 26-04-01 (low level waste), 26-05-05 (septic tank 2 - mixed waste), and 27-05-02 (PCB, hydrocarbon, and radiologically impacted media); the manhole at CAS 26-05-01 (mixed waste); and distribution boxes at CAS 27-05-02 (PCB, hydrocarbon, and radiologically impacted media) and CAS 26-04-01. If a hazardous component is present within the septic tank, distribution box, or manhole contents, the hazardous component must be removed, and closure in place is not an option. The following subsections discuss Alternative 3, Closure in Place with Administrative Controls, for each CAS evaluated.

\subsubsection{Security Checkpoint Septic System (CAS 25-04-01)}

Alternative 3 includes solidification of the septic tank contents. After solidification is complete, the septic tank will be filled with an inert material that will effectively seal the tank openings.

Administrative controls would consist of use restrictions to prevent unauthorized intrusive activities. The future use of the CAS would be restricted from any activity that would alter or modify the containment control unless appropriate concurrence was obtained from the NDEP. The combination of these measures will effectively prevent inadvertent intrusive activities by humans and native wildlife and mobilization of COCs.

The following evaluation of NAC 445A.227 (2) (a-k) (NAC, 2000c) supports the protection of groundwater from COCs at this CAS:

a. Depth to groundwater at the nearest well (J-11) is approximately 1,040 ft bgs (USGS, 1995). This well is located $2 \mathrm{mi}$ southwest of the CAS. Groundwater flow is generally to the southwest and may discharge at Ash Meadows (SNPO, 1970). 
b. The distance to the nearest active water-supply well, Well J-12, is $7.5 \mathrm{mi}$ southwest of the site (DOE/NV, 1998a). Well J-12 is primarily used to provide potable water for Area 25. Groundwater flow is generally to the southwest (Laczniak et al., 1996).

c. There is no soil contamination at this site.

d. Average annual precipitation for valleys in the South-Central Great Basin ranges from 3 to 6 in. (Winograd and Thordarson, 1975). Annual evaporation is roughly 5 to 25 times the annual precipitation (Winograd and Thordarson, 1975). The high evaporation and low precipitation rates create a negative water balance for the area; therefore, no driving force associated with precipitation is available to mobilize COCs vertically.

e. Total petroleum hydrocarbons are contained within the septic tank.

f. The contaminants are contained within the septic tank.

g. Presently, CAS 25-04-01 is located on a government-controlled facility. The NTS is a restricted area that is guarded on a 24-hour, 365 day-per-year basis; unauthorized personnel are not admitted to the facility. CAS 25-04-01 is contained within a restricted use zone classified as a "Research Test and Experiment Zone" (DOE/NV, 1998a). This zone is designated for small-scale research and development projects and demonstrations; pilot projects; outdoor test; and experiments for development, quality assurance, or reliability of material and equipment under controlled conditions. This includes compatible nondefense research, development and testing projects, and activities (DOE/NV, 1998a).

h. Preferred routes of vertical and lateral migration are nonexistent since the sources have been eliminated and driving forces are not viable.

i. See Section 2.3.1 for site-specific considerations.

j. The potential for a hazard related to fire, vapor, or explosion is nonexistent for the COCs at the site.

k. No other site-specific factors are known at this site.

Based on this evaluation, impacts to groundwater are not expected. Therefore, groundwater monitoring is not proposed for this site and is not considered an element of the alternatives.

\subsubsection{PAN-AM Trailers Septic System (CAS 25-04-03)}

Alternative 3 includes solidification of the septic tank contents. After solidification is complete, the septic tank will be filled with an inert material that will effectively seal the tank openings. Administrative controls would consist of use restrictions to prevent unauthorized intrusive activities. 
The future use of the CAS would be restricted from any activity that would alter or modify the containment control unless appropriate concurrence was obtained from the NDEP. The combination of these measures will effectively prevent inadvertent intrusive activities by humans and native wildlife and mobilization of COCs.

The following evaluation of NAC 445A.227 (2) (a-k) (NAC, 2000c) supports the protection of groundwater from COCs at this CAS:

a. Depth to groundwater at the nearest well (J-11) is approximately 1,040 ft bgs (USGS, 1995). This well is located 2.6 mi south of the CAS. Groundwater flow is generally to the southwest and may discharge at Ash Meadows (SNPO, 1970).

b. The distance to the nearest active water-supply well, Well J-12, is $7 \mathrm{mi}$ southwest of the site (DOE/NV, 1998a). Well J-12 is primarily used to provide potable water for Area 25. Groundwater flow is generally to the southwest (Laczniak et al., 1996).

c. There is no soil contamination at this site.

d. Average annual precipitation for valleys in the South-Central Great Basin ranges from 3 to 6 in. (Winograd and Thordarson, 1975). Annual evaporation is roughly 5 to 25 times the annual precipitation (Winograd and Thordarson, 1975). The high evaporation and low precipitation rates create a negative water balance for the area; therefore, no driving force associated with precipitation is available to mobilize COCs vertically.

e. Total petroleum hydrocarbons are contained within the septic tank.

f. The contaminants are contained within the septic tank.

g. Presently, CAS 25-04-03 is located on a government-controlled facility. The NTS is a restricted area that is guarded on a 24-hour, 365 day-per-year basis; unauthorized personnel are not admitted to the facility. CAS 25-04-03 is contained within a restricted use zone classified as a "Research Test and Experiment Zone" (DOE/NV, 1998a). This zone is designated for small-scale research and development projects and demonstrations; pilot projects; outdoor test; and experiments for development, quality assurance, or reliability of material and equipment under controlled conditions. This includes compatible nondefense research, development and testing projects, and activities (DOE/NV, 1998a).

h. Preferred routes of vertical and lateral migration are nonexistent since the sources have been eliminated and driving forces are not viable.

i. See Section 2.3.2 for site-specific considerations. 
j. The potential for a hazard related to fire, vapor, or explosion is nonexistent for the COCs at the site.

k. No other site-specific factors are known at this site.

Based on this evaluation, impacts to groundwater are not expected. Therefore, groundwater monitoring is not proposed for this site and is not considered an element of the alternatives.

\subsubsection{Reactor Control Point Septic System (CAS 25-04-04)}

Under Alternative 3, administrative controls will be implemented to restrict inadvertent contact with subsurface-contaminated soil in the leachfield and solidification of the inlet chamber septic tank contents. The outlet chamber septic tank contents (mixed waste) must be removed as described in Alternative 2 (Section 3.3.2.3). After solidification of the inlet chamber contents is complete, the septic tank will be filled with an inert material that will effectively seal the tank openings. These controls would consist of use restrictions to minimize access and prevent unauthorized intrusive activities (e.g., fencing, signage). Administrative controls with long-term monitoring will be required for the contaminated materials closed in place.

Additional measures under this alternative include closing the distribution box as outlined in Section 2.3.3. The future use of the CAS would be restricted from any activity that would alter or modify the containment control unless appropriate concurrence was obtained from the NDEP.

The combination of these measures will effectively prevent inadvertent intrusive activities by humans and native wildlife and mobilization of COCs.

The following evaluation of NAC 445A.227 (2) (a-k) (NAC, 2000c) supports the protection of groundwater from COCs at this CAS:

a. Depth to groundwater at the nearest well (J-11) is approximately 1,040 ft bgs (USGS, 1995). This well is located $2.6 \mathrm{mi}$ southeast of the CAS. Groundwater flow is generally to the southwest and may discharge at Ash Meadows (SNPO, 1970). Analytical data indicate that COCs are confined primarily within 4 to $14 \mathrm{ft}$ below the base of the influent end of the septic tank and within the septic tank. This indicates minimal vertical migration has occurred in the 
past, and with the removal of the man-made driving forces, vertical migration will be negligible in the future.

b. The distance to the nearest active water-supply well, Well J-12, is $7 \mathrm{mi}$ southwest of the site (DOE/NV, 1998a). Well J-12 is primarily used to provide potable water for Area 25. Groundwater flow is generally to the southwest (Laczniak et al., 1996).

c. The soil was a combination of alluvial, colluvial, and volcanic rocks of Cenozoic age. The soil appeared as a light brown, fine to silty sand with medium and small-sized gravels. No geotechnical tests were conducted on the soil.

d. Average annual precipitation for valleys in the South-Central Great Basin ranges from 3 to 6 in. (Winograd and Thordarson, 1975). Annual evaporation is roughly 5 to 25 times the annual precipitation (Winograd and Thordarson, 1975). The high evaporation and low precipitation rates create a negative water balance for the area; therefore, no driving force associated with precipitation is available to mobilize COCs vertically.

e. Total petroleum hydrocarbons are contained within the septic tank. The mixed waste present in the outlet chamber must be removed as described in Section 3.3.2.3. The types of regulated substances released within the soil include TPH. Downward migration of COCs is slowed by the following parameters:

- Volume of release - it is assumed that small volumes of COCs were released over a long period of time rather than a large volume over a short duration.

- Soil saturation - the soil tends to be very dry, especially near the surface and shallow subsurface where the COCs are concentrated.

- Soil particle adsorption/desorption - petroleum hydrocarbons tend to adsorb to the soil particles with little desorption as suggested by the limited vertical migration of COCs.

f. The lateral extent of the soil contamination is defined by analytical data indicating the lack of contamination found in the nearby sampling locations, thereby demonstrating minimal lateral mobility. Contaminant concentrations below the upper sampling horizons were significantly lower, demonstrating minimal vertical migration. The vertical extent of contamination is confined to $14 \mathrm{ft}$ bgs based on analytical data.

g. Presently, CAS 25-04-04 is located on a government-controlled facility. The NTS is a restricted area that is guarded on a 24-hour, 365 day-per-year basis; unauthorized personnel are not admitted to the facility. CAS 25-04-04 is contained within a restricted use zone classified as a "Research Test and Experiment Zone" (DOE/NV, 1998a). This zone is designated for small-scale research and development projects and demonstrations; pilot projects; outdoor test; and experiments for development, quality assurance, or reliability of material and equipment under controlled conditions. This includes compatible nondefense research, development and testing projects, and activities (DOE/NV, 1998a). 
h. Preferred routes of vertical and lateral migration are nonexistent since the sources have been eliminated and driving forces are not viable.

i. See Section 2.3.3 for site-specific considerations.

j. The potential for a hazard related to fire, vapor, or explosion is nonexistent for the COCs at the site.

k. No other site-specific factors are known at this site.

Based on this evaluation, impacts to groundwater are not expected. Therefore, groundwater monitoring is not proposed for this site and is not considered an element of the alternatives.

\subsubsection{BREN Tower Septic System (CAS 25-04-08)}

Under Alternative 3, administrative controls will be implemented to restrict inadvertent contact with subsurface contaminated soil in the leachfield. These controls would consist of use restrictions to minimize access and prevent unauthorized intrusive activities.

Alternative 3 also includes solidification of the septic tank contents. After solidification is complete, the septic tank will be filled with an inert material that will effectively seal the tank openings. Administrative controls would consist of use restrictions to prevent unauthorized intrusive activities (e.g., fencing, signage). Administrative controls with long-term monitoring will be required for the contaminated materials closed in place. The future use of the CAS would be restricted from any activity that would alter or modify the containment control unless appropriate concurrence was obtained from the NDEP.

The combination of these measures will effectively prevent inadvertent intrusive activities by humans and native wildlife and mobilization of COCs.

The following evaluation of NAC 445A.227 (2) (a-k) (NAC, 2000c) supports the protection of groundwater from COCs at this CAS:

a. Depth to groundwater at the nearest well (J-11) is approximately 1,040 ft bgs (USGS, 1995). This well is located $3.3 \mathrm{mi}$ west-southwest of the CAS. Groundwater flow is generally to the southwest and may discharge at Ash Meadows (SNPO, 1970). Analytical data indicate that COCs are confined within the southern portion of the leachfield at a depth between 3.5 to 
$5.6 \mathrm{ft}$ bgs. This indicates minimal vertical migration has occurred in the past, and with the removal of the man-made driving forces, vertical migration will be negligible in the future.

b. The distance to the nearest active water-supply well, Well J-12, is $10 \mathrm{mi}$ west-southwest of the site (DOE/NV, 1998a). Well J-12 is primarily used to provide potable water for Area 25. Groundwater flow is generally to the southwest (Laczniak et al., 1996).

c. The soil was a combination of alluvial, colluvial, and volcanic rocks of Cenozoic age. The soil appeared as a consolidated silty sand, light brown to grey in color. No geotechnical tests were conducted on the soil.

d. Average annual precipitation for valleys in the South-Central Great Basin ranges from 3 to 6 in. (Winograd and Thordarson, 1975). Annual evaporation is roughly 5 to 25 times the annual precipitation (Winograd and Thordarson, 1975). The high evaporation and low precipitation rates create a negative water balance for the area; therefore, no driving force associated with precipitation is available to mobilize COCs vertically.

e. Total petroleum hydrocarbons are contained within the septic tank. The types of regulated substances released within the leachfield include limited radionuclides. Downward migration of COCs is slowed by the following parameters:

- Volume of release - it is assumed that small volumes of COCs were released over a long period of time rather than a large volume over a short duration.

- Soil saturation - the soil tends to be very dry, especially near the surface and shallow subsurface where the COCs are concentrated.

- Soil particle adsorption/desorption - radionuclides tend to adsorb to the soil particles with little desorption as suggested by the limited vertical migration of COCs.

f. The lateral extent of contamination is defined by analytical data showing the lack of contamination found in nearby sampling locations, thereby demonstrating minimal lateral mobility. Contaminant concentrations below the upper sampling horizons were significantly lower, demonstrating minimal vertical migration. The vertical extent of contamination is confined to $5.6 \mathrm{ft}$ bgs based on analytical data.

g. Presently, CAS 25-04-08 is located on a government-controlled facility. The NTS is a restricted area that is guarded on a 24-hour, 365 day-per-year basis; unauthorized personnel are not admitted to the facility. CAS 25-04-08 is contained within a restricted use zone classified as a "Research Test and Experiment Zone" (DOE/NV, 1998a). This zone is designated for small-scale research and development projects and demonstrations; pilot projects; outdoor test; and experiments for development, quality assurance, or reliability of material and equipment under controlled conditions. This includes compatible nondefense research, development and testing projects, and activities (DOE/NV, 1998a). 
h. Preferred routes of vertical and lateral migration are nonexistent since the sources have been eliminated and driving forces are not viable.

i. See Section 2.3.4 for site-specific considerations.

j. The potential for a hazard related to fire, vapor, or explosion is nonexistent for the COCs at the site.

k. No other site-specific factors are known at this site.

Based on this evaluation, impacts to groundwater are not expected. Therefore, groundwater monitoring is not proposed for this site and is not considered an element of the alternatives.

\subsubsection{Engine Test Stand No. 1 Septic System (CAS 25-04-09)}

Alternative 3 includes solidification of the septic tank contents. After solidification is completed, the septic tank will be filled with an inert material that will effectively seal the tank openings.

Administrative controls would consist of use restrictions to prevent unauthorized intrusive activities.

The future use of the CAS would be restricted from any activity that would alter or modify the containment control unless appropriate concurrence was obtained from the NDEP. The combination of these measures will effectively prevent inadvertent intrusive activities by humans and native wildlife and mobilization of COCs.

The following evaluation of NAC 445A.227 (2) (a-k) (NAC, 2000c) supports the protection of groundwater from COCs at this CAS:

a. Depth to groundwater at the nearest well (J-11) is approximately 1,040 ft bgs (USGS, 1995). This well is located $4.5 \mathrm{mi}$ southeast of the CAS. Groundwater flow is generally to the southwest and may discharge at Ash Meadows (SNPO, 1970).

b. The distance to the nearest active water-supply well, Well J-13, is $5 \mathrm{mi}$ west of the site (DOE/NV, 1998a). Well J-13 is primarily used to provide potable water for Area 25. Groundwater flow is generally to the southwest (Laczniak et al., 1996).

c. There is no soil contamination at this site.

d. Average annual precipitation for valleys in the South-Central Great Basin ranges from 3 to 6 in. (Winograd and Thordarson, 1975). Annual evaporation is roughly 5 to 25 times the annual precipitation (Winograd and Thordarson, 1975). The high evaporation and low 
precipitation rates create a negative water balance for the area; therefore, no driving force associated with precipitation is available to mobilize COCs vertically.

e. Total petroleum hydrocarbons are contained within the septic tank.

f. The contaminants are contained within the septic tank.

g. Presently, CAS 25-04-09 is located on a government-controlled facility. The NTS is a restricted area that is guarded on a 24-hour, 365 day-per-year basis; unauthorized personnel are not admitted to the facility. CAS 25-04-09 is contained within a restricted use zone classified as a "Research Test and Experiment Zone" (DOE/NV, 1998a). This zone is designated for small-scale research and development projects and demonstrations; pilot projects; outdoor test; and experiments for development, quality assurance, or reliability of material and equipment under controlled conditions. This includes compatible nondefense research, development and testing projects, and activities (DOE/NV, 1998a).

h. Preferred routes of vertical and lateral migration are nonexistent since the sources have been eliminated and driving forces are not viable.

i. See Section 2.3.5 for site-specific considerations.

j. The potential for a hazard related to fire, vapor, or explosion is nonexistent for the COCs at the site.

k. No other site-specific factors are known at this site.

Based on this evaluation, impacts to groundwater are not expected. Therefore, groundwater monitoring is not proposed for this site and is not considered an element of the alternatives.

\subsubsection{South of LASL Trailers Septic System (CAS 25-04-11)}

Alternative 3 includes solidification of the septic tank/manhole contents. After solidification is completed, the septic tank and manhole will be filled with an inert material that will effectively seal the tank and manhole openings. Administrative controls would consist of use restrictions to prevent unauthorized intrusive activities. The future use of the CAS would be restricted from any activity that would alter or modify the containment control unless appropriate concurrence was obtained from the NDEP. The combination of these measures will effectively prevent inadvertent intrusive activities by humans and native wildlife and mobilization of COCs. 
The following evaluation of NAC 445A.227 (2) (a-k) (NAC, 2000c) supports the protection of groundwater from COCs at this CAS:

a. Depth to groundwater at the nearest well (J-11) is approximately 1,040 ft bgs (USGS, 1995). This well is located $2.5 \mathrm{mi}$ southwest of the CAS. Groundwater flow is generally to the southwest and may discharge at Ash Meadows (SNPO, 1970).

b. The distance to the nearest active water-supply well, Well J-12, is $7 \mathrm{mi}$ southwest of the site (DOE/NV, 1998a). Well J-12 is primarily used to provide potable water for Area 25. Groundwater flow is generally to the southwest (Laczniak et al., 1996).

c. There is no soil contamination at this site.

d. Average annual precipitation for valleys in the South-Central Great Basin ranges from 3 to 6 in. (Winograd and Thordarson, 1975). Annual evaporation is roughly 5 to 25 times the annual precipitation (Winograd and Thordarson, 1975). The high evaporation and low precipitation rates create a negative water balance for the area; therefore, no driving force associated with precipitation is available to mobilize COCs vertically.

e. Total petroleum hydrocarbons are contained within the septic tank and manhole.

f. The contaminants are contained within the septic tank and manhole.

g. Presently, CAS 25-04-11 is located on a government-controlled facility. The NTS is a restricted area that is guarded on a 24-hour, 365 day-per-year basis; unauthorized personnel are not admitted to the facility. CAS 25-04-11 is contained within a restricted use zone classified as a "Research Test and Experiment Zone" (DOE/NV, 1998a). This zone is designated for small-scale research and development projects and demonstrations; pilot projects; outdoor test; and experiments for development, quality assurance, or reliability of material and equipment under controlled conditions. This includes compatible nondefense research, development and testing projects, and activities (DOE/NV, 1998a).

h. Preferred routes of vertical and lateral migration are nonexistent since the sources have been eliminated and driving forces are not viable.

i. See Section 2.3.7 for site-specific considerations.

j. The potential for a hazard related to fire, vapor, or explosion is nonexistent for the COCs at the site.

k. No other site-specific factors are known at this site. 
Based on this evaluation, impacts to groundwater are not expected. Therefore, groundwater monitoring is not proposed for this site and is not considered an element of the alternatives.

\subsubsection{Port Gaston Training Area Contaminated Water Reservoir (CAS 26-03-01)}

Alternative 3 includes an engineered surface cap that will be constructed over the reservoir and extend to the boundaries of the reservoir. In addition, the drainage will be redirected within the wash, as feasible, to minimize erosion of the engineered cover. Administrative controls will be implemented to restrict inadvertent contact with contaminated soil within the reservoir. Administrative controls would consist of use restrictions to prevent unauthorized intrusive activities and impose long-term maintenance requirements for the surface cap. The future of the CAS would be restricted from any activity that would alter or modify the containment control unless appropriate concurrence was obtained from NDEP. The combination of these measures will effectively prevent inadvertent intrusive activities by humans and native wildlife and mobilization of COCs.

The following evaluation of NAC 445A.227 (2) (a-k) (NAC, 2000c) supports the protection of groundwater from COCs at this CAS:

a. Perched groundwater occurs in highly fractured and altered rock and may extend to a depth of $261 \mathrm{ft}$ bgs before encountering a low-permeable confining layer. Depth to perched groundwater ranges from 81 to $167 \mathrm{ft}$ bgs (Johnson and Ege, 1964). Depth to the regional groundwater table in Area 26 is about 1,700 ft bgs (DRI, 1988). Analytical data indicate that COCs are confined to the soil in the water reservoir basin above the plastic liner. This indicates minimal vertical migration has occurred in the past and with the removal of man-made driving forces, vertical migration will be negligible in the future.

b. The nearest water-supply well, Well 4a, is approximately $10 \mathrm{mi}$ northeast of the site (DOE/NV, 1998a). Well 4a is primarily used to provide potable water for Area 6.

c. The soil above the plastic liner was a combination of alluvial and colluvial that appears as dry, light brown silt. The soil beneath the liner is light brown, silty sand with small gravels. No geotechnical tests were conducted on the soil.

d. Average annual precipitation for valleys in the South-Central Great Basin ranges from 3 to 6 in. (Winograd and Thordarson, 1975). Annual evaporation is roughly 5 to 25 times the annual precipitation (Winograd and Thordarson, 1975). The high evaporation and low precipitation rates create a negative water balance for the area; therefore, no driving force associated with precipitation is available to mobilize COCs vertically. 
e. The types of regulated substances released include radionuclides (lead-214, thorium-227 [and by association, actinium-227]). Downward migration of COCs is slowed by the 30-mil plastic liner located approximately $0.5 \mathrm{ft}$ bgs.

- Volume of release - it is assumed that small volumes of COCs were released over a short period of time.

- Soil saturation - the soil tends to be very dry, especially near the surface where the COCs are concentrated.

- Soil particle adsorption/desorption - radionuclides tend to adsorb to the soil particles with little desorption as suggested by the limited vertical migration of COCs.

f. The lateral and vertical extent of contamination was limited due to the presence of the 30-mil plastic liner.

g. Presently, CAS 26-03-01 is located on a government-controlled facility. The NTS is a restricted area that is guarded on a 24-hour, 365 day-per-year basis; unauthorized personnel are not admitted to the facility. CAS 26-03-01 is contained within a restricted use zone classified as a "Research Test and Experiment Zone" (DOE/NV, 1998a). This zone is designated for small-scale research and development projects and demonstrations; pilot projects; outdoor test; and experiments for development, quality assurance, or reliability of material and equipment under controlled conditions. This includes compatible nondefense research, development and testing projects, and activities (DOE/NV, 1998a).

h. Small holes were placed in the liner during sampling activities. After sampling at each location was completed, the hole was covered with 6-mil plastic and additional soil was placed on top as an anchor. Preferred routes of vertical and lateral migration are nonexistent since the sources have been eliminated and driving forces are not viable.

i. See Section 2.3.8 for site-specific considerations.

j. The potential for a hazard related to fire, vapor, or explosion is nonexistent for the COCs at the site.

k. No other site-specific factors are known at this site.

Based on this evaluation, impacts to groundwater are not expected. Therefore, groundwater monitoring is not proposed for this site and is not considered an element of the alternatives. 


\subsubsection{Hot Critical Facility, Building 2103, Septic System (CAS 26-04-02)}

Alternative 3 includes solidification of the septic tank contents. After solidification is complete, the septic tank will be filled with an inert material that will effectively seal the tank openings.

Administrative controls would consist of use restrictions to prevent unauthorized intrusive activities.

Additional measures under this alternative include closing the distribution box as outlined in Section 2.3.10. The future use of the CAS would be restricted from any activity that would alter or modify the containment control unless appropriate concurrence was obtained from the NDEP.

The combination of these measures will effectively prevent inadvertent intrusive activities by humans and native wildlife and mobilization of COCs.

The following evaluation of NAC 445A.227 (2) (a-k) (NAC, 2000c) supports the protection of groundwater from COCs at this CAS:

a. Perched groundwater occurs in highly fractured and altered rock and may extend to a depth of $261 \mathrm{ft}$ bgs before encountering a low-permeable confining layer. Depth to perched groundwater ranges from 81 to $167 \mathrm{ft}$ bgs (Johnson and Ege, 1964). Depth to regional groundwater table in Area 26 is about 1,700 ft bgs (DRI, 1988).

b. The nearest water-supply well, Well 4a, is approximately $10 \mathrm{mi}$ northeast of the site (DOE/NV, 1998a). Well 4a is primarily used to provide potable water for Area 6.

c. There is no soil contamination at this site.

d. Average annual precipitation for valleys in the South-Central Great Basin ranges from 3 to $6 \mathrm{in}$. (Winograd and Thordarson, 1975). Annual evaporation is roughly 5 to 25 times the annual precipitation (Winograd and Thordarson, 1975). The high evaporation and low precipitation rates create a negative water balance for the area; therefore, no driving force associated with precipitation is available to mobilize COCs vertically.

e. Total petroleum hydrocarbons are contained within the septic tank.

f. The contaminants are contained within the septic tank.

g. Presently, CAS 26-04-02 is located on a government-controlled facility. The NTS is a restricted area that is guarded on a 24-hour, 365 day-per-year basis; unauthorized personnel are not admitted to the facility. CAS 26-04-02 is contained within a restricted use zone classified as a "Research Test and Experiment Zone" (DOE/NV, 1998a). This zone is 
designated for small-scale research and development projects and demonstrations; pilot projects; outdoor test; and experiments for development, quality assurance, or reliability of material and equipment under controlled conditions. This includes compatible nondefense research, development and testing projects, and activities (DOE/NV, 1998a).

h. Preferred routes of vertical and lateral migration are nonexistent since the sources have been eliminated and driving forces are not viable.

i. See Section 2.3.10 for site-specific considerations.

j. The potential for a hazard related to fire, vapor, or explosion is nonexistent for the COCs at the site.

k. No other site-specific factors are known at this site.

Based on this evaluation, impacts to groundwater are not expected. Therefore, groundwater monitoring is not proposed for this site and is not considered an element of the alternatives.

\subsubsection{Buildings 2201 and 2202 Radioactive Leachfield (CAS 26-05-01)}

Under Alternative 3, administrative controls will be implemented to restrict inadvertent contact with subsurface-contaminated soil in the leachfield. These controls would consist of use restrictions to minimize access and prevent unauthorized intrusive activities (e.g., fencing, signage). Administrative controls with long-term monitoring will be required for the contaminated materials closed in place.

Additional measures under this alternative include closing the distribution box as outlined in Section 2.3.11. The sediment in the manhole must be removed as outlined in Section 3.3.2.10. The future use of the CAS would be restricted from any activity that would alter or modify the containment control unless appropriate concurrence was obtained from the NDEP.

The combination of these measures will effectively prevent inadvertent intrusive activities by humans and native wildlife and mobilization of COCs.

The following evaluation of NAC 445A.227 (2) (a-k) (NAC, 2000c) supports the protection of groundwater from COCs at this CAS:

a. Perched groundwater occurs in highly fractured and altered rock and may extend to a depth of $261 \mathrm{ft}$ bgs before encountering a low-permeable confining layer. Depth to perched 
groundwater ranges from 81 to $167 \mathrm{ft}$ bgs (Johnson and Ege, 1964). Depth to the regional groundwater table in Area 26 is about 1,700 ft bgs (DRI, 1988). Analytical data indicate that COCs are confined primarily within 2 to $4.5 \mathrm{ft}$ bgs in the leachfield soil south of the distribution box. This indicates minimal vertical migration has occurred in the past, and with the removal of the man-made driving forces, vertical migration will be negligible in the future.

b. The nearest water-supply well, Well $4 \mathrm{a}$, is approximately $10 \mathrm{mi}$ northeast of the site (DOE/NV, 1998a). Well 4a is primarily used to provide potable water for Area 6.

c. The soil was a combination of alluvial and colluvial material. It varied in appearance from silty to course sand with no gravels or with pebble sized gravels. No geotechnical tests were conducted on the soil.

d. Average annual precipitation for valleys in the South-Central Great Basin ranges from 3 to 6 in. (Winograd and Thordarson, 1975). Annual evaporation is roughly 5 to 25 times the annual precipitation (Winograd and Thordarson, 1975). The high evaporation and low precipitation rates create a negative water balance for the area; therefore, no driving force associated with precipitation is available to mobilize COCs vertically.

e. The types of regulated substances released within the leachfield include U-234, U-235, and $\mathrm{Pu}-239$. Downward migration of COCs is slowed by the following parameters:

- Volume of release - it is assumed that small volumes of COCs were released over a long period of time rather than a large volume over a short duration.

- Soil saturation - the soil tends to be very dry, especially near the surface and shallow subsurface where the COCs are concentrated.

- Soil particle adsorption/desorption - radionuclides tend to adsorb to the soil particles with little desorption as suggested by the limited vertical migration of COCs.

f. The lateral extent of leachfield contamination is defined by analytical data showing the lack of contamination found in nearby sampling locations, thereby demonstrating minimal lateral mobility. Analytical data show that COCs are confined within the at a depth between 2 and $4.5 \mathrm{ft}$ bgs. This indicates minimal vertical migration has occurred in the past, and with the removal of the man-made driving forces, vertical migration will be negligible in the future.

g. Presently, CAS 26-05-01 is located on a government-controlled facility. The NTS is a restricted area that is guarded on a 24-hour, 365 day-per-year basis; unauthorized personnel are not admitted to the facility. CAS 26-05-01 is contained within a restricted use zone classified as a "Research Test and Experiment Zone" (DOE/NV, 1998a). This zone is designated for small-scale research and development projects and demonstrations; pilot projects; outdoor test; and experiments for development, quality assurance, or reliability of 
material and equipment under controlled conditions. This includes compatible nondefense research, development and testing projects, and activities (DOE/NV, 1998a).

h. Preferred routes of vertical and lateral migration are nonexistent since the sources have been eliminated and driving forces are not viable.

i. See Section 2.3.11 for site-specific considerations.

j. The potential for a hazard related to fire, vapor, or explosion is nonexistent for the COCs at the site.

k. No other site-specific factors are known at this site.

Based on this evaluation, impacts to groundwater are not expected. Therefore, groundwater monitoring is not proposed for this site and is not considered an element of the alternatives.

\subsubsection{Building 2203 Septic System (CAS 26-05-03)}

Alternative 3 includes solidification of the septic tank/manhole contents. After solidification is complete, the septic tank and manhole will be filled with an inert material that will effectively seal the tank and manhole openings. Administrative controls would consist of use restrictions to prevent unauthorized intrusive activities.

Additional measures under this alternative include closing the distribution box as outlined in Section 2.3.12. The future use of the CAS would be restricted from any activity that would alter or modify the containment control unless appropriate concurrence was obtained from the NDEP.

The combination of these measures will effectively prevent inadvertent intrusive activities by humans and native wildlife and mobilization of COCs.

The following evaluation of NAC 445A.227 (2) (a-k) (NAC, 2000c) supports the protection of groundwater from COCs at this CAS:

a. Perched groundwater occurs in highly fractured and altered rock and may extend to a depth of $261 \mathrm{ft}$ bgs before encountering a low-permeable confining layer. Depth to perched 
groundwater ranges from 81 to $167 \mathrm{ft}$ bgs (Johnson and Ege, 1964). Depth to the regional groundwater table in Area 26 is about 1,700 ft below the surface (DRI, 1988).

b. The nearest water-supply well, Well 4a, is approximately 9 mi northeast of the site (DOE/NV, 1998a). Well 4a is primarily used to provide potable water for Area 6.

c. There is no soil contamination at this site.

d. Average annual precipitation for valleys in the South-Central Great Basin ranges from 3 to 6 in. (Winograd and Thordarson, 1975). Annual evaporation is roughly 5 to 25 times the annual precipitation (Winograd and Thordarson, 1975). The high evaporation and low precipitation rates create a negative water balance for the area; therefore, no driving force associated with precipitation is available to mobilize COCs vertically.

e. Total petroleum hydrocarbons are present within the septic tank/manhole.

f. The contaminants are contained within the septic tank/manhole.

g. Presently, CAS 26-05-03 is located on a government-controlled facility. The NTS is a restricted area that is guarded on a 24-hour, 365 day-per-year basis; unauthorized personnel are not admitted to the facility. CAS 26-05-03 is contained within a restricted use zone classified as a "Research Test and Experiment Zone" (DOE/NV, 1998a). This zone is designated for small-scale research and development projects and demonstrations; pilot projects; outdoor test; and experiments for development, quality assurance, or reliability of material and equipment under controlled conditions. This includes compatible nondefense research, development and testing projects, and activities (DOE/NV, 1998a).

h. Preferred routes of vertical and lateral migration are nonexistent since the sources have been eliminated and driving forces are not viable.

i. See Section 2.3.12 for site-specific considerations.

j. The potential for a hazard related to fire, vapor, or explosion is nonexistent for the COCs at the site.

k. No other site-specific factors are known at this site.

Based on this evaluation, impacts to groundwater are not expected. Therefore, groundwater monitoring is not proposed for this site and is not considered an element of the alternatives. 


\subsubsection{Building 2201 Septic System (CAS 26-05-04)}

Alternative 3 includes solidification of the septic tank contents. After solidification is complete, the septic tank will be filled with an inert material that will effectively seal the tank openings.

Administrative controls would consist of use restrictions to prevent unauthorized intrusive activities.

Additional measures under this alternative include closing the distribution box as outlined in Section 2.3.13. The future use of the CAS would be restricted from any activity that would alter or modify the containment control unless appropriate concurrence was obtained from the NDEP. The combination of these measures will effectively prevent inadvertent intrusive activities by humans and native wildlife and mobilization of COCs.

The following evaluation of NAC 445A.227 (2) (a-k) (NAC, 2000c) supports the protection of groundwater from COCs at this CAS:

a. Perched groundwater occurs in highly fractured and altered rock and may extend to a depth of $261 \mathrm{ft}$ bgs before encountering a low-permeable confining layer. Depth to perched groundwater ranges from 81 to $167 \mathrm{ft}$ bgs (Johnson and Ege, 1964). Depth to the regional groundwater table in Area 26 is about 1,700 ft below the surface (DRI, 1988).

b. The nearest water-supply well, Well $4 \mathrm{a}$, is approximately $10 \mathrm{mi}$ northeast of the site (DOE/NV, 1998a). Well 4a is primarily used to provide potable water for Area 6.

c. There is no soil contamination at this site.

d. Average annual precipitation for valleys in the South-Central Great Basin ranges from 3 to 6 in. (Winograd and Thordarson, 1975). Annual evaporation is roughly 5 to 25 times the annual precipitation (Winograd and Thordarson, 1975). The high evaporation and low precipitation rates create a negative water balance for the area; therefore, no driving force associated with precipitation is available to mobilize COCs vertically.

e. Total petroleum hydrocarbons are present within the septic tank.

f. The contaminants are contained within the septic tank.

g. Presently, CAS 26-05-04 is located on a government-controlled facility. The NTS is a restricted area that is guarded on a 24-hour, 365 day-per-year basis; unauthorized personnel are not admitted to the facility. CAS 26-05-04 is contained within a restricted use zone classified as a "Research Test and Experiment Zone" (DOE/NV, 1998a). This zone is designated for small-scale research and development projects and demonstrations; pilot 
projects; outdoor test; and experiments for development, quality assurance, or reliability of material and equipment under controlled conditions. This includes compatible nondefense research, development and testing projects, and activities (DOE/NV, 1998a).

h. Preferred routes of vertical and lateral migration are nonexistent since the sources have been eliminated and driving forces are not viable.

i. See Section 2.3.13 for site-specific considerations.

j. The potential for a hazard related to fire, vapor, or explosion is nonexistent for the COCs at the site.

k. No other site-specific factors are known at this site.

Based on this evaluation, impacts to groundwater are not expected. Therefore, groundwater monitoring is not proposed for this site and is not considered an element of the alternatives.

\subsubsection{Buildings 2101, 2102, and 2107 Septic Systems (CAS 26-05-05)}

Under Alternative 3, administrative controls will be implemented to restrict inadvertent contact with subsurface-contaminated soil in the leachfield and solidification of septic tank 1 contents. Septic tank 2 contents (mixed waste) must be removed as described in Alternative 2 (Section 3.3.2.13). After solidification of septic tank 1 contents is complete, the septic tank will be filled with an inert material that will effectively seal the tank openings. These controls would consist of use restrictions to minimize access and prevent unauthorized intrusive activities (e.g., fencing, signage). Administrative controls with long-term monitoring will be required for the contaminated materials closed in place.

Additional measures under this alternative include closing the distribution boxes as outlined in Section 2.3.14. The future use of the CAS would be restricted from any activity that would alter or modify the containment control unless appropriate concurrence was obtained from the NDEP.

The combination of these measures will effectively prevent inadvertent intrusive activities by humans and native wildlife and mobilization of COCs.

The following evaluation of NAC 445A.227 (2) (a-k) (NAC, 2000c) supports the protection of groundwater from COCs at this CAS: 
a. Perched groundwater occurs in highly fractured and altered rock and may extend to a depth of $261 \mathrm{ft}$ bgs before encountering a low-permeable confining layer. Depth to perched groundwater ranges from 81 to $167 \mathrm{ft}$ bgs (Johnson and Ege, 1964). Depth to the regional groundwater table in Area 26 is about 1,700 ft bgs (DRI, 1988). Analytical data indicate that COCs are confined within the leachfield soil at a depth between 5 and $7 \mathrm{ft}$ bgs. This indicates minimal vertical migration has occurred in the past, and with the removal of the man-made driving forces, vertical migration will be negligible in the future.

b. The nearest active water-supply well, Well $4 \mathrm{a}$, is approximately $10 \mathrm{mi}$ northeast of the site (DOE/NV, 1998a). Well 4a is primarily used to provide potable water for Area 6.

c. The soil was a combination of alluvial and colluvial material. The soils appeared as silty to course sand with small- to medium-sized gravels. No geotechnical tests were conducted on the soil.

d. Average annual precipitation for valleys in the South-Central Great Basin ranges from 3 to 6 in. (Winograd and Thordarson, 1975). Annual evaporation is roughly 5 to 25 times the annual precipitation (Winograd and Thordarson, 1975). The high evaporation and low precipitation rates create a negative water balance for the area; therefore, no driving force associated with precipitation is available to mobilize COCs vertically.

e. Total petroleum hydrocarbons are present within septic tank 1 . The type of regulated substances released within the leachfield is TPH. Downward migration of COCs is slowed by the following parameters:

- Volume of release - it is assumed that small volumes of COCs were released over a long period of time rather than a large volume over a short duration.

- Soil saturation - the soil tends to be very dry, especially near the surface and shallow subsurface where the COCs are concentrated.

- Soil particle adsorption/desorption - petroleum hydrocarbons tend to adsorb to the soil particles with little desorption as suggested by the limited vertical migration of COCs.

f. The lateral extent of contamination is defined by analytical data showing the lack of contamination found in nearby sampling locations demonstrating minimal lateral mobility. Analytical data show that COCs are confined within the depth between 5 and $7 \mathrm{ft}$ bgs. This indicates minimal vertical migration has occurred in the past, and with the removal of the man-made driving forces, vertical migration will be negligible in the future.

g. Presently, CAS 26-05-05 is located on a government-controlled facility. The NTS is a restricted area that is guarded on a 24-hour, 365 day-per-year basis; unauthorized personnel are not admitted to the facility. CAS 26-05-05 is contained within a restricted use zone classified as a "Research Test and Experiment Zone" (DOE/NV, 1998a). This zone is designated for small-scale research and development projects and demonstrations; pilot 
projects; outdoor test; and experiments for development, quality assurance, or reliability of material and equipment under controlled conditions. This includes compatible nondefense research, development and testing projects, and activities (DOE/NV, 1998a).

h. Preferred routes of vertical and lateral migration are nonexistent since the sources have been eliminated and driving forces are not viable.

i. See Section 2.3.14 for site-specific considerations.

j. The potential for a hazard related to fire, vapor, or explosion is nonexistent for the COCs at the site.

k. No other site-specific factors are known at this site.

Based on this evaluation, impacts to groundwater are not expected. Therefore, groundwater monitoring is not proposed for this site and is not considered an element of the alternatives.

\subsubsection{Building 5200 Septic System (CAS 27-05-02)}

Under Alternative 3, administrative controls will be implemented to restrict inadvertent contact with contaminated surface and subsurface soil in the leachfield. These controls would consist of use restrictions to minimize access and prevent unauthorized intrusive activities (e.g., fencing, signage). Administrative controls with long-term monitoring will be required for the contaminated materials closed in place.

The future use of the CAS would be restricted from any activity that would alter or modify the containment control unless appropriate concurrence was obtained from the NDEP. These measures will effectively prevent inadvertent intrusive activities by humans and native wildlife and mobilization of COCs.

Additional measures under this alternative include closing the distribution box and septic tank as outlined in Section 2.3.15.

The following evaluation of NAC 445A.227 (2) (a-k) (NAC, 2000c) supports the protection of groundwater from COCs at this CAS: 
a. Information on depth to groundwater could not be located. Perched water may be present at shallower depths; however, the regional water table is relatively deep (500 ft bgs or greater). The leachfield contains COCs (PCBs) at depths ranging from 0 to $14 \mathrm{ft}$ bgs.

b. The nearest active water-supply well, Well 5c, is approximately $8 \mathrm{mi}$ northeast of the site (DOE/NV, 1998a). Well 5c is primarily used to provide potable water for Areas 6 and 3.

c. The soil was a combination of alluvial and colluvial material. The soils appeared as medium to course sand with small- to medium-sized gravels. No geotechnical tests were conducted on the soil.

d. Average annual precipitation for valleys in the South-Central Great Basin ranges from 3 to 6 in. (Winograd and Thordarson, 1975). Annual evaporation is roughly 5 to 25 times the annual precipitation (Winograd and Thordarson, 1975). The high evaporation and low precipitation rates create a negative water balance for the area; therefore, no driving force associated with precipitation is available to mobilize COCs vertically.

e. The type of regulated substances released within the leachfield soil is PCBs. Downward migration of COCs is slowed by the following parameters:

- Volume of release - it is assumed that small volumes of COCs were released over a long period of time rather than a large volume over a short duration; however, it is possible that contamination is related to a one-time event.

- Soil saturation - the soil tends to be very dry, especially near the surface and shallow subsurface where the COCs are concentrated.

- Soil particle adsorption/desorption - PCBs tend to adsorb to the soil particles with little desorption as suggested by the limited vertical migration of COCs.

f. The lateral extent of contamination is defined by the analytical data showing the lack of contamination found in nearby sampling locations, thereby demonstrating minimal lateral mobility. Analytical data indicate that COCs are confined within the depth between 0 to $14 \mathrm{ft}$ bgs. This indicates minimal vertical migration has occurred in the past, and with the removal of the man-made driving forces, vertical migration will be negligible in the future.

g. Presently, CAS 27-05-02 is located on a government-controlled facility. The NTS is a restricted area that is guarded on a 24-hour, 365 day-per-year basis; unauthorized personnel are not admitted to the facility. CAS 27-05-02 is contained within a restricted use zone classified as a "Defense Industrial Zone" (DOE/NV, 1998a). This zone is designated for stockpile management of weapons, including production, assembly, disassembly, or modification, staging, repair, retrofit, and surveillance. Permanent facilities for stockpile stewardship operations involving equipment and activities such as radiography, lasers, material processing, and pulsed power are located in this zone (DOE/NV, 1998a). 
h. Preferred routes of vertical and lateral migration are nonexistent since the sources have been eliminated and driving forces are not viable.

i. See Section 2.3.15 for site-specific considerations.

j. The potential for a hazard related to fire, vapor, or explosion is nonexistent for the COCs at the site.

k. No other site-specific factors are known at this site.

Based on this evaluation, impacts to groundwater are not expected. Therefore, groundwater monitoring is not proposed for this site and is not considered an element of the alternatives.

\subsection{Evaluation and Comparison of Alternatives}

The general corrective action standards and remedy selection decision factors described in Section 3.2 were used to conduct detailed and comparative analyses of each corrective action alternative presented in Section 3.3.3. The advantages and disadvantages of each alternative were assessed to select preferred alternatives for CAU 271. Table 3-2 and Table 3-3 present the detailed and comparative evaluation of closure alternatives for each CAS except CAS 25-04-10.

No COCs were identified at CAS 25-04-10, indicating that no further action is the preferred closure recommendation. As a best management practice, it is recommended that the septic tank be filled at as estimated cost of $\$ 11,851$. This cost estimate and the cost estimates listed in Table 3-2 and Table 3-3 are detailed in Appendix C. 
Table 3-2

Detailed Evaluation of Alternatives for

Corrective Action Unit 271

(Page 1 of 4)

\begin{tabular}{|c|c|c|c|}
\hline Evaluation Criteria & $\begin{array}{c}\text { Alternative } 1 \\
\text { No Further Action }\end{array}$ & $\begin{array}{l}\text { Alternative } 2 \\
\text { Clean Closure }\end{array}$ & $\begin{array}{c}\text { Alternative } 3 \\
\text { Closure in Place with } \\
\text { Administrative Controls }\end{array}$ \\
\hline \multicolumn{4}{|c|}{ Closure Standards } \\
\hline $\begin{array}{l}\text { Protection of Human Health and the } \\
\text { Environment }\end{array}$ & $\begin{array}{l}\text { Does not meet corrective action } \\
\text { objective of preventing or mitigating } \\
\text { exposure to surface and subsurface soil } \\
\text { containing contaminants of concern } \\
\text { (COCs) at concentrations exceeding } \\
\text { preliminary action levels (PALs). } \\
\text { Does not meet corrective action } \\
\text { objective of preventing or mitigating } \\
\text { exposure to septic tank, distribution box, } \\
\text { or manhole contents with concentrations } \\
\text { exceeding unrestricted release criteria. } \\
\text { Does not prevent potential spread of } \\
\text { COCs. } \\
\text { Nevada Administrative Code (NAC) } \\
445.227 \text { (2) (a-k) analysis shows the } \\
\text { contaminants are not expected to impact } \\
\text { groundwater. } \\
\text { No worker exposure associated with } \\
\text { implementation. }\end{array}$ & $\begin{array}{l}\text { - } \text { Meets corrective action objectives. } \\
\text { associated with heavy equipment and } \\
\text { potential contact with impacted media } \\
\text { during excavation, transportation, and } \\
\text { closure activities. } \\
\text { - Low risk to public due to remote location } \\
\text { and controlled access to Nevada Test } \\
\text { Site (NTS). Low to moderate risk to } \\
\text { public during transportation off NTS. } \\
\text { NAC } 445.227 \text { (2) (a-k) analysis shows } \\
\text { the contaminants are not expected to } \\
\text { impact groundwater. } \\
\text { Moving contaminated media to an } \\
\text { appropriate disposal facility mitigates } \\
\text { exposure to impacted media after } \\
\text { closure. }\end{array}$ & $\begin{array}{l}\text { - Meets corrective action objectives. } \\
\text { Prevents inadvertent intrusion into the } \\
\text { contaminated media. } \\
\text { Low risk to workers associated with } \\
\text { heavy equipment and potential contact } \\
\text { with impacted media during closure } \\
\text { activities. } \\
\text { - Low risk to public because of remote } \\
\text { location and controlled access to the } \\
\text { NTS. } \\
\text { NAC } 445.227 \text { (2) (a-k) analysis shows } \\
\text { the contaminants are not expected to } \\
\text { impact groundwater. }\end{array}$ \\
\hline Compliance with Media Cleanup Standards & $\begin{array}{l}\text { Does not comply with media cleanup } \\
\text { standards because COCs at levels } \\
\text { above PALs and media exceeding } \\
\text { unrestricted release criteria remain. } \\
\text { NAC } 445.227 \text { (2) (a-k) analysis shows } \\
\text { the contaminants are not expected to } \\
\text { impact groundwater. }\end{array}$ & $\begin{array}{l}\text { - Complies with media cleanup standards } \\
\text { because media containing COCs at } \\
\text { concentrations exceeding PALs will be } \\
\text { excavated and disposed of at an } \\
\text { appropriate facility. } \\
\text { - Removal of COC concentrations } \\
\text { exceeding PALs will be verified with } \\
\text { confirmation sampling. } \\
\text { NAC } 445.227 \text { (2) (a-k) analysis shows } \\
\text { the contaminants are not expected to } \\
\text { impact groundwater. }\end{array}$ & $\begin{array}{l}\text { - Complies with media cleanup standards } \\
\text { by controlling exposure pathways. } \\
\text { - NAC } 445.227 \text { (2) (a-k) analysis shows } \\
\text { the contaminants are not expected to } \\
\text { impact groundwater. }\end{array}$ \\
\hline Control the Source(s) of Release & $\begin{array}{l}\text { The sources of each Corrective Action } \\
\text { Site (CAS) have been discontinued. }\end{array}$ & $\begin{array}{l}\text { The sources of each CAS have been } \\
\text { discontinued. }\end{array}$ & $\begin{array}{l}\text { - The sources of each CAS have been } \\
\text { discontinued. }\end{array}$ \\
\hline
\end{tabular}


Table 3-2

Detailed Evaluation of Alternatives for

Corrective Action Unit 271

(Page 2 of 4 )

\begin{tabular}{|c|c|c|c|}
\hline Evaluation Criteria & $\begin{array}{c}\text { Alternative } 1 \\
\text { No Further Action }\end{array}$ & $\begin{array}{l}\text { Alternative } 2 \\
\text { Clean Closure }\end{array}$ & $\begin{array}{c}\text { Alternative } 3 \\
\text { Closure in Place with } \\
\text { Administrative Controls }\end{array}$ \\
\hline $\begin{array}{l}\text { Comply with Applicable Federal, State, and } \\
\text { Local Standards for Waste Management }\end{array}$ & - No waste generated. & $\begin{array}{l}\text { All waste (primarily sludge, liquid, } \\
\text { sediment, contaminated soil, and } \\
\text { disposable personal protective } \\
\text { equipment) will be handled and disposed } \\
\text { of in accordance with applicable } \\
\text { standards. }\end{array}$ & $\begin{array}{l}\text { All waste (primarily disposable personal } \\
\text { protective equipment, septic tank, } \\
\text { distribution box, and manhole covers) } \\
\text { will be handled and disposed of in } \\
\text { accordance with applicable standards. } \\
\text { CAS 25-04-04 septic tank outlet } \\
\text { chamber contents, CAS } 26-04-01 \text { septic } \\
\text { tank contents, CAS } 26-05-05 \text { septic tank } \\
2 \text { contents, and CAS } 27-05-02 \text { septic } \\
\text { tank and distribution box contents must } \\
\text { be removed. }\end{array}$ \\
\hline \multicolumn{4}{|c|}{ Remedy Selection Decision Factors } \\
\hline Short-Term Reliability and Effectiveness & Not evaluated & $\begin{array}{l}\text { - Low risk to workers associated with } \\
\text { heavy equipment and potential contact } \\
\text { with impacted media during excavation, } \\
\text { transportation, and closure activities. } \\
\text { - Public protected during removal by } \\
\text { remote location and NTS site access } \\
\text { controls. } \\
\text { - Low to moderate risk to public during } \\
\text { transportation off NTS. } \\
\text { Environmental impacts are not } \\
\text { anticipated due to implementation. } \\
\text { Appropriate measures will be taken at } \\
\text { the site to protect desert tortoises. } \\
\text { Implementation should not require an } \\
\text { extended period of time. }\end{array}$ & $\begin{array}{l}\text { Low risk to workers associated with } \\
\text { heavy equipment and potential contact } \\
\text { with impacted media during closure } \\
\text { activities. } \\
\text { Public protected by remote location and } \\
\text { NTS site access controls. } \\
\text { Environmental impacts are not } \\
\text { anticipated due to implementation. } \\
\text { Appropriate measures will be taken at } \\
\text { the site to protect desert tortoises. } \\
\text { Implementation should not require an } \\
\text { extended period of time. }\end{array}$ \\
\hline
\end{tabular}


Table 3-2

Detailed Evaluation of Alternatives for

Corrective Action Unit 271

(Page 3 of 4)

\begin{tabular}{|c|c|c|c|}
\hline Evaluation Criteria & $\begin{array}{c}\text { Alternative } 1 \\
\text { No Further Action }\end{array}$ & $\begin{array}{l}\text { Alternative } 2 \\
\text { Clean Closure }\end{array}$ & $\begin{array}{c}\text { Alternative } 3 \\
\text { Closure in Place with } \\
\text { Administrative Controls }\end{array}$ \\
\hline $\begin{array}{l}\text { Reduction of Toxicity, Mobility, and/or } \\
\text { Volume }\end{array}$ & Not evaluated & $\begin{array}{l}\text { Clean closure would effectively eliminate } \\
\text { associated toxicity, mobility, and volume } \\
\text { of wastes at each CAS. } \\
\text { - Proper disposal of the waste will result in } \\
\text { an ultimate reduction of mobility. }\end{array}$ & $\begin{array}{l}\text { The mobility of the remaining septic tank, } \\
\text { distribution box, or manhole } \\
\text { contamination is significantly reduced by } \\
\text { administrative controls, solidification of } \\
\text { any free liquid, and lack of viable driving } \\
\text { forces. } \\
\text { - The volume of septic tank, distribution } \\
\text { box, or manhole contaminated media is } \\
\text { increased through the addition of } \\
\text { solidification material. } \\
\text { Toxicity and volume of the soil } \\
\text { contamination are effectively } \\
\text { unchanged. } \\
\text { The mobility of the remaining subsurface } \\
\text { soil contamination is significantly } \\
\text { reduced by administrative controls and } \\
\text { lack of viable driving forces. }\end{array}$ \\
\hline Long-Term Reliability and Effectiveness & Not evaluated & $\begin{array}{l}\text { All risk will be eliminated on site upon } \\
\text { completion. } \\
\text { - No maintenance required. } \\
\text { Moving contaminated media to an } \\
\text { appropriate disposal media facility } \\
\text { addresses the persistent adsorption of } \\
\text { contaminants. }\end{array}$ & $\begin{array}{l}\text { - Controls inadvertent intrusion to } \\
\text { remaining contaminated media. } \\
\text { - Administrative controls must be } \\
\text { maintained. }\end{array}$ \\
\hline
\end{tabular}


Table 3-2

Detailed Evaluation of Alternatives for

Corrective Action Unit 271

(Page 4 of 4)

\begin{tabular}{|c|c|c|c|}
\hline Evaluation Criteria & $\begin{array}{c}\text { Alternative } 1 \\
\text { No Further Action }\end{array}$ & $\begin{array}{l}\text { Alternative } 2 \\
\text { Clean Closure }\end{array}$ & $\begin{array}{c}\text { Alternative } 3 \\
\text { Closure in Place with } \\
\text { Administrative Controls }\end{array}$ \\
\hline Feasibility & Not evaluated & $\begin{array}{l}\text { Depth of contaminated leachfield media } \\
\text { would require significant excavation or } \\
\text { shoring to protect workers. } \\
\text { - Removal of contaminated media from } \\
\text { the septic tanks, distribution boxes, and } \\
\text { manholes would require controls to } \\
\text { protect workers. } \\
\text { - Options for disposal of contaminated } \\
\text { media is limited and require coordination } \\
\text { with multiple entities. }\end{array}$ & $\begin{array}{l}\text { Easily implemented. } \\
\text { Coordination of all entities is necessary } \\
\text { to ensure compliance with administrative } \\
\text { controls to prevent intrusion into } \\
\text { contaminated zones. }\end{array}$ \\
\hline Cost & $\begin{array}{l}\text { CAS 25-04-01: } \$ 0 \\
\text { CAS 25-04-03: } \$ 0 \\
\text { CAS 25-04-04: } \$ 0 \\
\text { CAS 25-04-08: } \$ 0 \\
\text { CAS 25-04-09: } \$ 0 \\
\text { CAS 25-04-11: } \$ 0 \\
\text { CAS 26-03-01: } \$ 0 \\
\text { CAS 26-04-01: } \$ 0 \\
\text { CAS 26-04-02: } \$ 0 \\
\text { CAS 26-05-01: } \$ 0 \\
\text { CAS 26-05-03: } \$ 0 \\
\text { CAS 26-05-04: } \$ 0 \\
\text { CAS 26-05-05: } \$ 0 \\
\text { CAS 27-05-02: } \quad \$ 0\end{array}$ & 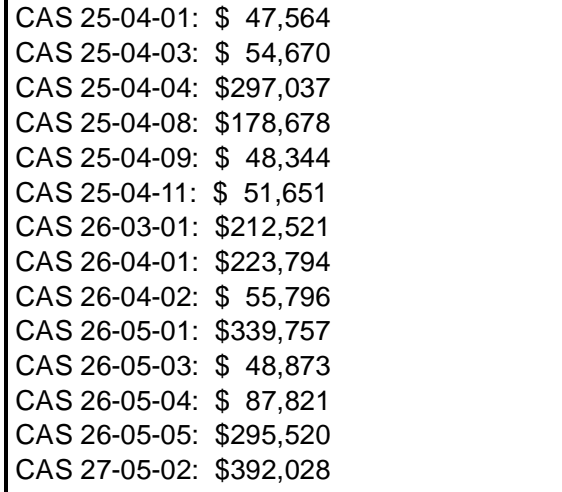 & 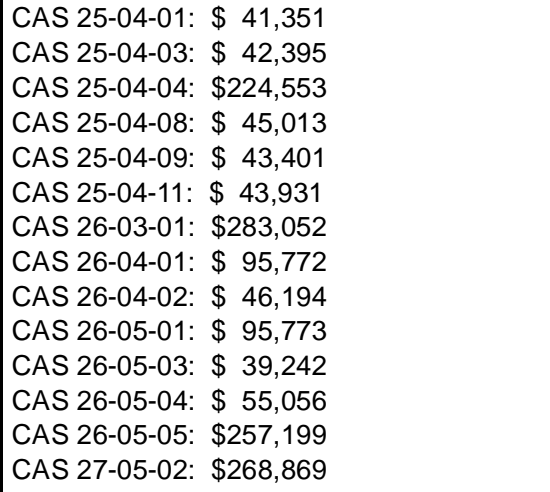 \\
\hline
\end{tabular}


Table 3-3

Comparative Evaluation of Alternatives for

Corrective Action Unit 271

\begin{tabular}{|c|c|c|c|}
\hline Evaluation Criteria & \multicolumn{3}{|c|}{ Comparative Evaluation } \\
\hline \multicolumn{4}{|c|}{ Closure Standards } \\
\hline $\begin{array}{l}\text { Protection of Human Health and the } \\
\text { Environment }\end{array}$ & \multicolumn{3}{|c|}{$\begin{array}{l}\text { Alternatives } 2 \text { and } 3 \text { meet corrective action objectives; Alternative } 1 \text { does not. No worker exposures to risks are associated with } \\
\text { Alternative 1. Low risks are associated with Alternative } 3 \text { and slightly higher risks with Alternative 2. Nevada Administrative Code } \\
\text { 445A.227 (2) (a-k) analysis shows the contaminants are not threatening groundwater. }\end{array}$} \\
\hline Compliance with Media Cleanup Standards & \multicolumn{3}{|c|}{$\begin{array}{l}\text { Alternative } 1 \text { does not comply with media cleanup standards. Alternative } 2 \text { meets media cleanup standards by removing contaminated } \\
\text { soil at concentrations exceeding preliminary action levels or unrestricted release criteria and eliminating exposure pathways at the site. } \\
\text { Alternative } 3 \text { controls access to contaminants, effectively eliminating exposure pathways. }\end{array}$} \\
\hline Control the Source(s) of Release & \multicolumn{3}{|c|}{ The sources at each Corrective Action Site (CAS) have been discontinued. } \\
\hline $\begin{array}{l}\text { Comply with Applicable Federal, State, and } \\
\text { Local Standards for Waste Management }\end{array}$ & \multicolumn{3}{|c|}{$\begin{array}{l}\text { Alternative } 1 \text { does not generate waste. Alternatives } 2 \text { and } 3 \text { will generate waste that will be handled in accordance with applicable } \\
\text { standards. }\end{array}$} \\
\hline \multicolumn{4}{|c|}{ Remedy Selection Decision Factors } \\
\hline Short-Term Reliability and Effectiveness & \multicolumn{3}{|c|}{ Low risks are associated with Alternative 3 and slightly higher risks with Alternative 2 . } \\
\hline $\begin{array}{l}\text { Reduction of Toxicity, Mobility, and/or } \\
\text { Volume }\end{array}$ & \multicolumn{3}{|c|}{$\begin{array}{l}\text { Alternative } 2 \text { results in an immediate reduction of all three characteristics at each CAS. Alternative } 3 \text { results in a reduction of mobility, but } \\
\text { does not reduce toxicity or volume. }\end{array}$} \\
\hline Long-Term Reliability and Effectiveness & \multicolumn{3}{|c|}{$\begin{array}{l}\text { Residual risk at each CAS is low for Alternative } 3 \text { and nonexistent for Alternative 2. Alternative } 3 \text { requires administrative measures to } \\
\text { control intrusive activities. }\end{array}$} \\
\hline Feasibility & \multicolumn{3}{|c|}{ Alternatives 2 and 3 are feasible; however, Alternative 2 will be more resource intensive. } \\
\hline Cost & $\begin{array}{l}\text { Alternative 1: } \\
\text { CAS 25-04-01: } \$ 0 \\
\text { CAS 25-04-03: } \$ 0 \\
\text { CAS 25-04-04: } \$ 0 \\
\text { CAS 25-04-08: } \$ 0 \\
\text { CAS 25-04-09: } \$ 0 \\
\text { CAS 25-04-11: } \$ 0 \\
\text { CAS 26-03-01: } \$ 0 \\
\text { CAS 26-04-01: } \$ 0 \\
\text { CAS 26-04-02: } \$ 0 \\
\text { CAS 26-05-01: } \$ 0 \\
\text { CAS 26-05-03: } \$ 0 \\
\text { CAS 26-05-04: } \$ 0 \\
\text { CAS 26-05-05: } \$ 0 \\
\text { CAS 27-05-02: } \$ 0\end{array}$ & $\begin{array}{ll}\text { Alternative 2: } & \\
\text { CAS 25-04-01: } & \$ 47,564 \\
\text { CAS 25-04-03: } & \$ 54,670 \\
\text { CAS 25-04-04: } & \$ 297,037 \\
\text { CAS 25-04-08: } & \$ 178,678 \\
\text { CAS 25-04-09: } & \$ 48,344 \\
\text { CAS 25-04-11: } & \$ 51,651 \\
\text { CAS 26-03-01: } & \$ 212,521 \\
\text { CAS 26-04-01: } & \$ 223,794 \\
\text { CAS 26-04-02: } & \$ 55,796 \\
\text { CAS 26-05-01: } & \$ 339,757 \\
\text { CAS 26-05-03: } & \$ 48,873 \\
\text { CAS 26-05-04: } & \$ 87,821 \\
\text { CAS 26-05-05: } & \$ 295,520 \\
\text { CAS 27-05-02: } & \$ 392,028\end{array}$ & 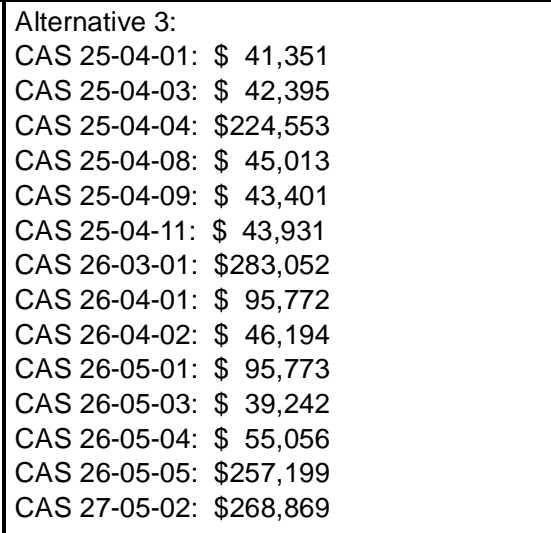 \\
\hline
\end{tabular}




\subsection{Recommended Alternatives}

The preferred corrective action alternatives were evaluated on their technical merits, focusing on performance, reliability, feasibility, and safety. The selected alternatives were judged to meet all requirements for the technical components evaluated. The selected alternatives meet all applicable state and federal regulations for closure of the sites and will minimize potential future exposure pathways to the contaminated media at CAU 271. Cost estimates were used to support the selection of preferred corrective action alternatives.

Alternative 1, No Further Action, is the preferred corrective action for CAS 25-04-10. The septic tank will be filled as a best management practice to prevent the potential for collection of stormwater and possible inadvertent discharge to the leachfield.

Alternative 2, Clean Closure, is the preferred corrective action for the following CASs:

- CAS 25-04-01 - Septic tank

- CAS 25-04-03 - Septic tank

- CAS 25-04-04 - Septic tank, distribution box, and contaminated soil adjacent to the influent end of the septic tank

- CAS 25-04-08 - Septic tank and contaminated leachfield soil

- CAS 25-04-09 - Septic tank

- CAS 25-04-11 - Septic tank and manhole

- CAS 26-03-01 - Contaminated reservoir surface soil

- CAS 26-04-01 - Septic tank and distribution box

- CAS 26-04-02 - Septic tank and distribution box

- CAS 26-05-01 - Manhole, distribution box, and contaminated leachfield soil

- CAS 26-05-03 - Septic tank, distribution box, and manhole

- CAS 26-05-04 - Septic tank and distribution box 
- CAS 26-05-05 - Septic tanks 1 and 2, distribution boxes 1 and 2, and contaminated leachfield soil

- CAS 27-05-02 - Septic tank, distribution box, and contaminated surface and subsurface leachfield soil within the fenced leachfield boundary

The preferred corrective action alternatives were evaluated on technical merit focusing on performance, reliability, feasibility, and safety. The alternatives were judged to meet all requirements for the technical components evaluated. The alternatives meet all applicable state and federal regulations for closure of the site and will eliminate potential future exposure pathways to the contaminated soils at Corrective Action Unit 271. Implementation of corrective actions may potentially present risks to site workers. Therefore, appropriate health and safety procedures will be developed and implemented. 


\subsection{References}

AEC, see U.S. Atomic Energy Commission.

Bechtel Nevada. 1995. Nevada Test Site Performance Objective for Certification of Nonradioactive Hazardous Waste, Rev. 0. Las Vegas, NV: Waste Management Program.

BN, see Bechtel Nevada.

CFR, see Code of Federal Regulations.

Code of Federal Regulations. 2000a. Title 40 CFR Parts 260 - 282, "RCRA Regulations."

Washington, DC: U.S. Government Printing Office.

Code of Federal Regulations. 2000b. Title 40 CFR 761.61, "PCB Remediation Waste."

Washington, DC: U.S. Government Printing Office.

Desert Research Institute. 1988. CERCLA Preliminary Assessment of DOE's Nevada Operations Office Nuclear Weapons Testing Areas, Vol. 1. Las Vegas, NV.

DOE/NV, see U.S. Department of Energy, Nevada Operations Office.

DRI, see Desert Research Institute.

EPA, see U.S. Environmental Protection Agency.

ERDA, see U.S. Energy Research and Development Administration.

FFACO, see Federal Facility Agreement and Consent Order.

Federal Facility Agreement and Consent Order. 1996 (as amended). Agreed to by the State of Nevada, the U.S. Department of Energy, and the U.S. Department of Defense.

Johnson, R.B, and J.R. Ege. 1964. Geology of the Pluto Site, Area 401, Nevada Test Site, Nye County, Nevada, USGS-TEI-841. Denver, CO: U.S. Geological Survey.

Laczniak, R.J., J.C. Cole, D.A. Sawyer, and D.T. Trudeau. 1996. Summary of Hydrogeological Controls on Ground-Water Flow at the Nevada Test Site, Nye County, Nevada, U.S. Geological Survey Water-Resources Investigations Report 96-4109. Denver, CO: U.S. Geological Survey.

Moore, J., IT Corporation, Las Vegas. 1999. Memo to M. Todd (ITLV), "Background Concentrations for NTS and TTR Soil Samples," 3 February. Las Vegas, NV. 
NAC, see Nevada Administrative Code.

NBMG, see Nevada Bureau of Mines and Geology.

Nevada Administrative Code. 2000a. NAC 444, "Sanitation." Carson City, NV.

Nevada Administrative Code. 2000b. NAC 444.818, "Limitations and site requirements." Carson City, NV.

Nevada Administrative Code. 2000c. NAC 445A, "Water Controls." Carson City, NV.

Nevada Administrative Code. 2000d. NAC 445A.2272, "Contamination of Soil: Establishment of Action Levels." Carson City, NV.

Nevada Administrative Code. 2000e. NAC 459, "Hazardous Materials." Carson City, NV.

Nevada Revised Statutes. 1998. NRS 459.400-459.600, “Disposal of Hazardous Waste.” Carson City, NV.

Nevada Bureau of Mines and Geology. 1998. Mineral and Energy Resource Assessment of the Nellis Air Force Range, Open-File Report 98-1. Reno, NV.

NRS, see Nevada Revised Statutes.

SNPO, see Space Nuclear Propulsion Office.

Space Nuclear Propulsion Office. 1970. NRDS Master Plan 1969-1970, Nuclear Rocket Development Station, Jackass Flats, Nevada. Las Vegas, NV.

U.S. Atomic Energy Commission. 1964. Tory IIC Reactor Test Report, UCRL-12069. Livermore, CA: University of California, Lawrence Radiation Laboratory.

U.S. Department of Energy, Nevada Operations Office. 1994. Project Management Plan, Rev. 0. Las Vegas, NV.

U.S. Department of Energy, Nevada Operations Office. 1996. Industrial Sites Quality Assurance Project Plan, Nevada Test Site, Nevada, Rev. 1, DOE/NV-372. Las Vegas, NV.

U.S. Department of Energy, Nevada Operations Office. 1998a. Nevada Test Site Resource Management Plan, DOE/NV-518. Las Vegas, NV.

U.S. Department of Energy, Nevada Operations Office. 1998b. Work Plan for Leachfield Corrective Action Units: Nevada Test Site and Tonopah Test Range, Nevada, Rev. 1, DOE/NV--514. Las Vegas, NV. 
U.S. Department of Energy, Nevada Operations Office. 2000. NV/YMP Radiological Control Manual Rev. 4, DOE/NV/11718-079. Prepared by Bechtel Nevada. Las Vegas, NV.

U.S. Department of Energy, Nevada Operations Office. 2001. Corrective Action Investigation Plan for Corrective Action Unit 271: Area 25, 26, and 27 Septic Systems, Nevada Test Site, Nevada, DOE/NV-704. Las Vegas, NV.

U.S. Energy Research and Development Administration. 1997. Final Environmental Impact Statement, Nevada Test Site, Nye County, Nevada, ERDA-1551. Washington, DC.

U.S. Environmental Protection Agency. 1991. Guidance on RCRA Corrective Action Decision Documents, EPA/540/G-91/011. Washington, DC: Office of Research and Development.

U.S. Environmental Protection Agency. 1994. Final RCRA Corrective Action Plan, EPA/520-R-94-004. Washington, DC: Office of Solid Waste and Emergency Response.

U.S. Environmental Protection Agency. 2000. Region IX Preliminary Remediation Goals (PRGs). As accessed at www.epa.gov/region09/waste/sfund/prg/index.htm on 8 January 2001. Prepared by S.J. Smucker. San Francisco, CA.

USGS, see U.S. Geological Survey.

U.S. Geological Survey. 1995. Selected Ground-Water Data for Yucca Mountain Region, Southern Nevada and Eastern California, Calendar Year 1993, USGS-OFR-95-158. Prepared by G.S. Hale and C.L. Westenburg. Denver, CO.

Winograd, I.J., and W. Thordarson. 1975. Hydrologic and Hydrochemical Framework South-Central Great Basin, Nevada-California, with Special Reference to the Nevada Test Site, USGS Professional Paper 712C. Washington, DC: U.S. Government Printing Office. 
Appendix A

Corrective Action Investigation Report for CAU 271 


\section{A.1.0 Introduction}

This appendix details corrective action investigation (CAI) activities and analytical results for CAU 271. The CAI was conducted in accordance with the Corrective Action Investigation Plan for Corrective Action Unit 271: Areas 25, 26, and 27 Septic Systems, Nevada Test Site, Nevada (DOE/NV, 2001), and the Work Plan for Leachfield Corrective Action Units: Nevada Test Site and Tonopah Test Range, Nevada, Rev. 1 (DOE/NV, 1998), as developed under the FFACO that was agreed to by the State of Nevada, DOE, and the U.S. Department of Defense (FFACO, 1996). These documents are hereafter referred to as the CAIP, Leachfield Work Plan, and FFACO, respectively.

The CAU is comprised of CASs 25-04-01, 25-04-03, 25-04-04, 25-04-08, 25-04-09, 25-04-10, 25-04-11, 26-03-01, 26-04-01, 26-04-02, 26-05-01, 26-05-03, 26-05-04, 26-05-05, and 27-05-02. The CASs addressed by CAU 271 are located at Guard Station 500, the RCP, BREN Tower, and ETS-1 facilities in Area 25 (Figure 1-2); the Port Gaston and Pluto Project facilities in Area 26 (Figure 1-3); and the Baker Site in Area 27 (Figure 1-4) of the NTS. The RCP and ETS-1 facilities supported nuclear rocket reactor and engine testing as part of the Nuclear Rocket Development Station. These facilities were used for activities associated with the testing program and various other projects. The Pluto Project facilities supported nuclear reactor testing for use as a ramjet propulsion system and various other projects, including the NUWAX Program's use of the Pluto control area for radiological emergency response training exercises. The Baker Site facilities were constructed to support the assembly, disassembly, and modification of nuclear explosives, nonnuclear explosives, and assemblies containing special nuclear material. The site served as the staging point for the manufactured components of nuclear devices.

This CAU was investigated because process knowledge indicated that many of the CASs addressed by this CAU may have been used to dispose of material considered to be hazardous or radioactive waste by current standards.

The CAU consists of thirteen septic waste systems, one contaminated water reservoir, and one radioactive leachfield. The description given to CAS 27-05-02 in the FFACO is "leachfield;" however, it has been identified as a septic system with a septic tank, distribution box, and leachfield. At each of the CAU 271 CASs, except for the CAS 26-03-01 water reservoir, effluents generated 
within facilities were routed through collection systems and disposed using distribution systems (i.e., leachfields). The septic systems included in CAU 271 were designed to receive sanitary and process effluent associated with building maintenance and personal hygiene. Only one CAS, the Pluto Project radioactive leachfield (26-05-01), was designed to receive radioactive effluent. The leachfield and the collection system for this CAS are radiologically posted. In addition, although CAS 26-05-03 is a sanitary system, the leachfield is radiologically posted. The CAS 26-03-01 water reservoir was intentionally contaminated with short-lived radionuclides as part of a radiological emergency response training exercise.

Designated systems were installed to segregate the various effluents. Additionally, at some facilities, engineering controls were in place to keep radioactive effluent separate from process and sanitary effluents, but the assumption that sanitary leachfields are not radioactively contaminated could not be made prior to investigation. The strategy presented in the CAIP and implemented during this investigation accounts for this potential variability in the composition of the effluent.

Additional information regarding the history of each site, planning, and the scope of the investigation is presented in the CAIP.

\section{A.1.1 Project Objectives}

The primary objectives of the investigation were to:

- Identify the presence and the vertical and lateral extent of COPCs.

- Provide sufficient information and data to develop appropriate corrective action alternatives for CAU 271.

The selection of soil sample locations was based on site conditions and the strategy developed during the DQO process as outlined in the CAIP.

\section{A.1.2 Content}

This appendix contains information and data in sufficient detail to support the selection of a preferred corrective action alternative in the CADD. The contents of this appendix are as follows:

- Section A.1.0 describes the investigation background, objectives, and content. 
- Section A.2.0 provides an investigation overview.

- Section A.3.0 through Section A.17.0 provide CAS-specific information regarding the field activities, sampling methods, and laboratory analytical results from the investigation sampling.

- Section A.18.0 summarizes waste management activities.

- Section A.19.0 discusses the quality assurance (QA) and quality control (QC) procedures that were followed and the results of the QA/QC activities.

- Section A.20.0 is a summary of the investigation results.

- Section A.21.0 lists the cited references.

The complete field documentation and laboratory data, including FADLs, Sample Collection Logs, Analysis Request/Chain-of-Custody Forms, soil sample descriptions, laboratory certificates of analyses, analytical results, and surveillance results are retained in project files as hard copy files or electronic media. 


\section{A.2.0 Investigation Overview}

Field investigation and sampling activities consisted of surface soil screening and sampling, housekeeping removal of debris, septic tank sampling, subsurface soil sampling from backhoe excavations, manhole inspections, radiological collection system pipe surveys, collection system pipe content determinations, and in situ radiation measurements of shallow subsurface soil. The field investigation and sampling activities were conducted from October 29, 2001, through February 22, 2002. Table A.2-1 lists the CAI activities that were conducted at each of the CASs.

Table A.2-1

Corrective Action Investigation Activities Conducted at Each Corrective Action Site to Meet Corrective Action Investigation Plan Requirements

\begin{tabular}{|c|c|c|c|c|c|c|c|c|c|c|c|c|c|c|c|}
\hline \multirow[b]{2}{*}{ Corrective Action Investigation Activities } & \multicolumn{15}{|c|}{ Corrective Action Site } \\
\hline & 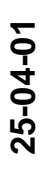 & 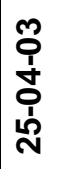 & 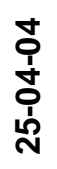 & 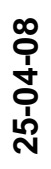 & 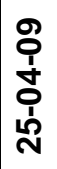 & 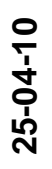 & 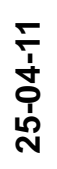 & 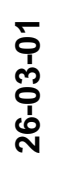 & 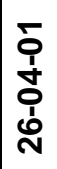 & 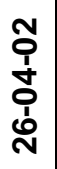 & $\begin{array}{l}\text { ' } \\
\text { ம் } \\
\text { ஸे }\end{array}$ & 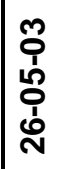 & 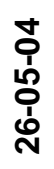 & 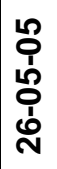 & 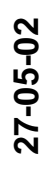 \\
\hline $\begin{array}{l}\text { Collected integrity samples from the influent and effluent } \\
\text { ends of the septic tank. }\end{array}$ & $\mathrm{X}$ & $\mathrm{x}$ & $\mathrm{x}$ & $x$ & $\mathrm{X}$ & $\mathrm{x}$ & $\mathrm{x}$ & & $\mathrm{x}$ & $\mathrm{x}$ & & $\mathrm{X}$ & $\mathrm{x}$ & $\mathrm{X}$ & $\mathrm{x}$ \\
\hline $\begin{array}{c}\text { Collected integrity samples from the effluent end of the } \\
\text { distribution box. }\end{array}$ & & & $\mathrm{x}$ & $\mathrm{X}$ & & $\mathrm{X}$ & $\mathrm{X}$ & & $\mathrm{X}$ & $\mathrm{x}$ & $\mathrm{x}$ & $\mathrm{X}$ & $\mathrm{X}$ & $\mathrm{X}$ & $\mathrm{x}$ \\
\hline Collected content samples from the septic tank. & $\mathrm{X}$ & $\mathrm{X}$ & $\mathrm{X}$ & $\mathrm{X}$ & $\mathrm{X}$ & & $\mathrm{X}$ & & $\mathrm{X}$ & $\mathrm{X}$ & & $\mathrm{X}$ & $\mathrm{X}$ & $\mathrm{X}$ & $\mathrm{X}$ \\
\hline Collected content samples from the distribution box. & & & & & & & & & $\mathrm{X}$ & & & & & & $\mathrm{X}$ \\
\hline Conducted on-site coliform bacteria analysis. & $\mathrm{X}$ & $\mathrm{X}$ & $\mathrm{X}$ & $\mathrm{X}$ & $\mathrm{X}$ & & $\mathrm{X}$ & & $\mathrm{X}$ & $\mathrm{X}$ & & $\mathrm{X}$ & $\mathrm{X}$ & $\mathrm{X}$ & $\mathrm{x}$ \\
\hline Inspected the collection system piping. & $\mathrm{X}$ & $\mathrm{X}$ & $\mathrm{X}$ & $\mathrm{X}$ & $\mathrm{X}$ & $\mathrm{X}$ & $\mathrm{X}$ & & $\mathrm{X}$ & $\mathrm{X}$ & $\mathrm{X}$ & $\mathrm{X}$ & $\mathrm{X}$ & $\mathrm{X}$ & $\mathrm{X}$ \\
\hline $\begin{array}{c}\text { Conducted exploratory excavations to confirm leachfield } \\
\text { configuration. }\end{array}$ & $x$ & $\mathrm{X}$ & $\mathrm{X}$ & $\mathrm{x}$ & $\mathrm{X}$ & $\mathrm{x}$ & $\mathrm{x}$ & & $\mathrm{X}$ & $\mathrm{x}$ & $\mathrm{X}$ & $\mathrm{x}$ & $\mathrm{x}$ & $\mathrm{x}$ & $\mathrm{x}$ \\
\hline Collected soil samples from the leachfield. & $\mathrm{X}$ & $\mathrm{X}$ & $\mathrm{X}$ & $\mathrm{X}$ & $\mathrm{X}$ & $\mathrm{X}$ & $\mathrm{X}$ & & $\mathrm{X}$ & $\mathrm{X}$ & $\mathrm{X}$ & $\mathrm{X}$ & $\mathrm{x}$ & $\mathrm{X}$ & $\mathrm{X}$ \\
\hline $\begin{array}{l}\text { Collected soil samples from biased and random locations } \\
\text { above and below the plastic liner. }\end{array}$ & & & & & & & & $\mathrm{x}$ & & & & & & & \\
\hline $\begin{array}{c}\text { Collected a geotechnical and hydrological sample from the } \\
\text { native soil. }\end{array}$ & $\mathrm{X}$ & $\mathrm{X}$ & $\mathrm{X}$ & $\mathrm{X}$ & $\mathrm{X}$ & $\mathrm{X}$ & $\mathrm{X}$ & $\mathrm{X}$ & $x$ & $\mathrm{X}$ & $\mathrm{X}$ & $x$ & $\mathrm{X}$ & $x$ & $\mathrm{x}$ \\
\hline $\begin{array}{c}\text { Field screened soil samples for volatile organic compounds } \\
\text { and alpha and beta/gamma radiation. }\end{array}$ & $\mathrm{X}$ & $x$ & $x$ & $\mathrm{X}$ & $\mathrm{X}$ & $\mathrm{X}$ & $\mathrm{X}$ & $x$ & $x$ & $\mathrm{X}$ & $\mathrm{X}$ & $\mathrm{x}$ & $\mathrm{x}$ & $\mathrm{X}$ & $\mathrm{x}$ \\
\hline Submitted select samples for off-site laboratory analysis. & $\mathrm{X}$ & $\mathrm{X}$ & $\mathrm{X}$ & $\mathrm{X}$ & $\mathrm{X}$ & $\mathrm{X}$ & $\mathrm{X}$ & $\mathrm{X}$ & $\mathrm{X}$ & $\mathrm{X}$ & $\mathrm{X}$ & $\mathrm{X}$ & $\mathrm{X}$ & $\mathrm{X}$ & $\mathrm{X}$ \\
\hline
\end{tabular}


The investigation and sampling program was managed in accordance with the requirements set forth in the CAIP. Field activities were performed in accordance with the approved CAU 271 site-specific health and safety plan (SSHASP) (IT, 2001), which is consistent with the DOE Integrated Safety Management System. Samples were collected and documented following approved protocols and procedures indicated in the CAIP (DOE/NV, 2001). Quality control samples (e.g., field blanks, equipment rinsate blanks, trip blanks, and duplicate samples) were collected as required by the Industrial Sites Quality Assurance Project Plan (DOE/NV, 1996) and approved procedures. During field activities, waste minimization practices were followed according to approved procedures, including segregation of waste by waste stream.

Weather conditions at the site varied to include rain, snow, sun (moderate temperatures), intermittent cloudiness, and light to strong winds. Winds and storms occasionally delayed site operations. The presence of asbestos transite piping at CAS 25-04-01 caused minor delays while the proper administrative and site controls were put in place for worker protection. Mechanical failures with one backhoe also resulted in additional delays.

The CASs were characterized by various combinations of radiological surface screening and soil sampling, in situ radiation measurements, and subsurface soil sampling. Surface soil samples were collected by hand excavation. Subsurface soil samples were collected using backhoe excavation. Investigation intervals and soil samples were field screened for VOCs and radiological contaminants. The results were compared against screening levels to guide the investigations. Resultant samples were shipped to off-site laboratories to be analyzed for chemical and radiological parameters. Backhoe excavation was also used to visually inspect leachfield system components, confirm the existence of leachfields, and verify the configuration and dimensions of leachfields. In situ radiation measurements were conducted at two leachfields using a gamma detector on the end of a CPT rod. These readings were used to guide sampling decisions and health and safety controls. Collection system piping sections (upstream of leachfield) and distribution boxes at radiological leachfields were characterized by comparing radiation screening results to unrestricted release criteria (free release criteria as discussed in CAIP). Finally, the contents of septic tanks and distribution boxes, both sludge and free liquid, were sampled and sent to off-site laboratories to be analyzed for chemical and radiological parameters. 
Except as noted in the following sections, CAU 271 sampling locations were accessible and sampling activities at planned locations were not restricted by buildings, storage areas, active operations, or aboveground and underground utilities. Required sampling step-out locations were accessible and remained within anticipated boundaries at all of the CASs, except at CASs 25-04-04 and 27-05-02. At these two CASs, step-out locations extended beyond the planned investigation boundaries.

Section A.2.1 through Section A.2.6 provide the investigation methodology, site geology and hydrology, and laboratory information. Additional activity-specific details for the individual CASs are presented in Section A.3.0 through Section A.17.0. Section A.18.0 provides information related to waste management activities, and Section A.19.0 provides quality assurance information.

The terminology used in this appendix to describe the leachfield system components follows the conventions established in the Leachfield Work Plan and CAIP. The "collection system" collects effluent from various sources. It refers to the piping, manholes, septic tanks, and distribution structures between the source building or facility foundation and the distribution system. The "distribution system" consists of distribution manifolds and pipes or other leachfield features required to dispose of effluent supplied by the collection system.

\section{A.2.1 Preliminary Conceptual Model}

The systems present at CAU 271 are similar to the generic conceptual model for leachfields provided in the Leachfield Work Plan and the site-specific conceptual models provided in the CAIP.

\section{A.2.2 Sample Locations}

Leachfield investigation locations selected for sampling were based on interpretation of engineering drawings and information obtained during site visits. Sampling points for each site were selected based on the approach provided in the Leachfield Work Plan and CAIP. The planned biased and random sample locations are shown in the CAIP. All actual sample locations, as well as planned locations, are depicted on the figures included in Sections A.3 through A.17. Some locations were modified slightly from planned positions due to field conditions and observations. In some cases, field-screening results and/or laboratory analytical results determined the need for step-out sampling locations. All sample locations were staked, labeled appropriately, and surveyed with a global 
positioning system (GPS) instrument. The actual locations have been plotted based on the coordinates collected by the GPS instrument, and what may appear as inaccuracies are due to the limited resolution of the technology.

\section{A.2.2.1 Housekeeping Removal of Debris}

Removal of housekeeping items was performed at CAS 26-05-03 as described in the CAIP (DOE/NV, 2001). Bechtel Nevada personnel placed a pallet (containing miscellaneous nuts, bolts, and metal parts) and pipes into a Radiological Materials Area for future disposition. After removal of the items, the ITLV Radiation Physics staff performed a Radiological Land Area Survey. Potential leakage or weathering from specific items did not contaminate the ground surface as evidenced by surface-screening results being less than FSLs beneath all of the housekeeping items. Therefore, no sampling or analysis of surface soil in these areas was required.

\section{A.2.3 Investigation Activities}

The investigation activities performed at CAU 271 were based on general field investigation activities discussed in the CAIP (DOE/NV, 2001). The technical approach for CAU 271 consisted of the following activities:

- Excavations

- Field-screening

- Septic tank and distribution box integrity soil sampling

- Leachfield soil sampling

- Septic tank, distribution box, and collection system piping inspections and sampling

- Unrestricted release criteria determination

- In situ gamma radiation measurements

- Surface soil sampling

This investigation strategy allowed the nature and extent of contamination associated with each CAS to be established. The following sections describe the specific investigation activities that took place at CAU 271.

\section{A.2.3.1 Excavations}

The primary purpose of backhoe excavation was to collect soil for characterization purposes. However, excavations at leachfields and collection systems served these additional purposes: 
- Located leachfield system components

- Exposed biased and/or random sampling horizons

- Removed soil from excavations for sampling at all fifteen CASs

- Exposed the septic tank lids at CASs 25-04-03, 25-04-08, 25-04-10, 25-04-11, 26-04-02, and 27-05-02

- Collected integrity samples at the influent and effluent ends of septic tanks (all CASs except 26-03-01 and 26-05-01)

- Collected integrity samples at the effluent end of distribution boxes (all CASs except 25-04-01, 25-04-03, 25-04-09, and 26-03-01)

- Provided access to inspect the collection system piping to appraise the contents of the pipes (all CASs except 26-03-01)

- Allowed for the access of pipe segments for unrestricted release criteria determinations at CASs 26-05-01 and 26-05-03

Excavating the leachfields at CASs 25-04-03, 25-04-10, and 26-05-05 revealed that leachfield and distribution pipes did not match the sampling locations proposed in the CAIP. Using this information, biased sample locations were adjusted to properly characterize the leachfields.

At CAS 25-04-01, it was discovered that an inlet pipe to the septic tank (not shown on the engineering drawing) was constructed of asbestos transite pipe. This information allowed for the proper health and safety controls to be put in place for worker protection prior to completing the characterization at CAS 25-04-01.

Excavated soil was returned as near to its original location as practical. Spoils were staged next to excavations. When left open overnight, excavations were fenced and open excavation signs were posted. Drilling was not required at CAU 271 because excavations were adequate for sample collection.

\section{A.2.3.2 Field Screening}

Field-screening activities were performed as specified in the CAIP. The FSL for VOC headspace was established at 20 parts per million (ppm) or 2.5 times background, whichever was greater. The 
site-specific FSLs for alpha and beta/gamma radiation were defined as the mean background activity level plus two times the standard deviation of readings from 20 background locations. The radiation FSLs are instrument-specific and were established for each instrument prior to use. Field screening was conducted for VOCs (using a photoionization detector) and for alpha and beta/gamma radiation (using an Electra survey instrument).

At CASs and general locations where FSLs were exceeded, statements are provided in CAS-specific sections (Section A.3.0 through Section A.17.0) of this document. Field-screening results are recorded on sample collection logs and are retained in project files.

\section{A.2.3.3 Septic Tank and Distribution Box Integrity Soil Sampling}

Septic tank and distribution box integrity samples were collected from backhoe excavations at pertinent CASs. These samples were collected from below the base of the influent and effluent ends of septic tanks, and below the base of the effluent end of the distribution boxes.

Soil was field screened for health and safety parameters to guide investigations. Labelled sample containers were filled according to the following sequence. The sample container for total VOCs was filled with soil directly from the backhoe bucket followed by collection of material for VOC field screening. Additional soil was transferred into a stainless-steel bowl and homogenized prior to being placed in the remaining sample containers. Excess soil was returned to the excavation, and custody seals were applied to the sample containers. This process also applies to soil samples collected from leachfields (Section A.2.3.4).

\section{A.2.3.4 Leachfield Soil Sampling}

Backhoe trenching consisted of cutting linear trenches perpendicular to the long axis of distribution pipes. Biased samples were collected with the backhoe from soil underlying the distribution pipes and leachrock. Soil samples were either directly collected from the backhoe bucket or from the trench using hand tools.

Consistent with the CAIP, the first sample was collected from the interval 0- to 1-ft below the leachfield/native soil interface, and the second sample was collected from the interval 2.5- to 3.5-ft 
below the interface. If FSLs were not exceeded, the initial intervals (0- to $1-\mathrm{ft})$ were submitted to the laboratory for analysis.

The number of samples collected and submitted to the laboratory depend on field-screening results. At each location, all samples were field screened, but a minimum of one sample was submitted for off-site analysis. Field screening was used to establish vertical and lateral contamination boundaries determined by two successive measurements below FSLs. When FSLs indicated that two consecutive soil sampling intervals were below FSLs, the first sample below the FSLs was submitted for laboratory analysis. The second (lower) sample collected with screening results below FSLs was returned to the sampling location and not submitted for off-site analysis. In addition, samples with screening results above FSLs were generally submitted for laboratory analysis.

Samples with results below FSLs were not obtained prior to reaching refusal or the deepest sampling interval achievable with backhoe excavation. These exceptions will be discussed in the CAS-specific sections. Generally, laboratory results confirmed the absence of contamination at the locations sampled.

\section{A.2.3.5 Septic Tank, Distribution Box, and Collection System Piping Inspections and Sampling}

Septic tanks, distribution boxes, and collection system piping were inspected for sludge and liquid. If appropriate and/or adequate material was present, it was sampled. The planned inspections were conducted through distribution box lids, through septic tank manholes, and by breaking pipes.

The septic tanks and distribution boxes were sampled and analyzed to support disposal of the contents during anticipated closure activities. Liquid and sludge samples were analyzed in accordance with the requirements in the CAIP, except as noted. The analyses are listed in CAS-specific sections and the analytical results are compared to the Federal limits for hazardous waste, NDEP hydrocarbon action limit, landfill acceptance criteria, and the POC established for the NTS. These POCs have been established for NTS hazardous waste generators to ensure that all hazardous waste being shipped off site contains no "added radioactivity" (BN, 1995).

Select samples were analyzed on site for fecal coliform bacteria. Excess liquid and sludge was returned to the septic tanks or distribution boxes after fecal coliform bacteria analysis. Conditions 
and content volumes of the septic tanks and distribution boxes are provided in the CAS-specific sections. To support ultimate disposal of the contents, all CASs, except 26-03-01 and 26-05-01, were sampled.

The septic tanks that contained liquid were sampled by inserting a suction rod-type sampler, called a mucksucker, or a liquid column coliwasa sampler into the tank contents at controlled depths. This enabled extraction of discrete phases of either liquid or sludge in the event two phases existed. To obtain a sludge sample using the mucksucker, it was inserted to total depth, opened, and slowly drawn up through the contents as it was filled. To obtain a liquid sample using the coliwasa, it was slowly lowered through the liquid column to the interface with the sludge layer (if present). The plug in the bottom of the coliwasa was then raised to close the sampler and obtain a representative sample for analysis. Material was transferred and placed directly from the mucksucker or coliwasa to sample containers. For those CASs with dry material (i.e., CASs 25-04-04, 25-04-09, 26-04-01, 26-04-02, and 26-05-05), large chunks of the dried sludge were removed with a scoop attached to extension rods. The material was then transferred into a stainless-steel bowl and subsequently into sample containers.

At applicable CASs, the planned collection system inspections were conducted through access locations such as distribution box openings, manholes, and excavated breaks in the collection system pipe upstream from the septic tanks. This strategy did not apply to CAS 26-03-01 as it was not a septic system. Inspections were primarily conducted by passing a video mole through an access point made in the pipe. Throughout the sampling, visual observations were recorded in FADLs. If present, appropriate and accessible material in the pipes was collected at the inspection locations and submitted for laboratory analyses. Material that is clearly not representative of system operation was not collected (e.g., gravel, minimal residue, material contaminated with animal excrement, media containing organic material). Photographs of distribution boxes and open manholes were taken to document the status of empty structures.

\section{A.2.3.6 Unrestricted Release Criteria Determination}

Select sections of collection system piping and distribution box interiors at the two radiologically posted leachfields (CASs 26-05-01 and 26-05-03) were screened to complete the unrestricted release criteria determination task. Collectively, the measurements provided representative characterizations 
of the collection systems relative to NTS criteria. The criteria are tabulated in Table 4-2 of the NV/YMP Radiological Control Manual (DOE/NV, 2000a). At CAS 26-05-01, this determination was performed at the distribution box and at manholes and excavated breaks along the main effluent supply pipes from Buildings 2201 and 2202. At CAS 26-05-03, a single collection system pipe connects Building 2203 to the leachfield; therefore, the distribution box, septic tank, and an upstream manhole were determined to be representative of the system and identified as the only required screening points. The unrestricted release criteria were not exceeded at any points accessed and screened during these activities.

\section{A.2.3.7 In Situ Measurements}

In situ gamma radiation measurements were obtained in subsurface soil using CPT at CASs 26-05-01 and 26-05-03. Measurements were made at background locations prior to the collection of leachfield measurements. Measurements consist of gross gamma radiation count rates and gamma spectra. The background gamma-screening measurements were taken at undisturbed locations adjacent to the two leachfields. In situ measurements were made at the majority of biased and random soil-investigation locations identified in the CAIP for CASs 26-05-01 and 26-05-03. At each location, data were obtained from the ground surface to the depth of the CPT refusal. The average refusal depth was approximately $7.0 \mathrm{ft}$ bgs at both leachfields. Gamma measurements obtained during these pushes were compared to the background measurements to determine if contamination was present, supporting sampling decisions and health and safety controls. Continuous profiles were generated that logged gamma measurements with depth, in addition to traditional geotechnical measurements. These geotechnical capabilities logged tip and sleeve parameters that display results reflecting the various stratigraphic layers of overburden material, leachrock, interface, and native material. This geotechnical/stratigraphic information supported the determination of interface depths for soil sampling during backhoe operations.

The CPT gamma measurements were converted to soil activity for comparison against allowable values for shipping, laboratory acceptance, action levels for the Radiological Work Permit and, to assist with waste management decisions. All data acquired by CPT have been archived in project files. 


\section{A.2.3.8 Surface Soil Sampling}

Surface soil samples were collected at CASs 26-03-01 and 27-05-02. The sampling interval was typically 0 to $0.5 \mathrm{ft}$ bgs.

At CAS 26-03-01, surface soil samples were collected above the reservoir plastic liner as planned. At CAS 27-05-02, surface soil samples were collected during additional sampling efforts conducted in June 2002. Samples were collected from locations and brought to a sampling area prior to being screened for radiological parameters. Samples were collected and placed into a stainless-steel bowl using a disposable scoop. After being homogenized, the material was screened for radiation and sample containers were filled. Excess soil was returned to the sampling location.

\section{A.2.4 Geology}

Leachfields consist of reworked and compacted sand and gravel fill overlying native soils. Regional native surface soil consists of poorly graded, moderately consolidated, alluvial silty sands with gravel and some cobble-sized volcanic detritus. Soil below the leachfields ranged from gravelly sands with fines to well-graded sands. The percentage of organic matter in the soil is low and decreases with depth beyond the native soil interface. Caliche was encountered during excavation sampling at several CASs. In places where the caliche was significant, the sampling intervals specified in the CAIP could not be reached, and the intervals were modified. All modifications were documented on sample collection logs.

At all CASs, most if not all of the ground surface at the site has been disturbed either during or subsequent to the construction of the leachfield or water reservoir. The larger leachfields appear to have been installed in trenches; therefore, the native soil profile remained between trenches. However, at the smaller leachfields (CASs 25-04-08 and 27-05-02), it appears that the entire leachfield area was excavated, the leachfield was constructed, and the area was backfilled. A general field description for each sample was recorded on sample collection logs. A description of the regional geology is provided in the CAIP (DOE/NV, 2001). 


\section{A.2.5 Hydrology}

Dry washes provide channels that concentrate surface runoff; however, there is no perennial streamflow in the region. Surface topography at all of the leachfield CASs ranged from nearly flat to sites where leachfield distribution planes slope gently in the down-flow direction. The contaminated water reservoir is located in a dry wash. The wash flows from Skull Mountain to the north, with steep sides sloping in from the east and west. It appears that water may pond in the reservoir during precipitation events.

Hydrologic conditions beneath the CASs are less important to site characterization because individual leachfields are less than $10 \mathrm{ft}$ below grade and alluvium is likely to reach depths of greater than $100 \mathrm{ft}$ bgs (DOE/NV, 2001). Due to depth to groundwater and climatic conditions, groundwater at the NTS Areas 25, 26, and 27 is not expected to have been impacted by COPCs. In Area 25, the depth to groundwater is estimated to be between 928 and 1,041 ft bgs (USGS, 1995). No saturated zones (e.g., perched water, contaminant saturation) were found anywhere in the subsurface adjacent to or below the leachfields. In Area 26, a perched water table occurs in a zone of the highly fractured rock at depths ranging from 81 to $167 \mathrm{ft}$ bgs (Johnson and Ege, 1964). The perched water may extend to depths exceeding $261 \mathrm{ft}$ before encountering rocks with a low-fracture permeability. The regional water table is thought to be at a depth of about 1,700 ft bgs (DRI, 1988). Information on the depth to groundwater beneath Area 27 could not be located.

\section{A.2.6 Laboratory Analytical Information}

Chemical and radiological analyses were performed by Paragon Analytics, Inc., in Fort Collins, Colorado. Chemical analyses were also performed by EMAX Laboratories, Incorporated of Torrance, California.

The analytical parameters and laboratory analytical methods used to analyze CAU 271 investigation samples are listed in Table A.2-2. Organic and inorganic analytical results, with the exception of beryllium, are compared to the minimum reporting limits (MRLs) established in the Leachfield Work Plan (DOE/NV, 1998). The MRL for beryllium is 5 micrograms per liter $(\mu \mathrm{g} / \mathrm{L})$ in water and $0.5 \mathrm{mg} / \mathrm{kg}$ in soil (DOE/NV, 1996). The analytical results for gamma-emitting radionuclides, Iso-U, Iso-Pu, Sr-90, and tritium are compared to the MRLs established in Table 3-2 of the CAIP. 
Table A.2-2

\section{Laboratory Analytical Parameters and Methods,} CAU 271 Investigation Samples

\begin{tabular}{|c|c|}
\hline Analytical Parameter & Analytical Method \\
\hline Total volatile organic compounds & SW-846 8260B ${ }^{a}$ \\
\hline Total semivolatile organic compounds & SW-846 $8270 \mathrm{C}^{\mathrm{a}}$ \\
\hline Total petroleum hydrocarbons - gasoline-range organics & SW-846 8015B (modified) ${ }^{a}$ \\
\hline Total petroleum hydrocarbons - diesel-range organics & SW-846 8015B (modified) ${ }^{a}$ \\
\hline Polychlorinated biphenyls & SW-846 $8082^{c}$ \\
\hline Total RCRA metals & \multirow{2}{*}{$\begin{array}{l}\text { Water - SW-846 6010B/7470A }{ }^{a, b} \\
\text { Soil - SW-846 6010B/7471A }\end{array}$} \\
\hline Total Beryllium & \\
\hline Total Herbicides & SW-846 8151A \\
\hline Total Pesticides & SW-846 8081A \\
\hline TCLP volatile organic compounds & SW-846 1311/8260B ${ }^{a}$ \\
\hline TCLP semivolatile organic compounds & SW-846 1311/8270C ${ }^{a}$ \\
\hline TCLP RCRA metals & SW-846 1311/6010B/7470A ${ }^{a, b}$ \\
\hline Gamma-Emitting Radionuclides & $\begin{array}{l}\text { Water - EPA } 901.1^{\mathrm{c}, \mathrm{d}} \\
\text { Soil - HASL-300 }\end{array}$ \\
\hline Isotopic uranium & $\begin{array}{l}\text { Water - ASTM D3972-97 }{ }^{e, f} \\
\text { Soil ASTM C1000-90 e,g }\end{array}$ \\
\hline Isotopic plutonium & $\begin{array}{l}\text { Water - ASTM D3865-97 c, h } \\
\text { Soil - ASTMC1001-90 c,i }\end{array}$ \\
\hline Strontium 90 & ASTM D5811-95 c, j \\
\hline Tritium & $\begin{array}{l}\text { Water - EPA 906.0 } \\
\text { Soil }^{\mathrm{k}}-\mathrm{EERF}^{\mathrm{l}}\end{array}$ \\
\hline
\end{tabular}

aU.S. Environmental Protection Agency (EPA), Test Methods for Evaluating Solid Waste, Physical/Chemical Methods, 3rd Edition, Parts 1-4, SW-846 (EPA, 1996)

${ }^{\mathrm{b}}$ Arsenic, barium, cadmium, lead, mercury, selenium, silver, and chromium

${ }^{\circ}$ Or equivalent laboratory method

${ }^{\mathrm{d}}$ Prescribed Methods for Measurement of Radioactivity in Drinking Water (EPA, 1980)

${ }^{\text {e} E n v i r o n m e n t a l ~ M e a s u r e m e n t s ~ L a b o r a t o r y ~ P r o c e d u r e ~ M a n u a l, ~ H A S L-300 ~(D O E, ~ 1997) ~}$

${ }^{\dagger}$ Standard Test Methods for Isotopic Uranium in Water by Radiochemistry (ASTM, 1997a)

${ }^{9}$ Standard Test Methods for Radiochemical Determination of Uranium in Soil by Alpha Spectroscopy (ASTM, 2000a)

${ }^{\mathrm{h}}$ Standard Test Methods for Plutonium in Water (ASTM, 1997b)

'Standard Test Methods for Radiochemical Determination of Plutonium in Soil by Alpha Spectroscopy (ASTM, 2000b)

'Standard Test Methods for Strontium-90 in Water (ASTM, 1995)

${ }^{\mathrm{k}}$ Sludge sample

'EERF - EPA Eastern Environmental Radiation Facility 
Validated analytical data for CAU 271 investigation samples have been compiled and evaluated to determine the presence and/or extent of contamination. The results for each CAS are presented in Section A.3.0 through Section A.17.0. The analytical results have been compared to MRLs, and only those above MRLs are included in CAS-specific tables. The complete laboratory data packages are available in the project central files.

The analytical parameters were selected through the application of site process knowledge according to the EPA's Guidance for the Data Quality Objectives Process (EPA, 1994). Bioassessment samples were not collected because field-screening results and observations did not indicate the need. Samples for geotechnical analysis have been collected and archived. They will be analyzed, if needed to support remediation efforts.

\section{A.2.7 Comparison to Preliminary Action Levels}

Chemicals and radionuclides detected in samples at concentrations greater than PALs are termed COCs. If COCs are present, corrective action must be considered. The PALs for the CAU 271 investigation were determined during the DQO process. For chemical COPCs, PALs are EPA PRGs (EPA, 2000). For radiological COPCs, PALs are listed in Table A.3-2 of the CAIP (DOE/NV, 2001).

Sample data that exceed MRLs are tabulated in the CAS-specific sections that follow (Sections A.3.0 through A.17.0). Results that are greater than PALs (a subset of those that exceed MRLs) are also identified by bold text in the corresponding tables and discussed in Sections A.3.0 to A.17.0. Samples collected during follow-up (step-out) sampling were analyzed for only the COPCs that exceeded PALs in the original samples. 


\section{A.3.0 Security Checkpoint Septic System (CAS 25-04-01)}

The security checkpoint septic system was designed to receive sanitary effluent generated by activities in four temporary office trailers (formerly used as offices for Wackenhut Services, Inc. and Sheriff's Department security personnel) in 1961. The septic system was located approximately $50 \mathrm{ft}$ east of Jackass Flats Road, just south of the guard station at Gate 500. The site was comprised of the leachfield, septic tank, and associated piping. More detail is provided in the CAIP (DOE/NV, 2001).

\section{A.3.1 Corrective Action Investigation}

Fourteen investigation samples, listed in Table A.3-1, were collected during investigation activities conducted at CAS 25-04-01. The planned and actual sample locations are shown in Figure A.3-1. The specific CAI activities that were conducted to meet CAIP requirements at CAS 25-04-01 are described in Table A.2-1.

\section{A.3.1.1 Deviations}

Minor delays were encountered when potential asbestos transite pipe was discovered during excavation. Excavation activities at this location were temporarily ceased until health and safety officials were notified of the condition. This pipe was not shown on any engineering drawing. The decision to allow video inspection of the potential asbestos transite pipe was later made with provisions to protect worker health and safety. This did not cause any deviation from the planned (CAIP-targeted) sample collection scheme.

\section{A.3.2 Investigation Results}

The following subsections provide details of the inspection and sampling of leachfield features, field-screening results, and sample selection and analysis.

\section{A.3.2.1 Septic Tank Contents}

The contents of the septic tank were sampled according to the CAIP. The septic tank was a concrete vertical cylinder with a 428-gal capacity. It was accessed by a manhole with a 3.4-ft diameter, loop-handled, concrete cover that was exposed at the ground surface. The interior dimensions of the 
Table A.3-1

Samples Collected at CAS 25-04-01

(Page 1 of 2)

\begin{tabular}{|c|c|c|c|c|c|c|c|c|c|c|c|c|c|}
\hline \multirow[b]{2}{*}{$\begin{array}{c}\text { Sample } \\
\text { Identification } \\
\text { Number }\end{array}$} & \multirow[b]{2}{*}{$\begin{array}{l}\text { Sample } \\
\text { Location }\end{array}$} & \multirow[b]{2}{*}{$\begin{array}{l}\text { Sample } \\
\text { Matrix }\end{array}$} & \multirow[b]{2}{*}{$\begin{array}{l}\text { Depth } \\
\text { (ft bgs) }\end{array}$} & \multirow[b]{2}{*}{ Purpose } & \multicolumn{9}{|c|}{ Analyses } \\
\hline & & & & & 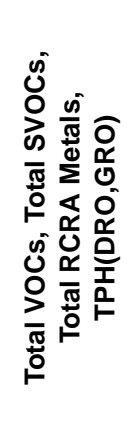 & 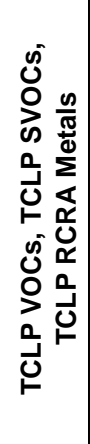 & 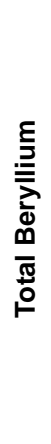 & O̊ & 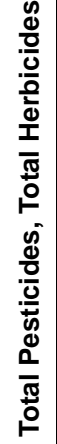 & 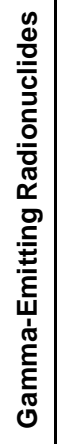 & 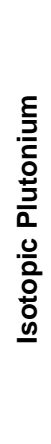 & 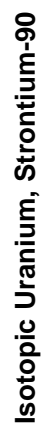 & $\stackrel{E}{E}$ \\
\hline $271 \mathrm{~A} 001$ & A02 & Soil & $8-9$ & Integrity & $\mathrm{X}$ & & & & & $\mathrm{X}$ & & & \\
\hline $271 \mathrm{~A} 002$ & $\mathrm{~A} 02$ & Soil & $10.5-11.5$ & Environmental & \multicolumn{9}{|c|}{ Not Submitted for Analyses ${ }^{a}$} \\
\hline $271 \mathrm{~A} 003$ & A03 & Soil & $5-6$ & Environmental & $\mathrm{X}$ & & & & & $\mathrm{X}$ & $\mathrm{X}$ & $X$ & \\
\hline $271 \mathrm{~A} 004$ & $\mathrm{~A} 03$ & Soil & $5-6$ & $\begin{array}{c}\text { Duplicate of } \\
271 \mathrm{~A} 003\end{array}$ & $x$ & & & & & $x$ & $x$ & $X$ & \\
\hline $271 \mathrm{~A} 005$ & $\mathrm{~A} 03$ & Soil & $7.5-8.5$ & Environmental & \multicolumn{9}{|c|}{ Not Submitted for Analyses ${ }^{a}$} \\
\hline $271 \mathrm{~A} 006$ & A05 & Soil & $5-6$ & Environmental & $\mathrm{X}$ & & & & & $\mathrm{X}$ & & & \\
\hline $271 \mathrm{~A} 007$ & A05 & Soil & $7.5-8.5$ & Environmental & \multicolumn{9}{|c|}{ Not Submitted for Analyses ${ }^{a}$} \\
\hline $271 \mathrm{~A} 008$ & A04 & Soil & $4-5$ & $\begin{array}{c}\text { Environmental } \\
\text { MS/MSD }\end{array}$ & $x$ & & & & & $\mathrm{x}$ & $x$ & $\mathrm{X}$ & \\
\hline $271 \mathrm{~A} 009$ & A04 & Soil & $6.5-7.5$ & Environmental & \multicolumn{9}{|c|}{ Not Submitted for Analyses ${ }^{a}$} \\
\hline $271 \mathrm{~A} 010$ & $\mathrm{~A} 01$ & Soil & $7.2-8.2$ & Integrity & $\mathrm{X}$ & & & & & $x$ & $x$ & $x$ & \\
\hline $271 \mathrm{~A} 011$ & $\mathrm{~A} 01$ & Soil & $9.7-10.7$ & Integrity & \multicolumn{9}{|c|}{ Not Submitted for Analyses ${ }^{a}$} \\
\hline $271 \mathrm{~A} 012$ & NA & Water & $5.25-6.4$ & Septic Tank & $\mathrm{X}$ & & & & & $\mathrm{X}$ & $\mathrm{x}$ & $x$ & $x$ \\
\hline $271 \mathrm{~A} 013$ & NA & Sludge & $6.4-7.7$ & Septic Tank & $\mathrm{X}$ & $x$ & & & & $x$ & $\mathrm{X}$ & $x$ & $x$ \\
\hline $271 \mathrm{~A} 014$ & A06 & Soil & $3-3.5$ & Geotechnical & \multicolumn{9}{|c|}{ Not Submitted for Analyses ${ }^{b}$} \\
\hline $271 \mathrm{~A} 301$ & NA & Water & NA & Trip Blank & VOC only & & & & & & & & \\
\hline $271 \mathrm{A3} 02$ & NA & Water & NA & Trip Blank & VOC only & & & & & & & & \\
\hline $271 \mathrm{~A} 303$ & NA & Water & NA & Rinsate & $\mathrm{X}$ & & & & & $X$ & $\mathrm{X}$ & $X$ & \\
\hline $271 \mathrm{~A} 304$ & NA & Water & NA & Source Blank & $x$ & & $x$ & $x$ & $x$ & $x$ & $x$ & $x$ & $x$ \\
\hline
\end{tabular}


Table A.3-1

Samples Collected at CAS 25-04-01

(Page 2 of 2)

\begin{tabular}{|c|c|c|c|c|c|c|c|c|c|c|c|c|c|}
\hline \multirow[b]{2}{*}{$\begin{array}{c}\text { Sample } \\
\text { Identification } \\
\text { Number }\end{array}$} & \multirow[b]{2}{*}{$\begin{array}{l}\text { Sample } \\
\text { Location }\end{array}$} & \multirow[b]{2}{*}{$\begin{array}{l}\text { Sample } \\
\text { Matrix }\end{array}$} & \multirow[b]{2}{*}{$\begin{array}{c}\text { Depth } \\
\text { (ft bgs) }\end{array}$} & \multirow[b]{2}{*}{ Purpose } & \multicolumn{9}{|c|}{ Analyses } \\
\hline & & & & & 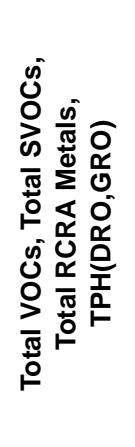 & 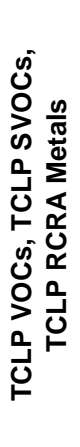 & 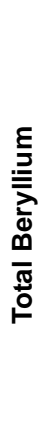 & 䓢 & 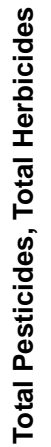 & 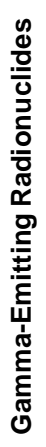 & 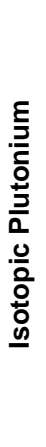 & 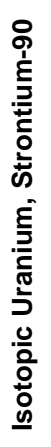 & 틀 \\
\hline $271 \mathrm{~A} 305$ & NA & Water & NA & Trip Blank & VOC only & & & & & & & & \\
\hline $271 \mathrm{~A} 306$ & NA & Water & NA & Field Blank & $x$ & & & & & $x$ & $x$ & $x$ & \\
\hline 271A307 & NA & Water & NA & Trip Blank & VOC only & & & & & & & & \\
\hline 271A501 & NA & Liquid & NA & $\begin{array}{l}\text { WM Sample } \\
\text { from Drum } \\
271 \mathrm{~A} 03\end{array}$ & $\begin{array}{l}\text { RCRA } \\
\text { Metals } \\
\text { (Lead) }\end{array}$ & & & $x$ & & & & & \\
\hline
\end{tabular}

${ }^{\text {aT }}$ The sample was collected, field screened, and returned to the site for disposal.

${ }^{\mathrm{b}}$ The sample was collected, field screened, and is being stored for possible geotechnical analysis.

$\mathrm{NA}=$ Not applicable

$\mathrm{MS} / \mathrm{MSD}=$ Matrix spike/matrix spike duplicate

tank are $3.1 \mathrm{ft}$ (diameter) by $7.67 \mathrm{ft}$ (depth). One liquid and one sludge sample were collected from the septic tank. Visual inspection revealed that approximately $1.2 \mathrm{ft}$ (65 gal) of liquid and a $1.25 \mathrm{ft}$ (70 gal) of sludge remained in the bottom of the tank. Photographs of the interior of the septic tank were taken to document the visual inspection (Figure A.3-2). The pipe-like features shown in Figure A.3-2 are old sampling devices.

\section{A.3.2.2 Septic Tank Integrity Soil Sampling}

Four integrity samples were collected from two sample locations adjacent to the influent and effluent ends of the septic tank. The following two samples were submitted for laboratory analysis:

- The upper sample (271A001) from the outlet end of the septic tank, collected at 8 to $9 \mathrm{ft}$ bgs

- The upper sample (271A010) from the inlet end of the septic tank, collected at 7.2 to $8.2 \mathrm{ft}$ bgs 


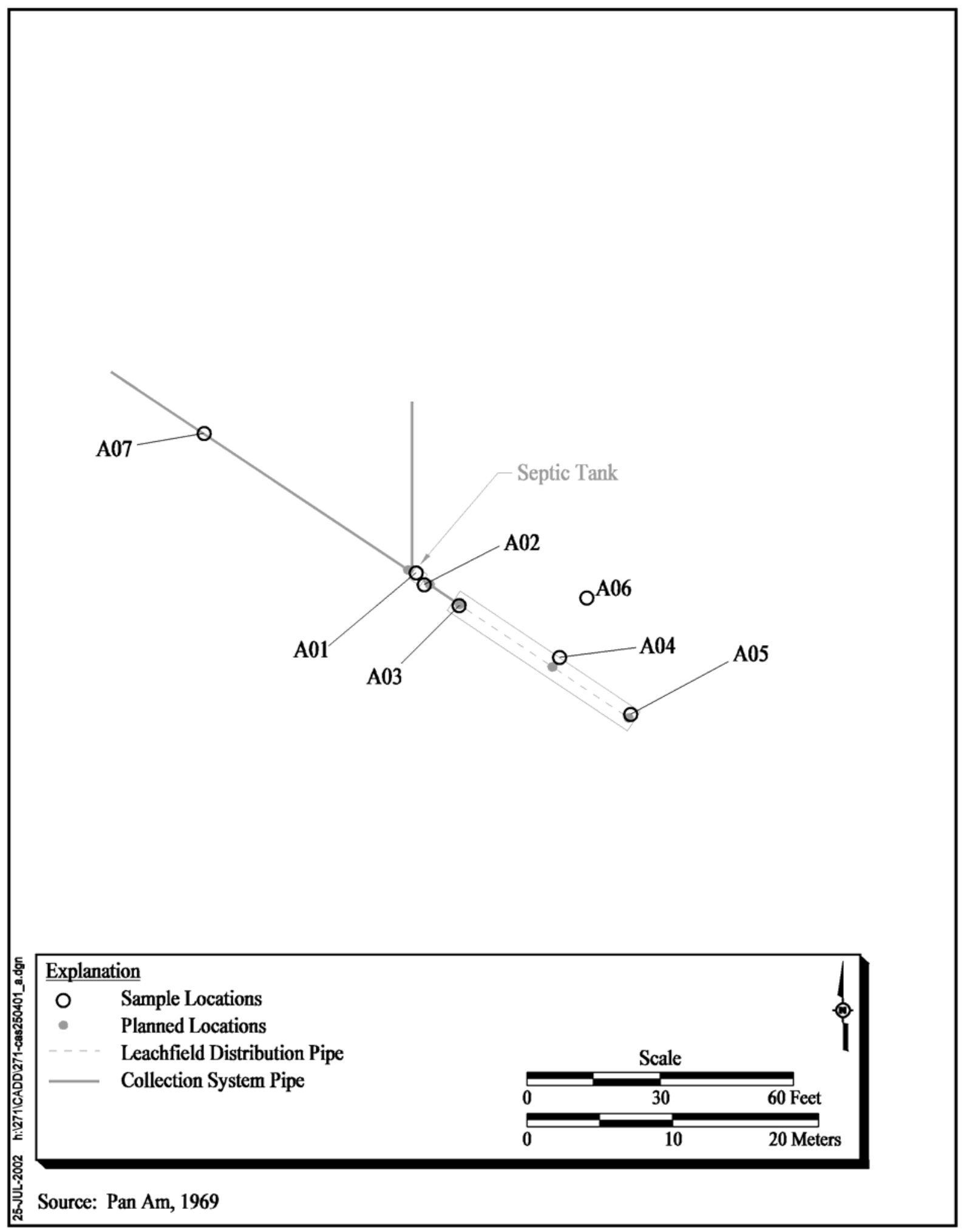

Figure A.3-1

Security Checkpoint Septic System

(CAS 25-04-01) Sample Locations 


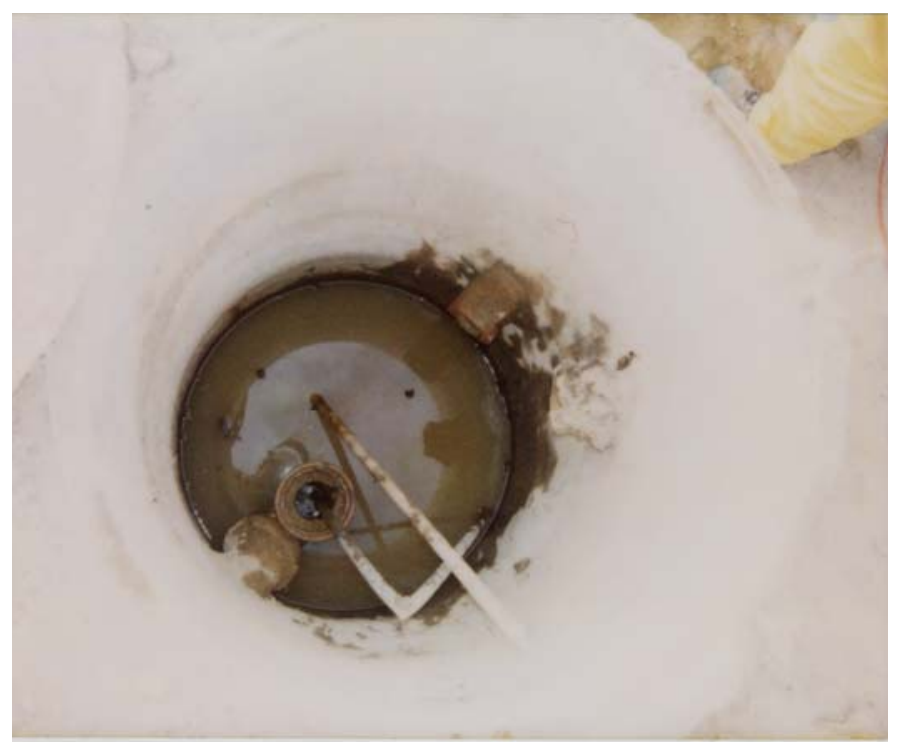

Figure A.3-2

CAS 25-04-01 Septic Tank, Interior View

(Photograph Taken 01-08-2002)

A photograph of the inlet end of the septic tank was taken to document the composition and integrity of the septic tank and the relative depth of the integrity samples (Figure A.3-3).

\section{A.3.2.3 Leachfield Excavation Soil Sampling}

Backhoe excavations were conducted to access sampling horizons at the biased locations presented in the CAIP. Excavations provided a visual verification of distribution pipes and confirmed that soil samples were collected from intervals beneath the pipes, as specified by the CAIP. Eight soil samples were collected from the planned locations excavated within the leachfield. These samples were collected from an interval at the leachrock/native soil interface and an interval $2.5 \mathrm{ft}$ below the interface. The interface was found at depths ranging from 4 to $5 \mathrm{ft}$ bgs. Four samples were submitted for laboratory analysis. In addition, one QC soil duplicate and one matrix spike/matrix spike duplicate (MS/MSD) sample were collected and analyzed. A geotechnical sample was collected outside the boundary of the leachfield. The sample will be sent to a laboratory for geotechnical analysis, if necessary. 


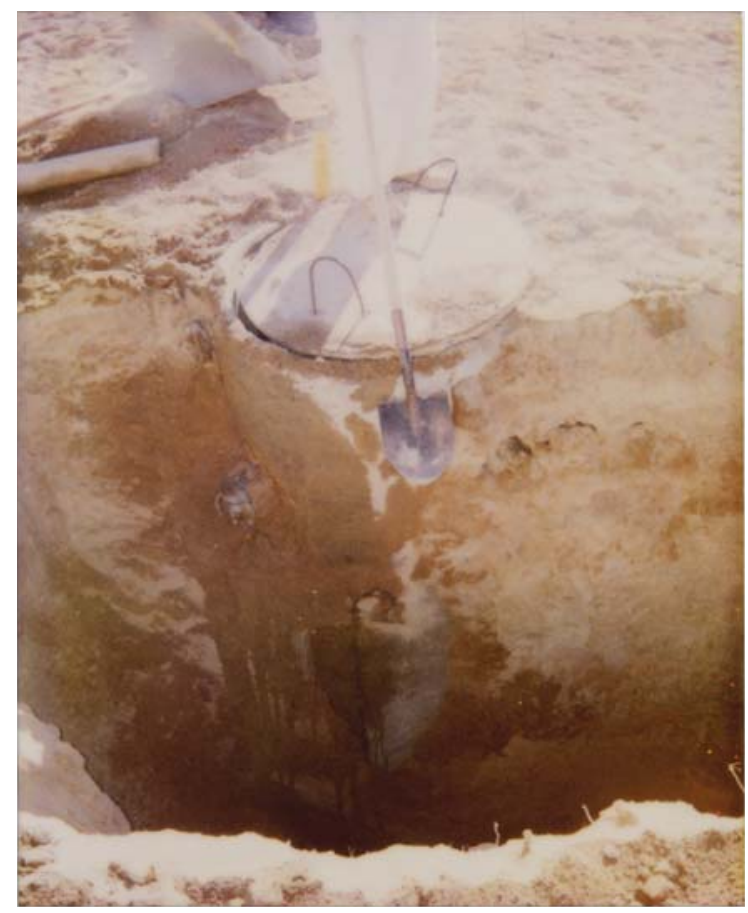

Figure A.3-3

CAS 25-04-01 Septic Tank, Inlet End (Photograph Taken 01-08-2002)

\section{A.3.2.4 Additional Sampling}

One waste management sample (271A501) was collected from investigation-derived waste (IDW) drum 271A03 to further determine the appropriate waste disposal method. This drum contains rinsate associated with fecal coliform testing for all of CAU 271 septic tanks. The sample was analyzed for PCBs and RCRA metals (i.e., lead).

\section{A.3.2.5 Collection System Pipe Inspections}

No distribution boxes were associated with this system. Access points for inspection by video mole survey were created at locations along the collection pipe via backhoe excavation.

There were two inlets leading into the septic tank, a line entering from the north and one from the northwest. First, the video mole was inserted through the northwest line at an excavated opening into the VCP leading into the septic tank. Refusal was encountered at $46 \mathrm{ft}$; therefore, another excavation (location A07, see Figure A.3-1) was made $13 \mathrm{ft}$ upstream of the obstruction (59 ft upstream of the septic tank). The video mole was sent downstream and was able to pass the location where refusal 
had been encountered. The video mole was then sent upstream for $32 \mathrm{ft}$, where a termination point in the form of a cleanout was discovered. Therefore, the entire 91-ft length of collection pipe was inspected. Scaling was present on the piping and a slight amount of moisture was present. Some sediment was identified in the piping, but was not an adequate amount for sampling. No breaches or offshoot lines were observed.

The video mole was then introduced through the transite pipe, trending in a northern direction. The line was surveyed for $34.5 \mathrm{ft}$. The line appeared to be blocked and refusal was encountered. No sediment, breaches, or offshoot lines were observed. Visual observations were recorded in the FADLs.

Portions of the pipe at location A07 were radiologically surveyed. The results are discussed in Section A.3.2.7.

\section{A.3.2.6 Field-Screening Results}

Soil samples were screened for VOCs and alpha and beta/gamma-emitting radionuclides, and the readings were compared to FSLs to guide sampling decisions. No VOCs greater than FSLs were found during soil sample screening. The results of field screening for alpha and beta/gamma radioactivity are discussed in Section A.3.2.7.

A sample of the septic tank content (sludge) was also collected and analyzed for fecal coliform bacteria. The sample was negative for fecal coliform bacteria.

\section{A.3.2.7 Radiological Survey Results}

All radiological field-screening results for soil samples from CAS 25-04-01 were below FSLs. The results of the survey of the collection system pipe at location A07 indicate that the pipeline meets the unrestricted release criteria as defined in the NV/YMP Radiological Control Manual (DOE/NV, 2000a). 


\section{A.3.2.8 Sample Analysis}

Environmental soil samples and associated QC samples were collected and analyzed for the CAIP-specified COPCs which include total VOCs, total SVOCs, total RCRA metals, and TPH (DRO and GRO). In addition, 25 percent of the soil samples and 100 percent of the associated QC samples were analyzed for Iso-U, Iso-Pu, and Sr-90. One-hundred percent of the soil and associated QC samples were analyzed for gamma-emitting radionuclides.

Both the sludge and liquid samples were analyzed for total VOCs, total SVOCs, TPH (GRO and DRO), total RCRA metals, gamma-emitting radionuclides, Iso-U, Iso-Pu, Sr-90, and tritium. The sludge sample was analyzed according to the TCLP for VOCs, SVOCs, and RCRA metals.

The analytical parameters and laboratory analytical methods used to analyze the investigation samples are listed in Table A.2-2. Table A.3-1 lists the sample-specific analytical parameters.

\section{A.3.3 Analytes Detected Above Minimum Reporting Limits}

The soil sample analytical results with concentrations exceeding corresponding MRLs or PALs (DOE/NV, 1998; DOE/NV, 2001) at CAS 25-04-01 are summarized in the following sections. The results of septic tank contents are compared to appropriate regulatory levels for disposal. A portion of the CAS 25-04-01 analytical results were rejected; however, these rejected data did not impact closure decisions as discussed in Section B.1.3.1.

\section{A.3.3.1 Analytical Results for Soil Samples}

The following sections discuss the results for soil samples in comparison to the levels established in the Leachfield Work Plan and the CAIP.

\section{A.3.3.1.1 Total Volatile Organic Compounds}

Volatile organic compound results are reported in Table A.3-2. The only organic compound detected above the MRL of $5 \mu \mathrm{g} / \mathrm{kg}$ was acetone. Concentrations ranged between 25 and $73 \mu \mathrm{g} / \mathrm{kg}$ (reported "J" values represent estimated concentrations above the minimum detection limit [MDL], but below laboratory reporting limits). Acetone concentrations were below EPA Region 9 PRG of $6,200,000 \mu \mathrm{g} / \mathrm{kg}$. Acetone is a common laboratory contaminant. 
Table A.3-2

Soil Sample Results for Total VOCs Detected Above Minimum Reporting Limits at CAS 25-04-01

\begin{tabular}{|c|c|c||}
\hline \multirow{2}{*}{$\begin{array}{c}\text { Sample } \\
\text { Identification Number }\end{array}$} & $\begin{array}{c}\text { Depth } \\
\text { (ft bgs) }\end{array}$ & Contaminants of Potential Concern $(\mu \mathrm{g} / \mathrm{kg})$ \\
\cline { 3 - 3 } & & Acetone \\
\hline Preliminary Action Levels & $\mathbf{6 , 2 0 0 , 0 0 0}$ \\
\hline \hline $271 \mathrm{~A} 004$ & $5-6$ & $25(\mathrm{~J})^{\mathrm{b}}$ \\
\hline $271 \mathrm{~A} 010$ & $7.2-8.2$ & $73(\mathrm{~J})^{\mathrm{c}}$ \\
\hline
\end{tabular}

aBased on U.S. Environmental Protection Agency, Region 9 Preliminary Remediation Goals (PRGs) (EPA, 2000).

${ }^{b} Q$ ualifier added to laboratory data; record accepted. Average relative response factor $<0.05$. Relative response factor $<0.05$.

${ }^{\circ}$ Qualifier added to laboratory data; record accepted. Average relative response factor $<0.05$. Relative response factor $<0.05$. Continuing calibration verification percent $>25$ percent. An associated trip blank was not analyzed.

$\mathrm{J}=$ Estimated value

\section{A.3.3.1.2 Total Semivolatile Organic Compounds}

Semivolatile organic compounds were not detected above MRLs in CAS 25-04-01 soil samples.

\section{A.3.3.1.3 Total Petroleum Hydrocarbons}

Total petroleum hydrocarbons were not detected above MRLs in CAS 25-04-01 soil samples.

\section{A.3.3.1.4 Total RCRA Metals}

As shown in Table A.3-3, the total RCRA metals detected in soil samples at concentrations exceeding the MRLs are arsenic (1 mg/kg), barium (20 mg/kg), chromium (1 mg/kg), and lead (0.3 mg/kg). All other RCRA metals (i.e., cadmium, mercury, selenium, silver) were below specified MRLs.

Barium concentrations ranged from 120 to $150 \mathrm{mg} / \mathrm{kg}$, chromium concentrations ranged from 4.2 to $6.3 \mathrm{mg} / \mathrm{kg}$, and lead concentrations ranged from 6.4 to $9.1 \mathrm{mg} / \mathrm{kg}$. All reported concentrations of these metals were below EPA Region 9 PRGs defined in this document as PALs.

Arsenic concentrations ranged from 3.7 to $5.5 \mathrm{mg} / \mathrm{kg}$. The highest and lowest concentrations were detected between 5 and $9 \mathrm{ft}$ bgs. The data indicate a consistent arsenic concentration across the site 
Table A.3-3

Soil Sample Results for Total RCRA Metals Detected Above Minimum Reporting Limits at CAS 25-04-01

\begin{tabular}{|c|c|c|c|c|c|}
\hline \multirow{2}{*}{$\begin{array}{c}\text { Sample } \\
\text { Identification } \\
\text { Number }\end{array}$} & \multirow{2}{*}{$\begin{array}{c}\text { Depth } \\
\text { (ft bgs) }\end{array}$} & \multicolumn{4}{|c|}{ Contaminants of Potential Concern (mg/kg) } \\
\hline & & Arsenic & Barium & Chromium & Lead \\
\hline \multicolumn{2}{|c|}{ Preliminary Action Levels $^{a}$} & 2.7 & 100,000 & 450 & 750 \\
\hline $271 \mathrm{~A} 001$ & $8-9$ & 3.7 & 120 & 4.9 & 6.7 \\
\hline $271 \mathrm{~A} 003$ & $5-6$ & 3.9 & 120 & 6.3 & 9.1 \\
\hline $271 \mathrm{~A} 004$ & $5-6$ & 4.5 & 140 & 6.2 & 9.1 \\
\hline 271A006 & $5-6$ & 5.5 & 130 & 6 & 8.4 \\
\hline $271 \mathrm{~A} 008$ & $4-5$ & 4.1 & 150 & 6 & 6.7 \\
\hline $271 \mathrm{~A} 010$ & $7.2-8.2$ & 4 & 130 & 4.2 & 6.4 \\
\hline
\end{tabular}

aBased on U.S. Environmental Protection Agency, Region 9 Preliminary Remediation Goals (PRGs) (EPA, 2000).

with no "hot spots" or evidence of a localized spill. The PAL for arsenic is defined by EPA Region 9 as $2.7 \mathrm{mg} / \mathrm{kg}$, indicating that a majority of the samples tested were above this PAL. The PAL is lower than the 7- to 8-mg/kg mean concentration of arsenic in silt from the Nevada Test and Training Range (formerly Nellis Air Force Range) (NBMG, 1998; Moore, 1999). The distribution of arsenic in the leachfield soil and known background concentrations in the region suggest that arsenic concentrations exceeding the PAL at CAS 25-04-01 represent ambient conditions, not contamination.

\section{A.3.3.1.5 Polychlorinated Biphenyls}

One sample (271A03) was collected from IDW drum number 271A03 for waste management purposes. Drum 271A03 contains rinsate associated with fecal coliform testing for all of CAU 271 septic tanks. Sampling for PCBs revealed that concentrations were below the regulatory limits and disposal criteria.

\section{A.3.3.1.6 Gamma Spectrometry}

Results of soil sample gamma spectrometry analysis are presented in Table A.3-4. The concentrations for actinium-228, bismuth-212, bismuth-214, lead-212, lead-214, potassium-40, and 
Table A.3-4

Soil Sample Results for Gamma-Emitting Radionuclides Detected Above Minimum Reporting Limits at CAS 25-04-01

\begin{tabular}{|c|c|c|c|c|c|c|c|c|}
\hline \multirow{2}{*}{$\begin{array}{c}\text { Sample } \\
\text { Identification } \\
\text { Number }\end{array}$} & \multirow{2}{*}{$\begin{array}{c}\text { Depth } \\
\text { (ft bgs) }\end{array}$} & \multicolumn{7}{|c|}{ Contaminants of Potential Concern $(\mathrm{pCi} / \mathrm{g})$} \\
\hline & & Actinium-228 ${ }^{a}$ & Bismuth-212 ${ }^{\mathrm{b}}$ & Bismuth-214 & Lead-212 ${ }^{\mathrm{a}}$ & Lead-214 ${ }^{b}$ & Potassium- $40^{a}$ & Thallium-208 \\
\hline \multicolumn{2}{|c|}{ Preliminary Action Level } & 3.64 & 2.4 & 3.47 & 2.9 & 2.9 & 96 & 3.4 \\
\hline $271 \mathrm{~A} 001$ & $8-9$ & $1.31 \pm 0.45$ & --- & $\overline{0.89 \pm 0.34}$ & $1.5 \pm 0.37$ & $\overline{71.09 \pm 0.28}$ & $24.4 \pm 5.5$ & $0.44 \pm 0.17$ \\
\hline $271 \mathrm{~A} 003$ & $5-6$ & $1.49 \pm 0.32$ & -- & $0.9 \pm 0.21$ & $1.69 \pm 0.31$ & $0.97 \pm 0.20$ & $26.6 \pm 4.7$ & $0.49 \pm 0.11$ \\
\hline $271 \mathrm{~A} 004$ & $5-6$ & $1.53 \pm 0.31$ & -- & $0.75 \pm 0.18$ & $1.63 \pm 0.30$ & $0.93 \pm 0.19$ & $28.7 \pm 5.0$ & $0.48 \pm 0.10$ \\
\hline $271 \mathrm{~A} 006$ & $5-6$ & -- & $\overline{--}$ & $0.83 \pm 0.34$ & $1.44 \pm 0.38$ & $1 \pm 0.32$ & $21.1 \pm 5.2$ & $0.51 \pm 0.19$ \\
\hline $271 \mathrm{~A} 008$ & $4-5$ & $1.43 \pm 0.34$ & -- & $0.89 \pm 0.22$ & $1.61 \pm 0.32$ & $0.85 \pm 0.20$ & $24.5 \pm 4.7$ & $0.51 \pm 0.12$ \\
\hline $271 \mathrm{~A} 010$ & $7.2-8.2$ & $1.49 \pm 0.31$ & $1.74 \pm 0.72$ & $0.85 \pm 0.19$ & $1.47 \pm 0.27$ & $0.94 \pm 0.19$ & $26.1 \pm 4.6$ & $0.395 \pm 0.089$ \\
\hline
\end{tabular}

aBackground concentration listed in Environmental Monitoring Report for the Proposed Ward Valley, California, Low-Level Radioactive Waste (LLRW) Facility (US Ecology and Atlan-Tech, 1992).

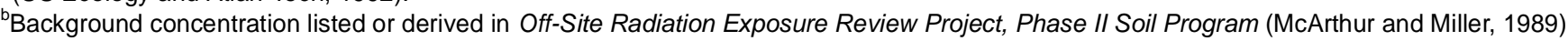

$--=$ Not detected above minimum reporting limit 
thallium-208 were detected above the MDLs. The total propagated uncertainty (TPU) in the radiological measurements is provided in the table along with the concentration for gamma emitters. The concentrations of the detected gamma-emitting radionuclides are below PALs and are not significantly different than concentrations measured in soil samples collected from undisturbed background locations.

\section{A.3.3.1.7 Isotopic Uranium}

Detected values of uranium isotopes along with associated TPUs are as reported in Table A.3-5. Sample numbers 271A003, 271A004, 271A008, and 271A010 had concentrations of U-235 above the PAL; therefore, a normalized difference based on a confidence level of 95 percent was used to determine if the concentrations were statistically distinguishable from background. Concentrations of the uranium isotopes were not significantly greater than concentrations in soil samples collected from undisturbed background locations.

Table A.3-5

Soil Sample Results for Isotopic Uranium Detected Above Minimum Reporting Limits at CAS 25-04-01

\begin{tabular}{|c|c|c|c|c|}
\hline \multirow{2}{*}{$\begin{array}{c}\text { Sample } \\
\text { Identification } \\
\text { Number }\end{array}$} & \multirow{2}{*}{$\begin{array}{c}\text { Depth } \\
\text { (ft bgs) }\end{array}$} & \multicolumn{3}{|c|}{ Contaminants of Potential Concern (pCi/g) } \\
\cline { 3 - 5 } & & Uranium-234 & Uranium-235 & Uranium-238 $^{\mathrm{b}}$ \\
\hline \multicolumn{2}{|c|}{ Preliminary Action Levels } & $\mathbf{1 . 5 6}$ & $\mathbf{0 . 0 7}$ & $\mathbf{3 . 2}$ \\
\hline \hline $271 \mathrm{~A} 003$ & $5-6$ & $1.04 \pm 0.19$ & $0.085 \pm 0.040$ & $0.96 \pm 0.18$ \\
\hline $271 \mathrm{~A} 004$ & $5-6$ & $1.12 \pm 0.21$ & $0.097 \pm 0.046$ & $1.03 \pm 0.20$ \\
\hline $271 \mathrm{~A} 008$ & $4-5$ & $1.23 \pm 0.22$ & $0.085 \pm 0.041$ & $0.98 \pm 0.18$ \\
\hline $271 \mathrm{~A} 010$ & $7.2-8.2$ & $1.12 \pm 0.20$ & $0.087 \pm 0.039$ & $1.04 \pm 0.19$ \\
\hline
\end{tabular}

\footnotetext{
aBackground concentration listed in Environmental Monitoring Report for the Proposed Ward Valley, California, Low-Level Radioactive Waste (LLRW) Facility (US Ecology and Atlan-Tech, 1992).

'Background concentration listed or derived in Off-Site Radiation Exposure Review Project, Phase II Soil Program (McArthur and Miller, 1989).

$\mathrm{pCi} / \mathrm{g}=$ Picocuries per gram
}

\section{A.3.3.1.8 Isotopic Plutonium}

Isotopic plutonium was not detected above MRLs in CAS 25-04-01 soil samples. 


\section{A.3.3.1.9 Strontium-90}

Strontium-90 was not detected above MRLs in CAS 25-04-01 soil samples.

\section{A.3.3.2 Septic Tank Sample Results}

Results of collected septic tank content samples were compared to regulatory levels based on disposal options. If the waste has no hazardous component, the regulatory level is based on NTS disposal options at landfills and lagoons (BN, 1995; CFR, 2000c and c; NDEP, 1997a, b, and c). Any sludge or liquid waste will be solidified before disposal at the NTS landfills (NDEP, 1997b). If the waste is hazardous, the release criteria are based on interpretation of the guidelines presented in the POC (BN, 1995; Alderson, 1999). For waste destined for off-site disposal, the POC radiological levels must be met to certify that the waste has no radioactivity added.

One sludge (271A013) and one liquid (271A012) sample were obtained from the septic tank. The analytical suite followed the CAIP and is detailed in Section A.3.2.8. Analytical results exceeding MRLs are listed in Table A.3-6.

Table A.3-6

Liquid and Sludge Sample Results Above Minimum Reporting Limits at CAS 25-04-01

(Page 1 of 2)

\begin{tabular}{|c|c|c|c|c|c|c|}
\hline $\begin{array}{c}\text { Sample } \\
\text { Identification } \\
\text { Number }\end{array}$ & Matrix & Parameter & Result & Units & Limits & Reference \\
\hline $271 \mathrm{~A} 012$ & Liquid & 1,4-Dichlorobenzene & 19 & $\mu g / L$ & 7,500 & CFR, 2000b \\
\hline $271 \mathrm{~A} 012$ & Liquid & Acetone & $9.3(\mathrm{~J})$ & $\mu g / L$ & NA & CFR, 2000b \\
\hline 271A012 & Liquid & Methylene Chloride & 5.2 & $\mu \mathrm{g} / \mathrm{L}$ & NA & CFR, 2000b \\
\hline $271 \mathrm{~A} 012$ & Liquid & 1,4-Dichlorobenzene & 13 & $\mu \mathrm{g} / \mathrm{L}$ & 7,500 & CFR, 2000b \\
\hline $271 \mathrm{~A} 012$ & Liquid & Uranium-234 & $2.04 \pm 0.36$ & $\mathrm{pCi} / \mathrm{L}$ & 100 & NDEP, 1997b \\
\hline $271 \mathrm{~A} 012$ & Liquid & Uranium-238 & $0.56 \pm 0.15$ & $\mathrm{pCi} / \mathrm{L}$ & 100 & NDEP, 1997b \\
\hline $271 \mathrm{~A} 013$ & Sludge & Mercury** & 10 & $\mathrm{mg} / \mathrm{kg}$ & NA & CFR, 2000b \\
\hline $271 A 013$ & Sludge & Diesel-Range Organics & $4,600(Z)$ & $\mathbf{m g} / \mathbf{k g}$ & 100 & NDEP, 1997b \\
\hline $271 \mathrm{~A} 013$ & Sludge & Chlorobenzene & $8,900(J)$ & $\mu \mathrm{g} / \mathrm{kg}$ & NA & CFR, 2000b \\
\hline 271A013 & Sludge & 1,4-Dichlorobenzene & $5,800,000$ & $\mu \mathrm{g} / \mathrm{kg}$ & NA & CFR, 2000b \\
\hline
\end{tabular}


Table A.3-6

Liquid and Sludge Sample Results Above Minimum Reporting Limits at CAS 25-04-01

(Page 2 of 2)

\begin{tabular}{|c|c|c|c|c|c|c|}
\hline $\begin{array}{c}\text { Sample } \\
\text { Identification } \\
\text { Number }\end{array}$ & Matrix & Parameter & Result & Units & Limits & Reference \\
\hline $271 \mathrm{~A} 013$ & Sludge & 4-Methylphenol & $7,800(J)^{a}$ & $\mu \mathrm{g} / \mathrm{kg}$ & NA & CFR, 2000b \\
\hline $271 \mathrm{~A} 013$ & Sludge & Gasoline-Range Organics & $2,400(Z)$ & $\mathrm{mg} / \mathrm{kg}$ & 100 & NDEP, 1997b \\
\hline $271 \mathrm{~A} 013$ & Sludge & Potassium-40 & $16.9 \pm 3.9$ & $\mathrm{pCi} / \mathrm{g}$ & - & $\mathrm{N}$ \\
\hline $271 \mathrm{~A} 013$ & Sludge & Lead-212 & $1.18 \pm 0.29$ & $\mathrm{pCi} / \mathrm{g}$ & - & $\mathrm{N}$ \\
\hline $271 \mathrm{~A} 013$ & Sludge & Uranium-234 & $8.5 \pm 1.2$ & $\mathrm{pCi} / \mathrm{g}$ & 100 & NDEP, 1997b \\
\hline $271 \mathrm{~A} 013$ & Sludge & Uranium-235 & $0.282 \pm 0.075$ & $\mathrm{pCi} / \mathrm{g}$ & 100 & NDEP, 1997b \\
\hline $271 \mathrm{~A} 013$ & Sludge & Uranium-238 & $1.73 \pm 0.28$ & $\mathrm{pCi} / \mathrm{g}$ & 100 & NDEP, 1997b \\
\hline $271 \mathrm{~A} 013$ & Sludge & Arsenic** & 27 & $\mathrm{mg} / \mathrm{kg}$ & NA & CFR, 2000b \\
\hline $271 \mathrm{~A} 013$ & Sludge & Barium** & 140 & $\mathrm{mg} / \mathrm{kg}$ & NA & CFR, 2000b \\
\hline $271 \mathrm{~A} 013$ & Sludge & Cadmium** & 3.4 & $\mathrm{mg} / \mathrm{kg}$ & NA & CFR, 2000b \\
\hline $271 \mathrm{~A} 013$ & Sludge & Chromium** & 9.5 & $\mathrm{mg} / \mathrm{kg}$ & NA & CFR, 2000b \\
\hline $271 \mathrm{~A} 013$ & Sludge & Lead $^{* *}$ & 53 & $\mathrm{mg} / \mathrm{kg}$ & NA & CFR, 2000b \\
\hline $271 \mathrm{~A} 013$ & Sludge & Silver** & 5.2 & $\mathrm{mg} / \mathrm{kg}$ & NA & CFR, 2000b \\
\hline $271 \mathrm{~A} 013$ & Sludge & TCLP 1,4-Dichlorobenzene & $2.8(\mathrm{~J})^{\mathrm{b}}$ & $\mathrm{mg} / \mathrm{L}$ & 7.5 & CFR, 2000b \\
\hline $271 \mathrm{~A} 013$ & Sludge & Chlorobenzene & 43 & $\mu \mathrm{g} / \mathrm{L}$ & 100,000 & CFR, 2000b \\
\hline $271 \mathrm{~A} 013$ & Sludge & Plutonium-239 & $0.171 \pm 0.050$ & $\mathrm{pCi} / \mathrm{g}$ & 10 & NDEP, 1997b \\
\hline 271A013RR1 & Leachate & TCLP 1,4-Dichlorobenzene & 4.1 & $\mathrm{mg} / \mathrm{L}$ & 7.5 & CFR, 2000b \\
\hline
\end{tabular}

${ }^{a}$ Qualifier added to laboratory data; record accepted. Surrogates diluted out.

${ }^{b}$ Qualifier added to laboratory data; record accepted. Value exceeded linear range of instrument.

** $=$ TCLP below minimum reporting limit

$\mathrm{J}=$ Estimated value

$\mathrm{N}=$ No limit established (NDEP, 1997b)

$\mathrm{NA}=$ Not applicable

$Z$ = The reported result did not resemble the patterns of the following petroleum hydrocarbon products: gasoline, JP-4, JP-8,

diesel, mineral spirits, motor oil, Stoddard solvent and Bunker C 
Several COPCs were detected in the sludge samples. Most COPCs were below regulatory limits except for TPH which was detected in sample 271A013. Diesel and gasoline concentrations in this sample were 4,600 mg/kg and 2,400 mg/kg, respectively (these results are shown as bold text in Table A.3-6). These levels exceed the NDEP action level of $100 \mathrm{mg} / \mathrm{kg}$ (NAC, 2000) for TPH.

\section{A.3.4 Contaminants of Concern}

Based on the aforementioned analytical results, there are no COCs present in the soil surrounding the septic tank or under the leachfield. The septic tank sludge contains TPH exceeding the NDEP action level of $100 \mathrm{mg} / \mathrm{kg}$.

\section{A.3.5 Nature and Extent of Contamination}

Total petroleum hydrocarbons are located within the septic tank in the sludge. Approximately 70 gal of sludge and 65 gal of liquid remains in the bottom of the tank.

\section{A.3.6 Revised Conceptual Model}

No variations in the conceptual model were identified. 


\section{A.4.0 Pan American Trailers Septic System (CAS 25-04-03)}

The Pan Am trailer septic system was designed to receive sanitary effluent generated by activities that took place in 17 Pan Am housing trailers and 1 recreational trailer in 1965. The septic system is located approximately $350 \mathrm{ft}$ west of the RCP fenceline. The site is comprised of a leachfield, septic tank, and associated piping. More detail is provided in the CAIP (DOE/NV, 2001).

\section{A.4.1 Corrective Action Investigation}

Seventy-eight investigation samples, listed in Table A.4-1, were collected during investigation activities conducted at CAS 25-04-03. The sample locations presented in the CAIP were estimated based on past site investigations and a schematic outline of the leachfield shown on an engineering drawing. Actual engineering drawings showing the as-built subsurface configuration of this leachfield were not available. When excavation of the leachfield was conducted, the actual configuration of the distribution system varied greatly from the estimated configuration. Therefore, sampling locations were modified from the planned locations based on field conditions and observations. The planned and actual sample locations are shown in Figure A.4-1. The specific CAI activities conducted to meet CAIP requirements at CAS 25-04-03 are described in Table A.2-1.

\section{A.4.1.1 Deviations}

The following deviations to the CAIP-requirements were the result of unforeseen circumstances and changes to the conceptual model:

- The configuration for CAS 25-04-03 was considerably different than proposed in the CAIP. Because the biased locations changed significantly from the planned locations, new random locations were selected using the "Visual Sample Plan" program (Davidson and Wildon, 1999). This approach was discussed as a contingency in the CAIP; therefore, a Record of Technical Change was not required to implement the new sampling locations.

- A soil sample was not collected from the gap in the line that connected the septic tank and the leachfield. This gap was not located during the field investigation. As discussed above, the actual and proposed leachfield configurations were significantly different. 
Table A.4-1

Samples Collected at CAS 25-04-03

(Page 1 of 5 )

\begin{tabular}{|c|c|c|c|c|c|c|c|c|c|c|c|c|c|c|}
\hline \multirow[b]{2}{*}{$\begin{array}{c}\text { Sample } \\
\text { Identification } \\
\text { Number }\end{array}$} & \multirow[b]{2}{*}{$\begin{array}{l}\text { Sample } \\
\text { Location }\end{array}$} & \multirow[b]{2}{*}{$\begin{array}{l}\text { Sample } \\
\text { Matrix }\end{array}$} & \multirow[b]{2}{*}{$\begin{array}{c}\text { Depth } \\
\text { (ft bgs) }\end{array}$} & \multirow[b]{2}{*}{ Purpose } & \multicolumn{10}{|c|}{ Analyses } \\
\hline & & & & & 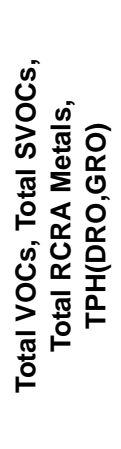 & 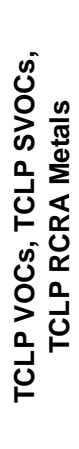 & 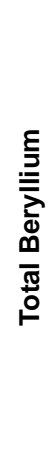 & 怘 & 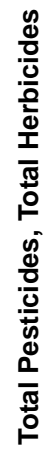 & 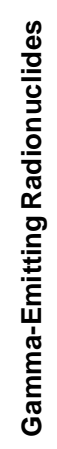 & 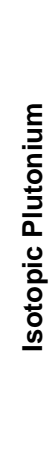 & 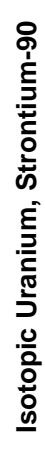 & $\stackrel{\sum}{E}$ & 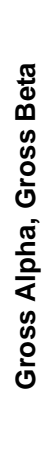 \\
\hline 271B004 & B02 & Soil & $13-14$ & Integrity & \multicolumn{10}{|c|}{ Not Submitted for Analyses ${ }^{a}$} \\
\hline 271B005 & B03 & Soil & $5-6$ & Environmental & $x$ & & & $x$ & & $x$ & $\mathrm{X}$ & $\mathrm{X}$ & & \\
\hline 271B006 & B03 & Soil & $7.4-8.4$ & Environmental & \multicolumn{10}{|c|}{ Not Submitted for Analyses ${ }^{a}$} \\
\hline 271B007 & B04 & Soil & $4.5-5.5$ & Environmental & $x$ & & & $x$ & & & & & & \\
\hline 271B008 & B04 & Soil & $7.5-8.5$ & Environmental & \multicolumn{10}{|c|}{ Not Submitted for Analyses ${ }^{a}$} \\
\hline 271B009 & B05 & Soil & $4.8-5.8$ & Environmental & $x$ & & & $x$ & & $\mathrm{X}$ & $\mathrm{X}$ & $\mathrm{X}$ & & \\
\hline 271B014 & B06 & Soil & $10.5-11.5$ & Environmental & \multicolumn{10}{|c|}{ Not Submitted for Analyses ${ }^{a}$} \\
\hline 271B015 & B07 & Soil & $5-6$ & Environmental & $X$ & & & $X$ & & & & & & \\
\hline 271B016 & B07 & Soil & $7.5-8.5$ & Environmental & \multicolumn{10}{|c|}{ Not Submitted for Analyses ${ }^{a}$} \\
\hline 271B017 & B08 & Soil & $5-6$ & Environmental & $X$ & & & $X$ & & $X$ & $\mathrm{X}$ & $x$ & & \\
\hline 271B018 & B08 & Soil & $7.5-8.5$ & Environmental & \multicolumn{10}{|c|}{ Not Submitted for Analyses ${ }^{a}$} \\
\hline 271B019 & B09 & Soil & $4.7-5.7$ & Environmental & $X$ & & & $X$ & & & & & & \\
\hline 271B020 & B09 & Soil & $7.4-8.4$ & Environmental & \multicolumn{10}{|c|}{ Not Submitted for Analyses ${ }^{a}$} \\
\hline 271B021 & B10 & Soil & $4.6-5.6$ & $\begin{array}{l}\text { Environmental } \\
\text { MS/MSD }\end{array}$ & $X$ & & & $X$ & & $\mathrm{X}$ & $x$ & $x$ & & \\
\hline
\end{tabular}


Table A.4-1

Samples Collected at CAS 25-04-03

(Page 2 of 5 )

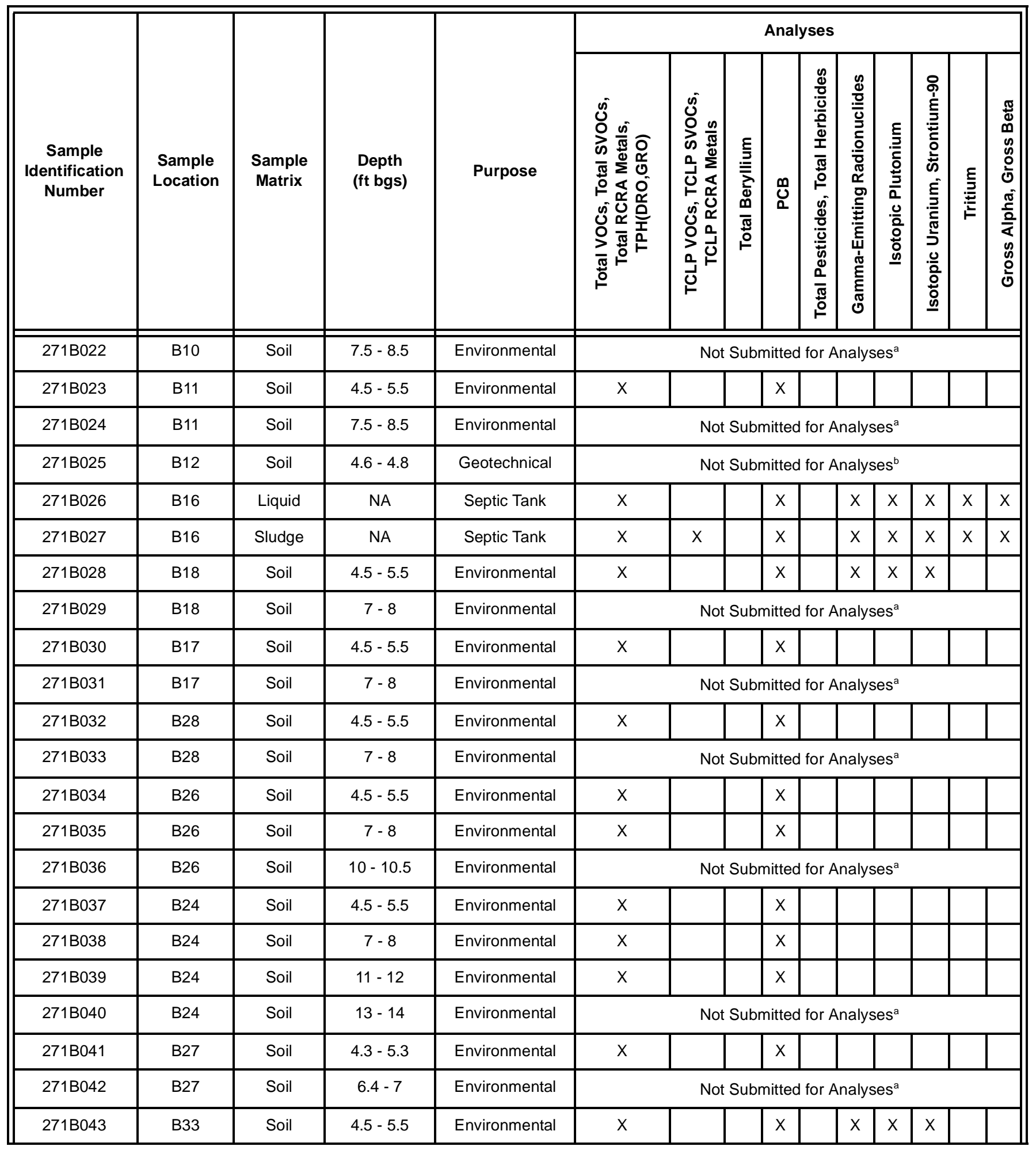


Table A.4-1

Samples Collected at CAS 25-04-03

(Page 3 of 5)

\begin{tabular}{|c|c|c|c|c|c|c|c|c|c|c|c|c|c|c|}
\hline \multirow[b]{2}{*}{$\begin{array}{c}\text { Sample } \\
\text { Identification } \\
\text { Number }\end{array}$} & \multirow[b]{2}{*}{$\begin{array}{l}\text { Sample } \\
\text { Location }\end{array}$} & \multirow[b]{2}{*}{$\begin{array}{l}\text { Sample } \\
\text { Matrix }\end{array}$} & \multirow[b]{2}{*}{$\begin{array}{c}\text { Depth } \\
\text { (ft bgs) }\end{array}$} & \multirow[b]{2}{*}{ Purpose } & \multicolumn{10}{|c|}{ Analyses } \\
\hline & & & & & 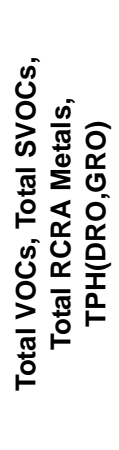 & 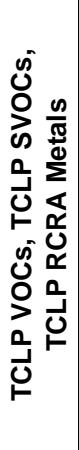 & 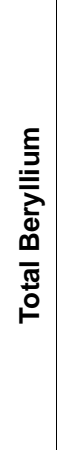 & 怘 & 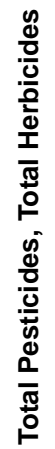 & 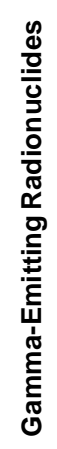 & 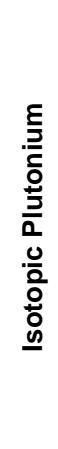 & 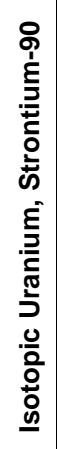 & 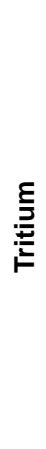 & 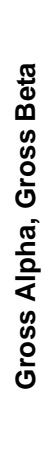 \\
\hline 271B044 & B33 & Soil & $4.5-5.5$ & $\begin{array}{c}\text { Duplicate of } \\
271 \mathrm{~B} 0043\end{array}$ & $x$ & & & $x$ & & $X$ & $\mathrm{x}$ & $\mathrm{X}$ & & \\
\hline 271B045 & B33 & Soil & $7-8$ & Environmental & \multicolumn{10}{|c|}{ Not Submitted for Analyses ${ }^{a}$} \\
\hline 271B046 & B32 & Soil & $4.5-5.5$ & Environmental & $x$ & & & $\mathrm{X}$ & & & & & & \\
\hline 271B047 & B32 & Soil & $7-8$ & Environmental & \multicolumn{10}{|c|}{ Not Submitted for Analyses ${ }^{a}$} \\
\hline 271B048 & B30 & Soil & $4.5-5.5$ & Environmental & $x$ & & & $X$ & & & & & & \\
\hline 271B049 & B30 & Soil & $7-8$ & Environmental & \multicolumn{10}{|c|}{ Not Submitted for Analyses ${ }^{a}$} \\
\hline 271B050 & B25 & Soil & $4.5-5.5$ & Environmental & $x$ & & & $x$ & & & & & & \\
\hline 271B051 & B25 & Soil & $7-7.5$ & Environmental & \multicolumn{10}{|c|}{ Not Submitted for Analyses ${ }^{a}$} \\
\hline 271B052 & B23 & Soil & $4.5-5.5$ & Environmental & $X$ & & & $X$ & & & & & & \\
\hline 271B053 & B23 & Soil & $7.3-8.3$ & Environmental & \multicolumn{10}{|c|}{ Not Submitted for Analyses ${ }^{a}$} \\
\hline 271B054 & B21 & Soil & $4.5-5.5$ & Environmental & $x$ & & & $x$ & & & & & & \\
\hline 271B055 & B21 & Soil & $8-9$ & Environmental & \multicolumn{10}{|c|}{ Not Submitted for Analyses ${ }^{a}$} \\
\hline 271B056 & B22 & Soil & $4.5-5.5$ & Environmental & $x$ & & & $x$ & & & & & & \\
\hline 271B057 & B22 & Soil & $7-8$ & Environmental & \multicolumn{10}{|c|}{ Not Submitted for Analyses ${ }^{a}$} \\
\hline 271B058 & B20 & Soil & $4.5-5.5$ & $\begin{array}{l}\text { Environmental } \\
\text { MS/MSD }\end{array}$ & $x$ & & & $x$ & & $X$ & $\mathrm{X}$ & $\mathrm{X}$ & & \\
\hline 271B059 & $\mathrm{B} 20$ & Soil & $7-8$ & Environmental & \multicolumn{10}{|c|}{ Not Submitted for Analyses ${ }^{a}$} \\
\hline 271B060 & B19 & Soil & $4.5-5.5$ & Environmental & $X$ & & & $X$ & & & & & & \\
\hline 271B061 & B19 & Soil & $7-8$ & Environmental & \multicolumn{10}{|c|}{ Not Submitted for Analyses ${ }^{a}$} \\
\hline 271B062 & B31 & Soil & $4.5-5.5$ & Environmental & $x$ & & & $X$ & & & & & & \\
\hline 271B063 & B31 & Soil & $7-8$ & Environmental & $x$ & & & $x$ & & & & & & \\
\hline 271B064 & B31 & Soil & $10-11$ & Environmental & $X$ & & & $X$ & & & & & & \\
\hline
\end{tabular}


Table A.4-1

Samples Collected at CAS 25-04-03

(Page 4 of 5 )

\begin{tabular}{|c|c|c|c|c|c|c|c|c|c|c|c|c|c|c|}
\hline \multirow[b]{2}{*}{$\begin{array}{c}\text { Sample } \\
\text { Identification } \\
\text { Number }\end{array}$} & \multirow[b]{2}{*}{$\begin{array}{l}\text { Sample } \\
\text { Location }\end{array}$} & \multirow[b]{2}{*}{$\begin{array}{c}\text { Sample } \\
\text { Matrix }\end{array}$} & \multirow[b]{2}{*}{$\begin{array}{l}\text { Depth } \\
\text { (ft bgs) }\end{array}$} & \multirow[b]{2}{*}{ Purpose } & \multicolumn{10}{|c|}{ Analyses } \\
\hline & & & & & 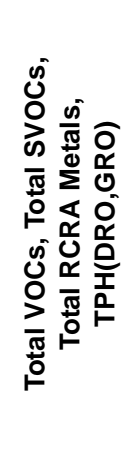 & 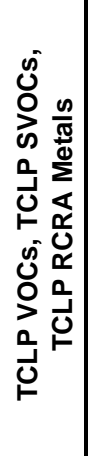 & 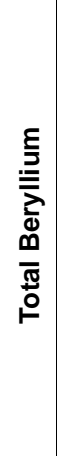 & O̊ & 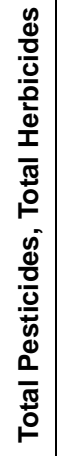 & 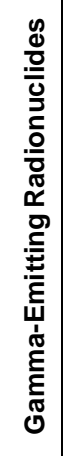 & 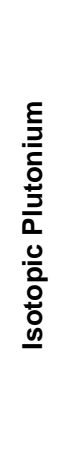 & 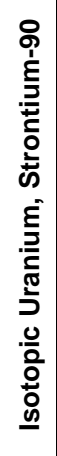 & 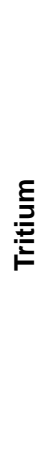 & 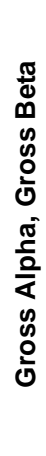 \\
\hline 271B068 & B35 & Soil & $7-8$ & Environmental & \multicolumn{10}{|c|}{ Not Submitted for Analyses ${ }^{a}$} \\
\hline 271B069 & B29 & Soil & $4.5-5.5$ & Environmental & $x$ & & & $x$ & & & & & & \\
\hline 271B070 & B29 & Soil & $7-8$ & Environmental & $x$ & & & $x$ & & & & & & \\
\hline 271B071 & B29 & Soil & $11-12$ & Environmental & $x$ & & & $x$ & & & & & & \\
\hline 271B072 & B36 & Soil & $4.5-5.5$ & Environmental & $x$ & & & $x$ & & & & & & \\
\hline 271B073 & B36 & Soil & $7-8$ & Environmental & \multicolumn{10}{|c|}{ Not Submitted for Analyses ${ }^{a}$} \\
\hline 271B301 & NA & Water & NA & Trip Blank & VOC only & & & & & & & & & \\
\hline 271B302 & NA & Water & NA & Trip Blank & VOC only & & & & & & & & & \\
\hline 271B303 & NA & Water & NA & Trip Blank & VOC only & & & & & & & & & \\
\hline 271B304 & NA & Water & NA & Trip Blank & VOC only & & & & & & & & & \\
\hline 271B305 & NA & Water & NA & Trip Blank & VOC only & & & & & & & & & \\
\hline 271B306 & NA & Water & NA & Field Blank & $x$ & & & $x$ & & $x$ & $x$ & $x$ & & \\
\hline 271B307 & NA & Water & NA & Trip Blank & VOC only & & & & & & & & & \\
\hline 271B308 & NA & Water & NA & Trip Blank & VOC only & & & & & & & & & \\
\hline 271B309 & NA & Water & NA & Trip Blank & VOC only & & & & & & & & & \\
\hline
\end{tabular}


Table A.4-1

Samples Collected at CAS 25-04-03

(Page 5 of 5 )

\begin{tabular}{|c|c|c|c|c|c|c|c|c|c|c|c|c|c|c|}
\hline \multirow[b]{2}{*}{$\begin{array}{c}\text { Sample } \\
\text { Identification } \\
\text { Number }\end{array}$} & \multirow[b]{2}{*}{$\begin{array}{l}\text { Sample } \\
\text { Location }\end{array}$} & \multirow[b]{2}{*}{$\begin{array}{l}\text { Sample } \\
\text { Matrix }\end{array}$} & \multirow[b]{2}{*}{$\begin{array}{l}\text { Depth } \\
\text { (ft bgs) }\end{array}$} & \multirow[b]{2}{*}{ Purpose } & \multicolumn{10}{|c|}{ Analyses } \\
\hline & & & & & 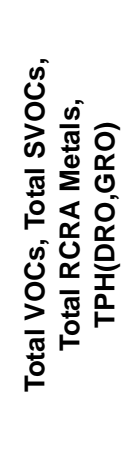 & 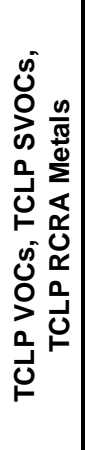 & 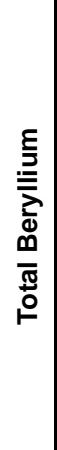 & 䢰 & 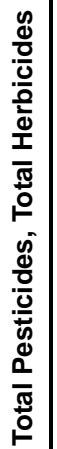 & 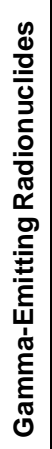 & 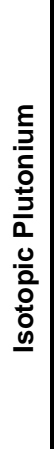 & 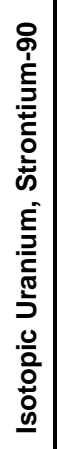 & $\stackrel{E}{E}$ & 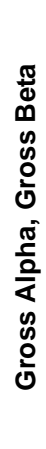 \\
\hline 271B310 & NA & Water & NA & Trip Blank & VOC only & & & & & & & & & \\
\hline 271B311 & NA & Water & NA & Trip Blank & VOC only & & & & & & & & & \\
\hline 271B312 & NA & Water & NA & Trip Blank & VOC only & & & & & & & & & \\
\hline 271B313 & NA & Water & NA & Rinsate & $x$ & & & $x$ & & $x$ & $x$ & $x$ & & \\
\hline 271B314 & NA & Water & NA & Trip Blank & VOC only & & & & & & & & & \\
\hline 271B315 & NA & Water & NA & Trip Blank & VOC only & & & & & & & & & \\
\hline 271B316 & NA & Water & NA & Trip Blank & VOC only & & & & & & & & & \\
\hline 271B320 & NA & Water & NA & Trip Blank & VOC only & & & & & & & & & \\
\hline
\end{tabular}

aThe samples were collected, field screened, and returned to the site for disposal.

${ }^{\mathrm{b}}$ The sample was collected, field screened, and is being stored for possible geotechnical analysis.

NA = Not applicable

MS/MSD = Matrix spike/matrix spike duplicate

- Sample number 271B004 was collected at a depth of 13 to $14 \mathrm{ft}$ bgs rather than the planned interval of 11.5 to $12.5 \mathrm{ft}$ bgs. This was necessary due to too much material being removed during excavation of the sampling location.

- The biased locations (B03 and B08) of samples 271B005, 271B006, 271B017, and 271B018 were moved further downstream because the distribution piping and leachrock close to the septic tank had been disturbed some time prior to this investigation.

- Refusal was met due to encountering subsurface hardpan (caliche); therefore:

- 271B036 was collected at 10 to $10.5 \mathrm{ft}$ bgs rather than the planned interval of 11 to $12 \mathrm{ft}$ bgs

- $271 \mathrm{~B} 040$ was collected at 13 to $14 \mathrm{ft}$ bgs rather than the planned interval of 15 to $16 \mathrm{ft}$ bgs 


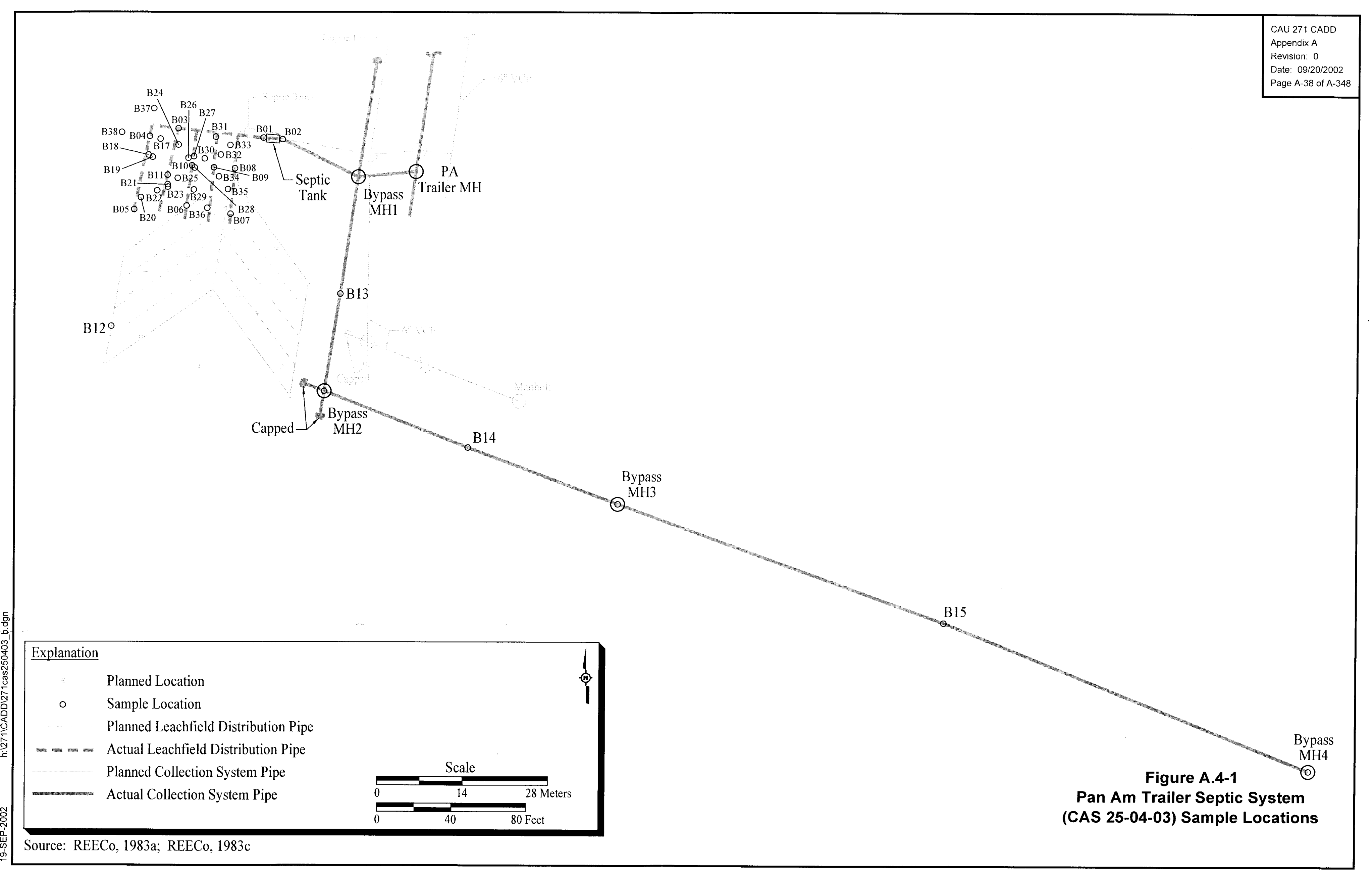


- 271B042 was collected at 6.5 to $7 \mathrm{ft}$ bgs rather than the planned interval of 7 to $8 \mathrm{ft}$ bgs

- 271B051 was collected at 7 to $7.5 \mathrm{ft}$ bgs rather than the planned interval of 7 to $8 \mathrm{ft}$ bgs

- 271B064 was collected at 10 to $11 \mathrm{ft}$ bgs rather than the planned interval of 11 to $12 \mathrm{ft} \mathrm{bgs;}$ however, the second interval planned at the 15 to $16 \mathrm{ft}$ bgs interval could not be obtained

- 271B071 was collected at the planned interval of 11 to $12 \mathrm{ft} \mathrm{bgs;} \mathrm{however,} \mathrm{the} \mathrm{second}$ interval planned at the 15 to $16 \mathrm{ft}$ bgs interval could not be obtained

Despite these deviations, the pertinent CAIP requirements were met.

\section{A.4.2 Investigation Results}

The following subsections provide details of the inspection and sampling of leachfield features, field-screening results, and sample selection and analysis.

\section{A.4.2.1 Septic Tank Contents}

The contents of the septic tank were sampled in accordance with the CAIP. The concrete, rectangular-shaped septic tank has a 1,043-gal capacity and one chamber. The depth to the top of the tank is approximately $3.5 \mathrm{ft}$ bgs and is accessed by two concrete manholes. The interior dimensions of the tank were $7.8 \mathrm{ft}$ (length) by $3.5 \mathrm{ft}$ (width) by $5.1 \mathrm{ft}$ (depth). One liquid and one sludge sample were collected from the septic tank. Visual inspection revealed that a maximum of $2 \mathrm{ft}$ (410 gal) of liquid and 2 in. (34 gal) of sludge remained in the bottom of the tank. Photographs of the exterior of the septic tank were taken to document the visual inspection (Figure A.4-2).

\section{A.4.2.2 Septic Tank Integrity Soil Sampling}

Four integrity samples were collected by excavating adjacent to the influent and effluent ends of the septic tank. The following two samples were submitted for laboratory analysis:

- The upper sample (271B001) from the influent end of the septic tank, collected at 9.6 to $10.7 \mathrm{ft}$ bgs

- The upper sample (271B003) from the effluent end of the septic tank, collected at 9.2 to $10.2 \mathrm{ft}$ bgs 

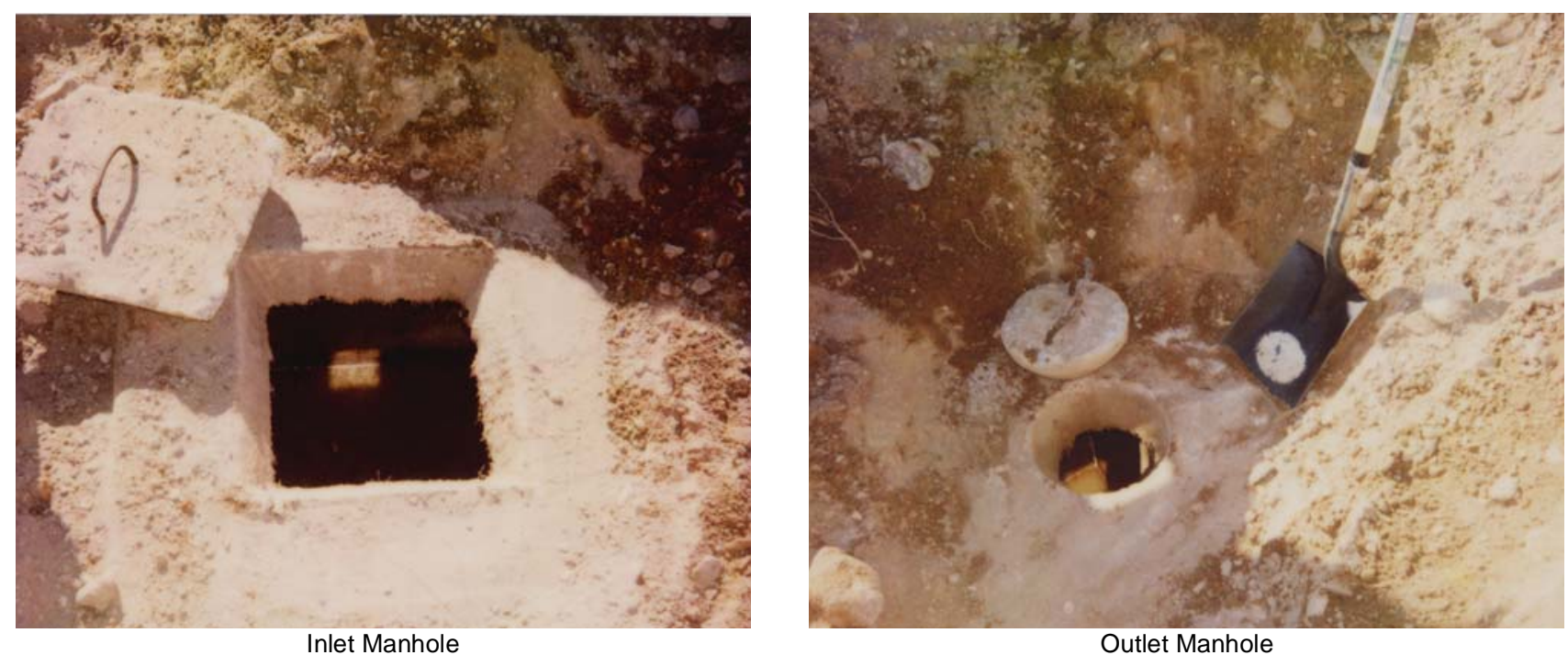

Figure A.4-2

CAS 25-04-03 Septic Tank, Manholes

(Photographs Taken 12-04-2001)

\section{A.4.2.3 Leachfield Excavation Soil Sampling}

Backhoe excavations were conducted to access sampling horizons. Excavations provided a visual verification of distribution pipes and enabled soil samples to be collected from appropriate intervals beneath the pipes. As discussed in Section A.4.1.1, the layout of the leachfield was significantly different than the anticipated configuration; therefore, new sample locations were selected in accordance with a contingency specified in the CAIP. Sixty-six soil samples were collected from the planned locations excavated within the leachfield. These samples were collected from an interval at the leachrock/native soil interface, an interval $2.5 \mathrm{ft}$ below the interface, and an interval $6.5 \mathrm{ft}$ below the interface. The interface was found at depths ranging from $3.5 \mathrm{ft}$ to $5.2 \mathrm{ft}$ bgs. Thirty-nine samples were submitted for laboratory analysis. In addition, two QC soil duplicates and two MS/MSD samples were collected and analyzed. A geotechnical sample was collected outside the boundary of the leachfield. The sample will be sent to a laboratory for geotechnical analysis if necessary.

\section{A.4.2.4 Additional Sampling}

To further define the extent of potential contamination, the field crew returned to this CAS on February 13, 2002, to conduct step-out sampling. Only one location (B04) was identified from the 
original sampling activities as a concern due to the presence of SVOCs. One vertical and four horizontal step-out samples were collected. The vertical sample (271B074) was collected from B04, at 10.5 to $11.5 \mathrm{ft}$ bgs. The horizontal step-outs were located $15 \mathrm{ft}$ north (designated as location B37) and west (designated as location B38) of location B04. At both of these step-out locations, samples were collected at depths of 0 to $1 \mathrm{ft}$ and 2.5 to $3.5 \mathrm{ft}$ below the native soil/leachrock interface. The vertical (271B074) and the upper-most horizontal step-out samples (271B075 and 271B077) were submitted for laboratory analysis.

\section{A.4.2.5 Collection System Pipe Inspections}

No distribution boxes were associated with this system. Access points for inspection by video mole survey were present (i.e., manholes) and were also created at locations along the collection pipe via backhoe excavation. As shown on Figure A.4-1, the CAS 25-04-03 leachfield was apparently bypassed, and effluent from the Pan Am trailer area was routed to a sewage lagoon. The original collection system, as well as the bypass line, was inspected during the investigation.

A video mole was inserted into the VCP collection line on the influent side of the septic tank at the excavation made during the collection of the integrity sample. Refusal of the video mole was encountered at $19 \mathrm{ft}$, so a fiber snake was inserted and passed through the collection piping. The fiber snake was able to pass through the pipe for a total distance of $77.5 \mathrm{ft}$. Ground measurements show that this was approximately $6 \mathrm{ft}$ short of Bypass Manhole 1 (Figure A.4-1).

Bypass Manhole 1 had one inlet and three outlets. The northern and western (outlet that would have led to the septic system) outlets were plugged with grout. The inlet was followed upgradient (east) for a total of $29 \mathrm{ft}$ to another manhole (labeled PA Trailer on Figure A.4-1). This manhole has one inlet and one outlet. There were multiple lines branching off of the inlet pipe leading into the PA Trailer Manhole. These branches led to the original trailer park connections and, in places, may be composed of transite piping. The trailer park collection pipes are further described in the FADLs.

A video mole was passed down the southern outlet of Bypass Manhole $1 \mathrm{for} 57 \mathrm{ft}$, to location B13. An excavation was made at location B13 and the video mole inspection continued upgradient to Bypass Manhole 2. The video mole was passed down the outlet end of Bypass Manhole 2 for $86 \mathrm{ft}$ to location B14. An excavation was made at location B14 and the video mole inspection continued 
upgradient for an additional $85 \mathrm{ft}$ to Bypass Manhole 3 (Figure A.4-1). The inspection was continued for $120 \mathrm{ft}$ to location B15. An excavation was made at location B15 and the video mole inspection

continued upgradient for an additional $155 \mathrm{ft}$ to Bypass Manhole 4. This manhole had three inlets and one outlet. The continuance of the video mole survey from Bypass Manhole 4 is discussed in Section A.9.2.6 (i.e., the pipe inspections conducted for CAS 25-04-11).

The video mole inspection revealed that the collection system pipes at CAS 25-04-03 were in good structural condition and did not contain any obstructions or material related to the operation of the system. Locations where leaks may occur were not observed. The only materials present were very small amounts of plant/animal debris and soil.

Portions of the collection pipe at locations B13, B14, and B15 were radiologically surveyed and swiped. Other access points (e.g., manholes) were also surveyed and swiped. Section A.4.2.7 describes the radiological results.

\section{A.4.2.6 Field-Screening Results}

Soil samples were screened for VOCs and alpha and beta/gamma radioactivity. The field readings were compared to FSLs to guide sampling decisions and determine which samples were to be submitted for laboratory analysis. No VOCs greater than FSLs were found during soil sample screening. The results of radiological field screening are discussed in Section A.4.2.7.

A sample of the septic tank content was collected and analyzed for fecal coliform bacteria. A positive result for fecal coliform bacteria was obtained for the septic tank contents at this CAS.

\section{A.4.2.7 Radiological Survey Results}

The beta/gamma field-screening results at four locations slightly exceeded FSLs. Screening results for samples collected from deeper intervals at these locations were below FSLs. All other radiological field-screening results at CAS 25-04-03 were below FSLs. Swipe and radiological survey data from manholes and pipe segments indicate the collection system meets the unrestricted radiological release criteria as defined in the $N V / Y M P$ Radiological Control Manual (DOE/NV, 2000a). 


\section{A.4.2.8 Sample Analysis}

Environmental soil samples and associated QC samples were collected and analyzed for the CAIP-specified COPCs (i.e., total VOCs, total SVOCs, total RCRA metals, TPH [DRO and GRO], and PCBs). In addition, 25 percent of the soil samples and 100 percent of the associated QC samples were analyzed for Iso-U, Iso-Pu, Sr-90, and gamma-emitting radionuclides.

Both the sludge and liquid samples from the septic tank were analyzed for total VOCs, total SVOCs, TPH (GRO and DRO), total RCRA metals, PCBs, gamma-emitting radionuclides, Iso-U, Iso-Pu, Sr-90, tritium, gross alpha, and gross beta. The sludge sample was also analyzed for TCLP VOCs, SVOCs, and RCRA metals.

The parameters and laboratory methods used to analyze the investigation samples are listed in Table A.2-2. Table A.4-1 lists the sample-specific analytical parameters.

\section{A.4.3 Analytes Detected Above Minimum Reporting Limits}

The soil sample analytical results with concentrations exceeding corresponding MRLs or PALs (DOE/NV, 1998; DOE/NV, 2001) at CAS 25-04-03 are summarized in the following sections. The results of septic tank content samples are compared to appropriate regulatory levels for disposal. A portion of the CAS 25-04-03 analytical results were rejected during validation; however, these rejected data did not impact closure decisions as discussed in Section B.1.3.2 of Appendix B.

\section{A.4.3.1 Analytical Results for Soil Samples}

The following sections discuss the results for soil samples in comparison to the levels established in the Leachfield Work Plan and the CAIP.

\section{A.4.3.1.1 Total Volatile Organic Compounds}

Volatile organic compound results are reported in Table A.4-2. The only organic compounds with concentrations detected above MRLs were acetone and methylene chloride. Estimated concentrations for acetone and methylene chloride as designated by the "J" qualifier were between 21 to 2,400 and 11 to $27 \mu \mathrm{g} / \mathrm{kg}$, respectively. These estimated concentrations were below reporting 
Table A.4-2

\section{Soil Sample Results for Total VOCs Detected Above Minimum Reporting Limits at CAS 25-04-03}

\begin{tabular}{|c|c|c|c|}
\hline \multirow{2}{*}{$\begin{array}{c}\text { Sample } \\
\text { Identification } \\
\text { Number }\end{array}$} & \multirow{2}{*}{$\begin{array}{l}\text { Depth } \\
\text { (ft bgs) }\end{array}$} & \multicolumn{2}{|c|}{ Contaminants of Potential Concern $(\mu \mathrm{g} / \mathrm{kg})$} \\
\hline & & Acetone & Methylene Chloride \\
\hline \multicolumn{2}{|c|}{ Preliminary Action Levels ${ }^{a}$} & $6,200,000$ & 21,000 \\
\hline 271B028 & $4.5-5.5$ & $100(J)^{b}$ & -- \\
\hline 271B030 & $4.5-5.5$ & $21(J)^{c}$ & -- \\
\hline 271B032 & $4.5-5.5$ & $120(J)^{b}$ & $27(\mathrm{~B})$ \\
\hline 271B034 & $4.5-5.5$ & $36(J)^{b}$ & $23(\mathrm{~B})$ \\
\hline 271B035 & $7-8$ & $56(J)^{b}$ & $24(\mathrm{~B})$ \\
\hline 271B037 & $4.5-5.5$ & $68(J)^{b}$ & $24(\mathrm{~B})$ \\
\hline 271B038 & $7-8$ & $73(J)^{b}$ & -- \\
\hline 271B041 & $4.3-5.3$ & $800(J)^{b}$ & -- \\
\hline 271B043 & $4.5-5.5$ & $1,800(J)^{c}$ & -- \\
\hline 271B044 & $4.5-5.5$ & $1,700(J)^{c}$ & -- \\
\hline 271B046 & $4.5-5.5$ & $1,400(J)^{c}$ & -- \\
\hline 271B048 & $4.5-5.5$ & $37(\mathrm{~J})^{\mathrm{b}}$ & 17 \\
\hline 271B050 & $4.5-5.5$ & -- & 13 \\
\hline 271B052 & $4.5-5.5$ & $84(J)^{b}$ & 11 \\
\hline 271B054 & $4.5-5.5$ & $72(J)^{b}$ & 14 \\
\hline 271B056 & $4.5-5.5$ & -- & 14 \\
\hline 271B062 & $4.5-5.5$ & $29(\mathrm{~J})^{\mathrm{C}}$ & -- \\
\hline
\end{tabular}

${ }^{a}$ Based on U.S. Environmental Protection Agency, Region 9 Preliminary Remediation Goals (PRGs) (EPA, 2000)

${ }^{b} Q u a l i f i e r$ added to laboratory data; record accepted. Relative response factor $<0.05$.

${ }^{\circ}$ Qualifier added to laboratory data; record accepted. Average relative response factor $<0.05$. Relative response factor $<0.05$.

$--=$ Not detected above minimum reporting limits

$\mathrm{B}=$ Analyte found in both sample and associated blank.

$\mathrm{J}=$ Estimated value

limits for the laboratory. All concentrations for acetone and methylene chloride were below PALs of $6,200,000$ and $21,000 \mu \mathrm{g} / \mathrm{kg}$, respectively. Both of these VOCs are common laboratory contaminants.

\section{A.4.3.1.2 Total Semivolatile Organic Compounds}

Table A.4-3 provides a list of the SVOCs in samples 271B007 and 271B046 at concentrations above the MRL of $660 \mu \mathrm{g} / \mathrm{kg}$. Of the reported compounds only benzo(a)pyrene (1,100 and $320 \mu \mathrm{g} / \mathrm{kg})$ in 
Table A.4-3

Soil Sample Results for Total SVOCs Detected Above Minimum Reporting Limits at CAS 25-04-03

\begin{tabular}{|c|c|c|c|c|c|c|c|c|c|c|c|}
\hline \multirow[b]{2}{*}{$\begin{array}{c}\text { Sample } \\
\text { Identification } \\
\text { Number }\end{array}$} & \multirow[b]{2}{*}{$\begin{array}{c}\text { Depth } \\
\text { (ft bgs) }\end{array}$} & \multicolumn{10}{|c|}{ Contaminants of Potential Concern $(\mu \mathrm{g} / \mathrm{kg})$} \\
\hline & & 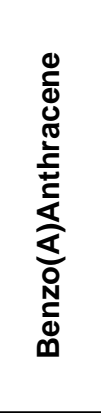 & 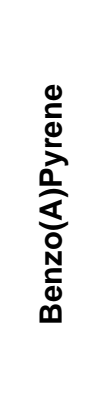 & 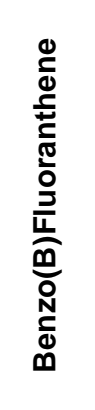 & 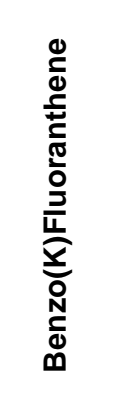 & 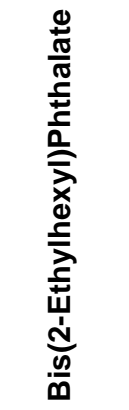 & $\begin{array}{l}\stackrel{0}{c} \\
\frac{c}{D} \\
\stackrel{n}{2} \\
\frac{c}{0}\end{array}$ & 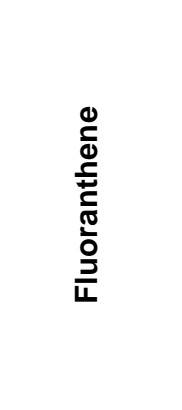 & 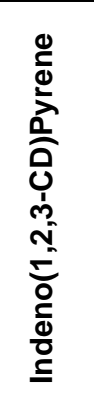 & 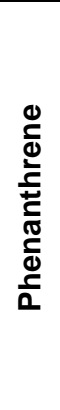 & 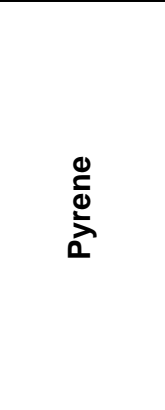 \\
\hline \multicolumn{2}{|c|}{ Preliminary Action Levels ${ }^{a}$} & 2,900 & 290 & 2,900 & 29,000 & 180,000 & 290,000 & $30,000,000$ & 2,900 & NI & $54,000,000$ \\
\hline 271B007 & $4.5-5.5$ & 1,800 & 1,100 & 1,700 & -- & -- & 1,600 & 2,300 & -- & -- & 2,700 \\
\hline 271B046 & $4.5-5.5$ & -- & $320(\mathrm{~J})$ & -- & -- & -- & -- & 760 & -- & -- & -- \\
\hline
\end{tabular}

a'Based on U.S. Environmental Protection Agency, Region 9 Preliminary Remediation Goals (PRGs) (EPA, 2000).

$\mathrm{J}=$ Estimated value

$-=$ Not detected above minimum reporting limits

$\mathrm{NI}=$ Not identified 
samples 271B007 (location B04) and 271B046 (location B32), respectively, exceeded the PAL $(290 \mu \mathrm{g} / \mathrm{kg})($ Table A.4-1).

Additional step-out samples were collected to determine the extent of potential SVOC contamination at location B04, which is on the edge of the leachfield (Figure A.4-1). Sample 271B074 was collected 10.5 to $11.5 \mathrm{ft}$ bgs at location B04 to define the vertical extent. Sample numbers 271B075 and 271B076 were collected at location B37 (located $15 \mathrm{ft}$ north of B04) as a step-out of 271B007. Sample numbers 271B077 and 271B078 were collected at location B38 (located $15 \mathrm{ft}$ east of B04) as a step-out of 271B007. None of the step-out samples contained SVOCs above MRLs or PALs. This indicated that the extent of SVOC contamination had been defined.

The leachfield distribution pipes were "Orangeburg" which is a brand of pipe that appears to be composed of a compressed tar paper. It is possible that some small pieces of the pipe were introduced into the sample. As described in Section A.9.3.1.2, the SVOC compounds may be related to pieces of the pipe material inadvertently introduced into the sample at the two locations.

\section{A.4.3.1.3 Total Petroleum Hydrocarbons}

Total petroleum hydrocarbons were not detected above MRLs in CAS 25-04-03 soil samples.

\section{A.4.3.1.4 Total RCRA Metals}

As shown in Table A.4-4, the total RCRA metals detected in soil samples at concentrations exceeding the MRLs are arsenic (1 mg/kg), barium (20 mg/kg), chromium (1 mg/kg), and lead (0.3 mg/kg). Other RCRA metals (i.e., cadmium, mercury, selenium, silver) were below specified MRLs.

Barium concentrations ranged from 61 to $130 \mathrm{mg} / \mathrm{kg}$, chromium concentrations ranged from 1.5 to $8.8 \mathrm{mg} / \mathrm{kg}$, and lead concentrations ranged from 4.1 to $7.5 \mathrm{mg} / \mathrm{kg}$. All reported concentrations of these metals were below EPA Region 9 PRGs defined in this document as PALs.

Arsenic concentrations ranged from 1.9 to $3.1 \mathrm{mg} / \mathrm{kg}$. Highest and lowest concentrations detected were between 4.5 and $12 \mathrm{ft}$ bgs, and all analyzed samples collected in the leachfield indicated a consistent arsenic concentration across the site, with no "hot spots" or evidence of a localized spill. The PAL for arsenic is defined by EPA Region 9 as $2.7 \mathrm{mg} / \mathrm{kg}$, and several of the samples tested were 
Table A.4-4

Soil Sample Results for Total RCRA Metals Detected Above Minimum Reporting Limits at CAS 25-04-03

(Page 1 of 2)

\begin{tabular}{|c|c|c|c|c|c|}
\hline \multirow{2}{*}{$\begin{array}{c}\text { Sample } \\
\text { Identification } \\
\text { Number }\end{array}$} & \multirow{2}{*}{$\begin{array}{l}\text { Depth } \\
\text { (ft bgs) }\end{array}$} & \multicolumn{4}{|c|}{ Contaminants of Potential Concern (mg/kg) } \\
\hline & & Arsenic & Barium & Chromium & Lead \\
\hline \multicolumn{2}{|c|}{ Preliminary Action Levels ${ }^{a}$} & 2.7 & 100,000 & 450 & 750 \\
\hline 271B001 & $9.6-10.7$ & 2.3 & 92 & 2.7 & 4.7 \\
\hline 271B003 & $9.2-10.2$ & 2.5 & 110 & 2.5 & 5.5 \\
\hline 271B005 & $5-6$ & 2.3 & 77 & 2 & 4.2 \\
\hline 271B007 & $4.5-5.5$ & 2.3 & 85 & 2.6 & 4.8 \\
\hline 271B009 & $4.1-5.1$ & 2.2 & 73 & 2.5 & 5 \\
\hline 271B011 & $4-5$ & 2.8 & 86 & 203.7 & 6.1 \\
\hline 271B012 & $6.5-7.5$ & 2.2 & 80 & 3.2 & 5 \\
\hline 271B013 & $6.5-7.5$ & 2.5 & 85 & 3.5 & 5.7 \\
\hline 271B015 & $5-6$ & 2 & 120 & 2.7 & 4.8 \\
\hline 271B017 & $5-6$ & 2.6 & 99 & 3.7 & 5.8 \\
\hline 271B019 & $4.7-5.7$ & 2 & 79 & 2.9 & 4.7 \\
\hline 271B021 & $4.6-5.6$ & 2.2 & 96 & 3.2 & 5 \\
\hline 271B023 & $4.5-5.5$ & 2.2 & 91 & 8.8 & 4.5 \\
\hline 271B028 & $4.5-5.5$ & 2 & 58 & 2.2 & 5 \\
\hline 271B030 & $4.5-5.5$ & 2.4 & 71 & 2.7 & 6.4 \\
\hline 271B032 & $4.5-5.5$ & 2.6 & 90 & 3 & 5.7 \\
\hline 271B034 & $4.5-5.5$ & 2.8 & 110 & 2.5 & 5.5 \\
\hline 271B035 & $7-8$ & 2.3 & 110 & 2.5 & 5 \\
\hline 271B037 & $4.5-5.5$ & 2 & 86 & 2 & 5.1 \\
\hline 271B038 & $7-8$ & 2.4 & 79 & 2.5 & 5.3 \\
\hline 271B039 & $11-12$ & 1.9 & 110 & 1.5 & 4.1 \\
\hline 271B041 & $4.3-5.3$ & 2.5 & 79 & 2.4 & 4.7 \\
\hline 271B043 & $4.5-5.5$ & 2.7 & 100 & 3.2 & 6.4 \\
\hline 271B044 & $4.5-5.5$ & 2.7 & 100 & 3.1 & 6.6 \\
\hline 271B046 & $4.5-5.5$ & 2.5 & 88 & 2.9 & 6 \\
\hline 271B048 & $4.5-5.5$ & 2.3 & 90 & $2.4(\mathrm{~J})$ & 6.9 \\
\hline 271B050 & $4.5-5.5$ & 2 & 75 & $2.5(\mathrm{~J})$ & 4.8 \\
\hline 271B052 & $4.5-5.5$ & 3.1 & 87 & $3.8(\mathrm{~J})$ & 7.1 \\
\hline 271B054 & $4.5-5.5$ & 2.3 & 110 & $2.7(\mathrm{~J})$ & 6.6 \\
\hline 271B056 & $4.5-5.5$ & 2.7 & 77 & 2.2 & $5.9(\mathrm{~J})$ \\
\hline 271B058 & $4.5-5.5$ & 2 & 81 & $2.4(\mathrm{~J})$ & 4.9 \\
\hline 271B060 & $4.5-5.5$ & 2.3 & 62 & $2.4(\mathrm{~J})$ & 4.8 \\
\hline
\end{tabular}


Table A.4-4

Soil Sample Results for Total RCRA Metals Detected Above Minimum Reporting Limits at CAS 25-04-03

(Page 2 of 2)

\begin{tabular}{||c|c|c|c|c|c||}
\hline \multirow{2}{*}{$\begin{array}{c}\text { Sample } \\
\text { Identification } \\
\text { Number }\end{array}$} & \multirow{2}{*}{$\begin{array}{c}\text { Depth } \\
\text { (ft bgs) }\end{array}$} & \multicolumn{4}{|c|}{ Contaminants of Potential Concern (mg/kg) } \\
\cline { 3 - 6 } & & Arsenic & Barium & Chromium & Lead \\
\hline Preliminary Action Levels & & & & & \\
\hline $271 \mathrm{~B} 062$ & $4.5-5.5$ & 2.7 & $\mathbf{1 0 0 , 0 0 0}$ & $\mathbf{4 5 0}$ & $\mathbf{7 5 0}$ \\
\hline \hline $271 \mathrm{~B} 063$ & $7-8$ & 2.4 & 130 & $3.2(\mathrm{~J})$ & 7.5 \\
\hline $271 \mathrm{~B} 064$ & $10-11$ & 2.4 & 120 & $2.9(\mathrm{~J})$ & 5.6 \\
\hline $271 \mathrm{~B} 065$ & $4.5-5.5$ & 2.4 & 130 & $2.4(\mathrm{~J})$ & 5.2 \\
\hline $271 \mathrm{~B} 067$ & $4.5-5.5$ & 2.3 & 98 & 2.8 & 4.8 \\
\hline $271 \mathrm{~B} 069$ & $4.5-5.5$ & 2.5 & 110 & 3.6 & 5.4 \\
\hline $271 \mathrm{~B} 070$ & $7-8$ & 2.1 & 110 & 2.4 & 6.6 \\
\hline $271 \mathrm{~B} 071$ & $11-12$ & $\mathbf{2 . 9}$ & 61 & 1.9 & 4.7 \\
\hline $271 \mathrm{~B} 072$ & $4.5-5.5$ & $\mathbf{2 . 8}$ & 110 & 3.8 & 6.8 \\
\hline
\end{tabular}

aBased on U.S. Environmental Protection Agency, Region 9 Preliminary Remediation Goals (PRGs) (EPA, 2000).

$\mathrm{J}=$ Estimated value. Qualifier added to laboratory data; record accepted. Inductively coupled plasma serial dilution recovery was not met.

above this PAL (Table A.4-4). The PAL for arsenic is lower than the 7 to $8 \mathrm{mg} / \mathrm{kg}$ mean concentration of arsenic in silt from the Nevada Test and Training Range (NBMG, 1998; Moore, 1999). Although some arsenic concentrations in the soil exceed the PAL, these concentrations are believed to be within the ambient conditions for CAS 25-04-03 and do not represent contamination.

\section{A.4.3.1.5 Polychlorinated Biphenyls}

Polychlorinated biphenyls were not detected above MRLs in CAS 25-04-03 soil samples.

\section{A.4.3.1.6 Gamma Spectrometry}

Results of the soil sample gamma spectrometry analysis are presented in Table A.4-5. Concentrations of actinium-228, bismuth-212, bismuth-214, lead-212, lead-214, potassium-40, and thallium-208 were detected above respective MDLs. The TPU in the radiological measurement is provided in the 
Table A.4-5

Soil Sample Results for Gamma-Emitting Radionuclides Detected Above Minimum Reporting Limits at CAS 25-04-03

\begin{tabular}{|c|c|c|c|c|c|c|c|c|}
\hline \multirow{2}{*}{$\begin{array}{c}\text { Sample } \\
\text { Identification } \\
\text { Number }\end{array}$} & \multirow{2}{*}{$\begin{array}{l}\text { Depth } \\
\text { (ft bgs) }\end{array}$} & \multicolumn{7}{|c|}{ Contaminants of Potential Concern $(\mathrm{pCi} / \mathrm{g})$} \\
\hline & & Actinium-228 ${ }^{a}$ & Bismuth-212 & Bismuth-214 & Potassium-40 & Lead-212 $^{\mathrm{a}}$ & Lead-214 ${ }^{b}$ & Thallium-208 \\
\hline \multicolumn{2}{|c|}{ Preliminary Action Level } & 3.64 & 2.4 & 3.47 & 96 & 2.9 & 2.9 & 3.4 \\
\hline 271B001 & $9.6-10.7$ & $1.66 \pm 0.33$ & $\overline{--}$ & $0.78 \pm 0.19$ & $28.7 \pm 5.0$ & $2.09 \pm 0.38$ & $0.96 \pm 0.20$ & $0.55 \pm 0.11$ \\
\hline 271B005 & $5-6$ & $1.65 \pm 0.37$ & -- & $0.89 \pm 0.24$ & $27.1 \pm 5.1$ & $1.94 \pm 0.37$ & $0.87 \pm 0.20$ & $0.6 \pm 0.14$ \\
\hline 271B009 & $4.8-5.8$ & $1.51 \pm 0.30$ & -- & $0.74 \pm 0.18$ & $26.8 \pm 4.7$ & $1.73 \pm 0.31$ & $0.93 \pm 0.19$ & $0.442 \pm 0.098$ \\
\hline 271B012 & $6.5-7.5$ & $1.53 \pm 0.31$ & -- & $0.8 \pm 0.19$ & $29.1 \pm 5.1$ & $1.85 \pm 0.33$ & $0.89 \pm 0.19$ & $0.48 \pm 0.10$ \\
\hline 271B013 & $6.5-7.5$ & $1.55 \pm 0.31$ & -- & $0.75 \pm 0.18$ & $26.8 \pm 4.7$ & $1.75 \pm 0.32$ & $0.84 \pm 0.17$ & $0.59 \pm 0.12$ \\
\hline 271B017 & $5-6$ & $1.57 \pm 0.35$ & -- & $0.9 \pm 0.22$ & $27.6 \pm 5.2$ & $2.01 \pm 0.38$ & $0.97 \pm 0.22$ & $0.59 \pm 0.14$ \\
\hline 271B021 & $4.6-5.6$ & $1.41 \pm 0.35$ & -- & $0.61 \pm 0.21$ & $30.4 \pm 5.9$ & $1.88 \pm 0.37$ & $0.83 \pm 0.20$ & $0.55 \pm 0.15$ \\
\hline 271B028 & $4.5-5.5$ & $1.1 \pm 0.30$ & -- & $0.61 \pm 0.21$ & $25.6 \pm 5.1$ & $1.64 \pm 0.33$ & $0.83 \pm 0.20$ & $0.55 \pm 0.14$ \\
\hline 271B035 & $7-8$ & $1.26 \pm 0.37$ & -- & $0.72 \pm 0.26$ & $25.1 \pm 5.1$ & $1.97 \pm 0.39$ & $0.78 \pm 0.22$ & $0.52 \pm 0.15$ \\
\hline 271B038 & $7-8$ & $1.7 \pm 0.49$ & -- & $0.66 \pm 0.28$ & $30.8 \pm 6.5$ & $1.88 \pm 0.42$ & $0.92 \pm 0.26$ & $0.65 \pm 0.19$ \\
\hline 271B039 & $11-12$ & $1.81 \pm 0.66$ & -- & -- & $31.7 \pm 7.2$ & $2.22 \pm 0.47$ & $0.73 \pm 0.26$ & $0.54 \pm 0.20$ \\
\hline 271B043 & $4.5-5.5$ & $1.06 \pm 0.29$ & -- & $0.95 \pm 0.27$ & $26.9 \pm 5.3$ & $1.71 \pm 0.35$ & $0.93 \pm 0.23$ & $0.47 \pm 0.14$ \\
\hline 271B044 & $4.5-5.5$ & $1.38 \pm 0.28$ & -- & $0.84 \pm 0.19$ & $29.1 \pm 5.1$ & $1.83 \pm 0.33$ & $0.89 \pm 0.19$ & $0.51 \pm 0.11$ \\
\hline 271B058 & $4.5-5.5$ & $1.37 \pm 0.28$ & $1.37 \pm 0.58$ & $0.73 \pm 0.17$ & $28.4 \pm 4.9$ & $1.65 \pm 0.30$ & $0.76 \pm 0.16$ & $0.54 \pm 0.11$ \\
\hline 271B063 & $7-8$ & $1.54 \pm 0.46$ & -- & $0.9 \pm 0.34$ & $30.5 \pm 6.3$ & $1.89 \pm 0.41$ & $0.79 \pm 0.24$ & $0.37 \pm 0.14$ \\
\hline 271B064 & $10-11$ & $1.56 \pm 0.55$ & -- & $1.03 \pm 0.41$ & $31.3 \pm 7.2$ & $1.87 \pm 0.43$ & -- & $0.52 \pm 0.19$ \\
\hline 271B067 & $4.5-5.5$ & $1.7 \pm 0.37$ & -- & $0.83 \pm 0.21$ & $25.2 \pm 4.8$ & $2.02 \pm 0.38$ & $0.81 \pm 0.19$ & $0.58 \pm 0.14$ \\
\hline 271B070 & $7-8$ & $1.6 \pm 0.55$ & -- & -- & $26.9 \pm 6.5$ & $1.65 \pm 0.40$ & $0.63 \pm 0.25$ & $0.53 \pm 0.20$ \\
\hline 271B071 & $11-12$ & $1.59 \pm 0.43$ & -- & $0.75 \pm 0.27$ & $29.2 \pm 5.6$ & $1.86 \pm 0.37$ & $1.01 \pm 0.26$ & $0.52 \pm 0.14$ \\
\hline
\end{tabular}

aBackground concentration listed in Environmental Monitoring Report for the Proposed Ward Valley, California, Low-Level Radioactive Waste (LLRW) Facility (US Ecology and Atlan-Tech, 1992).

background concentration listed or derived in Off-Site Radiation Exposure Review Project, Phase II Soil Program (McArthur and Miller, 1989). 
table along with the concentration for all detected gamma-emitters. The concentrations of the detected gamma-emitting radionuclides are below PALs and are not significantly different than concentrations measured in soil samples collected from undisturbed background locations.

\section{A.4.3.1.7 Isotopic Uranium}

Detected values of uranium isotopes, along with associated TPUs are reported in Table A.4-6. Sample numbers 271B028 and 271B039 had concentrations of U-235 above the PAL; therefore, a normalized difference based on a confidence level of 95 percent was used to determine if the concentrations were statistically distinguishable from background. These U-235 concentrations were not significantly greater than concentrations in soil samples collected from undisturbed background locations.

\section{A.4.3.1.8 Isotopic Plutonium}

Plutonium isotopes were not detected above PALs in CAS 25-04-03 soil samples.

\section{A.4.3.1.9 Strontium-90}

Strontium-90 was not detected above MRLs in CAS 25-04-03 soil samples.

\section{A.4.3.2 Septic Tank Sample Results}

Results of collected septic tank content samples were compared to regulatory levels based on disposal options. If the waste has no hazardous component, the regulatory level is based on disposal options at NTS landfills and lagoons (BN, 1995; CFR, 2000c and c; NDEP, 1997a, b, and c). Any sludge or liquid waste will be solidified before disposal at the NTS landfills (NDEP, 1997b). If the waste is hazardous, the release criteria are based on interpretation of the guidelines presented in the POC (BN, 1995; Alderson, 1999). For waste destined for off-site disposal, the POC radiological levels must be met to certify that the waste has no radioactivity added.

One sludge and one liquid sample were obtained from the CAS 25-04-03 septic tank. The analytical suite followed the CAIP and is detailed in Section A.4.2.8. Analytical results exceeding MRLs are listed in Table A.4-7. 
Table A.4-6

Soil Sample Results for Isotopic Plutonium and Uranium Detected Above Minimum Reporting Limits at CAS 25-04-03

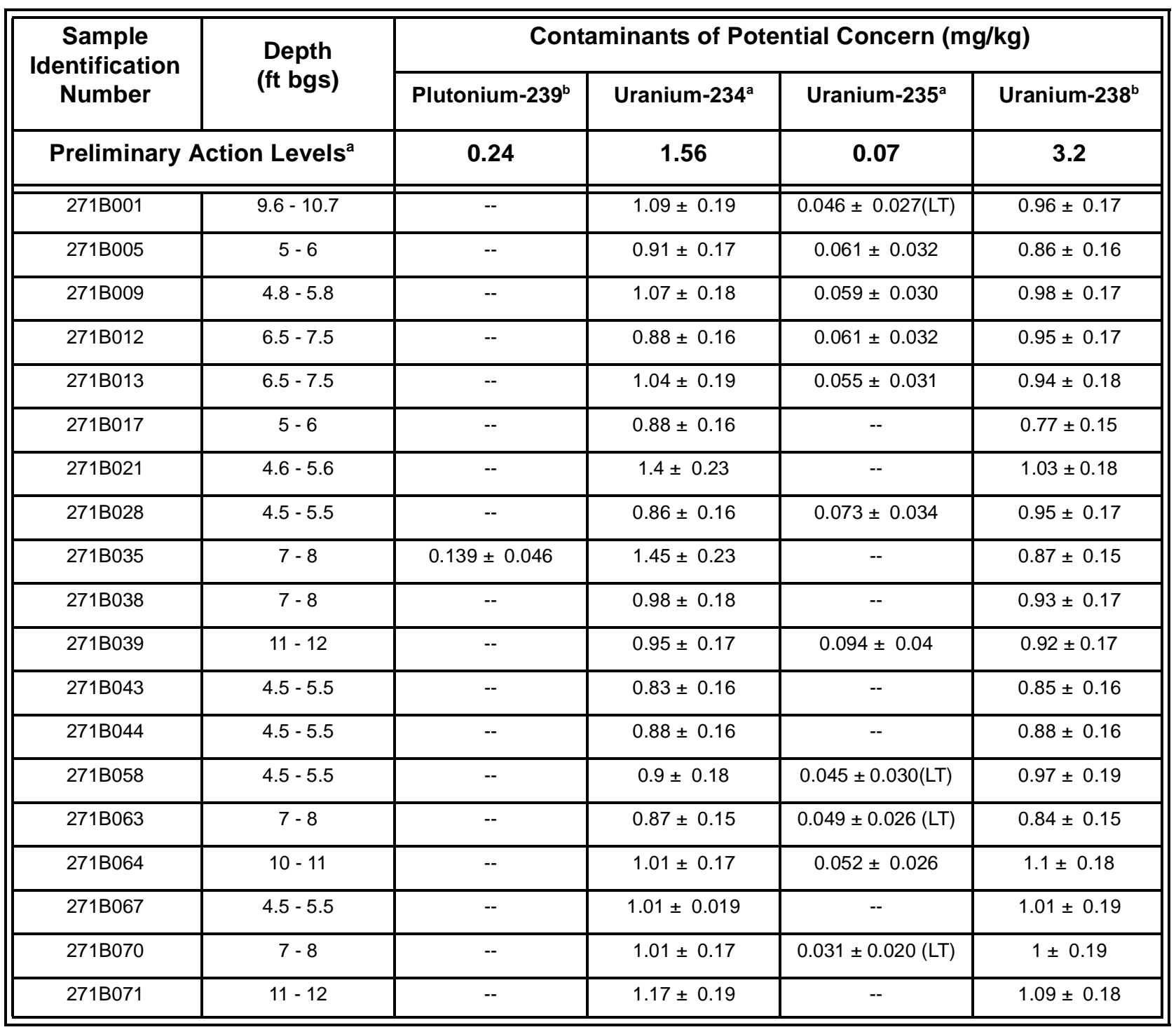

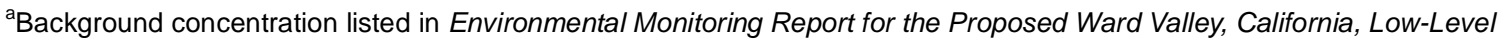
Radioactive Waste (LLRW) Facility (US Ecology and Atlan-Tech, 1992).

${ }^{b}$ Background concentration listed or derived in Off-Site Radiation Exposure Review Project, Phase II Soil Program (McArthur and Miller, 1989).

$\mathrm{LT}=$ Result is less than requested minimum detectable concentration (MDC), greater than sample specific MDC.

$--=$ Not detected above minimum reporting limit. 
Table A.4-7

\section{Liquid and Sludge Samples Results Detected Above Minimum Reporting Limits at CAS 25-04-03}

\begin{tabular}{|c|c|c|c|c|c|c|}
\hline $\begin{array}{c}\text { Sample } \\
\text { Identification } \\
\text { Number }\end{array}$ & Matrix & Parameter & Result & Units & Limits & Reference \\
\hline $271 \mathrm{~B} 026$ & Liquid & Arsenic & 0.02 & $\mathrm{mg} / \mathrm{L}$ & $\overline{5}$ & CFR, 2000b \\
\hline 271B026 & Liquid & Barium & 0.19 & $\mathrm{mg} / \mathrm{L}$ & 100 & CFR, 2000b \\
\hline 271B026 & Liquid & Lead & 0.0056 & $\mathrm{mg} / \mathrm{L}$ & 5 & CFR, 2000b \\
\hline 271B026 & Liquid & Uranium-234 & $1.94 \pm 0.35$ & $\mathrm{pCi} / \mathrm{L}$ & 100 & NDEP, 1997b \\
\hline 271B026 & Liquid & Uranium-238 & $0.65 \pm 0.16(\mathrm{~J})^{\mathrm{a}}$ & $\mathrm{pCi} / \mathrm{L}$ & 100 & NDEP, 1997b \\
\hline 271B027 & Sludge & Arsenic ${ }^{* *}$ & 3.3 & $\mathrm{mg} / \mathrm{kg}$ & NA & CFR, 2000b \\
\hline 271B027 & Sludge & Barium** $^{*}$ & 79 & $\mathrm{mg} / \mathrm{kg}$ & NA & CFR, 2000b \\
\hline 271B027 & Sludge & Chromium $^{\star *}$ & 3.8 & $\mathrm{mg} / \mathrm{kg}$ & NA & CFR, 2000b \\
\hline 271B027 & Sludge & Lead $^{* *}$ & 12 & $\mathrm{mg} / \mathrm{kg}$ & NA & CFR, 2000b \\
\hline 271B027 & Sludge & Mercury $^{\star *}$ & 0.15 & $\mathrm{mg} / \mathrm{kg}$ & NA & CFR, 2000b \\
\hline 271B027 & Sludge & Diesel Range Organics & $160(M)$ & $\mathrm{mg} / \mathrm{kg}$ & 100 & NDEP, 1997b \\
\hline 271B027 & Sludge & Gasoline Range Organics & $34(J)^{b}$ & $\mathrm{mg} / \mathrm{kg}$ & 100 & NDEP, 1997b \\
\hline 271B027 & Sludge & Acetone & $3,000(\mathrm{~J})^{\mathrm{c}}$ & $\mu \mathrm{g} / \mathrm{kg}$ & NA & CFR, 2000b \\
\hline 271B027 & Sludge & 1,4-Dichlorobenzene & 2,700 & $\mu \mathrm{g} / \mathrm{kg}$ & $\overline{N A}$ & CFR, 2000b \\
\hline 271B027 & Sludge & Actinium-228 & $1.52 \pm 0.42$ & $\mathrm{pCi} / \mathrm{g}$ & - & $\mathrm{N}$ \\
\hline $271 \mathrm{~B} 027$ & Sludge & Potassium-40 & $35.2 \pm 6.6$ & $\mathrm{pCi} / \mathrm{g}$ & - & $\mathrm{N}$ \\
\hline 271B027 & Sludge & Lead-212 & $1.89 \pm 0.38$ & $\mathrm{pCi} / \mathrm{g}$ & - & $\mathrm{N}$ \\
\hline 271B027 & Sludge & Lead-214 & $0.8 \pm 0.24$ & $\mathrm{pCi} / \mathrm{g}$ & - & $\mathrm{N}$ \\
\hline 271B027 & Sludge & Thallium-208 & $0.55 \pm 0.16$ & $\mathrm{pCi} / \mathrm{g}$ & - & $\mathrm{N}$ \\
\hline 271B027 & Sludge & Uranium-234 & $1.06 \pm 0.18$ & $\mathrm{pCi} / \mathrm{g}$ & 100 & NDEP, 1997b \\
\hline 271B027 & Sludge & Uranium-235 & $0.062 \pm 0.031$ & $\mathrm{pCi} / \mathrm{g}$ & 100 & NDEP, 1997b \\
\hline 271B027 & Sludge & Uranium-238 & $1.05 \pm 0.18$ & $\mathrm{pCi} / \mathrm{g}$ & 100 & NDEP, 1997b \\
\hline 271B027 & Sludge & Aroclor-1254 & 180 & $\mu \mathrm{g} / \mathrm{kg}$ & 50,000 & CFR, 2000c \\
\hline $271 \mathrm{~B} 026$ & Liquid & Gross Alpha & $4.0 \pm 2.5$ & $\mathrm{pCi} / \mathrm{L}$ & $3.8^{\mathrm{d}}$ & NA \\
\hline 271B026 & Liquid & Gross Beta & $91 \pm 13$ & $\mathrm{pCi} / \mathrm{L}$ & $4.0^{d}$ & NA \\
\hline 271B027 & Sludge & Gross Alpha & $6.3 \pm 1.1$ & $\mathrm{pCi} / \mathrm{L}$ & $0.32^{d}$ & NA \\
\hline 271B027 & Sludge & Gross Beta & $4.62 \pm 0.74$ & $\mathrm{pCi} / \mathrm{L}$ & $0.42^{d}$ & NA \\
\hline
\end{tabular}

${ }^{a}$ Qualifier added to laboratory data; record accepted. Duplicate relative percent difference over the control limits.

${ }^{b}$ Qualifier added to laboratory data; record accepted. Exceeded holding time.

${ }^{\circ}$ Qualifier added to laboratory data; record accepted. Relative response factor $<0.05$.

dMaximum detectable concentration.

$* *$ TCLP below minimum reporting limit

$M=$ Motor oil

$\mathrm{N}=$ No limit established (NDEP, 1997b)

$\mathrm{NA}=$ Not applicable

$\mathrm{J}=$ Estimated value 
Several COPCs were detected in the sludge samples. Most COPCs were below regulatory limits except for TPH which was detected in sample 271B027. Diesel-range organic compound concentrations in this sample were $160 \mathrm{mg} / \mathrm{kg}$. This level exceeds the NDEP action level of $100 \mathrm{mg} / \mathrm{kg}$ (NAC, 2000) for TPH.

\section{A.4.4 Contaminants of Concern}

Based on the aforementioned analytical results, COCs are present in the septic tank and in the soils under the leachfield. The septic tank contains sludge with TPH DRO that exceeds regulatory action levels and is, therefore, the only COC for the septic tank. The leachfield soil contains benzo(a)pyrene in concentrations above PALs in two locations. This SVOC is the only COC for the leachfield. However, because this leachfield contained "Orangeburg" pipe, it is possible that the results for benzo(a)pyrene may be related to pieces of the pipe material inadvertently introduced into the samples at the two locations (see Section A.9.3.1.2 for additional information). No COCs were identified in the soil surrounding the septic tank or within the collection system piping.

\section{A.4.5 Nature and Extent of Contamination}

Total petroleum hydrocarbons are located within the septic tank sludge. Approximately 34 gal of sludge and 410 gal of liquid remained in the bottom of the tank. Benzo(a)pyrene is only located at two locations (B04 and B32) in the soils of the leachfield. At both locations, the extent of potential contamination has been determined.

\section{A.4.6 Revised Conceptual Model}

Significant variations to the leachfield configuration were identified. The originally assumed configuration is depicted in Figure 4-3 of the CAIP. The actual configuration is depicted in Figure A.4-1. This change in configuration did not invalidate the conceptual model for this CAS. Biased soil samples were ultimately collected from the perforated distribution pipe/native soil and leachrock/native soil interfaces, and random soil samples were collected in accordance with the CAIP. 


\section{A.5.0 Reactor Control Point Septic System (CAS 25-04-04)}

The RCP septic system was designed to receive effluent generated within Building 3101 (Control Point), Building 3102 (Power House), Building 3103 (Los Alamos Scientific Laboratory Warehouse), Building 3106 (Storage Building), Building 3104 (Administration Building), Building 3105 (Former Medical/Cafeteria), Building 3107 (Service Station), and Building 3123 (Technical Services). The leachfield system is located just south of the RCP complex fenceline, and the septic tank is within the fenceline. The site is comprised of a leachfield, septic tank, distribution box and associated piping. More detail is provided in the CAIP (DOE/NV, 2001).

\section{A.5.1 Corrective Action Investigation}

Eighty investigation samples, listed in Table A.5-1, were collected during investigation activities conducted at CAS 25-04-04. The actual sample locations are shown in Figure A.5-1. The specific CAI activities conducted to meet CAIP requirements at CAS 25-04-04 are described in Table A.2-1.

\section{A.5.1.1 Deviations}

The following deviations to the CAIP requirements were the result of unforeseen circumstances:

- The location (C01) of samples 271C013 and 271C014 was altered to approximately $17.6 \mathrm{ft}$ from the northwest corner of the leachfield. The sampling location was altered, by the ITLV Task Manager in consultation with the Site Safety Officer, to avoid a power pole located near the end of the lateral line.

- Refusal was met due to encountering subsurface hardpan (caliche); therefore:

- Sample 271C003 was collected at 4.25 to $4.75 \mathrm{ft}$ bgs rather than the planned interval of 4.25 to $5.25 \mathrm{ft}$ bgs. However, the second consecutive clean sample was able to be collected at the planned interval of 6.75 to $7.75 \mathrm{ft}$ bgs

- Sample 271C009 was collected at 6.2 to $6.7 \mathrm{ft}$ bgs rather than the planned interval of 6.75 to $7.75 \mathrm{ft}$ bgs

- Sample 271C026 was collected at 5.25 to $5.75 \mathrm{ft}$ bgs rather than the planned interval of 6.5 to $7.5 \mathrm{ft} \mathrm{bgs}$ 
Table A.5-1

Samples Collected at CAS 25-04-04

(Page 1 of 7 )

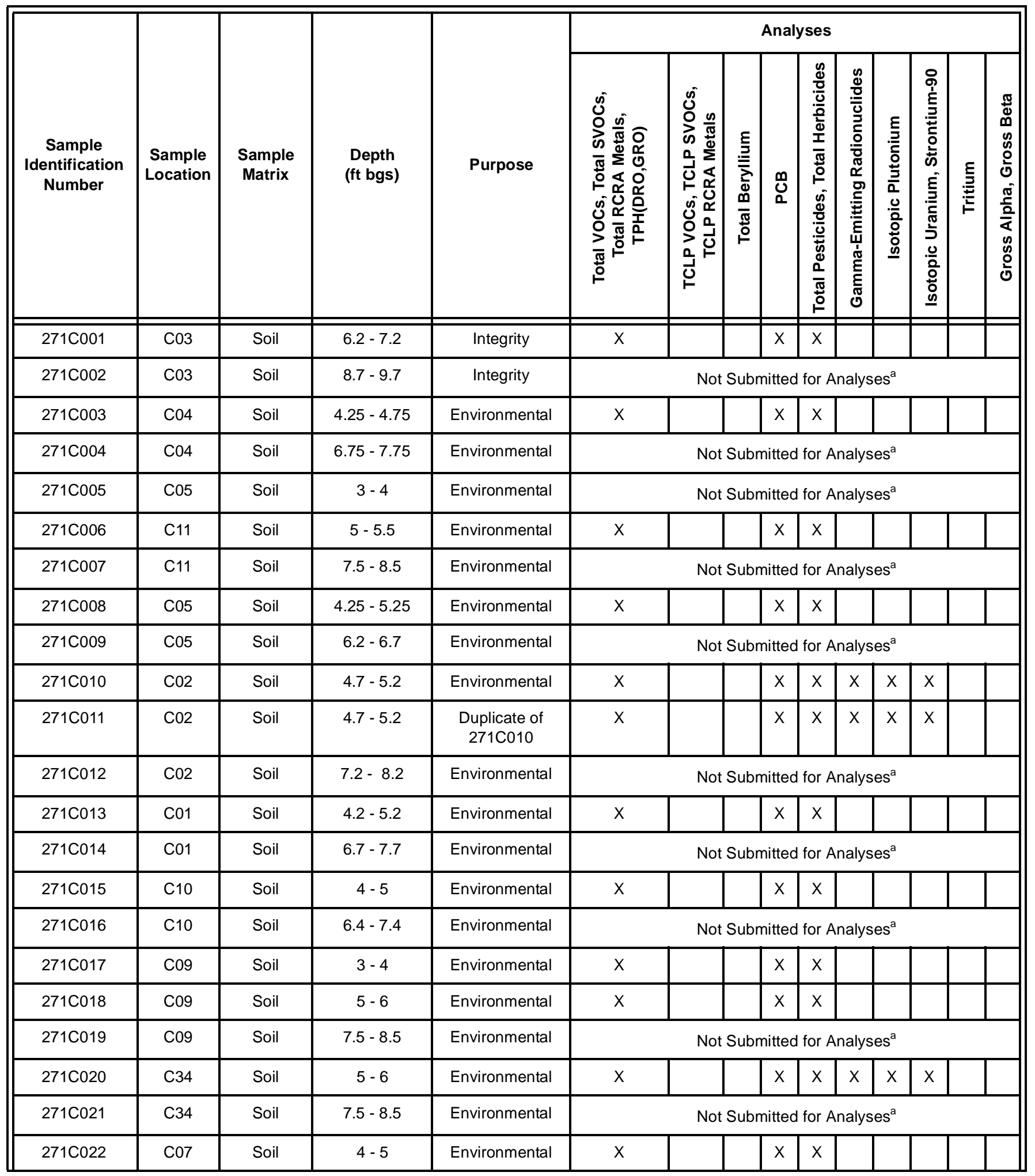


Table A.5-1

Samples Collected at CAS 25-04-04

(Page 2 of 7 )

\begin{tabular}{|c|c|c|c|c|c|c|c|c|c|c|c|c|c|c|}
\hline \multirow[b]{2}{*}{$\begin{array}{c}\text { Sample } \\
\text { Identification } \\
\text { Number }\end{array}$} & \multirow[b]{2}{*}{$\begin{array}{l}\text { Sample } \\
\text { Location }\end{array}$} & \multirow[b]{2}{*}{$\begin{array}{c}\text { Sample } \\
\text { Matrix }\end{array}$} & \multirow[b]{2}{*}{$\begin{array}{c}\text { Depth } \\
\text { (ft bgs) }\end{array}$} & \multirow[b]{2}{*}{ Purpose } & \multicolumn{10}{|c|}{ Analyses } \\
\hline & & & & & 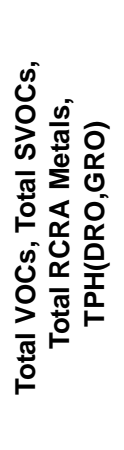 & 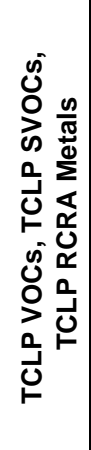 & 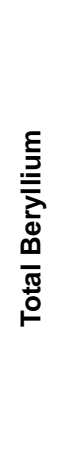 & 仓̊ & 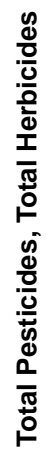 & 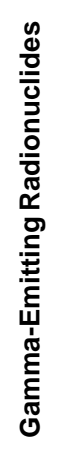 & 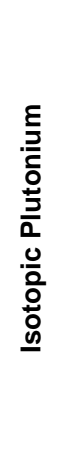 & 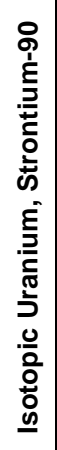 & 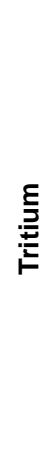 & 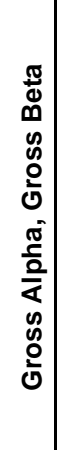 \\
\hline $271 \mathrm{C} 023$ & $\mathrm{C} 07$ & Soil & $6.5-7.5$ & Environmental & \multicolumn{10}{|c|}{ Not Submitted for Analyses ${ }^{a}$} \\
\hline $271 \mathrm{C} 026$ & C06 & Soil & $4-5$ & Environmental & $x$ & & & $X$ & $X$ & & & & & \\
\hline $271 \mathrm{C} 027$ & $\mathrm{C} 06$ & Soil & $5.25-5.75$ & Environmental & \multicolumn{10}{|c|}{ Not Submitted for Analyses ${ }^{a}$} \\
\hline $271 \mathrm{C} 028$ & $\mathrm{C} 08$ & Soil & $9.5-10$ & Environmental & \multicolumn{10}{|c|}{ Not Submitted for Analyses ${ }^{a}$} \\
\hline $271 C 029$ & $\mathrm{C08}$ & Soil & $11.5-12$ & Environmental & $x$ & & & $X$ & $X$ & $\mathrm{x}$ & $\mathrm{X}$ & $\mathrm{X}$ & & \\
\hline $271 \mathrm{C} 030$ & C12 & Soil & $4.25-5.25$ & Environmental & $x$ & & & $x$ & $x$ & & & & & \\
\hline $271 \mathrm{C} 031$ & C12 & Soil & $6.3-7.25$ & Environmental & \multicolumn{10}{|c|}{ Not Submitted for Analyses ${ }^{a}$} \\
\hline $271 \mathrm{C} 036$ & $\mathrm{C} 20$ & Soil & $4.25-5.25$ & Environmental & $x$ & & & $\mathrm{X}$ & $x$ & & & & & \\
\hline $271 \mathrm{C} 037$ & $\mathrm{C} 20$ & Soil & $6.75-7.25$ & Environmental & \multicolumn{10}{|c|}{ Not Submitted for Analyses ${ }^{a}$} \\
\hline $271 \mathrm{C} 038$ & $\mathrm{C} 26$ & Soil & $4.25-5.25$ & Environmental & $x$ & & & $x$ & $x$ & & & & & \\
\hline $271 C 039$ & C26 & Soil & $6.75-7.25$ & Environmental & \multicolumn{10}{|c|}{ Not Submitted for Analyses ${ }^{a}$} \\
\hline $271 \mathrm{C} 040$ & $\mathrm{C} 24$ & Soil & $4.25-5.25$ & Environmental & $x$ & & & $x$ & $x$ & & & & & \\
\hline $271 \mathrm{C} 041$ & $\mathrm{C} 24$ & Soil & $6.75-7.25$ & Environmental & \multicolumn{10}{|c|}{ Not Submitted for Analyses ${ }^{a}$} \\
\hline $271 \mathrm{C} 042$ & $\mathrm{C} 25$ & Soil & $4.25-5.25$ & Environmental & $x$ & & & $x$ & $x$ & & & & & \\
\hline $271 \mathrm{C} 043$ & $\mathrm{C} 25$ & Soil & $6.75-7.25$ & Environmental & \multicolumn{10}{|c|}{ Not Submitted for Analyses ${ }^{a}$} \\
\hline $271 \mathrm{C} 044$ & C13 & Soil & $3.5-4.5$ & Environmental & $\mathrm{x}$ & & & $x$ & $x$ & & & & & \\
\hline
\end{tabular}


Table A.5-1

Samples Collected at CAS 25-04-04

(Page 3 of 7 )

\begin{tabular}{|c|c|c|c|c|c|c|c|c|c|c|c|c|c|c|}
\hline \multirow[b]{2}{*}{$\begin{array}{c}\text { Sample } \\
\text { Identification } \\
\text { Number }\end{array}$} & \multirow[b]{2}{*}{$\begin{array}{l}\text { Sample } \\
\text { Location }\end{array}$} & \multirow[b]{2}{*}{$\begin{array}{c}\text { Sample } \\
\text { Matrix }\end{array}$} & \multirow[b]{2}{*}{$\begin{array}{c}\text { Depth } \\
\text { (ft bgs) }\end{array}$} & \multirow[b]{2}{*}{ Purpose } & \multicolumn{10}{|c|}{ Analyses } \\
\hline & & & & & 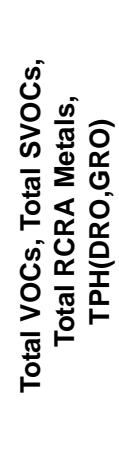 & 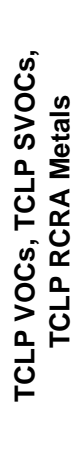 & 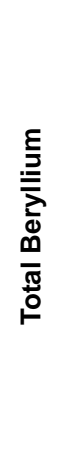 & O̊ & 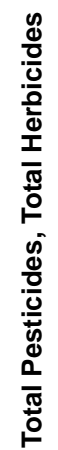 & 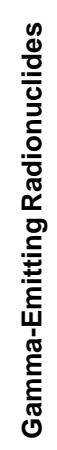 & 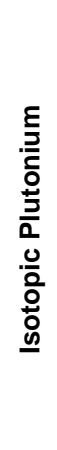 & 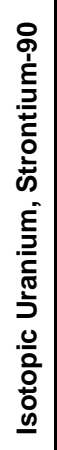 & 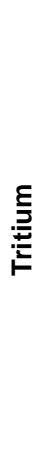 & 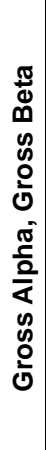 \\
\hline $271 \mathrm{C} 045$ & C13 & Soil & $6-7$ & Environmental & \multicolumn{10}{|c|}{ Not Submitted for Analyses ${ }^{a}$} \\
\hline $271 \mathrm{C} 046$ & C16 & Soil & $4.25-5.25$ & Environmental & $x$ & & & $x$ & $x$ & & & & & \\
\hline $271 \mathrm{C} 047$ & C16 & Soil & $6.75-7.25$ & Environmental & \multicolumn{10}{|c|}{ Not Submitted for Analyses ${ }^{a}$} \\
\hline $271 \mathrm{C} 048$ & C17 & Soil & $4.25-5.25$ & Environmental & $X$ & & & $X$ & $x$ & & & & & \\
\hline $271 C 049$ & C17 & Soil & $6.75-7.25$ & Environmental & \multicolumn{10}{|c|}{ Not Submitted for Analyses ${ }^{a}$} \\
\hline $271 C 050$ & C18 & Soil & $4.25-5.25$ & Environmental & $x$ & & & $\mathrm{X}$ & $\mathrm{X}$ & & & & & \\
\hline $271 \mathrm{C} 051$ & C18 & Soil & $6.75-7.25$ & Environmental & \multicolumn{10}{|c|}{ Not Submitted for Analyses ${ }^{a}$} \\
\hline $271 \mathrm{C} 052$ & $\mathrm{C} 21$ & Soil & $3.7-4.7$ & Environmental & $\mathrm{X}$ & & & $X$ & $X$ & & & & & \\
\hline $271 C 053$ & $\mathrm{C} 21$ & Soil & $6.2-7.2$ & Environmental & \multicolumn{10}{|c|}{ Not Submitted for Analyses ${ }^{a}$} \\
\hline $271 \mathrm{C} 054$ & C19 & Soil & $3.5-4.5$ & Environmental & $x$ & & & $x$ & $X$ & $X$ & $X$ & $X$ & & \\
\hline $271 C 055$ & C19 & Soil & $3.5-4.5$ & $\begin{array}{l}\text { Duplicate of } \\
271 \mathrm{C} 054\end{array}$ & $x$ & & & $\mathrm{X}$ & $\mathrm{X}$ & $\mathrm{X}$ & $x$ & $\mathrm{X}$ & & \\
\hline $271 \mathrm{C} 056$ & C19 & Soil & $6-7$ & Environmental & $x$ & & & $X$ & $X$ & $X$ & $\mathrm{X}$ & $X$ & & \\
\hline $271 \mathrm{C} 057$ & C19 & Soil & $9-10$ & Environmental & \multicolumn{10}{|c|}{ Not Submitted for Analyses ${ }^{a}$} \\
\hline $271 \mathrm{C} 058$ & $\mathrm{C} 22$ & Soil & $4.25-5.25$ & $\begin{array}{c}\text { Environmental } \\
\text { MS/MSD }\end{array}$ & $x$ & & & $\mathrm{X}$ & $X$ & $X$ & $x$ & $x$ & & \\
\hline $271 C 059$ & $\mathrm{C} 22$ & Soil & $6.75-7.75$ & Environmental & \multicolumn{10}{|c|}{ Not Submitted for Analyses ${ }^{a}$} \\
\hline $271 \mathrm{C} 060$ & $\mathrm{C} 23$ & Soil & $4.25-5.25$ & Environmental & $x$ & & & $\mathrm{X}$ & $\mathrm{X}$ & & & & & \\
\hline $271 \mathrm{C} 061$ & $\mathrm{C} 23$ & Soil & $6.75-7.75$ & Environmental & \multicolumn{10}{|c|}{ Not Submitted for Analyses ${ }^{a}$} \\
\hline 271C062 & C31 & Soil & $4.25-5.25$ & Environmental & $x$ & & & $\mathrm{X}$ & $\mathrm{X}$ & & & & & \\
\hline $271 \mathrm{C} 063$ & C31 & Soil & $6.75-7.25$ & Environmental & \multicolumn{10}{|c|}{ Not Submitted for Analyses ${ }^{a}$} \\
\hline $271 \mathrm{C} 064$ & C28 & Soil & $4.25-5.25$ & Environmental & $X$ & & & $X$ & $X$ & & & & & \\
\hline $271 \mathrm{C} 065$ & C28 & Soil & $6.75-7.75$ & Environmental & \multicolumn{10}{|c|}{ Not Submitted for Analyses ${ }^{a}$} \\
\hline
\end{tabular}


Table A.5-1

Samples Collected at CAS 25-04-04

(Page 4 of 7 )

\begin{tabular}{|c|c|c|c|c|c|c|c|c|c|c|c|c|c|c|}
\hline \multirow[b]{2}{*}{$\begin{array}{c}\text { Sample } \\
\text { Identification } \\
\text { Number }\end{array}$} & \multirow[b]{2}{*}{$\begin{array}{l}\text { Sample } \\
\text { Location }\end{array}$} & \multirow[b]{2}{*}{$\begin{array}{c}\text { Sample } \\
\text { Matrix }\end{array}$} & \multirow[b]{2}{*}{$\begin{array}{c}\text { Depth } \\
\text { (ft bgs) }\end{array}$} & \multirow[b]{2}{*}{ Purpose } & \multicolumn{10}{|c|}{ Analyses } \\
\hline & & & & & 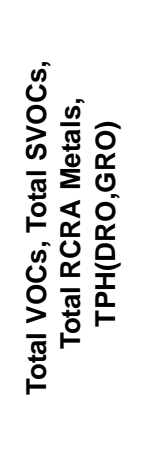 & 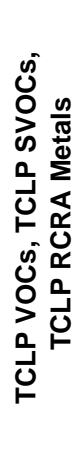 & 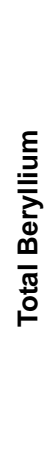 & 品 & 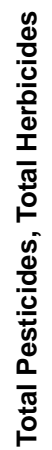 & 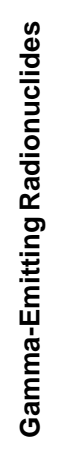 & 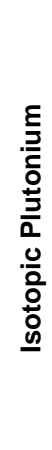 & 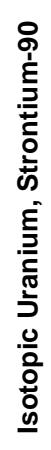 & 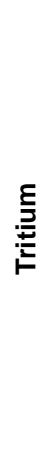 & 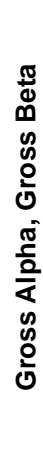 \\
\hline $271 \mathrm{C} 066$ & $\mathrm{C} 27$ & Soil & $4.25-5.25$ & Environmental & $x$ & & & $x$ & $x$ & & & & & \\
\hline $271 C 069$ & C30 & Soil & $7.4-8.4$ & Environmental & $x$ & & & $X$ & $x$ & $x$ & $\mathrm{X}$ & $x$ & & \\
\hline $271 C 070$ & C30 & Soil & $10.5-11.5$ & Environmental & \multicolumn{10}{|c|}{ Not Submitted for Analyses ${ }^{a}$} \\
\hline $271 \mathrm{C} 071$ & C30 & Soil & $12.25-13.25$ & Environmental & $x$ & & & $\mathrm{X}$ & $X$ & $x$ & $X$ & $\mathrm{X}$ & & \\
\hline $271 \mathrm{C} 072$ & C35 & Soil & $4-4.5$ & Geotechnical & \multicolumn{10}{|c|}{ Not Submitted for Analyses ${ }^{b}$} \\
\hline $271 C 073$ & C & Liquid & NA & Septic Tank & $x$ & & & $X$ & $X$ & $X$ & $X$ & $X$ & $x$ & \\
\hline $271 \mathrm{C} 074$ & $\mathrm{C}$ & Sludge & NA & Septic Tank & $x$ & $\mathrm{x}$ & & $x$ & $x$ & $\mathrm{X}$ & $x$ & $x$ & $x$ & \\
\hline $271 \mathrm{C} 080$ & C33 & Soil & $12.5-13.5$ & Environmental & \multicolumn{10}{|c|}{ Not Submitted for Analyses ${ }^{a}$} \\
\hline 271C201 & C32 & Soil & $15.5-16$ & Environmental & TPH DRO & & & & & & & & & \\
\hline $271 \mathrm{C} 202$ & C32 & Soil & $18.6-19$ & Environmental & TPH DRO & & & & & & & & & \\
\hline $271 \mathrm{C} 203$ & C32 & Soil & $21-21.5$ & Environmental & TPH DRO & & & & & & & & & \\
\hline $271 C 204$ & C32 & Soil & $21-21.5$ & $\begin{array}{l}\text { Duplicate of } \\
271 \mathrm{C} 203\end{array}$ & TPH DRO & & & & & & & & & \\
\hline $271 \mathrm{C} 205$ & C38 & Soil & $0-1$ & $\begin{array}{l}\text { Environmental } \\
\text { MS/MSD }\end{array}$ & TPH DRO & & & & & & & & & \\
\hline $271 C 206$ & C38 & Soil & $3-3.5$ & Environmental & TPH DRO & & & & & & & & & \\
\hline $271 \mathrm{C} 207$ & C38 & Soil & $6-6.5$ & Environmental & $x$ & & & $x$ & $X$ & & & & & \\
\hline
\end{tabular}


Table A.5-1

Samples Collected at CAS 25-04-04

(Page 5 of 7 )

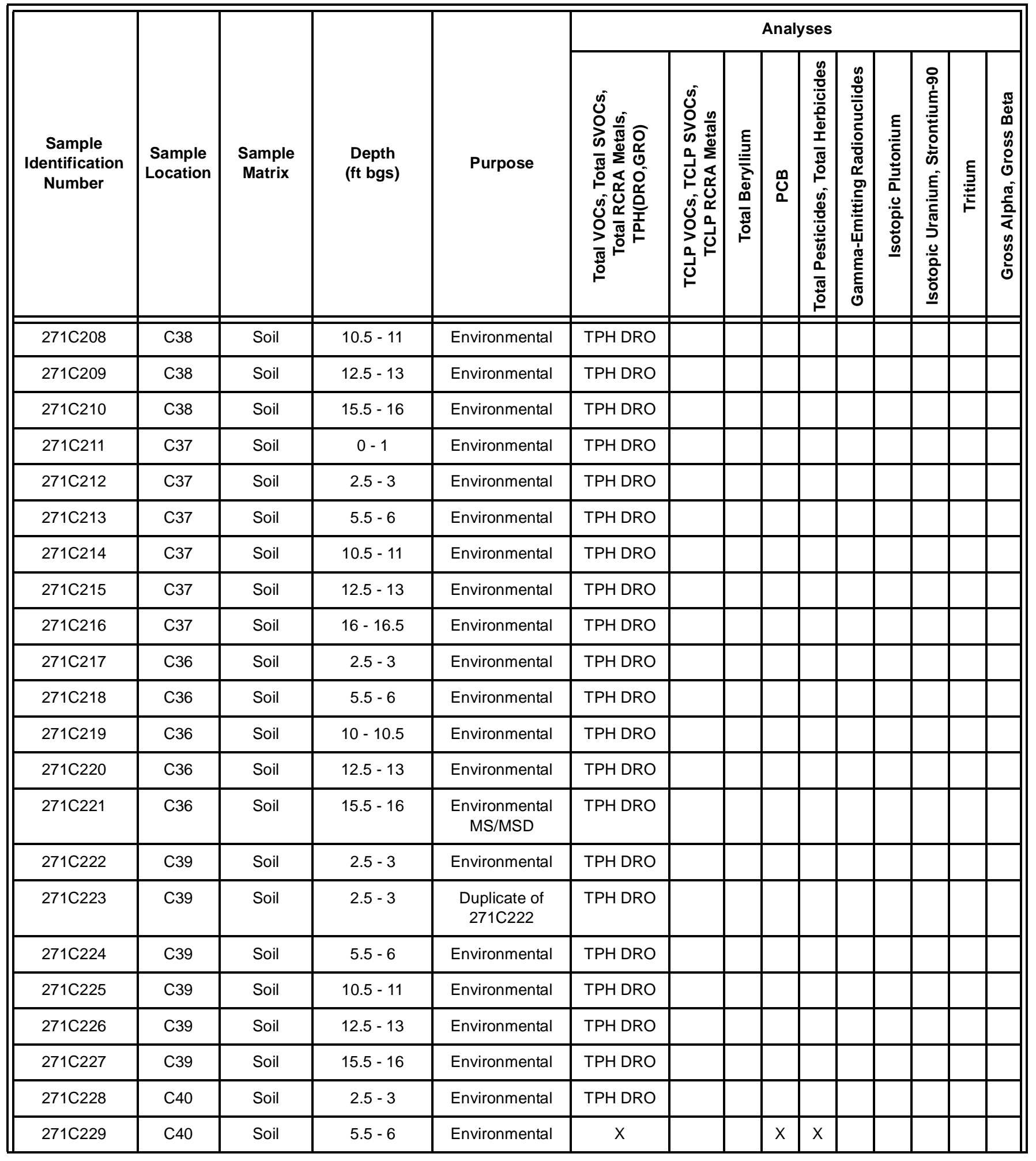


Table A.5-1

Samples Collected at CAS 25-04-04

(Page 6 of 7 )

\begin{tabular}{|c|c|c|c|c|c|c|c|c|c|c|c|c|c|c|}
\hline \multirow[b]{2}{*}{$\begin{array}{c}\text { Sample } \\
\text { Identification } \\
\text { Number }\end{array}$} & \multirow[b]{2}{*}{$\begin{array}{l}\text { Sample } \\
\text { Location }\end{array}$} & \multirow[b]{2}{*}{$\begin{array}{l}\text { Sample } \\
\text { Matrix }\end{array}$} & \multirow[b]{2}{*}{$\begin{array}{c}\text { Depth } \\
\text { (ft bgs) }\end{array}$} & \multirow[b]{2}{*}{ Purpose } & \multicolumn{10}{|c|}{ Analyses } \\
\hline & & & & & 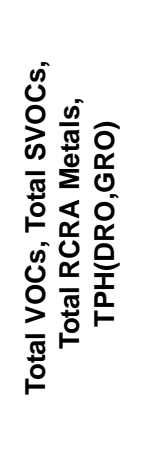 & 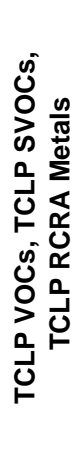 & 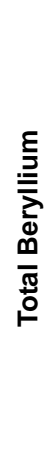 & O̊ & 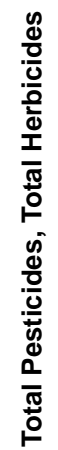 & 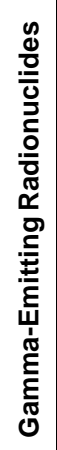 & 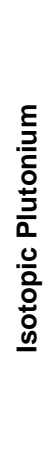 & 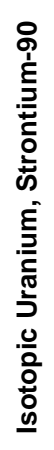 & 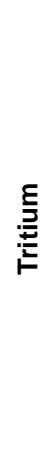 & 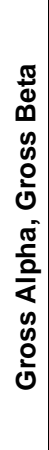 \\
\hline $271 \mathrm{C} 230$ & C40 & Soil & $10-10.5$ & Environmental & TPH DRO & & & & & & & & & \\
\hline $271 \mathrm{C} 231$ & $\mathrm{C} 40$ & Soil & $12.5-13$ & Environmental & TPH DRO & & & & & & & & & \\
\hline $271 \mathrm{C} 232$ & C40 & Soil & $15.5-16$ & Environmental & TPH DRO & & & & & & & & & \\
\hline $271 \mathrm{C} 233$ & C41 & Soil & $2.5-3$ & Environmental & TPH DRO & & & & & & & & & \\
\hline $271 \mathrm{C} 234$ & C41 & Soil & $5.5-6$ & Environmental & TPH DRO & & & & & & & & & \\
\hline $271 C 235$ & C41 & Soil & $10-10.5$ & Environmental & TPH DRO & & & & & & & & & \\
\hline $271 \mathrm{C} 236$ & C41 & Soil & $12.5-13$ & Environmental & TPH DRO & & & & & & & & & \\
\hline $271 \mathrm{C} 237$ & C41 & Soil & $15.5-16$ & Environmental & TPH DRO & & & & & & & & & \\
\hline $271 \mathrm{C} 238$ & C39 & Soil & $18.5-19$ & Environmental & TPH DRO & & & & & & & & & \\
\hline $271 \mathrm{C} 300$ & NA & Water & NA & Trip Blank & VOC only & & & & & & & & & \\
\hline $271 \mathrm{C} 301$ & NA & Water & NA & Trip Blank & VOC only & & & & & & & & & \\
\hline $271 \mathrm{C} 302$ & NA & Water & NA & Field Blank & $x$ & & & $x$ & & $x$ & $x$ & $x$ & & \\
\hline $271 \mathrm{C} 303$ & NA & Water & NA & Rinsate & $X$ & & & $x$ & & $x$ & $x$ & $\mathrm{X}$ & & \\
\hline $271 C 304$ & NA & Water & NA & Trip Blank & VOC only & & & & & & & & & \\
\hline $271 \mathrm{C} 305$ & NA & Water & NA & Trip Blank & VOC only & & & & & & & & & \\
\hline $271 \mathrm{C} 306$ & NA & Water & NA & Trip Blank & VOC only & & & & & & & & & \\
\hline $271 C 307$ & NA & Water & NA & Trip Blank & VOC only & & & & & & & & & \\
\hline $271 \mathrm{C} 308$ & NA & Water & NA & Trip Blank & VOC only & & & & & & & & & \\
\hline 271C309 & NA & Water & NA & Trip Blank & VOC only & & & & & & & & & \\
\hline $271 \mathrm{C} 310$ & NA & Water & NA & Trip Blank & VOC only & & & & & & & & & \\
\hline $271 \mathrm{C} 311$ & NA & Water & NA & Trip Blank & VOC only & & & & & & & & & \\
\hline $271 \mathrm{C} 312$ & NA & Water & NA & Trip Blank & VOC only & & & & & & & & & \\
\hline $271 C 313$ & NA & Water & NA & Source Blank & $x$ & & $x$ & $x$ & $\mathrm{x}$ & $X$ & $\mathrm{X}$ & $\mathrm{X}$ & $\mathrm{x}$ & \\
\hline
\end{tabular}


Table A.5-1

Samples Collected at CAS 25-04-04

(Page 7 of 7 )

\begin{tabular}{|c|c|c|c|c|c|c|c|c|c|c|c|c|c|c|}
\hline \multirow[b]{2}{*}{$\begin{array}{c}\text { Sample } \\
\text { Identification } \\
\text { Number }\end{array}$} & \multirow[b]{2}{*}{$\begin{array}{l}\text { Sample } \\
\text { Location }\end{array}$} & \multirow[b]{2}{*}{$\begin{array}{l}\text { Sample } \\
\text { Matrix }\end{array}$} & \multirow[b]{2}{*}{$\begin{array}{l}\text { Depth } \\
\text { (ft bgs) }\end{array}$} & \multirow[b]{2}{*}{ Purpose } & \multicolumn{10}{|c|}{ Analyses } \\
\hline & & & & & 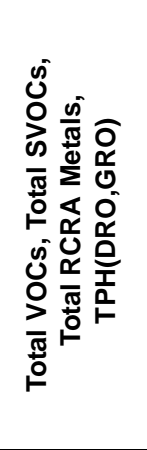 & 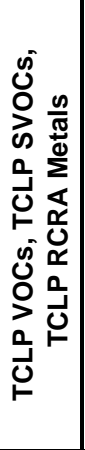 & 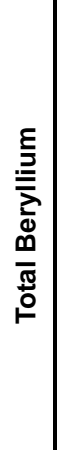 & 思 & 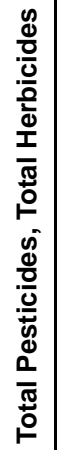 & 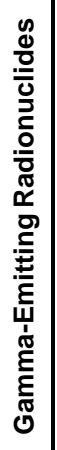 & 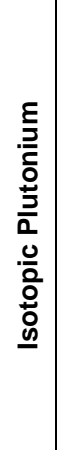 & 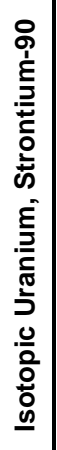 & $\stackrel{E}{\underline{z}}$ & 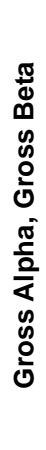 \\
\hline $271 C 314$ & NA & Water & NA & Trip Blank & VOC only & & & & & & & & & \\
\hline $271 \mathrm{C} 317$ & NA & Water & NA & Trip Blank & VOC only & & & & & & & & & \\
\hline $271 \mathrm{C} 318$ & NA & Water & NA & Trip Blank & VOC only & & & & & & & & & \\
\hline $271 C 319$ & NA & Water & NA & Trip Blank & VOC only & & & & & & & & & \\
\hline $271 C 350$ & NA & Water & NA & Trip Blank & VOC only & & & & & & & & & \\
\hline 271C351 & NA & Water & NA & Trip Blank & VOC only & & & & & & & & & \\
\hline
\end{tabular}

${ }^{2}$ The samples were collected, field screened, and returned to the site for disposal.

${ }^{\mathrm{b}}$ The sample was collected, field screened, and is being stored for possible geotechnical analysis.

$\mathrm{NA}=$ Not applicable

MS/MSD = Matrix spike/matrix spike duplicate 


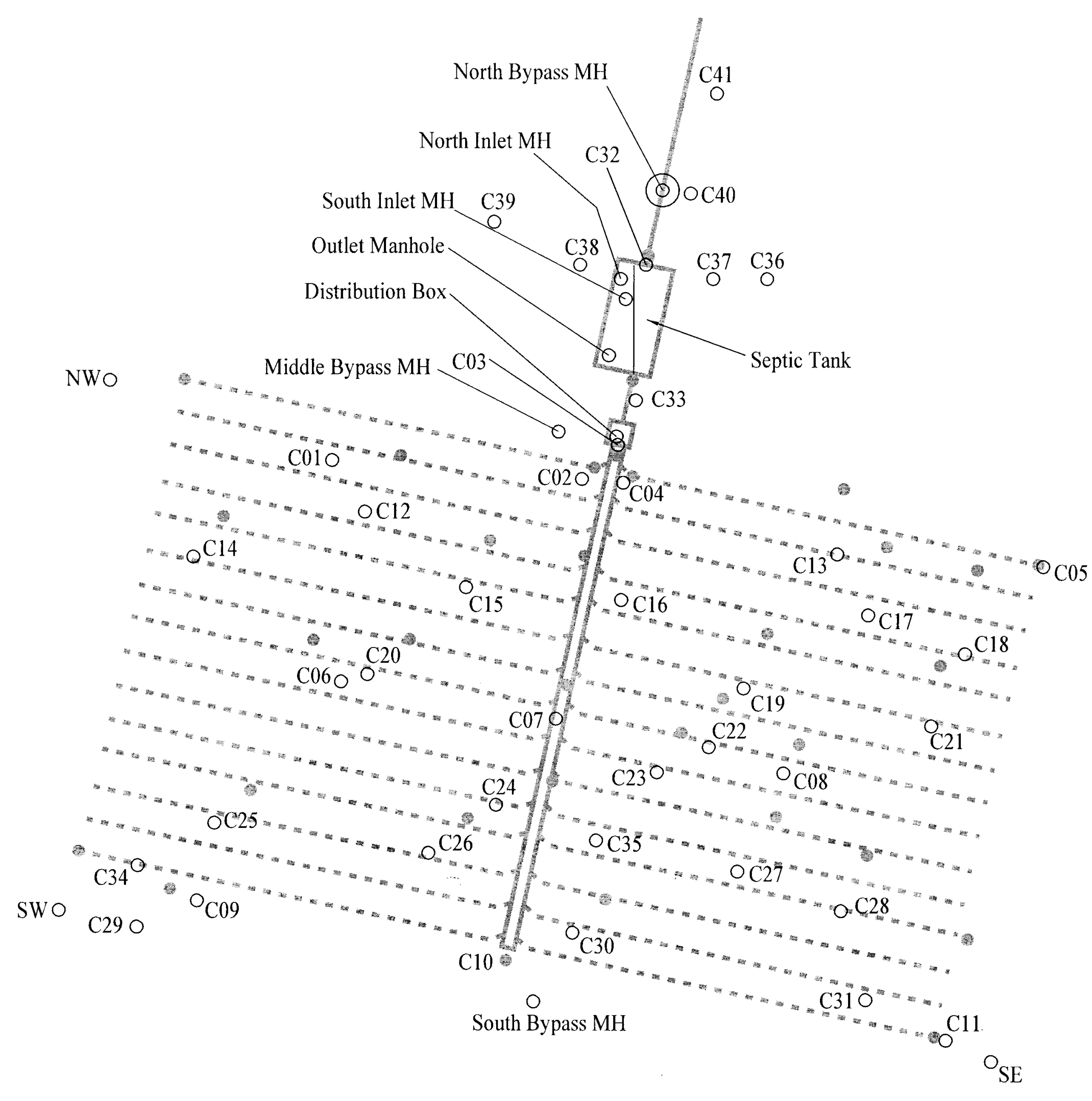

$\mathrm{ONE}$

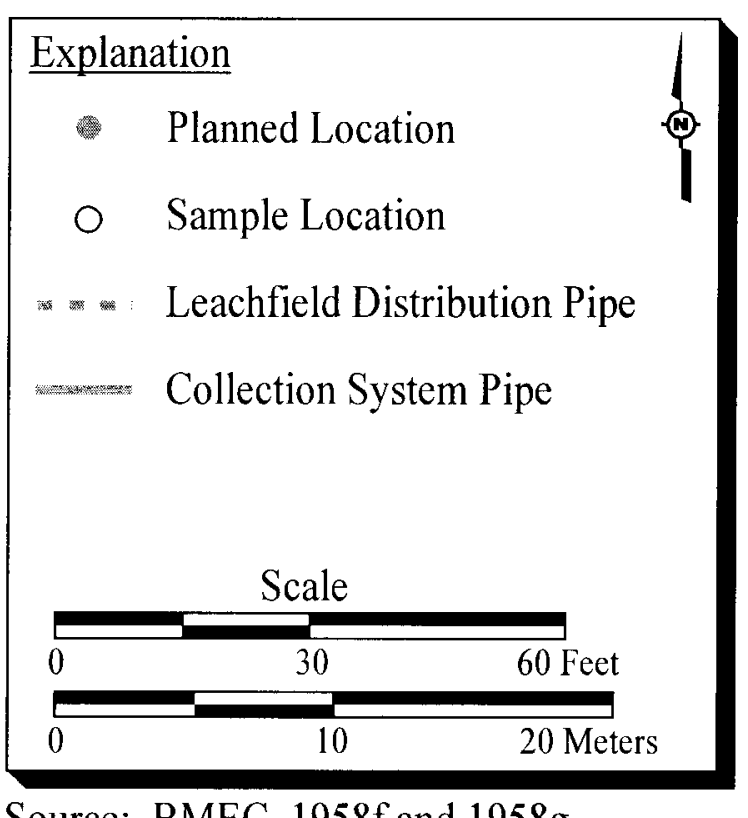

Figure A.5-1

RCP Septic System

(CAS 25-04-04) Sample Locations 
- Sample 271C029 was collected at 11.5 to $12 \mathrm{ft}$ bgs rather than the planned interval of 13 to $14 \mathrm{ft}$ bgs

- Sample 271C071 was collected at 12.25 to $13.25 \mathrm{ft}$ bgs rather than the planned interval of 14.5 to $15.5 \mathrm{ft}$ bgs (this sample exceeded field-screening levels, but no further depth could be obtained)

Despite these deviations, the pertinent CAIP requirements were met.

\section{A.5.2 Investigation Results}

The following subsections provide details of the inspection and sampling of leachfield features, field-screening results, and sample selection and analysis.

\section{A.5.2.1 Septic Tank Contents}

The contents of the septic tank were sampled according to the CAIP. The septic tank was an irregularly shaped rectangle with a 7,710-gal capacity. The tank was two-chambered, with the inlet and outlet chambers having a capacity of 6,252 and 1,458 gal, respectively. The tank was accessed by three manholes located at the ground surface. The interior dimensions of the tank were roughly $24 \mathrm{ft}$ (length) by $6 \mathrm{ft}$ (width) by $7.2 \mathrm{ft}$ (depth). One liquid and one sludge sample were collected from each of the two chambers in the septic tank. Visual inspection revealed that a maximum of $3.7 \mathrm{ft}(2,978$ gal) of liquid and $1.5 \mathrm{ft}(1,178 \mathrm{gal})$ of sludge remained in the bottom of the inlet chamber of the tank. A maximum of $1.5 \mathrm{ft}$ (438 gal) of liquid and $7 \mathrm{in.} \mathrm{(170} \mathrm{gal)} \mathrm{of} \mathrm{sludge} \mathrm{remained} \mathrm{in} \mathrm{the} \mathrm{bottom} \mathrm{of} \mathrm{the}$ outlet chamber of the tank.

Photographs of the septic tank were taken to document the visual inspection (Figure A.5-2). The photographs depict a layer of free product present on the top of the liquid layer in the inlet chamber. This free product layer was a viscous, gummy organic material. It appears to be related to the presence of a diesel tank trailer that is parked on the ground over the top of the inlet side of the septic tank. A strong diesel odor was present during the sampling activities. A free-product layer was not present on the liquid in the outlet chamber of the septic tank. 


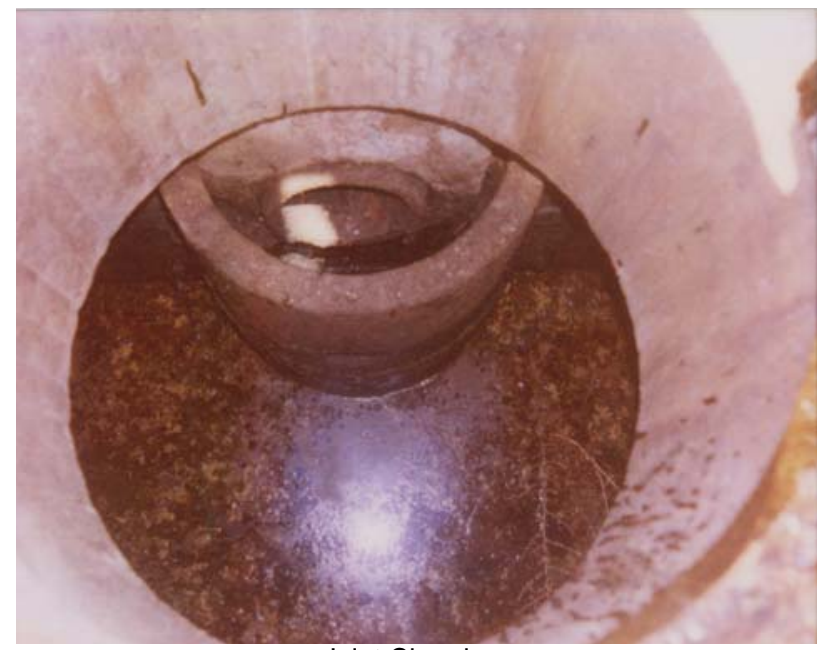

Inlet Chamber

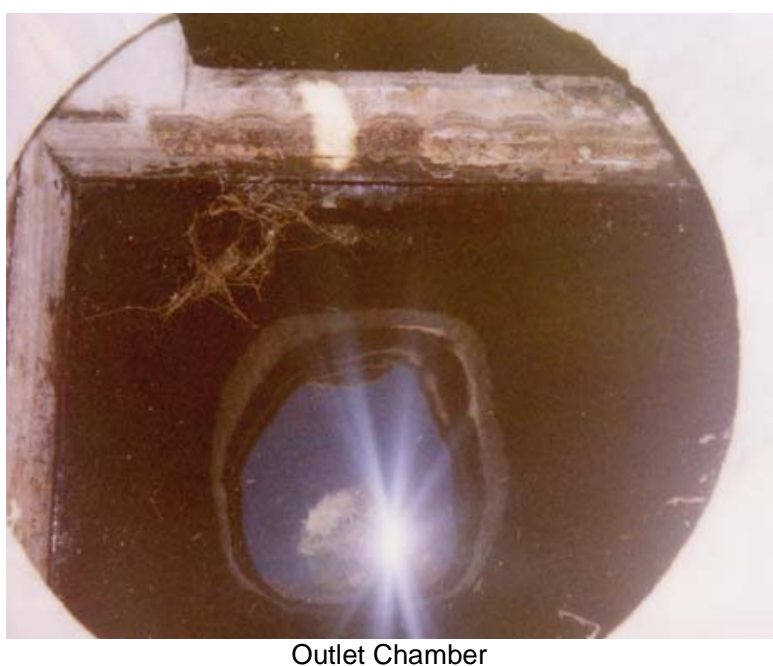

Outlet Chamber

Figure A.5-2

CAS 25-04-04 Septic Tank Manholes

(Photographs Taken 02-18-2002)

\section{A.5.2.2 Distribution Box Contents}

The distribution box was a concrete rectangular structure with a 718-gal capacity. It was accessed by two manholes at approximately $0.5 \mathrm{ft}$ above ground surface. The interior dimensions of the distribution box are $6 \mathrm{ft}$ (length) by $4 \mathrm{ft}$ (width) by $4 \mathrm{ft}$ (depth). The contents of the distribution box were not sampled, as visual inspection revealed that no liquid or sludge remained in the box.

Photographs (Figure A.5-3) of the interior of the distribution box were taken to document the visual inspection.

\section{A.5.2.3 Septic Tank and Distribution Box Integrity Soil Sampling}

Six integrity samples were collected by excavating adjacent to the influent and effluent ends of the septic tank and the effluent end of the distribution box. The following four samples were submitted for laboratory analysis:

- The upper sample (271C077) from the influent end of the septic tank, collected at 10 to $11 \mathrm{ft}$ bgs

- The lower sample (271C078) from the influent end of the septic tank, collected at 12.5 to $13.5 \mathrm{ft}$ bgs 


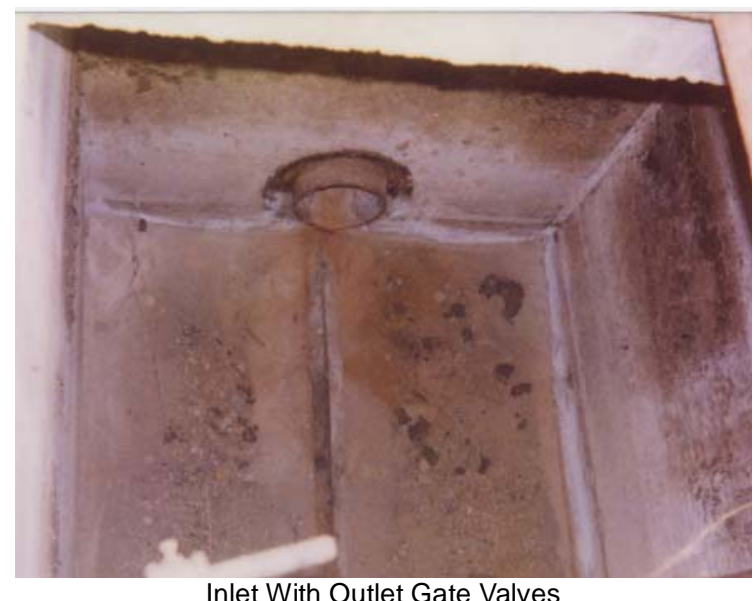

Inlet With Outlet Gate Valves

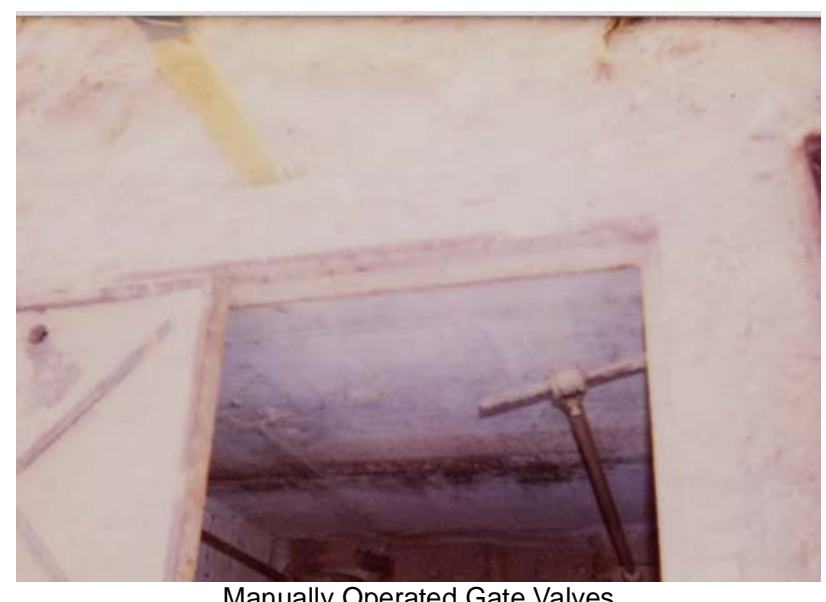

Manually Operated Gate Valves

Figure A.5-3

CAS 25-04-04 Distribution Box

(Photographs Taken 12-03-2001)

- The upper sample (271C079) from the effluent end of the septic tank, collected at 10 to $11 \mathrm{ft}$ bgs

- The upper sample (271C001) from the effluent end of the distribution box, collected at 6.2 to $7.2 \mathrm{ft}$ bgs

\section{A.5.2.4 Leachfield Excavation Soil Sampling}

Backhoe excavations were conducted to access sampling horizons at the biased and random locations presented in the CAIP. Excavations provided a visual verification of distribution pipes and enabled soil samples to be collected from appropriate intervals beneath the pipes, as specified by the CAIP. Seventy-three soil samples were collected from the planned locations excavated within the leachfield. These samples were collected from intervals at 0 to $1 \mathrm{ft}, 2.5$ to $3.5 \mathrm{ft}$, and 6.5 to $7.5 \mathrm{ft}$ below the leachrock/native soil interface. The interface was found at depths ranging from 3 to $5 \mathrm{ft}$ bgs. Forty samples were submitted for laboratory analysis. In addition, two QC soil duplicates and two MS/MSD samples were collected and analyzed. A geotechnical sample was collected outside the boundary of the leachfield. The sample will be sent to a laboratory for geotechnical analysis if necessary.

Figure A.5-4 depicts some soil staining observed at location C09. The staining, which appears to be related to the operation of the septic system, was only noted in this one location of the leachfield. 


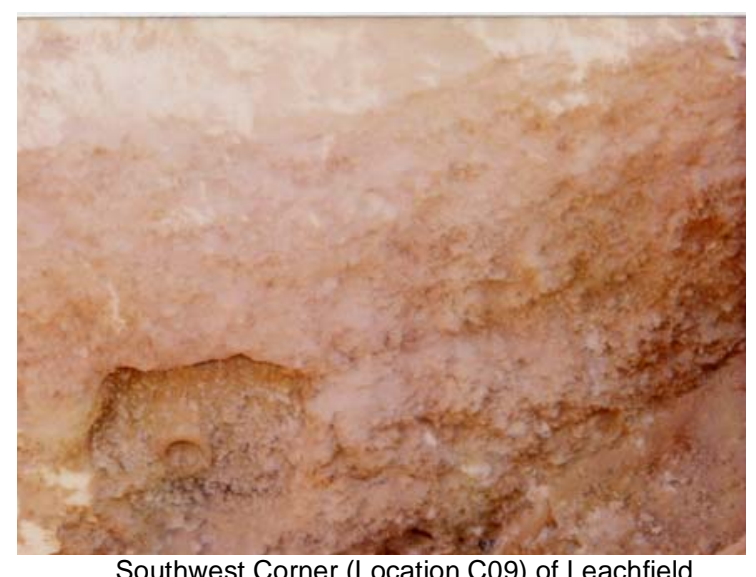

Southwest Corner (Location C09) of Leachfield

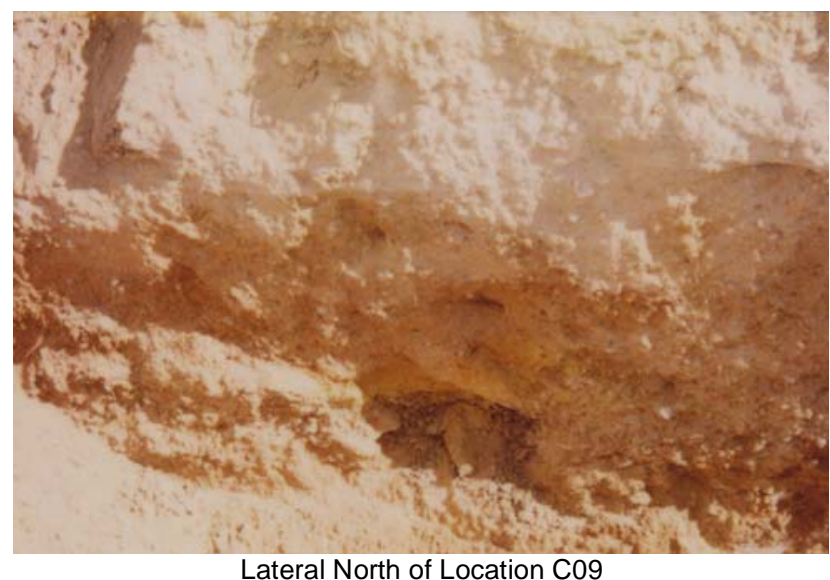

Lateral North of Location C09

Figure A.5-4

CAS 25-04-04 Location C09

(Photographs Taken 11-16-2001)

\section{A.5.2.5 Additional Sampling}

To further define the extent of TPH DRO contamination detected near the inlet of the septic tank, the field crew returned to this CAS on May 09, 2002 to conduct step-out sampling. This location (C32) was identified from the original sampling activities as a location of potential concern. Three vertical and thirty-two horizontal step-out samples were collected, as follows:

- Sample numbers 271C201, 271C202, and 271C203 were collected from C32

- Sample number 271C205 through 271C210 were collected from C38 (15 ft west of C32)

- Sample numbers 271C211 through 271C216 were collected from C37 (15 ft east of C32)

- Sample numbers 271C217 through 271C221 were collected from C36 (15 ft southeast of C37)

- Sample numbers 271C222 through 271C227 were collected from C39 (20 ft west of C38)

- Sample numbers 271C228 through 271C232 and 271C238 were collected from C40 (18 ft northwest of C32)

- Sample numbers 271C233 through 271C237 were collected from C41 (26 ft north of C40)

All of these samples were submitted for laboratory analysis for TPH DRO, with exception of sample numbers $271 \mathrm{C} 207$ and $271 \mathrm{C} 229$. These two samples were submitted for laboratory analysis of TPH 
DRO, PCBs, total VOCs, total SVOCs, total pesticides, and total herbicides. In addition, two QC soil duplicates (271C204 and 271C223) and two MS/MSDs (271C205 and 271C221) samples were collected and analyzed.

\section{A.5.2.6 Collection System Pipe Inspections}

As discussed in the CAIP, this system only included approximately $20 \mathrm{ft}$ of collection system pipe. Access points for inspection by video mole survey were present (i.e., manholes) and one was created at the inlet end of the septic tank via backhoe excavation.

A video mole was inserted through the $\mathrm{VCP}$ on the influent side of the septic tank, at the excavation made during the collection of the integrity sample. Some sediment was identified in the piping, but was not adequate material to be sampled. Refusal with the video mole was encountered at $11 \mathrm{ft}$. The line had been previously breached at approximately $14 \mathrm{ft}$ (broken and not plugged). No other breaches were noted. Ground measurements show that this is approximately $6 \mathrm{ft}$ short of the manhole providing access to the existing active sewer pipe line (North Bypass Manhole, Figure A.5-1).

Figure A.5-5 depicts the visual inspection of the interior of the North Bypass Manhole, and confirms that the line bypasses the RCP septic system.

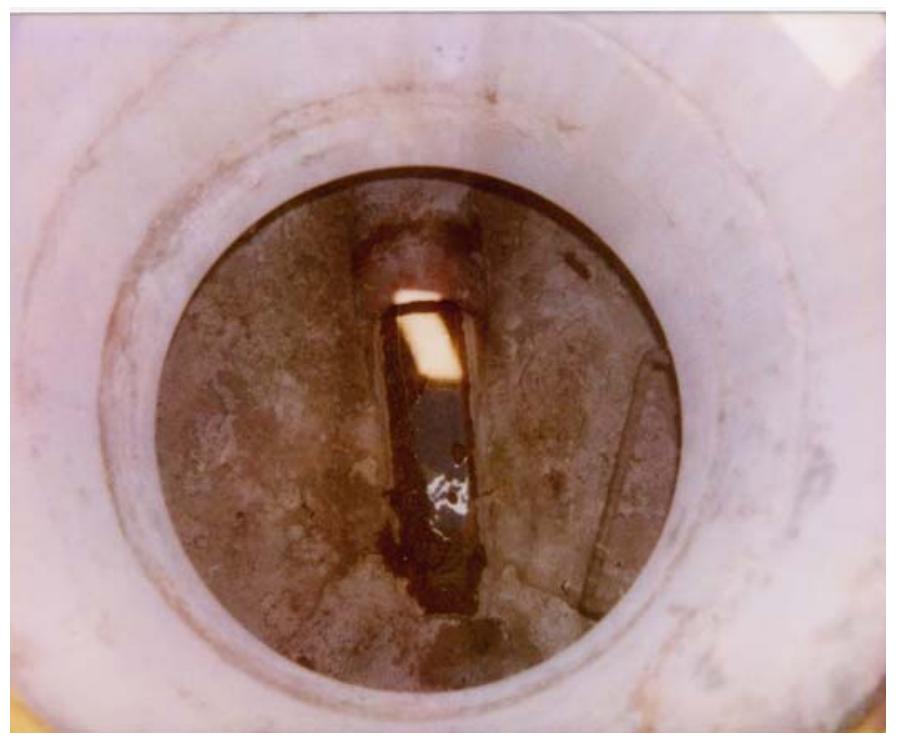

Figure A.5-5

CAS 25-04-04 North Bypass Manhole

(Photograph Taken 02-18-2002) 


\section{A.5.2.7 Field-Screening Results}

Soil samples were screened for VOCs and alpha and beta/gamma radioactivity. The field readings were compared to FSLs to guide sampling decisions and determine which samples were to be submitted for laboratory analysis. No VOCs greater than FSLs were found during soil sample screening. The results of radiological field screening are discussed in Section A.5.2.8.

A sample of the septic tank content was collected and analyzed for fecal coliform bacteria. A positive result for fecal coliform bacteria was obtained for the septic tank contents at this CAS.

A gas chromatograph was used to screen for TPH DRO during the additional sampling activities. Several samples (i.e., 271C207, 271C208, 271C213, 271C226, and 271C229) showed results above the PAL of $100 \mathrm{mg} / \mathrm{kg}$, leading the field crew to collect samples from deeper vertical intervals and/or additional lateral step-out locations.

\section{A.5.2.8 Radiological Survey Results}

The radiological field-screening level for alpha was 121 disintegrations per minute (dpm) per 100 square centimeters $\left(\mathrm{cm}^{2}\right)$ and the beta/gamma field-screening level was $3,397 \mathrm{dpm} / 100 \mathrm{~cm}^{2}$. Radiological FSLs were exceeded at the following locations:

- Location C08 - Sample 271C025 had an elevated reading of alpha at $133 \mathrm{dpm} / 100 \mathrm{~cm}^{2}$ and beta/gamma at $3,650 \mathrm{dpm} / 100 \mathrm{~cm}^{2}$. This sample was submitted for laboratory analysis and additional samples (271C028 and 271C029) were collected from the location. Sample $271 \mathrm{C} 028 \mathrm{had}$ an elevated beta/gamma reading of $3,440 \mathrm{dpm} / 100 \mathrm{~cm}^{2}$ and no elevated alpha reading. Sample 271C029 did not exceed radiological FSLs.

- Location C19 - Sample 271C054 and field duplicate 271C055 had an elevated beta/gamma reading of $3,403 \mathrm{dpm} / 100 \mathrm{~cm}^{2}$. This sample was submitted for laboratory analysis and additional samples (271C056 and 271C057) were collected from the location. Neither of these samples exceeded radiological FSLs.

- Location C30 - Samples 271C069 and 271C071 had elevated beta/gamma readings of $3,414 \mathrm{dpm} / 100 \mathrm{~cm}^{2}$ and $3,421 \mathrm{dpm} / 100 \mathrm{~cm}^{2}$, respectively. Both samples were submitted for laboratory analysis. A sample (271C070) was collected between these two sample intervals and had field-screening results below FSLs. 
The results of the radiological survey of the distribution box and pipe at location $\mathrm{C} 32$ indicate that the abandoned section of the collection system meets the unrestricted release criteria as defined in the NV/YMP Radiological Control Manual (DOE/NV, 2000a).

\section{A.5.2.9 Sample Analysis}

Environmental soil samples and associated QC samples were collected and analyzed for the CAIP-specified COPCs (i.e., total VOCs, total SVOCs, total RCRA metals, TPH [DRO and GRO], total pesticides, total herbicides, and PCBs). In addition, 25 percent of the soil samples and 100 percent of the associated QC samples were analyzed for Iso-U, Iso-Pu, Sr-90, and gamma-emitting radionuclides.

The septic tank sludge and liquid samples were analyzed for total VOCs, total SVOCs, TPH (GRO and DRO), total RCRA metals, total pesticides, total herbicides, PCBs, gamma-emitting radionuclides, Iso-U, Iso-Pu, Sr-90, and tritium. The liquid sample was also analyzed for gross alpha and gross beta radioactivity. The sludge sample was analyzed according to the TCLP for VOCs, SVOCs, and RCRA metals.

The parameters and laboratory methods used to analyze the investigation samples are listed in Table A.2-2. Table A.5-1 lists the sample-specific analytical parameters.

\section{A.5.3 Analytes Detected Above Minimum Reporting Limits}

The soil sample analytical results with concentrations exceeding corresponding MRLs or PALs (DOE/NV, 1998; DOE/NV, 2001) at CAS 25-04-04 are summarized in the following sections. The results of septic tank content samples are compared to appropriate regulatory levels for disposal. A portion of the CAS 25-04-04 analytical results were rejected during validation; however, these rejected data did not impact closure decisions as discussed in Section B.1.3.3 of Appendix B.

\section{A.5.3.1 Analytical Results for Soil Samples}

The following sections discuss the results for soil samples in comparison to the levels established in the Leachfield Work Plan and the CAIP. 


\section{A.5.3.1.1 Total Volatile Organic Compounds}

Volatile organic compound results are reported in Table A.5-2. The only organic compound detected above the MRL of $5 \mu \mathrm{g} / \mathrm{kg}$ was acetone. These estimated concentrations were below laboratory reporting limits. The acetone concentrations were below the EPA Region 9 PRG of 6,200,000 $\mu \mathrm{g} / \mathrm{kg}$. Acetone is a common laboratory contaminant.

Table A.5-2

Soil Sample Results for Total VOCs Detected Above Minimum Reporting Limits at CAS 25-04-04

\begin{tabular}{|c|c|c|}
\hline \multirow{2}{*}{$\begin{array}{c}\text { Sample } \\
\text { Identification } \\
\text { Number }\end{array}$} & $\begin{array}{c}\text { Depth } \\
\text { (ft bgs) }\end{array}$ & Contaminants of Potential Concern $(\mu \mathbf{g} / \mathbf{k g})$ \\
\cline { 3 - 3 } & & Acetone \\
\hline \multicolumn{2}{|c|}{ Preliminary Action Levels ${ }^{\mathbf{a}}$} & $\mathbf{6 , 2 0 0 , 0 0 0}$ \\
\hline \hline $271 \mathrm{C} 207$ & $6-6.5$ & $110(\mathrm{~J})$ \\
\hline $271 \mathrm{C} 026$ & $4-5$ & $26(\mathrm{~J})$ \\
\hline
\end{tabular}

aBased on U.S. Environmental Protection Agency, Region 9 Preliminary Remediation Goals (PRGs) (EPA, 2000)

$\mathrm{J}=$ Estimated value. Qualifier added to laboratory data; record accepted. Relative response factor $<0.05$.

\section{A.5.3.1.2 Total Semivolatile Organic Compounds}

Semivolatile organic compounds were not detected above MRLs in CAS 25-04-04 soil samples.

\section{A.5.3.1.3 Total Petroleum Hydrocarbon}

Total petroleum hydrocarbon DRO results are reported in Table A.5-3. In the original sampling effort, only one location (C32) was detected above the MRL of $25 \mathrm{mg} / \mathrm{kg}$ (sample number 271C078). This detection also exceeded the regulatory action level of $100 \mathrm{mg} / \mathrm{kg}$.

To further define the extent of potential TPH DRO contamination at location C32, step-out samples 271C201 through 271C238 were collected in a follow-up sampling event. The TPH DRO results for the follow-up sampling are listed in Table A.5-3. Concentrations exceeding the PAL were found in soil at step-out locations C38 (271C207, 271C208) and C40 (271C228, 271C229). Samples from step-out locations C36, C37, C39, and C40 with TPH DRO concentrations less than PALs define the lateral extent of contamination. The TPH DRO contamination is present at shallower depths at 
Table A.5-3

\section{Soil Sample Results for TPH-DRO Detected Above Minimum Reporting Limits at CAS 25-04-04}

\begin{tabular}{|c|c|c|}
\hline \multirow{2}{*}{$\begin{array}{c}\text { Sample } \\
\text { Identification } \\
\text { Numbers }\end{array}$} & \multirow{2}{*}{$\begin{array}{c}\text { Depth } \\
\text { (ft bgs) }\end{array}$} & Contaminants of Potential Concern (mg/kg) \\
\hline & & Diesel Range Organics \\
\hline \multicolumn{2}{|c|}{ Preliminary Action Levels ${ }^{a}$} & 100 \\
\hline $271 \mathrm{C} 078$ & $12.5-13.5$ & 300 \\
\hline $271 \mathrm{C} 201$ & $15.5-16$ & $42(\mathrm{H})$ \\
\hline $271 \mathrm{C} 206$ & $3-3.5$ & $91(Z)$ \\
\hline 271C207 & $6-6.5$ & $650(Z)$ \\
\hline 271C208 & $10.5-11$ & $420(Z)$ \\
\hline 271C228 & $2.5-3$ & $1100(Z)$ \\
\hline $271 C 229$ & $5.5-6$ & $1500(Z)$ \\
\hline
\end{tabular}

${ }^{a}$ Based on Nevada Administrative Code; Contamination of soil: Establishment of action levels (NAC, 2000).

$\mathrm{H}=$ The fuel pattern was in the heavier end of the retention time window for the analyte of interest.

$Z=$ The reported result did not resemble the patterns of the following petroleum hydrocarbon products: gasoline, JP-4, JP-8, diesel, mineral spirits, motor oil, Stoddard solvent, or Bunker C.

location C40 and deeper at locations C32 and C38. The vertical extent of contamination had been defined by sample results below the PAL at all step-out locations and also at the original location where TPH DRO contamination was detected.

\section{A.5.3.1.4 Total RCRA Metals}

As shown in Table A.5-4, the total RCRA metals detected in soil samples at concentrations exceeding the MRLs are arsenic (1 mg/kg), barium (20 mg/kg), cadmium $(0.5 \mathrm{mg} / \mathrm{kg})$, chromium ( $1 \mathrm{mg} / \mathrm{kg})$, lead $(0.3 \mathrm{mg} / \mathrm{kg})$, mercury $(0.1 \mathrm{mg} / \mathrm{kg})$, and silver $(1 \mathrm{mg} / \mathrm{kg})$.

Barium concentrations ranged from 64 to $130 \mathrm{mg} / \mathrm{kg}$, cadmium was detected at $0.58 \mathrm{mg} / \mathrm{kg}$, chromium concentrations ranged form 1.9 to $3.8 \mathrm{mg} / \mathrm{kg}$, lead concentrations ranged from 4.2 to $8.0 \mathrm{mg} / \mathrm{kg}$, mercury concentrations ranged from 0.11 to $0.57 \mathrm{mg} / \mathrm{kg}$, and silver concentrations ranged from 1.1 to $13 \mathrm{mg} / \mathrm{kg}$. All reported concentrations of these metals were below EPA Region 9 PRGs defined in this document as PALs. 
Table A.5-4

Soil Sample Results for Total RCRA Metals Detected Above Minimum Reporting Limits at CAS 25-04-04

(Page 1 of 2)

\begin{tabular}{|c|c|c|c|c|c|c|c|c|}
\hline \multirow{2}{*}{$\begin{array}{c}\text { Sample } \\
\text { Identification } \\
\text { Number }\end{array}$} & \multirow{2}{*}{$\begin{array}{l}\text { Depth } \\
\text { (ft bgs) }\end{array}$} & \multicolumn{7}{|c|}{ Contaminants of Potential Concern (mg/kg) } \\
\hline & & Arsenic & Barium & Cadmium & Chromium & Lead & Mercury & Silver \\
\hline \multicolumn{2}{|c|}{ Preliminary Action Levels ${ }^{a}$} & 2.7 & 100,000 & 810 & 450 & 750 & 610 & 10,000 \\
\hline $271 \mathrm{C} 001$ & $6.2-7.2$ & 2.5 & 130 & -- & 3.1 & 5.4 & -- & -- \\
\hline $271 \mathrm{C} 003$ & $4.25-4.75$ & 2.5 & 88 & -- & 3.1 & 5.7 & -- & 1.2 \\
\hline 271C006 & $5-5.5$ & 3 & 120 & -- & 3.8 & 6.4 & 0.11 & -- \\
\hline $271 \mathrm{C008}$ & $4.25-5.25$ & 2.6 & 99 & -- & 3.2 & 5.8 & -- & -- \\
\hline $271 \mathrm{C} 010$ & $4.7-5.2$ & 2 & 86 & -- & 2.5 & 5.2 & -- & -- \\
\hline $271 \mathrm{C} 011$ & $4.7-5.2$ & 2.1 & 89 & -- & 2.7 & 5.2 & -- & -- \\
\hline $271 \mathrm{C} 013$ & $4.2-5.2$ & 3.5 & 100 & -- & 3.1 & 6.4 & 0.26 & 4.8 \\
\hline $271 \mathrm{C} 015$ & $4-5$ & 2.2 & 64 & -- & 2.8 & 5.1 & -- & -- \\
\hline $271 \mathrm{C} 017$ & $3-4$ & 2.7 & 86 & -- & 3.6 & 6.4 & 0.11 & 3.7 \\
\hline $271 \mathrm{C} 018$ & $5-6$ & 2.2 & 80 & -- & 2.9 & 5.9 & -- & 1.4 \\
\hline $271 \mathrm{C} 020$ & $5-6$ & 2 & 100 & -- & 2.6 & 5 & -- & -- \\
\hline $271 \mathrm{C} 022$ & $4-5$ & 2.1 & 70 & -- & 2.3 & 4.8 & -- & -- \\
\hline $271 \mathrm{C} 024$ & $3.7-4.7$ & 2.3 & 74 & -- & 2.7 & 7 & -- & -- \\
\hline $271 \mathrm{C} 025$ & $6.2-6.7$ & 2.9 & 90 & -- & 2.5 & 5.1 & -- & -- \\
\hline $271 \mathrm{C} 026$ & $4-5$ & 2.4 & 92 & -- & 2.4 & 5.1 & -- & -- \\
\hline $271 \mathrm{C} 029$ & $11.5-12$ & 2.2 & 91 & -- & 1.9 & 5 & -- & -- \\
\hline $271 \mathrm{C} 030$ & $4.25-5.25$ & 2.3 & 79 & -- & 2.5 & 6.1 & -- & -- \\
\hline 271C032 & $4.25-5.25$ & 2 & 72 & -- & 2.7 & 5.5 & -- & -- \\
\hline $271 \mathrm{C} 034$ & $4.25-5.25$ & 2.4 & 100 & -- & 2 & 4.6 & -- & -- \\
\hline $271 \mathrm{C} 036$ & $4.25-5.25$ & 1.7 & 92 & -- & 2.4 & 4.6 & -- & -- \\
\hline $271 \mathrm{C038}$ & $4.25-5.25$ & 2 & 110 & -- & 2.1 & 4.6 & -- & -- \\
\hline $271 \mathrm{C} 040$ & $4.25-5.25$ & 2.2 & 67 & -- & 2.6 & 4.8 & 0.57 & -- \\
\hline $271 \mathrm{C} 042$ & $4.25-5.25$ & 1.7 & 100 & 0.58 & 3.7 & 7 & -- & 13 \\
\hline $271 \mathrm{C} 044$ & $3.5-4.5$ & 2.5 & 82 & -- & 3.8 & 6 & $0.21(\mathrm{~J})$ & 3.8 \\
\hline $271 \mathrm{C} 046$ & $4.25-5.25$ & 2.1 & 86 & -- & 2.9 & 5.2 & -- & -- \\
\hline $271 \mathrm{C} 048$ & $4.25-5.25$ & 2.9 & 90 & -- & 2.6 & 5.1 & -- & -- \\
\hline $271 \mathrm{C} 050$ & $4.25-5.25$ & 3 & 96 & -- & 3.1 & 5.6 & -- & -- \\
\hline $271 \mathrm{C} 052$ & $3.7-4.7$ & 2.9 & 86 & -- & 3.4 & 6.2 & $0.17(\mathrm{~J})$ & 3.3 \\
\hline $271 \mathrm{C} 054$ & $3.5-4.5$ & 2.1 & 97 & -- & 2.7 & 5.1 & $0.19(\mathrm{~J})$ & 1.5 \\
\hline $271 \mathrm{C} 055$ & $3.5-4.5$ & 2.7 & 86 & -- & 3 & 5.1 & $0.12(\mathrm{~J})$ & 2 \\
\hline
\end{tabular}


Table A.5-4

Soil Sample Results for Total RCRA Metals Detected Above Minimum Reporting Limits at CAS 25-04-04

(Page 2 of 2)

\begin{tabular}{|c|c|c|c|c|c|c|c|c|}
\hline \multirow{2}{*}{$\begin{array}{c}\text { Sample } \\
\text { Identification } \\
\text { Number }\end{array}$} & \multirow{2}{*}{$\begin{array}{l}\text { Depth } \\
\text { (ft bgs) }\end{array}$} & \multicolumn{7}{|c|}{ Contaminants of Potential Concern (mg/kg) } \\
\hline & & Arsenic & Barium & Cadmium & Chromium & Lead & Mercury & Silver \\
\hline \multicolumn{2}{|c|}{ Preliminary Action Levels ${ }^{a}$} & 2.7 & 100,000 & 810 & 450 & 750 & 610 & 10,000 \\
\hline $271 \mathrm{C} 056$ & $6-7$ & 2.6 & 85 & -- & 2 & 4.2 & -- & -- \\
\hline $271 \mathrm{C} 058$ & $4.25-5.25$ & 2.1 & 100 & -- & 2.4 & 4.2 & -- & -- \\
\hline $271 \mathrm{C} 060$ & $4.25-5.25$ & 2.2 & 90 & -- & 2.6 & 4.6 & -- & -- \\
\hline $271 \mathrm{C} 062$ & $4.25-5.25$ & 3.1 & 85 & -- & 3.2 & 7.4 & -- & 1.1 \\
\hline $271 \mathrm{C} 064$ & $4.25-5.25$ & 2.2 & 88 & -- & 2.1 & 4.2 & 0.12 & -- \\
\hline $271 \mathrm{C066}$ & $4.25-5.25$ & 2.1 & 91 & -- & 2.6 & 5.3 & -- & -- \\
\hline $271 \mathrm{C} 069$ & $7.4-8.4$ & 2.3 & 110 & -- & 2.4 & 6.3 & -- & -- \\
\hline $271 \mathrm{C} 071$ & $12.25-13.25$ & 2.9 & 98 & $\begin{array}{l}- \\
-\end{array}$ & 2.9 & 8 & $\begin{array}{l}- \\
-\end{array}$ & -- \\
\hline $271 \mathrm{C} 077$ & $10-11$ & 2.4 & $86.7(\mathrm{~J})$ & -- & 2.5 & 5.11 & -- & -- \\
\hline $271 \mathrm{C} 078$ & $12.5-13.5$ & 2.24 & 119 & -- & 2.74 & 6.02 & -- & -- \\
\hline $271 C 079$ & $10-11$ & 2.06 & 139 & -- & 1.52 & 4.89 & -- & -- \\
\hline
\end{tabular}

aBased on U.S. Environmental Protection Agency, Region 9 Preliminary Remediation Goals (PRGs) (EPA, 2000).

-- = Not detected above minimum reporting limits

$\mathrm{J}=$ Estimated value. Qualifier added to laboratory data; record accepted. Duplicate precision analyses were outside control limits.

Arsenic concentrations ranged from 1.7 to $3.5 \mathrm{mg} / \mathrm{kg}$. Concentrations of arsenic above the PAL of 2.7 $\mathrm{mg} / \mathrm{kg}$ were identified in sample numbers 271C006, 271C013, 271C048, 271C052, and 271C072.

The data indicate a consistent arsenic concentration across the site, with no "hot spots" or evidence of a localized spill. The PAL is lower than the 7 to $8 \mathrm{mg} / \mathrm{kg}$ mean concentration of arsenic in silt from the Nevada Test and Training Range (NBMG, 1998; Moore, 1999). The distribution of arsenic in the leachfield soil and known background concentrations in the region suggest that arsenic concentrations exceeding the PAL at CAS 25-04-04 represent ambient conditions, not contamination.

\section{A.5.3.1.5 Polychlorinated Biphenyls}

Polychlorinated biphenyls were not detected above MRLs in CAS 25-04-04 soil samples. 


\section{A.5.3.1.6 Total Pesticides}

During the SVOC analysis, the laboratory noticed evidence in the raw data that appeared to be due to the presence of pesticides. Therefore, analyses for pesticides were performed, although they are not an established COPC for this CAS. Pesticides were detected in soil samples at concentrations exceeding the laboratory MRLs. The results are presented in Table A.5-5. None of the samples exceeded PALs.

\section{A.5.3.1.7 Total Herbicides}

During follow-up sampling, soil samples for chlorinated herbicide analysis were collected at locations C38 (271C207) and C40 (271C229). The results were below the MRLs and PALs.

\section{A.5.3.1.8 Gamma Spectrometry Results}

Results of the soil sample gamma spectrometry analysis are presented in Table A.5-6. Concentrations of actinium-228, bismuth-212, bismuth-214, lead-212, lead-214, potassium-40, and thallium-208 were detected above the MDLs. The TPU of the radioanalytical measurement is provided in the table along with the concentration for all detected gamma emitters. The concentrations of detected gamma-emitting radionuclides are all below PALs and are not significantly different than concentrations measured in soil samples collected from undisturbed background locations.

\section{A.5.3.1.9 Isotopic Uranium}

Detected values of uranium isotopes, along with associated TPUs are reported in Table A.5-7. Sample number 271C056 had a U-235 concentration above the PAL; therefore, a normalized difference based on a confidence level of 95 percent was used to determine if the concentration was statistically distinguishable from background. This U-235 concentration, as well as the other concentrations of the uranium isotopes, were not significantly greater than concentrations in soil samples collected from undisturbed background locations.

\section{A.5.3.1.10 Isotopic Plutonium}

Isotopic plutonium was not detected above MRLs in CAS 25-04-04 soil samples. 
Table A.5-5

\section{Soil Sample Results for Pesticides Detected Above Minimum Reporting Limits at CAS 25-04-04}

\begin{tabular}{|c|c|c|c|c|c|c|c|}
\hline \multirow{2}{*}{$\begin{array}{c}\text { Sample } \\
\text { Identification } \\
\text { Number }\end{array}$} & \multirow{2}{*}{$\begin{array}{l}\text { Depth } \\
\text { (ft bgs) }\end{array}$} & \multicolumn{6}{|c|}{ Contaminants of Potential Concern $(\mu \mathrm{g} / \mathrm{kg})$} \\
\hline & & 4,4'-DDE & 4,4'-DDT & 4,4'-DDD & Alpha-Chlordane & Endrin & Gamma-Chlordane \\
\hline \multicolumn{2}{|c|}{ Preliminary Action Levels ${ }^{a}$} & 12,000 & 12,000 & 17,000 & $11,000^{b}$ & 260,000 & $11,000^{b}$ \\
\hline $271 \mathrm{C} 001$ & $6.2-7.2$ & $\overline{---}$ & -- & $\overline{---}$ & $25(\mathrm{~J})$ & $\overline{---}$ & $23(\mathrm{~J})$ \\
\hline $271 \mathrm{C003}$ & $4.25-4.75$ & -- & -- & -- & $95(J)$ & -- & $82(\mathrm{~J})$ \\
\hline $271 \mathrm{C} 006$ & $5-5.5$ & -- & -- & -- & $3.2(\mathrm{~J})$ & -- & $4(\mathrm{~J})$ \\
\hline $271 \mathrm{C008}$ & $4.25-5.25$ & -- & -- & -- & $4.4(\mathrm{~J})$ & -- & $4.1(\mathrm{~J})$ \\
\hline $271 \mathrm{C} 010$ & $4.7-5.2$ & -- & -- & -- & $220(\mathrm{~J})$ & -- & $190(\mathrm{~J})$ \\
\hline $271 \mathrm{C} 011$ & $4.7-5.2$ & $\begin{array}{l}- \\
\end{array}$ & -- & $\begin{array}{l}- \\
\end{array}$ & $230(\mathrm{~J})$ & -- & $210(\mathrm{~J})$ \\
\hline $271 \mathrm{C} 013$ & $4.7-5.2$ & -- & -- & -- & $11(\mathrm{~J})$ & -- & $15(\mathrm{~J})$ \\
\hline $271 \mathrm{C} 015$ & $4-5$ & $170(\mathrm{~J})$ & $110(\mathrm{~J})$ & $20(\mathrm{~J})$ & $18(\mathrm{~J})$ & -- & $26(\mathrm{~J})$ \\
\hline $271 \mathrm{C} 018$ & $5-6$ & -- & -- & -- & $8.4(\mathrm{~J})$ & -- & $8.9(\mathrm{~J})$ \\
\hline $271 \mathrm{C} 020$ & $5-6$ & -- & -- & -- & $5.7(\mathrm{~J})$ & -- & $9.7(\mathrm{~J})$ \\
\hline $271 \mathrm{C} 024$ & $3.7-4.7$ & -- & -- & -- & $5.9(\mathrm{~J})$ & -- & $6.1(\mathrm{~J})$ \\
\hline $271 \mathrm{C} 032$ & $4.25-5.25$ & -- & -- & -- & $3.2(\mathrm{~J})$ & -- & $3.3(\mathrm{~J})$ \\
\hline $271 \mathrm{C} 036$ & $4.25-5.25$ & -- & -- & -- & $4.5(\mathrm{~J})$ & -- & $4.1(\mathrm{~J})$ \\
\hline $271 \mathrm{C} 040$ & $4.25-5.25$ & -- & -- & -- & $3.9(\mathrm{~J})$ & -- & $3.9(\mathrm{~J})$ \\
\hline $271 \mathrm{C} 042$ & $4.25-5.25$ & $6.1(\mathrm{~J})$ & $8.1(\mathrm{~J})$ & $23(\mathrm{~J})$ & $32(\mathrm{~J})$ & -- & $33(\mathrm{~J})$ \\
\hline $271 \mathrm{C} 044$ & $3.5-4.5$ & -- & -- & -- & $9.6(\mathrm{~J})$ & -- & $8(\mathrm{~J})$ \\
\hline $271 \mathrm{C} 052$ & $3.7-4.7$ & -- & -- & -- & $9.5(\mathrm{~J})$ & -- & $8.6(\mathrm{~J})$ \\
\hline $271 \mathrm{C} 054$ & $3.5-4.5$ & -- & -- & -- & $5.8(\mathrm{~J})$ & -- & $5.4(\mathrm{~J})$ \\
\hline $271 \mathrm{C} 055$ & $3.5-4.5$ & -- & -- & -- & $6.2(\mathrm{~J})$ & -- & $5.9(\mathrm{~J})$ \\
\hline $271 \mathrm{C} 060$ & $4.25-5.25$ & -- & -- & -- & $5.3(\mathrm{~J})$ & -- & $4.7(\mathrm{~J})$ \\
\hline $271 \mathrm{C} 062$ & $4.25-5.25$ & $12(\mathrm{~J})$ & -- & -- & $11(\mathrm{~J})$ & -- & $11(\mathrm{~J})$ \\
\hline $271 \mathrm{C} 064$ & $4.25-5.25$ & -- & -- & -- & $2.6(\mathrm{~J})$ & -- & $2.5(\mathrm{~J})$ \\
\hline $271 \mathrm{C} 066$ & $4.25-5.25$ & -- & -- & -- & $3.7(\mathrm{~J})$ & -- & $3(\mathrm{~J})$ \\
\hline $271 C 069$ & $7.4-8.4$ & $8.8(\mathrm{~J})$ & -- & -- & -- & -- & -- \\
\hline $271 \mathrm{C} 078$ & $12.5-13.5$ & -- & -- & -- & 2.4 & 14 & -- \\
\hline $271 \mathrm{C} 207$ & $6-6.5$ & -- & -- & -- & -- & -- & 2 \\
\hline
\end{tabular}

${ }^{a} B a s e d$ on U.S. Environmental Protection Agency, Region 9 Preliminary Remediation Goals (PRGs) (EPA, 2000).

${ }^{\mathrm{b}}$ The PAL is for total chlordane. The comparison to this PAL is made by summing the chlordane concentrations for a given sample.

$\mathrm{J}=$ Estimated value. Qualifier added to laboratory data; record accepted. Exceeded holding time.

$\mathrm{NI}=$ Not identified 
Table A.5-6

Soil Sample Results for Gamma-Emitting Radionuclides Detected

Above Minimum Reporting Limits at CAS 25-04-04

\begin{tabular}{|c|c|c|c|c|c|c|c|c|}
\hline \multirow{2}{*}{$\begin{array}{c}\text { Sample } \\
\text { Identification } \\
\text { Number }\end{array}$} & \multirow{2}{*}{$\begin{array}{l}\text { Depth } \\
\text { (ft bgs) }\end{array}$} & \multicolumn{7}{|c|}{ Contaminants of Potential Concern $(\mathrm{pCi} / \mathrm{g})$} \\
\hline & & Actinium-228 ${ }^{a}$ & Bismuth-212 ${ }^{\mathrm{b}}$ & Bismuth-214 ${ }^{\mathrm{b}}$ & Lead-212 ${ }^{\mathrm{a}}$ & Lead-214 ${ }^{b}$ & Potassium-40 & Thallium-208 ${ }^{\mathrm{a}}$ \\
\hline \multicolumn{2}{|c|}{ Preliminary Action Level } & 3.64 & 2.4 & 3.47 & 2.9 & 2.9 & 96 & 3.4 \\
\hline $271 \mathrm{C010}$ & $4.7-5.2$ & $1.47 \pm 0.34$ & $\overline{--}$ & $0.72 \pm 0.20$ & $1.89 \pm 0.36$ & $0.82 \pm 0.20$ & $27.2 \pm 5.2$ & $0.6 \pm 0.15$ \\
\hline $271 \mathrm{C} 011$ & $4.7-5.2$ & $1.28 \pm 0.30$ & -- & $0.69 \pm 0.20$ & $1.72 \pm 0.34$ & $0.92 \pm 0.21$ & $26.2 \pm 4.9$ & $0.46 \pm 0.12$ \\
\hline $271 \mathrm{C} 020$ & $5-6$ & $1.52 \pm 0.40$ & -- & $0.75 \pm 0.23$ & $1.92 \pm 0.38$ & $0.71 \pm 0.20$ & $25.1 \pm 5.1$ & $0.48 \pm 0.14$ \\
\hline $271 \mathrm{C} 025$ & $6.2-6.7$ & $1.35 \pm 0.32$ & -- & $0.94 \pm 0.24$ & $1.98 \pm 0.38$ & $1 \pm 0.22$ & $26.4 \pm 5.0$ & $0.63 \pm 0.15$ \\
\hline $271 \mathrm{C} 029$ & $11.5-12$ & $1.59 \pm 0.32$ & $2.05 \pm 0.78$ & $0.84 \pm 0.19$ & $1.89 \pm 0.34$ & $1.1 \pm 0.21$ & $29.3 \pm 5.1$ & $0.61 \pm 0.12$ \\
\hline $271 \mathrm{C0} 32$ & $4.25-5.25$ & $1.62 \pm 0.32$ & -- & $0.76 \pm 0.18$ & $1.74 \pm 0.32$ & $0.88 \pm 0.18$ & $30 \pm 5.2$ & $0.51 \pm 0.11$ \\
\hline $271 \mathrm{C054}$ & $3.5-4.5$ & $1.37 \pm 0.28$ & $1.61 \pm 0.65$ & $0.81 \pm 0.18$ & $1.78 \pm 0.32$ & $0.84 \pm 0.17$ & $28.2 \pm 4.9$ & $0.52 \pm 0.11$ \\
\hline $271 \mathrm{C055}$ & $3.5-4.5$ & $1.4 \pm 0.29$ & -- & $0.8 \pm 0.18$ & $1.85 \pm 0.33$ & $0.93 \pm 0.19$ & $28.4 \pm 4.9$ & $0.52 \pm 0.11$ \\
\hline $271 \mathrm{C} 056$ & $6-7$ & $1.88 \pm 0.36$ & $2.18 \pm 0.77$ & $1 \pm 0.22$ & $2.22 \pm 0.40$ & $1.18 \pm 0.23$ & $30.4 \pm 5.3$ & $0.66 \pm 0.13$ \\
\hline $271 \mathrm{C058}$ & $4.25-5.25$ & $1.39 \pm 0.29$ & $1.58 \pm 0.65$ & $0.7 \pm 0.17$ & $1.73 \pm 0.32$ & $0.9 \pm 0.19$ & $27.9 \pm 4.9$ & $0.55 \pm 0.12$ \\
\hline $271 C 069$ & $7.4-8.4$ & $1.84 \pm 0.41$ & $\begin{array}{l}- \\
\text { - }\end{array}$ & $1.13 \pm 0.29$ & $2.3 \pm 0.44$ & $1.06 \pm 0.24$ & $30.5 \pm 5.7$ & $0.65 \pm 0.16$ \\
\hline $271 \mathrm{C} 071$ & $12.25-13.25$ & $1.62 \pm 0.40$ & -- & $0.82 \pm 0.26$ & $2 \pm 0.39$ & $1.05 \pm 0.24$ & $28.5 \pm 5.6$ & $0.58 \pm 0.15$ \\
\hline $271 \mathrm{C078}$ & $12.5-13.5$ & $1.8 \pm 0.40$ & -- & $0.78 \pm 0.21$ & $1.8 \pm 0.35$ & $0.76 \pm 0.19$ & $26.6 \pm 5.0$ & $0.54 \pm 0.13$ \\
\hline $271 C 079$ & $10-11$ & $1.59 \pm 0.38$ & -- & $0.83 \pm 0.23$ & $1.83 \pm 0.36$ & $0.94 \pm 0.22$ & $31 \pm 5.8$ & $0.56 \pm 0.14$ \\
\hline
\end{tabular}

${ }^{a}$ Background concentration listed in Environmental Monitoring Report for the Proposed Ward Valley, California, Low-Level Radioactive Waste (LLRW) Facility (US Ecology and Atlan-Tech, 1992)

${ }^{b}$ Background concentration listed or derived in Off-Site Radiation Exposure Review Project, Phase II Soil Program (McArthur and Miller, 1989).

-- = Not detected above minimum reporting limit 
Table A.5-7

Soil Sample Results for Isotopic Uranium Detected Above Minimum Reporting Limits at CAS 25-04-04

\begin{tabular}{|c|c|c|c|c|}
\hline \multirow{2}{*}{$\begin{array}{c}\text { Sample } \\
\text { Identification } \\
\text { Number }\end{array}$} & \multirow{2}{*}{$\begin{array}{c}\text { Depth } \\
\text { (ft bgs) }\end{array}$} & \multicolumn{3}{|c|}{ Contaminants of Potential Concern (pCi/g) } \\
\hline & & Uranium-234ª & Uranium-235 & Uranium-238 \\
\hline \multicolumn{2}{|c|}{ Preliminary Action Levels } & 1.56 & 0.07 & 3.2 \\
\hline $271 \mathrm{C} 010$ & $4.7-5.2$ & $0.86 \pm 0.16$ & -- & $0.91 \pm 0.17$ \\
\hline $271 \mathrm{C} 011$ & $4.7-5.2$ & $0.88 \pm 0.17$ & $0.069 \pm 0.033$ & $0.95 \pm 0.18$ \\
\hline $271 \mathrm{C} 020$ & $5-6$ & $1.07 \pm 0.20$ & -- & $1.05 \pm 0.20$ \\
\hline $271 \mathrm{C} 025$ & $6.2-6.7$ & $1.09 \pm 0.19$ & $0.064 \pm 0.030$ & $0.95 \pm 0.17$ \\
\hline 271C029 & $11.5-12$ & $1.09 \pm 0.20$ & -- & $1.03 \pm 0.19$ \\
\hline $271 \mathrm{C} 032$ & $4.25-5.25$ & $0.92 \pm 0.17$ & $0.048 \pm 0.027(\mathrm{LT})$ & $0.92 \pm 0.17$ \\
\hline $271 \mathrm{C} 054$ & $3.5-4.5$ & $0.94 \pm 0.17$ & $0.055 \pm 0.028$ & $0.87 \pm 0.16$ \\
\hline $271 \mathrm{C055}$ & $3.5-4.5$ & $1.09 \pm 0.19$ & $0.047 \pm 0.026(\mathrm{LT})$ & $0.93 \pm 0.17$ \\
\hline $271 \mathrm{C} 056$ & $6-7$ & $1.14 \pm 0.21$ & $0.073 \pm 0.036$ & $1.17 \pm 0.22$ \\
\hline $271 \mathrm{C} 058$ & $4.25-5.25$ & $1.35 \pm 0.23$ & $0.059 \pm 0.031$ & $1.08 \pm 0.20$ \\
\hline $271 C 069$ & $7.4-8.4$ & $0.83 \pm 0.15$ & $0.042 \pm 0.023(\mathrm{LT})$ & $0.89 \pm 0.16$ \\
\hline $271 \mathrm{C} 071$ & $12.25-13.25$ & $1 \pm 0.18$ & $0.063 \pm 0.031$ & $1.01 \pm 0.18$ \\
\hline $271 \mathrm{C} 078$ & $12.5-13.5$ & $0.89 \pm 0.17$ & -- & $0.88 \pm 0.17$ \\
\hline $271 C 079$ & $10-11$ & $0.93 \pm 0.18$ & -- & $1.1 \pm 0.21$ \\
\hline
\end{tabular}

aBackground concentration listed in Environmental Monitoring Report for the Proposed Ward Valley, California, Low-Level Radioactive Waste (LLRW) Facility (US Ecology and Atlan-Tech, 1992).

${ }^{\mathrm{b}}$ Background concentration listed or derived in Off-Site Radiation Exposure Review Project, Phase /I Soil Program (McArthur and Miller, 1989).

$\mathrm{LT}=$ Result is less than requested minimum detectable concentration (MDC), greater than sample specific MDC.

-- $=$ Not detected above minimum reporting limit.

\section{A.5.3.1.11 Strontium-90}

Strontium-90 was not detected above MRLs in CAS 25-04-04 soil samples.

\section{A.5.3.2 Septic Tank Sample Results}

Results of collected septic tank content samples were compared to regulatory levels based on disposal options. If the waste has no hazardous component, the regulatory level is based on disposal options at NTS landfills and lagoons (BN, 1995; CFR, 2000a and c; NDEP, 1997a, b, and c). Any sludge or liquid waste will be solidified before disposal at NTS landfills (NDEP, 1997b). If the waste is 
hazardous, the release criteria are based on interpretation of the guidelines presented in the POC (BN, 1995; Alderson, 1999). For waste destined for off-site disposal, the POC radiological levels must be met to certify that the waste has no radioactivity added.

Two sludge and two liquid samples were obtained from the septic tank. The analytical suite followed the CAIP and is detailed in Section A.5.2.9. Analytical results exceeding MRLs are listed in Table A.5-8.

Several COPCs were detected in the sludge samples. Most COPCs were below regulatory limits except for TPH and chlordane. Total petroleum hydrocarbons were present in sludge samples 271C074 and 271C076. Diesel concentrations in samples 271C074 and 271C076 were 45,000 and $1,000 \mathrm{mg} / \mathrm{kg}$, respectively. Gasoline concentrations in sample $271 \mathrm{C} 074$ were $6,500 \mathrm{mg} / \mathrm{kg}$. These levels exceed the NDEP TPH action level of $100 \mathrm{mg} / \mathrm{kg}$ (NAC, 2000).

Total chlordane was detected in the sludge sample 271C076 from the effluent chamber of the tank at $1,000 \mu \mathrm{g} / \mathrm{kg}$ (alpha chlordane) and $970 \mu \mathrm{g} / \mathrm{kg}$ (gamma chlordane). A conservative estimate of the TCLP result based on the total chlordane level exceeded the toxicity characteristic for chlordane established in 40 CFR 261. The EPA waste code D020 is assigned to sludge. Additionally, U-234 exceeded the unrestricted release criteria as established in the Nevada Test Site Performance Objective for Certification of Non-Radioactive Hazardous Waste (BN, 1995).

\section{A.5.4 Contaminants of Concern}

Based on the aforementioned analytical results, TPH concentrations above action levels are present in the septic tank and in an area of soil immediately north of the septic tank. Additionally, U-234 and chlordane were detected in the effluent chamber of the septic tank above regulated levels. Total petroleum hydrocarbons, U-234, and chlordane are the COCs for this collection system. No COCs were identified in the soil under the leachfield.

\section{A.5.5 Nature and Extent of Contamination}

Total petroleum hydrocarbons are located within the septic tank sludge and in the soil near the influent end of the septic tank. Total chlordane and U-234 are located in the effluent chamber of the septic tank. Approximately 1,178 and 170 gal of sludge and 2,978 and 438 gal of liquid remained in 
Table A.5-8

\section{Liquid and Sludge Sample Results Detected Above Minimum Reporting Limits at CAS 25-04-04}

(Page 1 of 3 )

\begin{tabular}{|c|c|c|c|c|c|c|}
\hline $\begin{array}{c}\text { Sample } \\
\text { Identification } \\
\text { Number }\end{array}$ & $\begin{array}{c}\text { Sample } \\
\text { Matrix }\end{array}$ & Parameter & Result & Units & Limits & Reference \\
\hline $271 \mathrm{C073}$ & Liquid & Barium & 0.23 & $\mathrm{mg} / \mathrm{L}$ & 100 & CFR, 2000b \\
\hline $271 \mathrm{C} 073$ & Liquid & Lead & 0.01 & $\mathrm{mg} / \mathrm{L}$ & 5 & CFR, 2000b \\
\hline $271 \mathrm{C} 073$ & Liquid & Silver & 0.014 & $\mathrm{mg} / \mathrm{L}$ & 5 & CFR, 2000b \\
\hline $271 \mathrm{C} 073$ & Liquid & Diesel-Range Organics & $13(\mathrm{M}, \mathrm{Z})$ & $\mathrm{mg} / \mathrm{L}$ & 100 & NDEP, 1997b \\
\hline $271 \mathrm{C} 073$ & Liquid & 1,1-Dichloroethene & 5.2 & $\mu \mathrm{g} / \mathrm{L}$ & 700 & CFR, 2000b \\
\hline $271 \mathrm{C} 073$ & Liquid & 1,4-Dichlorobenzene & 20 & $\mu \mathrm{g} / \mathrm{L}$ & 7,500 & CFR, 2000b \\
\hline $271 \mathrm{C} 073$ & Liquid & Acetone & $25(J)^{a}$ & $\mu \mathrm{g} / \mathrm{L}$ & NA & CFR, 2000b \\
\hline $271 \mathrm{C} 073$ & Liquid & Cis-1,2-Dichloroethene & $410(J)^{b}$ & $\mu \mathrm{g} / \mathrm{L}$ & NA & CFR, 2000b \\
\hline $271 \mathrm{C} 073$ & Liquid & Trans-1,2-Dichloroethene & 8.8 & $\mu \mathrm{g} / \mathrm{L}$ & NA & CFR, 2000b \\
\hline $271 \mathrm{C} 073$ & Liquid & Trichloroethene & 9.9 & $\mu \mathrm{g} / \mathrm{L}$ & 500 & CFR, 2000b \\
\hline $271 \mathrm{C} 075$ & Liquid & Cis-1,2-Dichloroethene & 34 & $\mu \mathrm{g} / \mathrm{L}$ & NA & CFR, 2000b \\
\hline $271 \mathrm{C073}$ & Liquid & 1,4-Dichlorobenzene & 18 & $\mu \mathrm{g} / \mathrm{L}$ & 7,500 & CFR, 2000b \\
\hline $271 \mathrm{C} 075$ & Liquid & Uranium-234 & $0.36 \pm 0.11$ & $\mathrm{pCi} / \mathrm{L}$ & 100 & NDEP, 1997b \\
\hline $271 \mathrm{C} 075$ & Liquid & Alpha-Chlordane & $0.044(J)^{c}$ & $\mu \mathrm{g} / \mathrm{L}$ & 30 & CFR, 2000b \\
\hline $271 \mathrm{C} 075$ & Liquid & Gamma-Chlordane & 0.065 & $\mu \mathrm{g} / \mathrm{L}$ & 30 & CFR, 2000b \\
\hline $271 \mathrm{C} 074$ & Sludge & Mercury & 19 & $\mathrm{mg} / \mathrm{kg}$ & NA & CFR, 2000b \\
\hline $271 \mathrm{C} 076$ & Sludge & Mercury $^{* *}$ & 3.9 & $\mathrm{mg} / \mathrm{kg}$ & NA & CFR, 2000b \\
\hline $271 \mathrm{C} 074$ & Sludge & Arsenic** & 9.4 & $\mathrm{mg} / \mathrm{kg}$ & NA & CFR, 2000b \\
\hline $271 \mathrm{C} 074$ & Sludge & Barium & 630 & $\mathrm{mg} / \mathrm{kg}$ & NA & CFR, 2000b \\
\hline $271 \mathrm{C} 074$ & Sludge & Cadmium $^{* *}$ & 39 & $\mathrm{mg} / \mathrm{kg}$ & NA & CFR, 2000b \\
\hline $271 \mathrm{C} 074$ & Sludge & Chromium** & 70 & $\mathrm{mg} / \mathrm{kg}$ & NA & CFR, 2000b \\
\hline $271 \mathrm{C} 074$ & Sludge & Lead $^{* *}$ & 130 & $\mathrm{mg} / \mathrm{kg}$ & NA & CFR, 2000b \\
\hline $271 \mathrm{C} 074$ & Sludge & Selenium ${ }^{\star *}$ & 3.1 & $\mathrm{mg} / \mathrm{kg}$ & NA & CFR, 2000b \\
\hline $271 \mathrm{C} 074$ & Sludge & Silver ${ }^{* *}$ & 290 & $\mathrm{mg} / \mathrm{kg}$ & NA & CFR, 2000b \\
\hline $271 \mathrm{C} 076$ & Sludge & Arsenic ${ }^{* *}$ & 7.6 & $\mathrm{mg} / \mathrm{kg}$ & NA & CFR, 2000b \\
\hline $271 \mathrm{C} 076$ & Sludge & Barium $^{* *}$ & 150 & $\mathrm{mg} / \mathrm{kg}$ & NA & CFR, 2000b \\
\hline $271 \mathrm{C} 076$ & Sludge & Cadmium $^{* *}$ & 6.6 & $\mathrm{mg} / \mathrm{kg}$ & NA & CFR, 2000b \\
\hline $271 \mathrm{C} 076$ & Sludge & Chromium** & 24 & $\mathrm{mg} / \mathrm{kg}$ & NA & CFR, 2000b \\
\hline $271 \mathrm{C} 076$ & Sludge & Lead $^{* *}$ & 57 & $\mathrm{mg} / \mathrm{kg}$ & NA & CFR, 2000b \\
\hline $271 \mathrm{C} 076$ & Sludge & Selenium ${ }^{* *}$ & 1.2 & $\mathrm{mg} / \mathrm{kg}$ & NA & CFR, 2000b \\
\hline $271 \mathrm{C} 076$ & Sludge & Silver ${ }^{* *}$ & 110 & $\mathrm{mg} / \mathrm{kg}$ & NA & CFR, 2000b \\
\hline $271 \mathrm{C} 074$ & Sludge & TCLP Mercury & 0.0051 & $\mathrm{mg} / \mathrm{L}$ & 0.2 & CFR, 2000b \\
\hline $271 \mathrm{C} 074$ & Sludge & TCLP Barium & 2.7 & $\mathrm{mg} / \mathrm{L}$ & 100 & CFR, 2000b \\
\hline $271 \mathrm{C} 074$ & Sludge & Diesel-Range Organics & $45,000(J)^{d}$ & $\mathrm{mg} / \mathrm{kg}$ & 100 & NDEP, 1997b \\
\hline
\end{tabular}


Table A.5-8

\section{Liquid and Sludge Sample Results Detected Above Minimum Reporting Limits at CAS 25-04-04}

(Page 2 of 3 )

\begin{tabular}{|c|c|c|c|c|c|c|}
\hline $\begin{array}{c}\text { Sample } \\
\text { Identification } \\
\text { Number }\end{array}$ & $\begin{array}{c}\text { Sample } \\
\text { Matrix }\end{array}$ & Parameter & Result & Units & Limits & Reference \\
\hline $271 \mathrm{C} 076$ & Sludge & Diesel-Range Organics & $1,000(M)$ & $\mathbf{m g} / \mathbf{k g}$ & 100 & NDEP, 1997b \\
\hline $271 \mathrm{C} 074$ & Sludge & Gasoline-Range Organics & $6,500(J)^{e}$ & $\mathrm{mg} / \mathrm{kg}$ & 100 & NDEP, 1997b \\
\hline $271 \mathrm{C} 074$ & Sludge & 1,4-Dichlorobenzene & 960,000 & $\mu \mathrm{g} / \mathrm{kg}$ & NA & CFR, 2000b \\
\hline $271 \mathrm{C} 074$ & Sludge & Cis-1,2-Dichloroethene & $4,900,000$ & $\mu \mathrm{g} / \mathrm{kg}$ & NA & CFR, 2000b \\
\hline $271 \mathrm{C} 074$ & Sludge & Trichloroethene & $13,000,000$ & $\mu \mathrm{g} / \mathrm{kg}$ & NA & CFR, 2000b \\
\hline $271 \mathrm{C} 076$ & Sludge & Acetone & $3,400(\mathrm{~J})^{a}$ & $\mu \mathrm{g} / \mathrm{kg}$ & NA & CFR, 2000b \\
\hline $271 \mathrm{C} 074$ & Sludge & Benzo(A)Anthracene & $31,000(J)^{f}$ & $\mu \mathrm{g} / \mathrm{kg}$ & NA & CFR, 2000b \\
\hline $271 \mathrm{C} 074$ & Sludge & Butyl Benzyl Phthalate & $31,000(J)^{f}$ & $\mu \mathrm{g} / \mathrm{kg}$ & NA & CFR, 2000b \\
\hline $271 \mathrm{C} 076$ & Sludge & Bis(2-Ethylhexyl)Phthalate & $1,300(J)^{9}$ & $\mu \mathrm{g} / \mathrm{kg}$ & NA & CFR, 2000b \\
\hline $271 \mathrm{C} 074$ & Sludge & TCLP 1,4-Dichlorobenzene & 0.82 & $\mathrm{mg} / \mathrm{L}$ & 7.5 & CFR, 2000b \\
\hline $271 \mathrm{C} 074$ & Sludge & TCLP 3+4-Methylphenol & 0.26 & $\mathrm{mg} / \mathrm{L}$ & 200 & CFR, 2000b \\
\hline $271 \mathrm{C} 074$ & Sludge & TCLP Trichloroethene & 0.15 & $\mathrm{mg} / \mathrm{L}$ & 0.5 & CFR, 2000b \\
\hline $271 \mathrm{C} 074$ & Sludge & Uranium-234 & $2.5 \pm 0.40$ & $\mathrm{pCi} / \mathrm{g}$ & 100 & NDEP, 1997b \\
\hline $271 \mathrm{C} 074$ & Sludge & Uranium-235 & $0.072 \pm 0.038$ & $\mathrm{pCi} / \mathrm{g}$ & 100 & NDEP, 1997b \\
\hline $271 \mathrm{C} 074$ & Sludge & Uranium-238 & $0.71 \pm 0.15$ & $\mathrm{pCi} / \mathrm{g}$ & 100 & NDEP, 1997b \\
\hline $271 \mathrm{C} 076$ & Sludge & Uranium-234 & $1.86 \pm 0.30$ & $\mathrm{pCi} / \mathrm{g}$ & 0.932 & BN, 1995 \\
\hline $271 \mathrm{C} 076$ & Sludge & Uranium-235 & $0.07 \pm 0.037$ & $\mathrm{pCi} / \mathrm{g}$ & 0.1614 & $\mathrm{BN}, 1995$ \\
\hline $271 \mathrm{C} 076$ & Sludge & Uranium-238 & $1.14 \pm 0.20$ & $\mathrm{pCi} / \mathrm{g}$ & 10 & BN, 1995 \\
\hline $271 \mathrm{C} 074$ & Sludge & Plutonium-239 & $0.087 \pm 0.038$ & $\mathrm{pCi} / \mathrm{g}$ & 0.5 & BN, 1995 \\
\hline $271 \mathrm{C} 076$ & Sludge & Plutonium-239 & $0.059 \pm 0.027$ & $\mathrm{pCi} / \mathrm{g}$ & 0.5 & BN, 1995 \\
\hline $271 \mathrm{C} 076$ & Sludge & Potassium-40 & $25.4 \pm 6.6$ & $\mathrm{pCi} / \mathrm{g}$ & - & $E$ \\
\hline $271 \mathrm{C} 076$ & Sludge & Lead-212 & $1.21 \pm 0.38$ & $\mathrm{pCi} / \mathrm{g}$ & - & $E$ \\
\hline $271 \mathrm{C} 076$ & Sludge & Lead-214 & $0.75 \pm 0.28$ & $\mathrm{pCi} / \mathrm{g}$ & - & $\bar{E}$ \\
\hline $271 \mathrm{C} 074$ & Sludge & Aroclor-1016 & 790 & $\mu \mathrm{g} / \mathrm{kg}$ & 50,000 & CFR, 2000c \\
\hline $271 \mathrm{C} 074$ & Sludge & Aroclor-1260 & 710 & $\mu \mathrm{g} / \mathrm{kg}$ & 50,000 & CFR, 2000c \\
\hline $271 \mathrm{C} 074$ & Sludge & $4,4^{\prime}-\mathrm{DDE}$ & $220(J)^{h}$ & $\mu \mathrm{g} / \mathrm{kg}$ & NA & CFR, 2000b \\
\hline $271 \mathrm{C} 074$ & Sludge & Alpha-Chlordane & $68(J)^{\mathrm{h}}$ & $\mu \mathrm{g} / \mathrm{kg}$ & 30 & CFR, 2000b \\
\hline $271 \mathrm{C} 074$ & Sludge & Gamma-Chlordane & $97(\mathrm{~J})^{\mathrm{h}}$ & $\mu \mathrm{g} / \mathrm{kg}$ & 30 & CFR, 2000b \\
\hline
\end{tabular}


Table A.5-8

\section{Liquid and Sludge Sample Results Detected Above Minimum Reporting Limits at CAS 25-04-04}

(Page 3 of 3 )

\begin{tabular}{|c|c|c|c|c|c|c|}
\hline \begin{tabular}{|c|} 
Sample \\
Identification \\
Number
\end{tabular} & $\begin{array}{c}\text { Sample } \\
\text { Matrix }\end{array}$ & Parameter & Result & Units & Limits & Reference \\
\hline $271 \mathrm{C} 076$ & Sludge & 4,4'-DDE & 51 & $\mu \mathrm{g} / \mathrm{kg}$ & NA & CFR, 2000b \\
\hline 271C076 & Sludge & Alpha-Chlordane & $1,000(J)^{b}$ & $\mu \mathbf{g} / \mathbf{k g}$ & 30 & CFR, 2000b \\
\hline $271 \mathrm{C} 076$ & Sludge & Beta-BHC & 70 & $\mu \mathrm{g} / \mathrm{kg}$ & NA & CFR, 2000b \\
\hline $271 \mathrm{C} 076$ & Sludge & Gamma-Chlordane & $970(\mathrm{~J})^{d}$ & $\mu \mathbf{g} / \mathbf{k g}$ & 30 & CFR, 2000b \\
\hline $271 \mathrm{C} 075$ & Liquid & Gross Alpha & $0.31 \pm 0.91$ & $\mathrm{pCi} / \mathrm{L}$ & $1.6^{i}$ & NA \\
\hline $271 \mathrm{C} 075$ & Liquid & Gross Beta & $11.4 \pm 2.0$ & $\mathrm{pCi} / \mathrm{L}$ & $1.7^{\mathrm{i}}$ & NA \\
\hline
\end{tabular}

${ }^{a} Q u a l i f i e r$ added to laboratory data; record accepted. Relative response factor $<0.05$.

${ }^{b}$ Qualifier added to laboratory data; record accepted. Value exceeded linear range of instrument

${ }^{\circ} Q$ ualifier added to laboratory data; record accepted. Surrogate recovery exceeded the lower limits

${ }^{d}$ Qualifier added to laboratory data; record accepted. Surrogates diluted out.

${ }^{e} Q$ Qualifier added to laboratory data; record accepted. Surrogate recovery exceeded the lower limits. Matrix effects may exist. Internal standard area count exceeded the quality control limits.

${ }^{\text {f}}$ Qualifier added to laboratory data; record accepted. Infernal standard count exceeded the quality control limits. Matrix effects may exist. Spike recovery was outside control limits.

${ }^{g}$ Qualifier added to laboratory data; record accepted. Infernal standard count exceeded the quality control limits. Matrix effects may exist.

${ }^{\text {h}}$ Qualifier added to laboratory data; record accepted. Surrogate recovery exceeded the upper limits. Matrix effects may exist.

'Maximum detectable concentration

$* *=$ TCLP below minimum reporting limit

$\mathrm{E}=$ No limit established $(\mathrm{BN}, 1995)$

$\mathrm{J}=$ Estimated value

$\mathrm{M}=$ Motor oil

NA $=$ Not applicable

$Z=$ The reported result did not resemble the patterns of the following petroleum hydrocarbon products: gasoline, JP-4, JP-8, diesel, mineral spirits, motor oil, Stoddard solvent, and Bunker $\mathrm{C}$

the inlet and outlet chambers, respectively, of the tank. Approximately $420 \mathrm{yd}^{3}$ of soil contain TPH DRO above PALs. The extent of COCs has been defined or it is confined to the interior of the septic tank.

\section{A.5.6 Revised Conceptual Model}

No variations in the conceptual model were identified. The TPH DRO contamination in the soil near the septic tank does not appear to have originated from the tank. Elevated concentrations away from the tank occur at shallower depths than would be expected if the tank was the source. The soil contamination may be due to a leak in collection system pipe, a surface spill, or contaminated fill material. 


\section{A.6.0 BREN Tower Septic System (CAS 25-04-08)}

The BREN Tower septic system was designed to receive effluent generated within a restroom trailer near the BREN Tower. The septic system is located approximately $100 \mathrm{ft}$ south of Cane Spring Road, at the entrance to BREN Tower, and east of the BREN Tower access road in Area 25. The site is comprised of a leachfield, septic tank, distribution box and associated piping. More detail is provided in the CAIP (DOE/NV, 2001).

\section{A.6.1 Corrective Action Investigation}

Thirty-four investigation samples, listed in Table A.6-1, were collected during investigation activities conducted at CAS 25-04-08. The planned and actual sample locations are shown in Figure A.6-1. The specific CAI activities conducted to meet CAIP requirements at CAS 25-04-08 are described in Table A.2-1.

Table A.6-1

Samples Collected at CAS 25-04-08

(Page 1 of 3 )

\begin{tabular}{|c|c|c|c|c|c|c|c|c|c|c|c|c|c|c|}
\hline \multirow[b]{2}{*}{$\begin{array}{c}\text { Sample } \\
\text { Identification } \\
\text { Number }\end{array}$} & \multirow[b]{2}{*}{$\begin{array}{l}\text { Sample } \\
\text { Location }\end{array}$} & \multirow[b]{2}{*}{$\begin{array}{l}\text { Sample } \\
\text { Matrix }\end{array}$} & \multirow[b]{2}{*}{$\begin{array}{l}\text { Depth } \\
\text { (ft bgs) }\end{array}$} & \multirow[b]{2}{*}{ Purpose } & \multicolumn{10}{|c|}{ Analyses } \\
\hline & & & & & 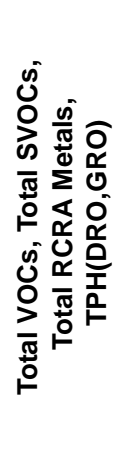 & 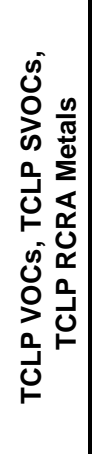 & 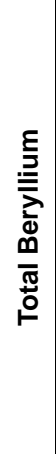 & OO & 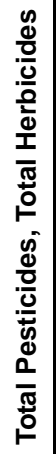 & 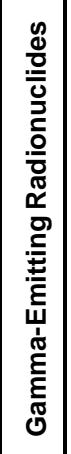 & 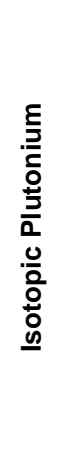 & 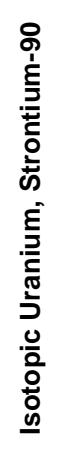 & $\stackrel{\xi}{E}$ & 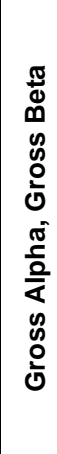 \\
\hline 271D001 & D01 & Soil & $7-8$ & Integrity & $x$ & & & & & & & & & \\
\hline 271D002 & D02 & Soil & $7.25-8.25$ & Integrity & $\mathrm{x}$ & & & & & & & & & \\
\hline 271D003 & D04 & Soil & $3.75-4.75$ & Integrity & $\mathrm{x}$ & & & & & & & & & \\
\hline 271D004 & D04 & Soil & $6.5-7.5$ & Integrity & \multicolumn{10}{|c|}{ Not Submitted for Analyses ${ }^{a}$} \\
\hline 271D005 & D05 & Soil & $4-5$ & Environmental & $\mathrm{x}$ & & & & & & & & & \\
\hline 271D006 & D05 & Soil & $6.5-7.5$ & Environmental & \multicolumn{10}{|c|}{ Not Submitted for Analyses ${ }^{a}$} \\
\hline 271D007 & D03 & Soil & $4-5$ & Environmental & $x$ & & & & & & & & & \\
\hline
\end{tabular}


Table A.6-1

Samples Collected at CAS 25-04-08

(Page 2 of 3 )

\begin{tabular}{|c|c|c|c|c|c|c|c|c|c|c|c|c|c|c|}
\hline \multirow[b]{2}{*}{$\begin{array}{c}\text { Sample } \\
\text { Identification } \\
\text { Number }\end{array}$} & \multirow[b]{2}{*}{$\begin{array}{c}\text { Sample } \\
\text { Location }\end{array}$} & \multirow[b]{2}{*}{$\begin{array}{l}\text { Sample } \\
\text { Matrix }\end{array}$} & \multirow[b]{2}{*}{$\begin{array}{l}\text { Depth } \\
\text { (ft bgs) }\end{array}$} & \multirow[b]{2}{*}{ Purpose } & \multicolumn{10}{|c|}{ Analyses } \\
\hline & & & & & 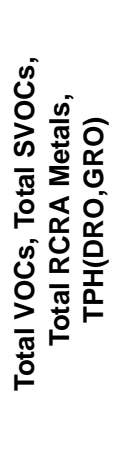 & 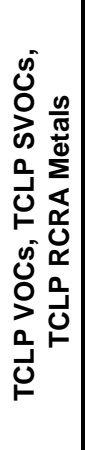 & 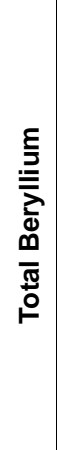 & 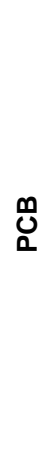 & 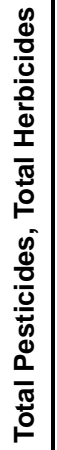 & 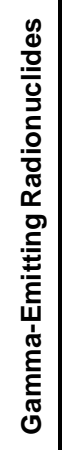 & 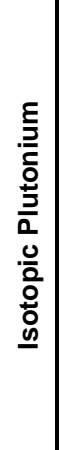 & 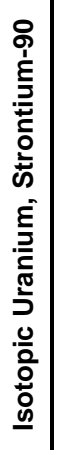 & 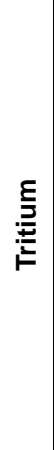 & 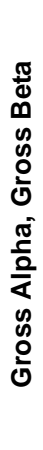 \\
\hline 271D008 & D03 & Soil & $6.5-7.5$ & Environmental & \multicolumn{10}{|c|}{ Not Submitted for Analyses ${ }^{a}$} \\
\hline 271D009 & D10 & Soil & $4-5$ & Environmental & $\mathrm{X}$ & & & & & $x$ & $x$ & $x$ & & \\
\hline 271D010 & D10 & Soil & $6.5-7.5$ & Environmental & \multicolumn{10}{|c|}{ Not Submitted for Analyses ${ }^{a}$} \\
\hline 271D011 & D07 & Soil & $4-5$ & $\begin{array}{l}\text { Environmental } \\
\text { MS/MSD }\end{array}$ & $\mathrm{X}$ & & & & & $\mathrm{x}$ & $x$ & $x$ & & \\
\hline 271D012 & D07 & Soil & $6.5-7.5$ & Environmental & \multicolumn{10}{|c|}{ Not Submitted for Analyses ${ }^{a}$} \\
\hline 271D013 & D08 & Soil & $4-5$ & Environmental & $\mathrm{X}$ & & & & & $x$ & $x$ & $x$ & & \\
\hline 271D014 & D08 & Soil & $4-5$ & $\begin{array}{l}\text { Duplicate of } \\
\text { 271D013 }\end{array}$ & $\mathrm{X}$ & & & & & $x$ & $X$ & $x$ & & \\
\hline 271D015 & D08 & Soil & $6.5-7.5$ & Environmental & \multicolumn{10}{|c|}{ Not Submitted for Analyses ${ }^{a}$} \\
\hline 271D016 & D09 & Soil & $4-5$ & Environmental & $x$ & & & & & & & & & \\
\hline 271D017 & D09 & Soil & $6.5-7.5$ & Environmental & \multicolumn{10}{|c|}{ Not Submitted for Analyses ${ }^{a}$} \\
\hline 271D018 & D06 & Soil & $4-5$ & Environmental & $x$ & & & & & & & & & \\
\hline 271D019 & D06 & Soil & $6.5-7$ & Environmental & \multicolumn{10}{|c|}{ Not Submitted for Analyses ${ }^{a}$} \\
\hline 271D020 & D11 & Soil & $3.75-4.25$ & Geotechnical & \multicolumn{10}{|c|}{ Not Submitted for Analyses ${ }^{b}$} \\
\hline 271D021 & D15 & Liquid & NA & Septic Tank & $x$ & & & & & $x$ & $\mathrm{x}$ & $x$ & $\mathrm{X}$ & $x$ \\
\hline 271D022 & D15 & Sludge & NA & Septic Tank & $\mathrm{x}$ & $x$ & & & & $\mathrm{x}$ & $\mathrm{X}$ & $x$ & $x$ & \\
\hline 271D023 & D16 & Liquid & NA & Septic Tank & $\mathrm{x}$ & & & & & $\mathrm{x}$ & $x$ & $x$ & $\mathrm{x}$ & $x$ \\
\hline 271D024 & D16 & Sludge & NA & Septic Tank & $\mathrm{X}$ & $x$ & & & & $x$ & $x$ & $x$ & $x$ & \\
\hline 271D025 & D07 & Soil & $8.5-9$ & Environmental & SVOCs & & & & & & $x$ & & & \\
\hline 271D026 & D17 & Soil & $4-5$ & Environmental & SVOCs & & & & & & $x$ & & & \\
\hline 271D027 & D17 & Soil & $6.5-7$ & Environmental & \multicolumn{10}{|c|}{ Not Submitted for Analyses ${ }^{a}$} \\
\hline 271D028 & D08 & Soil & $8.5-9$ & Environmental & SVOCs & & & & & & $x$ & & & \\
\hline
\end{tabular}


Table A.6-1

Samples Collected at CAS 25-04-08

(Page 3 of 3 )

\begin{tabular}{|c|c|c|c|c|c|c|c|c|c|c|c|c|c|c|}
\hline \multirow[b]{2}{*}{$\begin{array}{c}\text { Sample } \\
\text { Identification } \\
\text { Number }\end{array}$} & \multirow[b]{2}{*}{$\begin{array}{l}\text { Sample } \\
\text { Location }\end{array}$} & \multirow[b]{2}{*}{$\begin{array}{l}\text { Sample } \\
\text { Matrix }\end{array}$} & \multirow[b]{2}{*}{$\begin{array}{c}\text { Depth } \\
\text { (ft bgs) }\end{array}$} & \multirow[b]{2}{*}{ Purpose } & \multicolumn{10}{|c|}{ Analyses } \\
\hline & & & & & 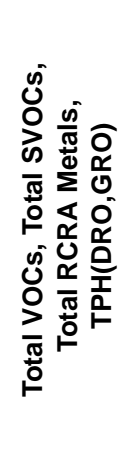 & 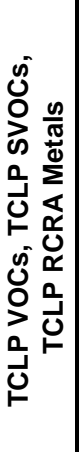 & 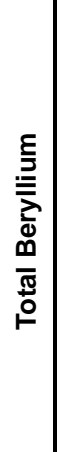 & O̊ & 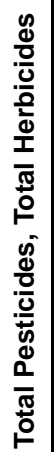 & 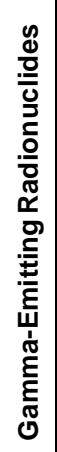 & 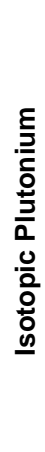 & 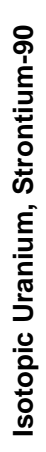 & 竞 & 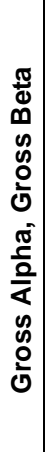 \\
\hline 271D029 & D19 & Soil & $4-5$ & Environmental & SVOCs & & & & & & $x$ & & & \\
\hline 271D030 & D19 & Soil & $6.5-7.5$ & Environmental & \multicolumn{10}{|c|}{ Not Submitted for Analyses ${ }^{a}$} \\
\hline 271D031 & D20 & Soil & $4-5$ & Environmental & SVOCs & & & & & & $x$ & & & \\
\hline 271D032 & D20 & Soil & $6.5-7.5$ & Environmental & \multicolumn{10}{|c|}{ Not Submitted for Analyses ${ }^{a}$} \\
\hline 271D033 & D18 & Soil & $4-5$ & Environmental & SVOCs & & & & & & $x$ & & & \\
\hline 271D034 & D18 & Soil & $6.5-7$ & Environmental & \multicolumn{10}{|c|}{ Not Submitted for Analyses ${ }^{a}$} \\
\hline 271D301 & NA & Water & NA & Trip Blank & VOC only & & & & & & & & & \\
\hline 271D302 & NA & Water & NA & Field Blank & $x$ & & & & & $x$ & $x$ & $x$ & & \\
\hline 271D303 & NA & Water & NA & Trip Blank & VOC only & & & & & & & & & \\
\hline 271D304 & NA & Water & NA & Trip Blank & VOC only & & & & & & & & & \\
\hline 271D305 & NA & Water & NA & Rinsate & $x$ & & & & & $x$ & $x$ & $x$ & & \\
\hline 271D307 & NA & Water & NA & Trip Blank & VOC only & & & & & & & & & \\
\hline 271D308 & NA & Water & NA & Trip Blank & VOC only & & & & & & & & & \\
\hline 271D309 & NA & Water & NA & Field Blank & $x$ & & $x$ & $x$ & & $x$ & $x$ & $x$ & $x$ & \\
\hline 271D310 & $\begin{array}{l}\text { Decontamination } \\
\text { pad }\end{array}$ & Water & NA & Rinsate & $x$ & & $x$ & $x$ & & $x$ & $x$ & $x$ & $x$ & \\
\hline
\end{tabular}

${ }^{a}$ The sample was collected, field screened, and returned to the site for disposal.

${ }^{\mathrm{b}}$ The sample was collected, field screened, and is being stored for possible geotechnical analysis.

NA = Not applicable

MS/MSD = Matrix spike/matrix spike duplicate 


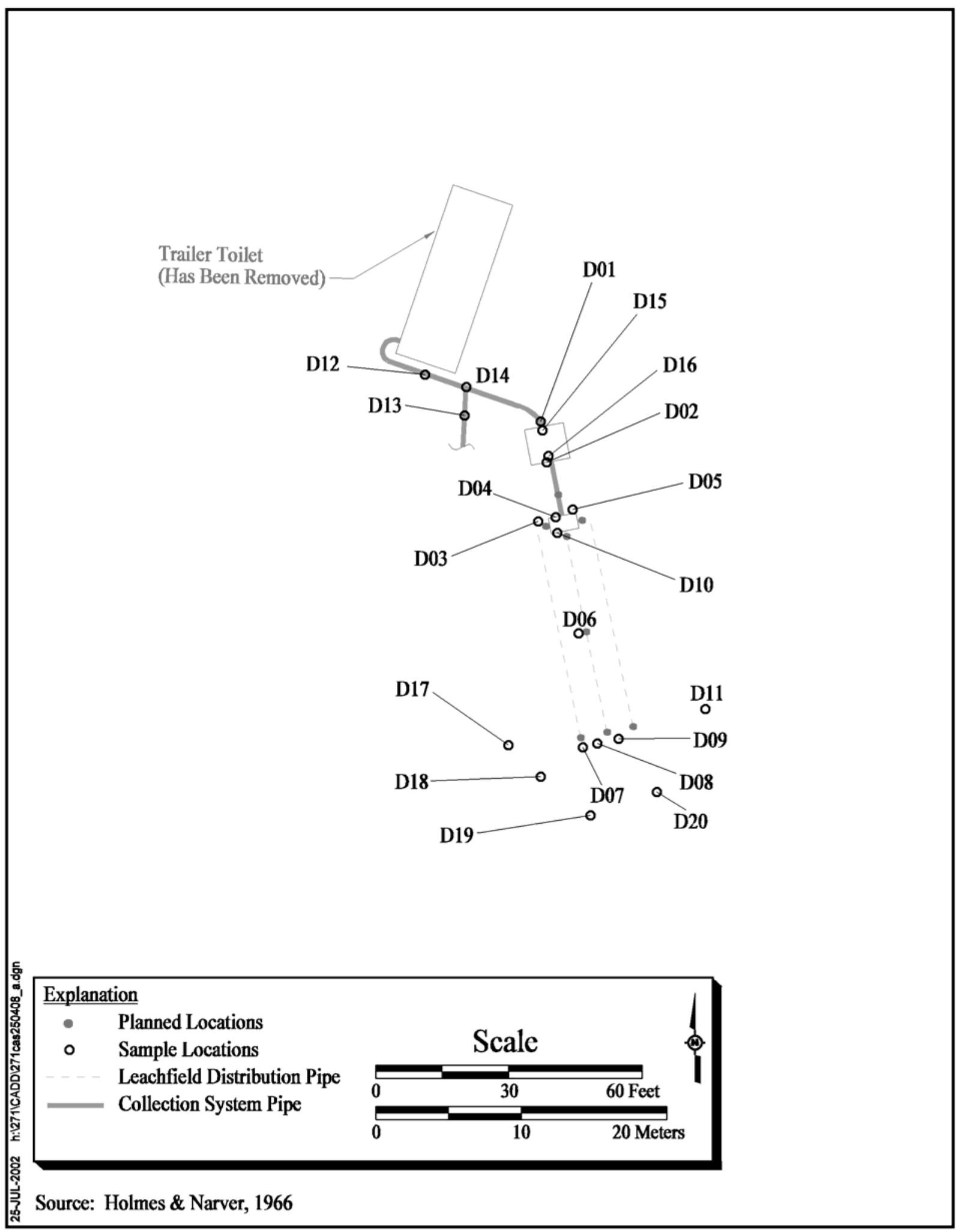

Figure A.6-1

BREN Tower Septic System (CAS 25-04-08) 


\section{A.6.1.1 Deviations}

The following deviations to the CAIP-requirements were the result of unforeseen circumstances:

- Refusal was met due to encountering subsurface hardpan (caliche); therefore:

- Sample 271D001 was collected at 7 to $8 \mathrm{ft}$ bgs (this was the planned interval; however, the second consecutive clean sample was not achievable)

- Sample 271D002 was collected at 7.25 to $8.25 \mathrm{ft}$ bgs (this was the planned interval; however, the second consecutive clean sample was not achievable)

Despite these deviations, the pertinent CAIP requirements were met.

\section{A.6.2 Investigation Results}

The following subsections provide details of the inspection and sampling of leachfield features, field-screening results, and sample selection and analysis.

\section{A.6.2.1 Septic Tank Contents}

The contents of the septic tank were sampled according to the CAIP. The rectangular-shaped septic tank was made of concrete with a tar-coated interior. The capacity of the tank was 898 gal. The tank was two-chambered, with the inlet and outlet chambers having capacities of 567 and 331 gal, respectively. It was accessed by two concrete manholes, buried approximately $2 \mathrm{ft}$ bgs. The interior dimensions of the tank were roughly $7.92 \mathrm{ft}$ (length) by $3.1 \mathrm{ft}$ (width) by $4.92 \mathrm{ft}$ (depth). One liquid and one sludge sample were collected from each of the two chambers. Visual inspection revealed that a maximum thickness of $2.5 \mathrm{ft}$ ( $288 \mathrm{gal}$ ) of liquid and $1.4 \mathrm{ft}$ (163 gal) of sludge remained in the bottom of the inlet chamber of the tank. A maximum thickness of $2.5 \mathrm{ft}$ (168 gal) of liquid and $1 \mathrm{in}$. (6 gal) of sludge remained in the bottom of the outlet chamber of the tank. Photographs of the septic tank were taken to document the visual inspection (Figure A.6-2).

\section{A.6.2.2 Distribution Box Contents}

The distribution box was a concrete rectangular structure accessed by one concrete manhole located $2.25 \mathrm{ft}$ bgs. The bottom of the box was at $3.75 \mathrm{ft}$ bgs. The exterior dimensions of the distribution box are $4 \mathrm{ft}$ (length) by $4 \mathrm{ft}$ (width) by $3.75 \mathrm{ft}$ (depth). The contents of the distribution box were not 


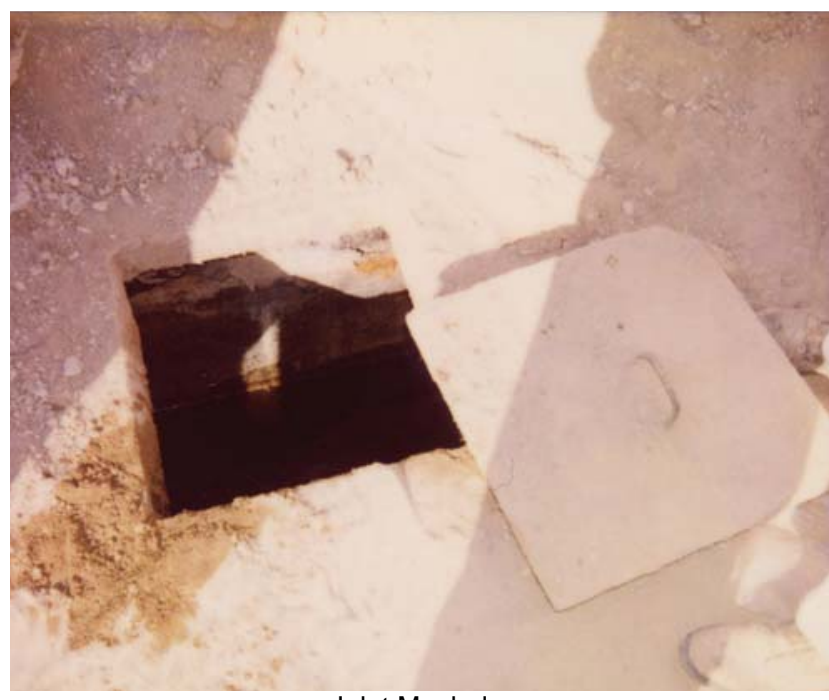

Inlet Manhole

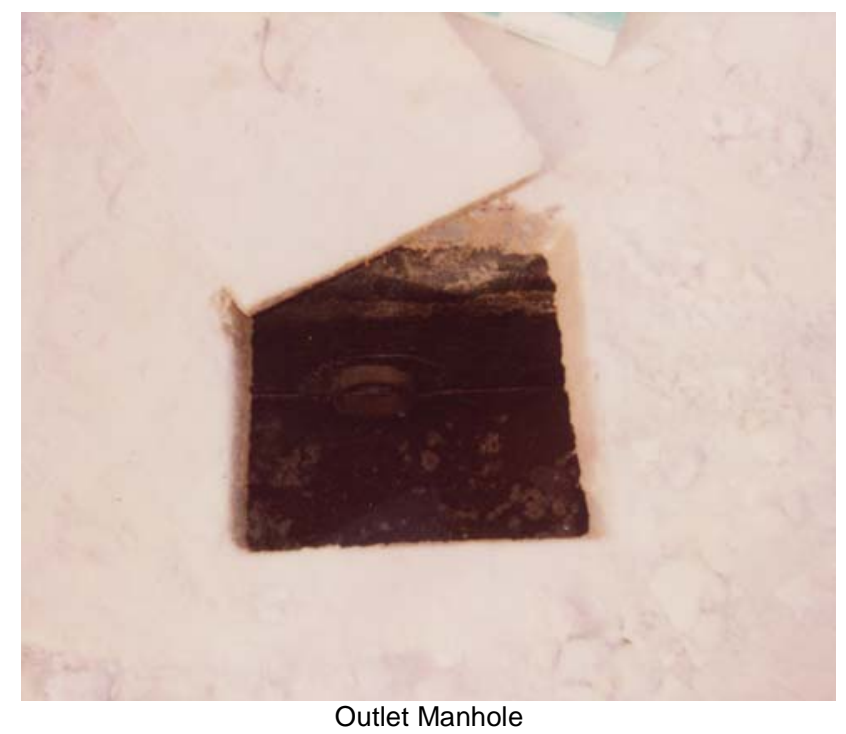

Outlet Manhole

Figure A.6-2

CAS 25-04-08 Septic Tank Manholes

(Photographs Taken 11-12-2001)

sampled as the box was found to be filled in with soil. Exterior inspection revealed that the distribution box had one inlet and three outlets. A photograph of the exterior of the distribution box was taken to document the visual inspection (Figure A.6-3). The distribution box and lid were broken during the investigation, and the pieces became buried during excavation activities.

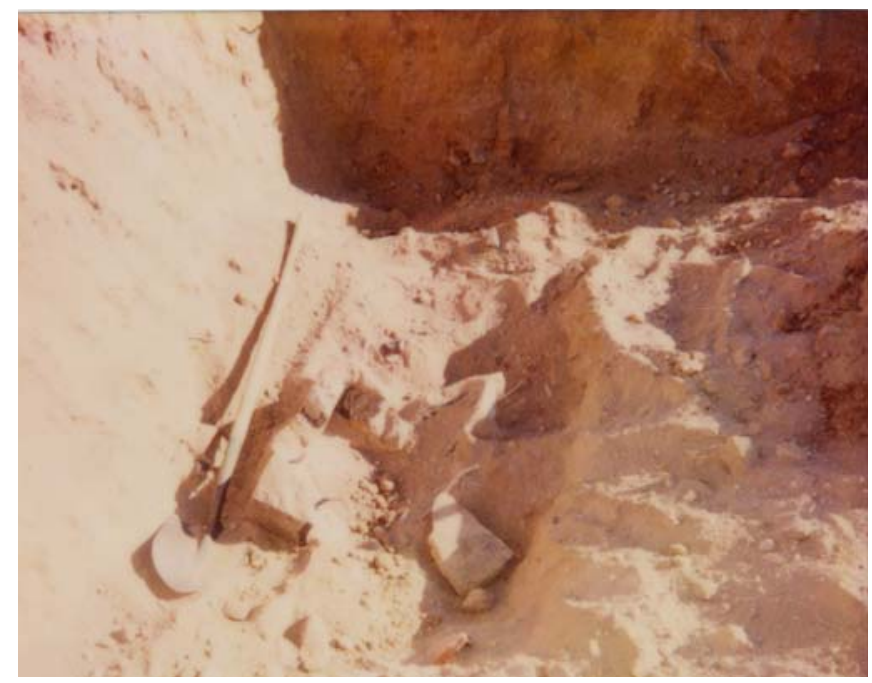

Figure A.6-3

CAS 25-04-08 Distribution Box (Photograph Taken 11-09-2001) 


\section{A.6.2.3 Septic Tank and Distribution Box Integrity Soil Sampling}

Four (six were planned; see Section A.6.1.1 for explanation of deviation) integrity samples were collected by excavating adjacent to the influent and effluent ends of the septic tank and the effluent end of the distribution box. The following three samples were submitted for laboratory analysis:

- The sample (271D001) from the influent end of the septic tank, collected at 7 to $8 \mathrm{ft}$ bgs

- The sample (271D002) from the effluent end of the septic tank, collected at 7.25 to $8.25 \mathrm{ft}$ bgs

- The upper sample (271D003) from the effluent end of the distribution box, collected at 3.75 to $4.75 \mathrm{ft}$ bgs

\section{A.6.2.4 Leachfield Excavation Soil Sampling}

Backhoe excavations were conducted to access sampling horizons at the biased locations presented in the CAIP. Excavations provided a visual verification of distribution pipes and enabled soil samples to be collected from appropriate intervals beneath the pipes, as specified by the CAIP. Fifteen soil samples were collected from the planned locations excavated within the leachfield. These samples were collected from an interval at the leachrock/native soil interface and an interval $2.5 \mathrm{ft}$ below the interface. The interface was found at depths ranging from 3.75 to $4 \mathrm{ft} \mathrm{bgs.} \mathrm{Eight} \mathrm{samples} \mathrm{were}$ submitted for laboratory analysis. In addition, one QC soil duplicate and one MS/MSD sample were collected and analyzed. A geotechnical sample was collected outside the boundary of the leachfield. The sample will be sent to a laboratory for geotechnical analysis, if necessary.

\section{A.6.2.5 Additional Sampling}

To further define the extent of potential soil contamination at the edge of the leachfield, the field crew returned to this CAS on February 07, 2002, to conduct step-out sampling. Two locations (D07 and D08) were identified from the original sampling activities as locations of concern. Two vertical and four horizontal step-out samples were collected. The vertical samples (271D025 and 271D028) were collected from 8.5 to $9.5 \mathrm{ft}$ bgs at D07 and D08, respectively. The horizontal step-outs were collected $15 \mathrm{ft}$ west (location D17), and south (locations D18, D19, and D20) of locations D07 and D08, at the leachrock/native soil interface and $2.5 \mathrm{ft}$ below the interface. These locations are shown on Figure A.6-1 and the associated sample numbers are listed in Table A.6-1. Samples collected at the leachrock/native soil interface were submitted for laboratory analysis. 


\section{A.6.2.6 Collection System Pipe Inspections}

The ends of some of the collection system pipes were exposed at ground surface. The pipes were relatively short in length; therefore, it was determined that a video mole survey would be unnecessary at this location. The western-most line was found to be a total of $19 \mathrm{ft}$ long from the beginning point to the junction where it joined with a line coming from the south (Figure A.6-1). An excavation (D12) was made halfway down the western-most line and pipe was exposed for radiological swiping and survey. The line from the south was found to be a total of $20 \mathrm{ft}$ long from beginning point to the junction. An excavation (D13) was made approximately $15 \mathrm{ft}$ from the end of this line and pipe was exposed for radiological swiping and survey. The two lines joined the junction, and a single pipe proceeded to the septic tank. An excavation (D14) was made at the junction and pipe was exposed for radiological swiping and survey. The line continued downgradient $17 \mathrm{ft}$ to the inlet of the septic tank.

Some material was identified in the piping, but the soil was not related to the operation of the system, and was not sampled. No breaches or other offshoot lines were observed. Visual observations were recorded in the FADLs.

\section{A.6.2.7 Field-Screening Results}

Soil samples were screened for VOCs and alpha and beta/gamma radioactivity. The field readings were compared to FSLs to guide sampling decisions and determine which samples were to be submitted for laboratory analysis. No VOCs greater than FSLs were found during soil sample screening. The results of radiological field screening are discussed in Section A.6.2.8.

A sample of the septic tank content was collected and analyzed for fecal coliform bacteria. Fecal coliform bacteria was not detected in the septic tank material from this CAS.

\section{A.6.2.8 Radiological Survey Results}

All radiological field screening results for soil samples from CAS 25-04-08 were below FSLs. Swipe and radiological survey data from inspection points D12, D13, and D14 indicate that the collection system meets the unrestricted radiological release criteria as defined in the NV/YMP Radiological Control Manual (DOE/NV, 2000a). 


\section{A.6.2.9 Sample Analysis}

Environmental soil samples and associated QC samples were collected and analyzed for the CAIP-specified COPCs (i.e., total VOCs, total SVOCs, total RCRA metals, and TPH [DRO and GRO]). In addition, 25 percent of the soil samples and 100 percent of the associated QC samples were analyzed for Iso-U, Iso-Pu, Sr-90, and gamma-emitting radionuclides.

The sludge and liquid samples from the septic tank were analyzed for total VOCs, total SVOCs, TPH (GRO and DRO), total RCRA metals, gamma-emitting radionuclides, Iso-U, Iso-Pu, Sr-90, and tritium. The sludge samples were analyzed according to the TCLP for VOCs, SVOC, and RCRA metals. The liquid samples were also analyzed for gross alpha and gross beta radioactivity.

The parameters and laboratory methods used to analyze the investigation samples are listed in Table A.2-2. Table A.6-1 lists the sample-specific analytical parameters.

\section{A.6.3 Analytes Detected Above Minimum Reporting Limits}

The soil sample analytical results with concentrations exceeding corresponding MRLs or PALs (DOE/NV, 1998; DOE/NV, 2001) at CAS 25-04-08 are summarized in the following sections. The results of septic tank content samples are compared to appropriate regulatory levels for disposal. A portion of the CAS 25-04-08 analytical results were rejected during validation; however, these rejected data did not impact closure decisions as discussed in Section B.1.3.4 of Appendix B.

\section{A.6.3.1 Analytical Results for Soil Samples}

The following sections discuss the results for soil samples in comparison to the levels established in the Leachfield Work Plan and the CAIP.

\section{A.6.3.1.1 Total Volatile Organic Compounds}

Volatile organic compounds were not detected above MRLs in CAS 25-04-08 soil samples. 


\section{A.6.3.1.2 Total Semivolatile Organic Compounds}

Semivolatile organic compound results are reported in Table A.6-2. Only one sample, 271D014, has SVOC analytes above MRLs of $660 \mu \mathrm{g} / \mathrm{kg}$ for fluoranthene. This detection was below the PAL. Sample number 271D014 was taken as a field duplicate of 271D013. Sample number 271D013 did not exceed MRLs or PALs.

Table A.6-2

Soil Sample Results for Total SVOCs

Detected Above Minimum Reporting Limits at CAS 25-04-08

\begin{tabular}{|c|c|c||}
\hline \multirow{2}{*}{$\begin{array}{c}\text { Sample } \\
\text { Identification Number }\end{array}$} & $\begin{array}{c}\text { Depth } \\
(\mathbf{f t ~ b g s})\end{array}$ & Contaminants of Potential Concern $(\mu \mathrm{g} / \mathrm{kg})$ \\
\cline { 3 - 4 } & & Fluoranthene \\
\hline \multicolumn{2}{|c|}{ Preliminary Action Levels } & $30,000,000$ \\
\hline \hline 271D014 & $4-5$ & 760 \\
\hline
\end{tabular}

${ }^{a}$ Based on U.S. EPA Region 9 Preliminary Remediation Goals (PRGs) (EPA, 2000)

\section{A.6.3.1.3 Total Petroleum Hydrocarbons}

Total petroleum hydrocarbons were not detected above MRLs in CAS 25-04-08 soil samples.

\section{A.6.3.1.4 Total RCRA Metals}

As shown in Table A.6-3, the total RCRA metals detected in soil samples above concentrations exceeding the MRLs are arsenic (1 mg/kg), barium (20 mg/kg), chromium (1 mg/kg), and lead $(0.3 \mathrm{mg} / \mathrm{kg})$. Other RCRA metals (i.e., cadmium, mercury, selenium, silver) were below specified MRLs.

Barium concentrations ranged from 110 to $170 \mathrm{mg} / \mathrm{kg}$, chromium concentrations ranged from 5.4 to $6.6 \mathrm{mg} . \mathrm{kg}$, and lead concentrations ranged from 6.1 to $8.4 \mathrm{mg} / \mathrm{kg}$. All reported concentrations of these metals were below EPA Region 9 PRGs defined in this document as PALs.

Arsenic concentrations ranged from 4.7 to $5.5 \mathrm{mg} / \mathrm{kg}$. Concentrations of arsenic above PALs were identified in eleven samples. Concentrations across the site were consistent, with no "hot spots" or evidence of a localized spill. The PAL for arsenic is defined by EPA Region 9 as $2.7 \mathrm{mg} / \mathrm{kg}$, 
Table A.6-3

Soil Sample Results for Total RCRA Metals Detected Above Minimum Reporting Limits at CAS 25-04-08

\begin{tabular}{|c|c|c|c|c|c|}
\hline \multirow{2}{*}{$\begin{array}{c}\text { Sample } \\
\text { Identification } \\
\text { Number }\end{array}$} & \multirow{2}{*}{$\begin{array}{l}\text { Depth } \\
\text { (ft bgs) }\end{array}$} & \multicolumn{4}{|c|}{ Contaminants of Potential Concern (mg/kg) } \\
\hline & & Arsenic & Barium & Chromium & Lead \\
\hline \multicolumn{2}{|c|}{ Preliminary Action Levels ${ }^{a}$} & 2.7 & 100,000 & 450 & 750 \\
\hline $271 \mathrm{D001}$ & $7-8$ & 4.9 & 140 & 6 & 7.5 \\
\hline 271D002 & $7.25-8.25$ & 5.4 & 110 & 5.4 & 6.1 \\
\hline $271 \mathrm{D} 003$ & $3.75-4.75$ & 4.9 & 140 & 6.1 & 7.1 \\
\hline 271D005 & $4-5$ & 5.3 & 130 & 5.6 & 6.8 \\
\hline 271D007 & $4-5$ & 5.1 & 120 & 6.5 & 7.9 \\
\hline 271D009 & $4-5$ & 5.2 & 140 & 5.9 & 7.3 \\
\hline 271D011 & $4-5$ & 5.5 & 140 & 6.6 & 8 \\
\hline $271 \mathrm{D013}$ & $4-5$ & 5.2 & 130 & 5.8 & 7.3 \\
\hline 271D014 & $4-5$ & 5.3 & 130 & 5.8 & 7.2 \\
\hline $271 \mathrm{D} 016$ & $4-5$ & 5.2 & 170 & 6.1 & 8.4 \\
\hline 271D018 & $4-5$ & 4.7 & 150 & 5.8 & 7.5 \\
\hline
\end{tabular}

a Based on U.S. Environmental Protection Agency, Region 9 Preliminary Remediation Goals (PRGs) (EPA, 2000)

indicating that samples tested were above this PAL. The PAL is lower than the 7 to $8 \mathrm{mg} / \mathrm{kg}$ mean concentration of arsenic in silt from the Nevada Test and Training Range (NBMG, 1998; Moore, 1999). Arsenic concentrations in the soil exceed the PAL, but are believed to be within ambient conditions for CAS 25-04-08 and do not represent contamination.

\section{A.6.3.1.5 Gamma Spectrometry Results}

Results of soil sample gamma spectroscopy analysis are presented in Table A.6-4. Concentrations of actinium-228, bismuth-212, bismuth-214, lead-212, lead-214, potassium-40, and thallium-208 were detected above the MDLs. The TPU in the radioanalytical measurement is provided in the table along with the concentration for all detected gamma emitters. The concentrations of the detected gamma-emitting radionuclides are below the PALs and are not significantly different than concentrations measured in soil samples collected from undisturbed background locations. 
Table A.6-4

Soil Sample Results for Gamma-Emitting Radionuclides Detected Above Minimum Reporting Limits at CAS 25-04-08

\begin{tabular}{|c|c|c|c|c|c|c|c|c|}
\hline \multirow{2}{*}{$\begin{array}{c}\text { Sample } \\
\text { Identification } \\
\text { Number }\end{array}$} & \multirow{2}{*}{$\begin{array}{c}\text { Depth } \\
\text { (ft bgs) }\end{array}$} & \multicolumn{7}{|c|}{ Contaminants of Potential Concern $(\mathrm{pCi} / \mathrm{g})$} \\
\hline & & Actinium-228 ${ }^{a}$ & Bismuth-212 ${ }^{\mathrm{b}}$ & Bismuth-214 ${ }^{\mathrm{b}}$ & Potassium-40 & Lead-212 ${ }^{\mathrm{a}}$ & Lead-214 ${ }^{\mathrm{b}}$ & Thallium-208 ${ }^{\mathrm{a}}$ \\
\hline \multicolumn{2}{|c|}{ Preliminary Action Level } & 3.64 & 2.4 & 3.47 & 96 & 2.9 & 2.9 & 3.4 \\
\hline 271D009 & $4-5$ & $1.22 \pm 0.26$ & $1.46 \pm 0.63$ & $0.85 \pm 0.19$ & $23.8 \pm 4.2$ & $1.4 \pm 0.26$ & $0.95 \pm 0.19$ & $0.389 \pm 0.092$ \\
\hline $271 \mathrm{D} 011$ & $4-5$ & $1.34 \pm 0.28$ & -- & $0.99 \pm 0.21$ & $26.7 \pm 4.7$ & $1.66 \pm 0.31$ & $1.05 \pm 0.21$ & $0.449 \pm 0.100$ \\
\hline $271 \mathrm{D} 013$ & $4-5$ & $1.4 \pm 0.29$ & -- & $0.84 \pm 0.19$ & $24 \pm 4.2$ & $1.56 \pm 0.29$ & $1.15 \pm 0.22$ & $0.47 \pm 0.10$ \\
\hline 271D014 & $4-5$ & $1.16 \pm 0.44$ & -- & $0.84 \pm 0.30$ & $22.2 \pm 5.3$ & $1.36 \pm 0.35$ & $1.22 \pm 0.31$ & $0.57 \pm 0.18$ \\
\hline
\end{tabular}

aBackground concentration listed in Environmental Monitoring Report for the Proposed Ward Valley, California, Low-Level Radioactive Waste (LLRW) Facility (US Ecology and Atlan-Tech, 1992)

${ }^{\mathrm{b} B a c k g r o u n d}$ concentration listed or derived in Off-Site Radiation Exposure Review Project, Phase II Soil Program (McArthur and Miller, 1989)

$--=$ Not detected above minimum reporting limit 


\section{A.6.3.1.6 Isotopic Uranium}

Detected values of uranium isotopes, along with associated TPUs are reported in Table A.6-5. The concentrations of the uranium isotopes are below PALs and are not significantly greater than concentrations in soil samples collected from undisturbed background locations.

\section{A.6.3.1.7 Isotopic Plutonium}

Detected values of plutonium isotopes, along with associated TPUs are reported in Table A.6-5. The $\mathrm{Pu}-239$ concentration of sample number 271D011 (location D07) was above the PAL; therefore, a normalized difference based on a confidence level of 95 percent was used to determine if the concentrations were statistically distinguishable from background. The concentration of $\mathrm{Pu}-239$ in the soil sample from 271D011 was significantly greater than concentrations in soil samples collected from undisturbed background locations. For this reason, additional sampling (Section A.6.2.5) was performed at step-out locations D17, D18, D19, and D20. Also, soil from a deeper interval at location D07 was collected. Isotopic plutonium was not detected above MRLs in any of the additional samples.

Table A.6-5

Soil Sample Results for Isotopic Plutonium and Uranium Detected Above Minimum Reporting Limits at CAS 25-04-08

\begin{tabular}{|c|c|c|c|c|c|c|}
\hline $\begin{array}{c}\text { Sample } \\
\text { Identification } \\
\text { Number }\end{array}$ & $\begin{array}{c}\text { Depth } \\
\text { (ft bgs) }\end{array}$ & \multicolumn{5}{|c|}{ Contaminants of Potential Concern (pCi/g) } \\
\cline { 3 - 7 } & Plutonium-238 & Plutonium-239 $^{\mathrm{b}}$ & Uranium-234 $^{\mathrm{a}}$ & Uranium-235 $^{\mathrm{a}}$ & Uranium-238 $^{\mathrm{b}}$ \\
\hline $\begin{array}{c}\text { Preliminary Action } \\
\text { Levels }\end{array}$ & $\mathbf{0 . 0 5}$ & $\mathbf{0 . 2 4}$ & $\mathbf{1 . 5 6}$ & $\mathbf{0 . 0 7}$ & $\mathbf{3 . 2}$ \\
\hline \hline 271D009 & $4-5$ & -- & -- & $1.09 \pm 0.15$ & $0.058 \pm 0.020$ & $1.02 \pm 0.14$ \\
\hline 271D011 & $4-5$ & $0.043 \pm 0.024$ & $\mathbf{0 . 5 2} \pm \mathbf{0 . 1 1}$ & $1.04 \pm 0.19$ & $0.049 \pm 0.029$ (LT) & $0.96 \pm 0.18$ \\
\hline 271D013 & $4-5$ & -- & -- & $1.3 \pm 0.22$ & -- & $1.01 \pm 0.18$ \\
\hline 271D014 & $4-5$ & -- & -- & $1.23 \pm 0.21$ & $0.048 \pm 0.027$ (LT) & $0.97 \pm 0.17$ \\
\hline
\end{tabular}

\footnotetext{
${ }^{a}$ Background concentration listed in Environmental Monitoring Report for the Proposed Ward Valley, California, Low-Level Radioactive Waste (LLRW) Facility (US Ecology and Atlan-Tech, 1992).

${ }^{b}$ Background concentration listed or derived in Off-Site Radiation Exposure Review Project, Phase II Soil Program (McArthur and Miller, 1989).

$\mathrm{LT}=$ Result is less than requested minimum detectable concentration (MDC), greater than sample specific MDC $--=$ Not detected above minimum reporting limit
} 


\section{A.6.3.1.8 Strontium-90}

Strontium-90 was not detected above MRLs in CAS 25-04-08 soil samples.

\section{A.6.3.2 Septic Tank Sample Results}

Results of collected septic tank content samples were compared to regulatory levels based on disposal options. If the waste has no hazardous component, the regulatory level is based on disposal options at NTS landfills and lagoons (BN, 1995; CFR, 2000b and c; NDEP, 1997a, b, and c). Any sludge or liquid waste will be solidified before disposal at NTS landfills (NDEP, 1997b). If the waste is hazardous, the release criteria are based on interpretation of the guidelines presented in the POC (BN, 1995; Alderson, 1999). For waste destined for off-site disposal, the POC radiological levels must be met to certify that the waste has no radioactivity added.

One sludge and one liquid sample were obtained from each chamber of the septic tank. The analytical suite followed the CAIP and is detailed in Section A.6.2.9. Analytical results exceeding MRLs are listed in Table A.6-6.

Several COPCs were detected in the sludge samples. Most COPCs were below regulatory limits except for TPH DRO, which were detected in sludge samples 271D022 and 271D024.

Concentrations were 1,700 and $440 \mathrm{mg} / \mathrm{kg}$, respectively. These levels exceed the NDEP action level of $100 \mathrm{mg} / \mathrm{kg}$ (NAC, 2000) for TPH.

\section{A.6.4 Contaminants of Concern}

Based on the aforementioned analytical results, COCs are present in the septic tank and possibly in a small area of leachfield soil. The septic tank contains TPH analytes in concentrations above the NDEP action level of $100 \mathrm{mg} / \mathrm{kg}$. The COC present at the southern end of the leachfield is Pu-239 at concentrations above PALs. No COCs were identified in the soil surrounding the septic tank.

\section{A.6.5 Nature and Extent of Contamination}

Total petroleum hydrocarbons are located within the septic tank sludge. Approximately 163 gal of sludge and 288 gal of liquid remained in the bottom of the inlet chamber of the septic tank. Approximately 6 gal of sludge and 168 gal of liquid remained in the bottom of the outlet chamber of 
Table A.6-6

\section{Liquid and Sludge Sample Results Detected Above Minimum Reporting Limits at CAS 25-04-08}

(Page 1 of 2 )

\begin{tabular}{|c|c|c|c|c|c|c|}
\hline $\begin{array}{c}\text { Sample } \\
\text { Identification } \\
\text { Number }\end{array}$ & Matrix & Parameter & Result & Units & Limits & Reference \\
\hline $271 \mathrm{D} 021$ & Liquid & Tritium & $1,090 \pm 290$ & $\mathrm{pCi} / \mathrm{L}$ & - & $\mathrm{N}$ \\
\hline 271D023 & Liquid & Tritium & $850 \pm 270$ & $\mathrm{pCi} / \mathrm{L}$ & - & $\mathrm{N}$ \\
\hline 271D021 & Liquid & Potassium-40 & $299 \pm 95$ & $\mathrm{pCi} / \mathrm{L}$ & - & $\mathrm{N}$ \\
\hline 271D023 & Liquid & Potassium-40 & $231 \pm 62$ & $\mathrm{pCi} / \mathrm{L}$ & - & $\mathrm{N}$ \\
\hline 271D021 & Liquid & Uranium-234 & $1.37 \pm 0.27$ & $\mathrm{pCi} / \mathrm{L}$ & 100 & NDEP, 1997b \\
\hline 271D021 & Liquid & Uranium-235 & $0.101 \pm 0.056(J)^{a}$ & $\mathrm{pCi} / \mathrm{L}$ & 100 & NDEP, 1997b \\
\hline 271D021 & Liquid & Uranium-238 & $0.5 \pm 0.14$ & $\mathrm{pCi} / \mathrm{L}$ & 100 & NDEP, 1997b \\
\hline 271D023 & Liquid & Uranium-234 & $1.45 \pm 0.29$ & $\mathrm{pCi} / \mathrm{L}$ & 100 & NDEP, 1997b \\
\hline 271D023 & Liquid & Uranium-238 & $0.82 \pm 0.20$ & $\mathrm{pCi} / \mathrm{L}$ & 100 & NDEP, 1997b \\
\hline 271D023 & Liquid & Arsenic & 0.013 & $\mathrm{mg} / \mathrm{L}$ & 5 & CFR, 2000a \\
\hline 271D022 & Sludge & Mercury** & 7.7 & $\mathrm{mg} / \mathrm{kg}$ & NA & CFR, 2000a \\
\hline 271D024 & Sludge & Mercury** & 0.59 & $\mathrm{mg} / \mathrm{kg}$ & NA & CFR, 2000a \\
\hline 271D022 & Sludge & Diesel-Range Organics & $1,700(D, M)$ & $\mathrm{mg} / \mathrm{kg}$ & 100 & NDEP, 1997b \\
\hline 271D024 & Sludge & Diesel-Range Organics & $440(D, M)$ & $\mathrm{mg} / \mathrm{kg}$ & 100 & NDEP, 1997b \\
\hline 271D022 & Sludge & 1,2,4-Trimethylbenzene & $110(\mathrm{~J})^{\mathrm{b}}$ & $\mu \mathrm{g} / \mathrm{kg}$ & NA & CFR, 2000a \\
\hline 271D022 & Sludge & 1,3,5-Trimethylbenzene & $52(\mathrm{~J})^{\mathrm{b}}$ & $\mu \mathrm{g} / \mathrm{kg}$ & NA & CFR, 2000a \\
\hline 271D022 & Sludge & Acetone & $170(\mathrm{~J})$ & $\mu \mathrm{g} / \mathrm{kg}$ & NA & CFR, 2000a \\
\hline 271D022 & Sludge & Carbon Disulfide & 230 & $\mu \mathrm{g} / \mathrm{kg}$ & NA & CFR, 2000a \\
\hline 271D022 & Sludge & Methylene Chloride & $92(\mathrm{~B})$ & $\mu \mathrm{g} / \mathrm{kg}$ & NA & CFR, 2000a \\
\hline 271D022 & Sludge & P-Isopropyltoluene & $160(J)^{b}$ & $\mu \mathrm{g} / \mathrm{kg}$ & NA & CFR, 2000a \\
\hline 271D022 & Sludge & Tritium & $7.4 \pm 2.6$ & $\mathrm{pCi} / \mathrm{g}$ & - & $\mathrm{N}$ \\
\hline 271D024 & Sludge & Tritium & $1.94 \pm 0.66$ & $\mathrm{pCi} / \mathrm{g}$ & - & $\mathrm{N}$ \\
\hline 271D022 & Sludge & Gasoline-Range Organics & $6.7(\mathrm{~J})^{\mathrm{c}}$ & $\mathrm{mg} / \mathrm{kg}$ & 100 & NDEP, 1997b \\
\hline 271D024 & Sludge & Gasoline-Range Organics & $1.7(\mathrm{H})$ & $\mathrm{mg} / \mathrm{kg}$ & 100 & NDEP, 1997b \\
\hline 271D022 & Sludge & Potassium-40 & $21.2 \pm 5.8$ & $\mathrm{pCi} / \mathrm{g}$ & - & $\mathrm{N}$ \\
\hline 271D022 & Sludge & Lead-212 & $1.01 \pm 0.42$ & $\mathrm{pCi} / \mathrm{g}$ & - & $\mathrm{N}$ \\
\hline 271D024 & Sludge & Bismuth-214 & $0.8 \pm 0.34$ & $\mathrm{pCi} / \mathrm{g}$ & - & $\mathrm{N}$ \\
\hline 271D024 & Sludge & Potassium-40 & $28.3 \pm 6.1$ & $\mathrm{pCi} / \mathrm{g}$ & - & $\mathrm{N}$ \\
\hline $271 \mathrm{D} 024$ & Sludge & Lead-212 & $1.62 \pm 0.37$ & $\mathrm{pCi} / \mathrm{g}$ & - & $\mathrm{N}$ \\
\hline 271D024 & Sludge & Lead-214 & $1.16 \pm 0.31$ & $\mathrm{pCi} / \mathrm{g}$ & - & $\mathrm{N}$ \\
\hline 271D024 & Sludge & Thallium-208 & $0.41 \pm 0.17$ & $\mathrm{pCi} / \mathrm{g}$ & - & $\mathrm{N}$ \\
\hline $271 \mathrm{D} 022$ & Sludge & Uranium-234 & $2.9 \pm 0.42$ & $\mathrm{pCi} / \mathrm{g}$ & 100 & NDEP, 1997b \\
\hline
\end{tabular}


Table A.6-6

\section{Liquid and Sludge Sample Results Detected Above Minimum Reporting Limits at CAS 25-04-08}

(Page 2 of 2)

\begin{tabular}{|c|c|c|c|c|c|c|}
\hline $\begin{array}{c}\text { Sample } \\
\text { Identification } \\
\text { Number }\end{array}$ & Matrix & Parameter & Result & Units & Limits & Reference \\
\hline 271D022 & Sludge & Uranium-235 & $0.151 \pm 0.049$ & $\mathrm{pCi} / \mathrm{g}$ & 100 & NDEP, 1997b \\
\hline 271D022 & Sludge & Uranium-238 & $1.54 \pm 0.24$ & $\mathrm{pCi} / \mathrm{g}$ & 100 & NDEP, 1997b \\
\hline $271 \mathrm{D} 024$ & Sludge & Uranium-234 & $1.83 \pm 0.27$ & $\mathrm{pCi} / \mathrm{g}$ & 100 & NDEP, 1997b \\
\hline 271D024 & Sludge & Uranium-235 & $0.086 \pm 0.032$ & $\mathrm{pCi} / \mathrm{g}$ & 100 & NDEP, 1997b \\
\hline 271D024 & Sludge & Uranium-238 & $1.18 \pm 0.19$ & $\mathrm{pCi} / \mathrm{g}$ & 100 & NDEP, 1997b \\
\hline 271D022 & Sludge & Arsenic ${ }^{* *}$ & 12 & $\mathrm{mg} / \mathrm{kg}$ & NA & CFR, 2000a \\
\hline 271D022 & Sludge & Barium** & 100 & $\mathrm{mg} / \mathrm{kg}$ & NA & CFR, 2000a \\
\hline $271 \mathrm{D} 022$ & Sludge & Cadmium $^{\star *}$ & 6.3 & $\mathrm{mg} / \mathrm{kg}$ & NA & CFR, 2000a \\
\hline $271 \mathrm{D} 022$ & Sludge & Chromium** & 13 & $\mathrm{mg} / \mathrm{kg}$ & NA & CFR, 2000a \\
\hline $271 \mathrm{D} 022$ & Sludge & Lead $^{\star \star}$ & 82 & $\mathrm{mg} / \mathrm{kg}$ & NA & CFR, 2000a \\
\hline 271D022 & Sludge & Silver ${ }^{* *}$ & $9.8(\mathrm{~J})^{\mathrm{d}}$ & $\mathrm{mg} / \mathrm{kg}$ & NA & CFR, 2000a \\
\hline $271 \mathrm{D} 024$ & Sludge & Arsenic ${ }^{\star *}$ & 8.4 & $\mathrm{mg} / \mathrm{kg}$ & NA & CFR, 2000a \\
\hline 271D024 & Sludge & Barium** & 130 & $\mathrm{mg} / \mathrm{kg}$ & NA & CFR, 2000a \\
\hline 271D024 & Sludge & Cadmium** & 1.4 & $\mathrm{mg} / \mathrm{kg}$ & NA & CFR, 2000a \\
\hline $271 \mathrm{D} 024$ & Sludge & Chromium** & 8.7 & $\mathrm{mg} / \mathrm{kg}$ & NA & CFR, 2000a \\
\hline $271 \mathrm{D} 024$ & Sludge & Lead $^{* *}$ & 20 & $\mathrm{mg} / \mathrm{kg}$ & NA & CFR, 2000a \\
\hline 271D024 & Sludge & Silver** & $4.1(\mathrm{~J})^{\mathrm{d}}$ & $\mathrm{mg} / \mathrm{kg}$ & NA & CFR, 2000a \\
\hline 271D021 & Liquid & Gross Alpha & $2.1 \pm 4.3$ & $\mathrm{pCi} / \mathrm{L}$ & $7.4^{\mathrm{e}}$ & NA \\
\hline 271D021 & Liquid & Gross Beta & $139 \pm 20$ & $\mathrm{pCi} / \mathrm{L}$ & $6.9^{\mathrm{e}}$ & NA \\
\hline 271D023 & Liquid & Gross Alpha & $4.0 \pm 5.2$ & $\mathrm{pCi} / \mathrm{L}$ & $8.7^{\mathrm{e}}$ & NA \\
\hline 271D023 & Liquid & Gross Beta & $190 \pm 27$ & $\mathrm{pCi} / \mathrm{L}$ & $9.9^{\mathrm{e}}$ & NA \\
\hline
\end{tabular}

${ }^{\mathrm{a}}$ Qualifier added to laboratory data; record accepted. Duplicate relative percent difference over the control limits.

${ }^{b}$ Qualifier added to laboratory data; record accepted. Internal standard area count exceeded the quality control limits. Matrix effects may exist.

${ }^{\circ}$ Qualifier added to laboratory data; record accepted. Surrogate recovery exceeded the lower limits.

${ }^{d}$ Qualifier added to laboratory data; record accepted. Spike recovery was outside control limits. Duplicate precision analyses were outside control limits.

${ }^{\mathrm{e}}$ Maximum detectable concentration

$* *=$ TCLP below minimum reporting limit

$\mathrm{J}=$ Estimated value

$\mathrm{D}=\mathrm{A}$ pattern resembling diesel was detected in this sample.

$M=$ Motor oil

$\mathrm{N}=$ No limit established (NDEP, 1997b)

$\mathrm{NA}=$ Not applicable

$\mathrm{H}=$ The fuel pattern was in the heavier end of the retention time window for the analyte of interest.

$B=$ Value less than the instrument detection limit, but greater than or equal to the contract required detection limit 
the septic tank. Approximately $3 \mathrm{yd}^{3}$ of radiologically contaminated soil was identified in the southern portion of the leachfield.

\section{A.6.6 Revised Conceptual Model}

No variations in the conceptual model were identified. 


\section{A.7.0 Engine Test Stand No.1 Septic System (CAS 25-04-09)}

The ETS-1 septic system was designed to receive sanitary effluent generated by activities from Building 3340 (Test Cell Building), Building 3330 (Fill Station/Tank Farm and Forward Control Area), Building 3320 (Utility Equipment Building/Substation Area), Building 3319 (Maintenance and Supply Building/Welding and Machine Shop), Building 3310 (Control Point Building), and as many as twenty-two trailers (no longer present). The septic system is located approximately $10 \mathrm{ft}$ south of the southernmost fence of the ETS-1 complex. The site is comprised of a leachfield, septic tank, and associated piping. More detail is provided in the CAIP (DOE/NV, 2001).

\section{A.7.1 Corrective Action Investigation}

Seventy-seven investigation samples, listed in Table A.7-1, were collected during investigation activities conducted at CAS 25-04-09. The planned and actual sample locations are shown in Figure A.7-1. The specific CAI activities conducted to meet CAIP requirements at CAS 25-04-09 are described in Table A.2-1.

\section{A.7.1.1 Deviations}

There were no deviations from the planned investigation of CAS 25-04-09.

\section{A.7.2 Investigation Results}

The following subsections provide details of the inspection and sampling of leachfield features, field-screening results, and sample selection and analysis.

\section{A.7.2.1 Septic Tank Contents}

The contents of the septic tank were sampled according to the CAIP. The septic tank was concrete, horizontal cylindrical-shaped with a flat top. The tank was two-chambered, with a capacity of 1,907 gal. The tank was accessed by two concrete manholes located at the ground surface. The interior dimensions of the tank were approximately $15.5 \mathrm{ft}$ (length) by $4.3 \mathrm{ft}$ (width) by $7.25 \mathrm{ft}$ (depth). One sediment sample was collected from each of the two chambers. The sediment samples 
Table A.7-1

Samples Collected at CAS 25-04-09

(Page 1 of 4 )

\begin{tabular}{|c|c|c|c|c|c|c|c|c|c|c|c|c|c|}
\hline \multirow[b]{2}{*}{$\begin{array}{c}\text { Sample } \\
\text { Identification } \\
\text { Number }\end{array}$} & \multirow[b]{2}{*}{$\begin{array}{l}\text { Sample } \\
\text { Location }\end{array}$} & \multirow[b]{2}{*}{$\begin{array}{l}\text { Sample } \\
\text { Matrix }\end{array}$} & \multirow[b]{2}{*}{$\begin{array}{c}\text { Depth } \\
\text { (ft bgs) }\end{array}$} & \multirow[b]{2}{*}{ Purpose } & \multicolumn{9}{|c|}{ Analyses } \\
\hline & & & & & 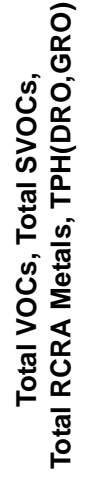 & 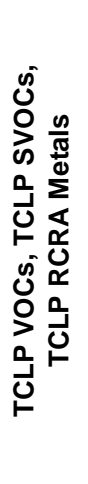 & 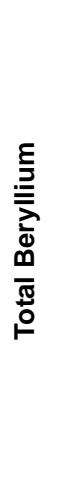 & Ö & 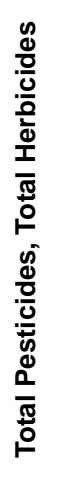 & 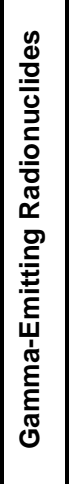 & 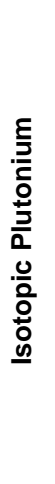 & 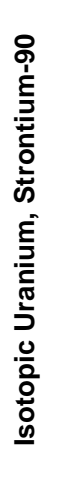 & 鹃 \\
\hline 271E001 & E01 & Soil & $8-9$ & Integrity & $\mathrm{X}$ & & & $\mathrm{X}$ & & & & & \\
\hline 271E002 & E01 & Soil & $10.5-11.5$ & Integrity & \multicolumn{9}{|c|}{ Not Submitted for Analyses ${ }^{a}$} \\
\hline 271E003 & E02 & Soil & 6 & Environmental & \multicolumn{9}{|c|}{ Not Submitted for Analyses ${ }^{a}$} \\
\hline 271E004 & E02 & Soil & $7.3-8.3$ & Integrity & $\mathrm{X}$ & & & $x$ & & $\mathrm{X}$ & $\mathrm{X}$ & $\mathrm{x}$ & \\
\hline 271E005 & E02 & Soil & $10-11$ & Integrity & \multicolumn{9}{|c|}{ Not Submitted for Analyses ${ }^{a}$} \\
\hline 271E006 & E04 & Soil & $3.6-4.6$ & Environmental & $\mathrm{x}$ & & & $\mathrm{x}$ & & $\mathrm{X}$ & $\mathrm{x}$ & $x$ & \\
\hline 271E007 & E04 & Soil & $3.6-4.6$ & $\begin{array}{l}\text { Duplicate of } \\
\text { 271E006 }\end{array}$ & $x$ & & & $\mathrm{X}$ & & $\mathrm{X}$ & $\mathrm{X}$ & $\mathrm{X}$ & \\
\hline 271E008 & E04 & Soil & $6.1-7.1$ & Environmental & \multicolumn{9}{|c|}{ Not Submitted for Analyses ${ }^{a}$} \\
\hline 271E009 & E05 & Soil & $3.6-4.6$ & Environmental & $\mathrm{X}$ & & & $\mathrm{X}$ & & & & & \\
\hline 271E010 & E05 & Soil & $6.1-7.1$ & Environmental & \multicolumn{9}{|c|}{ Not Submitted for Analyses ${ }^{a}$} \\
\hline 271E011 & E03 & Soil & $4.5-5.5$ & Environmental & $\mathrm{X}$ & & & $X$ & & $\mathrm{X}$ & $x$ & $x$ & \\
\hline $271 \mathrm{E} 012$ & E03 & Soil & $7-8$ & Environmental & \multicolumn{9}{|c|}{ Not Submitted for Analyses ${ }^{a}$} \\
\hline $271 \mathrm{E} 013$ & E10 & Soil & $3-4$ & Environmental & $x$ & & & $x$ & & & & & \\
\hline $271 \mathrm{E} 014$ & E10 & Soil & $5.5-6.5$ & Environmental & \multicolumn{9}{|c|}{ Not Submitted for Analyses ${ }^{a}$} \\
\hline $271 \mathrm{E} 015$ & E06 & Soil & $2.7-3.7$ & Environmental & $x$ & & & $x$ & & & & & \\
\hline 271E016 & E06 & Soil & $5.2-6.2$ & Environmental & \multicolumn{9}{|c|}{ Not Submitted for Analyses ${ }^{a}$} \\
\hline 271E017 & E11 & Soil & $1.5-2.5$ & Environmental & $x$ & & & $x$ & & & & & \\
\hline $271 \mathrm{E} 018$ & E11 & Soil & $4-5$ & Environmental & \multicolumn{9}{|c|}{ Not Submitted for Analyses ${ }^{a}$} \\
\hline 271E019 & E12 & Soil & $2-3$ & Environmental & $\mathrm{X}$ & & & $x$ & & $\mathrm{x}$ & $x$ & $x$ & \\
\hline 271E020 & E12 & Soil & $4.5-5.5$ & Environmental & \multicolumn{9}{|c|}{ Not Submitted for Analyses ${ }^{a}$} \\
\hline 271E021 & E08 & Soil & $2.7-3.7$ & $\begin{array}{c}\text { Environmental } \\
\text { MS/MSD }\end{array}$ & $\mathrm{X}$ & & & $\mathrm{X}$ & & $\bar{X}$ & $x$ & $x$ & \\
\hline 271E022 & E08 & Soil & $5.5-6.5$ & Environmental & \multicolumn{9}{|c|}{ Not Submitted for Analyses ${ }^{a}$} \\
\hline 271E023 & E07 & Soil & $4-5$ & Environmental & $\mathrm{X}$ & & & $x$ & & & & & \\
\hline $271 \mathrm{E} 024$ & E07 & Soil & $6.5-7.5$ & Environmental & \multicolumn{9}{|c|}{ Not Submitted for Analyses ${ }^{a}$} \\
\hline $271 \mathrm{E} 025$ & E09 & Soil & $3.25-4.25$ & Environmental & $X$ & & & $\mathrm{X}$ & & & & & \\
\hline $271 \mathrm{E} 026$ & E09 & Soil & $5.75-6.75$ & Environmental & \multicolumn{9}{|c|}{ Not Submitted for Analyses ${ }^{a}$} \\
\hline
\end{tabular}


Table A.7-1

Samples Collected at CAS 25-04-09

(Page 2 of 4 )

\begin{tabular}{|c|c|c|c|c|c|c|c|c|c|c|c|c|c|}
\hline \multirow[b]{2}{*}{$\begin{array}{c}\text { Sample } \\
\text { Identification } \\
\text { Number }\end{array}$} & \multirow[b]{2}{*}{$\begin{array}{c}\text { Sample } \\
\text { Location }\end{array}$} & \multirow[b]{2}{*}{$\begin{array}{c}\text { Sample } \\
\text { Matrix }\end{array}$} & \multirow[b]{2}{*}{$\begin{array}{c}\text { Depth } \\
\text { (ft bgs) }\end{array}$} & \multirow[b]{2}{*}{ Purpose } & \multicolumn{9}{|c|}{ Analyses } \\
\hline & & & & & 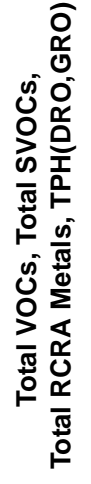 & 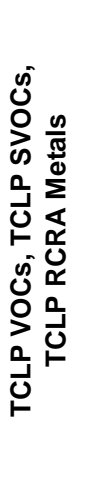 & 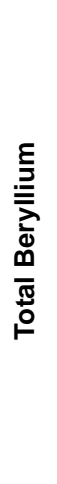 & 品 & 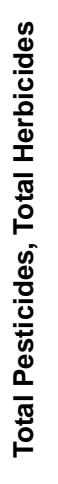 & 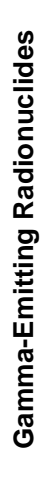 & 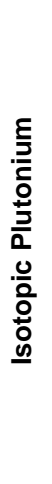 & 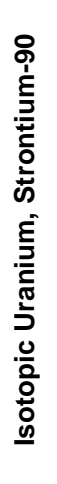 & $\stackrel{E}{\underline{\Xi}}$ \\
\hline $271 \mathrm{E} 027$ & E28 & Soil & $3.25-4.25$ & Environmental & $\bar{X}$ & & & $\mathrm{X}$ & & & & & \\
\hline $271 \mathrm{E} 028$ & E28 & Soil & $5.75-6.75$ & Environmental & \multicolumn{9}{|c|}{ Not Submitted for Analyses ${ }^{a}$} \\
\hline 271E029 & E19 & Soil & $3.75-4.75$ & Environmental & $\mathrm{x}$ & & & $\bar{x}$ & & & & & \\
\hline 271E030 & E19 & Soil & $6.25-7.25$ & Environmental & \multicolumn{9}{|c|}{ Not Submitted for Analyses ${ }^{a}$} \\
\hline $271 \mathrm{E} 031$ & E17 & Soil & $3.75-4.75$ & Environmental & $\mathrm{X}$ & & & $\bar{x}$ & & & & & \\
\hline $271 \mathrm{E} 032$ & E17 & Soil & $6.25-7.25$ & Environmental & \multicolumn{9}{|c|}{ Not Submitted for Analyses ${ }^{a}$} \\
\hline 271E033 & E21 & Soil & $2.9-3.9$ & Environmental & $\mathrm{X}$ & & & $\mathrm{X}$ & & & & & \\
\hline $271 \mathrm{E} 034$ & E21 & Soil & $5.4-6.4$ & Environmental & \multicolumn{9}{|c|}{ Not Submitted for Analyses ${ }^{a}$} \\
\hline 271E035 & E20 & Soil & $2.7-3.7$ & Environmental & $\mathrm{X}$ & & & $\mathrm{X}$ & & $\mathrm{X}$ & $\mathrm{X}$ & $\mathrm{X}$ & \\
\hline $271 \mathrm{E} 036$ & E20 & Soil & $5.2-6.2$ & Environmental & $\mathrm{x}$ & & & $\mathrm{x}$ & & & & & \\
\hline 271E037 & E20 & Soil & $8.2-9.2$ & Environmental & \multicolumn{9}{|c|}{ Not Submitted for Analyses ${ }^{a}$} \\
\hline 271E038 & E22 & Soil & $2-3$ & Environmental & $\mathrm{X}$ & & & $x$ & & & & & \\
\hline 271E039 & E22 & Soil & $4.5-5.5$ & Environmental & \multicolumn{9}{|c|}{ Not Submitted for Analyses ${ }^{a}$} \\
\hline $271 \mathrm{E} 040$ & E23 & Soil & $2.9-3.9$ & Environmental & $\mathrm{X}$ & & & $\bar{X}$ & & & & & \\
\hline $271 \mathrm{E} 041$ & E23 & Soil & $5.4-6.4$ & Environmental & $\mathrm{X}$ & & & $\mathrm{X}$ & & & & & \\
\hline 271E042 & E23 & Soil & $8.4-9.4$ & Environmental & \multicolumn{9}{|c|}{ Not Submitted for Analyses ${ }^{a}$} \\
\hline $271 \mathrm{E} 043$ & E18 & Soil & $2.8-3.8$ & Environmental & $\mathrm{x}$ & & & $\mathrm{X}$ & & $\mathrm{X}$ & $\mathrm{x}$ & $\bar{x}$ & \\
\hline $271 \mathrm{E} 044$ & E18 & Soil & $2.8-3.8$ & $\begin{array}{c}\text { Duplicate of } \\
271 \mathrm{E} 043\end{array}$ & $x$ & & & $\mathrm{X}$ & & $\mathrm{X}$ & $\mathrm{x}$ & $\mathrm{X}$ & \\
\hline 271E045 & E18 & Soil & $5.3-6.3$ & Environmental & \multicolumn{9}{|c|}{ Not Submitted for Analyses ${ }^{a}$} \\
\hline 271E046 & E16 & Soil & $2.9-3.9$ & Environmental & $\mathrm{X}$ & & & $\mathrm{X}$ & & & & & \\
\hline $271 \mathrm{E} 047$ & E16 & Soil & $5.4-6.4$ & Environmental & \multicolumn{9}{|c|}{ Not Submitted for Analyses ${ }^{a}$} \\
\hline 271E048 & E14 & Soil & $4-5$ & Environmental & $\mathrm{x}$ & & & $\bar{x}$ & & & & & \\
\hline 271E049 & E14 & Soil & $6.5-7.5$ & Environmental & \multicolumn{9}{|c|}{ Not Submitted for Analyses ${ }^{a}$} \\
\hline $271 \mathrm{E} 050$ & E13 & Soil & $3.5-4.5$ & Environmental & $\mathrm{X}$ & & & $\mathrm{X}$ & & & & & \\
\hline 271E051 & E13 & Soil & $6-7$ & Environmental & \multicolumn{9}{|c|}{ Not Submitted for Analyses ${ }^{a}$} \\
\hline 271E052 & E01 & Sediment & $7.2-7.6$ & Septic Tank & $\mathrm{X}$ & $\bar{X}$ & & $\mathrm{X}$ & & $\mathrm{X}$ & $\mathrm{X}$ & $\mathrm{X}$ & $\bar{x}$ \\
\hline 271E053 & E02 & Sediment & $7.2-7.6$ & Septic Tank & $\mathrm{X}$ & $\bar{X}$ & & $\mathrm{X}$ & & $\mathrm{X}$ & $\mathrm{X}$ & $\mathrm{X}$ & $\bar{x}$ \\
\hline
\end{tabular}


Table A.7-1

Samples Collected at CAS 25-04-09

(Page 3 of 4)

\begin{tabular}{|c|c|c|c|c|c|c|c|c|c|c|c|c|c|}
\hline \multirow[b]{2}{*}{$\begin{array}{c}\text { Sample } \\
\text { Identification } \\
\text { Number }\end{array}$} & \multirow[b]{2}{*}{$\begin{array}{l}\text { Sample } \\
\text { Location }\end{array}$} & \multirow[b]{2}{*}{$\begin{array}{c}\text { Sample } \\
\text { Matrix }\end{array}$} & \multirow[b]{2}{*}{$\begin{array}{c}\text { Depth } \\
\text { (ft bgs) }\end{array}$} & \multirow[b]{2}{*}{ Purpose } & \multicolumn{9}{|c|}{ Analyses } \\
\hline & & & & & 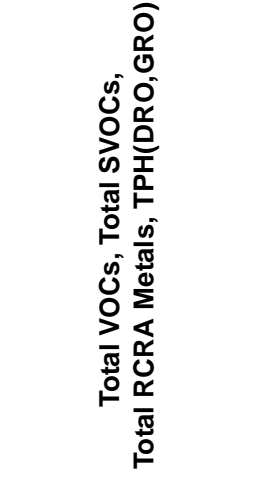 & 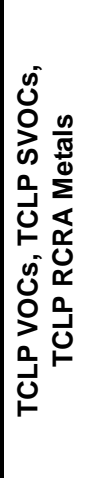 & 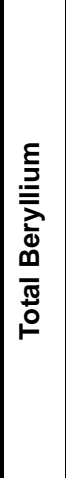 & Ơ̊ & 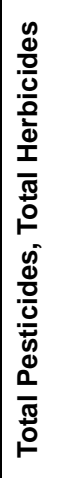 & 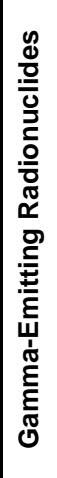 & 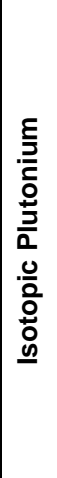 & 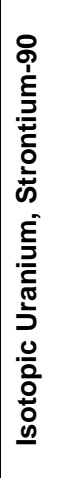 & 至 \\
\hline 271E054 & E15 & Soil & $3.9-4.9$ & Environmental & $\bar{x}$ & & & $\mathrm{X}$ & & & & & \\
\hline 271E055 & E15 & Soil & $6.4-7.4$ & Environmental & \multicolumn{9}{|c|}{ Not Submitted for Analyses ${ }^{a}$} \\
\hline 271E056 & E32 & Soil & $2.5-3.5$ & Environmental & $\mathrm{X}$ & & & $\mathrm{x}$ & & & & & \\
\hline $271 \mathrm{E} 057$ & E32 & Soil & $5-6$ & Environmental & \multicolumn{9}{|c|}{ Not Submitted for Analyses ${ }^{a}$} \\
\hline 271E058 & E31 & Soil & $3-4$ & Environmental & $\mathrm{X}$ & & & $\mathrm{X}$ & & & & & \\
\hline 271E059 & E31 & Soil & $5.5-6.5$ & Environmental & \multicolumn{9}{|c|}{ Not Submitted for Analyses ${ }^{a}$} \\
\hline $271 \mathrm{E} 060$ & E29 & Soil & $2.9-3.9$ & $\begin{array}{l}\text { Environmental } \\
\text { MS/MSD }\end{array}$ & $x$ & & & $\mathrm{X}$ & & $\mathrm{X}$ & $\mathrm{X}$ & $X$ & \\
\hline $271 \mathrm{E} 061$ & E29 & Soil & $5.4-6.4$ & Environmental & \multicolumn{9}{|c|}{ Not Submitted for Analyses ${ }^{a}$} \\
\hline $271 \mathrm{E} 062$ & E30 & Soil & $2.7-3.7$ & Environmental & $\mathrm{X}$ & & & $\mathrm{X}$ & & & & & \\
\hline 271E063 & E30 & Soil & $5.2-6.2$ & Environmental & \multicolumn{9}{|c|}{ Not Submitted for Analyses ${ }^{a}$} \\
\hline 271E064 & E26 & Soil & $2.7-3.7$ & Environmental & $\mathrm{X}$ & & & $X$ & & & & & \\
\hline 271E065 & E26 & Soil & $5.2-6.2$ & Environmental & \multicolumn{9}{|c|}{ Not Submitted for Analyses ${ }^{a}$} \\
\hline 271E066 & E25 & Soil & $2.8-3.8$ & Environmental & $\mathrm{X}$ & & & $\mathrm{X}$ & & & & & \\
\hline 271E067 & E25 & Soil & $5.3-6.3$ & Environmental & \multicolumn{9}{|c|}{ Not Submitted for Analyses ${ }^{a}$} \\
\hline 271E068 & E24 & Soil & $3.3-4.3$ & Environmental & $\mathrm{X}$ & & & $\mathrm{x}$ & & & & & \\
\hline $271 \mathrm{E} 069$ & E24 & Soil & $5.8-6.8$ & Environmental & \multicolumn{9}{|c|}{ Not Submitted for Analyses ${ }^{a}$} \\
\hline $271 \mathrm{E} 070$ & E27 & Soil & $2.9-3.9$ & Environmental & $\mathrm{X}$ & & & $\mathrm{X}$ & & $\mathrm{X}$ & $\mathrm{x}$ & $\mathrm{X}$ & \\
\hline 271E071 & E27 & Soil & $5.4-6.4$ & Environmental & \multicolumn{9}{|c|}{ Not Submitted for Analyses ${ }^{a}$} \\
\hline 271E072 & E33 & Soil & $3-3.5$ & Geotechnical & \multicolumn{9}{|c|}{ Not Submitted for Analyses ${ }^{b}$} \\
\hline 271E073 & E38 & Soil & $2.8-3.8$ & Environmental & Total RCRA Metals & & & & & & & & \\
\hline 271E074 & E39 & Soil & $2.8-3.8$ & Environmental & Total RCRA Metals & & & & & & & & \\
\hline $271 \mathrm{E} 075$ & $\mathrm{E} 40$ & Soil & $2.8-3.8$ & Environmental & Total RCRA Metals & & & & & & & & \\
\hline 271E076 & $\mathrm{E} 41$ & Soil & $2.8-3.8$ & Environmental & Total RCRA Metals & & & & & & & & \\
\hline 271E077 & $\mathrm{E} 42$ & Soil & $2.8-3.8$ & Environmental & Total RCRA Metals & & & & & & & & \\
\hline 271E301 & NA & Water & NA & Trip Blank & VOC only & & & & & & & & \\
\hline 271E302 & NA & Water & NA & Trip Blank & VOC only & & & & & & & & \\
\hline $271 \mathrm{E} 303$ & NA & Water & NA & Trip Blank & VOC only & & & & & & & & \\
\hline
\end{tabular}


Table A.7-1

Samples Collected at CAS 25-04-09

(Page 4 of 4 )

\begin{tabular}{|c|c|c|c|c|c|c|c|c|c|c|c|c|c|}
\hline \multirow[b]{2}{*}{$\begin{array}{c}\text { Sample } \\
\text { Identification } \\
\text { Number }\end{array}$} & \multirow[b]{2}{*}{$\begin{array}{l}\text { Sample } \\
\text { Location }\end{array}$} & \multirow[b]{2}{*}{$\begin{array}{c}\text { Sample } \\
\text { Matrix }\end{array}$} & \multirow[b]{2}{*}{$\begin{array}{c}\text { Depth } \\
\text { (ft bgs) }\end{array}$} & \multirow[b]{2}{*}{ Purpose } & \multicolumn{9}{|c|}{ Analyses } \\
\hline & & & & & 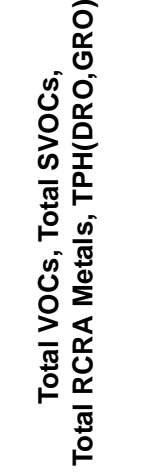 & 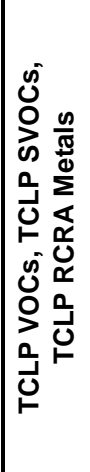 & 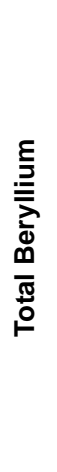 & 品 & 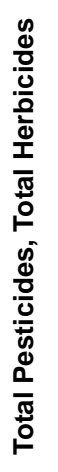 & 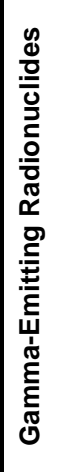 & 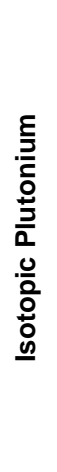 & 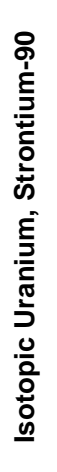 & $\stackrel{E}{\underline{3}}$ \\
\hline 271E304 & NA & Water & NA & Trip Blank & VOC only & & & & & & & & \\
\hline 271E305 & NA & Water & NA & Trip Blank & VOC only & & & & & & & & \\
\hline $271 \mathrm{E} 306$ & NA & Water & NA & Trip Blank & VOC only & & & & & & & & \\
\hline $271 \mathrm{E} 307$ & NA & Water & NA & Trip Blank & VOC only & & & & & & & & \\
\hline 271E308 & NA & Water & NA & Field Blank & $x$ & & & $x$ & & $x$ & $x$ & $x$ & \\
\hline 271E309 & NA & Water & NA & Trip Blank & VOC only & & & & & & & & \\
\hline 271E310 & NA & Water & NA & Trip Blank & VOC only & & & & & & & & \\
\hline 271E311 & NA & Water & NA & Trip Blank & VOC only & & & & & & & & \\
\hline 271E312 & NA & Water & NA & Trip Blank & VOC only & & & & & & & & \\
\hline $271 \mathrm{E} 313$ & NA & Water & NA & Rinsate & $x$ & & & $x$ & & $x$ & $x$ & $x$ & $\bar{x}$ \\
\hline $271 E 314$ & NA & Water & NA & Trip Blank & VOC only & & & & & & & & \\
\hline 271E315 & NA & Water & NA & Trip Blank & VOC only & & & & & & & & \\
\hline
\end{tabular}

${ }^{a}$ The samples were collected, field screened, and returned to the site for disposal.

${ }^{\mathrm{b}}$ The sample was collected, field screened, and is being stored for possible geotechnical analysis.

NA $=$ Not applicable

MS/MSD = Matrix spike/matrix spike duplicate 


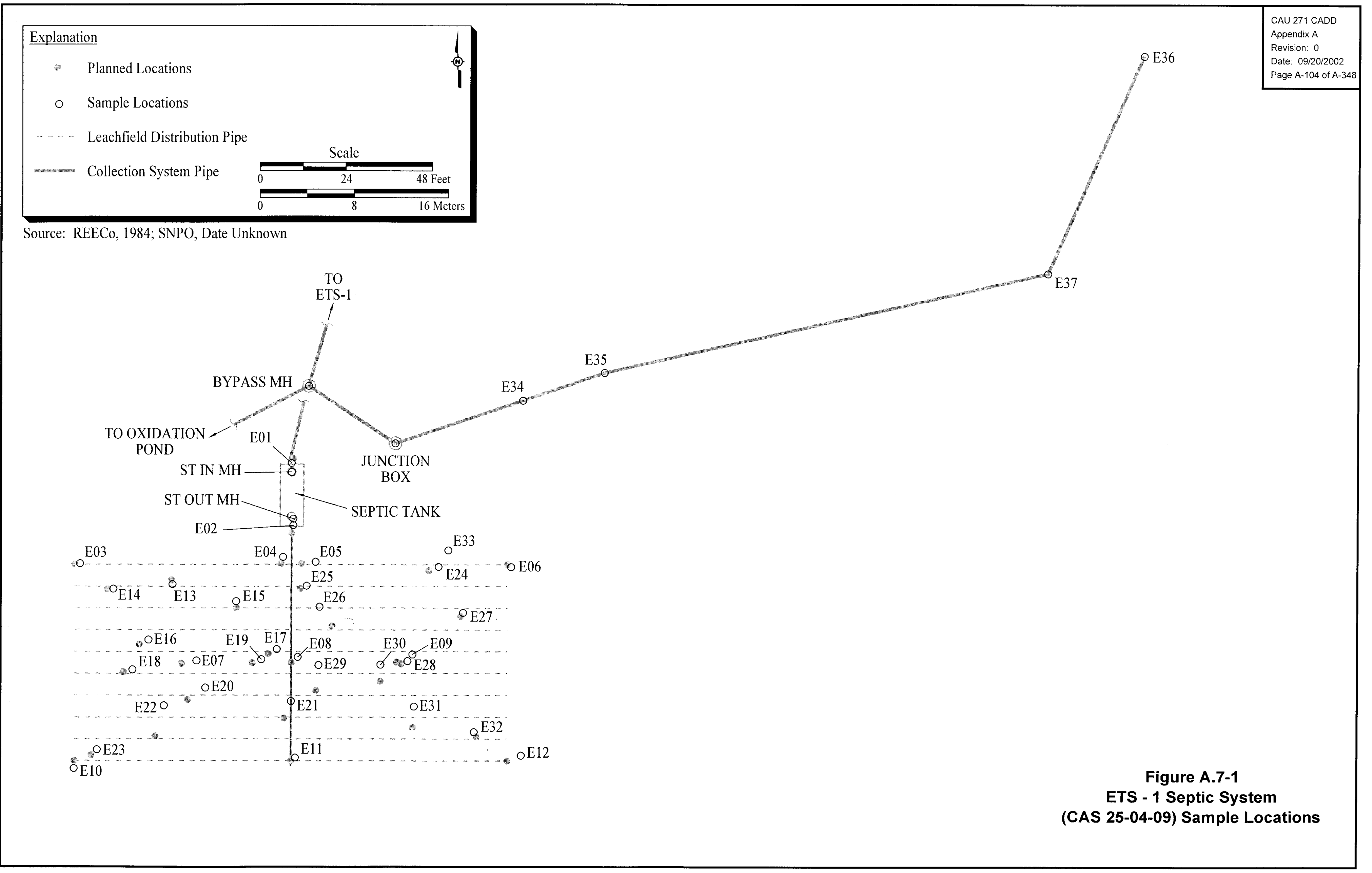


were dry. Visual inspection revealed that a maximum thickness of $0.4 \mathrm{ft}$ ( 55 gal) of sediment remained in the bottom of each chamber in the tank.

\section{A.7.2.2 Septic Tank Integrity Soil Sampling}

Four integrity samples were collected by excavating adjacent to the influent and effluent ends of the septic tank. The upper samples (271E001 and 271E004) were submitted for laboratory analysis. A photograph was taken to document the exterior condition of the septic tank and to document the integrity sampling (Figure A.7-2).

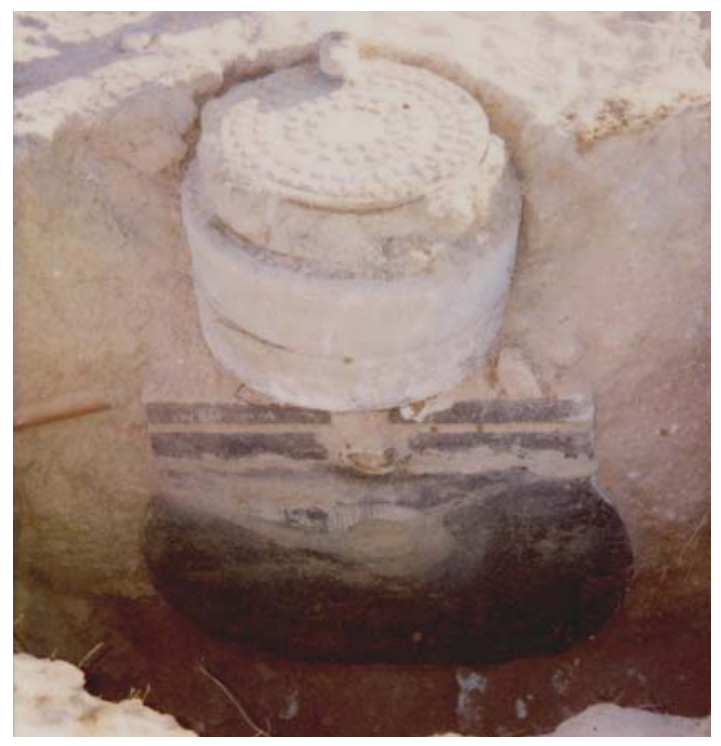

Figure A.7-2

CAS 25-04-09 Septic Tank, Integrity Sample and Inlet End (Photograph Taken 12-04-2001)

\section{A.7.2.3 Leachfield Excavation Soil Sampling}

Backhoe excavations were conducted to access sampling horizons at the biased and random locations presented in the CAIP. Excavations provided a visual verification of distribution pipes and enabled soil samples to be collected from appropriate intervals beneath the pipes, as specified by the CAIP. Sixty-five soil samples were collected from the planned locations excavated within the leachfield. 
These samples were collected from intervals 0 to $1 \mathrm{ft}, 2.5$ to $3.5 \mathrm{ft}$, and 6.5 to $7.5 \mathrm{ft}$ below the leachrock/native soil interface. The interface was found at depths ranging from 1.4 to $4.5 \mathrm{ft}$ bgs. Thirty-four samples were submitted for laboratory analysis. In addition, two QC soil duplicates and two MS/MSD samples were collected and analyzed. A geotechnical sample was collected outside the boundary of the leachfield. The sample will be sent to a laboratory for geotechnical analysis, if necessary.

\section{A.7.2.4 Collection System Pipe Inspections}

As discussed in the CAIP, the sewage line from the ETS-1 facility was rerouted to oxidation ponds, bypassing the septic system. However, some collection system pipes, including a line to trailer hook-ups, required inspection. Access points for inspection of these pipes by video mole survey were present (i.e., manhole, risers) and additional points were created via backhoe excavation.

The video mole was passed down through a riser (designated as location E34) located $32 \mathrm{ft}$ northeast of a junction box (Figure A.7-1). The video mole inspection proceeded southwest to the junction box without encountering an obstruction. An obstruction was encountered at $13 \mathrm{ft}$ when the video mole was passed to the northeast from location E34. The obstruction was reported to be an animal nest. An excavation (E35) was made $36 \mathrm{ft}$ northeast of E34 in an attempt to pass the obstruction. The video mole was passed down the pipe to the southwest for the entire $36 \mathrm{ft}$. It was also able to be passed upstream (northeast) from location E35 for a distance of $119 \mathrm{ft}$ to a blockage. The video mole was passed through a riser (designated as location E36) located $195 \mathrm{ft}$ northeast of E35. The video mole was passed southwest from location E36 for $33 \mathrm{ft}$, where an obstruction was encountered. An excavation (E37) was made at a 30 degree elbow in an attempt to complete video mole activities. The video mole was passed $11.5 \mathrm{ft}$ downstream (southwest) to where the blockage noted during the E35 inspection was encountered. This blockage appears to be sand and debris that accumulated downstream of the 30 degree elbow.

Some sediment was identified in the piping, but it was not appropriate or adequate material to be sampled. No unidentified offshoot lines were observed. The amount of sediment and plant and animal matter found in the collection system pipe segments was most likely due to the fact that these pipes had several access points (trailer risers) exposed at the ground surface. Portions of the pipe at 
the inspected locations (designated E34, E35, E36, and E37) were radiologically surveyed. See Section A.7.2.7 for further details regarding radiological results.

In addition to the collection system components pipe segments, the manhole providing a bypass of the sewer line leading from the ETS-1 facilities to the active sewage lagoons was inspected. Visual inspection confirmed that lines entered from the ETS-1 facilities and the trailer connection risers, and one line exited to the sewage lagoons. Figure A.7-3 depicts the interior of this manhole. This inspection confirmed that the CAS 25-04-09 septic system had been bypassed.

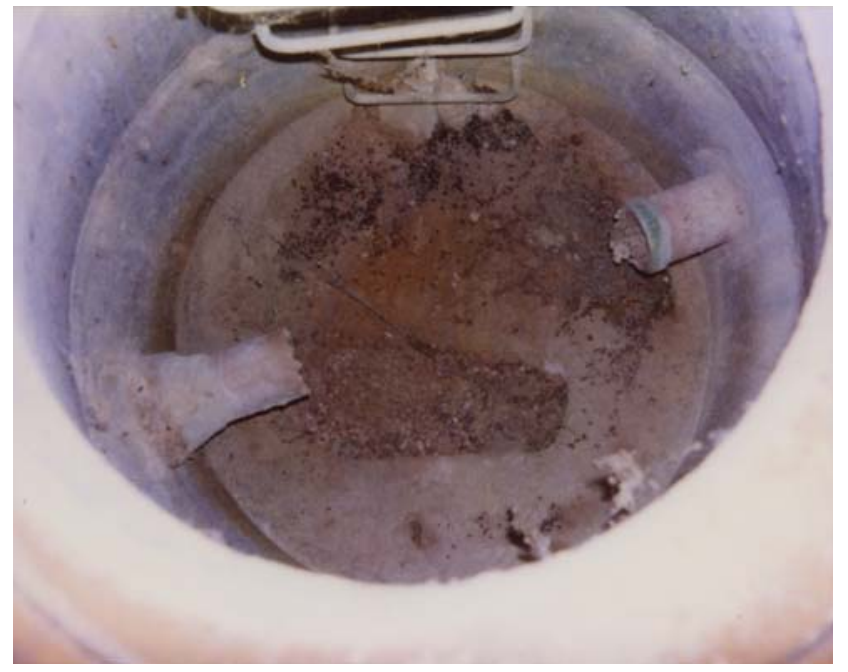

Figure A.7-3

CAS 25-04-09 Manhole Leading to Active Sewage Lagoons (Photograph Taken 12-04-2001)

\section{A.7.2.5 Field-Screening Results}

Soil samples were screened for VOCs and alpha and beta/gamma radioactivity. The field readings were compared to FSLs to guide sampling decisions and determine which samples were to be submitted for laboratory analysis. No VOCs greater than FSLs were found during soil sample screening. The results of radiological field screening are discussed in Section A.7.2.6.

A sample of the septic tank content was collected and analyzed for fecal coliform bacteria. Fecal coliform bacteria was not detected in the septic tank material from this CAS. 


\section{A.7.2.6 Radiological Survey Results}

The radiological FSL for alpha was $65 \mathrm{dpm} / 100 \mathrm{~cm}^{2}$ and the beta/gamma FSL was $3,325 \mathrm{dpm} / 100 \mathrm{~cm}^{2}$. These FSLs were exceeded at the following locations:

- Location E20 - Sample 271E035 had an elevated beta/gamma reading of 3,439 dpm/100 cm². This sample was submitted for laboratory analysis, and additional samples (271E036 and 271E037) were collected from the location. Neither of these samples exceeded radiological FSLs.

- Location E23 - Sample 271E040 had an elevated alpha reading of $91 \mathrm{dpm} / 100 \mathrm{~cm}^{2}$. This sample was submitted for laboratory analysis, and additional samples (271E041 and 271E042) were collected from the location. Neither of these samples exceeded radiological FSLs.

Radiological screening results for all other soil samples were below FSLs.

The results of the radiological survey of pipe at the septic tank inlet and locations E34, E35, and E36 indicate that the abandoned section of the collection system meets the unrestricted release criteria as defined in the NV/YMP Radiological Control Manual (DOE/NV, 2000a).

\section{A.7.2.7 Sample Analysis}

Environmental soil samples and associated QC samples were collected and analyzed for the CAIP-specified COPCs (i.e., total VOCs, total SVOCs, total RCRA metals, TPH [DRO and GRO], and PCBs). In addition, 25 percent of the soil samples and 100 percent of the associated QC samples were analyzed for Iso-U, Iso-Pu, Sr-90, and gamma-emitting radionuclides.

The sediment samples from the septic tank were analyzed for total VOCs, total SVOCs, TPH (GRO and DRO), total RCRA metals, PCBs, gamma-emitting radionuclides, Iso-U, Iso-Pu, Sr-90, and tritium. The sediment sample was analyzed according to the TCLP for VOCs, SVOCs, and RCRA metals.

The parameters and laboratory methods used to analyze the investigation samples are listed in Table A.2-2. Table A.7-1 lists the sample-specific analytical parameters. 


\section{A.7.3 Analytes Detected Above Minimum Reporting Limits}

The soil sample analytical results with concentrations exceeding corresponding MRLs or PALs (DOE/NV, 1998; DOE/NV, 2001) at CAS 25-04-09 are summarized in the following sections. The results of septic tank content samples are compared to appropriate regulatory levels for disposal. A portion of the CAS 25-04-09 analytical results were rejected during validation; however, these rejected data did not impact closure decisions as discussed in Section B.1.3.5 of Appendix B.

\section{A.7.3.1 Analytical Results for Soil Samples}

The following sections discuss the results for soil samples in comparison to the levels established in the Leachfield Work Plan and the CAIP.

\section{A.7.3.1.1 Total Volatile Organic Compounds}

Volatile organic compound results are reported in Table A.7-2. The only organic compound detected above the MRL of $5 \mu \mathrm{g} / \mathrm{kg}$ was acetone. Estimated concentrations as designated by the "J" qualifier were between 24 and $60 \mu \mathrm{g} / \mathrm{kg}$, below minimum quantitation values for the laboratory. Acetone is a common laboratory contaminant.

\section{A.7.3.1.2 Total Semivolatile Organic Compounds}

Semivolatile organic compounds were not detected above MRLs in CAS 25-04-09 soil samples

\section{A.7.3.1.3 Total Petroleum Hydrocarbons}

Total petroleum hydrocarbons were not detected above MRLs in CAS 25-04-09 soil samples.

\section{A.7.3.1.4 Total RCRA Metals}

As shown in Table A.7-3, the total RCRA metals detected in soil samples above concentrations exceeding the MRLs are arsenic ( $1 \mathrm{mg} / \mathrm{kg})$, barium $(20 \mathrm{mg} / \mathrm{kg})$, chromium $(1 \mathrm{mg} / \mathrm{kg})$, and lead $(0.3 \mathrm{mg} / \mathrm{kg})$. Other RCRA metals (i.e., cadmium, mercury, selenium, silver) were below specified MRLs. 
Table A.7-2

\section{Soil Samples Results for Total VOCs Detected Above Minimum Reporting Limits at CAS 25-04-09}

\begin{tabular}{|c|c|c||}
\hline \multirow{2}{*}{$\begin{array}{c}\text { Sample } \\
\text { Identification Number }\end{array}$} & $\begin{array}{c}\text { Depth } \\
\text { (ft bgs) }\end{array}$ & Contaminants of Potential Concern $(\mu \mathbf{g} / \mathbf{k g})$ \\
\cline { 3 - 4 } & & Acetone \\
\hline \hline \multicolumn{2}{|c|}{ Preliminary Action Levels ${ }^{\mathrm{a}}$} & $\mathbf{6 , 2 0 0 , 0 0 0}$ \\
\hline $271 \mathrm{E} 013$ & $3-4$ & $24(\mathrm{~J})^{\mathrm{b}}$ \\
\hline $271 \mathrm{E} 046$ & $2.9-3.9$ & $26(\mathrm{~J})^{\mathrm{b}}$ \\
\hline $271 \mathrm{E} 056$ & $2.5-3.5$ & $56(\mathrm{~J})^{\mathrm{c}}$ \\
\hline $271 \mathrm{E} 058$ & $3-4$ & $60(\mathrm{~J})^{\mathrm{c}}$ \\
\hline $271 \mathrm{E} 060$ & $2.9-3.9$ & $58(\mathrm{~J})^{\mathrm{c}}$ \\
\hline $271 \mathrm{E} 062$ & $2.7-3.7$ & $49(\mathrm{~J})^{\mathrm{c}}$ \\
\hline $271 \mathrm{E} 064$ & $2.7-3.7$ & $56(\mathrm{~J})^{\mathrm{c}}$ \\
\hline $271 \mathrm{E} 068$ & $3.3-4.3$ & $24(\mathrm{~J})^{\mathrm{c}}$ \\
\hline
\end{tabular}

\footnotetext{
${ }^{\mathrm{a} B a s e d}$ on U.S. Environmental Protection Agency, Region 9 Preliminary Remediation Goals (PRGs) (EPA, 2000).

${ }^{b}$ Qualifier added to laboratory data; record accepted. Relative response factor $<0.05$.

${ }^{\mathrm{C}} \mathrm{Qualifier}$ added to laboratory data; record accepted. Average relative response factor $<0.05$. Relative response factor $<0.05$.

$\mathrm{J}=$ Estimated value
}

Barium concentrations ranged from 66 to $95 \mathrm{mg} / \mathrm{kg}$, chromium concentrations ranged from 2.1 to $4.4 \mathrm{mg} / \mathrm{kg}$, and lead concentrations ranged from 4.1 to $6.7 \mathrm{mg} / \mathrm{kg}$. All reported concentrations of these metals were below EPA Region 9 PRGs defined in this document as PALs.

Arsenic concentrations ranged from 1.7 to $16 \mathrm{mg} / \mathrm{kg}$ in leachfield soil. Concentrations at most locations are greater than the PAL of $2.7 \mathrm{mg} / \mathrm{kg}$, which is the EPA Region 9 PRG for arsenic. Arsenic concentrations in soil in the NTS region commonly exceed the PAL. The mean concentration of arsenic in silt samples from the Nevada Test and Training Range is 7 to $8 \mathrm{mg} / \mathrm{kg}$ (NBMG, 1998; Moore, 1999). The arsenic concentrations are somewhat consistent in the leachfield soil and do not appear to represent "hot spots" or a spill. Although the arsenic soil concentrations generally exceeded PALs and several detections exceeded the regional levels discussed above, it is believed that the concentrations observed at CAS 25-04-09 are within the background range for NTS soil and do not represent contamination. 
Table A.7-3

Soil Sample Results for Total RCRA Metals Detected Above Minimum Reporting Limits at CAS 25-04-09

(Page 1 of 2)

\begin{tabular}{|c|c|c|c|c|c|}
\hline \multirow{2}{*}{$\begin{array}{c}\text { Sample } \\
\text { Identification } \\
\text { Number }\end{array}$} & \multirow{2}{*}{$\begin{array}{c}\text { Depth } \\
\text { (ft bgs) }\end{array}$} & \multicolumn{4}{|c|}{ Contaminants of Potential Concern (mg/kg) } \\
\hline & & Arsenic & Barium & Chromium & Lead \\
\hline \multicolumn{2}{|c|}{ Preliminary Action Levels ${ }^{a}$} & 2.7 & 100,000 & 450 & 750 \\
\hline 271E001 & $8-9$ & 5.7 & 78 & 2.4 & 4.9 \\
\hline 271E004 & $7.3-8.3$ & 4.5 & 74 & 2.7 & 6.3 \\
\hline 271E006 & $3.6-4.6$ & 6.8 & 81 & 2.3 & 4.4 \\
\hline 271E007 & $3.6-4.6$ & 6.5 & 84 & 2.3 & 5.1 \\
\hline 271E009 & $3.6-4.6$ & 12 & 71 & 2.9 & 5.6 \\
\hline 271E011 & $4.5-5.5$ & 3.7 & 74 & 2.7 & 5.2 \\
\hline $271 \mathrm{E} 013$ & $3-4$ & 3.3 & 87 & 3.1 & 4.9 \\
\hline 271E015 & $2.7-3.7$ & 2.6 & 79 & 4.4 & 6.4 \\
\hline 271E017 & $1.5-2.5$ & 2.7 & 86 & 4.3 & 5.6 \\
\hline 271E019 & $2-3$ & 11 & 81 & 4.1 & 5.5 \\
\hline 271E021 & $2.7-3.7$ & 7.5 & 85 & 3.5 & 5.5 \\
\hline 271E023 & $4-5$ & 2.7 & 80 & 2.7 & 4.5 \\
\hline 271E025 & $3.25-4.25$ & 3.1 & 83 & 3.4 & 5.2 \\
\hline 271E027 & $3.25-4.25$ & 2.9 & 89 & 3.5 & 5.2 \\
\hline 271E029 & $3.75-4.75$ & 2 & 79 & 2.7 & 4.5 \\
\hline 271E031 & $3.75-4.75$ & 2 & 86 & 2.6 & 4.2 \\
\hline 271E033 & $2.9-3.9$ & 3.3 & 89 & 3.9 & 6 \\
\hline 271E035 & $2.7-3.7$ & 2.3 & 86 & 3.2 & 5 \\
\hline 271E036 & $5.2-6.2$ & 1.8 & 78 & 2.5 & 4.1 \\
\hline 271E038 & $2-3$ & 4.7 & 77 & 3.4 & 5.6 \\
\hline 271E040 & $2.9-3.9$ & 2.6 & 95 & 3 & 5.1 \\
\hline 271E041 & $5.4-6.4$ & 2 & 83 & 2.3 & 4.2 \\
\hline 271E043 & $2.8-3.8$ & 2.5 & 84 & 2.9 & 5.1 \\
\hline 271E044 & $2.8-3.8$ & 2.7 & 83 & 3.1 & 5.3 \\
\hline 271E046 & $2.9-3.9$ & 4.8 & 75 & 3.3 & 5.1 \\
\hline 271E048 & $4-5$ & 2.3 & 81 & 2.6 & 4.6 \\
\hline 271E050 & $3.5-4.5$ & 1.7 & 86 & 2.3 & 4.3 \\
\hline 271E054 & $3.9-4.9$ & 2.1 & 79 & 2.1 & 4.7 \\
\hline 271E056 & $2.5-3.5$ & 8.3 & 66 & 3.1 & 5.6 \\
\hline 271E058 & $3-4$ & 7.6 & 71 & 3.3 & 5.4 \\
\hline
\end{tabular}


Table A.7-3

Soil Sample Results for Total RCRA Metals Detected Above Minimum Reporting Limits at CAS 25-04-09

(Page 2 of 2 )

\begin{tabular}{||c|c|c|c|c|c||}
\hline \multirow{2}{*}{$\begin{array}{c}\text { Sample } \\
\text { Identification } \\
\text { Number }\end{array}$} & \multirow{2}{*}{$\begin{array}{c}\text { Depth } \\
\text { (ft bgs) }\end{array}$} & \multicolumn{3}{|c|}{ Contaminants of Potential Concern (mg/kg) } \\
\cline { 3 - 6 } & & Arsenic & Barium & Chromium & Lead \\
\hline \multicolumn{2}{|c|}{ Preliminary Action Levels ${ }^{\text {a }}$} & $\mathbf{2 . 7}$ & $\mathbf{1 0 0 , 0 0 0}$ & $\mathbf{4 5 0}$ & $\mathbf{7 5 0}$ \\
\hline $271 \mathrm{E} 060$ & $2.9-3.9$ & $\mathbf{8 . 1}$ & 72 & 3.1 & 6.7 \\
\hline $271 \mathrm{E} 062$ & $2.7-3.7$ & $\mathbf{5 . 6}$ & 70 & 3.1 & 5.9 \\
\hline $271 \mathrm{E} 064$ & $2.7-3.7$ & $\mathbf{1 6}$ & 74 & 3.2 & 5.9 \\
\hline $271 \mathrm{E} 066$ & $2.8-3.8$ & $\mathbf{1 2}$ & 67 & 2.4 & 5.1 \\
\hline $271 \mathrm{E} 068$ & $3.3-4.3$ & $\mathbf{3 . 3}$ & 69 & $3(\mathrm{~J})$ & 5.5 \\
\hline $271 \mathrm{E} 070$ & $2.9-3.9$ & $\mathbf{1 4}$ & 82 & $3.5(\mathrm{~J})$ & 6.5 \\
\hline $271 \mathrm{E} 073$ & $2.8-3.8$ & 1.87 & 82 & 2.98 & 4.87 \\
\hline $271 \mathrm{E} 074$ & $2.8-3.8$ & 2.03 & 71.4 & 3 & 4.58 \\
\hline $271 \mathrm{E} 075$ & $2.8-3.8$ & 1.73 & 76.9 & 2.87 & 5.05 \\
\hline $271 \mathrm{E} 076$ & $2.8-3.8$ & 2.2 & 81.4 & 3.77 & 5.65 \\
\hline $271 \mathrm{E} 077$ & $2.8-3.8$ & 1.82 & 79.6 & 3.42 & 5.78 \\
\hline
\end{tabular}

${ }^{a}$ Based on U.S. Environmental Protection Agency, Region 9 Preliminary Remediation Goals (PRGs) (EPA, 2000).

$\mathrm{J}=$ Estimated value. Qualifier added to laboratory report; record accepted. Inductively coupled plasma serial dilution recovery was not met.

\section{A.7.3.1.5 Polychlorinated Biphenyls}

Polychlorinated biphenyls were not detected above MRLs in CAS 25-04-09 soil samples.

\section{A.7.3.1.6 Gamma Spectrometry}

Results of soil sample gamma spectrometry analysis are presented in Table A.7-4. Concentrations of actinium-228, bismuth-212, bismuth-214, lead-212, lead-214, potassium-40, thallium-208, and thorium-234 were detected above the MDLs. The TPU in the radioanalytical measurement is provided in the table along with the concentration for all detected gamma emitters. The concentration of the detected gamma-emitting radionuclides are below PALs and are not significantly different than concentrations measured in soil samples collected from undisturbed background locations. 
Table A.7-4

Soil Sample Results for Gamma-Emitting Radionuclides Detected Above Minimum Reporting Limits at CAS 25-04-09

\begin{tabular}{|c|c|c|c|c|c|c|c|c|c|}
\hline \multirow{2}{*}{$\begin{array}{c}\text { Sample } \\
\text { Identification } \\
\text { Number }\end{array}$} & \multirow{2}{*}{$\begin{array}{l}\text { Depth } \\
\text { (ft bgs) }\end{array}$} & \multicolumn{8}{|c|}{ Contaminants of Potential Concern $(\mathrm{pCi} / \mathrm{g})$} \\
\hline & & Actinium-228 ${ }^{a}$ & Bismuth-212 ${ }^{\mathrm{b}}$ & Bismuth-214 & Lead-212 & Lead-214 ${ }^{b}$ & Potassium-40 & Thallium-208 ${ }^{\mathrm{a}}$ & Thorium-234 \\
\hline \multicolumn{2}{|c|}{ Preliminary Action Level } & 3.64 & 2.4 & 3.47 & 2.9 & 2.9 & 96 & 3.4 & 3.47 \\
\hline $271 \mathrm{E} 004$ & $7.3-8.3$ & $1.09 \pm 0.27$ & $\overline{--}$ & $0.63 \pm 0.19$ & $\overline{1.41 \pm 0.29}$ & $0.74 \pm 0.18$ & $25.9 \pm 4.9$ & $0.35 \pm 0.10$ & $\overline{--}$ \\
\hline $271 \mathrm{E} 006$ & $3.6-4.6$ & $1.13 \pm 0.31$ & -- & $0.56 \pm 0.19$ & $1.41 \pm 0.28$ & $0.53 \pm 0.15$ & $25.5 \pm 5.0$ & $0.43 \pm 0.12$ & -- \\
\hline $271 \mathrm{E} 007$ & $3.6-4.6$ & $1.15 \pm 0.24$ & $1.21 \pm 0.52$ & $0.59 \pm 0.15$ & $1.34 \pm 0.25$ & $0.72 \pm 0.15$ & $28 \pm 4.9$ & $0.418 \pm 0.091$ & -- \\
\hline $271 \mathrm{E} 011$ & $4.5-5.5$ & $1.19 \pm 0.34$ & $\overline{--}$ & $0.52 \pm 0.20$ & $1.28 \pm 0.28$ & $0.63 \pm 0.18$ & $26.5 \pm 5.3$ & $0.39 \pm 0.12$ & -- \\
\hline 271E019 & $2-3$ & $1.25 \pm 0.26$ & -- & $0.61 \pm 0.15$ & $1.41 \pm 0.27$ & $0.71 \pm 0.16$ & $27 \pm 4.7$ & $0.435 \pm 0.095$ & -- \\
\hline $271 \mathrm{E} 021$ & $2.7-3.7$ & $1.36 \pm 0.33$ & $\overline{--}$ & $0.55 \pm 0.18$ & $1.47 \pm 0.29$ & $0.73 \pm 0.18$ & $25.3 \pm 4.8$ & $0.45 \pm 0.11$ & -- \\
\hline 271E035 & $2.7-3.7$ & $1 \pm 0.31$ & -- & $0.54 \pm 0.22$ & $1.3 \pm 0.28$ & $0.78 \pm 0.21$ & $25.8 \pm 5.2$ & $0.31 \pm 0.11$ & -- \\
\hline $271 \mathrm{E} 043$ & $2.8-3.8$ & $1.23 \pm 0.26$ & -- & $0.6 \pm 0.15$ & $1.33 \pm 0.25$ & $0.66 \pm 0.15$ & $28.4 \pm 4.9$ & $0.418 \pm 0.091$ & $2.21 \pm 0.83(\mathrm{TI})$ \\
\hline $271 \mathrm{E} 044$ & $2.8-3.8$ & $1.11 \pm 0.24$ & $\overline{--}$ & $0.6 \pm 0.15$ & $1.39 \pm 0.26$ & $0.62 \pm 0.14$ & $26 \pm 4.5$ & $0.423 \pm 0.95$ & -- \\
\hline 271E060 & $2.9-3.9$ & $1.18 \pm 0.29$ & -- & $0.49 \pm 0.17$ & $1.37 \pm 0.28$ & $0.7 \pm 0.17$ & $28 \pm 5.2$ & $0.47 \pm 0.12$ & $\begin{array}{l}- \\
-\end{array}$ \\
\hline $271 \mathrm{E} 070$ & $2.9-3.9$ & $1.01 \pm 0.29$ & -- & $0.54 \pm 0.22$ & $1.43 \pm 0.29$ & $0.65 \pm 0.18$ & $25.5 \pm 5.0$ & $0.34 \pm 0.11$ & -- \\
\hline
\end{tabular}

aBackground concentration listed in Environmental Monitoring Report for the Proposed Ward Valley, California, Low-Level Radioactive Waste (LLRW) Facility (US Ecology and Atlan-Tech, 1992).

background concentration listed or derived in Off-Site Radiation Exposure Review Project, Phase II Soil Program (McArthur and Miller, 1989).

$--=$ Not detected above minimum reporting limits

$\mathrm{TI}=$ Tentatively identified 


\section{A.7.3.1.7 Isotopic Uranium}

Detected values of uranium isotopes, along with associated TPUs are reported in Table A.7-5. The concentrations of the uranium isotopes are below PALs and are not significantly greater than concentrations in soil samples collected from undisturbed background locations.

Table A.7-5

Isotopic Uranium Sample Results Detected Above Minimum Reporting Limits at CAS 25-04-09

\begin{tabular}{|c|c|c|c|c|}
\hline \multirow{2}{*}{$\begin{array}{c}\text { Sample } \\
\text { Identification Number }\end{array}$} & \multirow{2}{*}{$\begin{array}{c}\text { Depth } \\
\text { (ft bgs) }\end{array}$} & \multicolumn{2}{|c|}{ Contaminants of Potential Concern (pCi/g) } \\
\cline { 2 - 5 } & & Uranium-234 & Uranium-235 & Uranium-238 $^{\text {a }}$ \\
\hline \multicolumn{2}{|c|}{ Preliminary Action Levels } & $\mathbf{1 . 5 6}$ & $\mathbf{0 . 0 7}$ & $\mathbf{3 . 2}$ \\
\hline \hline $271 \mathrm{E} 004$ & $7.3-8.3$ & $0.64 \pm 0.13$ & $0.041 \pm 0.025(\mathrm{LT})$ & $0.76 \pm 0.14$ \\
\hline $271 \mathrm{E} 006$ & $3.6-4.6$ & $0.67 \pm 0.13$ & $0.044 \pm 0.026(\mathrm{LT})$ & $0.67 \pm 0.13$ \\
\hline $271 \mathrm{E} 007$ & $3.6-4.6$ & $0.61 \pm 0.13$ & -- & $0.67 \pm 0.13$ \\
\hline $271 \mathrm{E} 011$ & $4.5-5.5$ & $0.64 \pm 0.13$ & -- & $0.79 \pm 0.15$ \\
\hline $271 \mathrm{E} 019$ & $2-3$ & $0.68 \pm 0.13$ & -- & $0.67 \pm 0.13$ \\
\hline $271 \mathrm{E} 021$ & $2.7-3.7$ & $0.73 \pm 0.14$ & $0.055 \pm 0.029$ & $0.59 \pm 0.12$ \\
\hline $271 \mathrm{E} 035$ & $2.7-3.7$ & $0.6 \pm 0.12$ & -- & $0.66 \pm 0.13$ \\
\hline $271 \mathrm{E} 043$ & $2.8-3.8$ & $0.72 \pm 0.14$ & -- & $0.62 \pm 0.12$ \\
\hline $271 \mathrm{E} 044$ & $2.8-3.8$ & $0.63 \pm 0.13$ & -- & $0.61 \pm 0.12$ \\
\hline $271 \mathrm{E} 060$ & $2.9-3.9$ & $0.63 \pm 0.14$ & $0.052 \pm 0.031$ & $0.66 \pm 0.14$ \\
\hline $271 \mathrm{E} 070$ & $2.9-3.9$ & $0.6 \pm 0.13$ & -- & $0.66 \pm 0.14$ \\
\hline
\end{tabular}

aackground concentration listed in Environmental Monitoring Report for the Proposed Ward Valley, California, Low-Level Radioactive Waste (LLRW) Facility (US Ecology and Atlan-Tech, 1992).

${ }^{\mathrm{b}}$ Background concentration listed or derived in Off-Site Radiation Exposure Review Project, Phase II Soil Program (McArthur and Miller, 1989).

$\mathrm{LT}=$ Result is less than requested minimum detectable concentration (MDC), greater than sample-specific MDC $--=$ Not detected above minimum reporting limit

\section{A.7.3.1.8 Isotopic Plutonium}

Isotopic plutonium was not detected above MRLs in CAS 25-04-09 soil samples.

\section{A.7.3.1.9 Strontium-90}

Strontium-90 was not detected above MRLs in CAS 25-04-09 soil samples. 


\section{A.7.3.2 Septic Tank Sample Results}

Results of collected septic tank content samples were compared to regulatory levels based on disposal options. If the waste has no hazardous component, the regulatory level is based on disposal options at NTS landfills and lagoons (BN, 1995; CFR, 2000b and c; NDEP, 1997a, b, and c). Any sludge or liquid waste will be solidified before disposal at NTS landfills (NDEP, 1997b). If the waste is hazardous, the release criteria are based on interpretation of the guidelines presented in the POC (BN, 1995; Alderson, 1999). For waste destined for off-site disposal, the POC radiological levels must be met to certify that the waste has no radioactivity added.

Two sediment samples were obtained from the septic tank. Sample 271E052 was collected from the inlet chamber and sample 271E053 was collected from the outlet chamber. The analytical suite followed the CAIP and is detailed in Section A.7.2.7. Analytical results exceeding MRLs are listed in Table A.7-6.

Several COPCs were detected in the sediment samples. Most COPCs were below regulatory limits except for TPH DRO which were detected in samples 271E052 and 271E053. Diesel concentrations in these samples were 460 and $660 \mathrm{mg} / \mathrm{kg}$, respectively. These levels exceed the NDEP TPH action level of $100 \mathrm{mg} / \mathrm{kg}$ (NAC, 2000).

\section{A.7.4 Contaminants of Concern}

Based on the aforementioned analytical results, the only COCs at CAS 25-04-09 are present in the septic tank. The septic tank contains sediment with TPH analytes in concentrations above the NDEP action level of $100 \mathrm{mg} / \mathrm{kg}$. No COCs were identified in the soil surrounding the septic tank or under the leachfield.

\section{A.7.5 Nature and Extent of Contamination}

Total petroleum hydrocarbons are located within the septic tank in the dry sediment. A maximum thickness of 5 in. (55 gal) of sediment remained in the bottom of each chamber in the tank.

\section{A.7.6 Revised Conceptual Model}

No variations in the conceptual model were identified. 
Table A.7-6

\section{Sludge Sample Results Detected Above Minimum Reporting Limits at CAS 25-04-09}

(Page 1 of 3 )

\begin{tabular}{|c|c|c|c|c|c|c|}
\hline $\begin{array}{c}\text { Sample } \\
\text { Identification } \\
\text { Number }\end{array}$ & $\begin{array}{l}\text { Sample } \\
\text { Matrix }\end{array}$ & Parameter & Result & Units & Limits & Reference \\
\hline 271E052 & Sediment & 1,4-Dichlorobenzene & 540 & $\mu \mathrm{g} / \mathrm{kg}$ & NA & CFR, 2000a \\
\hline 271E052 & Sediment & Bis(2-Ethylhexyl)Phthalate & $1,400(J)^{a}$ & $\mu \mathrm{g} / \mathrm{kg}$ & NA & CFR, 2000a \\
\hline 271E053 & Sediment & 1,4-Dichlorobenzene & 750 & $\mu \mathrm{g} / \mathrm{kg}$ & NA & CFR, 2000a \\
\hline 271E053 & Sediment & Bis(2-Ethylhexyl)Phthalate & $4,200(J)^{a}$ & $\mu \mathrm{g} / \mathrm{kg}$ & NA & CFR, 2000a \\
\hline 271E053 & Sediment & Butyl Benzyl Phthalate & $900(\mathrm{~J})^{\mathrm{a}}$ & $\mu \mathrm{g} / \mathrm{kg}$ & NA & CFR, 2000a \\
\hline 271E053 & Sediment & Di-n-Butyl Phthalate & $960(J)^{\mathrm{a}}$ & $\mu \mathrm{g} / \mathrm{kg}$ & NA & CFR, 2000a \\
\hline 271E052 & Sediment & Aroclor-1254 & $1,200(J)^{b}$ & $\mu \mathrm{g} / \mathrm{kg}$ & 50,000 & CFR, 2000b \\
\hline 271E053 & Sediment & Aroclor-1254 & $2,700(J)^{b}$ & $\mu \mathrm{g} / \mathrm{kg}$ & 50,000 & CFR, 2000b \\
\hline 271E052 & Sediment & Uranium-234 & $6.6 \pm 0.91$ & $\mathrm{pCi} / \mathrm{g}$ & 100 & NDEP, 1997b \\
\hline 271E052 & Sediment & Uranium-235 & $0.132 \pm 0.047$ & $\mathrm{pCi} / \mathrm{g}$ & 100 & NDEP, 1997b \\
\hline 271E052 & Sediment & Uranium-238 & $1.14 \pm 0.20$ & $\mathrm{pCi} / \mathrm{g}$ & 100 & NDEP, 1997b \\
\hline 271E053 & Sediment & Uranium-234 & $11.1 \pm 1.5$ & $\mathrm{pCi} / \mathrm{g}$ & 100 & NDEP, 1997b \\
\hline 271E053 & Sediment & Uranium-235 & $0.162 \pm 0.054$ & $\mathrm{pCi} / \mathrm{g}$ & 100 & NDEP, 1997b \\
\hline 271E053 & Sediment & Uranium-238 & $1.77 \pm 0.28$ & $\mathrm{pCi} / \mathrm{g}$ & 100 & NDEP, 1997b \\
\hline 271E052 & Sediment & Potassium-40 & $6.2 \pm 2.3$ & $\mathrm{pCi} / \mathrm{g}$ & - & $\mathrm{N}$ \\
\hline 271E053 & Sediment & Potassium-40 & $6.8 \pm 2.6$ & $\mathrm{pCi} / \mathrm{g}$ & - & $\mathrm{N}$ \\
\hline 271E052 & Sediment & Acetone & $39(\mathrm{~J})^{\mathrm{c}}$ & $\mu \mathrm{g} / \mathrm{kg}$ & NA & CFR, 2000a \\
\hline 271E053 & Sediment & Acetone & $310(\mathrm{~J})^{\mathrm{C}}$ & $\mu \mathrm{g} / \mathrm{kg}$ & NA & CFR, 2000a \\
\hline 271E053 & Sediment & Methylene Chloride & $11(J)^{d}$ & $\mu \mathrm{g} / \mathrm{kg}$ & NA & CFR, 2000a \\
\hline 271E052 & Sediment & Diesel-Range Organics & $460(M)$ & $\mathbf{m g} / \mathbf{k g}$ & 100 & NDEP, 1997b \\
\hline
\end{tabular}


Table A.7-6

\section{Sludge Sample Results Detected Above Minimum Reporting Limits at CAS 25-04-09}

(Page 2 of 3 )

\begin{tabular}{|c|c|c|c|c|c|c|}
\hline $\begin{array}{c}\text { Sample } \\
\text { Identification } \\
\text { Number }\end{array}$ & $\begin{array}{c}\text { Sample } \\
\text { Matrix }\end{array}$ & Parameter & Result & Units & Limits & Reference \\
\hline 271E053 & Sediment & Diesel-Range Organics & $660(M)$ & $\mathbf{m g} / \mathbf{k g}$ & 100 & NDEP, 1997b \\
\hline 271E052 & Sediment & Mercury ${ }^{* *}$ & 1.1 & $\mathrm{mg} / \mathrm{kg}$ & NA & CFR, 2000a \\
\hline 271E053 & Sediment & Mercury** & 1.3 & $\mathrm{mg} / \mathrm{kg}$ & NA & CFR, 2000a \\
\hline 271E052 & Sediment & Arsenic & 29 & $\mathrm{mg} / \mathrm{kg}$ & NA & CFR, 2000a \\
\hline 271E052 & Sediment & Barium** & $660(J)^{e}$ & $\mathrm{mg} / \mathrm{kg}$ & NA & CFR, 2000a \\
\hline 271E052 & Sediment & Cadmium & 11 & $\mathrm{mg} / \mathrm{kg}$ & NA & CFR, 2000a \\
\hline 271E052 & Sediment & Chromium** & $36(J)^{f}$ & $\mathrm{mg} / \mathrm{kg}$ & NA & CFR, 2000a \\
\hline 271E052 & Sediment & Lead** $^{* *}$ & 77 & $\mathrm{mg} / \mathrm{kg}$ & NA & CFR, 2000a \\
\hline 271E052 & Sediment & Selenium** & 1.8 & $\mathrm{mg} / \mathrm{kg}$ & NA & CFR, 2000a \\
\hline 271E052 & Sediment & Silver & 450 & $\mathrm{mg} / \mathrm{kg}$ & NA & CFR, 2000a \\
\hline 271E053 & Sediment & Arsenic & 73 & $\mathrm{mg} / \mathrm{kg}$ & NA & CFR, 2000a \\
\hline 271E053 & Sediment & Barium** & $290(\mathrm{~J})^{\mathrm{e}}$ & $\mathrm{mg} / \mathrm{kg}$ & NA & CFR, 2000a \\
\hline 271E053 & Sediment & Cadmium & 19 & $\mathrm{mg} / \mathrm{kg}$ & NA & CFR, 2000a \\
\hline 271E053 & Sediment & Chromium** & $52(\mathrm{~J})^{\mathrm{f}}$ & $\mathrm{mg} / \mathrm{kg}$ & NA & CFR, 2000a \\
\hline 271E053 & Sediment & Lead** $^{\star *}$ & 140 & $\mathrm{mg} / \mathrm{kg}$ & NA & CFR, 2000a \\
\hline 271E053 & Sediment & Silver & 370 & $\mathrm{mg} / \mathrm{kg}$ & NA & CFR, 2000a \\
\hline 271E052 & Sediment & TCLP Arsenic & 0.29 & $\mathrm{mg} / \mathrm{L}$ & 5 & CFR, 2000a \\
\hline 271E052 & Sediment & TCLP Cadmium & 0.16 & $\mathrm{mg} / \mathrm{L}$ & 1 & CFR, 2000a \\
\hline 271E052 & Sediment & TCLP Silver & 0.26 & $\mathrm{mg} / \mathrm{L}$ & 5 & CFR, 2000a \\
\hline 271E053 & Sediment & TCLP Arsenic & 0.19 & $\mathrm{mg} / \mathrm{L}$ & 5 & CFR, 2000a \\
\hline
\end{tabular}




\section{Table A.7-6 \\ Sludge Sample Results Detected \\ Above Minimum Reporting Limits at CAS 25-04-09}

(Page 3 of 3 )

\begin{tabular}{|c|c|c|c|c|c|c|}
\hline $\begin{array}{c}\text { Sample } \\
\text { Identification } \\
\text { Number }\end{array}$ & $\begin{array}{c}\text { Sample } \\
\text { Matrix }\end{array}$ & Parameter & Result & Units & Limits & Reference \\
\hline \hline $271 \mathrm{E} 053$ & Sediment & TCLP Cadmium & 0.081 & $\mathrm{mg} / \mathrm{L}$ & 1 & $\mathrm{CFR}, 2000 \mathrm{a}$ \\
\hline $271 \mathrm{E} 053$ & Sediment & TCLP Silver & 0.33 & $\mathrm{mg} / \mathrm{L}$ & 5 & $\mathrm{CFR}, 2000 \mathrm{a}$ \\
\hline
\end{tabular}

${ }^{a}$ Qualifier added to laboratory data; record accepted. Internal standard area count exceeded the quality control limits. Poor precision between undiluted and diluted analyses results.

${ }^{b}$ Qualifier added to laboratory data; record accepted. Surrogates diluted out.

${ }^{\circ}$ Qualifier added to laboratory data; record accepted. Surrogate recovery exceeded the lower limits. Matrix effects may exist.

Average relative response factor $<0.05$. Relative response factor $<0.05$.

${ }^{\mathrm{d}}$ Qualifier added to laboratory data; record accepted. Surrogate recovery exceeded the lower limits. Matrix effects may exist. Average relative response factor $<0.05$.

eQualifier added to laboratory data; record accepted. Poor matrix spike recovery $/<30$ percent recovery.

${ }^{\dagger} Q$ ualifier added to laboratory data; record accepted. Poor matrix spike recovery $/<30$ percent recovery. Duplicate precision analyses were outside control limits.

${ }^{* *}=$ TCLP below minimum reporting limit

$\mathrm{J}=$ Estimated value

$M=$ Motor oil

$\mathrm{N}=$ No limit established (NDEP, 1997b)

$\mathrm{NA}=$ Not applicable 


\section{A.8.0 Rad-Safe Trailers Septic System (CAS 25-04-10)}

The Rad-Safe trailers septic system was designed to receive sanitary effluent generated by activities from one or two trailers that are no longer present. The septic system is located approximately $0.10 \mathrm{mi}$ south of the intersection of C and G Roads in Area 25. The site is comprised of a leachfield, septic tank, distribution box, and associated piping. More detail is provided in the CAIP (DOE/NV, 2001).

\section{A.8.1 Corrective Action Investigation}

Seventy-three investigation samples, listed in Table A.8-1, were collected during investigation activities conducted at CAS 25-04-10. The planned and actual sample locations are shown in Figure A.8-1. The specific CAI activities conducted to meet CAIP requirements at CAS 25-04-10 are described in Table A.2-1.

Table A.8-1

Samples Collected at CAS 25-04-10

(Page 1 of 5 )

\begin{tabular}{|c|c|c|c|c|c|c|c|c|c|c|c|c|c|}
\hline \multirow[b]{2}{*}{$\begin{array}{c}\text { Sample } \\
\text { Identification } \\
\text { Number }\end{array}$} & \multirow[b]{2}{*}{$\begin{array}{l}\text { Sample } \\
\text { Location }\end{array}$} & \multirow[b]{2}{*}{$\begin{array}{l}\text { Sample } \\
\text { Matrix }\end{array}$} & \multirow[b]{2}{*}{$\begin{array}{c}\text { Depth } \\
\text { (ft bgs) }\end{array}$} & \multirow[b]{2}{*}{ Purpose } & \multicolumn{9}{|c|}{ Analyses } \\
\hline & & & & & 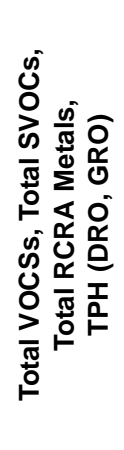 & 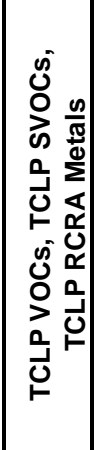 & 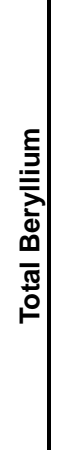 & : & 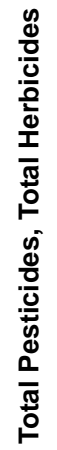 & 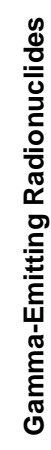 & 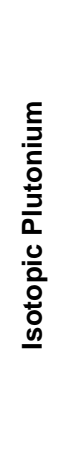 & 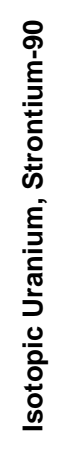 & $\underset{n}{E}$ \\
\hline 271F001 & F01 & Soil & $4.3-5.3$ & Environmental & $x$ & & & & & $x$ & $x$ & & \\
\hline 271F002 & F01 & Soil & $7-8$ & Environmental & \multicolumn{9}{|c|}{ Not Submitted for Analyses ${ }^{a}$} \\
\hline 271F003 & $\mathrm{F} 02$ & Soil & $4.4-5.4$ & Environmental & $x$ & & & & & $x$ & $x$ & & \\
\hline 271F004 & F02 & Soil & $7-8$ & Environmental & \multicolumn{9}{|c|}{ Not Submitted for Analyses ${ }^{a}$} \\
\hline 271F005 & F03 & Soil & $3.7-5$ & Environmental & $x$ & & & & & $x$ & $x$ & & \\
\hline 271F006 & F03 & Soil & $6.2-7$ & Environmental & \multicolumn{9}{|c|}{ Not Submitted for Analyses ${ }^{a}$} \\
\hline 271F007 & F04 & Soil & $4.4-5.5$ & Environmental & $x$ & & & & & $\mathrm{X}$ & $X$ & & \\
\hline
\end{tabular}


Table A.8-1

Samples Collected at CAS 25-04-10

(Page 2 of 5 )

\begin{tabular}{|c|c|c|c|c|c|c|c|c|c|c|c|c|c|}
\hline \multirow[b]{2}{*}{$\begin{array}{c}\text { Sample } \\
\text { Identification } \\
\text { Number }\end{array}$} & \multirow[b]{2}{*}{$\begin{array}{c}\text { Sample } \\
\text { Location }\end{array}$} & \multirow[b]{2}{*}{$\begin{array}{l}\text { Sample } \\
\text { Matrix }\end{array}$} & \multirow[b]{2}{*}{$\begin{array}{l}\text { Depth } \\
\text { (ft bgs) }\end{array}$} & \multirow[b]{2}{*}{ Purpose } & \multicolumn{9}{|c|}{ Analyses } \\
\hline & & & & & 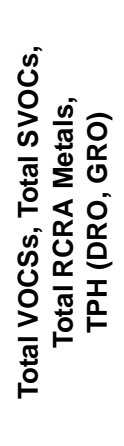 & 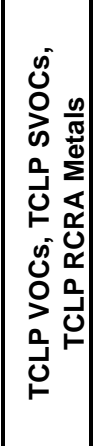 & 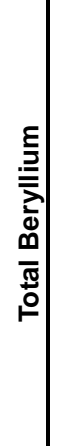 & : & 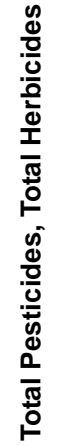 & 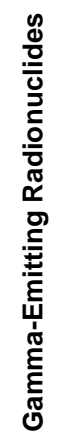 & 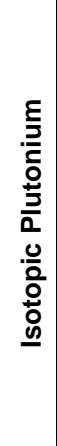 & 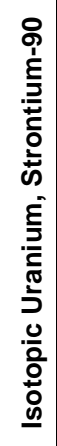 & $\stackrel{E}{\equiv}$ \\
\hline 271F008 & F04 & Soil & $6.7-7.7$ & Environmental & \multicolumn{9}{|c|}{ Not Submitted for Analyses ${ }^{a}$} \\
\hline 271F009 & F05 & Soil & $4.4-5.4$ & Environmental & $x$ & & & & & $x$ & $x$ & & \\
\hline 271F010 & F05 & Soil & $6.4-7.4$ & Environmental & \multicolumn{9}{|c|}{ Not Submitted for Analyses ${ }^{a}$} \\
\hline 271F011 & F06 & Soil & $3.4-4.4$ & Environmental & $x$ & & & & & $x$ & $x$ & & \\
\hline 271F012 & F06 & Soil & $6.4-7.4$ & Environmental & \multicolumn{9}{|c|}{ Not Submitted for Analyses ${ }^{a}$} \\
\hline $271 \mathrm{~F} 013$ & F07 & Soil & $4-5$ & Environmental & $X$ & & & & & $X$ & $X$ & & \\
\hline $271 \mathrm{~F} 014$ & F07 & Soil & $6.4-7.4$ & Environmental & \multicolumn{9}{|c|}{ Not Submitted for Analyses ${ }^{a}$} \\
\hline $271 \mathrm{~F} 015$ & F08 & Soil & $3.5-4.5$ & Environmental & $x$ & & & & & $x$ & $x$ & $x$ & \\
\hline 271F016 & F08 & Soil & $3.5-4.5$ & $\begin{array}{l}\text { Duplicate of } \\
\text { 271F015 }\end{array}$ & $\mathrm{X}$ & & & & & $x$ & $x$ & $x$ & \\
\hline $271 \mathrm{~F} 017$ & F08 & Soil & $6-7$ & Environmental & \multicolumn{9}{|c|}{ Not Submitted for Analyses ${ }^{a}$} \\
\hline 271F018 & F09 & Soil & $2.4-3.4$ & Environmental & $x$ & & & & & $\mathrm{X}$ & $x$ & & \\
\hline 271F019 & F09 & Soil & $5-6$ & Environmental & \multicolumn{9}{|c|}{ Not Submitted for Analyses ${ }^{a}$} \\
\hline $271 \mathrm{~F} 020$ & $\mathrm{~F} 13$ & Soil & $3.4-4.4$ & Environmental & $x$ & & & & & $x$ & $x$ & & \\
\hline 271F021 & F13 & Soil & $6-7$ & Environmental & \multicolumn{9}{|c|}{ Not Submitted for Analyses ${ }^{a}$} \\
\hline 271F022 & F10 & Soil & $3-4$ & Environmental & $x$ & & & & & $\mathrm{X}$ & $\mathrm{X}$ & & \\
\hline $271 \mathrm{~F} 023$ & $\mathrm{~F} 10$ & Soil & $6.4-7.4$ & Environmental & \multicolumn{9}{|c|}{ Not Submitted for Analyses ${ }^{a}$} \\
\hline 271F024 & $\mathrm{F} 12$ & Soil & $3.2-4.2$ & Environmental & $x$ & & & & & $x$ & $x$ & & \\
\hline $271 \mathrm{~F} 025$ & $\mathrm{~F} 12$ & Soil & $6-7$ & Environmental & \multicolumn{9}{|c|}{ Not Submitted for Analyses ${ }^{a}$} \\
\hline 271F026 & $\mathrm{F} 11$ & Soil & $3.4-4.4$ & $\begin{array}{l}\text { Environmental } \\
\text { MS/MSD }\end{array}$ & $x$ & & & & & $x$ & $x$ & & \\
\hline 271F027 & $\mathrm{F} 11$ & Soil & $6.2-7.2$ & Environmental & \multicolumn{9}{|c|}{ Not Submitted for Analyses ${ }^{a}$} \\
\hline $271 \mathrm{~F} 028$ & F14 & Soil & $5.25-6.25$ & Integrity & $x$ & & & & & $x$ & $x$ & & \\
\hline
\end{tabular}


Table A.8-1

Samples Collected at CAS 25-04-10

(Page 3 of 5 )

\begin{tabular}{|c|c|c|c|c|c|c|c|c|c|c|c|c|c|}
\hline \multirow[b]{2}{*}{$\begin{array}{c}\text { Sample } \\
\text { Identification } \\
\text { Number }\end{array}$} & \multirow[b]{2}{*}{$\begin{array}{l}\text { Sample } \\
\text { Location }\end{array}$} & \multirow[b]{2}{*}{$\begin{array}{l}\text { Sample } \\
\text { Matrix }\end{array}$} & \multirow[b]{2}{*}{$\begin{array}{c}\text { Depth } \\
\text { (ft bgs) }\end{array}$} & \multirow[b]{2}{*}{ Purpose } & \multicolumn{9}{|c|}{ Analyses } \\
\hline & & & & & 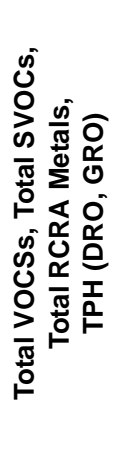 & 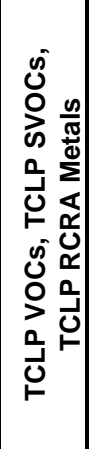 & 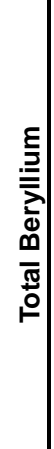 & 空 & 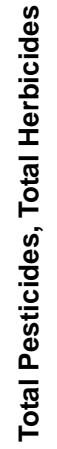 & 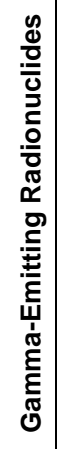 & 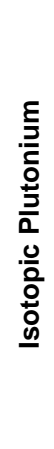 & 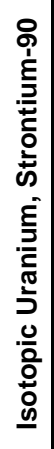 & 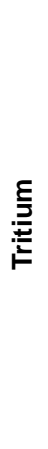 \\
\hline 271F029 & $\mathrm{F} 16$ & Soil & $3.4-4.4$ & Environmental & $x$ & & & & & $x$ & $x$ & & \\
\hline 271F030 & F16 & Soil & $6.4-7.4$ & Environmental & \multicolumn{9}{|c|}{ Not Submitted for Analyses ${ }^{a}$} \\
\hline 271F031 & F18 & Soil & $3.4-4.4$ & Environmental & $x$ & & & & & $x$ & $x$ & & \\
\hline 271F032 & $\mathrm{F} 18$ & Soil & $6.4-7.4$ & Environmental & \multicolumn{9}{|c|}{ Not Submitted for Analyses ${ }^{a}$} \\
\hline 271F033 & $\mathrm{F} 20$ & Soil & $3.4-4.4$ & Environmental & $x$ & & & & & $x$ & $x$ & & \\
\hline 271F034 & $\mathrm{F} 20$ & Soil & $6-7$ & Environmental & \multicolumn{9}{|c|}{ Not Submitted for Analyses ${ }^{a}$} \\
\hline 271F035 & F19 & Soil & $3.4-4.4$ & Environmental & $\mathrm{x}$ & & & & & $\mathrm{x}$ & $x$ & $\mathrm{x}$ & \\
\hline 271F036 & F19 & Soil & $6-7$ & Environmental & \multicolumn{9}{|c|}{ Not Submitted for Analyses ${ }^{a}$} \\
\hline 271F037 & F21 & Soil & $3-4$ & Environmental & $\mathrm{x}$ & & & & & $x$ & $x$ & & \\
\hline 271F038 & $\mathrm{F} 21$ & Soil & $5.5-6.5$ & Environmental & \multicolumn{9}{|c|}{ Not Submitted for Analyses ${ }^{a}$} \\
\hline 271F039 & $\mathrm{F} 22$ & Soil & $3.4-4.4$ & Environmental & $\mathrm{x}$ & & & & & $x$ & $x$ & & \\
\hline 271F040 & $\mathrm{F} 22$ & Soil & $6-7$ & Environmental & \multicolumn{9}{|c|}{ Not Submitted for Analyses ${ }^{a}$} \\
\hline 271F041 & $\mathrm{F} 23$ & Soil & $3.4-4.1$ & Environmental & $x$ & & & & & $X$ & $X$ & & \\
\hline 271F042 & F23 & Soil & $6-7$ & Environmental & \multicolumn{9}{|c|}{ Not Submitted for Analyses ${ }^{a}$} \\
\hline $271 \mathrm{~F} 043$ & $\mathrm{~F} 24$ & Soil & $3.4-4.4$ & Environmental & $x$ & & & & & $x$ & $X$ & & \\
\hline 271F044 & $\mathrm{F} 24$ & Soil & $6-7$ & Environmental & \multicolumn{9}{|c|}{ Not Submitted for Analyses ${ }^{a}$} \\
\hline 271F045 & $\mathrm{F} 17$ & Soil & $3.4-4.4$ & Environmental & $x$ & & & & & $x$ & $x$ & & \\
\hline $271 \mathrm{~F} 046$ & $\mathrm{~F} 17$ & Soil & $6-7$ & Environmental & \multicolumn{9}{|c|}{ Not Submitted for Analyses ${ }^{a}$} \\
\hline 271F047 & F25 & Soil & $3.4-4.4$ & $\begin{array}{l}\text { Environmental } \\
\text { MS/MSD }\end{array}$ & $x$ & & & & & $X$ & $\mathrm{x}$ & & \\
\hline 271F048 & $\mathrm{F} 25$ & Soil & $6-7$ & Environmental & \multicolumn{9}{|c|}{ Not Submitted for Analyses ${ }^{a}$} \\
\hline 271F049 & $\mathrm{F} 27$ & Soil & $3.2-4.2$ & Environmental & $\mathrm{X}$ & & & & & $X$ & $\mathrm{X}$ & & \\
\hline
\end{tabular}


Table A.8-1

Samples Collected at CAS 25-04-10

(Page 4 of 5 )

\begin{tabular}{|c|c|c|c|c|c|c|c|c|c|c|c|c|c|}
\hline \multirow[b]{2}{*}{$\begin{array}{c}\text { Sample } \\
\text { Identification } \\
\text { Number }\end{array}$} & \multirow[b]{2}{*}{$\begin{array}{l}\text { Sample } \\
\text { Location }\end{array}$} & \multirow[b]{2}{*}{$\begin{array}{l}\text { Sample } \\
\text { Matrix }\end{array}$} & \multirow[b]{2}{*}{$\begin{array}{c}\text { Depth } \\
\text { (ft bgs) }\end{array}$} & \multirow[b]{2}{*}{ Purpose } & \multicolumn{9}{|c|}{ Analyses } \\
\hline & & & & & 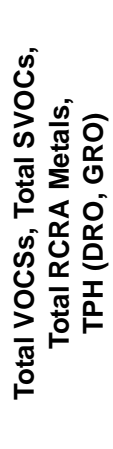 & 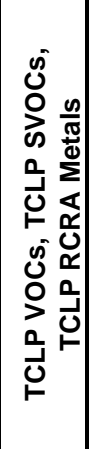 & 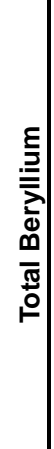 & 它 & 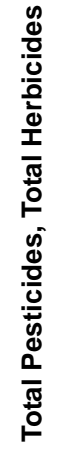 & 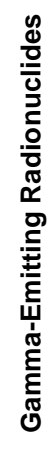 & 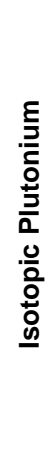 & 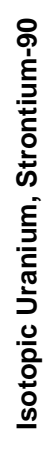 & $\underset{D}{E}$ \\
\hline 271F050 & $\mathrm{F} 27$ & Soil & $6-7$ & Environmental & \multicolumn{9}{|c|}{ Not Submitted for Analyses ${ }^{a}$} \\
\hline $271 \mathrm{~F} 051$ & F26 & Soil & $3.6-4.6$ & Environmental & $\mathrm{x}$ & & & & & $x$ & $\mathrm{x}$ & & \\
\hline 271F052 & $\mathrm{F} 26$ & Soil & $6-7$ & Environmental & \multicolumn{9}{|c|}{ Not Submitted for Analyses ${ }^{a}$} \\
\hline 271F053 & $\mathrm{F} 29$ & Soil & $3.4-4.4$ & Environmental & $x$ & & & & & $\mathrm{x}$ & $x$ & & \\
\hline 271F054 & $\mathrm{F} 29$ & Soil & $6-7$ & Environmental & \multicolumn{9}{|c|}{ Not Submitted for Analyses ${ }^{a}$} \\
\hline 271F055 & F30 & Soil & $3.4-4.4$ & Environmental & $x$ & & & & & $x$ & $x$ & & \\
\hline 271F056 & F30 & Soil & $3.4-4.4$ & $\begin{array}{c}\text { Duplicate of } \\
271 \mathrm{~F} 055\end{array}$ & $\mathrm{x}$ & & & & & $x$ & $x$ & & \\
\hline 271F057 & F30 & Soil & $6-7$ & Environmental & \multicolumn{9}{|c|}{ Not Submitted for Analyses ${ }^{a}$} \\
\hline 271F058 & F28 & Soil & $3.4-4.4$ & Environmental & $x$ & & & & & $x$ & $x$ & & \\
\hline 271F059 & $\mathrm{F} 28$ & Soil & $6-7$ & Environmental & \multicolumn{9}{|c|}{ Not Submitted for Analyses ${ }^{a}$} \\
\hline 271F060 & F31 & Soil & $3.4-4.4$ & Environmental & $x$ & & & & & $x$ & $x$ & & \\
\hline 271F061 & F31 & Soil & $6-7$ & Environmental & \multicolumn{9}{|c|}{ Not Submitted for Analyses ${ }^{a}$} \\
\hline 271F062 & F33 & Soil & $3.4-4.4$ & Environmental & $x$ & & & & & $x$ & $X$ & & \\
\hline 271F063 & F33 & Soil & $6-7$ & Environmental & \multicolumn{9}{|c|}{ Not Submitted for Analyses ${ }^{a}$} \\
\hline $271 \mathrm{~F} 064$ & F32 & Soil & $3.4-4.4$ & Environmental & $x$ & & & & & $x$ & $x$ & & \\
\hline 271F065 & F32 & Soil & $6-7$ & Environmental & \multicolumn{9}{|c|}{ Not Submitted for Analyses ${ }^{a}$} \\
\hline 271F066 & F34 & Soil & $3.4-4.4$ & Environmental & $x$ & & & & & $x$ & $x$ & & \\
\hline 271F067 & F34 & Soil & $6-7$ & Environmental & \multicolumn{9}{|c|}{ Not Submitted for Analyses ${ }^{a}$} \\
\hline 271F068 & F35 & Soil & $3.4-4.4$ & Environmental & $x$ & & & & & $x$ & $x$ & & \\
\hline 271F069 & F35 & Soil & $6-7$ & Environmental & \multicolumn{9}{|c|}{ Not Submitted for Analyses ${ }^{a}$} \\
\hline 271F070 & F15 & Soil & $6-7$ & Environmental & $x$ & & & & & $x$ & $x$ & & \\
\hline
\end{tabular}


Table A.8-1

Samples Collected at CAS 25-04-10

(Page 5 of 5)

\begin{tabular}{|c|c|c|c|c|c|c|c|c|c|c|c|c|c|}
\hline \multirow[b]{2}{*}{$\begin{array}{c}\text { Sample } \\
\text { Identification } \\
\text { Number }\end{array}$} & \multirow[b]{2}{*}{$\begin{array}{l}\text { Sample } \\
\text { Location }\end{array}$} & \multirow[b]{2}{*}{$\begin{array}{c}\text { Sample } \\
\text { Matrix }\end{array}$} & \multirow[b]{2}{*}{$\begin{array}{c}\text { Depth } \\
\text { (ft bgs) }\end{array}$} & \multirow[b]{2}{*}{ Purpose } & \multicolumn{9}{|c|}{ Analyses } \\
\hline & & & & & 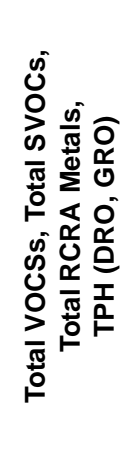 & 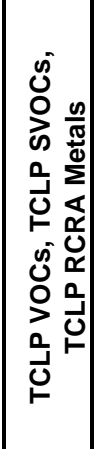 & 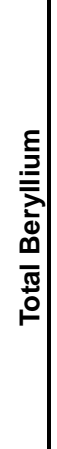 & 怘 & 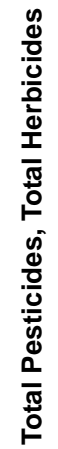 & 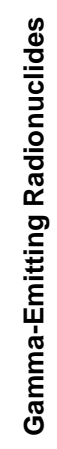 & 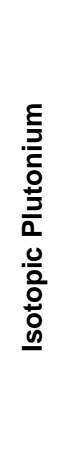 & 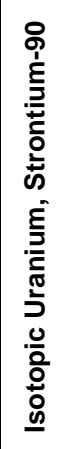 & 톨 \\
\hline 271F071 & F15 & Soil & $7.4-8.4$ & Environmental & \multicolumn{9}{|c|}{ Not Submitted for Analyses ${ }^{a}$} \\
\hline 271F072 & F38 & Soil & $3.4-4.4$ & Geotechnical & \multicolumn{9}{|c|}{ Not Submitted for Analyses ${ }^{b}$} \\
\hline 271F073 & F39 & Soil & $3-3.2$ & Environmental & \multicolumn{9}{|c|}{ Not Submitted for Analyses ${ }^{a}$} \\
\hline 271F301 & NA & Water & NA & Trip Blank & VOC only & & & & & & & & \\
\hline 271F302 & NA & Water & NA & Trip Blank & VOC only & & & & & & & & \\
\hline 271F303 & NA & Water & NA & Trip Blank & VOC only & & & & & & & & \\
\hline $271 \mathrm{~F} 304$ & NA & Water & NA & Trip Blank & VOC only & & & & & & & & \\
\hline 271F305 & NA & Water & NA & Trip Blank & VOC only & & & & & & & & \\
\hline 271F306 & NA & Water & NA & Rinsate & $x$ & & & & & $x$ & $x$ & $x$ & \\
\hline $271 \mathrm{~F} 307$ & NA & Water & NA & Field Blank & $x$ & & & & & $x$ & $x$ & $x$ & \\
\hline $271 \mathrm{~F} 308$ & NA & Water & NA & Source Blank & $x$ & & $X$ & $x$ & $X$ & $x$ & $x$ & $x$ & $x$ \\
\hline 271F309 & NA & Water & NA & Trip Blank & VOC only & & & & & & & & \\
\hline $271 \mathrm{~F} 310$ & NA & Water & NA & Trip Blank & VOC only & & & & & & & & \\
\hline 271F311 & NA & Water & NA & Trip Blank & VOC only & & & & & & & & \\
\hline 271F312 & NA & Water & NA & Trip Blank & VOC only & & & & & & & & \\
\hline $271 F 313$ & NA & Water & NA & Trip Blank & VOC only & & & & & & & & \\
\hline
\end{tabular}

${ }^{a}$ The sample was collected, field screened, and returned to the site for disposal.

${ }^{\mathrm{b}}$ The sample was collected, field screened, and is being stored for possible geotechnical analysis.

$\mathrm{NA}=$ Not applicable

MS/MSD = Matrix spike/matrix spike duplicate 


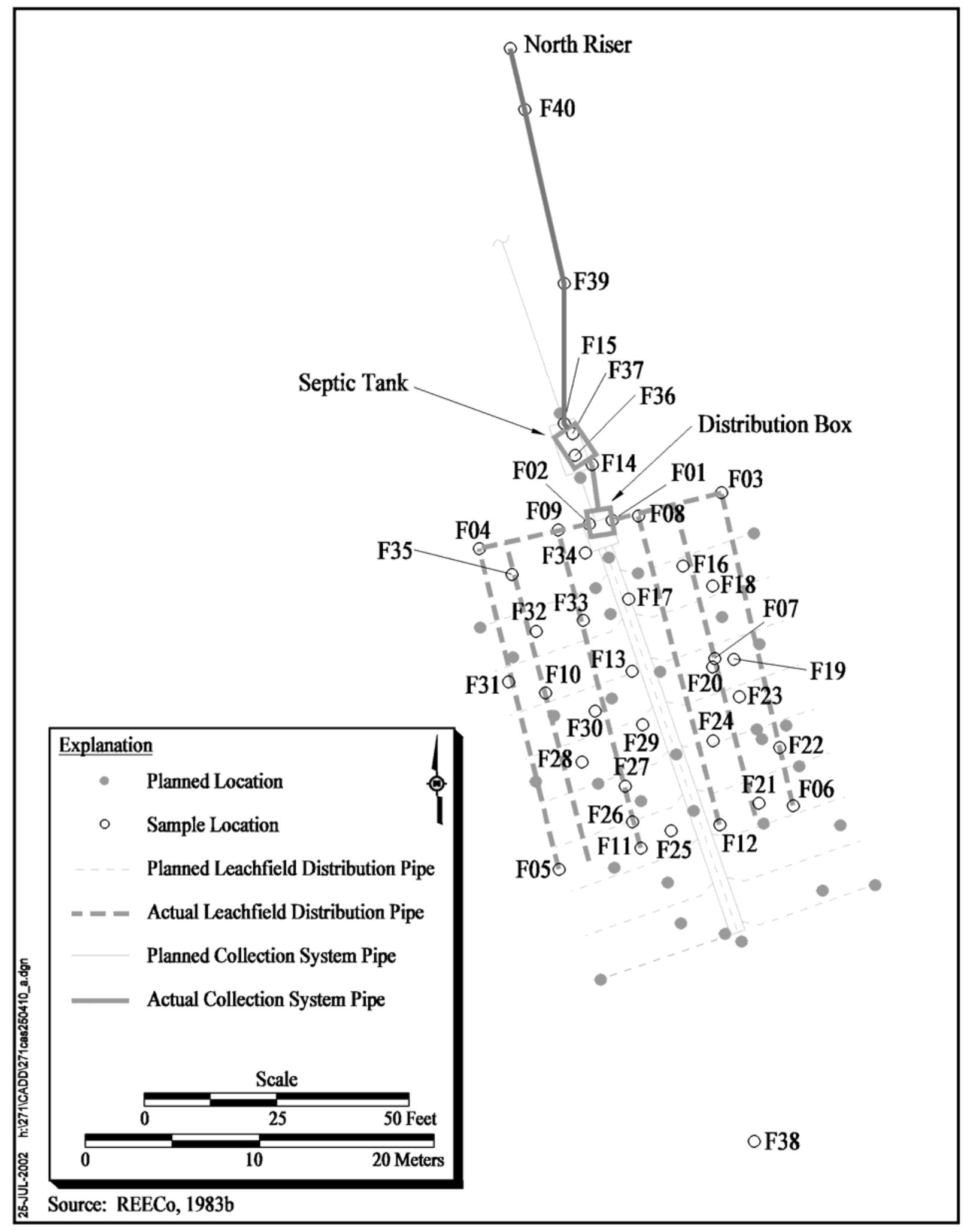

Figure A.8-1

Rad-Safe Trailers Septic System (CAS 25-04-10) 


\section{A.8.1.1 Deviations}

The following deviations to the CAIP-requirements were the result of unforeseen circumstances and changes to the conceptual model:

- The leachfield configuration was different than the planned configuration; however, the ITLV Task Manager decided that because the actual biased locations were similar to the planned locations, a transformation, rather than reselection, of random locations was appropriate. A linear transformation (a contingency of the CAIP) was necessary because the overall size of the leachfield was different than planned in the CAIP. The transformation was performed to rescale the points to fit the observed leachfield size. This process maintained the integrity of the random sampling scheme. No Record of Technical Change was required to implement the new sampling locations.

- Refusal was met due to encountering subsurface hardpan (caliche); therefore:

- Sample number 271F010 was collected at 6.5 to $7.5 \mathrm{ft}$ bgs rather than the planned interval of 7.5 to $8.5 \mathrm{ft}$ bgs

- Sample number 271F028 was collected at the planned interval of 5.25 to $6.25 \mathrm{ft}$ bgs (the second consecutive interval could not be obtained)

- Sample number 271F071 was collected at 7.5 to $8.5 \mathrm{ft}$ bgs rather than the planned interval of 8.5 to $9.5 \mathrm{ft}$ bgs

Despite these deviations, the pertinent CAIP requirements were met.

\section{A.8.2 Investigation Results}

The following subsections provide details of the inspection and sampling of leachfield features, field screening results, and sample selection and analysis.

\section{A.8.2.1 Septic Tank Contents}

The contents of the septic tank were not sampled as it did not contain adequate or appropriate material for sampling. The septic tank was a horizontal steel cylinder with a 729-gal capacity. The tank had two chambers and was accessed by two metal manholes located at approximately $2.75 \mathrm{ft}$ bgs. The interior dimensions of the tank were approximately $7.75 \mathrm{ft}$ (length) by $4 \mathrm{ft}$ (diameter). Photographs of the exterior of the septic tank were taken to document the visual inspection (Figure A.8-2). Some soil inadvertently spilled into the tank through the manholes during the investigation. 


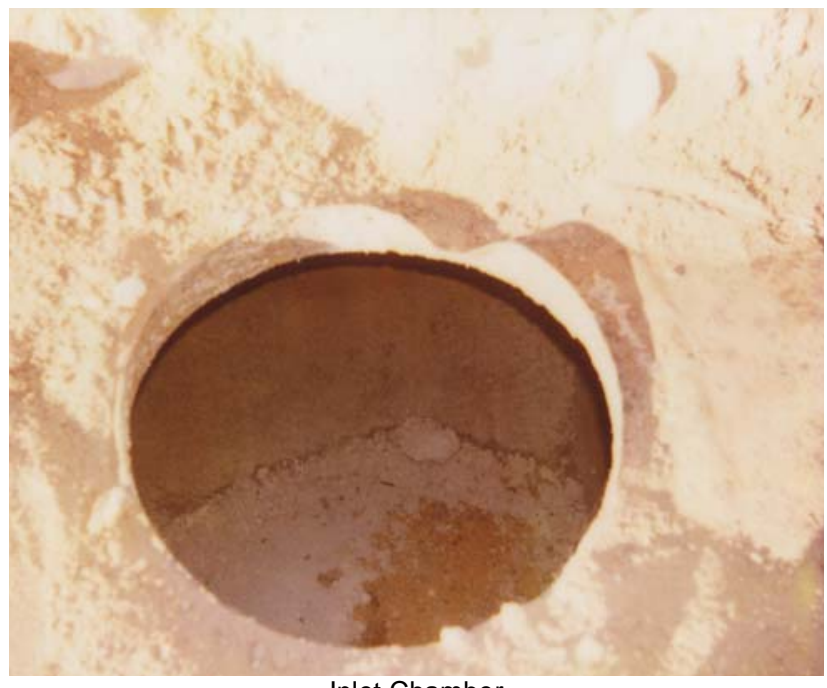

Inlet Chamber

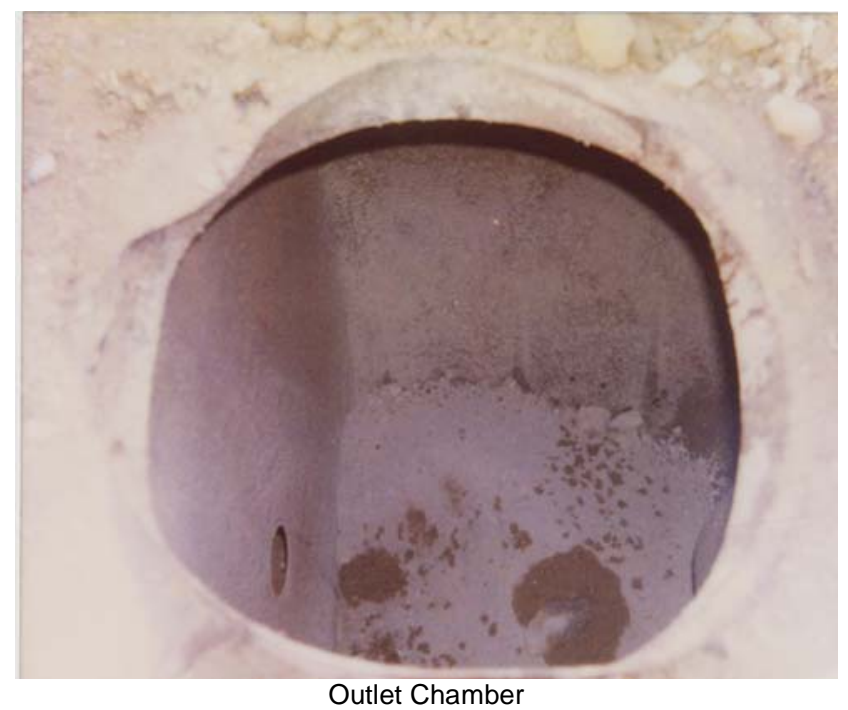

Outlet Chamber

Figure A.8-2

CAS 25-04-10 Septic Tank Chambers

(Photographs Taken 11-13-2001)

\section{A.8.2.2 Distribution Box Contents}

The distribution box was a concrete rectangular structure with a 233-gal capacity. The top of the box was approximately even with the ground surface. The exterior dimensions of the distribution box are $4.3 \mathrm{ft}$ (length) by $2.3 \mathrm{ft}$ (width) by $3.1 \mathrm{ft}$ (depth). The entire top of the distribution box was open. The box was filled with soils; therefore, no samples were collected from the box. A photograph of the distribution box was taken to document the visual inspection (Figure A.8-3).

\section{A.8.2.3 Septic Tank and Distribution Box Integrity Soil Sampling}

Seven (eight were planned; see Section A.8.1.1 for further details) integrity samples were collected by excavating adjacent to the influent and effluent ends of the septic tank and the effluent sides of the distribution box. A photograph (Figure A.8-4) of the influent end of the septic tank was taken to document the structural integrity and configuration. The distribution box had two effluent lines, so samples were collected on each side of the box. The following four samples were submitted for laboratory analysis:

- The upper sample (271F001) from the eastern effluent end of the distribution box, collected at 6.2 to $7.2 \mathrm{ft}$ bgs 


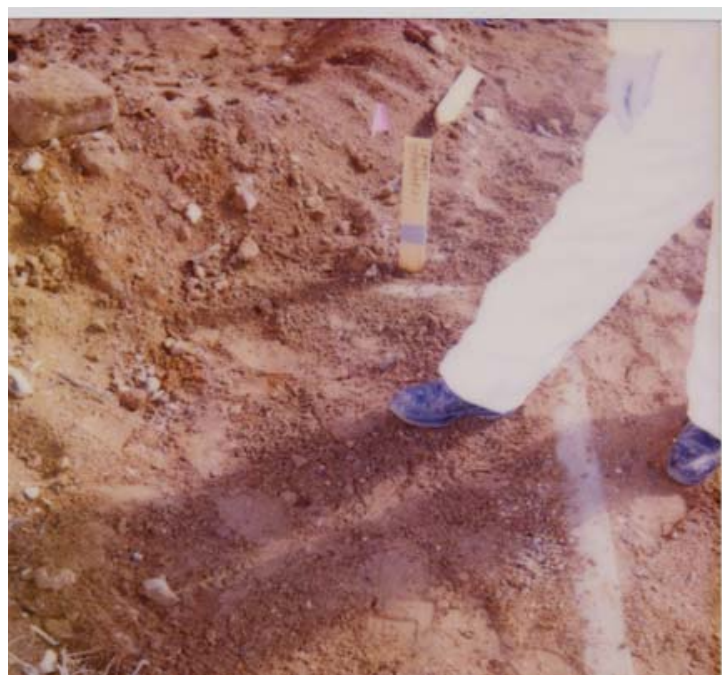

Figure A.8-3

CAS 25-04-10 Distribution Box (Photograph Taken 11-13-2001)

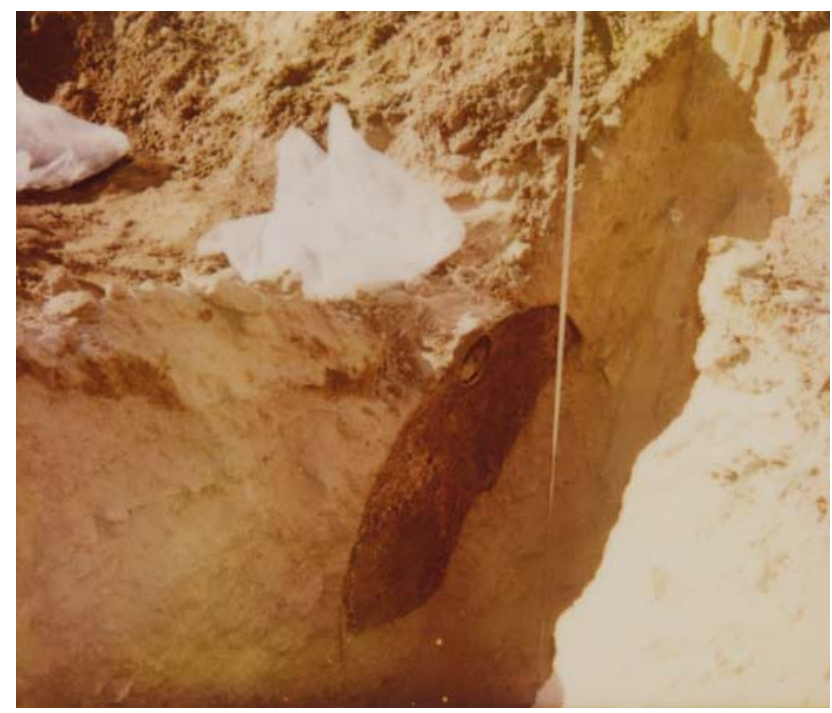

Figure A.8-4

CAS 25-04-10 Septic Tank, Influent End (Photograph Taken 11-13-2001) 
- The upper sample (271F003) from the western effluent end of the distribution box, collected at 4.4 to $5.4 \mathrm{ft}$ bgs

- The upper sample (271F028) from the effluent end of the septic tank, collected at 5.25 to $6.25 \mathrm{ft}$ bgs

- The upper sample (271F070) from the influent end of the septic tank, collected at 6 to $7 \mathrm{ft}$ bgs

\section{A.8.2.4 Leachfield Excavation Soil Sampling}

Backhoe excavations were conducted to access sampling horizons at the biased and random locations presented in the CAIP. Excavations provided a visual verification of distribution pipes and enabled soil samples to be collected from appropriate intervals beneath the pipes, as specified by the CAIP. Seventy-one-two soil samples were collected from the planned locations excavated within the leachfield. These samples were collected from an interval at the leachrock/native soil interface and an interval $2.5 \mathrm{ft}$ below the interface. The interface was found at depths ranging from 2.6 to $4 \mathrm{ft}$ bgs. Thirty-six samples were submitted for laboratory analysis. In addition, two QC soil duplicates and two MS/MSD samples were collected and analyzed. A geotechnical sample was collected outside the boundary of the leachfield. The sample will be sent to a laboratory for geotechnical analysis if necessary.

\section{A.8.2.5 Collection System Pipe Inspections}

Access points for inspection by video mole were created at locations along the collection system pipe via backhoe excavation.

The video mole was inserted through the VCP at the influent side of the septic tank, at the excavation made during the collection of the inlet side integrity sample. Some sediment was identified in the piping, but was not appropriate or adequate material to be sampled. The video mole was passed down through the pipe for $23 \mathrm{ft}$ where an obstruction in the form of a pipe break was encountered. Figure A.8-5 depicts the break in the pipe. An excavation (F39) was made at the location where the pipe break was noted. Additional pipe breaks were noted upstream of location F39, so the video mole survey could not be performed. An excavation (F40) was made approximately $63 \mathrm{ft}$ north of the septic tank (Figure A.8-1). The video mole was passed upstream in the pipe, and it was noted that the pipe diameter changed from 4 to 6 in. The 6 -in. pipe was inspected with the video mole for $8 \mathrm{ft}$, where a 
riser from an overlying concrete pad joined the 6 in. diameter pipe. This appeared to be the termination of the pipe. The total length of pipe from the influent end of the septic tank to the termination point is approximately $71 \mathrm{ft}$. Although the collection system pipe had been broken extensively between locations F39 and F40, no sediment related to the use of the septic system was found. All pipe segments were clean and contained soil where broken.

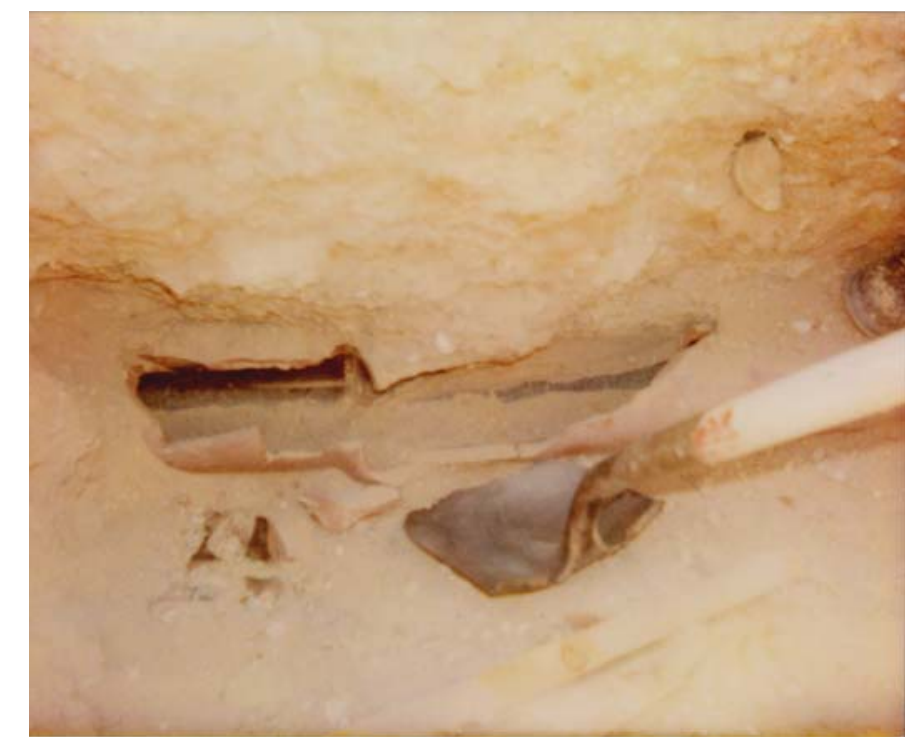

Figure A.8-5

\section{CAS 25-04-10 Pipe Break Located $23 \mathrm{ft}$ North of Septic Tank (Photograph Taken 11-13-2001)}

Visual observations were recorded in the FADLs. Portions of the pipe at the excavated locations (designated F39 and F40) were radiologically surveyed. Section A.8.2.7 provides further details regarding the radiological results.

\section{A.8.2.6 Field-Screening Results}

Soil samples were screened for VOCs and alpha and beta/gamma radioactivity. The field readings were compared to FSLs to guide sampling decisions and determine which samples were to be submitted for laboratory analysis. No VOCs greater than FSLs were found during soil sample screening. The results of radiological field screening are discussed in Section A.8.2.7. 


\section{A.8.2.7 Radiological Survey Results}

All radiological field screening results for soil samples from CAS 25-04-10 were below FSLs. The results of the radiological survey of pipe at locations F39, F40, and a riser at the end of the pipe indicate that the collection system pipeline meets the unrestricted release criteria as defined in the NV/YMP Radiological Control Manual (DOE/NV, 2000a).

\section{A.8.2.8 Sample Analysis}

Environmental soil samples and associated QC samples were collected and analyzed for the CAIP-specified COPC (i.e., total VOCs, total SVOCs, total RCRA metals, and TPH [DRO and GRO]). In addition, 25 percent of the soil samples and 100 percent of the associated QC samples were analyzed for Iso-U, Sr-90, and gamma-emitting radionuclides. One-hundred percent of the soil and the associated QC samples were analyzed for Iso-Pu.

The parameters and laboratory methods used to analyze the investigation samples are listed in Table A.2-2. Table A.8-1 lists the sample-specific analytical parameters.

\section{A.8.3 Analytes Detected Above Minimum Reporting Limits}

The soil sample analytical results with concentrations exceeding corresponding MRLs or PALs (DOE/NV, 1998; DOE/NV, 2001) at CAS 25-04-10 are summarized in the following sections. A portion of the CAS 25-04-10 analytical results were rejected during validation; however, these rejected data did not impact closure decisions as discussed in Section B.1.3.6 of Appendix B.

\section{A.8.3.1 Analytical Results for Soil Samples}

The following sections discuss the results for soil samples in comparison to the levels established in the Leachfield Work Plan and the CAIP.

\section{A.8.3.1.1 Total Volatile Organic Compounds}

Volatile organic compound results are reported in Table A.8-2. The only organic compound detected above its MRL of $5 \mu \mathrm{g} / \mathrm{kg}$ was methylene chloride at $51 \mu \mathrm{g} / \mathrm{kg}$ in sample $271 \mathrm{~F} 009$. The methylene 
chloride concentration was below the PAL of $21,000 \mu \mathrm{g} / \mathrm{kg}$. Methylene chloride is a common laboratory contaminant.

Table A.8-2

Soil Sample Results for Total VOCs Detected Above Minimum Reporting Limits at CAS 25-04-10

\begin{tabular}{|c|c|c|}
\hline \multirow{2}{*}{$\begin{array}{c}\text { Sample } \\
\text { Identification } \\
\text { Number }\end{array}$} & \multirow{2}{*}{$\begin{array}{l}\text { Depth } \\
\text { (ft bgs) }\end{array}$} & $\begin{array}{c}\text { Contaminants of Potential Concern } \\
\qquad(\mu \mathrm{g} / \mathrm{kg})\end{array}$ \\
\hline & & Methylene Chloride \\
\hline \multicolumn{2}{|c|}{ Preliminary Action Levels ${ }^{a}$} & 21,000 \\
\hline $271 \mathrm{~F} 009$ & $4.4-5.4$ & 51 \\
\hline
\end{tabular}

${ }^{a}$ Based on U.S. Environmental Protection Agency, Region 9 Preliminary Remediation Goals (PRGs) (EPA, 2000).

\section{A.8.3.1.2 Total Semivolatile Organic Compounds}

Semivolatile organic compounds were not detected above MRLs in CAS 25-04-10 soil samples.

\section{A.8.3.1.3 Total Petroleum Hydrocarbons}

Total petroleum hydrocarbons were not detected above MRLs in CAS 25-04-10 soil samples.

\section{A.8.3.1.4 Total RCRA Metals}

As shown in Table A.8-3, the total RCRA metals detected in soil samples at concentrations exceeding the MRLs are arsenic (1 mg/kg), barium (20 mg/kg), chromium (1 mg/kg), lead $(0.3 \mathrm{mg} / \mathrm{kg})$, and selenium $(0.5 \mathrm{mg} / \mathrm{kg})$. Other RCRA metals (i.e., cadmium, mercury, silver) were below specified MRLs.

Barium concentrations ranged from 68 to $140 \mathrm{mg} / \mathrm{kg}$, chromium concentrations ranged from 2.2 to $4 \mathrm{mg} / \mathrm{kg}$, lead concentrations ranged from 4.5 to $7.8 \mathrm{mg} / \mathrm{kg}$, and selenium concentrations were reported in only one sample (271F005) at an estimated concentration of $0.63 \mathrm{mg} / \mathrm{kg}$. All reported concentrations of these metals were below EPA Region 9 PRGs defined in this document as PALs. 
Table A.8-3

Soil Sample Results for Total RCRA Metals Detected Above Minimum Reporting Limits at CAS 25-04-10

(Page 1 of 2)

\begin{tabular}{|c|c|c|c|c|c|c|}
\hline \multirow{2}{*}{$\begin{array}{c}\text { Sample } \\
\text { Identification } \\
\text { Number }\end{array}$} & \multirow{2}{*}{$\begin{array}{l}\text { Depth } \\
\text { (ft bgs) }\end{array}$} & \multicolumn{5}{|c|}{ Contaminants of Potential Concern $(\mathrm{mg} / \mathrm{kg})$} \\
\hline & & Arsenic & Barium & Chromium & Lead & Selenium \\
\hline \multicolumn{2}{|c|}{ Preliminary Action Levels ${ }^{a}$} & 2.7 & 100,000 & 450 & 750 & 10,000 \\
\hline $271 \mathrm{~F} 001$ & $4.3-5.3$ & 2.5 & 89 & 3.1 & 5.1 & -- \\
\hline $271 \mathrm{~F} 003$ & $4.4-5.4$ & 2.8 & 89 & 3.2 & 5.3 & -- \\
\hline 271F005 & $3.7-5$ & $2.6(\mathrm{~J})$ & $73(\mathrm{~J})$ & $2.6(\mathrm{~J})$ & $6.2(\mathrm{~J})$ & $0.63(\mathrm{~J})$ \\
\hline $271 \mathrm{~F} 007$ & $4.4-5.4$ & 2.4 & 98 & 3.4 & 5.6 & -- \\
\hline 271F009 & $4.4-5.4$ & 2.4 & 86 & 3.5 & 7.8 & -- \\
\hline 271F011 & $3.4-4.4$ & 3.1 & 100 & 4 & 7.7 & -- \\
\hline $271 \mathrm{~F} 013$ & $4-5$ & 3 & 110 & 3.9 & 5.7 & -- \\
\hline 271F015 & $3.5-4.5$ & 2.6 & 110 & 3.8 & 5.6 & -- \\
\hline 271F016 & $3.5-4.5$ & 2.5 & 120 & 3.5 & 6.1 & -- \\
\hline 271F018 & $2.4-3.4$ & 2.7 & 79 & 3.3 & 5.2 & -- \\
\hline 271F020 & $3.4-4.4$ & 2 & 100 & 2.8 & 4.9 & -- \\
\hline 271F022 & $3-4$ & 2.3 & 84 & 3.5 & 5.9 & -- \\
\hline $271 \mathrm{~F} 024$ & $3.2-4.2$ & 2.9 & 120 & 3.6 & 5.1 & -- \\
\hline $271 \mathrm{~F} 026$ & $3.4-4.4$ & 2.8 & 110 & 3.2 & 4.9 & -- \\
\hline 271F028 & $5.25-6.25$ & 2.9 & 110 & 3.1 & 6.1 & -- \\
\hline $271 \mathrm{~F} 029$ & $3.4-4.4$ & 2.8 & 100 & 3 & 5.7 & $\begin{array}{l}- \\
\end{array}$ \\
\hline 271F031 & $3.4-4.4$ & 2.5 & 76 & 2.6 & 4.5 & -- \\
\hline 271F033 & $3.4-4.4$ & 2.8 & 96 & 3.1 & 6.4 & -- \\
\hline 271F035 & $3.4-4.4$ & 2.7 & 87 & 3 & 7 & -- \\
\hline 271F037 & $3-4$ & 3 & 140 & 3 & 5.5 & -- \\
\hline 271F039 & $3.4-4.4$ & 2.7 & 110 & 2.9 & 5.5 & -- \\
\hline $271 \mathrm{~F} 041$ & $3.4-4.4$ & 2.3 & 72 & 2.2 & 5.6 & -- \\
\hline 271F043 & $3.4-4.4$ & 2.8 & 86 & 3.7 & 5.6 & -- \\
\hline 271F045 & $3.4-4.4$ & 2.9 & 95 & 3.3 & 5.2 & -- \\
\hline $271 \mathrm{~F} 047$ & $3.4-4.4$ & 2.5 & 120 & 2.7 & 4.9 & -- \\
\hline $271 \mathrm{~F} 049$ & $3.2-4.2$ & 2.6 & 68 & 2.7 & 5.5 & -- \\
\hline 271F051 & $3.6-4.6$ & 2.6 & 85 & 2.6 & 4.6 & -- \\
\hline 271F053 & $3.4-4.4$ & 2.9 & 120 & 2.6 & 5.6 & -- \\
\hline 271F055 & $3.4-4.4$ & 2.8 & 81 & 2.6 & 5 & -- \\
\hline $271 \mathrm{~F} 056$ & $3.4-4.4$ & 2.5 & 86 & 2.6 & 5 & -- \\
\hline 271F058 & $3.4-4.4$ & 2.8 & 80 & 2.6 & 5 & -- \\
\hline 271F060 & $3.4-4.4$ & 2.9 & 95 & 2.9 & 5.7 & -- \\
\hline 271F062 & $3.4-4.4$ & 2.9 & 79 & 2.8 & 5 & -- \\
\hline
\end{tabular}




\section{Table A.8-3 \\ Soil Sample Results for Total RCRA Metals \\ Detected Above Minimum Reporting Limits at CAS 25-04-10}

(Page 2 of 2)

\begin{tabular}{|c|c|c|c|c|c|c|}
\hline \multirow{2}{*}{$\begin{array}{c}\text { Sample } \\
\text { Identification } \\
\text { Number }\end{array}$} & \multirow{2}{*}{$\begin{array}{l}\text { Depth } \\
\text { (ft bgs) }\end{array}$} & \multicolumn{5}{|c|}{ Contaminants of Potential Concern (mg/kg) } \\
\hline & & Arsenic & Barium & Chromium & Lead & Selenium \\
\hline \multicolumn{2}{|c|}{ Preliminary Action Levels ${ }^{a}$} & 2.7 & 100,000 & 450 & 750 & 10,000 \\
\hline 271F064 & $3.4-4.4$ & 2.4 & 81 & 2.9 & 5.1 & -- \\
\hline 271F066 & $3.4-4.4$ & 2.7 & 100 & 3.1 & 5.7 & -- \\
\hline $271 \mathrm{~F} 068$ & $3.4-4.4$ & 2 & 89 & 2.4 & 4.5 & -- \\
\hline 271F070 & $6-7$ & 2.9 & 120 & 3.4 & 6.5 & -- \\
\hline
\end{tabular}

aBased on U.S. Environmental Protection Agency, Region 9 Preliminary Remediation Goals (PRGs) (EPA, 2000).

-- = Not detected above minimum reporting limits

$\mathrm{J}=$ Estimated value. Qualifier added to laboratory data; record accepted. Improper preservation/pH or sample temperature not documented during analysis.

Arsenic concentrations ranged from 2 to $3.1 \mathrm{mg} / \mathrm{kg}$. Approximately half of the detections in the leachfield soil samples slightly exceeded the PAL of $2.7 \mathrm{mg} / \mathrm{kg}$. Concentrations were consistent across the site, with no "hot spots" or evidence of a localized spill. The PAL is lower than the 7 to $8 \mathrm{mg} / \mathrm{kg}$ mean concentration of arsenic in silt from the Nevada Test and Training Range (NBMG, 1998; Moore, 1999). Arsenic concentrations in the soil exceed the PAL, but are believed to be within ambient conditions for CAS 25-04-10 and do not represent contamination.

\section{A.8.3.1.5 Gamma Spectrometry Results}

Results of soil sample gamma spectrometry analysis are presented in Table A.8-4. Concentrations of actinium-228, bismuth-212, bismuth-214, lead-212, lead-214, potassium-40, and thallium-208 were detected above the MDLs. The TPU in the radioanalytical measurement is provided in the table along with the concentration for all detected gamma emitters. The concentrations of the detected gamma-emitting radionuclides are below PALs and are not significantly different than concentrations measured in soil samples collected from undisturbed background locations. 
Table A.8-4

Soil Sample Results for Gamma-Emitting Radionuclides Detected Above Minimum Reporting Limits at CAS 25-04-10

\begin{tabular}{|c|c|c|c|c|c|c|c|c|}
\hline \multirow{2}{*}{$\begin{array}{c}\text { Sample } \\
\text { Identification } \\
\text { Number }\end{array}$} & \multirow{2}{*}{$\begin{array}{l}\text { Depth } \\
\text { (ft bgs) }\end{array}$} & \multicolumn{7}{|c|}{ Contaminants of Potential Concern (pCi/g) } \\
\hline & & Actinium-228 ${ }^{\mathrm{a}}$ & Bismuth-212 ${ }^{\mathrm{b}}$ & Bismuth-214 ${ }^{\mathrm{b}}$ & Lead-212 $^{\mathrm{a}}$ & Lead-214 ${ }^{\mathrm{b}}$ & Potassium $-40^{\mathrm{a}}$ & Thallium-208 ${ }^{\mathrm{a}}$ \\
\hline \multicolumn{2}{|c|}{ Preliminary Action Level } & 3.64 & 2.4 & 3.47 & 2.9 & 2.9 & 96 & 3.4 \\
\hline $271 \mathrm{~F} 007$ & $4.4-5.4$ & $1.3 \pm 0.33$ & $\overline{---}$ & $0.63 \pm 0.20$ & $1.63 \pm 0.33$ & $0.74 \pm 0.20$ & $24.7 \pm 4.9$ & $0.41 \pm 0.12$ \\
\hline $271 \mathrm{~F} 011$ & $3.4-4.4$ & $1.16 \pm 0.34$ & -- & $0.7 \pm 0.23$ & $1.39 \pm 0.29$ & $0.88 \pm 0.22$ & $23.6 \pm 4.7$ & $0.52 \pm 0.14$ \\
\hline $271 \mathrm{~F} 013$ & $4-5$ & $1.47 \pm 0.38$ & -- & $0.8 \pm 0.24$ & $1.27 \pm 0.28$ & $0.66 \pm 0.18$ & $26.4 \pm 5.2$ & $0.45 \pm 0.13$ \\
\hline $271 \mathrm{~F} 015$ & $3.5-4.5$ & $1.07 \pm 0.30$ & $\overline{--}$ & $0.53 \pm 0.18$ & $1.41 \pm 0.31$ & $0.9 \pm 0.22$ & $26.5 \pm 5.3$ & $0.51 \pm 0.14$ \\
\hline $271 \mathrm{~F} 016$ & $3.5-4.5$ & $1.31 \pm 0.27$ & -- & $0.67 \pm 0.16$ & $1.54 \pm 0.28$ & $0.79 \pm 0.17$ & $27.8 \pm 4.8$ & $0.48 \pm 0.10$ \\
\hline $271 \mathrm{~F} 018$ & $2.4-3.4$ & $1.35 \pm 0.37$ & -- & $0.69 \pm 0.22$ & $1.49 \pm 0.32$ & $0.7 \pm 0.19$ & $28.7 \pm 5.6$ & $0.55 \pm 0.15$ \\
\hline 271F026 & $3.4-4.4$ & $1.23 \pm 0.26$ & -- & $0.71 \pm 0.16$ & $1.5 \pm 0.28$ & $0.85 \pm 0.17$ & $28.3 \pm 4.9$ & $0.51 \pm 0.11$ \\
\hline $271 \mathrm{~F} 028$ & $5.25-6.25$ & $1.49 \pm 0.30$ & $2.03 \pm 0.71$ & $0.71 \pm 0.17$ & $1.47 \pm 0.27$ & $0.77 \pm 0.17$ & $29.6 \pm 5.1$ & $0.456 \pm 0.099$ \\
\hline $271 \mathrm{~F} 047$ & $3.4-4.4$ & $1.29 \pm 0.27$ & $1.52 \pm 0.61$ & $0.74 \pm 0.17$ & $1.67 \pm 0.30$ & $0.81 \pm 0.17$ & $28.1 \pm 4.9$ & $0.54 \pm 0.11$ \\
\hline $271 \mathrm{~F} 055$ & $3.4-4.4$ & $1.41 \pm 0.29$ & -- & $0.65 \pm 0.16$ & $1.56 \pm 0.29$ & $0.8 \pm 0.17$ & $28.9 \pm 5.0$ & $0.45 \pm 0.10$ \\
\hline $271 \mathrm{~F} 056$ & $3.4-4.4$ & $1.02 \pm 0.30$ & -- & $0.78 \pm 0.24$ & $1.59 \pm 0.34$ & $0.65 \pm 0.19$ & $26.8 \pm 5.3$ & $0.37 \pm 0.12$ \\
\hline
\end{tabular}

aBackground concentration listed in Environmental Monitoring Report for the Proposed Ward Valley, California, Low-Level Radioactive Waste (LLRW) Facility (US Ecology and Atlan-Tech, 1992).

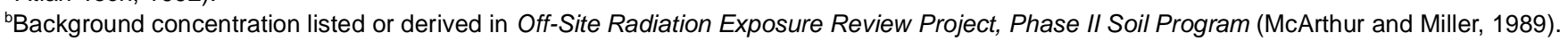

$--=$ Not detected above minimum reporting limit 


\section{A.8.3.1.6 Isotopic Uranium}

Detected values of uranium isotopes, along with associated TPUs are reported in Table A.8-5. Most data results are less than PALs. Sample numbers 271F018, 271F026, and 271F028 had concentrations of U-235 above the PAL; therefore, a normalized difference based on a confidence level of 95 percent was used to determine if the concentrations were statistically distinguishable from background. This method indicated that the U-235 concentrations in the soil samples were not significantly greater than concentrations in soil samples collected from undisturbed background locations.

Table A.8-5

Soil Sample Results for Plutonium and Uranium Isotopes Detected Above Minimum Reporting Limits at CAS 25-04-10

\begin{tabular}{|c|c|c|c|c|c|}
\hline \multirow{2}{*}{$\begin{array}{c}\text { Sample } \\
\text { Identification } \\
\text { Number }\end{array}$} & \multirow{2}{*}{$\begin{array}{c}\text { Depth } \\
\text { (ft bgs) }\end{array}$} & \multicolumn{4}{|c|}{ Contaminants of Potential Concern ( $\mathrm{pCi} / \mathrm{g})$} \\
\hline & & Plutonium-239 & Uranium-234 ${ }^{\mathrm{a}}$ & Uranium-235 ${ }^{\mathrm{a}}$ & Uranium-238 \\
\hline \multicolumn{2}{|c|}{ Preliminary Action Levels } & 0.24 & 1.56 & 0.07 & 3.2 \\
\hline $271 \mathrm{~F} 007$ & $4.4-5.4$ & -- & $0.85 \pm 0.16$ & $0.064 \pm 0.034$ & $0.77 \pm 0.15$ \\
\hline $271 \mathrm{~F} 011$ & $3.4-4.4$ & $0.047 \pm 0.025(\mathrm{LT})$ & $0.85 \pm 0.18$ & -- & $0.91 \pm 0.18$ \\
\hline $271 \mathrm{~F} 013$ & $4-5$ & -- & $1.05 \pm 0.19$ & -- & $0.96 \pm 0.18$ \\
\hline $271 \mathrm{~F} 015$ & $3.5-4.5$ & -- & $0.76 \pm 0.15$ & -- & $0.81 \pm 0.16$ \\
\hline $271 \mathrm{~F} 016$ & $3.5-4.5$ & -- & $0.81 \pm 0.16$ & $0.044 \pm 0.028(\mathrm{LT})$ & $0.87 \pm 0.17$ \\
\hline 271F018 & $2.4-3.4$ & -- & $0.87 \pm 0.17$ & $0.075 \pm 0.038$ & $0.91 \pm 0.17$ \\
\hline 271F022 & $3-4$ & $0.106 \pm 0.039$ & -- & -- & -- \\
\hline $271 \mathrm{~F} 026$ & $3.4-4.4$ & -- & $0.83 \pm 0.15$ & $0.082 \pm 0.035$ & $0.83 \pm 0.15$ \\
\hline 271F028 & $5.25-6.25$ & -- & $0.73 \pm 0.14$ & $0.076 \pm 0.036$ & $0.75 \pm 0.14$ \\
\hline $271 \mathrm{~F} 047$ & $3.4-4.4$ & -- & $0.89 \pm 0.19$ & -- & $0.87 \pm 0.18$ \\
\hline 271F055 & $3.4-4.4$ & -- & $0.84 \pm 0.18$ & -- & $0.85 \pm 0.18$ \\
\hline 271F056 & $3.4-4.4$ & -- & $0.72 \pm 0.16$ & -- & $0.79 \pm 0.17$ \\
\hline
\end{tabular}

${ }^{a}$ Background concentration listed in Environmental Monitoring Report for the Proposed Ward Valley, California, Low-Level Radioactive Waste (LLRW) Facility (US Ecology and Atlan-Tech, 1992).

${ }^{\mathrm{b}}$ Background concentration listed or derived in Off-Site Radiation Exposure Review Project, Phase II Soil Program (McArthur and Miller, 1989).

$\mathrm{LT}=$ Result is less than requested minimum detectable concentration (MDC), greater than sample specific MDC -- = Not detected above minimum reporting limit 


\section{A.8.3.1.7 Isotopic Plutonium}

Detected values of plutonium isotopes, along with associated TPUs are reported in Table A.8-5. The concentrations of $\mathrm{Pu}-239$ were below PALs and were not significantly greater than concentrations in soil samples collected from undisturbed background locations.

\section{A.8.3.1.8 Strontium-90}

Strontium-90 was not detected above MRLs in CAS 25-04-10 soil samples.

\section{A.8.3.2 Septic Tank, Distribution Box, and Pipe Content Sample Results}

There were no samples taken as the septic tank was dry and did not contain material related to the operation of the septic system. The distribution box was filled with native material.

\section{A.8.4 Contaminants of Concern}

Based on the aforementioned analytical results, no COCs are present in the soil surrounding the septic tank and distribution box, under the leachfield, or in the septic tank or distribution box.

\section{A.8.5 Nature and Extent of Contamination}

No COCs were identified for this CAS.

\section{A.8.6 Revised Conceptual Model}

Variations to the leachfield configuration were identified. The originally assumed configuration is depicted in Figure 4-6 of the CAIP. The actual configuration is depicted in Figure A.8-1. This change in configuration did not remove this site from the general conceptual model for leachfield systems presented in the Leachfield Work Plan (DOE/NV, 1998). Biased soil samples were ultimately collected from the leachrock/native soil interfaces, and random soil samples were collected in accordance with the CAIP. 


\section{A.9.0 South of LASL Trailers Septic System (CAS 25-04-11)}

The LASL trailers septic system was designed to receive sanitary effluent generated by activities from Building 3127 (Cafeteria), Building 3129 (Technical Operations Building), and approximately 48 LASL sleeping trailers. The septic system is located approximately $530 \mathrm{ft}$ south of the RCP complex fenceline. The site is comprised of a leachfield, septic tank, distribution box, and associated piping. More detail is provided in the CAIP (DOE/NV, 2001).

\section{A.9.1 Corrective Action Investigation}

Eighty-nine investigation samples, listed in Table A.9-1, were collected during investigation activities conducted at CAS 25-04-11. The planned and actual sample locations are shown in Figure A.9-1. The specific CAI activities conducted to meet CAIP requirements at CAS 25-04-11 are described in Table A.2-1.

\section{A.9.1.1 Deviations}

The following deviations to the CAIP-requirements were the result of unforeseen circumstances:

- Sample numbers 271G021 and 271G022 (field duplicate) were collected from 4 to $5 \mathrm{ft}$ bgs rather than the planned interval of $3.6 \mathrm{ft}$ to $4.6 \mathrm{ft}$ bgs due to too much slough material being removed from the excavation.

- Refusal was met due to encountering subsurface hardpan (caliche); therefore:

- Sample 271G001 was collected at 4.7 to $5 \mathrm{ft}$ bgs rather than the planned interval of 4.7 to $5.7 \mathrm{ft} \mathrm{bgs}$

- Sample 271G002 was collected at 6 to $6.5 \mathrm{ft}$ bgs rather than the planned interval of 6.2 to $7.2 \mathrm{ft} \mathrm{bgs}$

- Sample 271G012 was collected at 5 to $5.5 \mathrm{ft}$ bgs rather than the planned interval of 6 to $7 \mathrm{ft}$ bgs

- Sample 271G023 was collected at 5 to $5.5 \mathrm{ft}$ bgs rather than the planned interval of 5 to $6 \mathrm{ft}$ bgs 
Table A.9-1

Samples Collected at CAS 25-04-11

(Page 1 of 5 )

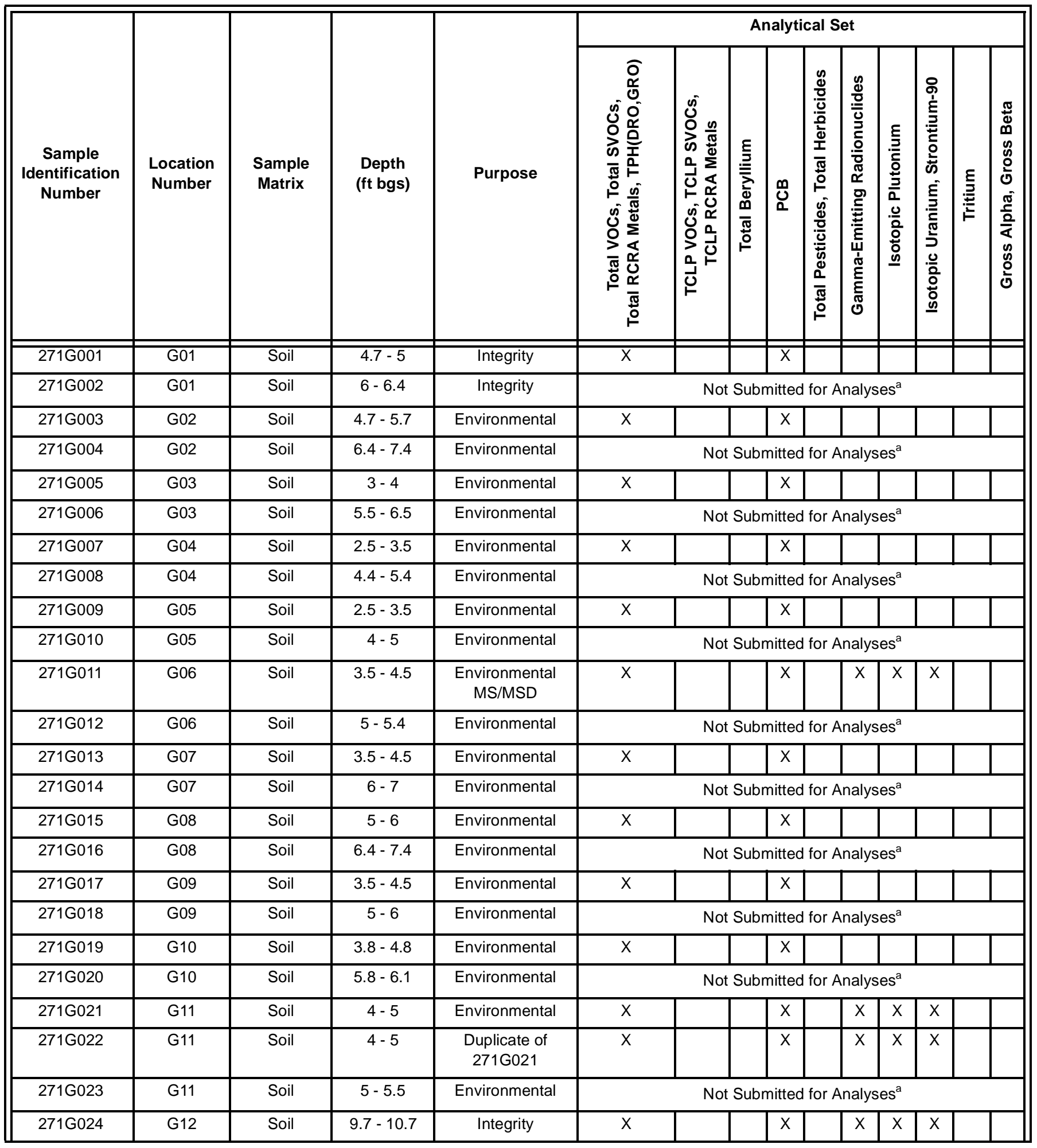


Table A.9-1

Samples Collected at CAS 25-04-11

(Page 2 of 5 )

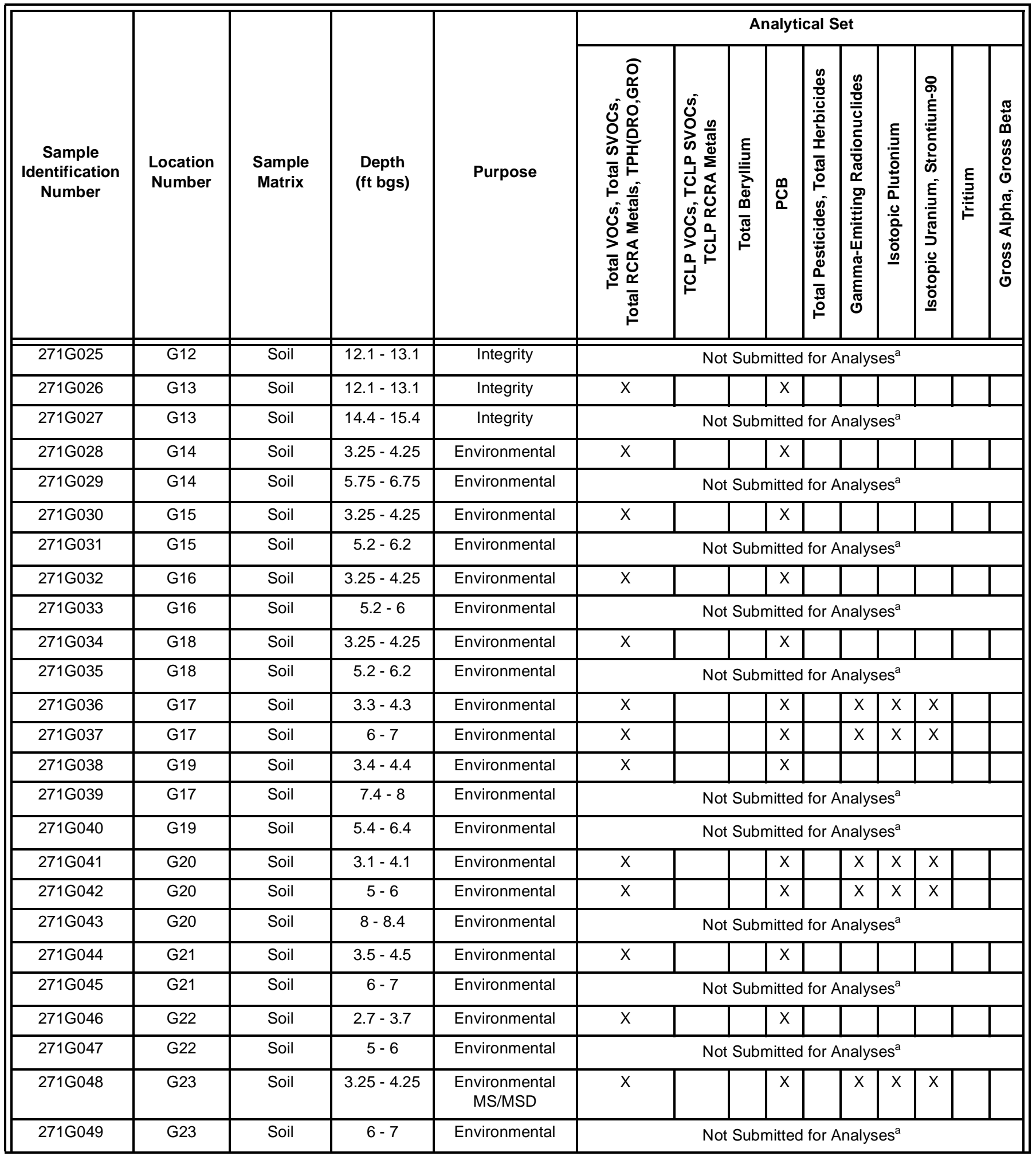


Table A.9-1

Samples Collected at CAS 25-04-11

(Page 3 of 5)

\begin{tabular}{|c|c|c|c|c|c|c|c|c|c|c|c|c|c|c|}
\hline \multirow[b]{2}{*}{$\begin{array}{c}\text { Sample } \\
\text { Identification } \\
\text { Number }\end{array}$} & \multirow[b]{2}{*}{$\begin{array}{l}\text { Location } \\
\text { Number }\end{array}$} & \multirow[b]{2}{*}{$\begin{array}{l}\text { Sample } \\
\text { Matrix }\end{array}$} & \multirow[b]{2}{*}{$\begin{array}{c}\text { Depth } \\
\text { (ft bgs) }\end{array}$} & \multirow[b]{2}{*}{ Purpose } & \multicolumn{10}{|c|}{ Analytical Set } \\
\hline & & & & & 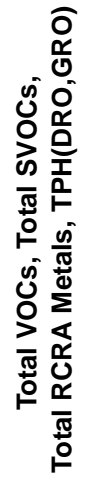 & 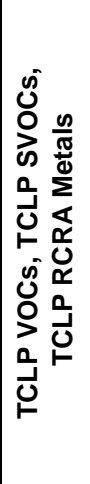 & 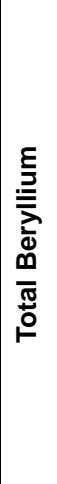 & O্口 & 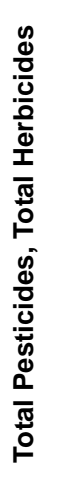 & 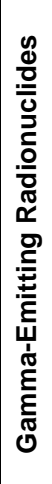 & 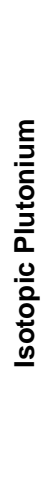 & 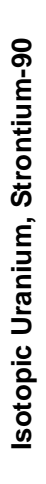 & 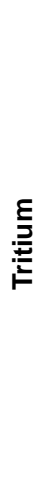 & 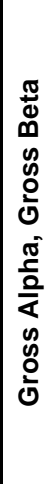 \\
\hline $271 \mathrm{G} 053$ & G25 & Soil & $3.25-4.25$ & $\begin{array}{c}\text { Duplicate of } \\
271 \mathrm{G} 052\end{array}$ & $\mathrm{X}$ & & & $\mathrm{X}$ & & $X$ & $x$ & $\mathrm{x}$ & & \\
\hline $271 \mathrm{G} 054$ & G25 & Soil & $5.2-6.2$ & Environmental & \multicolumn{10}{|c|}{ Not Submitted for Analyses ${ }^{a}$} \\
\hline $271 \mathrm{G} 055$ & G26 & Soil & $3.75-4.75$ & Environmental & $x$ & & & $X$ & & & & & & \\
\hline $271 \mathrm{G} 056$ & G26 & Soil & $5.9-6.9$ & Environmental & \multicolumn{10}{|c|}{ Not Submitted for Analyses ${ }^{a}$} \\
\hline $271 \mathrm{G} 057$ & G27 & Soil & $3.25-4.25$ & Environmental & $\mathrm{X}$ & & & $\mathrm{X}$ & & & & & & \\
\hline $271 \mathrm{G} 058$ & G27 & Soil & $5.25-6.25$ & Environmental & \multicolumn{10}{|c|}{ Not Submitted for Analyses ${ }^{a}$} \\
\hline 271G059 & G28 & Soil & $3.25-4.25$ & Environmental & $\mathrm{X}$ & & & $\mathrm{X}$ & & & & & & \\
\hline $271 \mathrm{G} 065$ & G30 & Soil & $9-9.4$ & Environmental & \multicolumn{10}{|c|}{ Not Submitted for Analyses ${ }^{a}$} \\
\hline $271 \mathrm{G} 066$ & G31 & Soil & $3.25-4.25$ & Environmental & $\mathrm{X}$ & & & $\mathrm{X}$ & & & & & & \\
\hline $271 \mathrm{G} 067$ & G31 & Soil & $6-7$ & Environmental & \multicolumn{10}{|c|}{ Not Submitted for Analyses ${ }^{a}$} \\
\hline $271 \mathrm{G} 068$ & G32 & Soil & $3.25-4.25$ & Environmental & $x$ & & & $\mathrm{X}$ & & & & & & \\
\hline $271 \mathrm{G} 069$ & G32 & Soil & $5.25-6.25$ & Environmental & \multicolumn{10}{|c|}{ Not Submitted for Analyses ${ }^{a}$} \\
\hline $271 \mathrm{G} 070$ & G33 & Soil & $3.25-4.25$ & Environmental & $x$ & & & $\mathrm{x}$ & & & & & & \\
\hline $271 \mathrm{G} 071$ & G33 & Soil & $5.2-6.2$ & Environmental & \multicolumn{10}{|c|}{ Not Submitted for Analyses ${ }^{a}$} \\
\hline $271 \mathrm{G} 072$ & G35 & Sediment & $5.4-5.7$ & Manhole & $\mathrm{X}$ & $\mathrm{X}$ & & $\mathrm{x}$ & & $\mathrm{X}$ & & $\mathrm{X}$ & & \\
\hline $271 \mathrm{G} 073$ & G36 & Soil & $3.25-3.5$ & Geotechnical & \multicolumn{10}{|c|}{ Not Submitted for Analyses ${ }^{b}$} \\
\hline $271 \mathrm{G} 074$ & G37 & Sludge & NA & Septic Tank & $\mathrm{X}$ & $X$ & & $\mathrm{X}$ & & $x$ & $\mathrm{x}$ & $x$ & $x$ & $\mathrm{x}$ \\
\hline
\end{tabular}


Table A.9-1

Samples Collected at CAS 25-04-11

(Page 4 of 5 )

\begin{tabular}{|c|c|c|c|c|c|c|c|c|c|c|c|c|c|c|}
\hline \multirow[b]{2}{*}{$\begin{array}{c}\text { Sample } \\
\text { Identification } \\
\text { Number }\end{array}$} & \multirow[b]{2}{*}{$\begin{array}{l}\text { Location } \\
\text { Number }\end{array}$} & \multirow[b]{2}{*}{$\begin{array}{c}\text { Sample } \\
\text { Matrix }\end{array}$} & \multirow[b]{2}{*}{$\begin{array}{c}\text { Depth } \\
\text { (ft bgs) }\end{array}$} & \multirow[b]{2}{*}{ Purpose } & \multicolumn{10}{|c|}{ Analytical Set } \\
\hline & & & & & 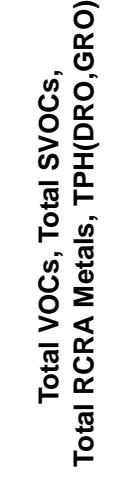 & 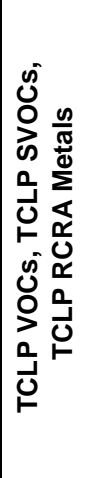 & 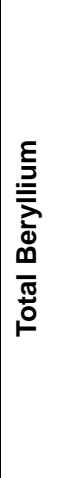 & $\stackrel{\mathscr{O}}{0}$ & 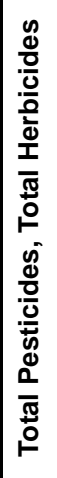 & 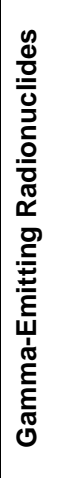 & 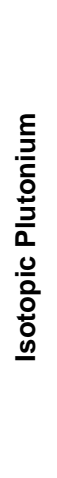 & 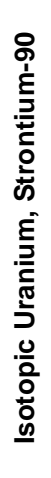 & $\stackrel{E}{E}$ & 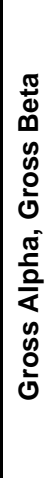 \\
\hline $271 \mathrm{G} 078$ & G02 & Soil & $9.5-10.5$ & Environmental & SVOCs & & & & & & & & & \\
\hline $271 \mathrm{G} 079$ & G02 & Soil & $9.5-10.5$ & $\begin{array}{l}\text { Duplicate of } \\
271 \mathrm{G} 078\end{array}$ & SVOCs & & & & & & & & & \\
\hline $271 \mathrm{G} 080$ & G41 & Soil & $4.7-5.7$ & Environmental & SVOC & & & & & & & & & \\
\hline $271 \mathrm{G} 081$ & G41 & Soil & $7.2-8.2$ & Environmental & \multicolumn{10}{|c|}{ Not Submitted for Analyses ${ }^{a}$} \\
\hline $271 \mathrm{G} 082$ & G42 & Soil & $4.7-5.7$ & $\begin{array}{l}\text { Environmental } \\
\text { MS/MSD }\end{array}$ & SVOCs & & & & & & & & & \\
\hline $271 \mathrm{G} 083$ & G42 & Soil & $7.2-8.2$ & Environmental & \multicolumn{10}{|c|}{ Not Submitted for Analyses ${ }^{a}$} \\
\hline $271 \mathrm{G} 089$ & G44 & Soil & $6.3-7.3$ & Environmental & \multicolumn{10}{|c|}{ Not Submitted for Analyses ${ }^{a}$} \\
\hline $271 \mathrm{G} 300$ & NA & Water & NA & Trip Blank & VOC only & & & & & & & & & \\
\hline 271G302 & NA & Water & NA & Trip Blank & VOC only & & & & & & & & & \\
\hline $271 \mathrm{G} 303$ & NA & Water & NA & Field Blank & $x$ & & & $x$ & & $x$ & $x$ & $x$ & & \\
\hline $271 \mathrm{G} 304$ & NAP & Water & NA & Rinsate & $x$ & & & $x$ & & $x$ & $x$ & $x$ & & \\
\hline 271G305 & NA & Water & NA & Trip Blank & VOC only & & & & & & & & & \\
\hline $271 \mathrm{G} 306$ & NA & Water & NA & Trip Blank & VOC only & & & & & & & & & \\
\hline 271G307 & NA & Water & NA & Trip Blank & VOC only & & & & & & & & & \\
\hline $271 \mathrm{G} 308$ & NA & Water & NA & Trip Blank & VOC only & & & & & & & & & \\
\hline 271G309 & NA & Water & NA & Trip Blank & VOC only & & & & & & & & & \\
\hline $271 \mathrm{G} 310$ & NA & Water & NA & Trip Blank & VOC only & & & & & & & & & \\
\hline
\end{tabular}


Table A.9-1

Samples Collected at CAS 25-04-11

(Page 5 of 5 )

\begin{tabular}{|c|c|c|c|c|c|c|c|c|c|c|c|c|c|c|}
\hline \multirow[b]{2}{*}{$\begin{array}{c}\text { Sample } \\
\text { Identification } \\
\text { Number }\end{array}$} & \multirow[b]{2}{*}{$\begin{array}{l}\text { Location } \\
\text { Number }\end{array}$} & \multirow[b]{2}{*}{$\begin{array}{l}\text { Sample } \\
\text { Matrix }\end{array}$} & \multirow[b]{2}{*}{$\begin{array}{c}\text { Depth } \\
\text { (ft bgs) }\end{array}$} & \multirow[b]{2}{*}{ Purpose } & \multicolumn{10}{|c|}{ Analytical Set } \\
\hline & & & & & 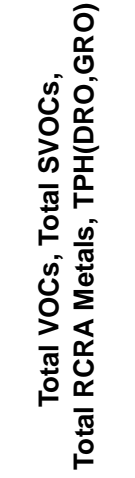 & 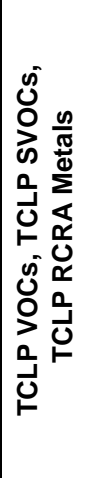 & 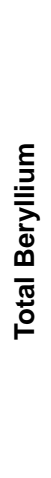 & O & 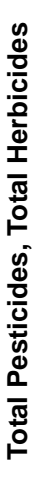 & 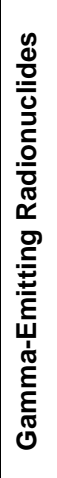 & 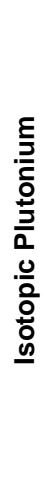 & 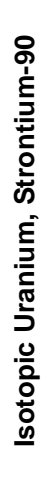 & $\stackrel{E}{\underline{3}}$ & 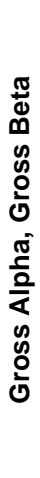 \\
\hline
\end{tabular}

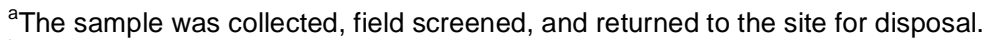

${ }^{\mathrm{b}}$ The sample was collected, field screened, and is being stored for possible geotechnical analysis.

NA $=$ Not applicable

MS/MSD = Matrix spike/matrix spike duplicate

- Sample 271G064 was collected at 5 to $6 \mathrm{ft}$ bgs rather than the planned interval of 5.5 to $6.5 \mathrm{ft}$ bgs

- Sample 271G065 was collected at 9 to $9.5 \mathrm{ft}$ bgs rather than the planned interval of 9.5 to $10.5 \mathrm{ft}$ bgs

Despite these deviations, the pertinent CAIP requirements were met.

\section{A.9.2 Investigation Results}

The following subsections provide details of the inspection and sampling of leachfield features, field-screening results, and sample selection and analysis.

\section{A.9.2.1 Septic Tank Contents}

The contents of the septic tank were sampled according to the CAIP. The septic tank was a steel horizontal cylinder with a 1,068-gal capacity. The tank was two-chambered, and was accessed by 


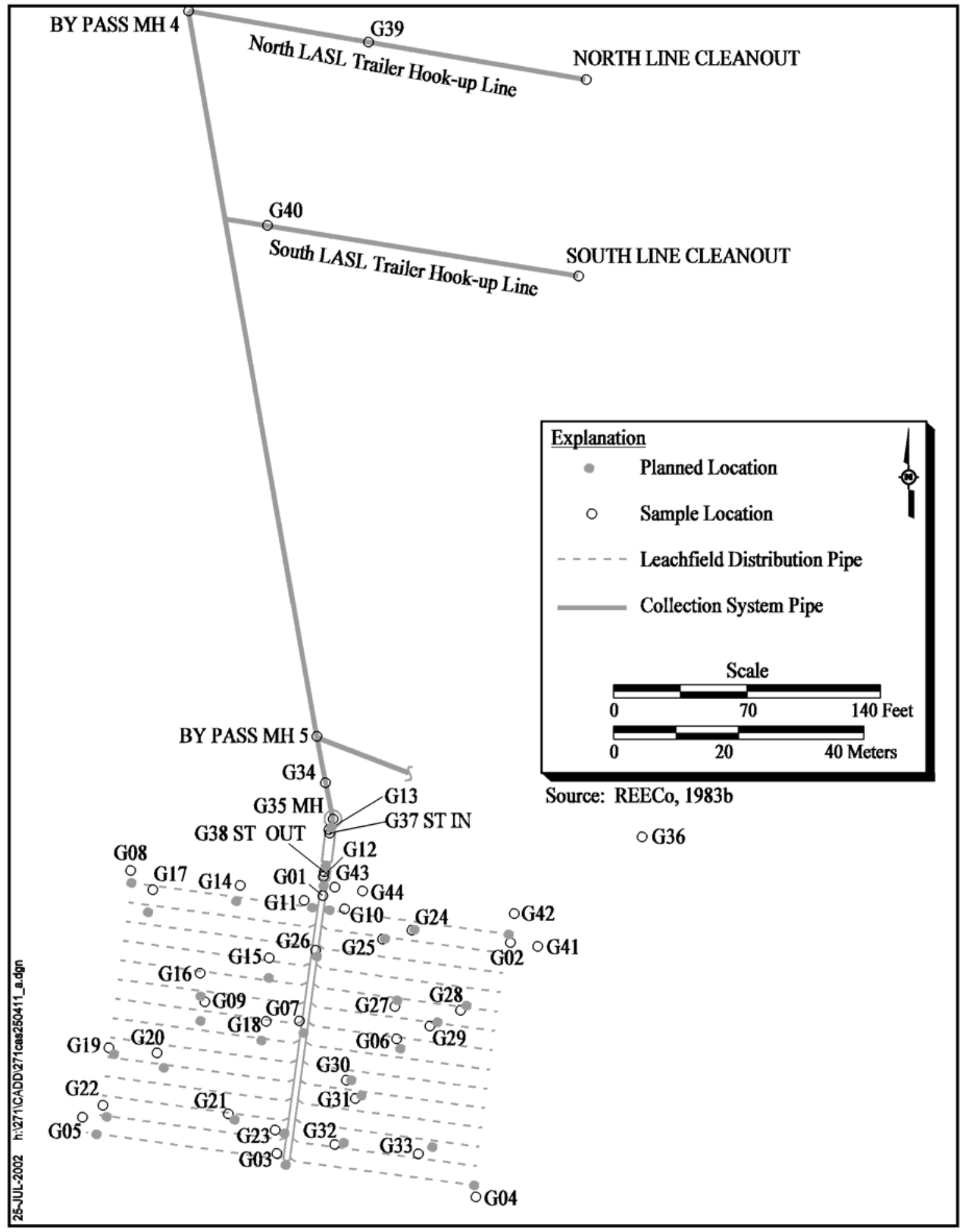

Figure A.9-1

LASL Trailers Septic System (CAS 25-04-11)

Sample Locations 
two manholes located $3.5 \mathrm{ft}$ bgs. Although the manholes are below-grade, they are accessible from the ground surface through metal casings. The interior dimensions of the septic tank were approximately $5.5 \mathrm{ft}$ (length) by $5.8 \mathrm{ft}$ (diameter). One liquid and one sludge sample were collected from each of the two chambers. Visual inspection revealed that a maximum thickness of $3.3 \mathrm{ft}$ (294 gal) of liquid and $1.8 \mathrm{ft}$ (120 gal) of sludge remained in the bottom of the inlet chamber of the tank. A maximum thickness of $3.2 \mathrm{ft}$ (247 gal) of liquid and $10 \mathrm{in}$. (39 gal) of sludge remained in the bottom of the outlet chamber of the tank.

\section{A.9.2.2 Distribution Box Contents}

The distribution box was a concrete rectangular structure with a 468-gal capacity. The exterior dimensions of the distribution box were $4 \mathrm{ft}$ (length) by $4 \mathrm{ft}$ (width) by $3.9 \mathrm{ft}$ (depth). The distribution box was partially filled with soil; therefore, no samples were collected. Figure A.9-2 shows a steel plate that apparently was the lid for the box and is still present, but it had been bent and caved in sometime in the past.

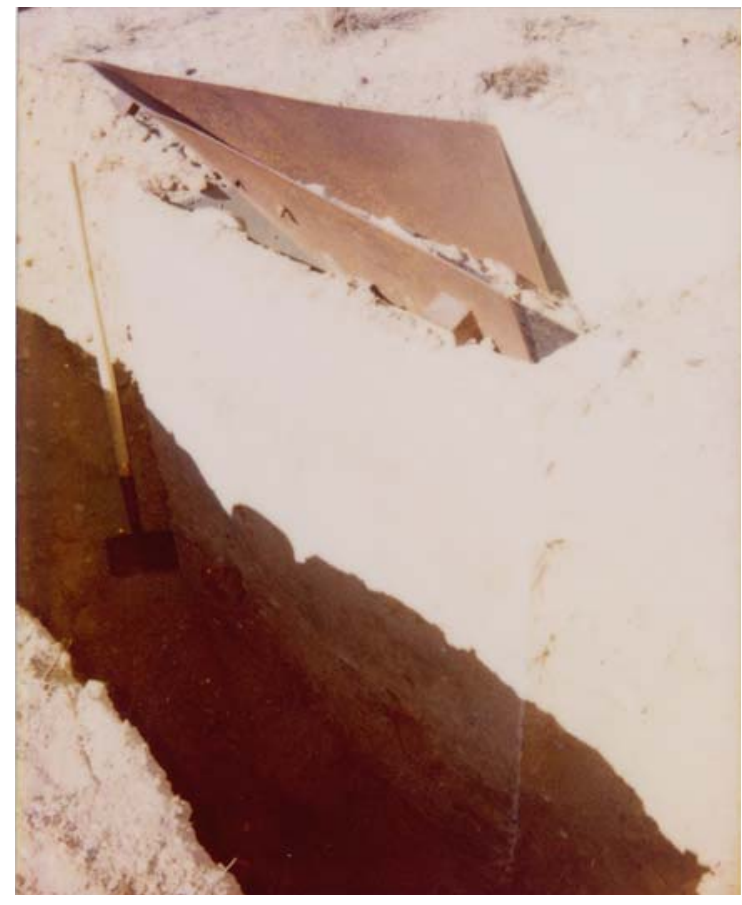

Figure A.9-2

CAS 25-04-11 Distribution Box, Integrity Sample (Photograph Taken 11-14-2001) 


\section{A.9.2.3 Septic Tank and Distribution Box Integrity Soil Sampling}

Seven (eight were planned; Section A.9.1.1 provides further detail regarding the deviation) integrity samples were collected by excavating adjacent to the influent and effluent ends of the septic tank and the effluent end of the distribution box. The following three samples were submitted for laboratory analysis:

- The upper sample (271G001) from the effluent end of the distribution box, collected at 4.7 to $5 \mathrm{ft} b g \mathrm{~s}$

- The upper sample (271G024) from the effluent end of the septic tank, collected at 9.7 to $10.7 \mathrm{ft}$ bgs

- The upper sample (271G026) from the influent end of the septic tank, collected at 12.1 to $13.1 \mathrm{ft}$ bgs

\section{A.9.2.4 Leachfield Excavation Soil Sampling}

Backhoe excavations were conducted to access sampling horizons at the biased and random locations presented in the CAIP. Excavations provided a visual verification of distribution pipes and enabled soil samples to be collected from appropriate intervals beneath the pipes, as specified by the CAIP. Sixty-five soil samples were collected from the planned locations excavated within the leachfield. These samples were collected from intervals at 0 to $1 \mathrm{ft}, 2.5$ to $3.5 \mathrm{ft}$, and 6.5 to $7.5 \mathrm{ft}$ below the leachrock/native soil interface. The interface was found at depths ranging from 2.5 to $5 \mathrm{ft}$ bgs. Thirty-five samples were submitted for laboratory analysis. In addition, two QC soil duplicates and two MS/MSD samples were collected and analyzed. A geotechnical sample was collected outside the boundary of the leachfield. The sample will be sent to a laboratory for geotechnical analysis if necessary.

\section{A.9.2.5 Additional Sampling}

To further define the extent of potential SVOC contamination, the field crew returned to this CAS on February 14, 2002, to conduct step-out sampling. Two locations (G02 and G10) were identified from the original sampling activities as locations of concern. Four vertical and eight horizontal step-out samples were collected. The vertical samples (271G078 and 271G084) were collected from G02 and G10 at 9.5 to $10.5 \mathrm{ft}$ and 8.5 to $9.5 \mathrm{ft}$ bgs, respectively. The horizontal step-outs were collected $15 \mathrm{ft}$ 
east of G02 (location G41), $15 \mathrm{ft}$ north of G02 (location G42), $15 \mathrm{ft}$ north of G10 (location G43), and $15 \mathrm{ft}$ northeast of G10 (location G44) (Figure A.9-1). Six soil samples collected during this sampling event were submitted for laboratory analysis. In addition, two QC soil duplicates (271G079 and 271G086) and one MS/MSD (271G082) sample were collected and analyzed.

\section{A.9.2.6 Collection System Pipe Inspections}

As detailed in the CAIP, the CAS 25-04-11 septic system was bypassed. Most of the collection system pipes are active and are not included in the investigation. However, some abandoned segments of the collection system were inspected. Access points for inspection by video mole were present (i.e., manholes and clean-outs) and created at locations along the collection system pipe via backhoe excavation.

An excavation (G34) was made approximately halfway between Bypass Manhole 5 and G35 Manhole (Figure A.9-1). A fishtape was run down the pipe (south) to G35 Manhole for a distance of $15 \mathrm{ft}$. The fishtape was then run up the pipe (north) for a distance of $21 \mathrm{ft}$. A video mole survey followed the fishtape. The majority of the distance was inspected in both directions from G34 with the video mole; however, obstructions in the form of various types of debris precluded inspecting the full distance. The survey found that the G35 Manhole contained septic system debris, so it was opened and sampled (271G072). Bypass Manhole 5 was opened and inspected. The inlet enters from the north and the outlet exits toward the southeast in the direction of the active oxidation ponds. This inspection confirmed that the manhole was installed to bypass the CAS 25-04-11 septic system.

Bypass Manhole 4 has three inlets and one outlet. The inlet from the west was discussed in Section A.4.2.5. Per direction obtained during the DQO phase, the northern inlet (line leading from the RCP) and the outlet were considered active and were not surveyed. The eastern outlet was surveyed by video mole from Bypass Manhole 4 for $100 \mathrm{ft}$. An excavation (G39) was made at this point (Figure A.9-1) and video mole activities continued. The video survey continued for another $104 \mathrm{ft}$, where a clean-out (north line clean-out) was noted as the termination point for the north LASL trailer hook-up line (Figure A.9-1). An excavation (G40) in the south LASL trailer hook-up line was made $19 \mathrm{ft}$ east from the junction point with the active line (Figure A.9-1). The video mole was passed upstream (east) through the line for a total of $111 \mathrm{ft}$. Risers entering from the north and south 
were noted at irregularly spaced intervals on both north and south LASL trailer hook-up lines. A clean-out was located at the eastern end of both of the lines.

Some sediment was identified in the piping of the trailer hook-up lines, but was not appropriate or adequate material to be sampled. The sediment may have entered the lines through the risers. Material apparently related to the septic system was present in the manhole and pipe segment immediately upstream of the septic tank, this material was sampled. Portions of the pipe at the excavated locations (designated G34, G39, and G40) were radiologically surveyed and swiped. See Section A.9.2.8 for further details regarding radiological results.

\section{A.9.2.7 Field-Screening Results}

Soil samples were screened for VOCs and alpha and beta/gamma radioactivity. The field readings were compared to FSLs to guide sampling decisions and determine which samples were to be submitted for laboratory analysis. No VOCs greater than FSLs were found during soil sample screening. The results of radiological field screening are discussed in Section A.9.2.8.

A sample of the septic tank contents was collected and analyzed for fecal coliform bacteria. Fecal coliform bacteria was not detected in the septic tank at this CAS.

\section{A.9.2.8 Radiological Survey Results}

Radiological screening results for soil samples were below FSLs with the exception of beta/gamma readings at these sample locations. The beta/gamma FSL was 3,349 dpm/100 cm${ }^{2}$. Radiological FSLs were exceeded at the following locations:

- Location G17 - Sample 271G036 had an elevated beta/gamma reading of 3,363 dpm/100 cm 2 . This sample was submitted for laboratory analysis, and additional samples (271G037 and 271G039) were collected from the location. Neither of these samples exceeded radiological FSLs.

- Location G20 - Sample 271G041 had an elevated beta/gamma reading of 3,469 dpm/100 cm². This sample was submitted for laboratory analysis, and additional samples (271G042 and 271G043) were collected from the location. Neither of these samples exceeded radiological FSLs. 
- Location G30 - Sample 271G063 had an elevated beta/gamma reading of 3,356 dpm/100 cm². This sample was submitted for laboratory analysis, and additional samples (271G064 and 271G065) were collected from the location. Neither of these samples exceeded radiological field screening levels.

Swipe and radiological survey data from inspection locations G34, G39, and G40 indicate that the collection system meets the unrestricted radiological release criteria as defined in the NV/YMP Radiological Control Manual (DOE/NV, 2000a).

\section{A.9.2.9 Sample Analysis}

Environmental soil samples and associated QC samples were collected and analyzed for the CAIP-specified COPCs (i.e., total VOCs, total SVOCs, total RCRA metals, TPH [DRO and GRO], and PCBs). In addition, 25 percent of the soil samples and 100 percent of the associated QC samples were analyzed for Iso-U, Iso-Pu, Sr-90, and gamma-emitting radionuclides.

Both the sludge and liquid septic tank samples were analyzed for total VOCs, total SVOCs, TPH (GRO and DRO), total RCRA metals, PCBs, gamma-emitting radionuclides, Iso-U, Iso-Pu, Sr-90, tritium and gross alpha and gross beta radioactivity. The sludge sample was analyzed according to the TCLP for VOCs, SVOC, and RCRA metals.

The analytical parameters and laboratory analytical methods used to analyze the investigation samples are listed in Table A.2-2. Table A.9-1 lists the sample-specific analytical parameters.

\section{A.9.3 Analytes Detected Above Minimum Reporting Limits}

The soil sample analytical results with concentrations exceeding corresponding MRLs or PALs (DOE/NV, 1998; DOE/NV, 2001) at CAS 26-04-11 are summarized in the following sections. The results of septic tank content samples are compared to appropriate regulatory levels for disposal. A portion of the CAS 26-04-11 analytical results were rejected during validation; however, these rejected data did not impact closure decisions as discussed in Section B.1.3.7 of Appendix B.

\section{A.9.3.1 Analytical Results for Soil Samples}

The following sections discuss the results for soil samples in comparison to the levels established in the Leachfield Work Plan and the CAIP. 


\section{A.9.3.1.1 Total Volatile Organic Compounds}

Volatile organic compounds were not detected above MRLs in CAS 25-04-11 soil samples.

\section{A.9.3.1.2 Total Semivolatile Organic Compounds}

Table A.9-2 provides a list of the SVOCs in samples 271G003, 271G019, and 271G086 above MRLs and PALs.

Step-out sampling was conducted to confirm whether SVOCs were present in the leachfield soil. The step-out sampling confirmed that detections of benzo(a)pyrene at locations G02 (271G003) and G10 (271G019) were isolated. No SVOCs above MRLs were detected in step-out samples, except for a field-spiked sample discussed below.

Sample 271G085 was collected at location G43 (located $15 \mathrm{ft}$ north of G10) as a step-out of $271 \mathrm{G} 019$. Sample 271G085 did not contain any SVOCs above MRLs or PALs. However, sample 271G086 was collected as a field duplicate of 271G085 and was field spiked with pieces of "Orangeburg" distribution pipe. This action was completed at the direction of the ITLV Task Manager to confirm whether SVOC results in soil at CASs containing this specific type of pipe were being skewed to produce false positive readings for SVOCs. Based on the results for sample 271G086 shown in Table A.9-2, it appears that soil samples containing pieces of "Orangeburg" pipe would show detections of SVOC compounds (specifically, benzo(a)pyrene) related to the pipe material. "Orangeburg" pipe is made of a black colored, compressed tar paper-like material, with small round perforations at regularly spaced intervals.

\section{A.9.3.1.3 Total Petroleum Hydrocarbons}

Total petroleum hydrocarbon values are presented in Table A.9-3. Samples 271G032 and 271G038 had TPH-DRO concentrations above the MRL of $25 \mathrm{mg} / \mathrm{kg}$; however, these concentrations were below the $100 \mathrm{mg} / \mathrm{kg}$ PAL. 
Table A.9-2

Soil Sample Results for Total SVOCs Detected Above Minimum Reporting Limits at CAS 25-04-11

\begin{tabular}{|c|c|c|c|c|c|c|c|c|c|c|c|c|c|c|c|c|}
\hline \multirow[b]{2}{*}{$\begin{array}{c}\text { Sample } \\
\text { Identification } \\
\text { Number }\end{array}$} & \multirow[b]{2}{*}{$\begin{array}{c}\text { Depth } \\
\text { (ft bgs) }\end{array}$} & \multicolumn{15}{|c|}{ Contaminants of Potential Concern $(\mu \mathrm{g} / \mathrm{kg})$} \\
\hline & & 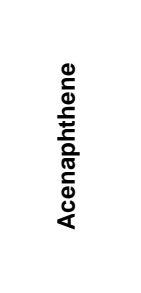 & 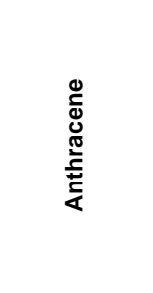 & 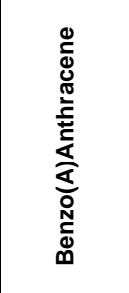 & 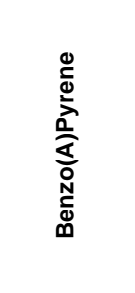 & 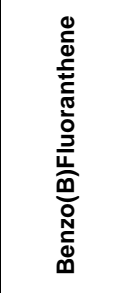 & 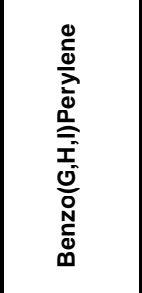 & 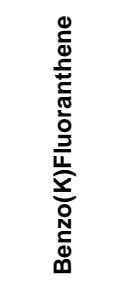 & 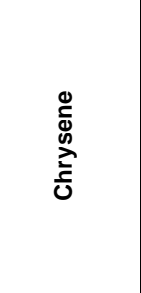 & 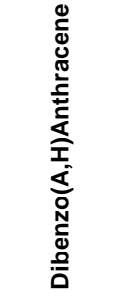 & 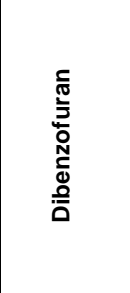 & 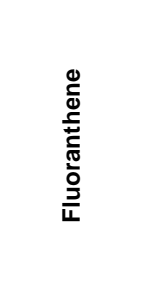 & 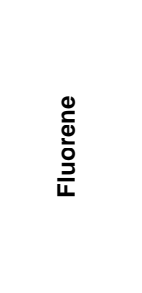 & 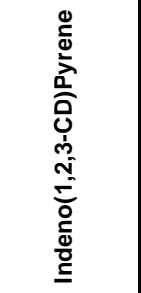 & 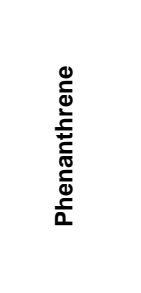 & 㐫 \\
\hline \multicolumn{2}{|c|}{ Preliminary Action Levels ${ }^{\mathrm{a}}$} & $38,000,000$ & $100,000,000$ & 2,900 & 290 & 2,900 & NI & 29,000 & 290,000 & 290 & $5,100,000$ & $30,000,000$ & $33,000,000$ & 2,900 & NI & $54,000,000$ \\
\hline $271 \mathrm{G} 003$ & $4.7-5.7$ & -- & -- & -- & 420 & -- & -- & -- & -- & -- & -- & 1200 & -- & -- & 720 & 980 \\
\hline $271 \mathrm{G} 019$ & $3.8-4.8$ & -- & -- & -- & $320(\mathrm{~J})$ & -- & -- & -- & -- & -- & -- & -- & -- & -- & -- & -- \\
\hline 271G086 & $3.8-4.8$ & $4,300(\mathrm{~J})^{\mathrm{b}}$ & $24,000(J)^{b}$ & $75,000(\mathrm{~J})^{\mathrm{b}}$ & $57,000(\mathrm{~J})^{\mathrm{b}}$ & $78,000(\mathrm{~J})^{\mathrm{b}}$ & $29,000(\mathrm{~J})^{\mathrm{c}}$ & $19,000(\mathrm{~J})^{\mathrm{c}}$ & $71,000(J)^{b}$ & $9,500(J)^{c b}$ & $2,600(\mathrm{~J})^{\mathrm{cb}}$ & $120,000(\mathrm{~J})^{\mathrm{c}}$ & $6,200(\mathrm{~J})^{\mathrm{b}}$ & $32,000(J)^{b}$ & $77,000(\mathrm{~J})^{\mathrm{b}}$ & $94,000(\mathrm{~J})^{\mathrm{b}}$ \\
\hline
\end{tabular}

aBased on U.S. Environmental Protection Agency, Region 9 Preliminary Remediation Goals (PRGs) (EPA, 2000)

${ }^{\mathrm{b}}$ Qualifier added to laboratory data; record accepted. Surrogates diluted out.

'Qualifier added to laboratory data; record accepted. Surrogates diluted out. Value exceeded linear range of instrument.

$\mathrm{J}=$ Estimated value

$\mathrm{NI}=$ Not identified 
Table A.9-3

\section{Soil Sample Results for TPH-DRO Detected Above Minimum Reporting Limits at CAS 25-04-11}

\begin{tabular}{|c|c|c|}
\hline $\begin{array}{c}\text { Sample } \\
\text { Identification } \\
\text { Number }\end{array}$ & $\begin{array}{c}\text { Depth } \\
\text { (ft bgs) }\end{array}$ & Contaminants of Potential Concern (mg/kg) \\
\cline { 3 - 3 } & & Diesel Range Organics \\
\hline Preliminary Action Levels & an & $\mathbf{1 0 0}$ \\
\hline \hline $271 \mathrm{G} 032$ & $3.25-4.25$ & $34(\mathrm{M})$ \\
\hline $271 \mathrm{G} 038$ & $3.4-4.4$ & $43(\mathrm{M})$ \\
\hline
\end{tabular}

aBased on Nevada Administrative Code; Contamination of soil: Establishment of action levels (NAC, 2000)

$M=$ Motor oil

\section{A.9.3.1.4 Total RCRA Metals}

As shown in Table A.9-4, the total RCRA metals detected in soil samples above concentrations exceeding the MRLs are arsenic ( $1 \mathrm{mg} / \mathrm{kg})$, barium $(20 \mathrm{mg} / \mathrm{kg})$, cadmium $(0.5 \mathrm{mg} / \mathrm{kg})$, chromium $(1 \mathrm{mg} / \mathrm{kg})$, lead $(0.3 \mathrm{mg} / \mathrm{kg})$, mercury $(0.1 \mathrm{mg} / \mathrm{kg})$, selenium $(0.5 \mathrm{mg} / \mathrm{kg})$, and silver $(1.0 \mathrm{mg} / \mathrm{kg})$.

Barium concentrations ranged from 69 to $130 \mathrm{mg} / \mathrm{kg}$, cadmium was detected in only one sample at $4.3 \mathrm{mg} / \mathrm{kg}$, chromium concentrations ranged from 1.9 to $16 \mathrm{mg} / \mathrm{kg}$, lead concentrations ranged from 4.1 to $82 \mathrm{mg} / \mathrm{kg}$, mercury was detected in one sample at $1.2 \mathrm{mg} / \mathrm{kg}$ with a "J" flag (estimated value), selenium was reported in only one sample at a concentration of $0.53 \mathrm{mg} / \mathrm{kg}$ (below the instrument detection limit but above the contract-required detection limit), and silver concentrations ranged from 4.9 to $180 \mathrm{mg} / \mathrm{kg}$. All reported concentrations of these metals were below EPA Region 9 PRGs defined in this document as PALs.

Arsenic concentrations ranged from 1.7 to $3.3 \mathrm{mg} / \mathrm{kg}$. Arsenic concentrations were consistent across the site, with no "hot spots" or evidence of a localized spill. The PAL for arsenic is defined by EPA Region 9 as $2.7 \mathrm{mg} / \mathrm{kg}$. The PAL is lower than the 7 to $8 \mathrm{mg} / \mathrm{kg}$ mean concentration of arsenic in silt from the Nevada Testing and Training Range (formerly Nellis Air Force Range) (NBMG, 1998; Moore, 1999. Although approximately 25 percent of the CAS 25-04-11 soil samples contain arsenic concentrations slightly in excess of the PAL, these concentrations are believed to be within ambient conditions for this CAS and do not represent contamination. 


\section{Table A.9-4 \\ Soil Sample Results for Total RCRA Metals Detected Above Minimum Reporting Limits at CAS 25-04-11}

(Page 1 of 2)

\begin{tabular}{|c|c|c|c|c|c|c|c|c|c|}
\hline \multirow{2}{*}{$\begin{array}{c}\text { Sample } \\
\text { Identification } \\
\text { Number }\end{array}$} & \multirow{2}{*}{$\begin{array}{l}\text { Depth } \\
\text { (ft bgs) }\end{array}$} & \multicolumn{8}{|c|}{ Contaminants of Potential Concern $(\mathrm{mg} / \mathrm{kg})$} \\
\hline & & Arsenic & Barium & Cadmium & Chromium & Lead & Mercury & Selenium & Silver \\
\hline \multicolumn{2}{|c|}{ Preliminary Action Levels ${ }^{a}$} & 2.7 & 100,000 & 810 & 450 & 750 & 610 & 10,000 & 10,000 \\
\hline $271 \mathrm{G} 001$ & $4.7-5.7$ & 2.4 & 92 & -- & 3.2 & 13 & -- & -- & 4.9 \\
\hline $271 \mathrm{G} 003$ & $4.7-5.7$ & 2.6 & 100 & -- & 3 & 5.7 & -- & -- & -- \\
\hline $271 \mathrm{G} 005$ & $3-4$ & 2.2 & 96 & -- & 2.7 & 4.8 & -- & -- & -- \\
\hline $271 \mathrm{G} 007$ & $2.5-3.5$ & 2.5 & 69 & -- & 2.7 & 4.6 & -- & -- & -- \\
\hline $271 \mathrm{G} 009$ & $2.5-3.5$ & 2.5 & 120 & -- & 3.3 & 5.2 & -- & -- & -- \\
\hline $271 \mathrm{G} 011$ & $3.5-4.5$ & 2.9 & 100 & -- & 3.4 & 5.7 & -- & -- & -- \\
\hline $271 \mathrm{G} 013$ & $3.5-4.5$ & 2.1 & 100 & -- & 2.3 & 4.7 & -- & -- & -- \\
\hline $271 \mathrm{G} 015$ & $5-6$ & 2.1 & 89 & -- & 2.7 & 4.7 & -- & -- & -- \\
\hline $271 \mathrm{G} 017$ & $3.5-4.5$ & 2.4 & 85 & -- & 3.7 & 5.8 & -- & -- & -- \\
\hline 271G019 & $3.8-4.8$ & 2.8 & 82 & -- & 3.1 & 5.6 & -- & -- & -- \\
\hline $271 \mathrm{G} 021$ & $4-5$ & 2.6 & 110 & -- & 2.9 & 6.1 & -- & -- & 7.4 \\
\hline $271 \mathrm{G} 022$ & $4-5$ & 2.1 & 120 & -- & 2.9 & 6 & -- & -- & 7.9 \\
\hline $271 \mathrm{G} 024$ & $9.7-10.7$ & 2.2 & 120 & -- & 2.5 & 4.8 & -- & -- & -- \\
\hline $271 \mathrm{G} 026$ & $12.1-13.1$ & 2.5 & 95 & -- & 2.7 & 6 & -- & -- & -- \\
\hline $271 \mathrm{G} 028$ & $3.25-4.25$ & 2.5 & 110 & -- & 2.8 & 5.2 & -- & -- & -- \\
\hline $271 \mathrm{G} 030$ & $3.25-4.25$ & 2.3 & 110 & $\begin{array}{l}- \\
\end{array}$ & 2.6 & 5.2 & -- & -- & -- \\
\hline $271 \mathrm{G} 032$ & $3.25-4.25$ & 2.7 & 84 & -- & 3 & 5.9 & -- & -- & -- \\
\hline $271 \mathrm{G} 034$ & $3.25-4.25$ & 2.6 & 83 & -- & 3.2 & 5.4 & -- & -- & -- \\
\hline $271 \mathrm{G} 036$ & $3.3-4.3$ & 2.7 & 110 & -- & 3.2 & 5.4 & -- & -- & -- \\
\hline $271 \mathrm{G} 037$ & $6-7$ & 2.9 & 89 & -- & 3.2 & 6.3 & -- & -- & -- \\
\hline $271 \mathrm{G} 038$ & $3.4-4.4$ & 2.8 & 88 & -- & 3.3 & 5.3 & -- & -- & -- \\
\hline $271 \mathrm{G} 041$ & $3.1-4.1$ & 2.5 & 84 & -- & 3 & 5.4 & -- & -- & -- \\
\hline $271 \mathrm{G} 042$ & $5-6$ & 3.1 & 100 & -- & 3.2 & 5.8 & -- & -- & -- \\
\hline $271 \mathrm{G} 044$ & $3.5-4.5$ & 3 & 120 & -- & 2.6 & 5.6 & -- & -- & -- \\
\hline $271 \mathrm{G} 046$ & $2.7-3.7$ & 2.7 & 110 & -- & 3.3 & 5.6 & -- & -- & -- \\
\hline $271 \mathrm{G} 048$ & $3.25-4.25$ & 2.3 & 85 & -- & 3 & 5.3 & -- & -- & -- \\
\hline $271 \mathrm{G} 050$ & $3.25-4.25$ & 2.9 & 75 & -- & 3.1 & 6.6 & -- & -- & -- \\
\hline $271 \mathrm{G} 052$ & $3.25-4.25$ & 2.9 & 76 & -- & 3.2 & 5.7 & -- & -- & -- \\
\hline 271G053 & $3.25-4.25$ & 3 & 100 & -- & 3.3 & 5.9 & -- & -- & -- \\
\hline 271G055 & $3.75-4.75$ & 2.9 & 130 & -- & 2.8 & 5.1 & -- & -- & -- \\
\hline $271 \mathrm{G} 057$ & $3.25-4.25$ & 2.9 & 110 & -- & 3.3 & 6.1 & -- & -- & -- \\
\hline $271 \mathrm{G} 059$ & $3.25-4.25$ & 2.5 & 78 & -- & 3.2 & 5.7 & -- & -- & -- \\
\hline $271 \mathrm{G} 061$ & $4-5$ & 1.7 & 73 & -- & 1.9 & 4.1 & -- & -- & -- \\
\hline
\end{tabular}




\section{Table A.9-4 \\ Soil Sample Results for Total RCRA Metals \\ Detected Above Minimum Reporting Limits at CAS 25-04-11}

(Page 2 of 2)

\begin{tabular}{|c|c|c|c|c|c|c|c|c|c|}
\hline \multirow{2}{*}{$\begin{array}{c}\text { Sample } \\
\text { Identification } \\
\text { Number }\end{array}$} & \multirow{2}{*}{$\begin{array}{l}\text { Depth } \\
\text { (ft bgs) }\end{array}$} & \multicolumn{8}{|c|}{ Contaminants of Potential Concern $(\mathrm{mg} / \mathrm{kg})$} \\
\hline & & Arsenic & Barium & Cadmium & Chromium & Lead & Mercury & Selenium & Silver \\
\hline \multicolumn{2}{|c|}{ Preliminary Action Levels ${ }^{a}$} & 2.7 & 100,000 & 810 & 450 & 750 & 610 & 10,000 & 10,000 \\
\hline $271 \mathrm{G} 063$ & $3-4$ & 2.4 & 89 & -- & 2.6 & 4.8 & -- & -- & -- \\
\hline $271 \mathrm{G} 064$ & $5-6$ & 2.6 & 190 & -- & 2.6 & 12 & -- & $0.53(\mathrm{~B})$ & -- \\
\hline $271 \mathrm{G} 066$ & $3.25-4.25$ & 2.4 & 100 & -- & 3.1 & 5.3 & -- & -- & -- \\
\hline $271 \mathrm{G} 068$ & $3.25-4.25$ & 2.4 & 110 & -- & 2.7 & 4.6 & -- & -- & -- \\
\hline $271 \mathrm{G} 070$ & $3.25-4.25$ & 2.2 & 96 & -- & 2.7 & 5 & -- & -- & -- \\
\hline
\end{tabular}

aBased on U.S. Environmental Protection Agency, Region 9 Preliminary Remediation Goals (PRGs) (EPA, 2000)

-- = Not detected above minimum reporting limits

$\mathrm{J}=$ Estimated value. Qualifier added to laboratory data; record accepted. Duplicate precision analyses were outside control limits.

$B=$ Value less than the instrument detection limit, but greater than or equal to the contract required detection limit.

\section{A.9.3.1.5 Polychlorinated Biphenyls}

Polychlorinated biphenyls were not detected above MRLs in CAS 25-04-11 soil samples.

\section{A.9.3.1.6 Gamma Spectrometry Results}

Results of soil sample gamma spectrometry analysis are presented in Table A.9-5. Concentrations of actinium-228, bismuth-212, bismuth-214, lead-212, lead-214, potassium-40, and thallium-208 were detected above the MDLs. The TPU in the radioanalytical measurement is provided in the table along with the concentration for all detected gamma emitters. The concentrations of the detected gamma-emitting radionuclides are below PALs and are not significantly different than concentrations measured in soil samples collected from undisturbed background locations.

\section{A.9.3.1.7 Isotopic Uranium}

Detected values of uranium isotopes, along with associated TPUs are reported in Table A.9-6. The concentration of U-235 in soil sample number 271G024 was greater than the PAL; therefore, a normalized difference based on a confidence level of 95 percent was used to determine if the detection was statistically distinguishable from background. This method indicated that the U-235 
Table A.9-5

Soil Sample Results for Gamma-Emitting Radionuclides Detected

Above Minimum Reporting Limits at CAS 25-04-11

\begin{tabular}{|c|c|c|c|c|c|c|c|c|}
\hline \multirow{2}{*}{$\begin{array}{c}\text { Sample } \\
\text { Identification } \\
\text { Number }\end{array}$} & \multirow{2}{*}{$\begin{array}{l}\text { Depth } \\
\text { (ft bgs) }\end{array}$} & \multicolumn{7}{|c|}{ Contaminants of Potential Concern $(\mathrm{pCi} / \mathrm{g})$} \\
\hline & & Actinium-228 ${ }^{a}$ & Bismuth-212 & Bismuth-214 & Lead-212 ${ }^{\mathrm{a}}$ & Lead-214 ${ }^{b}$ & Potassium-40 & Thallium-208 ${ }^{\mathrm{a}}$ \\
\hline \multicolumn{2}{|c|}{ Preliminary Action Level } & 3.64 & 2.4 & 3.47 & 2.9 & 2.9 & 96 & 3.4 \\
\hline $271 \mathrm{G} 011$ & $3.5-4.5$ & $1.19 \pm 0.29$ & $\overline{---}$ & $0.83 \pm 0.21$ & $1.65 \pm 0.32$ & $0.72 \pm 0.18$ & $28 \pm 5.2$ & $0.49 \pm 0.12$ \\
\hline $271 \mathrm{G} 021$ & $4-5$ & $1.33 \pm 0.34$ & -- & $0.79 \pm 0.23$ & $1.65 \pm 0.33$ & $0.78 \pm 0.19$ & $24.8 \pm 4.9$ & $0.44 \pm 0.13$ \\
\hline $271 \mathrm{G} 022$ & $4-5$ & $1.32 \pm 0.32$ & $\overline{--}$ & $0.78 \pm 0.22$ & $1.7 \pm 0.33$ & $0.86 \pm 0.20$ & $26.9 \pm 5.1$ & $0.5 \pm 0.12$ \\
\hline $271 \mathrm{G} 024$ & $9.7-10.7$ & $1.41 \pm 0.38$ & -- & $0.85 \pm 0.26$ & $1.64 \pm 0.35$ & $0.9 \pm 0.23$ & $27.2 \pm 5.3$ & $0.52 \pm 0.14$ \\
\hline $271 \mathrm{G} 036$ & $3.3-4.3$ & $1.41 \pm 0.28$ & $1.83 \pm 0.69$ & $0.85 \pm 0.19$ & $1.76 \pm 0.32$ & $0.87 \pm 0.18$ & $27.8 \pm 4.9$ & $0.5 \pm 0.11$ \\
\hline $271 \mathrm{G} 037$ & $6-7$ & $1.74 \pm 0.38$ & $1.77 \pm 0.81$ & $0.81 \pm 0.22$ & $1.67 \pm 0.33$ & $0.94 \pm 0.21$ & $27.4 \pm 5.1$ & $0.58 \pm 0.14$ \\
\hline $271 \mathrm{G} 041$ & $3.1-4.1$ & $1.38 \pm 0.34$ & -- & $0.81 \pm 0.23$ & $1.73 \pm 0.34$ & $0.78 \pm 0.20$ & $25.8 \pm 5.1$ & $0.54 \pm 0.14$ \\
\hline $271 \mathrm{G} 042$ & $5-6$ & $1.13 \pm 0.29$ & -- & $0.81 \pm 0.22$ & $1.51 \pm 0.31$ & $0.95 \pm 0.22$ & $26.4 \pm 5.0$ & $0.47 \pm 0.12$ \\
\hline $271 \mathrm{G} 048$ & $3.25-4.25$ & $1.39 \pm 0.28$ & -- & $0.61 \pm 0.15$ & $1.67 \pm 0.31$ & $0.82 \pm 0.17$ & $29.9 \pm 5.2$ & $0.446 \pm 0.097$ \\
\hline $271 \mathrm{G} 052$ & $3.25-4.25$ & $1.12 \pm 0.31$ & $\begin{array}{l}- \\
\end{array}$ & $0.64 \pm 0.21$ & $1.65 \pm 0.33$ & $0.78 \pm 0.20$ & $26.5 \pm 5.2$ & $0.55 \pm 0.15$ \\
\hline $271 \mathrm{G} 053$ & $3.25-4.25$ & $1.18 \pm 0.30$ & -- & $1.02 \pm 0.25$ & $1.74 \pm 0.34$ & $0.88 \pm 0.21$ & $27.5 \pm 5.2$ & $0.49 \pm 0.13$ \\
\hline $271 \mathrm{G} 063$ & $3-4$ & $1.4 \pm 0.39$ & -- & $0.74 \pm 0.21$ & $1.58 \pm 0.33$ & $0.92 \pm 0.23$ & $27.8 \pm 5.5$ & $0.46 \pm 0.13$ \\
\hline $271 \mathrm{G} 064$ & $5-6$ & $1.49 \pm 0.30$ & -- & $0.96 \pm 0.21$ & $1.84 \pm 0.34$ & $0.94 \pm 0.19$ & $29 \pm 5.1$ & $0.53 \pm 0.11$ \\
\hline
\end{tabular}

${ }^{a}$ Background concentration listed in Environmental Monitoring Report for the Proposed Ward Valley, California, Low-Level Radioactive Waste (LLRW) Facility (US Ecology and Atlan-Tech, 1992).

${ }^{\mathrm{b} B a c k g r o u n d}$ concentration listed or derived in Off-Site Radiation Exposure Review Project, Phase I/ Soil Program (McArthur and Miller, 1989)

$--=$ Not detected above minimum reporting limits 
detection was not significantly greater than concentrations in soil samples collected from undisturbed background locations.

Table A.9-6

Soil Sample Results for Isotopic Uranium

Detected Above Minimum Reporting Limits at CAS 25-04-11

\begin{tabular}{|c|c|c|c|c|}
\hline \multirow{2}{*}{$\begin{array}{l}\text { Sample } \\
\text { Identification Number }\end{array}$} & \multirow{2}{*}{$\begin{array}{l}\text { Depth } \\
\text { (ft bgs) }\end{array}$} & \multicolumn{3}{|c|}{ Contaminants of Potential Concern $(\mathrm{pCi} / \mathrm{g})$} \\
\hline & & Uranium-234 ${ }^{a}$ & Uranium-235 & Uranium-238 \\
\hline \multicolumn{2}{|c|}{ Preliminary Action Levels } & 1.56 & 0.07 & 3.2 \\
\hline $271 \mathrm{G} 011$ & $3.5-4.5$ & $0.83 \pm 0.16$ & -- & $0.8 \pm 0.15$ \\
\hline $271 \mathrm{G} 021$ & $4-5$ & $1.04 \pm 0.19$ & -- & $1 \pm 0.18$ \\
\hline $271 \mathrm{G} 022$ & $4-5$ & $0.83 \pm 0.15$ & -- & $0.88 \pm 0.16$ \\
\hline $271 \mathrm{G} 024$ & $9.7-10.7$ & $0.94 \pm 0.18$ & $0.082 \pm 0.041$ & $0.95 \pm 0.18$ \\
\hline $271 \mathrm{G} 041$ & $3.1-4.1$ & $0.78 \pm 0.16$ & -- & $0.82 \pm 0.16$ \\
\hline $271 \mathrm{G} 042$ & $5-6$ & $0.95 \pm 0.16$ & $0.062 \pm 0.030$ & $0.97 \pm 0.17$ \\
\hline $271 \mathrm{G} 048$ & $3.25-4.25$ & $0.92 \pm 0.16$ & $0.056 \pm 0.029$ & $0.86 \pm 0.15$ \\
\hline $271 \mathrm{G} 052$ & $3.25-4.25$ & $0.83 \pm 0.15$ & $\begin{array}{l}- \\
-\end{array}$ & $0.9 \pm 0.16$ \\
\hline 271G053 & $3.25-4.25$ & $0.82 \pm 0.15$ & -- & $0.82 \pm 0.15$ \\
\hline $271 \mathrm{G} 063$ & $3-4$ & $0.97 \pm 0.17$ & $0.055 \pm 0.029$ & $0.88 \pm 0.16$ \\
\hline $271 \mathrm{G} 064$ & $5-6$ & $1.05 \pm 0.18$ & -- & $0.99 \pm 0.17$ \\
\hline
\end{tabular}

aBackground concentration listed in Environmental Monitoring Report for the Proposed Ward Valley, California, Low-Level Radioactive Waste (LLRW) Facility (US Ecology and Atlan-Tech, 1992)

${ }^{b}$ Background concentration listed or derived in Off-Site Radiation Exposure Review Project, Phase II Soil Program (McArthur and Miller, 1989)

-- Not detected above minimum reporting limits

\section{A.9.3.1.8 Isotopic Plutonium}

Isotopic plutonium was not detected above MRLs in CAS 25-04-11 soil samples.

\section{A.9.3.1.9 Strontium-90}

Strontium-90 was not detected above MRLs in CAS 25-04-11 soil samples. 


\section{A.9.3.2 Septic Tank and Manhole Sample Results}

Results of collected septic tank content samples were compared to regulatory levels based on disposal options. If the waste has no hazardous component, the regulatory level is based on disposal options at NTS landfills and lagoons (BN, 1995; CFR, 2000b and c; NDEP, 1997a, b, and c). Any sludge or liquid waste will be solidified before disposal at NTS landfills (NDEP, 1997b). If the waste is hazardous, the release criteria are based on interpretation of the guidelines presented in the POC (BN, 1995; Alderson, 1999). For waste destined for off-site disposal, the POC radiological levels must be met to certify that the waste has no radioactivity added.

Sludge/sediment and liquid samples were obtained from the following locations:

- 271G072 from location G35 (G 35 Manhole)

- 271G074 and 271G075 from location G37 (inlet chamber of septic tank)

- $271 \mathrm{G} 076$ and 271G077 from location G38 (outlet chamber of septic tank)

The analytical suite followed the CAIP and is detailed in Section A.9.2.9. Table A.9-7 presents the results for the sediment sample collected from G35 Manhole. This sample had elevated PCB concentrations; however, summed together, the reported concentrations do not exceed the $50,000 \mu \mathrm{g} / \mathrm{kg}$ action level established in $40 \mathrm{CFR} 761$ (CFR, 2000b) for waste disposal purposes. The concentration of TPH DRO in the sediment sample collected from G35 Manhole also exceeded the NDEP action level of $100 \mathrm{mg} / \mathrm{kg}$ (NAC, 2000).

Table A.9-7 also presents the analytical results exceeding MRLs for the septic tank content samples. Several COPCs were detected in the sludge and liquid samples. Most COPCs were below regulatory limits except for TPH DRO which was detected in samples 271G074 and 271G076. These levels also exceeded the NDEP action level of $100 \mathrm{mg} / \mathrm{kg}$ (NAC, 2000) for TPH.

\section{A.9.4 Contaminants of Concern}

Based on the aforementioned analytical results, COCs are present in the septic tank contents, G35 Manhole material, and an area of soil under the leachfield. The septic tank contains sludge with TPH analytes (DRO) in concentrations above action levels. The TPH DRO is the only COC for the septic tank. The sediment in G35 Manhole contains TPH analytes in concentrations above NDEP action levels and is the only COC for the manhole. In two small areas, benzo(a)pyrene was detected 
Table A.9-7

\section{Sludge, Liquid, and Sediment Sample Results Detected Above Minimum Reporting Limits at CAS 25-04-11}

(Page 1 of 3 )

\begin{tabular}{|c|c|c|c|c|c|c|}
\hline $\begin{array}{c}\text { Sample } \\
\text { Identification } \\
\text { Number }\end{array}$ & Matrix & Parameter & Result & Units & Limits & Reference \\
\hline $271 \mathrm{G} 072$ & Sediment & Acetone & $48(\mathrm{~J})^{\mathrm{a}}$ & $\mu \mathrm{g} / \mathrm{kg}$ & NA & CFR, 2000a \\
\hline $271 \mathrm{G} 072$ & Sediment & Methylene Chloride & $18(\mathrm{~J})^{\mathrm{a}}$ & $\mu \mathrm{g} / \mathrm{kg}$ & NA & CFR, 2000a \\
\hline 271G075 & Liquid & Uranium-234 & $0.55 \pm 0.15$ & $\mathrm{pCi} / \mathrm{L}$ & 100 & NDEP, 1997b \\
\hline $271 \mathrm{G} 077$ & Liquid & Uranium-234 & $0.45 \pm 0.13$ & $\mathrm{pCi} / \mathrm{L}$ & 100 & NDEP, 1997b \\
\hline 271G072 & Sediment & Arsenic** & 3.3 & $\mathrm{mg} / \mathrm{kg}$ & NA & CFR, 2000a \\
\hline $271 \mathrm{G} 072$ & Sediment & Barium** & 76 & $\mathrm{mg} / \mathrm{kg}$ & NA & CFR, 2000a \\
\hline 271G072 & Sediment & Cadmium $^{* *}$ & 4.3 & $\mathrm{mg} / \mathrm{kg}$ & NA & CFR, 2000a \\
\hline $271 \mathrm{G} 072$ & Sediment & Chromium ${ }^{\star *}$ & 16 & $\mathrm{mg} / \mathrm{kg}$ & NA & CFR, 2000a \\
\hline $271 \mathrm{G} 072$ & Sediment & Lead $^{* \star}$ & 82 & $\mathrm{mg} / \mathrm{kg}$ & NA & CFR, 2000a \\
\hline $271 \mathrm{G} 072$ & Sediment & Mercury** & $1.2(\mathrm{~J})$ & $\mathrm{mg} / \mathrm{kg}$ & NA & CFR, 2000a \\
\hline 271G072 & Sediment & Silver** & 180 & $\mathrm{mg} / \mathrm{kg}$ & NA & CFR, 2000a \\
\hline $271 \mathrm{G} 074$ & Sludge & Arsenic** & 6.3 & $\mathrm{mg} / \mathrm{kg}$ & NA & CFR, 2000a \\
\hline $271 \mathrm{G} 074$ & Sludge & Barium ${ }^{* *}$ & 57 & $\mathrm{mg} / \mathrm{kg}$ & NA & CFR, 2000a \\
\hline $271 \mathrm{G} 074$ & Sludge & Cadmium ${ }^{* *}$ & 3.3 & $\mathrm{mg} / \mathrm{kg}$ & NA & CFR, 2000a \\
\hline $271 \mathrm{G} 074$ & Sludge & Chromium** & 16 & $\mathrm{mg} / \mathrm{kg}$ & NA & CFR, 2000a \\
\hline $271 \mathrm{G} 074$ & Sludge & Lead & 67 & $\mathrm{mg} / \mathrm{kg}$ & NA & CFR, 2000a \\
\hline $271 \mathrm{G} 074$ & Sludge & Silver ${ }^{* *}$ & 330 & $\mathrm{mg} / \mathrm{kg}$ & NA & CFR, 2000a \\
\hline $271 \mathrm{G} 076$ & Sludge & Arsenic** $^{* *}$ & 9.1 & $\mathrm{mg} / \mathrm{kg}$ & NA & CFR, 2000a \\
\hline $271 \mathrm{G} 076$ & Sludge & Cadmium $^{* *}$ & 7.8 & $\mathrm{mg} / \mathrm{kg}$ & NA & CFR, 2000a \\
\hline $271 \mathrm{G} 076$ & Sludge & Chromium** & 27 & $\mathrm{mg} / \mathrm{kg}$ & NA & CFR, 2000a \\
\hline $271 \mathrm{G} 076$ & Sludge & Lead & 130 & $\mathrm{mg} / \mathrm{kg}$ & NA & CFR, 2000a \\
\hline $271 \mathrm{G} 076$ & Sludge & Silver & 670 & $\mathrm{mg} / \mathrm{kg}$ & NA & CFR, 2000a \\
\hline 271G072 & Sediment & Diesel-Range Organics & $710(\mathrm{~J})$ & $\mathbf{m g} / \mathbf{k g}$ & 100 & NDEP, 1997b \\
\hline 271G074 & Sludge & Diesel-Range Organics & $580(Z)$ & $\mathrm{mg} / \mathbf{k g}$ & 100 & NDEP, 1997b \\
\hline 271G076 & Sludge & Diesel-Range Organics & $1,200(Z)$ & $\mathbf{m g} / \mathbf{k g}$ & 100 & NDEP, 1997b \\
\hline $271 \mathrm{G} 074$ & Sludge & Gasoline-Range Organics & $98(J)^{b}$ & $\mathrm{mg} / \mathrm{kg}$ & 100 & NDEP, 1997b \\
\hline $271 \mathrm{G} 076$ & Sludge & Gasoline-Range Organics & $31(\mathrm{~J})^{\mathrm{a}}$ & $\mathrm{mg} / \mathrm{kg}$ & 100 & NDEP, 1997b \\
\hline $271 \mathrm{G} 074$ & Sludge & P-Isopropyltoluene & 31,000 & $\mu \mathrm{g} / \mathrm{kg}$ & NA & CFR, 2000a \\
\hline $271 \mathrm{G} 076$ & Sludge & 1,4-Dichlorobenzene & $55,000(\mathrm{~B})$ & $\mu \mathrm{g} / \mathrm{kg}$ & NA & CFR, 2000a \\
\hline
\end{tabular}


Table A.9-7

\section{Sludge, Liquid, and Sediment Sample Results Detected Above Minimum Reporting Limits at CAS 25-04-11}

(Page 2 of 3 )

\begin{tabular}{|c|c|c|c|c|c|c|}
\hline $\begin{array}{c}\text { Sample } \\
\text { Identification } \\
\text { Number }\end{array}$ & Matrix & Parameter & Result & Units & Limits & Reference \\
\hline $271 G 076$ & Sludge & P-Isopropyltoluene & 96,000 & $\mu \mathrm{g} / \mathrm{kg}$ & NA & CFR, 2000a \\
\hline $271 \mathrm{G} 074$ & Sludge & 1,4-Dichlorobenzene & $81,000(\mathrm{~J})^{\mathrm{c}}$ & $\mu \mathrm{g} / \mathrm{kg}$ & NA & CFR, 2000a \\
\hline $271 \mathrm{G} 076$ & Sludge & 1,4-Dichlorobenzene & 76,000 & $\mu \mathrm{g} / \mathrm{kg}$ & NA & CFR, 2000a \\
\hline $271 \mathrm{G} 072$ & Sediment & Actinium-228 & $1.33 \pm 0.42^{d}$ & $\mathrm{pCi} / \mathrm{g}$ & - & $\mathrm{N}$ \\
\hline $271 \mathrm{G} 072$ & Sediment & Potassium-40 & $23 \pm 6.7^{d}$ & $\mathrm{pCi} / \mathrm{g}$ & - & $\mathrm{N}$ \\
\hline $271 \mathrm{G} 074$ & Sludge & Potassium-40 & $27.6 \pm 6.7$ & $\mathrm{pCi} / \mathrm{g}$ & - & $\mathrm{N}$ \\
\hline $271 \mathrm{G} 072$ & Sediment & Lead-212 & $1.51 \pm 0.39^{d}$ & $\mathrm{pCi} / \mathrm{g}$ & - & $\mathrm{N}$ \\
\hline $271 \mathrm{G} 074$ & Sludge & Lead-212 & $1.63 \pm 0.48$ & $\mathrm{pCi} / \mathrm{g}$ & - & $\mathrm{N}$ \\
\hline $271 \mathrm{G} 072$ & Sediment & Lead-214 & $0.76 \pm 0.25^{\mathrm{e}}$ & $\mathrm{pCi} / \mathrm{g}$ & - & $\mathrm{N}$ \\
\hline $271 \mathrm{G} 074$ & Sludge & Aroclor-1254 & $1,700(J)^{\dagger}$ & $\mu \mathrm{g} / \mathrm{kg}$ & 50,000 & CFR, 2000b \\
\hline $271 \mathrm{G} 076$ & Sludge & Aroclor-1254 & $4,900(J)^{g}$ & $\mu \mathrm{g} / \mathrm{kg}$ & 50,000 & CFR, 2000b \\
\hline $271 \mathrm{G} 072$ & Sediment & Aroclor-1260 & $2,600(J)^{g}$ & $\mu \mathrm{g} / \mathrm{kg}$ & 50,000 & CFR, 2000b \\
\hline $271 \mathrm{G} 076$ & Sludge & Aroclor-1260 & $2,000(J)^{g}$ & $\mu \mathrm{g} / \mathrm{kg}$ & 50,000 & CFR, 2000b \\
\hline $271 \mathrm{G} 072$ & Sediment & Uranium-234 & $2.12 \pm 0.34$ & $\mathrm{pCi} / \mathrm{g}$ & 100 & NDEP, 1997b \\
\hline $271 \mathrm{G} 072$ & Sediment & Uranium-238 & $0.91 \pm 0.17$ & $\mathrm{pCi} / \mathrm{g}$ & 100 & NDEP, 1997b \\
\hline $271 \mathrm{G} 074$ & Sludge & Uranium-234 & $1.67 \pm 0.28$ & $\mathrm{pCi} / \mathrm{g}$ & 100 & NDEP, 1997b \\
\hline $271 \mathrm{G} 074$ & Sludge & Uranium-235 & $0.08 \pm 0.039$ & $\mathrm{pCi} / \mathrm{g}$ & 100 & NDEP, 1997b \\
\hline $271 \mathrm{G} 074$ & Sludge & Uranium-238 & $1.04 \pm 0.19$ & $\mathrm{pCi} / \mathrm{g}$ & 100 & NDEP, 1997b \\
\hline $271 \mathrm{G} 076$ & Sludge & Uranium-234 & $3.59 \pm 0.52$ & $\mathrm{pCi} / \mathrm{g}$ & 100 & NDEP, 1997b \\
\hline $271 \mathrm{G} 076$ & Sludge & Uranium-235 & $0.075 \pm 0.035$ & $\mathrm{pCi} / \mathrm{g}$ & 100 & NDEP, 1997b \\
\hline $271 \mathrm{G} 076$ & Sludge & Uranium-238 & $0.99 \pm 0.18$ & $\mathrm{pCi} / \mathrm{g}$ & 100 & NDEP, 1997b \\
\hline $271 \mathrm{G} 072$ & Sediment & Thallium-208 & $0.41 \pm 0.17$ & $\mathrm{pCi} / \mathrm{g}$ & NA & NDEP, 1997b \\
\hline $271 \mathrm{G} 074$ & Sludge & TCLP 1,4-Dichlorobenzene & 0.36 & $\mathrm{mg} / \mathrm{L}$ & 7.5 & CFR, 2000a \\
\hline $271 \mathrm{G} 074$ & Sludge & TCLP Lead & 0.054 & $\mathrm{mg} / \mathrm{L}$ & 5.0 & CFR, 2000a \\
\hline 271G076 & Sludge & TCLP Lead & 0.079 & $\overline{\mathrm{mg} / \mathrm{L}}$ & 5.0 & CFR, 2000a \\
\hline $271 \mathrm{G} 076$ & Sludge & TCLP Silver & 0.12 & $\mathrm{mg} / \mathrm{L}$ & 5.0 & CFR, 2000a \\
\hline $271 \mathrm{G} 074$ & Sludge & Gross Alpha & $4.4 \pm 1.9$ & $\mathrm{pCi} / \mathrm{L}$ & $2.1^{\mathrm{h}}$ & NA \\
\hline $271 \mathrm{G} 074$ & Sludge & Gross Beta & $1.7 \pm 1.5$ & $\mathrm{pCi} / \mathrm{L}$ & $2.5^{\mathrm{h}}$ & NA \\
\hline $271 \mathrm{G} 075$ & Liquid & Gross Alpha & $1.7 \pm 2.0$ & $\mathrm{pCi} / \mathrm{L}$ & $3.2^{h}$ & NA \\
\hline $271 \mathrm{G} 075$ & Liquid & Gross Beta & $38.8 \pm 5.8$ & $\mathrm{pCi} / \mathrm{L}$ & $3.0^{h}$ & NA \\
\hline $271 \mathrm{G} 076$ & Sludge & Gross Alpha & $5.7 \pm 1.5$ & $\mathrm{pCi} / \mathrm{L}$ & $1.3^{\mathrm{h}}$ & NA \\
\hline $271 \mathrm{G} 076$ & Sludge & Gross Beta & $3.7 \pm 1.1$ & $\mathrm{pCi} / \mathrm{L}$ & $1.4^{\mathrm{h}}$ & NA \\
\hline
\end{tabular}


Table A.9-7

\section{Sludge, Liquid, and Sediment Sample Results Detected Above Minimum Reporting Limits at CAS 25-04-11}

(Page 3 of 3 )

\begin{tabular}{||c|c|c|c|c|c|c|}
\hline $\begin{array}{c}\text { Sample } \\
\text { Identification } \\
\text { Number }\end{array}$ & Matrix & Parameter & Result & Units & Limits & Reference \\
\hline \hline $271 \mathrm{G} 077$ & Liquid & Gross Alpha & $1.5 \pm 1.8$ & $\mathrm{pCi} / \mathrm{L}$ & $3.0^{\mathrm{h}}$ & $\mathrm{NA}$ \\
\hline $271 \mathrm{G} 077$ & Liquid & Gross Beta & $37.8 \pm 5.7$ & $\mathrm{pCi} / \mathrm{L}$ & $3.3^{\mathrm{h}}$ & $\mathrm{NA}$ \\
\hline
\end{tabular}

${ }^{a}$ Qualifier added to laboratory data; record accepted. Surrogate recovery exceeded the lower limits. Matrix effects may exist.

${ }^{b}$ Qualifier added to laboratory data; record accepted. Exceeded holding time.

${ }^{\mathrm{c}}$.Qualifier added to laboratory data; record accepted. Surrogates diluted out.

${ }^{\mathrm{d} B a c k g r o u n d}$ concentration listed in Environmental Monitoring Report for the Proposed Ward Valley, California, Low-Level Radioactive Waste (LLRW) Facility (US Ecology and Atlan-Tech, 1992).

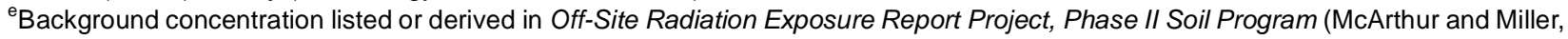
1989).

${ }^{f} Q$ ualifier added to laboratory data; record accepted. Surrogate recovery exceeded the upper limits.

${ }^{9}$ Qualifier added to laboratory data; record accepted. Surrogate recovery exceeded the upper limits. Matrix effects may exist.

${ }^{\mathrm{h}}$ Maximum detectable concentration

** $=$ TCLP below minimum reporting limit

$\mathrm{J}=$ Estimated value

$Z=$ The reported result did not resemble the patterns of the following petroleum hydrocarbon products: gasoline, JP-4, JP-8, diesel, mineral spirits, motor oil, Stoddard solvent and Bunker C.

$B=$ Analyte found in both sample and associated blank.

$\mathrm{N}=$ No limit established (NDEP, 1997b)

NA = Not applicable

in soil in concentrations above the PALs. As discussed in Section A.9.3.1.2, this detection may be a false positive result, due to the presence of pieces of "Orangeburg" pipe that was inadvertently introduced during sampling.

\section{A.9.5 Nature and Extent of Contamination}

Total petroleum hydrocarbons are located within the septic tank sludge and in the G35 Manhole sediment. Approximately 120 gal of sludge and 294 gal of liquid remained in the bottom of the inlet chamber of the septic tank. Approximately 39 gal of sludge and 247 gal of liquid remained in the bottom of the outlet chamber of the septic tank. The soils under the leachfield contain an SVOC analyte (benzo[a]pyrene) in concentrations above PALs at two locations. However, because this leachfield contained "Orangeburg" pipe it is possible that the results for benzo(a)pyrene may be related to the inadvertent introduction of pieces of the pipe in soil samples from these two locations. All COPCs are confined to the structural (i.e., septic tank, manhole) or to the spatial boundaries of the leachfield. 


\section{A.9.6 Revised Conceptual Model}

No variations in the conceptual model were identified. 


\section{A.10.0 Port Gaston Training Area Contaminated Water Reservoir (CAS 26-03-01)}

Corrective Action Site 26-03-01 was a water reservoir used for NUWAX training in 1981. The contaminated water reservoir is located approximately $800 \mathrm{ft}$ south of the Port Gaston Complex (Pluto Project control area). More detail is provided in the CAIP (DOE/NV, 2001).

\section{A.10.1 Corrective Action Investigation}

Twenty-six investigation samples, listed in Table A.10-1, were collected during investigation activities conducted at CAS 26-03-01. The planned and actual sample locations are shown in Figure A.10-1. The specific CAI activities conducted to meet CAIP requirements at CAS 26-03-01 are described in Table A.2-1.

\section{A.10.1.1 Deviations}

Two deviations to the CAIP-requirements occurred as the result of unforeseen circumstances. Refusal was met due to encountering subsurface hardpan; therefore: sample 271H020 was collected at 3 to $3.3 \mathrm{ft}$ bgs rather than the planned interval of 3 to $4 \mathrm{ft}$ bgs; and sample $271 \mathrm{H} 021$ was collected at 2.75 to $3.2 \mathrm{ft}$ bgs rather than the planned interval of 2.75 to $3.75 \mathrm{ft}$ bgs. Despite these deviations, the pertinent CAIP requirements were met.

\section{A.10.2 Investigation Results}

Hand and backhoe excavations were conducted to access sampling horizons at the biased locations presented in the CAIP. Excavation by hand was conducted for those sample intervals that had soil media above the plastic liner. Excavation by backhoe was needed to reach the sampling depths beneath the liner due to hard-packed soil conditions. Figure A.10-2 depicts the liner and demonstrates the two layers where sampling was conducted. Twenty-three soil samples were collected from the planned locations excavated within the leachfield. These samples were collected above and below the liner. Eighteen samples were submitted for laboratory analysis. In addition, one QC soil duplicate and one MS/MSD sample were collected and analyzed. A geotechnical sample was 
Table A.10-1

Samples Collected at CAS 26-03-01

(Page 1 of 2)

\begin{tabular}{|c|c|c|c|c|c|c|c|c|c|c|c|c|c|}
\hline \multirow[b]{2}{*}{$\begin{array}{c}\text { Sample } \\
\text { Identification } \\
\text { Number }\end{array}$} & \multirow[b]{2}{*}{$\begin{array}{l}\text { Sample } \\
\text { Location }\end{array}$} & \multirow[b]{2}{*}{$\begin{array}{l}\text { Sample } \\
\text { Matrix }\end{array}$} & \multirow[b]{2}{*}{$\begin{array}{l}\text { Depth } \\
\text { (ft bgs) }\end{array}$} & \multirow[b]{2}{*}{ Purpose } & \multicolumn{9}{|c|}{ Analyses } \\
\hline & & & & & 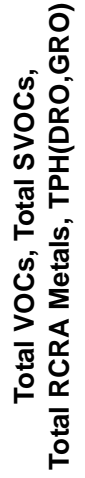 & 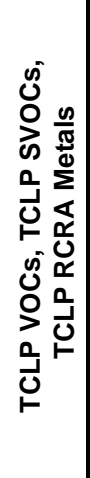 & 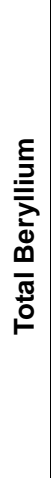 & O̊ & 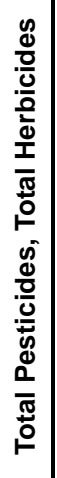 & 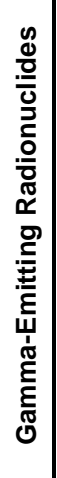 & 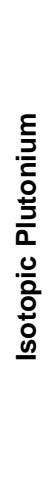 & 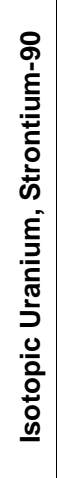 & 焉 \\
\hline $271 \mathrm{H} 001$ & $\mathrm{H} 01$ & Soil & $0-0.5$ & Environmental & $x^{a}$ & & & & $x$ & & & & \\
\hline $271 \mathrm{H} 002$ & $\mathrm{H} 02$ & Soil & $0-0.3$ & Environmental & $x^{a}$ & & & & $X$ & $X$ & & & \\
\hline $271 \mathrm{H} 003$ & $\mathrm{H} 04$ & Soil & $0-0.5$ & Environmental & $x^{a}$ & & & & $x$ & & & & \\
\hline $271 \mathrm{H} 004$ & $\mathrm{H} 03$ & Soil & $0-0.5$ & Environmental & $x^{a}$ & & & & $\mathrm{X}$ & & & & \\
\hline $271 \mathrm{H} 005$ & $\mathrm{H} 05$ & Soil & $0-0.5$ & Environmental & $x^{a}$ & & & & $x$ & & & & \\
\hline $271 \mathrm{H} 006$ & $\mathrm{H} 06$ & Soil & $0-0.7$ & Environmental & $x^{a}$ & & & & $x$ & & & & \\
\hline $271 \mathrm{H} 007$ & $\mathrm{H} 07$ & Soil & $0-0.3$ & Environmental & $x^{a}$ & & & & $\mathrm{X}$ & & & & \\
\hline $271 \mathrm{H} 008$ & $\mathrm{H} 01$ & Soil & $0.3-1.3$ & Environmental & $x$ & & & & $X$ & & & & \\
\hline $271 \mathrm{H} 009$ & $\mathrm{H} 01$ & Soil & $2.75-3.75$ & Environmental & $x$ & & & & $\mathrm{X}$ & & & & \\
\hline $271 \mathrm{H} 010$ & $\mathrm{H} 02$ & Soil & $0.3-1.3$ & Environmental & $x$ & & & & $x$ & $x$ & & & \\
\hline $271 \mathrm{H} 011$ & $\mathrm{H} 05$ & Soil & $0.5-1.2$ & Environmental & $x$ & & & & $x$ & & & & \\
\hline $271 \mathrm{H} 012$ & $\mathrm{H} 04$ & Soil & $0.3-1.2$ & Environmental & $x$ & & & & $x$ & & & & \\
\hline $271 \mathrm{H} 013$ & $\mathrm{H} 07$ & Soil & $0.3-0.7$ & Environmental & $x$ & & & & $x$ & & & & \\
\hline $271 \mathrm{H} 014$ & $\mathrm{H} 03$ & Soil & $0.5-1.5$ & Environmental & $x$ & & & & $x$ & & & & \\
\hline $271 \mathrm{H} 015$ & $\mathrm{H} 07$ & Soil & $0-0.5$ & Environmental & $x^{a}$ & & & & $x$ & $X$ & & & \\
\hline $271 \mathrm{H} 016$ & $\mathrm{H} 07$ & Soil & $0-0.5$ & $\begin{array}{c}\text { Duplicate of } \\
271 \mathrm{H} 015\end{array}$ & $x^{a}$ & & & & $\mathrm{X}$ & $x$ & & & \\
\hline $271 \mathrm{H} 017$ & $\mathrm{H} 06$ & Soil & $0.8-1.8$ & $\begin{array}{c}\text { Environmental } \\
\text { MS/MSD }\end{array}$ & $\mathrm{X}$ & & & & $\mathrm{X}$ & & & & \\
\hline $271 \mathrm{H} 018$ & $\mathrm{H} 07$ & Soil & $2.9-3.75$ & Environmental & $\mathrm{X}$ & & & & & & & & \\
\hline $271 \mathrm{H} 019$ & $\mathrm{H} 06$ & Soil & $3.8-4.2$ & Environmental & \multicolumn{9}{|c|}{ Not Submitted for Analyses ${ }^{b}$} \\
\hline $271 \mathrm{H} 020$ & $\mathrm{H} 05$ & Soil & $3-3.3$ & Environmental & \multicolumn{9}{|c|}{ Not Submitted for Analyses ${ }^{b}$} \\
\hline
\end{tabular}


Table A.10-1

Samples Collected at CAS 26-03-01

(Page 2 of 2)

\begin{tabular}{|c|c|c|c|c|c|c|c|c|c|c|c|c|c|}
\hline \multirow[b]{2}{*}{$\begin{array}{c}\text { Sample } \\
\text { Identification } \\
\text { Number }\end{array}$} & \multirow[b]{2}{*}{$\begin{array}{c}\text { Sample } \\
\text { Location }\end{array}$} & \multirow[b]{2}{*}{$\begin{array}{c}\text { Sample } \\
\text { Matrix }\end{array}$} & \multirow[b]{2}{*}{$\begin{array}{c}\text { Depth } \\
\text { (ft bgs) }\end{array}$} & \multirow[b]{2}{*}{ Purpose } & \multicolumn{9}{|c|}{ Analyses } \\
\hline & & & & & 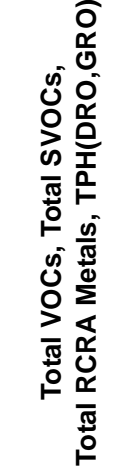 & 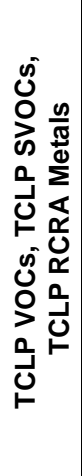 & 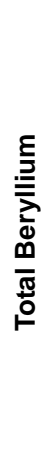 & 怘 & 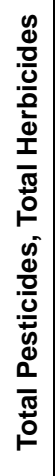 & 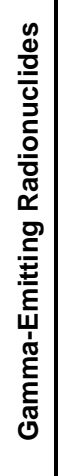 & 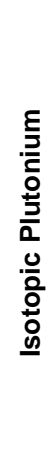 & 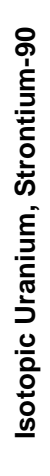 & $\stackrel{\frac{5}{3}}{\vdots}$ \\
\hline $271 \mathrm{H} 021$ & $\mathrm{H} 03$ & Soil & $2.75-3.2$ & Environmental & \multicolumn{9}{|c|}{ Not Submitted for Analyses ${ }^{b}$} \\
\hline $271 \mathrm{H} 022$ & $\mathrm{H} 02$ & Soil & $2.5-3.2$ & Environmental & \multicolumn{9}{|c|}{ Not Submitted for Analyses ${ }^{b}$} \\
\hline $271 \mathrm{H} 023$ & $\mathrm{H} 04$ & Soil & $2.5-3.2$ & Environmental & \multicolumn{9}{|c|}{ Not Submitted for Analyses ${ }^{b}$} \\
\hline $271 \mathrm{H} 024$ & $\mathrm{H} 08$ & Soil & $0.5-0.75$ & Geotechnical & \multicolumn{9}{|c|}{ Not Submitted for Analyses ${ }^{c}$} \\
\hline $271 \mathrm{H} 026$ & H09 & Sediment & $0-0.5$ & Environmental & & & & & & $x$ & & & \\
\hline $271 \mathrm{H} 302$ & NA & Water & NA & Trip Blank & VOC only & & & & & & & & \\
\hline $271 \mathrm{H} 303$ & NA & Water & NA & Field Blank & $X$ & & & & $x$ & $X$ & & & \\
\hline $271 \mathrm{H} 304$ & NA & Water & NA & Trip Blank & VOC only & & & & & & & & \\
\hline 271H305 & NA & Water & NA & Rinsate & $X$ & & & & $x$ & $X$ & & & \\
\hline $271 \mathrm{H} 306$ & NA & Water & NA & Trip Blank & VOC only & & & & & & & & \\
\hline $271 \mathrm{H} 307$ & NA & Water & NA & Trip Blank & VOC only & & & & & & & & \\
\hline 271H308 & NA & Water & NA & Rinsate & $X$ & & & & $X$ & $X$ & & & \\
\hline
\end{tabular}

${ }^{\text {a }}$ Surface soil samples were not analyzed for volatile organic compounds.

${ }^{\mathrm{b}}$ The sample was collected, field screened, and returned to the site for disposal.

${ }^{\mathrm{c}}$ The sample was collected, field screened, and is being stored for possible geotechnical analysis.

$\mathrm{NA}=$ Not applicable

MS/MSD = Matrix spike/matrix spike duplicate 


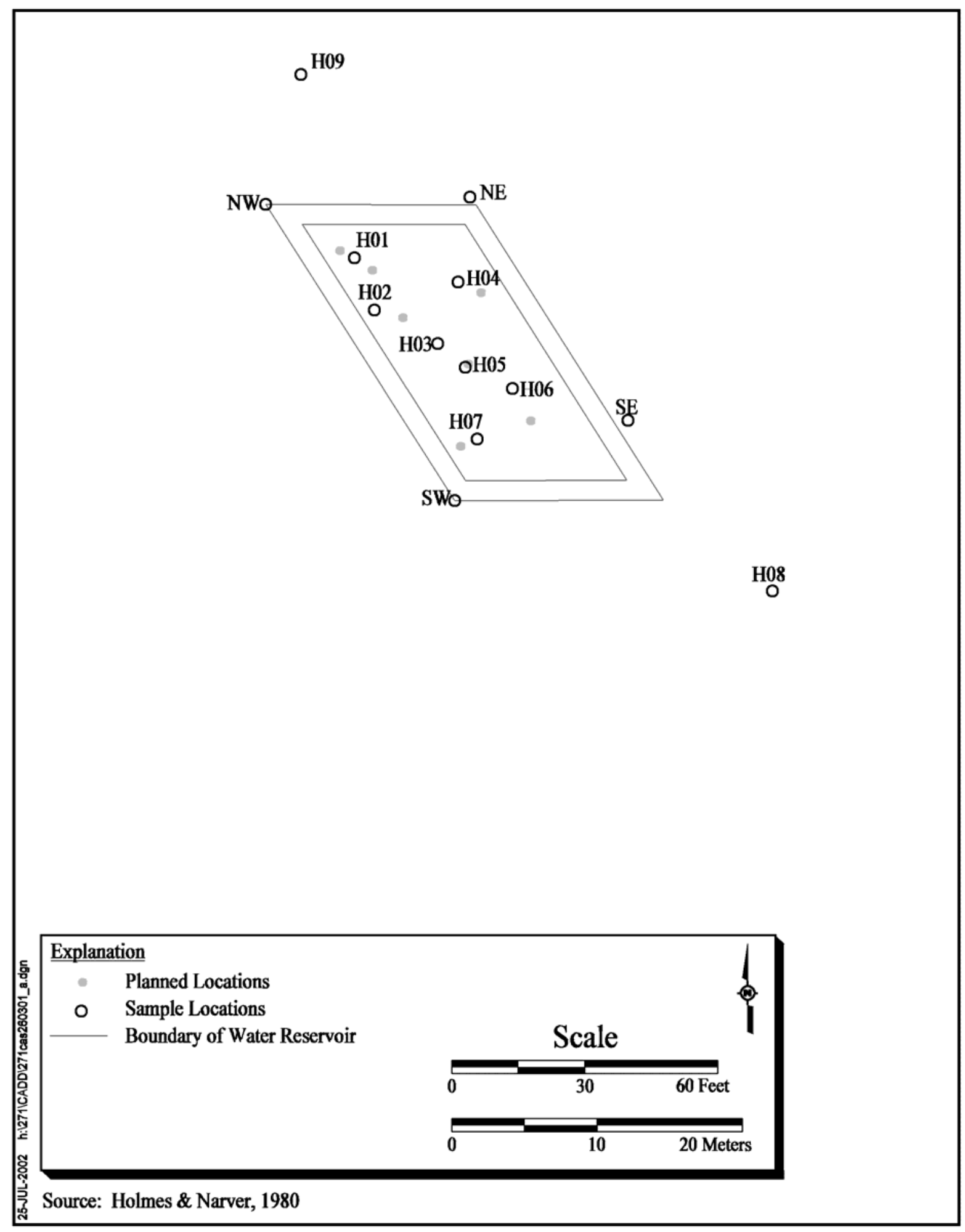

Figure A.10-1

Contaminated Water Reservoir (CAS 26-03-01)

Sample Locations 
collected outside the boundary of the water reservoir. The sample will be sent to a laboratory for geotechnical analysis if necessary.

\section{A.10.2.1 Additional Sampling}

To confirm that downgradient migration in the dry wash had not occurred, the field crew returned to this CAS on February 06, 2002. One sediment sample was collected and analyzed for gamma emitting radionuclides from location H09 (Figure A.10-1). The sample was collected from a downstream location for the purpose of confirming that migration from the water reservoir had not occurred. The sample was collected at 0 to $0.5 \mathrm{ft}$ bgs.

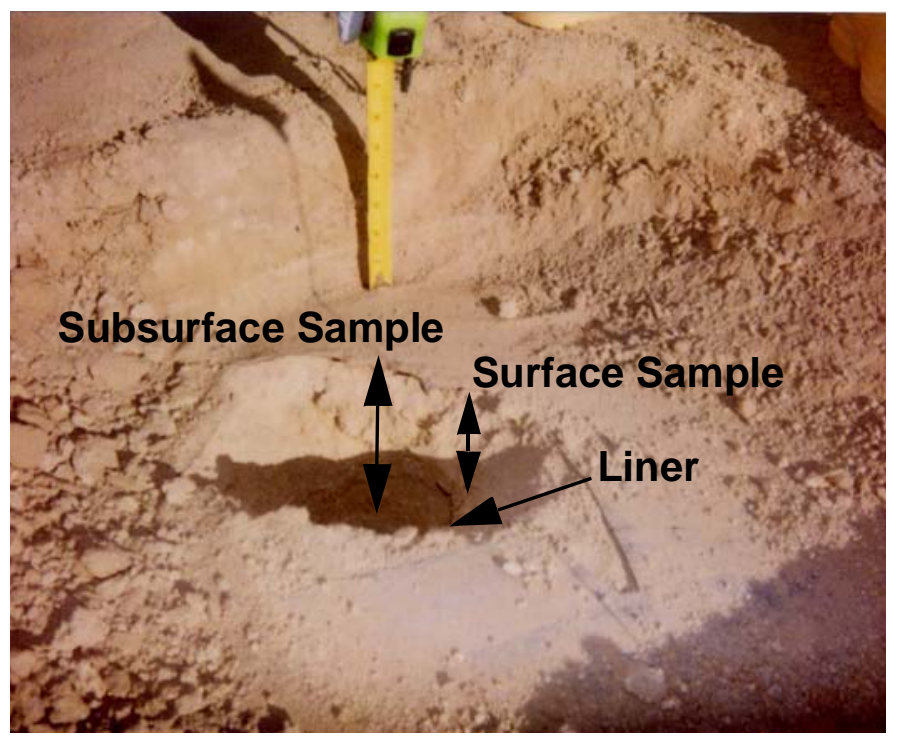

Figure A.10-2

CAS 26-03-01 Sampling Locations (Photograph Taken 01-10-2002)

\section{A.10.2.2 Field-Screening Results}

Soil samples were screened for VOCs, alpha and beta/gamma radioactivity, and gamma-emitters. The field readings were compared to FSLs to guide sampling decisions and determine which samples were to be submitted for laboratory analysis. No VOCs greater than FSLs were found during soil sample screening. The results of radiological field screening are discussed in Section A.10.2.3. 


\section{A.10.2.3 Radiological Survey Results}

Radiological field-screening ultimately aided in guiding sample selection, and assisting with health and safety and waste management decisions.

The radiological field-screening levels for alpha radiation was $86 \mathrm{dpm} / 100 \mathrm{~cm}^{2}$. The beta/gamma field-screening level was $3,300 \mathrm{dpm} / 100 \mathrm{~cm}^{2}$. Radiological field-screening levels were exceeded at the following locations:

- H01 - Sample number 271H001 (0 to 6 in.) had an elevated alpha reading at $123 \mathrm{dpm} / 100 \mathrm{~cm}^{2}$. Additional samples (271H008 and 271H009) were collected below the liner from the location. Neither of these additional samples exceeded radiological fieldscreening levels.

- H02 - Sample number 271H002 (0 to 4 in.) had elevated alpha and beta/gamma readings at 600 and 3,629 dpm/100 cm , respectively. This sample was submitted for laboratory analysis and additional samples $(271 \mathrm{H} 010$ and $271 \mathrm{H} 022)$ were collected below the liner from the location. Neither of these additional samples exceeded radiological field-screening levels.

- H04 - Sample number 271H003 (0 to 6 in.) had an elevated alpha reading at $303 \mathrm{dpm} / 100 \mathrm{~cm}^{2}$. Additional samples (271H012 and 271H023) were collected below the liner from the location. Neither of these additional samples exceeded radiological field-screening levels.

- H05 - Sample number 271H005 (0 to 6 in.) had an elevated alpha reading at $277 \mathrm{dpm} / 100 \mathrm{~cm}^{2}$. Additional samples (271H011 and 271H020) were collected below the liner from the location. Neither of these additional samples exceeded radiological fieldscreening levels.

- H07 - Sample number 271H007 (0 to 4 in.) had elevated alpha and beta/gamma readings at 948 and 4,235 dpm $/ 100 \mathrm{~cm}^{2}$, respectively. Additional samples $(271 \mathrm{H} 013,271 \mathrm{H} 015$, 271H016, and 271H018) were collected from this location. Sample numbers $271 \mathrm{H} 015$ and $271 \mathrm{H} 016$ (field duplicate of 271H015) were collected above the liner to confirm the elevated screening readings. The samples had elevated alpha and beta readings at 1,258 and $4,403 \mathrm{dpm} / 100 \mathrm{~cm}^{2}$, respectively. Both of these samples were submitted for laboratory analysis. Samples 271H013 and 271H018, collected below the liner, did not exceed radiological field-screening levels.

Confirmatory swipes were collected from the sample bottles and equipment. None of the swipe samples demonstrated removable radiological contamination above unrestricted release criteria. To guide sampling decisions, all samples were analyzed on-site with a gamma spectrometer. None of the 
samples demonstrated any analytes above PALs. Therefore, samples were submitted for laboratory gamma spectrometry from locations where the alpha and beta/gamma field-screening results indicated contamination was present.

\section{A.10.2.4 Sample Analysis}

Environmental soil samples and associated QC samples were collected and analyzed for the CAIP-specified COPCs (i.e., total VOCs (subsurface samples only), total SVOCs, total RCRA metals, TPH [DRO and GRO], total pesticides, and total herbicides). In addition, 25 percent of the soil samples (guided by field-screening results, see Section A.10.2.3) and 100 percent of the associated QC samples were analyzed for gamma-emitting radionuclides.

The parameters and laboratory methods used to analyze the investigation samples are listed in Table A.2-2. Table A.10-1 lists the sample-specific analytical parameters.

\section{A.10.3 Analytes Detected Above Minimum Reporting Limits}

The soil sample analytical results with concentrations exceeding corresponding MRLs or PALs (DOE/NV, 1998; DOE/NV, 2001) at CAS 26-03-01 are summarized in the following sections. A portion of the CAS 26-03-01 analytical results were rejected during validation; however, these rejected data did not impact closure decisions as discussed in Section B.1.3.8 of Appendix B.

\section{A.10.3.1 Analytical Results in Soil Samples}

The following sections discuss the results for soil samples in comparison to the levels established in the Leachfield Work Plan and the CAIP.

\section{A.10.3.1.1 Total Volatile Organic Compounds}

Only subsurface soil samples were analyzed for VOCs. Volatile organic compounds were not detected above MRLs in CAS 26-03-01 soil samples.

\section{A.10.3.1.2 Total Semivolatile Organic Compounds}

Semivolatile organic compounds were not detected above MRLs in CAS 26-03-01 soil samples. 


\section{A.10.3.1.3 Total Petroleum Hydrocarbons}

Total petroleum hydrocarbons were not detected above MRLs in CAS 26-03-01 soil samples.

\section{A.10.3.1.4 Total RCRA Metals and Beryllium}

As shown in Table A.10-2, the total RCRA metals detected in soil samples above concentrations exceeding the MRLs are arsenic $(1 \mathrm{mg} / \mathrm{kg})$, barium $(20 \mathrm{mg} / \mathrm{kg})$, beryllium $(0.5 \mathrm{mg} / \mathrm{kg})$, cadmium $(0.5 \mathrm{mg} / \mathrm{kg})$, chromium $(1 \mathrm{~g} / \mathrm{kg})$, and lead $(0.3 \mathrm{mg} / \mathrm{kg})$. Other RCRA metals (i.e., selenium, silver) were below specified MRLs.

Barium concentrations ranged from 201 to $494 \mathrm{mg} / \mathrm{kg}$, beryllium was detected in only one sample at $2.03 \mathrm{mg} / \mathrm{kg}$, cadmium was detected in only one sample at $0.54 \mathrm{mg} / \mathrm{kg}$, chromium concentrations ranged from 3.58 to $11.9 \mathrm{mg} / \mathrm{kg}$, and lead concentrations ranged from 9.08 to $16.7 \mathrm{mg} / \mathrm{kg}$ with a "J" flag (estimated value). All reported concentrations of these metals were below EPA Region 9 PRGs defined in this document as PALs.

Arsenic concentrations ranged from 5.01 to $20.9 \mathrm{mg} / \mathrm{kg}$. All of the arsenic detections in soil from CAS 26-03-01 exceed the PAL of $2.7 \mathrm{mg} / \mathrm{kg}$ (EPA Region 9 PRG). Concentrations in samples from above the liner are consistently lower than concentrations from samples taken below the liner. The PAL is lower than the 7 to $8 \mathrm{mg} / \mathrm{kg}$ mean concentration of arsenic in silt from the Nevada Test and Training Range (NBMG, 1998; Moore, 1999). Although arsenic concentrations in the soil exceed the PAL, they are believed to be within ambient conditions for CAS 26-03-01 and do not represent contamination.

\section{A.10.3.1.5 Total Pesticides and Total Herbicides}

Total pesticides and total herbicides were not detected above MRLs in CAS 26-03-01 soil samples.

\section{A.10.3.1.6 Gamma Spectrometry}

Results of gamma spectrometry analysis of soil samples by the off-site laboratory are presented in Table A.10-3. Concentrations of actinium-228, bismuth-214, lead-212, lead-214, potassium-40, thallium-208, and thorium-227 were detected above the MDLs. Lead-214 and thorium-227 were above PALs in sample numbers $271 \mathrm{H} 002,271 \mathrm{H} 015$, and 271H016. The TPU in the radioanalytical 
Table A.10-2

Soil Sample Results for Total RCRA Metals Detected Above Minimum Reporting Limits at CAS 26-03-01

\begin{tabular}{|c|c|c|c|c|c|c|c|}
\hline \multirow{2}{*}{$\begin{array}{c}\text { Sample } \\
\text { Identification } \\
\text { Number }\end{array}$} & \multirow{2}{*}{$\begin{array}{c}\text { Depth } \\
\text { (ft bgs) }\end{array}$} & \multicolumn{6}{|c|}{ Contaminants of Potential Concern (mg/kg) } \\
\hline & & Arsenic & Barium & Beryllium & Cadmium & Chromium & Lead \\
\hline \multicolumn{2}{|c|}{$\begin{array}{c}\text { Preliminary Action } \\
\text { Levels }^{a}\end{array}$} & 2.7 & 100,000 & 2,200 & 810 & 450 & 750 \\
\hline $271 \mathrm{H} 001$ & $0-0.5$ & 5.64 & $251(\mathrm{~J})^{\mathrm{b}}$ & -- & -- & 10.8 & $11.5(\mathrm{~J})^{\mathrm{c}}$ \\
\hline 271H001RR1 & $0-0.5$ & 5.69 & -- & -- & -- & -- & 11.4 \\
\hline $271 \mathrm{H} 002$ & $0-0.3$ & 5.01 & $251(\mathrm{~J})^{\mathrm{b}}$ & -- & -- & 9.26 & $10.5(\mathrm{~J})^{\mathrm{c}}$ \\
\hline 271H003 & $0-0.5$ & 7.55 & $251(J)^{b}$ & -- & -- & 8.49 & $10.5(\mathrm{~J})^{\mathrm{c}}$ \\
\hline $271 \mathrm{H} 004$ & $0-0.5$ & 5.48 & $251(\mathrm{~J})^{\mathrm{b}}$ & -- & -- & 10.8 & $10.8(\mathrm{~J})^{\mathrm{c}}$ \\
\hline 271H005 & $0-0.5$ & 5.58 & $250(\mathrm{~J})^{\mathrm{b}}$ & -- & -- & 9.34 & $11(\mathrm{~J})^{\mathrm{c}}$ \\
\hline $271 \mathrm{H} 006$ & $0-0.7$ & 5.2 & $201(\mathrm{~J})^{\mathrm{b}}$ & -- & -- & 6.4 & $9.08(\mathrm{~J})^{\mathrm{c}}$ \\
\hline $271 \mathrm{H} 007$ & $0-0.3$ & 5.53 & $439(\mathrm{~J})^{\mathrm{b}}$ & -- & .54 & 9.2 & $9.58(\mathrm{~J})^{\mathrm{C}}$ \\
\hline $271 \mathrm{H} 008$ & $0.3-1.3$ & 10.3 & $244(J)^{b}$ & -- & -- & 6.43 & $10.6(J)^{c}$ \\
\hline $271 \mathrm{H} 009$ & $2.75-3.75$ & 13.2 & $219(\mathrm{~J})^{\mathrm{b}}$ & -- & -- & 5.98 & $10.8(\mathrm{~J})^{\mathrm{c}}$ \\
\hline $271 \mathrm{H} 010$ & $0.3-1.3$ & 15 & $240(J)^{b}$ & -- & -- & 6.58 & $11(J)^{c}$ \\
\hline $271 \mathrm{H} 011$ & $0.5-1.2$ & 20.9 & $229(\mathrm{~J})^{\mathrm{b}}$ & -- & -- & 3.79 & $15.1(J)^{c}$ \\
\hline $271 \mathrm{H} 012$ & $0.3-1.2$ & 20.1 & $221(\mathrm{~J})^{\mathrm{b}}$ & -- & -- & 3.58 & $13.3(\mathrm{~J})^{\mathrm{c}}$ \\
\hline $271 \mathrm{H} 013$ & $0.3-0.7$ & 14 & $245(J)^{b}$ & -- & -- & 7.4 & $16.7(\mathrm{~J})^{\mathrm{c}}$ \\
\hline $271 \mathrm{H} 014$ & $0.5-1.5$ & 18.5 & $282(J)^{b}$ & -- & -- & 4.58 & $11.7(\mathrm{~J})^{\mathrm{c}}$ \\
\hline $271 \mathrm{H} 015$ & $0-0.5$ & 5.85 & $494(\mathrm{~J})^{\mathrm{b}}$ & -- & -- & 11.7 & $10.8(\mathrm{~J})^{\mathrm{c}}$ \\
\hline $271 \mathrm{H} 016$ & $0-0.5$ & 5.57 & $480(\mathrm{~J})^{\mathrm{b}}$ & -- & $\overline{--}$ & 11.9 & $10.8(\mathrm{~J})^{\mathrm{c}}$ \\
\hline $271 \mathrm{H} 017$ & $0.8-1.8$ & 20.6 & $234(\mathrm{~J})^{\mathrm{b}}$ & 2.03 & -- & 4.87 & $12(\mathrm{~J})^{\mathrm{c}}$ \\
\hline 271H017RR1 & $0.8-1.8$ & 19 & -- & -- & -- & -- & 12.4 \\
\hline
\end{tabular}

aBased on U.S. Environmental Protection Agency, Region 9 Preliminary Remediation Goals (PRGs) (EPA, 2000).

${ }^{b}$ Qualifier added to laboratory data; record accepted. Spike recovery was outside control limits. Matrix effects may exist.

${ }^{\circ}$ Qualifier added to laboratory data; record accepted. Inductively coupled plasma serial dilution recovery was not met. Matrix effects may exist.

$\mathrm{J}=$ Estimated value

-- $=$ Not detected above minimum reporting limits 
Table A.10-3

Soil Sample Results for Gamma-Emitting Radionuclides Detected Above Minimum Reporting Limits at CAS 26-03-01

\begin{tabular}{|c|c|c|c|c|c|c|c|c|}
\hline \multirow{2}{*}{$\begin{array}{c}\text { Sample } \\
\text { Identification } \\
\text { Number }\end{array}$} & \multirow{2}{*}{$\begin{array}{c}\text { Depth } \\
\text { (ft bgs) }\end{array}$} & \multicolumn{7}{|c|}{ Contaminants of Potential Concern (pCi/g) } \\
\hline & & Actinium-228 & Bismuth-214 & Potassium-40 & Lead-212 $^{\mathrm{a}}$ & Lead-214 ${ }^{b}$ & Thallium-208 & Thorium-227 \\
\hline \multicolumn{2}{|c|}{ Preliminary Action Level } & 3.64 & 3.47 & 96 & 2.9 & 2.9 & 3.4 & 0.07 \\
\hline $271 \mathrm{H} 002$ & $0-0.3$ & 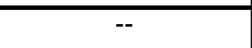 & 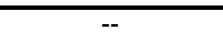 & $21.1 \pm 5.9$ & $1.63 \pm 0.44$ & $3.7 \pm 0.80$ & 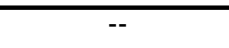 & $13.5 \pm 2.8$ \\
\hline $271 \mathrm{H} 010$ & $0.3-1.3$ & $\begin{array}{l}- \\
-\end{array}$ & -- & $24.5 \pm 6.2$ & $1.04 \pm 0.33$ & $0.95 \pm 0.32$ & $0.49 \pm 0.20$ & -- \\
\hline $271 \mathrm{H} 015$ & $0-0.5$ & $1.87 \pm 0.58$ & $0.87 \pm 0.38$ & $19.7 \pm 5.0$ & $1.37 \pm 0.43$ & $6.6 \pm 1.2$ & $\overline{--}$ & $30.3 \pm 5.5$ \\
\hline $271 \mathrm{H} 016$ & $0-0.5$ & $3.62 \pm 0.94$ & $1.08 \pm 0.45$ & $24.2 \pm 6.2$ & $1.54 \pm 0.42$ & $2.89 \pm 0.63$ & -- & $28.7 \pm 5.2$ \\
\hline $271 \mathrm{H} 017$ & $0.8-1.8$ & $1.44 \pm 0.36$ & $1.01 \pm 0.28$ & $23 \pm 4.5$ & $1.53 \pm 0.32$ & $0.92 \pm 0.22$ & $0.38 \pm 0.11$ & -- \\
\hline $271 \mathrm{H} 026$ & $0-0.5$ & $1.24 \pm 0.42$ & $1.17 \pm 0.35$ & $22.4 \pm 5.1$ & $1.25 \pm 0.32$ & $0.79 \pm 0.23$ & $\overline{--}$ & $\overline{--}$ \\
\hline
\end{tabular}

aBackground concentration listed in Environmental Monitoring Report for the Proposed Ward Valley, California, Low-Level Radioactive Waste (LLRW) Facility (US Ecology and Atlan-Tech, 1992).

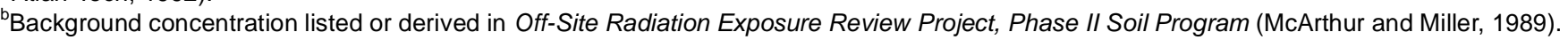

$--=$ Not detected above minimum reporting limit 
measurement is provided in the table along with the concentration for all detected gamma-emitters. Sample $271 \mathrm{H} 015$ had a lead-214 concentration statistically distinguishable from background concentrations. Samples 271H002, 271H015, and 271H016 had thorium-227 concentrations that were statistically distinguishable from background concentrations. Because of the short half-life of thorium-227 (18.7 days), the compound must be in equilibrium with its longer lived parent actinium-227 (21.8 years). This indicates that actinium-227 is present in these samples at the same concentrations as thorium-227.

\section{A.10.4 Contaminants of Concern}

Based on the aforementioned analytical results, COCs are present in the soils above the liner in the contaminated water reservoir. The soils contain lead-214 and thorium-227 (and by association actinium-227) in concentrations above PALs and statistically greater than background concentrations.

\section{A.10.5 Nature and Extent of Contamination}

The radiological contaminants are located in the first 6 in. of soil, which overlies the plastic liner, approximately $50 \mathrm{yd}^{3}$ of contaminated soil. All COCs have been confined to the spatial boundaries of the contaminated water reservoir. Radionuclides exceeding PALs were not detected in the sediment sample collected from the wash downgradient of the reservoir.

\section{A.10.6 Revised Conceptual Model}

No variations in the conceptual model were identified. 


\section{A.11.0 Area 26 Check Station (Building 2105) Septic System (CAS 26-04-01)}

The Check Station septic system was designed to receive sanitary effluent generated by activities from Building 2105 (Check Station). The septic system is located approximately $200 \mathrm{ft}$ west of the the intersection of the Pluto Road and Cane Springs Road. The site is comprised of a leachfield, septic tank, distribution box, and associated piping. More detail is provided in the CAIP (DOE/NV, 2001).

\section{A.11.1 Corrective Action Investigation}

Twenty-nine investigation samples, listed in Table A.11-1, were collected during investigation activities conducted at CAS 26-04-01. The planned sample locations at CAS 26-04-01 are shown in Figure 4-12 of the CAIP (DOE/NV, 2001). The actual sample locations are shown in Figure A.11-1. The specific activities conducted to meet CAIP requirements at CAS 26-04-01 are described in Table A.2-1.

\section{A.11.1.1 Deviations}

There were no deviations from the planned investigation of CAS 26-04-01.

\section{A.11.2 Investigation Results}

The following subsections provide details of the inspection and sampling of leachfield features, field screening results, and sample selection and analysis.

\section{A.11.2.1 Septic Tank Contents}

The contents of the septic tank were sampled according to the CAIP. The septic tank was a rectangular concrete structure with a 2,113-gal capacity. It was accessed by one manhole located at the ground surface. The interior dimensions of the tank are $7.2 \mathrm{ft}$ (length) by $5.5 \mathrm{ft}$ (width) by $7.2 \mathrm{ft}$ (depth). The bottom of the tank is at $7.5 \mathrm{ft}$ bgs. One liquid and one sludge sample were collected from the septic tank. Visual inspection revealed that a maximum thickness of $3 \mathrm{ft}$ ( 885 gal) of liquid and $0.5 \mathrm{ft}$ (147 gal) of sludge remained in the bottom of the tank. The sludge is extremely viscous, 
Table A.11-1

Samples Collected at CAS 26-04-01

(Page 1 of 2)

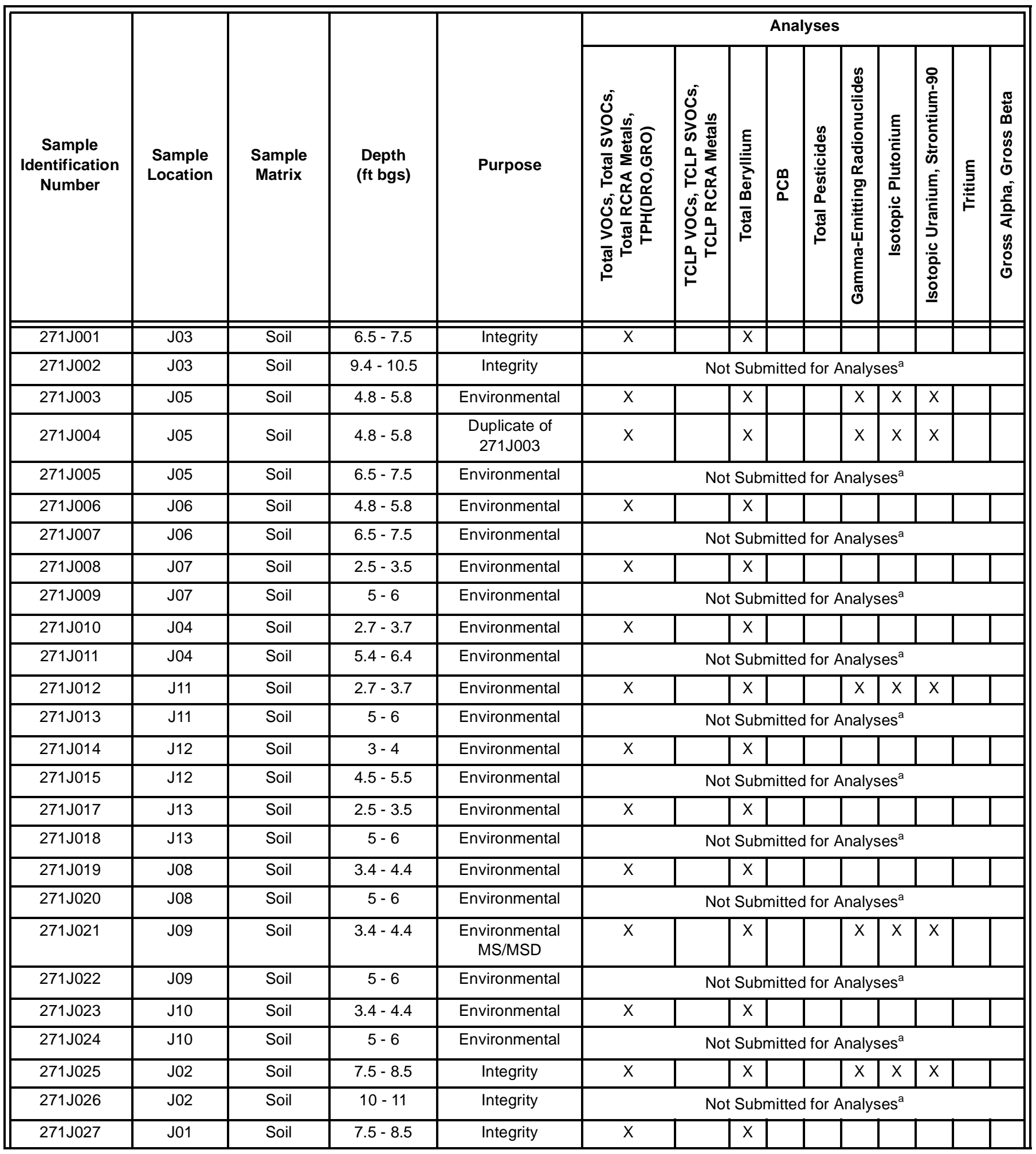


Table A.11-1

Samples Collected at CAS 26-04-01

(Page 2 of 2)

\begin{tabular}{|c|c|c|c|c|c|c|c|c|c|c|c|c|c|c|}
\hline \multirow[b]{2}{*}{$\begin{array}{c}\text { Sample } \\
\text { Identification } \\
\text { Number }\end{array}$} & \multirow[b]{2}{*}{$\begin{array}{c}\text { Sample } \\
\text { Location }\end{array}$} & \multirow[b]{2}{*}{$\begin{array}{l}\text { Sample } \\
\text { Matrix }\end{array}$} & \multirow[b]{2}{*}{$\begin{array}{c}\text { Depth } \\
\text { (ft bgs) }\end{array}$} & \multirow[b]{2}{*}{ Purpose } & \multicolumn{10}{|c|}{ Analyses } \\
\hline & & & & & 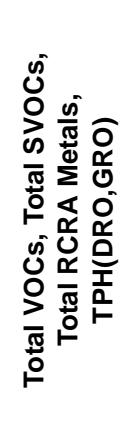 & 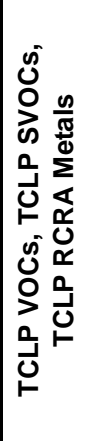 & 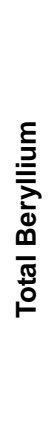 & O̊̊ & 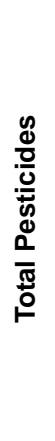 & 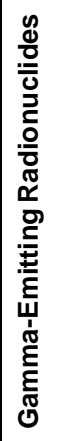 & 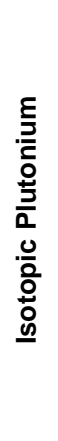 & 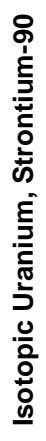 & $\stackrel{E}{\underline{E}}$ & 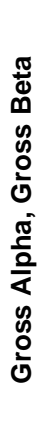 \\
\hline 271J028 & $\mathrm{J} 01$ & Soil & $10.2-11.2$ & Integrity & \multicolumn{10}{|c|}{ Not Submitted for Analyses ${ }^{a}$} \\
\hline 271J031 & J18 & Soil & $3.4-3.6$ & Geotechnical & \multicolumn{10}{|c|}{ Not Submitted for Analyses ${ }^{b}$} \\
\hline 271J201 & J03 & Soil & $11-11.5$ & Environmental & & & & & $x$ & & & & & \\
\hline 271J202 & $\mathrm{J} 03$ & Soil & $13-13.5$ & Environmental & & & & & $X$ & & & & & \\
\hline 271J203 & J19 & Soil & $4-4.5$ & Environmental & & & & & $x$ & & & & & \\
\hline 271J204 & J19 & Soil & $6.5-7$ & Environmental & & & & & $x$ & & & & & \\
\hline 271J205 & $\mathrm{J} 20$ & Soil & $3.5-4$ & Environmental & & & & & $x$ & & & & & \\
\hline 271J206 & J20 & Soil & $6-6.5$ & Environmental & & & & & $x$ & & & & & \\
\hline 271J301 & NA & Water & NA & Trip Blank & VOC only & & & & & & & & & \\
\hline 271J302 & NA & Water & NA & Rinsate & $x$ & & $x$ & & & $x$ & $x$ & $x$ & & \\
\hline 271J309 & J14 & Liquid & $4-7$ & Septic Tank & $x$ & & $x$ & & & $x$ & $x$ & $x$ & $x$ & $x$ \\
\hline 271J309 & \multicolumn{14}{|c|}{ Not a QA Sample, is a Septic Tank sample } \\
\hline $271 J 310$ & NA & Water & NA & Trip Blank & VOC only & & & & & & & & & \\
\hline 271J501 & NA & Liquid & NA & $\begin{array}{l}\text { WM Sample } \\
\text { from Drum } \\
\text { 271J02 }\end{array}$ & $\begin{array}{l}\text { RCRA } \\
\text { Metals } \\
\text { (Lead) }\end{array}$ & & & & & & & & & \\
\hline
\end{tabular}

aThe sample was collected, field screened, and returned to the site for disposal.

${ }^{\text {b}}$ The sample was collected, field screened, and is being stored for possible geotechnical analysis.

$\mathrm{NA}=$ Not applicable

MS/MSD = Matrix spike/matrix spike duplicate 


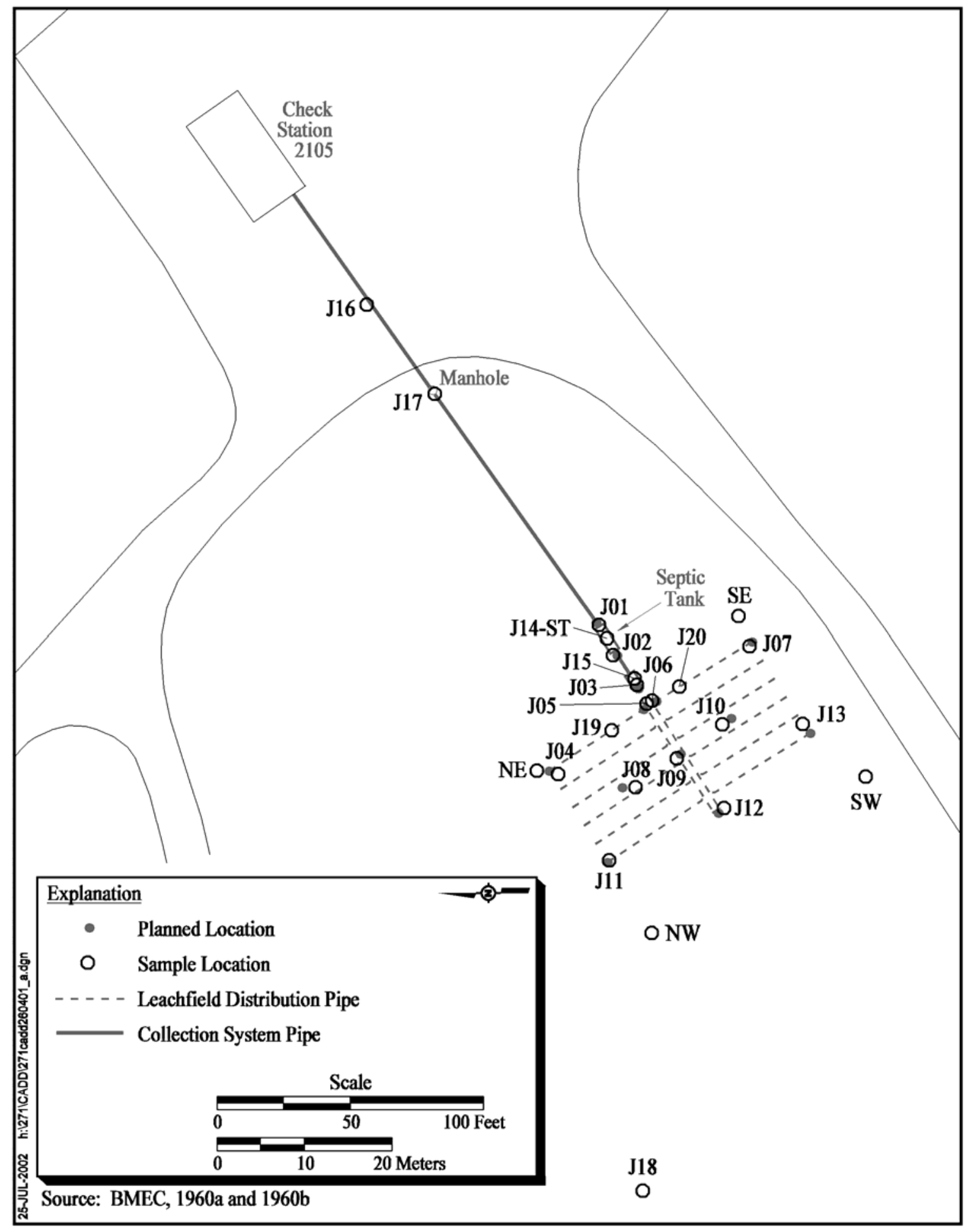

Figure A.11-1

Check Station Septic System (CAS 26-04-01) Sample Locations 
almost a liquid material. Photographs of the septic tank were taken to document the visual inspection (Figure A.11-2).

\section{A.11.2.2 Distribution Box Contents}

The distribution box was a rectangular concrete structure with a 668-gal capacity. It was accessed by a metal lid located 10 in. above the ground surface. The exterior dimensions of the distribution box were $5.1 \mathrm{ft}$ (length) by $5 \mathrm{ft}$ (width) by $6.5 \mathrm{ft}$ (depth). One sediment sample (271J030) was collected (scraped) from the bottom of the box. Visual inspection revealed that approximately $0.3 \mathrm{ft}$ ( $2.6 \mathrm{gal}$ ) of sediment remained in the bottom of the box. The material is dry, and this volume estimate is conservative. Photographs of the distribution box were taken to document the visual inspection (Figure A.11-3).

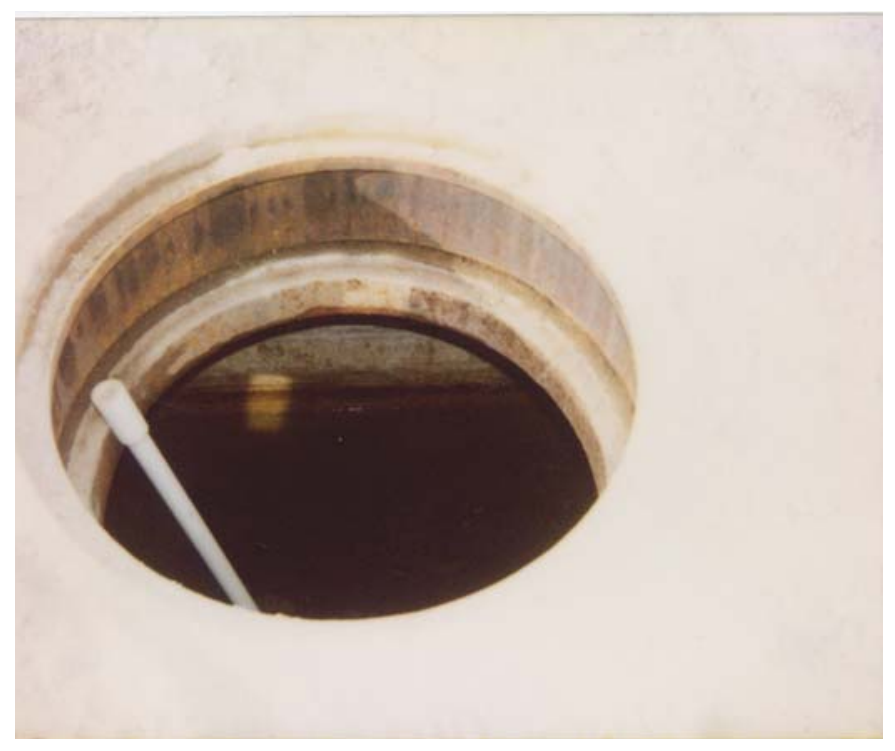

Figure A.11-2

CAS 26-04-01 Septic Tank, Interior (Photograph Taken 11-07-2001)

\section{A.11.2.3 Septic Tank and Distribution Box Integrity Soil Sampling}

Six integrity samples were collected by excavating adjacent to the influent and effluent ends of the septic tank and the effluent end of the distribution box. 


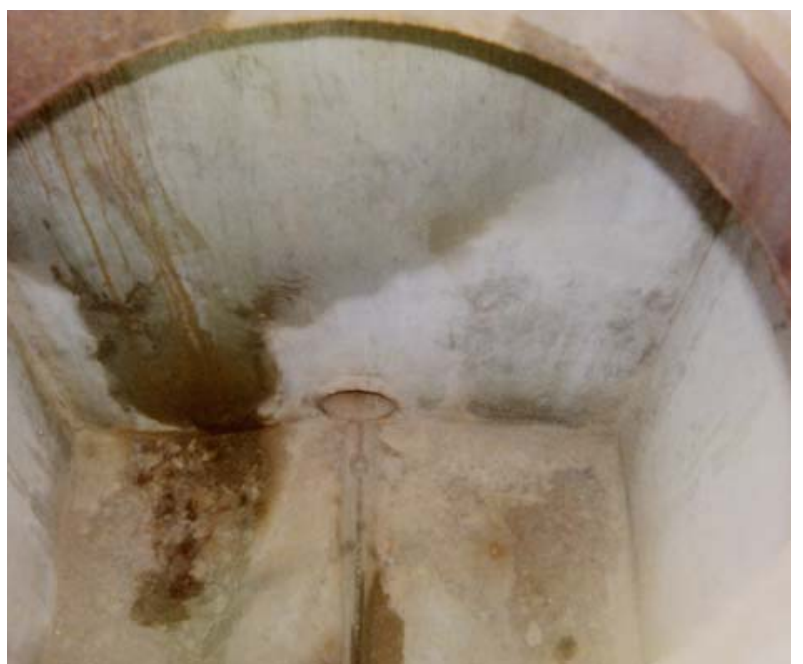

Depicts Inlet Line from Septic Tank

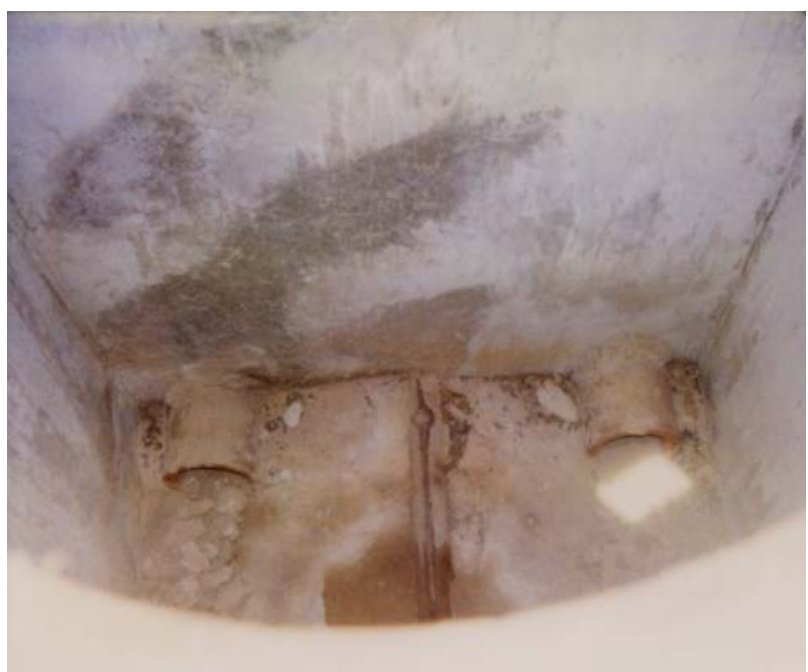

Depicts Outlet Lines to Leachfield

Figure A.11-3

CAS 26-04-01 Distribution Box, Interior

(Photographs Taken 11-07-2001)

Figure A.11-4 and Figure A.11-5 depict the structural integrity and composition of the effluent ends of the septic tank and distribution box. The following three samples were submitted for laboratory analysis:

- The upper sample (271J001) from the effluent end of the distribution box, collected at 6.5 to $7.5 \mathrm{ft}$ bgs

- The upper sample (271J025) from the effluent end of the septic tank, collected at 7.5 to $8.5 \mathrm{ft}$ bgs

- The upper sample (271J027) from the influent end of the septic tank, collected at 7 to $7.5 \mathrm{ft}$ bgs

\section{A.11.2.4 Leachfield Excavation Soil Sampling}

Backhoe excavations were conducted to access sampling horizons at the biased locations presented in the CAIP. Excavations provided a visual verification of distribution pipes and enabled soil samples to be collected from appropriate intervals beneath the pipes, as specified by the CAIP. Twenty-one soil samples were collected from the planned locations excavated within the leachfield. These samples 


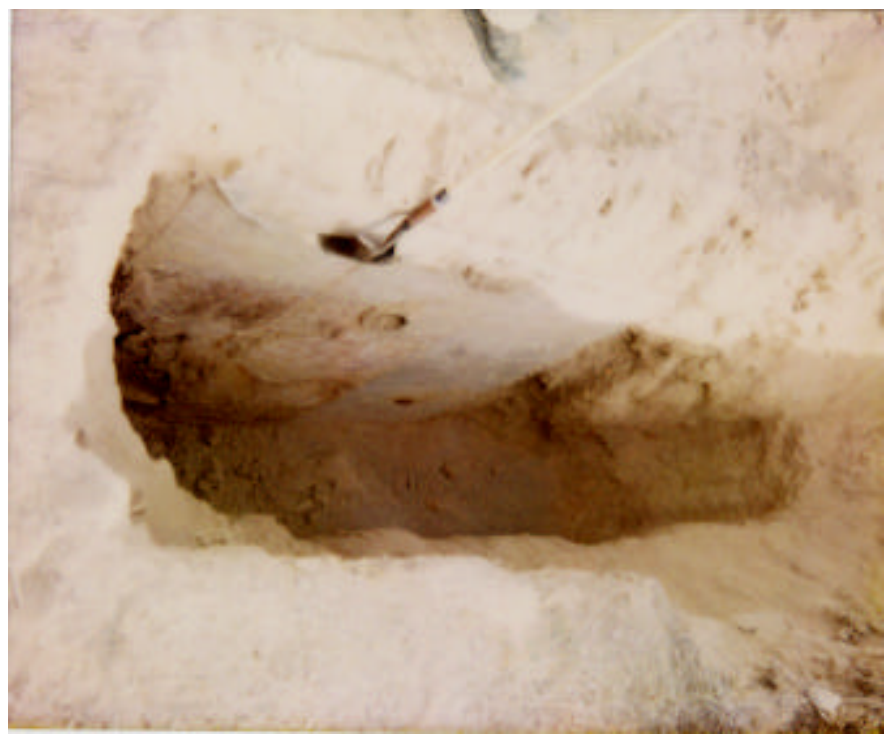

Figure A.11-4

CAS 26-04-01 Septic Tank, Effluent Integrity Sample (Photograph Taken 11-07-2001)

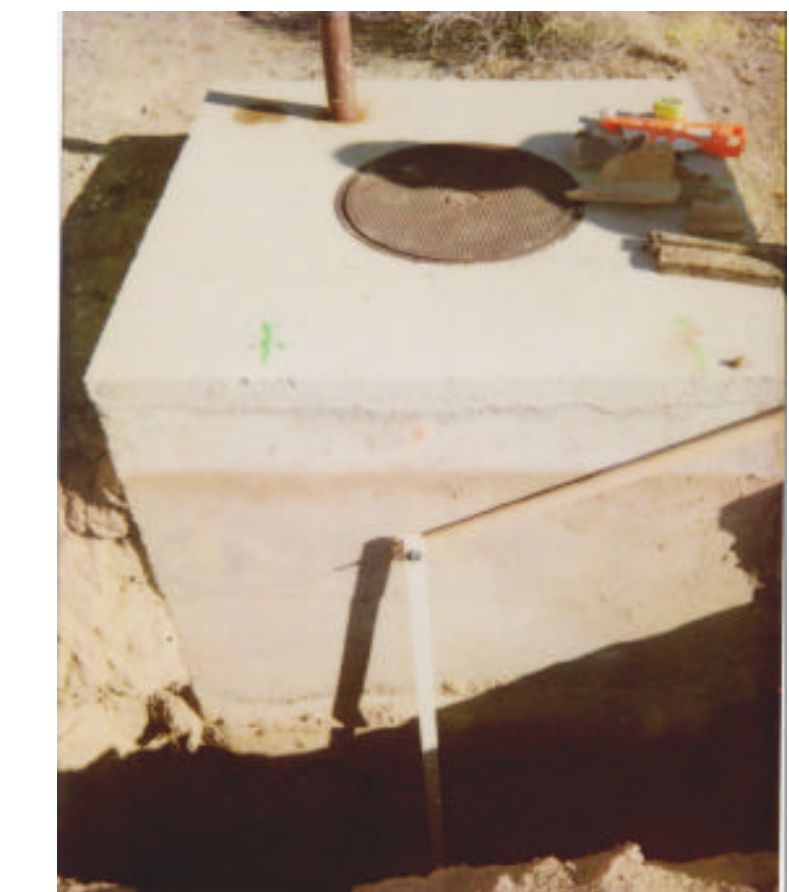

Front View

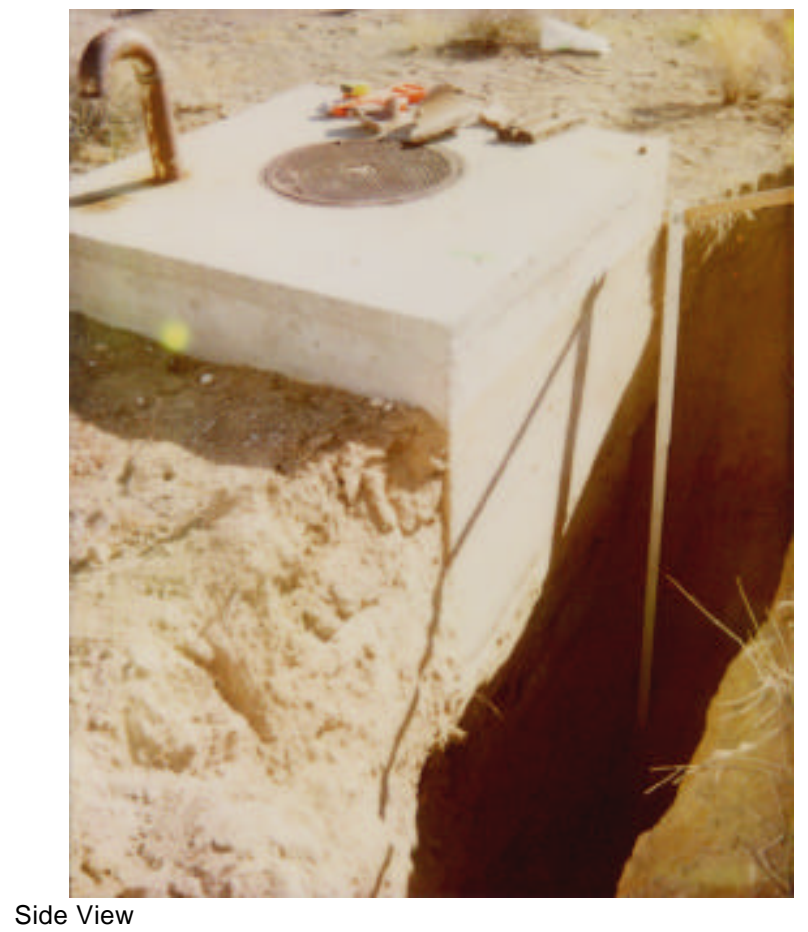

Figure A.11-5

CAS 26-04-01 Distribution Box, Effluent Integrity Sample

(Photographs Taken 12-19-2001) 
were collected from an interval at the leachrock/native soil interface and an interval $2.5 \mathrm{ft}$ below the interface. The interface was found at depths ranging from 2.5 to $4.8 \mathrm{ft}$ bgs. Eleven samples were submitted for laboratory analysis. In addition, one QC soil duplicate and one MS/MSD sample were collected and analyzed. A geotechnical sample was collected outside the boundary of the leachfield. The sample will be sent to a laboratory for geotechnical analysis, if necessary.

\section{A.11.2.5 Additional Sampling}

During the SVOC analysis of soil sample 271J001 (location J03), the analyst noted the presence of pesticides (chlordane) in the soil. To confirm the presence or absence of pesticides, since they were not identified as COPCs, the field crew returned to this CAS on May 06, 2002, to conduct step-out sampling. One location (J03) was identified from the original sampling activities as a location of concern. Two vertical and four horizontal step-out samples were collected. Sample numbers 271J201 and 271J202 were collected from J03 at 11 to 11.5 and 13 to $13.5 \mathrm{ft}$ bgs. Soil samples 271J203 and 271J204 were collected from step-out location J19. Soil samples 271J205 and 271J206 were collected from step-out location J20 (Figure A.11-1). All of the samples were submitted for laboratory analysis of total pesticides.

One waste management sample was collected from drum 271J02 to further determine the appropriate waste disposal method. The sample was analyzed for lead.

\section{A.11.2.6 Collection System Pipe Inspections}

Access points for inspection of collection system piping by video mole survey were a manhole and excavated locations.

First, a fishtape was inserted into the excavated opening in the VCP leading into the inlet side of the septic tank (location J01). The fishtape was pushed for a length of $110 \mathrm{ft}$. Then the video mole was passed upstream (northeast) through the pipe for $102 \mathrm{ft}$, it could not be pushed further due to equipment limitations. An excavation (J16) was made $50 \mathrm{ft}$ southwest of the concrete foundation (where Building 2105 once stood). The video mole was passed $39 \mathrm{ft}$ upstream (northeast) until an obstruction was encountered. The video mole was also passed downstream (southwest) for $43 \mathrm{ft}$, where it entered a manhole. The pipe was grouted shut prior to filling in the excavation. The 
manhole (location J17 on Figure A.11-1) was uncovered, inspected, and radiologically surveyed. The manhole was dry and free of sediment so no sample was collected.

Some sediment and plant and animal matter were identified in the piping, but was not appropriate or adequate material to be sampled. No breaks or blockages related to the operation of the septic system were noted during the inspection. Visual observations were recorded in the FADLs. The pipe was radiologically surveyed at location J16. Section A.11.2.8 describes the radiological results.

\section{A.11.2.7 Field-Screening Results}

Soil samples were screened for VOCs and alpha and beta/gamma radioactivity. The field readings were compared to FSLs to guide sampling decisions and determine which samples were to be submitted for laboratory analysis. No VOCs greater than FSLs were found during soil sample screening. The results of radiological field screening are discussed in Section A.11.2.8.

A sample of the septic tank content was collected and analyzed for fecal coliform bacteria. Fecal coliform bacteria was not detected in the septic tank at this CAS.

\section{A.11.2.8 Radiological Survey Results}

All radiological field screening results for soil samples at CAS 26-04-01 were below FSLs.

Samples of the VCP from the effluent pipes of the distribution box and from material within the distribution box were collected and on-site gamma spectroscopy performed. Table A.11-2

Table A.11-2

On-Site Gamma Spectroscopy Results at CAS 26-04-01

\begin{tabular}{|l|c|c|}
\hline \multirow{2}{*}{\multicolumn{2}{|c|}{ Sample Number }} & \multicolumn{2}{|c|}{ Isotope (pCi/g) } \\
\cline { 2 - 3 } & Cesium-137 & Cobalt-60 \\
\hline \hline VCP 26-04-01 (pipe) & 0.48 & - \\
\hline VCP Control (pipe) & 0.0 & - \\
\hline J015-DB-2 (distribution box) & 15 & 0.3 \\
\hline
\end{tabular}


lists the results from the gamma spectroscopy screening. No swipes were collected from this CAS. Radiological survey data for locations J16 and J17 indicate the collection system meets the unrestricted release criteria as defined in the NV/YMP Radiological Control Manual (DOE/NV, 2000a).

\section{A.11.2.9 Sample Analysis}

Environmental soil samples and associated QC samples were collected and analyzed for the CAIP-specified COPCs (i.e., total VOCs, total SVOCs, total RCRA metals, TPH [DRO and GRO], and total beryllium). In addition, 25 percent of the soil samples and 100 percent of the associated QC samples were analyzed for Iso-U, Iso-Pu, Sr-90, and gamma-emitting radionuclides. As discussed in Section A.11.2.5, additional samples from CAS 26-04-01 were analyzed for total pesticides.

Both the sludge and liquid septic tank samples were analyzed for total VOCs, total SVOCs, TPH (GRO and DRO), total RCRA metals, total beryllium, gamma-emitting radionuclides, Iso-U, Iso-Pu, Sr-90, tritium, gross alpha, and gross beta radioactivity. The sludge sample was also analyzed by TCLP for VOCs, SVOCs, and RCRA metals.

The parameters and laboratory methods used to analyze the investigation samples are listed in Table A.2-2. Table A.11-1 lists the sample-specific analytical parameters.

\section{A.11.3 Analytes Detected Above Minimum Reporting Limits}

The soil sample analytical results with concentrations exceeding corresponding MRLs or PALs (DOE/NV, 1998; DOE/NV, 2001) at CAS 26-04-01 are summarized in the following sections. The results of the septic tank content sampling are compared to appropriate regulatory levels for disposal. A portion of the CAS 26-04-01 analytical results were rejected during validation; however, these rejected data did not impact closure decisions as discussed in Section B.1.3.9 of Appendix B.

\section{A.11.3.1 Analytical Results for Soil Samples}

The following sections discuss the results for soil samples in comparison to the levels established in the Leachfield Work Plan and the CAIP. 


\section{A.11.3.1.1 Total Volatile Organic Compounds}

Volatile organic compound results are reported in Table A.11-3. The only organic compounds detected above MRLs were acetone and methylene chloride. Estimated concentrations for acetone and methylene chloride as designated by the "J" qualifier were between 41 to $290 \mu \mathrm{g} / \mathrm{kg}$ and 5.3 to $5.6 \mu \mathrm{g} / \mathrm{kg}$, respectively. These results are below laboratory reporting limits. Acetone and methylene chloride concentrations were below PALs of 6,200,000 $\mu \mathrm{g} / \mathrm{kg}$ and $21,000 \mu \mathrm{g} / \mathrm{kg}$, respectively. Both acetone and methylene chloride are common laboratory contaminants.

Table A.11-3

Soil Sample Results for Total VOCs

Detected Above Minimum Reporting Limits at CAS 26-04-01

\begin{tabular}{||c|c|c|c||}
\hline \multirow{2}{*}{$\begin{array}{c}\text { Sample } \\
\text { Identification } \\
\text { Number }\end{array}$} & \multirow{2}{*}{$\begin{array}{c}\text { Depth } \\
\text { (ft bgs) }\end{array}$} & \multicolumn{2}{|c|}{ Contaminants of Potential Concern $(\mu \mathbf{g} / \mathbf{k g})$} \\
\cline { 3 - 4 } & & Acetone & Methylene Chloride \\
\hline Preliminary Action Levels ${ }^{\mathrm{a}}$ & $\mathbf{6 , 2 0 0 , 0 0 0}$ & $\mathbf{2 1 , 0 0 0}$ \\
\hline \hline $271 \mathrm{~J} 017$ & $2.5-3.5$ & $41(\mathrm{~J})^{\mathrm{b}}$ & $5.3(\mathrm{~J})$ \\
\hline $271 \mathrm{~J} 021$ & $3.4-4.4$ & $42(\mathrm{~J})^{\mathrm{b}}$ & 5.6 \\
\hline $271 \mathrm{~J} 025$ & $7.5-8.5$ & $290(\mathrm{~J})^{\mathrm{c}}$ & -- \\
\hline
\end{tabular}

${ }^{a}$ Based on U.S. Environmental Protection Agency, Region 9 Preliminary Remediation Goals (PRGs) (EPA, 2000).

${ }^{b} Q u a l i f i e r$ added to laboratory data; record accepted. Average relative response factor $<0.05$. Relative response factor $<0.05$.

${ }^{\mathrm{C}} \mathrm{Qualifier}$ added to laboratory data; record accepted. Average relative response factor $<0.05$. Relative response factor $<0.05$. Continuing calibration verification percent $>25$ percent.

$--=$ Not detected above minimum reporting limits

$\mathrm{J}=$ Estimated value

\section{A.11.3.1.2 Total Semivolatile Organic Compounds}

Semivolatile organic compounds were not detected above MRLs in CAS 26-04-01 soil samples.

\section{A.11.3.1.3 Total Petroleum Hydrocarbons}

Total petroleum hydrocarbons were not detected above MRLs in CAS 26-04-01 soil samples. 


\section{A.11.3.1.4 Total RCRA Metals}

As shown in Table A.11-4, the total RCRA metals detected in soil samples at concentrations exceeding the MRLs are arsenic (1 mg/kg), barium (20 mg/kg), chromium ( $1 \mathrm{mg} / \mathrm{kg})$, lead $(0.3 \mathrm{mg} / \mathrm{kg})$, mercury $(0.1 \mathrm{mg} / \mathrm{kg})$, and selenium $(0.5 \mathrm{mg} / \mathrm{kg})$. Other RCRA metals (i.e., cadmium, silver) were below specified MRLs.

Table A.11-4

Soil Sample Results for Total RCRA Metals Detected Above Minimum Reporting Limits at CAS 26-04-01

\begin{tabular}{|c|c|c|c|c|c|c|c|c|}
\hline \multirow{2}{*}{$\begin{array}{c}\text { Sample } \\
\text { Identification } \\
\text { Number }\end{array}$} & \multirow{2}{*}{$\begin{array}{c}\text { Depth } \\
\text { (ft bgs) }\end{array}$} & \multicolumn{7}{|c|}{ Contaminants of Potential Concern $(\mathrm{mg} / \mathrm{kg})$} \\
\hline & & Arsenic & Barium & Beryllium & Chromium & Lead & Mercury & Selenium \\
\hline \multicolumn{2}{|c|}{ Preliminary Action Levels ${ }^{a}$} & 2.7 & 100,000 & 2,200 & 450 & 750 & 610 & 10,000 \\
\hline $271 \mathrm{~J} 001$ & $6.5-7.5$ & 4.2 & 150 & $0.59(\mathrm{~J})^{\mathrm{b}}$ & 12 & 8.3 & -- & $\overline{--}$ \\
\hline 271J003 & $4.8-5.8$ & 3.7 & 130 & -- & 17 & 8.4 & -- & -- \\
\hline 271J004 & $4.8-5.8$ & 3.5 & 130 & -- & 17 & 8.1 & -- & -- \\
\hline 271J006 & $4.8-5.8$ & 4 & 150 & $0.57(\mathrm{~J})^{\mathrm{b}}$ & 11 & 8.4 & $.927(\mathrm{~J})^{\mathrm{c}}$ & -- \\
\hline 271J008 & $2.5-3.5$ & 4.4 & 140 & $0.59(\mathrm{~J})^{\mathrm{b}}$ & 11 & 9.1 & -- & -- \\
\hline $271 \mathrm{~J} 010$ & $2.7-3.7$ & 4 & 130 & -- & $13(\mathrm{~J})^{\mathrm{b}}$ & 8.3 & -- & -- \\
\hline 271J012 & $2.7-3.7$ & 3.8 & 140 & -- & $17(\mathrm{~J})^{\mathrm{b}}$ & 8.3 & -- & 1.1 \\
\hline $271 \mathrm{~J} 014$ & $3-4$ & 4.2 & 120 & -- & $23(\mathrm{~J})^{\mathrm{b}}$ & 9.6 & -- & 1.1 \\
\hline 271J017 & $2.5-3.5$ & 4 & 150 & 0.55 & $9.3(\mathrm{~J})^{b}$ & 7.5 & -- & 0.68 \\
\hline 271J019 & $3.4-4.4$ & 3.9 & 140 & -- & $12(\mathrm{~J})^{\mathrm{b}}$ & 7.8 & -- & -- \\
\hline 271J021 & $3.4-4.4$ & 3.2 & 170 & -- & $19(\mathrm{~J})^{\mathrm{b}}$ & 11 & -- & -- \\
\hline 271J023 & $3.4-4.4$ & 3.2 & 120 & -- & $9.3(\mathrm{~J})^{b}$ & 6.6 & -- & 1.1 \\
\hline 271J025 & $7.5-8.5$ & 3.5 & 140 & -- & 10 & 8.1 & -- & 0.71 \\
\hline 271J027 & $7.5-8.5$ & 3.3 & 140 & -- & 12 & 7.3 & -- & -- \\
\hline
\end{tabular}

${ }^{a}$ Based on U.S. Environmental Protection Agency, Region 9 Preliminary Remediation Goals (PRGs) (EPA, 2000).

${ }^{\mathrm{b}}$ Qualifier added to laboratory data; record accepted. Inductively coupled plasma serial dilution recovery was not met.

${ }^{\mathrm{C}}$ Qualifier added to laboratory data; record accepted. Exceeded holding time.

$\mathrm{J}=$ Estimated value

Barium concentrations ranged from 120 to $170 \mathrm{mg} / \mathrm{kg}$, chromium concentrations ranged from 9.3 to $23 \mathrm{mg} / \mathrm{kg}$, lead concentrations ranged from 6.6 to $11 \mathrm{mg} / \mathrm{kg}$, mercury concentration at $0.927 \mathrm{mg} / \mathrm{kg}$ in one sample, and selenium concentrations were reported in very few samples above the MRL ranging 
from 0.68 to $1.1 \mathrm{mg} / \mathrm{kg}$. All reported concentrations of these metals were below EPA Region 9 PRGs defined in this document as PALs.

Arsenic concentrations ranged from 3.2 to $4.4 \mathrm{mg} / \mathrm{kg}$. These concentrations are all slightly above the PAL of $2.7 \mathrm{mg} / \mathrm{kg}$. The arsenic concentrations are consistent across the site, with no "hot spots" or evidence of a localized spill. The PAL is lower than the 7 to $8 \mathrm{mg} / \mathrm{kg}$ mean concentration of arsenic in silt from the Nevada Test and Training Range (NBMG, 1998; Moore, 1999). Although arsenic concentrations in the soil exceed the PAL, they are believed to be within ambient conditions for CAS 26-04-01 and do not represent contamination.

\section{A.11.3.1.5 Total Beryllium}

Results for beryllium above the MRL are reported in Table A.11-4. Beryllium concentrations ranged from approximately 0.55 to $0.59 \mathrm{mg} / \mathrm{kg}$. There were no beryllium concentrations reported above the PAL.

\section{A.11.3.1.6 Total Pesticides}

The pesticides detected in soil samples above concentrations exceeding the laboratory MRLs are presented in Table A.11-5. Additional samples 271J201 and 271J202 were taken at sample location J03 and indicated decreasing pesticide concentrations at greater depths. None of the samples exceeded EPA Region 9 PRG for combined chlordane.

\section{A.11.3.1.7 Gamma Spectrometry}

Results of soil sample gamma spectrometry analysis are presented in Table A.11-6. Concentrations of actinium-228, bismuth-214, lead-212, lead-214, potassium-40, and thallium-208 were detected above the MDLs. The TPU in the radioanalytical measurement is provided in the table along with the concentration for all detected gamma emitters. The concentrations of the detected gamma-emitting radionuclides are below PALs and are not significantly different than concentrations measured in soil samples collected from undisturbed background locations. 
Table A.11-5

Soil Sample Results for Pesticides

Detected Above Minimum Reporting Limits at CAS 26-04-01

\begin{tabular}{|c|c|c|c|}
\hline \multirow{2}{*}{$\begin{array}{c}\text { Sample } \\
\text { Identification } \\
\text { Number }\end{array}$} & \multirow{2}{*}{$\begin{array}{c}\text { Depth } \\
\text { (ft bgs) }\end{array}$} & \multicolumn{2}{|c|}{ Contaminants of Potential Concern $(\mu \mathrm{g} / \mathrm{kg})$} \\
\hline & & Alpha-Chlordane & Gamma-Chlordane \\
\hline \multicolumn{2}{|c|}{ Preliminary Action Levels ${ }^{a}$} & $11,000^{b}$ & $11,000^{b}$ \\
\hline $271 \mathrm{~J} 001$ & $6.5-7.5$ & $2,700(\mathrm{~J})$ & $1,900(\mathrm{~J})$ \\
\hline 271J201 & $11-11.5$ & 4.8 & 3.4 \\
\hline 271J202 & $13-13.5$ & 1.9 & -- \\
\hline
\end{tabular}

aBased on U.S. Environmental Protection Agency, Region 9 Preliminary Remediation Goals (PRGs) (EPA, 2000).

${ }^{b}$ Preliminary action level for total chlordane. The comparison to this PAL is made by summing the chlordane concentrations for a given sample.

$\mathrm{J}=$ Estimated value. Qualifier added to laboratory data; record accepted. Exceeded holding time. Surrogates diluted out.

$--=$ Not detected above minimum reporting limit

Table A.11-6

Soil Sample Results for Gamma-Emitting Radionuclides Detected Above Minimum Reporting Limits at CAS 26-04-01

\begin{tabular}{|c|c|c|c|c|c|c|c|}
\hline \multirow{2}{*}{$\begin{array}{c}\text { Sample } \\
\text { Identification } \\
\text { Number }\end{array}$} & \multirow{2}{*}{$\begin{array}{l}\text { Depth } \\
\text { (ft bgs) }\end{array}$} & \multicolumn{6}{|c|}{ Contaminants of Potential Concern (pCi/g) } \\
\hline & & Actinium-228 ${ }^{\mathrm{a}}$ & Bismuth-214 ${ }^{\mathrm{b}}$ & Potassium- $40^{\mathrm{a}}$ & Lead-212 $^{\mathrm{a}}$ & Lead-214 ${ }^{b}$ & Thallium-208 \\
\hline \multicolumn{2}{|c|}{ Preliminary Action Level } & 3.64 & 3.47 & 96 & 2.9 & 2.9 & 3.4 \\
\hline $271 \mathrm{~J} 003$ & $4.8-5.8$ & $1.56 \pm 0.36$ & $0.75 \pm 0.21$ & $23.5 \pm 4.5$ & $1.53 \pm 0.31$ & $1.01 \pm 0.23$ & $0.55 \pm 0.14$ \\
\hline 271J004 & $4.8-5.8$ & $1.17 \pm 0.34$ & $0.8 \pm 0.25$ & $23.4 \pm 4.7$ & $1.58 \pm 0.32$ & $0.86 \pm 0.21$ & $0.43 \pm 0.13$ \\
\hline 271J012 & $2.7-3.7$ & $1.6 \pm 0.33$ & $0.75 \pm 0.17$ & $24.5 \pm 4.3$ & $1.7 \pm 0.31$ & $0.94 \pm 0.19$ & $0.445 \pm 0.098$ \\
\hline 271J021 & $3.4-4.4$ & $1.18 \pm 0.31$ & $0.9 \pm 0.23$ & $19.1 \pm 3.8$ & $1.59 \pm 0.31$ & $1.12 \pm 0.24$ & $0.47 \pm 0.12$ \\
\hline 271J025 & $7.5-8.5$ & $1.4 \pm 0.29$ & $0.77 \pm 0.17$ & $23.1 \pm 4.1$ & $1.5 \pm 0.28$ & $0.96 \pm 0.19$ & $0.423 \pm 0.093$ \\
\hline
\end{tabular}

${ }^{a}$ Background concentration listed in Environmental Monitoring Report for the Proposed Ward Valley, California, Low-Level Radioactive Waste (LLRW) Facility (US Ecology and Atlan-Tech, 1992).

${ }^{b}$ Background concentration listed or derived in Off-Site Radiation Exposure Review Project, Phase II Soil Program (McArthur and Miller, 1989).

\section{A.11.3.1.8 Isotopic Uranium}

Detected values of uranium isotopes, along with associated TPUs are reported in Table A.11-7. Sample numbers 271J003, 271J004, 271J012, and 271J025 had concentrations of U-235 above the PAL; therefore, a normalized difference based on a confidence level of 95 percent was used to determine if the concentrations were statistically distinguishable from background. Concentrations of 
Table A.11-7

Soil Sample Results for Isotopic Uranium

Detected Above Minimum Reporting Limits at CAS 26-04-01

\begin{tabular}{|c|c|c|c|c|}
\hline \multirow{2}{*}{$\begin{array}{c}\text { Sample } \\
\text { Identification Number }\end{array}$} & \multirow{2}{*}{$\begin{array}{c}\text { Depth } \\
\text { (ft bgs) }\end{array}$} & \multicolumn{2}{|c|}{ Contaminants of Potential Concern (pCi/g) } \\
\cline { 3 - 5 } & & Uranium-234 & Uranium-235 & Uranium-238 $^{\mathbf{b}}$ \\
\hline \multicolumn{2}{|c|}{ Preliminary Action Levels } & $\mathbf{1 . 5 6}$ & $\mathbf{0 . 0 7}$ & $\mathbf{3 . 2}$ \\
\hline \hline 271J003 & $4.8-5.8$ & $0.83 \pm 0.15$ & $0.086 \pm 0.036$ & $0.89 \pm 0.16$ \\
\hline 271J004 & $4.8-5.8$ & $0.92 \pm 0.16$ & $0.079 \pm 0.032$ & $0.83 \pm 0.15$ \\
\hline 271J012 & $2.7-3.7$ & $0.84 \pm 0.16$ & $0.074 \pm 0.037$ & $0.81 \pm 0.16$ \\
\hline 271J021 & $3.4-4.4$ & $0.89 \pm 0.19$ & -- & $0.97 \pm 0.20$ \\
\hline 271J025 & $7.5-8.5$ & $0.87 \pm 0.17$ & $0.078 \pm 0.039$ & $0.98 \pm 0.18$ \\
\hline
\end{tabular}

aBackground concentration listed in Environmental Monitoring Report for the Proposed Ward Valley, California, Low-Level Radioactive Waste (LLRW) Facility (US Ecology and Atlan-Tech, 1992).

background concentration listed or derived in Off-Site Radiation Exposure Review Project, Phase II Soil Program (McArthur and Miller, 1989).

-- = Not detected above minimum reporting limit

U-235 were not significantly greater than concentrations in soil samples collected from undisturbed background locations.

\section{A.11.3.1.9 Isotopic Plutonium}

Isotopic plutonium was not detected above MRLs in CAS 26-04-01 soil samples.

\section{A.11.3.1.10 Strontium-90}

Strontium-90 was not detected above MRLs in CAS 26-04-01 soil samples.

\section{A.11.3.2 Septic Tank and Distribution Box Sample Results}

Results of collected septic tank and distribution box content samples were compared to regulatory levels based on disposal options. If the waste has no hazardous component, the regulatory level is based on disposal options at NTS landfills and lagoons (BN, 1995; CFR, 2000b and c; NDEP, 1997a, b, and c). Any sludge or liquid waste will be solidified before disposal at NTS landfills (NDEP, 1997b). If the waste is hazardous, the release criteria are based on interpretation of the guidelines presented in the POC (BN, 1995; Alderson, 1999). For the waste destined for off-site disposal, the POC radiological levels must be met to certify that the waste has no radioactivity added. 
One liquid and one sludge sample from the septic tank and one sediment sample from the distribution box were obtained for the waste management purposes. The analytical suite for both the septic tank and the distribution box followed the CAIP and is detailed in Section A.11.2.9. Analytical results exceeding MRLs are listed in Table A.11-8.

Several COPCs were detected in the septic tank liquid samples, but all COPCs were below regulatory disposal limits. Two COPCs were detected in the distribution box sediment sample (271J030); cesium-137 and cobalt-60. They were both below the landfill disposal criteria (NDEP, 1997c). The analytical results for the sludge phase of the septic tank contents included cesium-137 and $\mathrm{Pu}-239$ in the sludge sample greater than the NTS POC $(B N, 1995)$ limit set for unrestricted release of hazardous waste.

\section{A.11.4 Contaminants of Concern}

Based on the aforementioned analytical results, COCs are present in the septic tank. The septic tank contains cesium-137 and Pu-239 in concentrations above the POC. No COCs were identified in the soil surrounding the septic tank or under the leachfield.

\section{A.11.5 Nature and Extent of Contamination}

Cesium-137 is located within the 147 gal of sludge in the septic tank. Approximately 885 gal of liquid remained in the tank. Approximately 3 gal of sediment remained in the bottom of the distribution box. This is a conservative estimate.

\section{A.11.6 Revised Conceptual Model}

No variations in the conceptual model were identified. 
Table A.11-8

\section{Liquid and Sediment Sample Results Detected Above Minimum Reporting Limits at CAS 26-04-01}

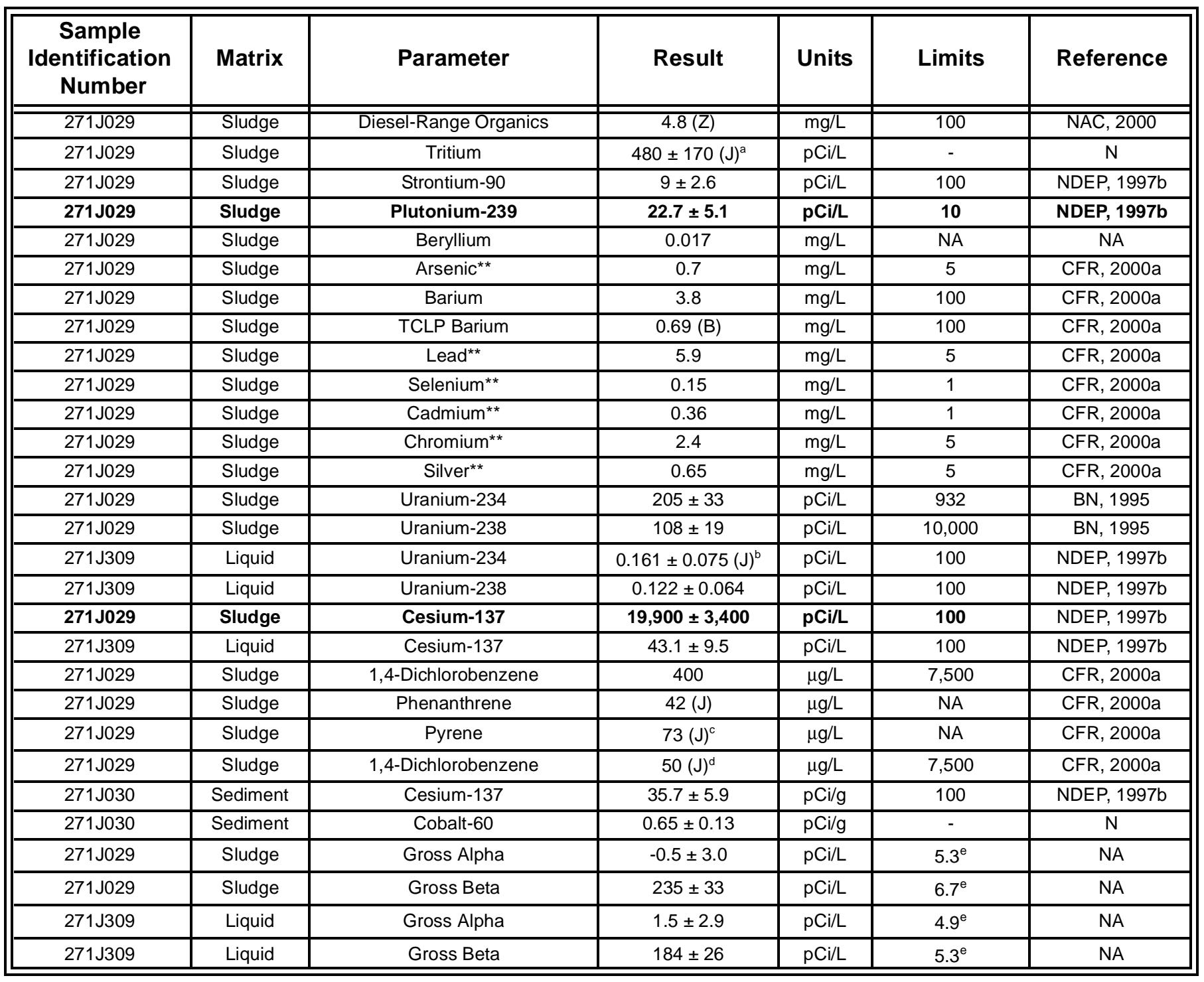

${ }^{a} Q u a l i f i e r$ added to laboratory data; record accepted. Duplicate normalized difference outside control limits.

${ }^{b}$ Qualifier added to laboratory data; record accepted. Field blank or equipment rinsate blank or source blank contamination.

${ }^{\circ}$ Qualifier added to laboratory data; record accepted. Internal standard area count exceeded the quality control limits. Matrix effects may exist.

${ }^{\mathrm{d}}$ Qualifier added to laboratory data; record accepted. Improper preservation/pH or sample temperature not documented during storage.

${ }^{\mathrm{e}}$ Maximum detectable concentration

${ }^{* *}=$ TCLP result below minimum reporting limit

$B=$ Value less than the instrument detection limit, but greater than or equal to the contract-required detection limit

$\mathrm{J}=$ Estimated value

$\mathrm{N}=$ No limit established (NDEP, 1997b)

NA = Not applicable

$\mathrm{Z}=$ The reported result did not resemble the patterns of the following hydrocarbon products: gasoline, JP-4, JP-8, diesel, mineral spirits, motor oil, Stoddard solvent and Bunker C 


\section{A.12.0 Hot Critical Facility (Building 2103) Septic System (CAS 26-04-02)}

The CAS 26-04-02 septic system was designed to receive sanitary effluent generated by activities from Building 2103 (Hot Critical Facility). The septic system is located approximately $100 \mathrm{ft}$ north of Building 2103. The site is comprised of a leachfield, septic tank, distribution box, and associated piping. More detail is provided in the CAIP (DOE/NV, 2001).

\section{A.12.1 Corrective Action Investigation}

Thirty-one investigation samples, listed in Table A.12-1, were collected during investigation activities conducted at CAS 26-04-02. The planned and actual sample locations are shown in Figure A.12-1. The specific activities that were conducted to meet CAIP requirements at CAS 26-04-02 are described in Table A.2-1.

\section{A.12.1.1 Deviations}

The following deviations to the CAIP-requirements were the result of unforeseen circumstances:

- At location K01 (sample 271K028), refusal was met due to encountering subsurface hardpan (caliche); therefore, the sample was collected at 8.6 to $9.1 \mathrm{ft}$ bgs rather than the planned interval of 8.6 to $9.6 \mathrm{ft}$ bgs.

Despite this deviation, the pertinent CAIP requirements were met.

\section{A.12.2 Investigation Results}

The following subsections provide details of the inspection and sampling of leachfield features, field-screening results, and sample selection and analysis.

\section{A.12.2.1 Septic Tank Contents}

The contents of the septic tank were sampled according to the CAIP. The concrete septic tank is rectangular-shaped with a 808-gal capacity. It was accessed by one concrete manhole located at the ground surface. The interior dimensions of the tank were $6 \mathrm{ft}$ (length) by $3 \mathrm{ft}$ (width) by $6 \mathrm{ft}$ (depth). One sediment sample was collected from the septic tank. Visual inspection revealed that a maximum 
Table A.12-1

Samples Collected at CAS 26-04-02

(Page 1 of 2)

\begin{tabular}{|c|c|c|c|c|c|c|c|c|c|c|c|c|c|}
\hline \multirow[b]{2}{*}{$\begin{array}{c}\text { Sample } \\
\text { Identification } \\
\text { Number }\end{array}$} & \multirow[b]{2}{*}{$\begin{array}{l}\text { Sample } \\
\text { Location }\end{array}$} & \multirow[b]{2}{*}{$\begin{array}{l}\text { Sample } \\
\text { Matrix }\end{array}$} & \multirow[b]{2}{*}{$\begin{array}{l}\text { Depth } \\
\text { (ft bgs) }\end{array}$} & \multirow[b]{2}{*}{ Purpose } & \multicolumn{9}{|c|}{ Analyses } \\
\hline & & & & & 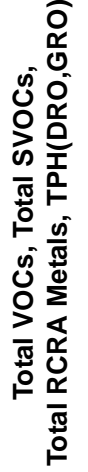 & 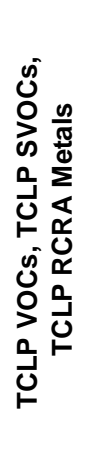 & 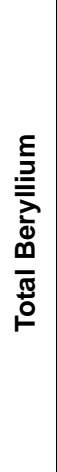 & 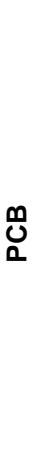 & 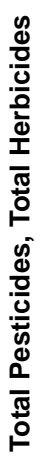 & 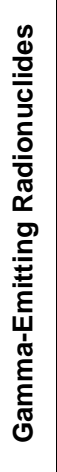 & 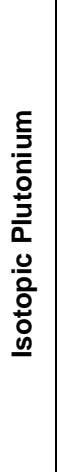 & 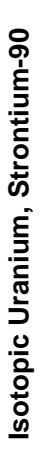 & 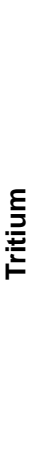 \\
\hline $271 \mathrm{~K} 001$ & K03 & Soil & $4-5$ & Integrity & $\mathrm{X}$ & & $\mathrm{X}$ & $\mathrm{X}$ & & $\mathrm{X}$ & & $\mathrm{X}$ & \\
\hline $271 \mathrm{~K} 002$ & K03 & Soil & $6.5-7.5$ & Integrity & \multicolumn{9}{|c|}{ Not Submitted for Analyses ${ }^{a}$} \\
\hline $271 \mathrm{~K} 003$ & K06 & Soil & $2.7-3.7$ & Environmental & $x$ & & $\mathrm{X}$ & $x$ & & $x$ & $x$ & $x$ & \\
\hline $271 \mathrm{~K} 004$ & K06 & Soil & $2.7-3.7$ & $\begin{array}{l}\text { Duplicate of } \\
271 \mathrm{~K} 003\end{array}$ & $x$ & & $x$ & $x$ & & $x$ & $x$ & $x$ & \\
\hline $271 \mathrm{~K} 005$ & K06 & Soil & $5.2-6.2$ & Environmental & \multicolumn{9}{|c|}{ Not Submitted for Analyses ${ }^{a}$} \\
\hline $271 \mathrm{~K} 006$ & K05 & Soil & $3.2-4.2$ & Environmental & $x$ & & $X$ & $x$ & & $\mathrm{x}$ & & $x$ & \\
\hline $271 \mathrm{~K} 007$ & K05 & Soil & $5.7-6.7$ & Environmental & \multicolumn{9}{|c|}{ Not Submitted for Analyses ${ }^{a}$} \\
\hline $271 \mathrm{~K} 008$ & K04 & Soil & $4-5$ & Environmental & $x$ & & $x$ & $x$ & & $x$ & $x$ & $x$ & \\
\hline $271 \mathrm{~K} 009$ & K04 & Soil & $6.5-7.5$ & Environmental & \multicolumn{9}{|c|}{ Not Submitted for Analyses ${ }^{a}$} \\
\hline $271 \mathrm{~K} 010$ & K07 & Soil & $4.7-5.7$ & Environmental & $x$ & & $\mathrm{X}$ & $x$ & & $x$ & & $x$ & \\
\hline $271 \mathrm{~K} 011$ & K07 & Soil & $7.2-8.2$ & Environmental & \multicolumn{9}{|c|}{ Not Submitted for Analyses ${ }^{a}$} \\
\hline $271 \mathrm{~K} 012$ & K12 & Soil & $2.5-3.5$ & Environmental & $x$ & & $X$ & $x$ & & $x$ & & $x$ & \\
\hline $271 K 013$ & K12 & Soil & $5-6$ & Environmental & $x$ & \multicolumn{8}{|c|}{ Not Submitted for Analyses ${ }^{a}$} \\
\hline $271 \mathrm{~K} 014$ & K11 & Soil & $3-4$ & Environmental & $x$ & & $X$ & $\mathrm{x}$ & & $x$ & & $x$ & \\
\hline $271 K 015$ & K11 & Soil & $5.5-6.5$ & Environmental & \multicolumn{9}{|c|}{ Not Submitted for Analyses ${ }^{a}$} \\
\hline $271 \mathrm{~K} 016$ & K13 & Soil & $4-5$ & Environmental & $\mathrm{x}$ & & $\mathrm{X}$ & $x$ & & $x$ & $x$ & $x$ & \\
\hline $271 \mathrm{~K} 017$ & K13 & Soil & $6.5-7.5$ & Environmental & \multicolumn{9}{|c|}{ Not Submitted for Analyses ${ }^{a}$} \\
\hline $271 \mathrm{~K} 018$ & K14 & Soil & $4-5$ & Environmental & $x$ & & $x$ & $x$ & & $x$ & & $x$ & \\
\hline $271 K 019$ & K14 & Soil & $6.5-7.5$ & Environmental & \multicolumn{9}{|c|}{ Not Submitted for Analyses ${ }^{a}$} \\
\hline $271 \mathrm{~K} 020$ & K09 & Soil & $2.5-3.5$ & $\begin{array}{l}\text { Environmental } \\
\text { MS/MSD }\end{array}$ & $x$ & & $x$ & $x$ & & $x$ & $x$ & $x$ & \\
\hline $271 \mathrm{~K} 021$ & K09 & Soil & $5-6$ & Environmental & \multicolumn{9}{|c|}{ Not Submitted for Analyses ${ }^{a}$} \\
\hline $271 \mathrm{~K} 022$ & K08 & Soil & $3-4$ & Environmental & $x$ & & $\mathrm{X}$ & $x$ & & $x$ & & $x$ & \\
\hline $271 \mathrm{~K} 023$ & K08 & Soil & $5.5-6.5$ & Environmental & \multicolumn{9}{|c|}{ Not Submitted for Analyses ${ }^{a}$} \\
\hline
\end{tabular}


Table A.12-1

Samples Collected at CAS 26-04-02

(Page 2 of 2 )

\begin{tabular}{|c|c|c|c|c|c|c|c|c|c|c|c|c|c|}
\hline \multirow[b]{2}{*}{$\begin{array}{c}\text { Sample } \\
\text { Identification } \\
\text { Number }\end{array}$} & \multirow[b]{2}{*}{$\begin{array}{l}\text { Sample } \\
\text { Location }\end{array}$} & \multirow[b]{2}{*}{$\begin{array}{l}\text { Sample } \\
\text { Matrix }\end{array}$} & \multirow[b]{2}{*}{$\begin{array}{l}\text { Depth } \\
\text { (ft bgs) }\end{array}$} & \multirow[b]{2}{*}{ Purpose } & \multicolumn{9}{|c|}{ Analyses } \\
\hline & & & & & 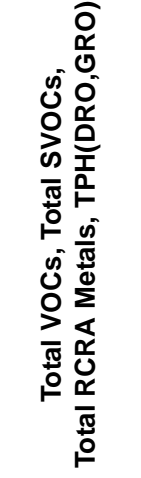 & 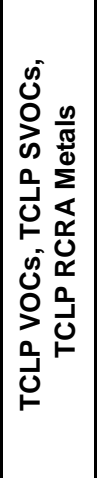 & 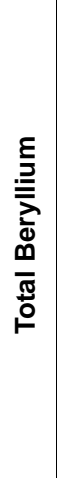 & 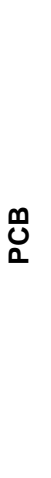 & 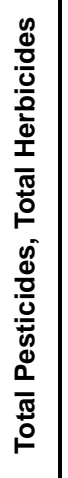 & 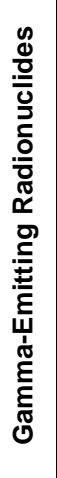 & 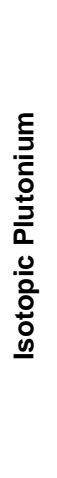 & 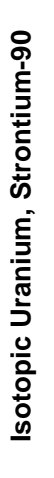 & $\stackrel{E}{\frac{E}{2}}$ \\
\hline $271 \mathrm{~K} 024$ & $\mathrm{~K} 10$ & Soil & $3-4$ & Environmental & $\bar{x}$ & & $\bar{x}$ & $\bar{x}$ & & $\bar{x}$ & & $\bar{x}$ & \\
\hline $271 K 025$ & $\mathrm{~K} 10$ & Soil & $5.5-6.5$ & Environmental & \multicolumn{9}{|c|}{ Not Submitted for Analyses ${ }^{a}$} \\
\hline $271 \mathrm{~K} 026$ & K15 & Soil & $3-3.5$ & Geotechnical & \multicolumn{9}{|c|}{ Not Submitted for Analyses ${ }^{b}$} \\
\hline $271 \mathrm{~K} 027$ & K01 & Soil & $7.6-8.6$ & Integrity & $x$ & & $x$ & $x$ & & $x$ & & $x$ & \\
\hline $271 \mathrm{~K} 028$ & K01 & Soil & $8.6-9.1$ & Integrity & \multicolumn{9}{|c|}{ Not Submitted for Analyses ${ }^{a}$} \\
\hline $271 K 029$ & K02 & Soil & $7.9-8.9$ & Integrity & $x$ & & $\mathrm{X}$ & $x$ & & $x$ & $x$ & $x$ & \\
\hline $271 \mathrm{~K} 030$ & K02 & Soil & $10.4-11.4$ & Integrity & \multicolumn{9}{|c|}{ Not Submitted for Analyses ${ }^{a}$} \\
\hline $271 \mathrm{~K} 031$ & NA & Sediment & $7.25-7.5$ & Septic Tank & $x$ & $x$ & $x$ & $X$ & & $x$ & $x$ & $x$ & \\
\hline $271 \mathrm{~K} 301$ & NA & Water & NA & Trip Blank & VOC only & & & & & & & & \\
\hline 271K302 & NA & Water & NA & Trip Blank & VOC only & & & & & & & & \\
\hline $271 \mathrm{~K} 303$ & NA & Water & NA & Trip Blank & VOC only & & & & & & & & \\
\hline $271 \mathrm{~K} 304$ & NA & Water & NA & Field Blank & $x$ & & $X$ & $X$ & & $x$ & $x$ & $x$ & \\
\hline $271 \mathrm{~K} 305$ & NA & Water & NA & Trip Blank & VOC only & & & & & & & & \\
\hline $271 \mathrm{~K} 306$ & NA & Water & NA & Trip Blank & VOC only & & & & & & & & \\
\hline $271 \mathrm{~K} 307$ & NA & Water & NA & Trip Blank & VOC only & & & & & & & & \\
\hline $271 K 308$ & NA & Water & NA & Rinsate & $x$ & & $x$ & $x$ & & $x$ & $x$ & $x$ & \\
\hline $271 K 309$ & NA & Water & NA & Trip Blank & VOC only & & & & & & & & \\
\hline $271 K 310$ & NA & Water & NA & Trip Blank & VOC only & & & & & & & & \\
\hline $271 \mathrm{~K} 311$ & NA & Water & NA & Trip Blank & VOC only & & & & & & & & \\
\hline
\end{tabular}

aThe sample was collected, field screened, and returned to the site for disposal.

${ }^{\mathrm{b}}$ The sample was collected, field screened, and is being stored for possible geotechnical analysis.

$\mathrm{NA}=$ Not applicable

MS/MSD = Matrix spike/matrix spike duplicate 


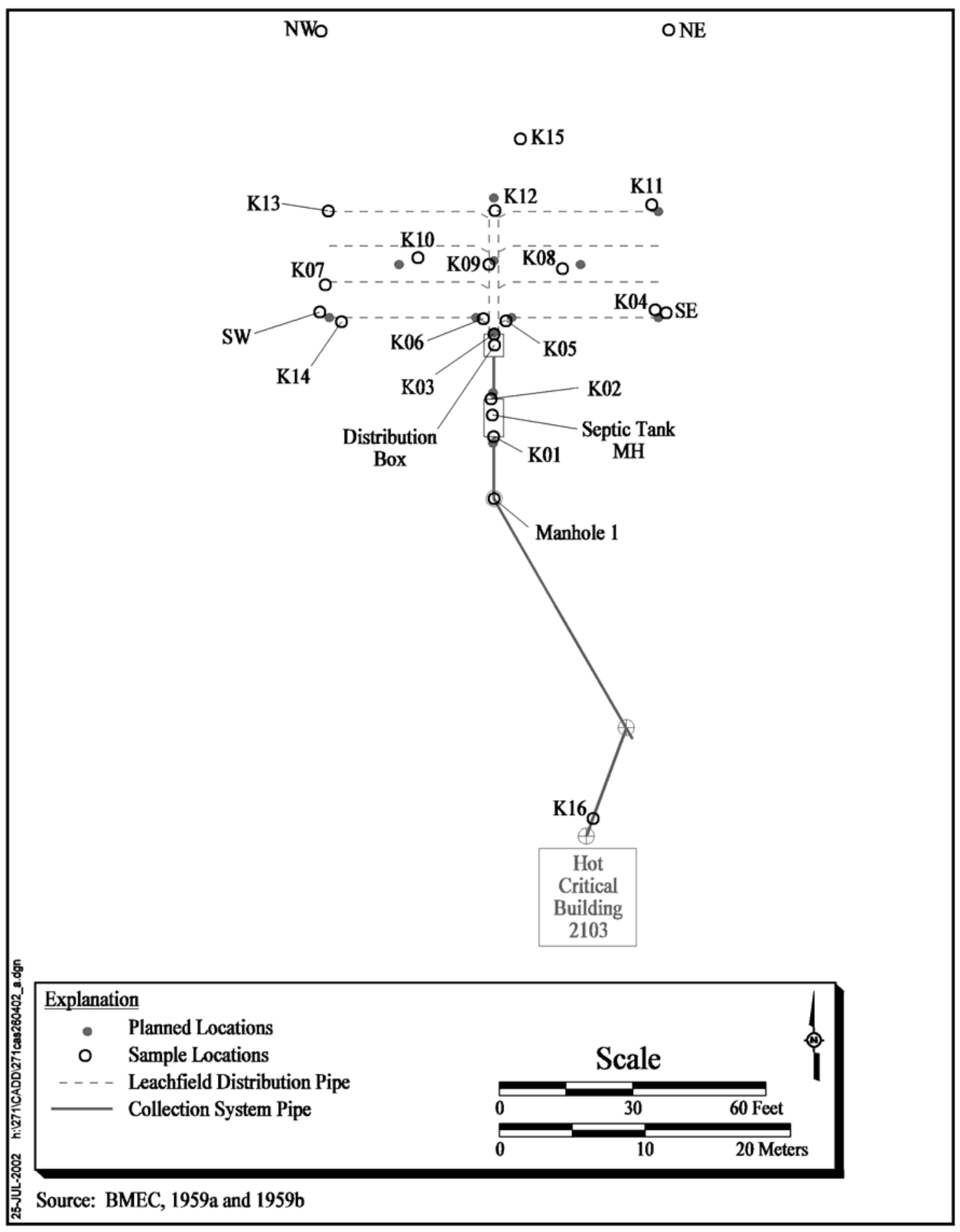

Figure A.12-1

Building 2103 Septic System (CAS 26-04-02)

Sample Locations 
thickness of 3 in. (34 gal) of dry sediment remained in the bottom of the tank. Photographs of the septic tank were taken to document the visual inspection (Figure A.12-2).

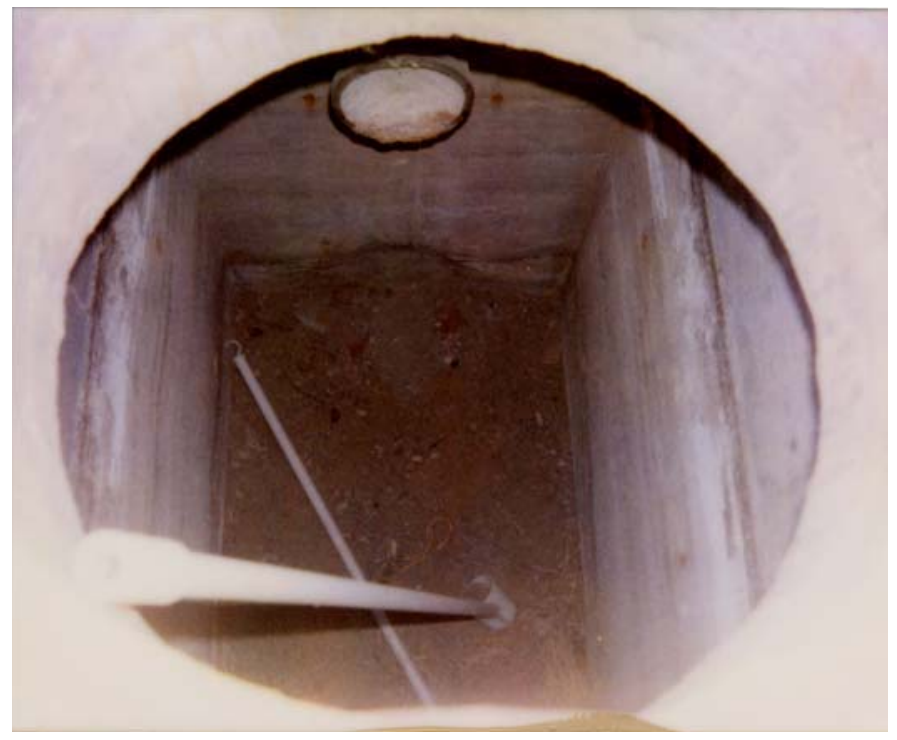

Figure A.12-2

CAS 26-04-02 Septic Tank, Interior (Photograph Taken 01-07-2002)

\section{A.12.2.2 Distribution Box Contents}

The concrete distribution box is rectangular-shaped with a 549-gal capacity. It was accessed by a manhole located at the ground surface. The interior of the distribution box was $4 \mathrm{ft}$ (length) by $4 \mathrm{ft}$ (width) by $4.75 \mathrm{ft}$ (depth). The box contained only a very small amount of material, so no samples were collected. A photograph of the distribution box was taken to document the visual inspection (Figure A.12-3).

\section{A.12.2.3 Septic Tank and Distribution Box Integrity Soil Sampling}

Six integrity samples were collected by excavating adjacent to the influent and effluent ends of the septic tank and the effluent end of the distribution box. Figure A.12-4 and Figure A.12-5 depict the structural integrity and composition of the effluent ends of the septic tank and distribution box, respectively. The following three samples were submitted for laboratory analysis: 

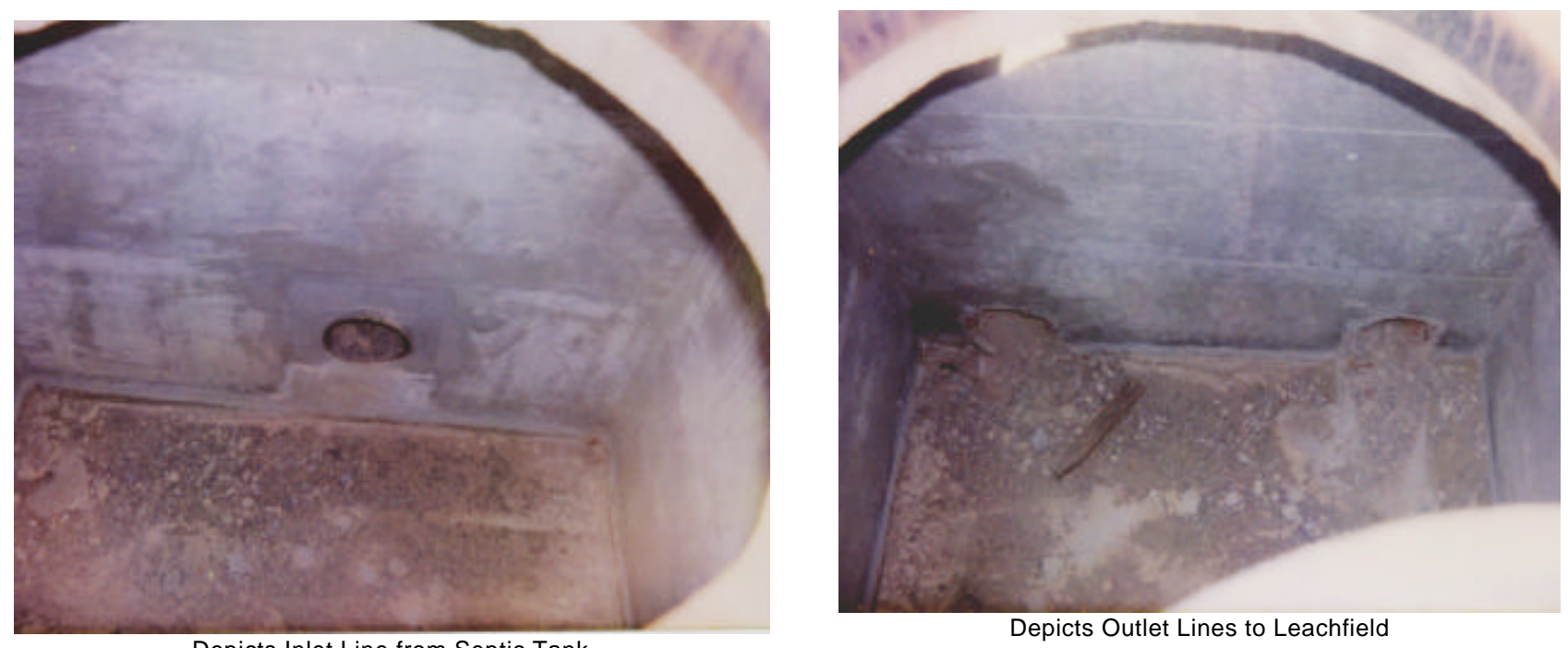

Depicts Inlet Line from Septic Tank

Depicts Outlet Lines to Leachfield

Figure A.12-3

CAS 26-04-02 Distribution Box, Interior

(Photographs Taken 01-07-2002)

- The upper sample (271K001) from the effluent end of the distribution box, collected at 4 to $5 \mathrm{ft}$ bgs

- The upper sample $(271 \mathrm{~K} 027)$ from the influent end of the septic tank, collected at 7.6 to $8.6 \mathrm{ft}$ bgs

- The upper sample $(271 \mathrm{~K} 029)$ from the effluent end of the septic tank, collected at 7.9 to $8.9 \mathrm{ft}$ bgs

\section{A.12.2.4 Leachfield Excavation Soil Sampling}

Backhoe excavations were conducted to access sampling horizons at the biased locations presented in the CAIP. Excavations provided a visual verification of distribution pipes and enabled soil samples to be collected from appropriate intervals beneath the pipes, as specified by the CAIP. Twenty-three soil samples were collected from the planned locations excavated within the leachfield. These samples were collected from an interval at the leachrock/native soil interface and an interval $2.5 \mathrm{ft}$ below the interface. The interface was found at depths ranging from 2.7 to $4.7 \mathrm{ft} \mathrm{bgs.} \mathrm{Thirteen}$ samples were submitted for laboratory analysis. In addition, one QC soil duplicate and one MS/MSD sample were collected and analyzed. A geotechnical sample was collected outside the boundary of the leachfield. The sample will be sent to a laboratory for geotechnical analysis, if necessary. 


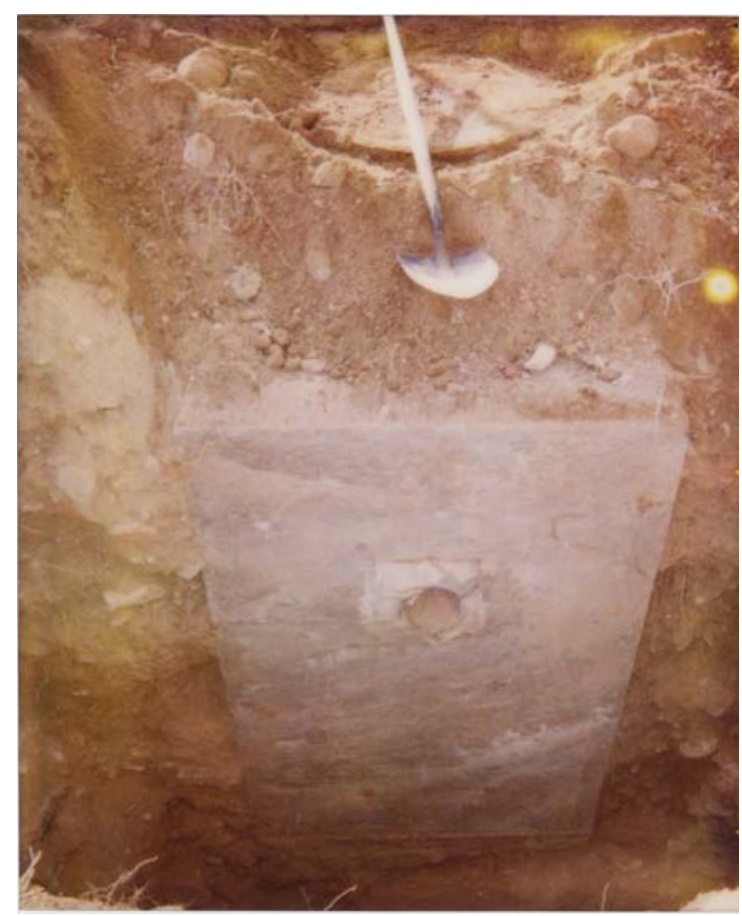

Figure A.12-4

CAS 26-04-02 Septic Tank, Effluent Integrity Sample (Photograph Taken 12-21-2001)

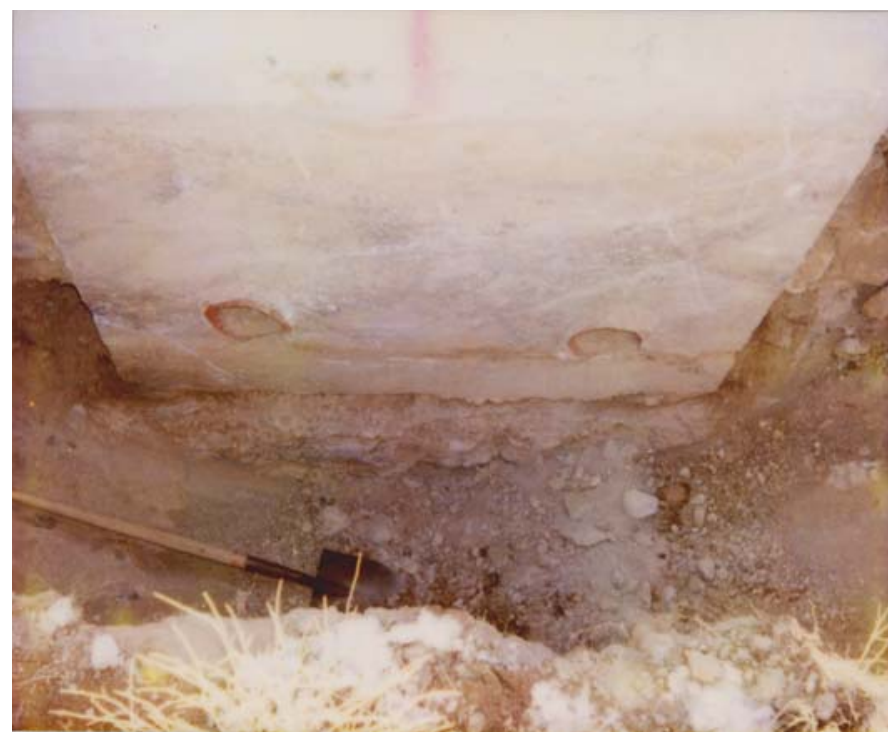

Figure A.12-5

CAS 26-04-02 Distribution Box, Effluent Integrity Sample (Photograph Taken 12-17-2001) 


\section{A.12.2.5 Collection System Pipe Inspections}

Access points for inspection of the collection system by video mole survey were at a manhole and at a break in the line excavated by the backhoe.

As shown in Figure A.12-1, one manhole (Manhole 1) is associated with this septic system. Manhole 1 was uncovered and inspected; it was dry and free of sediment; therefore, no sample was collected. The video mole was inserted into the manhole and passed $9 \mathrm{ft}$ downstream (north) until soils from the septic tank integrity sampling location were encountered. The video mole was then passed upstream (southeast) for $60 \mathrm{ft}$, where it stopped at a grout plug (clean-out). The collection pipe line continued to the southwest; $58 \mathrm{ft}$ upstream of Manhole 1.

An excavation (K16) was made $7 \mathrm{ft}$ north of Building 2103. The video mole was passed $22 \mathrm{ft}$ downstream (northeast) until an elbow was encountered. This elbow was the clean-out discussed above. The video mole was then passed upstream (south) for $5 \mathrm{ft}$, where it entered a clean-out. Location K16 was grouted prior to filling in the excavation.

Very little some sediment was observed in the piping, and no breaks or obstructions in the line were found. Visual observations were recorded in the FADLs. The collection system was radiologically surveyed at Manhole 1 and location K16. Section A.12.2.7 discusses the radiological results.

\section{A.12.2.6 Field-Screening Results}

Soil samples were screened for VOCs and alpha and beta/gamma radioactivity. The field readings were compared to FSLs to guide sampling decisions and determine which samples were to be submitted for laboratory analysis. No VOCs greater than FSLs were found during soil sample screening. The results of radiological field screening are discussed in Section A.12.2.7.

A sample of the septic tank content was collected and analyzed for fecal coliform bacteria. Fecal coliform bacteria was not detected in the septic tank at this CAS.

\section{A.12.2.7 Radiological Survey Results}

All radiological field-screening results for soil samples from CAS 26-04-02 were below FSLs. The results of the radiological survey of Manhole 1 and a pipe segment at location K16 indicate that the 
collection system meets the unrestricted release criteria as defined in the NV/YMP Radiological Control Manual (DOE/NV, 2000a).

\section{A.12.2.8 Sample Analysis}

Environmental soil samples and associated QC samples were collected and analyzed for the CAIP-specified COPCs (i.e., total VOCs, total SVOCs, total RCRA metals, TPH [DRO and GRO], total beryllium, and PCBs). Twenty-five percent of the soil samples were analyzed for Iso-Pu. One-hundred percent of the soil and associated QC samples were analyzed for Iso-U, Sr-90, and gamma-emitting radionuclides.

The septic tank sediment sample was analyzed for total VOCs, total SVOCs, TPH (GRO and DRO), total RCRA metals, total beryllium, PCBs, gamma-emitting radionuclides, Iso-U, Iso-Pu, and Sr-90. The sediment sample was also analyzed by TCLP for VOCs, SVOC, and RCRA metals.

The parameters and laboratory methods used to analyze the investigation samples are listed in Table A.2-2. Table A.12-1 lists the sample-specific analytical parameters.

\section{A.12.3 Analytes Detected Above Minimum Reporting Limits}

The soil sample analytical results detected with concentrations exceeding corresponding MRLs or PALs (DOE/NV, 1998; DOE/NV, 2001) at CAS 26-04-02 are summarized in the following sections. The results of septic tank content samples are compared to appropriate regulatory levels for disposal. A portion of the CAS 26-04-02 analytical results were rejected during validation; however, these rejected data did not impact closure decisions as discussed in Section B.1.3.10 of Appendix B.

\section{A.12.3.1 Analytical Results for Soil Samples}

The following sections discuss the results for soil samples in comparison to the levels established in the Leachfield Work Plan and the CAIP.

\section{A.12.3.1.1 Total Volatile Organic Compounds}

Volatile organic compound results are reported in Table A.12-2. The only organic compound detected above the MRL of $5 \mu \mathrm{g} / \mathrm{kg}$ was acetone. Estimated concentrations as designated by the "J" 
Table A.12-2

Soil Sample Results for Total VOCs Detected
Above Minimum Reporting Limits at CAS 26-04-02

\begin{tabular}{||c|c|c||}
\hline $\begin{array}{c}\text { Sample } \\
\text { Identification } \\
\text { Number }\end{array}$ & $\begin{array}{c}\text { Depth } \\
\text { (ft bgs) }\end{array}$ & Contaminants of Potential Concern $(\mu \mathbf{g} / \mathbf{k g})$ \\
\cline { 3 - 3 } & & Acetone \\
\hline \multicolumn{2}{|c|}{ Preliminary Action Levels ${ }^{\mathrm{a}}$} & $\mathbf{6 , 2 0 0 , 0 0 0}$ \\
\hline \hline $271 \mathrm{~K} 020$ & $2.5-3.5$ & $24(\mathrm{~J})^{\mathrm{b}}$ \\
\hline $271 \mathrm{~K} 022$ & $3-4$ & $37(\mathrm{~J})^{\mathrm{c}}$ \\
\hline
\end{tabular}

aBased on U.S. Environmental Protection Agency, Region 9 Preliminary Remediation Goals (PRGs) (EPA, 2000).

${ }^{\mathrm{b}}$ Qualifier added to laboratory data; record accepted. Relative response factor $<0.05$.

${ }^{\mathrm{C}} \mathrm{Qualifier}$ added to laboratory data; record accepted. Relative response factor $<0.05$. Surrogate recovery exceeded the upper limits. Matrix effects may exist.

$\mathrm{J}=$ Estimated value

qualifier were between 24 and $37 \mu \mathrm{g} / \mathrm{kg}$, below laboratory reporting limits. Acetone concentrations were below PALs of $6,200,000 \mu \mathrm{g} / \mathrm{kg}$. Acetone is a common laboratory contaminant.

\section{A.12.3.1.2 Total Semivolatile Organic Compounds}

Semivolatile organic compounds were not detected above MRLs in CAS 26-04-02 soil samples.

\section{A.12.3.1.3 Total Petroleum Hydrocarbons}

Total petroleum hydrocarbons were not detected above MRLs in CAS 26-04-02 soil samples.

\section{A.12.3.1.4 Total RCRA Metals}

As shown in Table A.12-3, the total RCRA metals detected in soil samples at concentrations exceeding the MRLs are arsenic $(1 \mathrm{mg} / \mathrm{kg})$, barium $(20 \mathrm{mg} / \mathrm{kg})$, chromium $(1 \mathrm{mg} / \mathrm{kg})$, lead $(0.3 \mathrm{mg} / \mathrm{kg})$, and selenium $(0.5 \mathrm{mg} / \mathrm{kg})$. Other RCRA metals (i.e., cadmium, mercury, silver) were below specified MRLs.

Barium concentrations ranged from 140 to $260 \mathrm{mg} / \mathrm{kg}$, chromium concentrations ranged from 7.5 to $12 \mathrm{mg} / \mathrm{kg}$, lead concentrations ranged from 4.9 to $7.8 \mathrm{mg} / \mathrm{kg}$, and selenium concentrations were 
Table A.12-3

Soil Sample Results for Total RCRA Metals Detected Above Minimum Reporting Limits at CAS 26-04-02

\begin{tabular}{|c|c|c|c|c|c|c|c|}
\hline \multirow{2}{*}{$\begin{array}{c}\text { Sample } \\
\text { Identification } \\
\text { Number }\end{array}$} & \multirow{2}{*}{$\begin{array}{l}\text { Depth } \\
\text { (ft bgs) }\end{array}$} & \multicolumn{6}{|c|}{ Contaminants of Potential Concern (mg/kg) } \\
\hline & & Arsenic & Barium & Beryllium & Chromium & Lead & Selenium \\
\hline \multicolumn{2}{|c|}{ Preliminary Action Levels $^{a}$} & 2.7 & 100,000 & 2,200 & 450 & 750 & 10,000 \\
\hline $271 \mathrm{~K} 001$ & $4-5$ & 2.9 & 140 & $\begin{array}{l}- \\
-\end{array}$ & 9 & 7.7 & 0.54 \\
\hline $271 \mathrm{~K} 003$ & $2.7-3.7$ & 3.8 & 200 & -- & 9.4 & 7.8 & -- \\
\hline $271 \mathrm{~K} 004$ & $2.7-3.7$ & 3.9 & 210 & -- & 10 & 6.3 & 0.76 \\
\hline $271 \mathrm{~K} 006$ & $3.2-4.2$ & 3.3 & 160 & -- & 9.3 & 7.2 & -- \\
\hline $271 \mathrm{~K} 008$ & $4-5$ & 2.4 & 130 & -- & 9.7 & 4.5 & 0.69 \\
\hline $271 \mathrm{~K} 010$ & $4.7-5.7$ & 2.8 & 210 & -- & 10 & 5.2 & 0.55 \\
\hline $271 \mathrm{~K} 012$ & $2.5-3.5$ & 3.7 & 180 & $0.64(J)^{b}$ & 11 & 5.7 & -- \\
\hline $271 \mathrm{~K} 014$ & $3-4$ & 3.3 & 140 & $0.58(J)^{b}$ & 9 & 5.1 & -- \\
\hline $271 \mathrm{~K} 016$ & $4-5$ & 3 & 170 & -- & 9.4 & 6.2 & -- \\
\hline $271 \mathrm{~K} 018$ & $4-5$ & 3.7 & 230 & $0.55(J)^{b}$ & 9.9 & 6.1 & -- \\
\hline $271 \mathrm{~K} 020$ & $2.5-3.5$ & 2.9 & 160 & -- & 11 & 5.2 & -- \\
\hline $271 \mathrm{~K} 022$ & $3-4$ & 5.4 & 180 & -- & 7.5 & 4.9 & -- \\
\hline $271 \mathrm{~K} 024$ & $3-4$ & 2.5 & 160 & $0.54(J)^{b}$ & 12 & 6.2 & -- \\
\hline $271 \mathrm{~K} 027$ & $7.6-8.6$ & 3.6 & 180 & -- & 12 & 6.2 & -- \\
\hline $271 \mathrm{~K} 029$ & $7.9-8.9$ & 3.8 & 260 & 0.55 & $8.5(J)^{c}$ & 5.8 & 0.57 \\
\hline
\end{tabular}

${ }^{a}$ Based on U.S. Environmental Protection Agency, Region 9 Preliminary Remediation Goals (PRGs) (EPA, 2000).

${ }^{b}$ Qualifier added to laboratory data; record accepted. Inductively coupled plasma serial dilution recovery was not met.

${ }^{\circ}$ Qualifier added to laboratory data; record accepted. Inductively coupled plasma serial dilution recovery was not met. Matrix effects may exist.

$--=$ Not detected above minimum reporting limits

$\mathrm{J}=$ Estimated value

reported in very few samples above the MRL ranging from 0.54 to $0.69 \mathrm{mg} / \mathrm{kg}$. All reported concentrations of these metals were below EPA Region 9 PRGs defined in this document as PALs.

Arsenic concentrations ranged from 2.5 to $5.4 \mathrm{mg} / \mathrm{kg}$. The PAL for arsenic is $2.7 \mathrm{mg} / \mathrm{kg}$, and most samples exhibited slightly higher concentrations. Arsenic concentrations across the site were consistent, with no "hot spots" or evidence of a localized spill. The PAL is lower than the 7 to $8 \mathrm{mg} / \mathrm{kg}$ mean concentration of arsenic in silt from the Nevada Test and Training Range (NBMG, 1998; Moore, 1999). Although arsenic concentrations in the soil exceed the PAL, these 
concentrations are believed to be within ambient conditions for CAS 26-04-02 and do not represent contamination.

\section{A.12.3.1.5 Total Beryllium}

Results for beryllium above the MRL are reported in Table A.12-3. Beryllium concentrations ranged from approximately 0.54 to $0.64 \mathrm{mg} / \mathrm{kg}$. There were no beryllium concentrations reported above the PAL.

\section{A.12.3.1.6 Polychlorinated Biphenyls}

Polychlorinated biphenyls were not detected above MRLs in CAS 26-04-02 soil samples.

\section{A.12.3.1.7 Gamma Spectrometry Results}

Results of soil sample gamma spectrometry analysis are presented in Table A.12-4. Concentrations of actinium-228, bismuth-212, bismuth-214, lead-212, lead-214, potassium-40, and thallium-208 were detected above the MDLs. The TPU in the radioanalytical measurement is provided in the table along with the concentration for all detected gamma emitters. The concentrations of the detected gamma-emitting radionuclides are below PALs and are not significantly different than concentrations measured in soil samples collected from undisturbed background locations.

\section{A.12.3.1.8 Isotopic Uranium}

Detected values of uranium isotopes, along with associated TPUs are reported in Table A.12-5. Soil samples 271K003, 271K004, 271K006, 271K008, 271K018, 271K022, and 271K024 had concentrations of U-235 above the PAL. A normalized difference based on a confidence level of 95 percent was used to determine if the concentrations were statistically distinguishable from background. This procedure revealed that the U-235 concentrations were not significantly greater than concentrations in soil samples collected from undisturbed background locations.

\section{A.12.3.1.9 Isotopic Plutonium}

Isotopic plutonium was not detected above MRLs in CAS 26-04-02 soil samples. 
Table A.12-4

Soil Sample Results for Gamma-Emitting Radionuclides Detected Above Minimum Reporting Limits at CAS 26-04-02

\begin{tabular}{|c|c|c|c|c|c|c|c|c|}
\hline \multirow{2}{*}{$\begin{array}{c}\text { Sample } \\
\text { Identification } \\
\text { Number }\end{array}$} & \multirow{2}{*}{$\begin{array}{c}\text { Depth } \\
\text { (ft bgs) }\end{array}$} & \multicolumn{7}{|c|}{ Contaminants of Potential Concern $(\mathrm{pCi} / \mathrm{g})$} \\
\hline & & Actinium-228 ${ }^{a}$ & Bismuth-212 ${ }^{\mathrm{b}}$ & Bismuth-214 & Lead-212 & Lead-214 ${ }^{b}$ & Potassium-40 & Thallium-208 \\
\hline \multicolumn{2}{|c|}{ Preliminary Action Level } & 3.64 & 2.4 & 3.47 & 2.9 & 2.9 & 96 & 3.4 \\
\hline $271 \mathrm{~K} 001$ & 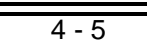 & $1.31 \pm 0.34$ & 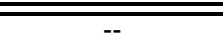 & $0.86 \pm 0.25$ & 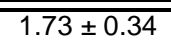 & $0.88 \pm 0.22$ & $21.7 \pm 4.5$ & $0.45 \pm 0.13$ \\
\hline $271 \mathrm{~K} 003$ & $2.7-3.7$ & $1.2 \pm 0.33$ & -- & $0.75 \pm 0.22$ & $1.3 \pm 0.27$ & $0.78 \pm 0.20$ & $19.5 \pm 4.0$ & $0.44 \pm 0.12$ \\
\hline $271 \mathrm{~K} 004$ & $2.7-3.7$ & $1.07 \pm 0.33$ & -- & $0.91 \pm 0.28$ & $1.37 \pm 0.30$ & $0.87 \pm 0.22$ & $18.5 \pm 4.0$ & $0.39 \pm 0.13$ \\
\hline $271 \mathrm{~K} 006$ & $3.2-4.2$ & $1.41 \pm 0.31$ & $1.76 \pm 0.73$ & $0.9 \pm 0.21$ & $1.58 \pm 0.30$ & $0.91 \pm 0.19$ & $23.5 \pm 4.2$ & $0.434 \pm 0.099$ \\
\hline $271 \mathrm{~K} 008$ & $4-5$ & $1.2 \pm 0.26$ & $\overline{--}$ & $0.75 \pm 0.18$ & $1.44 \pm 0.27$ & $0.83 \pm 0.17$ & $24 \pm 4.2$ & $0.46 \pm 0.10$ \\
\hline $271 \mathrm{~K} 010$ & $4.7-5.7$ & $1.38 \pm 0.34$ & -- & $0.91 \pm 0.24$ & $1.55 \pm 0.31$ & $0.99 \pm 0.22$ & $24.5 \pm 4.7$ & $0.53 \pm 0.13$ \\
\hline $271 \mathrm{~K} 012$ & $2.5-3.5$ & $1.25 \pm 0.33$ & -- & $0.74 \pm 0.22$ & $1.16 \pm 0.27$ & $0.92 \pm 0.22$ & $21.1 \pm 4.2$ & $0.49 \pm 0.13$ \\
\hline $271 \mathrm{~K} 014$ & $3-4$ & $1.26 \pm 0.37$ & -- & $0.79 \pm 0.26$ & $1.55 \pm 0.33$ & $0.84 \pm 0.23$ & $21.7 \pm 4.5$ & $0.49 \pm 0.14$ \\
\hline $271 \mathrm{~K} 016$ & $4-5$ & $1.35 \pm 0.29$ & -- & $0.74 \pm 0.18$ & $1.51 \pm 0.28$ & $0.89 \pm 0.18$ & $20.9 \pm 3.7$ & $0.431 \pm 0.097$ \\
\hline $271 \mathrm{~K} 018$ & $4-5$ & $1.38 \pm 0.33$ & $\overline{--}$ & $0.86 \pm 0.22$ & $1.44 \pm 0.29$ & $0.84 \pm 0.21$ & $22.1 \pm 4.3$ & $0.45 \pm 0.12$ \\
\hline $271 \mathrm{~K} 020$ & $2.5-3.5$ & $1.37 \pm 0.34$ & -- & $0.91 \pm 0.24$ & $1.61 \pm 0.32$ & $0.96 \pm 0.22$ & $19.4 \pm 3.8$ & $0.47 \pm 0.12$ \\
\hline $271 \mathrm{~K} 022$ & $3-4$ & $1.24 \pm 0.28$ & -- & $0.75 \pm 0.19$ & $1.31 \pm 0.26$ & $0.82 \pm 0.18$ & $20.5 \pm 3.7$ & $0.425 \pm 0.100$ \\
\hline $271 \mathrm{~K} 024$ & $3-4$ & $1.33 \pm 0.29$ & $1.56 \pm 0.62$ & $0.77 \pm 0.18$ & $1.56 \pm 0.29$ & $0.86 \pm 0.18$ & $24.3 \pm 4.3$ & $0.374 \pm 0.088$ \\
\hline $271 \mathrm{~K} 027$ & $7.6-8.6$ & $1.3 \pm 0.33$ & -- & $0.83 \pm 0.21$ & $1.59 \pm 0.31$ & $0.97 \pm 0.22$ & $22.2 \pm 4.3$ & $0.51 \pm 0.13$ \\
\hline $271 \mathrm{~K} 029$ & $7.9-8.9$ & $1.38 \pm 0.37$ & -- & $0.6 \pm 0.21$ & $1.61 \pm 0.33$ & $0.93 \pm 0.23$ & $20.7 \pm 4.3$ & $0.35 \pm 0.12$ \\
\hline
\end{tabular}

aBackground concentration listed in Environmental Monitoring Report for the Proposed Ward Valley, California, Low-Level Radioactive Waste (LLRW) Facility (US Ecology and Atlan-Tech, 1992).

${ }^{\mathrm{b} B a c k g r o u n d}$ concentration listed or derived in Off-Site Radiation Exposure Review Project, Phase /l Soil Program (McArthur and Miller, 1989).

$--=$ Not detected above minimum reporting limit 
Table A.12-5

Soil Sample Results for Isotopic Uranium Detected Above Minimum Reporting Limits at CAS 26-04-02

\begin{tabular}{|c|c|c|c|c|}
\hline \multirow{2}{*}{$\begin{array}{c}\text { Sample } \\
\text { Identification } \\
\text { Number }\end{array}$} & \multirow{2}{*}{$\begin{array}{c}\text { Depth } \\
\text { (ft bgs) }\end{array}$} & \multicolumn{3}{|c|}{ Contaminants of Potential Concern (pCi/g) } \\
\hline & & Uranium-234a & Uranium-235a & Uranium-238 \\
\hline \multicolumn{2}{|c|}{ Preliminary Action Levels } & 1.56 & 0.07 & 3.2 \\
\hline $271 \mathrm{~K} 001$ & $4-5$ & $1.12 \pm 0.21$ & -- & $0.99 \pm 0.19$ \\
\hline $271 \mathrm{~K} 003$ & $2.7-3.7$ & $1.06 \pm 0.19$ & $0.094 \pm 0.042$ & $0.97 \pm 0.18$ \\
\hline $271 \mathrm{~K} 004$ & $2.7-3.7$ & $1.14 \pm 0.20$ & $0.083 \pm 0.039$ & $0.97 \pm 0.18$ \\
\hline $271 \mathrm{~K} 006$ & $3.2-4.2$ & $0.99 \pm 0.19$ & $0.085 \pm 0.040$ & $0.98 \pm 0.18$ \\
\hline $271 \mathrm{~K} 008$ & $4-5$ & $0.9 \pm 0.17$ & $0.078 \pm 0.039$ & $0.89 \pm 0.17$ \\
\hline $271 \mathrm{~K} 010$ & $4.7-5.7$ & $1.1 \pm 0.20$ & -- & $0.86 \pm 0.17$ \\
\hline $271 \mathrm{~K} 012$ & $2.5-3.5$ & $0.97 \pm 0.17$ & -- & $0.83 \pm 0.15$ \\
\hline $271 \mathrm{~K} 014$ & $3-4$ & $0.93 \pm 0.17$ & -- & $0.9 \pm 0.17$ \\
\hline $271 \mathrm{~K} 016$ & $4-5$ & $0.85 \pm 0.16$ & $0.065 \pm 0.034$ & $0.88 \pm 0.17$ \\
\hline $271 \mathrm{~K} 018$ & $4-5$ & $1.05 \pm 0.19$ & $0.075 \pm 0.036$ & $0.89 \pm 0.17$ \\
\hline $271 \mathrm{~K} 020$ & $2.5-3.5$ & $0.82 \pm 0.16$ & -- & $1.02 \pm 0.19$ \\
\hline $271 \mathrm{~K} 022$ & $3-4$ & $1.27 \pm 0.22$ & $0.112 \pm 0.046$ & $1.01 \pm 0.19$ \\
\hline $271 \mathrm{~K} 024$ & $3-4$ & $1.08 \pm 0.20$ & $0.135 \pm 0.054$ & $1.05 \pm 0.20$ \\
\hline $271 \mathrm{~K} 027$ & $7.6-8.6$ & $1.04 \pm 0.21$ & $0.066 \pm 0.039$ & $1 \pm 0.20$ \\
\hline $271 \mathrm{~K} 029$ & $7.9-8.9$ & $1.29 \pm 0.24$ & -- & $1.11 \pm 0.21$ \\
\hline
\end{tabular}

a'Background concentration listed in Environmental Monitoring Report for the Proposed Ward Valley, California, Low-Level Radioactive Waste (LLRW) Facility (US Ecology and Atlan-Tech, 1992).

${ }^{b}$ Background concentration listed or derived in Off-Site Radiation Exposure Review Project, Phase II Soil Program (McArthur and Miller, 1989).

-- = Not detected above minimum reporting limit

\section{A.12.3.1.10 Strontium-90}

Strontium-90 was not detected above MRLs in CAS 26-04-02 soil samples.

\section{A.12.3.2 Septic Tank Sample Results}

Results of collected septic tank content samples were compared to regulatory levels based on disposal options. If the waste has no hazardous component, the regulatory level is based on disposal options at NTS landfills and lagoons (BN, 1995; CFR, 2000b and c; NDEP, 1997a, b, and c). Any sludge or 
liquid waste will be solidified before disposal at NTS landfills (NDEP, 1997b). If the waste is hazardous, the release criteria are based on interpretation of the guidelines presented in the POC (BN, 1995; Alderson, 1999). For waste destined for off-site disposal, the POC radiological levels must be met to certify that the waste has no radioactivity added.

One sediment sample was scraped from the bottom of the septic tank. The analytical suite followed the CAIP and is detailed in Section A.12.2.8. Analytical results exceeding MRLs are listed in Table A.12-6.

Table A.12-6

Septic Tank Sediment Sample Results Detected Above Minimum Reporting Limits at CAS 26-04-02

(Page 1 of 2 )

\begin{tabular}{|c|c|c|c|c|c|c|}
\hline $\begin{array}{c}\text { Sample } \\
\text { Identification } \\
\text { Number }\end{array}$ & Matrix & Parameter & Result & Units & Limits & Reference \\
\hline $271 \mathrm{~K} 031$ & Sediment & Mercury** & 0.8 & $\mathrm{mg} / \mathrm{kg}$ & NA & CFR, 2000a \\
\hline 271K031 & Sediment & Arsenic $^{* *}$ & 5.2 & $\mathrm{mg} / \mathrm{kg}$ & NA & CFR, 2000a \\
\hline $271 \mathrm{~K} 031$ & Sediment & Barium** & 160 & $\mathrm{mg} / \mathrm{kg}$ & NA & CFR, 2000a \\
\hline $271 \mathrm{~K} 031$ & Sediment & Cadmium** & 4.1 & $\mathrm{mg} / \mathrm{kg}$ & NA & CFR, 2000a \\
\hline $271 \mathrm{~K} 031$ & Sediment & Chromium** & 16 & $\mathrm{mg} / \mathrm{kg}$ & NA & CFR, 2000a \\
\hline $271 \mathrm{~K} 031$ & Sediment & Lead & 5,400 & $\mathrm{mg} / \mathrm{kg}$ & NA & CFR, 2000a \\
\hline $271 \mathrm{~K} 031$ & Sediment & Silver** & 3.6 & $\mathrm{mg} / \mathrm{kg}$ & NA & CFR, 2000a \\
\hline $271 \mathrm{~K} 031$ & Sediment & TCLP Lead & 0.03 & $\mathrm{mg} / \mathrm{L}$ & 5.0 & CFR, 2000a \\
\hline $271 \mathrm{~K} 031$ & Sediment & Benzo(A)Anthracene & $870(J)^{a}$ & $\mu \mathrm{g} / \mathrm{kg}$ & NA & CFR, 2000a \\
\hline $271 \mathrm{~K} 031$ & Sediment & Benzo(A)Pyrene & 950 & $\mu \mathrm{g} / \mathrm{kg}$ & NA & CFR, 2000a \\
\hline $271 \mathrm{~K} 031$ & Sediment & Benzo(G,H,I)Perylene & 680 & $\mu \mathrm{g} / \mathrm{kg}$ & NA & CFR, 2000a \\
\hline $271 \mathrm{~K} 031$ & Sediment & Bis(2-Ethylhexyl)Phthalate & $820(J)^{a}$ & $\mu \mathrm{g} / \mathrm{kg}$ & NA & CFR, 2000a \\
\hline $271 \mathrm{~K} 031$ & Sediment & Chrysene & $1,100(J)^{a}$ & $\mu \mathrm{g} / \mathrm{kg}$ & NA & CFR, 2000a \\
\hline $271 \mathrm{~K} 031$ & Sediment & Phenanthrene & 690 & $\mu \mathrm{g} / \mathrm{kg}$ & NA & CFR, 2000a \\
\hline $271 \mathrm{~K} 031$ & Sediment & Pyrene & $1,200(J)^{a}$ & $\mu \mathrm{g} / \mathrm{kg}$ & NA & CFR, 2000a \\
\hline $271 \mathrm{~K} 031$ & Sediment & Actinium-228 & $1.25 \pm 0.29$ & $\mathrm{pCi} / \mathrm{g}$ & - & $\mathrm{N}$ \\
\hline $271 \mathrm{~K} 031$ & Sediment & Bismuth-214 & $0.76 \pm 0.19$ & $\mathrm{pCi} / \mathrm{g}$ & - & $\mathrm{N}$ \\
\hline $271 \mathrm{~K} 031$ & Sediment & Potassium-40 & $23.5 \pm 4.2$ & $\mathrm{pCi} / \mathrm{g}$ & - & $\mathrm{N}$ \\
\hline
\end{tabular}


Table A.12-6

\section{Septic Tank Sediment Sample Results Detected Above Minimum Reporting Limits at CAS 26-04-02}

(Page 2 of 2)

\begin{tabular}{|c|c|c|c|c|c|c|}
\hline $\begin{array}{c}\text { Sample } \\
\text { Identification } \\
\text { Number }\end{array}$ & Matrix & Parameter & Result & Units & Limits & Reference \\
\hline $271 \mathrm{~K} 031$ & Sediment & Lead-212 & $1.46 \pm 0.28$ & $\mathrm{pCi} / \mathrm{g}$ & - & $\mathrm{N}$ \\
\hline $271 \mathrm{~K} 031$ & Sediment & Lead-214 & $0.97 \pm 0.20$ & $\mathrm{pCi} / \mathrm{g}$ & - & $\mathrm{N}$ \\
\hline $271 \mathrm{~K} 031$ & Sediment & Thallium-208 & $0.406 \pm 0.099$ & $\mathrm{pCi} / \mathrm{g}$ & - & $\mathrm{N}$ \\
\hline $271 \mathrm{~K} 031$ & Sediment & Uranium-234 & $1.56 \pm 0.25$ & $\mathrm{pCi} / \mathrm{g}$ & 100 & NDEP, 1997b \\
\hline $271 \mathrm{~K} 031$ & Sediment & Uranium-235 & $0.131 \pm 0.047$ & $\mathrm{pCi} / \mathrm{g}$ & 100 & NDEP, 1997b \\
\hline $271 \mathrm{~K} 031$ & Sediment & Uranium-238 & $0.98 \pm 0.18$ & $\mathrm{pCi} / \mathrm{g}$ & 100 & NDEP, 1997b \\
\hline $271 \mathrm{~K} 031$ & Sediment & Plutonium-239 & $0.075 \pm 0.038$ & $\mathrm{pCi} / \mathrm{g}$ & 10 & NDEP, 1997b \\
\hline $271 \mathrm{~K} 031$ & Sediment & Aroclor-1254 & 160 & $\mu \mathrm{g} / \mathrm{kg}$ & 50,000 & CFR, 2000b \\
\hline $271 \mathrm{~K} 031$ & Sediment & Acetone & $28(J)^{b}$ & $\mu \mathrm{g} / \mathrm{kg}$ & NA & CFR, 2000a \\
\hline $271 \mathrm{~K} 031$ & Sediment & Diesel-Range Organics & $160(M, Z)$ & $\mathrm{mg} / \mathrm{kg}$ & 100 & NDEP, 1997b \\
\hline
\end{tabular}

${ }^{a} Q u a l i f i e r$ added to laboratory data; record accepted. Internal standard area count exceeded the quality control limits. Matrix effects may exist.

${ }^{b}$ Qualifier added to laboratory data record accepted. Average relative response factor $<0.05$. Relative response factor $<0.05$.

Continuing calibration verification percent $>25$ percent.

${ }^{* *}=$ TCLP below minimum reporting limit

$\mathrm{J}=$ Estimated value

$\mathrm{M}=$ Motor oil

$\mathrm{N}=$ No limit established (NDEP, 1997b)

$\mathrm{NA}=$ Not applicable

$Z$ = The reported result did not resemble the patterns of the following petroleum hydrocarbon products: gasoline, JP-4, JP-8, diesel, mineral spirit, motor oil, Stoddard solvent and Bunker C

Several COPCs were detected in the sediment sample. Most COPCs were below regulatory limits except for TPH, which was detected at $160 \mathrm{mg} / \mathrm{kg}$, exceeding the NDEP action level of $100 \mathrm{mg} / \mathrm{kg}$ (NAC, 2000).

\section{A.12.4 Contaminants of Concern}

Based on the aforementioned analytical results, there are no COCs present in the soil surrounding the septic tank or under the leachfield. Contaminants of concern are present only in the septic tank, 
which contains a small amount of sediment with TPH analytes (DRO) in concentrations exceeding the NDEP action level of $100 \mathrm{mg} / \mathrm{kg}$.

\section{A.12.5 Nature and Extent of Contamination}

The TPH is located within sediment at the bottom of the septic tank. Approximately 34 gal of sediment is present in the tank, and this is a conservative estimate of the volume.

\section{A.12.6 Revised Conceptual Model}

No variations in the conceptual model were identified. 


\section{A.13.0 Buildings 2201 and 2202 Radioactive Leachfield (CAS 26-05-01)}

The radioactive leachfield was designed to receive radioactive effluent generated by activities in Building 2201 (Disassembly Building) and Building 2202 (Railcar Washdown). The leachfield system is located approximately $1,450 \mathrm{ft}$ southeast of Building 2201 . The site is comprised of a leachfield, distribution box, and associated piping. More detail is provided in the CAIP (DOE/NV, 2001).

\section{A.13.1 Corrective Action Investigation}

Sixty-seven investigation samples, listed in Table A.13-1, were collected during investigation activities conducted at CAS 26-05-01. The planned and actual sample locations are shown in Figure A.13-1. The specific CAI activities conducted to meet CAIP requirements at CAS 26-05-01 are described in Table A.2-1.

\section{A.13.1.1 Deviations}

There were no deviations from the planned investigation of CAS 26-05-01.

\section{A.13.2 Investigation Results}

The following subsections provide details of the inspection and sampling of leachfield features, field-screening results, and sample selection and analysis.

\section{A.13.2.1 Distribution Box Contents}

The concrete distribution box was rectangular-shaped with a 838-gal capacity. It was accessed by one manhole located $4.8 \mathrm{ft}$ above the ground surface. The interior dimensions of the box were $4 \mathrm{ft}$ (length) by $4 \mathrm{ft}$ (width) by $7 \mathrm{ft}$ (depth). There was very little sediment in the bottom of the distribution box; therefore, no sample was collected. Photographs of the distribution box were taken to document the visual inspection (Figure A.13-2). 
Table A.13-1

Samples Collected at CAS 26-05-01

(Page 1 of 3 )

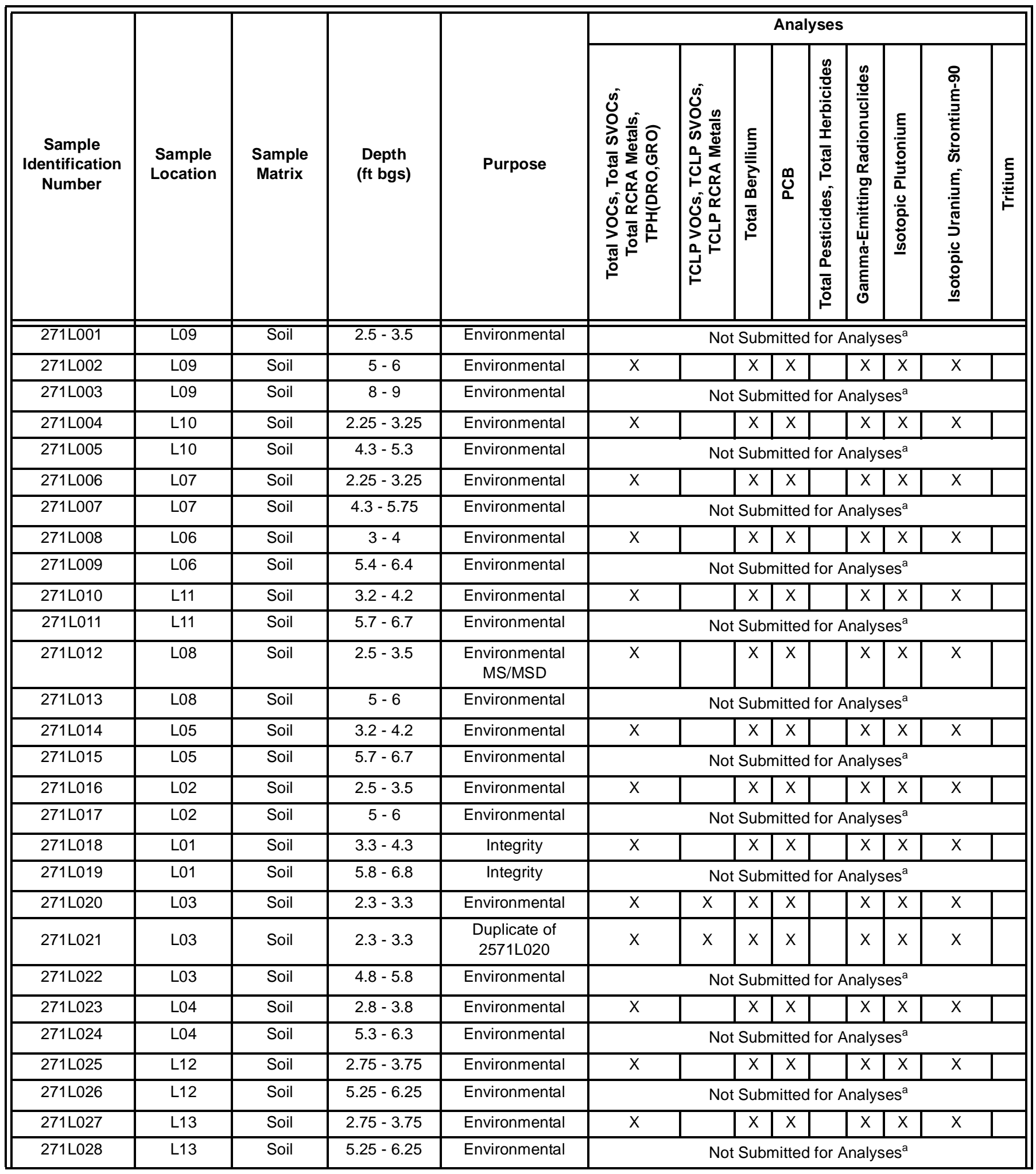


Table A.13-1

Samples Collected at CAS 26-05-01

(Page 2 of 3 )

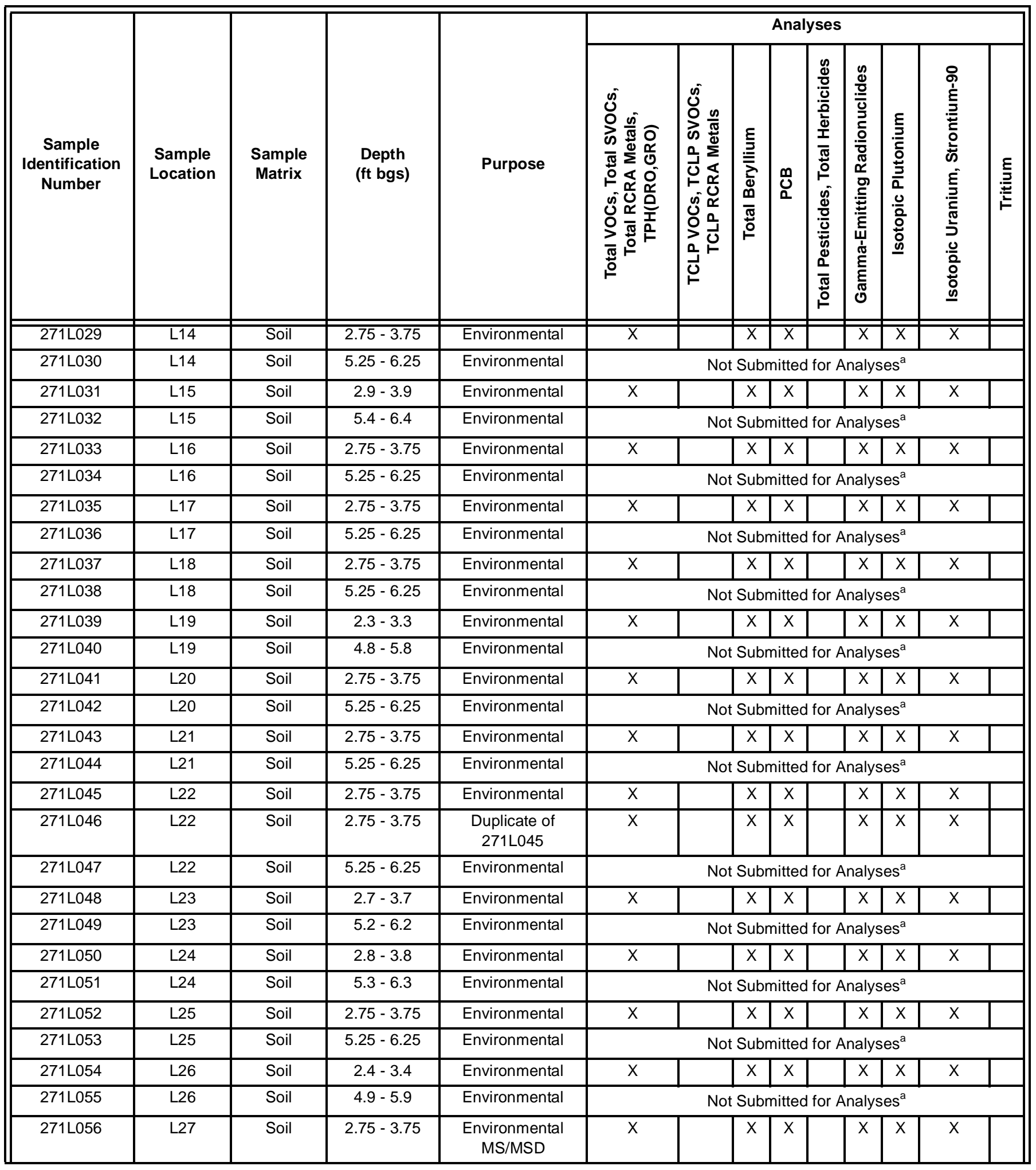


Table A.13-1

Samples Collected at CAS 26-05-01

(Page 3 of 3 )

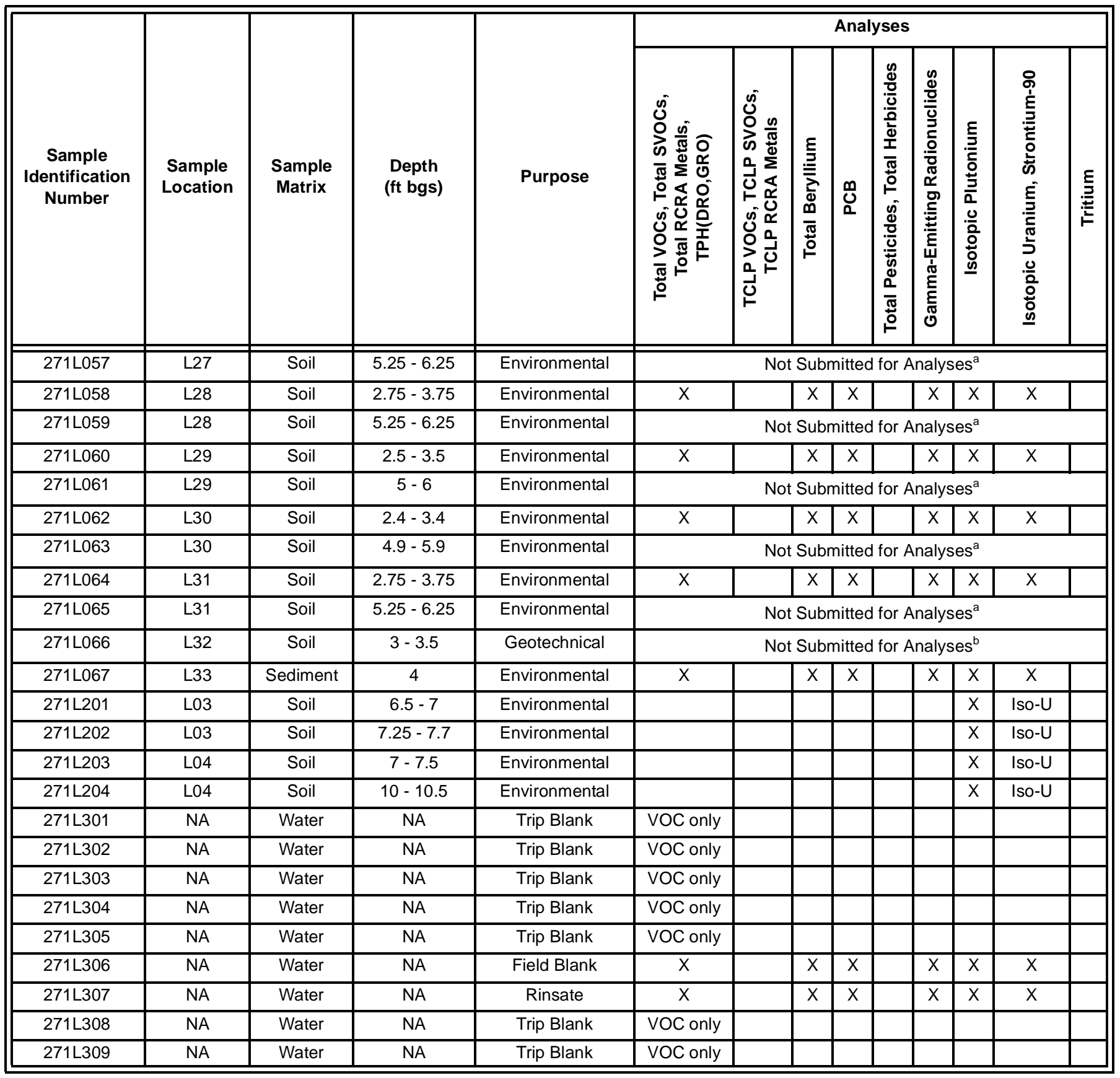

${ }^{a}$ The sample was collected, field screened, and returned to the site for disposal.

${ }^{\mathrm{b}}$ The sample was collected, field screened, and is being stored for possible geotechnical analysis. 


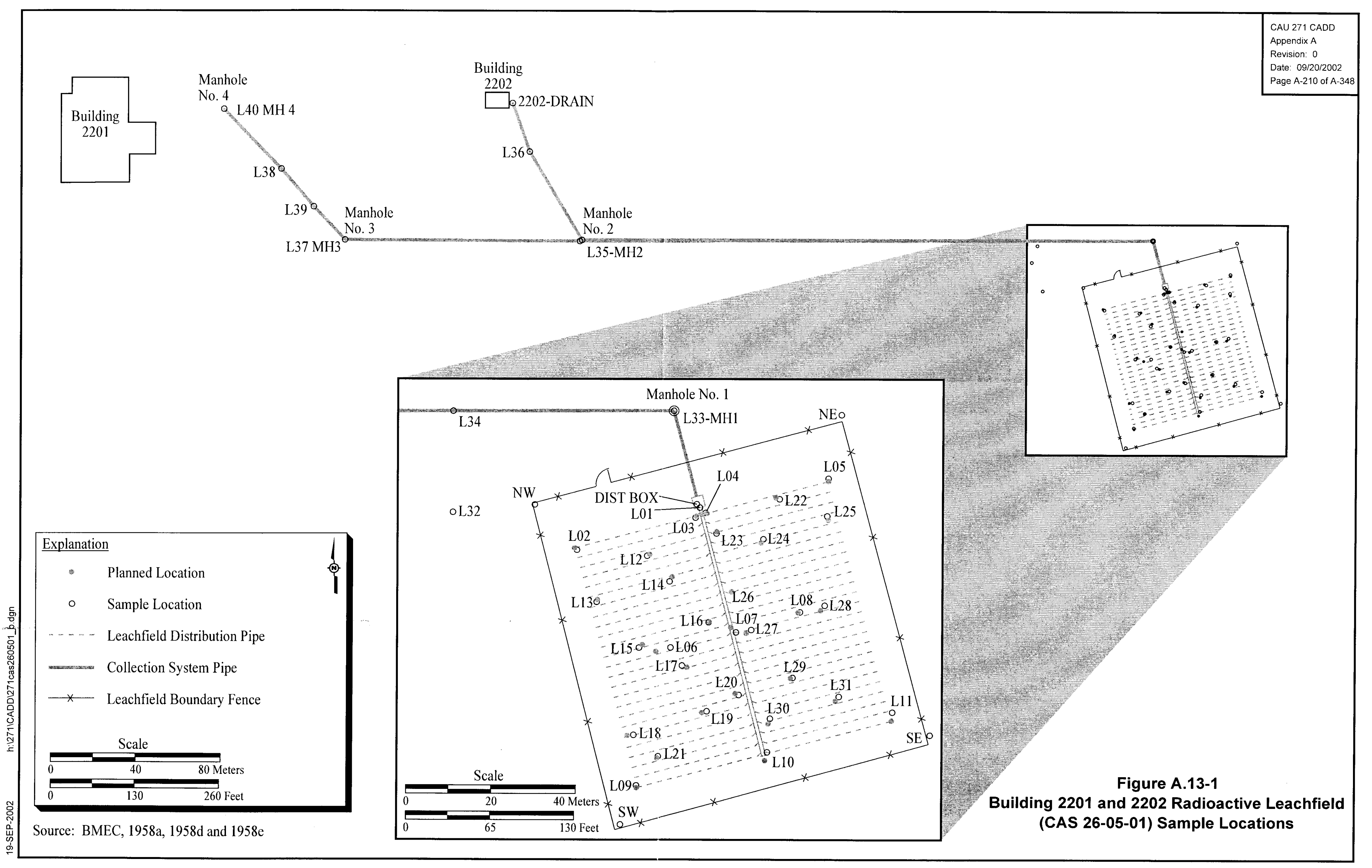




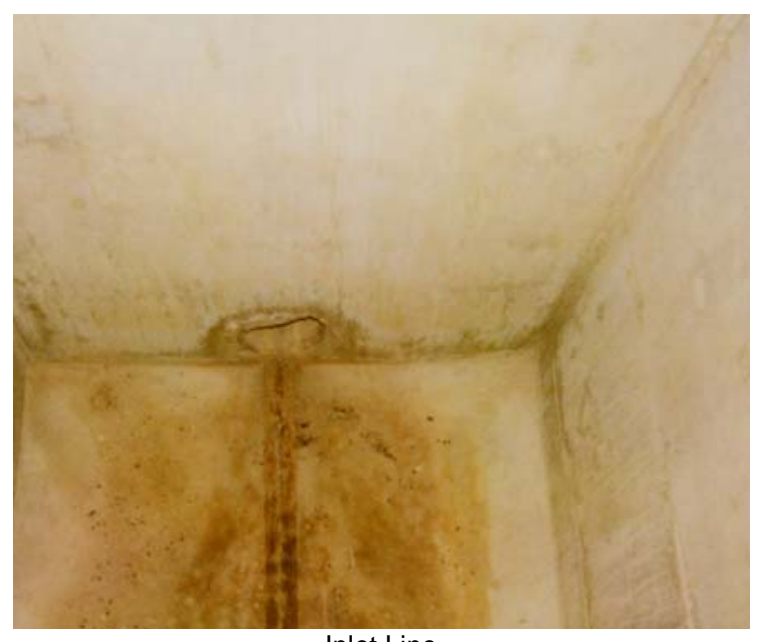

Inlet Line

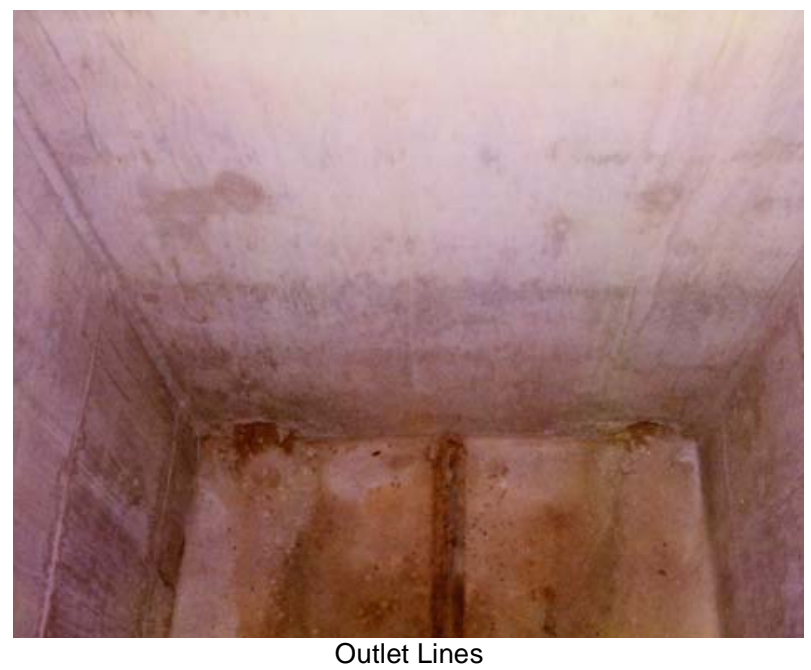

Outlet Lines

Figure A.13-2

CAS 26-05-01 Distribution Box, Interior

(Photographs Taken 02-01-2002)

\section{A.13.2.2 Distribution Box Integrity Soil Sampling}

Two integrity samples were collected by excavating adjacent to effluent end of the distribution box. Figure A.13-3 depicts the structural integrity and configuration of the effluent end of the distribution box. The upper sample (271L018), collected at 3.3 to $4.3 \mathrm{ft}$ bgs, was submitted for laboratory analysis.

\section{A.13.2.3 Leachfield Excavation Soil Sampling}

Backhoe excavations were conducted to access sampling horizons at the biased and random locations presented in the CAIP. Excavations provided a visual verification of distribution pipes and enabled soil samples to be collected from appropriate intervals beneath the pipes, as specified by the CAIP. Sixty-three soil samples were collected from the planned locations excavated within the leachfield. These samples were collected from intervals at 0 to $1 \mathrm{ft}, 2.5$ to $3.5 \mathrm{ft}$, and 6.5 to $7.5 \mathrm{ft}$ below the leachrock/native soil interface. The interface was found at depths ranging from 2.25 to $3.3 \mathrm{ft}$ bgs. Thirty-three samples were submitted for laboratory analysis. In addition, two QC soil duplicates and two MS/MSD samples were collected and analyzed. A geotechnical sample was collected outside the boundary of the leachfield. The sample will be sent to a laboratory for geotechnical analysis, if necessary. 


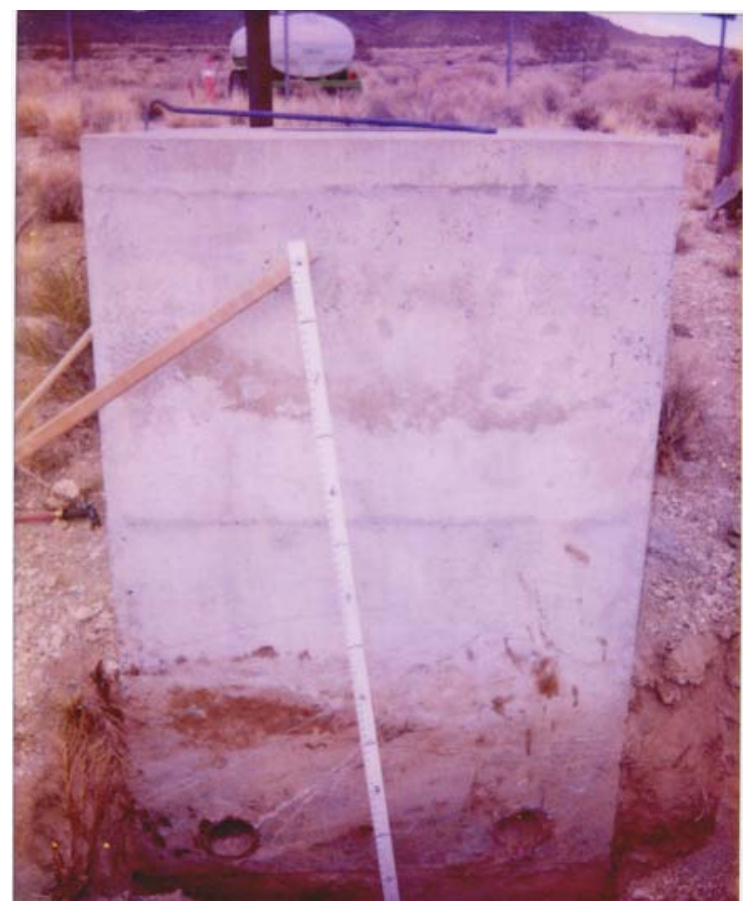

Figure A.13-3

CAS 26-05-01 Distribution Box, Effluent Integrity Sample (Photograph Taken 01-22-2002)

\section{A.13.2.4 Additional Sampling}

To define the extent of possible radiological contamination in leachfield soil, the field crew returned to this CAS on May 08, 2002, to conduct step-out sampling. Two locations (L03 and L04) were identified from the original sampling activities as locations of concern. Four vertical step-out samples were collected. Samples 271L201 and 271L202 were collected from L03 and samples 271L203 and 271L204 were collected from L04. All samples were submitted for laboratory analysis of Iso-Pu and Iso-U.

\section{A.13.2.5 Collection System Pipe Inspections}

The collection system for CAS 26-05-01 consists of approximately 1,800 ft of pipe that connects Buildings 2201 and 2202 with the leachfield. Access points for visual inspection and radiological screening of the collection system were four manholes (Figure A.13-4) and several excavated breaks. 


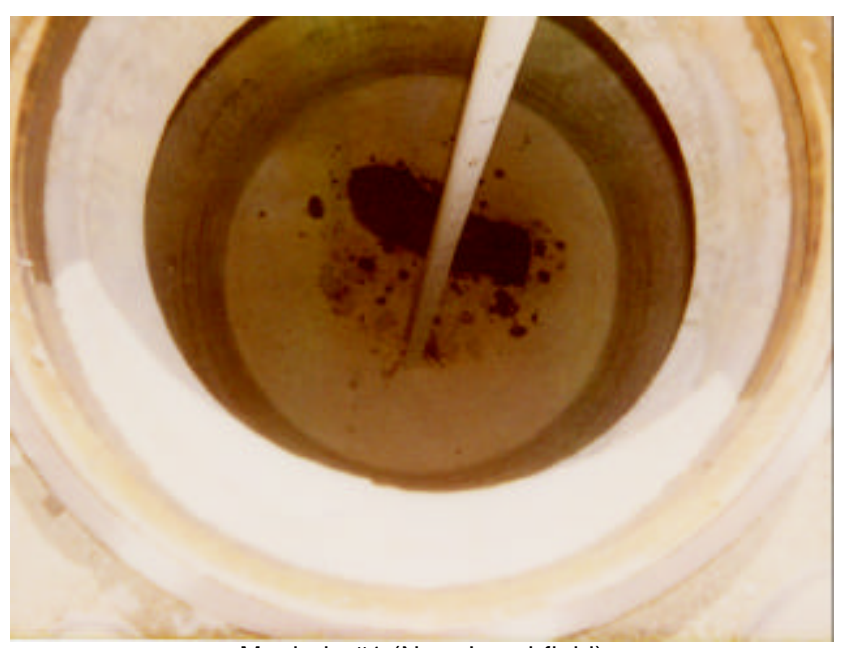

Manhole \#1 (Near Leachfield)

(Photograph Taken 01-28-2002)

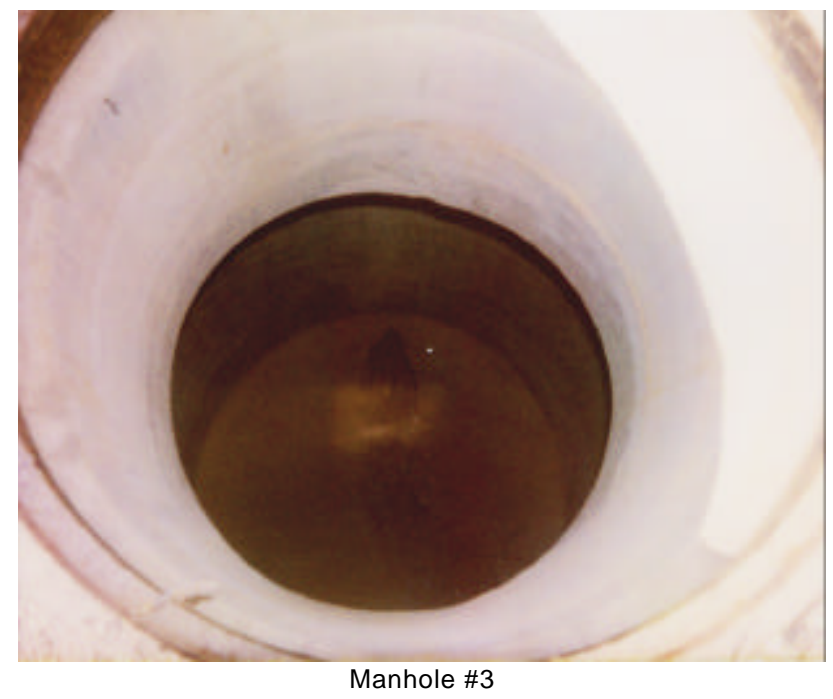

(Photograph Taken 01-30-2002)

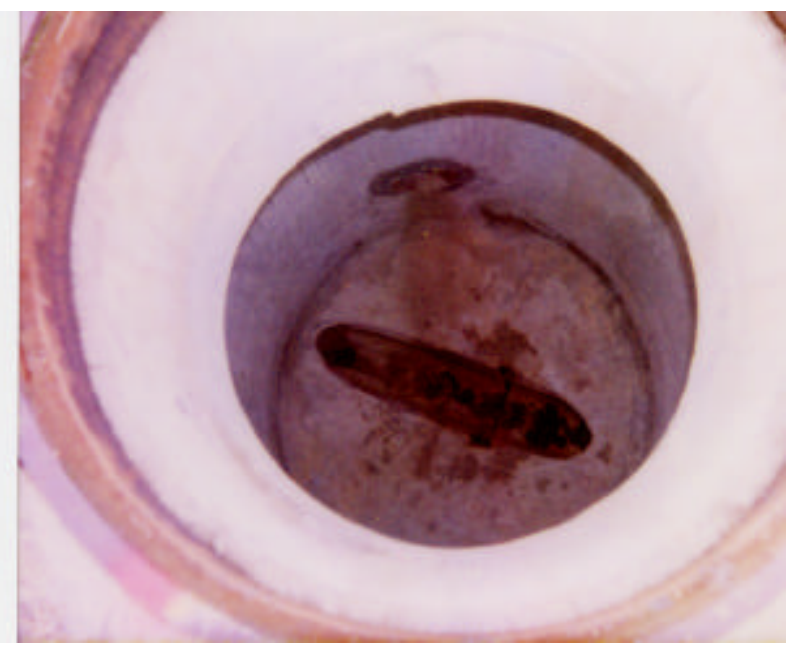

Manhole \#2 (Inlet Line from Building 2202) (Photograph Taken 01-29-2002)

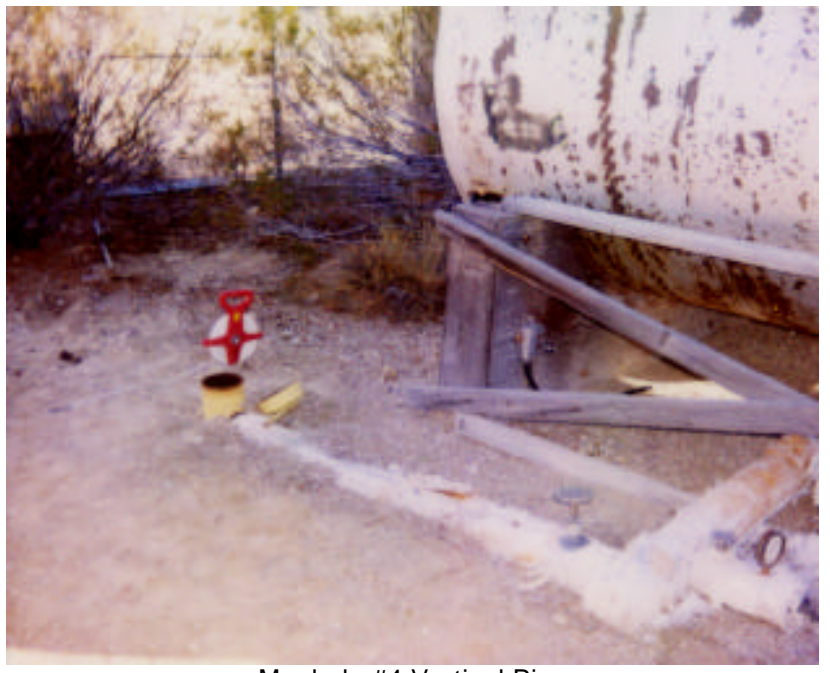

Manhole \#4 Vertical Pipe

(Photograph Taken 01-31-2002)

Figure A.13-4

CAS 26-05-01 Collection System Manholes

Manhole 1 (L33) was uncovered and inspected. The manhole contained sediment that appeared to be related to system operations; therefore, a sample (271L067) was collected. Approximately 10 gal of sediment were present in the manhole. A radiological survey was conducted on the manhole and swipes were collected for radiological characterization. The video mole was inserted through the manhole and passed $66 \mathrm{ft}$ downstream (southeast) until the distribution box was encountered. The video mole was then passed upstream (west) for $78 \mathrm{ft}$. An excavation (L34) was made $170 \mathrm{ft}$ 
upstream from Manhole 1 . The video mole was passed approximately $85 \mathrm{ft}$ downstream and upstream to inspect the pipe.

Manhole 2 (L35) was uncovered and inspected. The manhole did not contain adequate sediment for sample collection. This manhole serves as the junction point for the effluent lines from Buildings 2201 and 2202. A radiological survey was conducted on the manhole, and swipes were collected for radiological characterization. The video mole was inserted through Manhole 2 and passed $87.5 \mathrm{ft}$ upstream (northwest) toward Building 2202. The video mole was then passed $88 \mathrm{ft}$ downstream, (east) and $85 \mathrm{ft}$ upstream (west) to inspect the main line from Building 2201. An excavation (L36) was made $160 \mathrm{ft}$ upstream (northwest) from Manhole 2 on the pipe segment from Building 2202. The video mole was passed $121.5 \mathrm{ft}$ downstream (southeast) from location L36 and $85 \mathrm{ft}$ upstream (northwest) where the termination point at the drain pipe of Building 2202 was encountered. A 45-degree elbow was noted $21 \mathrm{ft}$ from the termination point.

Manhole 3 (L37) was uncovered and inspected. The manhole did not contain adequate sediment for sample collection. A radiological survey was conducted on the manhole, and swipes were collected for radiological characterization. The video mole was inserted through Manhole 3 and passed $71 \mathrm{ft}$ upstream (northwest) and $67.5 \mathrm{ft}$ downstream (east) to inspect the pipe line. An excavation (L38) was made $175 \mathrm{ft}$ upstream (northwest) from Manhole 3. The pipeline was too deep to inspect at this point, so another excavation (L39) was made $105 \mathrm{ft}$ downstream of L38 (70 ft upstream from Manhole 3). The video mole was passed through the pipe at L39, $76 \mathrm{ft}$ upstream (northwest) to inspect the pipe leading to Building 2201. The pipe segment downstream from location L39 had previously been inspected from Manhole 3. The upstream end of the pipe at location L39 was sealed with grout prior to backfilling the excavation.

Manhole 4 (L40) was located inside the Building 2201 fenceline. Manhole 4 was buried and a steel pipe extended from it to the surface. A radiological survey was conducted through the steel pipe and swipes were collected for radiological characterization. The video mole was inserted through the pipe and into the manhole. Inspection confirmed that the manhole had an inlet pipe originating from Building 2201 and an outlet pipe leading toward the leachfield. The video mole was not able to access either of the pipes due to its extreme angle of insertion. 
Overall, inspected segments of collection system pipe were dry, did not contain any material, and were not broken or obstructed. There was a little sediment observed in each manhole, and some moisture was noted in Manhole 2. Manhole 1 contained enough sediment to sample. This sediment appears to have collected where the pipeline makes a 75-degree bend to direct flow to the leachfield (Figure A.13-1). The results of the visual inspection were recorded in the FADLs. The results of radiological screening of collection system components and swipe collection are discussed in Section A.13.2.7.

\section{A.13.2.6 Field-Screening Results}

Soil samples were screened for VOCs and alpha and beta/gamma radioactivity. The field readings were compared to FSLs to guide sampling decisions and determine which samples were to be submitted for laboratory analysis. No VOCs greater than FSLs were found during soil sample screening. The results of radiological field screening are discussed in Section A.13.2.7.

\section{A.13.2.7 Radiological Survey Results}

The following sections discuss the results of radiological screening, surveys, and swipe measurements.

\section{A.13.2.7.1 In Situ Cone Penetrometer Measurements}

In situ shallow subsurface radiation measurements were collected using a gamma detector on the end of a CPT rod. The CPT radiation measurements were collected at biased leachfield sample locations. Four background pushes were completed at locations outside the fenced portion of the leachfield. The results of the in situ measurement effort showed that the radiological levels:

- Were low enough to select excavation as the method of intrusive investigation

- Did not warrant greater protection for workers or the use of on-site gamma spectrometry to screen samples

- $\quad$ Presented no mixed waste concerns

- Were low enough for samples to be practically handled, transported, analyzed, and shipped for off-site laboratory analysis 
- Were low enough to justify collection of all samples at planned intervals and locations

\section{A.13.2.7.2 Radiological Screening Results}

Radiological FSLs for beta/gamma was 3,300 dpm/100 $\mathrm{cm}^{2}$. Radiological FSLs were exceeded at the following location:

- Location L09 - Sample (271L001) had an elevated beta/gamma reading of $3,360 \mathrm{dpm} / 100 \mathrm{~cm}^{2}$. This sample was submitted for laboratory analysis, and additional samples (271L002 and 271L003) were collected from the location. Neither of these samples exceeded radiological FSLs

Radiological survey measurements of the piping representative of the collection system were obtained upstream from the distribution box. The pipe interior was screened for both removable and fixed radiological levels for comparison against unrestricted release criteria.

Table A.13-2 provides the fixed plus removable radiological survey results for locations taken along the collection system (locations L33 through L39; Section A.13.2.5). All fixed plus removable measurements were below the unrestricted release criteria for the collection system pipes. Only the floor of the distribution box exhibited total beta/gamma contamination exceeding the unrestricted release limit.

Measurements of the distribution box interior were also collected and the results are provided in Table A.13-2. Four survey locations (DB East Out, 6,652 dpm/100 cm²; DB West Out, 8,105 dpm/100 cm²; DB West Floor, 8,055 dpm/100 cm²; and DB East Floor, 7,026 dpm/100 cm²) inside the distribution box showed readings above the unrestricted release criteria of 5,000 dpm/100 $\mathrm{cm}^{2}(\mathrm{DOE} / \mathrm{NV}, 2000 \mathrm{a})$.

\section{A.13.2.7.3 Swipe Measurements}

A radiological swipe survey was conducted along the collection system piping and the distribution box. Table A.13-3 provides the survey results with comparisons made to the unrestricted release criteria for removable radioactive contamination. The unrestricted release criteria for removable contamination were not exceeded in swipes taken from collection system pipes. However, a large-area swipe from the bottom of Manhole 4 exhibited removable beta activity in excess of the 
Table A.13-2

Radiological Survey Results at CAS 26-05-01

(Page 1 of 2)

\begin{tabular}{|c|c|c|c|c|c|}
\hline \multirow{2}{*}{$\begin{array}{l}\text { Location } \\
\text { Number }\end{array}$} & \multirow{2}{*}{$\begin{array}{l}\text { Sample } \\
\text { Location }\end{array}$} & \multicolumn{2}{|c|}{$\begin{array}{l}\text { Gross Fixed + Removable } \\
\text { Contamination }\end{array}$} & \multicolumn{2}{|c|}{ Unrestricted Release Criteria } \\
\hline & & $\begin{array}{l}\text { Beta/Gamma } \\
\left(\mathrm{dpm} / 100 \mathrm{~cm}^{2}\right)\end{array}$ & $\begin{array}{c}\text { Alpha } \\
\left(\mathrm{dpm} / 100 \mathrm{~cm}^{2}\right)\end{array}$ & $\begin{array}{l}\text { Beta/Gamma } \\
\left(\mathrm{dpm} / 100 \mathrm{~cm}^{2}\right)\end{array}$ & $\begin{array}{c}\text { Alpha } \\
\text { (dpm/100 cm²) }\end{array}$ \\
\hline L01 & Leach Pipe & 2,950 & 21.4 & \multicolumn{2}{|c|}{5,000} \\
\hline L03 & $\begin{array}{l}\text { Leach Pipe at } \\
\text { Junction }\end{array}$ & 4,324 & 45.7 & \multicolumn{2}{|c|}{5,000} \\
\hline L06 & $\begin{array}{l}\text { Leach Pipe } \\
\text { (pieces) }\end{array}$ & 2,540 & 26.0 & \multicolumn{2}{|c|}{5,000} \\
\hline L08 & $\begin{array}{l}\text { Leach Pipe } \\
\text { (pieces) }\end{array}$ & 3,225 & 42.7 & \multicolumn{2}{|c|}{5,000} \\
\hline L13 & $\begin{array}{l}\text { Leach Pipe from } \\
\text { Sample Area }\end{array}$ & 3,687 & 17.1 & \multicolumn{2}{|c|}{5,000} \\
\hline L15 & Leach Pipe & 3,497 & 14.3 & \multicolumn{2}{|c|}{5,000} \\
\hline L23 & $\begin{array}{l}\text { Leach Pipe (piece) } \\
\text { Residue }\end{array}$ & 5,034 & 85.1 & \multicolumn{2}{|c|}{5,000} \\
\hline L26 & $\begin{array}{l}\text { Residue Inside } \\
\text { Leach Pipe }\end{array}$ & 5,886 & 44.1 & \multicolumn{2}{|c|}{5,000} \\
\hline L33 & $\begin{array}{l}\text { Manhole Pipe } \\
\text { Bottom }\end{array}$ & 3,355 & 13.8 & \multicolumn{2}{|c|}{5,000} \\
\hline L34 & Leachpipe Interior & 3,238 & 48.3 & \multicolumn{2}{|c|}{5,000} \\
\hline L34 & $\begin{array}{l}\text { Large Area Swipe } \\
\text { on Cable and } \\
\text { Camera from } \\
\text { Video }\end{array}$ & 2,903 & 74.3 & \multicolumn{2}{|c|}{5,000} \\
\hline L34 & $\begin{array}{l}\text { Large Area Swipe } \\
\text { on Cable and } \\
\text { Camera from } \\
\text { Video }\end{array}$ & 2,809 & 40.0 & \multicolumn{2}{|c|}{5,000} \\
\hline L35 & $\begin{array}{l}\text { Manhole \#2 - } \\
\text { North }\end{array}$ & 2,216 & 51.4 & \multicolumn{2}{|c|}{5,000} \\
\hline L35 & Manhole \#2 - East & 2,407 & 85.7 & \multicolumn{2}{|c|}{5,000} \\
\hline L35 & $\begin{array}{l}\text { Manhole \#2 - } \\
\text { West }\end{array}$ & 2,507 & 80.0 & \multicolumn{2}{|c|}{5,000} \\
\hline L36 & $\begin{array}{l}\text { Interior of } \\
\text { Leachpipe }\end{array}$ & 3,148 & 57.1 & \multicolumn{2}{|c|}{5,000} \\
\hline L36 & North & 2,036 & 11.4 & \multicolumn{2}{|c|}{5,000} \\
\hline L37 & South & 2,140 & 62.9 & \multicolumn{2}{|c|}{5,000} \\
\hline L37 & South & 2,399 & 80.0 & \multicolumn{2}{|c|}{5,000} \\
\hline L38 & North & 2,114 & 28.6 & \multicolumn{2}{|c|}{5,000} \\
\hline L39 & Inside Leach Pipe & 4,414 & 206 & \multicolumn{2}{|c|}{5,000} \\
\hline $\mathrm{DB}$ & East Out & 6,652 & 800 & \multicolumn{2}{|c|}{5,000} \\
\hline
\end{tabular}


Table A.13-2

Radiological Survey Results at CAS 26-05-01 (Page 2 of 2)

\begin{tabular}{|c|c|c|c|c|c|}
\hline \multirow{2}{*}{$\begin{array}{l}\text { Location } \\
\text { Number }\end{array}$} & \multirow{2}{*}{$\begin{array}{l}\text { Sample } \\
\text { Location }\end{array}$} & \multicolumn{2}{|c|}{$\begin{array}{c}\text { Gross Fixed + Removable } \\
\text { Contamination }\end{array}$} & \multicolumn{2}{|c|}{ Unrestricted Release Criteria } \\
\hline & & $\begin{array}{l}\text { Beta/Gamma } \\
\left(\mathrm{dpm} / 100 \mathrm{~cm}^{2}\right)\end{array}$ & $\begin{array}{c}\text { Alpha } \\
\left(\mathrm{dpm} / 100 \mathrm{~cm}^{2}\right)\end{array}$ & $\begin{array}{l}\text { Beta/Gamma } \\
\left(\mathrm{dpm} / 100 \mathrm{~cm}^{2}\right)\end{array}$ & $\begin{array}{c}\text { Alpha } \\
\text { (dpm/100 cm²) }\end{array}$ \\
\hline $\mathrm{DB}$ & West Out & 8,105 & 886 & \multicolumn{2}{|c|}{5,000} \\
\hline $\mathrm{DB}$ & In Center & 4,277 & 623 & \multicolumn{2}{|c|}{5,000} \\
\hline DB & West Floor & 8,055 & 737 & \multicolumn{2}{|c|}{5,000} \\
\hline DB & East Floor & 7,026 & 994 & \multicolumn{2}{|c|}{5,000} \\
\hline DB & South Wall & 2,568 & 931 & \multicolumn{2}{|c|}{5,000} \\
\hline DB & West Wall & 2,802 & 829 & \multicolumn{2}{|c|}{5,000} \\
\hline DB & East Wall & 2,493 & 766 & \multicolumn{2}{|c|}{5,000} \\
\hline DB & South Top Wall & 2,489 & 617 & \multicolumn{2}{|c|}{5,000} \\
\hline DB & Top & 2,252 & 257 & \multicolumn{2}{|c|}{5,000} \\
\hline DB (1) & North Interior & 2,099 & 78.4 & \multicolumn{2}{|c|}{5,000} \\
\hline DB (2) & South Interior & 2,020 & 52.3 & \multicolumn{2}{|c|}{5,000} \\
\hline DB (3) & West Interior & 2,286 & 45.4 & \multicolumn{2}{|c|}{5,000} \\
\hline DB (4) & East Interior & 2,163 & 39.2 & \multicolumn{2}{|c|}{5,000} \\
\hline DB (5) & Bottom & 2,952 & 6.5 & \multicolumn{2}{|c|}{5,000} \\
\hline
\end{tabular}

${ }^{a}$ NV/YMP Radiological Control Manual, Rev. 4 (DOE/NV, 2000a)

$\mathrm{dpm}=$ Disintegration(s) per minute $\mathrm{cm}^{2}=$ Square centimeter(s) 
Table A.13-3

Swipe Radiological Sample Analysis Results at CAS 26-05-01

\begin{tabular}{|c|c|c|c|c|c|}
\hline \multirow{2}{*}{$\begin{array}{l}\text { Location } \\
\text { Number }\end{array}$} & \multirow{2}{*}{$\begin{array}{l}\text { Sample } \\
\text { Location }\end{array}$} & \multicolumn{2}{|c|}{ Removable Contamination } & \multicolumn{2}{|c|}{ Unrestricted Release Criteria ${ }^{a}$} \\
\hline & & $\begin{array}{l}\text { Beta Activity } \\
\left(\text { dpm/100 cm }{ }^{2}\right)\end{array}$ & $\begin{array}{l}\text { Alpha Activity } \\
\left(\mathrm{dpm} / 100 \mathrm{~cm}^{2}\right)\end{array}$ & $\begin{array}{c}\text { Beta/Gamma } \\
\left(\mathrm{dpm} / 100 \mathrm{~cm}^{2}\right)\end{array}$ & $\begin{array}{c}\text { Alpha } \\
\text { (dpm/100 cm²) }\end{array}$ \\
\hline L34 & Pipe Interior & 6.3 & 15.6 & \multicolumn{2}{|c|}{1,000} \\
\hline L36 & Inside Leach Pipe & 38.2 & 14.1 & \multicolumn{2}{|c|}{1,000} \\
\hline L39 & Inside Leach Pipe & 117.0 & 70.9 & \multicolumn{2}{|c|}{1,000} \\
\hline L40 & Manhole 4 & $\begin{array}{c}4,997 \\
\left(2,043^{*}\right) \\
\left(1,291^{* *}\right)\end{array}$ & $\begin{array}{c}1,160 \\
\left(371^{*}\right) \\
\left(0^{* *}\right)\end{array}$ & \multicolumn{2}{|c|}{1,000} \\
\hline L40 & $\begin{array}{l}\text { Side Pipe to } \\
\text { Manhole }\end{array}$ & 49.2 & 7.1 & \multicolumn{2}{|c|}{1,000} \\
\hline L40 & Bottom of Manhole & 28.2 & 1.8 & \multicolumn{2}{|c|}{1,000} \\
\hline L40 & $\begin{array}{l}\text { Concrete Side } \\
\text { Bottom Manhole }\end{array}$ & 0.0 & 12.8 & \multicolumn{2}{|c|}{1,000} \\
\hline DB & North Interior & 0.0 & 9.6 & \multicolumn{2}{|c|}{1,000} \\
\hline DB & West Interior & 0.0 & 12.8 & \multicolumn{2}{|c|}{1,000} \\
\hline DB & East Interior & 0.0 & 6.4 & \multicolumn{2}{|c|}{1,000} \\
\hline DB & Bottom & 0.0 & 19.2 & \multicolumn{2}{|c|}{1,000} \\
\hline
\end{tabular}

${ }^{a}$ NV/YMP Radiological Control Manual, Rev. 4 (DOE/NV, 2000a)

* Large area swipe results after recounted one hour later.

** Large area swipe results recounted the next morning.

$\mathrm{dpm}=$ Disintegration(s) per minute

$\mathrm{cm}^{2}=$ Square centimeter(s)

unrestricted release criteria (Table A.13-3). Because an area larger than $100 \mathrm{~cm}^{2}$ was swiped, this result is considered an estimate and comparison to release criteria is not applicable.

\section{A.13.2.8 Sample Analysis}

Environmental soil, sediment, and associated QC samples were collected and analyzed for the CAIP-specified COPCs (i.e., total VOCs, total SVOCs, total RCRA metals, TPH [DRO and GRO], total beryllium, and PCBs). One-hundred percent of the soil and the associated QC samples were analyzed for Iso-Pu, Iso-U, Sr-90, and gamma-emitting radionuclides. 
The analytical parameters and laboratory analytical methods used to analyze the investigation samples are listed in Table A.2-2. Table A.13-1 lists the sample-specific analytical parameters.

\section{A.13.3 Analytes Detected Above Minimum Reporting Limits}

The soil sample analytical results with concentrations exceeding corresponding MRLs or PALs (DOE/NV, 1998; DOE/NV, 2001) at CAS 26-05-01 are summarized in the following sections. The results of manhole content samples are compared to appropriate regulatory levels for disposal. A portion of the CAS 26-05-01 analytical results were rejected during validation; however, these rejected data did not impact closure decisions as discussed in Section B.1.3.11 of Appendix B.

\section{A.13.3.1 Analytical Results for Soil Samples}

The following sections discuss the results for soil samples in comparison to the levels established in the Leachfield Work Plan and the CAIP.

\section{A.13.3.1.1 Total Volatile Organic Compounds}

Volatile organic compound results are reported in Table A.13-4. The only organic compound detected above the MRL of $5 \mu \mathrm{g} / \mathrm{kg}$ was acetone. The estimated concentration as designated by the "J" qualifier was $13 \mu \mathrm{g} / \mathrm{kg}$, below reporting limits for the laboratory. Acetone concentrations were below the PAL of $6,200,000 \mu \mathrm{g} / \mathrm{kg}$. Acetone is a common laboratory contaminant.

Table A.13-4

Soil Sample Results for Total VOCs

Detected Above Minimum Reporting Limits at CAS 26-05-01

\begin{tabular}{||c|c|c||}
\hline \multirow{2}{*}{$\begin{array}{c}\text { Sample } \\
\text { Identification } \\
\text { Number }\end{array}$} & $\begin{array}{c}\text { Depth } \\
(\mathrm{ft} \text { bgs })\end{array}$ & Contaminants of Potential Concern $(\mu \mathrm{g} / \mathrm{kg})$ \\
\cline { 3 - 3 } & & Acetone \\
\hline \multicolumn{2}{|c|}{ Preliminary Action Levels ${ }^{\mathrm{a}}$} & $\mathbf{6 , 2 0 0 , 0 0 0}$ \\
\hline \hline $271 \mathrm{~L} 008$ & $3-4$ & 13 \\
\hline
\end{tabular}

${ }^{a}$ Based on U.S. Environmental Protection Agency, Region 9 Preliminary Remediation Goals (PRGs) (EPA, 2000). 


\section{A.13.3.1.2 Total Semivolatile Organic Compounds}

Semivolatile organic compounds were not detected above MRLs in CAS 26-05-01 soil samples.

\section{A.13.3.1.3 Total Petroleum Hydrocarbons}

Total petroleum hydrocarbon values are presented in Table A.13-5. Samples 271L020, 271L021, and 271L050 reported TPH-DRO above the MRL of $25 \mathrm{mg} / \mathrm{kg}$. The concentrations for TPH compounds were below the PAL of $100 \mu \mathrm{g} / \mathrm{kg}$.

Table A.13-5

Soil Sample Results for TPH-DRO

Detected Above Minimum Reporting Limits at CAS 26-05-01

\begin{tabular}{|c|c|c|}
\hline \multirow{2}{*}{$\begin{array}{c}\text { Sample } \\
\text { Identification } \\
\text { Number }\end{array}$} & \multirow{2}{*}{$\begin{array}{l}\text { Depth } \\
\text { (ft bgs) }\end{array}$} & Contaminants of Potential Concern $(\mathrm{mg} / \mathrm{kg})$ \\
\hline & & Diesel Range Organics \\
\hline \multicolumn{2}{|c|}{ Preliminary Action Levels ${ }^{a}$} & 100 \\
\hline $271 \mathrm{~L} 020$ & $2.3-3.3$ & 32 \\
\hline $271 \mathrm{~L} 021$ & $2.3-3.3$ & 40 \\
\hline 271L050 & $2.8-3.8$ & 55 \\
\hline
\end{tabular}

aBased on Nevada Administrative Code; Contamination of Soil: Establishment of action levels (NAC, 2000)

\section{A.13.3.1.4 Total RCRA Metals}

As shown in Table A.13-6, the total RCRA metals detected in soil samples at concentrations exceeding the MRLs are arsenic (1 mg/kg), barium $(20 \mathrm{mg} / \mathrm{kg})$, chromium (1 mg/kg), lead $(0.3 \mathrm{mg} / \mathrm{kg})$, mercury $(0.1 \mathrm{mg} / \mathrm{kg})$, and silver $(1.0 \mathrm{mg} / \mathrm{kg})$. Other RCRA metals (i.e., cadmium, selenium) were below specified MRLs.

Barium concentrations ranged from 140 to $172 \mathrm{mg} / \mathrm{kg}$, chromium concentrations ranged from 2.8 to $6.9 \mathrm{mg} / \mathrm{kg}$, lead concentrations ranged from 5.7 to $12.4 \mathrm{mg} / \mathrm{kg}$, and mercury was detected in only one sample at a concentration of $0.13 \mathrm{mg} / \mathrm{kg}$. All reported concentrations of these metals were below EPA Region 9 PRGs defined in this document as PALs. 
Table A.13-6

Soil Sample Results for Total RCRA Metals

Detected Above Minimum Reporting Limits at CAS 26-05-01

\begin{tabular}{|c|c|c|c|c|c|c|c|}
\hline \multirow{2}{*}{$\begin{array}{c}\text { Sample } \\
\text { Identification } \\
\text { Number }\end{array}$} & \multirow{2}{*}{$\begin{array}{l}\text { Depth } \\
\text { (ft bgs) }\end{array}$} & \multicolumn{6}{|c|}{ Contaminants of Potential Concern (mg/kg) } \\
\hline & & Arsenic & Barium & Chromium & Lead & Mercury & Silver \\
\hline 271L002 & $5-6$ & $9.31(J)$ & 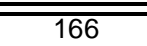 & $5.82(\mathrm{~J})$ & 10.3 & $\overline{---}$ & -- \\
\hline 271L004 & $2.25-3.25$ & $6.66(\mathrm{~J})$ & 159 & $4.86(\mathrm{~J})$ & 9.89 & -- & $\begin{array}{l}- \\
-\end{array}$ \\
\hline 271L008 & $3-4$ & $8.37(J)$ & 145 & $5.7(\mathrm{~J})$ & 9.87 & -- & -- \\
\hline 271L010 & $3.2-4.2$ & $7.24(J)$ & 148 & $6(\mathrm{~J})$ & 9.13 & -- & -- \\
\hline 271L012 & $2.5-3.5$ & $8.94(\mathrm{~J})$ & 151 & $7.5(\mathrm{~J})$ & 10.6 & -- & -- \\
\hline 271L014 & $3.2-4.2$ & $7.27(\mathrm{~J})$ & 103 & $3.89(\mathrm{~J})$ & 7.57 & -- & -- \\
\hline 271L016 & $2.5-3.5$ & $6.69(\mathrm{~J})$ & 136 & $5.28(\mathrm{~J})$ & 10.4 & -- & -- \\
\hline 271L023 & $2.8-3.8$ & $8.12(\mathrm{~J})$ & 174 & $6.65(\mathrm{~J})$ & 11.6 & & 3.47 \\
\hline 271L025 & $2.75-3.75$ & $9.25(\mathrm{~J})$ & 148 & $5.09(\mathrm{~J})$ & 8.1 & -- & -- \\
\hline 271L027 & $2.75-3.75$ & $11.4(\mathrm{~J})$ & 151 & 3.57 & 5.66 & -- & -- \\
\hline 271L029 & $2.75-3.75$ & $10.2(\mathrm{~J})$ & 134 & $4.63(\mathrm{~J})$ & 7.27 & -- & -- \\
\hline 271L031 & $2.9-3.9$ & 8.97 & 175 & 7.29 & 9.49 & -- & -- \\
\hline 271L033 & $2.75-3.75$ & 9.02 & 146 & 9.2 & 11.5 & -- & -- \\
\hline 271L035 & $2.75-3.75$ & 7.77 & 157 & 5.12 & 10.4 & -- & -- \\
\hline 271L037 & $2.75-3.75$ & 8.66 & 175 & 6.26 & 13.3 & -- & -- \\
\hline 271L039 & $2.3-3.3$ & 9.02 & 191 & 6.35 & 11.4 & -- & -- \\
\hline 271L052 & $2.75-3.75$ & 7.06 & 104 & 3.28 & 6.44 & -- & -- \\
\hline 271L054 & $2.4-3.4$ & 7.63 & 140 & 6.23 & 9.07 & -- & -- \\
\hline 271L056 & $2.75-3.75$ & 7.36 & 140 & 5.56 & 10.6 & -- & -- \\
\hline 271L058 & $2.75-3.75$ & 6.01 & 115 & 3.96 & 9.57 & -- & -- \\
\hline 271L060 & $2.5-3.5$ & 6.46 & 156 & 5.22 & 9.83 & -- & -- \\
\hline 271L062 & $2.4-3.4$ & 8.98 & 172 & 6.88 & 12.4 & -- & -- \\
\hline 271L064 & $2.75-3.75$ & 7.54 & 149 & 5.14 & 11.2 & -- & -- \\
\hline
\end{tabular}

aased on U.S. Environmental Protection Agency, Region 9 Preliminary Remediation Goals (PRGs) (EPA, 2000).

-- = Not detected above minimum reporting limits.

$\mathrm{J}=$ Estimated value. Qualifier added to laboratory report; record accepted. Inductively coupled plasma serial dilution recovery was not met. 
Arsenic concentrations ranged from 6.0 to $11.9 \mathrm{mg} / \mathrm{kg}$. All arsenic concentrations in soil from CAS 26-05-01 exceeded the PAL of $2.7 \mathrm{mg} / \mathrm{kg}$. Arsenic concentrations were consistent across the site, with no "hot spots" or evidence of a localized spill. The PAL is lower than the 7 to $8 \mathrm{mg} / \mathrm{kg}$ mean concentration of arsenic in silt from the Nevada Test and Training Range (NBMG, 1998; Moore, 1999). Although arsenic concentrations in the soil exceed the PAL, it is believed that these concentrations are within ambient conditions for CAS 26-05-01 and do not represent contamination.

\section{A.13.3.1.5 Total Beryllium}

Total beryllium was not detected above MRLS in CAS 26-05-01 soil samples.

\section{A.13.3.1.6 Polychlorinated Biphenyls}

Polychlorinated biphenyls were not detected above MRLs in CAS 26-05-01 soil samples.

\section{A.13.3.1.7 Gamma Spectrometry Results}

Results of soil sample gamma spectrometry analysis are presented in Table A.13-7. Concentrations of actinium-228, bismuth-212, bismuth-214, lead-212, lead-214, potassium-40, and thallium-208 were detected above the MDLs. The TPU in the radioanalytical measurement is provided in the table along with the concentration for all detected gamma emitters. The concentrations of the detected gamma-emitting radionuclides are below PALs and are not significantly different than concentrations measured in soil samples collected from undisturbed background locations.

\section{A.13.3.1.8 Isotopic Uranium}

Detected values of uranium isotopes, along with associated TPUs are reported in Table A.13-8. Results for U-234 and U-235 were above PALs in several soil samples; therefore, a normalized difference based on a confidence level of 95 percent was used to determine if the concentrations were statistically distinguishable from background. One sample, 271L021, was identified to have U-234 and U-235 in concentrations that were significantly greater than concentrations in soil samples collected from undisturbed background locations. 
Table A.13-7

Soil Sample Results for Gamma-Emitting Radionuclides Detected Above Minimum Reporting Limits at CAS 26-05-01

(Page 1 of 2)

\begin{tabular}{|c|c|c|c|c|c|c|c|c|c|}
\hline \multirow{2}{*}{$\begin{array}{c}\text { Sample } \\
\text { Identification } \\
\text { Number }\end{array}$} & \multirow{2}{*}{$\begin{array}{l}\text { Depth } \\
\text { (ft bgs) }\end{array}$} & \multicolumn{8}{|c|}{ Contaminants of Potential Concern $(\mathrm{pCi} / \mathrm{g})$} \\
\hline & & Actinium-228 ${ }^{a}$ & Bismuth-212 ${ }^{\mathrm{b}}$ & Bismuth-214 ${ }^{b}$ & Cesium-137 & Lead-212 $^{\mathrm{a}}$ & Lead-214 ${ }^{b}$ & Potassium-40 & Thallium-208 ${ }^{a}$ \\
\hline \multicolumn{2}{|c|}{ Preliminary Action Level } & 3.64 & 2.4 & 3.47 & 7.0 & 2.9 & 2.9 & 96 & 3.4 \\
\hline 271L002 & $5-6$ & $1.33 \pm 0.28$ & $1.5 \pm 0.64$ & $0.98 \pm 0.21$ & -- & $1.56 \pm 0.29$ & $0.99 \pm 0.20$ & $29 \pm 5.0$ & $0.425 \pm 0.095$ \\
\hline 271L004 & $2.25-3.25$ & $1.19 \pm 0.32$ & -- & $0.83 \pm 0.22$ & -- & $1.77 \pm 0.34$ & $1.15 \pm 0.25$ & $28.3 \pm 5.3$ & $0.45 \pm 0.11$ \\
\hline 271L006 & $2.25-3.25$ & $1.39 \pm 0.37$ & -- & $1 \pm 0.27$ & -- & $1.53 \pm 0.31$ & $0.95 \pm 0.23$ & $24.6 \pm 4.9$ & $0.4 \pm 0.12$ \\
\hline 271L008 & $3-4$ & $1.4 \pm 0.36$ & -- & $0.63 \pm 0.21$ & -- & $1.68 \pm 0.33$ & $0.98 \pm 0.23$ & $22.3 \pm 4.5$ & $0.48 \pm 0.13$ \\
\hline 271L010 & $3.2-4.2$ & $1.25 \pm 0.26$ & $\overline{--}$ & $1 \pm 0.21$ & -- & $1.42 \pm 0.26$ & $0.98 \pm 0.19$ & $26.8 \pm 4.7$ & $0.427 \pm 0.094$ \\
\hline 271L012 & $2.5-3.5$ & $1.33 \pm 0.34$ & -- & $0.99 \pm 0.25$ & -- & $1.67 \pm 0.33$ & $0.97 \pm 0.22$ & $25.5 \pm 4.8$ & $0.53 \pm 0.13$ \\
\hline 271L014 & $3.2-4.2$ & $1.42 \pm 0.30$ & -- & $1.29 \pm 0.26$ & -- & $1.55 \pm 0.29$ & $1.36 \pm 0.26$ & $26.3 \pm 4.6$ & $0.47 \pm 0.10$ \\
\hline 271L016 & $2.5-3.5$ & $1.52 \pm 0.38$ & -- & $1.54 \pm 0.34$ & -- & $1.44 \pm 0.30$ & $1.6 \pm 0.33$ & $22 \pm 4.3$ & $0.37 \pm 0.11$ \\
\hline 271L018 & $3.3-4.3$ & $1.12 \pm 0.33$ & -- & $1.28 \pm 0.32$ & -- & $1.24 \pm 0.27$ & $1.4 \pm 0.30$ & $21.2 \pm 4.4$ & $0.32 \pm 0.12$ \\
\hline 271L020 & $2.3-3.3$ & $1.2 \pm 0.33$ & $\begin{array}{l}- \\
-\end{array}$ & $1.46 \pm 0.33$ & $0.41 \pm 0.13$ & $1.18 \pm 0.26$ & $1.34 \pm 0.28$ & $18.9 \pm 3.9$ & $0.41 \pm 0.12$ \\
\hline 271L021 & $2.3-3.3$ & $1.05 \pm 0.24$ & -- & $1.42 \pm 0.28$ & $0.54 \pm 0.12$ & $1.24 \pm 0.24$ & $1.68 \pm 0.31$ & $19.7 \pm 3.5$ & $0.47 \pm 0.11$ \\
\hline 271L023 & $2.8-3.8$ & $1.49 \pm 0.36$ & -- & $1.13 \pm 0.28$ & $0.43 \pm 0.13$ & $1.53 \pm 0.31$ & $1.32 \pm 0.28$ & $24.8 \pm 4.8$ & $0.47 \pm 0.13$ \\
\hline 271L025 & $2.75-3.75$ & $1.17 \pm 0.33$ & -- & $1.32 \pm 0.32$ & -- & $1.36 \pm 0.29$ & $1.26 \pm 0.28$ & $19.3 \pm 4.1$ & $0.39 \pm 0.12$ \\
\hline 271L027 & $2.75-3.75$ & $0.77 \pm 0.21$ & -- & $2.25 \pm 0.42$ & -- & $1 \pm 0.21$ & $2.36 \pm 0.42$ & $18.1 \pm 3.4$ & $0.294 \pm 0.079$ \\
\hline 271L029 & $2.75-3.75$ & $1.24 \pm 0.32$ & -- & $1.11 \pm 0.26$ & -- & $1.45 \pm 0.29$ & $1.27 \pm 0.27$ & $22.9 \pm 4.4$ & $0.49 \pm 0.12$ \\
\hline 271L031 & $2.9-3.9$ & $1.34 \pm 0.36$ & -- & $0.88 \pm 0.27$ & -- & $1.59 \pm 0.32$ & $1.12 \pm 0.25$ & $23.7 \pm 4.9$ & $0.53 \pm 0.15$ \\
\hline 271L033 & $2.75-3.75$ & $1.39 \pm 0.36$ & -- & $0.85 \pm 0.25$ & -- & $1.86 \pm 0.37$ & $0.86 \pm 0.21$ & $24.5 \pm 4.9$ & $0.54 \pm 0.14$ \\
\hline 271L035 & $2.75-3.75$ & $1.57 \pm 0.33$ & -- & $0.89 \pm 0.21$ & -- & $1.73 \pm 0.32$ & $1 \pm 0.21$ & $27.5 \pm 4.8$ & $0.46 \pm 0.10$ \\
\hline 271L037 & $2.75-3.75$ & $1.62 \pm 0.32$ & -- & $0.92 \pm 0.19$ & -- & $1.63 \pm 0.30$ & $1.13 \pm 0.22$ & $29 \pm 5.0$ & $0.49 \pm 0.10$ \\
\hline 271L039 & $2.3-3.3$ & $1.57 \pm 0.36$ & -- & $0.93 \pm 0.24$ & -- & $1.48 \pm 0.29$ & $1.05 \pm 0.23$ & $25.6 \pm 4.8$ & $0.58 \pm 0.14$ \\
\hline 271L041 & $2.75-3.75$ & $1.45 \pm 0.36$ & -- & $1.02 \pm 0.27$ & -- & $1.55 \pm 0.31$ & $0.99 \pm 0.23$ & $24.8 \pm 4.9$ & $0.53 \pm 0.14$ \\
\hline 271L043 & $2.75-3.75$ & $1.68 \pm 0.39$ & -- & $1.08 \pm 0.27$ & -- & $1.48 \pm 0.30$ & $1.01 \pm 0.23$ & $25.3 \pm 4.8$ & $0.5 \pm 0.13$ \\
\hline
\end{tabular}


Table A.13-7

Soil Sample Results for Gamma-Emitting Radionuclides Detected Above Minimum Reporting Limits at CAS 26-05-01

(Page 2 of 2)

\begin{tabular}{|c|c|c|c|c|c|c|c|c|c|}
\hline \multirow{2}{*}{$\begin{array}{c}\text { Sample } \\
\text { Identification } \\
\text { Number }\end{array}$} & \multirow{2}{*}{$\begin{array}{c}\text { Depth } \\
\text { (ft bgs) }\end{array}$} & \multicolumn{8}{|c|}{ Contaminants of Potential Concern (pCi/g) } \\
\hline & & Actinium-228 ${ }^{a}$ & Bismuth-212 ${ }^{\mathrm{b}}$ & Bismuth-214 ${ }^{\mathrm{b}}$ & Cesium-137 & Lead-212 $^{\mathrm{a}}$ & Lead-214 ${ }^{b}$ & Potassium-40 & Thallium-208 \\
\hline \multicolumn{2}{|c|}{ Preliminary Action Level } & 3.64 & 2.4 & 3.47 & 7.0 & 2.9 & 2.9 & 96 & 3.4 \\
\hline 271L045 & $2.75-3.75$ & $1.1 \pm 0.25$ & -- & $1.42 \pm 0.28$ & -- & $1.25 \pm 0.25$ & $1.5 \pm 0.28$ & $20.1 \pm 3.6$ & $0.43 \pm 0.10$ \\
\hline 271L046 & $2.75-3.75$ & $1.29 \pm 0.34$ & -- & $1.49 \pm 0.33$ & -- & $1.2 \pm 0.26$ & $1.57 \pm 0.32$ & $19.4 \pm 3.9$ & $0.44 \pm 0.12$ \\
\hline 271L048 & $2.7-3.7$ & $1.12 \pm 0.36$ & -- & $1.29 \pm 0.32$ & -- & $1.38 \pm 0.29$ & $1.3 \pm 0.28$ & $20.5 \pm 4.3$ & $0.39 \pm 0.12$ \\
\hline 271L050 & $2.8-3.8$ & -- & -- & $1.31 \pm 0.32$ & -- & $1.01 \pm 0.23$ & $1.25 \pm 0.28$ & $11.5 \pm 2.7$ & -- \\
\hline 271L052 & $2.75-3.75$ & $1.15 \pm 0.28$ & $\begin{array}{l}- \\
-\end{array}$ & $1.4 \pm 0.29$ & -- & $1.32 \pm 0.26$ & $1.69 \pm 0.31$ & $20.7 \pm 3.7$ & $0.39 \pm 0.094$ \\
\hline 271L054 & $2.4-3.4$ & $1.43 \pm 0.31$ & -- & $1.1 \pm 0.23$ & -- & $1.6 \pm 0.30$ & $1.12 \pm 0.22$ & $23.3 \pm 4.1$ & $0.45 \pm 0.10$ \\
\hline 271L056 & $2.75-3.75$ & $1.54 \pm 0.37$ & -- & $0.83 \pm 0.22$ & -- & $1.79 \pm 0.35$ & $1.01 \pm 0.23$ & $23.9 \pm 4.6$ & $0.61 \pm 0.14$ \\
\hline 271L058 & $2.75-3.75$ & $1.46 \pm 0.36$ & -- & $0.97 \pm 0.26$ & -- & $1.61 \pm 0.32$ & $0.97 \pm 0.22$ & $24 \pm 4.7$ & $0.51 \pm 0.13$ \\
\hline 271L060 & $2.5-3.5$ & $1.24 \pm 0.27$ & -- & $1 \pm 0.21$ & -- & $1.57 \pm 0.29$ & $1.05 \pm 0.20$ & $27.5 \pm 4.8$ & $0.51 \pm 0.11$ \\
\hline 271L062 & $2.4-3.4$ & $1.35 \pm 0.35$ & -- & $1.03 \pm 0.25$ & -- & $1.71 \pm 0.33$ & $1.2 \pm 0.26$ & $28.5 \pm 5.3$ & $0.59 \pm 0.14$ \\
\hline 271L064 & $2.75-3.75$ & $1.26 \pm 0.33$ & -- & $0.98 \pm 0.26$ & -- & $1.7 \pm 0.33$ & $1.03 \pm 0.23$ & $26 \pm 5.1$ & $0.47 \pm 0.12$ \\
\hline
\end{tabular}

aBackground concentration listed in Environmental Monitoring Report for the Proposed Ward Valley, California, Low-Level Radioactive Waste (LLRW) Facility (US Ecology and Atlan-Tech, 1992)

${ }^{\mathrm{b} B a c k g r o u n d}$ concentration listed or derived in Off-Site Radiation Exposure Review Project, Phase II Soil Program (McArthur and Miller, 1989).

-- = Not detected above minimum reporting limit 
Table A.13-8

Soil Sample Results for Isotopic Plutonium and Uranium Detected Above Minimum Reporting Limits at CAS 26-05-01

(Page 1 of 2)

\begin{tabular}{|c|c|c|c|c|c|}
\hline \multirow{2}{*}{$\begin{array}{c}\text { Sample } \\
\text { Identification } \\
\text { Number }\end{array}$} & \multirow{2}{*}{$\begin{array}{l}\text { Depth } \\
\text { (ft bgs) }\end{array}$} & \multicolumn{4}{|c|}{ Contaminants of Potential Concern $(\mathrm{pCi} / \mathrm{g})$} \\
\hline & & Plutonium-239 & Uranium-234 ${ }^{a}$ & Uranium-235 ${ }^{a}$ & Uranium-238 ${ }^{\text {b }}$ \\
\hline \multicolumn{2}{|c|}{ Preliminary Action Levels } & 0.24 & 1.56 & 0.07 & 3.2 \\
\hline 271L002 & $5-6$ & -- & $1.02 \pm 0.18$ & -- & $0.89 \pm 0.16$ \\
\hline 271L004 & $2.25-3.25$ & -- & $0.83 \pm 0.15$ & $0.072 \pm 0.032$ & $0.84 \pm 0.15$ \\
\hline 271L006 & $2.25-3.25$ & -- & $0.97 \pm 0.19$ & $\overline{--}$ & $0.93 \pm 0.18$ \\
\hline 271L008 & $3-4$ & -- & $0.97 \pm 0.17$ & $0.093 \pm 0.037$ & $0.97 \pm 0.17$ \\
\hline 271L010 & $3.2-4.2$ & -- & $1.06 \pm 0.18$ & $0.057 \pm 0.030$ & $1.04 \pm 0.18$ \\
\hline 271L012 & $2.5-3.5$ & -- & $0.92 \pm 0.16$ & $0.063 \pm 0.030$ & $1.04 \pm 0.18$ \\
\hline 271L014 & $3.2-4.2$ & -- & $1.46 \pm 0.24$ & $0.115 \pm 0.044$ & $1.5 \pm 0.24$ \\
\hline 271L016 & $2.5-3.5$ & -- & $1.91 \pm 0.31$ & $0.16 \pm 0.055$ & $1.91 \pm 0.30$ \\
\hline 271L018 & $3.3-4.3$ & -- & $1.74 \pm 0.28$ & $0.12 \pm 0.046$ & $1.48 \pm 0.25$ \\
\hline $271 \mathrm{~L} 020$ & $2.3-3.3$ & $0.6 \pm 0.11$ & $2.78 \pm 0.41$ & $0.169 \pm 0.052$ & $1.8 \pm 0.28$ \\
\hline 271L021 & $2.3-3.3$ & $0.49 \pm 0.10$ & $4.81 \pm 0.68$ & $0.262 \pm 0.070$ & $1.78 \pm 0.28$ \\
\hline 271L023 & $2.8-3.8$ & $0.81 \pm 0.16$ & $2.87 \pm 0.42$ & $0.136 \pm 0.047$ & $1.15 \pm 0.20$ \\
\hline 271L025 & $2.75-3.75$ & -- & $1.68 \pm 0.26$ & $0.089 \pm 0.037$ & $1.5 \pm 0.24$ \\
\hline $271 \mathrm{~L} 027$ & $2.75-3.75$ & -- & $2.72 \pm 0.43$ & $0.108 \pm 0.048$ & $2.4 \pm 0.39$ \\
\hline 271L029 & $2.75-3.75$ & -- & $1.83 \pm 0.29$ & $0.124 \pm 0.047$ & $1.69 \pm 0.27$ \\
\hline 271L031 & $2.9-3.9$ & -- & $0.96 \pm 0.18$ & -- & $1.11 \pm 0.20$ \\
\hline 271L033 & $2.75-3.75$ & -- & $1 \pm 0.18$ & $0.05 \pm 0.029(\mathrm{LT})$ & $0.93 \pm 0.17$ \\
\hline 271L035 & $2.75-3.75$ & -- & $0.93 \pm 0.17$ & -- & $0.87 \pm 0.16$ \\
\hline 271L037 & $2.75-3.75$ & $0.067 \pm 0.034$ & $1.02 \pm 0.18$ & $0.055 \pm 0.031$ & $1.05 \pm 0.19$ \\
\hline 271L039 & $2.3-3.3$ & -- & $1.09 \pm 0.19$ & $0.077 \pm 0.037$ & $1.02 \pm 0.18$ \\
\hline 271L041 & $2.75-3.75$ & $0.323 \pm 0.083$ & $0.91 \pm 0.18$ & -- & $1.02 \pm 0.19$ \\
\hline 271L043 & $2.75-3.75$ & -- & $0.98 \pm 0.19$ & $0.104 \pm 0.046$ & $1.01 \pm 0.19$ \\
\hline 271L045 & $2.75-3.75$ & $\begin{array}{l}- \\
-\end{array}$ & $1.69 \pm 0.27$ & $0.102 \pm 0.042$ & $1.62 \pm 0.26$ \\
\hline $271 \mathrm{~L} 046$ & $2.75-3.75$ & $0.053 \pm 0.030$ & $1.93 \pm 0.31$ & $0.108 \pm 0.043$ & $1.81 \pm 0.29$ \\
\hline 271L048 & $2.7-3.7$ & $0.214 \pm 0.068$ & $1.82 \pm 0.31$ & $0.101 \pm 0.046$ & $1.62 \pm 0.28$ \\
\hline 271L050 & $2.8-3.8$ & $0.428 \pm 0.098$ & $2.07 \pm 0.33$ & $0.077 \pm 0.038$ & $1.67 \pm 0.28$ \\
\hline 271L052 & $2.75-3.75$ & -- & $2.05 \pm 0.32$ & $0.145 \pm 0.051$ & $1.7 \pm 0.28$ \\
\hline 271L054 & $2.4-3.4$ & $0.145 \pm 0.048$ & $1.17 \pm 0.20$ & -- & $1.01 \pm 0.18$ \\
\hline 271L056 & $2.75-3.75$ & $\begin{array}{l}- \\
-\end{array}$ & $0.99 \pm 0.19$ & $\begin{array}{l}- \\
-\end{array}$ & $1.1 \pm 0.21$ \\
\hline 271L058 & $2.75-3.75$ & -- & $1.04 \pm 0.19$ & $0.068 \pm 0.034$ & $1.05 \pm 0.19$ \\
\hline 271L060 & $2.5-3.5$ & -- & $1.01 \pm 0.18$ & -- & $0.99 \pm 0.18$ \\
\hline 271L062 & $2.4-3.4$ & -- & $0.87 \pm 0.17$ & $\overline{--}$ & $0.81 \pm 0.16$ \\
\hline
\end{tabular}


Table A.13-8

Soil Sample Results for Isotopic Plutonium and Uranium Detected Above Minimum Reporting Limits at CAS 26-05-01

(Page 2 of 2)

\begin{tabular}{|c|c|c|c|c|c|}
\hline \multirow{2}{*}{$\begin{array}{c}\text { Sample } \\
\text { Identification } \\
\text { Number }\end{array}$} & \multirow{2}{*}{$\begin{array}{l}\text { Depth } \\
\text { (ft bgs) }\end{array}$} & \multicolumn{4}{|c|}{ Contaminants of Potential Concern $(\mathrm{pCi} / \mathrm{g})$} \\
\hline & & Plutonium-239 & Uranium-234 ${ }^{\mathrm{a}}$ & Uranium-235 ${ }^{a}$ & Uranium-238 ${ }^{\mathrm{b}}$ \\
\hline \multicolumn{2}{|c|}{ Preliminary Action Levels } & 0.24 & 1.56 & 0.07 & 3.2 \\
\hline 271L064 & $2.75-3.75$ & -- & $1 \pm 0.18$ & -- & $0.96 \pm 0.17$ \\
\hline 271L201 & $6.5-7$ & -- & $1.11 \pm 0.2$ & $0.065 \pm 0.035$ & $0.98 \pm 0.18$ \\
\hline 271L202 & $7.25-7.7$ & -- & $1.45 \pm 0.24$ & -- & $1.29 \pm 0.22$ \\
\hline 271L203 & $7-7.5$ & -- & $1.55 \pm 0.26$ & $0.145 \pm 0.052$ & $1.49 \pm 0.25$ \\
\hline 271L204 & $10-10.5$ & -- & $0.99 \pm 0.17$ & $0.069 \pm 0.032$ & $0.95 \pm 0.17$ \\
\hline
\end{tabular}

${ }^{a}$ Background concentration listed in Environmental Monitoring Report for the Proposed Ward Valley, California, Low-Level Radioactive Waste (LLRW) Facility (US Ecology and Atlan-Tech, 1992).

${ }^{b}$ Background concentration listed or derived in Off-Site Radiation Exposure Review Project, Phase II Soil Program (McArthur and Miller, 1989).

$L T=$ Result is less than requested MDC, greater than sample-specific MDC

$--=$ Not detected above minimum reporting limit

\section{A.13.3.1.9 Isotopic Plutonium}

Detected values of plutonium isotopes, along with associated TPUs are reported in Table A.13-8. Results for Pu-239 were above PALs for sample numbers 271L020, 271L021, 271L023, 271L041, and 271L050. A normalized difference based on a confidence level of 95 percent was used to determine if the concentrations were statistically distinguishable from background. Samples 271L020, 271L021, and 271L023 were identified to have Pu-239 in concentrations that were significantly greater than concentrations in soil samples collected from undisturbed background locations. Based on these data and elevated uranium detections in sample 271L021, additional soil samples were collected and analyzed for Iso-Pu and Iso-U (Section A.13.2.4).

\section{A.13.3.1.10 Strontium-90}

Strontium-90 was not detected above MRLs in CAS 26-05-01 soil samples. 


\section{A.13.3.2 Manhole 1 Sample Results}

Results of a sediment sample collected at Manhole 1 were compared to regulatory levels based on disposal options. If the waste has no hazardous component, the regulatory level is based on disposal options at NTS landfills and lagoons (BN, 1995; CFR, 2000b and c; NDEP, 1997a, b, and c). Any sludge or liquid waste will be solidified before disposal at NTS landfills (NDEP, 1997b). If the waste is hazardous, the release criteria are based on interpretation of the guidelines presented in the POC (BN, 1995; Alderson, 1999). For waste destined for off-site disposal, the POC radiological levels must be met to certify that the waste has no radioactivity added.

One sediment sample was obtained for Manhole 1. The analytical suite followed the CAIP and is detailed in Section A.13.2.8. Analytical results exceeding MRLs are listed in Table A.13-9.

Several COPCs were detected in the sediment sample (271L067) from the manhole. Most COPCs were below regulatory limits except for TPH DRO at a concentration of $120 \mathrm{mg} / \mathrm{kg}$, which exceeds the NDEP action level of $100 \mathrm{mg} / \mathrm{kg}$ (NAC, 2000) for TPH. Cesium-137, Pu-239, U-234, and U-235 were also detected above the POC unrestricted release.

\section{A.13.4 Contaminants of Concern}

Based on the aforementioned analytical results, COCs are present in sediment at Manhole 1 and the soil near the distribution box in the leachfield. Manhole 1 contains sediment with TPH, cesium-137, $\mathrm{Pu}-239, \mathrm{U}-234$, and U-235 in concentrations of concern, and the TPH concentration exceeds the NDEP action level. Soil in the leachfield at biased sample locations L03 and L04 (Figure A.13-1) contain $\mathrm{Pu}-239$, U-234, and U-235 in concentrations above PALs.

\section{A.13.5 Nature and Extent of Contamination}

In a small area of the leachfield immediately south of the distribution box, Pu-239, U-234, and U-235 contamination is present in soil. Approximately $24 \mathrm{yd}^{3}$ of contaminated soil were identified. Approximately 10 gal of sediment contaminated with TPH-DRO, U-234, and cesium-137 are present in Manhole 1. As discussed in Section A.13.2.7, other parts of the collection system do not exceed limits for unrestricted release criteria (DOE/NV, 2000a). In addition to Manhole 1, an exception to 
Table A.13-9

\section{Manhole Sediment Sample Results Detected Above Minimum Reporting Limits at CAS 26-05-01}

(Page 1 of 2 )

\begin{tabular}{|c|c|c|c|c|c|c|}
\hline $\begin{array}{c}\text { Sample } \\
\text { Identification } \\
\text { Number }\end{array}$ & Matrix & Parameter & Result & Units & Limits & Reference \\
\hline 271L067 & Sediment & Mercury $^{\star \star}$ & 0.57 & $\mathrm{mg} / \mathrm{kg}$ & NA & CFR, 2000a \\
\hline 271L067 & Sediment & Arsenic** & 9.5 & $\mathrm{mg} / \mathrm{kg}$ & NA & CFR, 2000a \\
\hline 271L067 & Sediment & Barium** & $510(\mathrm{~J})^{\mathrm{a}}$ & $\mathrm{mg} / \mathrm{kg}$ & NA & CFR, 2000a \\
\hline 271L067 & Sediment & Cadmium & 9 & $\mathrm{mg} / \mathrm{kg}$ & NA & CFR, 2000a \\
\hline 271L067 & Sediment & TCLP Cadmium & 0.071 & $\mathrm{mg} / \mathrm{L}$ & 1 & CFR, 2000a \\
\hline 271L067 & Sediment & Chromium** & $71(\mathrm{~J})^{\mathrm{a}}$ & $\mathrm{mg} / \mathrm{kg}$ & NA & CFR, 2000a \\
\hline 271L067 & Sediment & Lead & $270(\mathrm{~J})^{\mathrm{a}}$ & $\mathrm{mg} / \mathrm{kg}$ & NA & CFR, 2000a \\
\hline 271L067 & Sediment & TCLP Lead & 0.39 & $\mathrm{mg} / \mathrm{L}$ & 5 & CFR, 2000a \\
\hline 271L067 & Sediment & Silver ${ }^{* *}$ & 34 & $\mathrm{mg} / \mathrm{kg}$ & NA & CFR, 2000a \\
\hline 271L067 & Sediment & Strontium-90 & $2.25 \pm 0.48$ & $\mathrm{pCi} / \mathrm{g}$ & 3 & BN, 1995 \\
\hline 271L067 & Sediment & Diesel-Range Organics & $120(M)$ & $\mathrm{mg} / \mathrm{kg}$ & 100 & NAC, 1997 \\
\hline 271L067 & Sediment & Acetone & $4,100(J)^{b}$ & $\mu \mathrm{g} / \mathrm{kg}$ & NA & CFR, 2000a \\
\hline 271L067 & Sediment & Anthracene & 700 & $\mu \mathrm{g} / \mathrm{kg}$ & NA & CFR, 2000a \\
\hline 271L067 & Sediment & Benzo(A)Anthracene & 1,600 & $\mu \mathrm{g} / \mathrm{kg}$ & NA & CFR, 2000a \\
\hline 271L067 & Sediment & Benzo(A)Pyrene & $1,500(J)^{c}$ & $\mu \mathrm{g} / \mathrm{kg}$ & NA & CFR, 2000a \\
\hline 271L067 & Sediment & Benzo(B)Fluoranthene & $1,600(J)^{c}$ & $\mu \mathrm{g} / \mathrm{kg}$ & NA & CFR, 2000a \\
\hline 271L067 & Sediment & Benzo(G,H,I)Perylene & $1,200(J)^{c}$ & $\mu \mathrm{g} / \mathrm{kg}$ & NA & CFR, 2000a \\
\hline 271L067 & Sediment & Benzo(K)Fluoranthene & $720(J)^{c}$ & $\mu \mathrm{g} / \mathrm{kg}$ & NA & CFR, 2000a \\
\hline 271L067 & Sediment & Chrysene & 1,800 & $\mu \mathrm{g} / \mathrm{kg}$ & NA & CFR, 2000a \\
\hline 271L067 & Sediment & Fluoranthene & 2,600 & $\mu \mathrm{g} / \mathrm{kg}$ & NA & CFR, 2000a \\
\hline 271L067 & Sediment & Indeno(1,2,3-CD)Pyrene & $1,100(J)^{c}$ & $\mu \mathrm{g} / \mathrm{kg}$ & $\overline{N A}$ & CFR, 2000a \\
\hline 271L067 & Sediment & Phenanthrene & 2,700 & $\mu \mathrm{g} / \mathrm{kg}$ & NA & CFR, 2000a \\
\hline $271 \mathrm{~L} 067$ & Sediment & Pyrene & $5,200(J)^{d}$ & $\mu \mathrm{g} / \mathrm{kg}$ & NA & CFR, 2000a \\
\hline 271L067 & Sediment & Di-N-Butyl Phthalate & 11,000 & $\mu \mathrm{g} / \mathrm{kg}$ & NA & CFR, 2000a \\
\hline 271L067 & Sediment & Actinium-228 & $1.47 \pm 0.61$ & $\mathrm{pCi} / \mathrm{g}$ & - & $\mathrm{E}$ \\
\hline 271L067 & Sediment & Cobalt-60 & $2.91 \pm 0.53$ & $\mathrm{pCi} / \mathrm{g}$ & 500 & BN, 1995 \\
\hline 271L067 & Sediment & Cesium-137 & $114 \pm 19$ & $\mathrm{pCi} / \mathrm{g}$ & 3 & BN, 1995 \\
\hline 271L067 & Sediment & Potassium-40 & $22.1 \pm 4.5$ & $\mathrm{pCi} / \mathrm{g}$ & - & $E$ \\
\hline 271L067 & Sediment & Lead-212 & $1.18 \pm 0.40$ & $\mathrm{pCi} / \mathrm{g}$ & - & $E$ \\
\hline 271L067 & Sediment & Uranium-235 & $7.3 \pm 1.6$ & $\mathrm{pCi} / \mathrm{g}$ & 0.1614 & BN, 1995 \\
\hline $271 L 067$ & Sediment & Uranium-234 & $160 \pm 21$ & $\mathrm{pCi} / \mathrm{g}$ & 0.932 & BN, 1995 \\
\hline 271L067 & Sediment & Uranium-235 & $4.62 \pm 0.64(\mathrm{~J})^{\mathrm{e}}$ & $\mathrm{pCi} / \mathrm{g}$ & 0.1614 & BN, 1995 \\
\hline 271L067 & Sediment & Uranium-238 & $1.23 \pm 0.20$ & $\mathrm{pCi} / \mathrm{g}$ & 10 & BN, 1995 \\
\hline
\end{tabular}


Table A.13-9

\section{Manhole Sediment Sample Results Detected Above Minimum Reporting Limits at CAS 26-05-01}

(Page 2 of 2 )

\begin{tabular}{|c|c|c|c|c|c|c|}
\hline $\begin{array}{c}\text { Sample } \\
\text { Identification } \\
\text { Number }\end{array}$ & Matrix & Parameter & Result & Units & Limits & Reference \\
\hline 271L067 & Sediment & Plutonium-238 & $0.097 \pm 0.038$ & $\mathrm{pCi} / \mathrm{g}$ & 10 & BN, 1995 \\
\hline 271L067 & Sediment & Plutonium-239 & $7.4 \pm 1.1$ & $\mathrm{pCi} / \mathrm{g}$ & 0.5 & BN, 1995 \\
\hline 271L067 & Sediment & Aroclor-1260 & 320 & $\mu \mathrm{g} / \mathrm{kg}$ & 50,000 & CFR, 2000b \\
\hline
\end{tabular}

aQualifier added to laboratory data; record accepted. Spike recovery was outside control limits.

${ }^{\text {b }}$ Qualifier added to laboratory data; record accepted. Relative response factor $<0.05$.

${ }^{\circ}$ Qualifier added to laboratory data; record accepted. Internal standard area count exceeded the quality control limits. Matrix effects may exist.

${ }^{\text {d}}$ Qualifier added to laboratory data; record accepted. Poor matrix spike recovery/<30 percent recovery. Matrix effects may exist.

${ }^{e} Q u a l i f i e r$ added to laboratory data; record accepted. Counts from U-234 tailing into the U-235 region-of-interest.

${ }^{* *}=$ TCLP below minimum reporting limit

$\mathrm{E}=$ Limit not established $(\mathrm{BN}, 1995)$

$\mathrm{J}=$ Estimated value

$\mathrm{NA}=$ Not applicable

this is the bottom of the distribution box interior. Radiological screening and/or swipe data for this feature indicate the presence of radioactivity above unrestricted release criteria.

\section{A.13.6 Revised Conceptual Model}

No variations in the conceptual model were identified. 


\section{A.14.0 Project Pluto Test Area - Building 2203 Septic System (CAS 26-05-03)}

The Pluto Test Bunker septic system was designed to receive sanitary effluent generated by activities at Building 2203 (Test Bunker). The septic system is located approximately $60 \mathrm{ft}$ southeast of Building 2203. The site is comprised of a leachfield, septic tank, distribution box, and associated piping. More detail is provided in the CAIP (DOE/NV, 2001).

\section{A.14.1 Corrective Action Investigation}

Eighty investigation samples, listed in Table A.14-1, were collected during investigation activities conducted at CAS 26-05-03. The planned and actual sample locations are shown in Figure A.14-1. The specific CAI activities conducted to meet CAIP requirements at CAS 26-05-01 are described in Table A.2-1.

\section{A.14.1.1 Deviations}

The following deviation to the CAIP requirements was the result of unforeseen circumstances:

- Sample 271M001 was collected from 5.5 to $6.5 \mathrm{ft}$ bgs rather than the planned interval of 5 to $6 \mathrm{ft}$ bgs due to too much slough material being removed from the excavation.

Despite this deviation, the pertinent CAIP requirements were met.

\section{A.14.2 Investigation Results}

The following subsections provide details of the inspection and sampling of leachfield features, field-screening results, and sample selection and analysis.

\section{A.14.2.1 Removal of Housekeeping Debris and Surface Surveys}

Removal of housekeeping items was performed by Bechtel Nevada personnel prior to conducting the CAI. Soil locations underlying removed housekeeping items were designated as screening points and evaluated by conducting a surface radiological survey. Radiological measurements of the 
Table A.14-1

Samples Collected at CAS 26-05-03

(Page 1 of 5 )

\begin{tabular}{|c|c|c|c|c|c|c|c|c|c|c|c|c|c|}
\hline \multirow[b]{2}{*}{$\begin{array}{c}\text { Sample } \\
\text { Identification } \\
\text { Number }\end{array}$} & \multirow[b]{2}{*}{$\begin{array}{l}\text { Sample } \\
\text { Location }\end{array}$} & \multirow[b]{2}{*}{$\begin{array}{c}\text { Sample } \\
\text { Matrix }\end{array}$} & \multirow[b]{2}{*}{$\begin{array}{l}\text { Depth } \\
\text { (ft bgs) }\end{array}$} & \multirow[b]{2}{*}{ Purpose } & \multicolumn{9}{|c|}{ Analyses } \\
\hline & & & & & 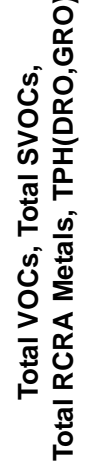 & 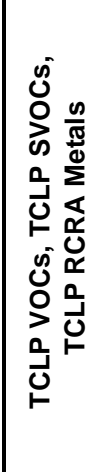 & 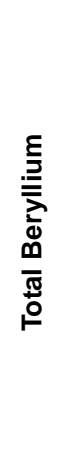 & O̊ & 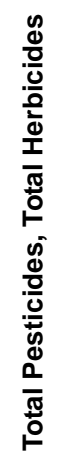 & 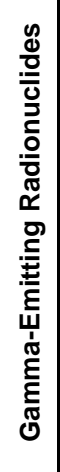 & 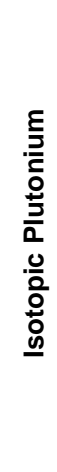 & 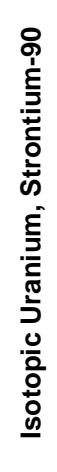 & $\stackrel{E}{\underline{3}}$ \\
\hline $271 \mathrm{M} 001$ & M03 & Soil & $5.5-6.5$ & Integrity & $x$ & & $x$ & $x$ & & $x$ & $x$ & $x$ & \\
\hline $271 \mathrm{M} 002$ & M03 & Soil & $7.5-8.5$ & Integrity & \multicolumn{9}{|c|}{ Not Submitted for Analyses ${ }^{a}$} \\
\hline $271 \mathrm{M} 003$ & M06 & Soil & $4.5-5.5$ & Environmental & $x$ & & $x$ & $x$ & & $x$ & $x$ & $x$ & \\
\hline $271 \mathrm{M} 004$ & M06 & Soil & $7-8$ & Environmental & \multicolumn{9}{|c|}{ Not Submitted for Analyses ${ }^{a}$} \\
\hline 271M005 & M05 & Soil & $4.5-5.5$ & Environmental & $x$ & & $x$ & $x$ & & $x$ & $X$ & $x$ & \\
\hline $271 \mathrm{M} 006$ & M05 & Soil & $4.5-5.5$ & $\begin{array}{l}\text { Duplicate of } \\
271 \mathrm{M} 005\end{array}$ & $x$ & & $x$ & $x$ & & $X$ & $x$ & $x$ & \\
\hline $271 \mathrm{M} 007$ & M05 & Soil & $7-8$ & Environmental & \multicolumn{9}{|c|}{ Not Submitted for Analyses ${ }^{a}$} \\
\hline $271 \mathrm{M} 008$ & M07 & Soil & $4-5$ & Environmental & $x$ & & $x$ & $x$ & & & & & \\
\hline 271M009 & M07 & Soil & $6.5-7.5$ & Environmental & \multicolumn{9}{|c|}{ Not Submitted for Analyses ${ }^{a}$} \\
\hline $271 \mathrm{M} 010$ & M13 & Soil & $4-5$ & Environmental & $x$ & & $x$ & $x$ & & $x$ & $x$ & $x$ & \\
\hline $271 \mathrm{M} 011$ & M13 & Soil & $6.5-7.5$ & Environmental & \multicolumn{9}{|c|}{ Not Submitted for Analyses ${ }^{a}$} \\
\hline $271 \mathrm{M} 012$ & M11 & Soil & $4-5$ & Environmental & $x$ & & $x$ & $x$ & & $x$ & $x$ & $x$ & \\
\hline $271 \mathrm{M} 013$ & M11 & Soil & $6.4-7.4$ & Environmental & \multicolumn{9}{|c|}{ Not Submitted for Analyses ${ }^{a}$} \\
\hline $271 \mathrm{M} 014$ & M04 & Soil & $3.4-4.4$ & Environmental & \multicolumn{9}{|c|}{ Not Submitted for Analyses ${ }^{a}$} \\
\hline $271 \mathrm{M} 015$ & M04 & Soil & $6-7$ & Environmental & \multicolumn{9}{|c|}{ Not Submitted for Analyses ${ }^{a}$} \\
\hline $271 \mathrm{M} 016$ & M12 & Soil & $4-5$ & $\begin{array}{l}\text { Environmental } \\
\text { MS/MSD }\end{array}$ & $x$ & & $x$ & $x$ & & $x$ & $x$ & $x$ & \\
\hline $271 \mathrm{M} 017$ & M12 & Soil & $6.4-7.4$ & Environmental & \multicolumn{9}{|c|}{ Not Submitted for Analyses ${ }^{a}$} \\
\hline $271 \mathrm{M} 018$ & M09 & Soil & $3-4$ & Environmental & \multicolumn{9}{|c|}{ Not Submitted for Analyses ${ }^{a}$} \\
\hline $271 \mathrm{M} 019$ & M09 & Soil & $5.4-6.4$ & Environmental & \multicolumn{9}{|c|}{ Not Submitted for Analyses ${ }^{a}$} \\
\hline $271 \mathrm{M} 020$ & M10 & Soil & $3.4-4.4$ & Environmental & \multicolumn{9}{|c|}{ Not Submitted for Analyses ${ }^{a}$} \\
\hline
\end{tabular}


Table A.14-1

Samples Collected at CAS 26-05-03

(Page 2 of 5 )

\begin{tabular}{|c|c|c|c|c|c|c|c|c|c|c|c|c|c|}
\hline \multirow[b]{2}{*}{$\begin{array}{c}\text { Sample } \\
\text { Identification } \\
\text { Number }\end{array}$} & \multirow[b]{2}{*}{$\begin{array}{l}\text { Sample } \\
\text { Location }\end{array}$} & \multirow[b]{2}{*}{$\begin{array}{l}\text { Sample } \\
\text { Matrix }\end{array}$} & \multirow[b]{2}{*}{$\begin{array}{c}\text { Depth } \\
\text { (ft bgs) }\end{array}$} & \multirow[b]{2}{*}{ Purpose } & \multicolumn{9}{|c|}{ Analyses } \\
\hline & & & & & 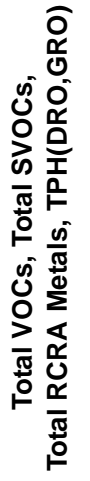 & 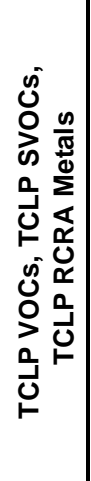 & 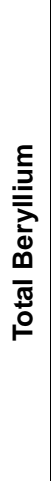 & $\stackrel{m}{0}$ & 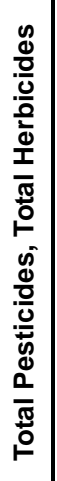 & 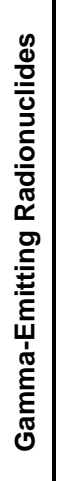 & 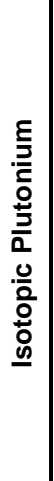 & 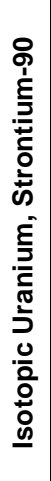 & $\underset{\underline{z}}{E}$ \\
\hline $271 \mathrm{M} 021$ & M10 & Soil & $6-7$ & Environmental & \multicolumn{9}{|c|}{ Not Submitted for Analyses ${ }^{a}$} \\
\hline 271M022 & M04 & Soil & $3.3-4.4$ & Environmental & $x$ & & $x$ & $\mathrm{X}$ & & $X$ & $X$ & $x$ & \\
\hline $271 \mathrm{M} 023$ & M04 & Soil & $6-7$ & Environmental & \multicolumn{9}{|c|}{ Not Submitted for Analyses ${ }^{a}$} \\
\hline $271 \mathrm{M} 024$ & M07 & Soil & $4.4-5.4$ & Environmental & $x$ & & $x$ & $\mathrm{X}$ & & $x$ & $x$ & $x$ & \\
\hline $271 \mathrm{M} 025$ & M07 & Soil & $7-8$ & Environmental & \multicolumn{9}{|c|}{ Not Submitted for Analyses ${ }^{a}$} \\
\hline 271M026 & M09 & Soil & $4-5$ & Environmental & $x$ & & $x$ & $\mathrm{X}$ & & $X$ & $X$ & $x$ & \\
\hline $271 \mathrm{M} 027$ & M09 & Soil & $6.4-7.4$ & Environmental & \multicolumn{9}{|c|}{ Not Submitted for Analyses ${ }^{a}$} \\
\hline 271M028 & M08 & Soil & $4-5$ & Environmental & $x$ & & $x$ & $\mathrm{X}$ & & $x$ & $x$ & $x$ & \\
\hline 271M029 & M08 & Soil & $6.5-7.5$ & Environmental & \multicolumn{9}{|c|}{ Not Submitted for Analyses ${ }^{a}$} \\
\hline $271 \mathrm{M} 030$ & M10 & Soil & $4-5$ & Environmental & $x$ & & $x$ & $\mathrm{X}$ & & $\mathrm{X}$ & $x$ & $x$ & \\
\hline $271 \mathrm{M} 031$ & M10 & Soil & $6.5-7.5$ & Environmental & \multicolumn{9}{|c|}{ Not Submitted for Analyses ${ }^{a}$} \\
\hline 271M032 & M23 & Soil & $3.5-4.5$ & Environmental & $x$ & & $x$ & $x$ & & $\mathrm{X}$ & $x$ & $x$ & \\
\hline $271 \mathrm{M} 033$ & M23 & Soil & $6-7$ & Environmental & \multicolumn{9}{|c|}{ Not Submitted for Analyses ${ }^{a}$} \\
\hline 271M034 & M20 & Soil & $4-5$ & Environmental & $x$ & & $x$ & $\mathrm{X}$ & & $x$ & $x$ & $x$ & \\
\hline 271M035 & M20 & Soil & $6.5-7.5$ & Environmental & \multicolumn{9}{|c|}{ Not Submitted for Analyses ${ }^{a}$} \\
\hline $271 \mathrm{M} 036$ & M22 & Soil & $3.5-4.5$ & Environmental & $x$ & & $x$ & $\mathrm{X}$ & & $\mathrm{X}$ & $x$ & $x$ & \\
\hline 271M037 & M22 & Soil & $6-7$ & Environmental & \multicolumn{9}{|c|}{ Not Submitted for Analyses ${ }^{a}$} \\
\hline $271 \mathrm{M} 038$ & M21 & Soil & $4-5$ & Environmental & $x$ & & $x$ & $\mathrm{X}$ & & $x$ & $x$ & $x$ & \\
\hline $271 \mathrm{M} 039$ & M21 & Soil & $6.5-7.5$ & Environmental & \multicolumn{9}{|c|}{ Not Submitted for Analyses ${ }^{a}$} \\
\hline $271 \mathrm{M} 040$ & M17 & Soil & $4-5$ & Environmental & $x$ & & $x$ & $\mathrm{X}$ & & $\mathrm{X}$ & $x$ & $x$ & \\
\hline 271M041 & M17 & Soil & $6.5-7.5$ & Environmental & \multicolumn{9}{|c|}{ Not Submitted for Analyses ${ }^{a}$} \\
\hline
\end{tabular}


Table A.14-1

Samples Collected at CAS 26-05-03

(Page 3 of 5 )

\begin{tabular}{|c|c|c|c|c|c|c|c|c|c|c|c|c|c|}
\hline \multirow[b]{2}{*}{$\begin{array}{c}\text { Sample } \\
\text { Identification } \\
\text { Number }\end{array}$} & \multirow[b]{2}{*}{$\begin{array}{l}\text { Sample } \\
\text { Location }\end{array}$} & \multirow[b]{2}{*}{$\begin{array}{l}\text { Sample } \\
\text { Matrix }\end{array}$} & \multirow[b]{2}{*}{$\begin{array}{l}\text { Depth } \\
\text { (ft bgs) }\end{array}$} & \multirow[b]{2}{*}{ Purpose } & \multicolumn{9}{|c|}{ Analyses } \\
\hline & & & & & 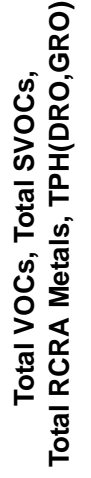 & 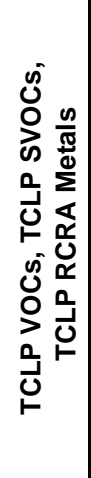 & 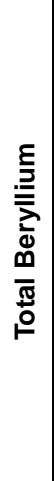 & 罢 & 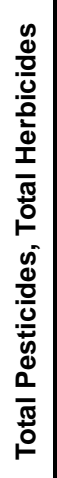 & 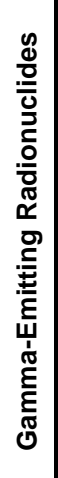 & $\begin{array}{l}\varepsilon \\
\frac{1}{2} \\
\frac{1}{0} \\
\frac{3}{0} \\
\frac{0}{0} \\
\frac{0}{0} \\
\frac{0}{0} \\
\underline{0}\end{array}$ & 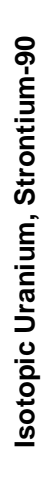 & 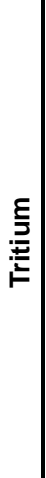 \\
\hline $271 \mathrm{M} 042$ & M18 & Soil & $4-5$ & Environmental & $x$ & & $x$ & $x$ & & $x$ & $x$ & $\mathrm{X}$ & \\
\hline $271 \mathrm{M} 043$ & M18 & Soil & $6.5-7.5$ & Environmental & \multicolumn{9}{|c|}{ Not Submitted for Analyses ${ }^{a}$} \\
\hline $271 \mathrm{M} 044$ & M19 & Soil & $4-5$ & Environmental & $\mathrm{X}$ & & $x$ & $x$ & & $x$ & $x$ & $\mathrm{x}$ & \\
\hline $271 \mathrm{M} 045$ & M19 & Soil & $6.5-7.5$ & Environmental & \multicolumn{9}{|c|}{ Not Submitted for Analyses ${ }^{a}$} \\
\hline $271 \mathrm{M} 046$ & M16 & Soil & $4-5$ & Environmental & $x$ & & $x$ & $x$ & & $\mathrm{X}$ & $x$ & $\mathrm{x}$ & \\
\hline $271 \mathrm{M} 047$ & M16 & Soil & $6.5-7.5$ & Environmental & \multicolumn{9}{|c|}{ Not Submitted for Analyses ${ }^{a}$} \\
\hline $271 \mathrm{M} 048$ & M15 & Soil & $4-5$ & Environmental & $x$ & & $\mathrm{x}$ & $x$ & & $x$ & $x$ & $\mathrm{x}$ & \\
\hline $271 \mathrm{M} 049$ & M15 & Soil & $6.5-7.5$ & Environmental & \multicolumn{9}{|c|}{ Not Submitted for Analyses ${ }^{a}$} \\
\hline $271 \mathrm{M} 050$ & M14 & Soil & $4-5$ & Environmental & $x$ & & $x$ & $x$ & & $x$ & $x$ & $x$ & \\
\hline $271 \mathrm{M} 051$ & M14 & Soil & $6.5-7.5$ & Environmental & \multicolumn{9}{|c|}{ Not Submitted for Analyses ${ }^{a}$} \\
\hline $271 \mathrm{M} 052$ & M24 & Soil & $4-5$ & Environmental & $\mathrm{X}$ & & $x$ & $x$ & & $x$ & $x$ & $\mathrm{X}$ & \\
\hline $271 \mathrm{M} 053$ & M24 & Soil & $6.5-7.5$ & Environmental & \multicolumn{9}{|c|}{ Not Submitted for Analyses ${ }^{a}$} \\
\hline $271 \mathrm{M} 054$ & M26 & Soil & $4-5$ & Environmental & $x$ & & $\mathrm{X}$ & $x$ & & $x$ & $x$ & $\mathrm{X}$ & \\
\hline $271 \mathrm{M} 055$ & M26 & Soil & $6.5-7.5$ & Environmental & \multicolumn{9}{|c|}{ Not Submitted for Analyses ${ }^{a}$} \\
\hline $271 \mathrm{M} 056$ & M25 & Soil & $4.5-5.5$ & Environmental & $x$ & & $x$ & $x$ & & $x$ & $x$ & $\mathrm{X}$ & \\
\hline $271 \mathrm{M} 057$ & M25 & Soil & $7-8$ & Environmental & \multicolumn{9}{|c|}{ Not Submitted for Analyses ${ }^{a}$} \\
\hline $271 \mathrm{M} 060$ & M33 & Soil & $4-5$ & Environmental & $\mathrm{X}$ & & $x$ & $x$ & & $x$ & $x$ & $\mathrm{X}$ & \\
\hline $271 \mathrm{M} 061$ & M33 & Soil & $6.5-7.5$ & Environmental & \multicolumn{9}{|c|}{ Not Submitted for Analyses ${ }^{a}$} \\
\hline $271 \mathrm{M} 062$ & M32 & Soil & $4.5-5.5$ & Environmental & $\mathrm{X}$ & & $x$ & $x$ & & $x$ & $x$ & $x$ & \\
\hline $271 \mathrm{M} 063$ & M32 & Soil & $6-7$ & Environmental & \multicolumn{9}{|c|}{ Not Submitted for Analyses ${ }^{a}$} \\
\hline $271 \mathrm{M} 064$ & M31 & Soil & $4-5$ & Environmental & $x$ & & $\mathrm{X}$ & $\mathrm{X}$ & & $x$ & $\mathrm{x}$ & $\mathrm{x}$ & \\
\hline
\end{tabular}


Table A.14-1

Samples Collected at CAS 26-05-03

(Page 4 of 5 )

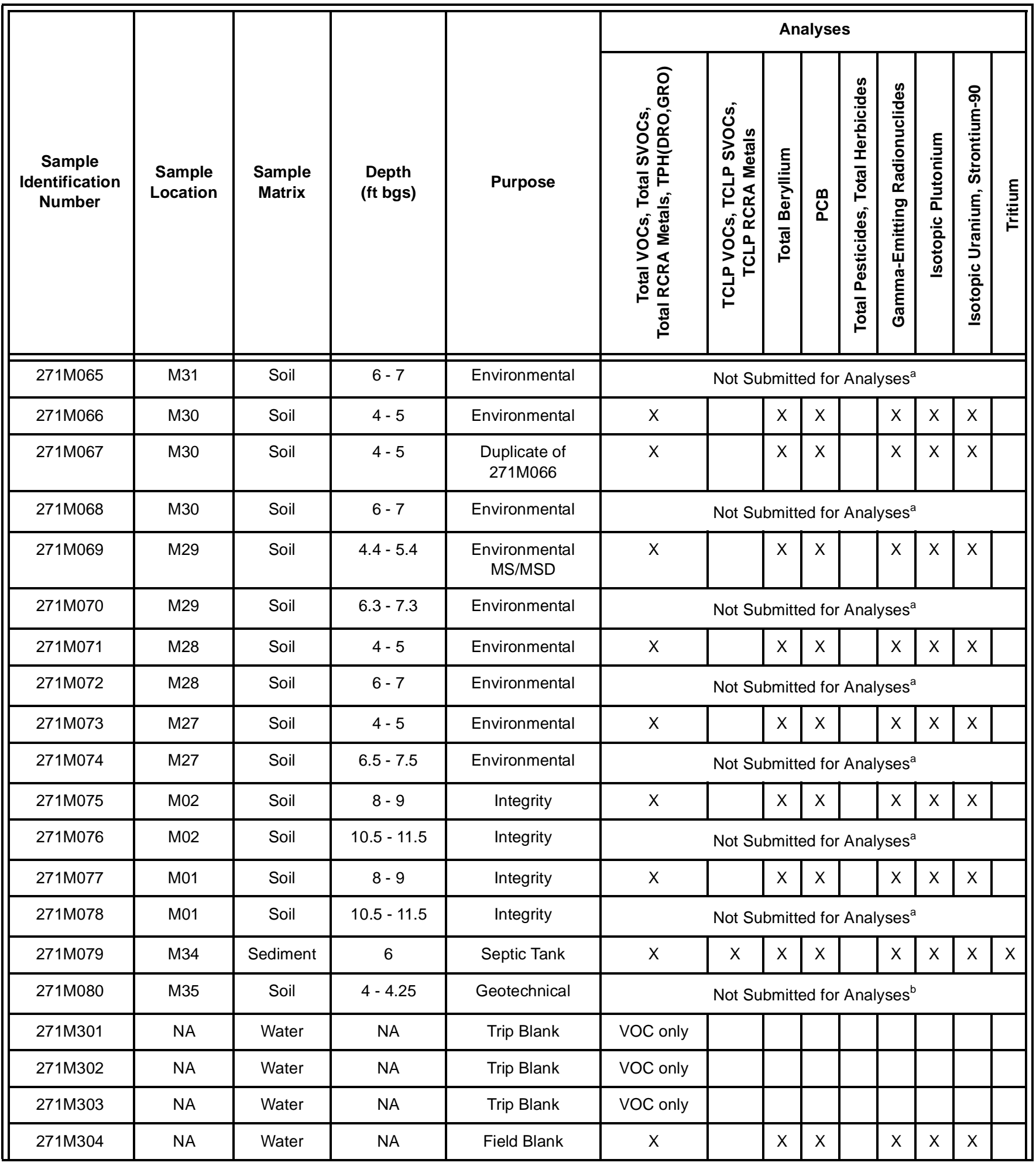


Table A.14-1

Samples Collected at CAS 26-05-03

(Page 5 of 5 )

\begin{tabular}{|c|c|c|c|c|c|c|c|c|c|c|c|c|c|}
\hline \multirow[b]{2}{*}{$\begin{array}{c}\text { Sample } \\
\text { Identification } \\
\text { Number }\end{array}$} & \multirow[b]{2}{*}{$\begin{array}{l}\text { Sample } \\
\text { Location }\end{array}$} & \multirow[b]{2}{*}{$\begin{array}{l}\text { Sample } \\
\text { Matrix }\end{array}$} & \multirow[b]{2}{*}{$\begin{array}{c}\text { Depth } \\
\text { (ft bgs) }\end{array}$} & \multirow[b]{2}{*}{ Purpose } & \multicolumn{9}{|c|}{ Analyses } \\
\hline & & & & & 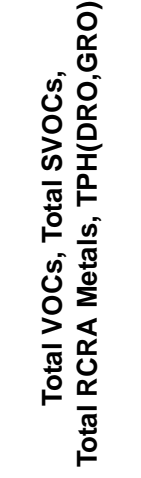 & 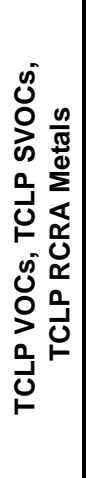 & 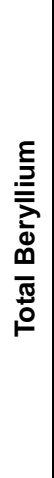 & 适 & 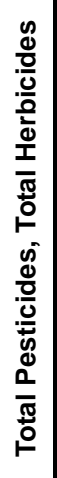 & 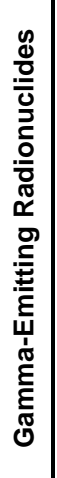 & 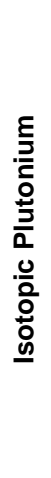 & 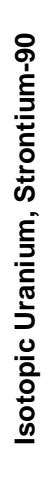 & $\stackrel{E}{E}$ \\
\hline $271 \mathrm{M} 305$ & NA & Water & NA & Trip Blank & VOC only & & & & & & & & \\
\hline $271 \mathrm{M} 306$ & NA & Water & NA & Trip Blank & VOC only & & & & & & & & \\
\hline $271 \mathrm{M} 307$ & NA & Water & NA & Trip Blank & VOC only & & & & & & & & \\
\hline 271M308 & NA & Water & NA & Trip Blank & VOC only & & & & & & & & \\
\hline 271M309 & NA & Water & NA & Trip Blank & VOC only & & & & & & & & \\
\hline $271 \mathrm{M} 312$ & NA & Water & NA & Trip Blank & VOC only & & & & & & & & \\
\hline $271 \mathrm{M} 313$ & NA & Water & NA & Rinsate & $x$ & & $x$ & $x$ & & $x$ & $x$ & $x$ & \\
\hline $271 \mathrm{M} 314$ & NA & Water & NA & Trip Blank & VOC only & & & & & & & & \\
\hline
\end{tabular}

${ }^{a}$ The sample was collected, field screened, and returned to the site for disposal.

${ }^{\mathrm{b}}$ The sample was collected, field screened, and is being stored for possible geotechnical analysis.

NA $=$ Not applicable

MS/MSD = Matrix spike/matrix spike duplicate

surrounding surface soils showed no areas with surface contamination above the established range for background.

\section{A.14.2.2 Septic Tank Contents}

The concrete septic tank was rectangular-shaped with a 2,618-gal capacity. It was accessed by one manhole located at the ground surface. The interior dimensions of the tank were $10 \mathrm{ft}$ (length) by $5 \mathrm{ft}$ (wide) by $7 \mathrm{ft}$ (depth). One composite sediment sample was collected from the septic tank at the manhole located upstream. Visual inspection revealed only a small amount of dry residue 


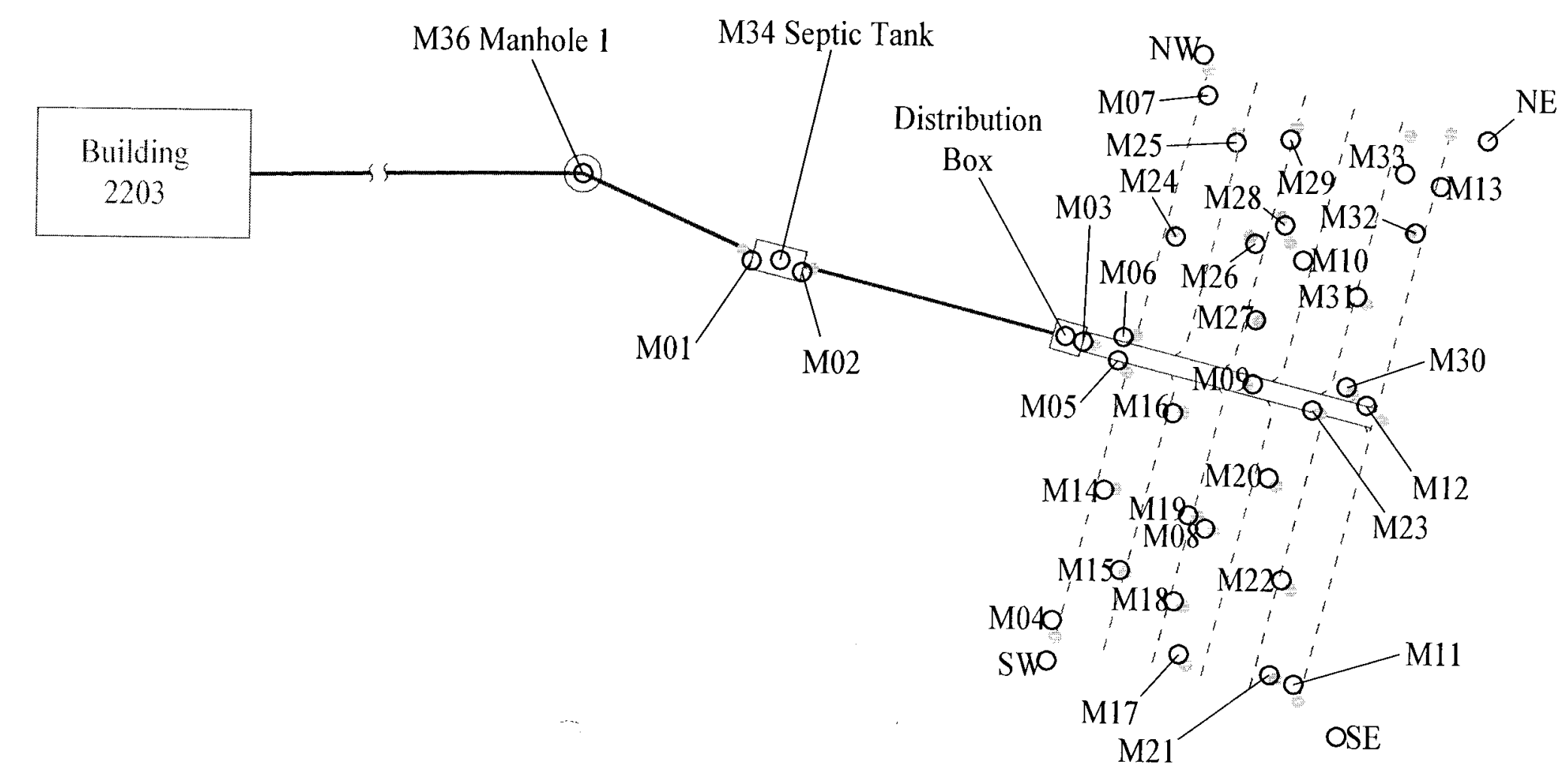

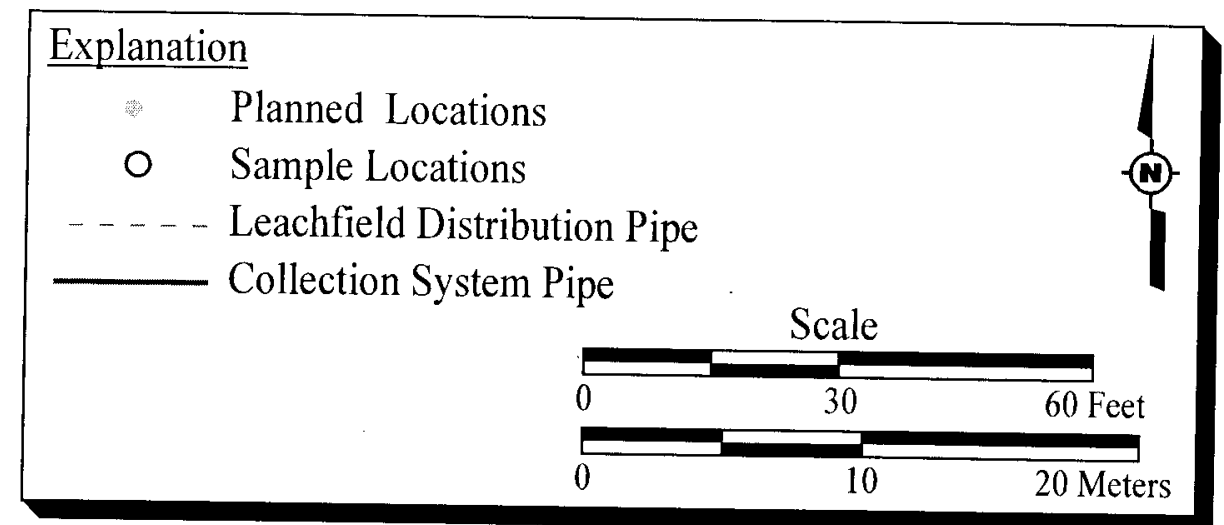

Source: BMEC, 1960c; BMEC, 1960d; Norman Engineering Co., 1961

Figure A.14-1

M350 Test Bunker Septic System (CAS 26-05-03) Sample Locations 
(approximately 1 gal) present in the bottom of the tank and manhole. Photographs of the septic tank were taken to document the visual inspection (Figure A.14-2).
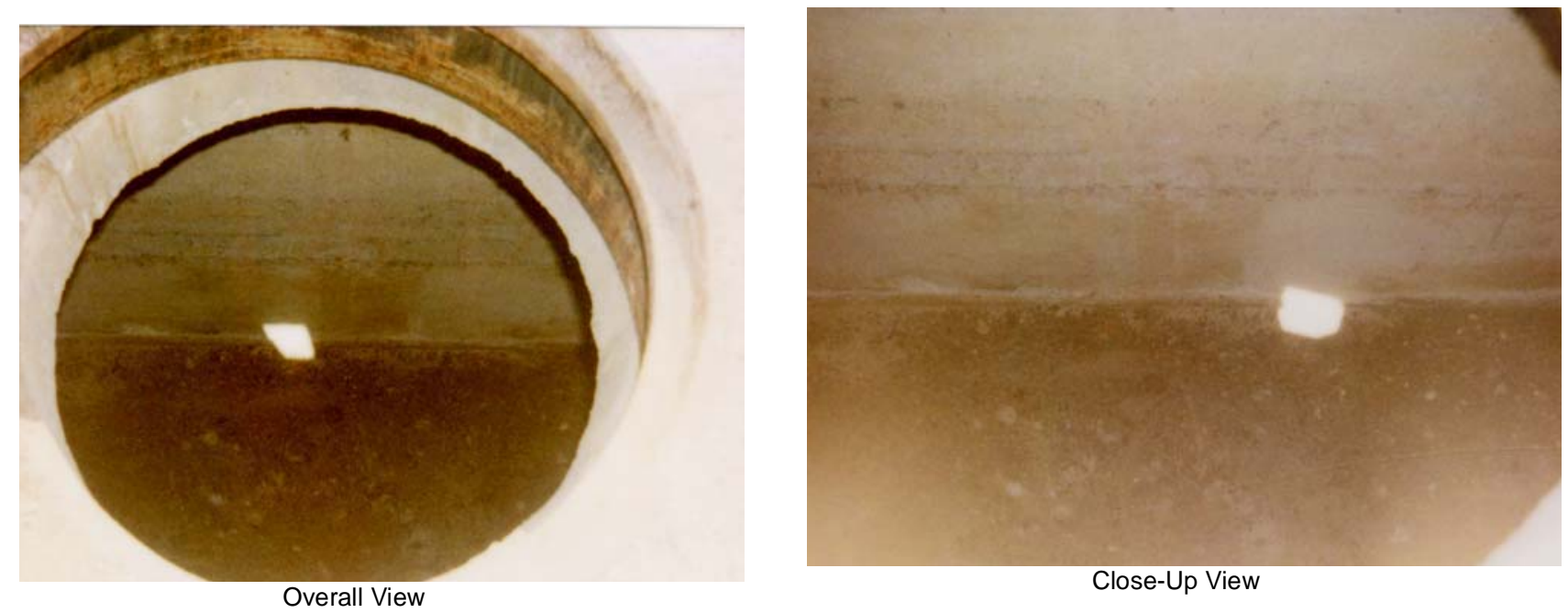

Figure A.14-2

CAS 26-05-03 Septic Tank, Interior

(Photographs Taken 02-04-2002)

\section{A.14.2.3 Distribution Box Contents}

The concrete distribution box was square-shaped with a 480-gal capacity. It was accessed by one concrete manhole located approximately $0.5 \mathrm{ft}$ above ground surface. The interior dimensions of the box were $4 \mathrm{ft}$ (length) by $4 \mathrm{ft}$ (width) by $4 \mathrm{ft}$ (depth). There was very little sediment in the bottom of the distribution box, so no sample was collected. A photograph of the distribution box was taken to document the visual inspection (Figure A.14-3).

\section{A.14.2.4 Septic Tank and Distribution Box Integrity Soil Sampling}

Six integrity samples were collected by excavating adjacent to the influent and effluent ends of the septic tank and the effluent end of the distribution box. Figure A.14-4 depicts the structural integrity and configuration of the effluent end of the septic tank. The following three samples were submitted for laboratory analysis:

- The upper sample (271M001) from the effluent end of the distribution box, collected at 5.5 to $6.5 \mathrm{ft}$ bgs 

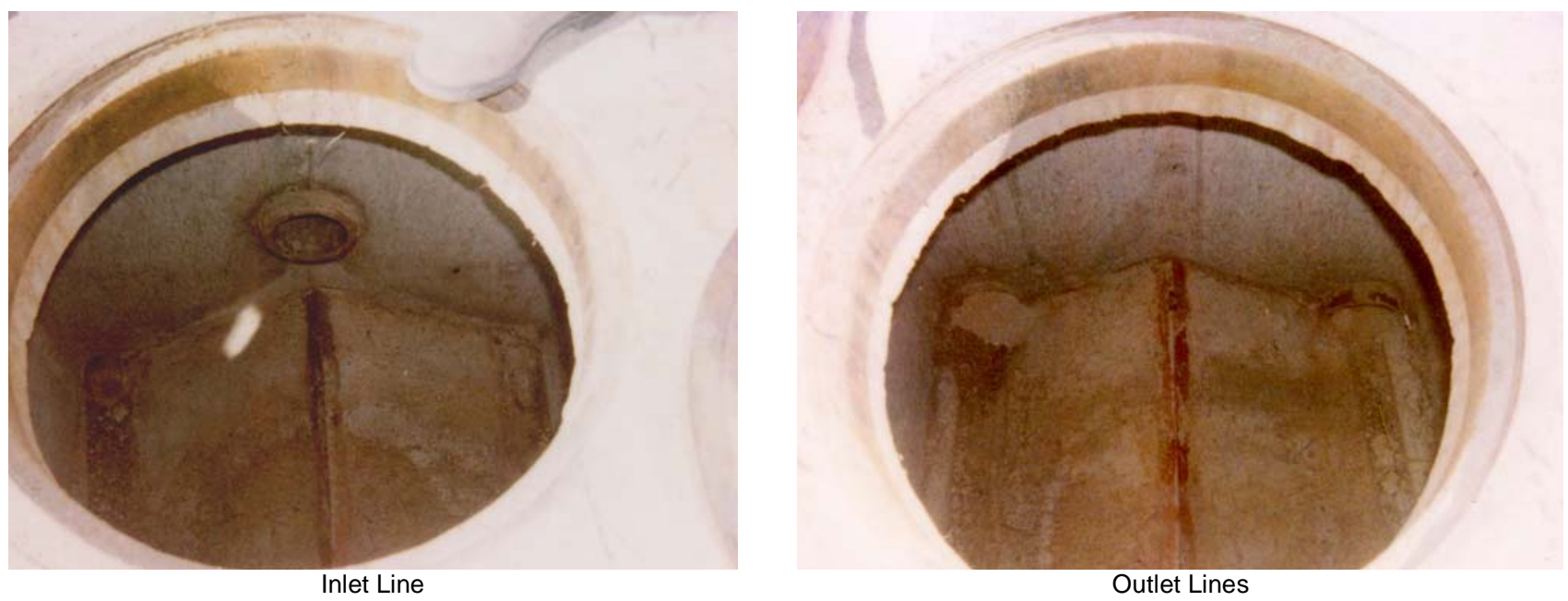

Figure A.14-3

CAS 26-05-03 Distribution Box, Interior (Photographs Taken 02-04-2002)

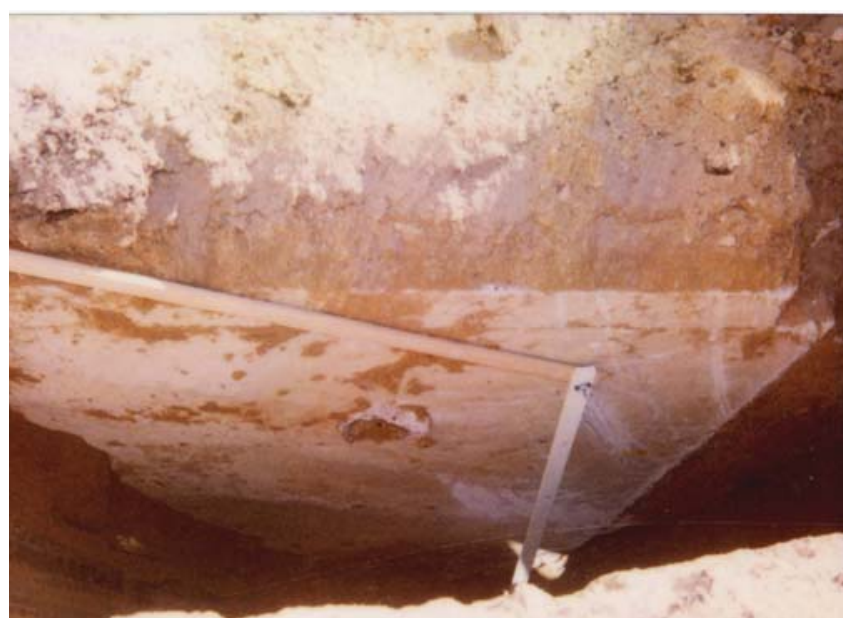

Figure A.14-4

CAS 26-05-03 Septic Tank, Effluent Integrity Sample (Photograph Taken 02-04-2002)

- The upper sample (271M075) from the effluent end of the septic tank, collected at 8 to $9 \mathrm{ft}$ bgs

- The upper sample (271M077) from the influent end of the septic tank, collected at 8 to $9 \mathrm{ft}$ bgs 


\section{A.14.2.5 Leachfield Excavation Soil Sampling}

Backhoe excavations were conducted to access sampling horizons at the biased and random locations presented in the CAIP. Excavations provided a visual verification of distribution pipes and enabled soil samples to be collected from intervals beneath the pipes, as specified by the CAIP. Seventy soil samples were collected from the planned locations excavated within the leachfield. These samples were collected from an interval at the leachrock/native soil interface and an interval $2.5 \mathrm{ft}$ below the interface. The interface was found at depths ranging from 3.4 to $4.5 \mathrm{ft}$ bgs. Thirty-three samples were submitted for laboratory analysis. In addition, two QC soil duplicates and two MS/MSD samples were collected and analyzed. A geotechnical sample was collected outside the boundary of the leachfield and will be sent to a laboratory for geotechnical analysis, as necessary.

\section{A.14.2.6 Collection System Pipe Inspections}

Access points for inspection of the collection system by video mole survey were present (i.e., a manhole) and were created at locations along the collection pipe via backhoe excavation.

The video mole was inserted through the breach in the pipe made during excavation activities at the influent side of the septic tank. The video mole was passed upstream for $29 \mathrm{ft}$, where it entered into a manhole (Manhole 1; Figure A.14-1). The video mole was then inserted through the breach in the pipe made during excavation activities at the effluent side of the septic tank. The video mole was passed downstream for $38 \mathrm{ft}$, where it entered the distribution box.

Manhole 1 was uncovered and inspected. The manhole contained sediment that appeared to be related to system operations, so a sample (271M079) was collected. Due to the lack of sample volume, 271M079 is a composite of material from Manhole 1 and the septic tank. A radiological survey was conducted on the manhole and swipes were collected for radiological characterization. The video mole was inserted through Manhole 1 and passed $81 \mathrm{ft}$ upstream to where the pipe sloped upward into the foundation of Building 2203. It was noted during the survey that the pipe was composed of both vitrified clay and steel. At $28 \mathrm{ft}$ from the manhole, the pipe changed from vitrified clay to a steel pipe. The inlet to Manhole 1 was sealed with grout after inspection activities were completed. 
Very little sediment was identified in the piping, and it was not appropriate or adequate material to be sampled. The pipes were in good condition, no breaks or obstructions were found. Visual observations were recorded in the FADLs. The results of the radiation surveys and swipes are discussed in Section A.14.2.8.

\section{A.14.2.7 Field-Screening Results}

Soil samples were screened for VOCs and alpha and beta/gamma radioactivity. The field readings were compared to FSLs to guide sampling decisions and determine which samples were to be submitted for laboratory analysis. No VOCs greater than FSLs were found during soil sample screening. The results of radiological field screening are discussed in Section A.14.2.8.

A sample of the septic tank/manhole content was collected and analyzed for fecal coliform bacteria. Fecal coliform bacteria was not detected in the septic tank/manhole at this CAS.

\section{A.14.2.8 Radiological Survey Results}

The following sections discuss the results of radiological screening, surveys, and swipe measurements.

\section{A.14.2.8.1 In Situ Cone Penetrometer Measurements}

In situ shallow subsurface radiation measurements were collected using a gamma detector on the end of a CPT rod. The CPT radiation measurements were collected at biased leachfield sample locations. Two background pushes were completed at this CAS. The results of the in situ measurement effort showed that the radiological levels:

- Were low enough to select excavation as the method of intrusive investigation

- Did not warrant greater protection for workers or the use of on-site gamma spectrometry to screen samples

- Presented no mixed waste concerns

- Were low enough to be practically handled, transported, analyzed, and shipped for off-site laboratory analysis 
- Were low enough to justify collection of all samples at planned intervals and locations

\section{A.14.2.8.2 Radiological Screening Results}

All radiological field-screening results for soil samples at CAS 26-05-03 were below FSLs.

Radiological survey measurements of the piping representative of the collection system were obtained upstream from the distribution box. The pipe interior was screened for both removable and fixed radiological levels for comparison against unrestricted release criteria. Table A.14-2 provides the radiological survey results for locations along the pipeline interior. Additionally, measurements of the distribution box interior were also collected and the results are provided in Table A.14-2. None of the measurements exceeded the unrestricted release limits as defined in the NV/YMP Radiological Control Manual (DOE/NV, 2000a).

Table A.14-2

Radiological Survey Results at CAS 26-05-03

\begin{tabular}{|c|c|c|c|c|c|}
\hline \multirow{2}{*}{$\begin{array}{l}\text { Location } \\
\text { Number }\end{array}$} & \multirow{2}{*}{$\begin{array}{l}\text { Sample } \\
\text { Location }\end{array}$} & \multicolumn{2}{|c|}{$\begin{array}{c}\text { Gross Fixed + Removable } \\
\text { Contamination }\end{array}$} & \multicolumn{2}{|c|}{ Unrestricted Release Criteria $^{a}$} \\
\hline & & $\begin{array}{l}\text { Beta/Gamma } \\
\left(\mathrm{dpm} / 100 \mathrm{~cm}^{2}\right)\end{array}$ & $\begin{array}{c}\text { Alpha } \\
\left(\mathrm{dpm} / 100 \mathrm{~cm}^{2}\right)\end{array}$ & $\begin{array}{c}\text { Beta/Gamma } \\
\left(\mathrm{dpm} / 100 \mathrm{~cm}^{2}\right)\end{array}$ & $\begin{array}{c}\text { Alpha } \\
\text { (dpm/100 cm })\end{array}$ \\
\hline M01 & Pipe Interior & 2,087 & 0.0 & \multicolumn{2}{|c|}{5,000} \\
\hline M02 & Pipe Interior & 2,104 & 12.9 & \multicolumn{2}{|c|}{5,000} \\
\hline M12 & Pipe Interior & 2,620 & 17.5 & \multicolumn{2}{|c|}{5,000} \\
\hline M36 & $\begin{array}{l}\text { Manhole West } \\
\text { Bottom }\end{array}$ & 1,597 & 0.0 & \multicolumn{2}{|c|}{5,000} \\
\hline M36 & $\begin{array}{l}\text { Manhole East } \\
\text { Bottom }\end{array}$ & 1,611 & 12.9 & \multicolumn{2}{|c|}{5,000} \\
\hline DB & $\begin{array}{l}\text { North Bottom } \\
\text { Outlet }\end{array}$ & 2,567 & 249 & \multicolumn{2}{|c|}{5,000} \\
\hline DB & $\begin{array}{l}\text { South Bottom } \\
\text { Outlet }\end{array}$ & 2,853 & 189 & \multicolumn{2}{|c|}{5,000} \\
\hline Inlet from Facility & $\begin{array}{l}\text { Pipe Interior } \\
\text { Facility }\end{array}$ & 3,666 & 308 & \multicolumn{2}{|c|}{5,000} \\
\hline
\end{tabular}

${ }^{a}$ NV/YMP Radiological Control Manual, Rev. 4 (DOE/NV, 2000a)

$\mathrm{dpm}=$ Disintegration(s) per minute

$\mathrm{cm}^{2}=$ Square centimeter(s) 


\section{A.14.2.8.3 Swipe Measurements}

A swipe survey was conducted at several points along the collection system pipeline and the distribution box. Table A.14-3 provides the swipe survey results with comparisons made to the unrestricted release criteria for removable contamination. None of the swipe measurements exceeded the unrestricted release limits.

Table A.14-3

Swipe Radiological Sample Analysis Results at CAS 26-05-03

\begin{tabular}{|c|c|c|c|c|c|}
\hline \multirow{2}{*}{$\begin{array}{l}\text { Location } \\
\text { Number }\end{array}$} & \multirow{2}{*}{$\begin{array}{l}\text { Sample } \\
\text { Location }\end{array}$} & \multicolumn{2}{|c|}{ Removable Contamination } & \multicolumn{2}{|c|}{ Unrestricted Release Criteria } \\
\hline & & $\begin{array}{l}\text { Beta Activity } \\
\left(\mathrm{dpm} / 100 \mathrm{~cm}^{2}\right)\end{array}$ & $\begin{array}{l}\text { Alpha Activity } \\
\left(\mathrm{dpm} / 100 \mathrm{~cm}^{2}\right)\end{array}$ & $\begin{array}{c}\text { Beta/Gamma } \\
(\text { dpm/100 cm²) }\end{array}$ & $\begin{array}{c}\text { Alpha } \\
\left(\mathrm{dpm} / 100 \mathrm{~cm}^{2}\right)\end{array}$ \\
\hline M36 & $\begin{array}{l}\text { Manhole West } \\
\text { Bottom }\end{array}$ & 0.0 & 0.0 & \multicolumn{2}{|c|}{1,000} \\
\hline M36 & $\begin{array}{l}\text { Manhole East } \\
\text { Bottom }\end{array}$ & 0.0 & 0.0 & \multicolumn{2}{|c|}{1,000} \\
\hline DB & North Outlet & 0.0 & 0.0 & \multicolumn{2}{|c|}{1,000} \\
\hline DB & South Outlet & 0.0 & 2.2 & \multicolumn{2}{|c|}{1,000} \\
\hline Inlet from Facility & Pipe Interior & 0.0 & 11.2 & \multicolumn{2}{|c|}{1,000} \\
\hline
\end{tabular}

${ }^{a}$ NV/YMP Radiological Control Manual, Rev. 4 (DOE/NV, 2000a)

$\mathrm{dpm}=$ Disintegration(s) per minute

$\mathrm{cm}^{2}=$ Square centimeter(s)

\section{A.14.2.9 Sample Analysis}

Environmental soil samples and associated QC samples were collected and analyzed for the CAIP-specified COPCs (i.e., total VOCs, total SVOCs, total RCRA metals, TPH [DRO and GRO], total beryllium, and PCBs). One-hundred percent of the soil and the associated QC samples were analyzed for Iso-Pu, Iso-U, Sr-90, and gamma-emitting radionuclides.

The sediment sample from the septic tank and manhole was analyzed for total VOCs, total SVOCs, TPH (DRO and GRO), total RCRA metals, total beryllium, PCBs, gamma-emitting radionuclides, Iso-U, Iso-Pu, Sr-90, and tritium. The sample was also analyzed for TCLP VOCs, SVOCs, and RCRA metals. 
The parameters and laboratory methods used to analyze the investigation samples are listed in Table A.2-2. Table A.14-1 lists the sample-specific analytical parameters.

\section{A.14.3 Analytes Detected Above Minimum Reporting Limits}

The soil sample analytical results with concentrations exceeding corresponding MRLs or PALs (DOE/NV, 1998; DOE/NV, 2001) at CAS 26-05-03 are summarized in the following sections. The results from the septic tank/manhole content sample are compared to appropriate regulatory levels for disposal. A portion of the CAS 26-05-03 analytical results were rejected during validation; however, these rejected data did not impact closure decisions as discussed in Section B.1.3.12 of Appendix B.

\section{A.14.3.1 Analytical Results for Soil Samples}

The following sections discuss the results for soil samples in comparison to the levels established in the Leachfield Work Plan and the CAIP.

\section{A.14.3.1.1 Total Volatile Organic Compounds}

Volatile organic compound results are reported in Table A.14-4. The only organic compound detected above the MRL of $5 \mu \mathrm{g} / \mathrm{kg}$ was acetone. The estimated concentration as designated by the "J" qualifier was $12 \mu \mathrm{g} / \mathrm{kg}$, below reporting limits for the laboratory. This acetone detection was below the PAL of $6,200,000 \mu \mathrm{g} / \mathrm{kg}$. Acetone is a common laboratory contaminant.

Table A.14-4

Soil Sample Results for Total VOCs

Detected Above Minimum Reporting Limits at CAS 26-05-03

\begin{tabular}{||c|c|c||}
\hline \multirow{2}{*}{$\begin{array}{c}\text { Sample } \\
\text { Identification } \\
\text { Number }\end{array}$} & $\begin{array}{c}\text { Depth } \\
(\mathrm{ft} \text { bgs })\end{array}$ & Contaminants of Potential Concern $(\mu \mathrm{g} / \mathrm{kg})$ \\
\cline { 3 - 3 } & & Acetone \\
\hline \multicolumn{2}{|c|}{ Preliminary Action Levels ${ }^{\mathrm{a}}$} & $\mathbf{6 , 2 0 0 , 0 0 0}$ \\
\hline \hline 271M066 & $4-5$ & 12 \\
\hline
\end{tabular}

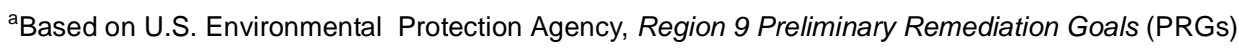
(EPA, 2000). 


\section{A.14.3.1.2 Total Semivolatile Organic Compounds}

Semivolatile organic compounds were not detected above MRLs in CAS 26-05-03 soil samples.

\section{A.14.3.1.3 Total Petroleum Hydrocarbons}

Total petroleum hydrocarbons were not detected above MRLs in CAS 26-05-03 soil samples.

\section{A.14.3.1.4 Total RCRA Metals}

As shown in Table A.14-5, the total RCRA metals detected in soil samples at concentrations exceeding the MRLs are arsenic (1 mg/kg), barium (20 mg/kg), chromium (1 mg/kg), and lead $(0.3 \mathrm{mg} / \mathrm{kg})$. Other RCRA metals (i.e., cadmium, mercury, selenium, silver) were below specified MRLs.

Barium concentrations ranged from 115 to $219 \mathrm{mg} / \mathrm{kg}$, chromium concentrations ranged from 3.63 to $7.66 \mathrm{mg} / \mathrm{kg}$, and lead concentrations ranged from 4.28 to $11.5 \mathrm{mg} / \mathrm{kg}$. All reported concentrations of these metals were below EPA Region 9 PRGs defined in this document as PALs.

Arsenic concentrations ranged from 3.91 to $9.79 \mathrm{mg} / \mathrm{kg}$. All detections in soil from CAS 26-05-03 exceeded the arsenic PAL of $2.7 \mathrm{mg} / \mathrm{kg}$. Arsenic concentrations were consistent across the site, with no "hot spots" or evidence of a localized spill. The PAL is lower than the 7 to $8 \mathrm{mg} / \mathrm{kg}$ mean concentration of arsenic in silt from the Nevada Test and Training Range (NBMG, 1998; Moore, 1999). Although arsenic concentrations in the soil exceed the PAL, these concentrations are believed to be within ambient conditions for CAS 26-05-03 and do not represent contamination.

\section{A.14.3.1.5 Total Beryllium}

Total beryllium was not detected above the MRL in CAS 26-05-03 soil samples.

\section{A.14.3.1.6 Polychlorinated Biphenyls}

Polychlorinated biphenyl compound results are reported in Table A.14-6. The only PCB compounds detected above the MRLs were aroclor-1254 and arochlor-1260 in sample 271M075. The concentrations of both of these compounds were below the PAL of $1,000 \mu \mathrm{g} / \mathrm{kg}$. 
Table A.14-5

Soil Sample Results for Total RCRA Metals

Detected Above Minimum Reporting Limits at CAS 26-05-03

\begin{tabular}{|c|c|c|c|c|c|}
\hline \multirow{2}{*}{$\begin{array}{c}\text { Sample } \\
\text { Identification } \\
\text { Number }\end{array}$} & \multirow{2}{*}{$\begin{array}{c}\text { Depth } \\
\text { (ft bgs) }\end{array}$} & \multicolumn{4}{|c|}{ Contaminants of Potential Concern (mg/kg) } \\
\hline & & Arsenic & Barium & Chromium & Lead \\
\hline \multicolumn{2}{|c|}{ Preliminary Action Levels ${ }^{a}$} & 2.7 & 100,000 & 450 & 750 \\
\hline $271 \mathrm{M} 001$ & $5.5-6.5$ & 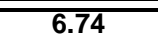 & 164 & 5.99 & 7.57 \\
\hline $271 \mathrm{M} 003$ & $4.5-5.5$ & 7.62 & 146 & 5.91 & 6.86 \\
\hline $271 \mathrm{M} 005$ & $4.5-5.5$ & 3.91 & 115 & 3.69 & 4.28 \\
\hline $271 \mathrm{M} 006$ & $4.5-5.5$ & 6.84 & 166 & 6.31 & 7.21 \\
\hline $271 \mathrm{M} 010$ & $4-5$ & 9.79 & 219 & 7.66 & 9.37 \\
\hline $271 \mathrm{M} 012$ & $4-5$ & 7.38 & 182 & 5.41 & 7.7 \\
\hline $271 \mathrm{M} 016$ & $4-5$ & 6.86 & 149 & 5.13 & 6.4 \\
\hline $271 \mathrm{M} 022$ & $3.3-4.4$ & 6.22 & 180 & 5.43 & 8.5 \\
\hline $271 \mathrm{M} 024$ & $4.4-5.4$ & 9.68 & 181 & 6.3 & 9.13 \\
\hline $271 \mathrm{M} 026$ & $4-5$ & 5.86 & 159 & 4.91 & 7.65 \\
\hline $271 \mathrm{M} 028$ & $4-5$ & 5.94 & 144 & 5.3 & 7.42 \\
\hline $271 \mathrm{M} 030$ & $4-5$ & 7.32 & 133 & 4.61 & 6.82 \\
\hline $271 \mathrm{M} 032$ & $3.5-4.5$ & 7.55 & 162 & 5.94 & 7.52 \\
\hline $271 \mathrm{M} 034$ & $4-5$ & 8.2 & 171 & 6.04 & 7.46 \\
\hline $271 \mathrm{M} 036$ & $3.5-4.5$ & 6.22 & 184 & 5.89 & 10.4 \\
\hline $271 \mathrm{M} 038$ & $4-5$ & 6.66 & 194 & 6.51 & 10.9 \\
\hline $271 \mathrm{M} 040$ & $4-5$ & 6.52 & 203 & 5.56 & 9.26 \\
\hline $271 \mathrm{M} 042$ & $4-5$ & 4.7 & 156 & 4.86 & 8.36 \\
\hline $271 \mathrm{M} 044$ & $4-5$ & 5.77 & 163 & 4.87 & 8.2 \\
\hline $271 \mathrm{M} 046$ & $4-5$ & 6.33 & 167 & 5.11 & 8.17 \\
\hline $271 \mathrm{M} 048$ & $4-5$ & 6.2 & 165 & 4.48 & 8.18 \\
\hline $271 \mathrm{M} 050$ & $4-5$ & 6.02 & 218 & 6.33 & 7.63 \\
\hline $271 \mathrm{M} 052$ & $4-5$ & 8.05 & 127 & 4.53 & 6.38 \\
\hline $271 \mathrm{M} 054$ & $4-5$ & 8.16 & 136 & 5.07 & 7.63 \\
\hline $271 \mathrm{M} 056$ & $4.5-5.5$ & 9.12 & 141 & 4.43 & 7.35 \\
\hline $271 \mathrm{M} 060$ & $4-5$ & 7.8 & 166 & 5.26 & 8.32 \\
\hline $271 \mathrm{M} 062$ & $4.5-5.5$ & 9.04 & 175 & 5.53 & 10 \\
\hline $271 \mathrm{M} 064$ & $4-5$ & 7.54 & 157 & 4.71 & 8.51 \\
\hline $271 \mathrm{M} 066$ & $4-5$ & 8.31 & 158 & 5.13 & 6.73 \\
\hline $271 \mathrm{M} 067$ & $4-5$ & 8.81 & 135 & 5.56 & 6.43 \\
\hline $271 \mathrm{M} 069$ & $4.4-5.4$ & 8.35 & 172 & 5.2 & 11 \\
\hline $271 \mathrm{M} 071$ & $4-5$ & 8.57 & 132 & 4.68 & 6.21 \\
\hline $271 \mathrm{M} 073$ & $4-5$ & 5.62 & 115 & 3.63 & 6.06 \\
\hline $271 \mathrm{M} 075$ & $8-9$ & 6.29 & 141 & 5.79 & 11.5 \\
\hline $271 \mathrm{M} 077$ & $8-9$ & 7.74 & 136 & 4.4 & 8.17 \\
\hline
\end{tabular}

aBased on U.S. Environmental Protection Agency, Region 9 Preliminary Remediation Goals (PRGs) (EPA, 2000). 
Table A.14-6

Soil Sample Results for PCB

Detected Above Minimum Reporting Limits at CAS 26-05-03

\begin{tabular}{||c|c|c|c|}
\hline \multirow{2}{*}{$\begin{array}{c}\text { Sample } \\
\text { Identification } \\
\text { Number }\end{array}$} & $\begin{array}{c}\text { Depth } \\
\text { (ft bgs) }\end{array}$ & \multicolumn{2}{|c|}{ Contaminants of Potential Concern $(\mu \mathrm{g} / \mathbf{k g})$} \\
\cline { 3 - 4 } & & Aroclor-1254 & Aroclor-1260 \\
\hline Preliminary Action Levels & & $\mathbf{1 , 0 0 0}$ & $\mathbf{1 , 0 0 0}$ \\
\hline \hline $271 \mathrm{M} 075$ & $8-9$ & 75 & 38 \\
\hline
\end{tabular}

${ }^{a}$ Based on U.S. Environmental Protection Agency, Region 9 Preliminary Remediation Goals (PRGs) (EPA, 2000).

\section{A.14.3.1.7 Gamma Spectrometry Results}

Results of soil sample gamma spectrometry analysis are presented in Table A.14-7. Concentrations of actinium-228, bismuth-212, bismuth-214, lead-212, lead-214, potassium-40, and thallium-208 were detected above MDLs. The TPU in the radioanalytical measurement is provided in the table along with the concentration for all detected gamma emitters. The concentrations of the detected gamma-emitting radionuclides are below PALs and are not significantly different than concentrations measured in soil samples collected from undisturbed background locations.

\section{A.14.3.1.8 Isotopic Uranium}

Detected values of uranium isotopes, along with associated TPUs are reported in Table A.14-8. Thirteen samples had concentrations of U-235 above the PAL. A normalized difference based on a confidence level of 95 percent was used to determine if the concentrations were statistically distinguishable from background. The results of this analysis determined that U-235 concentrations were not significantly greater than concentrations in soil samples collected from undisturbed background locations.

\section{A.14.3.1.9 Isotopic Plutonium}

Detected values of plutonium isotopes, along with associated TPUs are reported in Table A.14-8. The concentrations of $\mathrm{Pu}-239$ were below PALs and were not significantly greater than concentrations in soil samples collected from undisturbed background locations. 
Table A.14-7

Soil Sample Results for Gamma-Emitting Radionuclides

Detected Above Minimum Reporting Limits at CAS 26-05-03

(Page 1 of 2)

\begin{tabular}{|c|c|c|c|c|c|c|c|c|}
\hline \multirow{2}{*}{$\begin{array}{c}\text { Sample } \\
\text { Identification } \\
\text { Number }\end{array}$} & \multirow{2}{*}{$\begin{array}{l}\text { Depth } \\
\text { (ft bgs) }\end{array}$} & \multicolumn{7}{|c|}{ Contaminants of Potential Concern (pCi/g) } \\
\hline & & Actinium-228 ${ }^{a}$ & Bismuth-212 ${ }^{\mathrm{b}}$ & Bismuth-214 ${ }^{\mathrm{b}}$ & Lead-212 $^{\mathrm{a}}$ & Lead-214 ${ }^{b}$ & Potassium-40 & Thallium-208 ${ }^{a}$ \\
\hline \multicolumn{2}{|c|}{ Preliminary Action Level } & 3.64 & 2.4 & 3.47 & 2.9 & 2.9 & 96 & 3.4 \\
\hline $271 \mathrm{M} 001$ & $5.5-6.5$ & $1.19 \pm 0.26$ & $\overline{--}$ & $0.78 \pm 0.18$ & $1.42 \pm 0.27$ & $0.89 \pm 0.18$ & $21.2 \pm 3.8$ & $0.446 \pm 0.098$ \\
\hline $271 \mathrm{M} 003$ & $4.5-5.5$ & $1.22 \pm 0.32$ & -- & $0.84 \pm 0.21$ & $1.43 \pm 0.29$ & $1.03 \pm 0.23$ & $20.4 \pm 4.0$ & $0.45 \pm 0.12$ \\
\hline 271M005 & $4.5-5.5$ & $1.06 \pm 0.32$ & -- & $0.8 \pm 0.22$ & $1.44 \pm 0.29$ & $0.84 \pm 0.20$ & $18.3 \pm 3.9$ & $0.34 \pm 0.12$ \\
\hline $271 \mathrm{M} 006$ & $4.5-5.5$ & $1.4 \pm 0.34$ & -- & $0.9 \pm 0.23$ & $1.34 \pm 0.27$ & $0.85 \pm 0.20$ & $19.9 \pm 4.0$ & $0.37 \pm 0.11$ \\
\hline $271 \mathrm{M} 010$ & $4-5$ & $1.19 \pm 0.36$ & -- & $0.5 \pm 0.19$ & $1.34 \pm 0.28$ & $0.67 \pm 0.18$ & $16.3 \pm 3.4$ & $0.33 \pm 0.11$ \\
\hline $271 \mathrm{M} 012$ & $4-5$ & $1.3 \pm 0.28$ & -- & $0.69 \pm 0.17$ & $1.39 \pm 0.26$ & $0.92 \pm 0.19$ & $21.1 \pm 3.8$ & $0.442 \pm 0.098$ \\
\hline $271 \mathrm{M} 016$ & $4-5$ & $1.29 \pm 0.32$ & -- & $0.95 \pm 0.24$ & $1.36 \pm 0.28$ & $0.86 \pm 0.20$ & $20.2 \pm 4.0$ & $0.38 \pm 0.11$ \\
\hline $271 \mathrm{M} 022$ & $3.3-4.3$ & $1.22 \pm 0.33$ & -- & $0.63 \pm 0.21$ & $1.33 \pm 0.29$ & $0.75 \pm 0.20$ & $20.8 \pm 4.2$ & $0.43 \pm 0.12$ \\
\hline $271 \mathrm{M} 024$ & $4.4-5.4$ & $1.48 \pm 0.31$ & -- & $0.79 \pm 0.18$ & $1.58 \pm 0.30$ & $1 \pm 0.20$ & $22.2 \pm 4.0$ & $0.426 \pm 0.098$ \\
\hline $271 \mathrm{M} 026$ & $4-5$ & $1.36 \pm 0.33$ & -- & $0.87 \pm 0.23$ & $1.5 \pm 0.30$ & $1.03 \pm 0.23$ & $20 \pm 3.9$ & $0.49 \pm 0.12$ \\
\hline $271 \mathrm{M} 028$ & $4-5$ & $1.22 \pm 0.34$ & -- & $0.86 \pm 0.25$ & $1.39 \pm 0.29$ & $0.83 \pm 0.20$ & $20.3 \pm 4.2$ & $0.41 \pm 0.12$ \\
\hline $271 \mathrm{M} 030$ & $4-5$ & $1.35 \pm 0.34$ & -- & $0.8 \pm 0.22$ & $1.55 \pm 0.31$ & $0.84 \pm 0.20$ & $19.1 \pm 3.9$ & $0.48 \pm 0.13$ \\
\hline $271 \mathrm{M} 032$ & $3.5-4.6$ & $1.42 \pm 0.35$ & -- & $0.87 \pm 0.22$ & $1.37 \pm 0.29$ & $0.98 \pm 0.22$ & $20.6 \pm 4.0$ & $0.45 \pm 0.11$ \\
\hline $271 \mathrm{M} 034$ & $4-5$ & $1.19 \pm 0.34$ & -- & $0.82 \pm 0.25$ & $1.33 \pm 0.28$ & $0.85 \pm 0.21$ & $17.5 \pm 3.8$ & $0.51 \pm 0.14$ \\
\hline $271 \mathrm{M} 036$ & $3.5-4.6$ & $1.26 \pm 0.33$ & -- & $0.65 \pm 0.21$ & $1.33 \pm 0.28$ & $0.81 \pm 0.20$ & $21.4 \pm 4.2$ & $0.43 \pm 0.12$ \\
\hline $271 \mathrm{M} 038$ & $4-5$ & $1.2 \pm 0.26$ & $1.4 \pm 0.59$ & $0.86 \pm 0.20$ & $1.53 \pm 0.28$ & $0.88 \pm 0.18$ & $22.9 \pm 4.1$ & $0.47 \pm 0.10$ \\
\hline $271 \mathrm{M} 040$ & $4-5$ & $1.18 \pm 0.26$ & $1.33 \pm 0.55$ & $0.78 \pm 0.18$ & $1.46 \pm 0.27$ & $0.98 \pm 0.20$ & $22.7 \pm 4.0$ & $0.403 \pm 0.093$ \\
\hline $271 \mathrm{M} 042$ & $4-5$ & $1.39 \pm 0.35$ & -- & $0.8 \pm 0.23$ & $1.37 \pm 0.28$ & $0.94 \pm 0.21$ & $19.5 \pm 4.1$ & $0.44 \pm 0.12$ \\
\hline $271 \mathrm{M} 044$ & $4-5$ & $1.32 \pm 0.33$ & $1.91 \pm 0.86$ & $0.9 \pm 0.23$ & $1.41 \pm 0.29$ & $0.88 \pm 0.21$ & $20.4 \pm 4.1$ & $0.45 \pm 0.12$ \\
\hline $271 \mathrm{M} 046$ & $4-5$ & $1.23 \pm 0.35$ & -- & $0.87 \pm 0.26$ & $1.66 \pm 0.34$ & $0.92 \pm 0.23$ & $22.6 \pm 4.6$ & $0.45 \pm 0.14$ \\
\hline $271 \mathrm{M} 048$ & $4-5$ & $1.46 \pm 0.31$ & -- & $0.81 \pm 0.19$ & $1.59 \pm 0.30$ & $0.73 \pm 0.16$ & $23.5 \pm 4.2$ & $0.47 \pm 0.10$ \\
\hline $271 \mathrm{M} 050$ & $4-5$ & $1.4 \pm 0.30$ & -- & $0.68 \pm 0.17$ & $1.33 \pm 0.25$ & $0.99 \pm 0.20$ & $21.2 \pm 3.8$ & $0.426 \pm 0.098$ \\
\hline
\end{tabular}


Table A.14-7

Soil Sample Results for Gamma-Emitting Radionuclides Detected Above Minimum Reporting Limits at CAS 26-05-03 (Page 2 of 2)

\begin{tabular}{|c|c|c|c|c|c|c|c|c|}
\hline \multirow{2}{*}{$\begin{array}{c}\text { Sample } \\
\text { Identification } \\
\text { Number }\end{array}$} & \multirow{2}{*}{$\begin{array}{c}\text { Depth } \\
\text { (ft bgs) }\end{array}$} & \multicolumn{7}{|c|}{ Contaminants of Potential Concern $(\mathrm{pCi} / \mathrm{g})$} \\
\hline & & Actinium-228 & Bismuth-212 & Bismuth-214 ${ }^{\mathrm{b}}$ & Lead-212 $^{\mathrm{a}}$ & Lead-214 ${ }^{b}$ & Potassium-40 & Thallium-208 ${ }^{a}$ \\
\hline \multicolumn{2}{|c|}{ Preliminary Action Level } & 3.64 & 2.4 & 3.47 & 2.9 & 2.9 & 96 & 3.4 \\
\hline $271 \mathrm{M} 052$ & $4-5$ & $1.23 \pm 0.34$ & $\overline{---}$ & $0.98 \pm 0.26$ & $1.22 \pm 0.27$ & $0.98 \pm 0.23$ & $17.4 \pm 3.7$ & $0.44 \pm 0.13$ \\
\hline $271 \mathrm{M} 054$ & $4-5$ & $1.39 \pm 0.34$ & -- & $0.78 \pm 0.21$ & $1.27 \pm 0.26$ & $0.95 \pm 0.22$ & $19.6 \pm 3.9$ & $0.48 \pm 0.12$ \\
\hline $271 \mathrm{M} 056$ & $4.5-5.5$ & $1.36 \pm 0.37$ & -- & $0.89 \pm 0.25$ & $1.53 \pm 0.31$ & $0.94 \pm 0.23$ & $20.4 \pm 4.2$ & $0.43 \pm 0.13$ \\
\hline $271 \mathrm{M} 060$ & $4-5$ & $1.5 \pm 0.37$ & -- & $0.83 \pm 0.22$ & $1.64 \pm 0.33$ & $0.97 \pm 0.22$ & $20.9 \pm 4.1$ & $0.57 \pm 0.14$ \\
\hline $271 \mathrm{M} 062$ & $4.5-5.5$ & $1.26 \pm 0.35$ & -- & $0.85 \pm 0.25$ & $1.49 \pm 0.31$ & $0.96 \pm 0.23$ & $20.9 \pm 4.4$ & $0.39 \pm 0.12$ \\
\hline $271 \mathrm{M} 064$ & $4-5$ & $1.38 \pm 0.34$ & -- & $0.8 \pm 0.22$ & $1.33 \pm 0.27$ & $0.84 \pm 0.20$ & $22.6 \pm 4.4$ & $0.5 \pm 0.13$ \\
\hline $271 \mathrm{M} 066$ & $4-5$ & $1.29 \pm 0.37$ & -- & $0.87 \pm 0.26$ & $1.33 \pm 0.28$ & $0.97 \pm 0.23$ & $17.1 \pm 3.7$ & $0.37 \pm 0.13$ \\
\hline $271 \mathrm{M} 067$ & $4-5$ & $1.24 \pm 0.27$ & -- & $0.8 \pm 0.19$ & $1.42 \pm 0.27$ & $0.88 \pm 0.19$ & $20.4 \pm 3.7$ & $0.371 \pm 0.087$ \\
\hline 271M069 & $4.4-5.4$ & $1.53 \pm 0.32$ & -- & $0.68 \pm 0.16$ & $1.64 \pm 0.30$ & $0.87 \pm 0.18$ & $22.4 \pm 4.0$ & $0.451 \pm 0.099$ \\
\hline $271 \mathrm{M} 071$ & $4-5$ & $1.04 \pm 0.30$ & -- & $0.79 \pm 0.23$ & $1.46 \pm 0.29$ & $0.93 \pm 0.21$ & $17.9 \pm 3.8$ & $0.36 \pm 0.11$ \\
\hline $271 \mathrm{M} 073$ & $4-5$ & $1.06 \pm 0.29$ & -- & $0.82 \pm 0.22$ & $1.2 \pm 0.26$ & $0.79 \pm 0.19$ & $19.9 \pm 4.0$ & $0.41 \pm 0.11$ \\
\hline $271 \mathrm{M} 075$ & $8-9$ & $1.65 \pm 0.35$ & -- & $0.82 \pm 0.20$ & $1.6 \pm 0.30$ & $0.87 \pm 0.18$ & $23.6 \pm 4.2$ & $0.5 \pm 0.11$ \\
\hline $271 \mathrm{M} 077$ & $8-9$ & $1.55 \pm 0.47$ & -- & $0.66 \pm 0.28$ & $1.7 \pm 0.36$ & $0.87 \pm 0.25$ & $20.8 \pm 4.5$ & $0.43 \pm 0.15$ \\
\hline
\end{tabular}

${ }^{a}$ Background concentration listed in Environmental Monitoring Report for the Proposed Ward Valley, California, Low-Level Radioactive Waste (LLRW) Facility (US Ecology and Atlan-Tech, 1992).

${ }^{\mathrm{b}}$ Background concentration listed or derived in Off-Site Radiation Exposure Review Project, Phase II Soil Program (McArthur and Miller, 1989)

$--=$ Not detected above minimum reporting limit 
Table A.14-8

Soil Sample Results for Isotopic Plutonium and Uranium Detected Above Minimum Reporting Limits at CAS 26-05-03

(Page 1 of 2)

\begin{tabular}{|c|c|c|c|c|c|}
\hline \multirow{2}{*}{$\begin{array}{c}\text { Sample } \\
\text { Identification } \\
\text { Number }\end{array}$} & \multirow{2}{*}{$\begin{array}{l}\text { Depth } \\
\text { (ft bgs) }\end{array}$} & \multicolumn{4}{|c|}{ Contaminants of Potential Concern (pCi/g) } \\
\hline & & Plutonium-239 & Uranium-234a & Uranium-235a & Uranium-238 \\
\hline \multicolumn{2}{|c|}{ Preliminary Action Levels } & 0.24 & 1.56 & 0.07 & 3.2 \\
\hline $271 \mathrm{M} 001$ & $5.5-6.5$ & -- & $\overline{1.11 \pm 0.21}$ & $0.166 \pm 0.061$ & $0.85 \pm 0.17$ \\
\hline $271 \mathrm{M} 003$ & $4.5-5.5$ & -- & $0.94 \pm 0.17$ & $0.075 \pm 0.036$ & $0.98 \pm 0.18$ \\
\hline $271 \mathrm{M} 005$ & $4.5-5.5$ & -- & $0.94 \pm 0.18$ & $0.079 \pm 0.041$ & $0.82 \pm 0.17$ \\
\hline $271 \mathrm{M} 006$ & $4.5-5.5$ & $\begin{array}{l}- \\
-\end{array}$ & $1.04 \pm 0.19$ & $0.075 \pm 0.039$ & $0.84 \pm 0.17$ \\
\hline $271 \mathrm{M} 010$ & $4-5$ & -- & $0.98 \pm 0.18$ & $0.051 \pm 0.029$ & $0.88 \pm 0.16$ \\
\hline $271 \mathrm{M} 012$ & $4-5$ & -- & $1.05 \pm 0.19$ & $0.087 \pm 0.039$ & $1.01 \pm 0.18$ \\
\hline $271 \mathrm{M} 016$ & $4-5$ & -- & $1.01 \pm 0.18$ & -- & $0.82 \pm 0.15$ \\
\hline $271 \mathrm{M} 022$ & $3.3-4.4$ & -- & $1.02 \pm 0.20$ & -- & $1.03 \pm 0.20$ \\
\hline $271 \mathrm{M} 024$ & $4.4-5.4$ & -- & $1.02 \pm 0.19$ & -- & $0.9 \pm 0.17$ \\
\hline $271 \mathrm{M} 026$ & $4-5$ & -- & $1.02 \pm 0.19$ & $0.058 \pm 0.032$ & $1.04 \pm 0.19$ \\
\hline $271 \mathrm{M} 028$ & $4-5$ & -- & $0.89 \pm 0.17$ & -- & $0.98 \pm 0.18$ \\
\hline $271 \mathrm{M} 030$ & $4-5$ & -- & $1.07 \pm 0.19$ & $0.087 \pm 0.040$ & $0.93 \pm 0.17$ \\
\hline $271 \mathrm{M} 032$ & $3.5-4.5$ & $\overline{--}$ & $1 \pm 0.17$ & $0.074 \pm 0.032$ & $0.91 \pm 0.16$ \\
\hline $271 \mathrm{M} 034$ & $4-5$ & -- & $0.96 \pm 0.17$ & -- & $0.86 \pm 0.16$ \\
\hline $271 \mathrm{M} 036$ & $3.5-4.5$ & -- & $0.83 \pm 0.16$ & -- & $0.9 \pm 0.17$ \\
\hline $271 \mathrm{M} 038$ & $4-5$ & -- & $0.83 \pm 0.15$ & -- & $0.89 \pm 0.16$ \\
\hline $271 \mathrm{M} 040$ & $4-5$ & -- & $1 \pm 0.19$ & -- & $0.9 \pm 0.17$ \\
\hline $271 \mathrm{M} 042$ & $4-5$ & $\begin{array}{l}- \\
-\end{array}$ & $1.02 \pm 0.18$ & $0.076 \pm 0.034$ & $0.89 \pm 0.16$ \\
\hline $271 \mathrm{M} 044$ & $4-5$ & $0.052 \pm 0.027$ & $0.96 \pm 0.17$ & -- & $0.77 \pm 0.14$ \\
\hline $271 \mathrm{M} 046$ & $4-5$ & -- & $1.11 \pm 0.19$ & $0.096 \pm 0.037$ & $0.9 \pm 0.16$ \\
\hline $271 \mathrm{M} 048$ & $4-5$ & -- & $0.85 \pm 0.16$ & $0.068 \pm 0.034$ & $0.78 \pm 0.15$ \\
\hline $271 \mathrm{M} 050$ & $4-5$ & -- & $1.62 \pm 0.26$ & $0.144 \pm 0.050$ & $1.27 \pm 0.21$ \\
\hline $271 \mathrm{M} 052$ & $4-5$ & -- & $1.17 \pm 0.19$ & $0.064 \pm 0.030$ & $1.05 \pm 0.18$ \\
\hline $271 \mathrm{M} 054$ & $4-5$ & -- & $1.19 \pm 0.21$ & $0.074 \pm 0.037$ & $1.06 \pm 0.19$ \\
\hline $271 \mathrm{M} 056$ & $4.5-5.5$ & $\begin{array}{l}- \\
-\end{array}$ & $1.24 \pm 0.22$ & -- & $0.98 \pm 0.18$ \\
\hline $271 \mathrm{M} 060$ & $4-5$ & -- & $0.84 \pm 0.15$ & -- & $0.84 \pm 0.15$ \\
\hline $271 \mathrm{M} 062$ & $4.5-5.5$ & -- & $0.91 \pm 0.16$ & -- & $0.85 \pm 0.15$ \\
\hline $271 \mathrm{M} 064$ & $4-5$ & -- & $0.75 \pm 0.14$ & -- & $0.74 \pm 0.14$ \\
\hline $271 \mathrm{M} 066$ & $4-5$ & -- & $1.06 \pm 0.18$ & $0.061 \pm 0.030$ & $0.94 \pm 0.16$ \\
\hline $271 \mathrm{M} 067$ & $4-5$ & -- & $1.12 \pm 0.20$ & -- & $0.92 \pm 0.17$ \\
\hline $271 \mathrm{M} 069$ & $4.5-5.5$ & -- & $0.84 \pm 0.16$ & -- & $0.79 \pm 0.15$ \\
\hline $271 \mathrm{M} 071$ & $4-5$ & -- & $1.33 \pm 0.21$ & $0.074 \pm 0.032$ & $1.09 \pm 0.18$ \\
\hline
\end{tabular}


Table A.14-8

Soil Sample Results for Isotopic Plutonium and Uranium Detected Above Minimum Reporting Limits at CAS 26-05-03

(Page 2 of 2)

\begin{tabular}{|c|c|c|c|c|c|}
\hline \multirow{2}{*}{$\begin{array}{c}\text { Sample } \\
\text { Identification } \\
\text { Number }\end{array}$} & $\begin{array}{c}\text { Depth } \\
\text { (ft bgs) }\end{array}$ & \multicolumn{4}{|c|}{ Contaminants of Potential Concern (pCi/g) } \\
\cline { 3 - 6 } & Plutonium-239 & Uranium-234 $^{\mathrm{a}}$ & Uranium-235 $^{\mathrm{a}}$ & Uranium-238 $^{\mathrm{b}}$ \\
\hline Preliminary Action Levels & $\mathbf{0 . 2 4}$ & $\mathbf{1 . 5 6}$ & $\mathbf{0 . 0 7}$ & $\mathbf{3 . 2}$ \\
\hline \hline $271 \mathrm{M} 073$ & $4-5$ & -- & $1.2 \pm 0.20$ & $0.06 \pm 0.029$ & $1.04 \pm 0.18$ \\
\hline $271 \mathrm{M} 075$ & $8-9$ & -- & $0.8 \pm 0.15$ & -- & $0.86 \pm 0.16$ \\
\hline $271 \mathrm{M} 077$ & $8-9$ & -- & $0.84 \pm 0.16$ & $0.108 \pm 0.044$ & $0.9 \pm 0.17$ \\
\hline
\end{tabular}

aBackground concentration listed in Environmental Monitoring Report for the Proposed Ward Valley, California, Low-Level Radioactive Waste (LLRW) Facility (US Ecology and Atlan-Tech, 1992).

bBackground concentration listed or derived in Off-Site Radiation Exposure Review Project, Phase II Soil Program (McArthur and Miller, 1989).

-- = Not detected above minimum reporting limit

\section{A.14.3.1.10 Strontium-90}

Strontium-90 was not detected above MRLs in CAS 26-05-03 soil samples.

\section{A.14.3.2 Septic Tank/Manhole \#1 Results}

Results from the analysis of the septic tank/manhole content sample were compared to regulatory levels based on disposal options. If the waste has no hazardous component, the regulatory level is based on disposal options at NTS landfills and lagoons (BN, 1995; CFR, 2000b and c; NDEP, 1997a, b, and c). Any sludge or liquid waste will be solidified before disposal at NTS landfills (NDEP, 1997b). If the waste is hazardous, the release criteria are based on interpretation of the guidelines presented in the POC (BN, 1995; Alderson, 1999). For waste destined for off-site disposal, the POC radiological levels must be met to certify that the waste has no radioactivity added.

One composite sample obtained from sediment in the bottom of the septic tank and Manhole 1. The analytical suite followed the CAIP and is detailed in Section A.14.2.9. Analytical results exceeding MRLs are listed in Table A.14-9. 
Table A.14-9

Sediment Samples Results Detected Above Minimum Reporting Limits at CAS 26-05-03

(Page 1 of 2)

\begin{tabular}{|c|c|c|c|c|c|c|}
\hline $\begin{array}{c}\text { Sample } \\
\text { Identification } \\
\text { Number }\end{array}$ & Matrix & Parameter & Result & Units & Limits & Reference \\
\hline $271 \mathrm{M} 079$ & Sediment & Mercury $^{* *}$ & 0.46 & $\mathrm{mg} / \mathrm{kg}$ & $\mathrm{NA}$ & CFR, 2000a \\
\hline $271 \mathrm{M} 079$ & Sediment & Arsenic** & 23 & $\mathrm{mg} / \mathrm{kg}$ & NA & CFR, 2000a \\
\hline $271 \mathrm{M} 079$ & Sediment & Barium** & 120 & $\mathrm{mg} / \mathrm{kg}$ & NA & CFR, 2000a \\
\hline $271 \mathrm{M} 079$ & Sediment & Cadmium** & 32 & $\mathrm{mg} / \mathrm{kg}$ & NA & CFR, 2000a \\
\hline $271 \mathrm{M} 079$ & Sediment & Chromium** & 320 & $\mathrm{mg} / \mathrm{kg}$ & NA & CFR, 2000a \\
\hline $271 \mathrm{M} 079$ & Sediment & Lead & 340 & $\mathrm{mg} / \mathrm{kg}$ & NA & CFR, 2000a \\
\hline $271 \mathrm{M} 079$ & Sediment & Selenium ${ }^{\star *}$ & 10 & $\mathrm{mg} / \mathrm{kg}$ & NA & CFR, 2000a \\
\hline $271 \mathrm{M} 079$ & Sediment & Silver ${ }^{* *}$ & $19(\mathrm{~J})^{\mathrm{a}}$ & $\mathrm{mg} / \mathrm{kg}$ & NA & CFR, 2000a \\
\hline $271 \mathrm{M} 079$ & Sediment & TCLP Lead & 0.082 & $\mathrm{mg} / \mathrm{L}$ & 5 & CFR, 2000a \\
\hline 271 M079 & Sediment & Diesel-Range Organics & $1,300(M, Z)$ & $\mathrm{mg} / \mathrm{kg}$ & 100 & NDEP, 1997b \\
\hline $271 \mathrm{M} 079$ & Sediment & Methylene Chloride & 15 & $\mu \mathrm{g} / \mathrm{kg}$ & NA & CFR, 2000a \\
\hline $271 \mathrm{M} 079$ & Sediment & 2-Methylnaphthalene & 1,100 & $\mu \mathrm{g} / \mathrm{kg}$ & NA & CFR, 2000a \\
\hline $271 \mathrm{M} 079$ & Sediment & Benzo(A)Anthracene & $3,700(J)^{b}$ & $\mu \mathrm{g} / \mathrm{kg}$ & NA & CFR, 2000a \\
\hline $271 \mathrm{M} 079$ & Sediment & Benzo(A)Pyrene & $3,400(J)^{b}$ & $\mu \mathrm{g} / \mathrm{kg}$ & NA & CFR, 2000a \\
\hline $271 \mathrm{M} 079$ & Sediment & Benzo(B)Fluoranthene & $2,700(J)^{b}$ & $\mu \mathrm{g} / \mathrm{kg}$ & NA & CFR, 2000a \\
\hline $271 \mathrm{M} 079$ & Sediment & Benzo(G,H,I)Perylene & $2,500(J)^{c}$ & $\mu \mathrm{g} / \mathrm{kg}$ & NA & CFR, 2000a \\
\hline $271 \mathrm{M} 079$ & Sediment & Benzo(K)Fluoranthene & $850(J)^{b}$ & $\mu \mathrm{g} / \mathrm{kg}$ & NA & CFR, 2000a \\
\hline $271 \mathrm{M} 079$ & Sediment & Chrysene & $4,900(J)^{b}$ & $\mu \mathrm{g} / \mathrm{kg}$ & NA & CFR, 2000a \\
\hline $271 \mathrm{M} 079$ & Sediment & Fluoranthene & 1,700 & $\mu \mathrm{g} / \mathrm{kg}$ & NA & CFR, 2000a \\
\hline $271 \mathrm{M} 079$ & Sediment & Indeno(1,2,3-CD)Pyrene & $2,100(J)^{b}$ & $\mu \mathrm{g} / \mathrm{kg}$ & NA & CFR, 2000a \\
\hline $271 \mathrm{M} 079$ & Sediment & Naphthalene & 870 & $\mu \mathrm{g} / \mathrm{kg}$ & NA & CFR, 2000a \\
\hline $271 \mathrm{M} 079$ & Sediment & Phenanthrene & 4,700 & $\mu \mathrm{g} / \mathrm{kg}$ & NA & CFR, 2000a \\
\hline $271 \mathrm{M} 079$ & Sediment & Pyrene & $12,000(J)^{b}$ & $\mu \mathrm{g} / \mathrm{kg}$ & NA & CFR, 2000a \\
\hline $271 \mathrm{M} 079$ & Sediment & Potassium-40 & $8.6 \pm 2.7$ & $\mathrm{pCi} / \mathrm{g}$ & - & $\mathrm{N}$ \\
\hline $271 \mathrm{M} 079$ & Sediment & Lead-212 & $0.79 \pm 0.25$ & $\mathrm{pCi} / \mathrm{g}$ & - & $\mathrm{N}$ \\
\hline $271 \mathrm{M} 079$ & Sediment & Uranium-234 & $4.25 \pm 0.65$ & $\mathrm{pCi} / \mathrm{g}$ & 100 & NDEP, 1997b \\
\hline $271 \mathrm{M} 079$ & Sediment & Uranium-235 & $0.269 \pm 0.083(\mathrm{~J})^{\mathrm{d}}$ & $\mathrm{pCi} / \mathrm{g}$ & 100 & NDEP, 1997b \\
\hline $271 \mathrm{M} 079$ & Sediment & Uranium-238 & $2.23 \pm 0.37$ & $\mathrm{pCi} / \mathrm{g}$ & 100 & NDEP, 1997b \\
\hline
\end{tabular}


Table A.14-9

\section{Sediment Samples Results Detected \\ Above Minimum Reporting Limits at CAS 26-05-03}

(Page 2 of 2)

\begin{tabular}{|c|c|c|c|c|c|c|}
\hline $\begin{array}{c}\text { Sample } \\
\text { Identification } \\
\text { Number }\end{array}$ & Matrix & Parameter & Result & Units & Limits & Reference \\
\hline $271 \mathrm{M} 079$ & Sediment & Aroclor-1254 & $2,500(\mathrm{~J})^{\mathrm{e}}$ & $\mu \mathrm{g} / \mathrm{kg}$ & 50,000 & CFR, 2000 \\
\hline
\end{tabular}

${ }^{a} Q u a l i f i e r$ added to laboratory data; record accepted. Spike recovery was outside control limits.

${ }^{b}$ Qualifier added to laboratory data; record accepted. Internal standard area count exceeded the quality control limits. Matrix effects may exist.

${ }^{\circ}$ Qualifier added to laboratory data; record accepted. Internal standard area count exceeded the quality control limits. Matrix effects may exist.

Continuing calibration verification percent $>25$ percent.

${ }^{\mathrm{d}}$ Qualifier added to laboratory data; record accepted.

${ }^{\mathrm{e}}$ Qualifier added to laboratory data; record accepted. Surrogates diluted out.

** $=$ TCLP below minimum reporting limit

$\mathrm{J}=$ Estimated value

$M=$ Motor oil

$\mathrm{N}=$ No limit established (NDEP, 1997b)

NA $=$ Not applicable

$\mathrm{Z}=$ The reported result did not resemble the patterns of the following hydrocarbon products: gasoline, JP-4, JP-8, diesel, mineral spirits, motor oil, Stoddard solvent and Bunker C

Several COPCs were detected in the sediment sample. All COPCs were below regulatory limits except for TPH DRO. The concentration in this sample was $1,300 \mathrm{mg} / \mathrm{kg}$; this level exceeds the NDEP action level of $100 \mathrm{mg} / \mathrm{kg}$ (NAC, 2000) for TPH.

\section{A.14.4 Contaminants of Concern}

Based on the aforementioned analytical results, TPH DRO is present in the septic tank and manhole sediment in concentrations above the NDEP action level of $100 \mathrm{mg} / \mathrm{kg}$ (NAC, 2000). No COCs are present in the soil surrounding the distribution box or under the leachfield. Based on radiological survey and swipe results, total and removable radiological contamination levels of the collection system are below unrestricted release criteria.

\section{A.14.5 Nature and Extent of Contamination}

Approximately 1 gal of TPH DRO-contaminated sediment remained in the bottom of the septic tank/manhole.

\section{A.14.6 Revised Conceptual Model}

No variations in the conceptual model were identified. 


\section{A.15.0 Building 2201 Septic System (CAS 26-05-04)}

The Building 2201 septic system was designed to receive sanitary effluent generated by activities at Building 2201 (Disassembly Building). The septic system is located approximately $250 \mathrm{ft}$ south of Building 2201. The site is comprised of a leachfield, septic tank, distribution box, and associated piping. More detail is provided in the CAIP (DOE/NV, 2001).

\section{A.15.1 Corrective Action Investigation}

Ninety-six investigation samples, listed in Table A.15-1, were collected during investigation activities conducted at CAS 26-05-04. The planned and actual sample locations are shown in Figure A.15-1. The specific CAI activities that were conducted to meet CAIP requirements at CAS 26-05-04 are described in Table A.2-1.

\section{A.15.1.1 Deviations}

The following deviations to the CAIP requirements were the result of unforeseen circumstances:

- Refusal was met due to encountering subsurface hardpan (caliche), therefore:

- Sample 271N011 was collected at 4 to $5 \mathrm{ft}$ bgs rather than the planned interval of 5.5 to $6.5 \mathrm{ft}$ bgs. Additionally, two consecutive clean samples below this sampling interval were planned. Neither of the two consecutive clean samples could not be obtained due to the refusal.

- Sample 271N047 was collected at 10.5 to $11 \mathrm{ft}$ bgs rather than the planned interval of 11.1 to $12.1 \mathrm{ft}$ bgs. Additionally, two consecutive clean samples below this sampling interval were planned. Neither of the two consecutive clean samples could not be obtained due to the refusal.

- Sample 271N053 was collected at the planned interval of 11.1 to $12.1 \mathrm{ft}$ bgs. However, two consecutive clean samples below this sampling interval were planned. Neither of the two consecutive clean samples could not be obtained due to the refusal with the backhoe.

- Sample 271N057 was collected at 9.1 to $9.6 \mathrm{ft}$ bgs rather than the planned interval of 11.1 to $12.1 \mathrm{ft}$ bgs. An additional consecutive clean sample below this sampling interval was planned but could not be obtained due to the refusal. 
Table A.15-1

Samples Collected at CAS 26-05-04

(Page 1 of 6 )

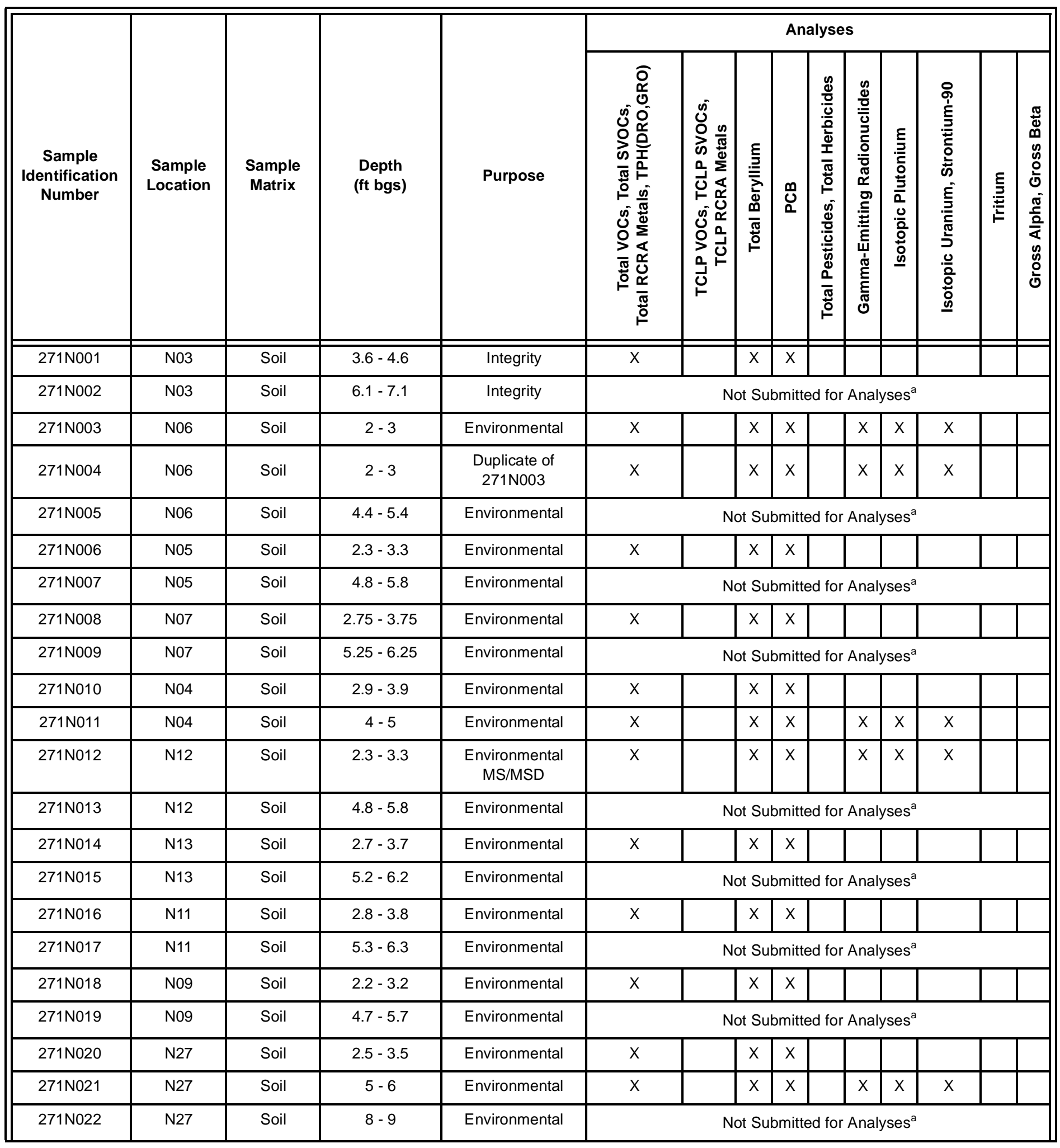


Table A.15-1

Samples Collected at CAS 26-05-04

(Page 2 of 6 )

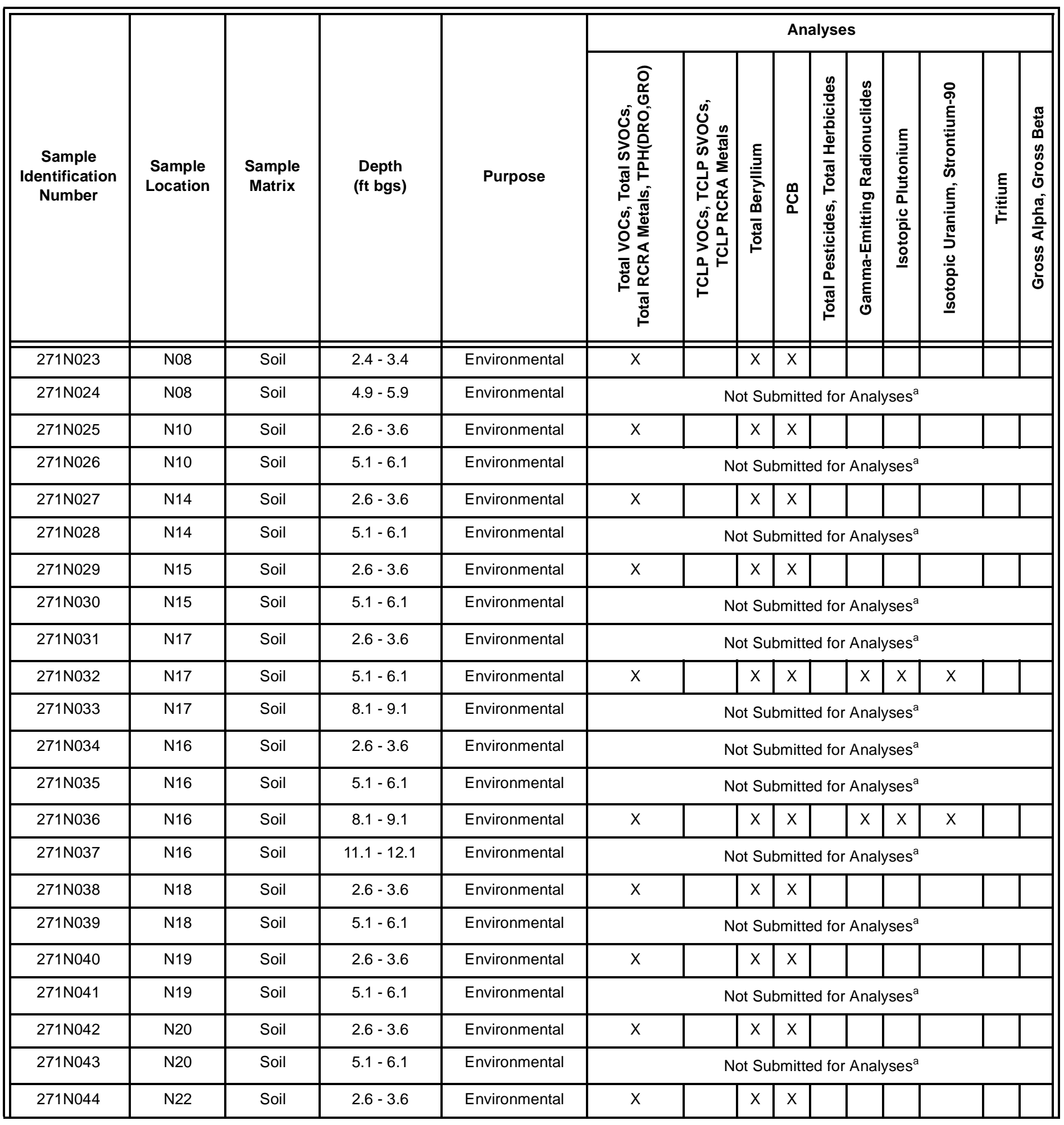


Table A.15-1

Samples Collected at CAS 26-05-04

(Page 3 of 6 )

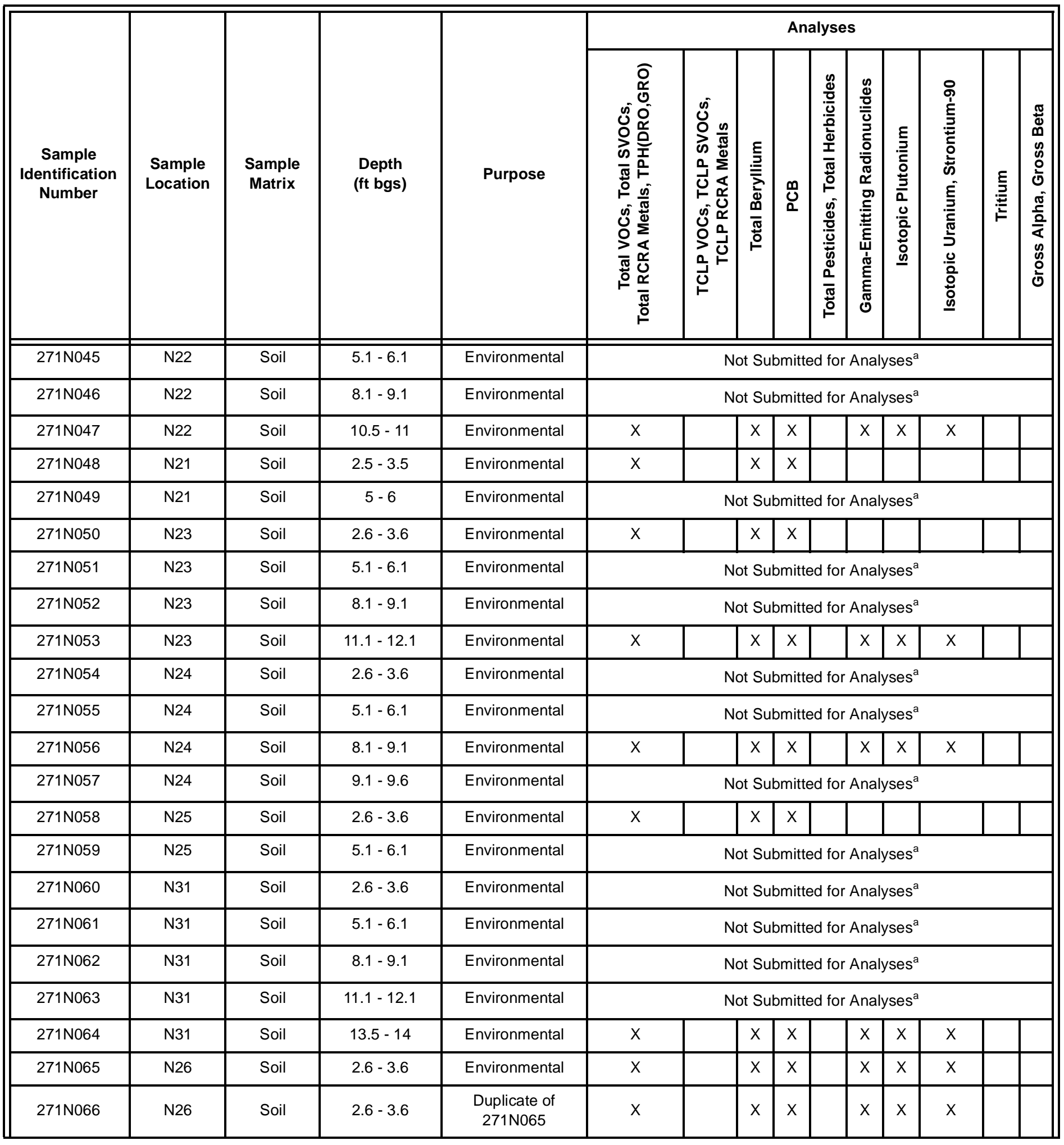


Table A.15-1

Samples Collected at CAS 26-05-04

(Page 4 of 6 )

\begin{tabular}{|c|c|c|c|c|c|c|c|c|c|c|c|c|c|c|}
\hline \multirow[b]{2}{*}{$\begin{array}{c}\text { Sample } \\
\text { Identification } \\
\text { Number }\end{array}$} & \multirow[b]{2}{*}{$\begin{array}{c}\text { Sample } \\
\text { Location }\end{array}$} & \multirow[b]{2}{*}{$\begin{array}{c}\text { Sample } \\
\text { Matrix }\end{array}$} & \multirow[b]{2}{*}{$\begin{array}{c}\text { Depth } \\
\text { (ft bgs) }\end{array}$} & \multirow[b]{2}{*}{ Purpose } & \multicolumn{10}{|c|}{ Analyses } \\
\hline & & & & & 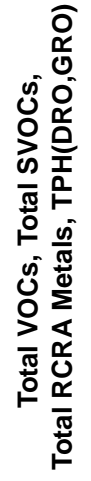 & 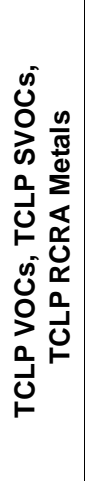 & 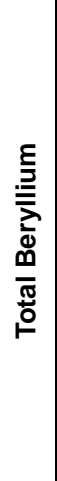 & $\begin{array}{l}m \\
0 \\
\mathbf{Q}\end{array}$ & 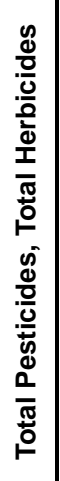 & 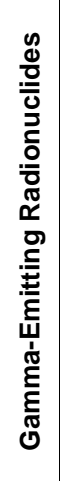 & 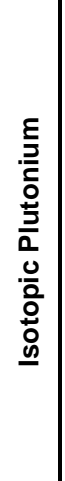 & 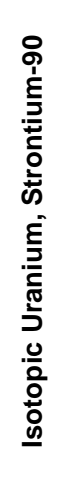 & 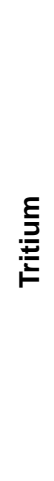 & 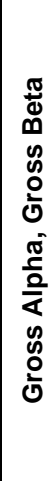 \\
\hline $271 \mathrm{~N} 067$ & N26 & Soil & $5.1-6.1$ & Environmental & \multicolumn{10}{|c|}{ Not Submitted for Analyses ${ }^{a}$} \\
\hline $271 \mathrm{~N} 068$ & N26 & Soil & $8.1-9.1$ & Environmental & \multicolumn{10}{|c|}{ Not Submitted for Analyses ${ }^{a}$} \\
\hline 271 N069 & N26 & Soil & $9.7-10.2$ & Environmental & $x$ & & $x$ & $\mathrm{x}$ & & $x$ & $x$ & $\mathrm{x}$ & & \\
\hline $271 \mathrm{~N} 070$ & N30 & Soil & $2.75-3.75$ & Environmental & $x$ & & $x$ & $\mathrm{x}$ & & & & & & \\
\hline $271 \mathrm{~N} 071$ & N29 & Soil & $2.6-3.6$ & Environmental & $x$ & & $\mathrm{x}$ & $\mathrm{x}$ & & & & & & \\
\hline $271 \mathrm{~N} 072$ & N30 & Soil & $5.25-6.25$ & Environmental & \multicolumn{10}{|c|}{ Not Submitted for Analyses ${ }^{a}$} \\
\hline $271 \mathrm{~N} 073$ & N29 & Soil & $5.1-6.1$ & Environmental & \multicolumn{10}{|c|}{ Not Submitted for Analyses ${ }^{a}$} \\
\hline $271 \mathrm{~N} 074$ & N32 & Soil & $2.6-3.6$ & Environmental & $x$ & & $\mathrm{x}$ & $\mathrm{x}$ & & & & & & \\
\hline $271 \mathrm{~N} 075$ & N32 & Soil & $5.1-6.1$ & Environmental & \multicolumn{10}{|c|}{ Not Submitted for Analyses ${ }^{a}$} \\
\hline $271 \mathrm{~N} 076$ & N33 & Soil & $2.6-3.6$ & $\begin{array}{l}\text { Environmental } \\
\text { MS/MSD }\end{array}$ & $x$ & & $x$ & $x$ & & $x$ & $x$ & $x$ & & \\
\hline $271 \mathrm{~N} 077$ & N33 & Soil & $5.1-6.1$ & Environmental & \multicolumn{10}{|c|}{ Not Submitted for Analyses ${ }^{a}$} \\
\hline $271 \mathrm{~N} 078$ & N28 & Soil & $2.5-3.5$ & Environmental & $x$ & & $\mathrm{X}$ & $x$ & & & & & & \\
\hline $271 \mathrm{~N} 079$ & N28 & Soil & $5-6$ & Environmental & \multicolumn{10}{|c|}{ Not Submitted for Analyses ${ }^{a}$} \\
\hline $271 \mathrm{~N} 080$ & N01 & Soil & $10.2-11.2$ & Integrity & $x$ & & $x$ & $\mathrm{x}$ & & & & & & \\
\hline $271 \mathrm{~N} 081$ & $\mathrm{~N}$ & Liquid & $4-8.9$ & $\begin{array}{c}\text { Septic Tank } \\
\text { MS/MSD }\end{array}$ & $x$ & & $x$ & $x$ & & $x$ & $x$ & $x$ & & \\
\hline 271 N082 & $\mathrm{N}$ & Sludge & $8.9-9.75$ & Septic Tank & $x$ & $x$ & $x$ & $x$ & & $x$ & $x$ & $x$ & & \\
\hline $271 \mathrm{~N} 083$ & $\mathrm{~N}$ & Sludge & $8.9-9.75$ & $\begin{array}{c}\text { Duplicate of } \\
271 \text { N082 }\end{array}$ & $x$ & $x$ & $x$ & $\mathrm{x}$ & & $x$ & $x$ & $x$ & & \\
\hline $271 \mathrm{~N} 084$ & $\mathrm{~N}$ & Sludge & $7.5-7.7$ & Septic Tank & $x$ & $x$ & $x$ & $\mathrm{x}$ & & $x$ & $x$ & $x$ & $x$ & \\
\hline $271 \mathrm{~N} 085$ & $\mathrm{~N}$ & Liquid & $7.5-7.7$ & Septic Tank & $x$ & & $\mathrm{x}$ & $x$ & & $x$ & $x$ & $x$ & $x$ & $\mathrm{x}$ \\
\hline 271 N086 & N34 & Soil & $2.5-2.75$ & Geotechnical & \multicolumn{10}{|c|}{ Not Submitted for Analyses ${ }^{b}$} \\
\hline
\end{tabular}


Table A.15-1

Samples Collected at CAS 26-05-04

(Page 5 of 6 )

\begin{tabular}{|c|c|c|c|c|c|c|c|c|c|c|c|c|c|c|}
\hline \multirow[b]{2}{*}{$\begin{array}{c}\text { Sample } \\
\text { Identification } \\
\text { Number }\end{array}$} & \multirow[b]{2}{*}{$\begin{array}{c}\text { Sample } \\
\text { Location }\end{array}$} & \multirow[b]{2}{*}{$\begin{array}{c}\text { Sample } \\
\text { Matrix }\end{array}$} & \multirow[b]{2}{*}{$\begin{array}{c}\text { Depth } \\
\text { (ft bgs) }\end{array}$} & \multirow[b]{2}{*}{ Purpose } & \multicolumn{10}{|c|}{ Analyses } \\
\hline & & & & & 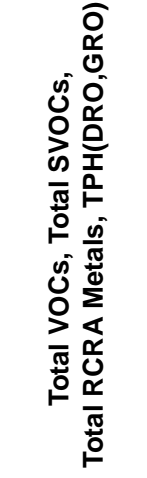 & 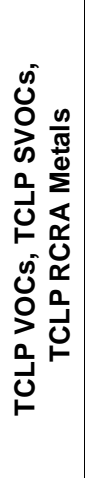 & 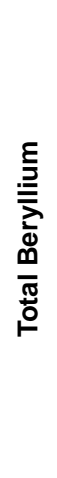 & O & 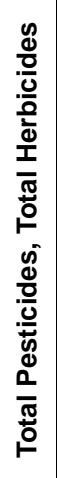 & 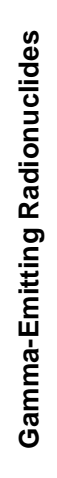 & 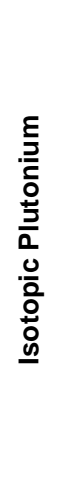 & 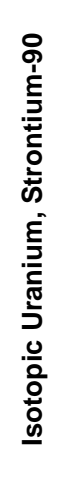 & 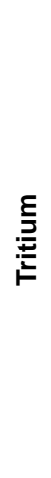 & 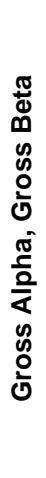 \\
\hline $271 \mathrm{~N} 087$ & N02 & Soil & $9.3-10.3$ & Integrity & $x$ & & $X$ & $X$ & & & & & & \\
\hline 271N088 & N02 & Soil & $11.8-12.8$ & Integrity & \multicolumn{10}{|c|}{ Not Submitted for Analyses ${ }^{a}$} \\
\hline $271 N 181$ & $\mathrm{~N}$ & Liquid & $4-8.9$ & Septic Tank & $\begin{array}{l}\text { VOC, TPH } \\
\text { GRO only }\end{array}$ & & & & & & & & & \\
\hline 271N182 & $\mathrm{N}$ & Sludge & $8.9-9.75$ & Septic Tank & $\begin{array}{l}\text { VOC, TPH } \\
\text { GRO only }\end{array}$ & & & & & & & & & \\
\hline $271 N 183$ & $\mathrm{~N}$ & Sludge & $8.9-9.75$ & $\begin{array}{c}\text { Duplicate of } \\
271 N 182\end{array}$ & $\begin{array}{l}\text { VOC, TPH } \\
\text { GRO only }\end{array}$ & & & & & & & & & \\
\hline 271N184 & $\mathrm{N}$ & Sludge & $7.5-7.7$ & Septic Tank & $\begin{array}{l}\text { VOC, TPH } \\
\text { GRO only }\end{array}$ & & & & & & & & & \\
\hline 271N185 & $\mathrm{N}$ & Liquid & $7.5-7.7$ & Septic Tank & $\begin{array}{l}\text { VOC, TPH } \\
\text { GRO only }\end{array}$ & & & & & & & & & \\
\hline 271N187 & N02 & Soil & $9.3-10.3$ & Integrity & $\begin{array}{l}\text { VOC, TPH } \\
\text { GRO only }\end{array}$ & & & & & & & & & \\
\hline 271 N201 & N38 & Soil & $2-2.5$ & $\begin{array}{c}\text { Environmental } \\
\text { MS/MSD }\end{array}$ & $\begin{array}{c}\text { RCRA } \\
\text { Metals } \\
\text { (Arsenic) }\end{array}$ & & & & & & & & & \\
\hline 271N202 & N39 & Soil & $3.5-4$ & Environmental & $\begin{array}{c}\text { RCRA } \\
\text { Metals } \\
\text { (Arsenic) }\end{array}$ & & & & & & & & & \\
\hline 271N203 & N39 & Soil & $3.5-4$ & $\begin{array}{c}\text { Duplicate of } \\
271 \text { N202 }\end{array}$ & $\begin{array}{c}\text { RCRA } \\
\text { Metals } \\
\text { (Arsenic) }\end{array}$ & & & & & & & & & \\
\hline 271N204 & N37 & Soil & $3-3.5$ & Environmental & $\begin{array}{c}\text { RCRA } \\
\text { Metals } \\
\text { (Arsenic) }\end{array}$ & & & & & & & & & \\
\hline 271N205 & N37 & Soil & $4-4.5$ & Environmental & $\begin{array}{c}\text { RCRA } \\
\text { Metals } \\
\text { (Arsenic) }\end{array}$ & & & & & & & & & \\
\hline $271 N 301$ & NA & Water & NA & Trip Blank & VOC only & & & & & & & & & \\
\hline
\end{tabular}


Table A.15-1

Samples Collected at CAS 26-05-04

(Page 6 of 6 )

\begin{tabular}{|c|c|c|c|c|c|c|c|c|c|c|c|c|c|c|}
\hline \multirow[b]{2}{*}{$\begin{array}{c}\text { Sample } \\
\text { Identification } \\
\text { Number }\end{array}$} & \multirow[b]{2}{*}{$\begin{array}{c}\text { Sample } \\
\text { Location }\end{array}$} & \multirow[b]{2}{*}{$\begin{array}{c}\text { Sample } \\
\text { Matrix }\end{array}$} & \multirow[b]{2}{*}{$\begin{array}{c}\text { Depth } \\
\text { (ft bgs) }\end{array}$} & \multirow[b]{2}{*}{ Purpose } & \multicolumn{10}{|c|}{ Analyses } \\
\hline & & & & & 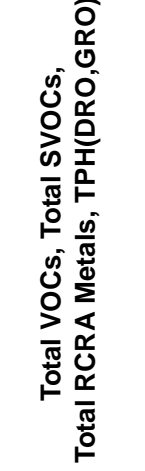 & 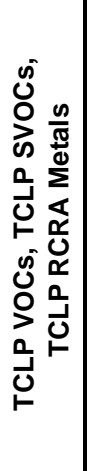 & 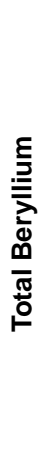 & O̊ & 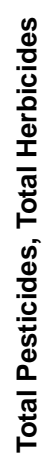 & 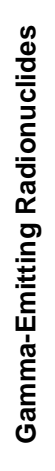 & 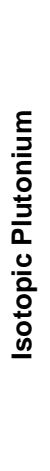 & 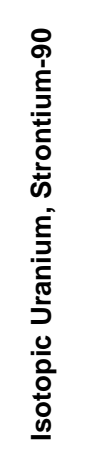 & 톨 & 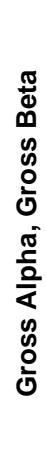 \\
\hline 271N302 & NA & Water & NA & Field Blank & $X$ & & $\mathrm{X}$ & $\mathrm{X}$ & & $X$ & $X$ & $\mathrm{X}$ & & \\
\hline 271N303 & NA & Water & NA & Trip Blank & VOC only & & & & & & & & & \\
\hline 217N304 & NA & Water & NA & Trip Blank & VOC only & & & & & & & & & \\
\hline 271N305 & NA & Water & NA & Trip Blank & VOC only & & & & & & & & & \\
\hline 271 N306 & NA & Water & NA & Trip Blank & VOC only & & & & & & & & & \\
\hline 271N307 & NA & Water & NA & Trip Blank & VOC only & & & & & & & & & \\
\hline 271N308 & NA & Water & NA & Rinsate & $x$ & & $x$ & $x$ & & $X$ & $X$ & $x$ & & \\
\hline 271N309 & NA & Water & NA & Trip Blank & VOC only & & & & & & & & & \\
\hline 271 N310 & NA & Water & NA & Trip Blank & VOC only & & & & & & & & & \\
\hline $271 N 311$ & NA & Water & NA & Trip Blank & VOC only & & & & & & & & & \\
\hline 271N312 & NA & Water & NA & Trip Blank & VOC only & & & & & & & & & \\
\hline 271 N313 & NA & Water & NA & Rinsate & $x$ & & $X$ & $x$ & & $x$ & $X$ & $X$ & $x$ & \\
\hline 271N314 & NA & Water & NA & Trip Blank & VOC only & & & & & & & & & \\
\hline 271N351 & NA & Water & NA & Rinsate & $\begin{array}{c}\text { TPH } \\
\text { (DRO), } \\
\text { RCRA } \\
\text { Metals } \\
\text { (Arsenic) }\end{array}$ & & & $x$ & $X$ & & $x$ & Iso-U & & \\
\hline 271N353 & NA & Water & NA & Rinsate & $\begin{array}{l}\text { VOC and } \\
\text { TPH GRO }\end{array}$ & & & & & & & & & \\
\hline 271N354 & NA & Water & NA & Trip Blank & VOC only & & & & & & & & & \\
\hline
\end{tabular}

a The sample was collected, field screened, and returned to the site for disposal.

${ }^{b}$ The sample was collected, field screened, and is being stored for possible geotechnical analysis.

NA = Not applicable

MS/MSD = Matrix spike/matrix spike duplicate 


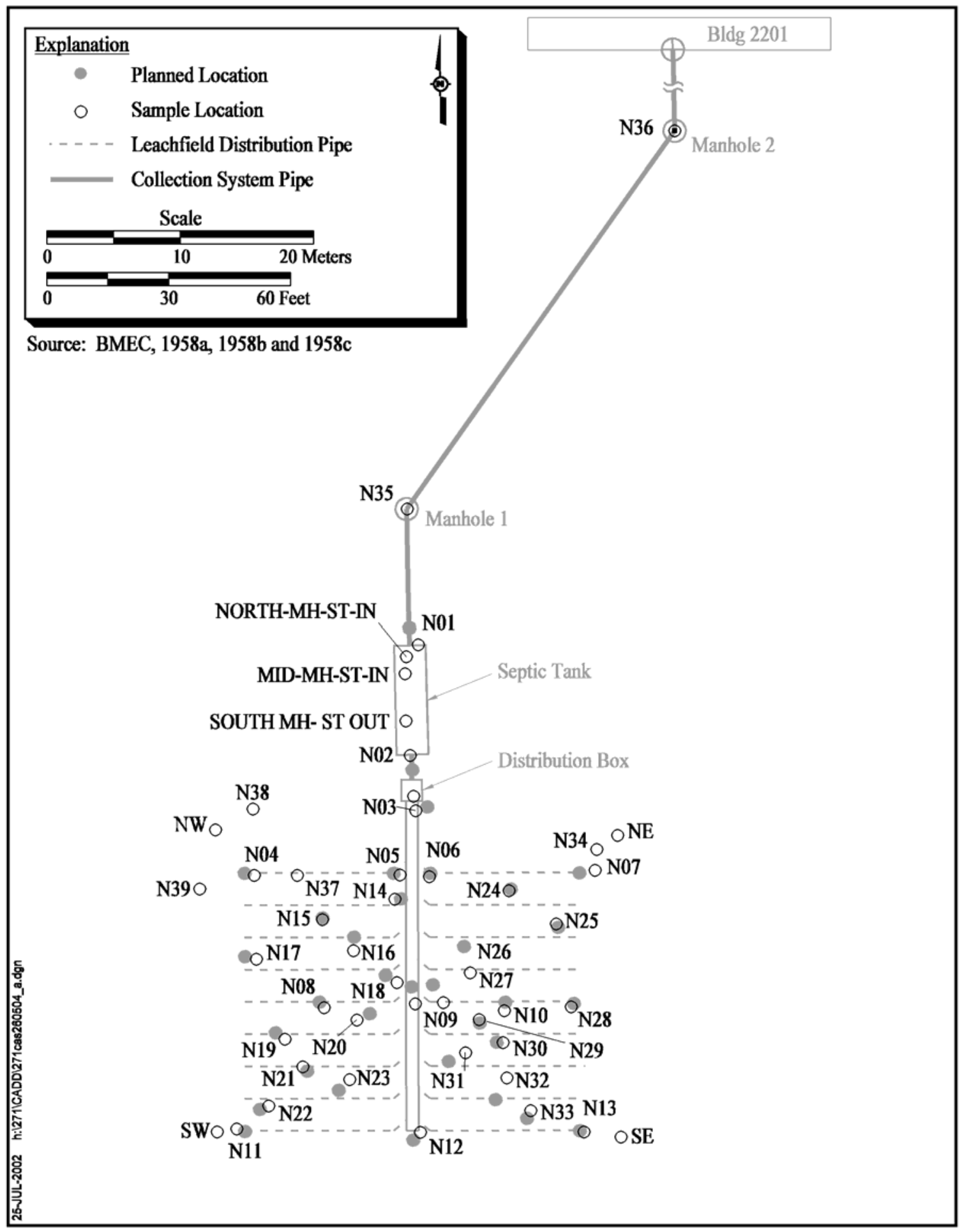

Figure A.15-1

Building 2201 Septic System (CAS 26-05-04) Sample Locations 
- Sample 271N064 was collected at 13.5 to $14 \mathrm{ft} \mathrm{bgs} \mathrm{rather} \mathrm{than} \mathrm{the} \mathrm{planned} \mathrm{interval} \mathrm{of}$ 15.1 to $16.1 \mathrm{ft}$ bgs. An additional consecutive clean sample below this sampling interval was planned but could not be obtained due to the refusal.

- Sample 271N069 was collected at 9.7 to $10.2 \mathrm{ft}$ bgs rather than the planned interval of 12.1 to $13.1 \mathrm{ft}$ bgs. An additional consecutive clean sample below this sampling interval was planned but could not be obtained due to the refusal.

- Sample 271N080 was collected at the planned interval of 10.2 to $11.2 \mathrm{ft}$ bgs. An additional consecutive clean sample below this sampling interval was planned but could not be obtained due to the refusal.

Despite these deviations, the pertinent CAIP requirements were met.

\section{A.15.2 Investigation Results}

The following subsections provide details of the inspection and sampling of leachfield features, field-screening results, and sample selection and analysis.

\section{A.15.2.1 Septic Tank Contents}

The large concrete septic tank was two-chambered and rectangular-shaped with a 8,245-gal capacity. It was accessed by three concrete manholes located at the ground surface. The inlet chamber was irregularly shaped and had a capacity of 6,252 gal. The interior dimensions of the outlet chamber were $6.5 \mathrm{ft}$ (length) by $6 \mathrm{ft}$ (width) by $6.8 \mathrm{ft}$ (depth) and had a capacity of 1,994 gal. One liquid and one sludge sample were collected from each of the chambers. Visual inspection revealed that a maximum thickness of $4.9 \mathrm{ft}$ (3,098 gal) of liquid and $10 \mathrm{in}$. (654 gal) of sludge remained in the bottom of the inlet chamber of the tank. A maximum thickness of $1 \mathrm{in.}(24 \mathrm{gal})$ of liquid and $1 \mathrm{in}$. (24 gal) of sludge remained in the bottom of the outlet chamber of the tank. Photographs of the septic tank were taken to document the visual inspection (Figure A.15-2).

\section{A.15.2.2 Distribution Box Contents}

The concrete distribution box was square-shaped with a 718-gal capacity. It was accessed by two manholes located at the ground surface. The interior dimensions of the distribution box were $4 \mathrm{ft}$ (length) by $4 \mathrm{ft}$ (width) by $6 \mathrm{ft}$ (depth). There was very little sediment in the bottom of the 


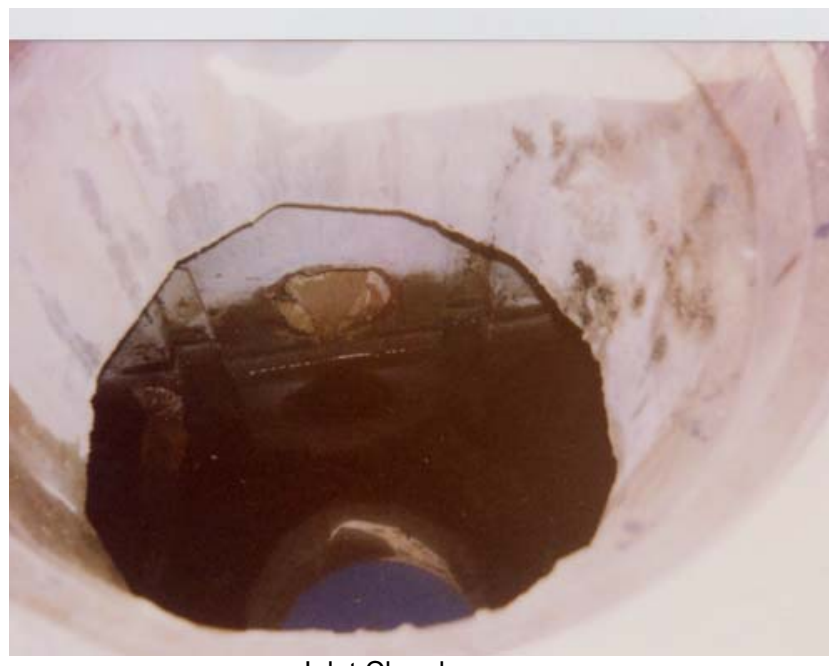

Inlet Chamber

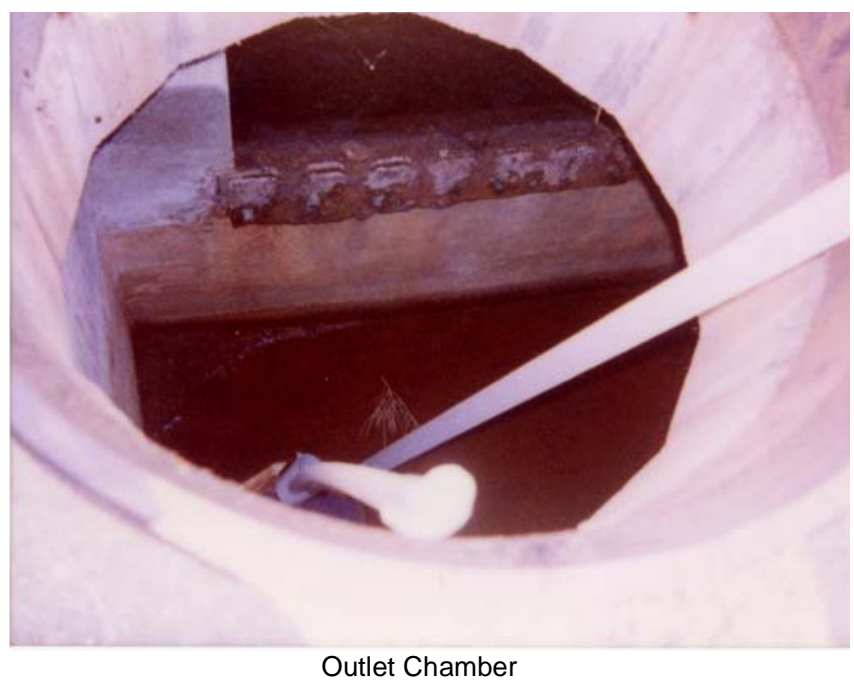

Outlet Chamber

Figure A.15-2

CAS 26-05-04 Septic Tank, Interior (Photographs Taken 01-17-2002)

distribution box, so no samples were collected. A photograph of the distribution box was taken to document the visual inspection (Figure A.15-3).

\section{A.15.2.3 Septic Tank and Distribution Box Integrity Soil Sampling}

Seven integrity samples were collected by excavating adjacent to influent and effluent ends of the septic tank and the effluent end of the distribution box. Figure A.15-4 and Figure A.15-5 depict the structural integrity and configuration of the influent end of the septic tank and the effluent end of the distribution box. The following four samples were submitted for laboratory analysis:

- The upper sample (271N001) from the effluent end of the distribution box, collected at 3.6 to $4.6 \mathrm{ft} \mathrm{bgs}$

- The upper sample (271N080) from the influent end of the septic tank, collected at 10.2 to $11.2 \mathrm{ft}$ bgs

- The upper sample (271N087) from the effluent end of the septic tank, collected at 9.3 to $10.3 \mathrm{ft}$ bgs 


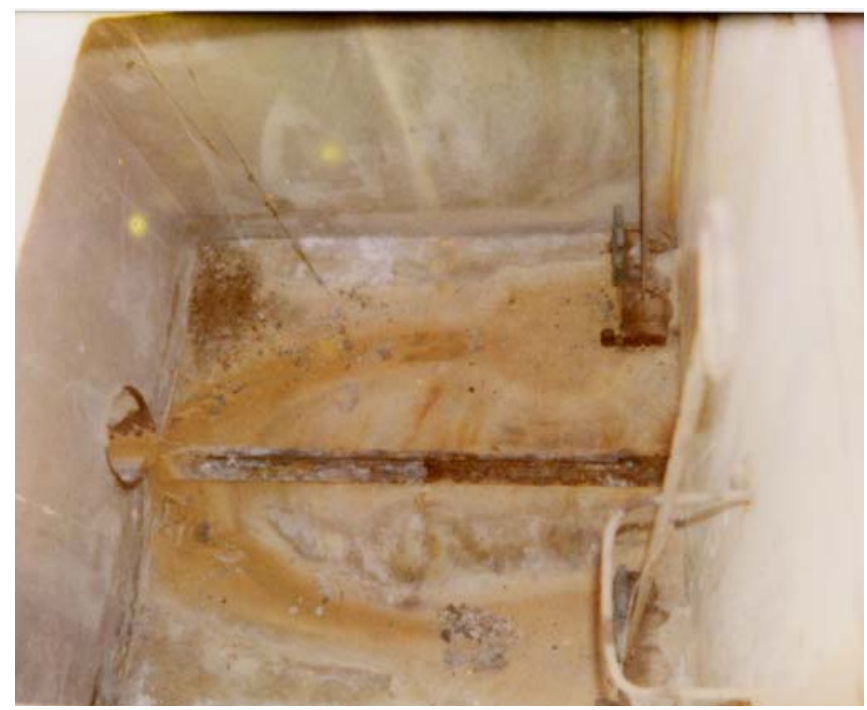

Interior View

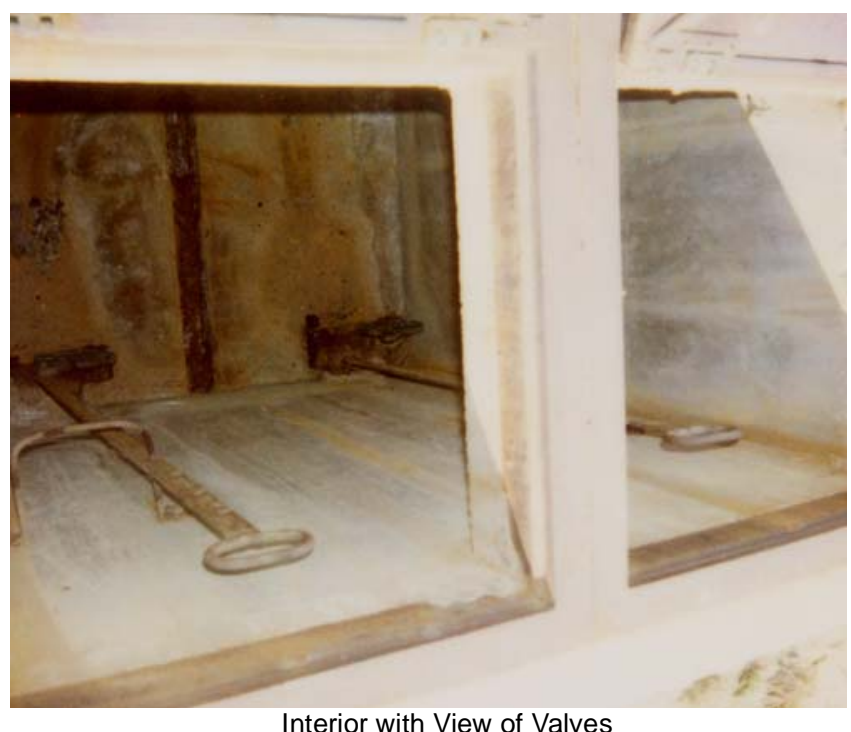

Interior with View of Valves

Figure A.15-3

CAS 26-05-04 Distribution Box, Interior (Photographs Taken 01-09-2002)

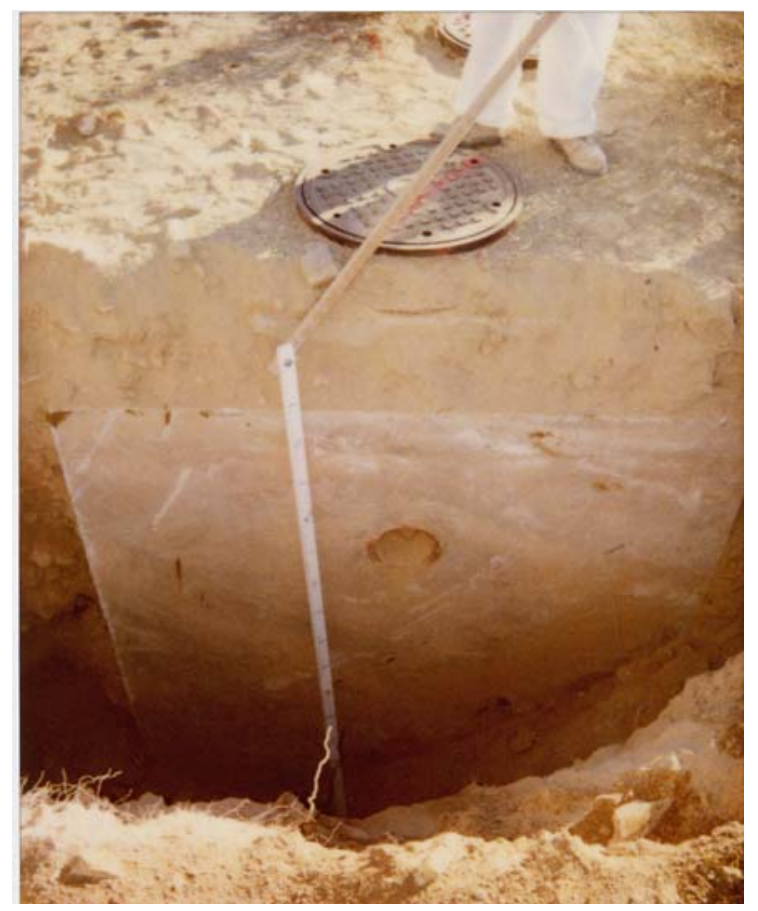

Figure A.15-4

CAS 26-05-04 Septic Tank, Influent Integrity Sample (Photograph Taken 01-16-2002) 


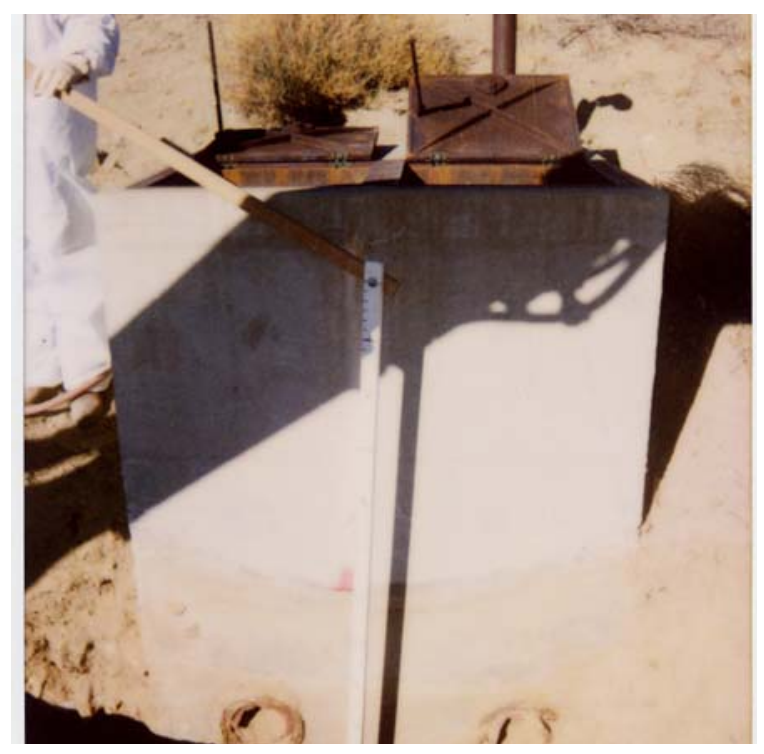

Figure A.15-5

\section{CAS 26-05-04 Distribution Box, Effluent Integrity Sample (Photograph Taken 01-09-2002)}

- A replacement sample (271N187) from the effluent end of the septic tank, collected for VOCs and TPH (GRO) only at 9.3 to $10.3 \mathrm{ft}$ bgs. This sample was required to replace the VOC and TPH GRO samples for original sample 271N087. This was necessary because of a laboratory error.

\section{A.15.2.4 Leachfield Excavation Soil Sampling}

Backhoe excavations were conducted to access sampling horizons at the biased and random locations presented in the CAIP. Excavations provided a visual verification of distribution pipes and enabled soil samples to be collected from appropriate intervals beneath the pipes, as specified by the CAIP. Seventy-seven soil samples were collected from the planned locations excavated within the leachfield. These samples were collected from multiple intervals below the leachrock/native soil interface. The interface was found at depths ranging from 2 to $2.75 \mathrm{ft}$ bgs. More soil samples were collected and field screened than anticipated at this leachfield. The reason was that the radiological field-screening results slightly exceeded the FSLs for several samples (Section A.15.2.8). Thirty-seven samples were submitted for laboratory analysis. In addition, two QC soil duplicates and two MS/MSD samples were collected and analyzed. A geotechnical sample was collected outside the boundary of the leachfield. The sample will be sent to a laboratory for geotechnical analysis, if necessary. 


\section{A.15.2.5 Additional Sampling}

To further investigate an elevated arsenic detection in the leachfield soil, the field crew returned to this CAS on May 07, 2002, to conduct step-out sampling. One location (N04) was identified from the original sampling activities as a location of concern. Four horizontal step-out samples were collected. Sample 271N201 was collected at N38 (15 ft north of N04) and sample 271N202 was collected at N39 (15 ft west of N04). Samples 271N204 and 271N205 were collected at N37 (11 ft east of N04). All samples were submitted for laboratory analysis of arsenic. In addition, one QC soil duplicate (271N203) and one MS/MSD (271N201) sample were collected and analyzed.

\section{A.15.2.6 Collection System Pipe Inspections}

Access points for inspection of the collection system by video mole survey were two manholes. Manhole 1 (location N35; Figure A.15-1) was uncovered and inspected. The manhole did not contain adequate sediment to sample. A radiological contamination survey was conducted on the manhole and swipes were collected for radiological characterization. The video mole was inserted through the manhole and passed $115 \mathrm{ft}$ upstream to a second manhole (Manhole 2). The video mole was passed downstream for $27 \mathrm{ft}$, where the backfill from the integrity sample taken at the inlet side of the septic tank was encountered. After video mole activities were completed, the inlet side of Manhole 1 was grouted closed.

Manhole 2 (N36) was relatively deep (greater than $10 \mathrm{ft}$ ) and did not contain adequate sediment to sample. A radiological contamination survey was conducted on the accessible portions of the manhole and swipes were collected for radiological characterization. The video mole was inserted through the manhole and passed $79 \mathrm{ft}$ upstream to a point where the pipe diameter changed from 6 to 4 in. The video mole could not be pushed beyond this point.

Some sediment was identified in the piping, but was not adequate to be sampled. The pipe segments surveyed were in good condition, and no breaks or obstructions were found. Visual observations were recorded in the FADLs. The results of the radiation surveys and swipes are discussed in Section A.15.2.8. 


\section{A.15.2.7 Field-Screening Results}

Soil samples were screened for VOCs and alpha and beta/gamma radioactivity. The field readings were compared to FSLs to guide sampling decisions and determine which samples were to be submitted for laboratory analysis. No VOCs greater than FSLs were found during soil sample screening. The results of radiological field screening are discussed in Section A.15.2.8.

A sample of the septic tank content was collected and analyzed for fecal coliform bacteria. A positive result for fecal coliform bacteria was detected in the septic tank at this CAS.

\section{A.15.2.8 Radiological Survey Results}

None of the soil sample screening results for alpha exceeded the FSLs. However, the beta/gamma FSL $\left(3,244 \mathrm{dpm} / 100 \mathrm{~cm}^{2}\right)$ was slightly exceeded at the following locations:

- Location N17 - Sample 271N031 had an elevated beta/gamma reading of 3,331 dpm/100 cm². This sample was submitted for laboratory analysis, and additional samples (271N032 and 271N033) were collected from the location. Neither of these samples exceeded the FSL.

- Location N16 - Sample 271N035 had an elevated beta/gamma reading of 3,324 dpm/100 cm². This sample was submitted for laboratory analysis, and additional samples (271N036, and 271N037) were collected from the location. None of these samples exceeded the FSL.

- Location N22 - Sample 271N044 had an elevated beta/gamma reading of 3,324 dpm/100 cm². This sample was submitted for laboratory analysis, and additional samples (271N045, 271 N046, and 271N047) were collected from the location. Sample 271N046 had an elevated reading of $3,428 \mathrm{dpm} / 100 \mathrm{~cm}^{2}$. Sample 271N047 had an elevated reading of $3,331 \mathrm{dpm} / 100 \mathrm{~cm}^{2}$.

- Location N23 - Sample 271N051 had an elevated beta/gamma reading of 3,331 dpm/100 cm². This sample was submitted for laboratory analysis, and additional samples (271N052, 271 N053, and 271N054) were collected from the location. Sample 271N053 had an elevated reading of $3,281 \mathrm{dpm} / 100 \mathrm{~cm}^{2}$.

- Location N24 - Sample 271N055 had an elevated beta/gamma reading of 3,356 dpm/100 cm 2. This sample was submitted for laboratory analysis and additional samples (271N056 and 271N057) were collected from the location. Neither of these samples exceeded radiological FSLs.

- Location N31 - Sample 271N061 had an elevated beta/gamma reading of 3,313 dpm/100 cm². This sample was submitted for laboratory analysis and additional samples (271N062, 
271N063, and 271N064) were collected from the location. Sample 271N063 had an elevated reading of $3,331 \mathrm{dpm} / 100 \mathrm{~cm}^{2}$.

- Location N26 - Sample 271N065 and field duplicate 271N066 had an elevated beta/gamma reading of $3,270 \mathrm{dpm} / 100 \mathrm{~cm}^{2}$. This sample was submitted for laboratory analysis, and additional samples (271N067, 271N068, and 271N069) were collected from the location. Sample 271N067 had an elevated reading of $3,371 \mathrm{dpm} / 100 \mathrm{~cm}^{2}$.

The background soil samples used to determine radiological FSLs for CAS 26-05-04 were collected in various locations in Area 26. Only one of these samples was collected from the immediate area of the CAS. Based on the number of mining prospects in the vicinity, the rock and soil in the area may be mineralized, and this could explain the slightly elevated screening results for the leachfield soil.

Swipe and radiological survey data from the interiors of Manhole 1 (N35) and Manhole 2 (N36) indicate that the collection system meets the unrestricted radiological release criteria, as defined in the NV/YMP Radiological Control Manual (DOE/NV, 2000a).

\section{A.15.2.9 Sample Analysis}

Environmental soil samples and associated QC samples were collected and analyzed for the CAIP-specified COPCs (i.e., total VOCs, total SVOCs, total RCRA metals, and TPH [DRO and GRO], total beryllium, and PCBs). In addition, 25 percent of the soil samples and 100 percent of the associated QC samples were analyzed for Iso-U, Iso-Pu, Sr-90, and gamma-emitting radionuclides.

Both sludge and liquid samples from the septic tank were analyzed for total VOCs, total SVOCs, TPH (GRO and DRO), total RCRA metals, total beryllium, PCBs, gamma-emitting radionuclides, Iso-U, Iso-Pu, Sr-90, and tritium. The liquid sample was also analyzed for gross alpha and gross beta radioactivity. The sludge sample was analyzed according to the TCLP for VOCs, SVOC, and RCRA metals.

The parameters and laboratory methods used to analyze the investigation samples are listed in Table A.2-2. Table A.15-1 lists the sample-specific analytical parameters. 


\section{A.15.3 Analytes Detected Above Minimum Reporting Limits}

The soil sample analytical results with concentrations exceeding corresponding MRLs or PALs (DOE/NV, 1998; DOE/NV, 2001) at CAS 26-05-04 are summarized in the following sections. The results of the septic tank content samples are compared to appropriate regulatory levels for disposal. A portion of the CAS 26-05-04 analytical results were rejected during validation; however, these rejected data did not impact closure decisions as discussed in Section B.1.3.13 of Appendix B.

\section{A.15.3.1 Analytical Results for Soil Samples}

The following sections discuss the results for soil samples in comparison to the levels established in the Leachfield Work Plan and the CAIP.

\section{A.15.3.1.1 Total Volatile Organic Compounds}

Volatile organic compound results are reported in Table A.15-2. The only VOC detected above the MRL of $5 \mu \mathrm{g} / \mathrm{kg}$ was acetone. The concentrations of 11 and $540 \mu \mathrm{g} / \mathrm{kg}$ are below the PAL of $6,200,000 \mu \mathrm{g} / \mathrm{kg}$. Acetone is a common laboratory contaminant.

Table A.15-2

Soil Sample Results for Total VOCs Detected Above Minimum Reporting Limits at CAS 26-05-04

\begin{tabular}{||c|c|c|}
\hline \multirow{2}{*}{$\begin{array}{c}\text { Sample } \\
\text { Identification } \\
\text { Number }\end{array}$} & $\begin{array}{c}\text { Depth } \\
(\mathrm{ft} \text { bgs })\end{array}$ & Contaminants of Potential Concern $(\mu \mathbf{g} / \mathbf{k g})$ \\
\cline { 3 - 3 } & & Acetone \\
\hline \multicolumn{2}{|c|}{ Preliminary Action Levels } & $\mathbf{6 , 2 0 0 , 0 0 0}$ \\
\hline \hline 271 N006 & $2.3-3.3$ & 11 \\
\hline 271 N187 & $9.3-10.3$ & $540(\mathrm{~J})$ \\
\hline
\end{tabular}

aBased on U.S. Environmental Protection Agency, Region 9 Preliminary Remediation Goals (PRGs) (EPA, 2000).

$\mathrm{J}=$ Estimated value. Qualifier added to laboratory data; record accepted. Average relative response factor $<0.05$. Relative response factor $<0.05$.

\section{A.15.3.1.2 Total Semivolatile Organic Compounds}

Semivolatile organic compounds were not detected above MRLs in CAS 26-05-04 soil samples. 


\section{A.15.3.1.3 Total Petroleum Hydrocarbons}

Total petroleum hydrocarbon values are presented in Table A.15-3. Sample 271N078 contained TPH DRO above the MRL of $25 \mathrm{mg} / \mathrm{kg}$. The TPH concentration in this sample was below the PAL of $100 \mu \mathrm{g} / \mathrm{kg}$.

Table A.15-3

Soil Sample Results for TPH-DRO

Detected Above Minimum Reporting Limits at CAS 26-05-04

\begin{tabular}{||c|c|c||}
\hline $\begin{array}{c}\text { Sample } \\
\text { Identification } \\
\text { Number }\end{array}$ & $\begin{array}{c}\text { Depth } \\
\text { (ft bgs) }\end{array}$ & Contaminants of Potential Concern (mg/kg) \\
\cline { 3 - 3 } & & Diesel Range Organics \\
\hline \multicolumn{2}{||c|}{ Preliminary Action Levels } & a \\
\hline \hline 271 N078 & $2.5-3.5$ & $\mathbf{1 0 0}$ \\
\hline \hline
\end{tabular}

aBased on Nevada Administrative Code; Contamination of Soil: Establishment of action levels (NAC, 2000).

\section{A.15.3.1.4 Total RCRA Metals}

As shown in Table A.15-4, the total RCRA metals detected in soil samples above concentrations exceeding the MRLs are arsenic $(1 \mathrm{mg} / \mathrm{kg})$, barium $(20 \mathrm{mg} / \mathrm{kg})$, cadmium $(0.5 \mathrm{mg} / \mathrm{kg})$, chromium $(1 \mathrm{mg} / \mathrm{kg})$, lead $(0.3 \mathrm{mg} / \mathrm{kg})$, selenium $(0.5 \mathrm{mg} / \mathrm{kg})$, and silver $(1.0 \mathrm{mg} / \mathrm{kg})$. All mercury concentrations were less than the MRL.

Barium concentrations ranged from 123 to $272 \mathrm{mg} / \mathrm{kg}$, cadmium concentrations ranged from 0.771 to $0.84 \mathrm{mg} / \mathrm{kg}$, chromium concentrations ranged from 1.51 to $25.4 \mathrm{mg} / \mathrm{kg}$, lead concentrations ranged from 9.42 to $26.8 \mathrm{mg} / \mathrm{kg}$, the single selenium concentration greater than the MRL was $1.54 \mathrm{mg} / \mathrm{kg}$, and silver concentrations ranged from 2.12 to $8.15 \mathrm{mg} / \mathrm{kg}$. All reported concentrations of these metals were below EPA Region 9 PRGs defined in this document as PALs.

Arsenic concentrations ranged from 10.5 to $96.1 \mathrm{mg} / \mathrm{kg}$. Due to the elevated arsenic concentration identified at sample location N04, additional sampling was conducted. As discussed in Section A.15.2.5, step-out samples 271N201through 271N205 were subsequently collected and analyzed for arsenic. Arsenic concentrations in these step-out samples ranged from 12 to $18 \mathrm{mg} / \mathrm{kg}$. 
Table A.15-4

Soil Sample Results for Total RCRA Metals

Detected Above Minimum Reporting Limits at CAS 26-05-04

(Page 1 of 3)

\begin{tabular}{|c|c|c|c|c|c|c|c|c|c|}
\hline \multirow{2}{*}{$\begin{array}{c}\text { Sample } \\
\text { Identification } \\
\text { Number }\end{array}$} & \multirow{2}{*}{$\begin{array}{c}\text { Depth } \\
\text { (ft bgs) }\end{array}$} & \multicolumn{8}{|c|}{ Contaminants of Potential Concern $(\mathrm{mg} / \mathrm{kg})$} \\
\hline & & Arsenic & Barium & Beryllium & Cadmium & Chromium & Lead & Selenium & Silver \\
\hline \multicolumn{2}{|c|}{ Preliminary Action Levels ${ }^{a}$} & 2.7 & 100,000 & 2,200 & 810 & 450 & 750 & 10,000 & 10,000 \\
\hline $271 \mathrm{~N} 001$ & $3.6-4.6$ & 13.8 & $164(J)^{b}$ & -- & -- & 6.73 & $13(\mathrm{~J})^{\mathrm{c}}$ & -- & -- \\
\hline $271 \mathrm{~N} 003$ & $2-3$ & 16.9 & $196(J)^{b}$ & -- & -- & 8.4 & $14.3(\mathrm{~J})^{\mathrm{c}}$ & -- & 2.12 \\
\hline $271 \mathrm{~N} 004$ & $2-3$ & 12.7 & $160(\mathrm{~J})$ & -- & -- & 6.72 & $11.5(J)^{c}$ & -- & -- \\
\hline $271 \mathrm{~N} 006$ & $2.3-3.3$ & 16.1 & $241(\mathrm{~J})^{b}$ & -- & -- & 7.05 & $15(\mathrm{~J})^{\mathrm{c}}$ & - & -- \\
\hline $271 \mathrm{~N} 008$ & $2.75-3.75$ & 12.7 & $137(\mathrm{~J})^{\mathrm{b}}$ & -- & -- & 5.59 & $9.42(\mathrm{~J})^{\mathrm{c}}$ & - & -- \\
\hline $271 \mathrm{~N} 010$ & $2.9-3.9$ & 23.2 & 231 & 1.24 & -- & 12.1 & $25.3(\mathrm{~J})^{\mathrm{c}}$ & -- & -- \\
\hline 271N011 & $4-5$ & 96.1 & 272 & -- & -- & 1.51 & $71.4(\mathrm{~J})^{\mathrm{c}}$ & 1.54 & -- \\
\hline $271 \mathrm{~N} 012$ & $2.3-3.3$ & 13 & 143 & -- & -- & 7.15 & $12(\mathrm{~J})^{\mathrm{c}}$ & -- & -- \\
\hline 271N012RR1 & $2.3-3.3$ & 13.6 & 149 & -- & $\begin{array}{l}- \\
-\end{array}$ & 8.24 & 14.9 & -- & $\begin{array}{l}- \\
\text { - }\end{array}$ \\
\hline $271 \mathrm{~N} 014$ & $2.7-3.7$ & 12.6 & 160 & -- & -- & 5.65 & $9.54(J)^{c}$ & -- & -- \\
\hline $271 \mathrm{~N} 016$ & $2.8-3.8$ & 11.3 & 138 & -- & -- & 5.76 & $10.8(\mathrm{~J})^{\mathrm{c}}$ & -- & -- \\
\hline $271 \mathrm{~N} 018$ & $2.2-3.2$ & 16.5 & 160 & -- & -- & 6.94 & $12.6(\mathrm{~J})^{\mathrm{C}}$ & -- & -- \\
\hline $271 \mathrm{~N} 020$ & $2.5-3.5$ & 16 & 170 & -- & -- & 7.9 & $14.5(\mathrm{~J})^{\mathrm{c}}$ & -- & 3.45 \\
\hline $271 \mathrm{~N} 021$ & $5-6$ & 12.9 & 181 & -- & -- & 6.22 & $15.2(\mathrm{~J})^{\mathrm{C}}$ & -- & -- \\
\hline $271 \mathrm{~N} 023$ & $2.4-3.4$ & 16.9 & $163(\mathrm{~J})^{\mathrm{b}}$ & -- & -- & 6.26 & $13.6(J)^{c}$ & -- & -- \\
\hline $271 \mathrm{~N} 025$ & $2.6-3.6$ & 15.1 & $173(\mathrm{~J})^{\mathrm{b}}$ & -- & -- & 6.91 & $12.1(\mathrm{~J})^{\mathrm{c}}$ & -- & -- \\
\hline $271 \mathrm{~N} 027$ & $2.6-3.6$ & 14.9 & $165(J)^{b}$ & -- & -- & 8.07 & $12.8(J)^{c}$ & -- & -- \\
\hline $271 \mathrm{~N} 029$ & $2.6-3.6$ & 14.2 & $173(\mathrm{~J})^{\mathrm{b}}$ & -- & -- & 7.86 & $14.9(\mathrm{~J})^{\mathrm{c}}$ & -- & -- \\
\hline $271 \mathrm{~N} 032$ & $5.1-6.1$ & 15.7 & 233 & 1.11 & -- & 10.2 & $21.4(\mathrm{~J})^{\mathrm{c}}$ & -- & -- \\
\hline
\end{tabular}


Table A.15-4

Soil Sample Results for Total RCRA Metals

Detected Above Minimum Reporting Limits at CAS 26-05-04

(Page 2 of 3 )

\begin{tabular}{|c|c|c|c|c|c|c|c|c|c|}
\hline \multirow{2}{*}{$\begin{array}{c}\text { Sample } \\
\text { Identification } \\
\text { Number }\end{array}$} & \multirow{2}{*}{$\begin{array}{c}\text { Depth } \\
\text { (ft bgs) }\end{array}$} & \multicolumn{8}{|c|}{ Contaminants of Potential Concern $(\mathrm{mg} / \mathrm{kg})$} \\
\hline & & Arsenic & Barium & Beryllium & Cadmium & Chromium & Lead & Selenium & Silver \\
\hline \multicolumn{2}{|c|}{ Preliminary Action Levels ${ }^{a}$} & 2.7 & 100,000 & 2,200 & 810 & 450 & 750 & 10,000 & 10,000 \\
\hline $271 \mathrm{~N} 036$ & $8.1-9.1$ & 13.1 & 157 & -- & -- & 11.3 & $13.4(\mathrm{~J})^{\mathrm{C}}$ & -- & -- \\
\hline $271 \mathrm{~N} 038$ & $2.6-3.6$ & 14.4 & 187 & -- & -- & 6.91 & $12(\mathrm{~J})^{\mathrm{c}}$ & -- & -- \\
\hline $271 \mathrm{~N} 040$ & $2.6-3.6$ & 26.7 & 202 & -- & -- & 6.63 & $15.6(J)^{c}$ & -- & -- \\
\hline 271N042 & $2.6-3.6$ & 15.4 & 144 & -- & -- & 6.31 & $12.9(\mathrm{~J})^{\mathrm{C}}$ & -- & -- \\
\hline $271 \mathrm{~N} 044$ & $2.6-3.6$ & 8.65 & 123 & -- & -- & 4.38 & $10.3(\mathrm{~J})^{\mathrm{C}}$ & -- & -- \\
\hline $271 \mathrm{~N} 047$ & $10.5-11$ & 11.4 & 159 & -- & -- & 9.6 & $13.7(\mathrm{~J})^{\mathrm{C}}$ & -- & -- \\
\hline 271N048 & $2.5-3.5$ & $16.2(\mathrm{~J})^{\mathrm{c}}$ & $191(\mathrm{~J})^{\mathrm{d}}$ & -- & -- & 13.4 & $13.5(J)^{c}$ & -- & -- \\
\hline 271 N050 & $2.6-3.6$ & $17.2(\mathrm{~J})^{\mathrm{c}}$ & $206(J)^{d}$ & -- & -- & 8.49 & $16.5(J)^{c}$ & -- & -- \\
\hline $271 \mathrm{~N} 053$ & $11.1-12.1$ & $14.8(\mathrm{~J})^{\mathrm{c}}$ & $235(J)^{d}$ & -- & -- & 6.22 & $26.8(\mathrm{~J})^{\mathrm{c}}$ & -- & -- \\
\hline 271N056 & $8.1-9.1$ & 14.5 & $186(J)^{e}$ & -- & -- & $6.91(\mathrm{~J})^{\mathrm{e}}$ & $13.6(\mathrm{~J})^{\mathrm{e}}$ & -- & -- \\
\hline 271 N058 & $2.6-3.6$ & 12.8 & $154(\mathrm{~J})^{\mathrm{e}}$ & -- & -- & $10.5(\mathrm{~J})^{\mathrm{e}}$ & $11.6(\mathrm{~J})^{\mathrm{e}}$ & -- & -- \\
\hline $271 \mathrm{~N} 064$ & $13.5-14$ & 18.5 & $207(\mathrm{~J})^{\mathrm{e}}$ & -- & -- & $8.32(\mathrm{~J})^{\mathrm{e}}$ & $24.4(\mathrm{~J})^{\mathrm{e}}$ & -- & -- \\
\hline $271 \mathrm{~N} 065$ & $2.6-3.6$ & $14.6(\mathrm{~J})^{\mathrm{c}}$ & $128(J)^{d}$ & -- & -- & 24.9 & $12.9(\mathrm{~J})$ & -- & -- \\
\hline 271N066 & $2.6-3.6$ & $15.3(\mathrm{~J})^{\mathrm{c}}$ & $125(J)^{d}$ & -- & -- & 25.4 & $13.5(\mathrm{~J})$ & -- & -- \\
\hline $271 \mathrm{~N} 069$ & $9.7-10.2$ & $13.9(\mathrm{~J})^{\mathrm{c}}$ & $233(\mathrm{~J})^{\mathrm{d}}$ & -- & -- & 8.96 & $19.5(\mathrm{~J})$ & -- & -- \\
\hline $271 \mathrm{~N} 070$ & $2.75-3.75$ & $13.4(\mathrm{~J})^{\mathrm{c}}$ & $162(\mathrm{~J})^{d}$ & -- & -- & 7.42 & $10.7(\mathrm{~J})$ & -- & -- \\
\hline $271 \mathrm{~N} 071$ & $2.6-3.6$ & $15.9(\mathrm{~J})^{\mathrm{c}}$ & $133(J)^{d}$ & -- & .771 & 7.89 & $14.4(\mathrm{~J})$ & -- & 8.15 \\
\hline $271 \mathrm{~N} 074$ & $2.6-3.6$ & $14.3(\mathrm{~J})^{\mathrm{c}}$ & $155(J)^{d}$ & -- & -- & 8.12 & $14.7(\mathrm{~J})^{\mathrm{c}}$ & -- & 2.88 \\
\hline $271 \mathrm{~N} 076$ & $2.6-3.6$ & $11.6(\mathrm{~J})^{\mathrm{c}}$ & $180(\mathrm{~J})^{\mathrm{d}}$ & -- & -- & 6.69 & $9.8(\mathrm{~J})^{\mathrm{c}}$ & -- & \\
\hline 271N078 & $2.5-3.5$ & $10.5(J)^{c}$ & $141(\mathrm{~J})^{\mathrm{d}}$ & -- & .84 & 7.31 & $11.8(\mathrm{~J})^{\mathrm{C}}$ & -- & 5.18 \\
\hline
\end{tabular}


Table A.15-4

Soil Sample Results for Total RCRA Metals

Detected Above Minimum Reporting Limits at CAS 26-05-04

(Page 3 of 3)

\begin{tabular}{|c|c|c|c|c|c|c|c|c|c|}
\hline \multirow{2}{*}{$\begin{array}{c}\text { Sample } \\
\text { Identification } \\
\text { Number }\end{array}$} & \multirow{2}{*}{$\begin{array}{c}\text { Depth } \\
\text { (ft bgs) }\end{array}$} & \multicolumn{8}{|c|}{ Contaminants of Potential Concern $(\mathrm{mg} / \mathrm{kg})$} \\
\hline & & Arsenic & Barium & Beryllium & Cadmium & Chromium & Lead & Selenium & Silver \\
\hline $271 \mathrm{~N} 080$ & $10.2-11.2$ & $11.3(\mathrm{~J})^{\mathrm{c}}$ & $148(J)^{d}$ & $\overline{--}$ & -- & 6.09 & $11(\mathrm{~J})^{\mathrm{C}}$ & -- & -- \\
\hline $271 \mathrm{~N} 087$ & $9.3-10.3$ & 14 & 160 & 0.55 & -- & 8.3 & 13 & -- & $\overline{--}$ \\
\hline 271 N202 & $3.5-4$ & 15 & NA & NA & NA & NA & NA & NA & NA \\
\hline 271 N203 & $3.5-4$ & 12 & NA & NA & NA & NA & NA & NA & NA \\
\hline 271 N204 & $3-3.5$ & 18 & NA & $\mathrm{NA}$ & NA & NA & NA & $\mathrm{NA}$ & NA \\
\hline 271 N205 & $4-4.5$ & 17 & NA & $\mathrm{NA}$ & NA & NA & NA & NA & NA \\
\hline
\end{tabular}

a'Based on U.S. Environmental Protection Agency, Region 9 Preliminary Remediation Goals (PRGs) (EPA, 2000).

${ }^{b}$ Qualifier added to laboratory data; record accepted. Spike recovery was outside control limits. Matrix effects may exist.

Qualifier added to laboratory data; record accepted. Inductively coupled plasma serial dilution recovery was not met. Matrix effects may exist.

${ }^{d}$ Qualifier added to laboratory data; record accepted. Spike recovery was outside control limits.

eualifier added to laboratory data; record accepted. Duplicate precision analyses were outside control limits.

$--=$ Not detected above minimum reporting limits

$\mathrm{NA}=$ Not analyzed

$\mathrm{J}=$ Estimated value 
The PAL for arsenic is defined by EPA Region 9 as $2.7 \mathrm{mg} / \mathrm{kg}$. Arsenic concentrations in soil at CAS 26-05-04 exceed both the PAL and the mean concentrations found in Nevada Test and Training Range soil (NBMG, 1998; Moore, 1999). As discussed in Section A.15.2.8, many mining prospects are located in the vicinity of Building 2201. It is believed the leachfield is located in an area of mineralized soil and the arsenic concentrations represent ambient conditions, not contamination.

\section{A.15.3.1.5 Total Beryllium}

Total beryllium, as shown in Table A.15-4, was detected in three soil samples at concentrations exceeding the MRL $(0.5 \mathrm{mg} / \mathrm{kg})$. Beryllium concentrations ranged from 0.55 to $1.24 \mathrm{mg} / \mathrm{kg}$. All reported concentrations of beryllium were below EPA Region 9 PRGs defined in this document as the PAL.

\section{A.15.3.1.6 Polychlorinated Biphenyls}

Polychlorinated biphenyl results are reported in Table A.15-5. The only PCB compounds detected above the MRLs were aroclor-1254 and arochlor-1260. The concentrations of both of these compounds were below the PAL of $1,000 \mu \mathrm{g} / \mathrm{kg}$.

Table A.15-5

Soil Sample Results for PCBs Detected Above Minimum Reporting Limits at CAS 26-05-04

\begin{tabular}{|c|c|c|c|}
\hline \multirow{2}{*}{$\begin{array}{c}\text { Sample } \\
\text { Identification } \\
\text { Number }\end{array}$} & \multirow{2}{*}{$\begin{array}{c}\text { Depth } \\
\text { (ft bgs) }\end{array}$} & \multicolumn{2}{|c|}{ Contaminants of Potential Concern $(\mu \mathbf{g} / \mathbf{k g})$} \\
\cline { 3 - 4 } & & Aroclor-1254 & Aroclor-1260 \\
\hline Preliminary Action Levels & $\mathbf{a}$ & $\mathbf{1 , 0 0 0}$ & $\mathbf{1 , 0 0 0}$ \\
\hline \hline 271 N065 & $2.6-3.6$ & 75 & -- \\
\hline 271 N066 & $2.6-3.6$ & 66 & 55 \\
\hline 271 N071 & $2.6-3.6$ & -- & 46 \\
\hline 271 N078 & $2.5-3.5$ & -- & - \\
\hline
\end{tabular}

aa Based on U.S. Environmental Protection Agency, Region 9 Preliminary Remediation Goals (PRGs) (EPA, 2000).

-- = Not detected above minimum reporting limits 


\section{A.15.3.1.7 Gamma Spectrometry Results}

Results of soil sample gamma spectrometry analysis are presented in Table A.15-6. Concentrations of actinium-228, bismuth-214, lead-212, lead-214, potassium-40, and thallium-208 were detected above the MDLs. The TPU in the radioanalytical measurements is provided in the table along with the concentration for all detected gamma emitters. The concentrations of the detected gamma-emitting radionuclides are below PALs and are not significantly different than concentrations measured in soil samples collected from undisturbed background locations.

\section{Table A.15-6 \\ Soil Sample Results for Gamma-Emitting Radionuclides Detected Above Minimum Reporting Limits at CAS 26-05-04}

\begin{tabular}{|c|c|c|c|c|c|c|c|}
\hline \multirow{2}{*}{$\begin{array}{c}\text { Sample } \\
\text { Identification } \\
\text { Number }\end{array}$} & \multirow{2}{*}{$\begin{array}{l}\text { Depth } \\
\text { (ft bgs) }\end{array}$} & \multicolumn{6}{|c|}{ Contaminants of Potential Concern $(\mathrm{pCi} / \mathrm{g})$} \\
\hline & & Actinium-228 ${ }^{\mathrm{a}}$ & Bismuth-214 ${ }^{\mathrm{b}}$ & Potassium- $40^{\mathrm{a}}$ & Lead-212 $^{\mathrm{a}}$ & Lead-214 ${ }^{\mathrm{b}}$ & Thallium-208 ${ }^{a}$ \\
\hline \multicolumn{2}{|c|}{ Preliminary Action Level } & 3.64 & 3.47 & 96 & 2.9 & 2.9 & 3.4 \\
\hline $271 \mathrm{~N} 003$ & $2-3$ & $1.62 \pm 0.38$ & $1.1 \pm 0.27$ & $28.5 \pm 5.4$ & $1.81 \pm 0.35$ & $1.08 \pm 0.24$ & $0.52 \pm 0.13$ \\
\hline $271 \mathrm{~N} 004$ & $2-3$ & $1.51 \pm 0.39$ & $0.98 \pm 0.27$ & $27 \pm 5.4$ & $1.62 \pm 0.33$ & $0.99 \pm 0.23$ & $0.43 \pm 0.13$ \\
\hline $271 \mathrm{~N} 011$ & $4-5$ & $1.23 \pm 0.32$ & $0.96 \pm 0.26$ & $28.3 \pm 5.4$ & $1.41 \pm 0.29$ & $1.16 \pm 0.25$ & $0.49 \pm 0.13$ \\
\hline $271 \mathrm{~N} 012$ & $2.3-3.3$ & $1.82 \pm 0.50$ & $1.08 \pm 0.31$ & $27.4 \pm 5.5$ & $1.86 \pm 0.38$ & $1.2 \pm 0.27$ & $0.55 \pm 0.15$ \\
\hline $271 \mathrm{~N} 021$ & $5-6$ & $1.72 \pm 0.35$ & $0.95 \pm 0.21$ & $30.4 \pm 5.3$ & $1.71 \pm 0.32$ & $1.08 \pm 0.21$ & $0.49 \pm 0.11$ \\
\hline $271 \mathrm{~N} 032$ & $5.1-6.1$ & $1.47 \pm 0.36$ & $1.02 \pm 0.26$ & $27.7 \pm 5.3$ & $1.85 \pm 0.37$ & $1.22 \pm 0.27$ & $0.57 \pm 0.15$ \\
\hline $271 \mathrm{~N} 036$ & $8.1-9.1$ & $1.56 \pm 0.39$ & $0.94 \pm 0.25$ & $27.9 \pm 5.5$ & $1.6 \pm 0.32$ & $0.95 \pm 0.23$ & $0.39 \pm 0.12$ \\
\hline $271 \mathrm{~N} 047$ & $10.5-11$ & $1.4 \pm 0.34$ & $0.79 \pm 0.22$ & $27.6 \pm 5.2$ & $1.6 \pm 0.32$ & $0.98 \pm 0.22$ & $0.41 \pm 0.12$ \\
\hline $271 \mathrm{~N} 053$ & $11.1-12.1$ & $1.31 \pm 0.38$ & $1.07 \pm 0.31$ & $23.7 \pm 4.9$ & $1.8 \pm 0.37$ & $1.09 \pm 0.26$ & $0.49 \pm 0.15$ \\
\hline 271 N056 & $8.1-9.1$ & $1.4 \pm 0.30$ & $0.84 \pm 0.19$ & $29.9 \pm 5.2$ & $1.75 \pm 0.32$ & $0.97 \pm 0.20$ & $0.5 \pm 0.11$ \\
\hline 271N064 & $13.5-14$ & $1.57 \pm 0.33$ & $0.87 \pm 0.20$ & $27.4 \pm 4.8$ & $1.59 \pm 0.30$ & $1.11 \pm 0.22$ & $0.51 \pm 0.11$ \\
\hline $271 \mathrm{~N} 065$ & $2.6-3.6$ & $1.58 \pm 0.39$ & $0.86 \pm 0.23$ & $29.2 \pm 5.5$ & $1.72 \pm 0.34$ & $1.21 \pm 0.26$ & $0.48 \pm 0.13$ \\
\hline $271 \mathrm{~N} 066$ & $2.6-3.6$ & $1.58 \pm 0.42$ & $1.04 \pm 0.29$ & $29.4 \pm 5.8$ & $1.68 \pm 0.35$ & $1.12 \pm 0.26$ & $0.57 \pm 0.15$ \\
\hline 271N069 & $9.7-10.2$ & $1.56 \pm 0.38$ & $0.93 \pm 0.25$ & $25.5 \pm 5.0$ & $1.68 \pm 0.33$ & $1.14 \pm 0.25$ & $0.51 \pm 0.14$ \\
\hline 271 N076 & $2.6-3.6$ & $1.47 \pm 0.43$ & $1.12 \pm 0.30$ & $24.4 \pm 5.0$ & $1.69 \pm 0.35$ & $1.6 \pm 0.34$ & $0.46 \pm 0.15$ \\
\hline
\end{tabular}

aBackground concentration listed in Environmental Monitoring Report for the Proposed Ward Valley, California, Low-Level Radioactive Waste (LLRW) Facility (US Ecology and Atlan-Tech, 1992).

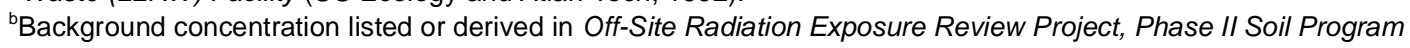
(McArthur and Miller, 1989). 


\section{A.15.3.1.8 Isotopic Uranium}

Detected values of uranium isotopes, along with associated TPUs are reported in Table A.15-7. Sample 271N032 has a U-235 concentration above the PAL; therefore, a normalized difference based on a confidence level of 95 percent was used to determine if the concentration was statistically distinguishable from background. The concentration of U-235 was not significantly greater than concentrations of U-235 in soil samples collected from undisturbed background locations.

Table A.15-7

Soil Sample Results for Strontium and Uranium Isotopes Detected Above Minimum Reporting Limits at CAS 26-05-04

\begin{tabular}{|c|c|c|c|c|c|}
\hline \multirow{2}{*}{$\begin{array}{c}\text { Sample } \\
\text { Identification } \\
\text { Number }\end{array}$} & \multirow{2}{*}{$\begin{array}{l}\text { Depth } \\
\text { (ft bgs) }\end{array}$} & \multicolumn{4}{|c|}{ Contaminants of Potential Concern (pCi/g) } \\
\hline & & Strontium $-90^{\mathrm{a}}$ & Uranium-234 ${ }^{\mathrm{a}}$ & Uranium-235 a & Uranium-238 \\
\hline \multicolumn{2}{|c|}{ Preliminary Action Levels } & 1.17 & 1.56 & 0.07 & 3.2 \\
\hline $271 \mathrm{~N} 003$ & $2-3$ & $0.68 \pm 0.28$ & $1.11 \pm 0.22$ & -- & $1.07 \pm 0.21$ \\
\hline 271 N004 & $2-3$ & -- & $0.87 \pm 0.16$ & -- & $1.07 \pm 0.19$ \\
\hline $271 \mathrm{~N} 011$ & $4-5$ & -- & $1.19 \pm 0.21$ & -- & $1.03 \pm 0.19$ \\
\hline $271 \mathrm{~N} 012$ & $2.3-3.3$ & -- & $1.01 \pm 0.18$ & $0.053 \pm 0.029$ & $0.9 \pm 0.16$ \\
\hline $271 \mathrm{~N} 021$ & $5-6$ & -- & $0.81 \pm 0.15$ & -- & $1.05 \pm 0.19$ \\
\hline $271 \mathrm{~N} 032$ & $5.1-6.1$ & -- & $1 \pm 0.19$ & $0.09 \pm 0.042$ & $1.01 \pm 0.19$ \\
\hline $271 \mathrm{~N} 036$ & $8.1-9.1$ & -- & $0.95 \pm 0.19$ & -- & $1.02 \pm 0.20$ \\
\hline $271 \mathrm{~N} 047$ & $10.5-11$ & -- & $1.02 \pm 0.19$ & $0.058 \pm 0.032$ & $1.06 \pm 0.19$ \\
\hline $271 \mathrm{~N} 053$ & $11.1-12.1$ & -- & $0.94 \pm 0.17$ & -- & $0.98 \pm 0.18$ \\
\hline $271 \mathrm{~N} 056$ & $8.1-9.1$ & $\begin{array}{l}- \\
\end{array}$ & $0.88 \pm 0.16$ & -- & $1.07 \pm 0.19$ \\
\hline $271 \mathrm{~N} 064$ & $13.5-14$ & -- & $1.02 \pm 0.19$ & -- & $0.92 \pm 0.17$ \\
\hline 271 N065 & $2.6-3.6$ & -- & $1.12 \pm 0.20$ & $0.07 \pm 0.036$ & $1.08 \pm 0.19$ \\
\hline 271 N066 & $2.6-3.6$ & $\begin{array}{l}- \\
\end{array}$ & $1.01 \pm 0.19$ & $0.066 \pm 0.035$ & $1.01 \pm 0.19$ \\
\hline 271 N069 & $9.7-10.2$ & -- & $1.04 \pm 0.20$ & -- & $1.1 \pm 0.21$ \\
\hline $271 \mathrm{~N} 076$ & $2.6-3.6$ & -- & $1.53 \pm 0.25$ & -- & $1.21 \pm 0.21$ \\
\hline
\end{tabular}

\footnotetext{
${ }^{a}$ Background concentration listed in Environmental Monitoring Report for the Proposed Ward Valley, California, Low-Level Radioactive Waste (LLRW) Facility (US Ecology and Atlan-Tech, 1992).

${ }^{\mathrm{b}}$ Background concentration listed or derived in Off-Site Radiation Exposure Review Project, Phase II Soil Program (McArthur and Miller, 1989).

$--=$ Not detected above minimum reporting limits.
}

\section{A.15.3.1.9 Isotopic Plutonium}

Isotopic plutonium was not detected above MRLs in CAS 26-05-04 soil samples. 


\section{A.15.3.1.10 Strontium-90}

Strontium-90 was only detected in one sample, $271 \mathrm{~N} 003$, at $0.68 \pm 0.28$ picocuries per gram (pCi/g) with associated uncertainty as reported in Table A.15-7. The Sr-90 concentration is less than the PAL of $1.17 \mathrm{pCi} / \mathrm{g}$.

\section{A.15.3.2 Septic Tank Sample Results}

Results of collected septic tank content samples were compared to regulatory levels based on disposal options. If the waste has no hazardous component, the regulatory level is based on disposal options at NTS landfills and lagoons (BN, 1995; CFR, 2000b and c; NDEP, 1997a, b, and c). Any sludge or liquid waste will be solidified before disposal at NTS landfills (NDEP, 1997b). If the waste is hazardous, the release criteria are based on interpretation of the guidelines presented in the POC (BN, 1995; Alderson, 1999). For waste destined for off-site disposal, the POC radiological levels must be met to certify that the waste has no radioactivity added.

Initially, four samples were taken from the septic tank. One liquid (271N081) and one sludge (271N082) sample were obtained from the influent chamber of the septic tank. Liquid sample 271 N083 and sludge sample 271N084 were taken from the effluent chamber of the septic tank. Samples 271N181, 271N182, and 271N183 were collected because of a laboratory error on the VOC and TPH GRO portions of the original samples. The analytical suite followed the CAIP and is detailed in Section A.15.2.9. Analytical results exceeding MRLs are listed in Table A.15-8.

Several COPCs were detected in the sludge samples. Most COPCs were below regulatory limits except for TPH DRO, which was detected in samples 271N082, 271N083, and 271N084. Diesel concentrations in these samples were 3,400; 9,000; and $250 \mathrm{mg} / \mathrm{kg}$, respectively. Gasoline concentrations in samples $271 \mathrm{~N} 082$ and 271N083 were 520 and $790 \mathrm{mg} / \mathrm{kg}$, respectively. These levels exceed the NDEP action level of $100 \mathrm{mg} / \mathrm{kg}$ (NAC, 2000) for TPH.

\section{A.15.4 Contaminants of Concern}

Based on the aforementioned analytical results, the only COCs present are in the septic tank. The septic tank contains sludge with TPH analytes (DRO and GRO) in concentrations that exceed the 
Table A.15-8

Liquid and Sludge Sample Results

Detected Above Minimum Reporting Limits at CAS 26-05-04

(Page 1 of 3 )

\begin{tabular}{|c|c|c|c|c|c|c|}
\hline $\begin{array}{c}\text { Sample } \\
\text { Identification } \\
\text { Number }\end{array}$ & Matrix & Parameter & Result & Units & Limits & Reference \\
\hline $271 \mathrm{~N} 085$ & Liquid & Arsenic & 0.03 & $\mathrm{mg} / \mathrm{L}$ & 5 & CFR, 2000a \\
\hline $271 \mathrm{~N} 085$ & Liquid & Chromium & 0.042 & $\mathrm{mg} / \mathrm{L}$ & 5 & CFR, 2000a \\
\hline $271 \mathrm{~N} 085$ & Liquid & Lead & 0.011 & $\mathrm{mg} / \mathrm{L}$ & 5 & CFR, 2000a \\
\hline $271 \mathrm{~N} 085$ & Liquid & Selenium & 0.0055 & $\mathrm{mg} / \mathrm{L}$ & 1 & CFR, 2000a \\
\hline $271 \mathrm{~N} 181$ & Liquid & 1,4-Dichlorobenzene & 19 & $\mu \mathrm{g} / \mathrm{L}$ & 7,500 & CFR, 2000a \\
\hline $271 \mathrm{~N} 181$ & Liquid & Cis-1,2-Dichloroethene & 15 & $\mu \mathrm{g} / \mathrm{L}$ & NA & CFR, 2000a \\
\hline $271 \mathrm{~N} 081$ & Liquid & Uranium-234 & $0.81 \pm 0.19$ & $\mathrm{pCi} / \mathrm{L}$ & 100 & NDEP, 1997b \\
\hline $271 \mathrm{~N} 081$ & Liquid & Uranium-238 & $0.48 \pm 0.14$ & $\mathrm{pCi} / \mathrm{L}$ & 100 & NDEP, 1997b \\
\hline 271 N085 & Liquid & Uranium-234 & $2.73 \pm 0.44$ & $\mathrm{pCi} / \mathrm{L}$ & 100 & NDEP, 1997b \\
\hline 271 N085 & Liquid & Uranium-235 & $0.105 \pm 0.055$ & $\mathrm{pCi} / \mathrm{L}$ & 100 & NDEP, 1997b \\
\hline $271 \mathrm{~N} 085$ & Liquid & Uranium-238 & $1.35 \pm 0.26$ & $\mathrm{pCi} / \mathrm{L}$ & 100 & NDEP, 1997b \\
\hline $271 \mathrm{~N} 081$ & Liquid & Aroclor-1254 & $3(J)^{a}$ & $\mu \mathrm{g} / \mathrm{L}$ & 50,000 & CFR, 2000a \\
\hline $271 \mathrm{~N} 083$ & Sludge & TCLP 1,4-Dichlorobenzene & 0.22 & $\mathrm{mg} / \mathrm{L}$ & 7.5 & CFR, 2000a \\
\hline $271 \mathrm{~N} 083$ & Sludge & Mercury** & 4.7 & $\mathrm{mg} / \mathrm{kg}$ & NA & CFR, 2000a \\
\hline $271 \mathrm{~N} 084$ & Sludge & Mercury ${ }^{* *}$ & 0.27 & $\mathrm{mg} / \mathrm{kg}$ & NA & CFR, 2000a \\
\hline $271 \mathrm{~N} 082$ & Sludge & Mercury** & 0.92 & $\mathrm{mg} / \mathrm{kg}$ & NA & CFR, 2000a \\
\hline 271 N082 & Sludge & Arsenic** & 19 & $\mathrm{mg} / \mathrm{kg}$ & NA & CFR, 2000a \\
\hline $271 \mathrm{~N} 082$ & Sludge & Barium** & 1,300 & $\mathrm{mg} / \mathrm{kg}$ & NA & CFR, 2000a \\
\hline $271 \mathrm{~N} 082$ & Sludge & Cadmium $^{* *}$ & 7.3 & $\mathrm{mg} / \mathrm{kg}$ & NA & CFR, 2000a \\
\hline $271 \mathrm{~N} 082$ & Sludge & Chromium** & 170 & $\mathrm{mg} / \mathrm{kg}$ & NA & CFR, 2000a \\
\hline $271 \mathrm{~N} 082$ & Sludge & Lead $^{* *}$ & 160 & $\mathrm{mg} / \mathrm{kg}$ & NA & CFR, 2000a \\
\hline $271 \mathrm{~N} 082$ & Sludge & Selenium ${ }^{\star *}$ & 1.7 & $\mathrm{mg} / \mathrm{kg}$ & NA & CFR, 2000a \\
\hline 271 N082 & Sludge & Silver** & 7.5 & $\mathrm{mg} / \mathrm{kg}$ & NA & CFR, 2000a \\
\hline $271 \mathrm{~N} 083$ & Sludge & Arsenic ${ }^{* *}$ & 82 & $\mathrm{mg} / \mathrm{kg}$ & NA & CFR, 2000a \\
\hline $271 \mathrm{~N} 083$ & Sludge & Barium & 510 & $\mathrm{mg} / \mathrm{kg}$ & NA & CFR, 2000a \\
\hline $271 \mathrm{~N} 083$ & Sludge & TCLP Barium & 1 & $\mathrm{mg} / \mathrm{L}$ & 100 & CFR, 2000a \\
\hline $271 \mathrm{~N} 083$ & Sludge & Cadmium $^{* *}$ & 8.2 & $\mathrm{mg} / \mathrm{kg}$ & NA & CFR, 2000a \\
\hline $271 \mathrm{~N} 083$ & Sludge & Chromium** & 780 & $\mathrm{mg} / \mathrm{kg}$ & NA & CFR, 2000a \\
\hline $271 \mathrm{~N} 083$ & Sludge & Lead $^{* *}$ & 400 & $\mathrm{mg} / \mathrm{kg}$ & NA & CFR, 2000a \\
\hline 271 N083 & Sludge & Selenium $^{* \star}$ & 5.4 & $\mathrm{mg} / \mathrm{kg}$ & NA & CFR, 2000a \\
\hline $271 \mathrm{~N} 083$ & Sludge & Silver** & 15 & $\mathrm{mg} / \mathrm{kg}$ & NA & CFR, 2000a \\
\hline $271 \mathrm{~N} 084$ & Sludge & Arsenic ${ }^{* *}$ & 43 & $\mathrm{mg} / \mathrm{kg}$ & NA & CFR, 2000a \\
\hline $271 \mathrm{~N} 084$ & Sludge & Barium** & 63 & $\mathrm{mg} / \mathrm{kg}$ & NA & CFR, 2000a \\
\hline 271 N084 & Sludge & Chromium** & 210 & $\mathrm{mg} / \mathrm{kg}$ & NA & CFR, 2000a \\
\hline
\end{tabular}


Table A.15-8

\section{Liquid and Sludge Sample Results \\ Detected Above Minimum Reporting Limits at CAS 26-05-04}

(Page 2 of 3 )

\begin{tabular}{|c|c|c|c|c|c|c|}
\hline $\begin{array}{c}\text { Sample } \\
\text { Identification } \\
\text { Number }\end{array}$ & Matrix & Parameter & Result & Units & Limits & Reference \\
\hline $271 \mathrm{~N} 084$ & Sludge & Lead $^{* \star}$ & 32 & $\mathrm{mg} / \mathrm{kg}$ & NA & CFR, 2000a \\
\hline 271N082 & Sludge & Diesel-Range Organics & $3,400(L, M, Z)$ & $\mathbf{m g} / \mathbf{k g}$ & 100 & NDEP, 1997b \\
\hline 271 N083 & Sludge & Diesel-Range Organics & $9,000(L, M, Z)$ & $\mathbf{m g} / \mathbf{k g}$ & 100 & NDEP, 1997b \\
\hline 271N084 & Sludge & Diesel-Range Organics & $250(M)$ & $\mathbf{m g} / \mathbf{k g}$ & 100 & NDEP, 1997b \\
\hline 271N182 & Sludge & Gasoline-Range Organics & $520(Z)$ & $\mathbf{m g} / \mathbf{k g}$ & 100 & NDEP, 1997b \\
\hline 271N183 & Sludge & Gasoline-Range Organics & $790(Z)$ & $\mathbf{m g} / \mathbf{k g}$ & 100 & NDEP, 1997b \\
\hline $271 N 182$ & Sludge & 1,2,4-Trimethylbenzene & 13,000 & $\mu \mathrm{g} / \mathrm{kg}$ & NA & CFR, 2000a \\
\hline $271 N 182$ & Sludge & 1,3,5-Trimethylbenzene & 6,400 & $\mu \mathrm{g} / \mathrm{kg}$ & NA & CFR, 2000a \\
\hline $271 \mathrm{~N} 182$ & Sludge & 1,4-Dichlorobenzene ${ }^{* *}$ & 230,000 & $\mu \mathrm{g} / \mathrm{kg}$ & NA & CFR, 2000a \\
\hline $271 \mathrm{~N} 182$ & Sludge & Cis-1,2-Dichloroethene & 39,000 & $\mu \mathrm{g} / \mathrm{kg}$ & NA & CFR, 2000a \\
\hline $271 \mathrm{~N} 182$ & Sludge & Ethylbenzene & 7,200 & $\mu \mathrm{g} / \mathrm{kg}$ & NA & CFR, 2000a \\
\hline $271 N 182$ & Sludge & M+P-Xylene & 35,000 & $\mu \mathrm{g} / \mathrm{kg}$ & NA & CFR, 2000a \\
\hline $271 \mathrm{~N} 182$ & Sludge & O-Xylene & 8,900 & $\mu \mathrm{g} / \mathrm{kg}$ & NA & CFR, 2000a \\
\hline $271 N 183$ & Sludge & 1,2,4-Trimethylbenzene & 34,000 & $\mu \mathrm{g} / \mathrm{kg}$ & NA & CFR, 2000a \\
\hline $271 N 183$ & Sludge & 1,4-Dichlorobenzene & 620,000 & $\mu \mathrm{g} / \mathrm{kg}$ & NA & CFR, 2000a \\
\hline $271 N 183$ & Sludge & Cis-1,2-Dichloroethene & 61,000 & $\mu \mathrm{g} / \mathrm{kg}$ & NA & CFR, 2000a \\
\hline $271 N 183$ & Sludge & M+P-Xylene & 55,000 & $\mu \mathrm{g} / \mathrm{kg}$ & NA & CFR, 2000a \\
\hline 271N184RR1RR1 & Sludge & Acetone & $1,100(J)^{b}$ & $\mu \mathrm{g} / \mathrm{kg}$ & NA & CFR, 2000a \\
\hline 271 N082 & Sludge & 1,4-Dichlorobenzene ${ }^{* *}$ & 1,900 & $\mu \mathrm{g} / \mathrm{kg}$ & NA & CFR, 2000a \\
\hline $271 \mathrm{~N} 082$ & Sludge & Fluoranthene & 900 & $\mu \mathrm{g} / \mathrm{kg}$ & NA & CFR, 2000a \\
\hline $271 \mathrm{~N} 082$ & Sludge & Phenanthrene & 1,200 & $\mu \mathrm{g} / \mathrm{kg}$ & NA & CFR, 2000a \\
\hline $271 \mathrm{~N} 082$ & Sludge & Pyrene & $1,100(J)^{c}$ & $\mu \mathrm{g} / \mathrm{kg}$ & NA & CFR, 2000a \\
\hline 271 N083 & Sludge & Phenanthrene & $1,500(J)^{d}$ & $\mu \mathrm{g} / \mathrm{kg}$ & NA & CFR, 2000a \\
\hline $271 \mathrm{~N} 083$ & Sludge & 1,4-Dichlorobenzene ${ }^{\star *}$ & 32,000 & $\mu \mathrm{g} / \mathrm{kg}$ & NA & CFR, 2000a \\
\hline $271 \mathrm{~N} 082$ & Sludge & Potassium-40 & $8.9 \pm 3.0$ & $\mathrm{pCi} / \mathrm{g}$ & - & $\mathrm{N}$ \\
\hline $271 \mathrm{~N} 082$ & Sludge & Lead-212 & $0.52 \pm 0.21$ & $\mathrm{pCi} / \mathrm{g}$ & - & $\mathrm{N}$ \\
\hline $271 \mathrm{~N} 083$ & Sludge & Cesium-137 & $0.6 \pm 0.16$ & $\mathrm{pCi} / \mathrm{g}$ & - & $\mathrm{N}$ \\
\hline $271 \mathrm{~N} 083$ & Sludge & Potassium-40 & $7.1 \pm 2.3$ & $\mathrm{pCi} / \mathrm{g}$ & - & $\mathrm{N}$ \\
\hline $271 \mathrm{~N} 083$ & Sludge & Lead-212 & $0.47 \pm 0.18$ & $\mathrm{pCi} / \mathrm{g}$ & - & $\mathrm{N}$ \\
\hline $271 \mathrm{~N} 084$ & Sludge & Potassium-40 & $3.9 \pm 1.4$ & $\mathrm{pCi} / \mathrm{g}$ & - & $\mathrm{N}$ \\
\hline 271 N082 & Sludge & Uranium-234 & $2.85 \pm 0.43$ & $\mathrm{pCi} / \mathrm{g}$ & 100 & NDEP, 1997b \\
\hline $271 \mathrm{~N} 082$ & Sludge & Uranium-235 & $0.105 \pm 0.045$ & $\mathrm{pCi} / \mathrm{g}$ & 100 & NDEP, 1997b \\
\hline $271 \mathrm{~N} 082$ & Sludge & Uranium-238 & $1.31 \pm 0.23$ & $\mathrm{pCi} / \mathrm{g}$ & 100 & NDEP, 1997b \\
\hline $271 \mathrm{~N} 083$ & Sludge & Uranium-234 & $3.89 \pm 0.56$ & $\mathrm{pCi} / \mathrm{g}$ & 100 & NDEP, 1997b \\
\hline
\end{tabular}


Table A.15-8

\section{Liquid and Sludge Sample Results \\ Detected Above Minimum Reporting Limits at CAS 26-05-04}

(Page 3 of 3 )

\begin{tabular}{|c|c|c|c|c|c|c|}
\hline $\begin{array}{c}\text { Sample } \\
\text { Identification } \\
\text { Number }\end{array}$ & Matrix & Parameter & Result & Units & Limits & Reference \\
\hline $271 \mathrm{~N} 083$ & Sludge & Uranium-235 & $0.151 \pm 0.052$ & $\mathrm{pCi} / \mathrm{g}$ & 100 & NDEP, 1997b \\
\hline $271 \mathrm{~N} 083$ & Sludge & Uranium-238 & $1.66 \pm 0.27$ & $\mathrm{pCi} / \mathrm{g}$ & 100 & NDEP, 1997b \\
\hline $271 \mathrm{~N} 084$ & Sludge & Uranium-234 & $2.01 \pm 0.32$ & $\mathrm{pCi} / \mathrm{g}$ & 100 & NDEP, 1997b \\
\hline $271 \mathrm{~N} 084$ & Sludge & Uranium-235 & $0.083 \pm 0.038$ & $\mathrm{pCi} / \mathrm{g}$ & 100 & NDEP, 1997b \\
\hline $271 \mathrm{~N} 084$ & Sludge & Uranium-238 & $0.94 \pm 0.17$ & $\mathrm{pCi} / \mathrm{g}$ & 100 & NDEP, 1997b \\
\hline $271 \mathrm{~N} 082$ & Sludge & Strontium-90 & $0.83 \pm 0.27$ & $\mathrm{pCi} / \mathrm{g}$ & 100 & NDEP, 1997b \\
\hline $271 \mathrm{~N} 084$ & Sludge & Strontium-90 & $0.47 \pm 0.24(\mathrm{LT})$ & $\mathrm{pCi} / \mathrm{g}$ & 100 & NDEP, 1997b \\
\hline 271 N082 & Sludge & Plutonium-239 & $0.314 \pm 0.075$ & $\mathrm{pCi} / \mathrm{g}$ & 10 & NDEP, 1997b \\
\hline $271 \mathrm{~N} 083$ & Sludge & Plutonium-239 & $0.269 \pm 0.069$ & $\mathrm{pCi} / \mathrm{g}$ & 10 & NDEP, 1997b \\
\hline $271 \mathrm{~N} 082$ & Sludge & Aroclor-1254 & 540 & $\mu \mathrm{g} / \mathrm{kg}$ & 50,000 & CFR, 2000b \\
\hline 271 N083 & Sludge & Aroclor-1254 & $2,100(\mathrm{~J})^{\mathrm{e}}$ & $\mu \mathrm{g} / \mathrm{kg}$ & 50,000 & CFR, 2000b \\
\hline 271 N084 & Sludge & Aroclor-1254 & 570 & $\mu \mathrm{g} / \mathrm{kg}$ & 50,000 & CFR, 2000b \\
\hline 271 N085 & Liquid & Gross Alpha & $5.5 \pm 1.4$ & $\mathrm{pCi} / \mathrm{L}$ & $1.6^{f}$ & NA \\
\hline 271 N085 & Liquid & Gross Beta & $18.5 \pm 2.9$ & $\mathrm{pCi} / \mathrm{L}$ & $1.9^{f}$ & NA \\
\hline
\end{tabular}

${ }^{a}$ Qualifier added to laboratory data; record accepted. Surrogate recovery exceeded the lower limits.

${ }^{b}$ Qualifier added to laboratory data; record accepted. Average relative response factor $<0.05$. Relative response factor $<0.05$.

${ }^{\circ} Q u a l i f i e r$ added to laboratory data; record accepted. Internal standard area count exceeded the quality control limits. Matrix effects may exist.

${ }^{d}$ Qualifier added to laboratory data; record accepted. Internal standard area count exceeded the quality control limits.

${ }^{e} Q$ Qualifier added to laboratory data; record accepted. Surrogates diluted out.

'Maximum detectable concentration.

$* *=$ TCLP below minimum reporting limit

$\mathrm{J}=$ Estimated value

$M=$ Motor Oil

$Z$ = The reported result did not resemble the patterns of the following hydrocarbon products: gasoline, JP-4, JP-8, diesel, mineral spirits, motor oil, Stoddard solvent and Bunker $\mathrm{C}$

$L=$ The fuel pattern was $n$ the lighter end of the retention time window for the analyte of interest

$\mathrm{LT}=$ Result is less than requested MDC, greater than sample specific MDC

$\mathrm{N}=$ No limit established (NDEP, 1997b)

NA $=$ Not applicable 
regulatory action level of $100 \mathrm{mg} / \mathrm{kg}$. There are no COCs in the soils surrounding the septic tank or under the leachfield.

\section{A.15.5 Nature and Extent of Contamination}

Total petroleum hydrocarbons are located within the septic tank in the sludge. Approximately 3,098 gal of liquid and 654 gal of sludge are present in the inlet chamber of the septic tank. Approximately 24 gal of liquid and 24 gal of sludge are present in the outlet chamber of the septic tank.

\section{A.15.6 Revised Conceptual Model}

No variations in the conceptual model were identified. However, one feature of the site setting that was not included in the conceptual site model is the presence of mineralized soil. 


\section{A.16.0 Buildings 2101, 2102, and 2107 Septic System (CAS 26-05-05)}

The septic system was designed to receive sanitary effluent generated by activities at Building 2101 (Control Building), Building 2102 (Assembly Building), and Building 2107 (Data Reduction Building). The septic system is located approximately $235 \mathrm{ft}$ north of Building 2102. The site is comprised of two leachfields, two septic tanks, two distribution boxes, and associated piping. It appears that one system was initially constructed and another system was added at a later time. Both septic systems share a common collection system. More detail on this CAS is provided in the CAIP (DOE/NV, 2001).

\section{A.16.1 Corrective Action Investigation}

Eighty-four investigation samples, listed in Table A.16-1, were collected during investigation activities conducted at CAS 26-05-05. The planned and actual sample locations are shown in Figure A.16-1. The specific CAI activities conducted to meet CAIP requirements at CAS 26-05-05 are described in Table A.2-1.

\section{A.16.1.1 Deviations}

The following deviations to the CAIP requirements were the result of unforeseen circumstances:

- A linear transformation of sampling points in the leachfield was necessary because the overall size of the leachfield was different than that planned in the CAIP. The transformation was performed to rescale the points to fit the observed leachfield size. This process maintained the integrity of the random sampling scheme. This approach was included as a contingency in the CAIP so no Record of Technical Change was required to implement the new sampling locations.

- Too much slough material was removed from the excavation; therefore:

- Sample 271P023 was collected at 7 to $8 \mathrm{ft}$ bgs rather than the planned interval of 6.8 to $7.8 \mathrm{ft} \mathrm{bgs}$

- Sample 271P067 was collected at 8.5 to $9 \mathrm{ft}$ bgs rather than the planned interval of 8 to $9 \mathrm{ft}$ bgs 
Table A.16-1

Samples Collected at CAS 26-05-05

(Page 1 of 5 )

\begin{tabular}{|c|c|c|c|c|c|c|c|c|c|c|c|c|c|c|}
\hline \multirow[b]{2}{*}{$\begin{array}{c}\text { Sample } \\
\text { Identification } \\
\text { Number }\end{array}$} & \multirow[b]{2}{*}{$\begin{array}{l}\text { Sample } \\
\text { Location }\end{array}$} & \multirow[b]{2}{*}{$\begin{array}{c}\text { Sample } \\
\text { Matrix }\end{array}$} & \multirow[b]{2}{*}{$\begin{array}{c}\text { Depth } \\
\text { (ft bgs) }\end{array}$} & \multirow[b]{2}{*}{ Purpose } & \multicolumn{10}{|c|}{ Analyses } \\
\hline & & & & & 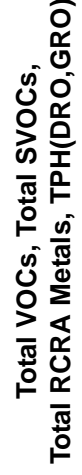 & 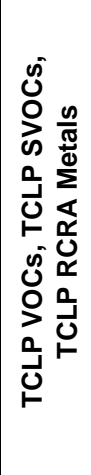 & 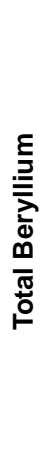 & 心 & 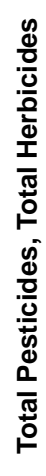 & 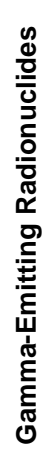 & 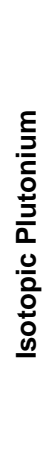 & 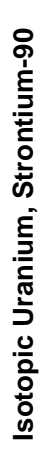 & 톨 & 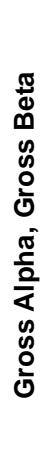 \\
\hline $271 \mathrm{P} 001$ & P03 & Soil & $6-7$ & Integrity & $\mathrm{X}$ & & $\mathrm{X}$ & $\mathrm{X}$ & & & & & & \\
\hline 271P002 & P03 & Soil & $7.5-7.75$ & Integrity & \multicolumn{10}{|c|}{ Not Submitted for Analyses ${ }^{a}$} \\
\hline $271 \mathrm{P} 003$ & $\mathrm{P} 04$ & Soil & $5-6$ & Integrity & $X$ & & $X$ & $X$ & & & & & & \\
\hline $271 \mathrm{P} 004$ & P04 & Soil & $7-7.5$ & Integrity & \multicolumn{10}{|c|}{ Not Submitted for Analyses ${ }^{a}$} \\
\hline 271P005 & P05 & Soil & $2.8-3.8$ & Environmental & $\mathrm{X}$ & & $x$ & $x$ & & & & & & \\
\hline $271 \mathrm{P} 006$ & P05 & Soil & $4.3-4.5$ & Environmental & \multicolumn{10}{|c|}{ Not Submitted for Analyses ${ }^{a}$} \\
\hline $271 \mathrm{P} 007$ & P06 & Soil & $2.8-3.8$ & Environmental & $X$ & & $X$ & $X$ & & $X$ & $X$ & $X$ & & \\
\hline 271P008 & P06 & Soil & $2.8-3.8$ & $\begin{array}{c}\text { Duplicate of } \\
2714 \mathrm{P} 007\end{array}$ & $X$ & & $X$ & $X$ & & $X$ & $X$ & $X$ & & \\
\hline 271P009 & P06 & Soil & $3.8-3.9$ & Environmental & \multicolumn{10}{|c|}{ Not Submitted for Analyses ${ }^{a}$} \\
\hline 271P010 & P07 & Soil & $5-6$ & Environmental & $X$ & & $X$ & $X$ & & $X$ & $X$ & $X$ & & \\
\hline 271P011 & P07 & Soil & $7.5-8$ & Environmental & \multicolumn{10}{|c|}{ Not Submitted for Analyses ${ }^{a}$} \\
\hline $271 \mathrm{P} 012$ & P08 & Soil & $5-6$ & Environmental & $X$ & & $\mathrm{X}$ & $X$ & & & & & & \\
\hline $271 \mathrm{P} 013$ & P08 & Soil & $7.5-8.5$ & Environmental & \multicolumn{10}{|c|}{ Not Submitted for Analyses ${ }^{a}$} \\
\hline 271P014 & P09 & Soil & $4.5-5.5$ & Environmental & $\mathrm{X}$ & & $x$ & $x$ & & & & & & \\
\hline $271 \mathrm{P} 015$ & P09 & Soil & $7-8$ & Environmental & \multicolumn{10}{|c|}{ Not Submitted for Analyses ${ }^{a}$} \\
\hline $271 \mathrm{P} 016$ & P10 & Soil & $3.7-4.7$ & Environmental & $X$ & & $X$ & $X$ & & & & & & \\
\hline $271 \mathrm{P} 017$ & P10 & Soil & $5.7-6.2$ & Environmental & \multicolumn{10}{|c|}{ Not Submitted for Analyses ${ }^{a}$} \\
\hline 271P018 & P11 & Soil & $2.75-3.75$ & Environmental & $X$ & & $X$ & $X$ & & & & & & \\
\hline $271 \mathrm{P} 019$ & $\mathrm{P} 11$ & Soil & $4.7-5.7$ & Environmental & \multicolumn{10}{|c|}{ Not Submitted for Analyses ${ }^{a}$} \\
\hline $271 \mathrm{P} 020$ & $\mathrm{P} 12$ & Soil & $5-6$ & Environmental & $\mathrm{X}$ & & $\mathrm{X}$ & $X$ & & $\mathrm{X}$ & $\mathrm{X}$ & $X$ & & \\
\hline $271 \mathrm{P} 021$ & $\mathrm{P} 12$ & Soil & $6.5-7.5$ & Environmental & \multicolumn{10}{|c|}{ Not Submitted for Analyses ${ }^{a}$} \\
\hline 271P022 & P13 & Soil & $4.3-5.4$ & Environmental & $X$ & & $X$ & $X$ & & $X$ & $x$ & $x$ & & \\
\hline
\end{tabular}


Table A.16-1

Samples Collected at CAS 26-05-05

(Page 2 of 5 )

\begin{tabular}{|c|c|c|c|c|c|c|c|c|c|c|c|c|c|c|}
\hline \multirow[b]{2}{*}{$\begin{array}{c}\text { Sample } \\
\text { Identification } \\
\text { Number }\end{array}$} & \multirow[b]{2}{*}{$\begin{array}{l}\text { Sample } \\
\text { Location }\end{array}$} & \multirow[b]{2}{*}{$\begin{array}{c}\text { Sample } \\
\text { Matrix }\end{array}$} & \multirow[b]{2}{*}{$\begin{array}{c}\text { Depth } \\
\text { (ft bgs) }\end{array}$} & \multirow[b]{2}{*}{ Purpose } & \multicolumn{10}{|c|}{ Analyses } \\
\hline & & & & & 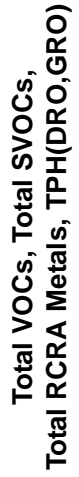 & 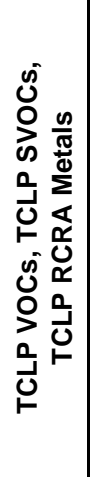 & 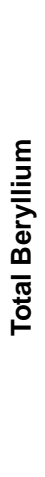 & $\begin{array}{l}\mathscr{M} \\
0\end{array}$ & 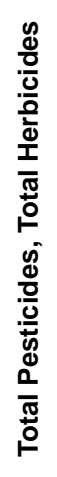 & 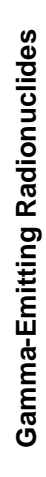 & 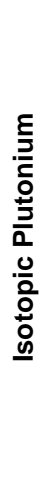 & 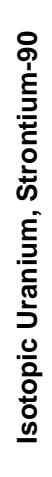 & 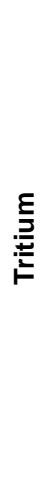 & 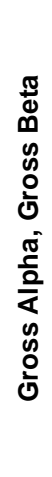 \\
\hline 271P023 & P13 & Soil & $7-8$ & Environmental & \multicolumn{10}{|c|}{ Not Submitted for Analyses ${ }^{a}$} \\
\hline 271P024 & P14 & Soil & $4-5$ & Environmental & $x$ & & $x$ & $X$ & & & & & & \\
\hline $271 \mathrm{P} 025$ & P14 & Soil & $6.5-7.5$ & Environmental & \multicolumn{10}{|c|}{ Not Submitted for Analyses ${ }^{a}$} \\
\hline 271P026 & P15 & Soil & $4-5$ & $\begin{array}{c}\text { Environmental } \\
\text { MS/MSD }\end{array}$ & $x$ & & $x$ & $\mathrm{X}$ & & $x$ & $x$ & $x$ & & \\
\hline $271 \mathrm{P} 027$ & P15 & Soil & $6.5-7.5$ & Environmental & \multicolumn{10}{|c|}{ Not Submitted for Analyses ${ }^{a}$} \\
\hline $271 \mathrm{P} 028$ & P16 & Soil & $5-6$ & Environmental & $x$ & & $x$ & $x$ & & & & & & \\
\hline 271P029 & P16 & Soil & $7.5-8.5$ & Environmental & \multicolumn{10}{|c|}{ Not Submitted for Analyses ${ }^{a}$} \\
\hline $271 \mathrm{P} 030$ & P37 & Soil & $7-7.25$ & Integrity & $x$ & & $x$ & $X$ & & $X$ & $x$ & $X$ & & \\
\hline 271P031 & P19 & Soil & $3.5-4.7$ & Environmental & $\mathrm{x}$ & & $x$ & $x$ & & & & & & \\
\hline 271P032 & P19 & Soil & $5-6$ & Environmental & \multicolumn{10}{|c|}{ Not Submitted for Analyses ${ }^{a}$} \\
\hline 271P033 & P18 & Soil & $4-5$ & Environmental & $x$ & & $\mathrm{x}$ & $x$ & & & & & & \\
\hline 271P034 & P18 & Soil & $7-8$ & Environmental & \multicolumn{10}{|c|}{ Not Submitted for Analyses ${ }^{a}$} \\
\hline 271P035 & P17 & Soil & $4-5$ & Environmental & $x$ & & $\mathrm{x}$ & $x$ & & & & & & \\
\hline 271P036 & P17 & Soil & $6.5-7.5$ & Environmental & \multicolumn{10}{|c|}{ Not Submitted for Analyses ${ }^{a}$} \\
\hline 271P037 & P21 & Soil & $4.5-5.5$ & Environmental & $x$ & & $x$ & $\mathrm{x}$ & & & & & & \\
\hline 271P038 & P21 & Soil & $5.5-6$ & Environmental & \multicolumn{10}{|c|}{ Not Submitted for Analyses ${ }^{a}$} \\
\hline 271P039 & P20 & Soil & $4-5$ & Environmental & $x$ & & $\mathrm{x}$ & $x$ & & & & & & \\
\hline 271P040 & P10 & Soil & $6.5-7.4$ & Environmental & \multicolumn{10}{|c|}{ Not Submitted for Analyses ${ }^{a}$} \\
\hline 271P041 & P23 & Soil & $4-5$ & Environmental & $x$ & & $x$ & $x$ & & & & & & \\
\hline 271P042 & P23 & Soil & $6-7$ & Environmental & \multicolumn{10}{|c|}{ Not Submitted for Analyses ${ }^{a}$} \\
\hline $271 \mathrm{P} 043$ & P22 & Soil & $5.5-6.5$ & $\begin{array}{l}\text { Environmental } \\
\text { MS/MSD }\end{array}$ & $X$ & & $X$ & $x$ & & $X$ & $x$ & $X$ & & \\
\hline 271P044 & P22 & Soil & $7-8$ & Environmental & \multicolumn{10}{|c|}{ Not Submitted for Analyses ${ }^{a}$} \\
\hline
\end{tabular}


Table A.16-1

Samples Collected at CAS 26-05-05

(Page 3 of 5 )

\begin{tabular}{|c|c|c|c|c|c|c|c|c|c|c|c|c|c|c|}
\hline \multirow[b]{2}{*}{$\begin{array}{c}\text { Sample } \\
\text { Identification } \\
\text { Number }\end{array}$} & \multirow[b]{2}{*}{$\begin{array}{l}\text { Sample } \\
\text { Location }\end{array}$} & \multirow[b]{2}{*}{$\begin{array}{c}\text { Sample } \\
\text { Matrix }\end{array}$} & \multirow[b]{2}{*}{$\begin{array}{c}\text { Depth } \\
\text { (ft bgs) }\end{array}$} & \multirow[b]{2}{*}{ Purpose } & \multicolumn{10}{|c|}{ Analyses } \\
\hline & & & & & 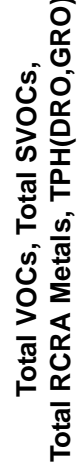 & 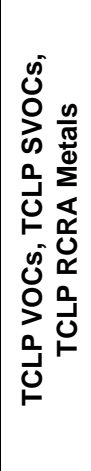 & 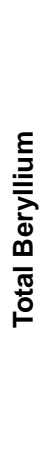 & 怘 & 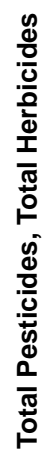 & 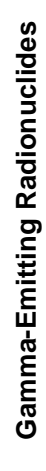 & 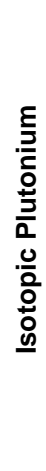 & 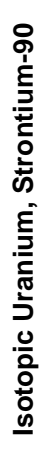 & 톨 & 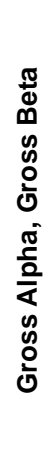 \\
\hline $271 \mathrm{P} 045$ & $\mathrm{P} 24$ & Soil & $4-5$ & Environmental & $\mathrm{X}$ & & $\mathrm{X}$ & $\mathrm{X}$ & & & & & & \\
\hline $271 \mathrm{P} 046$ & $\mathrm{P} 24$ & Soil & $6.5-7$ & Environmental & \multicolumn{10}{|c|}{ Not Submitted for Analyses ${ }^{a}$} \\
\hline $271 \mathrm{P} 047$ & P25 & Soil & $5.5-6.5$ & Environmental & $X$ & & $X$ & $X$ & & & & & & \\
\hline $271 \mathrm{P} 048$ & $\mathrm{P} 25$ & Soil & $7-8$ & Environmental & \multicolumn{10}{|c|}{ Not Submitted for Analyses ${ }^{a}$} \\
\hline 271P049 & P26 & Soil & $5.5-6.5$ & Environmental & $X$ & & $x$ & $x$ & & & & & & \\
\hline $271 \mathrm{P} 050$ & $\mathrm{P} 26$ & Soil & $8-9$ & Environmental & \multicolumn{10}{|c|}{ Not Submitted for Analyses ${ }^{a}$} \\
\hline $271 \mathrm{P} 051$ & P31 & Soil & $4.5-5.5$ & Environmental & $X$ & & $X$ & $X$ & & & & & & \\
\hline $271 \mathrm{P} 052$ & P31 & Soil & $7-8$ & Environmental & \multicolumn{10}{|c|}{ Not Submitted for Analyses ${ }^{a}$} \\
\hline $271 \mathrm{P} 053$ & P32 & Soil & $4-5$ & Environmental & $X$ & & $X$ & $X$ & & & & & & \\
\hline $271 \mathrm{P} 054$ & P32 & Soil & $6.5-7.5$ & Environmental & \multicolumn{10}{|c|}{ Not Submitted for Analyses ${ }^{a}$} \\
\hline 271P060 & P35 & Soil & $4-5$ & Environmental & $X$ & & $X$ & $X$ & & & & & & \\
\hline $271 \mathrm{P} 061$ & P35 & Soil & $6.5-7.5$ & Environmental & \multicolumn{10}{|c|}{ Not Submitted for Analyses ${ }^{a}$} \\
\hline 271P062 & P34 & Soil & $4-5$ & Environmental & $X$ & & $X$ & $X$ & & & & & & \\
\hline $271 \mathrm{P} 063$ & P34 & Soil & $6.5-7.5$ & Environmental & \multicolumn{10}{|c|}{ Not Submitted for Analyses ${ }^{a}$} \\
\hline $271 \mathrm{P} 064$ & P33 & Soil & $4-5$ & Environmental & $X$ & & $X$ & $\mathrm{X}$ & & $X$ & $X$ & $X$ & & \\
\hline $271 \mathrm{P} 065$ & P33 & Soil & $6.5-7.5$ & Environmental & \multicolumn{10}{|c|}{ Not Submitted for Analyses ${ }^{a}$} \\
\hline $271 \mathrm{P} 066$ & P36 & Soil & $5.5-6.5$ & Environmental & $X$ & & $x$ & $X$ & & & & & & \\
\hline $271 \mathrm{P} 067$ & P36 & Soil & $8.5-9$ & Environmental & \multicolumn{10}{|c|}{ Not Submitted for Analyses ${ }^{a}$} \\
\hline 271P068 & P30 & Soil & $5-6$ & Environmental & $x$ & & $x$ & $x$ & & & & & & \\
\hline $271 \mathrm{P} 069$ & P30 & Soil & $7.5-8$ & Environmental & \multicolumn{10}{|c|}{ Not Submitted for Analyses ${ }^{a}$} \\
\hline 271P070 & P29 & Soil & $4-5$ & Environmental & $x$ & & $X$ & $X$ & & & & & & \\
\hline $271 \mathrm{P} 071$ & P29 & Soil & $6.5-7.5$ & Environmental & \multicolumn{10}{|c|}{ Not Submitted for Analyses ${ }^{a}$} \\
\hline $271 \mathrm{P} 072$ & P28 & Soil & $4-5$ & Environmental & $X$ & & $x$ & $X$ & & $X$ & $X$ & $X$ & & \\
\hline
\end{tabular}


Table A.16-1

Samples Collected at CAS 26-05-05

(Page 4 of 5)

\begin{tabular}{|c|c|c|c|c|c|c|c|c|c|c|c|c|c|c|}
\hline \multirow[b]{2}{*}{$\begin{array}{c}\text { Sample } \\
\text { Identification } \\
\text { Number }\end{array}$} & \multirow[b]{2}{*}{$\begin{array}{l}\text { Sample } \\
\text { Location }\end{array}$} & \multirow[b]{2}{*}{$\begin{array}{l}\text { Sample } \\
\text { Matrix }\end{array}$} & \multirow[b]{2}{*}{$\begin{array}{c}\text { Depth } \\
\text { (ft bgs) }\end{array}$} & \multirow[b]{2}{*}{ Purpose } & \multicolumn{10}{|c|}{ Analyses } \\
\hline & & & & & 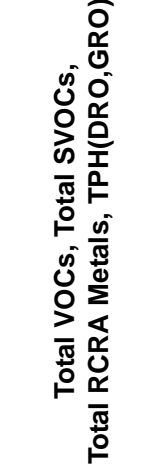 & 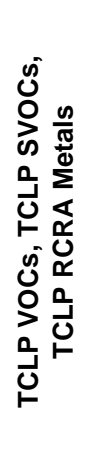 & 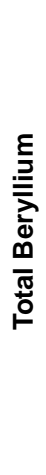 & 邑 & $\begin{array}{l}\frac{8}{0} \\
\frac{0}{0} \\
\frac{0}{2} \\
\frac{1}{1} \\
\frac{\pi}{0} \\
\frac{0}{0} \\
\frac{0}{0} \\
\frac{0}{0} \\
\frac{0}{0} \\
\frac{0}{0} \\
\frac{\pi}{0} \\
\frac{0}{1}\end{array}$ & 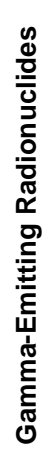 & 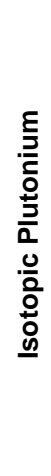 & 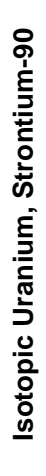 & $\frac{E}{3}$ & 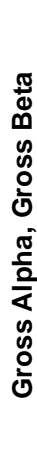 \\
\hline $271 \mathrm{P} 073$ & P28 & Soil & $4-5$ & $\begin{array}{l}\text { Duplicate of } \\
\text { 271P072 }\end{array}$ & $\mathrm{X}$ & & $\mathrm{X}$ & $X$ & & $\mathrm{X}$ & $\mathrm{X}$ & $\mathrm{X}$ & & \\
\hline 271P074 & P28 & Soil & $7.5-8.5$ & Environmental & \multicolumn{10}{|c|}{ Not Submitted for Analyses ${ }^{a}$} \\
\hline $271 \mathrm{P} 075$ & $\mathrm{P} 27$ & Soil & $3.5-4.5$ & Environmental & $X$ & & $\mathrm{X}$ & $\mathrm{X}$ & & & & & & \\
\hline $271 \mathrm{P} 076$ & P01 & Soil & $5.5-6.5$ & Integrity & $X$ & & $X$ & $X$ & & $X$ & $X$ & $X$ & & \\
\hline $271 \mathrm{P} 077$ & P01 & Soil & $8-8.5$ & Integrity & \multicolumn{10}{|c|}{ Not Submitted for Analyses ${ }^{a}$} \\
\hline 271P078 & P02 & Soil & $7.5-8.5$ & Integrity & $x$ & & $\mathrm{X}$ & $\mathrm{X}$ & & & & & & \\
\hline 271P079 & P02 & Soil & $7.6-8.1$ & Integrity & $X$ & & $X$ & $X$ & & & & & & \\
\hline $271 \mathrm{P} 090$ & $\mathrm{P} 40$ & Soil & $4-4.3$ & Geotechnical & \multicolumn{10}{|c|}{ Not Submitted for Analyses ${ }^{b}$} \\
\hline 271P080 & P39 & Liquid & $3.3-6.7$ & Septic Tank 1 & $x$ & & $X$ & $X$ & & $X$ & $x$ & $x$ & $x$ & $x$ \\
\hline $271 \mathrm{P} 081$ & P39 & Liquid & $3.3-6.7$ & Duplicate of P080 & $X$ & & $X$ & $X$ & & $X$ & $X$ & $X$ & $X$ & $\mathrm{X}$ \\
\hline $271 \mathrm{P} 082$ & P39 & Sludge & $6.7-7.2$ & $\begin{array}{c}\text { Septic Tank } 1 \\
\text { MS/MSD }\end{array}$ & $X$ & $X$ & $X$ & $X$ & & $X$ & $X$ & $X$ & $X$ & \\
\hline $271 \mathrm{P} 083$ & NA & Water & NA & Field Blank & $\mathrm{X}$ & & $X$ & $x$ & & $x$ & $X$ & $X$ & $X$ & \\
\hline 271P084 & P43 & Sediment & $7.5-7.6$ & Septic Tank 2 & $x$ & $x$ & $x$ & $\mathrm{X}$ & & $x$ & $x$ & $\mathrm{X}$ & $\mathrm{X}$ & \\
\hline 271P201 & P25 & Soil & $8.5-9$ & Environmental & TPH (DRO) & & & & & & & & & \\
\hline 271P202 & P25 & Soil & $8.5-9$ & $\begin{array}{l}\text { Duplicate of } \\
\text { 271P201 }\end{array}$ & TPH (DRO) & & & & & & & & & \\
\hline 271P203 & $\mathrm{P} 25$ & Soil & $11-11.5$ & $\begin{array}{c}\text { Environmental } \\
\text { MS/MSD }\end{array}$ & TPH (DRO) & & & & & & & & & \\
\hline 271P204 & P45 & Soil & $6-6.5$ & Environmental & TPH (DRO) & & & & & & & & & \\
\hline 271P205 & P45 & Soil & $8-8.5$ & Environmental & TPH (DRO) & & & & & & & & & \\
\hline 271P301 & NA & Water & NA & Trip Blank & VOC only & & & & & & & & & \\
\hline 271P302 & NA & Water & NA & Field Blank & $x$ & & $X$ & $x$ & & $x$ & $X$ & $X$ & & \\
\hline 271P303 & NA & Water & NA & Trip Blank & VOC only & & & & & & & & & \\
\hline
\end{tabular}


Table A.16-1

Samples Collected at CAS 26-05-05

(Page 5 of 5 )

\begin{tabular}{|c|c|c|c|c|c|c|c|c|c|c|c|c|c|c|}
\hline \multirow[b]{2}{*}{$\begin{array}{c}\text { Sample } \\
\text { Identification } \\
\text { Number }\end{array}$} & \multirow[b]{2}{*}{$\begin{array}{c}\text { Sample } \\
\text { Location }\end{array}$} & \multirow[b]{2}{*}{$\begin{array}{c}\text { Sample } \\
\text { Matrix }\end{array}$} & \multirow[b]{2}{*}{$\begin{array}{l}\text { Depth } \\
\text { (ft bgs) }\end{array}$} & \multirow[b]{2}{*}{ Purpose } & \multicolumn{10}{|c|}{ Analyses } \\
\hline & & & & & 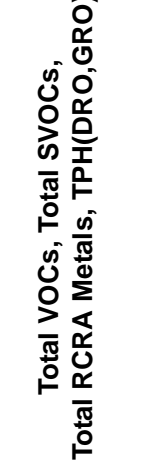 & 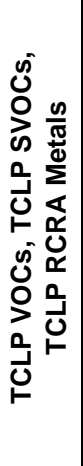 & 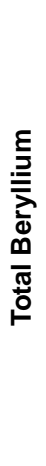 & 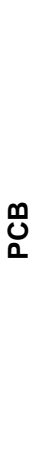 & 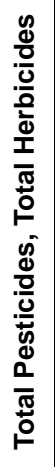 & 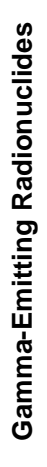 & 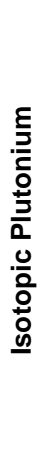 & 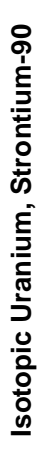 & 톨 & 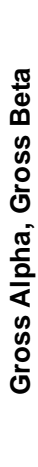 \\
\hline 271P304 & NA & Water & NA & Trip Blank & VOC only & & & & & & & & & \\
\hline 271P305 & NA & Water & NA & Rinsate & $x$ & & $X$ & $x$ & & $X$ & $X$ & $X$ & & \\
\hline 271P306 & NA & Water & NA & Trip Blank & VOC only & & & & & & & & & \\
\hline 271P307 & NA & Water & NA & Trip Blank & VOC only & & & & & & & & & \\
\hline 271P308 & NA & Water & NA & Trip Blank & VOC only & & & & & & & & & \\
\hline 271P312 & NA & Water & NA & Trip Blank & VOC only & & & & & & & & & \\
\hline 271P313 & NA & Water & NA & Trip Blank & VOC only & & & & & & & & & \\
\hline 271P314 & NA & Water & NA & Trip Blank & VOC only & & & & & & & & & \\
\hline 271P315 & NA & Water & NA & Trip Blank & VOC only & & & & & & & & & \\
\hline 271P316 & NA & Water & NA & Trip Blank & VOC only & & & & & & & & & \\
\hline
\end{tabular}

${ }^{a}$ The sample was collected, field screened, and returned to the site for disposal.

${ }^{\mathrm{b}}$ The sample was collected, field screened, and is being stored for possible geotechnical analysis.

NA $=$ Not applicable

$\mathrm{MS} / \mathrm{MSD}=$ Matrix spike/matrix spike duplicate 


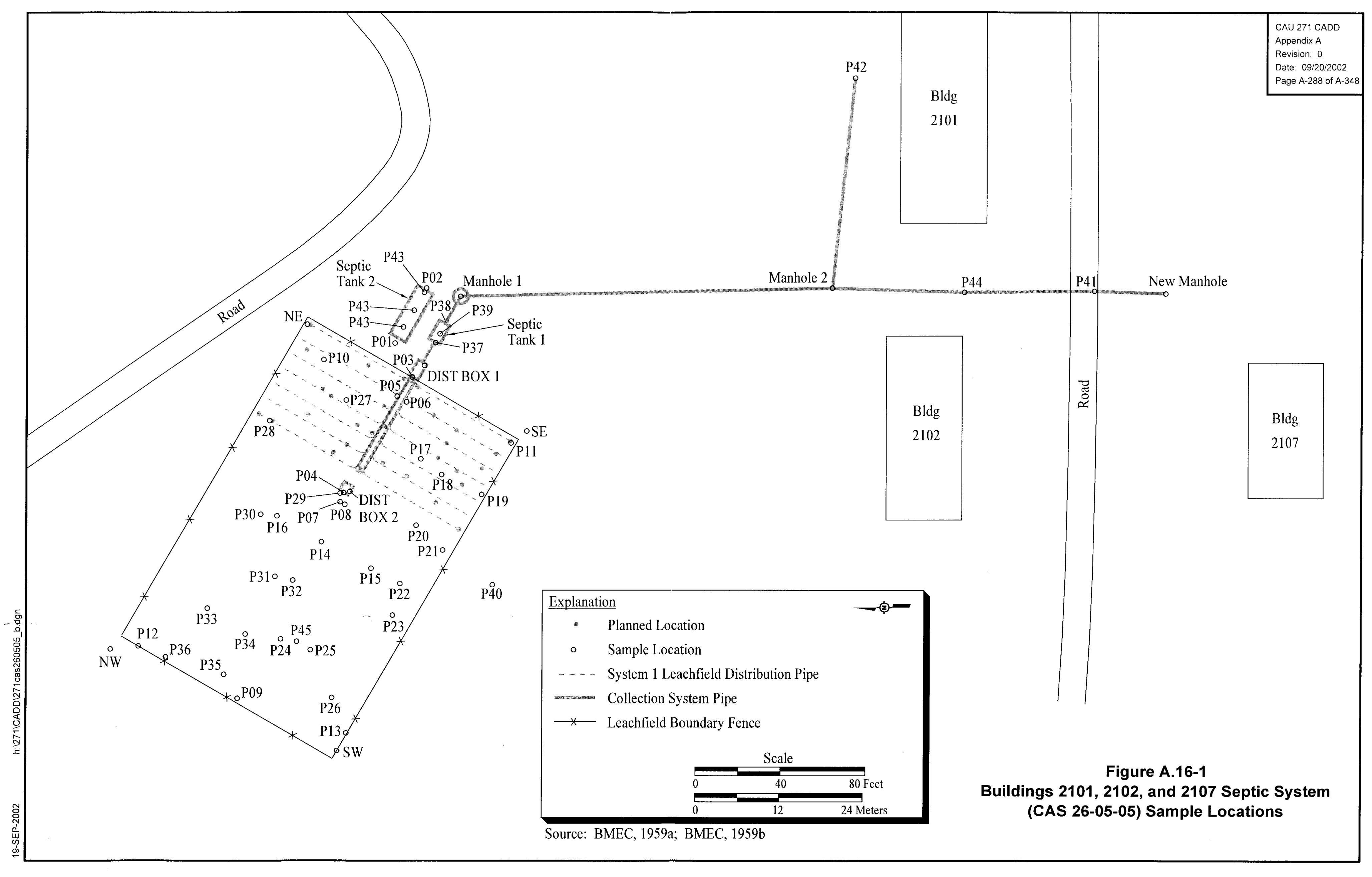


- Sample 271P074 was collected at 7.5 to $8.5 \mathrm{ft}$ bgs rather than the planned interval of 6.5 to $7.5 \mathrm{ft} \mathrm{bgs}$

- Refusal was met due to encountering subsurface hardpan (caliche); therefore:

- Sample 271P002 was collected at 7.5 to $7.75 \mathrm{ft}$ bgs rather than the planned interval of 8.5 to $9.5 \mathrm{ft} \mathrm{bgs}$

- Sample 271P004 was collected at 7 to $7.5 \mathrm{ft}$ bgs rather than the planned interval of 7.5 to $8.5 \mathrm{ft} \mathrm{bgs}$

- Sample 271P006 was collected at 4.3 to $4.5 \mathrm{ft}$ bgs rather than the planned interval of 5.3 to $6.3 \mathrm{ft}$ bgs

- Sample 271P009 was collected at 3.8 to $3.9 \mathrm{ft}$ bgs rather than the planned interval of 5.3 to $6.3 \mathrm{ft} \mathrm{bgs}$

- Sample 271P017 was collected at 5.7 to $6.2 \mathrm{ft}$ bgs rather than the planned interval of 6.2 to $7.2 \mathrm{ft}$ bgs

- Sample 271P019 was collected at 4.7 to $5.7 \mathrm{ft}$ bgs rather than the planned interval of 5.25 to $6.25 \mathrm{ft}$ bgs

- Sample 271P021 was collected at 6.5 to $7.5 \mathrm{ft}$ bgs rather than the planned interval of 7.5 to $8.5 \mathrm{ft}$ bgs

- Sample 271P030 was collected at 7 to $7.25 \mathrm{ft}$ bgs rather than the planned interval of 7 to $8 \mathrm{ft}$ bgs (an additional sample was planned below this sampling interval, but could not be achieved)

- Sample 271P032 was collected at 5 to $6 \mathrm{ft}$ bgs rather than the planned interval of 7 to $8 \mathrm{ft}$ bgs

- Sample 271P038 was collected at 5.5 to $6 \mathrm{ft}$ bgs rather than the planned interval of 7 to $8 \mathrm{ft}$ bgs

- Sample 271P042 was collected at 6 to $7 \mathrm{ft}$ bgs rather than the planned interval of 6.5 to $7.5 \mathrm{ft}$ bgs

- Sample 271P044 was collected at 7 to $8 \mathrm{ft}$ bgs rather than the planned interval of 8 to $9 \mathrm{ft}$ bgs

- Sample 271P048 was collected at 7 to $8 \mathrm{ft}$ bgs rather than the planned interval of 8 to $9 \mathrm{ft}$ bgs 
- Sample 271P075 was collected at the planned interval of 3.5 to $4.5 \mathrm{ft}$ bgs; however, an additional sample was planned below this interval and could not be obtained

- Sample 271P078 was collected at the planned interval of 7.5 to $8.5 \mathrm{ft}$ bgs; however, an additional sample was planned below this interval and could not be obtained

- Sample 271P079 was collected at 7.6 to $8.1 \mathrm{ft}$ bgs rather than the planned interval of 7.6 to $8.6 \mathrm{ft}$ bgs (an additional sample was planned below this interval, but could not be obtained)

Despite these deviations, the pertinent CAIP requirements were met.

\section{A.16.2 Investigation Results}

The following subsections provide details of the inspection and sampling of leachfield features, field screening results, and sample selection and analysis.

\section{A.16.2.1 Septic Tank Contents}

Septic tank 1 is concrete and square-shaped with a 1,135-gal capacity. It was accessed by one manhole located $1 \mathrm{ft}$ above the ground surface. The interior dimensions of the tank are $5.3 \mathrm{ft}$ (length) by $5.3 \mathrm{ft}$ (width) by $5.3 \mathrm{ft}$ (depth). One liquid and one sludge sample were collected from this single-chambered septic tank. Visual inspection revealed that a maximum thickness of $4 \mathrm{ft}$ (851 gal) of liquid and 4 in. (71 gal) of sludge remained in the bottom of the tank. No photographs were taken of the interior of the septic tank.

Septic tank 2 is located approximately $15 \mathrm{ft}$ northeast of septic tank 1 . Septic tank 2 is a concrete, three-chambered, rectangular-shaped tank with a 3,441-gal capacity. The tank was located $2 \mathrm{ft}$ below the ground surface and accessed by three concrete manholes. The manholes are recessed below grade within three metal tubes with metal covers. The interior dimensions of the tank are $24 \mathrm{ft}$ (length) by $3.8 \mathrm{ft}$ (width) by $5 \mathrm{ft}$ (depth). One sediment sample was collected from septic tank 2 . The sample was collected as a composite sample of all three chambers. Visual inspection revealed that a maximum of thickness 1 in. (19 gal) of sediment remained in the bottom of each chamber of the tank. No photographs were taken of the interior of the septic tank. 


\section{A.16.2.2 Distribution Box Contents}

Distribution box 1 is a square concrete box with a 365 -gal capacity. It was accessed by one manhole that was located $2 \mathrm{ft}$ above the ground surface. The interior dimensions of the box are $3.25 \mathrm{ft}$ (length) by $3 \mathrm{ft}$ (width) by $5 \mathrm{ft}$ (depth). Very little sediment remained in the bottom of the distribution box; therefore, no samples were collected. Figure A.16-2 depicts the distribution box.

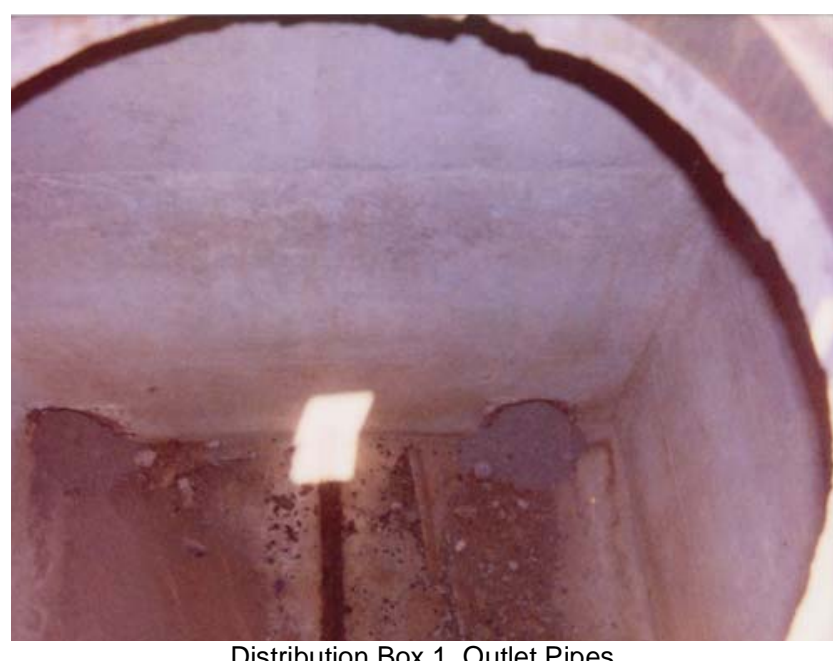

Distribution Box 1, Outlet Pipes

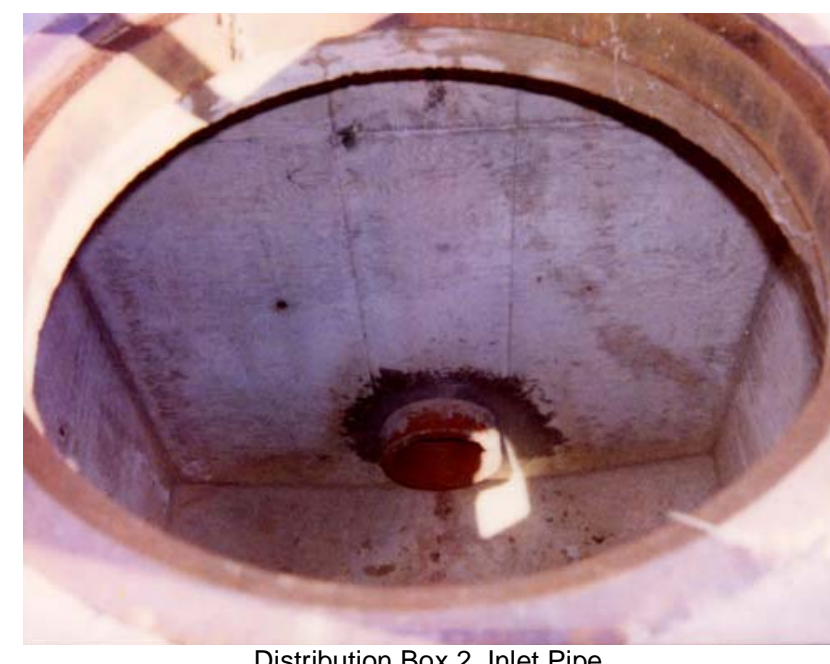

Distribution Box 2, Inlet Pipe

Figure A.16-2

CAS 26-05-05 Distribution Boxes, Interiors

(Photographs Taken 01-17-2002)

Distribution box 2 is located approximately $60 \mathrm{ft}$ northwest of distribution box 1 (Figure A.16-1). The distribution box is a square concrete box with a 337-gal capacity. It was accessed by one manhole that was located $1 \mathrm{ft}$ above the ground surface. The interior dimensions of the box are $3 \mathrm{ft}$ (length) by $3 \mathrm{ft}$ (width) by $5 \mathrm{ft}$ (depth). No sediment was present in the bottom of the distribution box; therefore, no samples were collected. Figure A.16-2 depicts the distribution box.

\section{A.16.2.3 Septic Tank and Distribution Box Integrity Soil Sampling}

Nine integrity samples were collected by excavating adjacent to influent and effluent ends of the septic tanks and the effluent end of the distribution boxes. Figure A.16-3 and Figure A.16-4 depict the structural integrity and configuration of the influent and effluent ends of the septic tanks. The following six samples were submitted for laboratory analysis: 


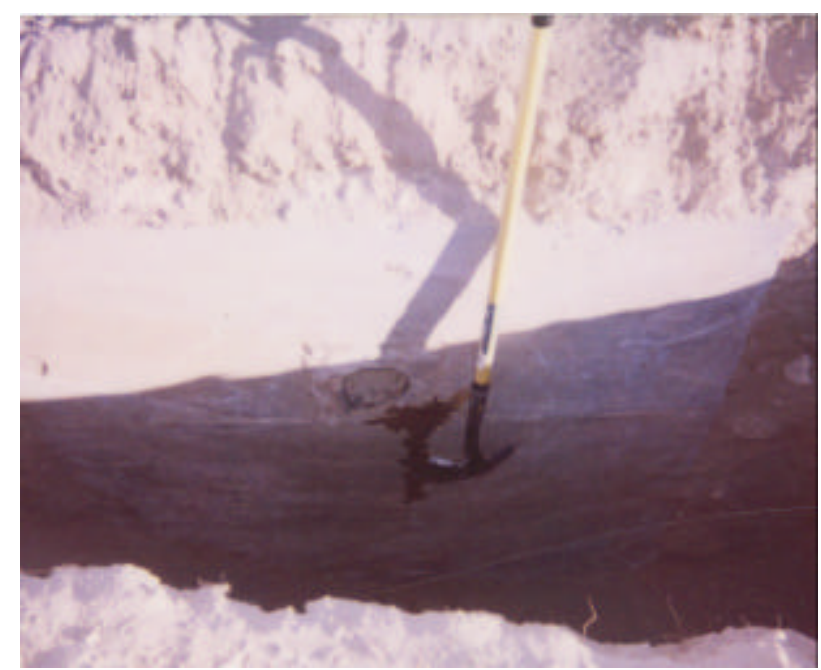

Outlet Side (Photograph Taken 01-17-2002)

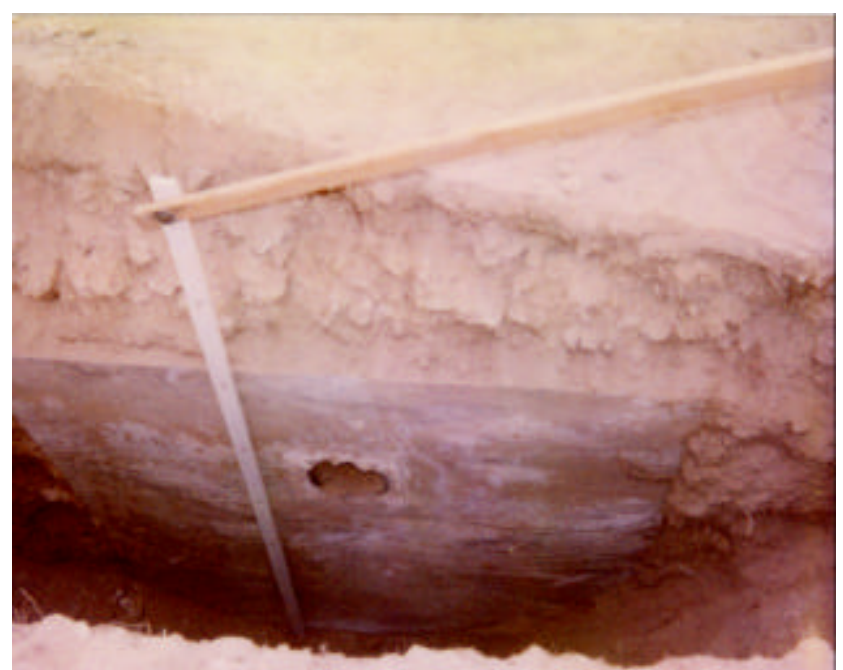

Inlet Side (Photograph Taken 01-22-2002)

Figure A.16-3

CAS 26-05-05 Septic Tank 1, Integrity Samples

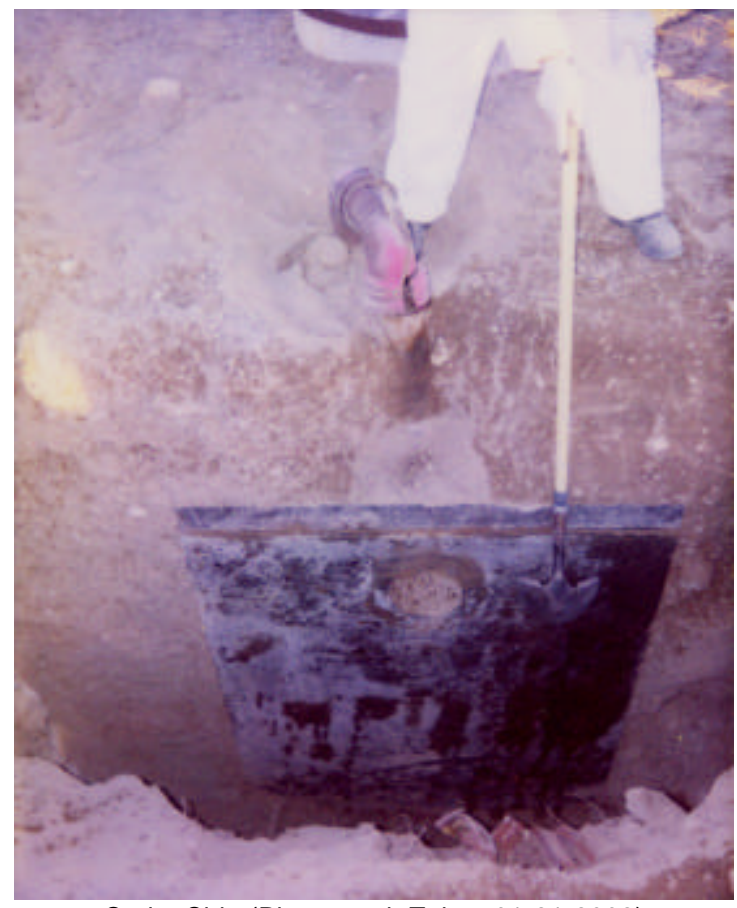

Outlet Side (Photograph Taken 01-21-2002)

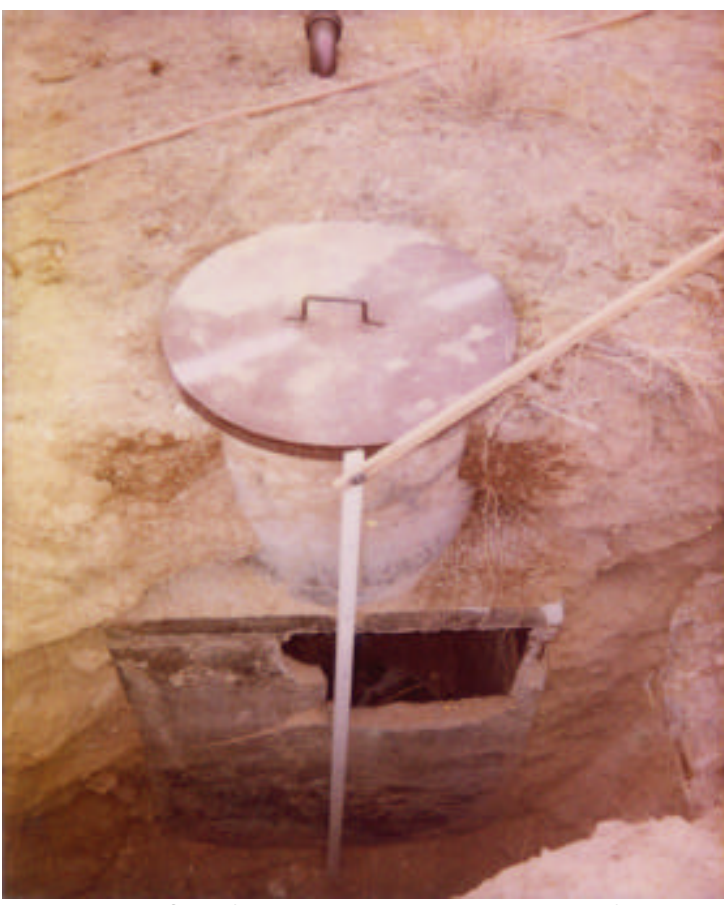

Inlet Side (Photograph Taken 01-22-2002)

Figure A.16-4

CAS 26-05-05 Septic Tank 2, Integrity Samples 
- The upper sample (271P001) from the effluent end of distribution box 1, collected at 6 to $7 \mathrm{ft}$ bgs

- The upper sample (271P003) from the effluent end of distribution box 2, collected at 5 to $6 \mathrm{ft}$ bgs

- The upper sample (271P030) from the effluent end of septic tank 1, collected at $7.25 \mathrm{ft}$ bgs

- The upper sample (271P076) from the effluent end of septic tank 2, collected at 5.5 to $6.5 \mathrm{ft}$ bgs

- The upper sample (271P078) from the influent end of septic tank 2, collected at 7.5 to $8.5 \mathrm{ft}$ bgs

- The upper sample (271P079) from the influent end of septic tank 1, collected at $7.6 \mathrm{ft}$ to $8.1 \mathrm{ft} \mathrm{bgs}$

\section{A.16.2.4 Leachfield Excavation Soil Sampling}

Backhoe excavations were conducted to access sampling horizons at the biased and random locations presented in the CAIP. Excavations provided a visual verification of distribution pipes and enabled soil samples to be collected from appropriate intervals beneath the pipes, as specified by the CAIP. Sixty-five soil samples were collected from the planned locations excavated within the leachfield. These samples were collected from an interval at 0 to $1 \mathrm{ft}$ and an interval 2.5 to $3.5 \mathrm{ft}$ below the leachrock/native soil interface. The interface was found at depths ranging from 2.75 to $5.5 \mathrm{ft}$ bgs. Thirty-five samples were submitted for laboratory analysis. In addition, two QC soil duplicates and two MS/MSD samples were collected and analyzed. A geotechnical sample was collected outside the boundary of the leachfield. The sample will be sent to a laboratory for geotechnical analysis, if necessary.

\section{A.16.2.5 Additional Sampling}

To define the extent of TPH DRO contamination, the field crew returned to this CAS on May 08, 2002, to conduct step-out sampling. One location (P25) was identified from the original sampling activities as a location of concern. Two vertical and two horizontal step-out samples were collected. Samples 271P201 and 271P203 were collected from deeper intervals at location P25. Samples 271P204 and 271P205 were collected from P45 (8.5 ft northeast of P25). All samples were submitted 
for laboratory analysis of TPH DRO. In addition, one QC soil duplicate (271P202) and one MS/MSD (271P203) sample were collected and analyzed.

\section{A.16.2.6 Collection System Pipe Inspections}

Access points for visual inspection of the collection system by video mole survey were present (i.e., manholes) and created at locations along the collection pipe via backhoe excavation.

The septic system has three associated manholes: Manhole 1, Manhole 2, and New Manhole (Figure A.16-1).

Manhole 1 was opened and inspected; it did not contain adequate sediment to sample. A radiological survey was conducted on the manhole and swipes were collected for radiological characterization. The manhole has two inlets and two outlets. The video mole was inserted through the manhole, into the lower inlet pipe (main collection system pipe), and passed $72 \mathrm{ft}$ upstream (south). The video mole was then inserted into the upper inlet pipe, and passed $97 \mathrm{ft}$ upstream (southwest) until a vent pipe preventing further inspection was encountered. This is a steel pipe, not shown on engineering drawings. The pipe is shallow, and appears to have been installed subsequent to the construction of septic system 1.

Manhole 2 was opened and inspected; it did not contain adequate sediment to sample. A radiological survey was conducted on the manhole and swipes were collected for radiological characterization. The manhole has two inlets and one outlet. One inlet is the main collection system line, and the other is the line from the northeast side of Building 2101 (Figure A.16-1). The video mole was inserted through Manhole 2 and passed $112 \mathrm{ft}$ downstream (north) until the limits of the video mole were reached. This completed the inspection of the pipe segment between Manholes 1 and 2. The video mole was inserted through the mainline inlet and passed $45 \mathrm{ft}$ upstream (south). The mole was then inserted into the inlet pipe from Building 2101 and passed $103 \mathrm{ft}$ upstream (east) to location P42, where an excavation was made to continue the inspection. The visual inspection continued on this pipe segment upstream for $56 \mathrm{ft}$ from location P42 until an obstruction, in the form of a grout plug (clean-out) was encountered. 
Activities were completed, a piece of pipe was radiologically surveyed and swiped, and the inlet side of this manhole was grouted closed.

Another excavation (P44) was made between Buildings 2101 and 2102. At this excavation point, two feeder lines, originating from Buildings 2101 and 2102, were observed. The video mole was inserted into the southern-most feeder line and passed upstream, where the pipe sloped upward as it entered the Building 2101 foundation. The video mole was then inserted into the northern-most feeder line and passed upstream where, again, the pipe sloped upward as it entered the Building 2102 foundation. After video mole activities were completed, the inlet side of each of these feeder lines were grouted closed. Radiological survey and swipe data were collected at location P44.

Manhole 3 (also described as "New Manhole") did not contain adequate sediment to sample. The manhole has two inlets and one outlet. The upper inlet led for $68 \mathrm{ft}$ south to a riser. The lower pipe led southwest to Building 2107. Video mole activities were not completed at this manhole as the depth (14 ft) was too great. A survey of the inlet line from Building 2107 was attempted; however, the video mole could be pushed only $10 \mathrm{ft}$ upstream. An excavation (P41) was made approximately $51 \mathrm{ft}$ north of the New Manhole to provide access to the collection system pipe. The video mole was inserted into the pipe and passed downstream (north) for $84 \mathrm{ft}$. This completed the inspection of the segment between Manhole 2 and location P41. The video mole was then passed upstream (south) for $37 \mathrm{ft}$ until it entered the New Manhole. After video mole activities were completed, a piece of pipe was radiologically surveyed and swiped, and the inlet side of this manhole was grouted closed.

Some sediment, soil, and plant and animal matter was identified in the piping, but was not appropriate or adequate material to be sampled. The collection system was found to be in good condition, with no breaks or blockages noted. Visual observations were recorded in the FADLs. The results of the radiation surveys and swipes are discussed in Section A.16.2.8.

\section{A.16.2.7 Field-Screening Results}

Soil samples were screened for VOCs and alpha and beta/gamma radioactivity. The field readings were compared to FSLs to guide sampling decisions and determine which samples were to be submitted for laboratory analysis. No VOCs greater than FSLs were found during soil sample screening. The results of radiological field screening are discussed in Section A.16.2.8. 
Samples of content from both septic tanks were collected and analyzed for fecal coliform bacteria. Fecal coliform bacteria was not detected in the septic tanks at this CAS.

\section{A.16.2.8 Radiological Survey Results}

All radiological field-screening results for soil samples from CAS 26-05-05 were below FSLs. Swipe and radiological survey data from inspection locations P41, P42, and P44 and Manholes 1 and 2 indicate that the collection system meets the unrestricted radiological release criteria, as defined in the NV/YMP Radiological Control Manual (DOE/NV, 2000a).

\section{A.16.2.9 Sample Analysis}

Environmental soil samples and associated QC samples were submitted and analyzed for the CAIP-specified COPCs (i.e., total VOCs, total SVOCs, total RCRA metals, and TPH [DRO and GRO], total beryllium, and PCBs). In addition, 25 percent of the soil samples and 100 percent of the associated QC samples were analyzed for Iso-U, Iso-Pu, Sr-90, and gamma-emitting radionuclides.

Both the sludge, liquid, and sediment samples were analyzed for total VOCs, total SVOCs, TPH (GRO and DRO), total RCRA metals, total beryllium, PCBs, gamma-emitting radionuclides, Iso-U, Iso-Pu, Sr-90, and tritium. The liquid sample was also analyzed for gross alpha and gross beta radioactivity. The sludge and sediment samples were analyzed according to the TCLP for VOCs, SVOC, and RCRA metals.

The parameters and laboratory methods used to analyze the investigation samples are listed in Table A.2-2. Table A.16-1 lists the sample-specific analytical parameters.

\section{A.16.3 Analytes Detected Above Minimum Reporting Limits}

The soil samples with concentrations exceeding corresponding MRLs and PALs (DOE/NV, 1998; DOE/NV, 2001) at CAS 26-05-05 are summarized in the following sections. The results of the septic tank contents are compared to appropriate regulatory levels for disposal. A portion of the CAS 26-05-05 results were rejected during validation; however, these rejected data did not impact closure decisions as discussed in Section B.1.3.14 of Appendix B. 


\section{A.16.3.1 Analytical Results for Soil Samples}

The following sections discuss the results for soil samples in comparison to the levels established in the Leachfield Work Plan and the CAIP.

\section{A.16.3.1.1 Total Volatile Organic Compounds}

Volatile organic compounds were not detected above MRLs in CAS 26-05-05 soil samples.

\section{A.16.3.1.2 Total Semivolatile Organic Compounds}

Semivolatile organic compounds were not detected above MRLs in CAS 26-05-05 soil samples.

\section{A.16.3.1.3 Total Petroleum Hydrocarbons}

The TPH values are presented in Table A.16-2. One sample had a reported TPH DRO level above the MRL of $25 \mathrm{mg} / \mathrm{kg}$. Sample 271P047 (from location P25, Figure A.16-1) had concentrations of TPH compounds above the PAL of $100 \mu \mathrm{g} / \mathrm{kg}$ (NAC, 2000). As discussed in Section A.16.2.5, additional soil samples were collected from the leachfield to determine the extent of this potential contamination. The additional samples were analyzed for TPH DRO, and none had detections above MRLs or PALs. This indicated that the TPH contamination is bounded both laterally and vertically in the leachfield soil.

Table A.16-2

Soil Sample Results for TPH-DRO

Detected Above Minimum Reporting Limits at CAS 26-05-05

\begin{tabular}{||c|c|c||}
\hline \multirow{2}{*}{$\begin{array}{c}\text { Sample } \\
\text { Identification } \\
\text { Number }\end{array}$} & $\begin{array}{c}\text { Depth } \\
\text { (ft bgs) }\end{array}$ & Contaminants of Potential Concern (mg/kg) \\
\cline { 3 - 3 } & & Diesel Range Organics \\
\hline Preliminary Action Levels & & $\mathbf{1 0 0}$ \\
\hline \hline $271 \mathrm{P} 047$ & $5.5-6.5$ & 1,500 \\
\hline
\end{tabular}

${ }^{a}$ Based on Nevada Administrative Code; Contamination of Soil: Establishment of Action Levels (NAC, 2000) 


\section{A.16.3.1.4 Total RCRA Metals}

As shown in Table A.16-3, the total RCRA metals detected in soil samples above concentrations exceeding the MRLs are arsenic (1 mg/kg), barium (20 mg/kg), chromium (1 mg/kg), lead $(0.3 \mathrm{mg} / \mathrm{kg})$, mercury $(0.1 \mathrm{mg} / \mathrm{kg})$, selenium $(0.5 \mathrm{mg} / \mathrm{kg})$, and silver $(1.0 \mathrm{mg} / \mathrm{kg})$. Other RCRA metals (i.e., cadmium, silver) were below specified MRLs.

Table A.16-3

Soil Sample Results for Total RCRA Metals Detected Above Minimum Reporting Limits at CAS 26-05-05 (Page 1 of 2)

\begin{tabular}{|c|c|c|c|c|c|c|c|}
\hline \multirow{2}{*}{$\begin{array}{c}\text { Sample } \\
\text { Identification } \\
\text { Number }\end{array}$} & \multirow{2}{*}{$\begin{array}{l}\text { Depth } \\
\text { (ft bgs) }\end{array}$} & \multicolumn{6}{|c|}{ Contaminants of Potential Concern $(\mathrm{mg} / \mathrm{kg})$} \\
\hline & & Arsenic & Barium & Chromium & Lead & Mercury & Selenium \\
\hline \multicolumn{2}{|c|}{ Preliminary Action Levels ${ }^{a}$} & 2.7 & 100,000 & 450 & 750 & 610 & 10,000 \\
\hline $271 \mathrm{P} 001$ & $6-7$ & 4.06 & $217(\mathrm{~J})^{\mathrm{b}}$ & $10.9(\mathrm{~J})^{\mathrm{b}}$ & $7.5(J)^{b}$ & -- & -- \\
\hline 271P003 & $5-6$ & 3.08 & $200(J)^{b}$ & $8.5(J)^{b}$ & $6.79(\mathrm{~J})^{\mathrm{b}}$ & -- & -- \\
\hline 271P005 & $2.8-3.8$ & 3.83 & $170(J)^{b}$ & $15.2(J)^{b}$ & $9.35(J)^{b}$ & -- & -- \\
\hline 271P007 & $2.8-3.8$ & 2.65 & $163(\mathrm{~J})^{\mathrm{b}}$ & $13.8(\mathrm{~J})^{\mathrm{b}}$ & $8.33(\mathrm{~J})^{b}$ & -- & -- \\
\hline 271P008 & $2.8-3.8$ & 2.93 & $188(J)^{b}$ & $15.4(J)^{b}$ & $9.18(\mathrm{~J})^{\mathrm{b}}$ & -- & -- \\
\hline 271P010 & $5-6$ & 3.61 & $195(J)^{b}$ & $10.1(\mathrm{~J})^{\mathrm{b}}$ & $8.01(\mathrm{~J})^{\mathrm{b}}$ & -- & -- \\
\hline 271P012 & $5-6$ & 3.28 & $186(J)^{b}$ & $10.3(\mathrm{~J})^{\mathrm{b}}$ & $7.29(\mathrm{~J})^{\mathrm{b}}$ & -- & -- \\
\hline 271P014 & $4.5-5.5$ & 3.89 & $201(J)^{b}$ & $9.67(\mathrm{~J})^{\mathrm{b}}$ & $7.2(\mathrm{~J})^{\mathrm{b}}$ & -- & -- \\
\hline 271P016 & $3.7-4.7$ & 3.91 & $168(J)^{b}$ & $11.6(\mathrm{~J})^{\mathrm{b}}$ & $10.1(\mathrm{~J})^{\mathrm{b}}$ & -- & -- \\
\hline 271P018 & $2.75-3.75$ & 3.78 & $194(J)^{b}$ & $14.5(\mathrm{~J})^{\mathrm{b}}$ & $9.36(\mathrm{~J})^{\mathrm{b}}$ & -- & -- \\
\hline 271P020 & $5-6$ & 3.26 & $164(J)^{b}$ & $5.9(\mathrm{~J})^{\mathrm{b}}$ & $4.54(J)^{b}$ & -- & -- \\
\hline 271P022 & $4.3-5.4$ & 2.17 & $152(J)^{b}$ & $7.44(\mathrm{~J})^{\mathrm{b}}$ & $4.28(J)^{b}$ & -- & -- \\
\hline 271P024 & 4- 5 & $3.21(\mathrm{~J})^{\mathrm{c}}$ & $219(\mathrm{~J})^{\mathrm{C}}$ & $10.4(\mathrm{~J})^{\mathrm{C}}$ & $7.09(\mathrm{~J})^{\mathrm{c}}$ & -- & -- \\
\hline 271P026 & $4-5$ & $3.27(\mathrm{~J})^{\mathrm{c}}$ & $199(\mathrm{~J})^{\mathrm{C}}$ & $9.48(\mathrm{~J})^{\mathrm{C}}$ & $6.64(\mathrm{~J})^{\mathrm{c}}$ & $0.105(J)^{d}$ & -- \\
\hline 271P028 & $5-6$ & $3.6(J)^{c}$ & $194(\mathrm{~J})^{\mathrm{C}}$ & $8.04(\mathrm{~J})^{\mathrm{c}}$ & $5.21(\mathrm{~J})^{\mathrm{C}}$ & -- & -- \\
\hline 271P030 & $7-7.25$ & $2.05(\mathrm{~J})^{\mathrm{c}}$ & -- & $6.16(\mathrm{~J})^{\mathrm{c}}$ & $5.52(\mathrm{~J})^{\mathrm{c}}$ & $0.105(J)^{d}$ & $1.05(\mathrm{~J})^{\mathrm{c}}$ \\
\hline 271P031 & $3.5-4.7$ & $3.75(J)^{c}$ & $172(\mathrm{~J})^{\mathrm{C}}$ & $9.85(\mathrm{~J})^{\mathrm{c}}$ & $7.41(\mathrm{~J})^{\mathrm{C}}$ & $0.107(\mathrm{~J})^{\mathrm{d}}$ & -- \\
\hline 271P033 & $4-5$ & 2.61 & 189 & 9.41 & 5.95 & -- & -- \\
\hline 271P035 & $4-5$ & 3.22 & 194 & 8.8 & 6.81 & -- & -- \\
\hline 271P037 & $4.5-5.5$ & 2.12 & 204 & 6.94 & 5.1 & -- & -- \\
\hline 271P039 & $4-5$ & 2.91 & 223 & 10.9 & 6.73 & -- & -- \\
\hline 271P041 & $4-5$ & 2.42 & 218 & 6.85 & 5.47 & -- & -- \\
\hline 271P043 & $5.5-6.5$ & 4.32 & 213 & 13.7 & 8.89 & -- & -- \\
\hline 271P045 & $4-5$ & 3.92 & 216 & 8.42 & 7.27 & -- & -- \\
\hline
\end{tabular}


Table A.16-3

\section{Soil Sample Results for Total RCRA Metals Detected Above Minimum Reporting Limits at CAS 26-05-05}

(Page 2 of 2)

\begin{tabular}{|c|c|c|c|c|c|c|c|}
\hline \multirow{2}{*}{$\begin{array}{c}\text { Sample } \\
\text { Identification } \\
\text { Number }\end{array}$} & \multirow{2}{*}{$\begin{array}{l}\text { Depth } \\
\text { (ft bgs) }\end{array}$} & \multicolumn{6}{|c|}{ Contaminants of Potential Concern $(\mathrm{mg} / \mathrm{kg}$ ) } \\
\hline & & Arsenic & Barium & Chromium & Lead & Mercury & Selenium \\
\hline \multicolumn{2}{|c|}{ Preliminary Action Levels ${ }^{a}$} & 2.7 & 100,000 & 450 & 750 & 610 & 10,000 \\
\hline $271 \mathrm{P} 047$ & $5.5-6.5$ & 3.88 & 212 & 7.81 & 7.33 & -- & -- \\
\hline 271P049 & $5.5-6.5$ & 3.43 & 198 & 16.9 & 9.29 & -- & -- \\
\hline 271P051 & $4.5-5.5$ & 3.61 & 176 & 8.85 & 6.9 & -- & -- \\
\hline 271P053 & $4-5$ & 3.55 & 214 & 8.94 & 7 & -- & -- \\
\hline 271P060 & $4-5$ & 1.9 & 180 & 6.84 & 6.47 & -- & $\begin{array}{l}- \\
\end{array}$ \\
\hline 271P062 & $4-5$ & 2.55 & 156 & 7.81 & 7 & -- & -- \\
\hline 271P064 & $4-5$ & 2.21 & 203 & 10.8 & 7.54 & -- & -- \\
\hline 271P066 & $5.5-6.5$ & 3.41 & 217 & 8.73 & 7.7 & -- & -- \\
\hline 271P068 & $5-6$ & 3.69 & 169 & 6.88 & 3.72 & -- & -- \\
\hline 271P070 & $4-5$ & 4.04 & 219 & 11.4 & 9.31 & -- & -- \\
\hline 271P072 & $4-5$ & 2.48 & 117 & 6.96 & 5.49 & -- & -- \\
\hline 271P073 & $4-5$ & 2.87 & 128 & 7.81 & 5.83 & -- & -- \\
\hline 271P075 & $3.5-4.5$ & 3.38 & 160 & 11.2 & 7.23 & -- & -- \\
\hline 271P076 & $5.5-6.5$ & 2.08 & 196 & 6.4 & 6.07 & -- & -- \\
\hline 271P078 & $7.5-8.5$ & $3.83(\mathrm{~J})^{\mathrm{d}}$ & 233 & $5.01(\mathrm{~J})^{d}$ & 7.48 & -- & -- \\
\hline 271P079 & $7.6-8.1$ & $2.53(\mathrm{~J})^{\mathrm{d}}$ & 225 & $8.09(\mathrm{~J})^{\mathrm{d}}$ & 6.41 & -- & -- \\
\hline
\end{tabular}

${ }^{a}$ Based on U.S. Environmental Protection Agency, Region 9 Preliminary Remediation Goals (PRGs) (EPA, 2000).

${ }^{b}$ Quality added to laboratory data; record accepted. Duplicate precision analyses were outside control limits.

${ }^{\mathrm{C}} \mathrm{Quality}$ added to laboratory data; record accepted. Improper preservation/pH or sample temperature not documented during storage.

${ }^{d}$ Quality added to laboratory data; record accepted. Inductively coupled plasma serial dilution recovery was not met.

-- = Not detected above minimum reporting limits

$\mathrm{J}=$ Estimated value. Qualifier added to laboratory data; record accepted.

Barium concentrations ranged from 117 to $233 \mathrm{mg} / \mathrm{kg}$, chromium concentrations ranged from 5.01 to $15.4 \mathrm{mg} / \mathrm{kg}$, lead concentrations ranged from 3.72 to $10.1 \mathrm{mg} / \mathrm{kg}$, mercury concentrations ranged from 0.105 to $0.107 \mathrm{mg} / \mathrm{kg}$, the only selenium and silver concentrations above the MRLs was $1.05 \mathrm{mg} / \mathrm{kg}$ and $1.36 \mathrm{mg} / \mathrm{kg}$, respectively. All reported concentrations of these metals were below EPA Region 9 PRGs, defined in this document as PALs. 
Arsenic concentrations ranged from 1.9 to $4.32 \mathrm{mg} / \mathrm{kg}$. Approximately half of the soil samples contained arsenic in concentrations slightly greater than the PAL of $2.7 \mathrm{mg} / \mathrm{kg}$. Concentrations across the site were relatively consistent, with no "hot spots" or evidence of a localized spill. The PAL is lower than the 7 to $8 \mathrm{mg} / \mathrm{kg}$ mean concentration of arsenic in silt from the Nevada Test and Training Range (NBMG, 1998; Moore, 1999). Although arsenic concentrations in the soil exceed the PAL, these concentrations are believed to be within ambient conditions for CAS 26-05-05 and do not represent contamination.

\section{A.16.3.1.5 Total Beryllium}

Total beryllium was not detected above MRLs in CAS 26-05-05 soil samples.

\section{A.16.3.1.6 Polychlorinated Biphenyls}

Polychlorinated biphenyl results are reported in Table A.16-4. The only PCB compounds detected above the MRLs were aroclor-1254 and arochlor-1260. The concentrations of both of these compounds were below the PAL of $1,000 \mu \mathrm{g} / \mathrm{kg}$.

Table A.16-4

Soil Sample Results for PCB Detected Above Minimum Reporting Limits at CAS 26-05-05

\begin{tabular}{|c|c|c|c|}
\hline \multirow{2}{*}{$\begin{array}{c}\text { Sample } \\
\text { Identification } \\
\text { Number }\end{array}$} & $\begin{array}{c}\text { Depth } \\
\text { (ft bgs) }\end{array}$ & \multicolumn{2}{|c|}{ Contaminants of Potential Concern $(\mu \mathrm{g} / \mathrm{kg})$} \\
\cline { 3 - 4 } & & Aroclor-1254 & Aroclor-1260 \\
\hline Preliminary Action Levels ${ }^{\mathrm{a}}$ & $\mathbf{1 , 0 0 0}$ & $\mathbf{1 , 0 0 0}$ \\
\hline \hline $271 \mathrm{P} 005$ & $2.8-3.8$ & -- & 53 \\
\hline $271 \mathrm{P} 007$ & $2.8-3.8$ & 50 & -- \\
\hline $271 \mathrm{P} 008$ & $2.8-3.8$ & 52 & -- \\
\hline $271 \mathrm{P} 016$ & $3.7-4.7$ & 160 & -- \\
\hline
\end{tabular}

aBased on U.S. Environmental Protection Agency, Region 9 Preliminary Remediation Goals (PRGs) (EPA, 2000).

$--=$ Not detected above minimum reporting limits 


\section{A.16.3.1.7 Gamma Spectrometry Results}

Results of soil sample gamma spectrometry analysis are presented in Table A.16-5. Concentrations of actinium-228, bismuth-212, bismuth-214, lead-212, lead-214, potassium-40, and thallium-208 were detected above the MDLs. The TPU in the radioanalytical measurement is provided in the table along with the concentration for all detected gamma emitters. The concentrations of the detected gamma-emitting radionuclides are below PALs and are not significantly different than concentrations measured in soil samples collected from undisturbed background locations.

\section{A.16.3.1.8 Isotopic Uranium}

Detected values of uranium isotopes, along with associated TPUs, are reported in Table A.16-6. Samples 271P008, 271P064, and 271P073 contained U-235 concentrations above the PAL; therefore, a normalized difference based on a confidence level of 95 percent was used to determine if the concentrations were statistically distinguishable from background. This determined that the concentrations of U-235 in the soil samples were not significantly greater than concentrations in soil samples collected from undisturbed background locations.

\section{A.16.3.1.9 Isotopic Plutonium}

Isotopic plutonium was not detected above MRLs in CAS 26-05-05 soil samples.

\section{A.16.3.1.10 Strontium-90}

Strontium-90 was not detected above MRLs in CAS 26-05-05 soil samples.

\section{A.16.3.2 Septic Tank Sample Results}

Results of collected septic tank content samples were compared to regulatory levels based on disposal options. If the waste has no hazardous component, the regulatory level is based on disposal options at NTS landfills and lagoons (BN, 1995; CFR, 2000b and c; NDEP, 1997a, b, and c). Any sludge or liquid waste will be solidified before disposal at NTS landfills (NDEP, 1997b). If the waste is hazardous, the release criteria are based on interpretation of the guidelines presented in the POC (BN, 1995; Alderson, 1999). For waste destined for off-site disposal, the POC radiological levels must be met to certify that the waste has no radioactivity added. 
Table A.16-5

Soil Sample Results for Gamma-Emitting Radionuclides Detected Above Minimum Reporting Limits at CAS 26-05-05

\begin{tabular}{|c|c|c|c|c|c|c|c|c|}
\hline \multirow{2}{*}{$\begin{array}{c}\text { Sample } \\
\text { Identification } \\
\text { Number }\end{array}$} & \multirow{2}{*}{$\begin{array}{c}\text { Depth } \\
\text { (ft bgs) }\end{array}$} & \multicolumn{7}{|c|}{ Contaminants of Potential Concern $(\mathrm{pCi} / \mathrm{g})$} \\
\hline & & Actinium-228 ${ }^{a}$ & Bismuth-212 ${ }^{\mathrm{b}}$ & Bismuth-214 ${ }^{\mathrm{b}}$ & Lead-212 ${ }^{\mathrm{a}}$ & Lead-214 ${ }^{\mathrm{b}}$ & Potassium- $40^{\mathrm{a}}$ & Thallium-208 ${ }^{\mathrm{a}}$ \\
\hline \multicolumn{2}{|c|}{ Preliminary Action Level } & 3.64 & 2.4 & 3.47 & 2.9 & 2.9 & 96 & 3.4 \\
\hline 271P007 & $2.8-3.8$ & $1.54 \pm 0.31$ & -- & $0.75 \pm 0.18$ & $1.59 \pm 0.29$ & $0.92 \pm 0.19$ & $24.7 \pm 4.4$ & $0.52 \pm 0.11$ \\
\hline 271P008 & $2.8-3.8$ & $1.67 \pm 0.40$ & -- & $0.88 \pm 0.24$ & $1.66 \pm 0.33$ & $1.04 \pm 0.23$ & $22.4 \pm 4.4$ & $0.53 \pm 0.13$ \\
\hline 271P010 & $5-6$ & $1.14 \pm 0.33$ & -- & $0.74 \pm 0.22$ & $1.49 \pm 0.31$ & $0.88 \pm 0.22$ & $21.9 \pm 4.5$ & $0.43 \pm 0.13$ \\
\hline 271P020 & $5-6$ & $1.22 \pm 0.33$ & -- & $0.86 \pm 0.24$ & $1.2 \pm 0.26$ & $0.88 \pm 0.21$ & $21.5 \pm 4.3$ & $0.48 \pm 0.13$ \\
\hline 271P022 & $4.3-5.4$ & $1.3 \pm 0.40$ & -- & $0.93 \pm 0.27$ & $1.66 \pm 0.34$ & $0.95 \pm 0.24$ & $24.4 \pm 4.9$ & $0.54 \pm 0.15$ \\
\hline 271P026 & $4-5$ & $1.59 \pm 0.33$ & -- & $0.76 \pm 0.18$ & $1.56 \pm 0.29$ & $0.88 \pm 0.18$ & $24.6 \pm 4.3$ & $0.452 \pm 0.097$ \\
\hline 271P030 & $7-7.25$ & $1.37 \pm 0.34$ & $2.43 \pm 0.90$ & $0.83 \pm 0.22$ & $1.77 \pm 0.34$ & $0.94 \pm 0.21$ & $23 \pm 4.4$ & $0.49 \pm 0.13$ \\
\hline 271P043 & $5.5-6.5$ & $1.45 \pm 0.38$ & -- & $0.95 \pm 0.26$ & $1.5 \pm 0.32$ & $0.83 \pm 0.21$ & $21.4 \pm 4.5$ & $0.47 \pm 0.13$ \\
\hline 271P064 & $4-5$ & $1.3 \pm 0.34$ & -- & $0.84 \pm 0.24$ & $1.37 \pm 0.28$ & $0.85 \pm 0.20$ & $21.2 \pm 4.2$ & $0.47 \pm 0.12$ \\
\hline 271P072 & $4-5$ & $1.18 \pm 0.35$ & -- & $1.03 \pm 0.29$ & $1.4 \pm 0.31$ & $0.95 \pm 0.24$ & $21.2 \pm 4.4$ & $0.36 \pm 0.14$ \\
\hline 271P073 & $4-5$ & $1.55 \pm 0.33$ & $1.97 \pm 0.80$ & $0.86 \pm 0.21$ & $1.66 \pm 0.31$ & $0.88 \pm 0.19$ & $24.3 \pm 4.3$ & $0.437 \pm 0.100$ \\
\hline 271P076 & $5.5-6.5$ & $1.36 \pm 0.28$ & -- & $0.83 \pm 0.18$ & $1.48 \pm 0.27$ & $0.87 \pm 0.17$ & $22.3 \pm 3.9$ & $0.424 \pm 0.093$ \\
\hline
\end{tabular}

${ }^{a}$ Background concentration listed in Environmental Monitoring Report for the Proposed Ward Valley, California, Low-Level Radioactive Waste (LLRW) Facility (US Ecology and Atlan-Tech, 1992).

${ }^{\text {b} B a c k g r o u n d}$ concentration listed or derived in Off-Site Radiation Exposure Review Project, Phase II Soil Program (McArthur and Miller, 1989)

$--=$ Not detected above minimum reporting limit 
Table A.16-6

Soil Sample Results for Isotopic Uranium

Detected Above Minimum Reporting Limits at CAS 26-05-05

\begin{tabular}{|c|c|c|c|c||}
\hline \multirow{2}{*}{$\begin{array}{c}\text { Sample } \\
\text { Identification } \\
\text { Number }\end{array}$} & $\begin{array}{c}\text { Depth } \\
\text { (ft bgs) }\end{array}$ & \multicolumn{3}{|c|}{ Contaminants of Potential Concern (pCi/g) } \\
\cline { 3 - 5 } & Uranium-234 & Uranium-235 & Uranium-238 $^{\text {b }}$ \\
\hline \multicolumn{2}{|c|}{ Preliminary Action Levels } & $\mathbf{1 . 5 6}$ & $\mathbf{0 . 0 7}$ & $\mathbf{3 . 2}$ \\
\hline \hline $271 \mathrm{P} 007$ & $2.8-3.8$ & $0.89 \pm 0.17$ & -- & $0.86 \pm 0.17$ \\
\hline $271 \mathrm{P} 008$ & $2.8-3.8$ & $0.83 \pm 0.16$ & $0.08 \pm 0.038$ & $0.85 \pm 0.16$ \\
\hline $271 \mathrm{P} 010$ & $5-6$ & $0.96 \pm 0.17$ & -- & $0.95 \pm 0.17$ \\
\hline $271 \mathrm{P} 020$ & $5-6$ & $1.3 \pm 0.22$ & $0.05 \pm 0.027(\mathrm{LT})$ & $1.24 \pm 0.21$ \\
\hline $271 \mathrm{P} 022$ & $4.3-5.4$ & $0.83 \pm 0.15$ & -- & $0.85 \pm 0.16$ \\
\hline $271 \mathrm{P} 026$ & $4-5$ & $0.84 \pm 0.15$ & -- & $0.66 \pm 0.13$ \\
\hline $271 \mathrm{P} 030$ & $7-7.25$ & $0.79 \pm 0.16$ & -- & $0.79 \pm 0.16$ \\
\hline $271 \mathrm{P} 043$ & $5.5-6.5$ & $0.81 \pm 0.15$ & $0.062 \pm 0.030$ & $0.85 \pm 0.15$ \\
\hline $271 \mathrm{P} 064$ & $4-5$ & $0.99 \pm 0.17$ & $0.091 \pm 0.038$ & $0.92 \pm 0.16$ \\
\hline $271 \mathrm{P} 072$ & $4-5$ & $0.99 \pm 0.18$ & -- & $1.06 \pm 0.19$ \\
\hline $271 \mathrm{P} 073$ & $4-5$ & $0.92 \pm 0$ & $0.079 \pm 0.035$ & $1.08 \pm 0.19$ \\
\hline $271 \mathrm{P} 076$ & $5.5-6.5$ & $0.85 \pm 0.16$ & -- & $0.81 \pm 0.15$ \\
\hline
\end{tabular}

a Background concentration listed in Environmental Monitoring Report for the Proposed Ward Valley, California, Low-Level Radioactive Waste (LLRW) Facility (US Ecology and Atlan-Tech, 1992).

bBackground concentration listed or derived in Off-Site Radiation Exposure Review Project, Phase II Soil Program (McArthur and Miller, 1989).

$--=$ Not detected above minimum reporting limit

$\mathrm{LT}=$ Result is less than requested MDC, greater than sample-specific MDC

In septic tank 1, two liquid (271P080 and field duplicate 271P081) and one sludge sample (271P082) were collected. In septic tank 2, one sediment sample (271P084) was collected as a composite sample from all three chambers. The analytical suite followed the CAIP and is detailed in Section A.16.2.9. Analytical results exceeding MRLs are listed in Table A.16-7.

Several COPCs were detected in the sludge and sediment samples. Most COPCs were below regulatory limits, except for TPH that was detected in samples 271P082 and 271P084. Diesel concentrations in these samples were 5,400 and $520 \mathrm{mg} / \mathrm{kg}$, respectively. The gasoline concentration 
Table A.16-7

\section{Liquid, Sediment, and Sludge Sample Results Detected Above Minimum Reporting Limits at CAS 26-05-05}

(Page 1 of 3 )

\begin{tabular}{|c|c|c|c|c|c|c|}
\hline $\begin{array}{c}\text { Sample } \\
\text { Identification } \\
\text { Number }\end{array}$ & Matrix & Parameter & Result & Units & Limits & Reference \\
\hline 271P082 & Sludge & TCLP 1,4-Dichlorobenzene & 2.5 & $\mathrm{mg} / \mathrm{L}$ & 7.5 & CFR, 2000a \\
\hline 271P082 & Sludge & TCLP Chromium & 0.24 & $\mathrm{mg} / \mathrm{L}$ & 5 & CFR, 2000a \\
\hline 271P082 & Sludge & TCLP Lead & 0.045 & $\mathrm{mg} / \mathrm{L}$ & 5 & CFR, 2000a \\
\hline 271P082 & Sludge & TCLP Chlorobenzene & 0.11 & $\mathrm{mg} / \mathrm{L}$ & 100 & CFR, 2000a \\
\hline 271P082 & Sludge & Plutonium-239 & $0.136 \pm 0.046$ & $\mathrm{pCi} / \mathrm{g}$ & 10 & NDEP, 1997b \\
\hline 271P082 & Sludge & Aroclor-1254 & 6,800 & $\mu \mathrm{g} / \mathrm{kg}$ & 50,000 & CFR, 2000b \\
\hline 271P082 & Sludge & Mercury** & 6.2 & $\mathrm{mg} / \mathrm{kg}$ & NA & CFR, 2000a \\
\hline 271P080 & Liquid & Chromium & 0.026 & $\mathrm{mg} / \mathrm{L}$ & 5 & CFR, 2000a \\
\hline 271P080 & Liquid & Lead & 0.0044 & $\mathrm{mg} / \mathrm{L}$ & 5 & CFR, 2000a \\
\hline 271P081 & Liquid & Chromium & 0.017 & $\mathrm{mg} / \mathrm{L}$ & 5 & CFR, 2000a \\
\hline 271P082 & Sludge & Arsenic** & 46 & $\mathrm{mg} / \mathrm{kg}$ & NA & CFR, 2000a \\
\hline 271P082 & Sludge & Barium** & 180 & $\mathrm{mg} / \mathrm{kg}$ & NA & CFR, 2000a \\
\hline 271P082 & Sludge & Cadmium** & 16 & $\mathrm{mg} / \mathrm{kg}$ & NA & CFR, 2000a \\
\hline 271P082 & Sludge & Chromium & 4,600 & $\mathrm{mg} / \mathrm{kg}$ & NA & CFR, 2000a \\
\hline 271P082 & Sludge & Lead & $790(J)^{\mathrm{a}}$ & $\mathrm{mg} / \mathrm{kg}$ & NA & CFR, 2000a \\
\hline 271P082 & Sludge & Silver ${ }^{* *}$ & 8 & $\mathrm{mg} / \mathrm{kg}$ & NA & CFR, 2000a \\
\hline 271P082 & Sludge & Diesel-Range Organics & $5,400(D, Z)$ & $\mathrm{mg} / \mathrm{kg}$ & 100 & NDEP, 1997b \\
\hline 271P082 & Sludge & Gasoline-Range Organics & $470(Z)$ & $\mathrm{mg} / \mathrm{kg}$ & 100 & NDEP, 1997b \\
\hline 271P082 & Sludge & 1,2-Dichlorobenzene & 4,500 & $\mu \mathrm{g} / \mathrm{kg}$ & NA & CFR, 2000a \\
\hline 271P082 & Sludge & 1,4-Dichlorobenzene & $920,000(J)^{b}$ & $\mu \mathrm{g} / \mathrm{kg}$ & NA & CFR, 2000a \\
\hline 271P082 & Sludge & Chlorobenzene & 66,000 & $\mu \mathrm{g} / \mathrm{kg}$ & NA & CFR, 2000a \\
\hline 271P082 & Sludge & 1,3-Dichlorobenzene & 15,000 & $\mu \mathrm{g} / \mathrm{kg}$ & NA & CFR, 2000a \\
\hline 271P082 & Sludge & 2-Methylnaphthalene & 4,300 & $\mu \mathrm{g} / \mathrm{kg}$ & NA & CFR, 2000a \\
\hline 271P082 & Sludge & Phenanthrene & 7,400 & $\mu \mathrm{g} / \mathrm{kg}$ & NA & CFR, 2000a \\
\hline 271P082 & Sludge & Pyrene & $7,200(\mathrm{~J})^{\mathrm{c}}$ & $\mu \mathrm{g} / \mathrm{kg}$ & NA & CFR, 2000a \\
\hline 271P082 & Sludge & Actinium-228 & $1.1 \pm 0.38$ & $\mathrm{pCi} / \mathrm{g}$ & - & $\mathrm{N}$ \\
\hline 271P082 & Sludge & Cesium-137 & $1.33 \pm 0.30$ & $\mathrm{pCi} / \mathrm{g}$ & 100 & NDEP, 1997b \\
\hline 271P082 & Sludge & Potassium-40 & $13.2 \pm 3.5$ & $\mathrm{pCi} / \mathrm{g}$ & - & $\mathrm{N}$ \\
\hline
\end{tabular}


Table A.16-7

\section{Liquid, Sediment, and Sludge Sample Results Detected Above Minimum Reporting Limits at CAS 26-05-05}

(Page 2 of 3 )

\begin{tabular}{|c|c|c|c|c|c|c|}
\hline $\begin{array}{c}\text { Sample } \\
\text { Identification } \\
\text { Number }\end{array}$ & Matrix & Parameter & Result & Units & Limits & Reference \\
\hline 271P082 & Sludge & Lead-212 & $0.89 \pm 0.25$ & $\mathrm{pCi} / \mathrm{g}$ & - & $\mathrm{N}$ \\
\hline 271P081 & Liquid & Uranium-234 & $0.152 \pm 0.067$ & $\mathrm{pCi} / \mathrm{L}$ & 100 & NDEP, 1997b \\
\hline 271P082 & Sludge & Uranium-234 & $2.68 \pm 0.41$ & $\mathrm{pCi} / \mathrm{g}$ & 100 & NDEP, 1997b \\
\hline 271P082 & Sludge & Uranium-235 & $0.224 \pm 0.068$ & $\mathrm{pCi} / \mathrm{g}$ & 100 & NDEP, 1997b \\
\hline 271P082 & Sludge & Uranium-238 & $1.42 \pm 0.24$ & $\mathrm{pCi} / \mathrm{g}$ & 100 & NDEP, 1997b \\
\hline 271P084 & Sediment & Plutonium-239 & $1.49 \pm 0.25(\mathrm{~J})^{d}$ & $\mathrm{pCi} / \mathrm{g}$ & 0.5 & BN, 1995 \\
\hline 271P084 & Sediment & Aroclor-1260 & $650(\mathrm{~J})^{\mathrm{e}}$ & $\mu \mathrm{g} / \mathrm{kg}$ & 50,000 & CFR, 2000b \\
\hline 271P084 & Sediment & Beryllium & 0.85 & $\mathrm{mg} / \mathrm{kg}$ & NA & CFR, 2000a \\
\hline 271P084 & Sediment & Mercury & 3.1 & $\mathrm{mg} / \mathrm{kg}$ & $0.2 \mathrm{mg} / \mathrm{L}^{\dagger}$ & CFR, 2000a \\
\hline 271P084 & Sediment & Barium** & 160 & $\mathrm{mg} / \mathrm{kg}$ & NA & CFR, 2000a \\
\hline 271P084 & Sediment & Cadmium** & 8.9 & $\mathrm{mg} / \mathrm{kg}$ & NA & CFR, 2000a \\
\hline 271P084 & Sediment & Chromium** & 8,300 & $\mathrm{mg} / \mathrm{kg}$ & NA & CFR, 2000a \\
\hline 271P084 & Sediment & Lead $^{* *}$ & 480 & $\mathrm{mg} / \mathrm{kg}$ & NA & CFR, 2000a \\
\hline 271P084 & Sediment & Selenium** & 1.9 & $\mathrm{mg} / \mathrm{kg}$ & NA & CFR, 2000a \\
\hline 271P084 & Sediment & Silver ${ }^{* *}$ & 4.3 & $\mathrm{mg} / \mathrm{kg}$ & NA & CFR, 2000a \\
\hline 271P084 & Sediment & Diesel-Range Organics & $520(M)$ & $\mathrm{mg} / \mathrm{kg}$ & 100 & NAC, 2000 \\
\hline 271P084 & Sediment & Acetone & $56(J)^{g}$ & $\mathrm{mg} / \mathrm{kg}$ & NA & CFR, 2000a \\
\hline 271P084 & Sediment & Fluoranthene & $740(J)^{\mathrm{h}}$ & $\mu \mathrm{g} / \mathrm{kg}$ & NA & CFR, 2000a \\
\hline 271P084 & Sediment & Phenanthrene & $1,100(J)^{\mathrm{h}}$ & $\mu \mathrm{g} / \mathrm{kg}$ & NA & CFR, 2000a \\
\hline 271P084 & Sediment & Phenol & 1,100 & $\mu \mathrm{g} / \mathrm{kg}$ & NA & CFR, 2000a \\
\hline 271P084 & Sediment & Pyrene & $940(J)^{i}$ & $\mu \mathrm{g} / \mathrm{kg}$ & NA & CFR, 2000a \\
\hline 271P084 & Sediment & Actinium-228 & $1.2 \pm 0.36$ & $\mathrm{pCi} / \mathrm{g}$ & - & $\mathrm{E}$ \\
\hline 271P084 & Sediment & Cesium-137 & $1.19 \pm 0.25$ & $\mathrm{pCi} / \mathrm{g}$ & 3 & BN, 1995 \\
\hline 271P084 & Sediment & Potassium-40 & $16.9 \pm 3.5$ & $\mathrm{pCi} / \mathrm{g}$ & - & $E$ \\
\hline 271P084 & Sediment & Lead-212 & $1.45 \pm 0.31$ & $\mathrm{pCi} / \mathrm{g}$ & - & $E$ \\
\hline 271P084 & Sediment & Lead-214 & $0.57 \pm 0.19$ & $\mathrm{pCi} / \mathrm{g}$ & - & $E$ \\
\hline 271P084 & Sediment & Thallium-208 & $0.38 \pm 0.12$ & $\mathrm{pCi} / \mathrm{g}$ & - & $E$ \\
\hline 271P084 & Sediment & Uranium-234 & $2.72 \pm 0.42$ & $\mathrm{pCi} / \mathrm{g}$ & 0.932 & BN, 1995 \\
\hline
\end{tabular}


Table A.16-7

\section{Liquid, Sediment, and Sludge Sample Results Detected Above Minimum Reporting Limits at CAS 26-05-05}

(Page 3 of 3 )

\begin{tabular}{|c|c|c|c|c|c|c|}
\hline $\begin{array}{c}\text { Sample } \\
\text { Identification } \\
\text { Number }\end{array}$ & Matrix & Parameter & Result & Units & Limits & Reference \\
\hline \hline 271P084 & Sediment & Uranium-235 & $\mathbf{0 . 1 8 9 \pm 0 . 0 6 2}$ & pCi/g & $\mathbf{0 . 1 6 1 4}$ & BN, 1995 \\
\hline 271P084 & Sediment & Uranium-238 & $1.47 \pm 0.25$ & pCi/g & 10 & BN, 1995 \\
\hline 271P082 & Sludge & 1,4-Dichlorobenzene & $750,000(\mathrm{~J})^{\mathrm{e}}$ & $\mu \mathrm{g} / \mathrm{kg}$ & $\mathrm{NA}$ & $\mathrm{CFR}, 2000 \mathrm{a}$ \\
\hline 271P082RR1 & Sludge & 1,4 -Dichlorobenzene & $3,400,000$ & $\mu \mathrm{g} / \mathrm{kg}$ & $\mathrm{NA}$ & $\mathrm{CFR,2000a}$ \\
\hline 271P080 & Liquid & Gross Alpha & $-0.1 \pm 1.3$ & $\mathrm{pCi} / \mathrm{L}$ & $2.3^{\mathrm{j}}$ & $\mathrm{NA}$ \\
\hline 271P080 & Liquid & Gross Beta & $19.3 \pm 3.0$ & $\mathrm{pCi} / \mathrm{L}$ & $1.8^{\mathrm{j}}$ & $\mathrm{NA}$ \\
\hline 271P081 & Liquid & Gross Alpha & $-0.9 \pm 1.0$ & $\mathrm{pCi} / \mathrm{L}$ & $2.0^{\mathrm{j}}$ & $\mathrm{NA}$ \\
\hline 271P081 & Liquid & Gross Beta & $19.2 \pm 3.0$ & $\mathrm{pCi} / \mathrm{L}$ & $1.7^{\mathrm{j}}$ & $\mathrm{NA}$ \\
\hline
\end{tabular}

${ }^{a}$ Qualifier added to laboratory data; record accepted. Spike recovery was outside control limits.

${ }^{\text {b }}$ Qualifier added to laboratory data; record accepted. Value exceeded linear range of instrument.

${ }^{\circ}$ Qualifier added to laboratory data; record accepted. Internal standard area count exceeded the quality control limits. Matrix effects may exist. Spike recovery was outside control limits.

${ }^{d}$ Qualifier added to laboratory data; record accepted. Duplicate relative percent difference over the control limits.

${ }^{e} Q$ Qualifier added to laboratory data; record accepted. Surrogates diluted out.

${ }^{\mathrm{f}} \mathrm{A}$ TCLP result was not available for regulatory comparison. The total result was used to calculate an estimate for the TCLP result and then compared to the TCLP RCRA limit.

${ }^{9}$ Qualifier added to laboratory data; record accepted. Surrogate recovery exceeded the lower limits. Matrix effects may exist.

Relative response factor $<0.05$.

${ }^{\mathrm{h}}$ Qualifier added to laboratory data; record accepted. Surrogate recovery exceeded the lower limits.

'Qualifier added to laboratory data; record accepted. Surrogate recovery exceeded the lower limits. Matrix effects may exist.

'Maximum detectable concentration.

${ }^{* *}=$ TCLP below minimum reporting limit

$\mathrm{D}=$ Indicates that a pattern resembling diesel was detected in the sample

$\mathrm{E}=$ No limit established $(\mathrm{BN}, 1995)$

$\mathrm{J}=$ Estimated value

$\mathrm{M}=$ Motor oil

$\mathrm{N}=$ No limit established (NDEP, 1997b)

NA $=$ Not applicable

$Z=$ The reported result did not resemble the patterns of the following petroleum hydrocarbon products: gasoline, JP-4, JP-8, diesel, mineral spirits, motor oil, Stoddard solvent and Bunker C 
in sample 271P082 was $470 \mathrm{mg} / \mathrm{kg}$. These levels exceeded the NDEP action level of $100 \mathrm{mg} / \mathrm{kg}$ for TPH (NAC, 2000). Sample 271 P084, sediment from septic tank 2, did not have a TCLP analysis performed. The waste will carry the EPA code for mercury (D009), unless a TCLP is performed to clarify the regulatory status. Plutonium-239, U-234, and U-235 were also present in the septic tank 2 sediment in concentrations above the POC limits.

\section{A.16.4 Contaminants of Concern}

Based on the aforementioned analytical results, COCs are present in both septic tanks and soil in one small area of the leachfield. Septic tank 1 contained liquid and sludge and septic tank 2 contained sediment. Both the sludge and the sediment in the tanks had TPH analytes (DRO and GRO) in concentrations above regulatory levels. Septic tank 2 contains RCRA metals of regulatory concern (see Section A.16.3.2). Plutonium-239, U-234, and U-235 were also detected in the sediment sample at concentrations exceeding regulatory levels. The leachfield connected to distribution box 2 contained soil with TPH analytes (DRO) in concentrations above the PAL of $100 \mathrm{mg} / \mathrm{kg}$. There are no COCs in the soils surrounding the septic tanks or under the soils of the leachfield connecting to distribution box 1 .

\section{A.16.5 Nature and Extent of Contamination}

Total petroleum hydrocarbons are located within each of the septic tanks, in the sludge (tank 1), and sediment (tank 2). Plutonium-239, U-234, U-235, and RCRA metals are also located within the sediment in septic tank 2. Approximately 71 gal of sludge and 851 gal of liquid remained in septic tank 1. Approximately 19 gal of sediment remained in each of the chambers of septic tank 2 . Only one location (P25) in the leachfield had concentrations of TPH DRO above the PALs. The estimated volume of contaminated soil is $26 \mathrm{yd}^{3}$. The contaminants associated with the septic tank contents are contained within the tanks. The extent of TPH DRO in the leachfield soil has been defined.

\section{A.16.6 Revised Conceptual Model}

A variation to the planned septic system configuration was identified in the field. The originally assumed septic system configuration is depicted in Figure 4-9 of the CAIP. The actual configuration is depicted in Figure A.16-1. An additional septic tank was identified northeast of the original septic tank for the system. The leachfield sampling area was expanded west of the second distribution box 
to include the entire fenced area. This change in configuration did not invalidate the conceptual model for this CAS. Samples were ultimately collected from the perforated distribution pipe/native soil and leachrock/native soil interfaces inside the fenced area. The leachrock/native soil interfaces were sampled on all four sides of the leachfield. Random soil sample locations were transformed to account for the larger leachfield area, and the locations were sampled. Samples were also collected from inside the second septic tank and the soil adjacent to the tank. 


\section{A.17.0 Building 5200 Leachfield (CAS 27-05-02)}

The septic system was designed to receive sanitary effluent generated by activities in Building 5200 (Mechanical Technician Shop) and Building 5210 (Cafeteria). The septic system is located southwest of Building 5210 and west of Building 5200. The site is comprised of a leachfield, septic tank, distribution structure, and associated piping. The investigation also included a natural wash (i.e., arroyo) on the west side of the leachfield. More detail is provided in the CAIP (DOE/NV, 2001).

\section{A.17.1 Corrective Action Investigation}

Twenty-seven investigation samples, listed in Table A.17-1, were collected during initial investigation activities conducted at CAS 27-05-02. The planned sample locations at CAS 27-05-02 are shown in the Figure 4-14 of the CAIP (DOE/NV, 2001). Thirty-nine additional samples were collected during expanded investigation activities and are also listed in Table A.17-1. The actual sample locations are shown in Figure A.17-1. The specific CAI activities conducted to meet CAIP requirements at CAS 27-05-02 are described in Table A.2-1.

\section{A.17.1.1 Deviations}

The following deviation to the CAIP-requirements was the result of unforeseen circumstances:

- Refusal was met due to encountering subsurface hardpan; therefore, sample 271Q002 was collected at 14 to $14.5 \mathrm{ft}$ bgs rather than the planned interval of 14.5 to $15.5 \mathrm{ft}$ bgs.

Despite this deviation, the pertinent CAIP requirements were met.

\section{A.17.2 Investigation Results}

The following subsections provide details of the inspection and sampling of leachfield features, field-screening results, and sample selection and analysis.

\section{A.17.2.1 Septic Tank Contents}

The concrete and steel septic tank is two-chambered, with a horizontal cylindrical shape and a 1,600-gal capacity. It is accessed by two manholes located $6.5 \mathrm{ft}$ bgs. The manhole to the inlet 
Table A.17-1

Samples Collected at CAS 27-05-02

(Page 1 of 4 )

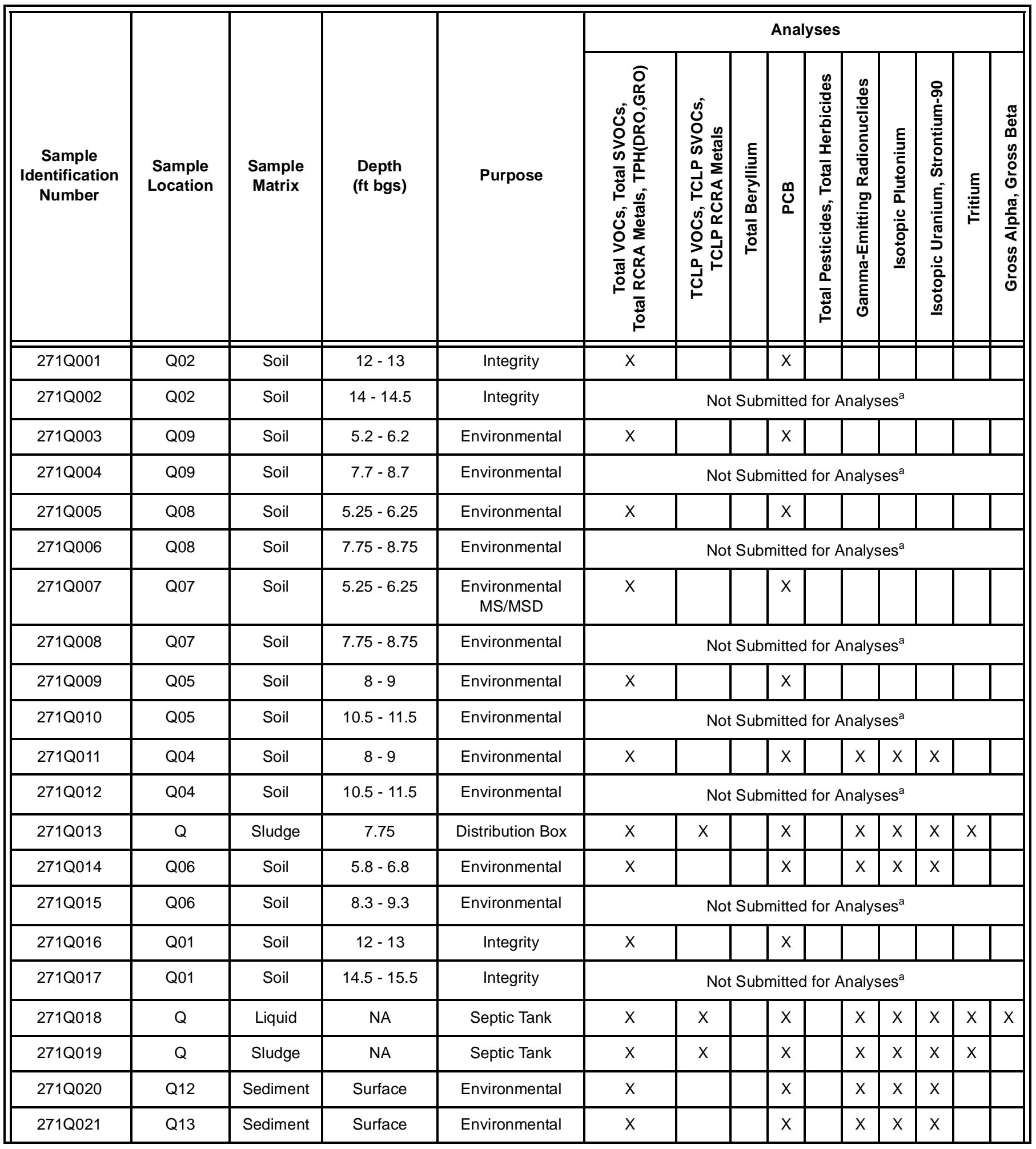


Table A.17-1

Samples Collected at CAS 27-05-02

(Page 2 of 4 )

\begin{tabular}{|c|c|c|c|c|c|c|c|c|c|c|c|c|c|c|}
\hline \multirow[b]{2}{*}{$\begin{array}{c}\text { Sample } \\
\text { Identification } \\
\text { Number }\end{array}$} & \multirow[b]{2}{*}{$\begin{array}{l}\text { Sample } \\
\text { Location }\end{array}$} & \multirow[b]{2}{*}{$\begin{array}{c}\text { Sample } \\
\text { Matrix }\end{array}$} & \multirow[b]{2}{*}{$\begin{array}{l}\text { Depth } \\
\text { (ft bgs) }\end{array}$} & \multirow[b]{2}{*}{ Purpose } & \multicolumn{10}{|c|}{ Analyses } \\
\hline & & & & & 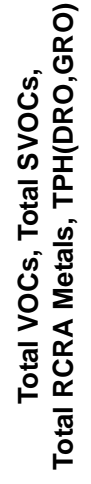 & 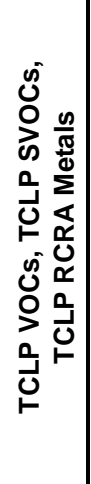 & 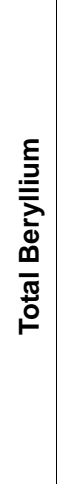 & O̊̊ & 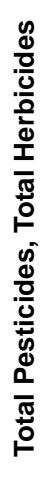 & 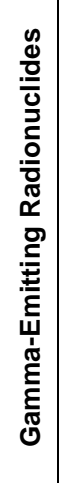 & 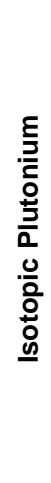 & 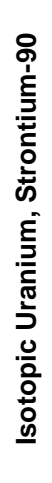 & $\stackrel{E}{E}$ & 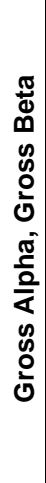 \\
\hline 271Q024 & Q03 & Soil & $9.5-10.5$ & Environmental & \multicolumn{10}{|c|}{ Not Submitted for Analyses ${ }^{a}$} \\
\hline 271Q025 & Q & Liquid & NA & Septic Tank & $\mathrm{X}$ & & & $x$ & & $\mathrm{X}$ & $\mathrm{X}$ & $X$ & $x$ & $\mathrm{x}$ \\
\hline 271Q026 & Q14 & Soil & $4-4.5$ & Geotechnical & \multicolumn{10}{|c|}{ Not Submitted for Analyses ${ }^{b}$} \\
\hline 271Q125 & Q & Liquid & NA & Septic Tank & $\mathrm{X}$ & & & $\mathrm{X}$ & & & & & & $x$ \\
\hline 271Q201 & Q09 & Soil & $9.5-10$ & Environmental & & & & $\mathrm{X}$ & & & & & & \\
\hline 271Q202 & Q09 & Soil & $12.5-13$ & Environmental & & & & $\mathrm{X}$ & & & & & & \\
\hline 271Q208 & Q23 & Soil & $0-0.5$ & Environmental & & & & $x$ & & & & & & \\
\hline 271Q209 & Q24 & Soil & $0-0.5$ & Environmental & & & & $\mathrm{X}$ & $x$ & & & & & \\
\hline 271Q210 & Q26 & Soil & $0-0.5$ & Environmental & & & & $X$ & $\mathrm{X}$ & & & & & \\
\hline 271Q211 & Q26 & Soil & $0-0.5$ & $\begin{array}{c}\text { Duplicate of } \\
\text { 271Q210 }\end{array}$ & & & & $x$ & $x$ & & & & & \\
\hline 271Q212 & Q18 & Soil & $0-1$ & Environmental & & & & $x$ & & & & & & \\
\hline 271Q213 & Q18 & Soil & $2.5-3.5$ & Environmental & & & & $X$ & & & & & & \\
\hline 271Q214 & Q18 & Soil & $6.5-7$ & Environmental & & & & $X$ & & & & & & \\
\hline 271Q215 & Q18 & Soil & $9.5-10.5$ & Environmental & & & & $\mathrm{X}$ & & & & & & \\
\hline
\end{tabular}


Table A.17-1

Samples Collected at CAS 27-05-02

(Page 3 of 4 )

\begin{tabular}{|c|c|c|c|c|c|c|c|c|c|c|c|c|c|c|}
\hline $\begin{array}{c}\text { Sample } \\
\text { Identification } \\
\text { Number }\end{array}$ & $\begin{array}{l}\text { Sample } \\
\text { Location }\end{array}$ & $\begin{array}{l}\text { Sample } \\
\text { Matrix }\end{array}$ & $\begin{array}{l}\text { Depth } \\
\text { (ft bgs) }\end{array}$ & Purpose & 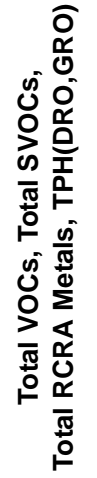 & 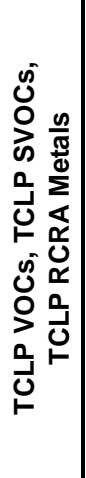 & 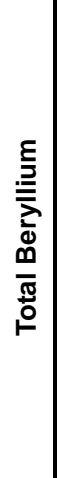 & 吾 & 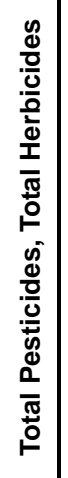 & 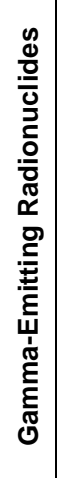 & 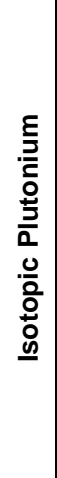 & 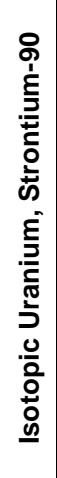 & 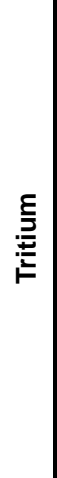 & 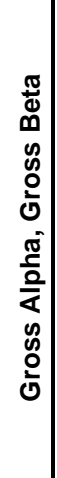 \\
\hline 271Q218 & Q19 & Soil & $6.5-7.5$ & Environmental & & & & $x$ & & & & & & \\
\hline 271Q219 & Q19 & Soil & $9.5-10.5$ & Environmental & & & & $x$ & & & & & & \\
\hline 271Q220 & Q21 & Soil & $0-1$ & Environmental & & & & $x$ & & & & & & \\
\hline 271Q221 & Q21 & Soil & $2.5-3.5$ & Environmental & & & & $x$ & & & & & & \\
\hline 271Q222 & Q21 & Soil & $6.5-7.5$ & Environmental & & & & $x$ & & & & & & \\
\hline 271Q223 & Q21 & Soil & $9.5-10.5$ & Environmental & & & & $x$ & & & & & & \\
\hline 271Q224 & Q20 & Soil & $0-1$ & $\begin{array}{c}\text { Environmental } \\
\text { MS/MSD }\end{array}$ & & & & $x$ & & & & & & \\
\hline 271Q229 & Q17 & Soil & $0-0.5$ & $\begin{array}{c}\text { Duplicate of } \\
271 Q 228\end{array}$ & & & & $x$ & & & & & & \\
\hline 271Q230 & Q17 & Soil & $2.5-3$ & $\begin{array}{c}\text { Environmental } \\
\text { MS/MSD }\end{array}$ & & & & $x$ & & & & & & \\
\hline 271Q231 & Q17 & Soil & $5.5-6$ & Environmental & & & & $x$ & & & & & & \\
\hline 271Q232 & Q17 & Soil & $8.5-9$ & Environmental & & & & $x$ & & & & & & \\
\hline 271Q233 & Q22 & Soil & $0-0.5$ & Environmental & & & & $x$ & $x$ & & & & & \\
\hline 271Q234 & Q22 & Soil & $2.5-3$ & Environmental & & & & $x$ & & & & & & \\
\hline 271Q235 & Q22 & Soil & $6.5-7$ & Environmental & & & & $x$ & $x$ & & & & & \\
\hline 271Q236 & Q22 & Soil & $9.5-10$ & Environmental & & & & $x$ & & & & & & \\
\hline
\end{tabular}


Table A.17-1

Samples Collected at CAS 27-05-02

(Page 4 of 4 )

\begin{tabular}{|c|c|c|c|c|c|c|c|c|c|c|c|c|c|c|}
\hline $\begin{array}{c}\text { Sample } \\
\text { Identification } \\
\text { Number }\end{array}$ & $\begin{array}{l}\text { Sample } \\
\text { Location }\end{array}$ & $\begin{array}{l}\text { Sample } \\
\text { Matrix }\end{array}$ & $\begin{array}{c}\text { Depth } \\
\text { (ft bgs) }\end{array}$ & Purpose & 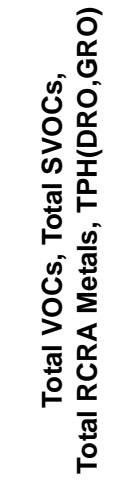 & 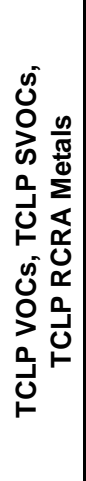 & 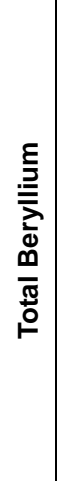 & 仓 & 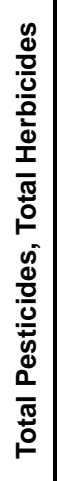 & 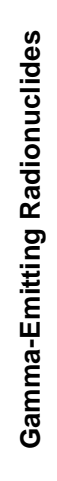 & 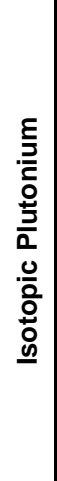 & 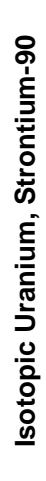 & 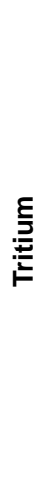 & 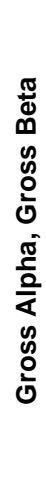 \\
\hline 271Q303 & NA & Water & NA & Field Blank & $x$ & & & $x$ & & $x$ & $x$ & $x$ & & \\
\hline 271Q304 & NA & Water & NA & Trip Blank & VOC only & & & & & & & & & \\
\hline 271Q305 & NA & Water & NA & Rinsate & $x$ & & & $X$ & & $X$ & $x$ & $X$ & & \\
\hline 271Q306 & NA & Water & NA & Trip Blank & VOC only & & & & & & & & & \\
\hline 271Q307 & NA & Water & NA & Trip Blank & VOC only & & & & & & & & & \\
\hline 271Q308 & NA & Water & NA & Trip Blank & VOC only & & & & & & & & & \\
\hline 271Q309 & NA & Water & NA & Trip Blank & VOC only & & & & & & & & & \\
\hline 271Q501 & NA & Water & NA & $\begin{array}{l}\text { WM Sample for } \\
\text { Drum 271Q01 }\end{array}$ & & & & $X$ & & & & & & \\
\hline
\end{tabular}

${ }^{a}$ The sample was collected, field screened, and returned to the site for disposal.

${ }^{\mathrm{b}}$ The sample was collected, field screened, and is being stored for possible geotechnical analysis.

NA $=$ Not applicable

MS/MSD = Matrix spike/matrix spike duplicate 


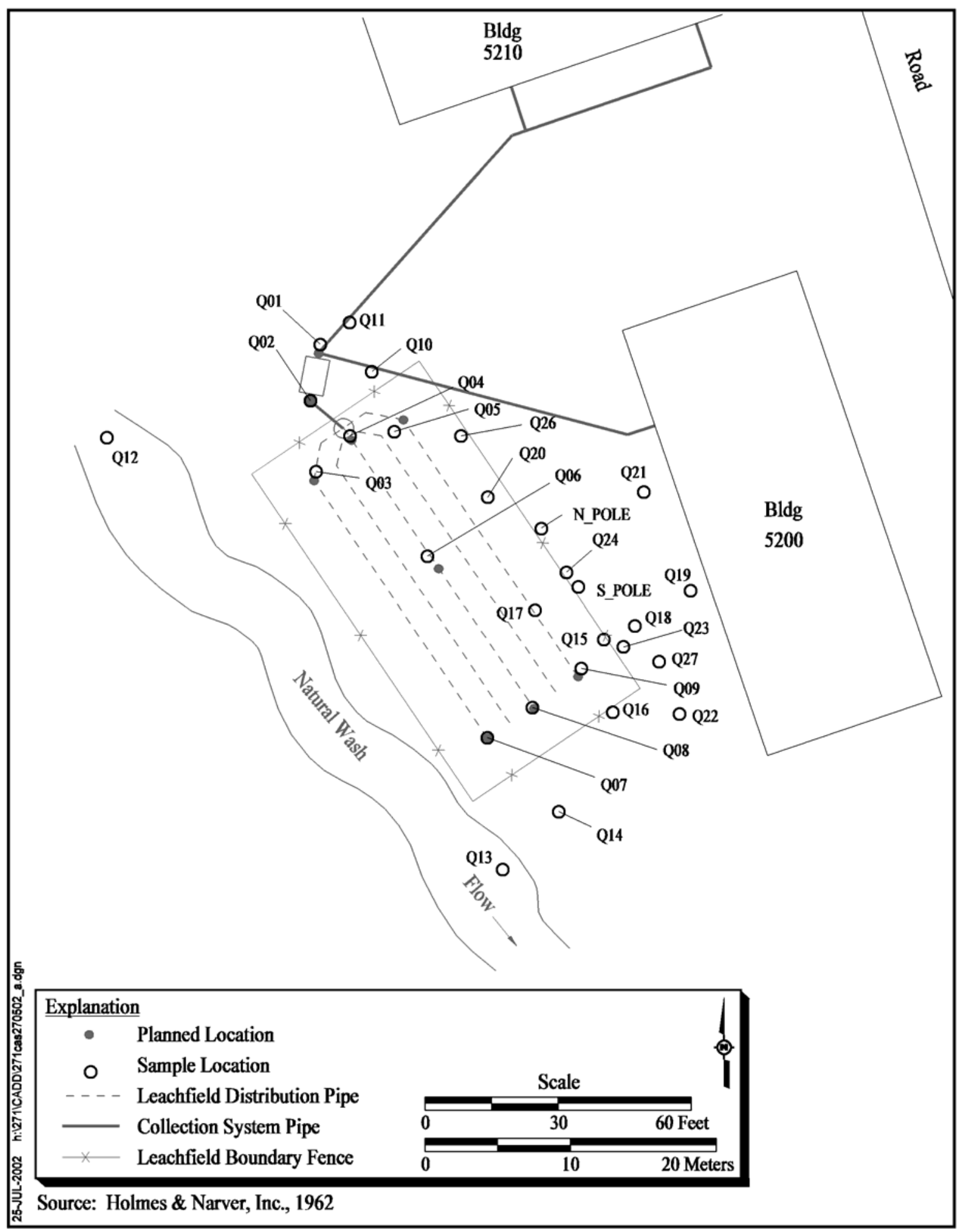

Figure A.17-1

Building 5200 Leachfield (CAS 27-05-02)

Sample Locations 
chamber is buried; however, the outlet chamber manhole is assessable from the ground surface through a vertical culvert (Figure A.17-2). The culvert is covered by a steel lid. The interior dimensions of the tank are $9 \mathrm{ft}$ (length) by $5.5 \mathrm{ft}$ (diameter). One liquid and one sludge sample were collected from the inlet chamber. One liquid sample was collected from the outlet chamber. Visual inspection revealed that a maximum thickness of $2.5 \mathrm{ft}$ (680 gal) of liquid and $1 \mathrm{ft}$ (155 gal) of sludge remained in the bottom of the inlet chamber. A maximum thickness of $3.5 \mathrm{ft}$ (238 gal) of liquid remained in the bottom of the outlet chamber. Figure A.17-2 and Figure A.17-3 depicts the visual inspection of the septic tank.

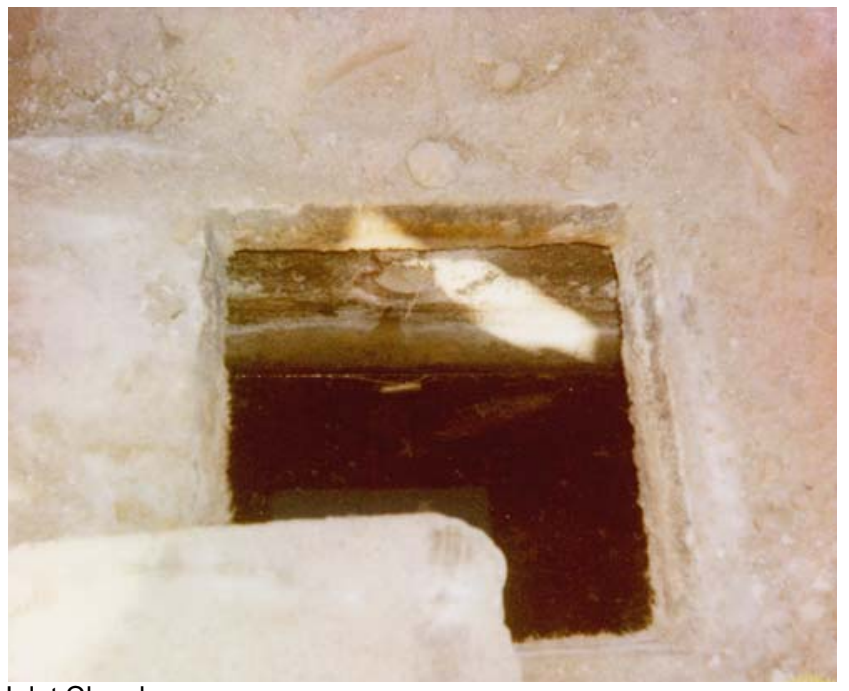

Inlet Chamber

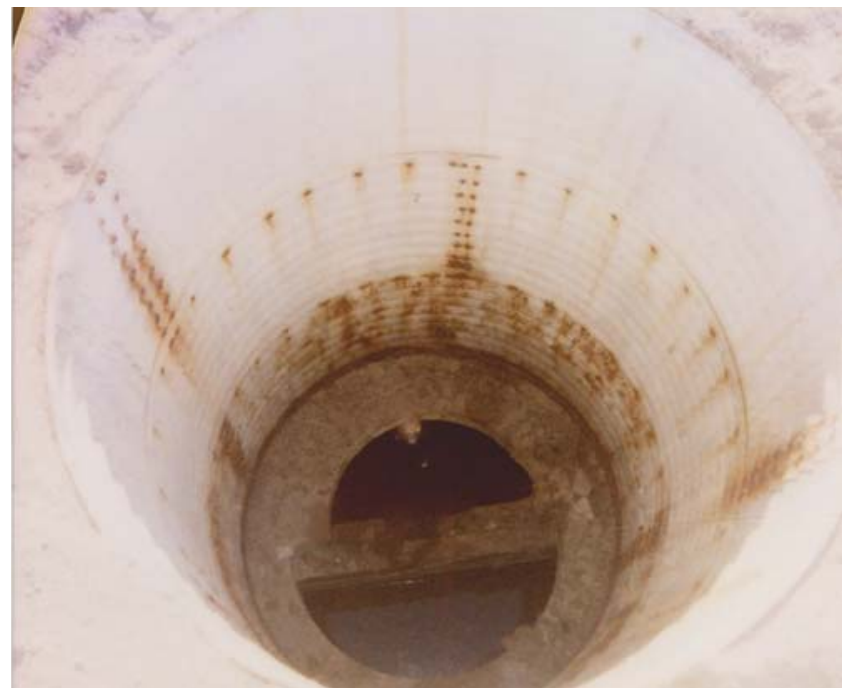

Outlet Chamber, Access Way from Ground Surface

Figure A.17-2

CAS 27-05-02 Septic Tank, Interior

(Photographs Taken 02-12-2002)

\section{A.17.2.2 Distribution Structure Contents}

The distribution structure was concrete with a vertical cylindrical shape and an 85-gal capacity. It is accessed by a circular concrete lid, located $4.5 \mathrm{ft}$ bgs. The interior dimensions of the structure are $2.7 \mathrm{ft}$ (length) by $2.3 \mathrm{ft}$ (diameter). One sludge sample was collected from the structure. Visual inspection revealed that approximately 2 in. ( $5 \mathrm{gal})$ of sludge remained in the structure. Figure A.17-3 depicts the visual inspection of the distribution structure. 


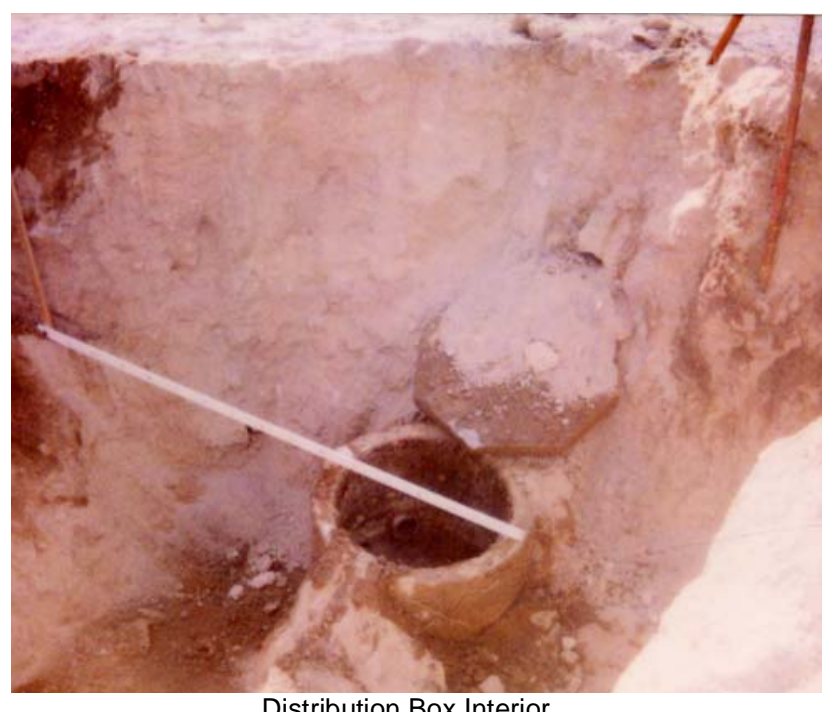

Distribution Box Interior

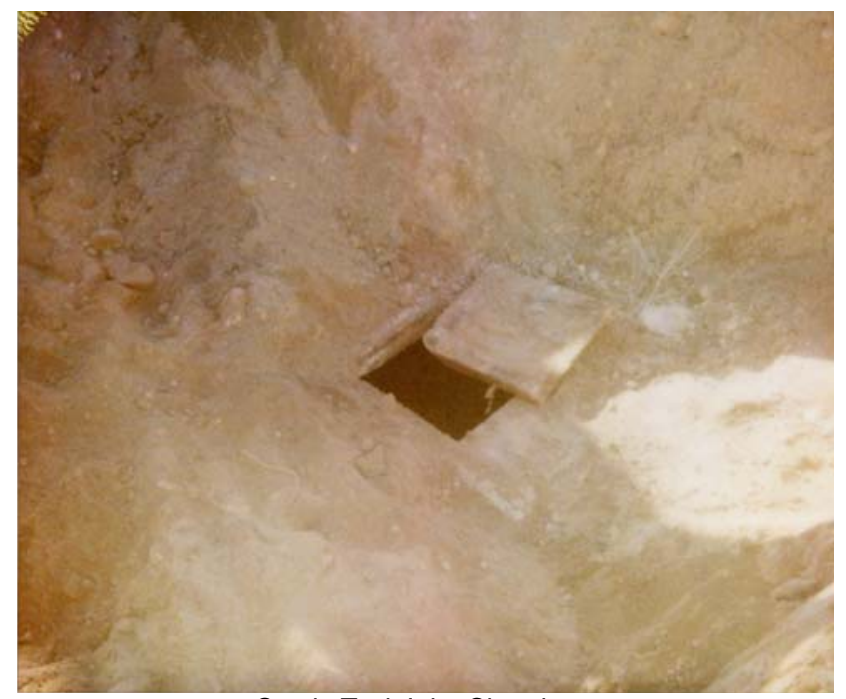

Septic Tank Inlet Chamber

Figure A.17-3

CAS 27-05-02 Distribution Box and Septic Tank

(Photographs Taken 02-07-2002)

\section{A.17.2.3 Septic Tank and Distribution Structure Integrity Soil Sampling}

Six integrity samples were collected by excavating adjacent to influent and effluent ends of the septic tank and the effluent end of the distribution structure. Figure A.17-4 depicts the structural integrity and composition of the influent end of the septic tank and the effluent end of the distribution box. The following three samples were submitted for laboratory analysis:

- The upper sample (271Q001) from the effluent end of the septic tank, collected at 12 to $13 \mathrm{ft}$ bgs

- $\quad$ The upper sample (271Q011) from the effluent end of the distribution box, collected at 7 to $9 \mathrm{ft}$ bgs

- The upper sample (271Q016) from the influent end of the septic tank, collected at 12 to $13 \mathrm{ft}$ bgs

\section{A.17.2.4 Leachfield Excavation Soil Sampling}

Backhoe excavations were conducted to access sampling horizons at the biased locations presented in the CAIP. Excavations provided a visual verification of distribution pipes and enabled soil samples to be collected from appropriate intervals beneath the pipes, as specified by the CAIP. Sixteen soil 


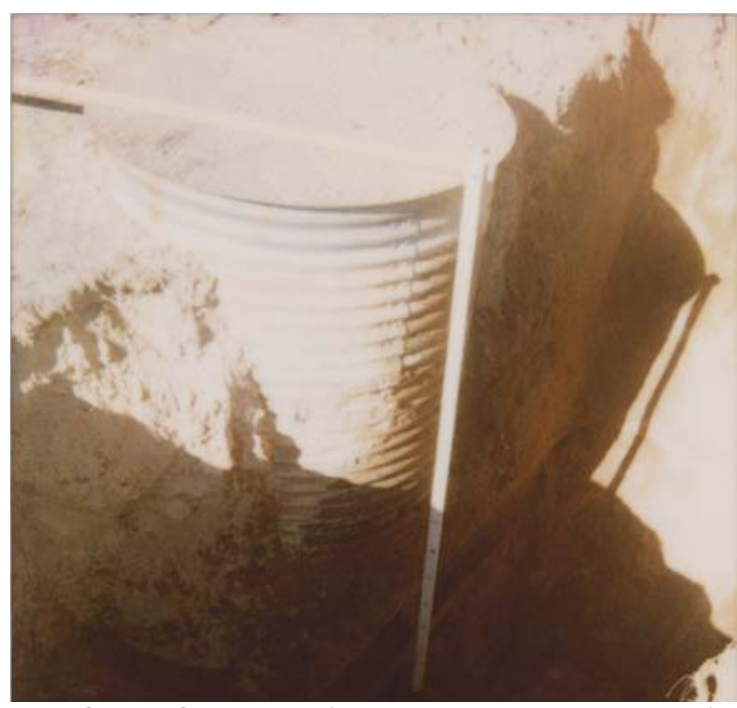

Inlet Side of Septic Tank (Photograph Taken 02-05-2002)

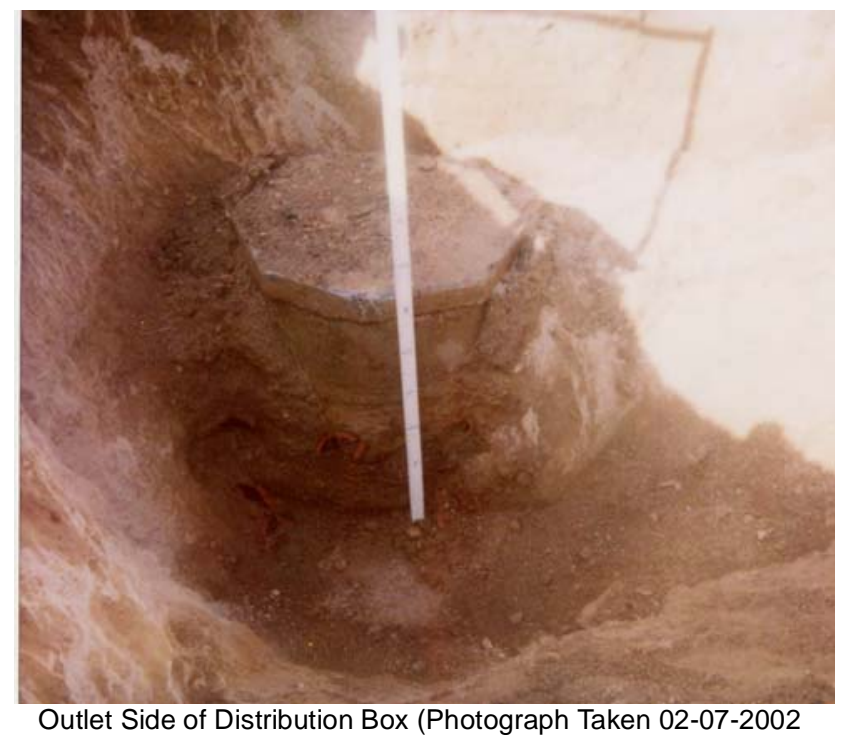

Outlet Side of Distribution Box (Photograph Taken 02-07-2002

Figure A.17-4

CAS 27-05-02 Integrity Samples

samples were collected from the planned locations excavated within the leachfield. These samples were collected from an interval of 0 to $1 \mathrm{ft}$ and 2.5 to $3.5 \mathrm{ft}$ below the leachrock/native soil interface. The interface was found at depths ranging from 5.2 to $8 \mathrm{ft}$ bgs. Eleven samples were submitted for laboratory analysis. In addition, one QC soil duplicate and one MS/MSD sample were collected and analyzed. A geotechnical sample was collected outside the boundary of the leachfield. The sample will be sent to a laboratory for geotechnical analysis, if necessary.

\section{A.17.2.5 Additional Sampling}

To further define the extent of PCB contamination in soil, the field crew returned to this CAS on May 9, 2002, to conduct step-out sampling. One location (Q09) was identified from the original sampling activities as an area of concern. Two vertical and four horizontal step-out samples were collected. Samples 271Q201 and 271Q202 were collected from Q09 at 9.5 to $10 \mathrm{ft}$ bgs and 12.5 to $13 \mathrm{ft}$ bgs. Samples 271Q203 and 271Q204 were collected from Q15 (7.5 ft east of Q09) at 5.5 to $6 \mathrm{ft}$ bgs and 8 to $8.5 \mathrm{ft}$ bgs. Samples 271Q205 and 271Q206 were collected from Q16 (15 ft south of Q09) at 5.5 to $6 \mathrm{ft}$ bgs and 8 to $8.5 \mathrm{ft}$ bgs. All samples were submitted for laboratory analysis of PCBs. 
A soil sample from step-out location Q15 contained PCBs in concentrations exceeding the PAL. Because the above sampling failed to define the lateral extent of contamination, a second additional sampling effort was required at CAS 27-05-02. This sampling event was conducted on June 24, 2002, to collect soil samples from additional step-out locations. Ten horizontal step-out locations were sampled. Surface soil samples were collected from all locations, and subsurface intervals were also sampled at six of the locations. The locations were designated Q17 through Q27

(Figure A.17-1). The associated sample numbers and depths are listed in Table A.17-1. All samples were submitted for laboratory analysis of PCBs, and select samples were also analyzed for pesticides (Section A.17.2.9).

One liquid waste management sample was collected from IDW drum 271Q01 to support waste characterization. The sample was analyzed for PCBs.

\section{A.17.2.6 Collection System Pipe Inspections}

Access points for inspection of the collection system by video mole survey were created at locations along the collection pipe via backhoe excavation.

The video mole was passed upstream (southeast) from location Q10, toward Building 5200, for $85 \mathrm{ft}$. The line turned at $78 \mathrm{ft}$, possibly a cleanout. Moisture was present in the pipe from 77 to $85 \mathrm{ft}$. When the video mole was removed from the pipe, the camera portion appeared to be covered in excrement. This material was not sampled. The pipe was grouted shut prior to filling in the excavation.

The video mole was passed upstream (northeast) from location Q11, toward Building 5210, for $103 \mathrm{ft}$ prior to a 90-degree bend that stopped the video mole. The pipe made a turn at $43 \mathrm{ft}$, which was probably at a cleanout based on engineering drawings. A line entered the pipe at $49 \mathrm{ft}$ from location Q11. The pipe was grouted shut prior to filling in the excavation.

With the exception of the material noted in the pipe from Building 5200, the inspected pipe segments contained only minor amounts of sediment and scaling. No breaks or blockages were observed. Visual observations were recorded in the FADLs. The pipe was radiologically surveyed and swiped at locations Q10 and Q11; the results are discussed in Section A.17.2.8. 


\section{A.17.2.7 Field-Screening Results}

Soil samples were screened for VOCs and alpha and beta/gamma radioactivity. The field readings were compared to FSLs to guide sampling decisions and determine which samples were to be submitted for laboratory analysis. No VOCs greater than FSLs were found during soil sample screening. The results of radiological field screening are discussed in Section A.17.2.8.

A sample of the septic tank content was collected and analyzed for fecal coliform bacteria. Fecal coliform bacteria was not detected in the septic tanks at this CAS.

\section{A.17.2.8 Radiological Survey Results}

All radiological field-screening results for soil samples from CAS 27-05-02 were below FSLs. The results of the radiological survey of pipe at locations Q10 and Q11 indicate that the collection system meets the unrestricted release criteria as defined in the NV/YMP Radiological Control Manual (DOE/NV, 2000a).

\section{A.17.2.9 Sample Analysis}

Environmental soil samples and associated QC samples were submitted and analyzed for the CAIP-specified COPCs (i.e., total VOCs, total SVOCs, total RCRA metals, and TPH [DRO and GRO], and PCBs). In addition, 25 percent of the soil samples, 100 percent of the associated QC samples, and the 2 sediment samples collected from the natural wash were analyzed for Iso-U, Iso-Pu, Sr-90, and gamma-emitting radionuclides.

The sludge and liquid samples from the septic tank and sludge from the distribution box were analyzed for total VOCs, total SVOCs, TPH (GRO and DRO), total RCRA metals, PCBs, gamma-emitting radionuclides, Iso-U, Iso-Pu, Sr-90, and tritium. The liquid samples were also analyzed for gross alpha and gross beta radioactivity. The sludge samples were analyzed according to the TCLP for VOCs, SVOCs, and RCRA metals.

The parameters and laboratory methods used to analyze the investigation samples are listed in Table A.2-2. Table A.17-1 lists the sample-specific analytical parameters. 


\section{A.17.3 Analytes Detected Above Minimum Reporting Limits}

The soil samples with concentrations exceeding corresponding MRLs and PALs (DOE/NV, 1998; DOE/NV, 2001) at CAS 27-05-02 are summarized in the following sections. The results of the septic tank and distribution box content samples are compared to appropriate regulatory levels for disposal. A portion of the CAS 27-05-02 analytical results were rejected during validation; however, these rejected data did not impact closure decisions as discussed in Section B.1.3.15 of Appendix B.

\section{A.17.3.1 Analytical Results for Soil Samples}

The following sections discuss the results for soil samples in comparison to the levels established in the Leachfield Work Plan and the CAIP.

\section{A.17.3.1.1 Total Volatile Organic Compounds}

Volatile organic compounds were not detected above MRLs in CAS 27-05-02 soil samples.

\section{A.17.3.1.2 Total Semivolatile Organic Compounds}

Semivolatile organic compounds were not detected above MRLs in CAS 27-05-02 soil samples.

\section{A.17.3.1.3 Total Petroleum Hydrocarbons}

Total petroleum hydrocarbons were not detected above MRLs in CAS 27-05-02 soil samples.

\section{A.17.3.1.4 Total RCRA Metals}

As shown in Table A.17-2, the total RCRA metals detected in soil samples at concentrations exceeding the laboratory MRLs are arsenic (1 mg/kg), barium $(20 \mathrm{mg} / \mathrm{kg})$, chromium (1 mg/kg), and lead $(0.3 \mathrm{mg} / \mathrm{kg})$. All other RCRA metals (i.e., cadmium, mercury, selenium, silver) were below laboratory-specified MRLs.

Barium concentrations ranged from 117 to $193 \mathrm{mg} / \mathrm{kg}$, chromium concentrations ranged from 3.93 to $10.4 \mathrm{mg} / \mathrm{kg}$, and lead concentrations ranged from 5.24 to $9.61 \mathrm{mg} / \mathrm{kg}$. All reported concentrations of these metals were below EPA Region 9 PRGs defined in this document as PALs. 
Table A.17-2

Soil Sample Results for Total RCRA Metals Detected Above Minimum Reporting Limits at CAS 27-05-02

\begin{tabular}{|c|c|c|c|c|c|}
\hline \multirow{2}{*}{$\begin{array}{c}\text { Sample } \\
\text { Identification } \\
\text { Number }\end{array}$} & \multirow{2}{*}{$\begin{array}{c}\text { Depth } \\
\text { (ft bgs) }\end{array}$} & \multicolumn{4}{|c|}{ Contaminants of Potential Concern (mg/kg) } \\
\hline & & Arsenic & Barium & Chromium & Lead \\
\hline \multicolumn{2}{|c|}{ Preliminary Action Levels ${ }^{a}$} & 2.7 & 100,000 & 450 & 750 \\
\hline $271 \mathrm{Q} 001$ & $12-13$ & 2.37 & 147 & 4.18 & 7.57 \\
\hline $271 \mathrm{Q} 003$ & $5.2-6.2$ & 2.86 & 170 & 5.96 & 8.69 \\
\hline 271Q005 & $5.25-6.25$ & 2.16 & 145 & 4.14 & 5.99 \\
\hline 271Q007 & $5.25-6.25$ & 2.89 & 193 & 10.4 & 6.67 \\
\hline 271Q009 & $8-9$ & 4.93 & 133 & 5.41 & 8.2 \\
\hline $271 Q 011$ & $8-9$ & 2.84 & 123 & 5.32 & 6.97 \\
\hline $271 Q 014$ & $5.8-6.8$ & 2.3 & 117 & 3.93 & 7.09 \\
\hline 271Q016 & $12-13$ & 2.5 & 149 & 4.91 & 6.41 \\
\hline 271Q020 & surface & 2.56 & 126 & 6.15 & 9.61 \\
\hline 271Q021 & surface & 2.22 & -- & -- & 5.24 \\
\hline 271Q022 & $7-8$ & 2.92 & -- & -- & 6.26 \\
\hline 271Q023 & $7-8$ & 3.2 & 186 & 6.56 & 7.65 \\
\hline
\end{tabular}

a'Based on U.S. Environmental Protection Agency, Region 9 Preliminary Remediation Goals (PRGs) (EPA, 2000).

$\mathrm{J}=$ Estimated value

-- = Not detected above minimum reporting limits

Arsenic concentrations ranged from 2.16 to $4.93 \mathrm{mg} / \mathrm{kg}$. Approximately half of the detected concentrations slightly exceed the PAL of $2.7 \mathrm{mg} / \mathrm{kg}$. Arsenic concentrations are consistent across the site, with no "hot spots" or evidence of a localized spill. The PAL is lower than the 7 to $8 \mathrm{mg} / \mathrm{kg}$ mean concentration of arsenic in silt from the Nevada Test and Training Range (NBMG, 1998; Moore, 1999). Although some arsenic concentrations in the soil exceed the PAL, these concentrations are believed to be within ambient conditions for CAS 27-05-02 and do not represent contamination.

\section{A.17.3.1.5 Polychlorinated Biphenyls}

Several soil samples had reported PCB concentrations that exceeded the MRL for aroclor-1248, aroclor-1254, and aroclor-1260. The results are presented in Table A.17-3. Aroclor-1248 was the 
Table A.17-3

Soil Sample Results for PCBs

Detected Above Minimum Reporting Limits at CAS 27-05-02

\begin{tabular}{|c|c|c|c|c|}
\hline \multirow{2}{*}{$\begin{array}{c}\text { Sample } \\
\text { Identification } \\
\text { Number }\end{array}$} & \multirow{2}{*}{$\begin{array}{c}\text { Depth } \\
\text { (ft bgs) }\end{array}$} & \multicolumn{3}{|c|}{ Contaminants of Potential Concern $(\mu \mathrm{g} / \mathrm{kg})$} \\
\hline & & Aroclor-1248 & Aroclor-1254 & Aroclor-1260 \\
\hline \multicolumn{2}{|c|}{ Preliminary Action Levels ${ }^{a}$} & 1,000 & 1,000 & 1,000 \\
\hline $271 Q 001$ & $12-13$ & 124 & -- & -- \\
\hline $271 Q 003$ & $5.2-6.2$ & 1,000 & -- & 95 \\
\hline $271 Q 005$ & $5.25-6.25$ & 120 & -- & -- \\
\hline $271 Q 007$ & $5.25-6.25$ & 120 & -- & -- \\
\hline $271 Q 011$ & $8-9$ & 164 & -- & -- \\
\hline $271 Q 014$ & $5.8-6.8$ & 92 & -- & -- \\
\hline $271 Q 016$ & $12-13$ & 620 & -- & 55 \\
\hline 271Q020 & surface & -- & 52 & -- \\
\hline 271Q021 & surface & 76 & -- & -- \\
\hline 271Q022 & $7-8$ & 117 & -- & -- \\
\hline 271Q023 & $7-8$ & 99 & -- & -- \\
\hline 271Q201 & $9.5-10$ & 730 & $940(\mathrm{~J})$ & -- \\
\hline 271Q203 & $5.5-6$ & 5,300 & $7,600(\mathrm{~J})$ & -- \\
\hline 271Q208 & $0-0.5$ & 19,000 & -- & -- \\
\hline 271Q224 & $0-1$ & 22,000 & -- & -- \\
\hline 271Q225 & $2.5-3$ & 4,700 & -- & -- \\
\hline 271Q226 & $5.5-6$ & 570 & -- & -- \\
\hline 271Q227 & $8.5-9$ & 120 & -- & -- \\
\hline 271Q228 & $0-0.5$ & 8,400 & -- & -- \\
\hline 271Q229 & $2.5-3$ & 9,400 & -- & -- \\
\hline 271Q230 & $2.5-3$ & 1,500 & -- & -- \\
\hline 271Q231 & $5.5-6$ & 2,800 & -- & -- \\
\hline 271Q232 & $8.5-9$ & 5,800 & -- & -- \\
\hline
\end{tabular}

aBased on U.S. Environmental Protection Agency, Region 9 Preliminary Remediation Goals (PRGs) (EPA, 2000).

$--=$ Not detected above minimum reporting limits

$\mathrm{J}=$ Estimated value

most prevalent PCB found in soil samples, with reported concentrations greater than the MRL (ranging from 76 to $22,000 \mu \mathrm{g} / \mathrm{kg}$ ). Polychlorinated biphenyl concentrations exceeded the PAL of $1,000 \mu \mathrm{g} / \mathrm{kg}$ at several locations in the leachfield surface and subsurface soils. As discussed in Section A.17.2.5, PCBs were initially detected in the subsurface at location Q09 (271Q003). 
Subsequent sampling detected higher concentrations (greater than the PAL) in the subsurface at locations Q15, Q17, and Q20. The highest PCB concentrations found in soil at CAS 27-05-02 were detected in surface soil samples from locations Q20 (271Q224) and Q23 (271Q208). Concentrations greater than the PAL were also detected in a surface soil sample from location Q17 (271Q228).

The extent of subsurface PCB contamination in the leachfield is bounded by results below PALs in samples from locations Q05, Q06, Q08, Q16, and Q18. The extent of surface soil PCB contamination is bounded by clean samples at locations Q12, Q13, Q18, Q26, and Q27 (Figure A.17-1). The contamination is located primarily along the eastern edge of the leachfield. The greatest concentrations are at the ground surface and concentrations above PALs persist to a depth of $9 \mathrm{ft}$ bgs at one location.

\section{A.17.3.1.6 Total Pesticides}

During the additional sampling, pesticide analysis was conducted on select samples although they are not established COPCs for this CAS. The laboratory analyst noted the presence of pesticides during the analysis of soil samples for PCBs. The pesticides detected in soil samples at concentrations exceeding the laboratory MRLs are presented in Table A.17-4. None of the samples exceeded PALs.

Table A.17-4

Soil Sample Results for Pesticides Detected Above Minimum Reporting Limits at CAS 27-05-02

\begin{tabular}{|c|c|c|c|c|c|c|}
\hline \multirow{2}{*}{$\begin{array}{c}\text { Sample } \\
\text { Identification } \\
\text { Number }\end{array}$} & \multirow{2}{*}{$\begin{array}{l}\text { Depth } \\
\text { (ft bgs) }\end{array}$} & \multicolumn{5}{|c|}{ Contaminants of Potential Concern $(\mu \mathrm{g} / \mathrm{kg})$} \\
\hline & & 4,4'-DDE & 4,4'-DDT & 4,4'-DDD & Alpha-Chlordane & Gamma-Chlordane \\
\hline \multicolumn{2}{|c|}{ Preliminary Action Levels ${ }^{a}$} & 12,000 & 12,000 & 17,000 & $11,000^{b}$ & $11,000^{b}$ \\
\hline 271Q207 & $\overline{0-0.5}$ & 100 & 240 & 200 & 210 & 220 \\
\hline 271Q209 & $0-0.5$ & 6.3 & 33 & -- & 12 & 12 \\
\hline $271 Q 210$ & $0-0.5$ & 230 & 620 & -- & 170 & 170 \\
\hline $271 Q 211$ & $0-0.5$ & 250 & 650 & -- & 180 & 190 \\
\hline 271Q233 & $0-0.5$ & 59 & 200 & 21 & 33 & 32 \\
\hline 271Q235 & $6.5-7$ & 15 & 57 & 6.7 & 8.8 & 8 \\
\hline
\end{tabular}

\footnotetext{
${ }^{a}$ Based on U.S. Environmental Protection Agency, Region 9 Preliminary Remediation Goals (PRGs) (EPA, 2000).

${ }^{\mathrm{b}}$ The PAL is for total chlordane. The comparison to this PAL is made by summing the chlordane concentrations for a given sample.

-- = Not detected above minimum reporting limits
} 


\section{A.17.3.1.7 Gamma Spectrometry Results}

Results of soil sample gamma spectrometry analysis are presented in Table A.17-5. Concentrations of actinium-228, bismuth-214, lead-212, lead-214, potassium-40, and thallium-208 were detected above the MRLs. The TPU in the radioanalytical measurement is provided in the table along with the concentration for all detected gamma emitters. The concentrations of the detected gamma-emitting radionuclides are below PALs and are not significantly different than concentrations measured in soil samples collected from undisturbed background locations.

\section{A.17.3.1.8 Isotopic Uranium}

Detected values of uranium isotopes, along with associated TPUs, are reported in Table A.17-6. Samples 271Q011, 271Q014, and 271Q022 had concentrations of U-235 above the PAL; therefore, a normalized difference based on a confidence level of 95 percent was used to determine if the concentrations were statistically distinguishable from background. Based on this evaluation, the U-235 detections were not significantly greater than concentrations in soil samples collected from undisturbed background locations.

\section{A.17.3.1.9 Isotopic Plutonium}

Isotopic plutonium was not detected above MRLs in CAS 27-02-05 soil samples.

\section{A.17.3.1.10 Strontium-90}

Strontium-90 was not detected above MRLs in CAS 27-02-05 soil samples.

\section{A.17.3.2 Septic Tank and Distribution Structure Sample Results}

Results of collected septic tank and distribution box content samples were compared to regulatory levels based on disposal options. If the waste has no hazardous component, the regulatory level is based on NTS disposal options at landfills and lagoons (BN, 1995; CFR, 2000b and c; NDEP, 1997a, $\mathrm{b}$, and $\mathrm{c}$ ). Any sludge or liquid waste will be solidified before disposal at NTS landfills (NDEP, 1997b). If the waste is hazardous, the release criteria are based on interpretation of the guidelines presented in the POC (BN, 1995; Alderson, 1999). For waste destined for off-site disposal, the POC radiological levels must be met to certify that the waste has no radioactivity added. 
Table A.17-5

Soil Sample Results for Gamma-Emitting Radionuclides Detected Above Minimum Reporting Limits at CAS 27-05-02

\begin{tabular}{|c|c|c|c|c|c|c|c|}
\hline \multirow{2}{*}{$\begin{array}{c}\text { Sample } \\
\text { Identification } \\
\text { Number }\end{array}$} & \multirow{2}{*}{$\begin{array}{l}\text { Depth } \\
\text { (ft bgs) }\end{array}$} & \multicolumn{6}{|c|}{ Contaminants of Potential Concern $(\mathrm{pCi} / \mathrm{g})$} \\
\hline & & Actinium-228 ${ }^{a}$ & Bismuth-214 ${ }^{\mathrm{b}}$ & Lead-212 & Lead-214 ${ }^{b}$ & Potassium-40 & Thallium-208 \\
\hline 271Q007 & $5.25-6.25$ & $1.35 \pm 0.29$ & $0.75 \pm 0.18$ & $1.43 \pm 0.27$ & $0.9 \pm 0.19$ & $22.1 \pm 3.9$ & $0.49 \pm 0.10$ \\
\hline $271 Q 011$ & $8-9$ & $1.5 \pm 0.38$ & $0.73 \pm 0.23$ & $1.66 \pm 0.34$ & $0.78 \pm 0.21$ & $20.7 \pm 4.3$ & $0.45 \pm 0.14$ \\
\hline $271 Q 020$ & surface & $1.23 \pm 0.31$ & $0.61 \pm 0.19$ & $1.29 \pm 0.27$ & $0.63 \pm 0.17$ & $18.1 \pm 3.6$ & $0.45 \pm 0.12$ \\
\hline $271 Q 021$ & surface & $1.14 \pm 0.32$ & $0.71 \pm 0.21$ & $1.33 \pm 0.28$ & $0.62 \pm 0.17$ & $19.2 \pm 4.0$ & $0.33 \pm 0.11$ \\
\hline $271 Q 022$ & $7-8$ & $1.48 \pm 0.31$ & $0.72 \pm 0.17$ & $1.46 \pm 0.27$ & $0.92 \pm 0.19$ & $23.4 \pm 4.1$ & $0.48 \pm 0.10$ \\
\hline $271 Q 023$ & $7-8$ & $1.23 \pm 0.31$ & $0.78 \pm 0.21$ & $1.69 \pm 0.33$ & $0.77 \pm 0.19$ & $22.3 \pm 4.3$ & $0.49 \pm 0.13$ \\
\hline
\end{tabular}

aBackground concentration listed in Environmental Monitoring Report for the Proposed Ward Valley, California, Low-Level Radioactive Waste (LLRW) Facility (US Ecology and Atlan-Tech, 1992).

${ }^{\mathrm{b}}$ Background concentration listed or derived in Off-Site Radiation Exposure Review Project, Phase II Soil Program (McArthur and Miller, 1989). 
Table A.17-6

Soil Sample Results for Isotopic Uranium Detected Above Minimum Reporting Limits at CAS 27-05-02

\begin{tabular}{||c|c|c|c|c||}
\hline \multirow{2}{*}{$\begin{array}{c}\text { Sample } \\
\text { Identification } \\
\text { Number }\end{array}$} & \multirow{2}{*}{$\begin{array}{c}\text { Depth } \\
\text { (ft bgs) }\end{array}$} & \multicolumn{3}{|c|}{ Contaminants of Potential Concern (pCi/g) } \\
\cline { 3 - 5 } & & Uranium-234 & Uranium-235 & Uranium-238 $^{\mathbf{b}}$ \\
\hline Preliminary Action Levels & $\mathbf{1 . 5 6}$ & $\mathbf{0 . 0 7}$ & $\mathbf{3 . 2}$ \\
\hline \hline $271 Q 007$ & $5.25-6.25$ & $1.04 \pm 0.21$ & -- & $0.96 \pm 0.20$ \\
\hline $271 Q 011$ & $8-9$ & $1 \pm 0.19$ & $0.071 \pm 0.038$ & $0.96 \pm 0.18$ \\
\hline $271 Q 014$ & $5.8-6.8$ & $0.87 \pm 0.17$ & $0.085 \pm 0.042$ & $1.16 \pm 0.21$ \\
\hline $271 Q 020$ & surface & $0.81 \pm 0.18$ & -- & $0.7 \pm 0.17$ \\
\hline $271 Q 021$ & surface & $0.85 \pm 0.19$ & -- & $0.89 \pm 0.19$ \\
\hline $271 Q 022$ & $7-8$ & $1.01 \pm 0.18$ & $0.079 \pm 0.037$ & $0.97 \pm 0.18$ \\
\hline $271 Q 023$ & $7-8$ & $1.01 \pm 0.20$ & -- & $1.01 \pm 0.20$ \\
\hline
\end{tabular}

aBackground concentration listed in Environmental Monitoring Report for the Proposed Ward Valley, California, Low-Level Radioactive Waste (LLRW) Facility (US Ecology and Atlan-Tech, 1992).

${ }^{\mathrm{b}}$ Background concentration listed or derived in Off-Site Radiation Exposure Review Project, Phase II Soil Program (McArthur and Miller, 1989).

$--=$ Not detected above minimum reporting limit

Several COPCs were detected in the sludge samples. Most COPCs were below regulatory limits except for TPH, PCBs, and radioisotopes. Total petroleum hydrocarbons were detected in sludge samples from the distribution box (271Q013) and septic tank (271Q019) as shown in Table A.17-7. Diesel concentrations in these samples were 870 and 3,000 mg/kg, respectively. Based on the data evaluation of organic TPH GROs, GROs were not detected in sample 271Q013 above the contract-required detection limit. Gasoline concentrations in sample 271Q019 were 4,100 mg/kg. These levels exceed the NDEP action level of $100 \mathrm{mg} / \mathrm{kg}$ for TPH (NAC, 2000).

Aroclor-1248 was detected in sludge samples 271Q013 and 271Q019 above regulatory levels of $50 \mathrm{ppm}$ (CFR, 2000b). The results were 1,500 and 2,900 ppm, respectively. Uranium-234/235/238 were above the POC release levels (BN, 1995) for samples 271Q013 and 271Q019.

\section{A.17.4 Contaminants of Concern}

Based on the aforementioned analytical results, COCs (i.e., TPH analytes, PCBs, and U-234/235/238) are present in the distribution structure and septic tank contents at concentrations of regulatory concern. The COCs present in soil at the south eastern end of the leachfield are PCBs in 
Table A.17-7

Liquid and Sludge Sample Results

Detected Above Minimum Reporting Limits at CAS 27-05-02

(Page 1 of 3 )

\begin{tabular}{|c|c|c|c|c|c|c|}
\hline $\begin{array}{c}\text { Sample } \\
\text { Identification } \\
\text { Number }\end{array}$ & Matrix & Parameter & Result & Units & Limits & Reference \\
\hline 271Q018 & Liquid & 1,4-Dichlorobenzene & 36 & $\mu \mathrm{g} / \mathrm{L}$ & 7,500 & CFR, 2000a \\
\hline 271Q018 & Liquid & Cis-1,2-Dichloroethene & 6.2 & $\mu \mathrm{g} / \mathrm{L}$ & NA & CFR, 2000a \\
\hline 271Q125 & Liquid & 1,4-Dichlorobenzene & 61 & $\mu \mathrm{g} / \mathrm{L}$ & 7,500 & CFR, 2000a \\
\hline 271Q018 & Liquid & 1,4-Dichlorobenzene & 22 & $\mu \mathrm{g} / \mathrm{L}$ & 7,500 & CFR, 2000a \\
\hline 271Q125 & Liquid & 1,4-Dichlorobenzene & 48 & $\mu \mathrm{g} / \mathrm{L}$ & 7,500 & CFR, 2000a \\
\hline 271Q018 & Liquid & Uranium-234 & $6.83 \pm 1.00$ & $\mathrm{pCi} / \mathrm{L}$ & 932 & BN, 1995 \\
\hline 271Q018 & Liquid & Uranium-235 & $0.146 \pm 0.070$ & $\mathrm{pCi} / \mathrm{L}$ & 0.1614 & BN, 1995 \\
\hline 271Q018 & Liquid & Uranium-238 & $1.94 \pm 0.35$ & $\mathrm{pCi} / \mathrm{L}$ & 10 & BN, 1995 \\
\hline 271Q025 & Liquid & Uranium-234 & $7.9 \pm 1.1$ & $\mathrm{pCi} / \mathrm{L}$ & 932 & BN, 1995 \\
\hline 271Q025 & Liquid & Uranium-235 & $0.34 \pm 0.10(\mathrm{~J})^{\mathrm{a}}$ & $\mathrm{pCi} / \mathrm{L}$ & 0.1614 & BN, 1995 \\
\hline $271 Q 025$ & Liquid & Uranium-238 & $2.35 \pm 0.38$ & $\mathrm{pCi} / \mathrm{L}$ & 10 & BN, 1995 \\
\hline 271Q018 & Liquid & Aroclor-1248 & $3.7(\mathrm{~J})^{\mathrm{b}}$ & $\mu \mathrm{g} / \mathrm{L}$ & 50,000 & CFR, 2000b \\
\hline 271Q125 & Liquid & Aroclor-1248 & $4.6(J)^{b}$ & $\mu \mathrm{g} / \mathrm{L}$ & 50,000 & CFR, 2000b \\
\hline 271Q019 & Sludge & Bis(2-Ethylnexyl) Phlthalate & $9,300(J)^{c}$ & $\mu \mathrm{g} / \mathrm{kg}$ & NA & CFR, 2000a \\
\hline 271Q019 & Sludge & TCLP 1,4-Dichlorobenzene & $5.6(\mathrm{~J})^{\mathrm{d}}$ & $\mathrm{mg} / \mathrm{L}$ & 7.5 & CFR, 2000a \\
\hline 271Q019 & Sludge & TCLP $3+4$ Methylphenol & 0.12 & $\mathrm{mg} / \mathrm{L}$ & 200 & CFR, 2000a \\
\hline 271Q019 & Sludge & TCLP 1,4-Dichlorobenzene & $6.9(\mathrm{~J})^{\mathrm{c}}$ & $\mathrm{mg} / \mathrm{L}$ & 7.5 & CFR, 2000a \\
\hline $271 Q 019$ & Sludge & TCLP Trichloroethene & 0.0074 & $\mathrm{mg} / \mathrm{L}$ & 0.5 & CFR, 2000a \\
\hline 271Q019 & Sludge & Mercury** & 0.78 & $\mathrm{mg} / \mathrm{kg}$ & NA & CFR, 2000a \\
\hline $271 Q 013$ & Sludge & Arsenic ${ }^{\star \star}$ & 60 & $\mathrm{mg} / \mathrm{kg}$ & NA & CFR, 2000a \\
\hline 271Q013 & Sludge & Barium $^{\star *}$ & 340 & $\mathrm{mg} / \mathrm{kg}$ & NA & CFR, 2000a \\
\hline 271Q013 & Sludge & Cadmium & 21 & $\mathrm{mg} / \mathrm{kg}$ & NA & CFR, 2000a \\
\hline 271Q013 & Sludge & Chromium** & 75 & $\mathrm{mg} / \mathrm{kg}$ & NA & CFR, 2000a \\
\hline 271Q013 & Sludge & Lead $^{* *}$ & 440 & $\mathrm{mg} / \mathrm{kg}$ & NA & CFR, 2000a \\
\hline $271 Q 013$ & Sludge & Mercury** & 2.5 & $\mathrm{mg} / \mathrm{kg}$ & NA & CFR, 2000a \\
\hline 271Q013 & Sludge & Selenium** & 3.3 & $\mathrm{mg} / \mathrm{kg}$ & NA & CFR, 2000a \\
\hline 271Q013 & Sludge & Silver ${ }^{* *}$ & 16 & $\mathrm{mg} / \mathrm{kg}$ & NA & CFR, 2000a \\
\hline 271Q019 & Sludge & Arsenic $^{* *}$ & 13 & $\mathrm{mg} / \mathrm{kg}$ & NA & CFR, 2000a \\
\hline 271Q019 & Sludge & Barium & 480 & $\mathrm{mg} / \mathrm{kg}$ & NA & CFR, 2000a \\
\hline 271Q019 & Sludge & Cadmium** & 8.3 & $\mathrm{mg} / \mathrm{kg}$ & NA & CFR, 2000a \\
\hline
\end{tabular}


Table A.17-7

Liquid and Sludge Sample Results

Detected Above Minimum Reporting Limits at CAS 27-05-02

(Page 2 of 3 )

\begin{tabular}{|c|c|c|c|c|c|c|}
\hline $\begin{array}{c}\text { Sample } \\
\text { Identification } \\
\text { Number }\end{array}$ & Matrix & Parameter & Result & Units & Limits & Reference \\
\hline 271Q019 & Sludge & Chromium** & 72 & $\mathrm{mg} / \mathrm{kg}$ & NA & CFR, 2000a \\
\hline 271Q019 & Sludge & Lead & 150 & $\mathrm{mg} / \mathrm{kg}$ & NA & CFR, 2000a \\
\hline 271Q019 & Sludge & Silver** & 8.6 & $\mathrm{mg} / \mathrm{kg}$ & NA & CFR, 2000a \\
\hline 271Q013 & Sludge & TCLP Cadmium & $0.13(\mathrm{~J})^{\mathrm{e}}$ & $\mathrm{mg} / \mathrm{L}$ & 1 & CFR, 2000a \\
\hline 271Q019 & Sludge & TCLP Barium & 1.7 & $\mathrm{mg} / \mathrm{L}$ & 100 & CFR,2000a \\
\hline 271Q019 & Sludge & TCLP Lead & 0.15 & $\mathrm{mg} / \mathrm{L}$ & 5.0 & CFR, 2000a \\
\hline $271 Q 013$ & Sludge & Diesel-Range Organics & $870(M, Z)$ & $\mathrm{mg} / \mathrm{kg}$ & 100 & NDEP, 1997b \\
\hline $271 Q 019$ & Sludge & Diesel-Range Organics & $3,000(Z)$ & $\mathrm{mg} / \mathrm{kg}$ & 100 & NDEP, 1997b \\
\hline 271Q019 & Sludge & Gasoline-Range Organics & $4,100(Z)$ & $\mathbf{m g} / \mathbf{k g}$ & 100 & NDEP, 1997b \\
\hline 271Q013 & Sludge & Acetone & $200(J)^{f}$ & $\mu \mathrm{g} / \mathrm{kg}$ & NA & CFR, 2000a \\
\hline 271Q019 & Sludge & 1,4-Dichlorobenzene & $2,400,000(J)^{d}$ & $\mu \mathrm{g} / \mathrm{kg}$ & NA & CFR, 2000a \\
\hline 271Q019RR1 & Sludge & 1,4-Dichlorobenzene & $2,800,000$ & $\mu \mathrm{g} / \mathrm{kg}$ & NA & CFR, 2000a \\
\hline $271 Q 013$ & Sludge & Bis(2-Ethylhexyl)Phthalate & $48,000(J)^{9}$ & $\mu \mathrm{g} / \mathrm{kg}$ & NA & CFR, 2000a \\
\hline 271Q019 & Sludge & 1,2,4-Trichlorobenzene & 13,000 & $\mu \mathrm{g} / \mathrm{kg}$ & NA & CFR, 2000a \\
\hline 271Q019 & Sludge & 1,2-Dichlorobenzene & 25,000 & $\mu \mathrm{g} / \mathrm{kg}$ & NA & CFR, 2000a \\
\hline 271Q019 & Sludge & 1,4-Dichlorobenzene & $820,000(E)$ & $\mu \mathrm{g} / \mathrm{kg}$ & NA & CFR, 2000a \\
\hline 271Q019RR1 & Sludge & 1,4-Dichlorobenzene & $1,200,000(J)^{c}$ & $\mu \mathrm{g} / \mathrm{kg}$ & NA & CFR, 2000a \\
\hline $271 Q 013$ & Sludge & Actinium-228 & $1.32 \pm 0.35$ & $\mathrm{pCi} / \mathrm{g}$ & - & $\mathrm{F}$ \\
\hline 271Q013 & Sludge & Bismuth-214 & $0.72 \pm 0.25$ & $\mathrm{pCi} / \mathrm{g}$ & - & $\mathrm{F}$ \\
\hline 271Q013 & Sludge & Potassium-40 & $5.8 \pm 1.6$ & $\mathrm{pCi} / \mathrm{g}$ & - & $\mathrm{F}$ \\
\hline 271Q013 & Sludge & Lead-212 & $1.51 \pm 0.31$ & $\mathrm{pCi} / \mathrm{g}$ & - & $\mathrm{F}$ \\
\hline 271Q013 & Sludge & Lead-214 & $0.77 \pm 0.20$ & $\mathrm{pCi} / \mathrm{g}$ & - & $\mathrm{F}$ \\
\hline 271Q013 & Sludge & Thorium-234 & $17.3 \pm 3.5$ & $\mathrm{pCi} / \mathrm{g}$ & - & $\mathrm{F}$ \\
\hline 271Q013 & Sludge & Thallium-208 & $0.35 \pm 0.11$ & $\mathrm{pCi} / \mathrm{g}$ & - & $\mathrm{F}$ \\
\hline 271Q019 & Sludge & Potassium-40 & $14.2 \pm 3.9$ & $\mathrm{pCi} / \mathrm{g}$ & - & $\mathrm{F}$ \\
\hline 271Q019 & Sludge & Lead-212 & $0.92 \pm 0.31$ & $\mathrm{pCi} / \mathrm{g}$ & - & $\mathrm{F}$ \\
\hline 271Q013 & Sludge & Uranium-234 & $38.3 \pm 5.5$ & $\mathrm{pCi} / \mathrm{g}$ & 0.932 & BN, 1995 \\
\hline $271 Q 013$ & Sludge & Uranium-235 & $0.99 \pm 0.24$ & $\mathrm{pCi} / \mathrm{g}$ & 0.1614 & BN, 1995 \\
\hline $271 Q 013$ & Sludge & Uranium-238 & $17.3 \pm 2.6$ & $\mathrm{pCi} / \mathrm{g}$ & 10 & BN, 1995 \\
\hline 271Q019 & Sludge & Uranium-234 & $5.09 \pm 0.74$ & $\mathrm{pCi} / \mathrm{g}$ & 0.932 & BN, 1995 \\
\hline
\end{tabular}


Table A.17-7

\section{Liquid and Sludge Sample Results \\ Detected Above Minimum Reporting Limits at CAS 27-05-02}

(Page 3 of 3 )

\begin{tabular}{|c|c|c|c|c|c|c|}
\hline $\begin{array}{c}\text { Sample } \\
\text { Identification } \\
\text { Number }\end{array}$ & Matrix & Parameter & Result & Units & Limits & Reference \\
\hline 271Q019 & Sludge & Uranium-235 & $0.219 \pm 0.070$ & $\mathrm{pCi} / \mathrm{g}$ & 0.1614 & BN, 1995 \\
\hline 271Q019 & Sludge & Uranium-238 & $3.07 \pm 0.47$ & $\mathrm{pCi} / \mathrm{g}$ & 10 & BN, 1995 \\
\hline 271Q013 & Sludge & Plutonium-238 & $1.35 \pm 0.24$ & $\mathrm{pCi} / \mathrm{g}$ & 10 & BN, 1995 \\
\hline 271Q013 & Sludge & Plutonium-239 & $0.111 \pm 0.047$ & $\mathrm{pCi} / \mathrm{g}$ & 0.5 & BN, 1995 \\
\hline 271Q019 & Sludge & Plutonium-239 & $0.036 \pm 0.023(\mathrm{LT})$ & $\mathrm{pCi} / \mathrm{g}$ & 0.5 & BN, 1995 \\
\hline 271Q013 & Sludge & Aroclor-1248 & $1,500,000(J)^{c}$ & $\mu \mathbf{g} / \mathbf{k g}$ & 50,000 & CFR, 2000b \\
\hline 271Q019 & Sludge & Aroclor-1248 & $2,900,000(J)^{b}$ & $\mu \mathbf{g} / \mathbf{k g}$ & 50,000 & CFR, 2000b \\
\hline 271Q018 & Liquid & Gross Alpha & $8.9 \pm 1.8$ & $\mathrm{pCi} / \mathrm{L}$ & $1.6^{\mathrm{h}}$ & NA \\
\hline 271Q018 & Liquid & Gross Beta & $29.5 \pm 4.3$ & $\mathrm{pCi} / \mathrm{L}$ & $1.9^{h}$ & NA \\
\hline 271Q025 & Liquid & Gross Alpha & $13.2 \pm 2.4$ & $\mathrm{pCi} / \mathrm{L}$ & $1.7^{\mathrm{h}}$ & NA \\
\hline 271Q025 & Liquid & Gross Beta & $31.8 \pm 4.6$ & $\mathrm{pCi} / \mathrm{L}$ & $1.9^{h}$ & NA \\
\hline 271Q125 & Liquid & Gross Alpha & $7.7 \pm 1.7$ & $\mathrm{pCi} / \mathrm{L}$ & $1.6^{\mathrm{h}}$ & NA \\
\hline 271Q125 & Liquid & Gross Beta & $31.7 \pm 4.6$ & $\mathrm{pCi} / \mathrm{L}$ & $1.9^{h}$ & NA \\
\hline
\end{tabular}

${ }^{a} Q u a l i f i e r$ added to laboratory data; record accepted. Duplicate normalized difference outside control limits,

${ }^{b}$ Qualifier added to laboratory data; record accepted. Surrogate recovery exceeded the lower limits.

${ }^{c} Q u a l i f i e r$ added to laboratory data; record accepted. Surrogates diluted out.

${ }^{\mathrm{d}}$ Qualifier added to laboratory data; record accepted. Value exceeded linear range of instrument.

${ }^{e}$ Qualifier added to laboratory data; record accepted. Inductively coupled plasma serial dilution recovery was not met.

${ }^{f} Q$ ualifier added to laboratory data; record accepted. Surrogate recovery exceeded the lower limits. Matrix effects may exist.

Relative response factor $<0.05$.

${ }^{9}$ Qualifier added to laboratory data; record accepted. The required final volume concentration could not be met so adequate surrogate recoveries were not achievable. Internal standard area count exceeded the quality control limits. Matrix effects may exist.

${ }^{\mathrm{h}}$ Maximum detectable concentration

** $=$ TCLP below minimum reporting limit

$E=$ Estimate, result outside linear range of instrument

$\mathrm{F}=$ No limit established $(\mathrm{BN}, 1995)$

$\mathrm{J}=$ Estimated value

$M=$ Motor oil

$\mathrm{NA}=$ Not applicable

$Z=$ The reported result did not resemble the patterns of the following petroleum hydrocarbon products: gasoline, JP-4, JP-8,

diesel, mineral spirit, motor oil, Stoddard solvent and Bunker $\mathrm{C}$

$\mathrm{LT}=$ Result is less than requested minimum detectable concentration (MDC), greater than sample MDC 
concentrations above the PAL of $1,000 \mu \mathrm{g} / \mathrm{kg}$. The TPH DRO and GRO exceed the regulatory action level of $100 \mathrm{mg} / \mathrm{kg}$ (NAC, 2000), the PCB results exceed the $50 \mathrm{ppm}$ regulatory level (CFR, 2000b), and the U-234/235/238 exceed the POC release levels (BN, 1995).

Polychlorinated biphenyls are the only COC in leachfield soil. Concentrations above the PAL of $1,000 \mu \mathrm{g} / \mathrm{kg}$ were detected in surface and subsurface soil at locations along the eastern edge of the leachfield, particularly near the southeast corner. Concentrations are greatest in surface soil and generally decrease with depth.

The soil surrounding the distribution box and the septic tank does not contain any analytes in concentrations above PALs.

\section{A.17.5 Nature and Extent of Contamination}

Total petroleum hydrocarbons, uranium, and PCBs are located within the septic tank in the sludge. An approximately 2-ft thick layer (155 gal) of sludge and 681 gal of liquid remains in the inlet chamber of the tank. No sludge is present in the outlet chamber of the tank. Approximately 239 gal of liquid remained in the outlet chamber of the septic tank. Approximately 2 in. (5 gal) of sludge coats the bottom of the distribution box.

Approximately $1,800 \mathrm{yd}^{3}$ of PCB contaminated soil is present in the CAS 27-05-02 leachfield. This is a very conservative volume calculation. Of this estimate, approximately $140 \mathrm{yd}^{3}$ of soil are located between the surface and $1 \mathrm{ft}$ bgs within the fenced leachfield boundaries. In the southwest portion of the leachfield, within the fenced boundaries, approximately $321 \mathrm{yd}^{3}$ of contaminated soil is located from 1 to $9.5 \mathrm{ft}$ bgs.

\section{A.17.6 Revised Conceptual Model}

Elevated levels of PCBs were detected in the contents of the septic tank and distribution box, and PCBs have been detected in soil at the leachrock/native soil interface. However, the results of step-out sampling indicate an additional source of PCBs at CAS 27-05-02. This source may have been present at the ground surface, since concentrations are greatest at the surface and generally decrease with depth at two locations. Possible sources of PCBs in the soil immediately west of the Building 5200 storage yard are a surface spill or contaminated fill. Electrical transformers are present on power poles associated with an overhead power line located along the eastern edge of the leachfield. 


\section{A.18.0 Waste Management}

Corrective Action Unit 271 integrated waste minimization into the field activities. Investigationderived waste was segregated to the greatest extent possible. Controls were in place to minimize the use of hazardous materials and the unnecessary generation of hazardous and/or mixed waste.

Decontamination activities were planned and executed to minimize the volume of rinsate generated.

Potentially hazardous waste generated during the investigation was placed in 55-gal steel drums and labeled as "Hazardous Waste - Pending Analysis." Fifteen Hazardous Waste Accumulation Areas (HWAAs) were established to manage the waste at the investigation areas. The amount, type, and source of waste placed into each drum were recorded in waste management logbooks at each location.

\section{A.18.1 Characterization}

Analytical results for each drum of waste or associated samples were reviewed to ensure compliance with federal regulations, state regulations, DOE directives/policies, guidance, waste disposal criteria, and ITLV Standard Quality Practices. Analytical data were reviewed through Tier I, II, and III validation.

\section{A.18.2 Waste Streams}

Newly generated IDW was segregated into the following waste streams:

- Personal protective equipment and disposable sampling equipment

- Decontamination rinsate

- Debris including, but not limited to, plastic sheeting, glass/plastic sample jars, PPE, soil, wood, sampling scoops, aluminum foil, and bowls

\section{A.18.3 IDW Generated}

To date, a total of 61 drums of IDW and one satellite accumulation area were generated during the investigation. 
- Eight drums of IDW were characterized as hydrocarbon waste exceeding the regulatory threshold established by State of Nevada regulations (NDEP, 1997b). The recommended disposal of these drums is at the permitted NTS Hydrocarbon Landfill. Hydrocarbon Waste was generated at CASs 25-04-01, 25-04-03, 25-04-04, 25-04-08, 25-04-09, 25-04-11, and 26-05-04.

- One satellite accumulation area for storage of aerosol cans associated with the field investigation was hazardous.

- Fifty-two drums were characterized as sanitary waste and recommended for disposal at the NTS permitted sanitary facilities. These drums were generated at all CASs.

- Additional waste (e.g., decontamination pad liners) may be generated during completion of waste management activities and closure of HWAAs.

\section{A.18.3.1 Waste Management Samples}

Waste management samples were collected from drummed waste, as necessary, to facilitate full characterization of the waste for disposal. Select drums of rinsate were sampled, based on analytical results from associated media samples, to determine the concentrations of chemical constituents and/or radiological isotopes present in the associated IDW. 


\section{A.19.0 Quality Assurance}

This section contains a summary of QA/QC measures implemented during the sampling and analysis activities conducted in support of the CAU 271 corrective action investigation. The following sections discuss the data validation process, QC samples, and nonconformances. The evaluation of the DQIs is presented in Appendix B.

Laboratory analyses were conducted for samples used in the decision-making process to provide a quantitative measurement of any COPCs present. Rigorous QA/QC was implemented for all laboratory samples including documentation, verification and validation of analytical results, and affirmation of DQI requirements related to laboratory analysis. Detailed information regarding the QA program is contained in the Industrial Sites QAPP (DOE/NV, 1996).

\section{A.19.1 Data Validation}

Data validation was performed in accordance with the Industrial Sites QAPP (DOE/NV, 1996) and approved protocols and procedures. All laboratory data from samples collected and analyzed for CAU 271 were evaluated for data quality according the EPA Functional Guidelines (EPA, 1994 and 1999). These guidelines are implemented in a tiered process and are presented in Section A.19.1.1 to Section A.19.1.3. Data were reviewed to ensure that samples were appropriately processed and analyzed, and the results passed data-validation criteria. Documentation of the data qualifications resulting from these reviews is retained in project files as a hard copy and electronic media.

One hundred percent of the data analyzed as part of this investigation were subjected to Tier I and Tier II evaluations. A Tier III evaluation was performed on five percent of the data analyzed.

\section{A.19.1.1 Tier I Evaluation}

Tier I evaluation for chemical and radiochemical analysis examines, but is not limited to:

- Sample count/type consistent with chain of custody

- Analysis count/type consistent with chain of custody

- Correct sample matrix

- Significant problems stated in cover letter or case narrative

- Completeness of certificates of analysis 
- Completeness of Contract Laboratory Program (CLP) or CLP-like packages

- Completeness of signatures, dates, and times on chain of custody

- Condition-upon-receipt variance form included

- Requested analyses performed on all samples

- Date received/analyzed given for each sample

- Correct concentration units indicated

- Electronic data transfer supplied

- Results reported for field and laboratory QC samples

- Whether or not the deliverable met the overall objectives of the project

\section{A.19.1.2 Tier II Evaluation}

Tier II evaluation for chemical and radiochemical analysis examines, but is not limited to:

\section{Chemical:}

- Correct detection limits achieved

- Sample date, preparation date, and analysis date for each sample

- Holding time criteria met

- Quality control batch association for each sample

- Cooler temperature upon receipt

- Sample $\mathrm{pH}$ for aqueous samples, as required

- Detection limits properly adjusted for dilution, as required

- Blank contamination evaluated and applied to sample results/qualifiers

- $\quad$ MS/MSD percent recoveries (\%R) and relative percent differences (RPDs) evaluated and applied to laboratory results/qualifiers

- Field duplicate RPDs evaluated using professional judgement and applied to laboratory results/qualifiers

- Laboratory duplicate RPDs evaluated and applied to laboratory results/qualifiers

- $\quad$ Surrogate $\% \mathrm{R}$ evaluated and applied to laboratory results/qualifiers

- Laboratory control sample \%R evaluated and applied to laboratory results/qualifiers

- Initial and continuing calibration evaluated and applied to laboratory results/qualifiers

- Internal standard evaluation

- Mass spectrometer tuning criteria

- Organic compound quantitation

- Inductively coupled plasma interference check sample evaluation 
- Graphite furnace atomic absorption quality control

- Inductively coupled plasma serial dilution effects

- Recalculation of 10 percent of laboratory results from raw data

\section{Radioanalytical:}

- Correct detection limits achieved

- Blank contamination evaluated and, if significant, qualifiers are applied to sample results

- Certificate of Analysis consistent with data package documentation

- Quality control sample results (duplicates, laboratory control samples, laboratory blanks) evaluated and used to determine laboratory result qualifiers

- Sample results, uncertainty, and minimum detectable concentration evaluated

- Detector system calibrated with National Institute for Standards and Technology (NIST)traceable sources

- Calibration sources preparation was documented, demonstrating proper preparation and appropriateness for sample matrix, emission energies, and concentrations

- Detector system response to daily or weekly background and calibration checks for peak energy, peak centroid, peak full-width half-maximum, and peak efficiency, depending on the detection system

- Tracers NIST-traceable, appropriate for the analysis performed, and recoveries that met QC requirements

- Documentation of all QC sample preparation complete and properly performed

- Spectra lines, photon emissions, particle energies, peak areas, and background peak areas support the identified radionuclide and its concentration

\section{A.19.1.3 Tier III}

The Tier III review is an examination of the Tier II evaluation. The Tier III review duplicates the Tier II review for a limited number of samples (typically 5 percent) and includes the following additional evaluations:

\section{Chemical:}

- Recalculation of all laboratory results from raw data 


\section{Radioanalytical:}

- QC sample results (e.g., calibration source concentration, percent recovery, and RPD) verified

- Radionuclides and their concentration validated as appropriate considering their decay schemes, half-lives, and process knowledge and history of the facility and site

- Each identified line in spectra verified against emission libraries and calibration results

- Independent identification of spectra lines, area under the peaks, and quantification of radionuclide concentration in a random number of sample results

A Tier III review of at least five percent of the sample analytical data was performed by TechLaw, Inc., of Lakewood, Colorado, and Laboratory Data Consultants, Inc., of Carlsbad, California. The Tier III review identified arsenic and chromium samples that did not require the "J" qualifier at CAS 26-05-03. The "J" qualifier was also determined unnecessary for several chromium samples at CAS 26-05-04. It was also determined that the laboratory did not correct the raw data as they usually do; and therefore, the reported barium and chromium values for three samples were 100 times less than should have been reported. Closure decisions were not affected by these modifications.

\section{A.19.2 Field Quality Control Samples}

A total of 146 trip blanks, 22 equipment rinsate blanks, 18 field blanks, 3 source blank, 33 MS/MSDs, and 34 field duplicates were collected and submitted for laboratory analysis as listed in the sample tables of Section A.3.0 through Section A.17.0 The blanks and duplicates were assigned individual sample numbers and sent to the laboratory "blind." Additional samples were selected by the laboratory to be analyzed as laboratory duplicates. Documentation related to the collection and analyses of these samples is retained in project files. The minimum requirements set forth in the Industrial Sites QAPP (DOE/NV, 1996) and the CAIP (DOE/NV, 2001) for collecting field QC samples were met.

Field blanks, source blanks, and equipment rinsate blanks were analyzed for the parameters listed in the sample tables in Section A.3.0 through Section A.17.0. Trip blanks were only analyzed for VOCs. There were no environmental samples rejected or deemed unusable based on the results of field-collected blank analytical data. 
Field duplicate samples were sent as blind samples to the laboratory to be analyzed for the investigation parameters listed in the sample tables in Section A.3.0 through Section A.17.0. The review and discussion of field duplicates and MS/MSD results as they apply to precision and/or accuracy is presented in Appendix B.

\section{A.19.2.1 Laboratory Quality Control Samples}

Analysis of surrogate spikes (for organic analyses), method blanks, preparation blanks (for chemical analyses), initial and continuing calibration blanks (for total metals), and laboratory control samples were performed for each sample delivery group (SDG) by Paragon Analytics, Inc. and EMAX Laboratories, Inc. The results of these analyses were used to qualify associated environmental sample results according to EPA Functional Guidelines (EPA, 1994 and 1999). Documentation of data qualifications resulting from the application of these guidelines is retained in project files as both hard copy and electronic media.

One laboratory duplicate analysis for metals was performed for each SDG that reported total metals. The duplicate results are compared to the original sample results to provide a measure of analytical laboratory precision. A more detailed discussion of the laboratory QC samples as they relate to precision and accuracy is presented in Appendix B.

\section{A.19.3 Field Nonconformances}

Seven field surveillances (OTS \#s 2277, 2283, 2328, 2432, 2501, 2962, and 3065) were conducted for this CAI by the DOE National Nuclear Security Administration Nevada Operations Office (NNSA/NV), Environmental Restoration Division (ERD). Five of the surveillances resulted in no-findings. One (OTS\# 2432) found that ITLV was not following the CAU 271 SSHASP. The NNSA/NV Environment Safety and Health Division (ESHD) determined that field personnel were following standard field practices but were not following what was listed in the SSHASP. This resulted in a technical change (Technical Change 4) to the SSHASP. Another NNSA/NV field surveillance found that soil from an excavation at CAS 25-04-04 was not stock piled on plastic, although TPH was present above PALs. The ITLV Task Manager notified the field crew; and subsequently, excavated soil with suspected contamination above PALs was staged on plastic sheeting. 
The NNSA/NV ERD and ESHD also conducted an assessment of the CAU 271 Real Estate/ Operations Permit (OTS \# 2179). The assessment resulted in six minor findings. Changes to address each of the findings were implemented.

During the CAI, one QA surveillance was conducted by ITLV personnel to verify that sampling activities were performed in accordance with applicable requirements. The surveillance did not result in any findings, deficiencies, or nonconformances.

The requirements of the plans and procedures governing the activities at the CAU 271 sites were met.

\section{A.19.4 Laboratory Nonconformances}

Laboratory nonconformances are generally due to inconsistencies in analytical instrumentation operation, sample preparations, extractions, missed holding times, and fluctuations in internal standard and/or calibration results. Several laboratory nonconformances were documented for this project. All nonconformances have been accounted for in the data qualification process and discussed in Appendix B in reference to rejected data. Documentation of these results is retained in project files. 


\section{A.20.0 Summary}

Analytes detected in soil samples during the CAI were evaluated against PALs to determine the nature and extent of COCs for CAU 271. Assessment of the data generated from CAI activities indicates the PALs were exceeded in soil samples at several CAU 271 CASs. Arsenic values exceeded PALs for many of the soil samples collected for CAU 271; however, the concentrations of arsenic are considered ambient at the investigated sites. Analyte concentrations detected in the septic tank and distribution box contents were evaluated against regulatory levels based on disposal options. The following summarizes the results for CASs where soil data exceeded PALs and septic tank/distribution box content data exceeded regulatory levels.

CAS 25-04-01. Several COPCs were detected in the septic tank sludge samples. Most COPCs were below regulatory limits except for TPH. Concentrations of diesel and gasoline TPH exceeded the NDEP action level of $100 \mathrm{mg} / \mathrm{kg}$ (NAC, 2000).

CAS 25-04-03. Contaminants of concern are present in the septic tank and soil under the leachfield. The septic tank contains sludge with TPH DRO analytes in concentrations above the regulatory action level of $100 \mathrm{mg} / \mathrm{kg}$. The TPH DRO is the only COC for the septic tank. A positive result for fecal coliform bacteria was obtained for the septic tank contents at this CAS. The soils under the leachfield may contain benzo(a)pyrene in concentrations above PALs; however, because this leachfield contains "Orangeburg" pipe, it is possible that the results may be related to the presence of fragments of pipe in soil samples. No COCs were identified in the soil surrounding the septic tank.

CAS 25-04-04. Contaminants of concern are present in the septic tank and soil immediately north of the influent end of the septic tank. The soil in this area contain TPH DRO in concentrations above PALs. It is possible that the contamination is unrelated to the operation of the septic system. The source may be a leaking collection system pipe or possibly a surface spill or contaminated fill. No COCs were identified in the soil under the leachfield. Total petroleum hydrocarbons (DRO and GRO) are present in sludge in the influent chamber of the septic tank at concentrations greater than the NDEP action level of $100 \mathrm{mg} / \mathrm{kg}$. Free product is floating on the surface of the liquid in the influent chamber. Additionally, TPH DRO, total chlordane, and U-234 were detected above 
regulatory limits in sludge in the effluent chamber of the tank. A positive result for fecal coliform bacteria was obtained for the septic tank contents at this CAS.

CAS 25-04-08. Contaminants of concern are present in the septic tank and possibly a small area of soil. Septic tank sludge samples contain TPH DRO analytes in concentrations above the regulatory action level of $100 \mathrm{mg} / \mathrm{kg}$. Plutonium-239 was detected above the PAL in one soil sample at the southern end of the leachfield. It was not detected in samples collected from step-out locations.

CAS 25-04-09. Contaminants of concern are present in the septic tank. The septic tank sediment contains TPH DRO in concentrations above the regulatory action level of $100 \mathrm{mg} / \mathrm{kg}$. No COCs were identified in the soil surrounding the septic tank or the soil underlying the leachfield.

CAS 25-04-10. Contaminants of concern were not detected in soil surrounding the septic tank and distribution box, or in soil underlying the leachfield. The septic tank was empty.

CAS 25-04-11. Contaminants of concern are present in the septic tank, the manhole immediately upstream (north) of the tank, and in a small area of soil under the leachfield. The septic tank and location G35 Manhole contain sludge/sediment with TPH DRO analytes in concentrations above the regulatory action level of $100 \mathrm{mg} / \mathrm{kg}$. This is the only analyte exceeding regulatory disposal limits and, therefore, the only COC for the septic tank and manhole. The soils under the leachfield may contain benzo(a)pyrene in concentrations above PALs; however, because this leachfield contains "Orangeburg" pipe, it is possible that the results may be related to the presence of fragments of pipe in soil samples. No COCs were identified in the soil surrounding the septic tank.

CAS 26-03-01. Radiological COCs are present in the soil above the liner at the contaminated water reservoir. The soil contains lead-214 and thorium-227 (and by association, actinium-227) in concentrations above PALs and statistically distinguishable from background concentrations.

CAS 26-04-01. Contaminants of concern are present in the septic tank only. The septic tank contains cesium-137 and Pu-239 in concentrations above the POC. No COCs were identified within the distribution box, in the soil surrounding the septic tank, or under the leachfield.

CAS 26-04-02. Contaminants of concern are present in the septic tank. A small volume of dry sediment in the septic tank contains TPH DRO analytes in concentrations exceeded the regulatory 
action level of $100 \mathrm{mg} / \mathrm{kg}$. No COCs were identified in the soil surrounding the septic tank or in the soil underlying the leachfield.

CAS 26-05-01. Contaminants of concern are present in the manhole nearest the leachfield (Manhole 1) and in soil in a small area of the leachfield immediately south of the distribution box. The pipe at Manhole 1 contains a small amount of sediment with TPH DRO analytes, U-234, U-235, cesium-137, and Pu-239 above regulatory action levels or established disposal criteria. The manhole is the location of a sharp (75-degree) bend in the effluent line, and it appears that some sediment accumulated at this location. Leachfield soil near the distribution box contains $\mathrm{Pu}-239, \mathrm{U}-234$, and U-235 in concentrations above PALs. Data obtained at several inspection points along the collection system pipeline indicate that radiological levels of the system do not exceed limits for unrestricted release.

CAS 26-05-03. Contaminants of concern are present in the septic tank and a collection system manhole. A small volume of dry sediment in a composite sample from the septic tank and manhole contains TPH DRO in concentrations that exceed the regulatory action level of $100 \mathrm{mg} / \mathrm{kg}$. No COCs were identified in the soil surrounding the septic tank or in the soil underlying the leachfield. Data obtained at several inspection points along the collection system pipeline indicate that radiological levels of the system do not exceed limits for unrestricted release.

CAS 26-05-04. Contaminants of concern are present in the septic tank. The influent and effluent chambers of the septic tank contain sludge with TPH DRO and GRO concentrations exceeding the regulatory action level of $100 \mathrm{mg} / \mathrm{kg}$. A positive result for fecal coliform bacteria was obtained for the septic tank contents at this CAS. No COCs were identified in the soil surrounding the septic tank or in the soil underlying the leachfield.

CAS 26-05-05. This CAS includes two septic systems that share a common collection system. Contaminants of concern are present in both septic tanks and in a small area of soil in the leachfield. Septic tank 1 contains sludge with TPH DRO and GRO above the regulatory action level of $100 \mathrm{mg} / \mathrm{kg}$. Septic tank 2 contains a small volume of sediment with TPH DRO and mercury, a RCRA metal, above regulatory levels. Plutonium-239, U-234, and U-235 were also identified within septic tank 2 at levels above established disposal criteria. One location in the leachfield contained soil with 
TPH DRO analytes in concentrations above the PAL. No COCs were identified in the soil surrounding the septic tanks or distribution boxes.

CAS 27-05-02. Contaminants of concern are present in the septic tank, distribution structure, and in leachfield soil. Sludge in the septic tank and distribution structure contain TPH, exceeding the action levels, PCBs above the Federal regulatory level, and radioisotopes above the landfill levels. Concentrations of PCBs exceeding the PAL of $1,000 \mu \mathrm{g} / \mathrm{kg}$ were detected in surface and subsurface soil at locations along the eastern edge of the leachfield, particularly near the southeast corner. Concentrations are greatest in surface soil samples and generally decrease with depth. This PCB contamination appears to be unrelated to the operation of the septic system. The source may be a surface spill or contaminated fill. No COCs were identified in the soil surrounding the septic tank and distribution box. 


\section{A.21.0 References}

Alderson, S.L., IT Corporation. 1999. Memorandum to D. Wilson (Science Applications International Corporation), "Response to State of Nevada Division of Environmental Protection Comments Concerning Corrective Action Units (CAUs) 261, 266, and 500," 27 August.

Las Vegas, NV.

American Society for Testing and Materials. 1995. Standard Test Method for Strontium-90 in Water, ASTM D 5811-95. West Conshohocken, PA.

American Society for Testing and Materials. 1997a. Standard Test Method for Isotopic Uranium in Water by Radiochemistry, ASTM D 3972-97. West Conshohocken, PA.

American Society for Testing and Materials. 1997b. Standard Test Method for Plutonium in Water, ASTM D 3865-97. West Conshohocken, PA.

American Society for Testing and Materials. 2000a. Standard Test Method for Radiochemical Determination of Plutonium in Soil by Alpha Spectroscopy, ASTM C 1001-90.

West Conshohocken, PA.

American Society for Testing and Materials. 2000b. Standard Test Method for Radiochemical Determination of Uranium in Soil by Alpha Spectroscopy, ASTM C 1000-90.

West Conshohocken, PA.

ASTM, see American Society for Testing and Materials.

Bechtel Nevada. 1995. Nevada Test Site Performance Objective for Certification of Nonradioactive Hazardous Waste, Rev. 0. Las Vegas, NV: Waste Management Program.

BMEC, see Burns and McDonnell Engineering Company.

BN, see Bechtel Nevada.

Burns and McDonnell Engineering Company. 1958a. As-built Engineering Drawing 2201 - SW1, entitled, "Disassembly Building General Layout and Sanitary Sewer Profile," 1 December. Mercury, NV: Archives and Records Center.

Burns and McDonnell Engineering Company. 1958b. As-built Engineering Drawing 2201 - SW4.A, entitled, "Disassembly Building Sanitary Sewer Details \#1," 1 December. Mercury, NV: Archives and Records Center. 
Burns and McDonnell Engineering Company. 1958c. As-built Engineering Drawing 2201 - SW6, entitled, "Disassembly Building Septic Tank Details," 1 December. Mercury, NV: Archives and Records Center.

Burns and McDonnell Engineering Company. 1958d. As-built Engineering Drawing 2201 - SW7.A, entitled, "Disassembly Building Hot Disposal Field Layout \& Details," 1 December. Mercury, NV: Archives and Records Center.

Burns and McDonnell Engineering Company. 1958e. As-built Engineering Drawing 2201 - SW9, entitled, "Hot Disposal Field Location \& Grading Plan," 1 December. Mercury, NV: Archives and Records Center.

Burns and McDonnell Engineering Company. 1958f. As-built Engineering Drawing 3101-SW1.2 entitled, "Control Point Area Sewer and Water Layout," 18 July. Mercury, NV: Archives and Records Center.

Burns and McDonnell Engineering Company. 1958g. As-built Engineering Drawing 3101-SW6.1 entitled, "Control Point Area Disposal Field Details," 18 July. Mercury, NV: Archives and Records Center.

Burns and McDonnell Engineering Company. 1959a. As-built Engineering Drawing 2101 - SW4.1, entitled, "Control Point Area-Sewer Plans, Profiles, and Disposal Field Layout," 2 February. Mercury, NV: Archives and Records Center.

Burns and McDonnell Engineering Company. 1959b. As-built Engineering Drawing 2101 - SW6.1, entitled, "Control Point Area-Sewer Plant Details," 2 February. Mercury, NV: Archives and Records Center.

Burns and McDonnell Engineering Company. 1960a. As-built Engineering Drawing 2105 - SW2, entitled, "Miscellaneous Structures-Check Station-Sewer and Water Layout," 8 June. Mercury, NV: Archives and Records Center.

Burns and McDonnell Engineering Company. 1960b. As-built Engineering Drawing 2105 - SW3, entitled, "Miscellaneous Structures-Check Station-Septic Tank Details," 8 June. Mercury, NV: Archives and Records Center.

Burns and McDonnell Engineering Company. 1960c. As-built Engineering Drawing 2203 - SW1.1, entitled, "Test Bunker and Miscellaneous Structures, Sewer Layout - Test Bunker \& Head House," 30 November. Mercury, NV: Archives and Records Center.

Burns and McDonnell Engineering Company. 1960d. As-built Engineering Drawing 2203 - SW5, entitled, "Test Bunker and Miscellaneous Structures, Sewage Plant Details," 30 November. Mercury, NV: Archives and Records Center.

CFR, see Code of Federal Regulations. 
Code of Federal Regulations. 2000a. Title 40 CFR 141.66, "Maximum Contaminant Levels for Radionuclides." Washington, DC: U.S. Government Printing Office.

Code of Federal Regulations. 2000b. Title 40 CFR 260-282, "Hazardous Waste Management." Washington, DC: U.S. Government Printing Office.

Code of Federal Regulations. 2000c. Title 40 CFR 761, "Polychlorinated Biphenyls."

Washington, DC: U.S. Government Printing Office.

Davidson, J.R., Jr., and J.E. Wildon. 1999. Visual Sample Plan, Previes Version 0.9f. Developed by Oak Ridge and Pacific Northwest National Laboratories. Oak Ridge, CA.

DOE/NV, see U.S. Department of Energy, Nevada Operations Office.

Desert Research Institute. 1988. CERCLA Preliminary Assessment of DOE's Nevada Operations Office Nuclear Weapons Testing Areas, Vol. 1. Las Vegas, NV.

DRI, see Desert Research Institute.

EPA, see U.S. Environmental Protection Agency.

FFACO, see Federal Facility Agreement and Consent Order.

Federal Facility Agreement and Consent Order. 1996 (as amended). Agreed to by the State of Nevada, the U.S. Department of Energy, and the U.S. Department of Defense.

Holmes \& Narver, Inc. 1962. Engineering Drawing 410-004-C10.2 entitled, "Project 410-2 Underground Utility Plan, Bldg. 5210, Site 'Baker,' Area 410,” 25 January. Los Angeles, CA.

Holmes \& Narver, Inc. 1966. Engineering Drawing JS-028-T2.8a-C7.2-M4.2 entitled, "Nevada Test Site Area 28 HENRE Trailer Park, Site Plan STA T28a, Civil Plan and Mechanical Details," 6 October. Mercury, NV: Archives and Records Center.

Holmes \& Narver, Inc. 1980. Engineering Drawing JS-026-002-C3 entitled, "Nevada Test Site Area 26, DOD 'NUWAX 81' Reservoir,” 30 December. Mercury, NV: Archives and Records Center.

IT, see IT Corporation.

IT Corporation. 2001. Site-Specific Health and Safety Plan for CAU 271, Areas 25, 26, and 27 Septic Systems, Nevada Test Site, Nevada. Las Vegas, NV.

Johnson, R.B. and J.R. Ege. 1964. Geology of the Pluto Site, Area 401, Nevada Test Site, Nye County, Nevada, USGS-TEI-841. Denver, CO: U.S. Geological Survey. 
McArthur, R.D., and F.L. Miller, Jr. 1989. Off-Site Radiation Exposure Review Project, Phase II Soil Program, DOE/NV/10384--23. Las Vegas, NV: Desert Research Institute.

Moore, J, Science Applications International Corporation. 1999. Memorandum to M. Todd (SAIC), "Background Concentrations for NTS and TTR Soil Samples," 3 February. Las Vegas, NV: IT Corporation.

NAC, see Nevada Administrative Code.

NBMG, see Nevada Bureau of Mines and Geology.

NDEP, see Nevada Division of Environmental Protection.

Nevada Administrative Code. 2000. NAC 445A.2272, "Contamination of Soil: Establishment of Action Levels." Carson City, NV.

Nevada Bureau of Mines and Geology. 1998. Mineral and Energy Resource Assessment of the Nellis Air Force Range, Open-File Report 98-1. Reno, NV.

Nevada Division of Environmental Protection. 1997a. Class II Solid Waste Disposal Site for Municipal and Industrial Solid Waste, Area 23 of the NTS, Permit SW 1309704 . Reno, NV.

Nevada Division of Environmental Protection. 1997b (as amended in August 2000). Class III Solid Waste Disposal Site for Hydrocarbon Burdened Soils, Area 6 of the NTS, Permit SW 1309702. Reno, NV.

Nevada Division of Environmental Protection. 1997c (as amended in August 2000). Class III Solid Waste Disposal Site; U10C, Area 9 of the NTS, Permit SW 1309703. Reno, NV.

Norman Engineering Co. 1961. As-built Engineering Drawing 2202A-C-10 entitled, "Site Civil Plan I," 2 October. Las Vegas, NV.

Pan Am, see Pan American World Airways, Inc.

Pan American World Airways, Inc. 1969. Engineering Drawing AUX-PAA-0009, "Security Checkpoint Trailer Layout," 20 May. Mercury, NV: Archives and Records Center.

REECo, see Reynolds Electrical \& Engineering Co., Inc.

Reynolds Electrical \& Engineering Co., Inc. 1983a. Engineering Drawing Number 25-CP-C1.1 entitled, "Existing Waste \& Sewer Layout, Control Point Area Plan (Sheet 1 of 3)," 18 March. Mercury, NV: Archives and Records Center. 
Reynolds Electrical \& Engineering Co., Inc. 1983b. Engineering Drawing Number 25-CP-C2 entitled, "Existing Waste \& Sewer Layout, Control Point Area Plan (Sheet 2 of 3)," 18 March. Mercury, NV: Archives and Records Center.

Reynolds Electrical \& Engineering Co., Inc. 1983c. Engineering Drawing Number 25-CP-C3 entitled, "Existing Waste \& Sewer Layout, Control Point Area Plan (Sheet 3 of 3)," 18 March. Mercury, NV: Archives and Records Center.

Reynolds Electrical \& Engineering Co., Inc. 1984. As-built Engineering Drawing Number 25-ETS-1-C1 entitled, "Existing Waste \& Sewer Layout, Engine Test Stand No. 1 (ETS-1) Plan (Sheet 1 of 3)," 2 February. Mercury, NV: Archives and Records Center.

Sandia National Laboratories. 1999. 1998 Annual Site Environmental Report, Tonopah Test Range, Nevada, SAND99-2279. Albuquerque, NM.

SNL, see Sandia National Laboratories.

SNPO, see Space Nuclear Propulsion Office.

Space Nuclear Propulsion Office. Date Unknown. Engineering Drawing 620-330-C-001 entitled, "ETS-1 Sewage Disposal Details." Mercury, NV: Archives and Records Center.

U.S. Department of Energy. 1997. Environmental Measurements Laboratory Procedures Manual, HASL-300, 28th Edition, Vol. 1. New York, NY.

U.S. Department of Energy, Nevada Operations Office. 1996. Industrial Sites Quality Assurance Project Plan, Nevada Test Site, Nevada, Rev. 1, DOE/NV--372. Las Vegas, NV.

U.S. Department of Energy, Nevada Operations Office. 1998. Work Plan for Leachfield Corrective Action Units: Nevada Test Site and Tonopah Test Range, Nevada, Rev. 1, DOE/NV--514. Las Vegas, NV.

U.S. Department of Energy, Nevada Operations Office. 2000a. NV/YMP Radiological Control Manual, Rev. 4, DOE/NV/11718-079. Prepared by Bechtel Nevada. Las Vegas, NV.

U.S. Department of Energy, Nevada Operations Office. 2000b. Nevada Test Site Waste Acceptance Criteria, Rev. 3, DOE/NV--325. Las Vegas, NV.

U.S. Department of Energy, Nevada Operations Office. 2001. Corrective Action Investigation Plan for Corrective Action Unit 271: Area 25, 26, and 27 Septic Systems, Nevada Test Site, Nevada, DOE/NV--704. Las Vegas, NV.

US Ecology and Atlan-Tech. 1992. Environmental Monitoring Report for the Proposed Ward Valley, California, Low-Level Radioactive Waste (LLRW) Facility. Auburn, CA. 
U.S. Environmental Protection Agency. 1980. Prescribed Procedures for Measurements of Radioactivity in Drinking Water, EPA-600/4-80-032. Cincinnati, OH.

U.S. Environmental Protection Agency. 1994. Guidance for the Data Quality Objectives Process, EPA QA/G-4. Washington, DC.

U.S. Environmental Protection Agency. 1996. Test Methods for Evaluating Solid Waste, Physical/Chemical Methods, SW-846 CD ROM PB97-501928GEI, which contains updates for 1986, 1992, 1994, and 1996. Washington, DC.

U.S. Environmental Protection Agency. 1999. Contract Laboratory Program National Functional Guidelines for Organic Data Review, EPA 540/R-99/008. Washington, DC.

U.S. Environmental Protection Agency. 2000. Region IX Preliminary Remediation Goals (PRGs). As accessed at www.epa.gov/region09/waste/sfund/prg/index.htm on 8 January 2001. Prepared by S.J. Smucker. San Francisco, CA.

USGS, see U.S. Geological Survey.

U.S. Geological Survey. 1995. Selected Ground-Water Data for Yucca Mountain Region, Southern Nevada and Eastern California, Calendar Year 1993, Open-File Report 95-158. Prepared by G.S. Hale and C.L. Westenburg. Denver, CO. 


\section{Appendix B}

\section{Data Assessment}




\section{B.1.0 Data Assessment}

The primary purpose of this section is to provide an evaluation of data quality for CAU 271 . Specifically, results of DQIs identified in the Industrial Sites Quality Assurance Project Plan (DOE/NV, 1996) (i.e., precision, accuracy, completeness, representativeness, and comparability) are compared to established criteria in relationship to predetermined DQOs. The DQO process is detailed in Appendix A of the CAU 271 CAIP (DOE/NV, 2001). This section discusses and evaluates whether DQIs meet DQO criteria. In addition, a reconciliation of the data with the general conceptual site model for each CAS within CAU 271 is provided.

\section{B.1.1 Precision}

Precision is a measure of agreement among a replicate set of measurements of the same property under similar conditions. This agreement is expressed as the RPD between duplicate measurements as defined in the Industrial Sites QAPP (DOE/NV, 1996).

Determinations of precision can be made for field samples, laboratory duplicates (LDs), or both. The field duplicate (FD) sample is treated independently of the original sample in order to assess field impacts and laboratory performance on total precision. Laboratory precision is then evaluated independent of total precision as part of the required laboratory internal QC program in order to assess the performance of analytical procedures.

The variability of results from the analysis of FDs is generally much greater than the variability of results for LDs. This is primarily because of the heterogeneity of the matrix being investigated. Higher variability for FDs also results from the increased potential to introduce factors influencing the analytical results during sampling, sample preparation, containerization, handling, packaging, preservation, and environmental conditions before the samples reach the laboratory. Laboratory QC samples assess only the variability of results introduced by sample handling and preparation in the laboratory, and that inherent in the analytical procedure. These same factors also impact FDs, resulting in an additive effect on total precision. 
The performance criterion for FD precision is given in the Industrial Sites QAPP (DOE/NV, 1996). The performance criteria for assessing analytical method precision are specified in the Leachfield Work Plan (DOE/NV, 1998) or are laboratory-specific.

\section{B.1.1.1 Precision for Chemical Analyses}

Precision for the measurement of target compounds or analytes collected at CAU 271 was determined by MSDs, laboratory control sample duplicates (LCSDs), and FDs for EPA methods 8260B VOCs, 1311/8260B TCLP VOCs, 8270C SVOCs, 1311/8270C TCLP SVOCs, 8015B TPH DRO and GRO, 8082 PCBs, 8081A Pesticides, 8151A Chlorinated Herbicides, 6010B TCLP metals, 1311/6010B metals, 7470A/7471A mercury, and 1311/7470A TCLP mercury. In addition, LDs were performed for inorganic analyses per SW-846 specifications (EPA, 1996). For the purpose of determining data precision for CAU 271, all water and soil samples including field QC samples (e.g., trip blanks, equipment rinsate samples, field blanks) were evaluated and incorporated into the precision calculation. Table B.1-1 and Table B.1-2 present the total number of measurements analyzed, the number of measurements within the specified criteria, and the percentage of measurements that met the precision criteria. The percent of acceptable precision measurements was determined by taking the number of measurements within criteria, dividing by the total number of measurements analyzed, and multiplying by 100 .

Relative percent difference values for organic and inorganic analyses that are within the established control criteria indicate that analytical results for associated samples are valid with respect to precision data quality. Relative percent difference values that are outside the criteria for organic analyses do not necessarily result in the qualification of analytical data. It is only one factor considered when making overall judgements about the quality of the reported analytical results. Relative percent difference values for inorganic analyses outside the established control criteria do result in the qualification of associated analytical results as estimated. Out of control RPD values do not necessarily indicate that the data are not useful for the purpose intended; however, it is an indication data precision should be considered for the overall assessment of the data quality and potential impact on achieving project characterization objectives.

Precision criteria for organic and inorganic analyses met established objectives and satisfied the DQOs. Data quality indicator (e.g., precision, accuracy) objectives are evaluated within the data 
Table B.1-1

\section{Chemical Analysis Precision Measurements for CAU 271}

(Page 1 of 2)

\begin{tabular}{|c|c|c|c|c|c|c|c|c|c|c|}
\hline & \multicolumn{7}{|c|}{ ORGANICS } & \multicolumn{3}{|c|}{ INORGANICS } \\
\hline & VOCs & SVOCs & $\begin{array}{l}\text { TPH- } \\
\text { DRO }\end{array}$ & $\begin{array}{l}\text { TPH- } \\
\text { GRO }\end{array}$ & PCBs & Pesticides & Herbicides & Metals $^{\mathbf{a}}$ & Beryllium & Mercury \\
\hline \multicolumn{11}{|c|}{ Matrix Spike Duplicate Precision } \\
\hline $\begin{array}{l}\text { Total Number of MSD } \\
\text { Measurements }\end{array}$ & 225 & 484 & 57 & 44 & 6 & 66 & 10 & 171 & 8 & 24 \\
\hline $\begin{array}{l}\text { Total Number of RPDs } \\
\text { within Criteria }\end{array}$ & 224 & 484 & 55 & 41 & 6 & 66 & 10 & 169 & 8 & 24 \\
\hline $\begin{array}{l}\text { Percent Acceptable MSD } \\
\text { Measurements }\end{array}$ & 99.6 & 100 & 96.49 & 93.18 & 100 & 100 & 100 & 98.83 & 100 & 100 \\
\hline \multicolumn{11}{|c|}{ Laboratory Control Sample Duplicate Precision } \\
\hline $\begin{array}{l}\text { Total Number of LCSD } \\
\text { Measurements }\end{array}$ & 480 & 715 & 61 & 72 & 133 & 90 & 16 & 382 & 27 & 47 \\
\hline $\begin{array}{l}\text { Total Number of RPDs } \\
\text { within Criteria }\end{array}$ & 480 & 715 & 60 & 72 & 133 & 90 & 16 & 382 & 27 & 47 \\
\hline $\begin{array}{l}\text { Percent Acceptable LCSD } \\
\text { Measurements }\end{array}$ & 100 & 100 & 98.36 & 100 & 100 & 100 & 100 & 100 & 100 & 100 \\
\hline \multicolumn{11}{|c|}{ Field Duplicate Precision } \\
\hline $\begin{array}{l}\text { Total Number of FD } \\
\text { Measurements }\end{array}$ & 1,446 & 1,829 & 29 & 26 & 161 & 63 & 10 & 183 & 12 & 26 \\
\hline $\begin{array}{l}\text { Total Number of RPDs } \\
\text { within Criteria }\end{array}$ & 1,436 & 1,814 & 26 & 25 & 160 & 63 & 10 & 165 & 11 & 21 \\
\hline $\begin{array}{l}\text { Percent Acceptable FD } \\
\text { Measurements }\end{array}$ & 99.31 & 99.18 & 89.66 & 96.15 & 99.38 & 100 & 100 & 90.16 & 91.67 & 80.77 \\
\hline
\end{tabular}


Table B.1-1

Chemical Analysis Precision Measurements for CAU 271

(Page 2 of 2)

\begin{tabular}{|c|c|c|c|c|c|c|c|c|c|c|}
\hline & \multicolumn{7}{|c|}{ ORGANICS } & \multicolumn{3}{|c|}{ INORGANICS } \\
\hline & VOCs & SVOCs & $\begin{array}{l}\text { TPH- } \\
\text { DRO }\end{array}$ & $\begin{array}{l}\text { TPH- } \\
\text { GRO }\end{array}$ & PCBs & Pesticides & Herbicides & Metals ${ }^{a}$ & Beryllium & Mercury \\
\hline \multicolumn{11}{|c|}{ Laboratory Sample Duplicate (Lab-Dup) Precision } \\
\hline $\begin{array}{l}\text { Total Number of Lab-Dup } \\
\text { Measurements }\end{array}$ & NA & NA & NA & NA & NA & NA & NA & 290 & 22 & 38 \\
\hline $\begin{array}{l}\text { Total Number of RPDs } \\
\text { within Criteria }\end{array}$ & NA & NA & NA & NA & NA & NA & NA & 286 & 22 & 37 \\
\hline $\begin{array}{l}\text { Percent Acceptable Lab-Dup } \\
\text { Measurements }\end{array}$ & NA & NA & NA & NA & NA & NA & NA & 98.62 & 100 & 97.37 \\
\hline
\end{tabular}

${ }^{a}$ Arsenic, Barium, Cadmium, Chromium, Lead, Selenium, and Silver

$\mathrm{NA}=$ Not applicable 
Table B.1-2

Toxicity Characteristic Leaching Procedure Precision Measurements for CAU 271

\begin{tabular}{|c|c|c|c|c|c|}
\hline & \multicolumn{2}{|c|}{ ORGANICS } & \multicolumn{3}{|c|}{ INORGANICS } \\
\hline & $\begin{array}{l}\text { TCLP } \\
\text { VOCs }\end{array}$ & $\begin{array}{l}\text { TCLP } \\
\text { SVOCs }\end{array}$ & $\begin{array}{c}\text { TCLP } \\
\text { Metals }^{\mathrm{a}}\end{array}$ & Beryllium & $\begin{array}{c}\text { TCLP } \\
\text { Mercury }\end{array}$ \\
\hline \multicolumn{6}{|c|}{ TCLP Matrix Spike Duplicate Precision } \\
\hline $\begin{array}{l}\text { Total Number of MSD } \\
\text { Measurements }\end{array}$ & 70 & 0 & 63 & 0 & 7 \\
\hline $\begin{array}{l}\text { Total Number of RPDs } \\
\text { within Criteria }\end{array}$ & 68 & 0 & 63 & 0 & 7 \\
\hline Percent acceptable MSD Measurements & 97.14 & NA & 100 & NA & 100 \\
\hline \multicolumn{6}{|c|}{ TCLP Laboratory Control Sample Duplicate Precision } \\
\hline Total Number of LCSD & 90 & 120 & 91 & 0 & 9 \\
\hline $\begin{array}{l}\text { Total Number of RPDs } \\
\text { within Criteria }\end{array}$ & 89 & 119 & 91 & 0 & 9 \\
\hline Percent acceptable LCSD Measurements & 98.89 & 99.17 & 100 & NA & 100 \\
\hline \multicolumn{6}{|c|}{ TCLP Field Duplicate Precision } \\
\hline Total Number of FD Measurements & 10 & 12 & 14 & 1 & 2 \\
\hline $\begin{array}{l}\text { Total Number of RPDs } \\
\text { within Criteria }\end{array}$ & 10 & 12 & 14 & 1 & 2 \\
\hline Percent acceptable FD Measurements & 100 & 100 & 100 & 100 & 100 \\
\hline \multicolumn{6}{|c|}{ TCLP Laboratory Sample Duplicate (Lab-Dup) Precision } \\
\hline $\begin{array}{l}\text { Total Number of Lab-Dup } \\
\text { Measurements }\end{array}$ & NA & NA & 70 & 1 & 8 \\
\hline $\begin{array}{l}\text { Total Number of RPDs } \\
\text { within Criteria }\end{array}$ & NA & NA & 70 & 1 & 8 \\
\hline Percent Acceptable Lab-Dup Measurements & NA & NA & 100 & 100 & 100 \\
\hline
\end{tabular}

\footnotetext{
${ }^{a}$ Arsenic, Barium, Cadmium, Chromium, Lead, Selenium, and Silver
} 
quality objective process and establish the usefulness of the collected data. Criteria are determined based upon data quality needs. If criteria are satisfied, as is the case for the field and laboratory precision, then a part of the data quality evaluation has met predetermined objectives. Other data quality indicators are summarized later in this section with respect to the DQO process.

\section{B.1.1.2 Precision for Radiochemical Analysis}

The precision of radiochemical measurements is evaluated by measuring two aliquots of a sample and comparing the results. Table B.1-3 presents results of FDs, while Table B.1-4 presents the results of the laboratory precision for duplicate aliquots. For the purpose of determining data precision of sample analyses for CAU 271, all water and soil duplicates were evaluated and incorporated into Table B.1-3. A LD (Table B.1-4) is measured with every batch of samples analyzed by the laboratory. The duplicate precision is evaluated using the RPD or normalized difference (ND). The RPD is applicable when both the sample and its duplicate have concentrations of the target radionuclide exceeding five times their minimum detectable concentration. This excludes many measurements because samples often contain non-detectable or low levels of the target radionuclide. In situations where the RPD does not apply, duplicate results are evaluated using the ND which is expressed by:

$$
\text { Normalized Difference }=\frac{\mathrm{S}-\mathrm{D}}{\sqrt{\left(\mathrm{TPU}_{\mathrm{S}}\right)^{2}+\left(\mathrm{TPU}_{\mathrm{D}}\right)^{2}}}
$$

$$
\begin{aligned}
& \text { Where: } \\
& \begin{array}{ll}
\mathrm{S} & =\text { Sample result } \\
\mathrm{D} & =\text { Duplicate Result } \\
\mathrm{TPU}_{\mathrm{S}} & =2 \sigma \mathrm{TPU} \text { of the sample } \\
\mathrm{TPU}_{\mathrm{D}} & =2 \sigma \mathrm{TPU} \text { of the duplicate } \\
\sigma & =\text { Standard deviation }
\end{array}
\end{aligned}
$$

The control limit for the normalized difference is -1.96 to 1.96 , which represents a confidence level of 95 percent.

Radioanalytical samples are qualified based on laboratory-prepared duplicates, but not FDs or MSDs. As with chemical analysis, a duplicate comparison that is outside control limits is an indication data precision should be considered for the overall assessment of the data quality and its potential impact 
Table B.1-3

Laboratory Results for Field Duplicates of Radioanalytes

\begin{tabular}{|c|c|c|c|}
\hline & Number within Criteria & Number Performed & $\%$ Precision \\
\hline \multicolumn{4}{|c|}{ Gamma Spectrometry Field Duplicate } \\
\hline RPD & 54 & 55 & 98 \\
\hline Normalized Difference & 842 & 842 & 100 \\
\hline \multicolumn{4}{|c|}{ Isotopic Uranium Field Duplicate } \\
\hline RPD & 43 & 45 & 96 \\
\hline Normalized Difference & 24 & 24 & 100 \\
\hline \multicolumn{4}{|c|}{ Isotopic Plutonium Field Duplicate } \\
\hline RPD & 1 & 1 & 100 \\
\hline Normalized Difference & 43 & 43 & 100 \\
\hline \multicolumn{4}{|c|}{ Strontium-90 Field Duplicate } \\
\hline RPD & 0 & 0 & NA \\
\hline Normalized Difference & 21 & 22 & 95 \\
\hline \multicolumn{4}{|c|}{ Tritium Field Duplicate } \\
\hline RPD & 0 & 0 & NA \\
\hline Normalized Difference & 2 & 2 & 100 \\
\hline
\end{tabular}

$\mathrm{NA}=$ Not applicable

Table B.1-4

Laboratory Precision for Radioanalytes

(Page 1 of 2)

\begin{tabular}{|c|c|c|c|}
\hline & $\begin{array}{c}\text { Number within } \\
\text { Criteria }\end{array}$ & $\begin{array}{l}\text { Number } \\
\text { Performed }\end{array}$ & $\begin{array}{c}\% \\
\text { Precision }\end{array}$ \\
\hline \multicolumn{4}{|c|}{ Laboratory Gamma Spectrometry Precision } \\
\hline Laboratory Sample RPD & 72 & 72 & 100 \\
\hline Normalized Difference & 2,111 & 2,112 & 100 \\
\hline \multicolumn{4}{|c|}{ Laboratory Isotopic Uranium Precision } \\
\hline Laboratory Sample RPD & 98 & 100 & 98 \\
\hline Normalized Difference & 107 & 107 & 100 \\
\hline Matrix Spike RPD & 41 & 42 & 98 \\
\hline \multicolumn{4}{|c|}{ Laboratory Isotopic Plutonium Precision } \\
\hline Laboratory Sample RPD & 4 & 5 & 80 \\
\hline Normalized Difference & 140 & 141 & 99 \\
\hline Matrix Spike RPD & 15 & 15 & 100 \\
\hline
\end{tabular}


Table B.1-4

Laboratory Precision for Radioanalytes

(Page 2 of 2)

\begin{tabular}{|c|c|c|c|}
\hline & $\begin{array}{c}\text { Number within } \\
\text { Criteria }\end{array}$ & $\begin{array}{c}\text { Number } \\
\text { Performed }\end{array}$ & $\begin{array}{c}\% \\
\text { Precision }\end{array}$ \\
\hline \multicolumn{4}{|c|}{ Laboratory Strontium-90 Precision } \\
\hline Laboratory Sample RPD & 6 & 6 & 100 \\
\hline Normalized Difference & 54 & 55 & 98 \\
\hline Matrix Spike RPD & 16 & 16 & 100 \\
\hline \multicolumn{4}{|c|}{ Laboratory Tritium Precision } \\
\hline Laboratory Sample RPD & 2 & 2 & 100 \\
\hline Normalized Difference & 19 & 20 & 95 \\
\hline Matrix Spike RPD & 2 & 2 & 100 \\
\hline
\end{tabular}

on data application in meeting project and/or site characterization objectives, as RPDs outside criteria do not necessarily result in immediate qualification.

Field duplicate results for radioanalyses are included in Table B.1.3. Laboratory precision for radioanalytes, as measured by LDs and/or MS/MSDs, is summarized in Table B.1.4. Gamma measurement MS/MSDs were not prepared by the laboratory due to the difficulty in preparing homogeneous spiked duplicates and the subsequent production of the radioactive waste. When duplicate samples were analyzed, often only two to three radionuclides were present in sufficient concentrations to allow the determination of their RPDs. The duplicate data for the majority of radionuclides are compared using the ND. Except for isotopic plutonium, all field and laboratory precision percentages were 95 percent or above. The laboratory RPD for isotopic plutonium was determined by five samples, and only one of the five did not meet criteria resulting in an 80 percent achieved success. If averaged with the isotopic plutonium precision as measured by ND and matrix spike RPD, this percentage is well over 99 percent and meets acceptable precision goals. Therefore, this data quality evaluation for precision demonstrates acceptance in regards to the data quality objectives. 


\section{B.1.1.3 Precision Summary}

Overall, the precision for CAU 271 measurements were within DQI specifications. The results of the duplicate comparison of the field and LDs for chemical analyses are provided in Table B.1-1. The results for TCLP analyses are given in Table B.1-2. Of the 3,824 precision tests performed on FDs, 3,770 or 98.6 percent were within control limits. Of the 3,997 precision tests for LDs, LCSD, and MSDs, 3,979 or 99.5 percent were within control limits. More importantly, individual precision summaries for the designated analyses as shown in the individual tables were also within control limits.

The results of the duplicate comparison of the FDs for radiochemical analyses are provided in Table B.1-3. Of the 1,034 precision tests performed on the FDs, 1,030 or 99.6 percent were within the control limits. The results of LDs for radiochemical analyses, including laboratory spike and matrix spike RPDs, are provided in Table B.1-4. Of the 2,695 precision tests performed for LDs, 2,687 or 99.7 percent were within control limits. More importantly, individual precision summaries for the designated analyses as shown in the section tables were also within control limits except for isotopic plutonium laboratory precision, as previously noted.

In summary, precision for CAU 271 should be considered to be within acceptable limits for evaluation of the resulting data, thereby achieving established DQOs.

\section{B.1.2 Accuracy}

Accuracy is a measure of the closeness of an individual measurement or the average of a number of measurements to the true value. Accuracy includes a combination of random error (precision) and systematic error (bias) components that result from sampling and analytical operations. Accuracy is determined by analyzing a reference material of known pollutant concentration or by reanalyzing a sample to which a material of known concentration or amount of pollutant has been added (spiked).

The accuracy of the laboratory control sample (LCS) determination and the accuracy of the MS determination are expressed as a percent recovery as defined in the Industrial Sites QAPP (DOE/NV, 1996). The purpose of the MS is to determine the effect of interference from the sample matrix. The LCS measures laboratory accuracy. Martix spike results outside acceptable control limits often do not result in qualification of the data. An assessment of the entire analytical process, 
including the sample matrix, is performed to determine if qualification is necessary. For example, corresponding LCS results associated with MS results outside acceptable limits indicate acceptable laboratory QC.

The performance criteria for assessing analytical method accuracy are specified in the Leachfield Work Plan (DOE/NV, 1998) or are laboratory-specific.

\section{B.1.2.1 Accuracy for Chemical Analysis}

Accuracy for the measurement of target analytes collected at CAU 271 was determined by analysis of LCSs and MS samples for EPA methods 8260B VOCs, 1311/8260B TCLP VOCs, 8270C SVOCs, 1311/8270 C TCLP SVOCs, 8015B TPH DRO and TPH GRO, 8082 PCBs, 8081A Pesticides, 8151A Chlorinated Herbicides, 6010B Metals, 1311/6010B TCLP Metals, 7470A/7471A mercury and 1311/7470A TCLP Mercury. For the purpose of determining data accuracy of sample analysis for CAU 271, all water and soil samples including field QC samples (e.g., trip blanks, equipment rinsate samples, field blanks) were evaluated and incorporated for the accuracy measurements.

For organic analyses, project-designated control limits are used to evaluate the accuracy of all analyses. The acceptable limits for inorganic analyses are established in the EPA Contract Laboratory Functional Guidelines for Inorganic Data Review (EPA, 1994) and in the Leachfield Work Plan (DOE/NV, 1998). Sample results within established control ranges for organic and inorganic analyses express when the analytical method is accurate and the data provided are valid.

Matrix spike samples are prepared by adding a known concentration of a target analyte to a specified amount of a sample for which an independent estimate of the target analyte concentration is available. Spiked samples are one component used to determine laboratory accuracy by comparing the percent recovered to the known true value. Laboratory control samples are generated to provide accuracy of analytical methods and laboratory performance. Surrogates (system-monitoring compounds) are used to assess the method performance for each sample analyzed by organic analyses.

Table B.1-5 and Table B.1-6 identify the number of MS, laboratory control, and surrogate measurements performed for CAU 271. The tables present the total number of measurements analyzed, the number of measurements within the specified criteria, and the percentage of 
Table B.1-5

Chemical Analysis Accuracy Measurements for CAU 271

\begin{tabular}{|c|c|c|c|c|c|c|c|c|c|c|}
\hline & \multicolumn{7}{|c|}{ ORGANICS } & \multicolumn{3}{|c|}{ INORGANICS } \\
\hline & VOCs & SVOCs & $\begin{array}{c}\text { TPH } \\
\text { DRO }\end{array}$ & $\begin{array}{l}\text { TPH } \\
\text { GRO }\end{array}$ & PCBs & Pesticides & Herbicides & Metals $^{a}$ & Beryllium & Mercury \\
\hline \multicolumn{11}{|c|}{ Matrix Spike Accuracy } \\
\hline Total Number of MS Measurements & 450 & 968 & 114 & 88 & 120 & 132 & 20 & 461 & 30 & 66 \\
\hline $\begin{array}{l}\text { Total Number of MS Measurements } \\
\text { within Criteria }\end{array}$ & 426 & 935 & 111 & 67 & 120 & 123 & 20 & 437 & 30 & 61 \\
\hline MS Percent Accuracy & 94.67 & 96.59 & 97.37 & 76.14 & 100 & 93.18 & 100 & 94.79 & 100 & 92.42 \\
\hline \multicolumn{11}{|c|}{ Laboratory Control Sample Accuracy } \\
\hline $\begin{array}{l}\text { Total Number of LCS } \\
\text { Measurements }\end{array}$ & 960 & 1,529 & 131 & 144 & 276 & 186 & 36 & 764 & 55 & 99 \\
\hline $\begin{array}{l}\text { Total Number of LCS } \\
\text { Measurements within Criteria }\end{array}$ & 959 & 1,529 & 131 & 144 & 276 & 186 & 36 & 764 & 55 & 99 \\
\hline LCS Percent Accuracy & 99.90 & 100 & 100 & 100 & 100 & 100 & 100 & 100 & 100 & 100 \\
\hline \multicolumn{11}{|c|}{ Surrogate Accuracy } \\
\hline $\begin{array}{l}\text { Total Number of Measurements } \\
\text { Analyzed }\end{array}$ & 36,816 & 35,153 & 535 & 493 & 3,093 & 1,850 & 250 & NA & NA & NA \\
\hline $\begin{array}{l}\text { Total Number of Measurements not } \\
\text { Affected by Out-of-Control } \\
\text { Surrogates }\end{array}$ & 36,471 & 34,588 & 533 & 476 & 2,733 & 1,615 & 250 & NA & NA & NA \\
\hline Surrogate Percent Accuracy & 99.06 & 98.39 & 99.63 & 96.55 & 88.36 & 87.30 & 100 & NA & NA & NA \\
\hline
\end{tabular}

${ }^{a}$ Arsenic, Barium, Cadmium, Chromium, Lead, Selenium, and Silver

NA = Not applicable 
Table B.1-6

Toxicity Characteristic Leaching Procedure Accuracy Measurement for CAU 271

\begin{tabular}{|c|c|c|c|c|c|}
\hline & \multicolumn{2}{|c|}{ ORGANICS } & \multicolumn{3}{|c|}{ INORGANICS } \\
\hline & $\begin{array}{l}\text { TCLP } \\
\text { VOCs }\end{array}$ & $\begin{array}{l}\text { TCLP } \\
\text { SVOCs }\end{array}$ & $\begin{array}{l}\text { TCLP } \\
{ }^{*} \text { Metals }\end{array}$ & Beryllium & $\begin{array}{l}\text { TCLP } \\
\text { Mercury }\end{array}$ \\
\hline \multicolumn{6}{|c|}{ Toxicity Characteristic Leaching Procedure Matrix Spike Accuracy } \\
\hline Total Number of MS Measurements & 150 & 108 & 133 & 1 & 15 \\
\hline $\begin{array}{l}\text { Total Number of MS Measurements within } \\
\text { Criteria }\end{array}$ & 147 & 108 & 133 & 1 & 15 \\
\hline MS Percent Accuracy & 98.00 & 100 & 100 & 100 & 100 \\
\hline \multicolumn{6}{|c|}{ TCLP Laboratory Control Sample Accuracy } \\
\hline Total Number of LCS Measurements & 180 & 240 & 182 & 0 & 18 \\
\hline $\begin{array}{l}\text { Total Number of LCS Measurements within } \\
\text { Criteria }\end{array}$ & 180 & 240 & 182 & 0 & 18 \\
\hline LCS Percent Accuracy & 100 & 100 & 100 & NA & 100 \\
\hline \multicolumn{6}{|c|}{ TCLP Surrogate Accuracy } \\
\hline Total Number of Measurements Analyzed & 200 & 252 & NA & NA & NA \\
\hline $\begin{array}{l}\text { Total Number of Measurements not Affected } \\
\text { by Out-of-Control Surrogates }\end{array}$ & 200 & 240 & NA & NA & NA \\
\hline Surrogate Percent Accuracy & 100 & 95.24 & NA & NA & NA \\
\hline
\end{tabular}

* Arsenic, Barium, Cadmium, Chromium, Lead, Selenium, and Silver

NA $=$ Not applicable

measurements that met the accuracy criteria. For organic analyses, each sample was accompanied by surrogate analysis; therefore, the number of surrogates is significantly greater than the number of MS samples and LCSs.

The matrix spike accuracy results for chemical analyses presented in Table B.1-5 and Table B.1-6 include the total number of MS measurements per analysis and the number of matrix spike measurements within criteria. If qualification of data based on MS results is required, all samples for organic analyses within the associated SDG are not qualified, only the native sample in which the spike was added. Overall, accuracy goals were achieved for matrix spikes in this CAU, with the 
exception of TPH GRO, which had an overall percentage of acceptable measurements of 76. This drop in accuracy was the result of low spike recoveries and does not affect the data quality evaluation.

Table B.1-5 and Table B.1-6 include the total number of LCS measurements per analysis and the number of LCS measurements within criteria. For organic analyses, an evaluation of the overall analytical process is performed to determine if data qualification is necessary. Inorganic LCS recoveries outside of established controls require data be qualified for the individual analyte out of control. If the LCS criteria are not met, the laboratory performance and method accuracy are in question. Overall, accuracy goals were achieved for LCSs for this CAU.

Surrogates reported within established control criteria indicate accurate data as determined on a per sample basis. Table B.1-5 and Table B.1-6 include the total number of sample measurements performed for each method and the total number of sample measurements qualified for surrogate recoveries exceeding criteria. Overall, accuracy for this CAU was within specified criteria for surrogates.

\section{B.1.2.2 Accuracy for Radiochemical Analysis}

Laboratory control samples and MS samples are used to determine the accuracy of radioanalytical measurements. One LCS is prepared with each batch of samples for analysis of a specified measurement. If the LCS results are outside acceptable control limits, qualifiers are added to the field samples analyzed with the LCS. The purpose of the MS is to determine the effect of interferences from the sample matrix. Isotopic uranium and plutonium utilize radioactive tracers to determine the chemical or processing yield. A stable strontium carrier is used to determine chemical yield for the strontium-90 measurement. Since the addition of tracers or carriers is similar to a matrix spike, MS samples are not usually needed for these measurements. Normally, an MS analysis is not performed for gamma measurements since this is a nondestructive analysis using large sample aliquots. This would not only result in radioactive waste, it is difficult to prepare homogeneous solid-spike samples.

Table B.1-7 gives the number of LCSs, including soil and water matrices, measured for each radioanalytical measurement for CAU 271. The percent accuracy for the procedure is determined as the number of LCS measurements that are within the control limits, divided by the total number LCS analyses, multiplied by 100 . 
Table B.1-7

Radioanalyte Laboratory Control Sample Accuracy

\begin{tabular}{||l|c|c|c|c|c|}
\hline & $\begin{array}{c}\text { Gamma } \\
\text { Spectrometry }\end{array}$ & $\begin{array}{c}\text { Isotopic } \\
\text { Uranium }\end{array}$ & $\begin{array}{c}\text { Isotopic } \\
\text { Plutonium }\end{array}$ & Strontium-90 & Tritium \\
\hline \hline Total Number & 243 & 122 & 66 & 65 & 61 \\
\hline Total Number within Criteria & 243 & 122 & 98 & 100 & 100 \\
\hline $\begin{array}{l}\text { Laboratory Control Sample } \\
\text { Percent Accuracy }\end{array}$ & 100 & 100 & 23 & 61 \\
\hline
\end{tabular}

Laboratory control samples within the specified criteria for radiological analyses indicate the laboratory is producing valid data with respect to accuracy goals. Radiological LCS recoveries outside of established controls require data to be qualified for the individual analyte out of control. Each gamma spectrometry LCS contains four or five radionuclides. The LCS and MS samples for isotopic plutonium, Sr-90, and tritium use only one radionuclide. Three uranium radionuclides are added to the isotopic uranium LCS and MS samples, but the U-235 concentration can be too low to allow evaluation. Laboratory control sample recoveries were 100 percent for all analyses except for $\mathrm{Pu}-239$ associated with a water batch in which only the duplicate sample included in that batch was qualified due to LCS recovery.

Table B.1-8 gives the number of MS measurements performed for each radioanalytical measurement for CAU 271. Since the recoveries for all the MS samples analyzed were within the acceptable control range, no qualifiers were added to field samples based on MS performance.

Table B.1-8

Radioanalyte Matrix Spike Sample Accuracy

\begin{tabular}{|l|c|c|c|c|}
\hline & $\begin{array}{c}\text { Isotopic } \\
\text { Uranium }\end{array}$ & $\begin{array}{c}\text { Isotopic } \\
\text { Plutonium }\end{array}$ & Strontium-90 & Tritium \\
\hline \hline Total Number & 84 & 30 & 32 & 14 \\
\hline Total Number within Criteria & 84 & 30 & 100 & 14 \\
\hline $\begin{array}{l}\text { Matrix Spike Sample Percent } \\
\text { Accuracy }\end{array}$ & 100 & 100 & 100 \\
\hline
\end{tabular}




\section{B.1.2.3 Accuracy Summary}

Overall accuracy for CAU 271 was within acceptable limits. Surrogate recoveries, which gauge the accuracy of individual sample results for specified chemical analyses, were within acceptable accuracy ranges ( 87 percent or better). Acceptable MS recovery results were 92 percent or better for chemical and radiochemical analyses except for TPH GRO, which was 76 percent. The percentage of acceptable LCS recoveries was greater than 99 percent for all chemical analyses indicating that the lower TPH GRO matrix spike recoveries were likely the result of matrix interferences and not an analytical problem. In fact, the likely reason for the lower percentage of TPH results within acceptable range was due to the high concentrations of TPH in some of the samples. This higher native contaminant concentration often masks the recovery percentage for spiked samples. Radioanalytical LCS recoveries were 98 percent or better.

In summary, accuracy results for CAU 271 should be considered acceptable and meet DQO requirements.

\section{B.1.3 Completeness}

Completeness is defined as sufficient data of the appropriate quality to satisfy DQO decision data requirements. The Industrial Sites QAPP (DOE/NV, 1996) sets the completeness objective at 80 percent for both measurement and sample completeness. A numerical definition is provided in the Industrial Sites QAPP (DOE/NV, 1996). All measurements for completeness include all sample reanalyses. Table B.1-9, Table B.1-10, and Table B.1-11 contain results of completeness per analytical method.

The specified sampling locations were used as planned and all samples were collected as specified in the CAIP (DOE/NV, 2001). Exceptions and deviations, including exercising planned contingencies, are discussed in Appendix A. No analyses were compromised as a result of sample containers not reaching the laboratory intact. However, some samples were rejected because their storage temperature was not maintained. Other reasons for rejected analyses include laboratory QC parameters that were not achieved or poor results for specified quality indicators.

Rejected data affecting completeness are presented and discussed on a CAS-by-CAS basis in the following subsections. 
Table B.1-9

Chemical Completeness Measurements for CAU 271

\begin{tabular}{|c|c|c|c|c|c|c|c|c|c|c|}
\hline \multirow{2}{*}{ Completeness Parameters } & \multicolumn{7}{|c|}{ ORGANICS } & \multicolumn{3}{|c|}{ INORGANICS } \\
\hline & VOCs & SVOCs & $\begin{array}{l}\text { TPH- } \\
\text { DRO }\end{array}$ & $\begin{array}{l}\text { TPH- } \\
\text { GRO }\end{array}$ & PCBs & Pesticides & Herbicides & Metals $^{a}$ & Beryllium & Mercury \\
\hline \multicolumn{11}{|c|}{ Sample Analysis Completeness } \\
\hline Total Samples Sent to Laboratory & 636 & 512 & 537 & 500 & 436 & 84 & 25 & 506 & 214 & 498 \\
\hline Total Samples Analyzed & 623 & 510 & 535 & 491 & 434 & 84 & 25 & 504 & 212 & 496 \\
\hline Total Samples not Analyzed by Laboratory & 13 & 2 & 2 & 9 & 2 & 0 & 0 & 2 & 2 & 2 \\
\hline -Broken Bottles, Lids, etc. & 0 & 0 & 0 & 0 & 0 & 0 & 0 & 0 & 0 & 0 \\
\hline -Analyses Cancelled per ITLV & 12 & 1 & 1 & 8 & 1 & 0 & 0 & 1 & 1 & 1 \\
\hline -Samples not Received by Laboratory & 1 & 1 & 1 & 1 & 1 & 0 & 0 & 1 & 1 & 1 \\
\hline -Samples Put on Hold by ITLV & 0 & 0 & 0 & 0 & 0 & 0 & 0 & 0 & 0 & 0 \\
\hline Percent Completeness & 97.96 & 99.61 & 99.63 & 98.2 & 99.54 & 100.0 & 100.0 & 99.6 & 99.07 & 99.6 \\
\hline \multicolumn{11}{|c|}{ Measurement Usability Completeness } \\
\hline Total Measurements ${ }^{b}$ & 36,816 & 35,153 & 535 & 493 & 3,093 & 1,850 & 250 & 3,494 & 213 & 500 \\
\hline Total Measurements Rejected - Field & 0 & 0 & 0 & 0 & 0 & 0 & 0 & 0 & 0 & 0 \\
\hline Total Measurements Rejected - Lab/Matrix & 1,421 & 137 & 0 & 0 & 14 & 70 & 0 & 0 & 0 & 0 \\
\hline Percent Completeness & 96.14 & 99.61 & 100 & 100 & 99.55 & 96.22 & 100 & 100 & 100 & 100 \\
\hline
\end{tabular}

${ }^{a}$ Arsenic, barium, cadmium, lead, selenium, and silver

${ }^{\mathrm{b}}$ Measurements include reanalyses 
Table B.1-10

Toxicity Characteristic Leaching Procedure Chemical Completeness Measurements for CAU 271

\begin{tabular}{|c|c|c|c|c|}
\hline \multirow[b]{2}{*}{ Completeness Parameters } & \multicolumn{2}{|c|}{ ORGANICS } & \multicolumn{2}{|c|}{ INORGANICS } \\
\hline & VOCs & SVOCs & Metals $^{a}$ & Mercury \\
\hline \multicolumn{5}{|c|}{ Sample Analysis Completeness } \\
\hline Total Samples Sent to Laboratory & 20 & 20 & 23 & 22 \\
\hline Total Samples Analyzed & 20 & 20 & 23 & 22 \\
\hline Total Samples not Analyzed by the Laboratory & 0 & 0 & 0 & 0 \\
\hline -Broken Bottles, Lids, etc. & 0 & 0 & 0 & 0 \\
\hline -Analyses Cancelled per ITLV & 0 & 0 & 0 & 0 \\
\hline -Samples not Received by Laboratory & 0 & 0 & 0 & 0 \\
\hline -Samples Put on Hold by ITLV & 0 & 0 & 0 & 0 \\
\hline Percent Completeness & 100 & 100 & 100 & 100 \\
\hline \multicolumn{5}{|c|}{ Measurement Usability Completeness } \\
\hline Total Measurements $^{\mathrm{b}}$ & 200 & 252 & 163 & 22 \\
\hline Total Measurements Rejected - Field & 0 & 0 & 0 & 0 \\
\hline Total Measurements Rejected - Lab/Matrix & 0 & 3 & 0 & 0 \\
\hline Percent Completeness & 100 & 98.81 & 100 & 100 \\
\hline
\end{tabular}

${ }^{\text {a }}$ Arsenic, barium, cadmium, lead, selenium, and silver

${ }^{\mathrm{b}}$ Measurements include reanalyses 
Table B.1-11

Radiological Completeness Measurements for CAU 271

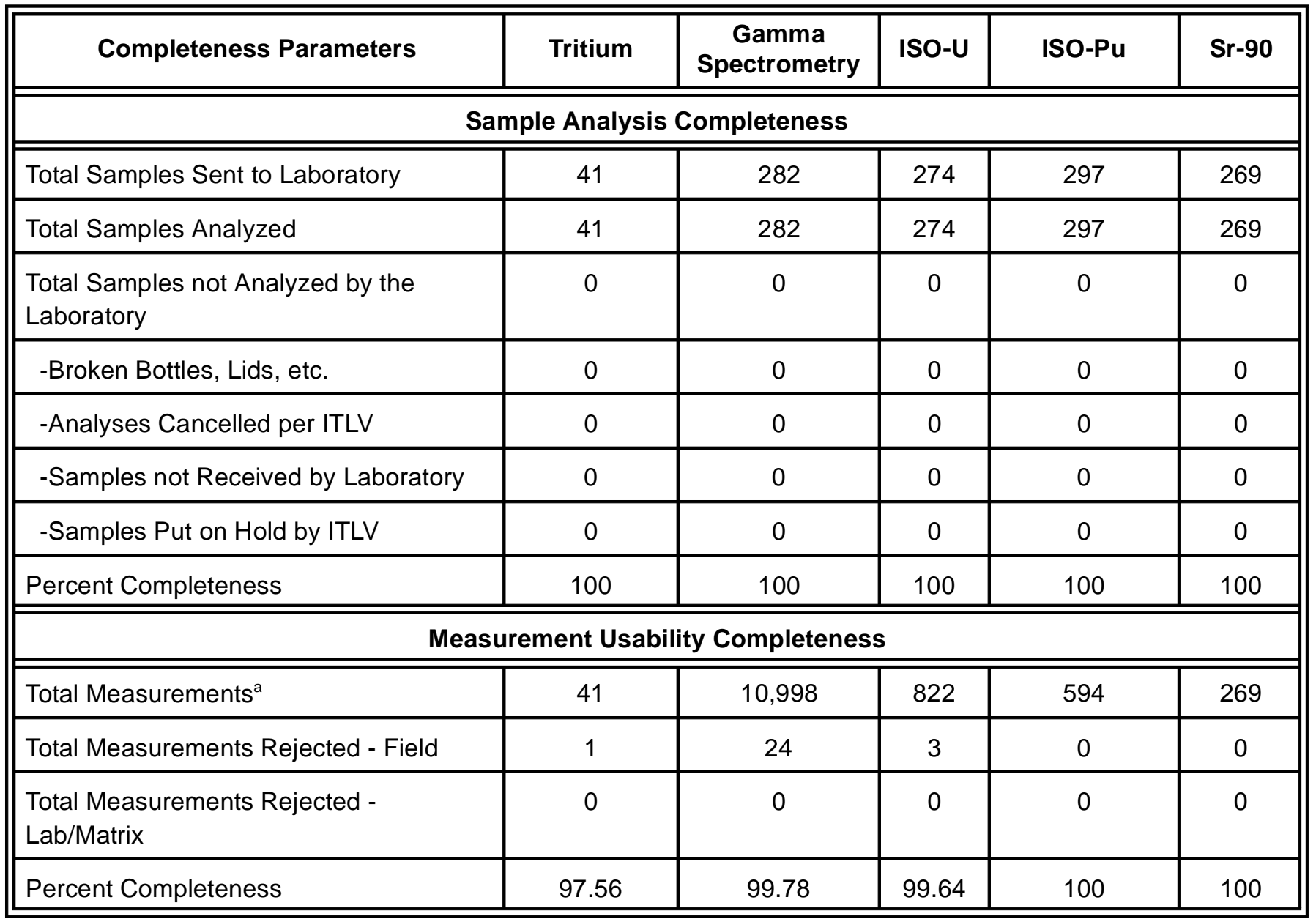

${ }^{\mathrm{a}}$ Measurements include reanalyses 


\section{B.1.3.1 Security Checkpoint Septic System (CAS 25-04-01) Rejected Data}

Table B.1-12 lists the rejected results per analytical method for CAS 25-04-01.

Table B.1-12

CAU 271 Rejected Data for CAS 25-04-01

\begin{tabular}{||c|c|c|c||}
\hline $\begin{array}{c}\text { Sample } \\
\text { Identification } \\
\text { Number }\end{array}$ & $\begin{array}{c}\text { Laboratory } \\
\text { Method }\end{array}$ & Parameter & Sample Matrix \\
\hline \hline $271 \mathrm{~A} 013 \mathrm{RR} 1$ & SW8270 - TCLP & Pyridine & Leachate \\
\hline $271 \mathrm{~A} 013$ & SW8260 & Acetone & Sludge \\
\hline $271 \mathrm{~A} 013 \mathrm{RR} 1$ & SW8260 & Acetone & Sludge \\
\hline $271 \mathrm{~A} 013$ & SW8270 - TCLP & Pyridine & Soil \\
\hline $271 \mathrm{~A} 001$ & SW8260 & Acetone & Soil \\
\hline $271 \mathrm{~A} 003$ & SW8260 & Acetone & Soil \\
\hline $271 \mathrm{~A} 006$ & SW8260 & Acetone & Liquid \\
\hline $271 \mathrm{~A} 008$ & SW8260 & Acetone & Liquid \\
\hline $271 \mathrm{~A} 501$ & PCBs & Aroclor-1016 & Liquid \\
\hline $271 \mathrm{~A} 501$ & PCBs & Aroclor-1221 & Liquid \\
\hline $271 \mathrm{~A} 501$ & PCBs & Aroclor-1232 & Liquid \\
\hline $271 \mathrm{~A} 501$ & PCBs & Aroclor-1242 & Liquid \\
\hline $271 \mathrm{~A} 501$ & PCBs & Aroclor-1248 & Aroclor-1254 \\
\hline $271 \mathrm{~A} 501$ & PCBs & Aroclor-1260 & \\
\hline $271 \mathrm{~A} 501$ & PCBs & \multicolumn{2}{|c|}{}
\end{tabular}

Acetone soil results were rejected in several samples due to a low relative response factor.

Laboratory reported values were just above the MDL for all rejected soil samples. Because acetone data were rejected and some quantity of acetone could remain undetected, it is possible that acetone is present at a higher concentration. In a worst-case scenario, this suggests that rejected data for acetone could be higher than the MRL. However, acetone was found in only two samples for CAS 25-04-01, and both were very low concentrations which were well below the PAL. Therefore, there is virtually no concern that acetone concentrations would approach PALs for the rejected results noted above. In addition, the acetone PAL is much greater than the MRL. These rejected soil data are considered acceptable data gaps and should not affect closure decisions for CAS 25-04-01. 
Acetone sludge results were rejected in two samples due to a low relative response factor and QC results outside specifications for continuing calibration. Acetone values in sludge have no designated action levels. In addition, acetone was not reported in any of the sludge sample analyses conducted for this site. Acetone for CAU 271 is well below PALs for all samples collected. One sludge sample also had a pyridine result rejected due to a low relative response factor. Pyridine was not found in any other samples at the site. These rejected sludge data for acetone and pyridine are considered acceptable data gaps and should not affect closure decisions for CAS 25-04-01.

One leachate sample had a pyridine result rejected due to a low relative response factor. Pyridine was not found in sludge samples prior to TCLP extraction. Rejected leachate data are considered acceptable data gaps and should not affect closure decisions for CAS 25-04-01.

A waste management sample (271A501) had rejected data for PCBs due to poor surrogate recoveries and potential matrix effects. Surrogate recoveries were below 10 percent, suggesting there could be potential concentrations of PCBs in rejected data because of inefficient extraction techniques or poor column response during analysis. Surrogate recoveries are a means for monitoring analytical efficiency. These results need to be examined with respect to the disposal requirements for IDW drum 271A03. This drum contains IDW from fecal coliform testing and is not specific to CAS 25-04-01.

\section{B.1.3.2 PAN-AM Trailers Septic System (CAS 25-04-03) Rejected Data}

Table B.1-13 contains the rejected results per analytical method for CAS 25-04-03.

Acetone soil results were rejected in several samples due to a low relative response factor. Laboratory reported values were just above the MDL for all rejected soil samples. Because acetone data were rejected and some quantity of acetone likely remained undetected, it is also possible that acetone is present at a higher concentration. In a worst-case scenario, this suggests that rejected data for acetone could be higher than the MRL. Because acetone concentrations in nonrejected samples for CAS 25-04-03 were very low concentrations and well below the PAL, there is virtually no concern that acetone concentrations would even approach the PAL for the rejected results noted above. In addition, the acetone PAL is much greater than the MRL. These rejected soil data are considered acceptable data gaps and should not affect closure decisions for CAS 26-04-03. 
Table B.1-13

CAU 271 Rejected Data for CAS 25-04-03

(Page 1 of 2)

\begin{tabular}{|c|c|c|c|}
\hline $\begin{array}{c}\text { Sample } \\
\text { Identification } \\
\text { Number }\end{array}$ & $\begin{array}{l}\text { Laboratory } \\
\text { Method }\end{array}$ & Parameter & Sample Matrix \\
\hline 271B027RR1 & SW8260 & Acetone & Sludge \\
\hline 271B027 & SW8270 & 3,3'-Dichlorobenzidine & Sludge \\
\hline 271B027 & SW8270 & Benzo(g,h,i)Perylene & Sludge \\
\hline 271B027 & SW8270 & Butyl Benzyl Phthalate & Sludge \\
\hline 271B027 & SW8270 & Di-n-Octyl Phthalate & Sludge \\
\hline 271B027 & SW8270 & Dibenzo(a,h)Anthracene & Sludge \\
\hline 271B027 & SW8270 & Indeno(1,2,3-cd)Pyrene & Sludge \\
\hline 271B001 & SW8260 & Acetone & Soil \\
\hline 271B003 & SW8260 & Acetone & Soil \\
\hline 271B005 & SW8260 & Acetone & Soil \\
\hline 271B007 & SW8260 & Acetone & Soil \\
\hline 271B009 & SW8260 & Acetone & Soil \\
\hline 271B011 & SW8260 & Acetone & Soil \\
\hline 271B012 & SW8260 & Acetone & Soil \\
\hline 271B013 & SW8260 & Acetone & Soil \\
\hline 271B015 & SW8260 & Acetone & Soil \\
\hline 271B017 & SW8260 & Acetone & Soil \\
\hline 271B019 & SW8260 & Acetone & Soil \\
\hline 271B021 & SW8260 & Acetone & Soil \\
\hline 271B023 & SW8260 & Acetone & Soil \\
\hline 271B039 & SW8260 & Acetone & Soil \\
\hline 271B050 & SW8260 & Acetone & Soil \\
\hline 271B056 & SW8260 & Acetone & Soil \\
\hline 271B058 & SW8260 & Acetone & Soil \\
\hline 271B060 & SW8260 & Acetone & Soil \\
\hline
\end{tabular}


Table B.1-13

CAU 271 Rejected Data for CAS 25-04-03

(Page 2 of 2)

\begin{tabular}{|c|c|c|c|}
\hline $\begin{array}{c}\text { Sample } \\
\text { Identification } \\
\text { Number }\end{array}$ & $\begin{array}{c}\text { Laboratory } \\
\text { Method }\end{array}$ & Parameter & Sample Matrix \\
\hline \hline $271 \mathrm{~B} 063$ & SW8260 & Acetone & Soil \\
\hline $271 \mathrm{~B} 064$ & SW8260 & Acetone & Soil \\
\hline $271 \mathrm{~B} 065$ & SW8260 & Acetone & Soil \\
\hline $271 \mathrm{~B} 067$ & SW8260 & Acetone & Soil \\
\hline $271 \mathrm{~B} 069$ & SW8260 & Acetone & Soil \\
\hline $271 \mathrm{~B} 070$ & SW8260 & Acetone & Soil \\
\hline $271 \mathrm{~B} 071$ & SW8260 & Acetone & Soil \\
\hline $271 \mathrm{~B} 072$ & SW8260 & Acetone & Cadmium-109 \\
\hline $271 \mathrm{~B} 009$ & PAl713R6 & & \\
\hline
\end{tabular}

In addition to acetone, the cadmium-109 result was rejected in soil sample 271B009 due to spectral problems preventing accurate identification. This radionuclide was not considered a COPC for this CAS per the CAIP. Also, the half-life for cadmium-109 is too short to be considered a COPC for CAU 271. These rejected data and the rejected data noted above should not affect conclusions in regards to contamination problems or affect closure decisions for CAS 25-04-03. These rejected soil results are considered acceptable data gaps given the explanations provided above.

Acetone sludge results were rejected in one sample due to a low relative response factor. Acetone values in sludge have no designated action levels. In addition, acetone was not reported in any of the sludge sample analyses conducted for this site. Acetone for CAU 271 is well below PALs for all samples collected.

Several SVOC results were rejected in sludge sample 271B027 because of internal standards not meeting QC requirements. These results were rejected because the analytical method could not distinguish the internal standard; therefore, sample results could be higher than the reporting limit. However, semivolatile organic compounds were not reported for any other sludge samples in this 
CAS; therefore, these rejected sludge results are considered acceptable data gaps given the explanations provided above and noting that only one sample was affected by laboratory QC.

\section{B.1.3.3 Reactor Control Point Septic System (CAS 25-04-04) Rejected Data}

Table B.1-14 contains the rejected results per analytical method for CAS 25-04-04.

Acetone results were rejected in several soil samples due to a low relative response factor. Laboratory reported values were just above the MDL for all rejected soil samples. Because acetone data were rejected and some quantity of acetone likely remained undetected, it is possible that acetone is present at a higher concentration, suggesting that rejected data for acetone could be higher than the MRL. However, acetone was detected at very low concentrations in only one sample in this CAS. Potential concentrations of acetone in these rejected data would be far below the PAL; therefore, these rejected results would not likely affect conclusions with regard to acetone contamination.

Soil sample 271C071 was rejected for all VOC analytical results with the exception of methylene chloride due to improper storage. Improperly stored samples for VOC analysis would suggest a potential loss of volatile compounds. Without knowing exact storage conditions and subsequent effects, the magnitude of possible lost compounds would be difficult to gauge. Therefore, reported values of volatiles for this sample provide no indication of actual concentrations. While volatile concentrations could be at much higher levels, it is unlikely that loss of this one sample would affect closure decisions. There were no VOCs detected in CAS 25-04-04 except acetone. In addition, there have been very few VOCs found in CAU 271. All VOCs detected in CAU 271 have been well below PALs; therefore, the loss of this sample should not affect closure decisions. This sample was collected at location C30 (Figure A.5-1). There is nothing to indicate that VOCs should be detected at this location given the absence of VOCs in soil at other locations in the leachfield.

One SVOC (4,6-dinitro-2-methylphenol) was rejected in one soil sample due to a poor relative response factor. Similar to acetone, this indicates that some small quality of this compound could have remained undetected. Semivolatiles were not detected above PALs for any other samples in this CAS; therefore, this rejected data point would not have an impact upon closure decisions. 
Table B.1-14

CAU 271 Rejected Data for CAS 25-04-04

(Page 1 of 5 )

\begin{tabular}{|c|c|c|c|}
\hline $\begin{array}{c}\text { Sample } \\
\text { Identification Number }\end{array}$ & $\begin{array}{l}\text { Laboratory } \\
\text { Method }\end{array}$ & Parameter & $\begin{array}{c}\text { Sample } \\
\text { Matrix }\end{array}$ \\
\hline $271 \mathrm{C} 075$ & SW8260 & Acetone & Liquid \\
\hline $271 \mathrm{C} 073$ & SW8270 & Benzo(a)Pyrene & Liquid \\
\hline $271 \mathrm{C} 073$ & SW8270 & Benzo(b)Fluoranthene & Liquid \\
\hline $271 \mathrm{C} 073$ & SW8270 & Benzo(g,h,i)Perylene & Liquid \\
\hline $271 \mathrm{C} 073$ & SW8270 & Benzo(k)Fluoranthene & Liquid \\
\hline $271 \mathrm{C} 073$ & SW8270 & Di-n-Octyl Phthalate & Liquid \\
\hline $271 \mathrm{C} 073$ & SW8270 & Dibenzo(a,h)Anthracene & Liquid \\
\hline $271 \mathrm{C} 073$ & SW8270 & Indeno(1,2,3-cd)Pyrene & Liquid \\
\hline $271 \mathrm{C} 074$ & SW8260 & Acetone & Sludge \\
\hline 271C074RR1 & SW8260 & Acetone & Sludge \\
\hline $271 \mathrm{C} 074$ & SW8270 & 4-Nitrophenol & Sludge \\
\hline $271 \mathrm{C} 074$ & SW8270 & Benzo(a)Pyrene & Sludge \\
\hline $271 \mathrm{C} 074$ & SW8270 & Benzo(b)Fluoranthene & Sludge \\
\hline $271 \mathrm{C} 074$ & SW8270 & Benzo(g,h,i)Perylene & Sludge \\
\hline $271 \mathrm{C} 074$ & SW8270 & Benzo(k)Fluoranthene & Sludge \\
\hline $271 \mathrm{C} 074$ & SW8270 & Di-n-Octyl Phthalate & Sludge \\
\hline $271 \mathrm{C} 074$ & SW8270 & Dibenzo(a,h)Anthracene & Sludge \\
\hline $271 \mathrm{C} 074$ & SW8270 & Indeno(1,2,3-cd)Pyrene & Sludge \\
\hline $271 \mathrm{C} 074$ & SW8270 & N-Nitroso-Di-n-Propylamine & Sludge \\
\hline 271C074RR1 & SW8270 & 4-Nitrophenol & Sludge \\
\hline 271C074RR1 & SW8270 & N-Nitroso-Di-n-Propylamine & Sludge \\
\hline $271 \mathrm{C} 020$ & SW8260 & Acetone & Soil \\
\hline $271 \mathrm{C} 022$ & SW8260 & Acetone & Soil \\
\hline $271 \mathrm{C} 024$ & SW8260 & Acetone & Soil \\
\hline $271 \mathrm{C} 025$ & SW8260 & Acetone & Soil \\
\hline $271 \mathrm{C} 044$ & SW8260 & Acetone & Soil \\
\hline $271 \mathrm{C} 046$ & SW8260 & Acetone & Soil \\
\hline $271 \mathrm{C} 048$ & SW8260 & Acetone & Soil \\
\hline $271 \mathrm{C} 050$ & SW8260 & Acetone & Soil \\
\hline $271 \mathrm{C052}$ & SW8260 & Acetone & Soil \\
\hline $271 \mathrm{C} 054$ & SW8260 & Acetone & Soil \\
\hline $271 \mathrm{C} 055$ & SW8260 & Acetone & Soil \\
\hline $271 \mathrm{C} 056$ & SW8260 & Acetone & Soil \\
\hline
\end{tabular}


Table B.1-14

CAU 271 Rejected Data for CAS 25-04-04

(Page 2 of 5 )

\begin{tabular}{|c|c|c|c|}
\hline $\begin{array}{c}\text { Sample } \\
\text { Identification Number }\end{array}$ & $\begin{array}{l}\text { Laboratory } \\
\text { Method }\end{array}$ & Parameter & $\begin{array}{c}\text { Sample } \\
\text { Matrix }\end{array}$ \\
\hline $271 \mathrm{C} 058$ & SW8260 & Acetone & Soil \\
\hline $271 \mathrm{C} 060$ & SW8260 & Acetone & Soil \\
\hline $271 \mathrm{C} 062$ & SW8260 & Acetone & Soil \\
\hline $271 \mathrm{C} 064$ & SW8260 & Acetone & Soil \\
\hline $271 \mathrm{C} 066$ & SW8260 & Acetone & Soil \\
\hline $271 C 069$ & SW8260 & Acetone & Soil \\
\hline $271 \mathrm{C} 071$ & SW8260 & 1,1,1,2-Tetrachloroethane & Soil \\
\hline $271 \mathrm{C} 071$ & SW8260 & 1,1,1-Trichloroethane & Soil \\
\hline $271 \mathrm{C} 071$ & SW8260 & 1,1,2,2-Tetrachloroethane & Soil \\
\hline $271 \mathrm{C} 071$ & SW8260 & 1,1,2-Trichloroethane & Soil \\
\hline $271 \mathrm{C} 071$ & SW8260 & 1,1-Dichloroethane & Soil \\
\hline $271 \mathrm{C} 071$ & SW8260 & 1,1-Dichloroethene & Soil \\
\hline $271 \mathrm{C} 071$ & SW8260 & 1,1-Dichloropropene & Soil \\
\hline $271 \mathrm{C} 071$ & SW8260 & 1,2,3-Trichlorobenzene & Soil \\
\hline $271 \mathrm{C} 071$ & SW8260 & 1,2,3-Trichloropropane & Soil \\
\hline $271 \mathrm{C} 071$ & SW8260 & 1,2,4-Trichlorobenzene & Soil \\
\hline $271 \mathrm{C} 071$ & SW8260 & 1,2,4-Trimethylbenzene & Soil \\
\hline $271 \mathrm{C} 071$ & SW8260 & 1,2-Dibromo-3-Chloropropane & Soil \\
\hline $271 \mathrm{C} 071$ & SW8260 & 1,2-Dibromoethane & Soil \\
\hline $271 \mathrm{C} 071$ & SW8260 & 1,2-Dichlorobenzene & Soil \\
\hline $271 \mathrm{C} 071$ & SW8260 & 1,2-Dichloroethane & Soil \\
\hline $271 \mathrm{C} 071$ & SW8260 & 1,2-Dichloropropane & Soil \\
\hline $271 \mathrm{C} 071$ & SW8260 & 1,3,5-Trimethylbenzene & Soil \\
\hline $271 \mathrm{C} 071$ & SW8260 & 1,3-Dichlorobenzene & Soil \\
\hline $271 \mathrm{C} 071$ & SW8260 & 1,3-Dichloropropane & Soil \\
\hline $271 \mathrm{C} 071$ & SW8260 & 1,4-Dichlorobenzene & Soil \\
\hline $271 \mathrm{C} 071$ & SW8260 & 1-Chlorohexane & Soil \\
\hline $271 \mathrm{C} 071$ & SW8260 & 2,2-Dichloropropane & Soil \\
\hline $271 \mathrm{C} 071$ & SW8260 & 2-Butanone & Soil \\
\hline $271 \mathrm{C} 071$ & SW8260 & 2-Chlorotoluene & Soil \\
\hline $271 \mathrm{C} 071$ & SW8260 & 2-Hexanone & Soil \\
\hline $271 \mathrm{C} 071$ & SW8260 & 4-Chlorotoluene & Soil \\
\hline $271 \mathrm{C} 071$ & SW8260 & 4-Methyl-2-Pentanone & Soil \\
\hline
\end{tabular}


Table B.1-14

CAU 271 Rejected Data for CAS 25-04-04

(Page 3 of 5)

\begin{tabular}{|c|c|c|c|}
\hline $\begin{array}{c}\text { Sample } \\
\text { Identification Number }\end{array}$ & $\begin{array}{l}\text { Laboratory } \\
\text { Method }\end{array}$ & Parameter & $\begin{array}{l}\text { Sample } \\
\text { Matrix }\end{array}$ \\
\hline $271 \mathrm{C} 071$ & SW8260 & Acetone & $\overline{\text { Soil }}$ \\
\hline $271 \mathrm{C} 071$ & SW8260 & Benzene & Soil \\
\hline $271 \mathrm{C} 071$ & SW8260 & Bromobenzene & Soil \\
\hline $271 \mathrm{C} 071$ & SW8260 & Bromochloromethane & Soil \\
\hline $271 \mathrm{C} 071$ & SW8260 & Bromodichloromethane & Soil \\
\hline $271 \mathrm{C} 071$ & SW8260 & Bromoform & Soil \\
\hline $271 \mathrm{C} 071$ & SW8260 & Bromomethane & Soil \\
\hline $271 \mathrm{C} 071$ & SW8260 & Carbon Disulfide & Soil \\
\hline $271 \mathrm{C} 071$ & SW8260 & Carbon Tetrachloride & Soil \\
\hline $271 \mathrm{C} 071$ & SW8260 & Chlorobenzene & Soil \\
\hline $271 \mathrm{C} 071$ & SW8260 & Chloroethane & Soil \\
\hline $271 \mathrm{C} 071$ & SW8260 & Chloroform & Soil \\
\hline $271 \mathrm{C} 071$ & SW8260 & Chloromethane & Soil \\
\hline $271 \mathrm{C} 071$ & SW8260 & Cis-1,2-Dichloroethene & Soil \\
\hline $271 \mathrm{C} 071$ & SW8260 & Cis-1,3-Dichloropropene & Soil \\
\hline $271 \mathrm{C} 071$ & SW8260 & Dibromochloromethane & Soil \\
\hline $271 \mathrm{C} 071$ & SW8260 & Dibromomethane & Soil \\
\hline $271 \mathrm{C} 071$ & SW8260 & Dichlorodifluoromethane & Soil \\
\hline $271 \mathrm{C} 071$ & SW8260 & Ethylbenzene & Soil \\
\hline $271 \mathrm{C} 071$ & SW8260 & Hexachlorobutadiene & Soil \\
\hline $271 \mathrm{C} 071$ & SW8260 & lodomethane & Soil \\
\hline $271 \mathrm{C} 071$ & SW8260 & Isopropylbenzene & Soil \\
\hline $271 \mathrm{C} 071$ & SW8260 & M+P-Xylene & Soil \\
\hline $271 \mathrm{C} 071$ & SW8260 & Methyl Tertiary Butyl Ether & Soil \\
\hline $271 \mathrm{C} 071$ & SW8260 & N-Butylbenzene & Soil \\
\hline $271 \mathrm{C} 071$ & SW8260 & N-Propylbenzene & Soil \\
\hline $271 \mathrm{C} 071$ & SW8260 & Naphthalene & Soil \\
\hline $271 \mathrm{C} 071$ & SW8260 & O-Xylene & Soil \\
\hline $271 \mathrm{C} 071$ & SW8260 & P-Isopropyltoluene & Soil \\
\hline $271 \mathrm{C} 071$ & SW8260 & Sec-Butylbenzene & Soil \\
\hline $271 \mathrm{C} 071$ & SW8260 & Styrene & Soil \\
\hline $271 \mathrm{C} 071$ & SW8260 & Tert-Butylbenzene & Soil \\
\hline $271 \mathrm{C} 071$ & SW8260 & Tetrachloroethene & Soil \\
\hline
\end{tabular}


Table B.1-14

CAU 271 Rejected Data for CAS 25-04-04

(Page 4 of 5)

\begin{tabular}{|c|c|c|c|}
\hline $\begin{array}{c}\text { Sample } \\
\text { Identification Number }\end{array}$ & $\begin{array}{l}\text { Laboratory } \\
\text { Method }\end{array}$ & Parameter & $\begin{array}{l}\text { Sample } \\
\text { Matrix }\end{array}$ \\
\hline $271 \mathrm{C} 071$ & SW8260 & Toluene & $\overline{\text { Soil }}$ \\
\hline $271 \mathrm{C} 071$ & SW8260 & Trans-1,2-Dichloroethene & Soil \\
\hline $271 \mathrm{C} 071$ & SW8260 & Trans-1,3-Dichloropropene & Soil \\
\hline $271 \mathrm{C} 071$ & SW8260 & Trichloroethene & Soil \\
\hline $271 \mathrm{C} 071$ & SW8260 & Trichlorofluoromethane & Soil \\
\hline $271 \mathrm{C} 071$ & SW8260 & Trichlorotrifluoroethane & Soil \\
\hline $271 \mathrm{C} 071$ & SW8260 & Vinyl Acetate & Soil \\
\hline $271 \mathrm{C} 071$ & SW8260 & Vinyl Chloride & Soil \\
\hline $271 \mathrm{C} 020$ & PAl713R6 & Cadmium-109 & Soil \\
\hline $271 \mathrm{C} 025$ & PAl713R6 & Cadmium-109 & Soil \\
\hline $271 C 079$ & PAl713R6 & Cadmium-109 & Soil \\
\hline $271 \mathrm{C} 001$ & SW8081 & 4,4'-DDD & Soil \\
\hline $271 \mathrm{C} 001$ & SW8081 & $4,4^{\prime}-\mathrm{DDE}$ & Soil \\
\hline $271 \mathrm{C} 001$ & SW8081 & $4,4^{\prime}-\mathrm{DDT}$ & Soil \\
\hline $271 \mathrm{C} 001$ & SW8081 & ALDRIN & Soil \\
\hline $271 \mathrm{C} 001$ & SW8081 & Alpha-BHC & Soil \\
\hline $271 \mathrm{C} 001$ & SW8081 & Beta-BHC & Soil \\
\hline $271 \mathrm{C} 001$ & SW8081 & Delta-BHC & Soil \\
\hline $271 \mathrm{C} 001$ & SW8081 & Dieldrin & Soil \\
\hline $271 \mathrm{C} 001$ & SW8081 & Endosulfan I & Soil \\
\hline $271 \mathrm{C} 001$ & SW8081 & Endosulfan II & Soil \\
\hline $271 \mathrm{C} 001$ & SW8081 & Endosulfan Sulfate & Soil \\
\hline $271 \mathrm{C} 001$ & SW8081 & Endrin Aldehyde & Soil \\
\hline $271 \mathrm{C} 001$ & SW8081 & Endrin Ketone & Soil \\
\hline $271 \mathrm{C} 001$ & SW8081 & Gamma-BHC (Lindane) & Soil \\
\hline $271 \mathrm{C} 001$ & SW8081 & Heptachlor & Soil \\
\hline $271 \mathrm{C} 001$ & SW8081 & Heptachlor Epoxide & Soil \\
\hline $271 \mathrm{C} 001$ & SW8081 & Methoxychlor & Soil \\
\hline $271 \mathrm{C} 001$ & SW8081 & Toxaphene & Soil \\
\hline $271 \mathrm{C} 003$ & SW8081 & 4,4'-DDD & Soil \\
\hline $271 \mathrm{C003}$ & SW8081 & $4,4^{\prime}-\mathrm{DDE}$ & Soil \\
\hline $271 \mathrm{C003}$ & SW8081 & Aldrin & Soil \\
\hline $271 \mathrm{C003}$ & SW8081 & Alpha-BHC & Soil \\
\hline
\end{tabular}


Table B.1-14

CAU 271 Rejected Data for CAS 25-04-04

(Page 5 of 5)

\begin{tabular}{|c|c|c|c|}
\hline $\begin{array}{c}\text { Sample } \\
\text { Identification Number }\end{array}$ & $\begin{array}{l}\text { Laboratory } \\
\text { Method }\end{array}$ & Parameter & $\begin{array}{l}\text { Sample } \\
\text { Matrix }\end{array}$ \\
\hline $271 \mathrm{C003}$ & SW8081 & Beta-BHC & Soil \\
\hline $271 \mathrm{C003}$ & SW8081 & Delta-BHC & Soil \\
\hline $271 \mathrm{C003}$ & SW8081 & Dieldrin & Soil \\
\hline $271 \mathrm{C003}$ & SW8081 & Endosulfan I & Soil \\
\hline $271 \mathrm{C003}$ & SW8081 & Endosulfan II & Soil \\
\hline $271 \mathrm{C003}$ & SW8081 & Endosulfan Sulfate & Soil \\
\hline $271 \mathrm{C} 003$ & SW8081 & Endrin & Soil \\
\hline $271 \mathrm{C} 003$ & SW8081 & Endrin Aldehyde & Soil \\
\hline $271 \mathrm{C003}$ & SW8081 & Endrin Ketone & Soil \\
\hline $271 \mathrm{C} 003$ & SW8081 & Gamma-BHC (Lindane) & Soil \\
\hline $271 \mathrm{C} 003$ & SW8081 & Heptachlor & Soil \\
\hline $271 \mathrm{C} 003$ & SW8081 & Heptachlor Epoxide & Soil \\
\hline $271 \mathrm{C003}$ & SW8081 & Methoxychlor & Soil \\
\hline $271 \mathrm{C003}$ & SW8081 & Toxaphene & Soil \\
\hline $271 \mathrm{C} 006$ & SW8081 & $4,4^{\prime}-\mathrm{DDD}$ & Soil \\
\hline $271 \mathrm{C006}$ & SW8081 & Aldrin & Soil \\
\hline $271 \mathrm{C} 006$ & SW8081 & Alpha-BHC & Soil \\
\hline $271 \mathrm{C} 006$ & SW8081 & Beta-BHC & Soil \\
\hline $271 \mathrm{C006}$ & SW8081 & Delta-BHC & Soil \\
\hline $271 \mathrm{C} 006$ & SW8081 & Dieldrin & Soil \\
\hline $271 \mathrm{C006}$ & SW8081 & Endosulfan I & Soil \\
\hline $271 \mathrm{C} 006$ & SW8081 & Endosulfan II & Soil \\
\hline $271 \mathrm{C} 006$ & SW8081 & Endosulfan Sulfate & Soil \\
\hline $271 \mathrm{C} 006$ & SW8081 & Endrin & Soil \\
\hline $271 \mathrm{C} 006$ & SW8081 & Endrin Aldehyde & Soil \\
\hline $271 \mathrm{C} 006$ & SW8081 & Endrin Ketone & Soil \\
\hline $271 \mathrm{C} 006$ & SW8081 & Gamma-BHC (Lindane) & Soil \\
\hline $271 \mathrm{C} 006$ & SW8081 & Heptachlor & Soil \\
\hline $271 \mathrm{C006}$ & SW8081 & Heptachlor Epoxide & Soil \\
\hline $271 \mathrm{C} 006$ & SW8081 & Methoxychlor & Soil \\
\hline $271 \mathrm{C006}$ & SW8081 & Toxaphene & Soil \\
\hline $271 \mathrm{C} 207$ & SW8270 & 4,6-Dinitro-2-Methylphenol & Soil \\
\hline 271 C229 & SW8260 & Acetone & Soil \\
\hline
\end{tabular}


In addition to volatiles, cadmium-109 was rejected in several samples due to spectral problems, thereby preventing accurate identification. Cadmium-109 was not considered a COPC for CAS 25-04-04 per the CAIP (its half-life is too short to be a COPC).

Three samples (i.e., 271C001, 271C003, and 271C006) were rejected for pesticide analysis because they exceeded the holding time. While this type of infraction provides little information in terms of how sample analyses are affected, the loss of these pesticide data for this CAS may not have a significant impact on closure decisions. Pesticides are also not drastically affected by longer holding times. Pesticides in all other nonrejected samples were well below the PAL; therefore, it is unlikely that results from these samples would affect closure decisions.

The rejected results for VOCs, SVOCs, cadmium-109, and pesticides in soils are considered acceptable data gaps given the explanations provided above and should not affect closure decisions for CAS 25-04-04.

Acetone results were rejected in two sludge samples (i.e., 271C074 and 271C074RR1) due to a low relative response factor. Acetone values in sludge have no designated action levels. In addition, acetone was reported in only one sludge sample analysis conducted for this site and was much lower than the values noted above. Acetone for CAU 271 has been well below PALs for all samples collected.

Several SVOC results were rejected in sludge sample 271C074 because laboratory QC specifications could not be achieved. Reported concentrations were below detection limits, but actual concentrations are unknown. Laboratory detection limits could be disposal limits for this sample due to reported dilution factors. This could affect data quality given the uncertainty of the results. However, the rejected compounds were not detected above concentrations of regulatory concern in a TCLP SVOC analysis of sample 271C074.

Several SVOC results for liquid sample 271C073 were rejected because of internal QC problems within the laboratory. Internal standard area counts exceeded QC standards, suggesting improper calibration for the reported results. Because SVOCs for this CAS were not found to be above PALs in soils, the data gap caused by the above sample should be considered acceptable and should not affect closure decisions for CAS 25-04-04. 
Acetone results were rejected in one water sample (i.e., 2271C075) due to a low relative response factor. Because the data were rejected and it is possible that some quantity of acetone remained undetected, it is also possible that acetone is present at a higher concentration. The actual concentrations remain unknown. However, it is unlikely that acetone in these rejected data would exceed PALs since acetone contamination has not been a problem for this CAS.

\section{B.1.3.4 BREN Tower Septic System (CAS 25-04-08) Rejected Data}

Table B.1-15 contains the rejected results per analytical method for CAS 25-04-08.

Acetone results were rejected in several soil samples due to a low relative response factor. Laboratory reported values were just above the MDL for all rejected soil samples. Because acetone data were rejected and some quantity of acetone likely remained undetected, it is possible that acetone is present at a higher concentration, suggesting in a worst-case scenario that rejected data for acetone could be higher than the MRL. However, acetone was not detected in any of the nonrejected samples in this CAS. It should also be noted that acetone has not been found at levels even close to the PAL for any of the CAU 271 sites. Potential concentrations of acetone in these rejected data would be far below PALs; therefore, these rejected results would not likely affect closure decisions for CAS 25-04-08.

In addition to acetone, one soil sample had rejected results for thorium-234 due to spectral problems preventing accurate identification. The rejected result was below any potential action level for this compound. This radionuclide was not considered a COPC for this CAS per the CAIP and was not reported above MRLs for any other samples. Rejected data for acetone and thorium-234 are considered acceptable data gaps and should not affect closure decisions for CAS 25-04-08.

Two sludge samples (i.e., 271D022 and 271D024) had rejected results for several SVOCs due to internal standards that did not meet QC requirements. The QC failure was possibly due to sample matrix effects; therefore, compound identification should be considered positive, but reported values are likely biased. One sample (i.e., 271D022) had rejected results for several VOCs due to internal standards that did not meet QC requirements. The results were rejected because of possible sample matrix effects; therefore, compound identification should be considered positive but reported values are likely biased. In addition, there were no VOCs reported above the MRL for this sample, and 
Table B.1-15

CAU 271 Rejected Data for CAS 25-04-08

(Page 1 of 2)

\begin{tabular}{|c|c|c|c|}
\hline $\begin{array}{c}\text { Sample } \\
\text { Identification } \\
\text { Number }\end{array}$ & $\begin{array}{l}\text { Laboratory } \\
\text { Method }\end{array}$ & Parameter & Sample Matrix \\
\hline$\overline{\overline{271 D 022}}$ & $\overline{\text { SW8260 }}$ & 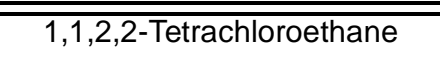 & 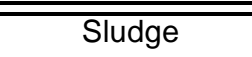 \\
\hline 271D022 & SW8260 & 1,2,3-Trichlorobenzene & Sludge \\
\hline $271 \mathrm{D} 022$ & SW8260 & 1,2,3-Trichloropropane & Sludge \\
\hline $271 \mathrm{D} 022$ & SW8260 & 1,2,4-Trichlorobenzene & Sludge \\
\hline 271D022 & SW8260 & 1,2-Dibromo-3-Chloropropane & Sludge \\
\hline 271D022 & SW8260 & 1,2-Dichlorobenzene & Sludge \\
\hline $271 \mathrm{D} 022$ & SW8260 & 1,4-Dichlorobenzene & Sludge \\
\hline $271 \mathrm{D} 022$ & SW8260 & 2-Chlorotoluene & Sludge \\
\hline 271D022 & SW8260 & 4-Chlorotoluene & Sludge \\
\hline 271D022 & SW8260 & Bromobenzene & Sludge \\
\hline $271 \mathrm{D} 022$ & SW8260 & Hexachlorobutadiene & Sludge \\
\hline $271 \mathrm{D} 022$ & SW8260 & Isopropylbenzene & Sludge \\
\hline $271 \mathrm{D} 022$ & SW8260 & N-Propylbenzene & Sludge \\
\hline $271 \mathrm{D} 022$ & SW8260 & Naphthalene & Sludge \\
\hline 271D022 & SW8260 & Tert-Butylbenzene & Sludge \\
\hline $271 \mathrm{D} 022$ & SW8270 & 3,3'-Dichlorobenzidine & Sludge \\
\hline $271 \mathrm{D} 022$ & SW8270 & Benzo(a)Anthracene & Sludge \\
\hline $271 \mathrm{D} 022$ & SW8270 & Benzo(a)Pyrene & Sludge \\
\hline 271D022 & SW8270 & Benzo(b)Fluoranthene & Sludge \\
\hline 271D022 & SW8270 & Benzo(g,h,i)Perylene & Sludge \\
\hline 271D022 & SW8270 & Benzo(k)Fluoranthene & Sludge \\
\hline 271D022 & SW8270 & Butyl Benzyl Phthalate & Sludge \\
\hline $271 \mathrm{D} 022$ & SW8270 & Chrysene & Sludge \\
\hline $271 \mathrm{D} 022$ & SW8270 & Di-N-Octyl Phthalate & Sludge \\
\hline 271D022 & SW8270 & Dibenzo(a,h)Anthracene & Sludge \\
\hline 271D022 & SW8270 & Indeno(1,2,3-cd)Pyrene & Sludge \\
\hline $271 \mathrm{D} 022$ & SW8270 & Pyrene & Sludge \\
\hline $271 \mathrm{D} 024$ & SW8270 & 3,3'-Dichlorobenzidine & Sludge \\
\hline $271 \mathrm{D} 024$ & SW8270 & Benzo(a)Anthracene & Sludge \\
\hline $271 \mathrm{D} 024$ & SW8270 & Benzo(a)Pyrene & Sludge \\
\hline $271 \mathrm{D} 024$ & SW8270 & Benzo(b)Fluoranthene & Sludge \\
\hline $271 \mathrm{D} 024$ & SW8270 & Benzo(g,h,i)Perylene & Sludge \\
\hline $271 \mathrm{D} 024$ & SW8270 & Benzo(k)Fluoranthene & Sludge \\
\hline
\end{tabular}


Table B.1-15

CAU 271 Rejected Data for CAS 25-04-08

(Page 2 of 2)

\begin{tabular}{|c|c|c|c|}
\hline $\begin{array}{c}\text { Sample } \\
\text { Identification } \\
\text { Number }\end{array}$ & $\begin{array}{c}\text { Laboratory } \\
\text { Method }\end{array}$ & Sample Matrix \\
\hline \hline $271 \mathrm{D} 024$ & SW8270 & Butyl Benzyl Phthalate & Sludge \\
\hline $271 \mathrm{D} 024$ & SW8270 & Chrysene & Sludge \\
\hline $271 \mathrm{D} 024$ & SW8270 & Di-N-Octyl Phthalate & Sludge \\
\hline $271 \mathrm{D} 024$ & SW8270 & Dibenzo(a,h)Anthracene & Sludge \\
\hline $271 \mathrm{D} 024$ & SW8270 & Indeno(1,2,3-cd)Pyrene & Sludge \\
\hline $271 \mathrm{D} 024$ & SW8270 & Pyrene & Soil \\
\hline $271 \mathrm{D} 011$ & PAl713R6 & Thorium-234 & Soil \\
\hline $271 \mathrm{D} 011$ & SW8260 & Acetone & Soil \\
\hline $271 \mathrm{D} 013$ & SW8260 & Acetone & Soil \\
\hline 271D014 & SW8260 & Acetone & Soil \\
\hline 271D016 & SW8260 & Acetone & Soil \\
\hline $271 \mathrm{D} 018$ & SW8260 & Acetone & \\
\hline
\end{tabular}

detected VOC concentrations have been consistently below PALs. There were no detections of SVOCs or VOCs above regulatory limits in TCLP analyses for both of the sludge samples. Rejected sludge data are considered acceptable data gaps and should not affect closure decisions for CAS 25-04-08.

\section{B.1.3.5 Engine Test Stand No. 1 Septic System (CAS 25-04-09) Rejected Data}

Table B.1-16 contains the rejected results per analytical method for CAS 25-04-09.

Acetone results were rejected in several soil samples due to a low relative response factor.

Laboratory reported values were just above the MDL for all rejected soil samples. Because acetone data were rejected and some quantity of acetone likely remained undetected, it is possible that acetone is present at a higher concentration, suggesting in a worst-case scenario that rejected data for acetone could be higher than the MRL. Potential concentrations of acetone in these rejected data would be far below PALs. Therefore, these rejected results would not likely affect conclusions with regard to 
Table B.1-16

CAU 271 Rejected Data for CAS 25-04-09

(Page 1 of 2)

\begin{tabular}{|c|c|c|c|}
\hline $\begin{array}{c}\text { Sample } \\
\text { Identification } \\
\text { Number }\end{array}$ & $\begin{array}{l}\text { Laboratory } \\
\text { Method }\end{array}$ & Parameter & Sample Matrix \\
\hline 271E001 & SW8260 & Acetone & Soil \\
\hline 271E004 & SW8260 & Acetone & Soil \\
\hline 271E006 & SW8260 & Acetone & Soil \\
\hline 271E007 & SW8260 & Acetone & Soil \\
\hline 271E009 & SW8260 & Acetone & Soil \\
\hline 271E011 & SW8260 & Acetone & Soil \\
\hline 271E015 & SW8260 & Acetone & Soil \\
\hline 271E017 & SW8260 & Acetone & Soil \\
\hline 271E019 & SW8260 & Acetone & Soil \\
\hline 271E021 & SW8260 & Acetone & Soil \\
\hline 271E023 & SW8260 & Acetone & Soil \\
\hline 271E025 & SW8260 & Acetone & Soil \\
\hline 271E027 & SW8260 & Acetone & Soil \\
\hline 271E029 & SW8260 & Acetone & Soil \\
\hline 271E031 & SW8260 & Acetone & Soil \\
\hline 271E033 & SW8260 & Acetone & Soil \\
\hline 271E035 & SW8260 & Acetone & Soil \\
\hline 271E036 & SW8260 & Acetone & Soil \\
\hline 271E038 & SW8260 & Acetone & Soil \\
\hline 271E040 & SW8260 & Acetone & Soil \\
\hline 271E041 & SW8260 & Acetone & Soil \\
\hline 271E043 & SW8260 & Acetone & Soil \\
\hline 271E044 & SW8260 & Acetone & Soil \\
\hline 271E048 & SW8260 & Acetone & Soil \\
\hline 271E050 & SW8260 & Acetone & Soil \\
\hline
\end{tabular}


Table B.1-16

CAU 271 Rejected Data for CAS 25-04-09

(Page 2 of 2)

\begin{tabular}{|c|c|c|c|}
\hline $\begin{array}{c}\text { Sample } \\
\text { Identification } \\
\text { Number }\end{array}$ & $\begin{array}{l}\text { Laboratory } \\
\text { Method }\end{array}$ & Parameter & Sample Matrix \\
\hline 271E054 & SW8260 & Acetone & Soil \\
\hline 271E070 & SW8260 & Acetone & Soil \\
\hline 271E052 & SW8270 & 3,3'-Dichlorobenzidine & Sediment \\
\hline 271E052 & SW8270 & Benzo(a)Anthracene & Sediment \\
\hline 271E052 & SW8270 & Butyl Benzyl Phthalate & Sediment \\
\hline 271E052 & SW8270 & Chrysene & Sediment \\
\hline 271E052 & SW8270 & Pyrene & Sediment \\
\hline 271E053 & SW8270 & 3,3'-Dichlorobenzidine & Sediment \\
\hline 271E053 & SW8270 & Benzo(a)pyrene & Sediment \\
\hline 271E053 & SW8270 & Benzo(b)fluoranthene & Sediment \\
\hline 271E053 & SW8270 & Benzo(g,h,i)perylene & Sediment \\
\hline 271E053 & SW8270 & Benzo(k)fluoranthene & Sediment \\
\hline 271E053 & SW8270 & Di-n-octyl phthalate & Sediment \\
\hline 271E053 & SW8270 & Dibenzo(a,h)anthracene & Sediment \\
\hline 271E053 & SW8270 & Indeno(1,2,3-cd)pyrene & Sediment \\
\hline 271E052 & PAI704R5 & Tritium & Sediment \\
\hline 271E043 & PAI713R6 & Cadmium-109 & Soil \\
\hline
\end{tabular}


acetone contamination. It should be noted that acetone has not been found at levels even close to the PAL for any of the CAU 271 sites.

In addition to acetone, the cadmium-109 result was rejected in soil sample 271E043 due to spectral problems, thereby preventing accurate identification. Tritium was rejected in sediment sample $271 \mathrm{E} 052$ at a concentration below the MRL but potentially above the action limit. Tritium was not a COPC for CAS 25-04-09. Cadmium-109 was not considered a COPC for CAS 25-04-09 per the CAIP (its half-life is too short to be a COPC). The tritium result remains in question but tritium was not found in any other CAS, suggesting that this result was an analytical artifact. Also, the sediment in the septic tank at this CAS was dry, so it is not likely that tritium is present. These rejected results are considered acceptable data gaps given the explanations provided above and should not affect closure decisions for CAS 25-04-09.

Two sediment (i.e., 271E052 and 271E053) had rejected results for several SVOCs due to internal standards that did not meet QC requirements. The QC failure was possibly due to sample matrix effects. Compound identification should be considered positive but reported values are likely biased. In addition, results of nonrejected data showed that some SVOCs were present in the sludge; however, there are no designated PALs for total analysis of any of the detected SVOCs. This is not an issue because a TCLP analysis of the sediment samples indicates that SVOCs are not present in concentrations of regulatory concern. These rejected results are considered acceptable data gaps given the explanations provided above and should not affect closure decisions for CAS 25-04-09.

\section{B.1.3.6 Rad-Safe Trailers Septic System (CAS 25-04-10) Rejected Data}

Table B.1-17 contains the rejected results per analytical method for CAS 25-04-10.

Acetone results were rejected in several soil samples due to a low relative response factor. Laboratory reported values were just above the MDL for all rejected soil samples. Because acetone data were rejected and some quantity of acetone likely remained undetected, it is possible that acetone is present at a higher concentration, suggesting in a worst-case scenario that rejected data for acetone could be higher than the MRL. However, acetone was not detected in any of the nonrejected samples in this CAS. It should be noted that acetone has not been found at levels even close to the PAL for any of the CAU 271 sites. Potential concentrations of acetone in these rejected data would be far 
Table B.1-17

CAU 271 Rejected Data for CAS 25-04-10

\begin{tabular}{|c|c|c|c|}
\hline $\begin{array}{c}\text { Sample } \\
\text { Identification } \\
\text { Number }\end{array}$ & $\begin{array}{l}\text { Laboratory } \\
\text { Method }\end{array}$ & Parameter & Sample Matrix \\
\hline$\overline{271 \mathrm{~F} 001}$ & SW8260 & Acetone & Soil \\
\hline $271 \mathrm{~F} 003$ & SW8260 & Acetone & Soil \\
\hline 271F005 & SW8260 & Acetone & Soil \\
\hline $271 \mathrm{~F} 007$ & SW8260 & Acetone & Soil \\
\hline 271F009 & SW8260 & Acetone & Soil \\
\hline 271F011 & SW8260 & Acetone & Soil \\
\hline $271 \mathrm{~F} 013$ & SW8260 & Acetone & Soil \\
\hline $271 \mathrm{~F} 015$ & SW8260 & Acetone & Soil \\
\hline $271 \mathrm{~F} 016$ & SW8260 & Acetone & Soil \\
\hline $271 \mathrm{~F} 018$ & SW8260 & Acetone & Soil \\
\hline 271F020 & SW8260 & Acetone & Soil \\
\hline 271F022 & SW8260 & Acetone & Soil \\
\hline $271 \mathrm{~F} 037$ & SW8260 & Acetone & Soil \\
\hline 271F039 & SW8260 & Acetone & Soil \\
\hline $271 \mathrm{~F} 041$ & SW8260 & Acetone & Soil \\
\hline $271 \mathrm{~F} 043$ & SW8260 & Acetone & Soil \\
\hline $271 \mathrm{~F} 045$ & SW8260 & Acetone & Soil \\
\hline $271 \mathrm{~F} 047$ & SW8260 & Acetone & Soil \\
\hline 271F049 & SW8260 & Acetone & Soil \\
\hline $271 \mathrm{~F} 051$ & SW8260 & Acetone & Soil \\
\hline $271 \mathrm{~F} 053$ & SW8260 & Acetone & Soil \\
\hline 271F055 & SW8260 & Acetone & Soil \\
\hline $271 \mathrm{~F} 056$ & SW8260 & Acetone & Soil \\
\hline $271 \mathrm{~F} 058$ & SW8260 & Acetone & Soil \\
\hline 271F060 & SW8260 & Acetone & Soil \\
\hline 271F062 & SW8260 & Acetone & Soil \\
\hline 271F064 & SW8260 & Acetone & Soil \\
\hline 271F066 & SW8260 & Acetone & Soil \\
\hline 271F068 & SW8260 & Acetone & Soil \\
\hline $271 \mathrm{~F} 026$ & PAl713R6 & Cadmium-109 & Soil \\
\hline $271 \mathrm{~F} 047$ & PAI713R6 & Cadmium-109 & Soil \\
\hline
\end{tabular}


below PALs, and these rejected results would not likely affect conclusions with regard to acetone contamination.

In addition to acetone, two soil samples had rejected results for cadmium-109 due to spectral problems preventing accurate identification. The rejected results were below any potential action level for this compound. This radionuclide was not considered a COPC for this CAS per the CAIP (its half-life is too short to be a COPC). Rejected data for acetone and cadmium-109 are considered acceptable data gaps and should not affect closure decisions for CAS 25-04-10.

\section{B.1.3.7 South of LASL Trailers Septic System (CAS 25-04-11) Rejected Data}

Table B.1-18 contains the rejected results per analytical method for CAS 25-04-11.

Acetone results were rejected in several soil samples due to a low relative response factor. Laboratory reported values were just above the MDL for all rejected soil samples. Because acetone data were rejected and some quantity of acetone likely remained undetected, it is possible that acetone is present at a higher concentration, suggesting in a worst-case scenario that rejected data for acetone could be higher than the MRL. Potential concentrations of acetone in these rejected data would be far below PALs, and these rejected results would not likely affect conclusions with regard to acetone contamination. It should also be noted that acetone has not been found at levels even close to the PAL for any of the CAU 271 sites.

Manhole sediment sample 271G072 had several rejected data results for VOCs (other than acetone) due to poor surrogate and internal standard recovery. These rejected results represent a potential for unreported contamination present in this CAS; however, volatiles have not been found in concentrations approaching their PALs for this CAS or for CAU 271 in general. Few nonrejected samples have had detectable concentrations of VOCs above the MRL; therefore, it would seem unlikely that this sample contains VOC contamination.

Two soil samples (i.e., 271G022 and 271G042) had rejected results for cadmium-109 due to spectral problems preventing accurate identification. The rejected results were below any potential action level for this radionuclide. Cadmium-109 was not considered a COPC for this CAS per the CAIP 
Table B.1-18

CAU 271 Rejected Data for CAS 25-04-11

(Page 1 of 3 )

\begin{tabular}{|c|c|c|c|}
\hline $\begin{array}{c}\text { Sample } \\
\text { Identification } \\
\text { Number }\end{array}$ & $\begin{array}{l}\text { Laboratory } \\
\text { Method }\end{array}$ & Parameter & Sample Matrix \\
\hline $271 \mathrm{G} 019$ & SW8260 & Acetone & $\overline{\text { Soil }}$ \\
\hline $271 \mathrm{G} 021$ & SW8260 & Acetone & Soil \\
\hline $271 G 022$ & SW8260 & Acetone & Soil \\
\hline $271 G 024$ & SW8260 & Acetone & Soil \\
\hline $271 \mathrm{G} 026$ & SW8260 & Acetone & Soil \\
\hline $271 \mathrm{G} 028$ & SW8260 & Acetone & Soil \\
\hline 271G030 & SW8260 & Acetone & Soil \\
\hline $271 \mathrm{G} 032$ & SW8260 & Acetone & Soil \\
\hline $271 \mathrm{G} 034$ & SW8260 & Acetone & Soil \\
\hline $271 \mathrm{G} 036$ & SW8260 & Acetone & Soil \\
\hline $271 \mathrm{G} 037$ & SW8260 & Acetone & Soil \\
\hline $271 \mathrm{G} 038$ & SW8260 & Acetone & Soil \\
\hline $271 \mathrm{G} 041$ & SW8260 & Acetone & Soil \\
\hline $271 \mathrm{G} 042$ & SW8260 & Acetone & Soil \\
\hline $271 \mathrm{G} 044$ & SW8260 & Acetone & Soil \\
\hline $271 \mathrm{G} 046$ & SW8260 & Acetone & Soil \\
\hline $271 \mathrm{G} 048$ & SW8260 & Acetone & Soil \\
\hline $271 \mathrm{G} 050$ & SW8260 & Acetone & Soil \\
\hline $271 \mathrm{G} 052$ & SW8260 & Acetone & Soil \\
\hline $271 \mathrm{G} 053$ & SW8260 & Acetone & Soil \\
\hline $271 \mathrm{G} 055$ & SW8260 & Acetone & Soil \\
\hline 271G057 & SW8260 & Acetone & Soil \\
\hline $271 G 059$ & SW8260 & Acetone & Soil \\
\hline $271 \mathrm{G} 061$ & SW8260 & Acetone & Soil \\
\hline $271 G 063$ & SW8260 & Acetone & Soil \\
\hline $271 \mathrm{G} 064$ & SW8260 & Acetone & Soil \\
\hline $271 \mathrm{G} 066$ & SW8260 & Acetone & Soil \\
\hline $271 G 068$ & SW8260 & Acetone & Soil \\
\hline 271G070 & SW8260 & Acetone & Soil \\
\hline $271 \mathrm{G} 072$ & SW8260 & 1,1,2,2-Tetrachloroethane & Sediment \\
\hline $271 G 072$ & SW8260 & 1,2,3-Trichlorobenzene & Sediment \\
\hline $271 \mathrm{G} 072$ & SW8260 & 1,2,3-Trichloropropane & Sediment \\
\hline $271 \mathrm{G} 072$ & SW8260 & 1,2,4-Trichlorobenzene & Sediment \\
\hline
\end{tabular}


Table B.1-18

CAU 271 Rejected Data for CAS 25-04-11

(Page 2 of 3 )

\begin{tabular}{|c|c|c|c|}
\hline $\begin{array}{c}\text { Sample } \\
\text { Identification } \\
\text { Number }\end{array}$ & $\begin{array}{l}\text { Laboratory } \\
\text { Method }\end{array}$ & Parameter & Sample Matrix \\
\hline $271 \mathrm{G} 072$ & SW8260 & 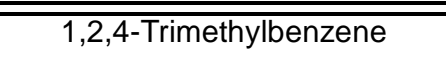 & Sediment \\
\hline $271 \mathrm{G} 072$ & SW8260 & 1,2-Dibromo-3-Chloropropane & Sediment \\
\hline 271G072 & SW8260 & 1,2-Dichlorobenzene & Sediment \\
\hline $271 \mathrm{G} 072$ & SW8260 & 1,3,5-Trimethylbenzene & Sediment \\
\hline $271 \mathrm{G} 072$ & SW8260 & 1,3-Dichlorobenzene & Sediment \\
\hline $271 \mathrm{G} 072$ & SW8260 & 1,4-Dichlorobenzene & Sediment \\
\hline 271G072 & SW8260 & 2-Chlorotoluene & Sediment \\
\hline $271 \mathrm{G} 072$ & SW8260 & 4-Chlorotoluene & Sediment \\
\hline $271 \mathrm{G} 072$ & SW8260 & Bromobenzene & Sediment \\
\hline $271 \mathrm{G} 072$ & SW8260 & Hexachlorobutadiene & Sediment \\
\hline $271 \mathrm{G} 072$ & SW8260 & Isopropylbenzene & Sediment \\
\hline $271 \mathrm{G} 072$ & SW8260 & N-Butylbenzene & Sediment \\
\hline $271 \mathrm{G} 072$ & SW8260 & N-Propylbenzene & Sediment \\
\hline $271 \mathrm{G} 072$ & SW8260 & Naphthalene & Sediment \\
\hline $271 \mathrm{G} 072$ & SW8260 & P-Isopropyltoluene & Sediment \\
\hline $271 \mathrm{G} 072$ & SW8260 & Sec-Butylbenzene & Sediment \\
\hline $271 \mathrm{G} 072$ & SW8260 & Tert-Butylbenzene & Sediment \\
\hline $271 \mathrm{G} 074$ & SW8260 & Acetone & Sludge \\
\hline $271 \mathrm{G} 076$ & SW8260 & Acetone & Sludge \\
\hline $271 \mathrm{G} 072$ & SW8270 & 3,3'-Dichlorobenzidine & Sediment \\
\hline $271 \mathrm{G} 072$ & SW8270 & Benzo(a)Anthracene & Sediment \\
\hline 271G072 & SW8270 & Benzo(a)Pyrene & Sediment \\
\hline $271 G 072$ & SW8270 & Benzo(b)Fluoranthene & Sediment \\
\hline $271 \mathrm{G} 072$ & SW8270 & Benzo(g,h,i)Perylene & Sediment \\
\hline $271 \mathrm{G} 072$ & SW8270 & Benzo(k)Fluoranthene & Sediment \\
\hline $271 \mathrm{G} 072$ & SW8270 & Butyl Benzyl Phthalate & Sediment \\
\hline $271 \mathrm{G} 072$ & SW8270 & Chrysene & Sediment \\
\hline $271 \mathrm{G} 072$ & SW8270 & Di-N-Octyl Phthalate & Sediment \\
\hline 271G072 & SW8270 & Dibenzo(a,h)Anthracene & Sediment \\
\hline $271 \mathrm{G} 072$ & SW8270 & Indeno(1,2,3-cd)Pyrene & Sediment \\
\hline $271 \mathrm{G} 072$ & SW8270 & Pyrene & Sediment \\
\hline $271 G 074$ & SW8270 & 3,3'-Dichlorobenzidine & Sludge \\
\hline $271 \mathrm{G} 074$ & SW8270 & Benzo(a)Anthracene & Sludge \\
\hline
\end{tabular}


Table B.1-18

CAU 271 Rejected Data for CAS 25-04-11

(Page 3 of 3 )

\begin{tabular}{|c|c|c|c|}
\hline $\begin{array}{c}\text { Sample } \\
\text { Identification } \\
\text { Number }\end{array}$ & $\begin{array}{l}\text { Laboratory } \\
\text { Method }\end{array}$ & Parameter & Sample Matrix \\
\hline $271 \mathrm{G} 074$ & SW8270 & Benzo(a)Pyrene & $\overline{\text { Sludge }}$ \\
\hline $271 \mathrm{G} 074$ & SW8270 & Benzo(b)Fluoranthene & Sludge \\
\hline $271 \mathrm{G} 074$ & SW8270 & Benzo(g,h,i)Perylene & Sludge \\
\hline $271 \mathrm{G} 074$ & SW8270 & Benzo(k)Fluoranthene & Sludge \\
\hline $271 \mathrm{G} 074$ & SW8270 & Butyl Benzyl Phthalate & Sludge \\
\hline $271 \mathrm{G} 074$ & SW8270 & Chrysene & Sludge \\
\hline $271 \mathrm{G} 074$ & SW8270 & Di-N-Octyl Phthalate & Sludge \\
\hline $271 G 074$ & SW8270 & Dibenzo(a,h)Anthracene & Sludge \\
\hline $271 \mathrm{G} 074$ & SW8270 & Indeno(1,2,3-cd)Pyrene & Sludge \\
\hline $271 \mathrm{G} 074$ & SW8270 & Pyrene & Sludge \\
\hline 271G076RR1 & SW8270 & Benzo(a)Pyrene & Sludge \\
\hline 271G076RR1 & SW8270 & Benzo(b)Fluoranthene & Sludge \\
\hline 271G076RR1 & SW8270 & Benzo(g,h,i)Perylene & Sludge \\
\hline 271G076RR1 & SW8270 & Benzo(k)Fluoranthene & Sludge \\
\hline 271G076RR1 & SW8270 & Bis (2-Ethylhexl) Phthalate & Sludge \\
\hline 271G076RR1 & SW8270 & Di-N-Octyl Phthalate & Sludge \\
\hline 271G076RR1 & SW8270 & Dibenzo(a,h)Anthracene & Sludge \\
\hline 271G076RR1 & SW8270 & Indeno(1,2,3-cd)Pyrene & Sludge \\
\hline $271 \mathrm{G} 022$ & PAI713R6 & Cadmium-109 & Soil \\
\hline $271 \mathrm{G} 042$ & PAI713R6 & Cadmium-109 & Soil \\
\hline $271 \mathrm{G} 052$ & PAI713R6 & Cadmium-109 & Soil \\
\hline
\end{tabular}

(its half-life is too short to be a COPC). Rejected data for VOCs and cadmium-109 are considered acceptable data gaps and, therefore, should not affect closure decisions for CAS 25-04-11.

Acetone results were rejected in two sludge samples (i.e., 271G074 and 271G076) due to a low relative response factor. Acetone values in sludge have no designated action levels. Acetone was not detected in concentrations of regulatory concern in TCLP analysis of these two sludge samples. 
Samples 271G074 and 271G076RR1 had rejected results for several SVOCs due to internal QC checks not meeting specifications. It was suggested that "Orangeburg" pipe present in this CAS is the source of soil contamination leading to false positive results for benzo(a)pryene, one of the rejected values in the sludge. Discussion of SVOC COPCs is included in Appendix A. Rejected data for volatiles and semivolatiles in sludge are considered acceptable data gaps and should not affect closure decisions for CAS 25-04-11. Although, the absence of benzo(a)pyrene data in septic tanks results must be evaluated.

\section{B.1.3.8 Port Gaston Training Area Contaminated Water Reservoir (CAS 26-03-01) Rejected Data}

Table B.1-19 contains the rejected results per analytical method for CAS 26-03-01.

Two soil samples (i.e., 271H015 and 271H016) had rejected results for cadmium-109 due to spectral problems preventing accurate identification; however, cadmium-109 was not considered a COPC for this CAS per the CAIP (its half-life is too short to be a COPC).

Cobalt-57, antimony-125, and europium-152 results were rejected in several soil samples due to spectral problems preventing accurate identification. Of these, europium-152 was the only radiological isotope identified in the CAIP. The rejected results would be below any potential action level for this radionuclide. None of these isotopes were considered COPCs and were not detected in nonrejected data for this CAS. Also, the half-lives for cobalt-57 and antimony-125 are too short for to be COPCs for CAU 271. Europium-152 cannot be eliminated by half-life considerations; however, its presence at CAS 26-03-01 is unlikely based on process knowledge. Rejected data for isotopes cobalt-57, antimony-125, and europium-152 are considered acceptable data gaps and should not affect closure decisions for CAS 26-03-01.

\section{B.1.3.9 Area 26 Check Station (BIdg. 2105) Septic System (CAS 26-04-01) Rejected Data}

Table B.1-20 contains the rejected results per analytical method for CAS 26-04-01.

Acetone results were rejected in several soil samples due to a low relative response factor.

Laboratory reported values were just above the MDL for all rejected soil samples. Because acetone 
Table B.1-19

CAU 271 Rejected Data for CAS 26-03-01

\begin{tabular}{||c|c|c|c||}
\hline $\begin{array}{c}\text { Sample } \\
\text { Identification } \\
\text { Number }\end{array}$ & $\begin{array}{c}\text { Laboratory } \\
\text { Method }\end{array}$ & Parameter & Sample Matrix \\
\hline \hline $271 \mathrm{H} 015$ & PAl713R6 & Cadmium-109 & Soil \\
\hline $271 \mathrm{H} 015$ & PAl713R6 & Cobalt-57 & Soil \\
\hline $271 \mathrm{H} 015$ & PAl713R6 & Antimony-125 & Soil \\
\hline $271 \mathrm{H} 016$ & PAl713R6 & Cadmium-109 & Soil \\
\hline $271 \mathrm{H} 016$ & PAl713R6 & Cobalt-57 & Soil \\
\hline $271 \mathrm{H} 016$ & PAl713R6 & Europium-152 & \\
\hline
\end{tabular}

data were rejected and some quantity of acetone likely remained undetected, it is possible that acetone is present at a higher concentration, suggesting in a worst-case scenario that rejected data for acetone could be higher than the MRL. Potential concentrations of acetone in these rejected data would be far below PALs; therefore, these rejected results would not likely affect conclusions in regards to acetone contamination. It should also be noted that acetone has not been found at levels close to the PAL for any of the CAU 271 sites.

In addition to acetone, cadmium-109 results were rejected in soil samples 271J024 and 271J021 due to spectral problems preventing accurate identification. The rejected results for cadmium-109 would be below any potential action level for this radionuclide, and its half-life is too short to be a COPC.

Uranium-234, -235, and -238 results were rejected in sediment sample 271J030. Loss of this single sample would still be acceptable in terms of achieving completeness objectives for this CAS. There is no indication that isotopic uranium analyses for this sample would have had results any different from other nonrejected data, which were not statistically distinguishable from background concentrations. Also, this sediment was collected from the distribution box and there is little to no sediment remaining in the box.

Pesticide analyses for soil sample 271J001 were rejected because the analysis exceeded holding time (additionally, surrogates were diluted out of the sample), meaning sample QC specifications could not be confirmed. This resulted in the loss of sample data; however, completeness objectives were 
Table B.1-20

CAU 271 Rejected Data for CAS 26-04-01

\begin{tabular}{|c|c|c|c|}
\hline $\begin{array}{c}\text { Sample } \\
\text { Identification } \\
\text { Number }\end{array}$ & $\begin{array}{l}\text { Laboratory } \\
\text { Method }\end{array}$ & Parameter & Sample Matrix \\
\hline $271 J 029$ & 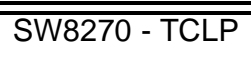 & Pyridine & Leachate \\
\hline 271J001 & SW8260 & Acetone & Soil \\
\hline 271J003 & SW8260 & Acetone & Soil \\
\hline 271J004 & SW8260 & Acetone & Soil \\
\hline 271J006 & SW8260 & Acetone & Soil \\
\hline 271J008 & SW8260 & Acetone & Soil \\
\hline 271J012 & SW8260 & Acetone & Soil \\
\hline 271J014 & SW8260 & Acetone & Soil \\
\hline 271J019 & SW8260 & Acetone & Soil \\
\hline 271J023 & SW8260 & Acetone & Soil \\
\hline 271J027 & SW8260 & Acetone & Soil \\
\hline 271J004 & PAI713R6 & Cadmium-109 & Soil \\
\hline 271J021 & PAl713R6 & Cadmium-109 & Soil \\
\hline 271J030 & PAI714R7 & Uranium-234 & Sediment \\
\hline 271J030 & PAI714R7 & Uranium-235 & Sediment \\
\hline 271J030 & PAI714R7 & Uranium-238 & Sediment \\
\hline 271J001 & SW8081 & 4,4'-DDD & Soil \\
\hline 271J001 & SW8081 & 4,4'-DDT & Soil \\
\hline $271 \mathrm{~J} 001$ & SW8081 & Aldrin & Soil \\
\hline $271 \mathrm{~J} 001$ & SW8081 & Alpha-BHC & Soil \\
\hline 271J001 & SW8081 & Beta-BHC & Soil \\
\hline 271J001 & SW8081 & Delta-BHC & Soil \\
\hline 271J001 & SW8081 & Dieldrin & Soil \\
\hline 271J001 & SW8081 & Endosulfan I & Soil \\
\hline 271J001 & SW8081 & Endosulfan II & Soil \\
\hline 271J001 & SW8081 & Endosulfan Sulfate & Soil \\
\hline 271J001 & SW8081 & Endrin Aldehyde & Soil \\
\hline 271J001 & SW8081 & Endrin Ketone & Soil \\
\hline 271J001 & SW8081 & Gamma-BHC (Lindane) & Soil \\
\hline 271J001 & SW8081 & Heptachlor Epoxide & Soil \\
\hline 271J001 & SW8081 & Methoxychlor & Soil \\
\hline 271J001 & SW8081 & Toxaphene & Soil \\
\hline
\end{tabular}


not compromised because of the loss of this single sample. In addition, pesticide analyses for nonrejected samples from this CAS showed that only two samples had concentrations of pesticides above the MRL and the reported results were below PALs. Rejected results for pesticides, acetone, cadmium-109, and isotopic uranium are considered acceptable data gaps given the explanations provided above and should not affect closure decisions for CAS 26-04-01.

A single TCLP SVOC result for pyridine was rejected due to a low relative response factor. Considering the fact that pyridine was not detected in the total SVOC analysis of sludge sample 271J029, the loss of this sample result should not affect closure decisions.

\section{B.1.3.10 Hot Critical Facility (BIdg. 2103) Septic System (CAS 26-04-02) Rejected Data}

Table B.1-21 contains the rejected results per analytical method for CAS 26-04-02.

Acetone results were rejected in several soil samples due to a low relative response factor.

Laboratory reported values were just above the MDL for all rejected soil samples. Because acetone data were rejected and some quantity of acetone likely remained undetected, it is possible that acetone is present at a higher concentration, suggesting that rejected data for acetone could be higher than the MRL. Potential concentrations of acetone in these rejected data would be far below PALs; therefore, these rejected results would not likely affect conclusions in regards to acetone contamination. It should also be noted that acetone has not been found at levels close to the PAL for any of the CAU 271 sites. These are considered acceptable data gaps and should not affect closure decisions for CAS 26-04-02.

A single pyridine result was rejected in a TCLP SVOC analysis for sludge. Because this analyte was not found in the total SVOC analysis performed for this sample, this rejected result has no affect on the reported data. This is considered acceptable data gap and should not affect closure decisions for CAS 26-04-02.

\section{B.1.3.11 Buildings 2201 and 2202 Radioactive Leachfield (CAS 26-05-01) Rejected Data}

Table B.1-22 contains the rejected results per analytical method for CAS 26-05-01. 
Table B.1-21

CAU 271 Rejected Data for CAS 26-04-02

\begin{tabular}{|c|c|c|c|}
\hline $\begin{array}{c}\text { Sample } \\
\text { Identification } \\
\text { Number }\end{array}$ & $\begin{array}{l}\text { Laboratory } \\
\text { Method }\end{array}$ & Parameter & Sample Matrix \\
\hline $271 \mathrm{~K} 031$ & SW8270 - TCLP & Pyridine & Leachate \\
\hline 271K001 & SW8260 & Acetone & Soil \\
\hline $271 \mathrm{~K} 003$ & SW8260 & Acetone & Soil \\
\hline $271 \mathrm{~K} 004$ & SW8260 & Acetone & Soil \\
\hline $271 \mathrm{~K} 006$ & SW8260 & Acetone & Soil \\
\hline 271K008 & SW8260 & Acetone & Soil \\
\hline $271 \mathrm{~K} 010$ & SW8260 & Acetone & Soil \\
\hline $271 \mathrm{~K} 012$ & SW8260 & Acetone & Soil \\
\hline $271 \mathrm{~K} 014$ & SW8260 & Acetone & Soil \\
\hline $271 \mathrm{~K} 018$ & SW8260 & Acetone & Soil \\
\hline $271 \mathrm{~K} 024$ & SW8260 & Acetone & Soil \\
\hline $271 \mathrm{~K} 027$ & SW8260 & Acetone & Soil \\
\hline $271 \mathrm{~K} 029$ & SW8260 & Acetone & Soil \\
\hline
\end{tabular}

Bromomethane results were rejected in several soil samples due to a low relative response factor. Laboratory reported values were at the MDL for all rejected soil samples. Because bromomethane data were rejected and some quantity of bromomethane could have remained undetected, it is also possible that bromomethane is present at a higher concentration, suggesting that rejected data for bromomethane could be higher than the MRL. However, bromomethane was not detected in any of the nonrejected samples in this CAS or any samples for CAU 271. Any potential concentrations of bromomethane in these rejected data would be unlikely to be above the PAL. Therefore, these rejected results would not affect conclusions in regards to bromomethane contamination.

In addition to bromomethane, two soil samples had rejected results for cadmium-109 due to spectral problems preventing accurate identification. The rejected results were below any potential action level for this radionuclide. Cadmium-109 was not detected in any other sample in this CAS, and its half-life is too short to be a COPC. The loss of these two samples do not affect completeness objectives. In addition, other radionuclides have been identified in this CAS as being statistically 
Table B.1-22

CAU 271 Rejected Data for CAS 26-05-01

\begin{tabular}{|c|c|c|c|}
\hline $\begin{array}{c}\text { Sample } \\
\text { Identification } \\
\text { Number }\end{array}$ & $\begin{array}{l}\text { Laboratory } \\
\text { Method }\end{array}$ & Parameter & Sample Matrix \\
\hline 271L002 & SW8260B & Bromomethane & Soil \\
\hline 271L004 & SW8260B & Bromomethane & Soil \\
\hline 271L006 & SW8260B & Bromomethane & Soil \\
\hline 271L008 & SW8260B & Bromomethane & Soil \\
\hline 271L010 & SW8260B & Bromomethane & Soil \\
\hline 271L012 & SW8260B & Bromomethane & Soil \\
\hline 271L014 & SW8260B & Bromomethane & Soil \\
\hline 271L016 & SW8260B & Bromomethane & Soil \\
\hline 271L018 & SW8260B & Bromomethane & Soil \\
\hline 271L020 & SW8260B & Bromomethane & Soil \\
\hline 271L021 & SW8260B & Bromomethane & Soil \\
\hline 271L023 & SW8260B & Bromomethane & Soil \\
\hline 271L025 & SW8260B & Bromomethane & Soil \\
\hline 271L027 & SW8260B & Bromomethane & Soil \\
\hline 271L029 & SW8260B & Bromomethane & Soil \\
\hline 271L031 & SW8260B & Bromomethane & Soil \\
\hline 271L033 & SW8260B & Bromomethane & Soil \\
\hline 271L035 & SW8260B & Bromomethane & Soil \\
\hline 271L037 & SW8260B & Bromomethane & Soil \\
\hline 271L039 & SW8260B & Bromomethane & Soil \\
\hline 271L041 & SW8260B & Bromomethane & Soil \\
\hline 271L043 & SW8260B & Bromomethane & Soil \\
\hline 271L045 & SW8260B & Bromomethane & Soil \\
\hline 271L046 & SW8260B & Bromomethane & Soil \\
\hline 271L048 & SW8260B & Bromomethane & Soil \\
\hline 271L050 & SW8260B & Bromomethane & Soil \\
\hline 271L052 & SW8260B & Bromomethane & Soil \\
\hline 271L054 & SW8260B & Bromomethane & Soil \\
\hline 271L056 & SW8260B & Bromomethane & Soil \\
\hline 271L058 & SW8260B & Bromomethane & Soil \\
\hline 271L060 & SW8260B & Bromomethane & Soil \\
\hline 271L062 & SW8260B & Bromomethane & Soil \\
\hline 271L064 & SW8260B & Bromomethane & Soil \\
\hline 271L008 & PAI713R6 & Cadmium-109 & Soil \\
\hline 271L021 & PAI713R6 & Cadmium-109 & Soil \\
\hline
\end{tabular}


greater than background and would overshadow any rejected cadmium-109 results in terms of recommended corrective actions. Rejected data for bromomethane and cadmium-109 are considered acceptable data gaps and should not affect closure decisions for CAS 26-05-01.

\section{B.1.3.12 Building 2203 Septic System (26-05-03) Rejected Data}

Table B.1-23 contains the rejected results per analytical method for CAS 26-05-03.

Bromomethane results were rejected in several soil samples due to a low relative response factor. Laboratory reported values were at the MDL for all rejected soil samples. Because bromomethane data were rejected and some quantity of bromomethane could have remained undetected, it is also possible that bromomethane is present at a higher concentration, suggesting that rejected data for bromomethane could be higher than the MRL. However, bromomethane was not detected in any of the nonrejected samples in this CAS or any samples for CAU 271. Potential concentrations of bromomethane in these rejected data would be unlikely to be above PALs. Therefore, these rejected results would not affect conclusions in regards to potential VOC contamination.

In addition to bromomethane, one soil sample (i.e., 271M062) had rejected results for cadmium-109 due to spectral problems preventing accurate identification. The rejected results were below any potential action level for this radionuclide, and its half-life is too short to be a COPC. Rejected data for bromomethane and cadmium-109 are considered acceptable data gaps and should not affect closure decisions for CAS 26-05-03.

Acetone results were rejected in one sediment sample (i.e., 271M079) due to a low relative response factor. Laboratory reported values were just above the minimum reporting limit. Because acetone data were rejected and some quantity of acetone likely remained undetected, it is possible that acetone in this sample is in reality present at a higher concentration, suggesting that rejected data for acetone could be higher than the MRL. The sediment in the septic tank and manhole are dry and present only in residual amounts. It is not likely that a VOC could remain in this material given these conditions. Sediment sample 271M079 also had rejected results for several SVOCs due to laboratory internal QC not meeting specifications. In this case, the reason for the rejected data would suggest inaccurate quantitation. The TCLP results for SVOCs and VOCs demonstrate that acetone and SVOCs are not present in the sediment at concentrations of regulatory concern. Rejected data for acetone and 
Table B.1-23

CAU 271 Rejected Data for CAS 26-05-03

\begin{tabular}{|c|c|c|c|}
\hline $\begin{array}{c}\text { Sample } \\
\text { Identification } \\
\text { Number }\end{array}$ & $\begin{array}{l}\text { Laboratory } \\
\text { Method }\end{array}$ & Parameter & Sample Matrix \\
\hline $271 \mathrm{M} 079$ & SW8260 & Acetone & Sediment \\
\hline $271 \mathrm{M} 079$ & SW8270 & 3,3'-Dichlorobenzidine & Sediment \\
\hline $271 \mathrm{M} 079$ & SW8270 & Butyl Benzyl Phthalate & Sediment \\
\hline 271M079 & SW8270 & Di-N-Octyl Phthalate & Sediment \\
\hline $271 \mathrm{M} 079$ & SW8270 & Dibenzo(a,h)Anthracene & Sediment \\
\hline 271M079RR1RR1 & SW8270 & 3,3'-Dichlorobenzidine & Sediment \\
\hline 271M079RR1RR1 & SW8270 & Butyl Benzyl Phthalate & Sediment \\
\hline 271M079RR1RR1 & SW8270 & Di-N-Octyl Phthalate & Sediment \\
\hline 271M079RR1RR1 & SW8270 & Dibenzo(a,h)Anthracene & Sediment \\
\hline $271 \mathrm{M} 001$ & SW8260B & Bromomethane & Soil \\
\hline $271 \mathrm{M} 003$ & SW8260B & Bromomethane & Soil \\
\hline $271 \mathrm{M} 005$ & SW8260B & Bromomethane & Soil \\
\hline $271 \mathrm{M} 006$ & SW8260B & Bromomethane & Soil \\
\hline $271 \mathrm{M} 010$ & SW8260B & Bromomethane & Soil \\
\hline $271 \mathrm{M} 012$ & SW8260B & Bromomethane & Soil \\
\hline $271 \mathrm{M} 024$ & SW8260B & Bromomethane & Soil \\
\hline $271 \mathrm{M} 026$ & SW8260B & Bromomethane & Soil \\
\hline $271 \mathrm{M} 028$ & SW8260B & Bromomethane & Soil \\
\hline $271 \mathrm{M} 034$ & SW8260B & Bromomethane & Soil \\
\hline $271 \mathrm{M} 062$ & PAI713R6 & Cadmium-109 & Soil \\
\hline
\end{tabular}


semivolatiles are considered acceptable data gaps and should not affect closure decisions for CAS 26-05-03.

\section{B.1.3.13 Building 2201 Septic System (CAS 26-05-04) Rejected Data}

Table B.1-24 contains the rejected results per analytical method for CAS 26-05-04.

Bromomethane results and one bromoform result were rejected in several soil samples due to a low relative response factor. Laboratory reported values were just above the MDL for all rejected soil samples. Because bromomethane and bromoform data were rejected and some quantity of bromomethane or bromoform could have remained undetected, it is also possible that bromomethane and bromoform are present at higher concentrations, suggesting that rejected data for these VOCs could be higher than the MRL. However, bromomethane and bromoform were not detected in any of the nonrejected samples in this CAS. It should also be noted that bromomethane or bromoform have not been detected in any samples for CAU 271. Potential concentrations of bromomethane or bromoform in these rejected data would be unlikely to be above PALs. Therefore, these rejected results would not affect conclusions with regard to VOC contamination.

In addition to volatiles, cadmium-109 and thorium-234 results were rejected in soil samples $271 \mathrm{~N} 021$ and 271N056, respectively. This rejection was due to spectral problems preventing accurate identification. The rejected results for cadmium-109 would be below any potential action level for this radionuclide, and its half-life is too short to be a COPC. Thorium-234 was not identified as a COPC or an analyte of interest in the CAIP. In addition, it is also present in natural background concentrations. Rejected data for these radionuclides are considered acceptable data gaps and should not affect closure decisions for CAS 26-05-04.

Acetone results were rejected in the septic tank sludge samples due to a low relative response factor. Acetone values in sludge have no designated action levels. Acetone was reported in only one of the sludge sample analyses conducted for this CAS, and it was not detected above MRLs in TCLP analysis of the sludge samples. Acetone concentrations for CAU 271 are well below PALs for all samples collected. 
Table B.1-24

CAU 271 Rejected Data for CAS 26-05-04

(Page 1 of 2)

\begin{tabular}{|c|c|c|c|}
\hline $\begin{array}{c}\text { Sample } \\
\text { Identification } \\
\text { Number }\end{array}$ & $\begin{array}{l}\text { Laboratory } \\
\text { Method }\end{array}$ & Parameter & Sample Matrix \\
\hline $271 \mathrm{~N} 181$ & SW8260 & Acetone & Liquid \\
\hline $271 \mathrm{~N} 185$ & SW8260 & Acetone & Liquid \\
\hline $271 N 182$ & SW8260 & Acetone & Sludge \\
\hline $271 N 183$ & SW8260 & Acetone & Sludge \\
\hline $271 \mathrm{~N} 184$ & SW8260 & Acetone & Sludge \\
\hline $271 \mathrm{~N} 083$ & SW8270 & 3,3'-Dichlorobenzidine & Sludge \\
\hline $271 \mathrm{~N} 083$ & SW8270 & Butyl Benzyl Phthalate & Sludge \\
\hline $271 \mathrm{~N} 010$ & SW8260B & Bromomethane & Soil \\
\hline $271 \mathrm{~N} 011$ & SW8260B & Bromomethane & Soil \\
\hline $271 \mathrm{~N} 012$ & SW8260B & Bromomethane & Soil \\
\hline $271 \mathrm{~N} 014$ & SW8260B & Bromomethane & Soil \\
\hline $271 \mathrm{~N} 016$ & SW8260B & Bromomethane & Soil \\
\hline $271 \mathrm{~N} 018$ & SW8260B & Bromomethane & Soil \\
\hline $271 \mathrm{~N} 020$ & SW8260B & Bromomethane & Soil \\
\hline $271 \mathrm{~N} 021$ & SW8260B & Bromomethane & Soil \\
\hline $271 \mathrm{~N} 032$ & SW8260B & Bromomethane & Soil \\
\hline $271 \mathrm{~N} 036$ & SW8260B & Bromomethane & Soil \\
\hline $271 \mathrm{~N} 038$ & SW8260B & Bromomethane & Soil \\
\hline $271 \mathrm{~N} 040$ & SW8260B & Bromomethane & Soil \\
\hline $271 \mathrm{~N} 042$ & SW8260B & Bromomethane & Soil \\
\hline $271 \mathrm{~N} 044$ & SW8260B & Bromomethane & Soil \\
\hline $271 \mathrm{~N} 047$ & SW8260B & Bromomethane & Soil \\
\hline $271 \mathrm{~N} 048$ & SW8260B & Bromomethane & Soil \\
\hline $271 \mathrm{~N} 050$ & SW8260B & Bromoform & Soil \\
\hline $271 \mathrm{~N} 053$ & SW8260B & Bromomethane & Soil \\
\hline 271 N056 & SW8260B & Bromomethane & Soil \\
\hline $271 \mathrm{~N} 058$ & SW8260B & Bromomethane & Soil \\
\hline $271 \mathrm{~N} 064$ & SW8260B & Bromomethane & Soil \\
\hline 271 N065 & SW8260B & Bromomethane & Soil \\
\hline $271 \mathrm{~N} 066$ & SW8260B & Bromomethane & Soil \\
\hline 271 N069 & SW8260B & Bromomethane & Soil \\
\hline $271 \mathrm{~N} 070$ & SW8260B & Bromomethane & Soil \\
\hline $271 \mathrm{~N} 071$ & SW8260B & Bromomethane & Soil \\
\hline
\end{tabular}


Table B.1-24

CAU 271 Rejected Data for CAS 26-05-04

(Page 2 of 2)

\begin{tabular}{||c|c|c|c||}
\hline $\begin{array}{c}\text { Sample } \\
\text { Identification } \\
\text { Number }\end{array}$ & $\begin{array}{c}\text { Laboratory } \\
\text { Method }\end{array}$ & Parameter & Sample Matrix \\
\hline \hline $271 \mathrm{~N} 074$ & SW8260B & Bromomethane & Soil \\
\hline $271 \mathrm{~N} 076$ & SW8260B & Bromomethane & Soil \\
\hline $271 \mathrm{~N} 078$ & SW8260B & Bromomethane & Soil \\
\hline $271 \mathrm{~N} 080$ & SW8260B & Bromomethane & Soil \\
\hline $271 \mathrm{~N} 021$ & PAl713R6 & Thorium-234 & Soil \\
\hline $271 \mathrm{~N} 056$ & PAl713R6 & Cadmium-109 & S \\
\hline
\end{tabular}

Sludge sample 271N083 had rejected results for several SVOCs due to laboratory internal QC not meeting specifications. In this case, the reason for the rejected data would suggest inaccurate quantitation. All reported data for the rejected results were below laboratory detection limits for these compounds and are unlikely to pose an unacceptable risk. Other than 1,4-dichlorobenzene, no organic compounds were detected above MRLs in TCLP data for septic tank sludge from this CAS. Rejected data for acetone and SVOCs are considered acceptable data gaps and should not affect closure decisions for CAS 26-05-04.

Acetone results were rejected in two liquid samples from the septic tank (271N181 and 271N185) due to a low relative response factor. The absence of acetone in TCLP data for the septic tank suggests acetone is not present in the tank contents. Rejected data for acetone are considered acceptable data gaps and should not affect closure decisions for CAS 26-05-04.

\section{B.1.3.14 Buildings 2101, 2102, and 2107 Septic System (CAS 26-05-05) Rejected Data}

Table B.1-25 contains the rejected result per analytical method for CAS 26-05-05.

Bromomethane results were rejected in several soil samples due to a low relative response factor. Laboratory reported values were just above the MDL for all rejected soil samples. Because bromomethane data were rejected and some quantity of bromomethane could have remained undetected, it is also possible that bromomethane in these samples is present at a higher 
Table B.1-25

CAU 271 Rejected Data for CAS 26-05-05

\begin{tabular}{|c|c|c|c|}
\hline $\begin{array}{c}\text { Sample } \\
\text { Identification } \\
\text { Number }\end{array}$ & $\begin{array}{l}\text { Laboratory } \\
\text { Method }\end{array}$ & Parameter & Sample Matrix \\
\hline $271 \mathrm{P} 081$ & SW8260 & Acetone & Liquid \\
\hline 271P082 & SW8260 & Acetone & Sludge \\
\hline 271P082 & SW8270 & Benzo(g,h,i)Perylene & Sludge \\
\hline $271 \mathrm{P} 082$ & SW8270 & Benzo(k)Fluoranthene & Sludge \\
\hline 271P082 & SW8270 & Di-N-Octyl Phthalate & Sludge \\
\hline 271P082 & SW8270 & Dibenzo(a,h)Anthracene & Sludge \\
\hline 271P082 & SW8270 & Indeno(1,2,3-cd)Pyrene & Sludge \\
\hline 271P082RR1 & SW8260 & Acetone & Sludge \\
\hline 271P001 & SW8260B & Bromomethane & Soil \\
\hline 271P003 & SW8260B & Bromomethane & Soil \\
\hline 271P005 & SW8260B & Bromomethane & Soil \\
\hline 271P007 & SW8260B & Bromomethane & Soil \\
\hline 271P008 & SW8260B & Bromomethane & Soil \\
\hline $271 \mathrm{P} 010$ & SW8260B & Bromomethane & Soil \\
\hline 271P012 & SW8260B & Bromomethane & Soil \\
\hline $271 \mathrm{P} 014$ & SW8260B & Bromomethane & Soil \\
\hline 271P016 & SW8260B & Bromomethane & Soil \\
\hline 271P018 & SW8260B & Bromomethane & Soil \\
\hline 271P020 & SW8260B & Bromomethane & Soil \\
\hline 271P022 & SW8260B & Bromomethane & Soil \\
\hline 271P060 & SW8260B & Bromomethane & Soil \\
\hline 271P062 & SW8260B & Bromomethane & Soil \\
\hline 271P064 & SW8260B & Bromomethane & Soil \\
\hline 271P066 & SW8260B & Bromomethane & Soil \\
\hline 271P068 & SW8260B & Bromomethane & Soil \\
\hline 271P070 & SW8260B & Bromomethane & Soil \\
\hline 271P072 & SW8260B & Bromomethane & Soil \\
\hline 271P073 & SW8260B & Bromomethane & Soil \\
\hline 271P075 & SW8260B & Bromomethane & Soil \\
\hline 271P076 & SW8260B & Bromomethane & Soil \\
\hline 271P078 & SW8260B & Bromomethane & Soil \\
\hline 271P079 & SW8260B & Bromomethane & Soil \\
\hline
\end{tabular}


concentration, suggesting in a worst-case scenario the rejected data for bromomethane could be higher than the MRL. However, bromomethane was not detected in any of the nonrejected samples in this CAS or in any samples for CAU 271. Potential concentrations of bromomethane in these rejected data would be unlikely to be above the PAL; therefore, these rejected results would not affect conclusions in regards to VOC contamination. Rejected data for bromomethane are considered acceptable data gaps and should not affect closure decisions for CAS 26-05-05.

Acetone results were rejected in one sludge sample (i.e., 271P082RR1) due to a low relative response factor. Acetone values in sludge have no designated action levels. Acetone contamination has not been an issue for this CAU, and soil samples in this CAS have not had acetone concentrations reported above the MRL. Also, acetone was not present above the MRL in a TCLP analysis of sample 271P082. This is considered an acceptable data gap and should not affect closure decisions for CAS 26-05-05.

Sludge sample 271P082 had rejected results for several SVOCs due to internal QC checks not meeting specifications. Other than 1,4-dichlorobenzene and chlorobenzene, no organic compounds were detected above MRLs in TCLP results for this sample. It is unlikely the rejected SVOC results would have a significant impact on closure decisions. Previous results indicate semivolatile compounds were not found at this CAS.

Acetone results were rejected in liquid sample (271P081) and sludge sample (271P082) due to a low relative response factor. Acetone contamination has not been an issue for this CAU, and soil samples in this CAS have not had acetone concentrations reported above the MRL. These rejected acetone data are considered an acceptable data gap and should not affect closure decisions for CAS 26-05-05.

\section{B.1.3.15 Building 5200 Septic System (CAS 27-05-02) Rejected Data}

Table B.1-26 contains the rejected results per analytical method for CAS 27-05-02.

Acetone results were rejected in two sludge samples (i.e., 271Q019 and 271Q019RR1) due to a low relative response factor. Acetone contamination has not been an issue for this CAU, and soil samples in this CAS have not had acetone concentrations reported above the MRL. Acetone was detected in a sludge sample from the distribution box at an estimated concentration of $200 \mu \mathrm{g} / \mathrm{kg}$. It was not 
Table B.1-26

CAU 271 Rejected Data for CAS 27-05-02

\begin{tabular}{|c|c|c|c|}
\hline $\begin{array}{c}\text { Sample } \\
\text { Identification } \\
\text { Number }\end{array}$ & $\begin{array}{l}\text { Laboratory } \\
\text { Method }\end{array}$ & Parameter & Sample Matrix \\
\hline $271 Q 125$ & SW8260 & Acetone & Liquid \\
\hline $271 Q 018$ & SW8270 & 2,3,4,6-Tetrachlorophenol & Liquid \\
\hline 271Q018 & SW8270 & 2,4,5-Trichlorophenol & Liquid \\
\hline $271 Q 018$ & SW8270 & 2,4,6-Trichlorophenol & Liquid \\
\hline 271Q018 & SW8270 & 2,4-Dichlorophenol & Liquid \\
\hline $271 Q 018$ & SW8270 & 2,4-Dimethylphenol & Liquid \\
\hline 271Q018 & SW8270 & 2,4-Dinitrophenol & Liquid \\
\hline $271 Q 018$ & SW8270 & 2-Chlorophenol & Liquid \\
\hline 271Q018 & SW8270 & 2-Methylphenol & Liquid \\
\hline $271 Q 018$ & SW8270 & 2-Nitroaniline & Liquid \\
\hline $271 Q 018$ & SW8270 & 2-Nitrophenol & Liquid \\
\hline 271Q018 & SW8270 & 3-Nitroaniline & Liquid \\
\hline $271 Q 018$ & SW8270 & 4,6-Dinitro-2-Methylphenol & Liquid \\
\hline $271 Q 018$ & SW8270 & 4-Chloro-3-Methylphenol & Liquid \\
\hline $271 Q 018$ & SW8270 & 4-Chloroaniline & Liquid \\
\hline 271Q018 & SW8270 & 4-Methylphenol & Liquid \\
\hline $271 Q 018$ & SW8270 & 4-Nitroaniline & Liquid \\
\hline $271 \mathrm{Q} 018$ & SW8270 & 4-Nitrophenol & Liquid \\
\hline 271Q018 & SW8270 & Aniline & Liquid \\
\hline $271 \mathrm{Q} 018$ & SW8270 & Pentachlorophenol & Liquid \\
\hline $271 \mathrm{Q} 018$ & SW8270 & Phenol & Liquid \\
\hline $271 Q 019$ & SW8260 & Acetone & Sludge \\
\hline 271Q019RR1 & SW8260 & Acetone & Sludge \\
\hline 271Q019 & SW8270 & 3,3'-Dichlorobenzidine & Sludge \\
\hline $271 Q 019$ & SW8270 & Benzo(b)Fluoranthene & Sludge \\
\hline $271 Q 019$ & SW8270 & Benzo(k)Fluoranthene & Sludge \\
\hline $271 \mathrm{Q} 019$ & SW8270 & Butyl Benzyl Phthalate & Sludge \\
\hline 271Q019 & SW8270 & Di-N-Octyl Phthalate & Sludge \\
\hline 271Q019 & SW8270 & Dibenzo(a,h)Amthracene & Sludge \\
\hline 271Q019 & SW8270 & Indeno(1,2,3-cd)Pyrene & Sludge \\
\hline 271Q019 & SW8270 & Pentachlorophenol & Sludge \\
\hline 271Q207RR1 & SW8081 & Dieldrin & Soil \\
\hline
\end{tabular}


detected above the MRL in a TCLP analysis of 271Q019. The rejected acetone results are considered as acceptable data gap and should not affect closure decisions for CAS 27-05-02.

Sludge sample 271Q019 had rejected data for several SVOCs. These data were rejected due to internal QC measures that did not meet specifications. Quantitation or even detection of these compounds remains questionable. No SVOC was detected in concentrations of regulatory concern in a TCLP analysis of 271Q019. These rejected data should have no affect on closure decisions for CAS 27-05-02.

Acetone results were rejected in one liquid sample (i.e., 271Q0125) due to a low relative response factor. As discussed above, acetone contamination has not been an issue for this CAU.

Liquid sample 271Q018 (inlet chamber of septic tank) had rejected data for several SVOCs. These data were rejected due to internal QC measures which did not meet specifications. Quantitation or even detection of these compounds remains questionable. There were no SVOCs detected in liquid samples collected from the outlet chamber (i.e., 271Q025 and 271Q125); therefore, this is considered an acceptable data gap and should not affect closure decisions for CAS 27-05-02.

\section{B.1.3.16 Completeness Summary}

As shown in Table B.1-9, Table B.1-10, and Table B.1-11, completeness objectives for this CAU have been achieved. Completeness for chemical analyses were 95 percent or better, completeness for TCLP analyses were 98 percent or better. Completeness for radiochemical analyses were 99 percent or better for all measurements except tritium, which was 97.6 percent. Rejected data have been thoroughly reviewed and questions concerning these data have been addressed on a CAS-by-CAS basis. Most rejected data have been determined to have no affect on closure decisions for this CAU. Overall, measurements and sampling completeness criteria (as specified in the QAPP) have been satisfied for the CAU 271 CAI.

\section{B.1.4 Representativeness}

The DQO process as identified in Appendix A of the CAIP was used to address sampling and analytical requirements for CAU 271. During this process, appropriate locations were selected that enabled the samples collected to be representative of the area being evaluated. In many cases, both a 
biased and random sampling approach was proposed in order to provide the most conservative evaluation possible. Biased sampling in this case was performed to ensure sampling of suspected or known contamination. This was performed on a CAS-by-CAS basis. In addition, analytical requirements were specified in order to ensure appropriate methods were selected for COPCs. This was performed to address the concerns of all stakeholders and project personnel. The DQO approach was based upon process knowledge gained during the preliminary assessment. Samples were collected and analyzed as planned with the completeness issues discussed above. In addition, QC blanks were used as a way of measuring outside factors that could impact sample results. No data were qualified due to QC blanks. Therefore, the analytical data acquired during the CAU 271 corrective action investigation are considered representative of site characteristics and contamination.

\section{B.1.5 Comparability}

Field sampling, as described in the CAU 271 CAIP, was performed and documented in accordance with approved procedures that are comparable to standard industry practices. Approved analytical methods and procedures per DOE were used to analyze, report, and validate the data. These are comparable to other methods used not only in industry and government practices, but most importantly are comparable to other investigations conducted for the NTS. Therefore, datasets within this project are considered comparable to other datasets generated using these same standardized DOE procedures, thereby meeting DQO requirements.

Also, standard, approved field and analytical methods ensured that data were appropriate for comparison to the investigation action levels specified in the CAIP.

\section{B.1.6 Reconciliation of Conceptual Site Model(s) to the Data}

This section provides a reconciliation of the data collected and analyzed during this investigation with the conceptual site models established in the DQO process.

\section{B.1.6.1 Initial Conceptual Site Models}

One conceptual site model was developed for almost all of the CAU 271 CASs as presented in the CAIP (DOE/NV, 2001). The conceptual site models were based on historical information and process knowledge. In general, each CAS-specific conceptual model follows the general conceptual 
site model presented in the Leachfield Work Plan (DOE/NV, 1998). It assumed release of COPCs into (1) soil below and immediately surrounding collection system lines; (2) soil immediately surrounding septic tank inlets, outlets, and contents; and (3) soil directly below and immediately surrounding the leachfield distribution pipes. Therefore, the general conceptual site model included soil potentially impacted by subsurface disposal/release of effluent. The mechanisms for this type of release include both designed (e.g., underground discharge point) and accidental (e.g., septic tank breach) releases. This model assumed that any contamination would be concentrated in the soil located immediately beneath and adjacent to the disposal system component (e.g., distribution lines). The extent of underlying soil impact is expected to be variable and is dependent upon the volume of effluent released, leachfield system design, geologic conditions, nature of COPCs, and other factors.

The only exception to the use of this general conceptual site model was the contaminated water reservoir, CAS 26-03-01. The conceptual site model followed a strategy designed specifically for this CAS. The conceptual site model for CAS 26-03-01 included soil potentially impacted by surface disposal/release of radioanalytes. The mechanisms for this type of release were designed as part of the system (e.g., lined water reservoir). This model assumed that any contamination would be concentrated in the soil located immediately above the liner. The extent of underlying soil impact is expected to be minimal and dependent upon the integrity of the liner, the volume of radioanalytes released, and other factors.

\section{B.1.6.2 Investigation Design and Contaminant Identification}

The general conceptual site model and the CAS 26-03-01 model were used as the basis for identifying appropriate sampling strategies and data collection methods. Results of DQIs were successful in identifying the accuracy of the conceptual site model as a predictor of nature and extent of potential contamination. Precision and accuracy results from field samples identified sample homogeneity and minimal matrix interference, thereby providing confidence in collected data.

To address the conceptual model, surface (at CAS 26-03-01 only) and subsurface samples were collected for analyses designed to define the nature and extent of the COPCs identified in the CAIP. Biased (at CASs 25-04-01, 25-04-08, 26-04-01, 26-04-02, and 27-05-02) and biased and random (at CASs 25-04-03, 25-04-04, 25-04-09, 25-04-10, 25-04-11, 26-03-01, 26-05-01, 26-05-03, 26-05-04, and 26-05-05) strategies were developed to focus the investigation on areas of potential 
contamination. The general conceptual site model assumed that contamination would be limited to shallow subsurface soils within the boundaries of the site due to the minimal potential for migration based on the geological information for the area. The general model also assumed that contamination would be present within septic/effluent disposal system components (e.g., septic tanks, distribution boxes, and pipes) and, if these features failed, within the soil surrounding or beneath them. The conceptual site model for CAS 26-03-01 assumed contamination would be present in surface soil above the liner, within the boundaries of the reservoir. This model also assumed that if the liner failed, contamination could be present in soil beneath the reservoir.

With the exception of CASs 25-04-04 and 27-05-02, the investigation design has shown that contamination did not extend beyond the septic system components (or contaminated reservoir boundaries); therefore, the initial conceptual site models accurately predicted the extent of COPCs. This is a reasonable assumption because the model is designed to determine the extent of impact on any contaminated effluent released to the soil. The conceptual site model design was successful in predicting contamination release, and the DQIs provided a measure of the success of this design.

At CAS 25-04-04 (TPH DRO), contamination was noted at locations upstream of the septic tank and outside of the spatial boundaries of the CAS. It is unclear if contamination outside the spatial boundaries was related to system operations or was due to surface releases (e.g., from aboveground storage tanks containing diesel), or was due to the presence of contaminated fill. Revision of the conceptual model for CAS 25-04-04 was able to redefine spatial boundaries and provide the necessary data to ensure successful prediction of the extent of contamination. By showing that the extent of contamination was within model boundaries, one is able to conclude that the model design achieved DQOs.

At CAS 27-05-02, PCB contamination was detected at the edge of the leachfield, and the highest contamination was found in surface soil samples. The general leachfield conceptual site model predicts that contaminant concentrations should be greatest beneath distribution lines closest to the septic tank and distribution box. This is not the case at CAS 27-05-02, where PCB contamination near the tank and box are below PALs. In addition, concentrations increase in the subsurface moving toward the edge of the leachfield. This is in conflict with the general model, which assumes the distribution lines are the source of subsurface contamination. At CAS 27-05-02, the conceptual site 
model was revised to include a surficial source of PCB contamination along the eastern edge of the leachfield, with emphasis on the southeastern corner. The extent of PCB contamination was within the boundaries of the revised model, and the objectives of the investigation at this CAS were met.

\section{B.1.6.3 Contaminant Nature and Extent}

The presence of contamination was identified by sample results showing COPC soil concentrations exceeding PALs, thereby defining COCs at the CASs. With the exception of CASs 25-04-04 and 27-05-02, soil sample results demonstrated that the vertical and lateral extent of COCs was limited to the physical boundaries of the general subsurface model defined in the Leachfield Work Plan (DOE/NV, 1998) and CAIP (DOE/NV, 2001). Field screening was conducted and samples were collected at locations to bound contaminated areas with results below action levels. This confirmed the contamination extent was limited to regions of the leachfield, as was anticipated by the regions defined by the conceptual site model(s). With the exception of CASs 25-04-04, 26-05-01, and 27-05-02, areas of soil contamination in leachfields are rather dubious. They represent "hot spots" and are based on detection of a single COC at a single location. At all CASs with septic tanks containing material (i.e., sludge and/or liquid), the material contained COCs that were either not present in leachfield soil or were present at lower concentrations. In general, septic tank sludge was the medium that contained COCs in the greatest concentrations for the investigation. Results for integrity soil samples associated with septic tanks and distribution boxes indicated that none of the structures served as a source for the release of contamination into the surrounding and underlying soil. This suggests that the septic systems functioned as designed, and it supports the validity of the application of the general conceptual site model to determine the extent of contamination.

At CAS 26-03-01, the contaminants were located just above the plastic liner and appeared to be contained within the confines of the reservoir berms. These findings are consistent with that anticipated by the conceptual site model. The CAS-specific investigation findings, analytical results, and descriptions of site conditions are presented in Appendix A. The extent of identified COCs is described in Section 2.3 and Appendix A.

Contaminant releases from aboveground sources at CASs 25-04-04 and 27-05-02 were not specifically defined in the original leachfield conceptual site model, and may not be consistent with the release and transport mechanisms defined by the original model. However, step-out sampling 
was conducted to bound the migration of the COCs at both CASs because it could not be determined if the release was consistent with the release mechanism for a septic system. Soil sample results demonstrated that the vertical and lateral extent of COCs were bounded. Contaminant concentrations in soil decreased with depth and distance. Redesign of the conceptual model using step-out samples achieved the objective of defining the lateral and vertical extent of contamination for CASs 25-04-04 and 27-05-02. Defining the extent of contamination was critical to the determination that the conceptual model met DQO requirements.

\section{B.1.7 Conclusions}

Except as noted in Appendix A and within acceptable performance limits, samples were collected as planned and where planned, and were submitted for the planned analyses.

The DQIs (i.e., precision, accuracy, completeness, representativeness, and comparability) were evaluated for quality and impact to the data. All of the data, except data qualified as rejected, can be used in project decisions. The rejected data have been discussed and determined to have little impact on closure decisions.

Thus, the DQOs for the investigation have been met, and the data can be used to develop corrective action alternatives and to support selection of a preferred closure option for each site. 


\section{B.2.0 References}

DOE/NV, see U.S. Department of Energy, Nevada Operations Office.

EPA, see U.S. Environmental Protection Agency.

U.S. Department of Energy, Nevada Operations Office. 1996. Industrial Site Quality Assurance Project Plan, Nevada Test Site, Nevada, DOE/NV-372, Rev. 1. Las Vegas, NV.

U.S. Department of Energy, Nevada Operations Office. 1998. Work Plan for Leachfield Corrective Action Units: Nevada Test Site and Tonopah Test Range, Nevada, DOE/NV--514, Rev. 1. Las Vegas, NV.

U.S. Department of Energy, Nevada Operations Office. 2001. Corrective Action Investigation Plan for Corrective Action Unit 271: Areas 25, 26, and 27 Septic Systems, Nevada Test Site, Nevada, DOE/NV--704. Las Vegas, NV.

U.S. Environmental Protection Agency. 1994. Contracts Laboratory Program National Functional Guidelines for Inorganic Data Review, EPA 540-R-94/013. Washington, DC.

U.S. Environmental Protection Agency. 1996. Test Methods for Evaluating Solid Waste, Physical/Chemical Methods, SW-846 CD ROM PB97-501928GEI, which contains updates for 1986, 1992, 1994, and 1996. Washington, DC. 


\section{Appendix C}

\section{Cost Estimates for CAU 271}

(30 Pages) 


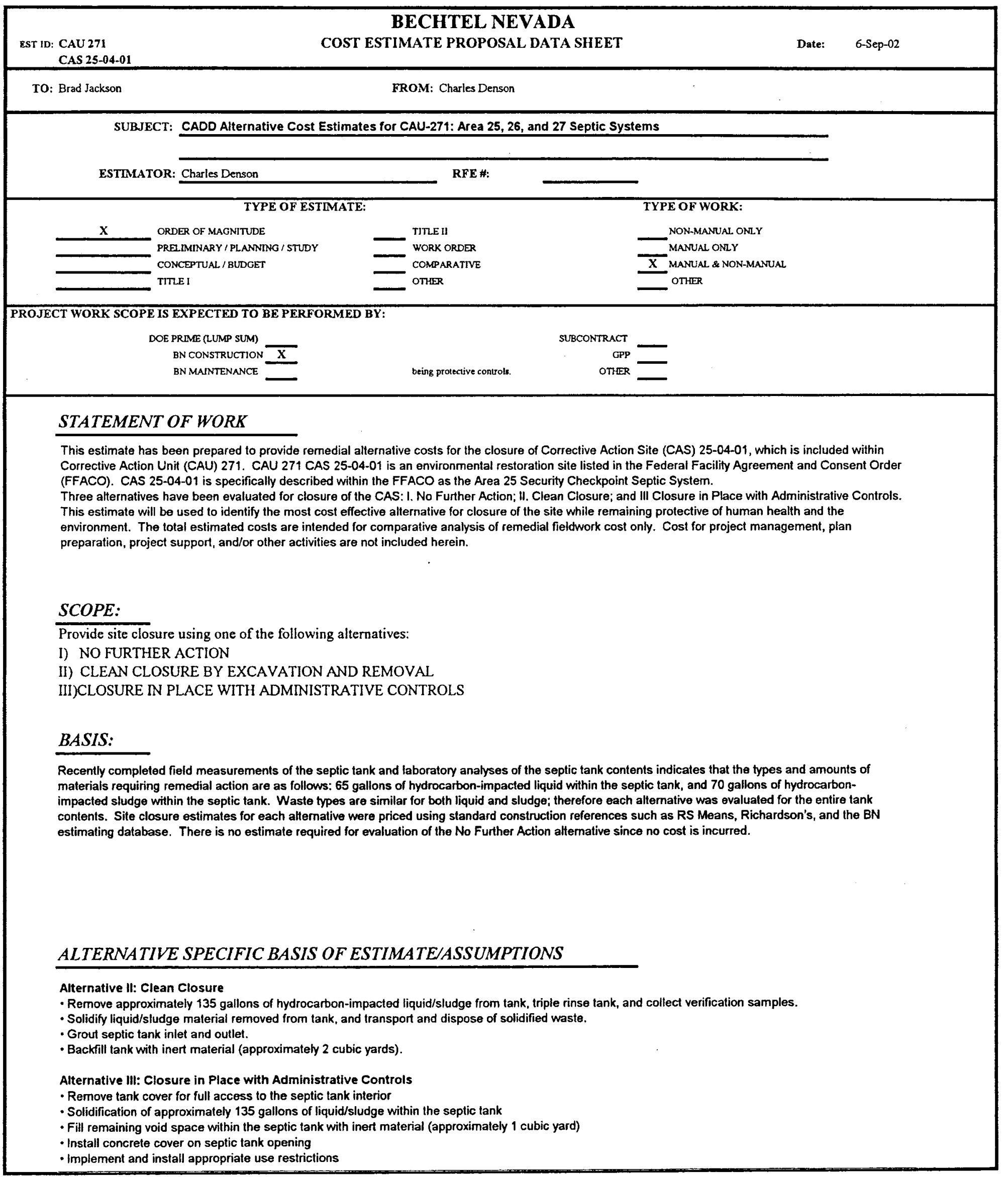




\section{ASSUMPTIONS:}

- No corrective actions are required for the leachfield and/or septic system piping

- No distribution box is present.

- All COPCs at the site have been identified during the CADD investigation and analytical data accurately represents site conditions and waste

characteristics.

- The septic tank is cylindrical and is oriented vertically, constructed of concrete, and has a volume of approximately 57 cubic feet (426 gallons).

- Fecal coliform is not present in the septic tank contents.

- The septic tank top will be removed to allow complete mixing of tank contents and solidifying agent, or pressure washing of the tank interior, depending on the alternative selected.

- Waste volumes are based on field measurements collected during the corrective action investigation and may be affected by weather events prior to

completing the corrective actions.

- Sludge can be completely removed by triple rinsing the tank interior.

- Inert material, such as clean soil , will be used to solidify the liquid/sludge for transportation and disposal.

- Inert material, such as cement or bentonite, will be used to solidify the liquid/sludge for closure in place.

- Inert material, such as cement/concrete will be used to fill the septic tank void space.

- Work to be performed by BN during a "normal" workday (no provision for overtime has been provided). Shifts are based on 10-hour days / 4-days per week.

- Efficiencies will be realized if work for similar activities at similar sites can be completed concurrently.

- This estimate does not include costs for preparation of required project plans, permits, reports, mobilization and demobilization, site preparations, or project management.

- A soil borrow area is located within one mile of the site.

- There will be no surface impediments.

- Dimensions, volumes, measurements, and analytical data provided by the A\&E contractor accurately represent site conditions and waste characteristics.

\section{ESCALATION:}

No escalation factors have been applied. Al costs are in FY03 dollars.

\section{CONTINGENCY:}

Contingency costs are not included in this estimate.

\section{RATES:}

Rates are based on FY03 preliminary rates (Rev 0) effective 7/2/02 and were applied using the BN FY03 cost model.

\section{COST ALTERNATIVES SUMMARY:}

Alternative I: No Further Action

Alternative II:

Alternative 111: Closure in Place with Administrative Controls

\section{REVIEW/CONCURRENCE:}

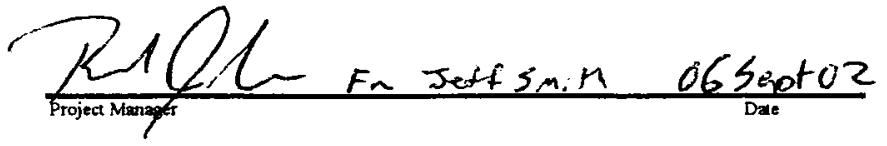

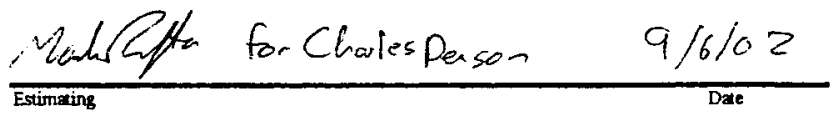

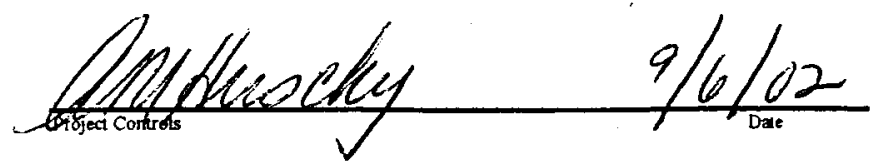




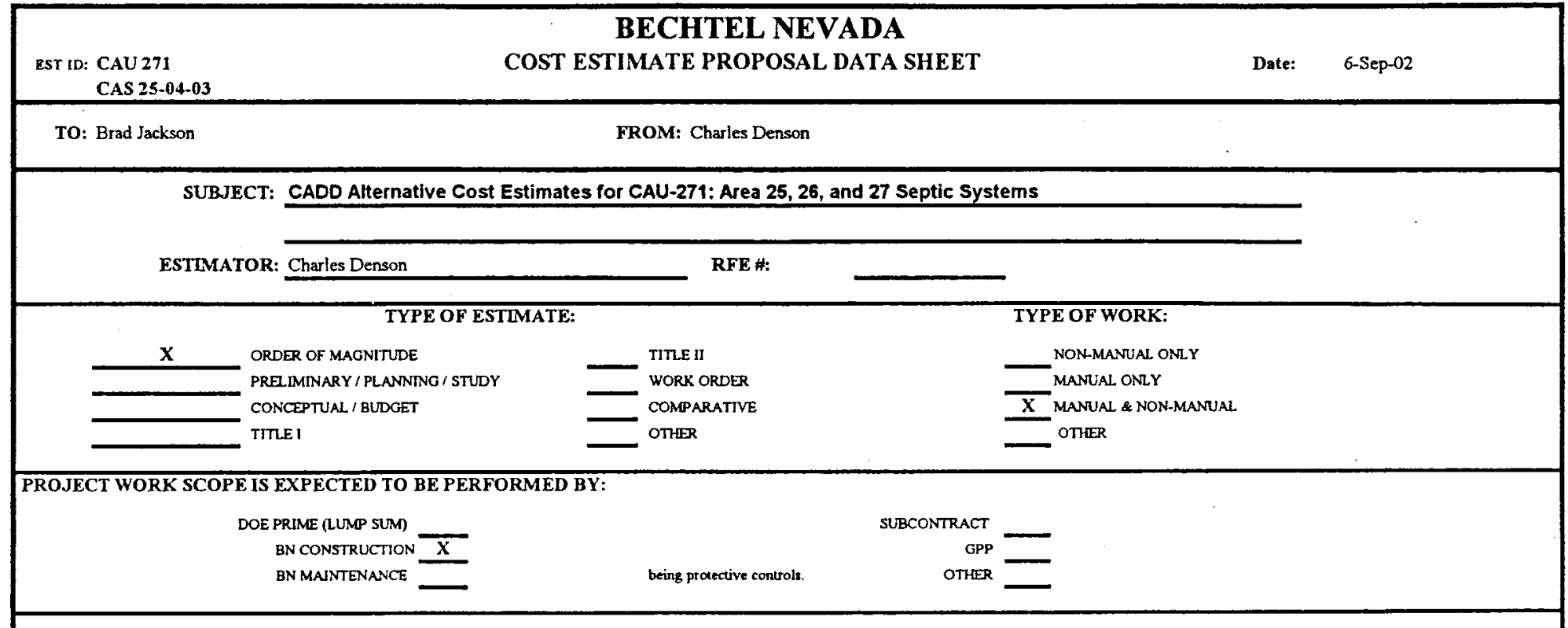

\section{STATEMENT OF WORK}

This estimate has been prepared to provide remedial alternative costs for the closure of Corrective Action Sile (CAS) 25-04-03, which is included within Corrective Action Unit (CAU) 271. CAU 271 CAS 25-04-03 is an environmental restoration site listed in the Federal Facility Agreement and Consent Order (FFACO). CAS 25-04-03is specifically described within the FFACO as the Area 25 Pan-Am Trailer Septic System.

Three alternatives have been evaluated for closure of the CAS: I. No Further Action; II. Clean Closure; and ill Closure in Place with Administrative Controls.

This estimate will be used to identify the most cost effective alternative for closure of the site while remaining protective of human health and the environment. The tolal estimated cosis are intended for comparative analysis of remedial fieldwork cost only. Cost for project management, plan preparation, project support, and/or other activities are not included herein.

\section{SCOPE:}

Provide site closure using one of the following alternatives:

1) NO FURTHER ACTION

II) CLEAN CLOSURE BY EXCAVATION AND REMOVAL

III)CLOSURE IN PLACE WITH ADMINISTRATIVE CONTROLS

\section{BASIS:}

Recently completed field measurements of the septic tank and laboratory analyses of the septic tank contents indicales that the types and amounts of materials requiring remedial action are as follows: $\mathbf{4 1 0}$ gallons of hydrocarbon-impacted liquid within the septic tank and 34 gallons of hydrocarbonimpacted sludge within the septic tank. The septic tank contents have been determined to contain fecal coliform. Waste types are similar for both liquid and sludge; therefore each alternative was evaluated for the entire tank contents. No distribution box is present. Site closure estimates for each alternative were priced using standard construction references such as RS Means, Richardson's, and the BN estimating database. There is no estimate required for evaluation of the No Further Action allernative since no cost is incurred.

\section{ALTERNATIVE SPECIFIC BASIS OF ESTIMATEASSUMPTIONS}

Alternative II: Clean Closure

- Neutralize fecal coliform in liquid/sludge.

- Remove approximately $\mathbf{4 4 4}$ gallons of hydrocarbon-impacted liquid/sludge from tank, triple rinse tank, and collect verification samples.

- Solidify liquid/sludge material removed from tank, and transport and dispose of solidified waste.

- Grout septic tank inlet and outlet.

- Backfill tank with inert material (approximately 8 cubic yards).

Alternative III: Closure in Place with Administrative Controls

- Remove tank lop for full access to the septic lank interior

- Solidification of approximately 444 gallons of liquid/sludge within the septic tank

- Fill remaining void space within the septic tank with inert material (approximately 5 cubic yards)

- Install concrete cover on septic lank opening

- Implement and install appropriate use restrictions 


\section{ASSUMPTIONS:}

- No corrective actions are required for the leachfield and/or septic system piping.

- No distribution box is present.

- All COPCs at the site have been identified during the CADD investigation and analytical data accurately represents site conditions and waste characteristics.

- The septic tank is rectangular, constructed of concrete, and has a total volume of approximately 230 cubic feet (1,700 gallons).

- Fecal coliform has been determined to be present within the tank contents and will require neutralization.

- The septic tank top will be removed to allow complete mixing of tank contents and solidifying agent, or pressure washing of the tank interior, depending on the alternative selected.

- Waste volumes are based on field measurements collected during the corrective action investigation and may be affected by weather events prior to

completing the corrective actions.

- Sludge can be completely removed by triple rinsing the tank interior.

- Inert material, such as clean soil, will be used to solidify the liquid/sludge for transportation and disposal.

- Inert material, such as cement or bentonite, will be used to solidify the liquid/sludge for closure in place.

- Inert material, such as cemenUconcrete will be used to fill the septic tank void space.

- Work to be performed by BN during a "normal" workday (no provision for overtime has been provided). Shifts are based on 10-hour days / 4-days per week.

- Efficiencies will be realized if work for similar activities at similar sites can be completed concurrently.

- This estimate does not include cosis for preparation of required project plans, permits, reports, mobilization and demobilization, site preparations, or project management.

- A soil borrow area is located within one mile of the site.

- There will be no surface impediments.

- Dimensions, volumes, measurements, and analytical data provided by the A\&E contractor accurately represent site conditions and waste characteristics.

\section{ESCALATION:}

No escalation factors have been applied. All costs are in FY03 dollars.

\section{CONTINGENCY:}

Contingency costs are not included in this estimate.

\section{RATES:}

Rates are based on FY03 preliminary rates (Rev 0) effective 7/2/02 and were applied using the BN FY03 cost model.

\section{COST ALTERNATIVES SUMMARY:}

Alternative I: No Further Action $\quad \$$

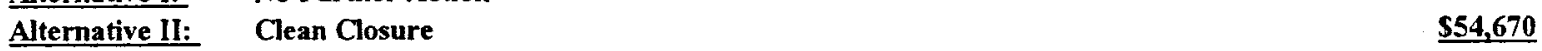

a. Clean and fill septic tank $\quad \$ 42,819$

b. Waste management and analytical $\quad \$ 11,851$

Alternative III: Closure in Place with Administrative Controls $\quad \underline{\$ 42,395}$

a. Solidify sludge and fill tank $\quad \$ 21,074$

$\begin{array}{ll}\text { b. Use restrictions and Post Closure Care } & \$ 21,321\end{array}$

\section{REVIEW/CONCURRENCE:}

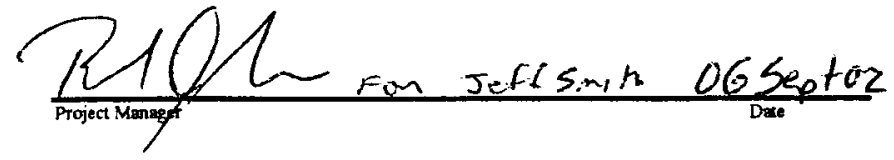

Molkffer for Charlespenson 9/6/02

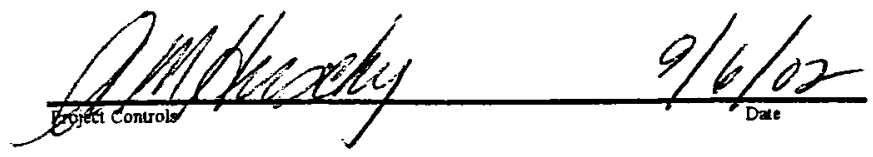




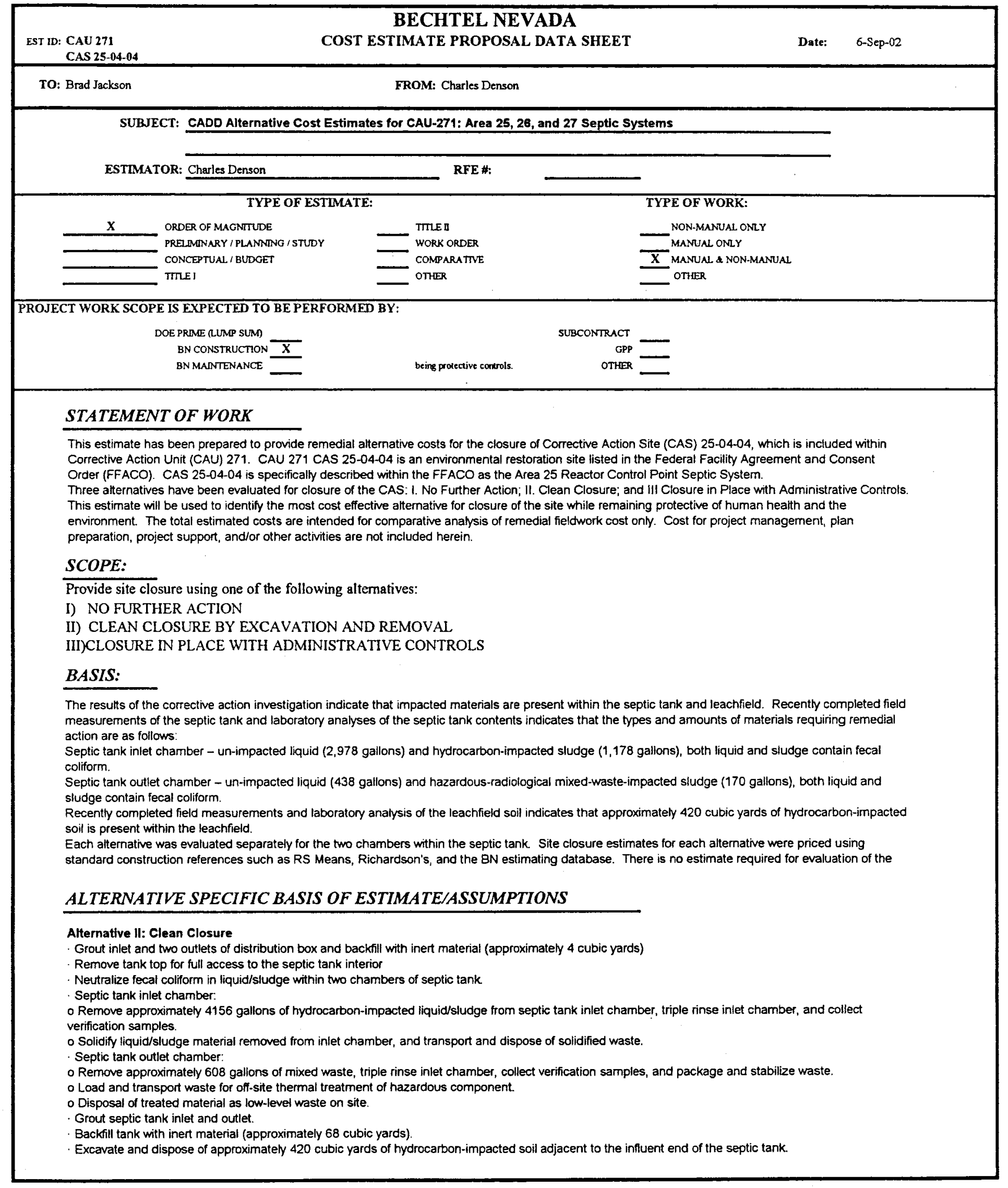


TO: Brad Jackson

FROM: Charles Denson

Alternative III: Closure in Place with Administrative Controls

Since hazardous waste must be disposed of in an approved hazardous waste disposal unit, closure in place is not feasible for the mixed waste present in the outlet chamber of the septic tank. Mixed waste present within the outlet chamber will be removed and managed as described in Alternative II

Solidification of approximately $\mathbf{4 1 5 6}$ gallons of liquid/sludge within the septic tank inlet chamber.

Fill remaining void space within the septic tank (Including the empty outlet chamber) with inert material (approximately 42 cubic yards) Install concrete cover on septic tank opening

implement and install appropriate use restrictions for closed in place septic tank and leachfieid soil.

\section{ASSUMPTIONS:}

No corrective actions are required for the leachfield and/or septic system piping

A distribution box is present, but has been verified empty.

- All COPCs at the site have been identified during the CADD investigation and analytical data accurately represents site conditions and waste characteristics.

The septic tank is rectangular, constructed of concrete, and has a total volume of approximately 1840 cubic feet $(13,770$ gallons).

The septic tank inlet chamber contains hydrocarbon-impacted sludge.

The septic tank outlet chamber contains mixed waste consisting of TPH DRO, U-234, Alpha chlordane, and gamma chlordane.

Fecal coliform has been determined to be present within the tank contents in both inlet and outlet chambers and will require neutralization.

The septic tank top will be removed to allow complete mixing of tank contents and solidifying agent, or pressure washing of the tank interior, depending on the alternative selected.

- Waste volumes are based on field measurements collected during the corrective action investigation and may be affected by weather events prior to completing the corrective actions.

Sludge can be complelely removed by triple rinsing the tank interior.

Inert material, such as clean soil, will be used to solidify the liquid/sludge for transportation and disposal.

Inert material, such as cement or bentonite, will be used to solidify the liquid/sludge for closure in place.

- Inert material, such as cement/concrete will be used to fill the septic tank void space.

- Work to be performed by BN during a "normal" workday (no provision for overtime has been provided). Shifts are based on 10-hour days / 4-days per week.

Efficiencies will be realized if work for similar activities at similar sites can be completed concurrently.

This estimate does not include costs for preparation of required project plans, permits, reports, mobilization and demobilization, site preparations, or project management.

A soil borrow area is located within one mile of the site.

There will be no surface impediments.

Dimensions, volumes, measurements, and anahytical data provided by the A\&E contractor accurately represent site conditions and waste characteristics.

ESCALATION:

No escalation factors have been applied. All costs are in FY03 dollars.

\section{CONTINGENCY:}

Contingency costs are not included in this estimate.

\section{RATES:}

Rates are based on FY03 preliminary rates (Rev 0) effective 7/2/02 and were applied using the BN FY03 cost model.

\section{COST ALTERNATIVES SUMMARY:}

Alternative 1: $\quad$ No Further Action

Altemative II: Clean Closure

$\underline{\$ 297,037}$

a. Clean and fill septic tank

$\$ 122,566$

b. Excavate and dispose of leachifield soil

$\$ 55,309$

c. Mixed waste management and analytical

$\$ 85,052$

d. Hydrocarbon waste management and analytical

$\$ 34,110$

Alternative III: Closure in Place with Administrative Controls

a. Solidify sludge and fill septic tank inlet chamber

b. Clean and fill septic tank outlet chamber

$\$ 80,687$

c. Mixed waste management and analytical

$\$ 94,135$

d. Use restrictions and Post Closure Care

$\$ 18,889$

REVEW/CONCURRENCE:
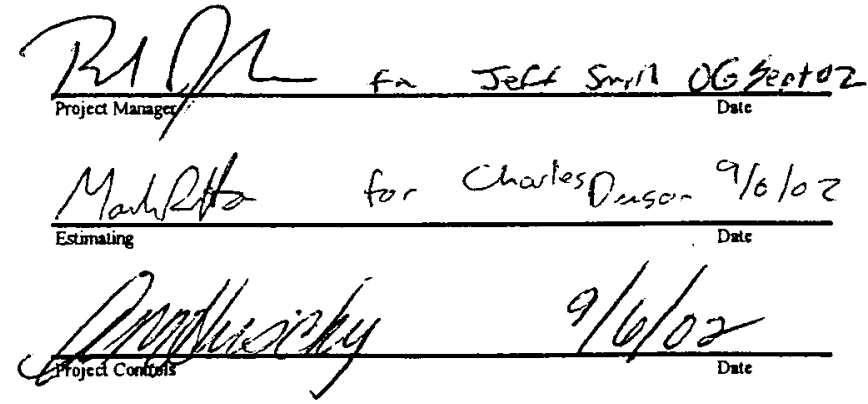
SUBJECT: CADD Aiternative Cost Estimates for CAU-271: Area 25, 26, and 27 Septic Systems

ESTIMATOR: Charles Denson

RFE \#:

TYPE OF ESTMATE:

\section{TYPE OF WORK:}

\begin{tabular}{ll}
$\mathbf{X}$ & $\begin{array}{l}\text { ORDER OF MAGNITUDE } \\
\text { PREL IMINARY / PLANNING / STUDY } \\
\text { CONCEPTUAL / BUDGET } \\
\text { TITLE I }\end{array}$ \\
\hline
\end{tabular}

NON-MANUAL ONLY

MANUAL ONLY

$X$ ManUal \& NON-MANUAL

OTHER

PROJECT WORK SCOPE IS EXPECTED TO BE PERFORMED BY:

DOE PRIME (LUMP SUM)

BN CONSTRUCTION $\mathrm{X}$ BN MANTENANCE

$\mathrm{x}$

SUBCONTRACT

GPP

being procective controls.

OTHER

\section{STATEMENT OF WORK}

This estimate has been prepared to provide remedial alternative costs for the closure of Corrective Action Site (CAS) 25-04-08, which is included within Corrective Action Unit (CAU) 271. CAU 271 CAS 25-04-08 is an environmental restoration site listed in the Federal Facility Agreement and Consent Order (FFACO). CAS 25-04-08 is specifically described within the FFACO as the Area 25 BREN Tower Septic System.

Three alternatives have been evaluated for closure of the CAS: I. No Further Action; II. Clean Closure; and III Closure in Place with Administrative Controls. This estimate will be used to identify the most cost effective alternative for closure of the site while remaining protective of human health and the environment. The total estimated costs are intended for comparative analysis of remedial fieldwork cost only. Cost for project management, plan preparation, project support, and/or other activities are not included herein.

\section{SCOPE:}

Provide site closure using one of the following alternatives:

1) NO FURTHER ACTION

II) CLEAN CLOSURE BY EXCAVATION AND REMOVAL

III)CLOSURE IN PLACE WITH ADMINISTRATIVE CONTROLS

\section{BASIS:}

The results of the corrective action investigation indicate that impacted materials are present within the septic tank and leachfield. Recently completed field measurements of the septic tank and laboratory analyses of the septic tank contents indicates that the types and amounts of materials requiring remedial action are as follows:

Septic tank influent chamber - un-impacted liquid (288 gallons) and hydrocarbon-impacted sludge (163 gallons), both liquid and sludge do not contain fecal coliform.

Septic tank effluent chamber - un-impacted liquid (168 gallons) and hydrocarbon-impacted sludge ( 6 gallons), both liquid and sludge do not contain fecal coliform.

Waste types are similar for both chambers of the septic tank; therefore each allernative was evaluated for the entire tank contents.

Recently completed field measurements and laboratory analysis of the leachfield soil indicates that approximately 3 cubic yards of radiologically-impacted soil (isotopic Pu) is present within the leachfield.

Each alternative was evaluated separately for the two chambers within the septic tank. Site closure estimates for each altemative were priced using standard construction references such as RS Means, Richardson's, and the BN estimating database. There is no estimate required for evaluation of the

No Further Action alternative since no cost is incurred.

\section{ALTERNATIVE SPECIFIC BASIS OF ESTIMATE/ASSUMPTIONS}

Altemative Il: Clean Closure

- Remove approximately 630 gallons of hydrocarbon-impacted liquid/sludge from the septic tank, triple rinse tank, and collect verification samples.

- Solidify liquid/sludge material removed from tank, and transport and dispose of solidified waste.

Grout septic tank inlet and outlet

Backfill tank with inert material (approximalely 6 cubic yards).

Excavate and dispose of approximately 3 cubic yards of radiologically-impacted soil.

Alternative Ill: Closure in Place with Administrative Controls

- Remove tank cover for full access to the septic tank interior

- Solidification of approximately 630 gallons of liquid/sludge within the septic tank

- Fill remaining void space within the septic tank with inert material (approximately 2 cubic yards)

- Install concrele cover on septic tank opening

- Implement and install appropriate use restrictions for septic tank and impacted leachfield soil 


\section{ASSUMPTIONS:}

- No corrective actions are required for the septic system piping.

- Total petroleum hydrocarbons (Diesel Range Organics) is the only contaminant present within the septic system, and isotopic Pu is the only contaminant present within the leachfield.

- All COPCs at the site have been identified during the CADD investigation and analytical data accurately represents site conditions and waste characleristics.

- The distribution box was destroyed during the corrective action investigation; therefore no corrective action is required for the distribution box.

- The septic tank is rectangular, constructed of concrete, and has a volume of approximately 148 cubic feet ( 1,100 gallons).

- Fecal coliform is not present in the septic tank contents

- The septic tank top will be removed to allow complete mixing of tank contents and solidifying agent, or pressure washing of the tank interior, depending on the alternative selected.

- Waste volumes are based on field measurements collected during the corrective action investigation and may be affecled by weather events prior to

completing the corrective actions.

Sludge can be completely removed by triple rinsing the tank interior.

- Inert material, such as clean soil, will be used to solidify the liquid/sludge for transportation and disposal.

- Inert material, such as cement or bentonite, will be used to solidify the liquid/sludge for closure in place.

- Inert material, such as cement/concrete will be used to fill the septic tank void space.

- Work to be performed by BN during a "normal" workday (no provision for overtime has been provided). Shifts are based on 10-hour days / 4-days per week.

- This estimate does not include costs for preparation of required project plans, permits, reports, mobilization and demobilization, site preparations, or project management.

Efficiencies will be realized if work for similar activities at similar sites can be completed concurrently.

- Inert material, such as cement/concrete will be used to fill the septic tank void space.

- A soil borrow area is located within one mile of the site.

- There will be no surface impediments.

- Dimensions, volumes, measurements, and analytical data provided by the A\&E contractor accurately represent sile conditions and waste characteristics.

\section{ESCALATION:}

No escalation factors have been applied. All costs are in FY03 dollars.

\section{CONTINGENCY:}

Contingency costs are not included in this estimate.

\section{RATES:}

Rates are based on FY03 preliminary rates ( Rev 0 ) effective 7/2/02 and were applied using the BN FY03 cost model.

\section{COST ALTERNATIVES SUMMARY:}

Alternative I: No Further Action

Alternative II: Clean Closure

a. Clean and fill septic tank

b. Excavate radiologically impacted soil from leachfield

c. Waste management and analytical

Alternative III: Closure in Place with Administrative Controls

$\$ 45,013$

a. Solidify sludge and fill septic tank

$\$ 20,646$

b. Use restrictions and Post Closure Care

\section{REVIEW/CONCURRENCE:}
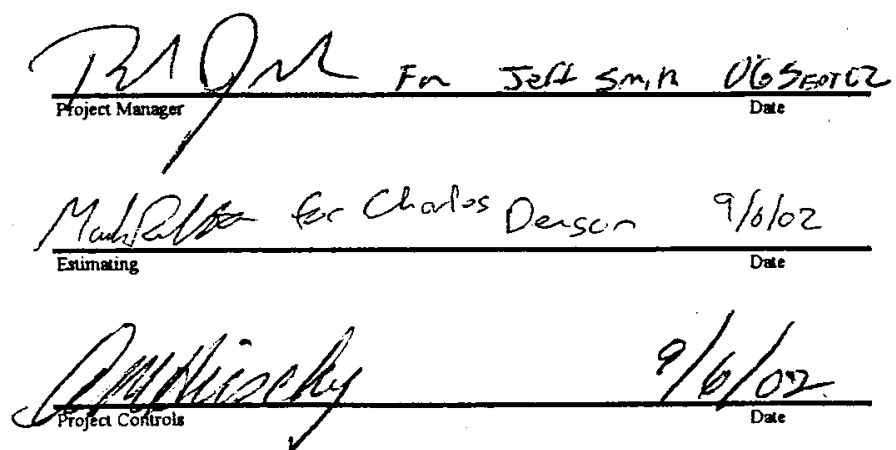
FROM: Charles Denson

SUBJECT: CADD Alternative Cost Estimates for CAU-271: Area 25, 26, and 27 Septic Systems

ESTMMATOR: Charles Denson

RFE \#:

TYPE OF ESTIMATE:

ORDER OF MAGNITUDE PREDIMNARY / PLANNING / STUDY CONCEPTUAL / BUDGET TITLE I
TITEE WORK ORDER COMPARATIVE OTHER
TYPE OF WORK:

NON-MANUAL, ONLY MANUAL ONLY

$\mathrm{X}$ MANUAL \& NON-MANUAI OTHER

PROJECT WORK SCOPE IS EXPECTED TO BE PERFORMED BY:

DOE PRIME (LUMP SUM) BN CONSTRUCTION BN MAINTENANCE

$\mathrm{x}$

西

Date: 6 sep-02




\section{ASSUMPTIONS:}

- No corrective actions are required for the leachfield and/or seplic system piping.

- No distribution box is present.

- All COPCs at the site have been identified during the CADD investigation and analytical data accurately represents site conditions and waste characteristics.

- The septic tank has an irregular cylindrical shape with a flat side exposed at the ground surface and is oriented horizontally, constructed of concrete, and

has a volume of approximately 486 cubic feet $(3,635$ gallons).

- Fecal coliform is not present in the septic tank contents.

- The septic tank top will be removed to allow complete mixing of tank contents and solidifying agent, or pressure washing of the tank interior, depending on the alternative selected.

- Waste volumes are based on field measurements collected during the corrective action investigation and may be affected by weather events prior to completing the corrective actions.

- Inert material, such as cement/concrete will be used to fill the septic lank void space.

Sediment within the septic tank can be completely removed by triple rinsing the tank interior.

No liquid and/or sludge is present within the septic tank.

Work to be performed by BN during a "normal" workday (no provision for overtime has been provided). Shifts are based on 10-hour days / 4-days per week.

- This estimate does not include costs for preparation of required project plans, permits, reports, mobilization and demobilization, site preparations, or project management.

- Efficiencies will be realized if work for similar activities at similar sites can be completed concurrently.

Inert material, such as cement/concrele will be used to fill the septic tank void space.

A soil borrow area is located within one mile of the site.

- There will be no surface impediments.

Dimensions, volumes, measurements, and analytical data provided by the A\&E contractor accurately represent site conditions and waste characteristics.

\section{ESCALATION:}

No escalation factors have been applied. All costs are in FY03 dollars.

\section{CONTINGENCY:}

Contingency costs are not included in this estimate.

\section{RATES:}

Rates are based on FY03 preliminary rates (Rev 0) effective 7/2/02 and were applied using the BN FY03 cost model.

\section{COST ALTERNATIVES SUMMARY:}

Alternative I: No Further Action

Alternative 1I: Clean Closure

a. Clean and fill septic tank

b. Waste management and analytical

Alternative III: Closure in Place with Administrative Controls

\section{REVIEW/CONCURRENCE:}
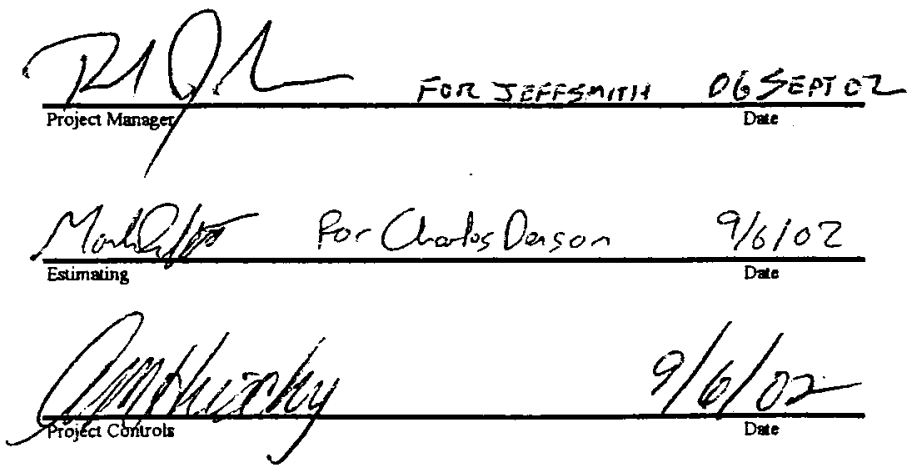


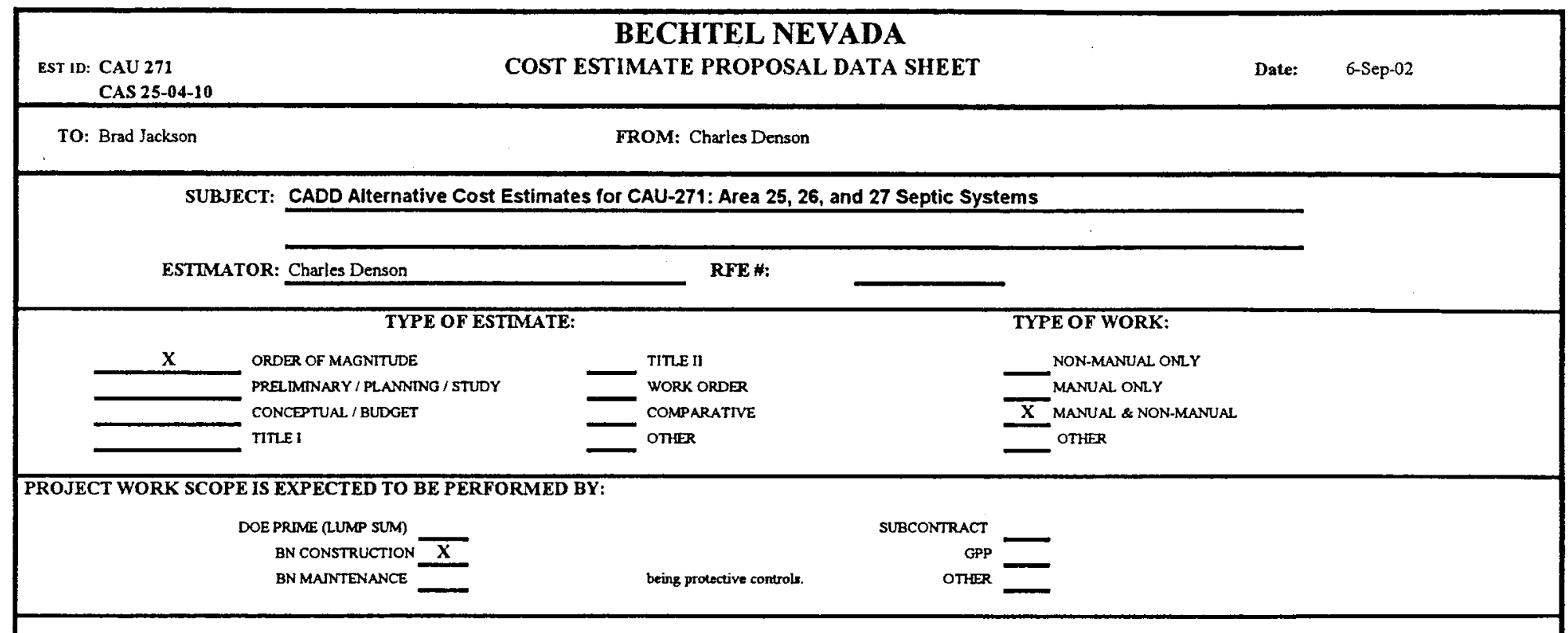

\section{STATEMENT OF WORK}

This estimate has been prepared to provide remedial alternative costs for the closure of Corrective Action Site (CAS) 25-04-10, which is included within Corrective Action Unit (CAU) 271. CAU 271 CAS 25-04-10 is an environmental restoration site listed in the Federal Facility Agreement and Consent Order (FFACO). CAS 25-04-10 is specifically described within the FFACO as the Area 25 Rad Safe Trailer Septic System.

Three alternatives have been evaluated for closure of the CAS: I. No Further Action; II. Clean Closure; and III Closure in Place with Administrative Controls. This estimate will be used to identify the most cost effective alternative for closure of the site while remaining protective of human health and the environment. The total estimated costs are intended for comparative analysis of remedial fieldwork cost only. Cost for project management, plan preparation, project support, and/or other activities are not included herein.

\section{SCOPE:}

Provide site closure using one of the following alternatives:

I) NO FURTHER ACTION

II) CLEAN CLOSURE BY EXCAVATION AND REMOVAL

III)CLOSURE IN PLACE WITH ADMINISTRATIVE CONTROLS

\section{BASIS:}

Recently completed field measurements of the septic tank and laboratory analyses of the septic tank contents indicates that the distribution piping does not contain sediment or debris, the distribution box has previously been filled with inert material, and the 750 gallon cylindrical (horizontal) steel septic tank contains no liquid, sludge, or sediment. Therefore, no further action is required for the septic tank. However, as a best management practice the septic tank will be grouted and filled with an inert solid to prevent future accumulation of liquid and potential discharge to the leachfield. The site closure estimate for this alternative was priced using standard construction references such as RS Means, Richardson's, and the BN estimating database.

\section{ALTERNATIVE SPECIFIC BASIS OF ESTIMATE/ASSUMPTIONS}

\section{Alternative I: No Further Action (Best Management Practice)}

- Remove tank cover for full access to the septic tank interior

Grout influent and effluent openings and fill remaining void space within the septic tank with inert material (approximately 4 cubic yard)

- Install concrete cover on septic tank opening 
EST ID: CAU 271

BECHTEL NEVADA

CAS 25-04-18

\section{ASSUMPTIONS:}

- No contaminants are present, therefore no corrective actions are required for the distribution box, septic tank, leachfield, and/or septic system piping.

- The septic tank will be filled with an inert material to prevent future collection of liquids.

- The septic tank is cylindrical and is oriented horizontally, constructed of steel, and has a volume of approximately 100 cubic feet (750 gallons).

- There is no liquid, sludge, sediment, or debris within the septic tank.

- Inert material, such as concrete, will be used to fill the septic lank.

- Work to be performed by BN during a "normal" workday (no provision for overtime has been provided). Shifts are based on 10-hour days / 4-days per week.

- Efficiencies will be realized if work for similar activities at similar sites can be compleled concurrently.

- This estimate does not include costs for preparation of required project plans, permits, reports, mobilization and demobilization, site preperations, or project management.

- A soil borrow area is located within one mile of the site.

- There will be no surface impediments.

- Dimensions, volumes, measuremenis, and analytical data provided by the A\&E contractor accurately represent site conditions and waste characteristics.

\section{ESCALATION:}

No escalation factors have been applied. All costs are in FY03 dollars.

\section{CONTINGENCY:}

Contingency costs are not included in this estimate.

\section{RATES:}

Rates are based on FY03 preliminary rates (Rev 0 ) effective 7/2/02 and were applied using the BN FY03 cost model.

\section{COST ALTERNATIVES SUMMARY:}

Alternative I: No Further Action

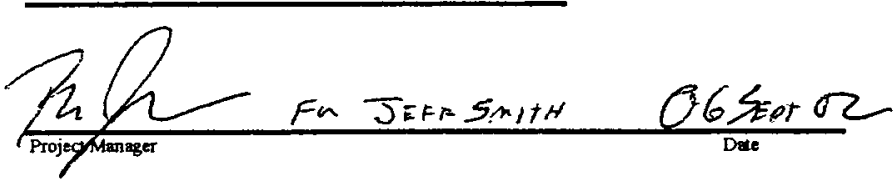

Manklote

$$
\text { for ChanlesDensor }
$$

$9 / 6 / 62$

Estimating
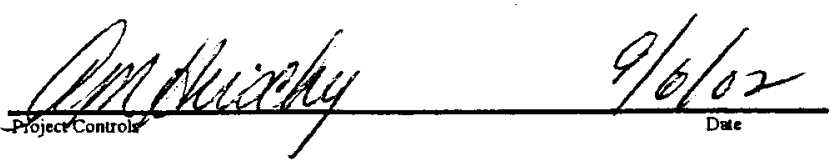


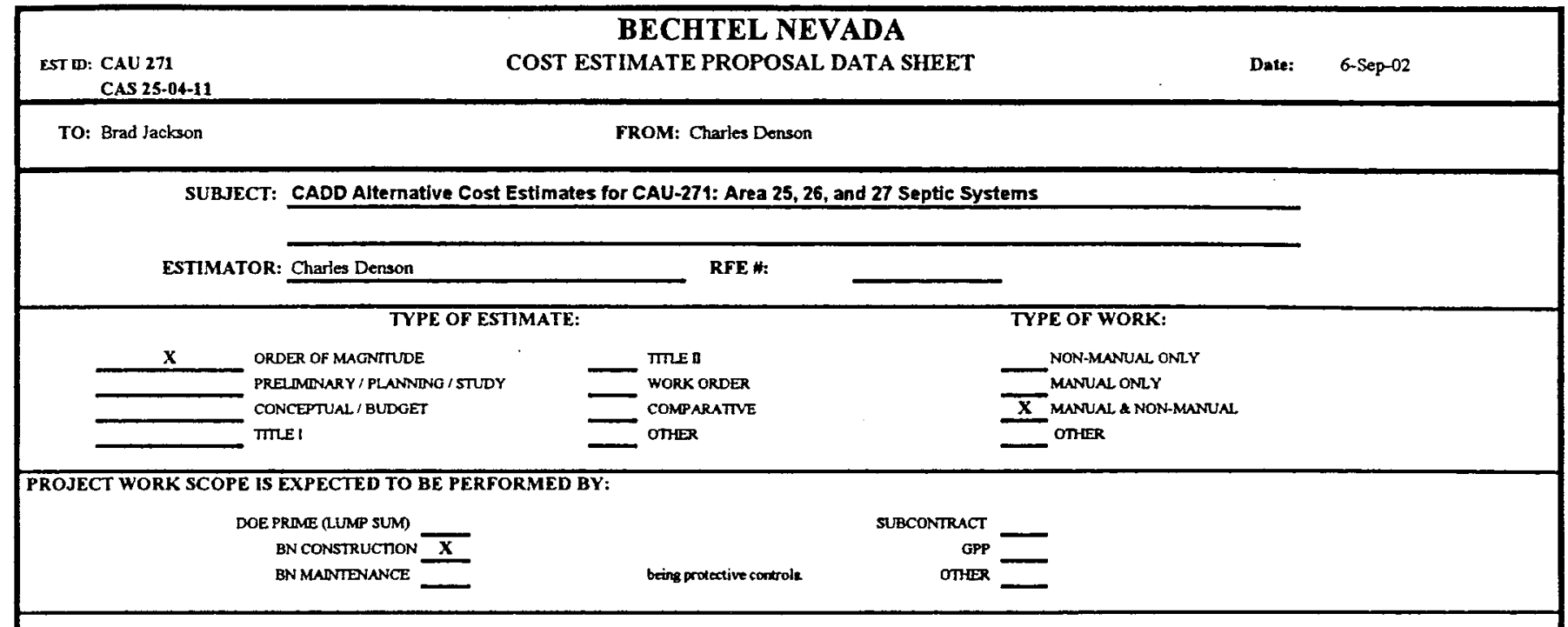

\section{STATEMENT OF WORK}

This estimate has been prepared to provide remedial alternative costs for the closure of Corrective Action Site (CAS) 25-04-11, which is included within Corrective Action Unit (CAU) 271. CAU 271 CAS 25-04-11 is an environmental restoration site listed in the Federal Facility Agreement and Consent Order (FFACO). CAS 25-04-11 is specifically described within the FFACO as the Area 25 Septic System located south of the LASL Traiier.

Three alternatives have been evaluated for closure of the CAS: I. No Further Action; II. Clean Closure; and ill Closure in Place with Administrative Controls. This estimate will be used to identify the most cost effective alternative for closure of the site while remaining protective of human health and the environment. The total estimated casts are intended for comparative analysis of remedial fieldwork cost only. Cost for project management, plan preparation, project support, and/or other activities are not included herein.

\section{SCOPE:}

Provide site closure using one of the following alternatives:

D) NO FURTHER ACTION

II) CLEAN CLOSURE BY EXCAVATION AND REMOVAL

III)CLOSURE IN PLACE WTTH ADMINISTRATIVE CONTROLS

\section{BASIS:}

Recently completed field measurements of the septic system and laboratory analyses of the septic system contents indicates that the septic system piping does not contain liquid, sludge, or sediment, the concrete distribution box has been previously filled with inert material; a minimal amount of sludge is present in a manhole located adjacent to the septic tank, approximately 700 gallons of hydrocarbon-impacted liquid and sludge is present within the septic tank, and there is no impacted media within the leachfield. Waste types are similar for both liquid and sludge within the manhole and both chambers of the septic tank, therefore each alternative was evaluated for the manhole and entire septic tank contents. Site closure estimates for each alternative were priced using standard construction references such as RS Means, Richardson's, and the BN estimating database. There is no estimate required for evaluation of the No Further Action alternative since no cost is incurred.

\section{ALTERNATIVE SPECIFIC BASIS OF ESTIMATE/ASSUMPTIONS}

\section{Alternative II: Clean Closure}

- Remove septic tank cover and remove approximately 700 gallons of hydrocarbon-impacted liquid/sludge from manhole and septic tank, triple rinse the manhole and septic tank, and collect verification samples.

Solidify liquid/sludge material removed from the manhole and septic tank, and transport and dispose of solidified waste.

Grout manhole and septic tank inlets and outlets.

Backfill manhole and septic tank with inert material (approximately 4 cubic yards).

Alternative if: Closure in Place with Administrative Controls

- Remove tank cover for full access to the septic tank interior

- Solidification of approximately 700 galions of liquid/sludge within the manhole and septic tank

- Fill remaining void space within the septic tank with inert material (approximately 4 cubic yards)

- Install concrete cover on manhoie and septic tank opening

- implement and install appropriate use restrictions 


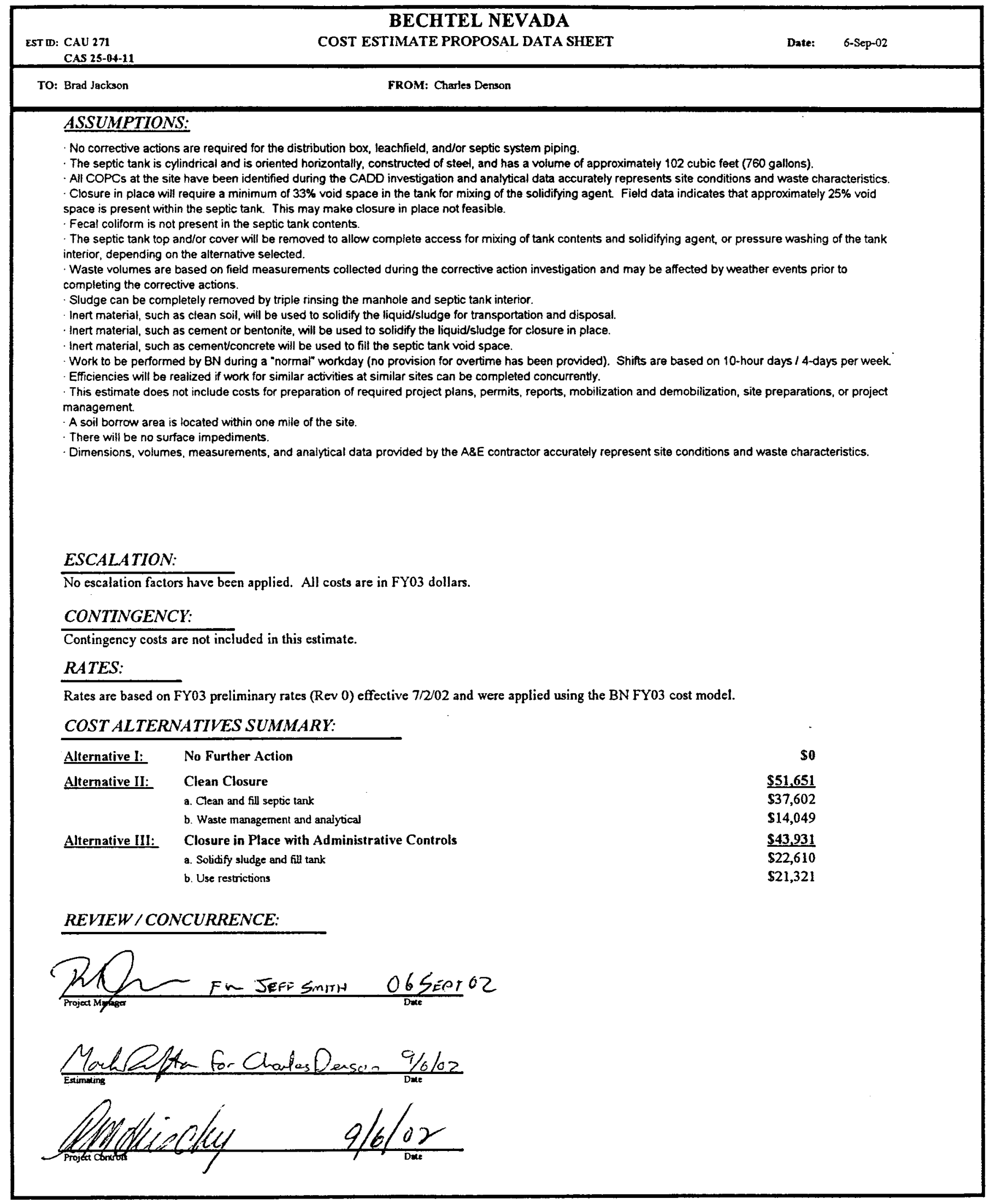




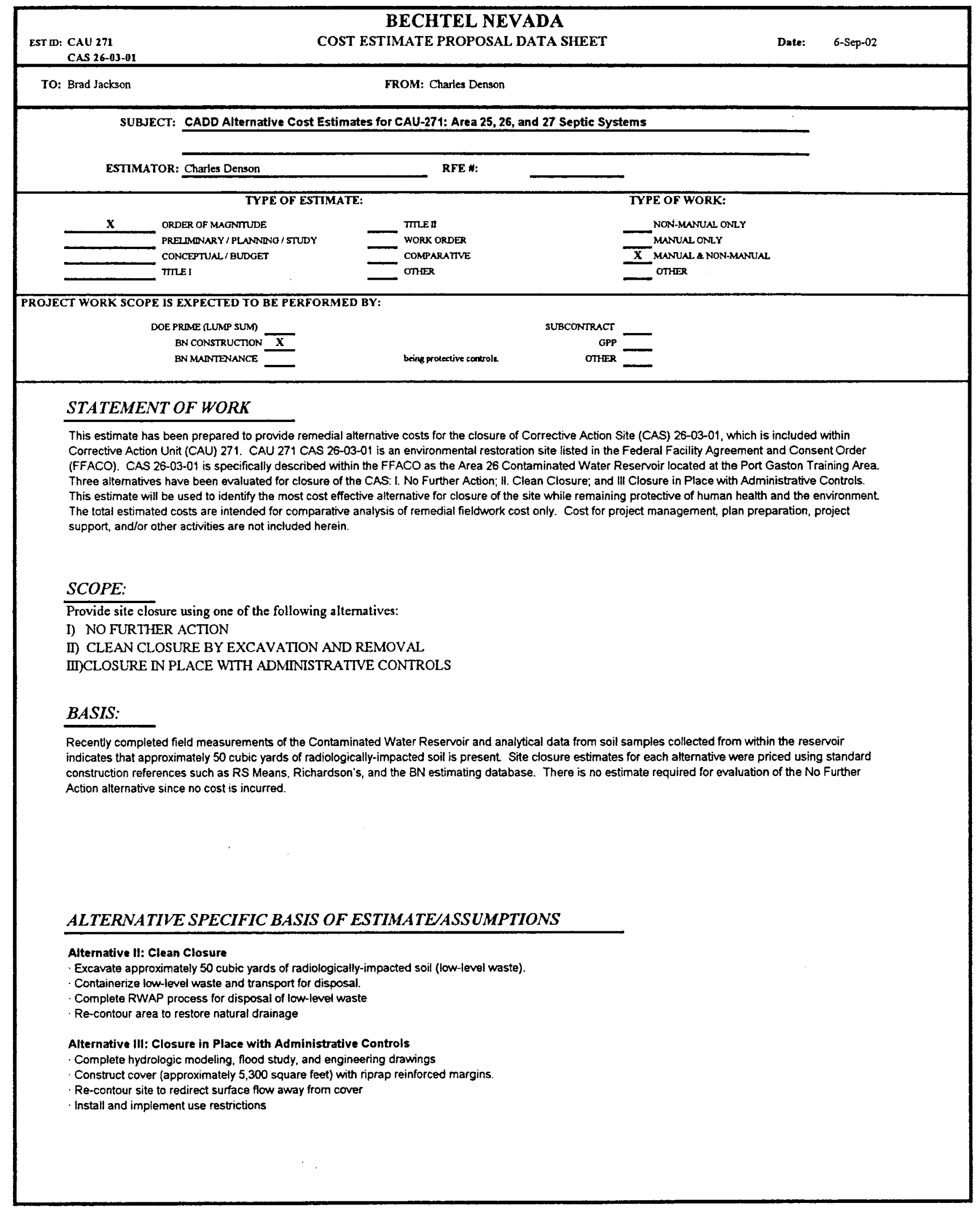




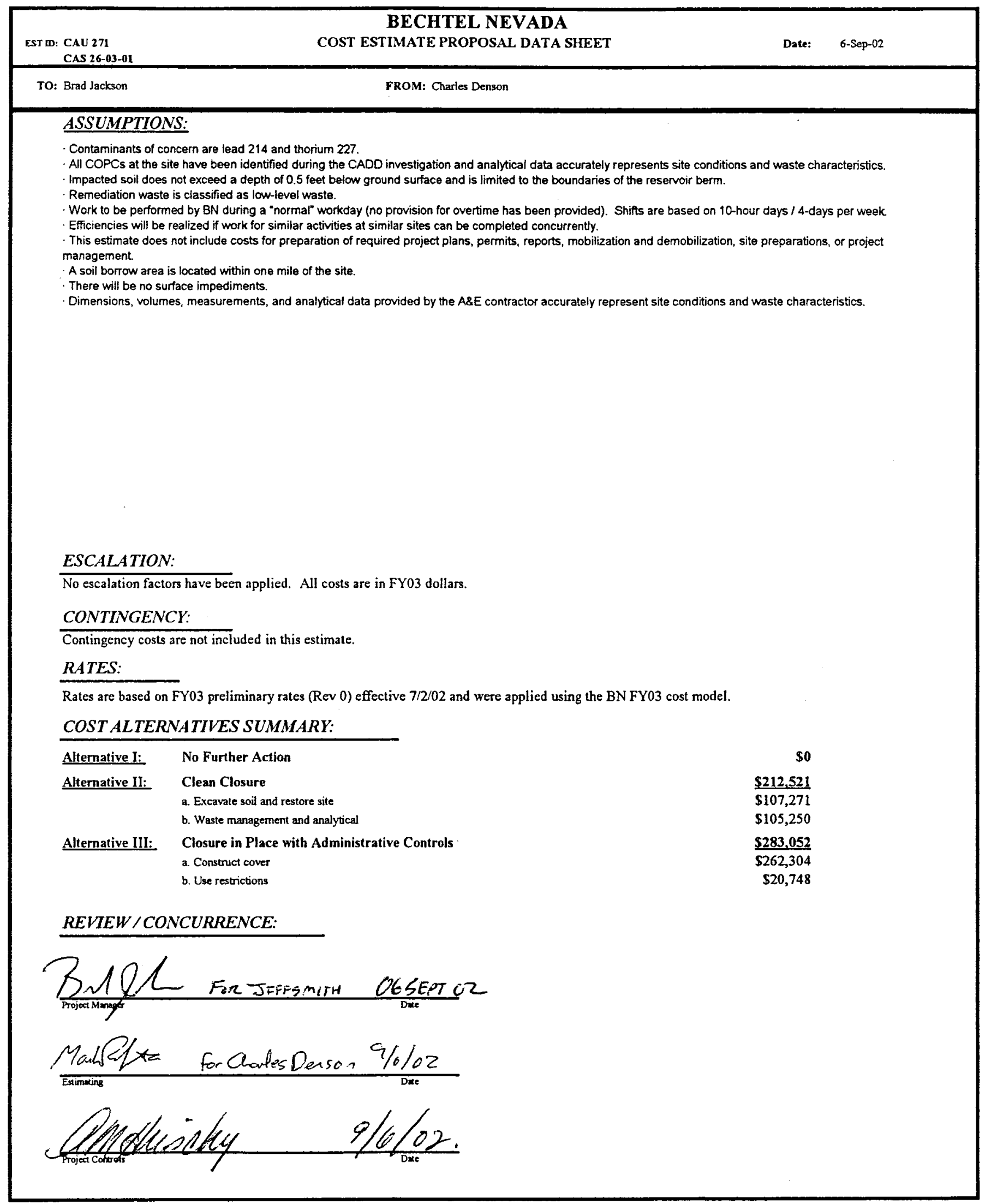




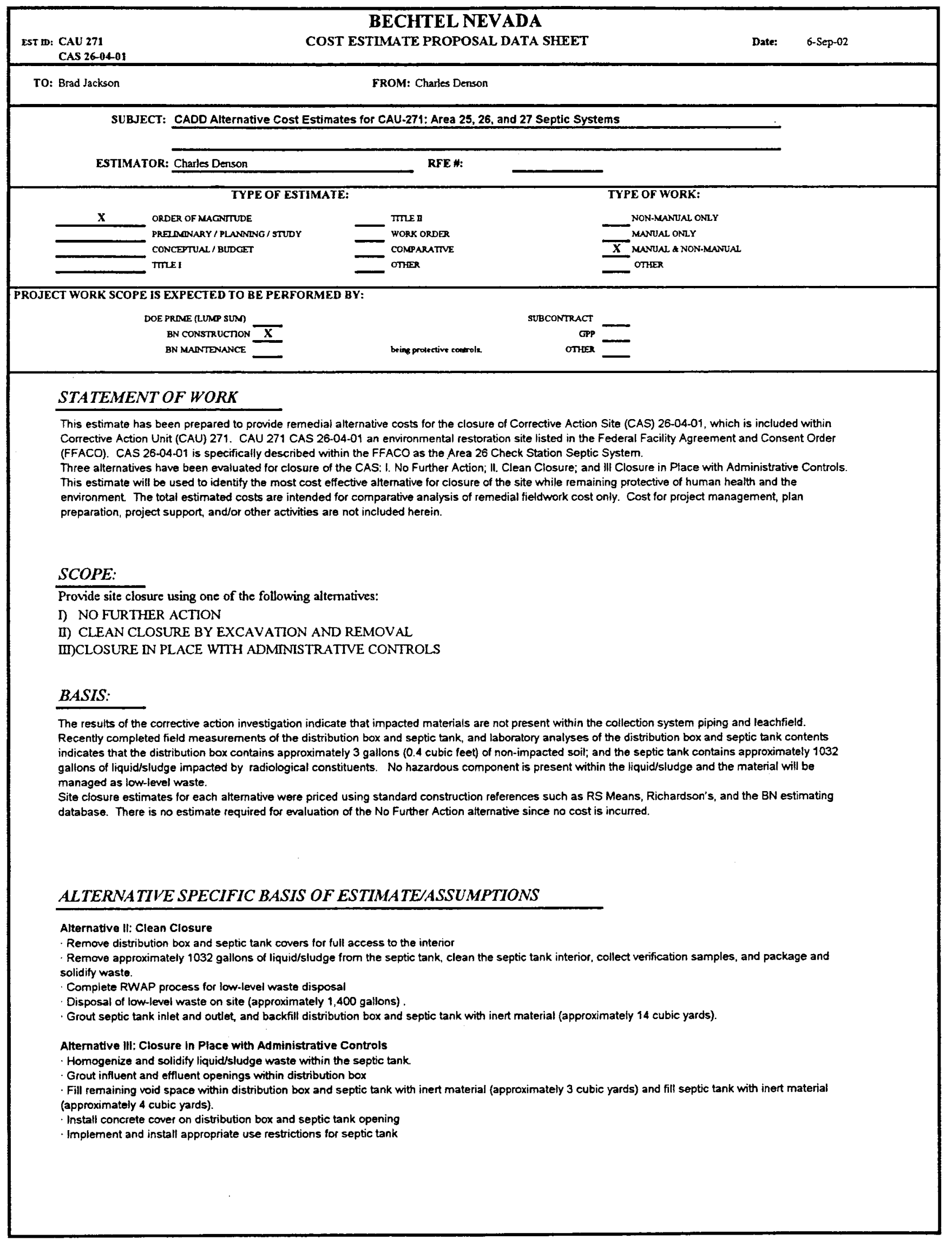




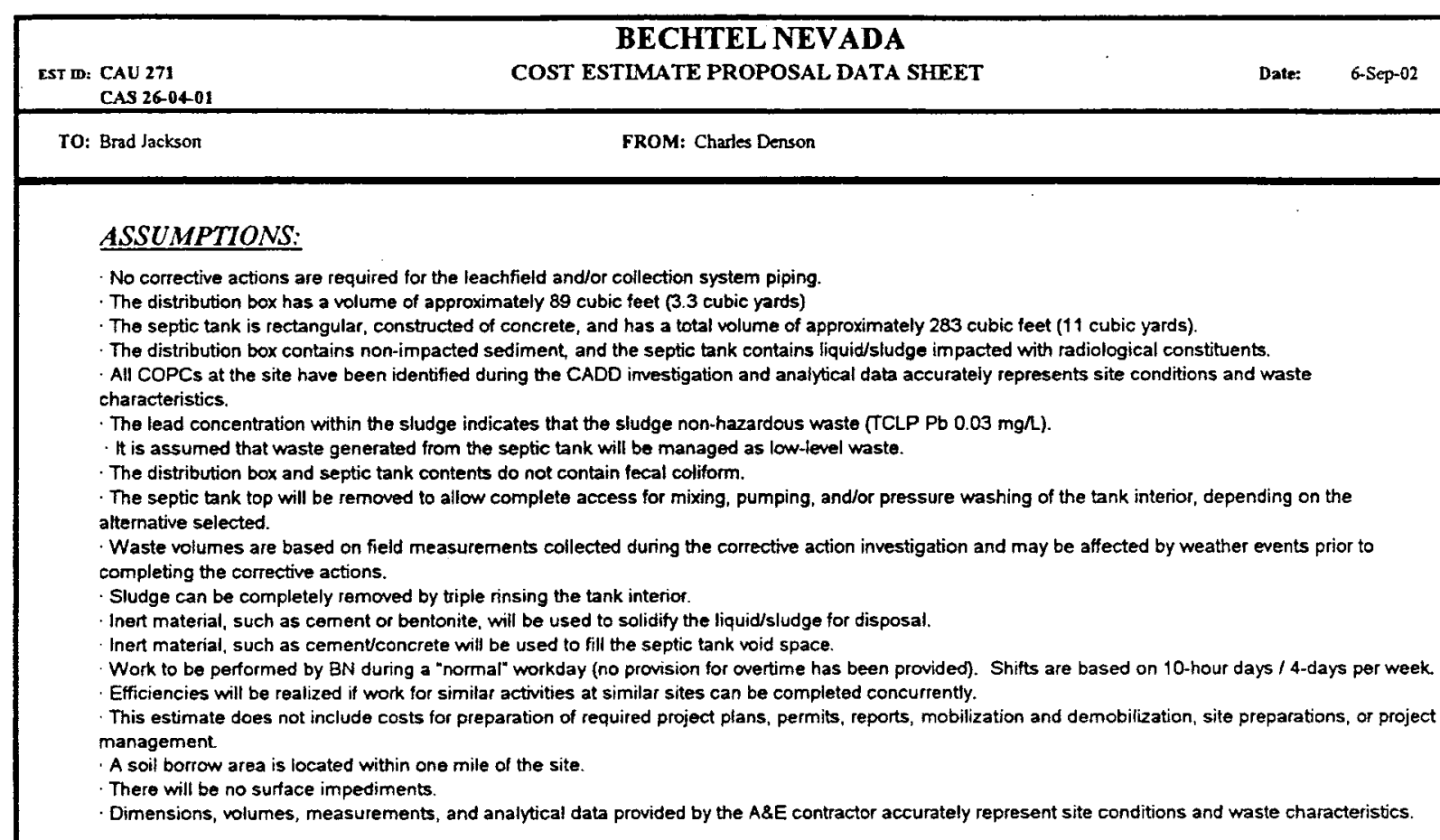

\section{ESCALATION:}

No escalation factors have been applied. All costs are in FY03 dollars.

\section{CONTINGENCY:}

Contingency costs are not included in this estimate.

RATES:

Rates are based on FY03 preliminary rates (Rev 0) effective 7/2/02 and were applied using the BN FY03 cost model.

\section{COSTALTERNATIVES SUMMARY:}

Alternative I: No Further Action $\quad$ so

Alternative II: Clean Closure $\quad \underline{\$ 223,794}$

a. Clean and fill septic tank $\$ \$ 122,398$

$\begin{array}{lr}\text { b. Waste management and analytical } & \$ 101,396\end{array}$

Alternative 11I: Closure in Place with Administrative Controls $\$ \mathbf{\$ 9 5 , 7 7 2}$

a. Solidify studge and fill septic tanks
b. U74,451

$\begin{array}{ll}\text { b. Use restrictions } & \$ 21,321\end{array}$

\section{REVIEW/CONCURRENCE:}

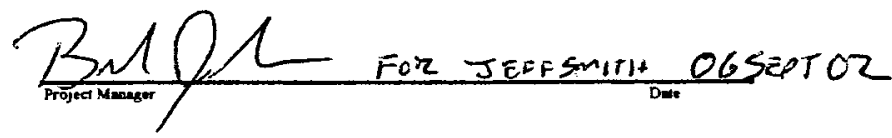

Manllefter for ChailesDenso- 9/6102

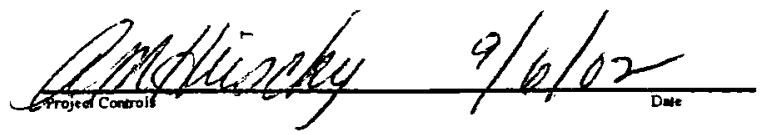




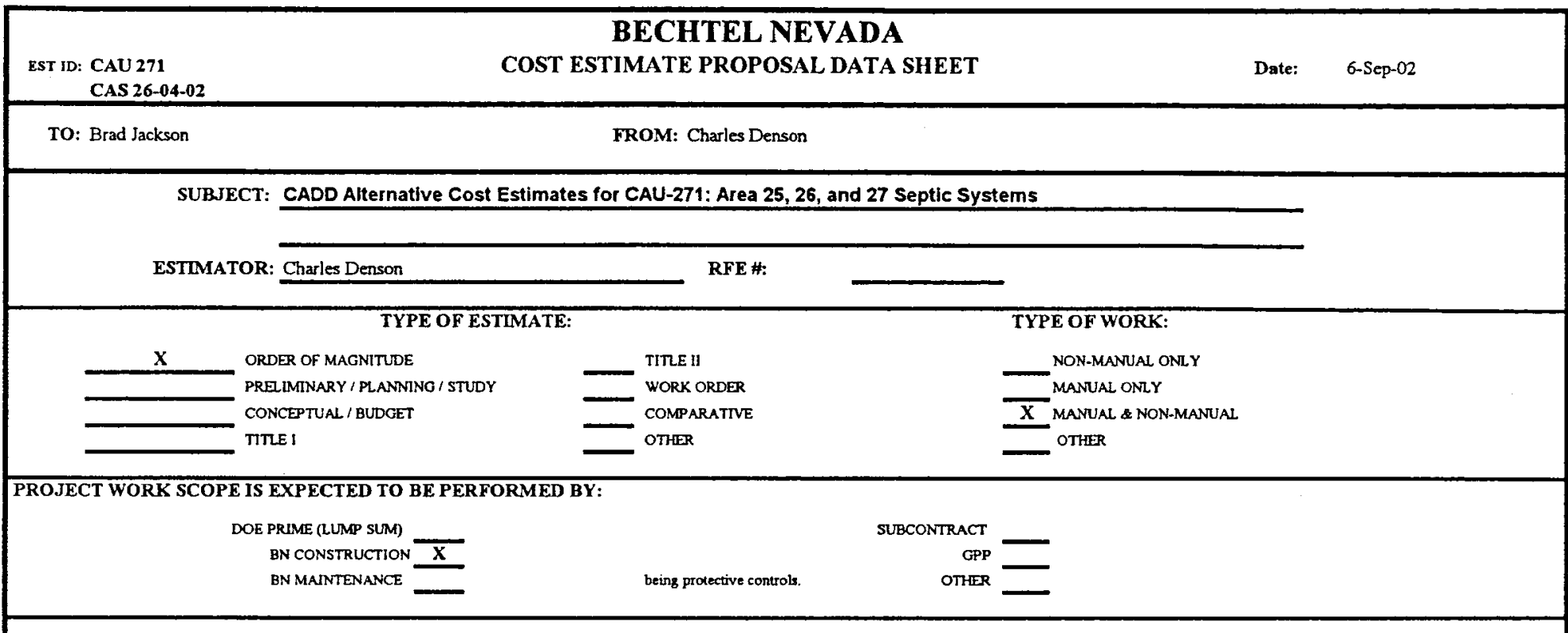

\section{STATEMENT OF WORK}

This estimate has been prepared to provide remedial altemative costs for the closure of Corrective Action Site (CAS) 26-04-02, which is included within Corrective Action Unil (CAU) 271. CAU 271 CAS 26-04-02 is an environmental restoration site listed in the Federal Facility Agreement and Consent Order (FFACO). CAS 26-04-02 is specifically described within the FFACO as the Area 26 Hot Critical Facility Septic System.

Three alternatives have been evaluated for closure of the CAS: I. No Further Action; II. Clean Closure; and III Closure in Place with Administrative Controls. This estimate will be used to identify the most cost effective alternative for closure of the site while remaining prolective of human health and the environment. The total estimated costs are intended for comparative analysis of remedial fieldwork cost only. Cost for project management, plan preparation, project support, and/or other activities are not included herein.

SCOPE:

Provide site closure using one of the following alternatives:

I) NO FURTHER ACTION

II) CLEAN CLOSURE BY EXCAVATION AND REMOVAL

III)CLOSURE IN PLACE WITH ADMINISTRATIVE CONTROLS

\section{BASIS:}

Recently completed field measurements of the septic tank and laboratory analyses of the septic lank contents indicates that approximately 34 gallons of hydrocarbon-impacted sludge is present. The distribution box is empty. Sile closure estimates for each alternative were priced using standard construction references such as RS Means, Richardson's, and the BN estimating database. There is no estimate required for evaluation of the No Further Action alternative since no cost is incurred.

\section{ALTERNATIVE SPECIFIC BASIS OF ESTIMATEASSUMPTIONS}

\section{Alternative II: Clean Closure}

- Remove approximately 34 gallons of hydrocarbon-impacted sludge from the septic tank, triple rinse tank, and collect verification samples.

- Solidify sludge material removed from tank, and transport and dispose of solidified waste.

- Grout distribution box and septic tank inlets and outlets.

- Backfill distribution box and septic tank with inert material (approximately 7 cubic yards).

Alternative III: Closure in Place with Administrative Controls

- Remove tank cover for full access to the septic tank interior

- Solidify approximately $\mathbf{3 4}$ gallons of sludge within the septic tank

- Fill remaining void space within the septic tank, and the distribution box, with inert material (approximately 7 cubic yard)

- Install concrete cover on septic tank opening

- Implement and install appropriate use restrictions 


\section{ASSUMPTIONS:}

- No corrective actions are required for the leachfield and/or collection system piping.

- The distribution box is empty.

- The septic tank is rectangular, constructed of concrete, and has a volume of approximately 108 cubic feet ( 800 gallons).

- Fecal coliform is not present in the septic tank contents.

- All COPCs at the site have been identified during the CADD investigation and analytical data accurately represents sile conditions and waste

characteristics.

- The septic tank top will be removed to allow complete mixing of tank contents and solidifying agent, or pumping and pressure washing of the tank interior, depending on the alternative selected.

- Waste volumes are based on field measurements collected during the corrective action investigation and may be affected by weather events prior to completing the corrective actions.

- Sludge can be completely removed by triple rinsing the tank interior.

- Inert material, such as clean soil, will be used to solidify the liquid/sludge for transportation and disposal.

- Inert material, such as cement or bentonile, will be used to solidify the liquid/sludge for closure in place.

- Inert material, such as clean soil or concrete, will be used to fill the manhole and distribution box.

- Work to be performed by BN during a "normal" workday (no provision for overtime has been provided). Shifts are based on 10-hour days / 4-days per week.

- Efficiencies will be realized if work for similar activities at similar sites can be completed concurrently.

- This estimate does not include costs for preparation of required project plans, permits, reports, mobilization and demobilization, site preparation, or project management.

- A soil borrow area is located within one mile of the site.

- There will be no surface impediments.

- Dimensions, volumes, measurements, and analytical data provided by the A\&E contractor accurately represent site conditions and waste characteristics.

\section{ESCALATION:}

No escalation factors have been applied. All costs are in FY03 dollars.

\section{CONTINGENCY:}

Contingency costs are not included in this estimate.

\section{RATES:}

Rates are based on FY03 preliminary rates (Rev 0 ) effective 7/2/02 and were applied using the BN FY03 cost model.

\section{COST ALTERNATIVES SUMMARY:}

Alternative I: No Further Action $\quad$ S0

Alternative II: Clean Closure $\quad \underline{\$ 55,796}$

a. Clean and fill septic tank and distribution box $\$ \$ 44,353$

$\begin{array}{ll}\text { b. Waste management and analytical } & \$ 11,443\end{array}$

Alternative III: Closure in Place with Administrative Controls $\quad \underline{\$ 46,194}$

a. Solidify sludge and fill septic tank and distribution box $\$ \mathbf{\$ 2 4 , 8 7 3}$

b. Use restrictions

$\$ 21,321$
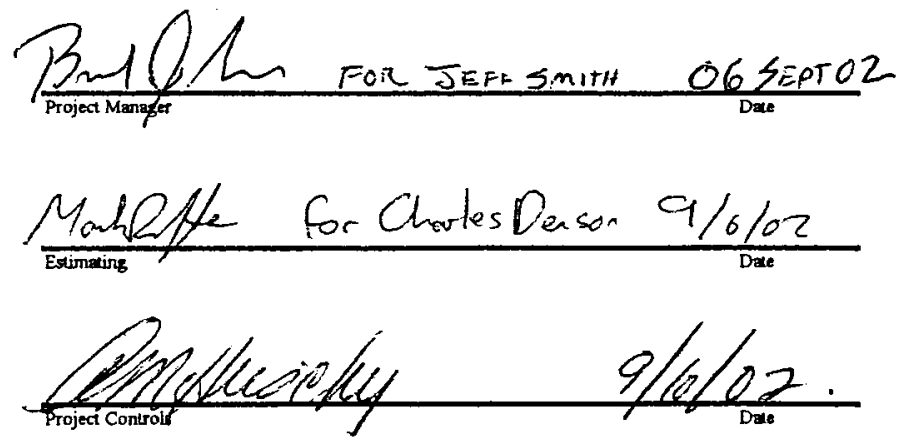


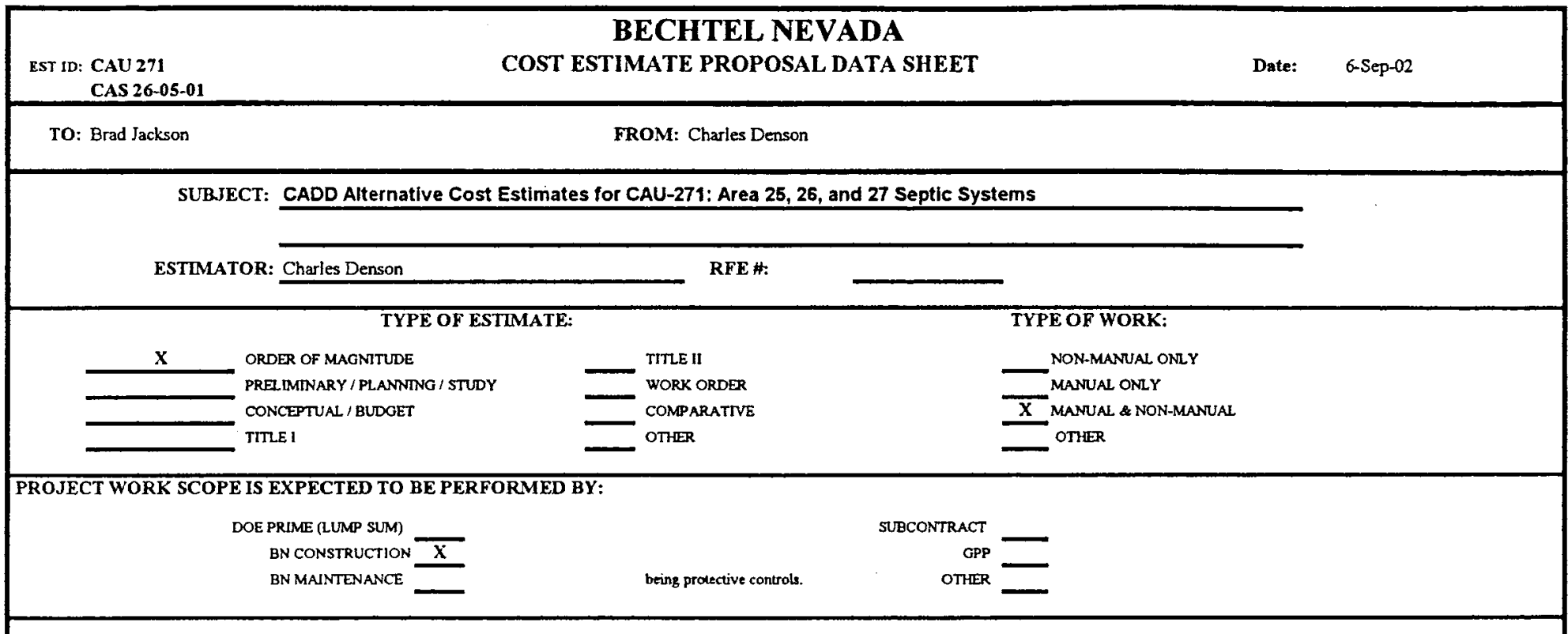

\section{STATEMENT OF WORK}

This estimate has been prepared to provide remedial alternative costs for the closure of Corrective Action Site (CAS) 26-05-01, which is included within Corrective Action Unit (CAU) 271. CAU 271 CAS 26-05-01 is an environmental restoration site listed in the Federal Facility Agreement and Consent Order (FFACO). CAS 26-05-01 is specifically described within the FFACO as the Area 26 Buildings 2201 and 2202 Radioactive Leachfield.

Three alternatives have been evaluated for closure of the CAS: I. No Further Action; II. Clean Closure; and III Closure in Place with Administrative Controls.

This estimate will be used to identify the most cost effective alternative for closure of the site while remaining protective of human health and the environment. The total estimated costs are intended for comparative analysis of remedial fieldwork cost only. Cost for project management, plan preparation, project support, and/or other activities are not included herein.

\section{SCOPE:}

Provide site closure using one of the following alternatives:

I) NO FURTHER ACTION

II) CLEAN CLOSURE BY EXCAVATION AND REMOVAL

III)CLOSURE IN PLACE WITH ADMINISTRATIVE CONTROLS

\section{BASIS:}

The results of the corrective action investigation indicale that impacted materials are present within manhole \#1 and the leachfield. Recently completed field measurements and laboratory analyses of materials collected from manhole \#1 and the leachifield indicates that the types and amounts of materials requiring remedial action are as follows:

Manhole \#1 contains approximately 10 gallons ( 1.3 cubic feet) of sediment impacted by TPH, cesium-137, and uranium-234. Elevated total lead will be reevaluated to determine if the waste material possesses a hazardous component.

The leachfield contains approximately 24 cubic yards of soil impacled by plutonium-239, uranium-234, and uranium-235.

No sediment, liquid, sludge, or debris are present within the collection system and distribution box. There is no septic tank present.

Site closure estimates for each alternative were priced using standard construction references such as RS Means. Richardson's, and the BN estimating database. There is no estimate required for evaluation of the No Further Action alternative since no cost is incurred.

\section{ALTERNATIVE SPECIFIC BASIS OF ESTIMATEJASSUMPTIONS}

Alternative II: Clean Closure

- Remove approximately 10 gallons of radiologically-impacted sediment from manhole \#1, rinse, and collect verification samples.

- Grout manhole and distribution box inlets and outlets and backfill with inert material.

- Excavate and dispose of approximately 24 cubic yards of radiologically-impacted soil from leachfield.

- Manage and dispose of waste.

Alternative III: Closure in Place with Administrative Controls

- Remove manhole opening for full access to the interior

- Grout inlet and outlet and fill manhole with inert material

- Implement and install appropriate use restrictions 


\section{ASSUMPTIONS:}

- No corrective actions are required for the collection system piping.

- Based on data collected during the CADD investigation radiological constituents are present within the septic system manhole \#1 and leachfield. Additional waste classification will be required to determine if lead within the manhole\#1 sludge exhibits hazardous characteristics.

- Only low-level waste is expected at this CAS. The results of future TCLP analyses will delermine if the material within manhole 1 is mixed waste.

- The distribution box is empty.

- No septic tank is present.

- Fecal coliform is not present in any of the impacted media.

- The manhole and distribution box lops will be removed to allow access for filling, pumping and pressure washing of the tank interior, depending on the alternative selected.

- Waste volumes are based on field measurements collected during the corrective action investigation and may be affected by weather events prior to completing the corrective actions.

- Impacted sludge can be completety removed by triple rinsing the manhole interior.

- Inert material, such as clean soil or concrete, will be used to fill the manhole and distribution box.

- Work to be performed by BN during a "normal" workday (no provision for overtime has been provided). Shifts are based on 10-hour days / 4-days per week.

- Efficiencies will be realized if work for similar activities at similar sites can be completed concurrently.

- This estimate does not include costs for preparation of required project plans, permits, reports, mobilization and demobilization, site preparation, or project management.

- A soil borrow area is located within one mile of the site.

- There will be no surface impediments.

Existing leachfield fencing is adequate for access control. No additional fencing will be required.

- Dimensions, volumes, measurements, and analytical data provided by the A\&E contractor accurately represent site conditions and waste characteristics.

\section{ESCALATION:}

No escalation factors have been applied. All costs are in FY03 dollars.

\section{CONTINGENCY:}

Contingency costs are not included in this estimate.

\section{RATES:}

Rates are based on FY03 preliminary rates (Rev 0) effective 7/2/02 and were applied using the BN FY03 cost model.

\section{COST ALTERNATIVES SUMMARY:}

\section{Alternative I: No Further Action}

Alternative II: Clean Closure

a. Clean and fill manhole\#]

b. clean close impacted leachfield soil

b. Waste management and analytical

Alternative IIl: Closure in Place with Administrative Controls

\section{REVIEW/CONCURRENCE:}
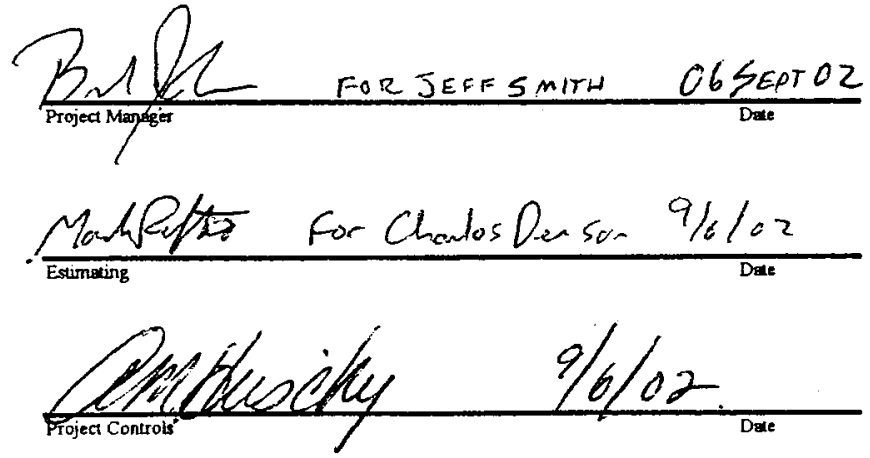


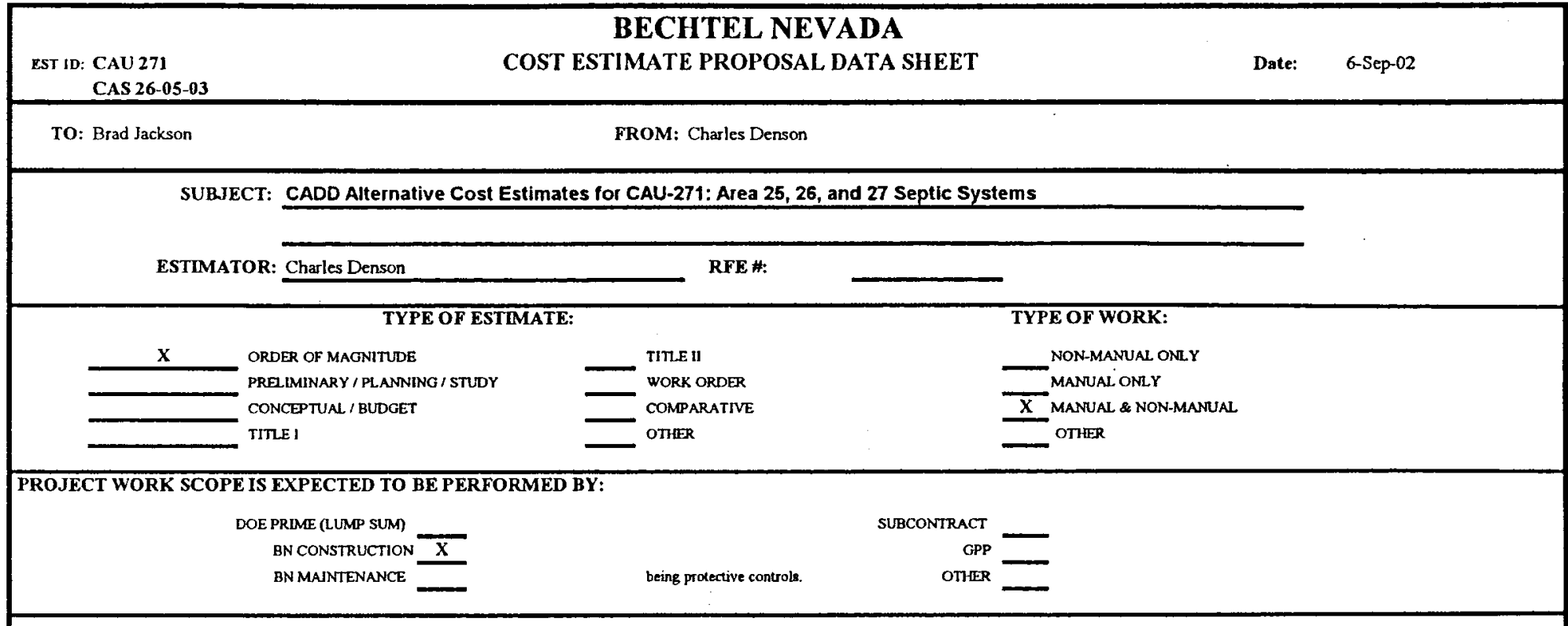

\section{STATEMENT OF WORK}

This estimate has been prepared to provide remedial alternative costs for the closure of Corrective Action Site (CAS) 26-05-03, which is included within Corrective Action Unit (CAU) 271. CAU 271 CAS 26-05-03 is an environmental restoration site listed in the Federal Facility Agreement and Consent Order (FFACO). CAS 26-05-03 is specifically described within the FFACO as the Area 26 Building 2203 Septic System.

Three allernatives have been evaluated for closure of the CAS: I. No Further Action; II. Clean Closure; and III Closure in Place with Administrative Conirols.

This estimate will be used to identify the most cost effective alternative for closure of the site while remaining protective of human health and the environment. The tolal estimated costs are inlended for comparative analysis of remedial fieldwork cost only. Cost for project management, plan preparation, project support, and/or other activities are not included herein.

\section{SCOPE:}

Provide site closure using one of the following alternatives:

I) NO FURTHER ACTION

II) CLEAN CLOSURE BY EXCAVATION AND REMOVAL

III)CLOSURE IN PLACE WITH ADMINISTRATIVE CONTROLS

\section{BASIS:}

The results of the corrective action investigation indicate that impacted materials are present within the septic tank/manhole. Recently completed field measurements and laboratory analyses of materials collected from the septic tank/manhole indicates approximately 1 gallon of hydrocarbon-impacted sediment/residue is present.

No sediment, liquid, sludge, or debris are present within the collection system and distribution box. The concrete distribution box is empty. No impacted soil is present within the leachfield.

Each allernative was evaluated separately for the two chambers within the seplic tank. Site closure estimates for each allernative were priced using standard construction references such as RS Means, Richardson's, and the BN estimating database. There is no estimate required for evaluation of the No Further Action alternalive since no cost is incurred.

\section{ALTERNATIVE SPECIFIC BASIS OF ESTIMATE/ASSUMPTIONS}

\footnotetext{
Alternative II: Clean Closure

- Grout septic tank/manhole inlels and outlets and backfill with inert material.

Manage and dispose of waste.

Alternative III: Closure in Place with Administrative Controls

Remove manhole opening for full access to the septic tank interior

Grout inlet and outlet and fill septic tank/manhole with inert material

Implement and install appropriale use restrictions
}

- Remove approximately 1 gallon of hydrocarbon-impacted sediment from the septic tank/manhole, rinse, and collect verificalion samples. 


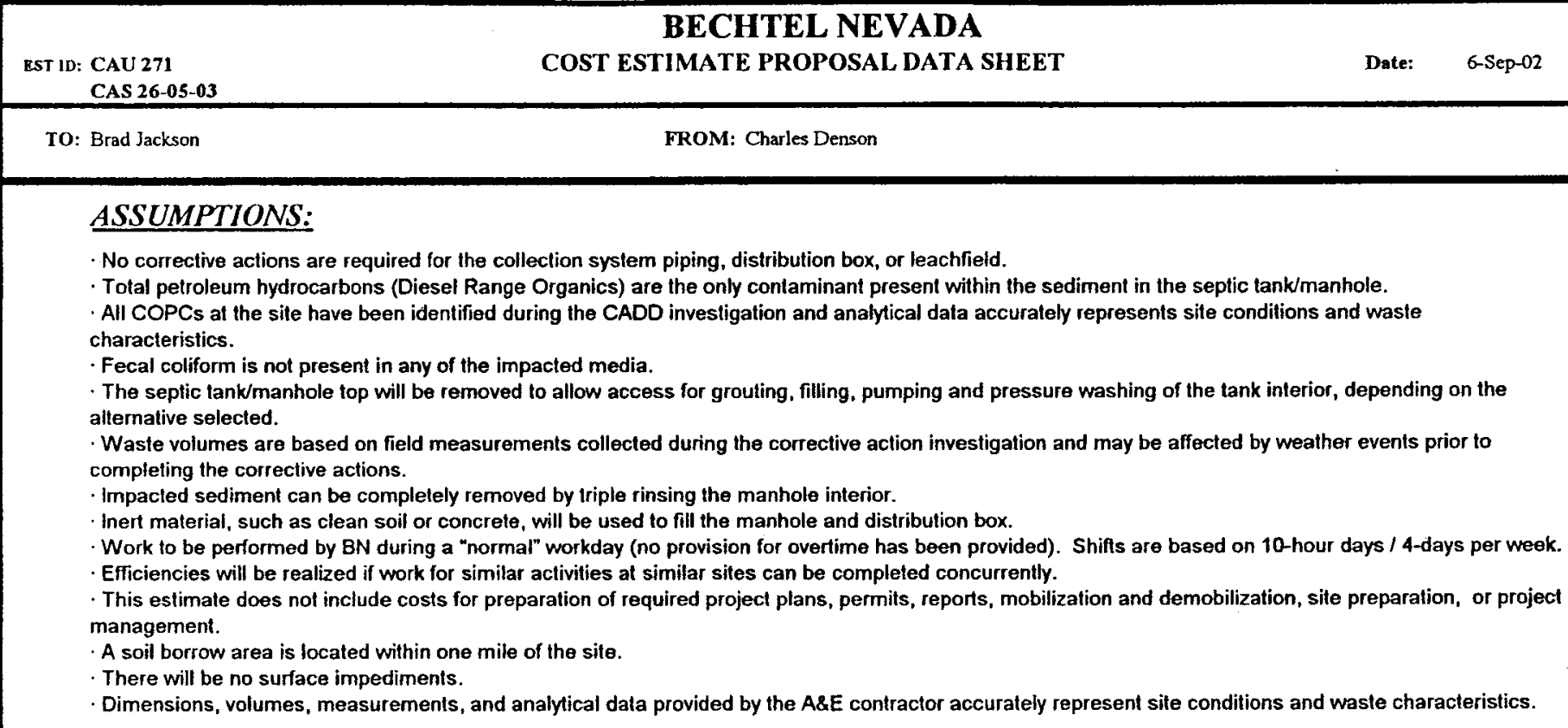

\section{ESCALATION:}

No escalation factors have been applied. All costs are in FY03 dollars.

\section{CONTINGENCY:}

Contingency costs are not included in this estimate.

\section{RATES:}

Rates are based on FY03 preliminary rates (Rev 0 ) effective 7/2/02 and were applied using the BN FY03 cost model.

\section{COST ALTERNATIVES SUMMARY:}

Alternative I: No Further Action

Alternative II: Clean Closure

a. Clean and fill septic tank

b. Waste management and analytical

Alternative III: Closure in Place with Administrative Controls

\section{REVIEW/CONCURRENCE:}
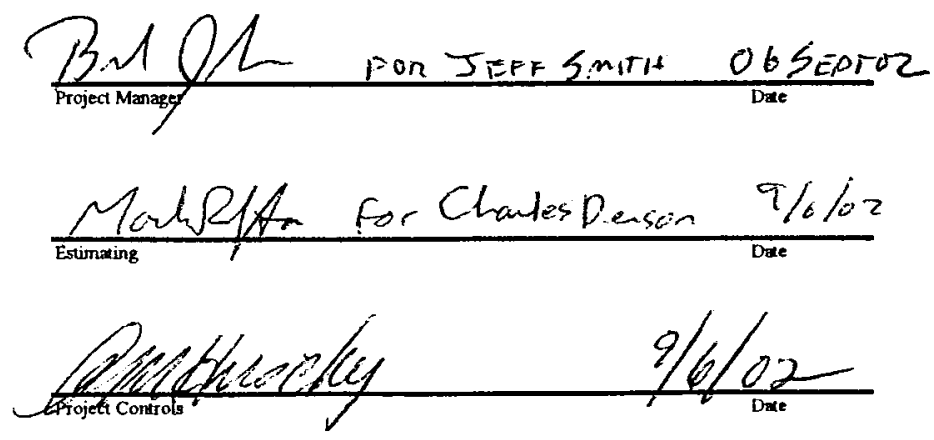


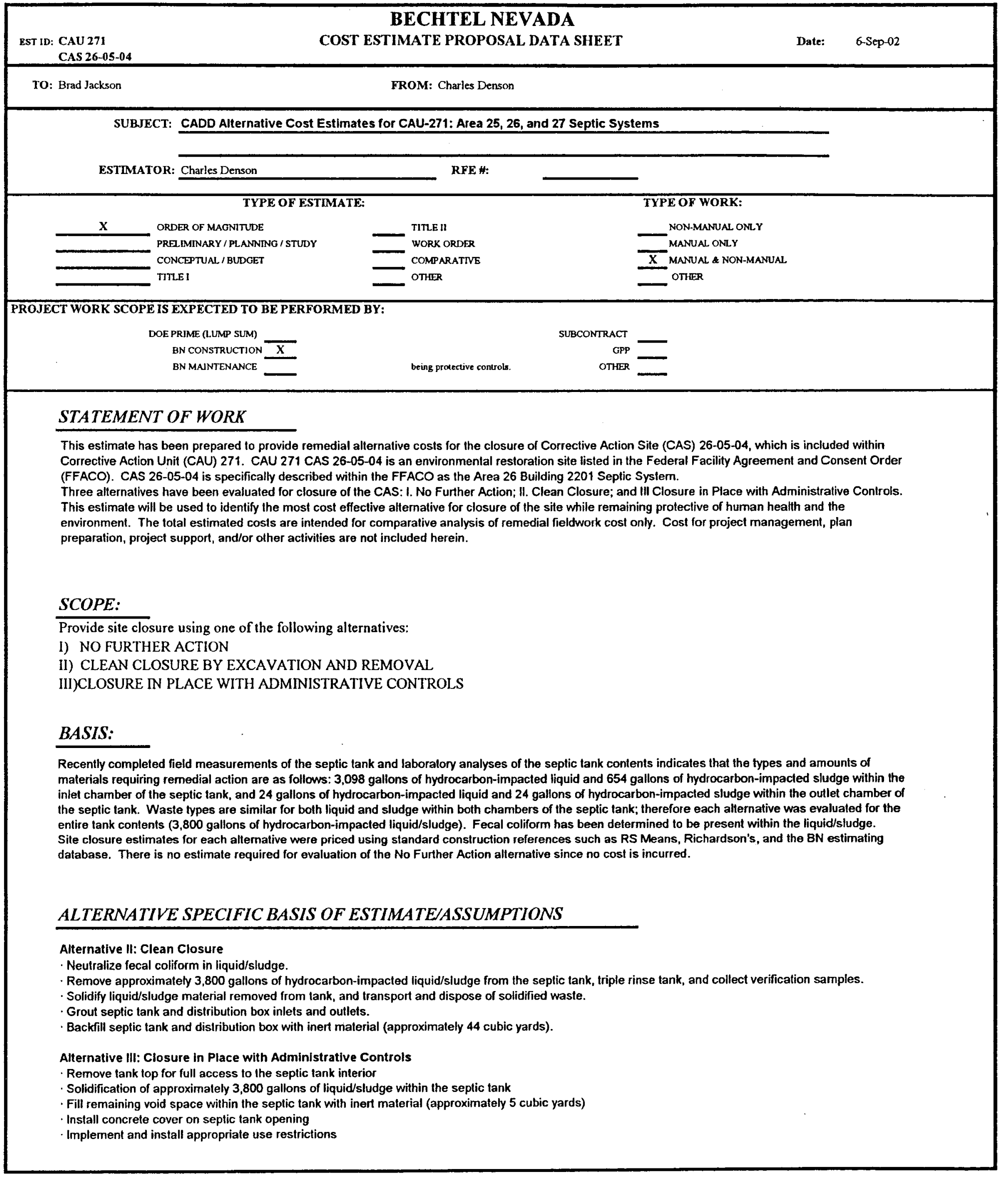




\section{ASSUMPTIONS:}

- No corrective actions are required for the leachfield and/or septic system piping.

- No distribution box is present.

- The septic tank is rectangular, constructed of concrete, and has a total volume of approximately 1,000 cubic feet $(7,500$ gallons).

- Fecal coliform has been determined to be present within the tank contents and will require neutralization.

- All COPCs at the sile have been identified during the CADD investigation and analytical data accurately represents site conditions and waste characteristics.

- The septic lank top will be removed to allow complete mixing of tank contents and solidifying agent, or pressure washing of the tank interior, depending on the alternative selected.

- Waste volumes are based on field measurements collected during the corrective action investigation and may be affected by weather events prior to completing the corrective actions.

- Sludge can be completely removed by triple rinsing the tank interior.

- Inert material, such as clean soil, will be used to solidify the liquid/sludge for Iransportation and disposal.

- Inert material, such as cement or bentonite, will be used to solidify the liquid/sludge for closure in place.

- Inert material, such as cement/concrete will be used to fill the septic tank void space.

- Work to be performed by BN during a "normal" workday (no provision for overlime has been provided). Shifts are based on 10-hour days / 4-days per week.

- Efficiencies will be realized if work for similar activities at similar siles can be compleled concurrently.

- This estimate does not include costs for preparation of required project plans, permits, reports, mobilization and demobilization, sile preparation, or project management.

- A soil borrow area is located within one mile of the site.

- There will be no surface impediments.

- Dimensions, volumes, measurements, and analytical data provided by the A\&E contractor accurately represent site conditions and waste characteristics.

\section{ESCALATION:}

No escalation factors have been applied. All costs are in FY03 dollars.

\section{CONTINGENCY:}

Contingency costs are not included in this estimate.

\section{RATES:}

'Rates are based on FY03 preliminary rates (Rev 0) effective 7/2/02 and were applied using the BN FY03 cost model.

\section{COST ALTERNATIVES SUMMARY:}

Alternative I: No Further Action

Alternative II: Clean Closure

a. Clean and fill septic tank

b. Waste management and analytical

Alternative [II: Closure in Place with Administrative Controls

\section{REVIEW/CONCURRENCE:}
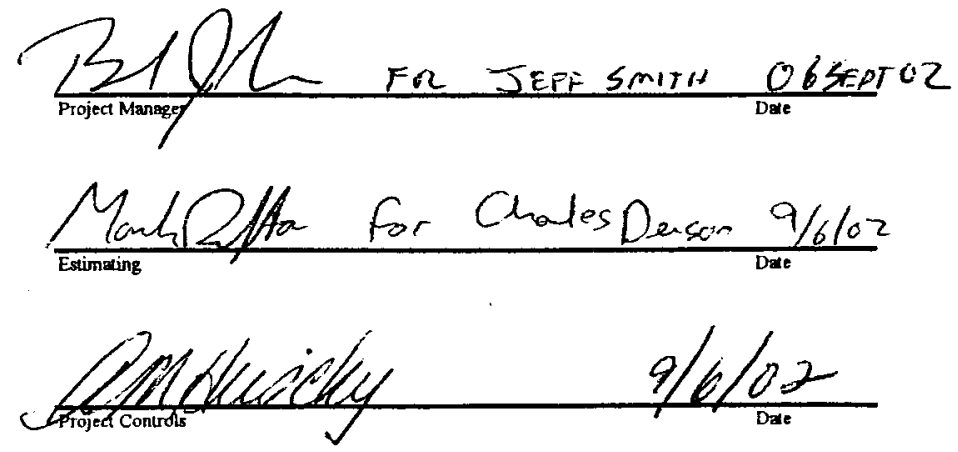


\section{BECHTEL NEVADA}

EST ID: CAU 271

COST ESTIMATE PROPOSAL DATA SHEET

Date: 6-Sep-02

CAS 26-05-05

FROM: Charles Denson

TO: Brad Jackson

SUBJECT: CADD Alternative Cost Estimates for CAU-271: Area 25, 26, and 27 Septic Systems

ESTIMATOR: Charles Denson

RFE \#:

TYPE OF ESTIMATE:

$\mathbf{X}$

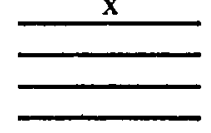
ORDER OF MAGNTTUE THE II PREIMMNARY / PLANNING / STUDY WORK ORDER CONCEPTUAL / BUDGET TTILE I

DOE PRIME (LUMP SUM)

BN CONSTRUCTION BN MAINTENANCE

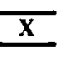

\section{-}

\section{STATEMENT OF WORK}

This estimate has been prepared to provide remedial alternative costs for the closure of Corrective Action Site (CAS) 26-05-05, which is included within Corrective Action Unit (CAU) 271. CAU 271 CAS 26-05-05 is an environmental restoration site listed in the Federal Facility Agreement and Consent Order (FFACO). CAS 26-05-05 is specifically described within the FFACO as the Area 26 Buildings 2101, 2102, and 2107 Septic System.

Three alternatives have been evaluated for closure of the CAS: I. No Further Action; II. Clean Closure; and III Closure in Place with Administrative Controls This estimate will be used to identify the most cost effective alternative for closure of the site while remaining protective of human health and the environment. The total estimated costs are intended for comparative analysis of remedial fieldwork cost only. Cost for project management, plan preparation, project support, and/or other activities are not included herein.

\section{SCOPE:}

Provide site closure using one of the following alternatives:

I) NO FURTHER ACTION

II) CLEAN CLOSURE BY EXCAVATION AND REMOVAL

III)CLOSURE IN PLACE WITH ADMINISTRATIVE CONTROLS

\section{BASIS:}

The results of the corrective action investigation indicate that impacted materials are present within the two septic tanks and leachfield. In addition, two distribution boxes are present but do not contain any liquid, sludge, or sediment. Recently completed field measurements of the septic tanks and leachfield, and laboratory analyses of the septic tank contents and soil in the leachfield indicates that the types and amounts of materials requiring remedial action are as follows:

Septic tank one - 851 gallons of hydrocarbon-impacted liquid and 71 gallons of hydrocarbon-impacted sludge (both liquid and sludge have the same waste characteristic and will be managed together)

Septic tank two - 57 gallons (7.6 cubic feet) of radiologically and hazardous (mixed waste)-impacted sediment

Leachfield - approximately 26 cubic yards of hydrocarbon-impacted soil

Since two waste streams are present, each alternative was evaluated separately for the two chambers within the septic tank. Site closure estimates for each alternative were priced using standard construction references such as RS Means, Richardson's, and the BN estimating database. There is no estimate required for evaluation of the No Further Action alternative since no cost is incurred.

\section{ALTERNATIVE SPECIFIC BASIS OF ESTIMATE/ASSUMPTIONS}

\footnotetext{
Alternative If: Clean Closure

- Grout inlet and two outlets of distribution boxes one and two and backfil with inert material (approximately 4 cubic yards)

- Remove tank top for full access to the septic tank interiors

Septic tank one:

o Remove approximately 922 gallons of hydrocarbon-impacted liquid/sludge from septic tank inlet chamber and outlet chamber, triple rinse inlet chamber, and collect verification samples.

- Solidify liquid/sludge material removed from inlet chamber, and transport and dispose of solidified waste.

Septic tank two:

o Remove approximately 57 gallons ( 7.6 cubic feet) of mixed waste, triple rinse inlet chamber, collect verification samples, and package and stabilize the liquid rinsale waste.

o Load and transport waste for off-site treatment and return to NTS.

o Disposal of treated material on site.

- Grout septic tanks iniets and outlets.

Backfil septic tanks with inert material (approximately 23 cubic yards).

Excavate and dispose of approximately 26 cubic yards of hydrocarbon-impacted soil from the leachifield
} 
Alternative lit: Closure in Place with Administrative Controls

Since hazardous waste must be disposed of in an approved hazardous waste disposal unit, closure in place is not feasible for the mixed waste present in septic tank two. Mixed waste present within the outlet chamber will be removed and managed as described in Alternative II and the cleaned tank will be filled with inert material.

Solidification of approximately 922 gallons of liquid/sludge within the septic tank \#1 inlet chamber

Fill remaining void space within the septic tank (Including the empty outlet chamber) with inert material (approximately 20 cubic yards)

- Install concrete cover on septic tank opening

- Implement and install appropriate use restrictions for septic tank one and the leachfield.

\section{ASSUMPTIONS:}

No corrective actions are required for the collection system piping

- Two distribution boxes are present, but have been verified empty.

All COPCs at the site have been identified during the CADO investigation and analytical data accurately represents site conditions and waste

characteristics.

Septic tanks are assumed to be constructed of concrete and are structurally sound.

Septic tank one contains hydrocarbon-impacted sludge.

Septic tank two contains mixed waste consisting of TPH DRO, U-234, U-235, PU-239, and mercury.

- Fecal coliform has been determined not to be present at the site.

- The septic tank top will be removed to allow complete mixing of tank contents and soliditying agent, or pressure washing of the tank interior, depending on the alternative selected.

Waste volumes are based on field measurements collected during the corrective action investigation and may be affected by weather events prior to completing the corrective actions.

Sludge and sediment can be completely removed by triple rinsing the tank interior

Inert material, such as clean soil, will be used to solidity the liquid/sludge for transportation and disposal.

- Inert material, such as cement or bentonite, will be used to solidify the liquid/sludge for closure in place

Inert material, such as cement/concrete will be used to fill the septic tank void space.

. Work to be performed by BN during a "normal" workday (no provision for overtime has been provided). Shifts are based on 10-hour days / 4-days per week.

Efficiencies will be realized if work for similar activities at similar sites can be completed concurrently.

This estimate does not include costs for preparation of required project plans, permits, reports, mobilization and demobilization, site preparation, or project management.

A soil borrow area is located within one mile of the site.

There will be no surface impediments.

ESCALATION:

No escalation factors have been applied. All costs are in FY03 dollars.

CONTINGENCY:

Contingency costs are not included in this estimate.

RATES:

Rates are based on FY03 preliminary rates (Rev 0) effective 7/2/02 and were applied using the BN FY03 cost model.

\section{COST ALTERNATIVES SUMMARY:}

Alternative I: No Further Action

b. clean close leachfield soil

Alternative III: Closure in Place with Administrative Controls

$\$ \mathbf{2 5 7 , 1 9 9}$

a. Clean close mixed waste

$\$ 205,383$

b. Close in place hydrocarbon waste

$\$ 31,352$

c. Use restrictions

$\$ 20,464$

REVIEW/CONCURRENCE:
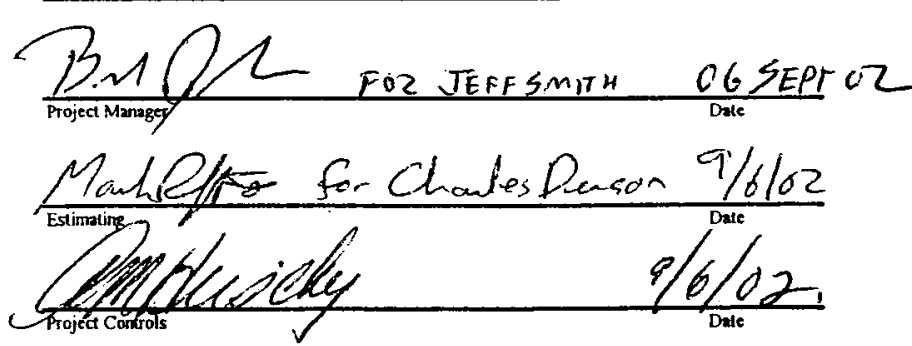


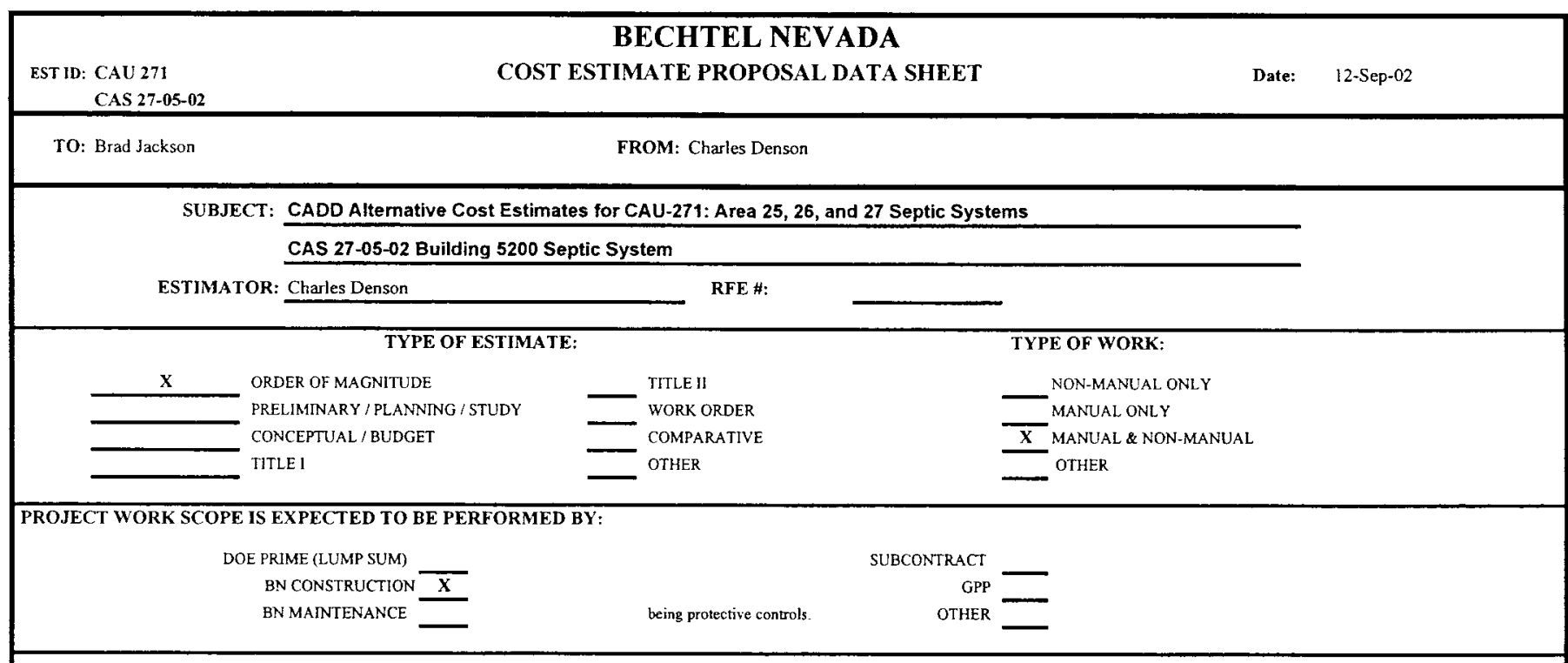

\section{STATEMENT OF WORK}

This estimate has been prepared to provide remedial altemative costs for the closure of Corrective Action Site (CAS) 27-05-02, which is included within Corrective Action Unit (CAU) 271. CAU 271 CAS 27-05-02 is an environmental restoration site listed in the Federal Facility Agreement and Consent Order (FFACO). CAS 27-05-02 is specifically described within the FFACO as the Area 27 Building 5200 Septic System.

Three altematives have been evaluated for closure of the CAS: I. No Further Action; II. Clean Closure; and III Closure in Place with Administrative Controls. This estimate will be used to identify the most cost effective altemative for closure of the site while remaining protective of human health and the environment The total estimated costs are intended for comparative analysis of remedial fieldwork cost only. Cost for project management, plan preparation, project support, and/or other activities are not included herein.

\section{SCOPE:}

Provide site closure using one of the following alternatives

1) NO FURTHER ACTION

II) CLEAN CLOSURE BY EXCAVATION AND REMOVAL

III)CLOSURE IN PLACE WITH ADMINISTRATIVE CONTROLS

\section{BASIS:}

The results of the corrective action investigation indicate that impacted materials are present within the distribution box, the septic tank, and the leachfield. Recently completed field measurements of the distribution box, septic tank and leachfield, and laboratory analyses of the distribution box, septic tank, and soil in the leachfield indicates that the types and amounts of materials requiring remedial action are as follows:

Distribution box - approximately 5 gallons ( 0.7 cubic foot) of hydrocarbon, PCB, and radiologically-impacted sediment (mixed waste)

Septic tank - approximately 1075 gallons of hydrocarbon, PCB, and radiologically-impacted liquid and sludge (mixed waste)

Leachfield - approximately 461 cubic yards of PCB-impacted soil

Each altemative was evaluated separately for the two chambers within the septic tank. Site closure estimates for each alternative were priced using standard construction references such as RS Means, Richardson's, and the BN estimating database. There is no estimate required for evaluation of the No Further

Action altemative since no cost is incurred.

\section{ALTERNATIVE SPECIFIC BASIS OF ESTIMATE/ASSUMPTIONS}

\section{Alternative H: Clean Closure}

- Remove approximately 5 gallons of hydrocarbon, PCB, and radiologically-impacted sediment from distribution box, rinse tank, and collect verification samples - Remove approximately 1,075 gallons of hydrocarbon, PCB, and radiologically-impacted liquid/sludge from the septic tank, rinse tank, and collect verification samples.

- Stabilize-solidify liquid/sludge from septic tank (approximately 1,400 gallons solidified, including waste from distribution box), off-site treatment of PCB component, and retum for on-site disposal.

- Remove approximately 461 cubic yards of PCB-impacted soil ( $<50 \mathrm{mg} / \mathrm{kg}$ ) from the leachfield, transport, and on-site disposal

- Grout distribution box and septic tank inlets and outlets, and backfill with inert material (approximately 8 cubic yards)

Alternative III: Closure in Place with Administrative Controls

- The TSCA component of the waste stream from the distribution box and septic tank precludes closure in place. The distribution box and septic tank will be closed as described in Altemative II.

- Implement and install appropriate use restrictions for PCB-impacted soil present within the leachfield. 


\section{BECHTEL NEVADA}

EST ID: CAU 271

COST ESTIMATE PROPOSAL DATA SHEET

Date: $\quad 12-\operatorname{Sep}-02$

CAS 27-05-02

TO: Brad Jackson

FROM: Charles Denson

\section{ASSUMPTIONS:}

- No corrective actions are required for the collection system piping.

The distribution box is cylindrical and is oriented vertically, constructed of concrete, and has a volume of approximately 13 cubic feet ( 97 gallons).

- The septic tank is cylindrical and is oriented horizontally, constructed of concrete/steel, and has a volume of approximately 216 cubic feet (1,600 gallons).

- All COPCs at the site have been identified during the CADD investigation and analytical data accurately represents site conditions and waste characteristics.

- Leachfield soil contains $<50 \mathrm{mg} / \mathrm{kg}$ PCBs and no hydrocarbons, and can be disposed of at the NTS as solid waste.

Fecal coliform is not present in the septic tank contents.

- The septic tank top will be removed to allow complete access for pumping and pressure washing of the tank interior.

- Waste volumes are based on field measurements collected during the corrective action investigation and may be affected by weather events prior to

completing the corrective actions.

- Sludge and sediment can be completely removed by triple rinsing the tank interior.

- Inert material, such as cement or bentonite, will be used to solidify the liquid/sludge for off-site treatment and disposal

- Inert material, such as cement/concrete will be used to fill the septic tank void space

- Work to be performed by BN during a "normal" workday (no provision for overtime has been provided). Shifts are based on 10-hour days / 4-days per week.

- Efficiencies will be realized if work for similar activities at similar sites can be completed concurrently.

- This estimate does not include costs for preparation of required project plans, permits, reports, mobilization and demobilization, site preparation,., or project management.

- A soil borrow area is located within one mile of the site.

- There will be no surface impediments.

- Dimensions, volumes, measurements, and analytical data provided by the A\&E contractor accurately represent site conditions and waste characteristics.

\section{ESCALATION:}

No escalation factors have been applied. All costs are in FY03 dollars.

\section{CONTINGENCY:}

Contingency costs are not inciuded in this estimate.

\section{RATES:}

Rates are based on FY03 preliminary rates (Rev 0) effective 7/2/02 and were applied using the BN FY03 cost model.

\section{COST ALTERNATIVES SUMMARY:}

Alternative I: No Further Action

c. Mixed waste management and analytical

Alternative III: Closure in Place with Administrative Controls

\section{REVIEW/CONCURRENCE:}

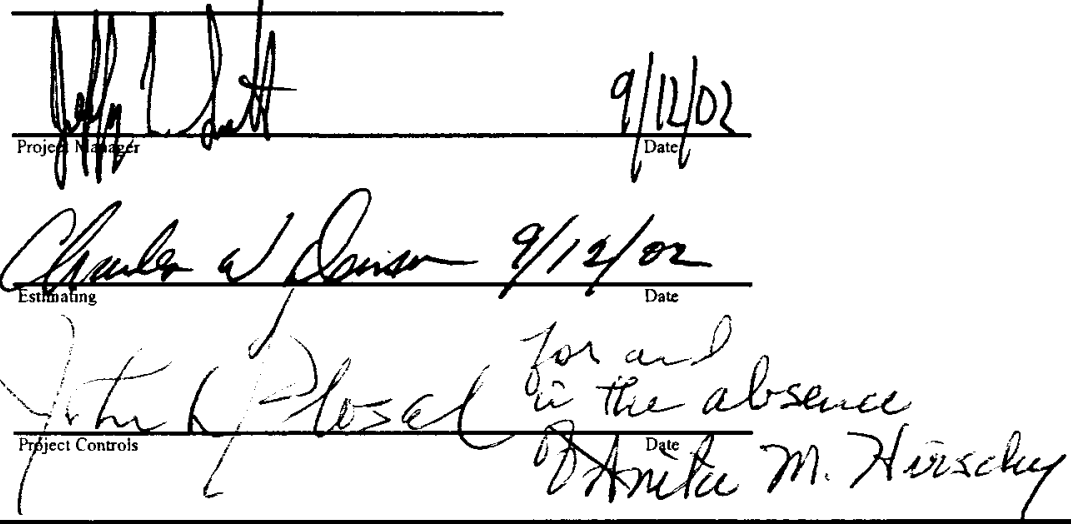




\section{Appendix D}

\section{Sample Location Coordinates for CAU 271: Areas 25, 26, and 27 Septic Systems \\ Nevada Test Site, Nevada}




\section{D.1.0 Sample Location Coordinates}

Sample location coordinates were collected February 20 and 21, 2002, using a Trimble GPS, Model TSCI. These coordinates identify the field sampling locations (e.g., latitude, longitude, elevation) and points of interest at each CAS in CAU 271.

\section{D.1.1 Security Checkpoint Septic System (CAS 25-04-01)}

Sample locations and pertinent points (locations) of interest at CAS 25-04-01 are shown on Figure A.3-1. The corresponding coordinates for CAS 25-04-01 sample locations are listed in Table D.1-1.

\section{D.1.2 PAN-AM Trailers Septic System (CAS 25-04-03)}

Sample locations and pertinent points (locations) of interest at CAS 25-04-03 are shown on Figure A.4-1. The corresponding coordinates for CAS 25-04-03 sample locations are listed in Table D.1-2.

\section{D.1.3 Reactor Control Point Septic System (CAS 25-04-04)}

Sample locations and pertinent points (locations) of interest at CAS 25-04-04 are shown on Figure A.5-1. The corresponding coordinates for CAS 25-04-04 sample locations are listed in Table D.1-3.

\section{D.1.4 BREN Tower Septic System (CAS 25-04-08)}

Sample locations and pertinent points (locations) of interest at CAS 25-04-08 are shown on Figure A.6-1. The corresponding coordinates for CAS 25-04-08 sample locations are listed in Table D.1-4. 
Table D.1-1

Sample Location Coordinates for CAS 25-04-01 Sample Locations and Points of Interest

\begin{tabular}{|c|c|c|c|c|c|c|c|c|c|c|c|c|}
\hline Latitude & Longitude & Northing $^{a}$ & Easting $^{a}$ & $\begin{array}{c}\text { HAE } \\
\text { (meters) }\end{array}$ & ID & Location & $\begin{array}{l}\text { Maximum } \\
\text { PDOP }\end{array}$ & $\begin{array}{l}\text { GPS } \\
\text { Time }\end{array}$ & $\begin{array}{l}\text { Unfiltered } \\
\text { Position }\end{array}$ & $\begin{array}{l}\text { Standard } \\
\text { Deviation }^{b}\end{array}$ & $\begin{array}{l}\text { Horizontal } \\
\text { Position } \\
\text { (meters) }\end{array}$ & $\begin{array}{l}\text { Vertical } \\
\text { Position } \\
\text { (meters) }\end{array}$ \\
\hline 36.7878514 & -116.2652894 & 4071387.55 & 565554.93 & $1,065.74$ & 2 & $\mathrm{~A} 01$ & 2.1 & $13: 21: 51$ & 13 & 0.061574 & 0.323 & 0.506 \\
\hline 36.7878438 & -116.2652835 & 4071386.71 & 565555.46 & $1,067.50$ & 3 & $\mathrm{~A} 02$ & 1.7 & $13: 22: 10$ & 11 & 0.054913 & 0.287 & 0.410 \\
\hline 36.7878309 & -116.2652568 & 4071385.29 & 565557.86 & $1,067.41$ & 4 & A03 & 1.7 & $13: 22: 34$ & 12 & 0.080906 & 0.271 & 0.388 \\
\hline 36.7877983 & -116.2651798 & 4071381.73 & 565564.76 & $1,065.73$ & 5 & A04 & 2.1 & 13:23:00 & 12 & 0.037557 & 0.326 & 0.513 \\
\hline 36.7877628 & -116.2651255 & 4071377.83 & 565569.63 & $1,067.15$ & 7 & A05 & 1.7 & 13:23:43 & 10 & 0.025875 & 0.275 & 0.393 \\
\hline 36.7878351 & -116.2651586 & 4071385.83 & 565566.62 & $1,065.90$ & 6 & A06 & 2.1 & 13:23:20 & 10 & 0.043591 & 0.336 & 0.531 \\
\hline 36.7879385 & -116.2654517 & 4071397.10 & 565540.38 & $1,066.50$ & 1 & A07 & 2.1 & $13: 20: 42$ & 32 & 0.154021 & 0.319 & 0.496 \\
\hline
\end{tabular}

Feature Name: Point Generic

Correction Type: Realtime Corrected

GPS Date: 02/20/2002

Receiver Type: Pro XRS

HAE $=$ Height above ellipsoid

PDOP $=$ Position dilution of precision

${ }^{\mathrm{a} U T M}$ Zone 11, NAD 27

b + - 1 sigma 
Table D.1-2

Sample Location Coordinates for CAS 25-04-01 Sample Locations and Points of Interest

(Page 1 of 3)

\begin{tabular}{|c|c|c|c|c|c|c|c|c|c|c|c|c|}
\hline Latitude & Longitude & Northing $^{a}$ & Easting $^{a}$ & $\begin{array}{c}\text { HAE } \\
\text { (meters) }\end{array}$ & ID & Location & $\begin{array}{l}\text { Maximum } \\
\text { PDOP }\end{array}$ & $\begin{array}{l}\text { GPS } \\
\text { Time }\end{array}$ & $\begin{array}{l}\text { Unfiltered } \\
\text { Position }\end{array}$ & $\begin{array}{l}\text { Standard } \\
\text { Deviation }^{b}\end{array}$ & $\begin{array}{c}\text { Horizontal } \\
\text { Position } \\
\text { (meters) }\end{array}$ & $\begin{array}{l}\text { Vertical } \\
\text { Position } \\
\text { (meters) }\end{array}$ \\
\hline 36.8052927 & -116.2746963 & 4073315.89 & 564700.91 & $1,093.93$ & 4 & B01 & 1.8 & $14: 04: 16$ & 10 & 0.030936 & 0.303 & 0.442 \\
\hline 36.8052903 & -116.2746612 & 4073315.65 & 564704.04 & $1,093.99$ & 3 & B02 & 1.8 & $14: 03: 56$ & 12 & 0.069350 & 0.295 & 0.429 \\
\hline 36.8053075 & -116.2748523 & 4073317.42 & 564686.98 & $1,093.23$ & 23 & B03 & 1.8 & $14: 10: 30$ & 11 & 0.031956 & 0.309 & 0.430 \\
\hline 36.8052965 & -116.2749049 & 4073316.18 & 564682.30 & $1,089.84$ & 31 & B04 & 1.6 & $14: 12: 55$ & 10 & 0.046546 & 0.281 & 0.357 \\
\hline 36.8051889 & -116.2749344 & 4073304.22 & 564679.76 & $1,088.85$ & 36 & B05 & 1.6 & $14: 14: 42$ & 12 & 0.642068 & 0.302 & 0.381 \\
\hline 36.8051935 & -116.2748379 & 4073304.79 & 564688.37 & $1,093.06$ & 20 & B06 & 2.6 & $14: 09: 25$ & 11 & 0.288148 & 0.324 & 0.461 \\
\hline 36.8051808 & -116.2747574 & 4073303.44 & 564695.56 & $1,093.34$ & 8 & B07 & 1.8 & $14: 05: 46$ & 12 & 0.031371 & 0.318 & 0.456 \\
\hline 36.8052478 & -116.2747487 & 4073310.88 & 564696.27 & $1,093.81$ & 6 & B08 & 1.8 & $14: 05: 07$ & 12 & 0.028539 & 0.299 & 0.436 \\
\hline 36.8052496 & -116.2747876 & 4073311.05 & 564692.80 & $1,093.39$ & 11 & B09 & 1.8 & $14: 06: 44$ & 11 & 0.069653 & 0.317 & 0.454 \\
\hline 36.8052528 & -116.2748276 & 4073311.38 & 564689.23 & $1,093.05$ & 17 & B10 & 1.8 & $14: 08: 36$ & 11 & 0.017940 & 0.312 & 0.441 \\
\hline 36.8052391 & -116.2748725 & 4073309.83 & 564685.23 & $1,089.20$ & 24 & B11 & 1.6 & $14: 10: 51$ & 11 & 0.034974 & 0.306 & 0.391 \\
\hline 36.8050160 & -116.2749774 & 4073285.01 & 564676.07 & $1,089.50$ & 37 & B12 & 1.6 & $14: 15: 17$ & 11 & 0.068536 & 0.290 & 0.365 \\
\hline 36.8050613 & -116.2745566 & 4073290.32 & 564713.57 & $1,089.81$ & 38 & B13 & 1.6 & $14: 16: 14$ & 11 & 0.053101 & 0.289 & 0.362 \\
\hline 36.8048329 & -116.2743232 & 4073265.14 & 564734.58 & $1,092.56$ & 40 & B14 & 1.7 & $14: 17: 25$ & 15 & 0.033990 & 0.310 & 0.403 \\
\hline 36.8045688 & -116.2734498 & 4073236.43 & 564812.71 & $1,092.73$ & 42 & B15 & 1.6 & $14: 19: 12$ & 11 & 0.235788 & 0.291 & 0.338 \\
\hline 36.8052922 & -116.2748853 & 4073315.72 & 564684.05 & $1,089.40$ & 30 & B17 & 1.6 & 14:12:38 & 11 & 0.218226 & 0.300 & 0.381 \\
\hline 36.8052690 & -116.2749075 & 4073313.12 & 564682.09 & $1,089.53$ & 34 & B18 & 1.6 & $14: 13: 58$ & 11 & 0.034160 & 0.282 & 0.359 \\
\hline 36.8052656 & -116.2748997 & 4073312.75 & 564682.79 & $1,093.06$ & 28 & B19 & 1.8 & 14:12:04 & 11 & 0.032408 & 0.298 & 0.406 \\
\hline
\end{tabular}


Table D.1-2

Sample Location Coordinates for CAS 25-04-01 Sample Locations and Points of Interest

(Page 2 of 3 )

\begin{tabular}{|c|c|c|c|c|c|c|c|c|c|c|c|c|}
\hline Latitude & Longitude & Northing $^{a}$ & Easting $^{a}$ & $\begin{array}{c}\text { HAE } \\
\text { (meters) }\end{array}$ & ID & Location & $\begin{array}{l}\text { Maximum } \\
\text { PDOP }\end{array}$ & $\begin{array}{l}\text { GPS } \\
\text { Time }\end{array}$ & $\begin{array}{l}\text { Unfiltered } \\
\text { Position }\end{array}$ & $\begin{array}{l}\text { Standard } \\
\text { Deviation }^{b}\end{array}$ & $\begin{array}{c}\text { Horizontal } \\
\text { Position } \\
\text { (meters) }\end{array}$ & $\begin{array}{l}\text { Vertical } \\
\text { Position } \\
\text { (meters) }\end{array}$ \\
\hline 36.8052064 & -116.2749221 & 4073306.17 & 564680.84 & $1,089.39$ & 35 & B20 & 1.6 & $14: 14: 20$ & 10 & 0.058249 & 0.291 & 0.368 \\
\hline 36.8052250 & -116.2748727 & 4073308.26 & 564685.23 & $1,089.95$ & 25 & B21 & 1.8 & 14:11:09 & 10 & 0.782449 & 0.289 & 0.374 \\
\hline 36.8052163 & -116.2748918 & 4073307.29 & 564683.53 & $1,092.94$ & 27 & B22 & 1.8 & $14: 11: 42$ & 10 & 0.050993 & 0.316 & 0.433 \\
\hline 36.8052215 & -116.2748723 & 4073307.87 & 564685.27 & $1,093.10$ & 26 & B23 & 1.8 & $14: 11: 24$ & 11 & 0.040406 & 0.307 & 0.421 \\
\hline 36.8052832 & -116.2748521 & 4073314.74 & 564687.02 & $1,093.11$ & 22 & B24 & 1.8 & $14: 10: 04$ & 19 & 0.033303 & 0.297 & 0.414 \\
\hline 36.8052343 & -116.2748541 & 4073309.31 & 564686.88 & $1,092.93$ & 21 & B25 & 1.8 & $14: 09: 45$ & 11 & 0.035872 & 0.318 & 0.442 \\
\hline 36.8052637 & -116.2748342 & 4073312.58 & 564688.64 & $1,093.11$ & 16 & B26 & 1.8 & $14: 08: 21$ & 10 & 0.066245 & 0.306 & 0.431 \\
\hline 36.8052660 & -116.2748238 & 4073312.85 & 564689.56 & $1,093.07$ & 15 & B27 & 1.8 & 14:08:06 & 11 & 0.023954 & 0.299 & 0.422 \\
\hline 36.8052493 & -116.2748224 & 4073310.99 & 564689.70 & $1,093.01$ & 18 & B28 & 1.8 & 14:08:50 & 11 & 0.042558 & 0.320 & 0.451 \\
\hline 36.8052171 & -116.2748245 & 4073307.42 & 564689.54 & $1,093.11$ & 19 & B29 & 1.8 & 14:09:08 & 11 & 0.021252 & 0.300 & 0.418 \\
\hline 36.8052628 & -116.2748041 & 4073312.51 & 564691.32 & $1,093.02$ & 14 & B30 & 1.8 & 14:07:42 & 11 & 0.056163 & 0.316 & 0.446 \\
\hline 36.8052945 & -116.2747835 & 4073316.04 & 564693.13 & $1,093.22$ & 13 & B31 & 1.8 & $14: 07: 26$ & 11 & 0.062351 & 0.307 & 0.440 \\
\hline 36.8052683 & -116.2747746 & 4073313.14 & 564693.95 & $1,093.36$ & 12 & B32 & 1.8 & $14: 07: 03$ & 13 & 0.023270 & 0.297 & 0.426 \\
\hline 36.8052823 & -116.2747569 & 4073314.69 & 564695.51 & $1,093.68$ & 5 & B33 & 1.8 & $14: 04: 50$ & 11 & 0.018167 & 0.319 & 0.465 \\
\hline 36.8052362 & -116.2747782 & 4073309.57 & 564693.65 & $1,093.54$ & 10 & B34 & 1.8 & $14: 06: 28$ & 11 & 0.034293 & 0.309 & 0.442 \\
\hline 36.8052174 & -116.2747618 & 4073307.50 & 564695.13 & $1,093.46$ & 7 & B35 & 1.8 & $14: 05: 28$ & 11 & 0.040052 & 0.308 & 0.449 \\
\hline 36.8051899 & -116.2748000 & 4073304.42 & 564691.75 & $1,093.29$ & 9 & B36 & 1.8 & $14: 06: 06$ & 12 & 0.035182 & 0.298 & 0.428 \\
\hline 36.8053371 & -116.2748966 & 4073320.68 & 564683.00 & $1,089.97$ & 32 & B37 & 1.6 & $14: 13: 14$ & 12 & 0.061616 & 0.289 & 0.367 \\
\hline 36.8053025 & -116.2749560 & 4073316.80 & 564677.73 & $1,090.03$ & 33 & B38 & 1.6 & $14: 13: 35$ & 12 & 0.055930 & 0.298 & 0.379 \\
\hline 36.8052341 & -116.2745223 & 4073309.51 & 564716.49 & $1,094.34$ & 2 & BY PASS MH1 & 1.9 & 14:02:35 & 44 & 0.037248 & 0.312 & 0.463 \\
\hline
\end{tabular}


Table D.1-2

Sample Location Coordinates for CAS 25-04-01 Sample Locations and Points of Interest

(Page 3 of 3)

\begin{tabular}{|c|c|c|c|c|c|c|c|c|c|c|c|c|}
\hline Latitude & Longitude & Northing ${ }^{a}$ & Easting $^{a}$ & $\begin{array}{c}\text { HAE } \\
\text { (meters) }\end{array}$ & ID & Location & $\begin{array}{l}\text { Maximum } \\
\text { PDOP }\end{array}$ & $\begin{array}{l}\text { GPS } \\
\text { Time }\end{array}$ & $\begin{array}{l}\text { Unfiltered } \\
\text { Position }\end{array}$ & $\begin{array}{l}\text { Standard } \\
\text { Deviation }\end{array}$ & $\begin{array}{l}\text { Horizontal } \\
\text { Position } \\
\text { (meters) }\end{array}$ & $\begin{array}{l}\text { Vertical } \\
\text { Position } \\
\text { (meters) }\end{array}$ \\
\hline 36.8049176 & -116.2745872 & 4073274.35 & 564710.96 & $1,091.70$ & 39 & BY PASS MH2 & 1.7 & $14: 16: 45$ & 16 & 0.975744 & 0.312 & 0.401 \\
\hline 36.8047477 & -116.2740482 & 4073255.87 & 564759.19 & $1,091.05$ & 41 & BY PASS MH3 & 1.6 & $14: 18: 08$ & 16 & 0.048569 & 0.286 & 0.357 \\
\hline 36.8043467 & -116.2727795 & 4073212.26 & 564872.70 & $1,092.15$ & 43 & BY PASS MH4 & 1.5 & $14: 20: 18$ & 11 & 0.050217 & 0.276 & 0.330 \\
\hline 36.8052414 & -116.2744160 & 4073310.39 & 564725.95 & $1,094.56$ & 1 & $\begin{array}{l}\text { PA TRAILER } \\
\text { PAD EASTMH }\end{array}$ & 1.9 & $14: 01: 31$ & 46 & 0.038364 & 0.309 & 0.459 \\
\hline
\end{tabular}

Feature Name: Point Generic

Correction Type: Realtime Corrected

Receiver Type: Pro XRS

HAE = Height above ellipsoid

PDOP $=$ Position dilution of precision

${ }^{a}$ UTM Zone 11, NAD 27

b + - 1 sigma
GPS Date: 02/20/2002

Data File: B250403.ssf 
Table D.1-3

Sample Location Coordinates for CAS 25-04-04 Sample Locations and Points of Interest

(Page 1 of 3)

\begin{tabular}{|c|c|c|c|c|c|c|c|c|c|c|c|c|}
\hline Latitude & Longitude & Northing ${ }^{a}$ & Easting $^{a}$ & $\begin{array}{c}\text { HAE } \\
\text { (meters) }\end{array}$ & ID & Location & $\begin{array}{l}\text { Maximum } \\
\text { PDOP }\end{array}$ & $\begin{array}{l}\text { GPS } \\
\text { Time }\end{array}$ & $\begin{array}{c}\text { Unfiltere } \\
\text { d } \\
\text { Position }\end{array}$ & $\begin{array}{l}\text { Standard } \\
\text { Deviation } \\
\mathbf{b}\end{array}$ & $\begin{array}{l}\text { Horizonta } \\
\text { I Position } \\
\text { (meters) }\end{array}$ & $\begin{array}{l}\text { Vertical } \\
\text { Position } \\
\text { (meters) }\end{array}$ \\
\hline 36.8043998 & -116.2715515 & 4073218.98 & 564982.20 & $1,093.70$ & 37 & $\mathrm{C} 01$ & 2.2 & $11: 13: 47$ & 11 & 0.028611 & 0.331 & 0.581 \\
\hline 36.8043867 & -116.2713542 & 4073217.66 & 564999.82 & $1,093.51$ & 28 & $\mathrm{C} 02$ & 2.3 & $11: 08: 11$ & 12 & 0.026348 & 0.319 & 0.584 \\
\hline 36.8044083 & -116.2713260 & 4073220.07 & 565002.31 & $1,094.46$ & 26 & $\mathrm{C03}$ & 2.3 & $11: 07: 22$ & 12 & 0.062743 & 0.326 & 0.602 \\
\hline 36.8043843 & -116.2713217 & 4073217.42 & 565002.71 & $1,093.66$ & 25 & $\mathrm{C} 04$ & 2.3 & $11: 06: 55$ & 15 & 0.059692 & 0.313 & 0.578 \\
\hline 36.8043291 & -116.2709911 & 4073211.52 & 565032.25 & $1,094.76$ & 9 & $\mathrm{C} 05$ & 2.5 & $10: 57: 57$ & 12 & 0.736202 & 0.321 & 0.587 \\
\hline 36.8042592 & -116.2715452 & 4073203.38 & 564982.88 & $1,093.28$ & 34 & $\mathrm{C} 06$ & 2.3 & $11: 11: 07$ & 12 & 0.057248 & 0.314 & 0.563 \\
\hline 36.8042347 & -116.2713758 & 4073200.78 & 564998.02 & $1,093.22$ & 30 & $\mathrm{C} 07$ & 2.3 & $11: 09: 11$ & 13 & 0.037460 & 0.319 & 0.581 \\
\hline 36.8041991 & -116.2711967 & 4073196.95 & 565014.02 & $1,092.73$ & 16 & $\mathrm{C} 08$ & 2.5 & $11: 02: 03$ & 11 & 0.035906 & 0.325 & 0.616 \\
\hline 36.8041205 & -116.2716596 & 4073187.92 & 564972.79 & $1,094.95$ & 41 & $\mathrm{C} 09$ & 1.6 & $11: 16: 15$ & 12 & 0.039694 & 0.255 & 0.373 \\
\hline 36.8040811 & -116.2714164 & 4073183.71 & 564994.52 & $1,093.15$ & 33 & C10 & 2.3 & $11: 10: 23$ & 10 & 0.040977 & 0.323 & 0.585 \\
\hline 36.8040284 & -116.2710694 & 4073178.11 & 565025.52 & $1,094.18$ & 7 & C11 & 2.5 & $10: 56: 35$ & 11 & 0.332254 & 0.329 & 0.558 \\
\hline 36.8043669 & -116.2715259 & 4073215.35 & 564984.51 & $1,094.78$ & 36 & C12 & 1.6 & $11: 13: 17$ & 13 & 0.063590 & 0.256 & 0.378 \\
\hline 36.8043379 & -116.2711535 & 4073212.39 & 565017.76 & $1,093.11$ & 18 & C13 & 2.4 & $11: 02: 56$ & 14 & 0.034499 & 0.320 & 0.603 \\
\hline 36.8043393 & -116.2716614 & 4073212.20 & 564972.45 & $1,094.40$ & 38 & C14 & 2.2 & $11: 14: 15$ & 12 & 0.048326 & 0.314 & 0.550 \\
\hline 36.8043185 & -116.2714465 & 4073210.03 & 564991.64 & $1,093.11$ & 29 & C15 & 2.3 & $11: 08: 45$ & 11 & 0.060073 & 0.336 & 0.612 \\
\hline 36.8043099 & -116.2713238 & 4073209.16 & 565002.59 & $1,093.47$ & 24 & C16 & 2.4 & $11: 06: 19$ & 11 & 0.035557 & 0.326 & 0.603 \\
\hline 36.8042992 & -116.2711292 & 4073208.11 & 565019.96 & $1,092.90$ & 17 & C17 & 2.4 & $11: 02: 33$ & 12 & 0.015576 & 0.339 & 0.638 \\
\hline 36.8042740 & -116.2710532 & 4073205.36 & 565026.76 & $1,092.83$ & 11 & C18 & 2.6 & $10: 59: 08$ & 29 & 0.047909 & 0.361 & 0.644 \\
\hline 36.8042532 & -116.2712281 & 4073202.94 & 565011.17 & $1,092.89$ & 19 & C19 & 2.4 & $11: 03: 32$ & 11 & 0.038944 & 0.337 & 0.632 \\
\hline 36.8042638 & -116.2715245 & 4073203.91 & 564984.72 & $1,093.35$ & 35 & C20 & 2.3 & $11: 11: 27$ & 14 & 0.042113 & 0.323 & 0.580 \\
\hline
\end{tabular}


Table D.1-3

Sample Location Coordinates for CAS 25-04-04 Sample Locations and Points of Interest

(Page 2 of 3 )

\begin{tabular}{|c|c|c|c|c|c|c|c|c|c|c|c|c|}
\hline Latitude & Longitude & Northing ${ }^{a}$ & Easting $^{a}$ & $\begin{array}{c}\text { HAE } \\
\text { (meters) }\end{array}$ & ID & Location & $\begin{array}{l}\text { Maximum } \\
\text { PDOP }\end{array}$ & $\begin{array}{l}\text { GPS } \\
\text { Time }\end{array}$ & $\begin{array}{c}\text { Unfiltere } \\
\text { d } \\
\text { Position }\end{array}$ & $\begin{array}{l}\text { Standard } \\
\text { Deviation } \\
\mathbf{b}\end{array}$ & $\begin{array}{l}\text { Horizonta } \\
\text { I Position } \\
\text { (meters) }\end{array}$ & $\begin{array}{l}\text { Vertical } \\
\text { Position } \\
\text { (meters) }\end{array}$ \\
\hline 36.8042284 & -116.2710798 & 4073200.28 & 565024.42 & $1,092.77$ & 12 & $\mathrm{C} 21$ & 2.5 & $10: 59: 49$ & 11 & 0.054281 & 0.353 & 0.670 \\
\hline 36.8042160 & -116.2712557 & 4073198.79 & 565008.74 & $1,092.94$ & 20 & $\mathrm{C} 22$ & 2.4 & $11: 04: 00$ & 14 & 0.073704 & 0.320 & 0.600 \\
\hline 36.8042002 & -116.2712965 & 4073197.01 & 565005.12 & $1,092.98$ & 21 & $\mathrm{C} 23$ & 2.4 & $11: 04: 29$ & 12 & 0.022488 & 0.334 & 0.623 \\
\hline 36.8041800 & -116.2714235 & 4073194.68 & 564993.81 & $1,093.17$ & 31 & $\mathrm{C} 24$ & 2.3 & $11: 09: 36$ & 11 & 0.030780 & 0.330 & 0.598 \\
\hline 36.8041699 & -116.2716457 & 4073193.41 & 564974.00 & $1,095.13$ & 40 & $\mathrm{C} 25$ & 1.6 & $11: 15: 52$ & 11 & 0.070155 & 0.270 & 0.396 \\
\hline 36.8041496 & -116.2714770 & 4073191.27 & 564989.06 & $1,093.26$ & 32 & $\mathrm{C} 26$ & 2.3 & $11: 09: 58$ & 11 & 0.029689 & 0.311 & 0.563 \\
\hline 36.8041366 & -116.2712334 & 4073190.00 & 565010.80 & $1,092.74$ & 15 & $\mathrm{C} 27$ & 2.5 & $11: 01: 25$ & 12 & 0.047219 & 0.337 & 0.638 \\
\hline 36.8041111 & -116.2711516 & 4073187.23 & 565018.12 & $1,092.76$ & 13 & $\mathrm{C} 28$ & 2.5 & $11: 00: 18$ & 13 & 0.034477 & 0.335 & 0.638 \\
\hline 36.8041041 & -116.2717072 & 4073186.07 & 564968.56 & $1,094.82$ & 42 & $\mathrm{C} 29$ & 1.6 & $11: 16: 40$ & 11 & 0.023254 & 0.265 & 0.387 \\
\hline 36.8040983 & -116.2713632 & 4073185.66 & 564999.25 & $1,093.02$ & 22 & C30 & 2.4 & $11: 05: 07$ & 10 & 0.044731 & 0.322 & 0.599 \\
\hline 36.8040544 & -116.2711324 & 4073180.95 & 565019.88 & $1,092.78$ & 14 & C31 & 2.5 & $11: 00: 49$ & 12 & 0.030437 & 0.352 & 0.669 \\
\hline 36.8045228 & -116.2713034 & 4073232.79 & 565004.23 & $1,095.00$ & 6 & C32 & 2.6 & $10: 51: 40$ & 12 & 0.031294 & 0.361 & 0.691 \\
\hline 36.8044365 & -116.2713119 & 4073223.22 & 565003.55 & $1,095.05$ & 27 & C33 & 2.3 & $11: 07: 44$ & 13 & 0.030094 & 0.338 & 0.623 \\
\hline 36.8041431 & -116.2717061 & 4073190.39 & 564968.63 & $1,094.92$ & 43 & C34 & 1.6 & $11: 17: 02$ & 12 & 0.033369 & 0.250 & 0.365 \\
\hline 36.8041570 & -116.2713442 & 4073192.18 & 565000.90 & $1,093.19$ & 23 & C35 & 2.4 & $11: 05: 32$ & 16 & 0.040478 & 0.335 & 0.623 \\
\hline 36.8044136 & -116.2713269 & 4073220.66 & 565002.22 & $1,094.75$ & 47 & DIST BOX & 2.5 & $11: 20: 37$ & 12 & 0.197537 & 0.324 & 0.542 \\
\hline 36.8044170 & -116.2713727 & 4073221.01 & 564998.13 & $1,095.24$ & 46 & MIDDLE BY PASS MH & 2.1 & $11: 19: 55$ & 26 & 0.038256 & 0.329 & 0.549 \\
\hline 36.8045139 & -116.2713231 & 4073231.79 & 565002.48 & $1,098.52$ & 3 & NORTH INLET MH & 2.6 & $10: 49: 29$ & 28 & 0.539811 & 0.327 & 0.539 \\
\hline 36.8045727 & -116.2713103 & 4073238.32 & 565003.58 & $1,098.59$ & 2 & NORTH MANHOLE & 2.1 & $10: 48: 19$ & 43 & 0.070628 & 0.320 & 0.520 \\
\hline 36.8044654 & -116.2713326 & 4073226.40 & 565001.67 & $1,098.43$ & 5 & OUTLET MANHOLE & 2.2 & $10: 50: 54$ & 26 & 0.052735 & 0.352 & 0.495 \\
\hline
\end{tabular}


Table D.1-3

Sample Location Coordinates for CAS 25-04-04 Sample Locations and Points of Interest

(Page 3 of 3 )

\begin{tabular}{|c|c|c|c|c|c|c|c|c|c|c|c|c|}
\hline Latitude & Longitude & Northing $^{a}$ & Easting $^{a}$ & $\begin{array}{c}\text { HAE } \\
\text { (meters) }\end{array}$ & ID & Location & $\begin{array}{l}\text { Maximum } \\
\text { PDOP }\end{array}$ & $\begin{array}{l}\text { GPS } \\
\text { Time }\end{array}$ & $\begin{array}{c}\text { Unfiltere } \\
\text { d } \\
\text { Position }\end{array}$ & $\begin{array}{l}\text { Standard } \\
\text { Deviation } \\
\mathbf{b}\end{array}$ & $\begin{array}{l}\text { Horizonta } \\
\text { I Position } \\
\text { (meters) }\end{array}$ & $\begin{array}{l}\text { Vertical } \\
\text { Position } \\
\text { (meters) }\end{array}$ \\
\hline 36.8040548 & -116.2713946 & 4073180.81 & 564996.49 & $1,093.71$ & 45 & SOUTH BY MH & 2 & $11: 18: 34$ & 38 & 0.186649 & 0.310 & 0.467 \\
\hline 36.8045011 & -116.2713194 & 4073230.38 & 565002.82 & $1,095.56$ & 4 & SOUTH INLET MH & 2.6 & $10: 50: 13$ & 22 & 0.392261 & 0.341 & 0.632 \\
\hline 36.8044011 & -116.2709192 & 4073219.55 & 565038.61 & $1,095.66$ & 10 & NE & 3.1 & $10: 58: 32$ & 12 & 0.550833 & 0.380 & 0.768 \\
\hline 36.8044519 & -116.2717262 & 4073224.63 & 564966.57 & $1,094.47$ & 39 & NW & 3.6 & $11: 14: 55$ & 15 & 0.123881 & 0.362 & 0.620 \\
\hline 36.8040148 & -116.2710338 & 4073176.62 & 565028.71 & $1,093.92$ & 8 & SE & 2.5 & $10: 57: 00$ & 20 & 0.321143 & 0.325 & 0.597 \\
\hline 36.8041150 & -116.2717684 & 4073187.23 & 564963.09 & $1,094.31$ & 44 & SW & 2.5 & $11: 17: 33$ & 19 & 0.240330 & 0.315 & 0.531 \\
\hline 36.8045107 & -116.2711951 & 4073232 & 565013.9 & $1,092.56$ & 11 & C36 & 1.8 & $14: 52: 33$ & 53 & 0.427 & 0.361 & 0.058456 \\
\hline 36.8045178 & -116.271238 & 4073232 & 565010.1 & $1,092.41$ & 12 & $\mathrm{C} 37$ & 1.8 & $14: 53: 58$ & 52 & 0.427 & 0.361 & 0.171531 \\
\hline 36.8045289 & -116.2713423 & 4073233 & 565000.8 & $1,092.88$ & 14 & C38 & 1.8 & $14: 57: 05$ & 51 & 0.426 & 0.361 & 0.071858 \\
\hline 36.8045517 & -116.2714098 & 4073236 & 564994.7 & $1,091.27$ & 15 & C39 & 2.1 & $14: 58: 13$ & 50 & 0.51 & 0.383 & 0.235158 \\
\hline 36.8045684 & -116.2712557 & 4073238 & 565008.5 & $1,092.2$ & 16 & C40 & 3.3 & $14: 59: 44$ & 52 & 0.656 & 0.426 & 0.424234 \\
\hline 36.8046315 & -116.2712344 & 4073245 & 565010.3 & $1,092.81$ & 17 & C41 & 2.5 & 15:00:59 & 51 & 0.485 & 0.364 & 0.138743 \\
\hline
\end{tabular}

Feature Name: Point Generic

Correction Type: Realtime Corrected

Receiver Type: Pro XRS

$\mathrm{HAE}=$ Height above ellipsoid

$\mathrm{PDOP}=$ Position dilution of precision

aUTM Zone 11, NAD 27

b+/- 1 sigma
GPS Date: 02/20/2002 and 5/14/2002

Data File: C250404.ssf and 271PS2.ssf 
Table D.1-4

Sample Location Coordinates for CAS 25-04-08 Sample Locations and Points of Interest

\begin{tabular}{|c|c|c|c|c|c|c|c|c|c|c|c|c|}
\hline Latitude & Longitude & Northing $^{a}$ & Easting $^{a}$ & $\begin{array}{c}\text { HAE } \\
\text { (meters) }\end{array}$ & ID & Location & $\begin{array}{l}\text { Maximum } \\
\text { PDOP }\end{array}$ & $\begin{array}{l}\text { GPS } \\
\text { Time }\end{array}$ & $\begin{array}{l}\text { Unfiltered } \\
\text { Position }\end{array}$ & $\begin{array}{l}\text { Standard } \\
\text { Deviation }\end{array}$ & $\begin{array}{c}\text { Horizontal } \\
\text { Position } \\
\text { (meters) }\end{array}$ & $\begin{array}{l}\text { Vertical } \\
\text { Position } \\
\text { (meters) }\end{array}$ \\
\hline 36.7954837 & -116.2321919 & 4072257.38 & 568501.33 & $1,143.68$ & $\overline{4}$ & D01 & $\overline{1.6}$ & 15:43:41 & 10 & 0.040665 & 0.284 & 0.395 \\
\hline 36.7954582 & -116.2321873 & 4072254.56 & 568501.76 & $1,143.38$ & 7 & D02 & 1.6 & $15: 44: 30$ & 11 & 0.053500 & 0.279 & 0.389 \\
\hline 36.7954217 & -116.2321944 & 4072250.51 & 568501.16 & $1,144.01$ & 10 & D03 & 1.6 & $15: 45: 23$ & 12 & 0.054320 & 0.276 & 0.385 \\
\hline 36.7954243 & -116.2321810 & 4072250.81 & 568502.35 & $1,143.89$ & 9 & D04 & 1.6 & $15: 45: 06$ & 11 & 0.184762 & 0.269 & 0.376 \\
\hline 36.7954290 & -116.2321679 & 4072251.34 & 568503.52 & $1,143.33$ & 8 & D05 & 1.6 & $15: 44: 47$ & 12 & 0.068751 & 0.287 & 0.401 \\
\hline 36.7953525 & -116.2321637 & 4072242.85 & 568503.96 & $1,143.92$ & 12 & D06 & 1.9 & $15: 46: 04$ & 12 & 0.038359 & 0.306 & 0.450 \\
\hline 36.7952741 & -116.2321605 & 4072234.15 & 568504.32 & $1,140.53$ & 15 & D07 & 1.9 & $15: 47: 06$ & 12 & 0.357286 & 0.293 & 0.375 \\
\hline 36.7952839 & -116.2321503 & 4072235.25 & 568505.22 & $1,143.62$ & 14 & D08 & 1.6 & $15: 46: 48$ & 13 & 0.164598 & 0.287 & 0.403 \\
\hline 36.7952860 & -116.2321426 & 4072235.49 & 568505.90 & $1,143.96$ & 13 & D09 & 1.6 & $15: 46: 32$ & 13 & 0.050858 & 0.280 & 0.393 \\
\hline 36.7954144 & -116.2321800 & 4072249.70 & 568502.44 & $1,144.19$ & 11 & D10 & 1.6 & $15: 45: 43$ & 12 & 0.090354 & 0.285 & 0.399 \\
\hline 36.7953047 & -116.2320668 & 4072237.62 & 568512.64 & $1,142.11$ & 20 & D11 & 1.5 & $15: 48: 58$ & 11 & 0.148948 & 0.285 & 0.375 \\
\hline 36.7955131 & -116.2322806 & 4072260.58 & 568493.39 & $1,143.35$ & 1 & $\mathrm{D} 12$ & 2 & $15: 42: 31$ & 17 & 0.139958 & 0.321 & 0.474 \\
\hline 36.7954876 & -116.2322504 & 4072257.78 & 568496.10 & $1,143.54$ & 3 & D13 & 2 & $15: 43: 17$ & 11 & 0.074177 & 0.315 & 0.464 \\
\hline 36.7955053 & -116.2322489 & 4072259.74 & 568496.22 & $1,143.68$ & 2 & D14 & 2 & $15: 42: 59$ & 11 & 0.038573 & 0.306 & 0.452 \\
\hline 36.7954781 & -116.2321905 & 4072256.76 & 568501.45 & $1,143.71$ & 5 & D15 & 1.6 & $15: 43: 55$ & 12 & 0.059111 & 0.291 & 0.404 \\
\hline 36.7954620 & -116.2321859 & 4072254.98 & 568501.88 & $1,143.41$ & 6 & $\overline{D 16}$ & 1.6 & $15: 44: 13$ & 11 & 0.110274 & 0.272 & 0.379 \\
\hline 36.7952834 & -116.2322186 & 4072235.14 & 568499.12 & $1,141.80$ & 19 & D17 & 1.5 & $15: 48: 29$ & 10 & 0.044642 & 0.272 & 0.358 \\
\hline 36.7952636 & -116.2321939 & 4072232.96 & 568501.34 & $1,143.74$ & 18 & D18 & 1.7 & $15: 48: 11$ & 10 & 0.015403 & 0.271 & 0.382 \\
\hline 36.7952395 & -116.2321560 & 4072230.32 & 568504.74 & $1,141.47$ & 17 & D19 & 1.5 & $15: 47: 48$ & 11 & 0.046979 & 0.280 & 0.367 \\
\hline 36.7952537 & -116.2321050 & 4072231.94 & 568509.28 & $1,140.35$ & 16 & D20 & 1.7 & $15: 47: 28$ & 11 & 0.032644 & 0.302 & 0.382 \\
\hline
\end{tabular}

Feature Name: Point Generic

Correction Type: Realtime Corrected

Receiver Type: Pro XRS

HAE $=$ Height above ellipsoid

PDOP $=$ Position dilution of precision

${ }^{\mathrm{a} U T M}$ Zone 11, NAD 27

${ }^{b}+/-1$ sigma
GPS Date: 02/20/2002

Data File: D250408.ss 


\section{D.1.5 Engine Test Stand No. 1 Septic System (CAS 25-04-09)}

Sample locations and pertinent points (locations) of interest at CAS 25-04-09 are shown on Figure A.7-1. The corresponding coordinates for CAS 25-04-09 sample locations are listed in Table D.1-5. The five sample locations (E38-E42) are listed in the table, but are not plotted on Figure A.7-1. These coordinates are identified in Table D.1-5 with an asterisk next to the location label.

\section{D.1.6 Rad-Safe Trailers Septic System (CAS 25-04-10)}

Sample locations and pertinent points (locations) of interest at CAS 25-04-10 are shown on Figure A.8-1. The corresponding coordinates for CAS 25-04-10 sample locations are listed in Table D.1-6.

\section{D.1.7 South of LASL Trailers Septic System (CAS 25-04-11)}

Sample locations and pertinent points (locations) of interest at CAS 25-04-11 are shown on Figure A.9-1. The corresponding coordinates for CAS 25-04-11 sample locations are listed in Table D.1-7.

\section{D.1.8 Port Gaston Training Area Contaminated Water Reservoir (CAS 26-03-01)}

Sample locations and pertinent points (locations) of interest at CAS 26-03-01 are shown on Figure A.10-1. The corresponding coordinates for CAS 26-03-01 sample locations are listed in Table D.1-8. One sample location (H09) is listed in the table, but is not plotted on Figure A.10-1. This coordinate is identified in Table D.1-8 with an asterisk next to the location label. The sample location is located downstream of the lagoon.

\section{D.1.9 Area 26 Check Station, BIdg. 2105, Septic System (CAS 26-04-01)}

Sample locations and pertinent points (locations) of interest at CAS 26-04-01 are shown on Figure A.11-1. The corresponding coordinates for CAS 26-04-01 sample locations are listed in Table D.1-9. 
Table D.1-5

Sample Location Coordinates for CAS 25-04-09 Sample Locations and Points of Interest

(Page 1 of 3 )

\begin{tabular}{|c|c|c|c|c|c|c|c|c|c|c|c|c|}
\hline Latitude & Longitude & Northing $^{a}$ & Easting $^{a}$ & $\begin{array}{c}\text { HAE } \\
\text { (meters) }\end{array}$ & ID & Location & $\begin{array}{l}\text { Maximum } \\
\text { PDOP }\end{array}$ & $\begin{array}{l}\text { GPS } \\
\text { Time }\end{array}$ & $\begin{array}{l}\text { Unfiltered } \\
\text { Position }\end{array}$ & $\begin{array}{l}\text { Standard } \\
\text { Deviation }\end{array}$ & $\begin{array}{c}\text { Horizontal } \\
\text { Position } \\
\text { (meters) }\end{array}$ & $\begin{array}{l}\text { Vertical } \\
\text { Position } \\
\text { (meters) }\end{array}$ \\
\hline 36.828873 & -116.309685 & 4075908.56 & 561560.85 & $1,137.36$ & 9 & E01 & 2.2 & $14: 49: 25$ & 11 & 0.115277 & 0.349 & 0.539 \\
\hline 36.828825 & -116.309683 & 4075903.27 & 561561.00 & $1,137.00$ & 8 & E02 & 2.2 & $14: 49: 07$ & 10 & 0.034079 & 0.340 & 0.524 \\
\hline 36.828797 & -116.309886 & 4075900.01 & 561542.93 & $1,136.25$ & 39 & E03 & 1.9 & 15:01:01 & 13 & 0.042785 & 0.297 & 0.430 \\
\hline 36.828801 & -116.309693 & 4075900.57 & 561560.13 & $1,135.78$ & 28 & E04 & 1.8 & $14: 56: 58$ & 11 & 0.029464 & 0.297 & 0.420 \\
\hline 36.828797 & -116.309662 & 4075900.14 & 561562.92 & $1,136.27$ & 27 & E05 & 2.2 & $14: 56: 40$ & 11 & 0.162525 & 0.337 & 0.527 \\
\hline 36.828792 & -116.309476 & 4075899.71 & 561579.52 & $1,138.16$ & 1 & E06 & 1.6 & $14: 44: 32$ & 16 & 0.219396 & 0.296 & 0.357 \\
\hline 36.828722 & -116.309776 & 4075891.77 & 561552.84 & $1,135.38$ & 31 & E07 & 1.8 & 14:58:04 & 13 & 1.224929 & 0.299 & 0.423 \\
\hline 36.828724 & -116.309680 & 4075892.07 & 561561.41 & $1,135.36$ & 23 & E08 & 1.8 & $14: 55: 26$ & 12 & 0.046104 & 0.310 & 0.432 \\
\hline 36.828726 & -116.309570 & 4075892.28 & 561571.15 & $1,134.97$ & 16 & E09 & 1.8 & $14: 52: 27$ & 11 & 0.051898 & 0.312 & 0.428 \\
\hline 36.828641 & -116.309893 & 4075882.63 & 561542.46 & $1,135.16$ & 37 & $\mathrm{E} 10$ & 1.8 & 15:00:09 & 12 & 0.036502 & 0.301 & 0.432 \\
\hline 36.828648 & -116.309683 & 4075883.54 & 561561.21 & $1,134.76$ & 19 & E11 & 1.8 & $14: 53: 56$ & 12 & 0.116890 & 0.297 & 0.412 \\
\hline 36.828648 & -116.309467 & 4075883.72 & 561580.40 & $1,135.02$ & 14 & E12 & 2.2 & $14: 51: 40$ & 12 & 0.246014 & 0.323 & 0.451 \\
\hline 36.828781 & -116.309798 & 4075898.26 & 561550.81 & $1,135.78$ & 32 & E13 & 1.8 & 14:58:28 & 11 & 0.038799 & 0.310 & 0.443 \\
\hline 36.828778 & -116.309854 & 4075897.86 & 561545.78 & $1,135.83$ & 38 & E14 & 1.8 & $15: 00: 40$ & 12 & 0.022231 & 0.315 & 0.454 \\
\hline 36.828768 & -116.309738 & 4075896.80 & 561556.18 & $1,135.50$ & 29 & E15 & 1.8 & $14: 57: 24$ & 12 & 0.022784 & 0.308 & 0.436 \\
\hline 36.828739 & -116.309821 & 4075893.55 & 561548.79 & $1,135.65$ & 33 & E16 & 1.8 & $14: 58: 47$ & 12 & 0.041185 & 0.319 & 0.455 \\
\hline 36.828731 & -116.309700 & 4075892.73 & 561559.61 & $1,135.34$ & 22 & E17 & 1.8 & $14: 55: 07$ & 11 & 0.095050 & 0.302 & 0.421 \\
\hline 36.828716 & -116.309836 & 4075891.00 & 561547.43 & $1,135.45$ & 34 & E18 & 1.8 & 14:59:07 & 12 & 0.019129 & 0.300 & 0.428 \\
\hline 36.828723 & -116.309714 & 4075891.87 & 561558.31 & $1,135.36$ & 21 & E19 & 1.8 & $14: 54: 43$ & 14 & 0.035490 & 0.319 & 0.445 \\
\hline 36.828702 & -116.309767 & 4075889.47 & 561553.59 & $1,135.20$ & 30 & E20 & 1.8 & $14: 57: 49$ & 12 & 0.036598 & 0.320 & 0.453 \\
\hline
\end{tabular}


Table D.1-5

Sample Location Coordinates for CAS 25-04-09 Sample Locations and Points of Interest

(Page 2 of 3 )

\begin{tabular}{|c|c|c|c|c|c|c|c|c|c|c|c|c|}
\hline Latitude & Longitude & Northing $^{a}$ & Easting $^{a}$ & $\begin{array}{c}\text { HAE } \\
\text { (meters) }\end{array}$ & ID & Location & $\begin{array}{l}\text { Maximum } \\
\text { PDOP }\end{array}$ & $\begin{array}{l}\text { GPS } \\
\text { Time }\end{array}$ & $\begin{array}{l}\text { Unfiltered } \\
\text { Position }\end{array}$ & $\begin{array}{l}\text { Standard } \\
\text { Deviation }^{\mathrm{b}}\end{array}$ & $\begin{array}{c}\text { Horizontal } \\
\text { Position } \\
\text { (meters) }\end{array}$ & $\begin{array}{l}\text { Vertical } \\
\text { Position } \\
\text { (meters) }\end{array}$ \\
\hline 36.828691 & -116.309686 & 4075888.33 & 561560.85 & $1,135.18$ & 20 & E21 & 1.8 & 14:54:20 & 11 & 0.047238 & 0.308 & 0.427 \\
\hline 36.828688 & -116.309807 & 4075887.96 & 561550.10 & $1,135.17$ & 35 & E22 & 1.8 & 14:59:28 & 12 & 0.100638 & 0.310 & 0.442 \\
\hline 36.828655 & -116.309871 & 4075884.22 & 561544.42 & $1,135.17$ & 36 & E23 & 1.8 & $14: 59: 51$ & 11 & 0.065374 & 0.321 & 0.461 \\
\hline 36.828793 & -116.309545 & 4075899.74 & 561573.34 & $1,136.55$ & 11 & E24 & 2.2 & $14: 50: 32$ & 10 & 0.018847 & 0.350 & 0.552 \\
\hline 36.828779 & -116.309670 & 4075898.14 & 561562.21 & $1,135.57$ & 26 & E25 & 1.8 & $14: 56: 24$ & 11 & 0.041169 & 0.309 & 0.431 \\
\hline 36.828763 & -116.309658 & 4075896.32 & 561563.27 & $1,135.55$ & 25 & E26 & 1.8 & $14: 56: 05$ & 11 & 0.083150 & 0.301 & 0.419 \\
\hline 36.828757 & -116.309522 & 4075895.83 & 561575.44 & $1,135.95$ & 12 & E27 & 2.2 & $14: 50: 50$ & 14 & 0.276197 & 0.314 & 0.466 \\
\hline 36.828721 & -116.309575 & 4075891.72 & 561570.72 & $1,134.76$ & 17 & E28 & 1.8 & $14: 52: 45$ & 13 & 0.053753 & 0.321 & 0.441 \\
\hline 36.828718 & -116.309660 & 4075891.37 & 561563.20 & $1,135.37$ & 24 & E29 & 1.8 & $14: 55: 46$ & 11 & 0.040681 & 0.320 & 0.446 \\
\hline 36.828718 & -116.309601 & 4075891.42 & 561568.44 & $1,134.98$ & 18 & E30 & 1.8 & $14: 53: 19$ & 11 & 0.044789 & 0.308 & 0.426 \\
\hline 36.828686 & -116.309569 & 4075887.87 & 561571.28 & $1,134.86$ & 15 & E31 & 1.8 & 14:52:09 & 11 & 0.020260 & 0.303 & 0.416 \\
\hline 36.828666 & -116.309512 & 4075885.71 & 561576.40 & $1,136.18$ & 13 & E32 & 2.2 & $14: 51: 18$ & 11 & 0.019130 & 0.341 & 0.542 \\
\hline 36.828805 & -116.309536 & 4075901.13 & 561574.17 & $1,136.78$ & 10 & E33 & 2.2 & $14: 50: 17$ & 11 & 0.096976 & 0.342 & 0.538 \\
\hline 36.828920 & -116.309464 & 4075913.86 & 561580.49 & $1,137.27$ & 3 & E34 & 2.2 & $14: 45: 47$ & 11 & 0.036121 & 0.365 & 0.556 \\
\hline 36.828940 & -116.309387 & 4075916.21 & 561587.35 & $1,137.20$ & 2 & E35 & 2.2 & $14: 45: 25$ & 12 & 0.037565 & 0.352 & 0.535 \\
\hline 36.829179 & -116.308873 & 4075943.05 & 561632.96 & $1,138.17$ & 41 & E36 & 2.3 & $15: 03: 12$ & 12 & 0.036713 & 0.331 & 0.568 \\
\hline 36.829014 & -116.308965 & 4075924.64 & 561624.90 & $1,137.18$ & 40 & E37 & 2.3 & 15:02:35 & 12 & 0.064460 & 0.343 & 0.588 \\
\hline 36.828457 & -116.308394 & 4075863.18 & 561676.30 & $1,134.81$ & 42 & E38* & 2.3 & $15: 04: 58$ & 12 & 0.036524 & 0.324 & 0.563 \\
\hline 36.827945 & -116.308951 & 4075806.04 & 561627.00 & $1,131.80$ & 43 & E39* & 2.4 & $15: 10: 54$ & 10 & 0.160242 & 0.353 & 0.634 \\
\hline 36.827930 & -116.309232 & 4075804.25 & 561601.95 & $1,131.30$ & 44 & $\mathrm{E} 40^{*}$ & 2.4 & $15: 11: 59$ & 11 & 0.160415 & 0.314 & 0.534 \\
\hline
\end{tabular}


Table D.1-5

Sample Location Coordinates for CAS 25-04-09 Sample Locations and Points of Interest

(Page 3 of 3 )

\begin{tabular}{|c|c|c|c|c|c|c|c|c|c|c|c|c|}
\hline Latitude & Longitude & Northing $^{a}$ & Easting $^{a}$ & $\begin{array}{c}\text { HAE } \\
\text { (meters) }\end{array}$ & ID & Location & $\begin{array}{l}\text { Maximum } \\
\text { PDOP }\end{array}$ & $\begin{array}{l}\text { GPS } \\
\text { Time }\end{array}$ & $\begin{array}{l}\text { Unfiltered } \\
\text { Position }\end{array}$ & $\begin{array}{l}\text { Standard } \\
\text { Deviation }^{b}\end{array}$ & $\begin{array}{c}\text { Horizontal } \\
\text { Position } \\
\text { (meters) }\end{array}$ & $\begin{array}{l}\text { Vertical } \\
\text { Position } \\
\text { (meters) }\end{array}$ \\
\hline 36.827981 & -116.309482 & 4075809.74 & 561579.61 & $1,132.64$ & 45 & $\mathrm{E} 41^{*}$ & 2.4 & $15: 12: 49$ & 11 & 0.097967 & 0.350 & 0.633 \\
\hline 36.828552 & -116.310396 & 4075872.46 & 561497.67 & $1,135.66$ & 46 & $\mathrm{E} 42^{*}$ & 1.9 & $15: 14: 48$ & 10 & 0.036946 & 0.341 & 0.476 \\
\hline 36.828888 & -116.309586 & 4075910.21 & 561569.64 & $1,137.28$ & 4 & BOX & 2.2 & $14: 46: 24$ & 54 & 0.065232 & 0.350 & 0.537 \\
\hline 36.828932 & -116.309668 & 4075915.09 & 561562.31 & $1,138.13$ & 5 & NORTH MH & 2.2 & $14: 47: 33$ & 19 & 0.105282 & 0.353 & 0.546 \\
\hline 36.828866 & -116.309684 & 4075907.80 & 561560.86 & $1,137.20$ & 6 & ST IN MH & 2.2 & $14: 48: 04$ & 33 & 0.060789 & 0.339 & 0.523 \\
\hline 36.828830 & -116.309683 & 4075903.82 & 561561.01 & $1,137.21$ & 7 & ST OUT MH & 2.2 & $14: 48: 45$ & 15 & 0.081642 & 0.360 & 0.555 \\
\hline
\end{tabular}

Feature Name: Point Generic

Correction Type: Realtime Corrected

GPS Date: $02 / 20 / 2002$

Receiver Type: Pro XRS

Data File: E250409.ssf

HAE $=$ Height above ellipsoid

PDOP $=$ Position dilution of precision

*Background sample locations that are not plotted on Figure A.7-1

aUTM Zone 11, NAD 27

${ }^{b}+/-1$ sigma 
Table D.1-6

Sample Location Coordinates for CAS 25-04-10 Sample Locations and Points of Interest

(Page 1 of 2)

\begin{tabular}{|c|c|c|c|c|c|c|c|c|c|c|c|c|}
\hline Latitude & Longitude & Northing $^{a}$ & Easting $^{a}$ & $\begin{array}{c}\text { HAE } \\
\text { (meters) }\end{array}$ & ID & Location & $\begin{array}{l}\text { Maximum } \\
\text { PDOP }\end{array}$ & $\begin{array}{l}\text { GPS } \\
\text { Time }\end{array}$ & $\begin{array}{l}\text { Unfiltered } \\
\text { Position }\end{array}$ & $\begin{array}{c}\text { Standard } \\
\text { Deviation }^{b}\end{array}$ & $\begin{array}{c}\text { Horizontal } \\
\text { Position } \\
\text { (meters) }\end{array}$ & $\begin{array}{l}\text { Vertical } \\
\text { Position } \\
\text { (meters) }\end{array}$ \\
\hline 36.8037572 & -116.2696584 & 4073148.98 & 565151.63 & $1,094.75$ & $\overline{11}$ & F01 & 1.7 & $13: 36: 08$ & $\overline{11}$ & 0.046589 & 0.288 & 0.406 \\
\hline 36.8037554 & -116.2696732 & 4073148.77 & 565150.30 & $1,093.16$ & 8 & F02 & 2.1 & $13: 35: 02$ & 11 & 0.033770 & 0.318 & 0.520 \\
\hline 36.8037710 & -116.2695878 & 4073150.56 & 565157.91 & $1,095.12$ & 13 & $\mathrm{~F} 03$ & 1.7 & $13: 36: 46$ & 12 & 0.044321 & 0.278 & 0.392 \\
\hline 36.8037431 & -116.2697438 & 4073147.35 & 565144.02 & $1,093.15$ & 5 & F04 & 2.1 & $13: 34: 04$ & 11 & 0.026068 & 0.320 & 0.523 \\
\hline 36.8035770 & -116.2696941 & 4073128.97 & 565148.59 & $1,092.86$ & 39 & F05 & 2 & $13: 45: 24$ & 11 & 0.045730 & 0.295 & 0.480 \\
\hline 36.8036091 & -116.2695433 & 4073132.63 & 565162.01 & $1,093.10$ & 32 & F06 & 2 & $13: 43: 27$ & 11 & 0.060913 & 0.297 & 0.483 \\
\hline 36.8036855 & -116.2695931 & 4073141.07 & 565157.51 & $1,094.38$ & 24 & F07 & 1.7 & $13: 40: 13$ & 10 & 0.036096 & 0.290 & 0.407 \\
\hline 36.8037594 & -116.2696415 & 4073149.24 & 565153.13 & $1,094.91$ & 12 & F08 & 1.7 & $13: 36: 26$ & 11 & 0.052275 & 0.270 & 0.381 \\
\hline 36.8037525 & -116.2696930 & 4073148.44 & 565148.54 & $1,093.75$ & 7 & F09 & 2.1 & $13: 34: 43$ & 13 & 0.366761 & 0.296 & 0.459 \\
\hline 36.8036683 & -116.2697021 & 4073139.09 & 565147.80 & $1,094.84$ & 20 & F10 & 1.7 & $13: 38: 59$ & 13 & 0.022370 & 0.284 & 0.397 \\
\hline 36.8035877 & -116.2696414 & 4073130.19 & 565153.28 & $1,092.91$ & 36 & F11 & 2 & $13: 44: 33$ & 10 & 0.034182 & 0.299 & 0.486 \\
\hline 36.8035994 & -116.2695907 & 4073131.52 & 565157.80 & $1,092.98$ & 34 & F12 & 2 & 13:44:01 & 11 & 0.029729 & 0.313 & 0.509 \\
\hline 36.8036791 & -116.2696464 & 4073140.33 & 565152.76 & $1,094.53$ & 22 & F13 & 1.7 & 13:39:39 & 10 & 0.233573 & 0.276 & 0.386 \\
\hline 36.8037860 & -116.2696710 & 4073152.16 & 565150.47 & $1,093.15$ & 4 & F14 & 2.1 & $13: 33: 32$ & 15 & 0.057570 & 0.306 & 0.499 \\
\hline 36.8038075 & -116.2696886 & 4073154.55 & 565148.89 & $1,094.71$ & 1 & F15 & 1.7 & $13: 32: 17$ & 22 & 0.048485 & 0.292 & 0.415 \\
\hline 36.8037333 & -116.2696131 & 4073146.36 & 565155.69 & $1,095.25$ & 15 & F16 & 1.7 & $13: 37: 26$ & 11 & 0.051413 & 0.270 & 0.381 \\
\hline 36.8037165 & -116.2696481 & 4073144.47 & 565152.58 & $1,094.42$ & 16 & F17 & 1.7 & $13: 37: 44$ & 11 & 0.047522 & 0.278 & 0.391 \\
\hline 36.8037229 & -116.2695941 & 4073145.22 & 565157.39 & $1,095.18$ & 14 & F18 & 1.7 & $13: 37: 09$ & 10 & 0.035419 & 0.289 & 0.407 \\
\hline 36.8036850 & -116.2695809 & 4073141.03 & 565158.60 & $1,094.55$ & 25 & F19 & 1.7 & $13: 40: 28$ & 11 & 0.021878 & 0.271 & 0.380 \\
\hline 36.8036811 & -116.2695945 & 4073140.59 & 565157.39 & $1,094.28$ & 23 & F20 & 1.7 & $13: 39: 58$ & 11 & 0.026482 & 0.284 & 0.397 \\
\hline 36.8036104 & -116.2695655 & 4073132.77 & 565160.03 & $1,092.91$ & 33 & $\mathrm{~F} 21$ & 2 & $13: 43: 45$ & 11 & 0.049484 & 0.305 & 0.496 \\
\hline 36.8036392 & -116.2695519 & 4073135.96 & 565161.22 & $1,093.30$ & 31 & F22 & 2 & $13: 42: 49$ & 11 & 0.093852 & 0.307 & 0.499 \\
\hline 36.8036655 & -116.2695773 & 4073138.86 & 565158.94 & $1,094.70$ & 26 & F23 & 1.7 & $13: 40: 46$ & 12 & 0.037237 & 0.278 & 0.389 \\
\hline 36.8036430 & -116.2695945 & 4073136.35 & 565157.42 & $1,093.20$ & 30 & F24 & 2 & $13: 42: 17$ & 10 & 0.024886 & 0.321 & 0.522 \\
\hline
\end{tabular}


Table D.1-6

Sample Location Coordinates for CAS 25-04-10 Sample Locations and Points of Interest

(Page 2 of 2)

\begin{tabular}{|c|c|c|c|c|c|c|c|c|c|c|c|c|}
\hline Latitude & Longitude & Northing $^{a}$ & Easting $^{a}$ & $\begin{array}{c}\text { HAE } \\
\text { (meters) }\end{array}$ & ID & Location & $\begin{array}{l}\text { Maximum } \\
\text { PDOP }\end{array}$ & $\begin{array}{l}\text { GPS } \\
\text { Time }\end{array}$ & $\begin{array}{l}\text { Unfiltered } \\
\text { Position }\end{array}$ & $\begin{array}{l}\text { Standard } \\
\text { Deviation }^{b}\end{array}$ & $\begin{array}{c}\text { Horizontal } \\
\text { Position } \\
\text { (meters) }\end{array}$ & $\begin{array}{l}\text { Vertical } \\
\text { Position } \\
\text { (meters) }\end{array}$ \\
\hline 36.8035965 & -116.2696220 & 4073131.18 & 565155.01 & $1,092.99$ & 35 & $\mathrm{~F} 25$ & 2 & $13: 44: 18$ & 10 & 0.032867 & 0.320 & 0.521 \\
\hline 36.8036014 & -116.2696467 & 4073131.70 & 565152.80 & $1,093.04$ & 37 & $\mathrm{~F} 26$ & 2 & $13: 44: 47$ & 11 & 0.041922 & 0.306 & 0.497 \\
\hline 36.8036199 & -116.2696513 & 4073133.76 & 565152.37 & $1,093.05$ & 38 & $\mathrm{~F} 27$ & 2 & $13: 45: 05$ & 10 & 0.030464 & 0.314 & 0.510 \\
\hline 36.8036324 & -116.2696790 & 4073135.12 & 565149.89 & $1,093.04$ & 29 & F28 & 2 & $13: 41: 52$ & 11 & 0.058510 & 0.308 & 0.502 \\
\hline 36.8036516 & -116.2696396 & 4073137.28 & 565153.39 & $1,094.85$ & 27 & F29 & 1.7 & $13: 41: 10$ & 10 & 0.029602 & 0.289 & 0.404 \\
\hline 36.8036582 & -116.2696695 & 4073138.00 & 565150.72 & $1,095.06$ & 28 & $\mathrm{~F} 30$ & 1.7 & $13: 41: 26$ & 12 & 0.023949 & 0.270 & 0.378 \\
\hline 36.8036741 & -116.2697256 & 4073139.71 & 565145.70 & $1,094.72$ & 19 & F31 & 1.7 & 13:38:41 & 11 & 0.046275 & 0.276 & 0.389 \\
\hline 36.8037002 & -116.2697077 & 4073142.63 & 565147.27 & $1,094.68$ & 18 & F32 & 1.7 & $13: 38: 21$ & 10 & 0.071653 & 0.268 & 0.378 \\
\hline 36.8037057 & -116.2696774 & 4073143.25 & 565149.98 & $1,094.55$ & 17 & F33 & 1.7 & $13: 38: 03$ & 12 & 0.036431 & 0.286 & 0.403 \\
\hline 36.8037406 & -116.2696756 & 4073147.12 & 565150.11 & $1,095.05$ & 9 & F34 & 1.7 & $13: 35: 17$ & 14 & 0.064421 & 0.293 & 0.414 \\
\hline 36.8037296 & -116.2697229 & 4073145.87 & 565145.89 & $1,093.18$ & 10 & F35 & 2.1 & $13: 35: 40$ & 16 & 0.064573 & 0.308 & 0.503 \\
\hline 36.8037909 & -116.2696818 & 4073152.70 & 565149.51 & $1,094.93$ & 3 & F36 & 2.1 & 13:33:03 & 15 & 0.202441 & 0.288 & 0.412 \\
\hline 36.8038021 & -116.2696834 & 4073153.94 & 565149.35 & $1,094.33$ & 2 & F37 & 2.1 & $13: 32: 44$ & 12 & 0.340176 & 0.289 & 0.431 \\
\hline 36.8034357 & -116.2695702 & 4073113.38 & 565159.76 & $1,092.60$ & 40 & F38 & 2 & $13: 45: 53$ & 10 & 0.034417 & 0.308 & 0.501 \\
\hline 36.8038799 & -116.2696879 & 4073162.57 & 565148.89 & $1,094.34$ & 41 & F39 & 2 & $13: 46: 52$ & 12 & 0.174552 & 0.306 & 0.491 \\
\hline 36.8039698 & -116.2697125 & 4073172.53 & 565146.62 & $1,094.25$ & 42 & $\mathrm{~F} 40$ & 2 & $13: 47: 11$ & 23 & 2.997226 & 0.315 & 0.505 \\
\hline 36.8040014 & -116.2697216 & 4073176.02 & 565145.78 & $1,094.18$ & 43 & NORTH RISER & 2 & $13: 47: 46$ & 32 & 0.073409 & 0.303 & 0.485 \\
\hline
\end{tabular}

Feature Name: Point Generic

Correction Type: Realtime Corrected

Receiver Type: Pro XRS

$\mathrm{HAE}=$ Height above ellipsoid

PDOP $=$ Position dilution of precision

aUTM Zone 11, NAD 27

b+/- 1 sigma
GPS Date: 02/20/2002

Data File: F250410.ssf 
Table D.1-7

Sample Location Coordinates for CAS 25-04-11 Sample Locations and Points of Interest

(Page 1 of 3 )

\begin{tabular}{|c|c|c|c|c|c|c|c|c|c|c|c|c|}
\hline Latitude & Longitude & Northing ${ }^{a}$ & Easting $^{a}$ & $\begin{array}{c}\text { HAE } \\
\text { (meters) }\end{array}$ & ID & Location & $\begin{array}{l}\text { Maximum } \\
\text { PDOP }\end{array}$ & $\begin{array}{l}\text { GPS } \\
\text { Time }\end{array}$ & $\begin{array}{l}\text { Unfiltered } \\
\text { Position }\end{array}$ & $\begin{array}{l}\text { Standard } \\
\text { Deviation }^{b}\end{array}$ & $\begin{array}{c}\text { Horizontal } \\
\text { Position } \\
\text { (meters) }\end{array}$ & $\begin{array}{c}\text { Vertical } \\
\text { Position } \\
\text { (meters) }\end{array}$ \\
\hline 36.8030971 & -116.2725353 & 4073073.80 & 564895.54 & $1,089.96$ & 9 & G01 & 2.4 & $11: 43: 55$ & 12 & 0.051118 & 0.391 & 0.629 \\
\hline 36.8030277 & -116.2721993 & 4073066.33 & 564925.57 & $1,090.30$ & 14 & G02 & 2.4 & $11: 46: 35$ & 18 & 0.098404 & 0.380 & 0.604 \\
\hline 36.8027260 & -116.2726207 & 4073032.58 & 564888.23 & $1,090.59$ & 34 & G03 & 2.4 & $11: 56: 43$ & 12 & 0.074844 & 0.390 & 0.584 \\
\hline 36.8026612 & -116.2722646 & 4073025.63 & 564920.05 & $1,089.70$ & 18 & G04 & 2.4 & $11: 48: 48$ & 13 & 0.059684 & 0.390 & 0.609 \\
\hline 36.8027806 & -116.2729690 & 4073038.39 & 564857.11 & $1,090.34$ & 36 & G05 & 2.4 & $11: 57: 57$ & 10 & 0.070184 & 0.399 & 0.597 \\
\hline 36.8028897 & -116.2724049 & 4073050.88 & 564907.35 & $1,090.20$ & 22 & G06 & 2.4 & $11: 51: 06$ & 12 & 0.048740 & 0.366 & 0.565 \\
\hline 36.8029168 & -116.2725786 & 4073053.77 & 564891.83 & $1,091.01$ & 32 & G07 & 2.4 & $11: 55: 52$ & 12 & 0.076249 & 0.396 & 0.592 \\
\hline 36.8031359 & -116.2728793 & 4073077.88 & 564864.82 & $1,090.80$ & 42 & G08 & 1.8 & $12: 00: 48$ & 12 & 0.048305 & 0.366 & 0.401 \\
\hline 36.8029454 & -116.2727481 & 4073056.83 & 564876.68 & $1,089.98$ & 40 & G09 & 1.8 & $11: 59: 50$ & 11 & 0.056966 & 0.368 & 0.404 \\
\hline 36.8030778 & -116.2724965 & 4073071.68 & 564899.02 & $1,091.26$ & 27 & G10 & 2.4 & $11: 53: 46$ & 11 & 0.046817 & 0.390 & 0.596 \\
\hline 36.8030908 & -116.2725688 & 4073073.08 & 564892.55 & $1,091.09$ & 28 & G11 & 2.4 & $11: 54: 15$ & 11 & 0.055279 & 0.372 & 0.569 \\
\hline 36.8031251 & -116.2725338 & 4073076.91 & 564895.65 & $1,090.07$ & 7 & G12 & 2.4 & $11: 43: 05$ & 11 & 0.048045 & 0.361 & 0.583 \\
\hline 36.8031925 & -116.2725234 & 4073084.39 & 564896.52 & $1,091.39$ & 4 & G13 & 2.1 & $11: 41: 29$ & 15 & 0.024278 & 0.347 & 0.513 \\
\hline 36.8031132 & -116.2726833 & 4073075.49 & 564882.32 & $1,090.73$ & 44 & G14 & 1.8 & $12: 01: 37$ & 11 & 0.045035 & 0.359 & 0.393 \\
\hline 36.8030083 & -116.2726319 & 4073063.89 & 564887.00 & $1,090.83$ & 30 & G15 & 2.4 & $11: 55: 08$ & 11 & 0.056211 & 0.368 & 0.563 \\
\hline 36.8029865 & -116.2727563 & 4073061.39 & 564875.91 & $1,090.56$ & 41 & G16 & 1.8 & $12: 00: 13$ & 11 & 0.030227 & 0.347 & 0.381 \\
\hline 36.8031076 & -116.2728399 & 4073074.76 & 564868.36 & $1,090.68$ & 43 & G17 & 1.8 & $12: 01: 11$ & 11 & 0.067673 & 0.345 & 0.378 \\
\hline 36.8029164 & -116.2726386 & 4073053.69 & 564886.48 & $1,090.86$ & 31 & G18 & 2.4 & $11: 55: 32$ & 11 & 0.043293 & 0.383 & 0.575 \\
\hline
\end{tabular}


Table D.1-7

Sample Location Coordinates for CAS 25-04-11 Sample Locations and Points of Interest

(Page 2 of 3 )

\begin{tabular}{|c|c|c|c|c|c|c|c|c|c|c|c|c|}
\hline Latitude & Longitude & Northing ${ }^{a}$ & Easting $^{a}$ & $\begin{array}{c}\text { HAE } \\
\text { (meters) }\end{array}$ & ID & Location & $\begin{array}{l}\text { Maximum } \\
\text { PDOP }\end{array}$ & $\begin{array}{l}\text { GPS } \\
\text { Time }\end{array}$ & $\begin{array}{l}\text { Unfiltered } \\
\text { Position }\end{array}$ & $\begin{array}{l}\text { Standard } \\
\text { Deviation }^{b}\end{array}$ & $\begin{array}{c}\text { Horizontal } \\
\text { Position } \\
\text { (meters) }\end{array}$ & $\begin{array}{c}\text { Vertical } \\
\text { Position } \\
\text { (meters) }\end{array}$ \\
\hline 36.8028804 & -116.2729209 & 4073049.50 & 564861.32 & $1,089.33$ & 38 & G19 & 1.8 & $11: 58: 41$ & 22 & 0.036914 & 0.364 & 0.399 \\
\hline 36.8028724 & -116.2728340 & 4073048.67 & 564869.08 & $1,089.79$ & 39 & G20 & 1.8 & $11: 59: 15$ & 13 & 0.029375 & 0.349 & 0.383 \\
\hline 36.8027836 & -116.2727077 & 4073038.91 & 564880.43 & $1,090.82$ & 35 & G21 & 2.4 & $11: 57: 15$ & 12 & 0.049269 & 0.374 & 0.559 \\
\hline 36.8027976 & -116.2729322 & 4073040.31 & 564860.39 & $1,090.25$ & 37 & G22 & 2.3 & $11: 58: 16$ & 11 & 0.037713 & 0.376 & 0.554 \\
\hline 36.8027601 & -116.2726241 & 4073036.36 & 564887.90 & $1,090.67$ & 33 & G23 & 2.4 & $11: 56: 24$ & 10 & 0.046296 & 0.378 & 0.566 \\
\hline 36.8030464 & -116.2723759 & 4073068.28 & 564909.80 & $1,090.11$ & 11 & G24 & 2.4 & $11: 45: 07$ & 11 & 0.163185 & 0.355 & 0.551 \\
\hline 36.8030342 & -116.2724284 & 4073066.90 & 564905.13 & $1,090.32$ & 24 & G25 & 2.4 & $11: 52: 16$ & 11 & 0.040863 & 0.373 & 0.571 \\
\hline 36.8030185 & -116.2725484 & 4073065.08 & 564894.44 & $1,090.88$ & 29 & G26 & 2.4 & $11: 54: 39$ & 12 & 0.053271 & 0.385 & 0.590 \\
\hline 36.8029370 & -116.2724077 & 4073056.12 & 564907.06 & $1,090.30$ & 23 & G27 & 2.4 & $11: 51: 38$ & 19 & 0.058671 & 0.385 & 0.594 \\
\hline 36.8029307 & -116.2722900 & 4073055.51 & 564917.57 & $1,090.01$ & 15 & G28 & 2.4 & $11: 47: 10$ & 14 & 0.058049 & 0.367 & 0.578 \\
\hline 36.8029078 & -116.2723446 & 4073052.93 & 564912.71 & $1,090.09$ & 16 & G29 & 2.4 & $11: 47: 36$ & 11 & 0.025072 & 0.381 & 0.601 \\
\hline 36.8028310 & -116.2724954 & 4073044.31 & 564899.32 & $1,089.72$ & 21 & G30 & 2.4 & $11: 50: 12$ & 21 & 0.065109 & 0.369 & 0.572 \\
\hline 36.8028046 & -116.2724797 & 4073041.40 & 564900.74 & $1,090.42$ & 20 & G31 & 2.4 & $11: 49: 50$ & 10 & 0.143364 & 0.373 & 0.549 \\
\hline 36.8027383 & -116.2725167 & 4073034.01 & 564897.50 & $1,090.62$ & 19 & G32 & 2.1 & $11: 49: 26$ & 10 & 0.039937 & 0.351 & 0.501 \\
\hline 36.8027236 & -116.2723677 & 4073032.48 & 564910.81 & $1,090.29$ & 17 & G33 & 2.1 & $11: 48: 07$ & 27 & 0.057093 & 0.340 & 0.489 \\
\hline 36.8032846 & -116.2725342 & 4073094.60 & 564895.48 & $1,090.47$ & 3 & G34 & 2.4 & $11: 41: 00$ & 11 & 0.044672 & 0.357 & 0.584 \\
\hline 36.8032079 & -116.2725154 & 4073086.10 & 564897.22 & $1,091.61$ & 2 & G35 MH & 2.1 & $11: 40: 33$ & 12 & 0.041753 & 0.349 & 0.517 \\
\hline 36.8031784 & -116.2719617 & 4073083.21 & 564946.64 & $1,092.31$ & 45 & G36 & 2.3 & $12: 02: 47$ & 13 & 0.072042 & 0.389 & 0.529 \\
\hline
\end{tabular}


Table D.1-7

Sample Location Coordinates for CAS 25-04-11 Sample Locations and Points of Interest

(Page 3 of 3 )

\begin{tabular}{|c|c|c|c|c|c|c|c|c|c|c|c|c|}
\hline Latitude & Longitude & Northing $^{a}$ & Easting $^{a}$ & $\begin{array}{c}\text { HAE } \\
\text { (meters) }\end{array}$ & ID & Location & $\begin{array}{l}\text { Maximum } \\
\text { PDOP }\end{array}$ & $\begin{array}{l}\text { GPS } \\
\text { Time }\end{array}$ & $\begin{array}{l}\text { Unfiltered } \\
\text { Position }\end{array}$ & $\begin{array}{l}\text { Standard } \\
\text { Deviation }^{b}\end{array}$ & $\begin{array}{l}\text { Horizontal } \\
\text { Position } \\
\text { (meters) }\end{array}$ & $\begin{array}{l}\text { Vertical } \\
\text { Position } \\
\text { (meters) }\end{array}$ \\
\hline 36.8031877 & -116.2725215 & 4073083.86 & 564896.69 & $1,089.73$ & 5 & G37 STN & 2.4 & 11:42:02 & 12 & 0.087447 & 0.355 & 0.572 \\
\hline 36.8031317 & -116.2725323 & 4073077.64 & 564895.77 & $1,089.64$ & 6 & G38 ST OUT & 2.4 & $11: 42: 26$ & 31 & 0.045709 & 0.372 & 0.604 \\
\hline 36.8043268 & -116.2724413 & 4073210.27 & 564902.88 & $1,095.03$ & 47 & G39 & 2.3 & $12: 05: 32$ & 12 & 0.038294 & 0.388 & 0.548 \\
\hline 36.8040635 & -116.2726252 & 4073180.94 & 564886.70 & $1,094.66$ & 46 & G40 & 1.8 & $12: 04: 44$ & 14 & 0.048873 & 0.361 & 0.395 \\
\hline 36.8030215 & -116.2721502 & 4073065.68 & 564929.95 & $1,090.18$ & 13 & G41 & 2.4 & $11: 46: 15$ & 10 & 0.051040 & 0.368 & 0.586 \\
\hline 36.8030693 & -116.2721923 & 4073070.95 & 564926.16 & $1,090.42$ & 12 & G42 & 2.4 & $11: 45: 53$ & 11 & 0.056537 & 0.391 & 0.621 \\
\hline 36.8031154 & -116.2725119 & 4073075.85 & 564897.61 & $1,091.38$ & 26 & G43 & 2.4 & 11:53:21 & 11 & 0.041625 & 0.375 & 0.574 \\
\hline 36.8031074 & -116.2724645 & 4073074.99 & 564901.84 & $1,090.73$ & 25 & G44 & 2.4 & $11: 52: 56$ & 13 & 0.092825 & 0.397 & 0.607 \\
\hline 36.8033269 & -116.2725434 & 4073099.29 & 564894.62 & $1,090.68$ & 1 & EZ BY PASS & 2.4 & $11: 39: 28$ & 45 & 0.054256 & 0.369 & 0.610 \\
\hline 36.8042704 & -116.2720518 & 4073204.28 & 564937.68 & $1,095.67$ & 48 & $\begin{array}{l}\text { NORTH LINE } \\
\text { CLEANOUT }\end{array}$ & 1.8 & $12: 06: 18$ & 35 & 0.043105 & 0.346 & 0.378 \\
\hline 36.8039875 & -116.2720681 & 4073172.89 & 564936.46 & $1,094.46$ & 49 & $\begin{array}{l}\text { SOUTH LINE } \\
\text { CLEANOUT }\end{array}$ & 2.3 & 12:07:32 & 27 & 0.126595 & 0.374 & 0.478 \\
\hline
\end{tabular}

Feature Name: Point Generic

Correction Type: Realtime Corrected

Receiver Type: Pro XRS

$\mathrm{HAE}=$ Height above ellipsoid

PDOP $=$ Position dilution of precision

${ }^{\mathrm{a}}$ UTM Zone 11, NAD 27

b +/- 1 sigma
GPS Date: 02/20/2002 Data File: G250411.ss 
Table D.1-8

Sample Location Coordinates for CAS 26-03-01 Sample Locations and Points of Interest

\begin{tabular}{|c|c|c|c|c|c|c|c|c|c|c|c|c|}
\hline Latitude & Longitude & Northing $^{a}$ & Easting $^{a}$ & $\begin{array}{c}\text { HAE } \\
\text { (meters) }\end{array}$ & ID & Location & $\begin{array}{l}\text { Maximum } \\
\text { PDOP }\end{array}$ & $\begin{array}{l}\text { GPS } \\
\text { Time }\end{array}$ & $\begin{array}{l}\text { Unfiltered } \\
\text { Position }\end{array}$ & $\begin{array}{l}\text { Standard } \\
\text { Deviation }\end{array}$ & $\begin{array}{l}\text { Horizontal } \\
\text { Position } \\
\text { (meters) }\end{array}$ & $\begin{array}{l}\text { Vertical } \\
\text { Position } \\
\text { (meters) }\end{array}$ \\
\hline 36.8059415 & -116.1543118 & 4073476.07 & 575439.41 & $1,338.56$ & 2 & $\mathrm{H} 01$ & 2 & $15: 45: 57$ & 12 & 0.059469 & 0.341 & 0.472 \\
\hline 36.8059091 & -116.1542968 & 4073472.49 & 575440.78 & $1,338.67$ & 3 & $\mathrm{H} 02$ & 2 & $15: 46: 18$ & 12 & 0.047801 & 0.352 & 0.488 \\
\hline 36.8058878 & -116.1542484 & 4073470.17 & 575445.12 & $1,338.67$ & 4 & $\mathrm{H} 03$ & 2 & $15: 46: 42$ & 10 & 0.056037 & 0.332 & 0.460 \\
\hline 36.8059260 & -116.1542322 & 4073474.41 & 575446.53 & $1,338.57$ & 1 & $\mathrm{H} 04$ & 2 & $15: 45: 30$ & 16 & 0.063860 & 0.359 & 0.496 \\
\hline 36.8058730 & -116.1542274 & 4073468.54 & 575447.01 & $1,338.80$ & 5 & H05 & 2 & $15: 46: 58$ & 11 & 0.038508 & 0.341 & 0.472 \\
\hline 36.8058596 & -116.1541911 & 4073467.09 & 575450.26 & 1,338.95 & 6 & H06 & 2 & $15: 47: 17$ & 11 & 0.040239 & 0.351 & 0.486 \\
\hline 36.8058286 & -116.1542185 & 4073463.62 & 575447.85 & $1,338.78$ & 7 & $\mathrm{H} 07$ & 2 & $15: 47: 36$ & 10 & 0.038397 & 0.361 & 0.500 \\
\hline 36.8057328 & -116.1539925 & 4073453.18 & 575468.10 & $1,342.38$ & 8 & $\mathrm{H} 08$ & 2 & $15: 48: 28$ & 14 & 0.048625 & 0.354 & 0.495 \\
\hline 36.8062074 & -116.1543921 & 4073505.51 & 575431.98 & $1,336.34$ & 13 & $\mathrm{H} 09^{*}$ & 1.8 & $15: 52: 49$ & 19 & 0.098902 & 0.282 & 0.413 \\
\hline 36.8059785 & -116.1542226 & 4073480.26 & 575447.33 & $1,338.77$ & 12 & NE & 1.8 & $15: 50: 56$ & 18 & 0.039586 & 0.319 & 0.422 \\
\hline 36.8058392 & -116.1541024 & 4073464.89 & 575458.19 & $1,340.00$ & 9 & SE & 2 & $15: 49: 13$ & 11 & 0.037768 & 0.345 & 0.483 \\
\hline 36.8059751 & -116.1543799 & 4073479.75 & 575433.30 & $1,339.08$ & 11 & NW & 1.8 & $15: 50: 24$ & 12 & 0.042397 & 0.334 & 0.439 \\
\hline 36.8057904 & -116.1542365 & 4073459.37 & 575446.28 & $1,339.93$ & 10 & SW & 2 & $15: 49: 44$ & 10 & 0.038756 & 0.330 & 0.462 \\
\hline
\end{tabular}

Feature Name: Point Generic

Correction Type: Realtime Corrected

Receiver Type: Pro XRS

$\mathrm{HAE}=$ Height above ellipsoid

PDOP $=$ Position dilution of precision

*GPS sample location taken downstream of the lagoon and is not

plotted on Figure A.10-1

UTM Zone 11, NAD 27

+/- 1 sigma
GPS Date: 02/21/2002

Data File: H260301.ssf 
Table D.1-9

Sample Location Coordinates for CAS 26-04-01 Sample Locations and Points of Interest

(Page 1 of 2)

\begin{tabular}{|c|c|c|c|c|c|c|c|c|c|c|c|c|}
\hline Latitude & Longitude & Northing ${ }^{a}$ & Easting $^{a}$ & $\begin{array}{c}\text { HAE } \\
\text { (meters) }\end{array}$ & ID & Location & $\begin{array}{l}\text { Maximum } \\
\text { PDOP }\end{array}$ & $\begin{array}{l}\text { GPS } \\
\text { Time }\end{array}$ & $\begin{array}{l}\text { Unfiltered } \\
\text { Position }\end{array}$ & $\begin{array}{l}\text { Standard } \\
\text { Deviation }^{b}\end{array}$ & $\begin{array}{c}\text { Horizontal } \\
\text { Position } \\
\text { (meters) }\end{array}$ & $\begin{array}{l}\text { Vertical } \\
\text { Position } \\
\text { (meters) }\end{array}$ \\
\hline 36.8116542 & -116.1594117 & 4074105.8 & 574978.9 & $1,307.9$ & 2 & J01 & 1.7 & $16: 06: 27$ & 11 & 0.095480 & 0.308 & 0.403 \\
\hline 36.8116400 & -116.1594503 & 4074104.2 & 574975.5 & $1,307.9$ & 4 & J02 & 1.7 & 16:07:07 & 12 & 0.018915 & 0.298 & 0.390 \\
\hline 36.8116158 & -116.1594889 & 4074101.5 & 574972.1 & $1,307.9$ & 6 & J03 & 2.1 & $16: 07: 45$ & 15 & 0.161696 & 0.284 & 0.408 \\
\hline 36.8116979 & -116.1596022 & 4074110.5 & 574961.9 & $1,307.5$ & 9 & $\mathrm{~J} 04$ & 1.6 & $16: 08: 54$ & 11 & 0.042328 & 0.265 & 0.374 \\
\hline 36.8116059 & -116.1595126 & 4074100.3 & 574970.0 & $1,307.7$ & 8 & J05 & 1.6 & $16: 08: 24$ & 10 & 0.053713 & 0.278 & 0.391 \\
\hline 36.8116003 & -116.1595091 & 4074099.7 & 574970.3 & $1,307.7$ & 7 & J06 & 1.6 & 16:08:07 & 11 & 0.047813 & 0.271 & 0.382 \\
\hline 36.8114993 & -116.1594401 & 4074088.6 & 574976.5 & $1,306.8$ & 16 & $\mathrm{~J} 07$ & 1.4 & $16: 11: 59$ & 11 & 0.050074 & 0.239 & 0.319 \\
\hline 36.8116180 & -116.1596202 & 4074101.6 & 574960.3 & $1,307.0$ & 13 & J08 & 1.3 & $16: 10: 49$ & 11 & 0.039950 & 0.214 & 0.300 \\
\hline 36.8115752 & -116.1595832 & 4074096.9 & 574963.7 & $1,306.7$ & 14 & J09 & 1.3 & $16: 11: 09$ & 13 & 0.051949 & 0.221 & 0.309 \\
\hline 36.8115278 & -116.1595401 & 4074091.7 & 574967.6 & $1,306.7$ & 15 & $\mathrm{~J} 10$ & 1.4 & $16: 11: 33$ & 13 & 0.079861 & 0.242 & 0.336 \\
\hline 36.8116459 & -116.1597136 & 4074104.6 & 574952.0 & $1,307.6$ & 11 & J11 & 1.6 & $16: 09: 49$ & 11 & 0.027129 & 0.263 & 0.372 \\
\hline 36.8115268 & -116.1596476 & 4074091.5 & 574958.0 & $1,307.1$ & 20 & $\mathrm{~J} 12$ & 1.3 & $16: 13: 34$ & 12 & 0.045284 & 0.229 & 0.322 \\
\hline 36.8114450 & -116.1595405 & 4074082.5 & 574967.6 & $1,307.1$ & 18 & $\mathrm{~J} 13$ & 1.3 & $16: 12: 42$ & 11 & 0.367976 & 0.212 & 0.298 \\
\hline 36.8116459 & -116.1594291 & 4074104.8 & 574977.4 & $1,307.8$ & 3 & J14--ST & 1.7 & $16: 06: 45$ & 15 & 0.335675 & 0.289 & 0.377 \\
\hline 36.8116181 & -116.1594805 & 4074101.7 & 574972.8 & $1,308.1$ & 5 & J15 & 1.7 & $16: 07: 27$ & 10 & 0.068335 & 0.308 & 0.403 \\
\hline 36.8118908 & -116.1589977 & 4074132.4 & 575015.6 & $1,308.7$ & 23 & $\mathrm{~J} 16$ & 1.3 & $16: 17: 04$ & 16 & 0.050784 & 0.219 & 0.310 \\
\hline 36.8118213 & -116.1591133 & 4074124.6 & 575005.4 & $1,308.4$ & 22 & $\mathrm{~J} 17$ & 2.1 & $16: 16: 36$ & 11 & 0.303542 & 0.289 & 0.409 \\
\hline 36.8116144 & -116.1601382 & 4074100.8 & 574914.1 & $1,308.0$ & 21 & J18 & 1.6 & $16: 14: 54$ & 12 & 0.024139 & 0.264 & 0.375 \\
\hline 36.8117463 & -116.1595307 & 4074115.9 & 574968.2 & $1,307.6$ & 1 & HY1529 & 1.6 & $16: 05: 11$ & 48 & 0.039116 & 0.273 & 0.382 \\
\hline 36.8117197 & -116.1595976 & 4074112.9 & 574962.3 & $1,307.7$ & 10 & NE & 1.6 & $16: 09: 18$ & 12 & 0.029679 & 0.275 & 0.389 \\
\hline
\end{tabular}


Table D.1-9

Sample Location Coordinates for CAS 26-04-01 Sample Locations and Points of Interest

(Page 2 of 2)

\begin{tabular}{|c|c|c|c|c|c|c|c|c|c|c|c|c|}
\hline Latitude & Longitude & Northing $^{a}$ & Easting $^{a}$ & $\begin{array}{c}\text { HAE } \\
\text { (meters) }\end{array}$ & ID & Location & $\begin{array}{l}\text { Maximum } \\
\text { PDOP }\end{array}$ & $\begin{array}{l}\text { GPS } \\
\text { Time }\end{array}$ & $\begin{array}{l}\text { Unfiltered } \\
\text { Position }\end{array}$ & $\begin{array}{l}\text { Standard } \\
\text { Deviation }^{b}\end{array}$ & $\begin{array}{l}\text { Horizontal } \\
\text { Position } \\
\text { (meters) }\end{array}$ & $\begin{array}{l}\text { Vertical } \\
\text { Position } \\
\text { (meters) }\end{array}$ \\
\hline 36.8116026 & -116.1598076 & 4074099.7 & 574943.6 & $1,307.5$ & 12 & NW & 1.6 & $16: 10: 19$ & 11 & 0.165148 & 0.234 & 0.329 \\
\hline 36.8115101 & -116.1594019 & 4074089.8 & 574979.9 & $1,306.7$ & 17 & SE & 1.5 & $16: 12: 18$ & 11 & 0.045101 & 0.260 & 0.343 \\
\hline 36.8113805 & -116.1596092 & 4074075.3 & 574961.6 & $1,308.3$ & 19 & sW & 1.3 & 16:13:06 & 11 & 0.064079 & 0.220 & 0.309 \\
\hline 36.81167 & -116.1596 & 4074108 & 574966.2 & $1,308.67$ & 2 & J19 & 2 & $10: 10: 00$ & 57 & 0.054859 & 0.333 & 0.489 \\
\hline 36.81158 & -116.1595 & 4074097 & 574972.4 & $1,308.52$ & 3 & $\mathrm{~J} 20$ & 2 & $10: 11: 44$ & 52 & 0.090185 & 0.324 & 0.479 \\
\hline
\end{tabular}

Feature Name: Point Generic

Correction Type: Realtime Corrected

Receiver Type: Pro XRS

$\mathrm{HAE}=$ Height above ellipsoid

PDOP $=$ Position dilution of precision

aUTM Zone 11, NAD 27

$\mathrm{b}_{+/-} 1$ sigma
GPS Date: $02 / 20 / 2002$ and 5/7/2002

Data File: J260401.ssf and 271PHSE2.ssf 


\section{D.1.10 Hot Critical Facility, Bldg. 2103, Septic System (CAS 26-04-02)}

Sample locations and pertinent points (locations) of interest at CAS 26-04-02 are shown on Figure A.12-1. The corresponding coordinates for CAS 26-04-02 sample locations are listed in Table D.1-10.

\section{D.1.11 Buildings 2201 and 2202 Radioactive Leachfield (CAS 26-05-01)}

Sample locations and pertinent points (locations) of interest at CAS 26-05-01 are shown on Figure A.13-1. The corresponding coordinates for CAS 26-05-01 sample locations are listed in Table D.1-11.

\section{D.1.12 Building 2203 Septic System (CAS 26-05-03)}

Sample locations and pertinent points (locations) of interest at CAS 26-05-03 are shown on Figure A.14-1. The corresponding coordinates for CAS 26-05-03 sample locations are listed in Table D.1-12.

\section{D.1.13 Building 2201 Septic System (CAS 26-05-04)}

Sample locations and pertinent points (locations) of interest at CAS 26-05-04 are shown on Figure A.15-1. The corresponding coordinates for CAS 26-05-04 sample locations are listed in Table D.1-13.

\section{D.1.14 Buildings 2101, 2102, and 2107 Septic System (CAS 26-05-05)}

Sample locations and pertinent points (locations) of interest at CAS 26-05-05 are shown on Figure A.16-1. The corresponding coordinates for CAS 26-05-05 sample locations are listed in Table D.1-14.

\section{D.1.15 Building 5200 Septic System (CAS 27-05-02)}

Sample locations and pertinent points (locations) of interest at CAS 27-05-02 are shown on Figure A.17-1. The corresponding coordinates for CAS 27-05-02 sample locations are listed in Table D.1-15. 
Table D.1-10

Sample Location Coordinates for CAS 26-04-02 Sample Locations and Points of Interest

(Page 1 of 2 )

\begin{tabular}{|c|c|c|c|c|c|c|c|c|c|c|c|c|}
\hline Latitude & Longitude & Northing ${ }^{a}$ & Easting $^{a}$ & $\begin{array}{c}\text { HAE } \\
\text { (meters) }\end{array}$ & ID & Location & $\begin{array}{l}\text { Maximum } \\
\text { PDOP }\end{array}$ & $\begin{array}{l}\text { GPS } \\
\text { Time }\end{array}$ & $\begin{array}{l}\text { Unfiltered } \\
\text { Position }\end{array}$ & $\begin{array}{l}\text { Standard } \\
\text { Deviation }^{b}\end{array}$ & $\begin{array}{c}\text { Horizontal } \\
\text { Position } \\
\text { (meters) }\end{array}$ & $\begin{array}{l}\text { Vertical } \\
\text { Position } \\
\text { (meters) }\end{array}$ \\
\hline 36.8105184 & -116.1490768 & 4073987.93 & 575901.89 & $1,325.15$ & 3 & K01 & 2.1 & $15: 21: 50$ & 11 & 0.062734 & 0.383 & 0.480 \\
\hline 36.8105419 & -116.1490784 & 4073990.54 & 575901.73 & $1,324.58$ & 5 & K02 & 2.1 & $15: 22: 37$ & 10 & 0.043579 & 0.373 & 0.470 \\
\hline 36.8105820 & -116.1490757 & 4073994.99 & 575901.92 & $1,324.16$ & 7 & K03 & 2.1 & $15: 23: 17$ & 13 & 0.061373 & 0.362 & 0.456 \\
\hline 36.8105962 & -116.1489515 & 4073996.67 & 575912.99 & $1,324.34$ & 1 & K04 & 2.1 & $15: 20: 48$ & 23 & 0.063744 & 0.382 & 0.477 \\
\hline 36.8105901 & -116.1490667 & 4073995.90 & 575902.72 & $1,323.98$ & 9 & K05 & 2.1 & $15: 23: 47$ & 10 & 0.026513 & 0.380 & 0.478 \\
\hline 36.8105916 & -116.1490840 & 4073996.05 & 575901.17 & $1,324.09$ & 8 & K06 & 2.1 & $15: 23: 33$ & 10 & 0.049048 & 0.372 & 0.468 \\
\hline 36.8106135 & -116.1492054 & 4073998.39 & 575890.32 & $1,324.32$ & 12 & K07 & 2.1 & $15: 24: 47$ & 10 & 0.033543 & 0.377 & 0.478 \\
\hline 36.8106221 & -116.1490226 & 4073999.48 & 575906.62 & $1,323.97$ & 16 & K08 & 2.1 & 15:26:06 & 10 & 0.036785 & 0.387 & 0.493 \\
\hline 36.8106252 & -116.1490791 & 4073999.78 & 575901.58 & $1,324.00$ & 15 & K09 & 2.1 & $15: 25: 48$ & 10 & 0.073210 & 0.375 & 0.478 \\
\hline 36.8106300 & -116.1491338 & 4074000.27 & 575896.69 & $1,324.11$ & 14 & K10 & 2.1 & $15: 25: 29$ & 10 & 0.041712 & 0.365 & 0.465 \\
\hline 36.8106614 & -116.1489533 & 4074003.89 & 575912.77 & $1,324.25$ & 19 & K11 & 2.1 & $15: 27: 07$ & 10 & 0.054839 & 0.387 & 0.493 \\
\hline 36.8106587 & -116.1490743 & 4074003.50 & 575901.98 & $1,324.08$ & 17 & K12 & 2.1 & $15: 26: 24$ & 10 & 0.041191 & 0.363 & 0.462 \\
\hline 36.8106593 & -116.1492028 & 4074003.47 & 575890.51 & $1,324.19$ & 22 & K13 & 2.1 & $15: 28: 39$ & 10 & 0.039620 & 0.366 & 0.473 \\
\hline 36.8105906 & -116.1491934 & 4073995.85 & 575891.42 & $1,324.42$ & 10 & K14 & 2.1 & $15: 24: 15$ & 11 & 0.040516 & 0.360 & 0.456 \\
\hline 36.8107030 & -116.1490541 & 4074008.43 & 575903.74 & $1,323.96$ & 18 & K15 & 2.1 & $15: 26: 44$ & 11 & 0.037549 & 0.374 & 0.476 \\
\hline 36.8102808 & -116.1490030 & 4073961.64 & 575908.70 & $1,329.05$ & 23 & K16 & 3 & $15: 32: 28$ & 21 & 2.464216 & 0.570 & 0.629 \\
\hline 36.8105751 & -116.1490755 & 4073994.22 & 575901.95 & $1,324.63$ & 6 & DIST BOX & 2.1 & $15: 22: 57$ & 10 & 0.029552 & 0.386 & 0.485 \\
\hline 36.8105319 & -116.1490778 & 4073989.43 & 575901.79 & $1,324.58$ & 4 & ST $\mathrm{MH}$ & 2.1 & $15: 22: 21$ & 9 & 0.018201 & 0.366 & 0.460 \\
\hline 36.8104800 & -116.1490771 & 4073983.68 & 575901.90 & $1,325.68$ & 24 & $\mathrm{MH}--1$ & 2.1 & $15: 33: 33$ & 18 & 0.037347 & 0.355 & 0.469 \\
\hline 36.8107699 & -116.1489392 & 4074015.95 & 575913.91 & $1,323.89$ & 20 & $\mathrm{NE}$ & 2.1 & $15: 27: 35$ & 11 & 0.042089 & 0.366 & 0.470 \\
\hline
\end{tabular}


Table D.1-10

Sample Location Coordinates for CAS 26-04-02 Sample Locations and Points of Interest

(Page 2 of 2)

\begin{tabular}{|c|c|c|c|c|c|c|c|c|c|c|c|c|}
\hline Latitude & Longitude & Northing & Easting & $\begin{array}{c}\text { HAE } \\
\text { (meters) }\end{array}$ & ID & Location & $\begin{array}{c}\text { Maximum } \\
\text { PDOP }\end{array}$ & $\begin{array}{c}\text { GPS } \\
\text { Time }\end{array}$ & $\begin{array}{c}\text { Unfiltered } \\
\text { Position }\end{array}$ & $\begin{array}{c}\text { Standard } \\
\text { Deviation }\end{array}$ & $\begin{array}{c}\text { Horizontal } \\
\text { Position } \\
\text { (meters) }\end{array}$ & $\begin{array}{c}\text { Vertical } \\
\text { Position } \\
\text { (meters) }\end{array}$ \\
\hline \hline 36.8107709 & -116.1492071 & 4074015.85 & 575890.02 & $1,324.15$ & 21 & NW & 2.1 & $15: 28: 11$ & 11 & 0.040684 & 0.385 & 0.497 \\
\hline 36.8105943 & -116.1489432 & 4073996.46 & 575913.73 & $1,324.51$ & 2 & SE & 2.1 & $15: 21: 16$ & 11 & 0.077258 & 0.364 & 0.455 \\
\hline 36.8105966 & -116.1492099 & 4073996.51 & 575889.94 & $1,324.59$ & 11 & SW & 2.1 & $15: 24: 32$ & 10 & 0.064264 & 0.369 & 0.468 \\
\hline
\end{tabular}

Feature Name: Point Generic

Correction Type: Realtime Corrected

Receiver Type: Pro XRS

$\mathrm{HAE}=$ Height above ellipsoid

$\mathrm{PDOP}=$ Position dilution of precision

aUTM Zone 11, NAD 27

b+/- 1 sigma
GPS Date: 02/21/2002

Data File: K260402.sst 
Table D.1-11

Sample Location Coordinates for CAS 26-05-01 Sample Locations and Points of Interest

(Page 1 of 3$)$

\begin{tabular}{|c|c|c|c|c|c|c|c|c|c|c|c|c|}
\hline Latitude & Longitude & Northing ${ }^{a}$ & Easting $^{a}$ & $\begin{array}{c}\text { HAE } \\
\text { (meters) }\end{array}$ & ID & Location & $\begin{array}{l}\text { Maximum } \\
\text { PDOP }\end{array}$ & $\begin{array}{l}\text { GPS } \\
\text { Time }\end{array}$ & $\begin{array}{l}\text { Unfiltered } \\
\text { Position }\end{array}$ & $\begin{array}{l}\text { Standard } \\
\text { Deviation }^{b}\end{array}$ & $\begin{array}{l}\text { Horizontal } \\
\text { Position } \\
\text { (meters) }\end{array}$ & $\begin{array}{l}\text { Vertical } \\
\text { Position } \\
\text { (meters) }\end{array}$ \\
\hline 36.8158225 & -116.1584057 & 4074568.95 & 575064.56 & $1,325.42$ & 7 & L01 & 1.5 & $14: 19: 43$ & 11 & 0.225830 & 0.277 & 0.330 \\
\hline 36.8157343 & -116.1587299 & 4074558.92 & 575035.73 & $1,325.93$ & 26 & L02 & 2.4 & $14: 29: 25$ & 12 & 0.335374 & 0.320 & 0.426 \\
\hline 36.8158009 & -116.1584173 & 4074566.56 & 575063.55 & $1,325.14$ & 8 & L03 & 1.5 & $14: 20: 01$ & 11 & 0.216861 & 0.285 & 0.338 \\
\hline 36.8158109 & -116.1583903 & 4074567.68 & 575065.95 & $1,325.15$ & 6 & L04 & 1.5 & $14: 19: 26$ & 10 & 0.277859 & 0.271 & 0.322 \\
\hline 36.8158821 & -116.1580655 & 4074575.83 & 575094.85 & $1,324.52$ & 10 & L05 & 2.2 & 14:21:09 & 11 & 0.096074 & 0.403 & 0.524 \\
\hline 36.8155246 & -116.1584849 & 4074535.85 & 575057.78 & $1,325.55$ & 31 & L06 & 1.5 & $14: 31: 42$ & 10 & 0.046153 & 0.285 & 0.344 \\
\hline 36.8155556 & -116.1583116 & 4074539.43 & 575073.21 & $1,325.55$ & 21 & L07 & 1.5 & 14:27:04 & 11 & 0.099679 & 0.294 & 0.353 \\
\hline 36.8155977 & -116.1581416 & 4074544.22 & 575088.34 & $1,325.31$ & 13 & L08 & 1.5 & $14: 22: 51$ & 11 & 0.135740 & 0.288 & 0.345 \\
\hline 36.8152320 & -116.1585769 & 4074503.32 & 575049.86 & $1,322.98$ & 36 & L09 & 2.2 & $14: 33: 55$ & 11 & 0.035001 & 0.363 & 0.524 \\
\hline 36.8153009 & -116.1582301 & 4074511.23 & 575080.73 & $1,324.67$ & 19 & L10 & 1.5 & $14: 26: 06$ & 12 & 0.030588 & 0.295 & 0.355 \\
\hline 36.8153836 & -116.1578997 & 4074520.66 & 575110.13 & $1,324.55$ & 16 & L11 & 1.5 & $14: 24: 28$ & 12 & 0.275256 & 0.271 & 0.317 \\
\hline 36.8157204 & -116.1585456 & 4074557.52 & 575052.18 & $1,325.91$ & 27 & L12 & 1.5 & $14: 29: 56$ & 11 & 0.100693 & 0.291 & 0.351 \\
\hline 36.8156228 & -116.1586787 & 4074546.59 & 575040.40 & $1,325.58$ & 29 & L13 & 1.5 & $14: 30: 53$ & 10 & 0.021260 & 0.290 & 0.349 \\
\hline 36.8156654 & -116.1584864 & 4074551.47 & 575057.52 & $1,325.85$ & 28 & L14 & 1.5 & $14: 30: 21$ & 10 & 0.026902 & 0.276 & 0.333 \\
\hline 36.8155248 & -116.1585680 & 4074535.80 & 575050.38 & $1,325.43$ & 30 & L15 & 1.5 & $14: 31: 20$ & 10 & 0.064451 & 0.276 & 0.332 \\
\hline 36.8155778 & -116.1583840 & 4074541.83 & 575066.73 & $1,324.70$ & 23 & L16 & 1.5 & $14: 27: 44$ & 10 & 0.065215 & 0.278 & 0.321 \\
\hline 36.8154863 & -116.1584550 & 4074531.63 & 575060.49 & $1,325.55$ & 32 & L17 & 1.5 & $14: 32: 03$ & 12 & 0.108353 & 0.295 & 0.355 \\
\hline 36.8153399 & -116.1585833 & 4074515.28 & 575049.19 & $1,325.69$ & 35 & L18 & 1.6 & $14: 33: 29$ & 12 & 0.158825 & 0.280 & 0.338 \\
\hline 36.8153889 & -116.1583899 & 4074520.87 & 575066.39 & $1,325.55$ & 33 & L19 & 1.5 & $14: 32: 35$ & 11 & 0.041485 & 0.282 & 0.339 \\
\hline 36.8154228 & -116.1583051 & 4074524.70 & 575073.93 & $1,325.12$ & 20 & L20 & 1.5 & $14: 26: 36$ & 11 & 0.033119 & 0.282 & 0.339 \\
\hline
\end{tabular}


Table D.1-11

Sample Location Coordinates for CAS 26-05-01 Sample Locations and Points of Interest

(Page 2 of 3 )

\begin{tabular}{|c|c|c|c|c|c|c|c|c|c|c|c|c|}
\hline Latitude & Longitude & Northing ${ }^{a}$ & Easting $^{a}$ & $\begin{array}{c}\text { HAE } \\
\text { (meters) }\end{array}$ & ID & Location & $\begin{array}{l}\text { Maximum } \\
\text { PDOP }\end{array}$ & $\begin{array}{l}\text { GPS } \\
\text { Time }\end{array}$ & $\begin{array}{l}\text { Unfiltered } \\
\text { Position }\end{array}$ & $\begin{array}{l}\text { Standard } \\
\text { Deviation }^{b}\end{array}$ & $\begin{array}{l}\text { Horizontal } \\
\text { Position } \\
\text { (meters) }\end{array}$ & $\begin{array}{l}\text { Vertical } \\
\text { Position } \\
\text { (meters) }\end{array}$ \\
\hline 36.8152936 & -116.1585192 & 4074510.19 & 575054.95 & $1,325.52$ & 34 & L21 & 1.7 & $14: 33: 07$ & 11 & 0.077760 & 0.301 & 0.361 \\
\hline 36.8158391 & -116.1581940 & 4074570.97 & 575083.43 & $1,325.31$ & 9 & L22 & 1.5 & $14: 20: 37$ & 13 & 0.244799 & 0.275 & 0.325 \\
\hline 36.8157669 & -116.1583624 & 4074562.82 & 575068.47 & $1,325.67$ & 25 & L23 & 1.5 & $14: 28: 41$ & 10 & 0.052946 & 0.277 & 0.319 \\
\hline 36.8157538 & -116.1582377 & 4074561.47 & 575079.62 & $1,326.05$ & 12 & L24 & 1.5 & $14: 22: 17$ & 18 & 0.067318 & 0.298 & 0.358 \\
\hline 36.8158022 & -116.1580693 & 4074566.96 & 575094.59 & $1,325.31$ & 11 & L25 & 1.5 & $14: 21: 32$ & 11 & 0.297039 & 0.272 & 0.321 \\
\hline 36.8156429 & -116.1583219 & 4074549.10 & 575072.21 & $1,325.23$ & 24 & L26 & 1.5 & $14: 28: 07$ & 10 & 0.063547 & 0.287 & 0.333 \\
\hline 36.8155606 & -116.1582709 & 4074540.01 & 575076.84 & $1,325.35$ & 22 & L27 & 1.8 & 14:27:22 & 11 & 0.052276 & 0.309 & 0.403 \\
\hline 36.8156116 & -116.1580768 & 4074545.82 & 575094.11 & $1,325.16$ & 14 & L28 & 1.5 & $14: 23: 13$ & 14 & 0.043695 & 0.298 & 0.358 \\
\hline 36.8154583 & -116.1581619 & 4074528.75 & 575086.66 & $1,324.41$ & 17 & L29 & 1.5 & $14: 25: 22$ & 11 & 0.041405 & 0.268 & 0.313 \\
\hline 36.8153722 & -116.1582219 & 4074519.14 & 575081.39 & $1,324.61$ & 18 & L30 & 1.5 & $14: 25: 44$ & 11 & 0.068549 & 0.278 & 0.323 \\
\hline 36.8154176 & -116.1580408 & 4074524.33 & 575097.50 & $1,325.19$ & 15 & L31 & 1.5 & $14: 23: 51$ & 12 & 0.035251 & 0.281 & 0.329 \\
\hline 36.8158169 & -116.1590564 & 4074567.82 & 575006.53 & $1,325.76$ & 51 & L32 & 2.2 & $15: 02: 31$ & 11 & 0.038438 & 0.361 & 0.505 \\
\hline 36.8160285 & -116.1584729 & 4074591.75 & 575058.37 & $1,328.09$ & 1 & L33--MH1 & 1.7 & $14: 15: 12$ & 48 & 0.493018 & 0.312 & 0.389 \\
\hline 36.8160097 & -116.1590830 & 4074589.19 & 575003.96 & $1,329.72$ & 41 & L34 & 1.6 & $14: 39: 43$ & 12 & 0.032538 & 0.290 & 0.349 \\
\hline 36.8160433 & -116.1614942 & 4074591.03 & 574788.86 & 1,333.28 & 42 & L35 & 2.5 & $14: 43: 00$ & 34 & 0.636895 & 0.367 & 0.435 \\
\hline 36.8160480 & -116.1614831 & 4074591.56 & 574789.85 & $1,330.69$ & 43 & L35--MH2 & 2.5 & $14: 43: 50$ & 13 & 0.031756 & 0.394 & 0.606 \\
\hline 36.8164244 & -116.1617592 & 4074633.10 & 574764.86 & $1,333.90$ & 44 & L36 & 2.5 & $14: 44: 58$ & 15 & 0.052774 & 0.399 & 0.618 \\
\hline 36.8160562 & -116.1627364 & 4074591.49 & 574678.06 & $1,332.68$ & 49 & L37 MH3 & 2.6 & $14: 57: 16$ & 16 & 0.034433 & 0.411 & 0.664 \\
\hline 36.8163597 & -116.1630691 & 4074624.90 & 574648.09 & $1,335.55$ & 47 & L38 & 2.2 & $14: 56: 05$ & 11 & 0.033455 & 0.382 & 0.531 \\
\hline 36.8161983 & -116.1629013 & 4074607.12 & 574663.21 & $1,333.92$ & 48 & L39 & 2.6 & $14: 56: 43$ & 11 & 0.053289 & 0.391 & 0.631 \\
\hline
\end{tabular}


Table D.1-11

Sample Location Coordinates for CAS 26-05-01 Sample Locations and Points of Interest

(Page 3 of 3 )

\begin{tabular}{|c|c|c|c|c|c|c|c|c|c|c|c|c|}
\hline Latitude & Longitude & Northing $^{a}$ & Easting $^{a}$ & $\begin{array}{c}\text { HAE } \\
\text { (meters) }\end{array}$ & ID & Location & $\begin{array}{l}\text { Maximum } \\
\text { PDOP }\end{array}$ & $\begin{array}{l}\text { GPS } \\
\text { Time }\end{array}$ & $\begin{array}{l}\text { Unfiltered } \\
\text { Position }\end{array}$ & $\begin{array}{l}\text { Standard } \\
\text { Deviation }\end{array}$ & $\begin{array}{l}\text { Horizontal } \\
\text { Position } \\
\text { (meters) }\end{array}$ & $\begin{array}{l}\text { Vertical } \\
\text { Position } \\
\text { (meters) }\end{array}$ \\
\hline 36.8166302 & -116.1618478 & 4074655.86 & 574756.75 & $1,335.17$ & 45 & 2202-DRAIN & 2.5 & $14: 46: 30$ & 21 & 0.081139 & 0.382 & 0.595 \\
\hline 36.8158297 & -116.1584137 & 4074569.75 & 575063.84 & $1,326.44$ & 5 & DIST BOX & 1.5 & $14: 18: 58$ & 15 & 0.257259 & 0.284 & 0.338 \\
\hline 36.8166147 & -116.1633702 & 4074652.96 & 574620.98 & $1,336.11$ & 46 & $\begin{array}{l}\text { MH-4 } 15 \mathrm{FT} \\
\text { EAST OF MH }\end{array}$ & 3.7 & $14: 50: 08$ & 29 & 0.073108 & 0.416 & 0.654 \\
\hline 36.8160169 & -116.1580301 & 4074590.81 & 575097.88 & $1,326.23$ & 39 & NE & 2.7 & $14: 37: 15$ & 11 & 0.207591 & 0.414 & 0.557 \\
\hline 36.8158313 & -116.1588412 & 4074569.59 & 575025.71 & $1,326.81$ & 40 & NW & 2.4 & 14:38:32 & 12 & 0.113048 & 0.394 & 0.539 \\
\hline 36.8153341 & -116.1578008 & 4074515.25 & 575118.99 & $1,320.92$ & 38 & SE & 4.7 & $14: 35: 52$ & 12 & 0.203258 & 0.547 & 0.670 \\
\hline 36.8151493 & -116.1586190 & 4074494.11 & 575046.20 & $1,326.04$ & 37 & SW & 3.8 & $14: 34: 18$ & 11 & 0.821261 & 0.469 & 0.649 \\
\hline
\end{tabular}

Feature Name: Point Generic

Correction Type: Realtime Corrected

Receiver Type: Pro XRS

$\mathrm{HAE}=$ Height above ellipsoid

$\mathrm{PDOP}=$ Position dilution of precision

aUTM Zone 11, NAD 27

b + - 1 sigma
GPS Date: 02/21/2002

Data File: L260501.ssf 
Table D.1-12

Sample Location Coordinates for CAS 26-05-03 Sample Locations and Points of Interest

(Page 1 of 2)

\begin{tabular}{|c|c|c|c|c|c|c|c|c|c|c|c|c|}
\hline Latitude & Longitude & Northing ${ }^{a}$ & Easting $^{a}$ & $\begin{array}{c}\text { HAE } \\
\text { (meters) }\end{array}$ & ID & Location & $\begin{array}{l}\text { Maximum } \\
\text { PDOP }\end{array}$ & $\begin{array}{l}\text { GPS } \\
\text { Time }\end{array}$ & $\begin{array}{l}\text { Unfiltered } \\
\text { Position }\end{array}$ & $\begin{array}{l}\text { Standard } \\
\text { Deviation }^{b}\end{array}$ & $\begin{array}{c}\text { Horizontal } \\
\text { Position } \\
\text { (meters) }\end{array}$ & $\begin{array}{l}\text { Vertical } \\
\text { Position } \\
\text { (meters) }\end{array}$ \\
\hline 36.8293810 & -116.1405965 & 4076087.14 & 576639.54 & $1,334.66$ & 1 & M01 & 2.4 & $13: 40: 37$ & 15 & 0.066857 & 0.382 & 0.596 \\
\hline 36.8293762 & -116.1405695 & 4076086.63 & 576641.95 & $1,333.89$ & 2 & M02 & 2.4 & $13: 40: 57$ & 19 & 1.224307 & 0.300 & 0.483 \\
\hline 36.8293466 & -116.1404185 & 4076083.47 & 576655.44 & $1,332.82$ & 6 & M03 & 2 & $13: 43: 38$ & 10 & 0.027974 & 0.316 & 0.506 \\
\hline 36.8292260 & -116.1404343 & 4076070.08 & 576654.16 & $1,332.46$ & 39 & M04 & 1.9 & $13: 55: 27$ & 11 & 0.035270 & 0.306 & 0.471 \\
\hline 36.8293386 & -116.1403996 & 4076082.60 & 576657.14 & $1,332.49$ & 7 & M05 & 2 & $13: 43: 55$ & 14 & 0.087640 & 0.296 & 0.473 \\
\hline 36.8293486 & -116.1403968 & 4076083.71 & 576657.37 & $1,332.43$ & 8 & M06 & 2 & $13: 44: 13$ & 11 & 0.022382 & 0.304 & 0.486 \\
\hline 36.8294532 & -116.1403523 & 4076095.35 & 576661.24 & $1,333.06$ & 10 & M07 & 2.3 & $13: 44: 59$ & 10 & 0.021873 & 0.361 & 0.542 \\
\hline 36.8292658 & -116.1403525 & 4076074.56 & 576661.41 & $1,332.30$ & 31 & M08 & 1.9 & $13: 52: 36$ & 11 & 0.075196 & 0.311 & 0.479 \\
\hline 36.8293285 & -116.1403272 & 4076081.54 & 576663.60 & $1,332.49$ & 23 & M09 & 1.9 & $13: 49: 50$ & 12 & 0.025139 & 0.319 & 0.496 \\
\hline 36.8293819 & -116.1403007 & 4076087.48 & 576665.91 & $1,332.58$ & 19 & M10 & 2.3 & $13: 48: 21$ & 14 & 0.041048 & 0.376 & 0.541 \\
\hline 36.8291983 & -116.1403043 & 4076067.12 & 576665.78 & $1,332.38$ & 34 & M11 & 1.9 & $13: 53: 36$ & 14 & 0.085046 & 0.311 & 0.479 \\
\hline 36.8293193 & -116.1402663 & 4076080.57 & 576669.04 & $1,332.29$ & 26 & M12 & 1.9 & $13: 51: 01$ & 11 & 0.028828 & 0.296 & 0.460 \\
\hline 36.8294139 & -116.1402269 & 4076091.09 & 576672.47 & $1,332.66$ & 15 & M13 & 2.3 & $13: 46: 52$ & 13 & 0.049068 & 0.359 & 0.525 \\
\hline 36.8292826 & -116.1404066 & 4076076.38 & 576656.57 & $1,332.69$ & 29 & M14 & 1.9 & $13: 52: 00$ & 11 & 0.030892 & 0.295 & 0.454 \\
\hline 36.8292478 & -116.1403980 & 4076072.52 & 576657.37 & $1,332.46$ & 38 & M15 & 1.9 & 13:55:09 & 10 & 0.044396 & 0.298 & 0.459 \\
\hline 36.8293159 & -116.1403701 & 4076080.10 & 576659.79 & $1,332.60$ & 28 & M16 & 1.9 & $13: 51: 42$ & 10 & 0.052518 & 0.315 & 0.484 \\
\hline 36.8292113 & -116.1403661 & 4076068.50 & 576660.25 & $1,332.17$ & 36 & M17 & 1.9 & $13: 54: 33$ & 11 & 0.056483 & 0.310 & 0.476 \\
\hline 36.8292343 & -116.1403689 & 4076071.05 & 576659.98 & $1,332.36$ & 37 & M18 & 1.9 & $13: 54: 50$ & 11 & 0.028056 & 0.318 & 0.490 \\
\hline 36.8292716 & -116.1403615 & 4076075.20 & 576660.60 & $1,332.53$ & 30 & M19 & 1.9 & $13: 52: 18$ & 12 & 0.035742 & 0.303 & 0.466 \\
\hline 36.8292878 & -116.1403185 & 4076077.02 & 576664.42 & $1,332.38$ & 27 & M20 & 1.9 & $13: 51: 22$ & 11 & 0.054658 & 0.305 & 0.469 \\
\hline 36.8292024 & -116.1403172 & 4076067.56 & 576664.62 & $1,332.40$ & 33 & M21 & 1.9 & $13: 53: 20$ & 12 & 0.041879 & 0.304 & 0.467 \\
\hline 36.8292436 & -116.1403111 & 4076072.13 & 576665.12 & 1,332.36 & 32 & M22 & 1.9 & $13: 52: 55$ & 10 & 0.030645 & 0.292 & 0.450 \\
\hline 36.8293172 & -116.1402952 & 4076080.31 & 576666.47 & $1,332.44$ & 24 & M23 & 1.9 & $13: 50: 09$ & 11 & 0.017373 & 0.299 & 0.466 \\
\hline 36.8293921 & -116.1403692 & 4076088.55 & 576659.79 & $1,332.91$ & 9 & M24 & 2.3 & 13:44:37 & 11 & 0.029198 & 0.383 & 0.575 \\
\hline
\end{tabular}


Table D.1-12

Sample Location Coordinates for CAS 26-05-03 Sample Locations and Points of Interest

(Page 2 of 2 )

\begin{tabular}{|c|c|c|c|c|c|c|c|c|c|c|c|c|}
\hline Latitude & Longitude & Northing $^{a}$ & Easting $^{a}$ & $\begin{array}{c}\text { HAE } \\
\text { (meters) }\end{array}$ & ID & Location & $\begin{array}{l}\text { Maximum } \\
\text { PDOP }\end{array}$ & $\begin{array}{l}\text { GPS } \\
\text { Time }\end{array}$ & $\begin{array}{l}\text { Unfiltered } \\
\text { Position }\end{array}$ & $\begin{array}{l}\text { Standard } \\
\text { Deviation }^{\mathrm{b}}\end{array}$ & $\begin{array}{c}\text { Horizontal } \\
\text { Position } \\
\text { (meters) }\end{array}$ & $\begin{array}{l}\text { Vertical } \\
\text { Position } \\
\text { (meters) }\end{array}$ \\
\hline 36.8294329 & -116.1403368 & 4076093.11 & 576662.64 & $1,332.91$ & 12 & M25 & 2.3 & $13: 45: 49$ & 13 & 0.056136 & 0.390 & 0.586 \\
\hline 36.8293892 & -116.1403263 & 4076088.27 & 576663.62 & $1,332.93$ & 21 & M26 & 2.3 & $13: 49: 03$ & 11 & 0.045439 & 0.365 & 0.525 \\
\hline 36.8293562 & -116.1403257 & 4076084.61 & 576663.71 & $1,332.43$ & 22 & M27 & 1.9 & $13: 49: 24$ & 14 & 0.033208 & 0.307 & 0.477 \\
\hline 36.8293971 & -116.1403104 & 4076089.16 & 576665.03 & $1,332.81$ & 20 & M28 & 2.3 & $13: 48: 46$ & 11 & 0.040018 & 0.390 & 0.561 \\
\hline 36.8294341 & -116.1403079 & 4076093.27 & 576665.22 & $1,332.59$ & 13 & M29 & 2.3 & $13: 46: 11$ & 11 & 0.044241 & 0.368 & 0.552 \\
\hline 36.8293273 & -116.1402769 & 4076081.44 & 576668.08 & $1,332.27$ & 25 & M30 & 1.9 & $13: 50: 45$ & 11 & 0.050614 & 0.316 & 0.492 \\
\hline 36.8293663 & -116.1402717 & 4076085.78 & 576668.51 & $1,332.15$ & 18 & M31 & 1.9 & $13: 47: 58$ & 11 & 0.019076 & 0.295 & 0.463 \\
\hline 36.8293939 & -116.1402404 & 4076088.86 & 576671.28 & $1,332.58$ & 17 & M32 & 2.3 & $13: 47: 36$ & 12 & 0.036451 & 0.384 & 0.556 \\
\hline 36.8294195 & -116.1402462 & 4076091.70 & 576670.73 & $1,332.70$ & 14 & M33 & 2.3 & $13: 46: 34$ & 11 & 0.023137 & 0.381 & 0.572 \\
\hline 36.8293813 & -116.1405811 & 4076087.19 & 576640.91 & $1,333.86$ & 3 & M34--ST MH & 2 & $13: 41: 29$ & 19 & 0.028592 & 0.312 & 0.504 \\
\hline 36.8290106 & -116.1398149 & 4076046.68 & 576709.60 & $1,329.26$ & 41 & M35 & 1.8 & $13: 59: 21$ & 15 & 0.031595 & 0.304 & 0.445 \\
\hline 36.8294184 & -116.1406877 & 4076091.22 & 576631.37 & $1,333.51$ & 4 & M36 MH & 4.3 & $13: 42: 07$ & 15 & 0.190246 & 0.613 & 1.054 \\
\hline 36.8293490 & -116.1404279 & 4076083.73 & 576654.60 & $1,332.97$ & 5 & DIST BOX & 2 & $13: 43: 13$ & 16 & 0.090702 & 0.304 & 0.487 \\
\hline 36.8294338 & -116.1402015 & 4076093.32 & 576674.70 & $1,332.00$ & 16 & $\mathrm{NE}$ & 2 & $13: 47: 15$ & 11 & 0.028378 & 0.303 & 0.477 \\
\hline 36.8294708 & -116.1403549 & 4076097.30 & 576660.99 & $1,333.14$ & 11 & NW & 2.3 & $13: 45: 16$ & 12 & 0.035402 & 0.371 & 0.556 \\
\hline 36.8291758 & -116.1402812 & 4076064.64 & 576667.85 & $1,332.11$ & 35 & SE & 1.9 & $13: 54: 11$ & 11 & 0.031505 & 0.299 & 0.461 \\
\hline 36.8292084 & -116.1404371 & 4076068.13 & 576653.92 & $1,332.48$ & 40 & SW & 1.9 & $13: 55: 44$ & 11 & 0.040797 & 0.315 & 0.484 \\
\hline
\end{tabular}

Feature Name: Point Generic

GPS Date: 02/21/2002

Correction Type: Realtime Corrected

Data File: M260503.ssf

Receiver Type: Pro XRS

$\mathrm{HAE}=$ Height above ellipsoid

$\mathrm{PDOP}=$ Position dilution of precision

${ }^{\mathrm{a} U T M}$ Zone 11, NAD 27

${ }^{b}+/-1$ sigma 
Table D.1-13

Sample Location Coordinates for CAS 26-05-04 Sample Locations and Points of Interest

(Page 1 of 3 )

\begin{tabular}{|c|c|c|c|c|c|c|c|c|c|c|c|c|}
\hline Latitude & Longitude & Northing ${ }^{a}$ & Easting $^{a}$ & $\begin{array}{c}\text { HAE } \\
\text { (meters) }\end{array}$ & ID & Location & $\begin{array}{c}\text { Maximum } \\
\text { PDOP }\end{array}$ & $\begin{array}{l}\text { GPS } \\
\text { Time }\end{array}$ & $\begin{array}{l}\text { Unfiltered } \\
\text { Position }\end{array}$ & $\begin{array}{l}\text { Standard } \\
\text { Deviation }^{b}\end{array}$ & $\begin{array}{l}\text { Horizontal } \\
\text { Position } \\
\text { (meters) }\end{array}$ & $\begin{array}{l}\text { Vertical } \\
\text { Position } \\
\text { (meters) }\end{array}$ \\
\hline 36.8157136 & -116.1642354 & 4074552.32 & 574544.69 & $1,332.24$ & 4 & N01 & 1.6 & $16: 32: 46$ & 12 & 0.09163 & 0.269 & 0.368 \\
\hline 36.8156390 & -116.1642432 & 4074544.04 & 574544.06 & $1,331.16$ & 8 & N02 & 1.5 & $16: 35: 13$ & 11 & 0.03257 & 0.262 & 0.369 \\
\hline 36.8156014 & -116.1642390 & 4074539.87 & 574544.47 & $1,329.30$ & 10 & N03 & 1.5 & $16: 35: 59$ & 11 & 0.04597 & 0.257 & 0.362 \\
\hline 36.8155586 & -116.1643750 & 4074535.01 & 574532.38 & $1,328.13$ & 45 & N04 & 1.7 & $16: 48: 17$ & 10 & 0.01983 & 0.275 & 0.427 \\
\hline 36.8155580 & -116.1642525 & 4074535.04 & 574543.31 & $1,328.11$ & 32 & N05 & 1.7 & $16: 43: 45$ & 10 & 0.03947 & 0.251 & 0.353 \\
\hline 36.8155569 & -116.1642279 & 4074534.93 & 574545.51 & $1,328.71$ & 12 & N06 & 1.7 & $16: 36: 42$ & 11 & 0.05151 & 0.254 & 0.367 \\
\hline 36.8155600 & -116.1640885 & 4074535.39 & 574557.93 & $1,329.02$ & 15 & N07 & 1.7 & $16: 37: 53$ & 11 & 0.11710 & 0.257 & 0.369 \\
\hline 36.8154688 & -116.1643174 & 4074525.10 & 574537.61 & $1,327.43$ & 42 & N08 & 1.7 & $16: 47: 06$ & 10 & 0.12743 & 0.260 & 0.367 \\
\hline 36.8154709 & -116.1642406 & 4074525.38 & 574544.46 & $1,328.15$ & 30 & N09 & 1.7 & $16: 42: 42$ & 11 & 0.08371 & 0.254 & 0.370 \\
\hline 36.8154656 & -116.1641660 & 4074524.86 & 574551.12 & $1,328.02$ & 24 & N10 & 1.5 & $16: 40: 40$ & 10 & 0.11204 & 0.248 & 0.348 \\
\hline 36.8153872 & -116.1643916 & 4074515.98 & 574531.07 & $1,327.95$ & 39 & N11 & 1.7 & $16: 45: 57$ & 13 & 0.05182 & 0.255 & 0.356 \\
\hline 36.8153839 & -116.1642373 & 4074515.74 & 574544.84 & $1,328.26$ & 28 & N12 & 1.7 & $16: 42: 01$ & 11 & 0.03166 & 0.266 & 0.397 \\
\hline 36.8153830 & -116.1640997 & 4074515.75 & 574557.11 & $1,328.63$ & 19 & N13 & 1.5 & $16: 39: 12$ & 11 & 0.04808 & 0.261 & 0.367 \\
\hline 36.8155416 & -116.1642572 & 4074533.22 & 574542.91 & $1,328.35$ & 33 & N14 & 1.7 & $16: 44: 02$ & 11 & 0.12406 & 0.266 & 0.398 \\
\hline 36.8155282 & -116.1643182 & 4074531.68 & 574537.48 & $1,327.88$ & 44 & N15 & 1.7 & $16: 47: 51$ & 10 & 0.08583 & 0.261 & 0.396 \\
\hline 36.8155072 & -116.1642924 & 4074529.37 & 574539.81 & $1,328.17$ & 34 & N16 & 1.5 & $16: 44: 21$ & 11 & 0.06201 & 0.265 & 0.368 \\
\hline 36.8155020 & -116.1643738 & 4074528.73 & 574532.55 & $1,327.36$ & 43 & N17 & 1.5 & $16: 47: 25$ & 10 & 0.05127 & 0.265 & 0.367 \\
\hline 36.8154854 & -116.1642561 & 4074526.98 & 574543.06 & $1,328.14$ & 31 & N18 & 1.5 & $16: 43: 02$ & 10 & 0.04288 & 0.257 & 0.359 \\
\hline 36.8154476 & -116.1643506 & 4074522.72 & 574534.67 & $1,327.74$ & 41 & N19 & 1.7 & $16: 46: 44$ & 14 & 0.15426 & 0.257 & 0.381 \\
\hline 36.8154601 & -116.1642900 & 4074524.15 & 574540.06 & $1,328.14$ & 35 & N20 & 1.7 & $16: 44: 40$ & 12 & 0.11605 & 0.251 & 0.357 \\
\hline
\end{tabular}


Table D.1-13

Sample Location Coordinates for CAS 26-05-04 Sample Locations and Points of Interest

(Page 2 of 3 )

\begin{tabular}{|c|c|c|c|c|c|c|c|c|c|c|c|c|}
\hline Latitude & Longitude & Northing $^{a}$ & Easting $^{a}$ & $\begin{array}{c}\text { HAE } \\
\text { (meters) }\end{array}$ & ID & Location & $\begin{array}{c}\text { Maximum } \\
\text { PDOP }\end{array}$ & $\begin{array}{l}\text { GPS } \\
\text { Time }\end{array}$ & $\begin{array}{l}\text { Unfiltered } \\
\text { Position }\end{array}$ & $\begin{array}{l}\text { Standard } \\
\text { Deviation }^{\mathrm{b}}\end{array}$ & $\begin{array}{l}\text { Horizontal } \\
\text { Position } \\
\text { (meters) }\end{array}$ & $\begin{array}{l}\text { Vertical } \\
\text { Position } \\
\text { (meters) }\end{array}$ \\
\hline 36.8154289 & -116.1643357 & 4074520.66 & 574536.02 & $1,327.96$ & 37 & $\mathrm{~N} 21$ & 1.5 & $16: 45: 20$ & 10 & 0.11906 & 0.264 & 0.367 \\
\hline 36.8154026 & -116.1643645 & 4074517.72 & 574533.47 & $1,328.02$ & 38 & N22 & 1.5 & $16: 45: 39$ & 11 & 0.02531 & 0.248 & 0.344 \\
\hline 36.8154198 & -116.1642965 & 4074519.68 & 574539.52 & $1,328.02$ & 36 & N23 & 1.5 & $16: 45: 02$ & 11 & 0.06208 & 0.257 & 0.357 \\
\hline 36.8155467 & -116.1641612 & 4074533.86 & 574551.47 & $1,328.59$ & 13 & N24 & 1.7 & $16: 37: 07$ & 12 & 0.04997 & 0.273 & 0.414 \\
\hline 36.8155242 & -116.1641215 & 4074531.40 & 574555.03 & $1,328.81$ & 17 & N25 & 1.5 & $16: 38: 32$ & 10 & 0.07929 & 0.246 & 0.346 \\
\hline 36.8154916 & -116.1641942 & 4074527.72 & 574548.57 & $1,328.10$ & 25 & N26 & 1.7 & $16: 41: 06$ & 10 & 0.06977 & 0.259 & 0.366 \\
\hline 36.8154716 & -116.1642169 & 4074525.49 & 574546.57 & $1,328.06$ & 29 & N27 & 1.5 & $16: 42: 24$ & 11 & 0.03284 & 0.266 & 0.372 \\
\hline 36.8154677 & -116.1641097 & 4074525.14 & 574556.13 & $1,328.71$ & 18 & N28 & 1.7 & $16: 38: 51$ & 10 & 0.08469 & 0.266 & 0.405 \\
\hline 36.8154597 & -116.1641872 & 4074524.18 & 574549.23 & $1,328.10$ & 26 & N29 & 1.5 & $16: 41: 22$ & 10 & 0.01301 & 0.265 & 0.372 \\
\hline 36.8154441 & -116.1641673 & 4074522.48 & 574551.02 & $1,328.01$ & 23 & N30 & 1.5 & $16: 40: 25$ & 10 & 0.03439 & 0.267 & 0.374 \\
\hline 36.8154375 & -116.1641990 & 4074521.71 & 574548.20 & $1,328.10$ & 27 & N31 & 1.5 & $16: 41: 40$ & 10 & 0.06235 & 0.249 & 0.348 \\
\hline 36.8154200 & -116.1641643 & 4074519.80 & 574551.31 & $1,328.07$ & 22 & N32 & 1.5 & $16: 40: 08$ & 11 & 0.04212 & 0.260 & 0.364 \\
\hline 36.8153979 & -116.1641443 & 4074517.37 & 574553.12 & $1,328.12$ & 21 & N33 & 1.5 & $16: 39: 51$ & 11 & 0.04138 & 0.253 & 0.356 \\
\hline 36.8155741 & -116.1640872 & 4074536.96 & 574558.04 & $1,328.84$ & 14 & N34 & 1.5 & $16: 37: 38$ & 10 & 0.05131 & 0.249 & 0.350 \\
\hline 36.8158186 & -116.1642453 & 4074563.96 & 574543.70 & $1,334.27$ & 2 & N35 & 1.3 & $16: 31: 39$ & 12 & 0.77388 & 0.218 & 0.306 \\
\hline 36.8158053 & -116.1642438 & 4074562.49 & 574543.85 & $1,332.49$ & 3 & N35--MH1 & 1.4 & $16: 32: 18$ & 15 & 0.13158 & 0.232 & 0.326 \\
\hline 36.8160598 & -116.1640161 & 4074590.89 & 574563.91 & $1,335.67$ & 1 & N36--MH2 & 2.1 & $16: 29: 00$ & 88 & 0.15030 & 0.323 & 0.509 \\
\hline 36.8156112 & -116.1642406 & 4074540.95 & 574544.32 & $1,330.66$ & 9 & DIST BOX & 1.5 & $16: 35: 36$ & 11 & 0.05920 & 0.248 & 0.349 \\
\hline 36.8156942 & -116.1642470 & 4074550.15 & 574543.67 & $1,331.09$ & 6 & MID-MH-ST-IN & 1.5 & $16: 33: 50$ & 31 & 0.36420 & 0.246 & 0.345 \\
\hline 36.8157057 & -116.1642456 & 4074551.44 & 574543.79 & $1,331.69$ & 5 & NORTH-MH-ST-IN & 1.4 & $16: 33: 08$ & 37 & 0.09487 & 0.228 & 0.319 \\
\hline
\end{tabular}


Table D.1-13

Sample Location Coordinates for CAS 26-05-04 Sample Locations and Points of Interest

(Page 3 of 3 )

\begin{tabular}{|c|c|c|c|c|c|c|c|c|c|c|c|c|}
\hline Latitude & Longitude & Northing $^{a}$ & Easting $^{a}$ & $\begin{array}{c}\text { HAE } \\
\text { (meters) }\end{array}$ & ID & Location & $\begin{array}{c}\text { Maximum } \\
\text { PDOP }\end{array}$ & $\begin{array}{l}\text { GPS } \\
\text { Time }\end{array}$ & $\begin{array}{l}\text { Unfiltered } \\
\text { Position }\end{array}$ & $\begin{array}{c}\text { Standard } \\
\text { Deviation }^{\mathrm{b}}\end{array}$ & $\begin{array}{c}\text { Horizontal } \\
\text { Position } \\
\text { (meters) }\end{array}$ & $\begin{array}{l}\text { Vertical } \\
\text { Position } \\
\text { (meters) }\end{array}$ \\
\hline 36.8156622 & -116.1642464 & 4074546.60 & 574543.75 & $1,331.66$ & 7 & SOUTH MH- ST OUT & 1.7 & $16: 34: 30$ & 30 & 0.23931 & 0.248 & 0.353 \\
\hline 36.8155837 & -116.1640695 & 4074538.03 & 574559.61 & $1,329.41$ & 16 & $\mathrm{NE}$ & 1.5 & $16: 38: 11$ & 11 & 0.01967 & 0.261 & 0.367 \\
\hline 36.8155899 & -116.1644103 & 4074538.46 & 574529.21 & $1,328.57$ & 46 & NW & 1.7 & $16: 48: 33$ & 11 & 0.05268 & 0.258 & 0.400 \\
\hline 36.8153793 & -116.1640686 & 4074515.36 & 574559.89 & $1,328.74$ & 20 & SE & 1.7 & $16: 39: 28$ & 10 & 0.06674 & 0.248 & 0.356 \\
\hline 36.8153853 & -116.1644080 & 4074515.77 & 574529.61 & $1,328.26$ & 40 & SW & 1.7 & $16: 46: 16$ & 13 & 0.03579 & 0.275 & 0.427 \\
\hline 36.81557 & -116.1643 & 4074537 & 574536 & $1,328.07$ & 5 & N37 & 1.6 & $14: 28: 54$ & 67 & 0.081079 & 0.27 & 0.364 \\
\hline 36.81562 & -116.1644 & 4074542 & 574532.7 & $1,328.76$ & 6 & N38 & 1.6 & $14: 30: 42$ & 57 & 0.198442 & 0.265 & 0.353 \\
\hline 36.81557 & -116.1644 & 4074536 & 574528.7 & $1,327.72$ & 7 & N39 & 1.7 & $14: 32: 10$ & 54 & 0.102278 & 0.303 & 0.39 \\
\hline
\end{tabular}

Feature Name: Point Generic

Correction Type: Realtime Corrected

Receiver Type: Pro XRS

$\mathrm{HAE}=$ Height above ellipsoid

PDOP $=$ Position dilution of precision

aUTM Zone 11, NAD 27

$\mathrm{b}_{+} /-1$ sigma
GPS Date: $02 / 20 / 2002$ and 5/7/2002

Data File: N260504.ssf and 271PHSE2.ssf 
Table D.1-14

Sample Location Coordinates for CAS 26-05-05 Sample Locations and Points of Interest

(Page 1 of 3 )

\begin{tabular}{|c|c|c|c|c|c|c|c|c|c|c|c|c|}
\hline Latitude & Longitude & Northing $^{a}$ & Easting $^{a}$ & $\begin{array}{c}\text { HAE } \\
\text { (meters) }\end{array}$ & ID & Location & $\begin{array}{l}\text { Maximum } \\
\text { PDOP }\end{array}$ & $\begin{array}{l}\text { GPS } \\
\text { Time }\end{array}$ & $\begin{array}{l}\text { Unfiltered } \\
\text { Position }\end{array}$ & $\begin{array}{c}\text { Standard } \\
\text { Deviation }^{\mathrm{b}}\end{array}$ & \begin{tabular}{|c|} 
Horizontal \\
Position \\
(meters)
\end{tabular} & $\begin{array}{l}\text { Vertical } \\
\text { Position } \\
\text { (meters) }\end{array}$ \\
\hline 36.8090987 & -116.1535749 & 4073826.88 & 575502.04 & $1,326.47$ & 9 & P01 & 1.4 & $16: 07: 54$ & 10 & 0.024663 & 0.234 & 0.359 \\
\hline 36.8090574 & -116.1534865 & 4073822.37 & 575509.97 & $1,328.53$ & 5 & P02 & 1.9 & $16: 06: 24$ & 13 & 0.026053 & 0.288 & 0.456 \\
\hline 36.8090766 & -116.1536296 & 4073824.39 & 575497.19 & $1,325.96$ & 11 & P03 & 1.4 & $16: 08: 50$ & 10 & 0.029491 & 0.232 & 0.359 \\
\hline 36.8091660 & -116.1538147 & 4073834.16 & 575480.59 & $1,326.16$ & 26 & P04 & 2.6 & $16: 15: 38$ & 12 & 0.319806 & 0.282 & 0.455 \\
\hline 36.8090963 & -116.1536606 & 4073826.55 & 575494.40 & $1,326.71$ & 16 & P05 & 1.5 & $16: 11: 03$ & 12 & 0.044844 & 0.227 & 0.345 \\
\hline 36.8090843 & -116.1536696 & 4073825.21 & 575493.62 & $1,326.54$ & 17 & P06 & 1.5 & $16: 11: 20$ & 11 & 0.038675 & 0.233 & 0.353 \\
\hline 36.8091706 & -116.1538296 & 4073834.66 & 575479.26 & $1,326.71$ & 28 & $\mathrm{P} 07$ & 1.9 & $16: 16: 16$ & 10 & 0.512793 & 0.237 & 0.380 \\
\hline 36.8091645 & -116.1538339 & 4073833.98 & 575478.88 & $1,326.80$ & 29 & P08 & 1.4 & $16: 16: 35$ & 12 & 0.068356 & 0.225 & 0.359 \\
\hline 36.8093054 & -116.1541452 & 4073849.37 & 575450.97 & $1,325.76$ & 45 & P09 & 1.5 & $16: 23: 43$ & 12 & 0.045870 & 0.228 & 0.368 \\
\hline 36.8091906 & -116.1536005 & 4073837.07 & 575499.67 & $1,327.56$ & 13 & P10 & 1.9 & $16: 09: 43$ & 13 & 0.350392 & 0.256 & 0.404 \\
\hline 36.8089488 & -116.1537370 & 4073810.13 & 575487.73 & $1,327.52$ & 18 & P11 & 1.9 & $16: 11: 50$ & 11 & 0.243586 & 0.258 & 0.411 \\
\hline 36.8094326 & -116.1540594 & 4073863.55 & 575458.50 & $1,326.44$ & 48 & P12 & 1.5 & $16: 24: 45$ & 11 & 0.030570 & 0.228 & 0.369 \\
\hline 36.8091646 & -116.1542024 & 4073833.70 & 575446.01 & $1,326.14$ & 43 & $\mathrm{P} 13$ & 1.5 & $16: 22: 47$ & 12 & 0.033429 & 0.229 & 0.370 \\
\hline 36.8091951 & -116.1538938 & 4073837.33 & 575473.51 & $1,326.47$ & 32 & P14 & 1.4 & $16: 18: 07$ & 12 & 0.126104 & 0.216 & 0.345 \\
\hline 36.8091312 & -116.1539376 & 4073830.21 & 575469.66 & $1,326.33$ & 33 & P15 & 1.4 & $16: 18: 30$ & 12 & 0.046458 & 0.223 & 0.359 \\
\hline 36.8092526 & -116.1538513 & 4073843.74 & 575477.24 & $1,326.65$ & 31 & P16 & 1.4 & $16: 17: 45$ & 12 & 0.058852 & 0.229 & 0.366 \\
\hline 36.8090662 & -116.1537615 & 4073823.13 & 575485.43 & $1,327.68$ & 22 & P17 & 1.4 & $16: 13: 18$ & 11 & 0.083136 & 0.219 & 0.347 \\
\hline 36.8090392 & -116.1537871 & 4073820.12 & 575483.17 & $1,327.84$ & 21 & P18 & 1.4 & $16: 12: 58$ & 11 & 0.056614 & 0.213 & 0.337 \\
\hline 36.8089872 & -116.1538195 & 4073814.32 & 575480.34 & $1,328.02$ & 20 & P19 & 1.4 & $16: 12: 38$ & 11 & 0.035755 & 0.227 & 0.357 \\
\hline 36.8090727 & -116.1538684 & 4073823.77 & 575475.89 & $1,327.19$ & 24 & P20 & 1.4 & $16: 14: 43$ & 11 & 0.040168 & 0.228 & 0.362 \\
\hline 36.8090383 & -116.1539087 & 4073819.92 & 575472.33 & $1,327.21$ & 23 & $\mathrm{P} 21$ & 1.4 & $16: 14: 18$ & 12 & 0.047673 & 0.219 & 0.348 \\
\hline 36.8090940 & -116.1539625 & 4073826.06 & 575467.48 & $1,328.10$ & 34 & P22 & 1.9 & $16: 18: 50$ & 11 & 0.035996 & 0.296 & 0.481 \\
\hline 36.8091040 & -116.1540135 & 4073827.13 & 575462.92 & $1,326.31$ & 35 & P23 & 1.9 & 16:19:09 & 11 & 0.307759 & 0.223 & 0.360 \\
\hline
\end{tabular}


Table D.1-14

Sample Location Coordinates for CAS 26-05-05 Sample Locations and Points of Interest

(Page 2 of 3 )

\begin{tabular}{|c|c|c|c|c|c|c|c|c|c|c|c|c|}
\hline Latitude & Longitude & Northing ${ }^{a}$ & Easting $^{a}$ & $\begin{array}{c}\text { HAE } \\
\text { (meters) }\end{array}$ & ID & Location & $\begin{array}{c}\text { Maximum } \\
\text { PDOP }\end{array}$ & $\begin{array}{l}\text { GPS } \\
\text { Time }\end{array}$ & $\begin{array}{l}\text { Unfiltered } \\
\text { Position }\end{array}$ & $\begin{array}{l}\text { Standard } \\
\text { Deviation }\end{array}$ & $\begin{array}{c}\text { Horizontal } \\
\text { Position } \\
\text { (meters) }\end{array}$ & $\begin{array}{l}\text { Vertical } \\
\text { Position } \\
\text { (meters) }\end{array}$ \\
\hline 36.8092488 & -116.1540502 & 4073843.17 & 575459.50 & $1,324.84$ & 40 & P24 & 1.7 & $16: 21: 34$ & 13 & 0.130306 & 0.259 & 0.412 \\
\hline 36.8092103 & -116.1540679 & 4073838.88 & 575457.96 & $1,326.18$ & 41 & P25 & 1.5 & $16: 21: 56$ & 11 & 0.030161 & 0.232 & 0.375 \\
\hline 36.8091827 & -116.1541454 & 4073835.75 & 575451.07 & $1,326.15$ & 42 & P26 & 1.5 & $16: 22: 22$ & 15 & 0.033917 & 0.221 & 0.356 \\
\hline 36.8091620 & -116.1536659 & 4073833.84 & 575493.87 & $1,326.77$ & 15 & $\mathrm{P} 27$ & 1.5 & $16: 10: 41$ & 12 & 0.035259 & 0.241 & 0.366 \\
\hline 36.8092614 & -116.1536977 & 4073844.83 & 575490.93 & $1,327.12$ & 14 & P28 & 1.9 & $16: 10: 13$ & 11 & 0.360699 & 0.230 & 0.361 \\
\hline 36.8091706 & -116.1538155 & 4073834.67 & 575480.51 & $1,327.61$ & 27 & P29 & 1.4 & $16: 15: 57$ & 14 & 0.062002 & 0.233 & 0.372 \\
\hline 36.8092737 & -116.1538485 & 4073846.08 & 575477.47 & $1,326.55$ & 30 & P30 & 1.4 & $16: 17: 26$ & 10 & 0.033080 & 0.222 & 0.356 \\
\hline 36.8092558 & -116.1539490 & 4073844.01 & 575468.52 & $1,325.97$ & 37 & P31 & 1.5 & $16: 20: 01$ & 15 & 0.070529 & 0.214 & 0.344 \\
\hline 36.8092328 & -116.1539553 & 4073841.47 & 575467.98 & $1,325.83$ & 36 & P32 & 1.5 & $16: 19: 41$ & 12 & 0.048062 & 0.227 & 0.365 \\
\hline 36.8093433 & -116.1539995 & 4073853.69 & 575463.93 & $1,325.81$ & 38 & P33 & 1.5 & $16: 20: 48$ & 12 & 0.055884 & 0.230 & 0.370 \\
\hline 36.8092944 & -116.1540418 & 4073848.23 & 575460.21 & $1,326.10$ & 39 & P34 & 1.5 & $16: 21: 09$ & 11 & 0.114614 & 0.216 & 0.349 \\
\hline 36.8093227 & -116.1541064 & 4073851.31 & 575454.42 & $1,326.28$ & 46 & P35 & 1.5 & $16: 24: 02$ & 11 & 0.134263 & 0.214 & 0.346 \\
\hline 36.8093973 & -116.1540773 & 4073859.62 & 575456.94 & $1,326.44$ & 47 & P36 & 1.5 & $16: 24: 26$ & 11 & 0.029327 & 0.222 & 0.359 \\
\hline 36.8090460 & -116.1535746 & 4073821.04 & 575502.12 & $1,328.10$ & 4 & P37 & 1.8 & $16: 05: 54$ & 11 & 0.031860 & 0.302 & 0.475 \\
\hline 36.8090322 & -116.1535429 & 4073819.54 & 575504.97 & $1,328.24$ & 2 & P38 & 1.8 & $16: 05: 02$ & 10 & 0.027405 & 0.279 & 0.439 \\
\hline 36.8090403 & -116.1535604 & 4073820.41 & 575503.39 & $1,328.17$ & 3 & P39 ST1 & 1.8 & $16: 05: 21$ & 24 & 0.052893 & 0.287 & 0.451 \\
\hline 36.8089739 & -116.1539657 & 4073812.73 & 575467.31 & $1,327.03$ & 50 & $\mathrm{P} 40$ & 1.5 & $16: 26: 50$ & 12 & 0.036255 & 0.231 & 0.372 \\
\hline 36.8081934 & -116.1535005 & 4073726.52 & 575509.57 & $1,330.69$ & 54 & $\mathrm{P} 41$ & 2.5 & $16: 31: 34$ & 13 & 0.045987 & 0.338 & 0.631 \\
\hline 36.8085005 & -116.1531550 & 4073760.86 & 575540.10 & $1,332.25$ & 52 & P42 & 2.7 & $16: 29: 02$ & 12 & 0.477892 & 0.338 & 0.655 \\
\hline 36.8090879 & -116.1535489 & 4073825.71 & 575504.38 & $1,326.95$ & 8 & P43 ST2W & 1.4 & $16: 07: 31$ & 13 & 0.023287 & 0.225 & 0.346 \\
\hline 36.8090604 & -116.1534931 & 4073822.70 & 575509.39 & $1,328.71$ & 6 & P43-ST2E & 1.9 & $16: 06: 44$ & 16 & 0.020425 & 0.297 & 0.471 \\
\hline 36.8090737 & -116.1535221 & 4073824.15 & 575506.78 & $1,328.22$ & 7 & P43-ST2M & 1.9 & $16: 07: 08$ & 14 & 0.332480 & 0.266 & 0.420 \\
\hline 36.8083614 & -116.1535008 & 4073745.16 & 575509.38 & $1,343.64$ & 53 & P44 & 3.8 & $16: 30: 32$ & 36 & 3.052482 & 0.622 & 0.634 \\
\hline
\end{tabular}


Table D.1-14

Sample Location Coordinates for CAS 26-05-05 Sample Locations and Points of Interest

(Page 3 of 3 )

\begin{tabular}{|c|c|c|c|c|c|c|c|c|c|c|c|c|}
\hline Latitude & Longitude & Northing ${ }^{a}$ & Easting $^{a}$ & $\begin{array}{c}\text { HAE } \\
\text { (meters) }\end{array}$ & ID & Location & $\begin{array}{c}\text { Maximum } \\
\text { PDOP }\end{array}$ & $\begin{array}{l}\text { GPS } \\
\text { Time }\end{array}$ & $\begin{array}{l}\text { Unfiltered } \\
\text { Position }\end{array}$ & $\begin{array}{l}\text { Standard } \\
\text { Deviation }^{b}\end{array}$ & \begin{tabular}{|c|} 
Horizontal \\
Position \\
(meters)
\end{tabular} & $\begin{array}{l}\text { Vertical } \\
\text { Position } \\
\text { (meters) }\end{array}$ \\
\hline 36.8090607 & -116.1536112 & 4073822.65 & 575498.85 & $1,329.04$ & 10 & DIST BOX 1 & 1.9 & $16: 08: 22$ & 17 & 0.049379 & 0.287 & 0.458 \\
\hline 36.8091579 & -116.1538130 & 4073833.27 & 575480.75 & $1,327.43$ & 25 & DIST BOX 2 & 1.4 & $16: 15: 10$ & 13 & 0.055443 & 0.217 & 0.346 \\
\hline 36.8085316 & -116.1534923 & 4073764.05 & 575509.97 & $1,337.80$ & 51 & $\mathrm{MH} 2$ & 2.5 & $16: 28: 21$ & 11 & 1.687110 & 0.258 & 0.400 \\
\hline 36.8090129 & -116.1535003 & 4073817.43 & 575508.79 & $1,328.83$ & 1 & $\mathrm{MH}-1$ & 1.8 & $16: 04: 33$ & 20 & 0.054385 & 0.292 & 0.459 \\
\hline 36.8081010 & -116.1535054 & 4073716.27 & 575509.23 & $1,334.18$ & 55 & NEW MH & 1.7 & $16: 32: 39$ & 29 & 0.055595 & 0.259 & 0.425 \\
\hline 36.8092121 & -116.1535432 & 4073839.49 & 575504.76 & $1,327.41$ & 12 & NE & 1.4 & 16:09:21 & 11 & 0.196289 & 0.221 & 0.344 \\
\hline 36.8094690 & -116.1540640 & 4073867.58 & 575458.05 & $1,326.39$ & 49 & NW & 1.5 & $16: 25: 05$ & 12 & 0.039199 & 0.215 & 0.347 \\
\hline 36.8089286 & -116.1537181 & 4073807.90 & 575489.45 & $1,327.84$ & 19 & SE & 1.9 & $16: 12: 12$ & 11 & 0.063668 & 0.239 & 0.379 \\
\hline 36.8091767 & -116.1542307 & 4073835.02 & 575443.47 & $1,326.10$ & 44 & SW & 1.5 & $16: 23: 08$ & 11 & 0.037537 & 0.216 & 0.349 \\
\hline 36.80924 & -116.154 & 4073842 & 575462.2 & $1,325.22$ & 9 & P45 & 1.8 & $11: 01: 06$ & 51 & 0.14827 & 0.224 & 0.31 \\
\hline
\end{tabular}

Feature Name: Point Generic

GPS Date: 02/21/2002 and 5/8/2002

Correction Type: Realtime Corrected

Data File: P260505.ssf and 271PHSE2.ssf

Receiver Type: Pro XRS

$\mathrm{HAE}=$ Height above ellipsoid

PDOP $=$ Position dilution of precision

aUTM Zone 11, NAD 27

${ }^{b}+/-1$ sigma 
Table D.1-15

Sample Location Coordinates for CAS 27-05-02 Sample Locations and Points of Interest

(Page 1 of 2)

\begin{tabular}{|c|c|c|c|c|c|c|c|c|c|c|c|c|}
\hline Latitude & Longitude & Northing $^{a}$ & Easting $^{a}$ & $\begin{array}{c}\text { HAE } \\
\text { (meters) }\end{array}$ & ID & Location & $\begin{array}{l}\text { Maximum } \\
\text { PDOP }\end{array}$ & $\begin{array}{l}\text { GPS } \\
\text { Time }\end{array}$ & $\begin{array}{l}\text { Unfiltered } \\
\text { Position }\end{array}$ & $\begin{array}{l}\text { Standard } \\
\text { Deviation }^{\mathrm{b}}\end{array}$ & $\begin{array}{c}\text { Horizontal } \\
\text { Position } \\
\text { (meters) }\end{array}$ & $\begin{array}{l}\text { Vertical } \\
\text { Position } \\
\text { (meters) }\end{array}$ \\
\hline 36.7699065 & -116.1164237 & 4069509.26 & 578856.20 & $1,288.61$ & 5 & Q01 & 3.1 & $15: 14: 43$ & 43 & 1.427985 & 0.366 & 0.555 \\
\hline 36.7698718 & -116.1164316 & 4069505.41 & 578855.53 & $1,288.77$ & 6 & Q02 & 2.3 & $15: 15: 34$ & 33 & 2.266771 & 0.356 & 0.562 \\
\hline 36.7698279 & -116.1164279 & 4069500.54 & 578855.91 & $1,288.71$ & 13 & Q03 & 2.2 & $15: 21: 56$ & 15 & 0.046405 & 0.333 & 0.528 \\
\hline 36.7698498 & -116.1164014 & 4069502.99 & 578858.25 & $1,288.54$ & 10 & Q04 & 2.2 & $15: 17: 57$ & 19 & 0.068990 & 0.334 & 0.529 \\
\hline 36.7698523 & -116.1163673 & 4069503.30 & 578861.29 & $1,287.08$ & 4 & Q05 & 2.3 & $15: 13: 37$ & 14 & 0.030199 & 0.391 & 0.579 \\
\hline 36.7697749 & -116.1163427 & 4069494.73 & 578863.57 & $1,288.51$ & 18 & Q06 & 2.3 & $15: 23: 49$ & 8 & 0.023617 & 0.325 & 0.542 \\
\hline 36.7696621 & -116.1162977 & 4069482.25 & 578867.70 & $1,287.44$ & 23 & Q07 & 2.3 & $15: 25: 42$ & 14 & 0.074163 & 0.351 & 0.597 \\
\hline 36.7696806 & -116.1162628 & 4069484.33 & 578870.79 & $1,287.89$ & 22 & Q08 & 2.3 & $15: 25: 29$ & 5 & 0.025833 & 0.345 & 0.575 \\
\hline 36.7697044 & -116.1162250 & 4069487.00 & 578874.14 & $1,287.48$ & 20 & Q09 & 2.3 & $15: 24: 59$ & 8 & 0.019921 & 0.330 & 0.550 \\
\hline 36.7698894 & -116.1163841 & 4069507.40 & 578859.76 & $1,287.78$ & 3 & Q10 & 3 & $15: 12: 39$ & 43 & 3.373056 & 0.382 & 0.580 \\
\hline 36.7699186 & -116.1164002 & 4069510.62 & 578858.29 & $1,288.52$ & 2 & Q11 & 2.9 & 15:09:39 & 119 & 1.183972 & 0.424 & 0.641 \\
\hline 36.7698505 & -116.1165881 & 4069502.91 & 578841.59 & $1,287.46$ & 29 & Q12 & 3 & $15: 29: 16$ & 10 & 0.028894 & 0.392 & 0.787 \\
\hline 36.7695803 & -116.1162869 & 4069473.18 & 578868.75 & $1,285.90$ & 26 & Q13 & 2.3 & $15: 27: 37$ & 10 & 0.019343 & 0.348 & 0.596 \\
\hline 36.7696159 & -116.1162432 & 4069477.17 & 578872.61 & $1,286.52$ & 24 & Q14 & 2.3 & $15: 26: 44$ & 10 & 0.053533 & 0.352 & 0.601 \\
\hline 36.7697186 & -116.1162077 & 4069489 & 578875.7 & $1,288.64$ & 9 & Q15 & 2.9 & 12:29:01 & 53 & 0.705 & 0.502 & 0.185216 \\
\hline 36.7696778 & -116.1162013 & 4069484 & 578876.3 & $1,287.09$ & 10 & Q16 & 2.2 & $12: 30: 08$ & 54 & 0.561 & 0.338 & 0.148536 \\
\hline 36.7697407 & -116.1162603 & 4069491 & 578870.96 & $1,288.57$ & 12 & Q17 & 4.2 & $17: 14: 25$ & 25 & 0.155762 & 0.384 & 0.691 \\
\hline 36.7697304 & -116.1161834 & 4069489.93 & 578877.83 & $1,291.68$ & 7 & Q18 & 2 & $9: 56: 52$ & 26 & 0.270267 & 0.341 & 0.501 \\
\hline 36.7697599 & -116.116144 & 4069493.22 & 578881.32 & $1,291.25$ & 6 & Q19 & 4.3 & $9: 56: 07$ & 25 & 0.158744 & 0.64 & 1.038 \\
\hline 36.7698032 & -116.1163028 & 4069497.9 & 578867.1 & $1,288.91$ & 11 & Q20 & 2.5 & $17: 13: 17$ & 25 & 0.084681 & 0.38 & 0.681 \\
\hline
\end{tabular}


Table D.1-15

Sample Location Coordinates for CAS 27-05-02 Sample Locations and Points of Interest

(Page 2 of 2)

\begin{tabular}{|c|c|c|c|c|c|c|c|c|c|c|c|c|}
\hline Latitude & Longitude & Northing $^{a}$ & Easting $^{a}$ & $\begin{array}{c}\text { HAE } \\
\text { (meters) }\end{array}$ & ID & Location & $\begin{array}{l}\text { Maximum } \\
\text { PDOP }\end{array}$ & $\begin{array}{l}\text { GPS } \\
\text { Time }\end{array}$ & $\begin{array}{l}\text { Unfiltered } \\
\text { Position }\end{array}$ & $\begin{array}{l}\text { Standard } \\
\text { Deviation }^{b}\end{array}$ & $\begin{array}{c}\text { Horizontal } \\
\text { Position } \\
\text { (meters) }\end{array}$ & $\begin{array}{l}\text { Vertical } \\
\text { Position } \\
\text { (meters) }\end{array}$ \\
\hline 36.7698134 & -116.1161756 & 4069499.14 & 578878.45 & $1,289.06$ & 5 & Q21 & 2.4 & $9: 55: 25$ & 25 & 0.042736 & 0.418 & 0.602 \\
\hline 36.7696758 & -116.1161496 & 4069483.89 & 578880.9 & $1,289.17$ & 13 & Q22 & 4.2 & $17: 15: 18$ & 26 & 0.195912 & 0.572 & 1.073 \\
\hline 36.7697174 & -116.1161926 & 4069488.48 & 578877.03 & $1,289.19$ & 3 & Q23 & 2.3 & $9: 52: 48$ & 34 & 0.032573 & 0.418 & 0.593 \\
\hline 36.7697641 & -116.1162358 & 4069493.62 & 578873.12 & $1,289.27$ & 2 & Q24 & 2.9 & $9: 51: 44$ & 33 & 0.101276 & 0.434 & 0.656 \\
\hline 36.7698491 & -116.1163158 & 4069502.98 & 578865.89 & $1,289.3$ & 1 & Q26 & 2.1 & $9: 50: 18$ & 30 & 0.029052 & 0.376 & 0.544 \\
\hline 36.7697082 & -116.1161651 & 4069487.47 & 578879.48 & $1,289.75$ & 4 & Q27 & 1.9 & $9: 53: 44$ & 38 & 0.099398 & 0.34 & 0.49 \\
\hline 36.7697914 & -116.1162547 & 4069496.63 & 578871.41 & $1,288.65$ & 8 & N POLE & 2.6 & 9:58:26 & 25 & 0.090434 & 0.44 & 0.649 \\
\hline 36.7697549 & -116.1162266 & 4069492.6 & 578873.95 & $1,289.49$ & 9 & S POLE & 2.4 & $9: 59: 36$ & 33 & & 0.419 & 0.616 \\
\hline
\end{tabular}

Feature Name: Point Generic

Correction Type: Realtime Corrected

Receiver Type: Pro XRS

$\mathrm{HAE}=$ Height above ellipsoid

PDOP $=$ Position dilution of precision

aUTM Zone 11, NAD 27

$\mathrm{b}_{+} /-1$ sigma
GPS Date: $02 / 14 / 2002,5 / 9 / 2002$, and 6/25/2002

Data File: Q270502.ssf, 271PS2.ssf, and 271ADDL.cor 


\section{D.1.16 Cone Penetrometer Technology Survey Locations}

The investigation of posted leachfields, CASs 26-05-01 and 26-05-03, required that in situ measurements of subsurface radioactivity be determined using direct-push, CPT. Prior to sample collection, shallow subsurface radioactivity levels were measured by in situ survey at several locations in CASs 26-05-01 and 26-05-03. Vertical profiles of gamma radioactivity were measured using CPT to provide enough data to support and document decisions regarding soil sampling methods and shipping requirements. Survey coordinates were collected at the CPT locations in CASs 26-05-01 and 26-05-03 on January 18 and 25, 2002, using a Trimble GPS, Model TSCI. The CPT sample locations for CASs 26-05-01 and 26-05-03 are marked on Figure D.1-1 and Figure D.1-2, respectively. The corresponding coordinates for CASs 26-05-01 and 26-05-03 sample locations are listed in Table D.1-16 and Table D.1-17, respectively. 


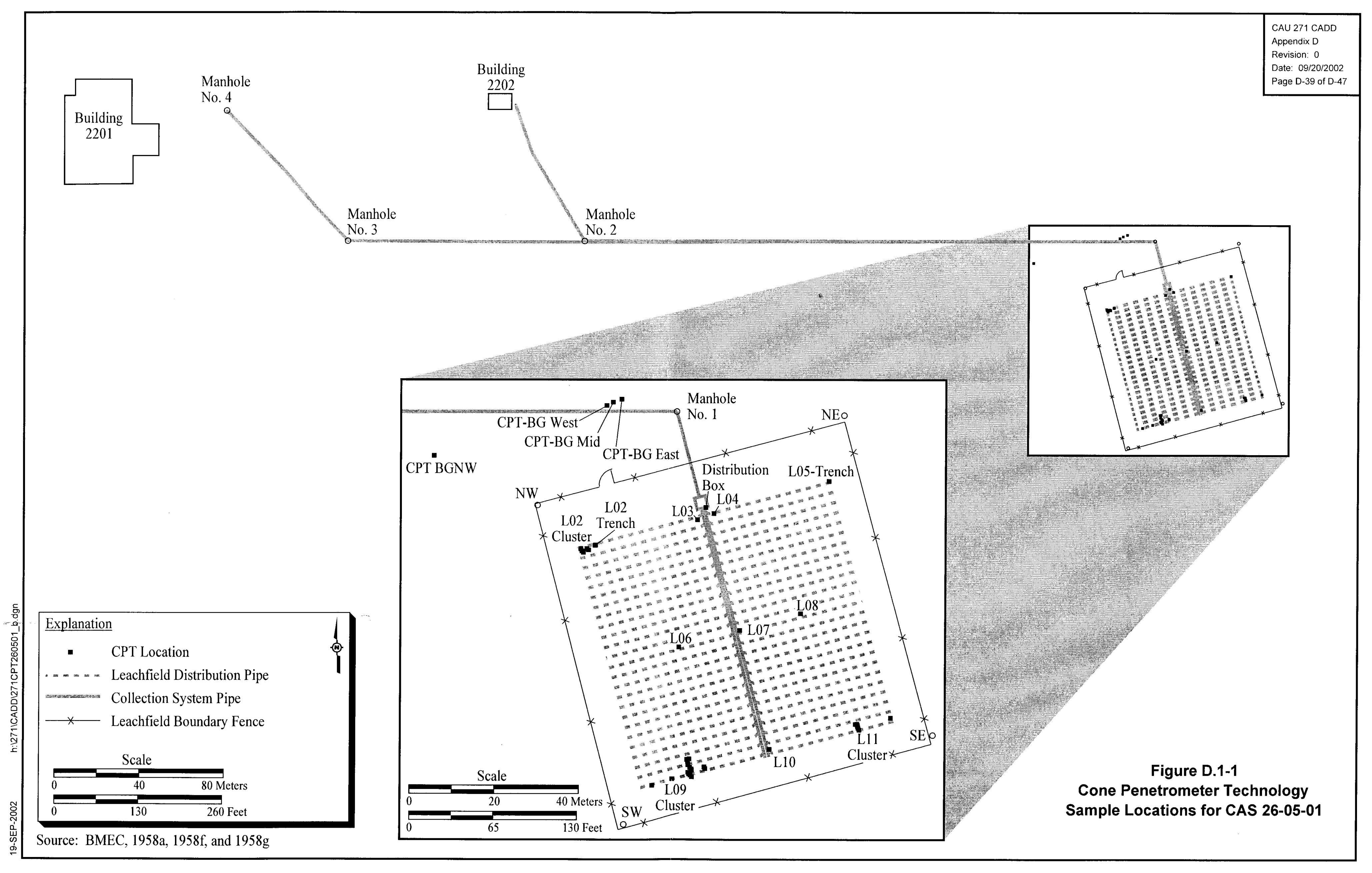




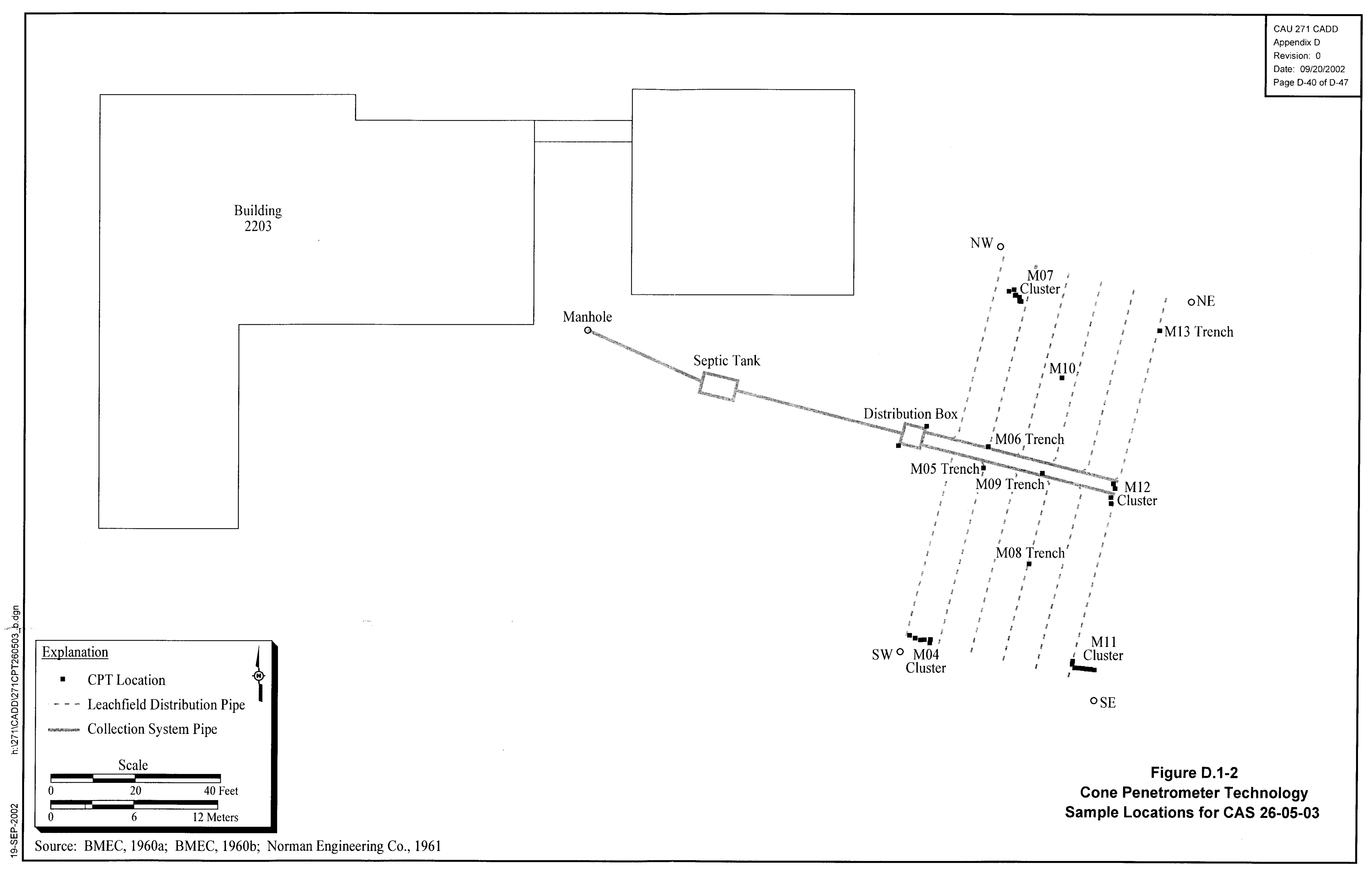




\section{Sample Location Coordinates for CAS 26-05-01 CPT Survey Locations}

(Page 1 of 3 )

\begin{tabular}{|c|c|c|c|c|c|c|c|c|c|c|c|}
\hline Latitude & Longitude & Northing $^{a}$ & Easting $^{\mathrm{a}}$ & $\begin{array}{c}\text { HAE } \\
\text { (meters) }\end{array}$ & ID & Location & $\begin{array}{l}\text { GPS } \\
\text { Time }\end{array}$ & $\begin{array}{l}\text { Unfiltered } \\
\text { Position }\end{array}$ & $\begin{array}{l}\text { Standard } \\
\text { Deviation }\end{array}$ & $\begin{array}{l}\text { Horizontal } \\
\text { Position } \\
\text { (meters) }\end{array}$ & $\begin{array}{l}\text { Vertical } \\
\text { Position } \\
\text { (meters) }\end{array}$ \\
\hline 36.81569 & -116.15958870 & 4074756.40 & 574957.35 & 1329.31 & 3 & L02 & $11: 36: 42$ & 20 & 0.608 & 0.398 & 0.000039 \\
\hline 36.81569 & -116.15958930 & 4074756.51 & 574957.29 & 1329.14 & 4 & L02-1 & $11: 37: 45$ & 25 & 0.612 & 0.400 & 0.000064 \\
\hline 36.81569 & -116.15958620 & 4074755.97 & 574957.58 & 1329.15 & 5 & L02-2 & $11: 38: 17$ & 32 & 0.612 & 0.400 & 0.000066 \\
\hline 36.81569 & -116.15958280 & 4074755.61 & 574957.89 & 1329.09 & 6 & L02-3 & $11: 38: 55$ & 32 & 0.612 & 0.400 & 0.000054 \\
\hline 36.81569 & -116.15956920 & 4074756.19 & 574959.10 & 1329.13 & 7 & L02-4 & $11: 39: 33$ & 39 & 0.612 & 0.400 & 0.000068 \\
\hline 36.81569 & -116.15957370 & 4074756.52 & 574958.69 & 1328.97 & 8 & L02-5 & $11: 41: 07$ & 17 & 0.612 & 0.400 & 0.000053 \\
\hline 36.81570 & -116.15955200 & 4074757.27 & 574960.62 & 1329.43 & 1 & L02-6 & $11: 35: 18$ & 33 & 0.661 & 0.413 & 0.000150 \\
\hline 36.81570 & -116.15955110 & 4074757.35 & 574960.70 & 1329.17 & 2 & L02 TRENCH & $11: 36: 05$ & 17 & 0.617 & 0.399 & 0.000048 \\
\hline 36.81575 & -116.15928090 & 4074763.38 & 574984.74 & 1329.23 & 9 & L03 & $11: 42: 06$ & 32 & 0.612 & 0.400 & 0.000039 \\
\hline 36.81577 & -116.15923760 & 4074764.84 & 574988.59 & 1329.18 & 10 & L04 TRENCH & $11: 44: 09$ & 32 & 0.626 & 0.408 & 0.000061 \\
\hline 36.81577 & -116.15922630 & 4074765.38 & 574989.60 & 1329.23 & 11 & L04 TRENCH & $11: 44: 50$ & 32 & 0.626 & 0.408 & 0.000040 \\
\hline 36.81583 & -116.15893310 & 4074772.49 & 575015.69 & 1329.26 & 12 & L05-TRENCH & $11: 45: 57$ & 32 & 0.626 & 0.408 & 0.000050 \\
\hline 36.81548 & -116.15933230 & 4074733.22 & 574980.42 & 1328.41 & 16 & L06 TRENCH & $11: 49: 18$ & 32 & 0.646 & 0.442 & 0.000054 \\
\hline 36.81552 & -116.15917080 & 4074737.14 & 574994.80 & 1328.52 & 15 & L07 PIPE & $11: 48: 31$ & 31 & 0.646 & 0.442 & 0.000049 \\
\hline 36.81555 & -116.15900980 & 4074741.16 & 575009.12 & 1328.43 & 14 & L08 & $11: 47: 57$ & 16 & 0.646 & 0.442 & 0.000049 \\
\hline 36.81519 & -116.15940560 & 4074700.54 & 574974.17 & 1328.11 & 17 & L09 & $11: 50: 31$ & 16 & 0.646 & 0.442 & 0.000030 \\
\hline 36.81520 & -116.15935220 & 4074702.09 & 574978.93 & 1328.34 & 18 & L09-1 & $11: 50: 59$ & 19 & 0.646 & 0.442 & 0.000036 \\
\hline 36.81522 & -116.15929990 & 4074704.19 & 574983.57 & 1328.59 & 23 & L09-2 & $11: 53: 42$ & 18 & 0.646 & 0.442 & 0.000091 \\
\hline 36.81523 & -116.15930940 & 4074705.41 & 574982.72 & 1328.53 & 26 & L09-3 & $11: 54: 49$ & 21 & 0.646 & 0.442 & 0.000059 \\
\hline 36.81523 & -116.15930440 & 4074704.81 & 574983.16 & 1328.60 & 25 & L09-4 & $11: 54: 26$ & 18 & 0.646 & 0.442 & 0.000073 \\
\hline
\end{tabular}




\section{Sample Location Coordinates for CAS 26-05-01 CPT Survey Locations}

(Page 2 of 3 )

\begin{tabular}{|c|c|c|c|c|c|c|c|c|c|c|c|}
\hline Latitude & Longitude & Northing $^{a}$ & Easting $^{\mathrm{a}}$ & $\begin{array}{c}\text { HAE } \\
\text { (meters) }\end{array}$ & ID & Location & $\begin{array}{l}\text { GPS } \\
\text { Time }\end{array}$ & $\begin{array}{l}\text { Unfiltered } \\
\text { Position }\end{array}$ & $\begin{array}{l}\text { Standard } \\
\text { Deviation }\end{array}$ & $\begin{array}{l}\text { Horizontal } \\
\text { Position } \\
\text { (meters) }\end{array}$ & $\begin{array}{l}\text { Vertical } \\
\text { Position } \\
\text { (meters) }\end{array}$ \\
\hline 36.81521 & -116.15930330 & 4074703.00 & 574983.28 & 1328.57 & 20 & L09-5 & $11: 52: 35$ & 18 & 0.646 & 0.442 & 0.000058 \\
\hline 36.81521 & -116.15930680 & 4074703.26 & 574982.96 & 1328.65 & 21 & L09-6 & $11: 52: 57$ & 17 & 0.646 & 0.442 & 0.000050 \\
\hline 36.81521 & -116.15929970 & 4074702.59 & 574983.60 & 1328.42 & 19 & L09-7 & $11: 51: 59$ & 32 & 0.646 & 0.442 & 0.000045 \\
\hline 36.81522 & -116.15930960 & 4074703.61 & 574982.71 & 1328.68 & 22 & L09-8 & $11: 53: 18$ & 17 & 0.646 & 0.442 & 0.000030 \\
\hline 36.81523 & -116.15926620 & 4074704.95 & 574986.57 & 1328.45 & 30 & L09-9 & $11: 56: 26$ & 17 & 0.646 & 0.442 & 0.000042 \\
\hline 36.81522 & -116.15926420 & 4074704.56 & 574986.75 & 1328.29 & 31 & L09-10 & $11: 56: 46$ & 16 & 0.646 & 0.442 & 0.000036 \\
\hline 36.81524 & -116.15931000 & 4074706.23 & 574982.65 & 1328.58 & 27 & L09-11 & $11: 55: 17$ & 16 & 0.646 & 0.442 & 0.000034 \\
\hline 36.81524 & -116.15931210 & 4074706.71 & 574982.46 & 1328.56 & 28 & L09-12 & $11: 55: 37$ & 16 & 0.646 & 0.442 & 0.000040 \\
\hline 36.81524 & -116.15930610 & 4074706.84 & 574982.99 & 1328.55 & 29 & L09-13 & $11: 55: 59$ & 17 & 0.646 & 0.442 & 0.000027 \\
\hline 36.81522 & -116.15930060 & 4074704.44 & 574983.50 & 1328.56 & 24 & L09-14 & $11: 54: 04$ & 17 & 0.646 & 0.442 & 0.000057 \\
\hline 36.81526 & -116.15909390 & 4074709.13 & 575001.90 & 1328.29 & 32 & L10 & $11: 57: 19$ & 16 & 0.646 & 0.442 & 0.000062 \\
\hline 36.81533 & -116.15877310 & 4074716.53 & 575030.46 & 1328.27 & 39 & L11 & $12: 00: 32$ & 19 & 0.646 & 0.442 & 0.000059 \\
\hline 36.81530 & -116.15885660 & 4074713.72 & 575023.03 & 1328.00 & 33 & L11-1 & 11:58:07 & 18 & 0.646 & 0.442 & 0.000040 \\
\hline 36.81531 & -116.15885910 & 4074714.16 & 575022.80 & 1328.05 & 34 & L11-2 & $11: 58: 27$ & 16 & 0.646 & 0.442 & 0.000021 \\
\hline 36.81531 & -116.15886030 & 4074714.53 & 575022.70 & 1328.07 & 35 & L11-3 & $11: 58: 47$ & 17 & 0.646 & 0.442 & 0.000039 \\
\hline 36.81531 & -116.15886120 & 4074714.84 & 575022.61 & 1328.21 & 36 & L11-4 & $11: 59: 07$ & 17 & 0.646 & 0.442 & 0.000039 \\
\hline 36.81532 & -116.15886220 & 4074715.09 & 575022.52 & 1328.23 & 37 & L11-5 TRENCH & $11: 59: 37$ & 18 & 0.646 & 0.442 & 0.000039 \\
\hline 36.81532 & -116.15886650 & 4074715.04 & 575022.14 & 1328.24 & 38 & L11-6 TRENCH & $11: 59: 59$ & 17 & 0.646 & 0.442 & 0.000040 \\
\hline 36.81578 & -116.15925860 & 4074766.41 & 574986.70 & 1329.01 & 40 & DB & 12:02:02 & 29 & 0.010 & 0.646 & 0.442000 \\
\hline 36.81599 & -116.15933900 & 4074789.60 & 574979.34 & 1330.95 & 41 & $\mathrm{MH} \# 1$ & 12:03:32 & 30 & 0.613 & 0.420 & 0.000051 \\
\hline
\end{tabular}


Table D.1-16

Sample Location Coordinates for CAS 26-05-01 CPT Survey Locations

(Page 3 of 3 )

\begin{tabular}{|c|c|c|c|c|c|c|c|c|c|c|c|}
\hline Latitude & Longitude & Northing $^{a}$ & Easting $^{\mathrm{a}}$ & $\begin{array}{c}\text { HAE } \\
\text { (meters) }\end{array}$ & ID & Location & $\begin{array}{l}\text { GPS } \\
\text { Time }\end{array}$ & $\begin{array}{l}\text { Unfiltered } \\
\text { Position }\end{array}$ & $\begin{array}{l}\text { Standard } \\
\text { Deviation }\end{array}$ & $\begin{array}{l}\text { Horizontal } \\
\text { Position } \\
\text { (meters) }\end{array}$ & $\begin{array}{l}\text { Vertical } \\
\text { Position } \\
\text { (meters) }\end{array}$ \\
\hline 36.81600 & -116.16234500 & 4074788.78 & 574711.20 & 1335.87 & 42 & $\mathrm{MH} \# 2$ & 12:09:20 & 16 & 0.589 & 0.412 & 0.000087 \\
\hline 36.81605 & -116.1586182 & 4074594.55 & 575045.38 & 1327.2 & 2 & CPT-BG EAST & $14: 16: 27$ & 2.3 & 0.554777 & 0.326 & 0.412 \\
\hline 36.81605 & -116.1586406 & 4074593.93 & 575043.39 & 1326.81 & 3 & CPT-BG MID & $14: 17: 03$ & 1.5 & 0.024909 & 0.286 & 0.341 \\
\hline 36.81604 & -116.1586576 & 4074593.07 & 575041.88 & 1327.3 & 4 & CPT-BG WEST & $14: 17: 26$ & 1.5 & 0.085482 & 0.271 & 0.323 \\
\hline 36.81594 & -116.1591141 & 4074581.28 & 575001.26 & 1326.65 & 50 & CPT BGNW & $15: 02: 00$ & 2.2 & 0.03389 & 0.378 & 0.528 \\
\hline
\end{tabular}

Feature Name: Point Generic/Area Generic

GPS Date: $01 / 18 / 2002$ and 2/21/2002

Correction Type: Realtime Corrected

Receiver Type: Pro XRS

$\mathrm{HAE}=$ Height above ellipsoid

PDOP $=$ Position dilution of precision

aUTM Zone 11, NAD 27

${ }^{b}+/-1$ sigma 
Table D.1-17

Sample Location Coordinates for CAS 26-05-03 CPT Survey Locations

(Page 1 of 3 )

\begin{tabular}{|c|c|c|c|c|c|c|c|c|c|c|c|}
\hline Latitude & Longitude & Northing $^{a}$ & Easting $^{\mathrm{a}}$ & $\begin{array}{c}\text { HAE } \\
\text { (meters) }\end{array}$ & ID & Location & GPS Time & $\begin{array}{l}\text { Unfiltered } \\
\text { Position }\end{array}$ & $\begin{array}{l}\text { Standard } \\
\text { Deviation }\end{array}$ & $\begin{array}{c}\text { Horizontal } \\
\text { Position } \\
\text { (meters) }\end{array}$ & $\begin{array}{l}\text { Vertical } \\
\text { Position } \\
\text { (meters) }\end{array}$ \\
\hline 36.829178 & -116.1412840 & 4076266.76 & 576576.56 & 1336.97 & 4 & M04 & $18: 10: 04$ & 33 & 0.6640 & 0.3670 & 0.000063 \\
\hline 36.829179 & -116.1412882 & 4076266.89 & 576576.19 & 1336.77 & 5 & M04-1 & $18: 10: 48$ & 32 & 0.6640 & 0.3670 & 0.000057 \\
\hline 36.829181 & -116.1412926 & 4076267.09 & 576575.80 & 1336.68 & 6 & M04-2 & $18: 11: 32$ & 32 & 0.4950 & 0.3510 & 0.000051 \\
\hline 36.829178 & -116.1412809 & 4076266.78 & 576576.84 & 1337.13 & 3 & M04-2 & $18: 09: 15$ & 32 & 0.6630 & 0.3670 & 0.000044 \\
\hline 36.829176 & -116.1412765 & 4076266.54 & 576577.24 & 1336.82 & 2 & $\begin{array}{l}\text { M04-3 } \\
\text { Trench }\end{array}$ & 18:08:23 & 32 & 0.6620 & 0.3670 & 0.000034 \\
\hline 36.829178 & -116.1412760 & 4076266.79 & 576577.28 & 1336.95 & 1 & $\begin{array}{l}\text { M04-4 } \\
\text { Trench }\end{array}$ & $18: 07: 25$ & 33 & 0.5690 & 0.3600 & 0.000138 \\
\hline 36.829397 & -116.1412028 & 4076291.16 & 576583.59 & 1337.02 & 32 & $\begin{array}{l}\text { M04-5 } \\
\text { Trench }\end{array}$ & $18: 25: 50$ & 19 & 0.4990 & 0.3450 & 0.000080 \\
\hline 36.829289 & -116.1412326 & 4076279.15 & 576581.04 & 1337.73 & 23 & M05 Trench & 18:21:02 & 18 & 0.6660 & 0.3760 & 0.000051 \\
\hline 36.829303 & -116.1412286 & 4076280.69 & 576581.38 & 1337.54 & 24 & M06 Trench & $18: 21: 40$ & 18 & 0.6660 & 0.3760 & 0.000051 \\
\hline 36.829404 & -116.1412073 & 4076291.98 & 576583.18 & 1337.35 & 27 & M07 & $18: 23: 53$ & 16 & 0.6640 & 0.3780 & 0.000032 \\
\hline 36.829404 & -116.1412113 & 4076291.87 & 576582.82 & 1337.53 & 28 & M07-1 & $18: 24: 12$ & 16 & 0.6640 & 0.3780 & 0.000097 \\
\hline 36.829401 & -116.1412065 & 4076291.57 & 576583.26 & 1337.74 & 29 & M07-2 & $18: 24: 32$ & 17 & 0.6640 & 0.3780 & 0.000042 \\
\hline 36.829401 & -116.1412059 & 4076291.6 & 576583.31 & 1337.40 & 30 & M07-3 & $18: 25: 00$ & 17 & 0.5730 & 0.3630 & 0.000202 \\
\hline 36.829400 & -116.1412030 & 4076291.44 & 576583.57 & 1336.84 & 31 & $\begin{array}{l}\text { M07-4 } \\
\text { Trench }\end{array}$ & $18: 25: 27$ & 21 & 0.4990 & 0.3450 & 0.000052 \\
\hline 36.829397 & -116.1412018 & 4076291.13 & 576583.68 & 1337.45 & 33 & $\begin{array}{l}\text { M07-5 } \\
\text { Trench }\end{array}$ & $18: 26: 21$ & 17 & 0.5100 & 0.3480 & 0.000075 \\
\hline 36.829227 & -116.1411960 & 4076272.25 & 576584.37 & 1337.31 & 15 & M08 Trench & $18: 16: 19$ & 17 & 0.6520 & 0.3700 & 0.000054 \\
\hline 36.829285 & -116.1411851 & 4076278.78 & 576585.28 & 1336.65 & 22 & M09 Trench & $18: 20: 25$ & 17 & 0.5000 & 0.3470 & 0.000032 \\
\hline
\end{tabular}


Table D.1-17

Sample Location Coordinates for CAS 26-05-03 CPT Survey Locations

(Page 2 of 3 )

\begin{tabular}{|c|c|c|c|c|c|c|c|c|c|c|c|}
\hline Latitude & Longitude & Northing $^{a}$ & Easting $^{a}$ & $\begin{array}{c}\text { HAE } \\
\text { (meters) }\end{array}$ & ID & Location & GPS Time & $\begin{array}{l}\text { Unfiltered } \\
\text { Position }\end{array}$ & $\begin{array}{l}\text { Standard } \\
\text { Deviation }\end{array}$ & $\begin{array}{c}\text { Horizontal } \\
\text { Position } \\
\text { (meters) }\end{array}$ & $\begin{array}{l}\text { Vertical } \\
\text { Position } \\
\text { (meters) }\end{array}$ \\
\hline 36.829347 & -116.1411691 & 4076285.64 & 576586.64 & 1336.91 & 21 & M10 & $18: 19: 54$ & 17 & 0.6680 & 0.3740 & 0.000060 \\
\hline 36.829157 & -116.1411440 & 4076264.62 & 576589.07 & 1336.64 & 7 & M11 & $18: 12: 26$ & 34 & 0.4960 & 0.3510 & 0.000077 \\
\hline 36.829158 & -116.1411471 & 4076264.67 & 576588.80 & 1336.59 & 8 & M11-1 & $18: 13: 03$ & 33 & 0.4960 & 0.3510 & 0.000048 \\
\hline 36.829158 & -116.1411504 & 4076264.69 & 576588.50 & 1336.75 & 9 & M11-2 & 18:13:39 & 18 & 0.4960 & 0.3510 & 0.000040 \\
\hline 36.829158 & -116.1411534 & 4076264.73 & 576588.24 & 1336.83 & 10 & M11-3 & $18: 14: 04$ & 18 & 0.4960 & 0.3510 & 0.000050 \\
\hline 36.829159 & -116.1411562 & 4076264.75 & 576587.99 & 1337.14 & 11 & M11-4 & $18: 14: 25$ & 18 & 0.6690 & 0.3700 & 0.000033 \\
\hline 36.829159 & -116.1411597 & 4076264.77 & 576587.67 & 1336.94 & 12 & M11-5 & $18: 14: 47$ & 17 & 0.6210 & 0.3660 & 0.000062 \\
\hline 36.829161 & -116.1411616 & 4076265.05 & 576587.49 & 1337.13 & 13 & $\begin{array}{l}\text { M11-6 } \\
\text { Trench }\end{array}$ & $18: 15: 20$ & 18 & 0.6690 & 0.3710 & 0.000025 \\
\hline 36.829163 & -116.1411612 & 4076265.25 & 576587.53 & 1337.24 & 14 & $\begin{array}{l}\text { M11-7 } \\
\text { Trench }\end{array}$ & $18: 15: 41$ & 18 & 0.6690 & 0.3710 & 0.000041 \\
\hline 36.829278 & -116.1411281 & 4076278.04 & 576590.37 & 1336.61 & 16 & M12 Trench & $18: 17: 09$ & 19 & 0.4990 & 0.3490 & 0.000047 \\
\hline 36.829275 & -116.1411268 & 4076277.7 & 576590.49 & 1336.83 & 17 & $\begin{array}{l}\text { M12-1 } \\
\text { Trench }\end{array}$ & $18: 17: 33$ & 19 & 0.5730 & 0.3620 & 0.000143 \\
\hline 36.829269 & -116.1411302 & 4076277.05 & 576590.20 & 1337.13 & 18 & M12-2 & 18:18:07 & 18 & 0.6380 & 0.3700 & 0.000078 \\
\hline 36.829265 & -116.1411300 & 4076276.62 & 576590.21 & 1337.40 & 19 & $\begin{array}{l}\text { M12-3 } \\
\text { Trench }\end{array}$ & 18:18:30 & 20 & 0.6690 & 0.3730 & 0.000059 \\
\hline 36.829377 & -116.1410903 & 4076289.04 & 576593.65 & 1337.05 & 20 & M13 Trench & 18:19:10 & 18 & 0.6680 & 0.3740 & 0.000063 \\
\hline 36.829319 & -116.1412922 & 4076282.4 & 576575.70 & 1336.16 & 25 & $\mathrm{db}$ & $18: 22: 27$ & 29 & 0.0100 & 0.5950 & 0.387000 \\
\hline
\end{tabular}


Table D.1-17

Sample Location Coordinates for CAS 26-05-03 CPT Survey Locations

(Page 3 of 3 )

\begin{tabular}{|c|c|c|c|c|c|c|c|c|c|c|c|}
\hline Latitude & Longitude & Northing ${ }^{a}$ & Easting $^{\mathrm{a}}$ & $\begin{array}{c}\text { HAE } \\
\text { (meters) }\end{array}$ & ID & Location & GPS Time & $\begin{array}{l}\text { Unfiltered } \\
\text { Position }\end{array}$ & $\begin{array}{l}\text { Standard } \\
\text { Deviation }\end{array}$ & $\begin{array}{c}\text { Horizontal } \\
\text { Position } \\
\text { (meters) }\end{array}$ & $\begin{array}{l}\text { Vertical } \\
\text { Position } \\
\text { (meters) }\end{array}$ \\
\hline 36.829300 & -116.1412850 & 4076280.32 & 576576.36 & 1337.72 & 25 & $\mathrm{db}$ & $18: 22: 27$ & 29 & 0.0100 & 0.5950 & 0.387000 \\
\hline
\end{tabular}

Feature Name: Point Generic/Area Generic

GPS Date: $01 / 25 / 2002$

Correction Type: Realtime Corrected

Receiver Type: Pro XRS

$\mathrm{HAE}=$ Height above ellipsoid

PDOP $=$ Position dilution of precision

aUTM Zone 11, NAD 27

b /- 1 sigma 


\section{D.2.0 References}

BMEC, see Burns and McDonnell Engineering Company.

Burns and McDonnell Engineering Company. 1958a. Engineering Drawing 2201 - SW1, "Disassembly Building General Layout and Sanitary Sewer Profile," 1 December. Mercury, NV: Archives and Records Center.

Burns and McDonnell Engineering Company. 1958b. Engineering Drawing 2201 - SW7.A, "Disassembly Building Hot Disposal Field Layout \& Details," 1 December. Mercury, NV: Archives and Records Center.

Burns and McDonnell Engineering Company. 1958c. Engineering Drawing 2201 - SW9, "Hot Disposal Field Location \& Grading Plan," 1 December. Mercury, NV: Archives and Records Center.

Burns and McDonnell Engineering Company. 1960a. As-built Engineering Drawing 2203 - SW1.1 entitled, "Test Bunker and Miscellaneous Structures, Sewer Layout - Test Bunker \& Head House," 30 November. Las Vegas, NV.

Burns and McDonnell Engineering Company. 1960b. As-built Engineering Drawing 2203 - SW5 entitled, "Test Bunker and Miscellaneous Structures, Sewage Plant Details," 30 November. Las Vegas, NV.

Norman Engineering Co. 1961. As-built Engineering Drawing 2202A-C-10 entitled, "Site Civil Plan I," 2 October. Las Vegas, NV. 


\section{Appendix E}

\section{Project Organization for CAU 271}




\section{E.1.0 Project Organization}

The Project Manager is Janet Appenzeller-Wing and her telephone number is (702) 295-0461.

The identification of the project Health and Safety Officer and the Quality Assurance Officers can be found in the appropriate plan. However, personnel are subject to change and it is suggested that the appropriate Department of Energy Project Manager be contacted for further information. The Task Manager will be identified in the FFACO Biweekly Activity Report prior to the start of field activities. 


\section{Appendix F}

\section{NDEP Comment Responses}


NEVADA ENVIRONMENTAL RESTORATION PROJECT

DOCUMENT REVIEW SHEET

\begin{tabular}{|c|c|c|c|c|c|}
\hline \multicolumn{4}{|c|}{$\begin{array}{l}\text { 1. Document Title/Number: Draft Corrective Decision Document for Corrective Action Unit 271: Areas 25, 26, } \\
\text { and } 27 \text { Septic Systems, Nevada Test Site, Nevada }\end{array}$} & \multicolumn{2}{|l|}{ 2. Document Date: July, 2002} \\
\hline \multicolumn{4}{|c|}{ 3. Revision Number: 0} & \multicolumn{2}{|c|}{ 4. Originator/Organization: IT Corporation } \\
\hline \multicolumn{4}{|c|}{ 5. Responsible NNSA/NV ERP Project Mgr.: Janet Appenzeller-Wing } & \multicolumn{2}{|c|}{ 6. Date Comments Due: August 16, 2002} \\
\hline \multicolumn{6}{|c|}{ 7. Review Criteria: Full } \\
\hline \multicolumn{4}{|c|}{ 8. Reviewer/Organization/Phone No.: Donald R. Elle, NDEP, 486-2874 } & \multicolumn{2}{|l|}{ 9. Reviewer's Signature: } \\
\hline $\begin{array}{l}\text { 10. Comment } \\
\text { Number/ } \\
\text { Location }\end{array}$ & 11. Type* & 12. Comment & \multicolumn{2}{|c|}{ 13. Comment Response } & 14. Accept \\
\hline $\begin{array}{l}\text { 1) General } \\
\text { Comment }\end{array}$ & M & $\begin{array}{l}\text { Throughout the draft CADD, the phrase "... regulatory disposal } \\
\text { limits..." is used when discussing hydrocarbon results that } \\
\text { exceed the regulatory action levels. The phrase should be } \\
\text { changed, throughout the document, to "...regulatory action } \\
\text { levels..." in those areas that discuss hydrocarbon findings } \\
\text { which exceed Nevada Administrative Code 445A.2272. }\end{array}$ & \multicolumn{2}{|c|}{$\begin{array}{l}\text { The text was changed in those areas that discuss } \\
\text { hydrocarbon findings which exceed Nevada Administrative } \\
\text { Code 445A.2272. }\end{array}$} & Yes \\
\hline $\begin{array}{l}\text { 2) Executive } \\
\text { Summary } \\
\text { Page ES-1 } \\
2^{\text {nd }} \text { Bullet }\end{array}$ & M & “...CAS 25-0-03..." should read “...CAS 25-04-03..." & \multicolumn{2}{|c|}{ The text was modified as requested. } & Yes \\
\hline $\begin{array}{c}\text { 3) Executive } \\
\text { Summary } \\
\text { Page ES-2 } \\
1^{\text {st }} \text { Bullet after } \\
\text { Paragraph at Top of } \\
\text { Page }\end{array}$ & M & $\begin{array}{l}\text { Mention should also be made that Manhole } 1 \text {, included in CAS } \\
26-05-03 \text {, contains hydrocarbon-contaminated sediment which } \\
\text { exceeds regulatory action levels. }\end{array}$ & \multicolumn{2}{|c|}{$\begin{array}{l}\text { The text was modified as requested to include } \\
\text { hydrocarbon-contaminated sediment exceeding regulatory } \\
\text { action levels in the CAS } 26-05-03 \text { Manhole } 1 .\end{array}$} & Yes \\
\hline $\begin{array}{l}\text { 4) Executive } \\
\text { Summary } \\
\text { Page } 4 \\
2^{\text {nd }} \text { Paragraph } \\
2^{\text {nd }} \text { Sentence }\end{array}$ & S & $\begin{array}{l}\text { "...No further action was identified at any of the CASs within } \\
\text { Corrective Action Unit } 271 . . . " \text { should probably read "...The No } \\
\text { Further Action alternative was not identified for any of the } \\
\text { CASs within Corrective Action Unit } 271 . . . "\end{array}$ & \multicolumn{2}{|c|}{$\begin{array}{l}\text { No further action was subsequently identified for CAS } \\
25-04-10 \text {. The text was modified to address this change. }\end{array}$} & Yes \\
\hline
\end{tabular}


NEVADA ENVIRONMENTAL RESTORATION PROJECT

DOCUMENT REVIEW SHEET

\begin{tabular}{|c|c|c|c|c|}
\hline $\begin{array}{l}\text { 10. Comment } \\
\text { Number/ } \\
\text { Location }\end{array}$ & 11. Type* & 12. Comment & 13. Comment Response & 14. Accept \\
\hline $\begin{array}{l}\text { 5) Section } 2.2 .1 \\
\text { Summary of } \\
\text { Characterization } \\
\text { Data } \\
\text { Page } 41 \\
1^{\text {st }} \text { Bullet }\end{array}$ & M & $\begin{array}{l}\text { Mention should also be made that Manhole } 1 \text {, included in CAS } \\
26-05-03 \text {, contains hydrocarbon-contaminated sediment which } \\
\text { exceeds regulatory action levels. }\end{array}$ & $\begin{array}{l}\text { The text was modified as requested to include } \\
\text { hydrocarbon-contaminated sediment exceeding regulatory } \\
\text { action levels in the CAS } 26-05-03 \text { Manhole } 1 \text {. }\end{array}$ & Yes \\
\hline $\begin{array}{l}\text { 6) Section } 4.0 \\
\text { Recommended } \\
\text { Alternatives } \\
\text { Page } 122\end{array}$ & M & $\begin{array}{l}\text { If the selection of the recommended alternatives changes once } \\
\text { the missing cost estimates are known, the draft will have to be } \\
\text { reviewed further. }\end{array}$ & $\begin{array}{l}\text { Several changes have been made to the recommended } \\
\text { alternatives. The changes are the following: } \\
\text { 1. CAS } 25-04-10 \text { was changed from Clean Closure to No } \\
\text { Further Action. } \\
\text { 2. Soil contamination at CAS } 25-04-04 \text { was changed from } \\
\text { Closure in Place to Clean Closure. } \\
\text { 3. Soil contamination at CAS } 27-05-02 \text { was changed from } \\
\text { Closure in Place to Clean Closure. } \\
\text { For CAS } 25-04-10 \text {, this change has no effect on activities at } \\
\text { the site because contamination was not present, and the } \\
\text { septic tank will be filled with inert material. For CASs } \\
25-04-04 \text { and } 27-05-02 \text {, the change to Clean Closure is } \\
\text { more protective of human health and the environment } \\
\text { because contamination will be removed from the sites. }\end{array}$ & Yes \\
\hline $\begin{array}{l}\text { 7) Appendix A } \\
\text { Section A.5.3.2 } \\
\text { Septic Tank Sample } \\
\text { Results Page A-79 } \\
4^{\text {th }} \text { Paragraph of the } \\
\text { Section }\end{array}$ & M & $\begin{array}{l}\text { "...1,000 mg/kg (alpha chlordane)..." should probably read } \\
\text { "...1,000 } \mathrm{\mu g} / \mathrm{kg} \text { (alpha chlordane)..." }\end{array}$ & The text was modified as requested. & Yes \\
\hline $\begin{array}{l}\text { 8) Appendix A } \\
\text { Section A.20.0 } \\
\text { Summary } \\
\text { Page A-344 }\end{array}$ & $\mathrm{s}$ & $\begin{array}{l}\text { Mention should also be made in the paragraphs for both CAS } \\
25-04-03 \text { and CAS } 25-04-04 \text { that fecal matter was also found in } \\
\text { the septic tanks. }\end{array}$ & $\begin{array}{l}\text { The text was modified as requested to identify the positive } \\
\text { result of fecal coliform bacteria in the septic tanks at CASs } \\
25-04-03 \text { and } 25-04-04 \text {. }\end{array}$ & Yes \\
\hline
\end{tabular}


NEVADA ENVIRONMENTAL RESTORATION PROJECT

DOCUMENT REVIEW SHEET

\begin{tabular}{|c|c|l|l|}
\hline $\begin{array}{c}\text { 10. Comment } \\
\text { Number/ } \\
\text { Location }\end{array}$ & 11. Type* & 12. Comment & 13. Comment Response \\
\hline \hline $\begin{array}{c}\text { 9) Appendix A } \\
\begin{array}{c}\text { Section A.20.0 } \\
\text { Summary } \\
\text { Page 346 }\end{array}\end{array}$ & S & $\begin{array}{l}\text { Mention should also be made that fecal matter was found in the } \\
\text { CAS 26-05-04 septic tank. }\end{array}$ & $\begin{array}{l}\text { The text was modified as requested to identify the positive } \\
\text { result of fecal coliform bacteria in the septic tank at CAS } \\
26-05-04 .\end{array}$ \\
\hline
\end{tabular}

${ }^{a}$ Comment Types: $M=$ Mandatory, $\mathrm{S}=$ Suggested

Return Document Review Sheets to NNSA/NV Environmental Restoration Division, Attn: QAC, M/S 505 


\section{Distribution}

* Provide a copy in distribution of Rev. 0 and subsequent revisions, if applicable. Copies of only the NDEP-approved document will be distributed to others.

\section{Copies}

Paul J. Liebendorfer

1 (Controlled)*

State of Nevada

Bureau of Federal Facilities

Division of Environmental Protection

333 W. Nye Lane, Room 138

Carson City, NV 89706-0851

D.R. Elle

1 (Controlled)*

State of Nevada

Bureau of Federal Facilities

Division of Environmental Protection

1771 E. Flamingo Rd., Suite 121-A

Las Vegas, NV 89119

Sabrina Lawrence

Environmental Restoration Division

1 (Controlled)*

U.S. Department of Energy

National Nuclear Security Administration

Nevada Operations Office

P.O. Box 98518, M/S 505

Las Vegas, NV 89193-8518

Janet Appenzeller-Wing

1 (Uncontrolled)*

Environmental Restoration Division

U.S. Department of Energy

National Nuclear Security Administration

Nevada Operations Office

P.O. Box 98518, M/S 505

Las Vegas, NV 89193-8518 
Kevin Cabble

Environmental Restoration Division

U.S. Department of Energy

National Nuclear Security Administration

Nevada Operations Office

P.O. Box 98518, M/S 505

Las Vegas, NV 89193-8518

Jeffrey L. Smith

Bechtel Nevada

P.O. Box 98521, M/S NTS306

Las Vegas, NV 89193-8521

Brad Jackson

Bechtel Nevada

P.O. Box 98521, M/S NTS306

Las Vegas, NV 89193-8521

Robert W. Sobocinski

IT Corporation/Las Vegas

P.O. Box 93838

Las Vegas, NV 89193

Brandi Mulkey

IT Corporation/Las Vegas

P.O. Box 93838

Las Vegas, NV 89193

FFACO Support Office

IT Corporation/Las Vegas

P.O. Box 93838

Las Vegas, NV 89193

IT Corporation Central Files

P.O. Box 93838

Las Vegas, NV 89193

Manager, Southern Nevada FFACO

Public Reading Facility

P.O. Box 98521, M/S NLV040

Las Vegas, NV 89193-8521
1 (Uncontrolled)*

1 (Uncontrolled)*

1 (Uncontrolled)*

1 (Uncontrolled)*

1 (Uncontrolled)*

1 (Uncontrolled)

1 (Uncontrolled)*

1 (Controlled)

1 (Uncontrolled) 
Manager, Northern Nevada FFACO

Public Reading Facility

c/o Nevada State Library \& Archives

Carson City, NV 89701-4285

Technical Information Resource Center

U.S. Department of Energy

National Nuclear Security Administration

Nevada Operations Office

P.O. Box 98518, M/S 505

Las Vegas, NV 89193-8518

U.S. Department of Energy

Office of Scientific and Technical Information

P.O. Box 62

Oak Ridge, TN 37831
1 (Uncontrolled)

1 (Uncontrolled)

1 (Uncontrolled, electronic copy) 